\title{
Cobalt(III)- and Manganese(I)-Catalyzed C-H and C-C Activations
}

\author{
Dissertation \\ for the award of the degree \\ "Doctor rerum naturalium" \\ of the Georg-August-Universität Göttingen \\ within the doctoral program of chemistry \\ of the Georg-August-Universität School of Science (GAUSS)
}

Submitted by

Hui Wang

From Anhui (China)

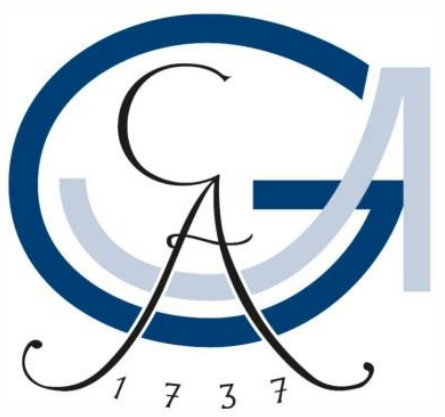

Göttingen, 2019 



\section{Thesis Committee}

Prof. Dr. Lutz Ackermann, Institute of Organic and Biomolecular Chemistry

Dr. Alexander Breder, Institute of Organic and Biomolecular Chemistry

\section{Members of the Examination Board}

Reviewer: Prof. Dr. Lutz Ackermann, Institute of Organic and Biomolecular Chemistry

Second Reviewer: Dr. Alexander Breder, Institute of Organic and Biomolecular

Chemistry

\section{Further members of the Examination Board}

Prof. Dr. Dr. h.c. Lutz-F. Tietze, Institute of Organic and Biomolecular Chemistry

Prof. Dr. Manuel Alcarazo, Institute of Organic and Biomolecular Chemistry

Prof. Dr. Dietmar Stalke, Institute of Inorganic Chemistry

Dr. Shoubhik Das, Institute of Organic and Biomolecular Chemistry

Date of the oral examination: March $22^{\text {nd }}, 2019$ 



\section{Contents}

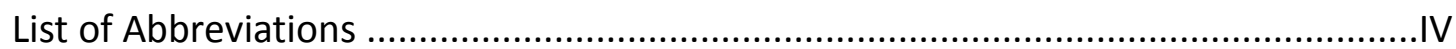

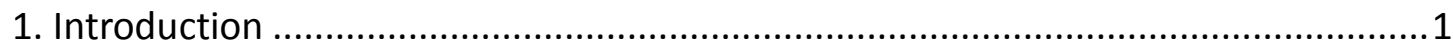

1.1 Transition Metal-Catalyzed C-H Functionalizations .........................................2

1.1.1 The Advantages of Transition Metal-Catalyzed C-H Activation.....................2

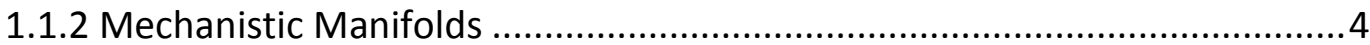

1.1.3 Selectivity Control in Transition Metal-Catalyzed C-H Functionalizations ...5

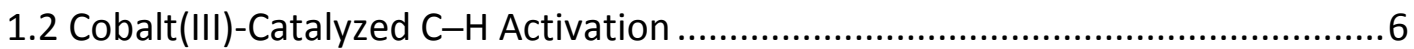

1.2.1 Early Examples of Cobalt-Catalyzed C-H Activations .................................6

1.2.2 High-Valent Cobalt(III)-Catalyzed C-H Activations.....................................9

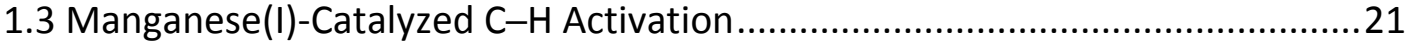

1.3.1 Early Examples of Manganese-Catalyzed C-H Functionalizations ..............22

1.3.2 Examples of Manganese(I)-Catalyzed C-H Functionalizations ...................24

1.4 Transition Metal-Catalyzed C-C Functionalizations.......................................37

1.4.1 Transition Metal-Catalyzed C-C Functionalizations .................................38

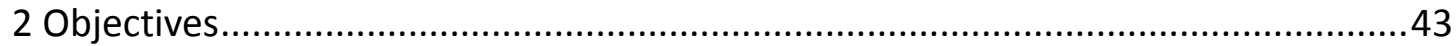

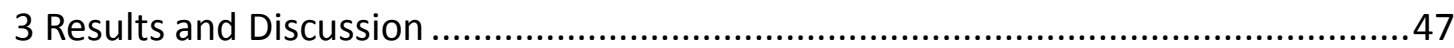

3.1 Cobalt(III)-Catalyzed C-H/N-O Functionalizations: Isohypsic Access to

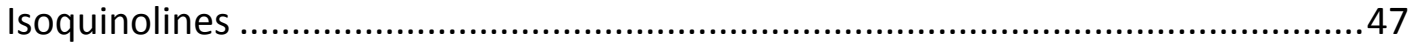

3.1.1 Optimization Studies for the Synthesis of Isoquinoline ..........................47

3.1.2 Scope of Cobalt(III)-Catalyzed C-H/N-O Functionalization .......................49

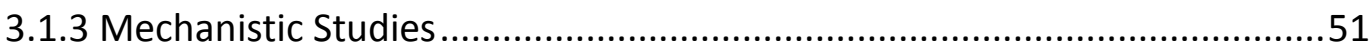

3.1.4 Proposed Catalytic Cycle …...................................................................5

3.2 Selective Synthesis of Indoles by Cobalt(III)-Catalyzed $\mathrm{C}-\mathrm{H} / \mathrm{N}-\mathrm{O}$

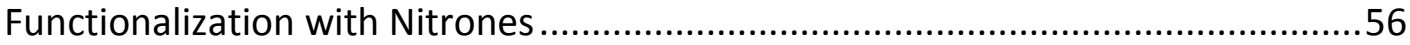

3.2.1 Optimization of Cobalt(III)-Catalyzed $\mathrm{C}-\mathrm{H} / \mathrm{N}-\mathrm{O}$ Alkyne Annulation ............56

3.2.2 Influence of the $C$-Substitution Pattern................................................59

3.2.3 Scope of Cobat-Catalyzed C-H/N-O Functionalization.............................60

3.2.4 Formation of $3 \mathrm{H}$-Indole and Cationic Cobalt(III) as the Catalyst................63 
3.2.5 Mechanistic Studies

3.2.6 Plausible Catalytic Cycle

3.3 Overcoming the Limitations of $\mathrm{C}-\mathrm{H}$ Activation with Strongly Coordinating $\mathrm{N}$-Heterocycles by Cobalt Catalysis

3.3.1 Optimization of the Cobalt(III)-Catalyzed C-H Amidation of Imidates

3.3.2 Cobalt-Catalyzed C-H Amidation of Imidates 69

3.3.3 Overriding the Conventional Selectivity Dictated by Strongly Coordinating

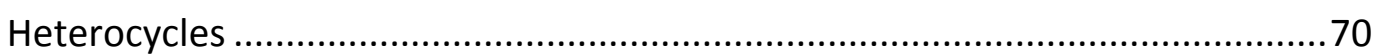

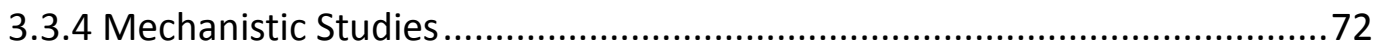

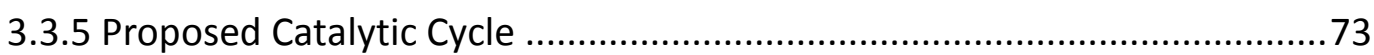

3.4 Domino $\mathrm{C}-\mathrm{H} / \mathrm{N}-\mathrm{H}$ Allylation of Imidates by Cobalt Catalysis ............................75

3.4.1 Optimization of the Domino $\mathrm{C}-\mathrm{H} / \mathrm{N}-\mathrm{H}$ Allylation of Imidate .....................75

3.4.2 Scope of Cobalt(III)-Catalyzed Domino $\mathrm{C}-\mathrm{H} / \mathrm{N}-\mathrm{H}$ Allylation ......................77

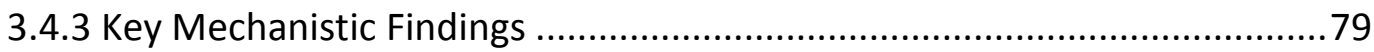

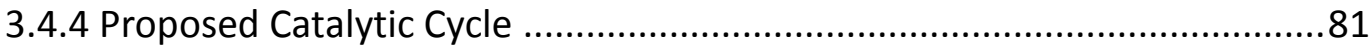

3.4.5 Diversification of Vinylated Heteroarenes .................................................82

3.5 Air-Stable Manganese(I)-Catalyzed C-H Activation for Decarboxylative C-H/C-

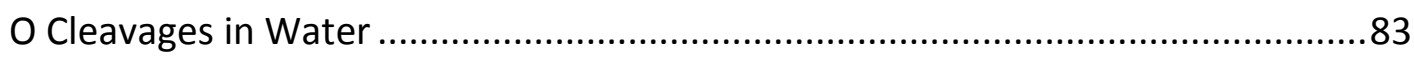

3.5.1 Optimization of Decarboxylative $\mathrm{C}-\mathrm{H} / \mathrm{C}-\mathrm{O}$ Activation..............................83

3.5.2 Scope of Manganese(I)-Catalyzed C-H/C-O Activation .............................85

3.5.3 Manganese(I)-Catalyzed C-H/C-O Functionalization of Tryptophan and

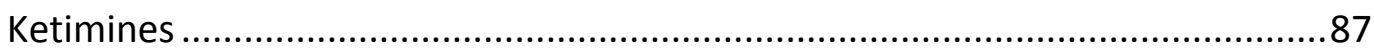

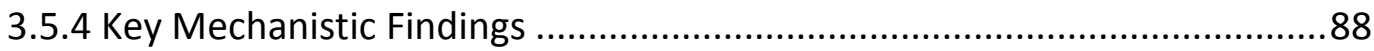

3.6 Synergistic Manganese(I) C-H Activation Catalysis in Continuous Flow: Chemoselective Hydroarylation ......................................................................91

3.6.1 Optimization of Synergistic Hydroarylation in Flow.................................91

3.6.2 Scope of Synergistic C-H Activation in Flow ...........................................93

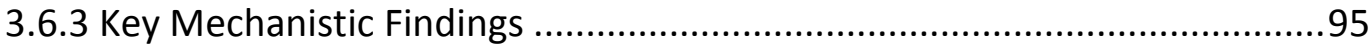

3.6.4 Continuous Flow Manganese-Catalyzed C-H Activation on Scale and

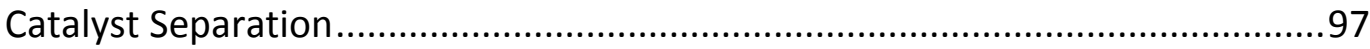

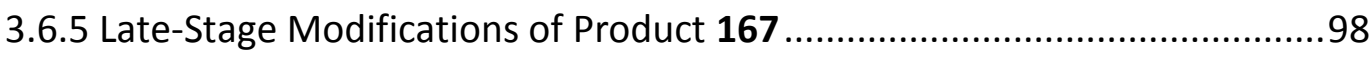


3.7 Versatile and Robust C-C Activation by Chelation-Assisted Manganese-Catalysis

3.7.1 Optimization of Manganese-Catalyzed C-C Cleavage

3.7.2 Effect of Different Leaving Groups ... 101

3.7.3 Substrate Scope of C-C Functionalization in Water. 101

3.7.4 Position-Selective Manganese(I)-Catalyzed C-C Activation Highlighting Unique Benefits over $\mathrm{C}-\mathrm{H}$ Activation .105

3.7.5 Key Mechanistic Findings 107

3.7.6 Traceless Removal of the Pyrazole Group. 112

4 Summary and Outlook 114

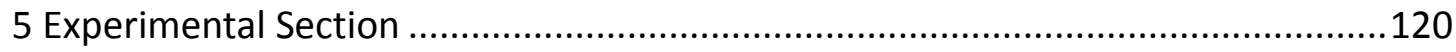

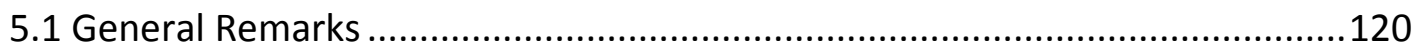

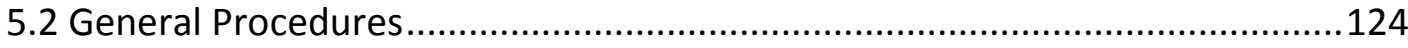

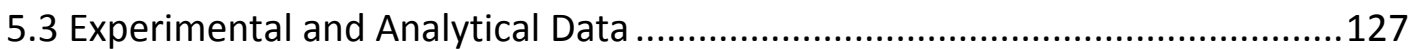

5.3.1 Data for Cobalt(III)-Catalyzed C-H/N-O Functionalizations: Isohypsic Access to Isoquinolines

5.3.2 Data for the Products of Indoles by Cobalt(III)-Catalyzed $\mathrm{C}-\mathrm{H} / \mathrm{N}-\mathrm{O}$

Functionalizations with Nitrones.

5.3.3 Data for the Products of Quinazolines by Cobalt(III)-Catalyzed $\mathrm{C}-\mathrm{H} / \mathrm{N}-\mathrm{O}$ Functionalizations with Benzimidates

5.3.4 Data for Cobalt(III)-Catalyzed Domino C-H/N-H Allylations of Imidates .197

5.3.5 Data for Maganese(I)-Catalyzed C-H Activation for Decarboxylative

$\mathrm{C}-\mathrm{H} / \mathrm{C}-\mathrm{O}$ Functionalization in Water

5.3.6 Data for Synergistic Manganese(I)-Catalyzed Chem-Selective C-H Hydroarylation in Continous Flow

5.3.7 Data for the Products of Quinazolines by Cobalt(III)-Catalyzed $\mathrm{C}-\mathrm{H} / \mathrm{N}-\mathrm{O}$

Functionalizations with Benzimidates

References

Acknowledgements

Curriculum Vitae 


\section{List of Abbreviations}

\begin{tabular}{|c|c|}
\hline Ac & acetyl \\
\hline acac & acetyl acetonate \\
\hline Alk & alkyl \\
\hline AMLA & ambiphilic metal-ligand activation \\
\hline aq. & aqueous \\
\hline $\operatorname{Ar}$ & aryl \\
\hline atm & atmospheric pressure \\
\hline BHT & 2,6-di-tert-butyl-4-methylphenol \\
\hline BIES & base-assisted internal electrophilic substitution \\
\hline $\mathrm{Bn}$ & benzyl \\
\hline Boc & tert-butyloxycarbonyl \\
\hline $\mathrm{Bu}$ & butyl \\
\hline $\mathrm{Bz}$ & benzoyl \\
\hline calc. & calculated \\
\hline cat. & catalytic \\
\hline CMD & concerted-metalation-deprotonation \\
\hline conv. & conversion \\
\hline $\mathrm{Cp} *$ & cyclopentadienyl \\
\hline Cy & cyclohexyl \\
\hline$\delta$ & chemical shift \\
\hline$d$ & doublet \\
\hline DCE & 1,2-dichloroethane \\
\hline dd & doublet of doublet \\
\hline DFT & density functional theory \\
\hline DG & directing group \\
\hline DME & dimethoxyethane \\
\hline DMF & $N, N$-dimethylformamide \\
\hline
\end{tabular}




\begin{tabular}{|c|c|}
\hline DMSO & dimethyl sulfoxide \\
\hline DMPU & 1,3-dimethyl-3,4,5,6-tetrahydro-2(1H)-pyrimidinone \\
\hline $\mathrm{dt}$ & doublet of triplet \\
\hline El & electron ionization \\
\hline equiv & equivalent \\
\hline ES & electrophilic substitution \\
\hline ESI & electronspray ionization \\
\hline Et & ethyl \\
\hline FG & functional group \\
\hline g & gram \\
\hline GC & gas chromatography \\
\hline h & hour \\
\hline Hal & halogen \\
\hline Het & hetero atom \\
\hline Hept & heptyl \\
\hline Hex & hexyl \\
\hline HPLC & high performance liquid chromatography \\
\hline HR-MS & high resolution mass spectrometry \\
\hline $\mathrm{Hz}$ & Hertz \\
\hline$i$ & iso \\
\hline IR & infrared spectroscopy \\
\hline IES & internal electrophilic substitution \\
\hline J & coupling constant \\
\hline KIE & kinetic isotope effect \\
\hline $\mathrm{L}$ & ligand \\
\hline$m$ & meta \\
\hline $\mathrm{m}$ & multiplet \\
\hline M & molar \\
\hline$[\mathrm{M}]^{+}$ & molecular ion peak \\
\hline
\end{tabular}




\begin{tabular}{|c|c|}
\hline Me & methyl \\
\hline Mes & mesityl \\
\hline $\mathrm{mg}$ & milligram \\
\hline $\mathrm{MHz}$ & megahertz \\
\hline $\min$ & minute \\
\hline $\mathrm{mL}$ & milliliter \\
\hline mmol & millimol \\
\hline M. p. & melting point \\
\hline MS & mass spectrometry \\
\hline$m / z$ & mass-to-charge ratio \\
\hline NCTS & $N$-cyano-4-methyl- $N$-phenyl benzenesulfonamide \\
\hline NMTS & $N$-cyano- $N$-(4-methoxy)phenyl-p-toluenesulfonamide \\
\hline NMP & $N$-methylpyrrolidinone \\
\hline NMR & nuclear magnetic resonance \\
\hline 0 & ortho \\
\hline OA & oxidative addition \\
\hline OPV & oil pump vacuum \\
\hline$p$ & para \\
\hline $\mathrm{Ph}$ & phenyl \\
\hline PMP & para-methoxyphenyl \\
\hline Piv & pivaloyl \\
\hline ppm & parts per million \\
\hline $\operatorname{Pr}$ & propyl \\
\hline PTSA & $p$-Toluenesulfonic acid \\
\hline py & pyridyl \\
\hline pym & pyrimidine \\
\hline pyr & pyrazol \\
\hline q & quartet \\
\hline RT & room temperature \\
\hline
\end{tabular}




$\begin{array}{ll}\text { S } & \text { singlet } \\ \text { sat. } & \text { saturated } \\ \text { SPS } & \text { solvent purification system } \\ t & \text { tert } \\ \mathrm{t} & \text { triplet } \\ \mathrm{T} & \text { temperature } \\ \text { THF } & \text { tetrahydrofuran } \\ \text { TLC } & \text { thin layer chromatography } \\ \text { TM } & \text { transition metal } \\ \text { TMP } & \text { 2,2,6,6-tetramethylpiperidine } \\ \text { TMS } & \text { trimethylsilyl } \\ \text { Ts } & \text { para-toluenesulfonyl } \\ \text { TS } & \text { transition state } \\ w t \% & \text { weight by volume }\end{array}$




\section{Introduction}

Life is based on the properties of carbon, which leads to the importance of organic molecules for the various species of living organisms as well as individuals. ${ }^{[1]}$ Most organic molecules have a carbon backbone, whose versatility provides the key skeleton to biomolecule structures. Understanding the chemical structures of organic molecules allows us to understand better the action of life and modification of them. The range of applications of organic molecules is enormous, which are widely found in pharmaceuticals, agrochemicals, materials, fuels and a vast number of other areas. ${ }^{[2]}$ As a consequence, methods to synthesize these complex molecules are highly desired not only in fundamental research but also in pharmaceutical and fine chemical industries. In modern synthetic chemistry, the main challenges are how to seek efficient, green and economic ways to construct chemical bonds from simple precursors.

Hydrocarbons are organic compounds consisting of hydrogen and carbon, which could be found in crude oil and natural gas. The efficiency of the transformation process of hydrocarbons into other more useful and high value organic molecules, such as alcohols, ketones and acids, is of high importance in chemical industies. ${ }^{[3]} \mathrm{C}-\mathrm{H}$ bonds are ubiquitous in organic molecules. Thus, from an atom- and step-economic point of view, the direct functionalization of $\mathrm{C}-\mathrm{H}$ bonds to $\mathrm{C}-\mathrm{C}$ and $\mathrm{C}-\mathrm{Het}$ (Het $=\mathrm{N}, \mathrm{O}, \mathrm{P}, \mathrm{S}, \mathrm{Si}$, etc.) bonds has emerged as one of the most straightforward and valuable approaches in organic synthesis.

Catalysis is one of the foundations of the chemical industry. Significant successes in this field of chemistry have already been achieved on solving numerous economic, environmental and technological problems during the last century. ${ }^{[4]}$ Furthermore, catalysis is also one of the twelve principles of green chemistry, as defined by Warner and Anastas in 1998. ${ }^{[5]}$ Therefore, the combination of direct $\mathrm{C}-\mathrm{H}$ activation and catalysis could provide a more effective, atom- and step-economic platform for developing novel products in synthetic chemistry. 


\subsection{Transition Metal-Catalyzed C-H Functionalizations}

\subsubsection{The Advantages of Transition Metal-Catalyzed C-H Activation}

The direct catalyzed $\mathrm{C}-\mathrm{H}$ functionalization is a highly important method, as it allows the conversion of $\mathrm{C}-\mathrm{H}$ bonds into valuable $\mathrm{C}-\mathrm{C}$ and $\mathrm{C}-\mathrm{Het}$ bonds. However, the main question is how to directly activate the $\mathrm{C}-\mathrm{H}$ bond. It is well known that the dissociation energy of $\mathrm{C}-\mathrm{H}$ bond is generally very high ( $\approx 110 \mathrm{kcal} \mathrm{mol}^{-1}$ for $\mathrm{C}\left(\right.$ aryl) $-\mathrm{H}$ and $\approx 105 \mathrm{kcal} \mathrm{mol}^{-1}$ for alkanes). ${ }^{[6]}$ In early studies the cleavage of $\mathrm{C}-\mathrm{H}$ bonds often required harsh reaction condition. ${ }^{[7]}$ Therefore, a strategy in which the transition metal catalyst directly reacts with a $\mathrm{C}-\mathrm{H}$ bond to generate a $\mathrm{C}-\mathrm{TM}$ bond under mild reaction conditions is an ideal option to achieve $\mathrm{C}-\mathrm{H}$ functionalization (Scheme 1.1.1a). The resulting $\mathrm{C}-\mathrm{TM}$ bonds are more reactive than the $\mathrm{C}-\mathrm{H}$ bonds, and can thus be easily converted to other valuable functional groups. Indeed, the last few decades have witnessed explosive progress in the field of transition metal-catalyzed $\mathrm{C}-\mathrm{H}$ functionalization. ${ }^{[8]}$

a)

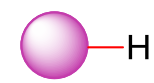

b)

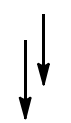

(1)

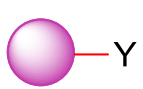

\section{[TM]}

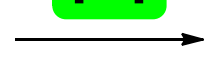

\section{[TM]}

$$
\mathrm{Y}=\mathrm{Sn}, \mathrm{B}, \mathrm{Zn}, \mathrm{Mg} \text {, etc. }
$$

Scheme 1.1.1 Transition metal-catalyzed C-H functionalization.

It is well known that traditional cross-coupling reactions have been one of the most useful synthetic methods for the formation of carbon-carbon bonds, such as Suzuki-Miyaura, Negishi and Heck reactions, which led to the 2010 Nobel Prize in chemistry. ${ }^{[9]}$ In these transformations, one of the key steps is the generation of the organometallic C-TM species (Scheme 1.1.1b). However, cross coupling reactions heavily rely on the transformations of various functional groups, thus requiring the pre-functionalized substrates, such as organic halides and organometallic compounds, such as highly reactive Grignard reagents. Moreover, some of the reagents are difficult to handle and store, 
and the generation of stoichiometric amounts of salt wastes, significantly decreases the atom- and step-economy. In sharp contrast, the direct transition metal-catalyzed $\mathrm{C}-\mathrm{H}$ activation could reduce the steps of those procedures, thus making the reaction cost-effective and environmentally-friendly. As a result, over the last 20 years creative applications of metal-catalyzed $\mathrm{C}-\mathrm{H}$ functionalizations have been made in the synthesis of natural products, pharmaceuticals, and functional materials, among others. ${ }^{[8]}$ For example, Stoltz and co-workers in 2002 completed the synthesis of dragmacidin D (1) in 25 steps, $^{[10]}$ while Yamaguchi and Itami in 2011 achieved it in only 15 steps based on three-fold $\mathrm{C}-\mathrm{H}$ arylation (Scheme 1.1.2). ${ }^{[11]}$ Therefore, the traditional synthetic methods could be revised by using $\mathrm{C}-\mathrm{H}$ functionalizations.

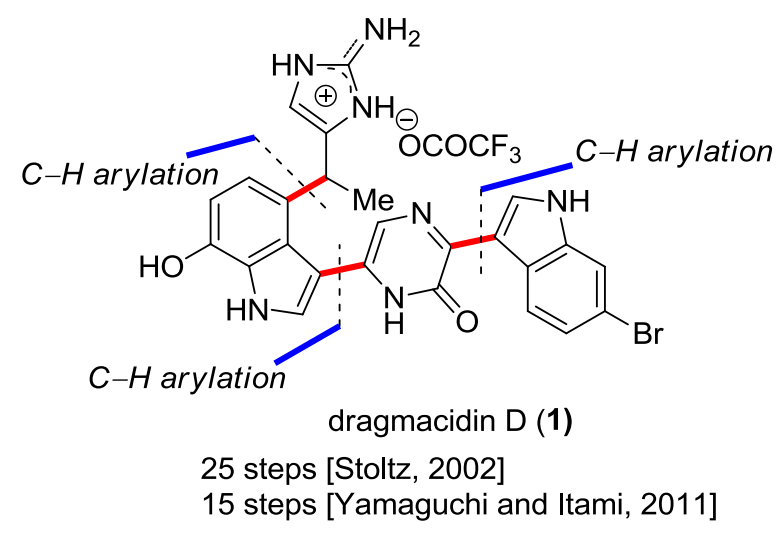

Scheme 1.1.2 Example of $\mathrm{C}-\mathrm{H}$ functionalizations in the total synthesis of natural product.

Meanwhile, experimental and computational mechanistic studies for transition metal-catalyzed $\mathrm{C}-\mathrm{H}$ functionalization have also provided detailed insights into those reactions. ${ }^{[12]}$ In many cases, the great achievements of $\mathrm{C}-\mathrm{H}$ activation have resulted from the good understanding of the reaction mechanism. Even though the details of reaction mechanism may change from in select cases, the catalytic cycle can be often devided into three main steps (Scheme 1.1.3): (i) the C-H activation; (ii) functionalization of the organometallic intermediate; and finally, (iii) regeneration of the active catalyst, in some cases, if required, an oxidant is needed. 


\subsubsection{Mechanistic Manifolds}

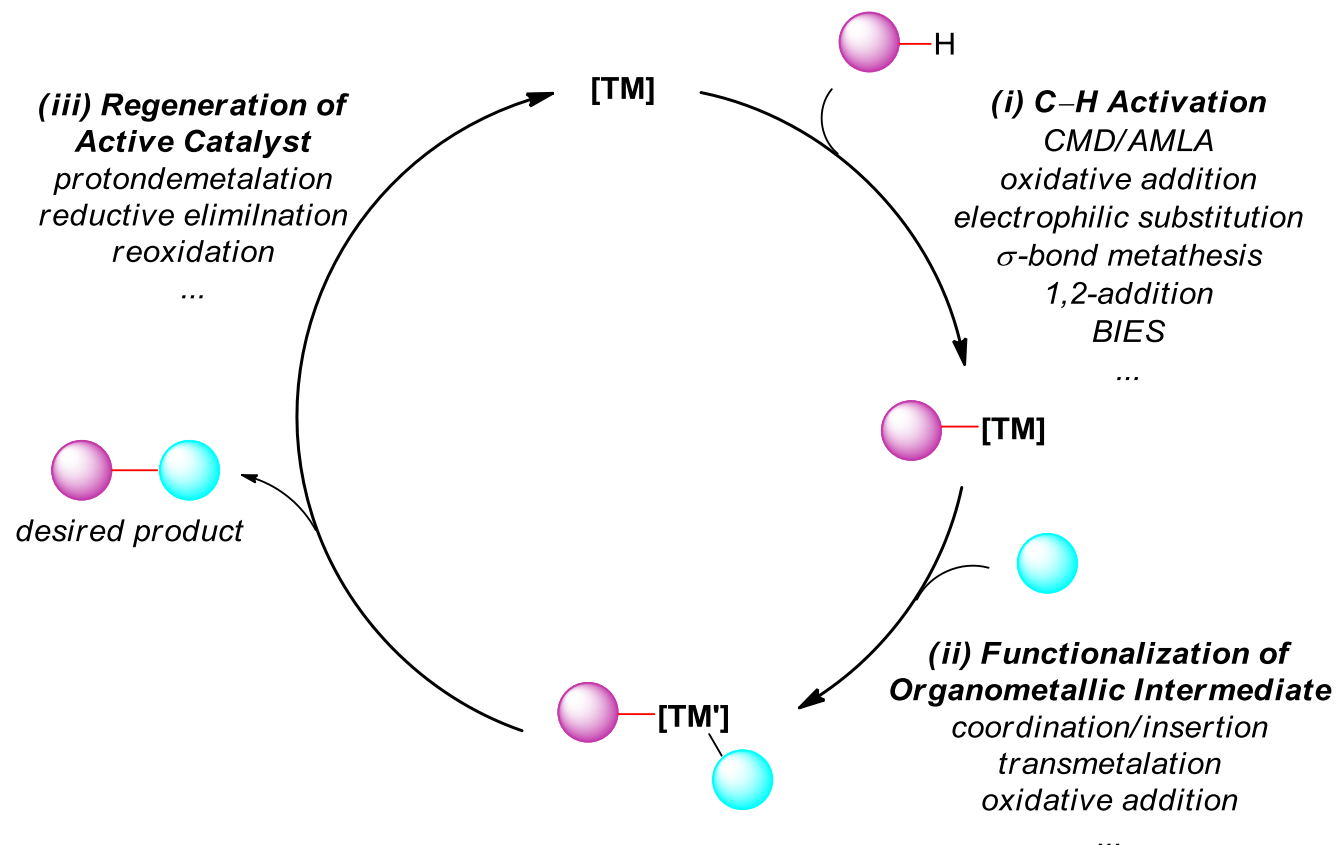

Scheme 1.1.3 General catalytic cycle for transition metal-catalyzed C-H activation reactions.

In general terms, the $\mathrm{C}-\mathrm{H}$ cleavage event is a key step of the mechanism. It is very important to understand how the $\mathrm{C}-\mathrm{H}$ bond can be cleaved by transition metals. Recent mechanistic studies indicated that several distinct transition states could be involved in the $\mathrm{C}-\mathrm{H}$ metalation step (Scheme 1.1.4). ${ }^{[13]}$ The possible mechanistic modes of action include: oxidative addition (OA); ${ }^{[14]}$ $\sigma$-bond metathesis $(\sigma-B M) ;^{[15]}$ electrophilic substitution (ES); $;^{[16]} 1,2$-addition; ${ }^{[17]}$ concerted metalation-deprotonation $(\mathrm{CMD}),^{[18]}$ also called ambiphilic metal ligand activation (AMLA); ${ }^{[19]}$ internal electrophilic substitution (IES) based on a four-membered transition state; ${ }^{[20]}$ and base-assisted internal electrophilic substitution (BIES) via a six-membered transition state. ${ }^{[21]}$ For example, a cobalt(III)-catalyzed $\mathrm{C}-\mathrm{H}$ alkylation provided the branched products based on a BIES-type addition, which has been studied by Ackermann and co-workers using detailed experimental and computational methods. ${ }^{[22]}$ 


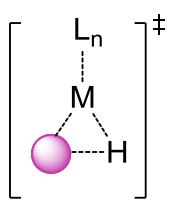

$\mathrm{OA}$

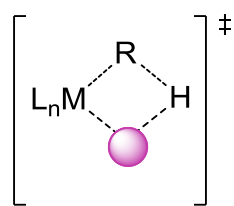

$\sigma-B M$

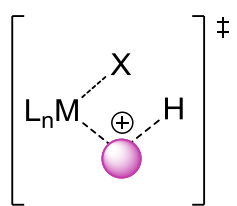

ES

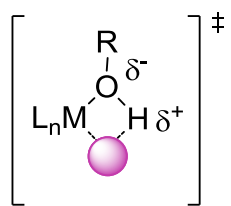

IES

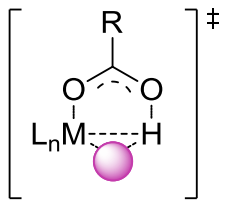

CMD/AMLA

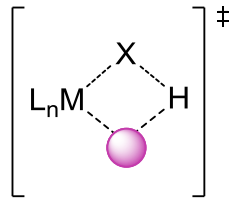

1,2-Addition

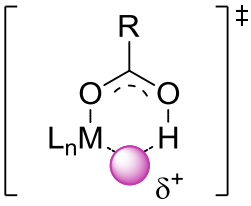

BIES

Scheme 1.1.4 Possible transition states for $\mathrm{C}-\mathrm{H}$ metalation.

\subsubsection{Selectivity Control in Transition Metal-Catalyzed C-H Functionalizations}

Although the strategy of direct $\mathrm{C}-\mathrm{H}$ functionalization has enormous potential in synthetic chemistry, there are still some fundamental challenges which have to be addressed. The $\mathrm{C}-\mathrm{H}$ bonds are ubiquitous in organic molecules and often exhibit similar dissociation energies. Therefore, selective and efficient functionalization of one specific $\mathrm{C}-\mathrm{H}$ bond is highly challenging. This goal has been identified as the "Holy Grail" of organic synthesis, ${ }^{[23]}$ and several different strategies have been employed to address this issue (Scheme 1.1.5).

a) electronic bias (pKa-values)

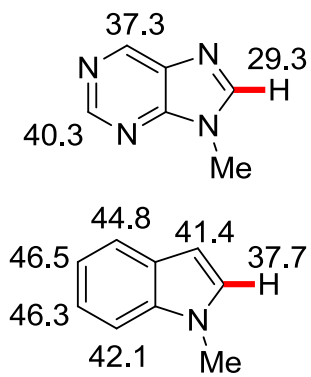

b) seric control

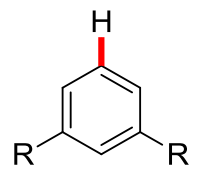

c) directing group (substrate contaning coordinating ligands)

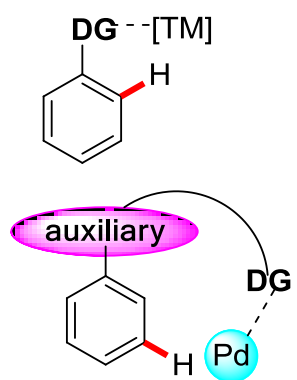

Scheme 1.1.5 Strategies to achieve site-selectivity in $\mathrm{C}-\mathrm{H}$ activation.

The site-selectivity can be controlled by (a) enhancing the acidity of specific $\mathrm{C}-\mathrm{H}$ bonds, ${ }^{[24]}$ (b) using sterically hindered substrates in combination with catalyst, ${ }^{[25]}$ and (c) using coordinating directing 
groups. ${ }^{[26]}$ However, due to the dependency on the substrate substitution patten, the first two strategies are difficult to be widely used in this field. In contrast, a variety of catalytic transformations have been achieved by using directing groups to control the site-selectivities. The directing group can be the part of various different substrates, and in many cases it also can be easily removed after the transformation. ${ }^{[27]}$ Generally, Lewis basic directing atom can coordinate to the metal center and bring the catalyst to a proximal $\mathrm{C}-\mathrm{H}$ bond. Then, the transition metal can directly activate this $\mathrm{C}-\mathrm{H}$ bond. Many different transition metals, such as palladium, rhodium, ruthenium and iridium, can undergo this cyclometalation step. ${ }^{[28]}$

In contrast, the rise of green chemistry has increased the emphasis on low-waste transformations. ${ }^{\text {[29] }}$ The same strategy generally could reduce the cost and toxicity of the reaction by employing $3 d$ metals, such as cobalt and manganese.

\subsection{Cobalt(III)-Catalyzed C-H Activation}

Although transition metal-catalyzed $\mathrm{C}-\mathrm{H}$ functionalization has been considered as one of the most powerful and reliable tools for constructing $\mathrm{C}-\mathrm{C}$ and $\mathrm{C}-\mathrm{Het}$ bonds over the last decades, precious metals, such as palladium, ${ }^{[30]}$ rhodium, ${ }^{[31]}$ platinum, ${ }^{[32]}$ ruthenium $^{[33]}$ and iridium ${ }^{[34]}$ have been thus far dominant in this field. However, there are some problems associated with their continuous use in catalytic processes, such as their low natural abundance, ${ }^{[35]}$ high cost and toxicity. ${ }^{[36]}$ In contrast, the inexpensive, Earth-abundant, and low toxic base metals could serve as a suitable alternative to precious metals for $\mathrm{C}-\mathrm{H}$ activation. As a result, various inexpensive early transition metals have recently attracted much attention in the area of $\mathrm{C}-\mathrm{H}$ activations. In this regard, cobalt is an attractive candidate because of its unique properties. ${ }^{[3]}$ Compared with $4 \mathrm{~d}$ transition metals, for example rhodium, cobalt exhibits a lower electronegativity leading to the formation of more nucleophilic intermediates, which could set the stage for unexpected reaction outcomes.

\subsubsection{Early Examples of Cobalt-Catalyzed C-H Activations}

In 1955, the first example of chelation-assisted cobalt-catalyzed C-H functionalization was disclosed by Murahashi, providing access to phthalimidine $\mathbf{3}$ or indazolone $\mathbf{5}$ through the carbonylation/cyclization of Schiff base with $\mathrm{CO}_{2}(\mathrm{CO})_{8}$ as the catalyst (Scheme 1.2.1a). ${ }^{[38]}$ However, 
further applications were limited because of the harsh reaction conditions. Until recent years, only few examples have been sporadically reported for cobalt-catalyzed $\mathrm{C}-\mathrm{H}$ activation. For example, in 1973, Kochi and co-workers reported the first example of high-valent cobalt(III)-mediated trifluoroacetylation of aromatic compounds operating via a proposed SET mechanism (Scheme 1.2.1b). ${ }^{[39]}$ And in 1994, Kisch and coworkers developed the alkenylation of alkynes by well-defined

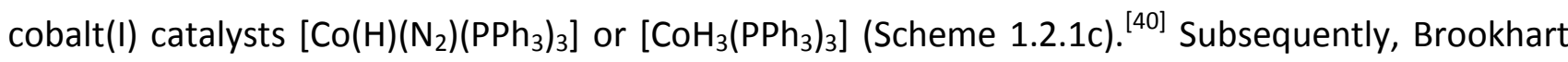
and coworkers developed various $\mathrm{Cp} * \mathrm{Co}(\mathrm{I})$-catalyzed $\mathrm{C}-\mathrm{H}$ functionalizations (Scheme 1.2.1d), including $\mathrm{C}-\mathrm{H}$ hydroacylation of olefins, ${ }^{[41]}$ synthesis of enamines by $\mathrm{C}\left(s p^{3}\right)-\mathrm{H}$ bond activation, ${ }^{[42]}$ and $\mathrm{C}-\mathrm{H}$ activation of simple benzene. ${ }^{[43]}$

a)

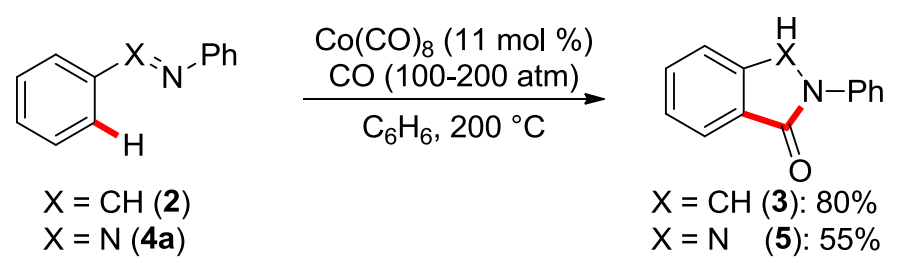

b)

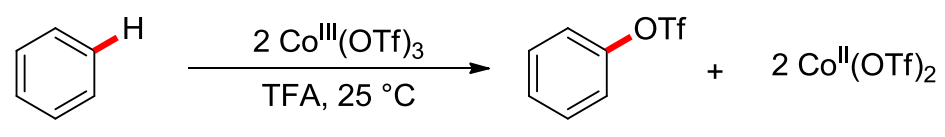

c) $\mathrm{v}$

6

7<smiles>[X]c1ccc([X])c(/N=N/c2ccccc2)c1[1H]</smiles>

$$
X=F(4 b)
$$

d)

$$
\mathrm{X}=\mathrm{Cl}(\mathbf{4 c})
$$
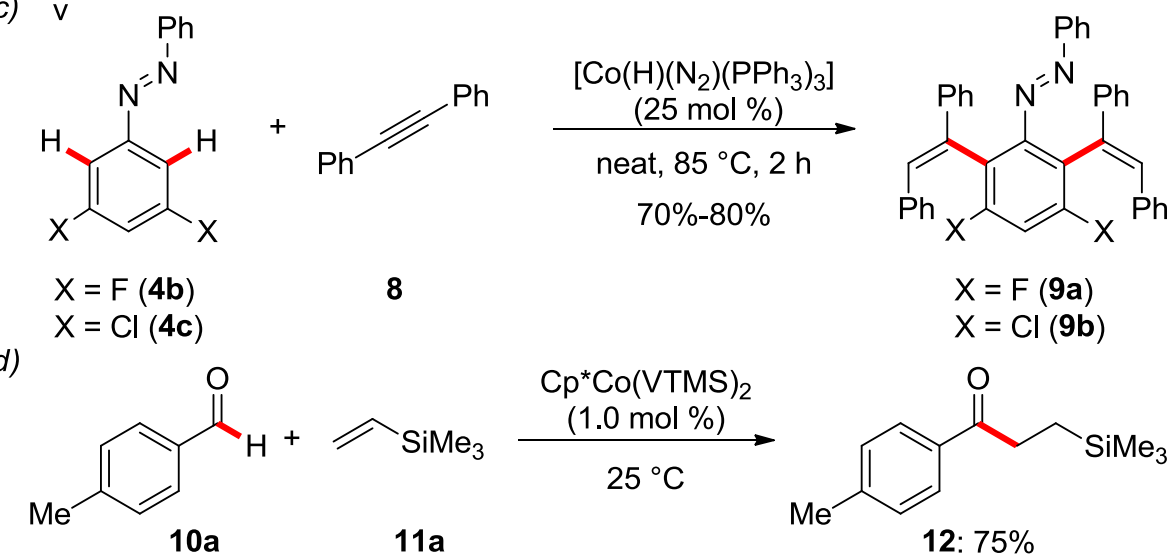

$$
\begin{aligned}
& X=F(9 a) \\
& X=C l(9 b)
\end{aligned}
$$

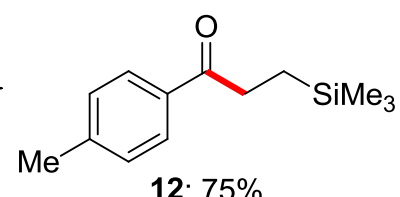

12: $75 \%$

Scheme 1.2.1 Early examples of cobalt-catalyzed/mediated $\mathrm{C}-\mathrm{H}$ activation.

It is noteworthy that a cyclometalated cobalt complex is often the key intermediate in $\mathrm{C}-\mathrm{H}$ activation catalytic cycles. Thus, the isolation and characterization of such cyclocobaltated complexes are essential to understand the mechanism of these reactions. In 1993, Klein and co-workers isolated the cyclometalated cobalt complex of azobenzene (4a) and phenyl phosphites (14) with stoichiometric $\left[\mathrm{Co}\left(\mathrm{CH}_{3}\right)\left(\mathrm{PMe}_{3}\right)_{4}\right] .{ }^{[44]}$ Later, the cyclometalation could be achieved with various substrates bearing different donor groups, featuring oxygen, ${ }^{[45]}$ nitrogen, ${ }^{[46]}$ sulfur, ${ }^{[47]}$ and 
phosphorus $^{[48]}$ (Scheme 1.2.2).

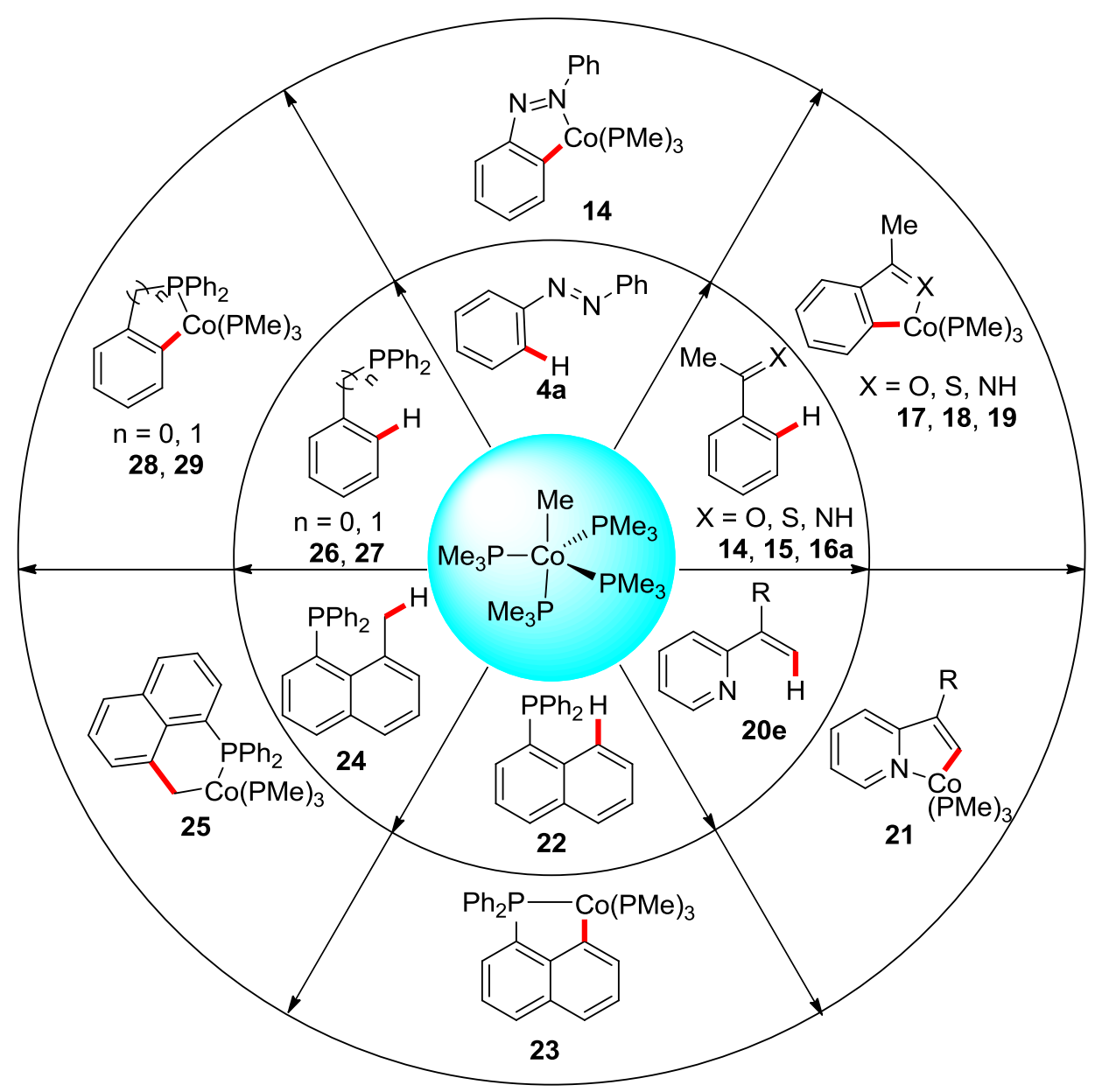

Scheme 1.2.2 Cyclocobaltated complexes prepared by $\mathrm{C}-\mathrm{H}$ activation using stoichiometric $\left[\mathrm{Co}\left(\mathrm{CH}_{3}\right)\left(\mathrm{PMe}_{3}\right)_{4}\right]$.

In 2008, Li and Wang also reported a cyclocobaltated complex of azobenzene (4) with hydroxyl as an additional donor group using stoichiometric $\mathrm{Co}\left(\mathrm{PMe}_{3}\right)_{3} \mathrm{Cl}$, along with the complete cleavage of the $\mathrm{N}=\mathrm{N}$ bond (Scheme 1.2.3). ${ }^{[49]}$

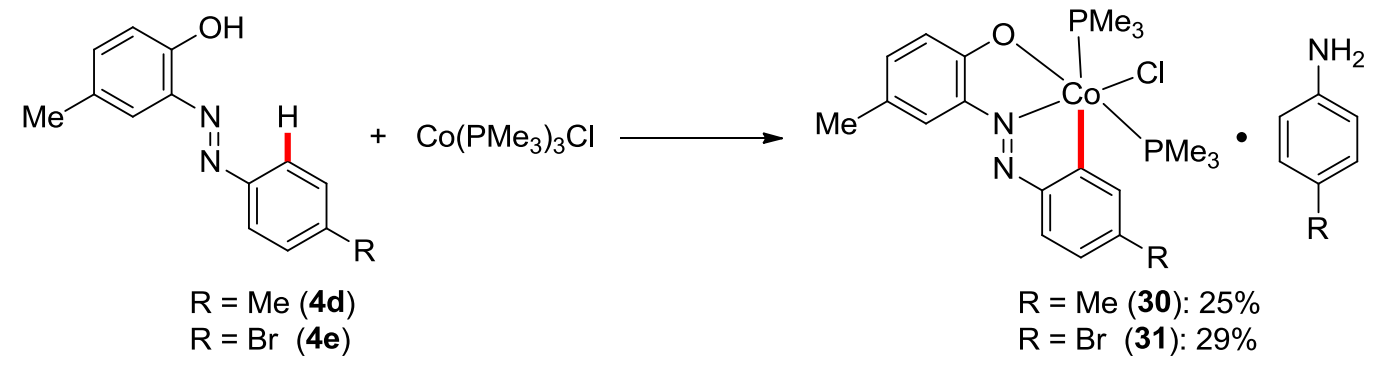

Scheme 1.2.3 Reaction of $\mathrm{Co}\left(\mathrm{PMe}_{3}\right)_{3} \mathrm{Cl}$ with 2-(arylazo)phenols for $\mathrm{C}-\mathrm{H}$ activation.

Based on the Kisch's work, significant contribution was achieved by Yoshikai and coworkers on the 
low-valent cobalt-catalyzed hydroarylation of internal alkynes 8 in 2010. ${ }^{[50]}$ The electron-rich cobalt species could be generated in situ from the simple cobalt(II) salts, phosphine ligands and Grignard reagents. The role of the Grignard reagent was proposed to serve as a base and a reductant in the reaction (Scheme 1.2.4). Thereafter, the low-valent cobalt-catalyzed $\mathrm{C}-\mathrm{H}$ functionalizations have been rapidly developed by the groups of Yoshikai, ${ }^{[8 a, 51]}$ Nakamura, ${ }^{[52]}$ Ackermann, ${ }^{[53]}$ among others $^{[54]}$ over the last 10 years. However, a disadvantage of this manifold is the requirement of large amount of Grignard reagents, which could make undesired coupling reactions, generate lots of metal wastes, and limit the functional group tolerance. Therefore, the development of new cobalt-catalyzed $\mathrm{C}-\mathrm{H}$ functionalizations without Grignard reagents under mild reaction conditions was in high demand.

a)<smiles>FC=C(F)F</smiles>

20a

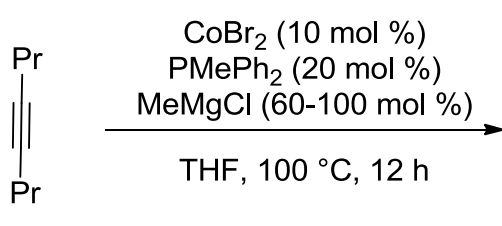

8I

b)<smiles>CC(=NP)c1ccccc1[18F]</smiles>

$34 a$
$8 a$<smiles>CCCC=Cc1ccccc1-c1ccccn1</smiles>

32: $4 \%$<smiles>CC=C(CCCC)c1cccc(C(=CPC)CC)c1-c1ccccn1</smiles>

33: $83 \%$

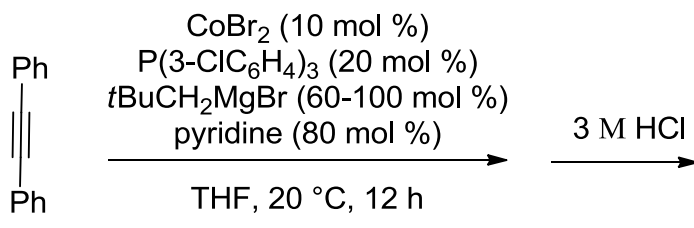

THF, $20^{\circ} \mathrm{C}, 12 \mathrm{~h}$

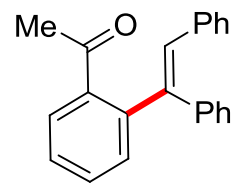

35: $90 \%(E / Z=89 / 11)$

Scheme 1.2.4 Low-valent cobalt-catalyzed hydroarylation of internal alkynes.

\subsubsection{High-Valent Cobalt(III)-Catalyzed C-H Activations}

Based on the earlier work of Brookhart, ${ }^{[55]}$ in 2013, a significant advance in high-valent cobalt(III)-catalyzed C-H activation was made by Matsunaga/Kanai and coworkers, which employed a Cp*Co(III)-type complexes as catalysts (Scheme 1.2.5a). ${ }^{[56]}$ This work showed the high catalytic activity of $\left[\mathrm{Cp}^{*} \mathrm{Co}\left(\mathrm{C}_{6} \mathrm{H}_{6}\right)\right]\left(\mathrm{PF}_{6}\right)_{2}(\mathbf{3 7})$ in addition reactions of 2-phenylpyridine (20a) to sulfonyl imines (36) and $\alpha, \beta$-unsaturated ketones (39). Afterwards, the same auther successfully extended this approach with catalytic amounts of cobalt complex 37 and KOAc to the $\mathrm{N}$-(2-pyrimidyl)-indole $(\mathbf{4 1 a})^{[57]}$ substrates (Scheme 1.2.5b). ${ }^{[58]}$ 
a)<smiles>O=C1CCC(c2ccccc2-c2ccccn2)C1</smiles>

38: $90 \%$

b)<smiles>c1cnc(-n2ccc3ccccc32)nc1</smiles>

41a

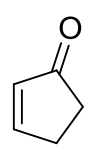

39

$\left[\mathrm{Cp} * \mathrm{Co}\left(\mathrm{C}_{6} \mathrm{H}_{6}\right)\right]\left(\mathrm{PF}_{6}\right)_{2}$

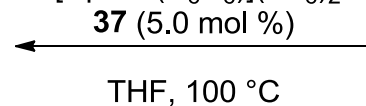
$24 \mathrm{~h}$<smiles>c1ccc(-c2ccccn2)cc1</smiles>

$20 a$<smiles>O=S(=O)(/N=C/c1ccccc1)c1cccs1</smiles>

36

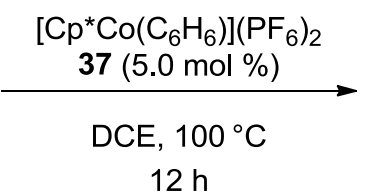

$12 \mathrm{~h}$<smiles>O=S(=O)(NC(c1ccccc1)c1ccccc1-c1ccccn1)c1ccccc1</smiles>

40: $80 \%$

b)

Scheme 1.2.5 Cobalt(III)-catalyzed hydroarylation of electrophiles via $\mathrm{C}-\mathrm{H}$ activation.

The following year, the same group further developed a more general catalytic system using $\mathrm{Cp} * \mathrm{Co}(\mathrm{CO}) \mathrm{I}_{2}$ in combination with a silver salt, which displayed a superior activity for $\mathrm{C}-2$ selective $\mathrm{C}-\mathrm{H}$ amidation of indoles 41a with sulfonyl azides (43) (Scheme 1.2.6). ${ }^{[59]}$ They also disclosed a procedure for preparing the catalyst of $\mathrm{Cp} * \mathrm{Co}(\mathrm{CO}) \mathrm{I}_{2}$ with slight modification of reported methods. ${ }^{[60]}$<smiles>c1cnc(-n2ccc3ccccc32)nc1</smiles>

41a

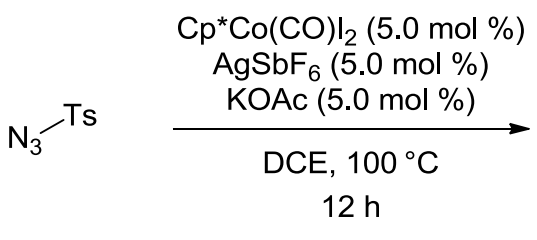

43

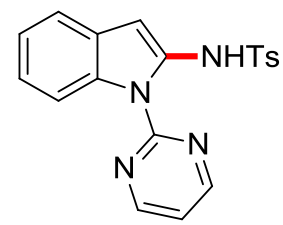

44: $92 \%$

Scheme 1.2.6 Cobalt(III)-catalyzed C-H amidation.

In 2014, Daugulis and coworkers also developed a new method for the Co(III)-catalyzed C-H alkenylation with alkynes with the aid of aminoquinolines $\mathbf{4 5}$ as the directing groups (Scheme 1.2.7). ${ }^{[61]}$ This reaction employed $\mathrm{Co}(\mathrm{OAc})_{2} \cdot 4 \mathrm{H}_{2} \mathrm{O}$ as the precatalyst, which then was oxidized in situ to the activated $\mathrm{Co}^{\text {III }}$ species by adding an external chemical oxidant of $\mathrm{Mn}(\mathrm{OAc})_{2}$. This reaction showed high functional group tolerance, and both internal and terminal alkynes were compatible 
with the coupling.<smiles>O=C(Nc1cccc2cccnc12)c1ccccc1</smiles>

45<smiles>[R]C#[R]</smiles>

8

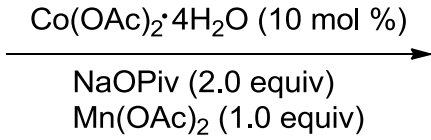

TFE, $80^{\circ} \mathrm{C}, 16 \mathrm{~h}$<smiles>[R]c1c([R])n(-c2cccc3cccnc23)c(=O)c2ccccc12</smiles>

46

Scheme 1.2.7 Cobalt(III)-catalyzed, aminoquinoline-directed $\mathrm{C}-\mathrm{H}$ bond alkenylation with alkynes.

Since then, the recent years witnessed a rapid growth in high-valent cobalt(III)-catalyzed $\mathrm{C}-\mathrm{H}$ functionalizations. The next chapter will discuss some typical examples of the high-valent $\mathrm{Cp} * \mathrm{Co}(\mathrm{III})$-catalyzed $\mathrm{C}-\mathrm{H}$ activation reactions.

\subsubsection{Cp*Co(III)-Catalyzed Cyanation and Halogenation}

In 2015, Ackermann and coworkers developed the first example of $\mathrm{Cp}{ }^{*} \mathrm{Co}(\mathrm{III})$-catalyzed $\mathrm{C}-\mathrm{H}$ cyanation of 2-phenylpyridines (20) and (hetero)arenes with $N$-cyano- $N$-phenyl- $p$ toluenesulfonamide (NCTS) (47a) as the cyanating reagent (Scheme 1.2.8) ${ }^{[62]}$. This reaction showed high functional group tolerance, as well as high site-selectivity and ample scope. The pyrimidyl group could be easily removed in a traceless fashion.

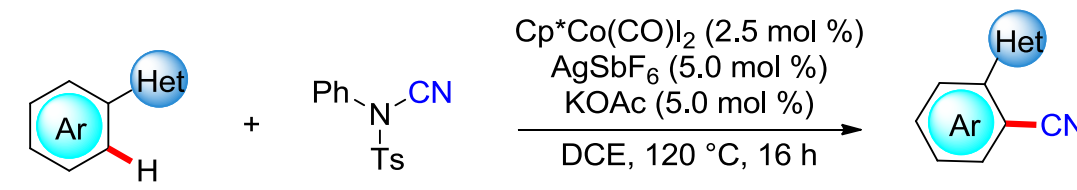

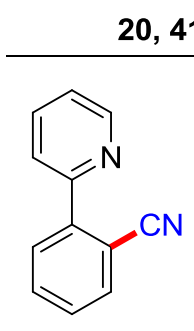

48a: $90 \%$<smiles>N#Cc1ccc(C(F)(F)F)cc1-c1ccccn1</smiles>

48b: $89 \%$<smiles>N#Cc1ccccc1-n1cccn1</smiles>

48c: $98 \%$
48, 49<smiles>[Z]n1c(C#N)cc2cc(NC(C)C)ccc21</smiles>

49a: $71 \%$

Scheme 1.2.8 Cobalt(III)-catalyzed C-H cyanation.

A plausible catalytic cycle was proposed for this cobalt(III)-catalyzed cyanation protocol. After reversible $\mathrm{C}-\mathrm{H}$ bond cobaltation of substrate $\mathbf{2 0}$ resulting from the active cationic cobalt species $\mathbf{5 0}$, 
thus generated the cobalt intermediate $\mathbf{5 1}$ undergoes coordination and insertion with NCTS (47a), and then affords the complex $\mathbf{5 3}$. The desired cyanation product $\mathbf{4 8}$ is obtained by $\beta$-elimination and the active cobalt(III) catalyst $\mathbf{5 0}$ is regenerated by proto-demetalation (Scheme 1.2.9).

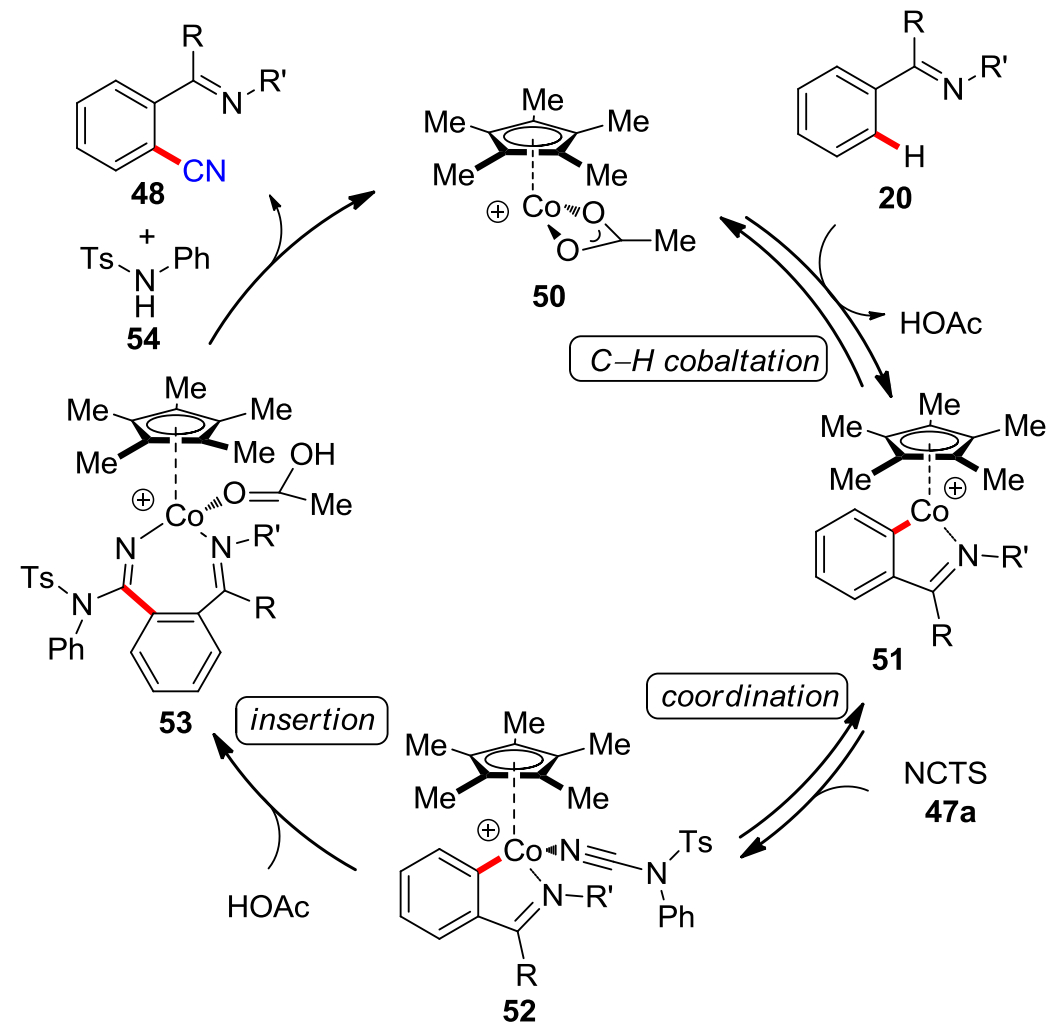

Scheme 1.2.9 Plausible catalytic cycle for cobalt(III)-catalyzed C-H cyanation.

Thereafter, Glorius and coworkers reported a similar work on cobalt(III)-catalyzed $\mathrm{C}-\mathrm{H}$ cyanation using $\mathrm{NaOAc}$ as the base (Scheme 1.2.10). ${ }^{[63]}$ At the same time, a selective $\mathrm{C}-\mathrm{H}$ halogenation in the presence of $\mathrm{Cp}^{*} \mathrm{Co}(\mathrm{CO}) \mathrm{I}_{2}, \mathrm{AgSbF}_{6}$, and $\mathrm{PivOH}$ was also developed.

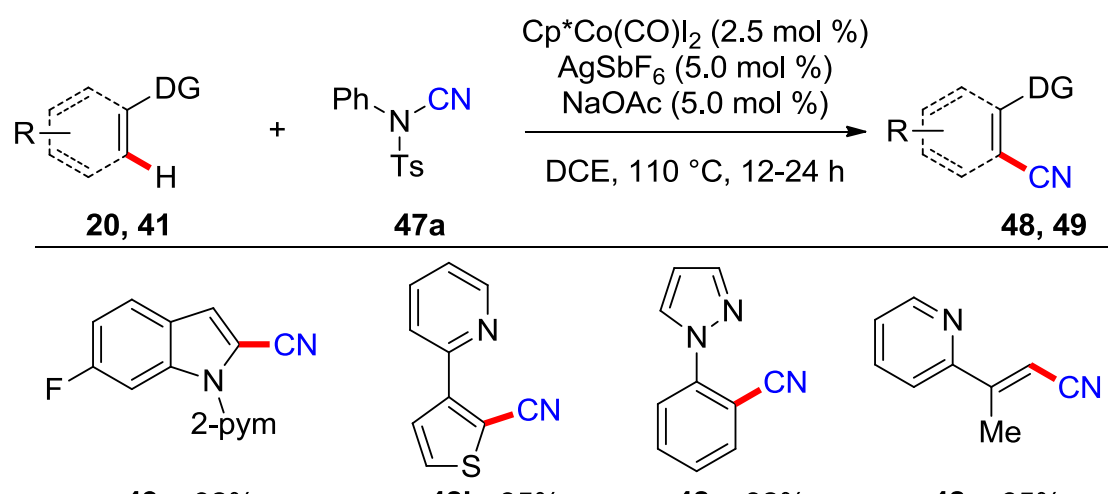

49a: $92 \%$

48b: $85 \%$

48c: $82 \%$

48e: $65 \%$

Scheme 1.2.10 Cobalt(III)-catalyzed C-H cyanation and halogenation. 
Moreover, a similar approach of $\mathrm{C}-\mathrm{H}$ cyanation was developed by Chang and coworkers using $\mathrm{N}$-cyanosuccinimide (51) as a more efficient cyanating reagent (Scheme 1.2.11). ${ }^{[64]}$. 6-Arylpurines $\mathbf{5 0}$ were found to be suitable substrates and furnished the desired products $\mathbf{5 2}$ in moderate to good yields

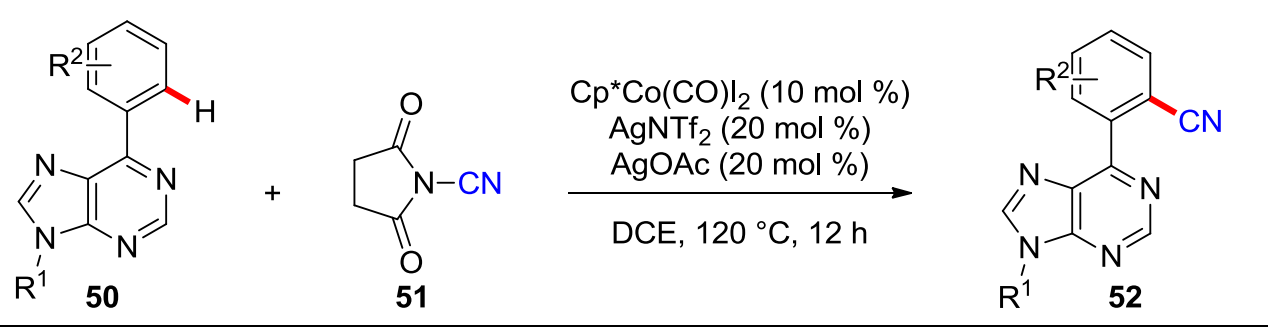

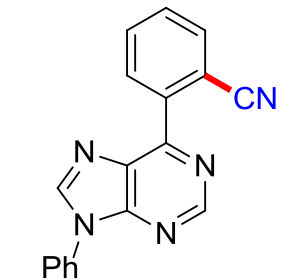

52a: $52 \%$<smiles>CCn1cnc2c(-c3ccccc3C#N)ncnc21</smiles>

52b: $70 \%$<smiles>N#Cc1cc(Cl)ccc1-c1ncnc2[nH]cnc12</smiles>

$\operatorname{PPr}^{\prime}$ 52c: $41 \%$<smiles>CC(C)n1cnc2c(-c3ccccc3C#N)ncnc21</smiles>

52d: $77 \%$

Scheme 1.2.11 Cobalt(III)-catalyzed C-H cyanation of arylpurines.

\subsubsection{Cp*Co(III)-Catalyzed Allylations}

The allyl group can be easily manipulated to access a wide variety of functionalized building blocks, ${ }^{[65]}$ making allylation reactions very important in organic synthesis. However, metal-catalyzed $\mathrm{C}-\mathrm{H}$ allylation reactions have been dominated by precious metals over the last decade. ${ }^{[66]}$ Recently, efforts toward cobalt(III)-catalyzed $\mathrm{C}-\mathrm{H}$ allylation have been made by Glorius, ${ }^{[63]}$ Ackermann, ${ }^{[67]}$ Matsunaga/Kanai, ${ }^{[68]}$ and $\mathrm{Li}^{[69]}$ Glorius and coworkers developed the cobalt(III)-catalyzed C-H allylation reactions of $N$-pyrimidylindoles 41 with allyl carbonates (53a) in the presence of $\mathrm{Cp}^{*} \mathrm{Co}(\mathrm{CO}) \mathrm{I}_{2}, \mathrm{AgSbF}_{6}$ and $\mathrm{PivOH}$ (Scheme 1.2.12). ${ }^{[63]} \mathrm{A}$ remarkable feature of this reaction was that when even lowering the $\mathrm{Cp}^{*} \mathrm{Co}(\mathrm{CO}) \mathrm{I}_{2}$ catalyst loading to $0.5 \mathrm{~mol} \%$, the desired $\mathrm{C}-2$ allylated indole products 54 could still be obtained over $90 \%$ yield at ambient temperature with a 2200 TON. 


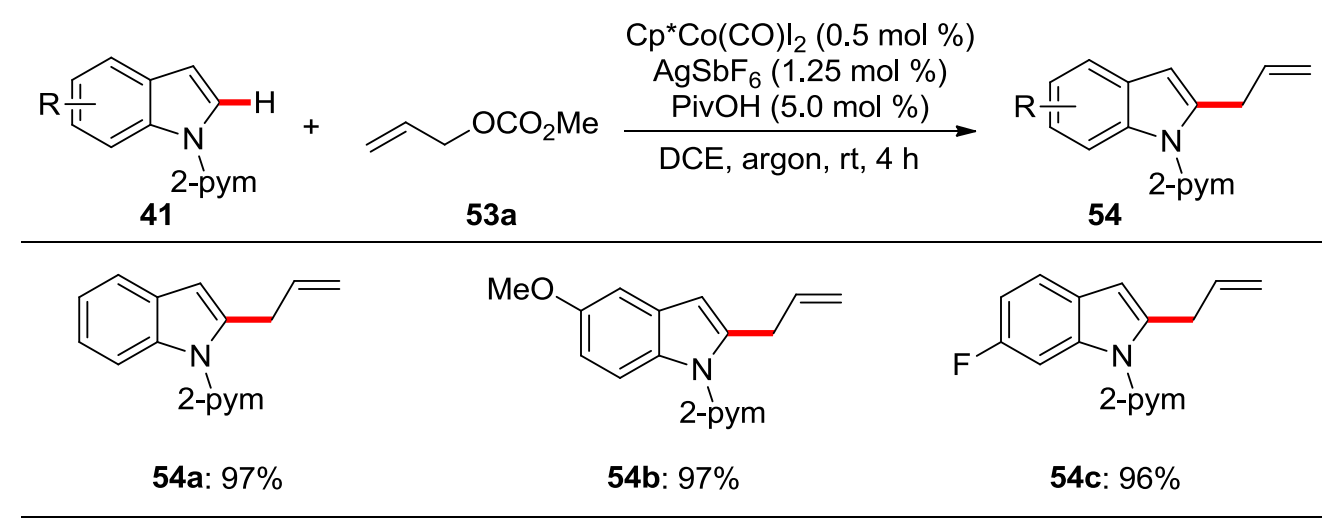

Scheme $\mathbf{1 . 2 . 1 2} \mathrm{Cp} * \mathrm{Co}(\mathrm{III})$-catalyzed $\mathrm{C}-\mathrm{H}$ allylation with allyl methyl carbonate 53a.

Matsunaga and Kanai developed the dehydrative allylation of indoles $\mathbf{4 1}$ with allylic alcohols (Scheme 1.2.13). ${ }^{[68 \mathrm{a}]}$ The desired products could be more efficiently obtained with $\mathrm{Cp} * \mathrm{Co}(\mathrm{CO}) \mathrm{I}_{2}$ compared with the analogous $\left[\mathrm{Cp}^{*} \mathrm{RhCl}_{2}\right]_{2}$ catalyst. Various functional groups were tolerated under the optimized conditions. The $\mathrm{Cp}{ }^{*} \mathrm{Co}(\mathrm{III})$ catalysis was successfully applied to 6-arylpurines 50, benzamides $\mathbf{5 5}$, and aromatic Weinreb amide substrates. ${ }^{[68 \mathrm{~b}]}$

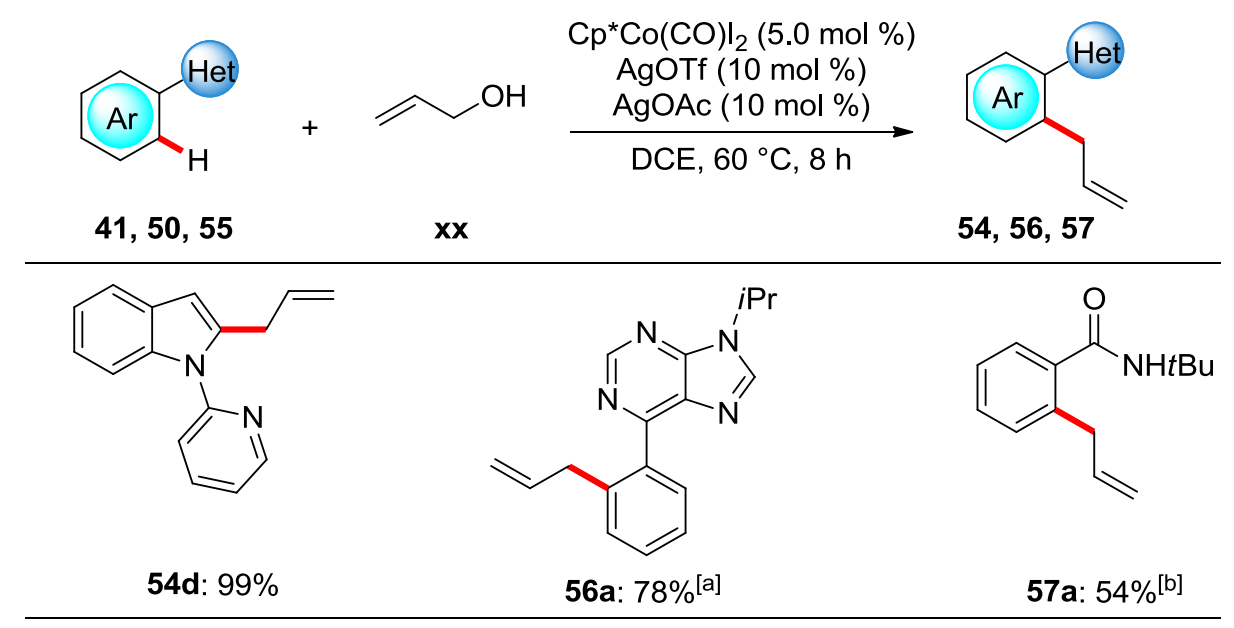

Scheme 1.2.13 $\mathrm{Cp}^{*} \mathrm{Co}(\mathrm{III})$-catalyzed $\mathrm{C}-\mathrm{H}$ allylation with prop-2-en-1-ol. ${ }^{[\mathrm{a}]}$ TFE as the solvent. ${ }^{[\mathrm{b}]}$ $20 \mathrm{~mol}^{\%} \mathrm{AgNTf}_{2}$ instead of AgOTf, HFIP as the solvent, $80^{\circ} \mathrm{C}, 24 \mathrm{~h}$. 
a)

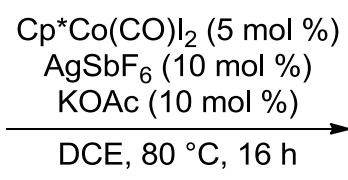

53c

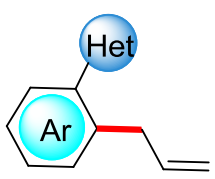

54,58

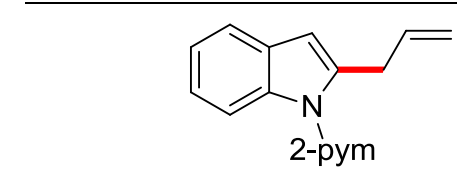

54a: $92 \%$

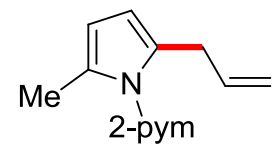

54e: $84 \%$

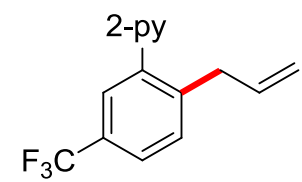

58a: $61 \%$

b)

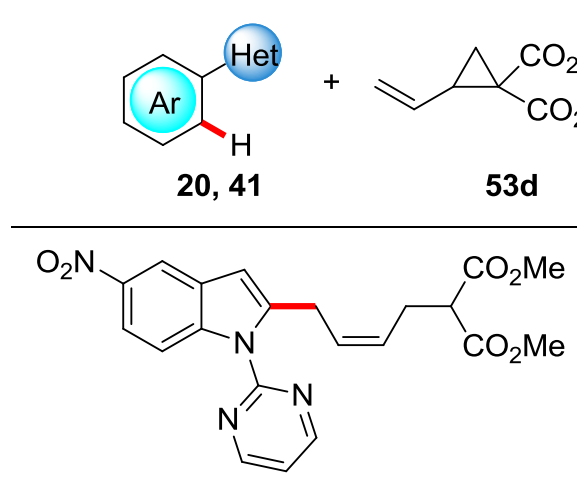

60a: $88 \%(E / Z: 1: 17)$

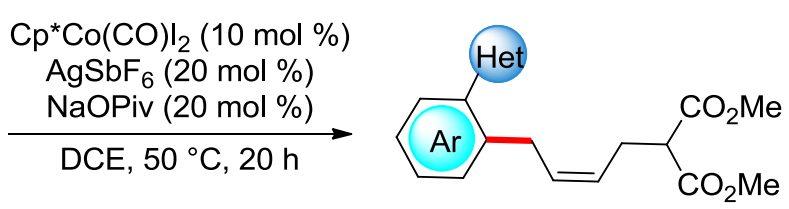

59,60

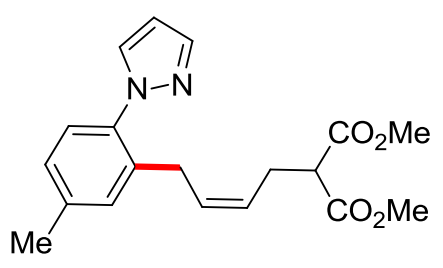

59a: $69 \%(E / Z: 1: 19)$

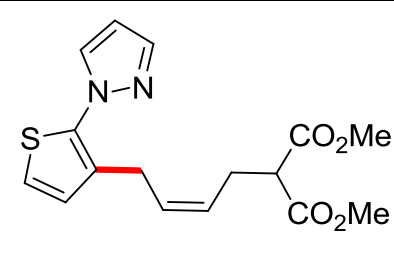

59b: $40 \%(E / Z: 1: 12)$

Scheme 1.2.14 $\mathrm{Cp}{ }^{*} \mathrm{Co}(\mathrm{III})$-catalyzed $\mathrm{C}-\mathrm{H}$ allylation via $\mathrm{C}-\mathrm{H} / \mathrm{C}-\mathrm{C}$ activation.

In 2015, Ackermann and coworkers disclosed a versatile cobalt(III)-catalyzed C-H allylation reaction on arenes 20, indoles 41, and pyrroles 20e with allyl acetates 53c (Scheme 1.2.14a). ${ }^{[67]}$ The following year, the same group also reported the Z-selective allylation via $\mathrm{C}-\mathrm{H} / \mathrm{C}-\mathrm{C}$ activation by cobalt(III) catalysis under mild conditions (Scheme 1.2.14b). ${ }^{[70]}$ Remarkably, this reaction showed a broad reaction scope and delivered the thermodynamically less stable (Z)-alkenes with excellent diastereoselectivity. Thereafter, $\mathrm{Li}$ developed a $\mathrm{C}-\mathrm{H} / \mathrm{C}-\mathrm{O}$ allylation reaction of $\mathrm{N}$-pyrimidinylindoles with strained rings such as 7-oxabenzonorbornadienes and 2-vinyloxirane under mild conditions. ${ }^{[69]}$ A plausible catalytic cycle of these cobalt(III)-catalyzed allylations is proposed to be initiated by the formation of an active cobalt species $\mathbf{6 1}$ from the precatalyst $\mathrm{Cp}^{*} \mathrm{Co}(\mathrm{CO}) \mathrm{I}_{2}$ and silver salts (Scheme 1.2.15). The following $\mathrm{C}-\mathrm{H}$ metalation resulting in the formation of complex 62 involves a BIES pathway. Subsequent coordination and olefin insertion give the intermediate 63, which then undergoes $\beta$-oxygen elimination to afford the desired product $\mathbf{5 4 a}$. The active cobalt catalyst $\mathbf{6 1}$ is then regenerated with the assistance of acid. 


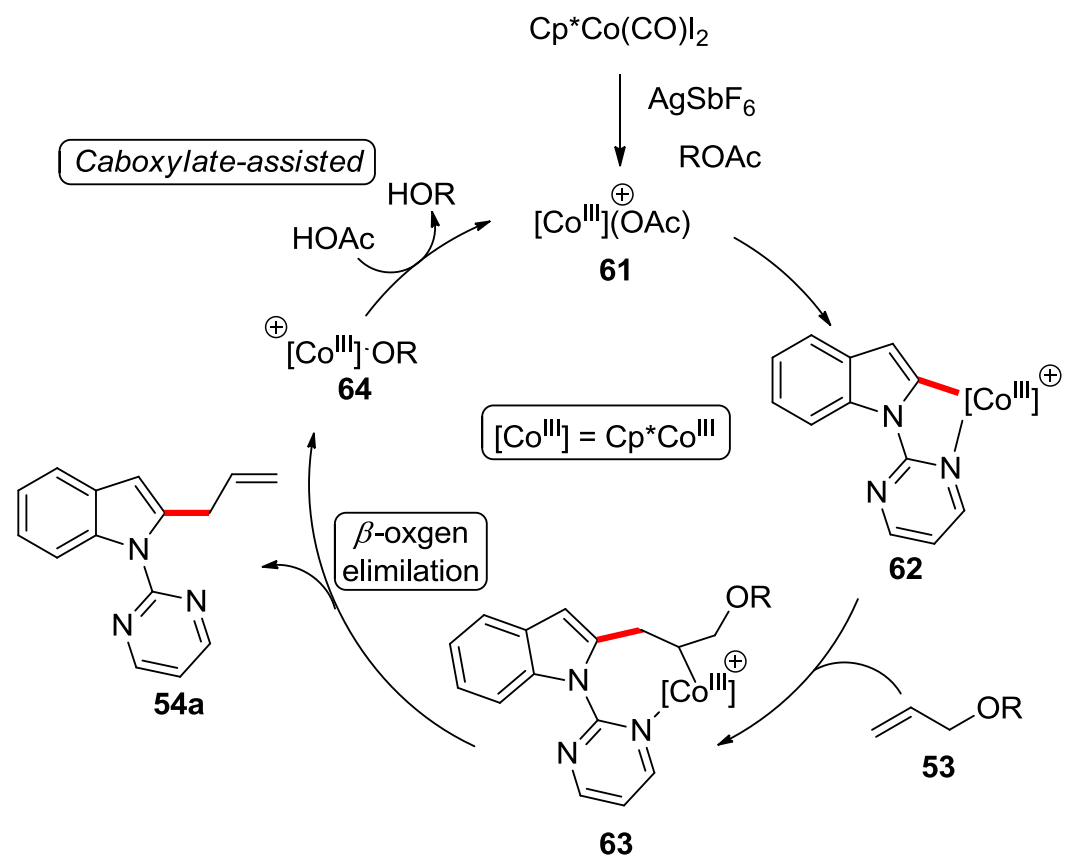

Scheme 1.2.15 Plausible catalytic cycle for cobalt(III)-catalyzed C-H allylation.

\subsubsection{Cp*Co(III)-Catalyzed Annulation}

Annulation reactions are among the most fundamental and useful transformation in organic synthesis. ${ }^{[71]}$ They provide a straightforward and step-economical method for the synthesis of heterocycles, which are important motifs in pharmaceuticals, natural products and agrochemicals. ${ }^{[72]}$ During the last years, a broad range of examples using $\mathrm{Cp}^{*} \mathrm{Co}(\mathrm{III})$-type catalysts for annulation reactions have been developed. ${ }^{[37 a, 37 b, 73]}$ Here, only selected examples of cobalt(III)-catalyzed annulation reactions will be discussed in this context.

Matsunaga and Kanai developed a $\mathrm{Cp} * \mathrm{Co}(\mathrm{III})$-catalyzed redox-neutral C-2 selective C-H alkenylation/annulation of $\mathrm{N}$-carbamoyl indoles 65 with internal alkynes 8 (Scheme 1.2.16). ${ }^{[74]}$ The intramolecular addition of an alkenyl-Cp*Co species 67 to a carbamoyl moiety provided pyrroloindolones 66 in moderate to good yields. A variety of unsymmetrical alkynes underwent this reaction smoothly and afforded the desired products in high yields and regioselectivities. In addition, when the reaction temperature was decreased to $80^{\circ} \mathrm{C}$, only simple $\mathrm{C}-\mathrm{H}$ alkenylated products were obtained. In contrast, the analogous $\mathrm{Cp} * \mathrm{Rh}$ (III) catalysis failed to achieve the intramolecular additions, highlighting the unique nucleophilicity of the organocobalt species. 


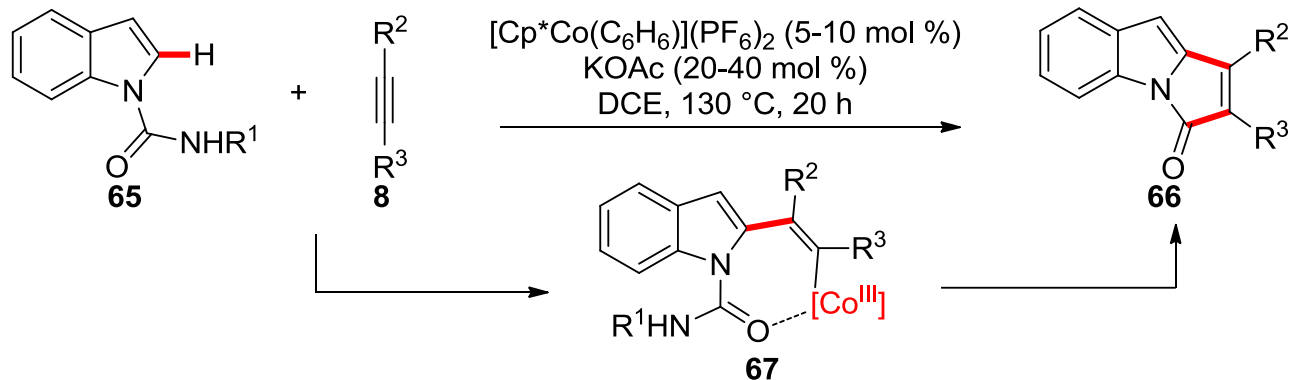

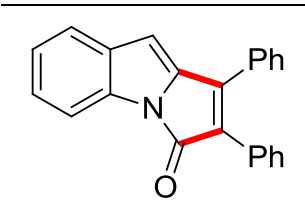

66a: $72 \%$

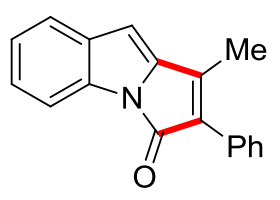

66b: $78 \%$<smiles>CC1=C(c2cccc3ccccc23)C(=O)n2c1cc1ccccc12</smiles>

66c: $89 \%$<smiles>CCCOCCOCCC1=C(c2ccccc2)C(=O)n2c1cc1ccccc12</smiles>

$66 \mathrm{~d}: 82 \%$

Scheme 1.2.16 Pyrroloindolone 66 synthesis via $\mathrm{Cp} * \mathrm{Co}(\mathrm{III})$-catalyzed $\mathrm{C}-\mathrm{H}$ alkenylation/annulation.

Ellman and Hummel disclosed a cobalt(III)-catalyzed $\mathrm{C}-\mathrm{H}$ addition reaction to aldehydes (Scheme 1.2.17). ${ }^{[75]}$ The air-stable cationic cobalt catalyst $\left[\mathrm{Cp} * \mathrm{Co}\left(\mathrm{C}_{6} \mathrm{H}_{6}\right)\right]\left[\mathrm{B}\left(\mathrm{C}_{6} \mathrm{H}_{5}\right)_{4}\right]_{2}$ was developed to achieve the cyclization and aromatization with a catalytic amount of $\mathrm{AcOH}$, affording $\mathrm{N}$-aryl-2H-indazoles $\mathbf{7 0}$ and furans 69 in good yield. A wide range of aryl, heteroaryl, and alkyl aldehydes were found to be suitable substrates, efficiently delivering the desired substituted heterocycles.<smiles>[R]C=C([R])C([R])=NOC</smiles>

68<smiles>[R]C1CCCCC1[R]</smiles>

4<smiles>[R]c1oc([R])c([R])c1[R]</smiles>

$\left[\mathrm{Cp}{ }^{*} \mathrm{Co}\left(\mathrm{C}_{6} \mathrm{H}_{6}\right)\right]\left[\mathrm{B}\left(\mathrm{C}_{6} \mathrm{~F}_{5}\right)_{4}\right]_{2}(10 \mathrm{~mol} \%)$ $\mathrm{AcOH}(10 \mathrm{~mol} \%)$

1,4-dioxane, $100{ }^{\circ} \mathrm{C}, 24 \mathrm{~h}$

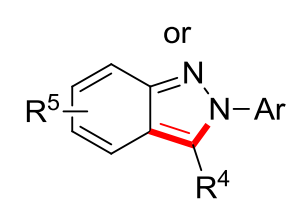

70

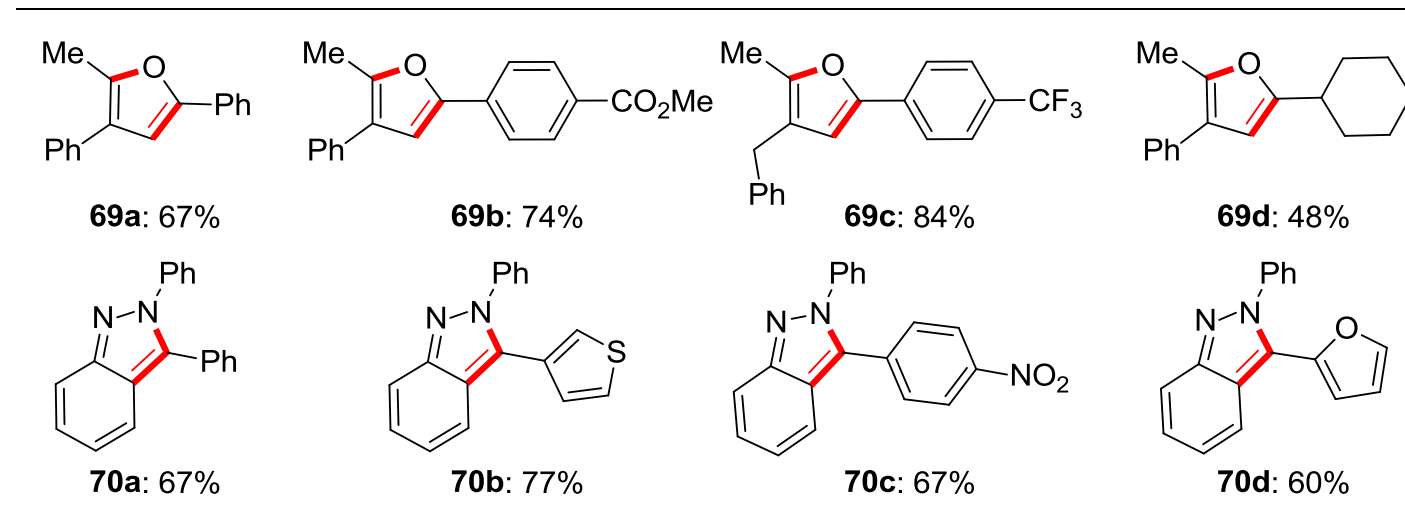

Scheme 1.2.17 Cp*Co(III)-catalyzed C-H hydroarylation/annulation of azos 4 and oximes 68 with 
aldehydes.

Recently, Ackermann and coworkers reported a $\mathrm{C}-\mathrm{H} / \mathrm{N}-\mathrm{H}$ bond functionalization for the synthesis of 1-aminoisoquinolines $\mathbf{7 3}$ from aryl benzimidamide $\mathbf{7 1}$ and diazo compounds $\mathbf{7 2}$ under mild conditions by cobalt(III) catalysis (Scheme 1.2.18). ${ }^{[76]}$ This reaction showed a broad substrate scope and functional groups tolerance. Moreover, $\mathrm{H}_{2} \mathrm{O}$ and $\mathrm{N}_{2}$ were the sole byproducts of the transformation, making the process environmentally-benign.<smiles>[R]NC(=N)c1cc[R1]cc1</smiles>

71<smiles>CCOC(=O)c1c(C)nc(NC(C)(C)C)c2ccc(F)cc12</smiles>

73a: $83 \%$<smiles>[R]C(=O)C([R])=[W]</smiles>

72<smiles>CCOC(=O)c1c(C)nc(NC(C)(C)C)c2ccsc12</smiles>

73b: $67 \%$

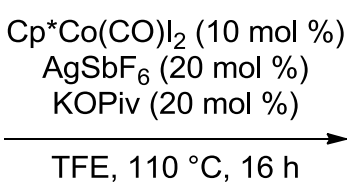

TFE, $110^{\circ} \mathrm{C}, 16 \mathrm{~h}$<smiles>[R]c1nc(C)c2ccccc2c1[R]</smiles>

73<smiles>COC(=O)c1c(C)nc(NC(C)(C)C)c2ccc(Cl)cc12</smiles>

73d: $71 \%$

Scheme 1.2.18 Cobalt(III)-catalyzed $\mathrm{C}-\mathrm{H} / \mathrm{N}-\mathrm{H}$ functionalization for the synthesis of isoquinolines 73 .

\subsubsection{Cp*Co(III)-Catalyzed Hydroarylation}

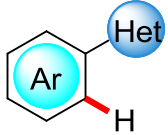

20,50

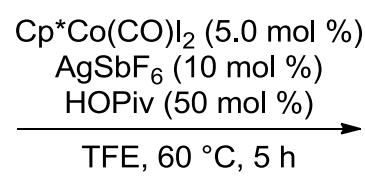

8

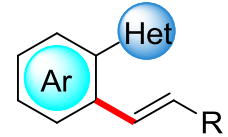

74, 75<smiles>C(=C/c1ccccc1-n1cccn1)\c1ccccc1</smiles>

74a: $75 \%$<smiles>C(=C/c1ccsc1-c1ccccn1)\c1ccccc1</smiles>

74b: $99 \%$<smiles>C(=C/c1ccccc1-c1ccccn1)\c1ccsc1</smiles>

74c: $90 \%$<smiles>CC(C)n1cnc2c(-c3ccccc3/C=C/c3ccccc3)ncnc21</smiles>

75a: $93 \%$

Scheme 1.2.19 Cp*Co(III)-catalyzed hydroarylation of alkynes. 
The $\mathrm{Cp}{ }^{*} \mathrm{Co}(\mathrm{III})$-catalyzed direct addition of unactivated arenes and 6-arylpurines to terminal alkynes under mild conditions was described by Yu and Chen in 2016 (Scheme 1.2.19). ${ }^{[77]}$ This process selectively provided only the $(E)$-stereoisomer in very high yield and also showed high functional group compatibility.

Recently, Ackermann and coworkers reported a cobalt(III)-catalyzed C-H alkylations with unactivated alkenes, in which the excellent regio-selectivities (linear-and branched-products) could be controlled by tunning the reaction conditions (Scheme 1.2.20). ${ }^{[22]} \mathrm{A}$ combination of $\mathrm{Cp} * \mathrm{Co}(\mathrm{CO}) \mathrm{I}_{2}$ and $\mathrm{AgSbF}_{6}$ was employed (under additive free conditions) to provide the linear anti-Markovnikov products 76. In contrast, when using sterically hindered 1- $\mathrm{AdCO}_{2} \mathrm{H}$ as the additive and decreasing the reaction temperature to $50{ }^{\circ} \mathrm{C}$, the unexpected branched-selective $\mathrm{C}-\mathrm{H}$ alkylation products 77 and $\mathbf{7 8}$ were obtained. Detailed mechanistic studies showed that the selectivity was obtained by a change of mechanism from a linear-selective ligand-to-ligand hydrogen transfer (LLHT) to a branched-selective base-assisted internal electrophilic-type substitution (BIES).

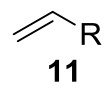

11

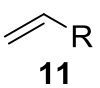

11
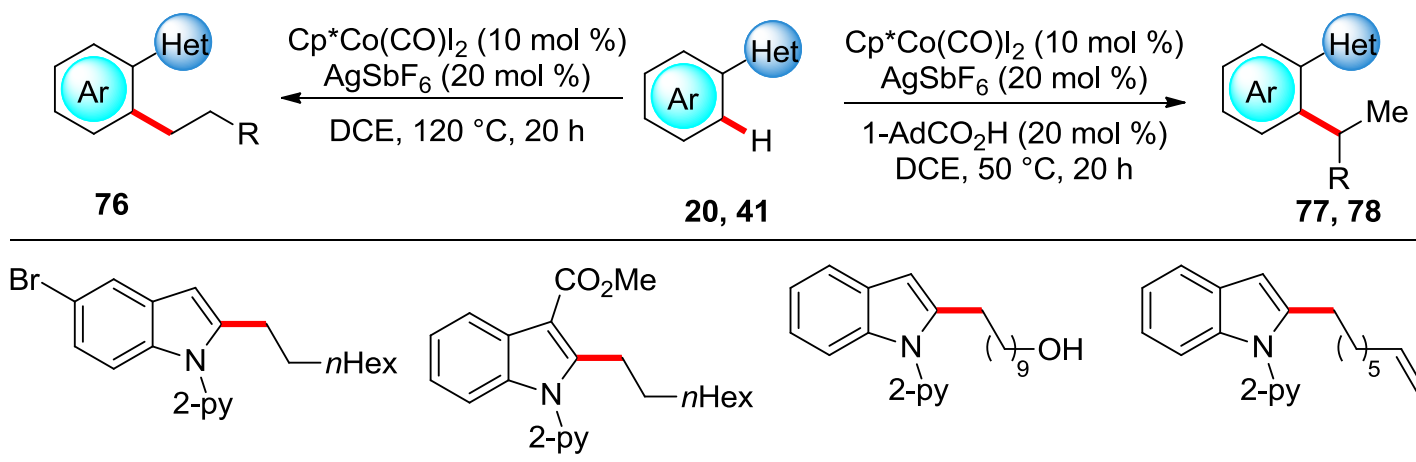

20,41

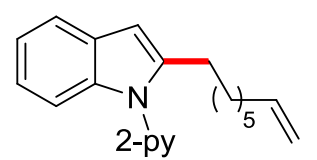

76a: $79 \%$ (> 99:1)

76b: $77 \%$ (> 99:1)

76c: $67 \%(>99: 1)$

76d: $66 \%(>99: 1)$

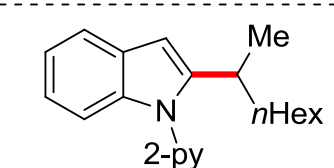

78a: $80 \%(95: 5)$

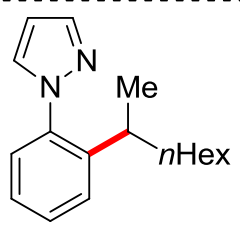

77a: $56 \%(91: 9)$

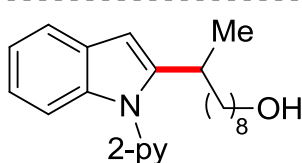

78b: $62 \%(92: 8)$

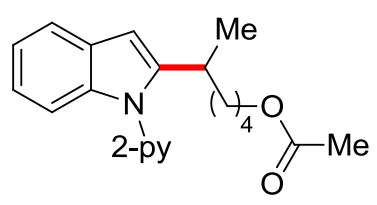

78c: $73 \%(99: 1)$

Scheme 1.2.20 Full selectivity control in cobalt(III)-catalyzed C-H alkylations.

\subsubsection{5 $\mathrm{Cp} * \mathrm{Co}(\mathrm{III})-$ Catalyzed $\mathrm{C}\left(s p^{3}\right)-\mathrm{H}$ activation}

Although great achievements in $\mathrm{Cp}{ }^{*} \mathrm{Co}(\mathrm{III})$-catalyzed $\mathrm{C}\left(s p^{2}\right)-\mathrm{H}$ bond functionalizations have been 
reported in recent years, significantly less efforts have been devoted to $\mathrm{C}\left(s p^{3}\right)-\mathrm{H}$ bond activation in this field. Thus, Sundararaju and coworkers reported the $\mathrm{C}\left(s p^{3}\right)-\mathrm{H}$ alkenylation of 8-methylquinolines 79 in the presence of catalytic amounts of $\mathrm{Cp} * \mathrm{Co}(\mathrm{CO}) \mathrm{I}_{2}, \mathrm{AdCO}_{2} \mathrm{H}$, and $\mathrm{AgOTf}$ (Scheme 1.2.21). ${ }^{[78]}$ Compared to $\mathrm{Cp} * \mathrm{Rh}(\mathrm{III})$ catalysis, stoichiometric amount of copper salts were not necessary in this $\mathrm{Cp}{ }^{*} \mathrm{Co}(\mathrm{III})$ catalysis. However, a low reactivity of aryl alkynes under the optimized conditions was observed. A Cp* $\mathrm{Co}(\mathrm{III})$-catalyzed $\mathrm{C}\left(s p^{3}\right)-\mathrm{H}$ amidation of 8-methylquinoline with dioxazolones was also developed. ${ }^{[79]}$

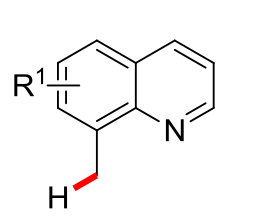

79

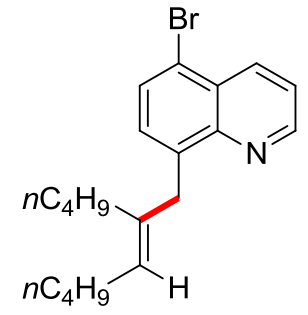

$80 \mathrm{a}: 85 \%$

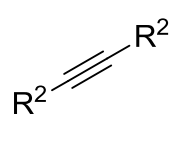

8

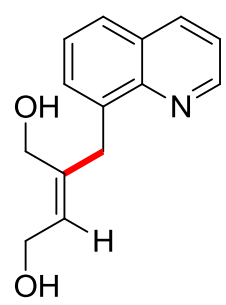

80b: $88 \%$
$\mathrm{Cp}^{*} \mathrm{Co}(\mathrm{CO}) \mathrm{I}_{2}(5.0 \mathrm{~mol} \%)$ $\mathrm{AdCO}_{2} \mathrm{H}(10 \mathrm{~mol} \%)$ AgOTf (10 mol \%)

TFE, $80^{\circ} \mathrm{C}, 24 \mathrm{~h}$

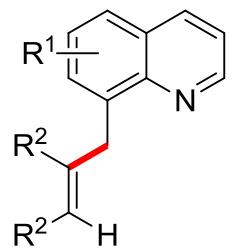

80<smiles></smiles>

80d: $35 \%$

Scheme 1.2.21 Cp*Co(III)-catalyzed $\mathrm{C}\left(s p^{3}\right)-\mathrm{H}$ alkenylation and amidation.

\subsubsection{Asymmetric Cp*Co(III)-Catalyzed C-H Functionalization}

Ackermann and coworkers disclosed the first enantioselective $\mathrm{Cp}^{*} \mathrm{Co}(\mathrm{III})$-catalyzed $\mathrm{C}-\mathrm{H}$ alkylation of indoles $\mathbf{8 1}$ with alkenes 11 using a novel chiral acid as ligand 83 (Scheme 1.2.22). ${ }^{[80]}$ A variety of substituted indoles and alkenes were successfully converted, yielding the corresponding products in moderate to good yields with high regio- and enantio-selectivities. A combination of experimental and computational studies in a chiral setting demonstrated that the $\mathrm{C}-\mathrm{H}$ activation step is reversible and the formation of the $(R)$-enantiomer could be rationalized by DFT studies. Moreover, the 5-methylpyridine could be easily removed, yielding the free indole 83 in $86 \%$ yield without loss in the enantiomeric excess. 


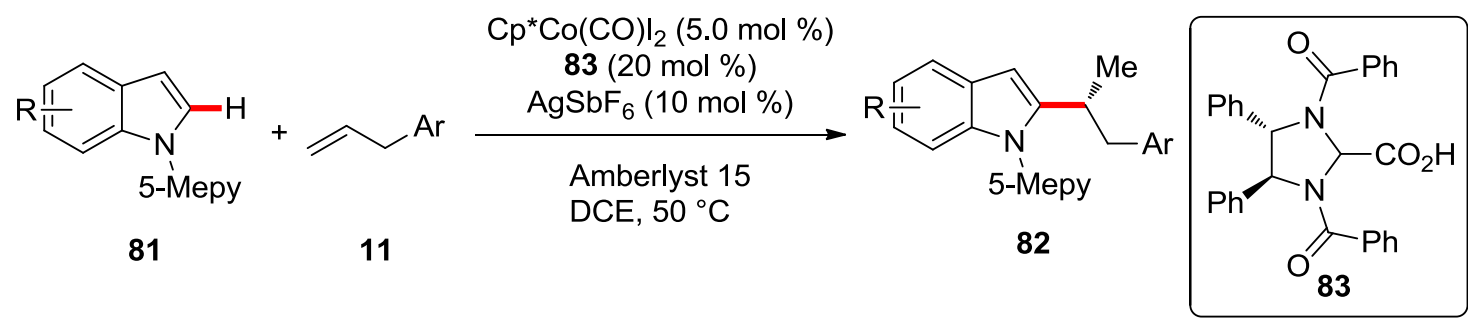

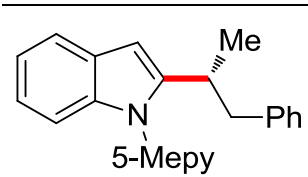

82a: 51\% (92:8) 92:8 e.r.

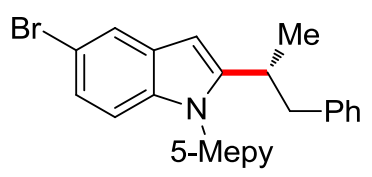

82b: $66 \%$ (94:6) 93:7 e.r.

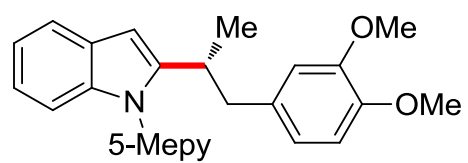

82c: $63 \%(91: 9)$ 92:8 e.r.

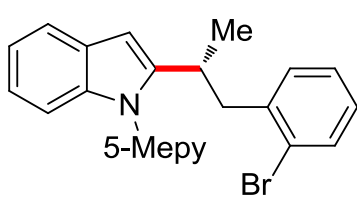

82d: $49 \%(86: 14)$ $92: 8$ e.r.

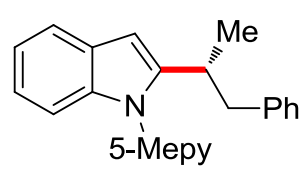

82c (92:8) 92:8 e.r.
1) $\mathrm{MeOTf}(1.2$ equiv)
$\mathrm{CH}_{2} \mathrm{Cl}_{2}, 0^{\circ} \mathrm{C}$ to $25^{\circ} \mathrm{C}, 6 \mathrm{~h}$
2) $\mathrm{Pd}(\mathrm{OH})_{2} / \mathrm{C}$ (10 wt.- $\left.\%\right)$
$\mathrm{HCO}_{2} \mathrm{NH}_{4}$ (10 equiv)

$\mathrm{MeOH}, 60^{\circ} \mathrm{C}, 6 \mathrm{~h}$

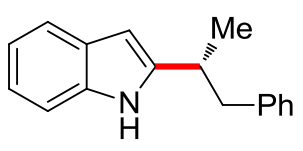

83: $86 \%(92: 8)$ 92:8 e.r.

Scheme 1.2.22 First example of $\mathrm{Cp}{ }^{*} \mathrm{Co}(\mathrm{III})$-catalyzed asymmetric reaction by $\mathrm{C}-\mathrm{H}$ activation.

\subsection{Manganese(I)-Catalyzed C-H Activation}

Although transition metal catalysis has revolutionized the hydrocarbon chemistry compared to traditional synthetic strategies, the field of $\mathrm{C}-\mathrm{H}$ functionalization to date was still dominated by precious metals. ${ }^{[81]}$ Recent developments have changed the potential of catalytic reactions using Earth-abundant $3 \mathrm{~d}$ metals, such as iron, cobalt, and manganese. ${ }^{[35 \mathrm{~b}]}$ In this regard, manganese is an attractive alternative for the $\mathrm{C}-\mathrm{H}$ activation catalysis due to its natural abundancy, low toxicity, and unique reactivity. The low toxicity is reflected by its key importance as an essential trace element for several organisms on Earth. ${ }^{[82]}$ The range of oxidation states of manganese is from -3 to +7 , which bears great potential of exhibiting extraordinary activity. The recent years have witnessed many advances in manganese-catalyzed $\mathrm{C}-\mathrm{H}$ functionalizations. ${ }^{\left[{ }^{83]}\right.}$

Only representative examples of manganese(I)-catalyzed $\mathrm{C}-\mathrm{H}$ functionalizations developed in recent years are summarized herein. The high-valent manganese species catalyzed $\mathrm{C}-\mathrm{H}$ oxygenations, ${ }^{[84]}$ halogenations, ${ }^{[85]}$ and nitrogenations ${ }^{[86]}$ via outer-sphere radical mechanisms are not discussed here. 


\subsubsection{Early Examples of Manganese-Catalyzed C-H Functionalizations}

An early example of stoichiometric manganese-mediated $\mathrm{C}-\mathrm{H}$ activation of azobenzene (4a) was reported by Stone/Bruce and coworkers in 1970 (Scheme 1.3.1). ${ }^{[87]}$ The cyclometalated manganese complex 85 could be isolated in $93 \%$ yield from the $\mathrm{MnMe}(\mathrm{CO})_{5}$ precursor under thermal conditions.<smiles>c1ccc(/N=N/c2ccccc2)cc1</smiles>

4a

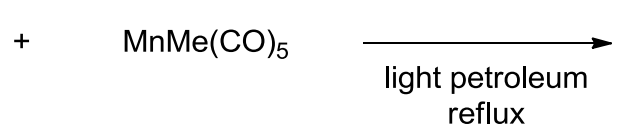

84

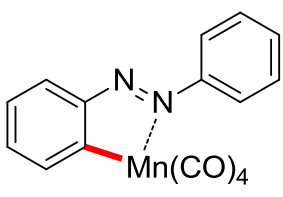

85: $93 \%$

Scheme 1.3.1 The first synthesis of five-membered manganaycle 85 via $\mathrm{C}-\mathrm{H}$ activation.

Based on the pioneering work of Stone and Bruce, a wide range of well-defined manganacycles were successfully prepared according to a similar strategy using stoichiometric amounts of $\mathrm{MnR}(\mathrm{CO})_{5}$ (with $\mathrm{R}=\mathrm{Me}, \mathrm{Bn}$, or $\mathrm{Ph}$ ). Notably, the directing groups were necessary for manganese to achieve the $\mathrm{C}-\mathrm{H}$ metalation. Representative directing groups include imidazole, ${ }^{[88]}$ azo $^{[89]}{ }^{\text {imino }}{ }^{[90]}$ amido, ${ }^{[91]}$ keton, ${ }^{[92]}$ and formyl, ${ }^{[93]}$ among others. ${ }^{\left[{ }^{[9]}\right.}$ The directing atom can bind to the manganese center of $\mathrm{MnR}(\mathrm{CO})_{5}$ and bring it to the proximal $\mathrm{C}-\mathrm{H}$ bond, which is followed by $\mathrm{C}-\mathrm{H}$ activation along with the release of $\mathrm{CO}$ and $\mathrm{RH}$.

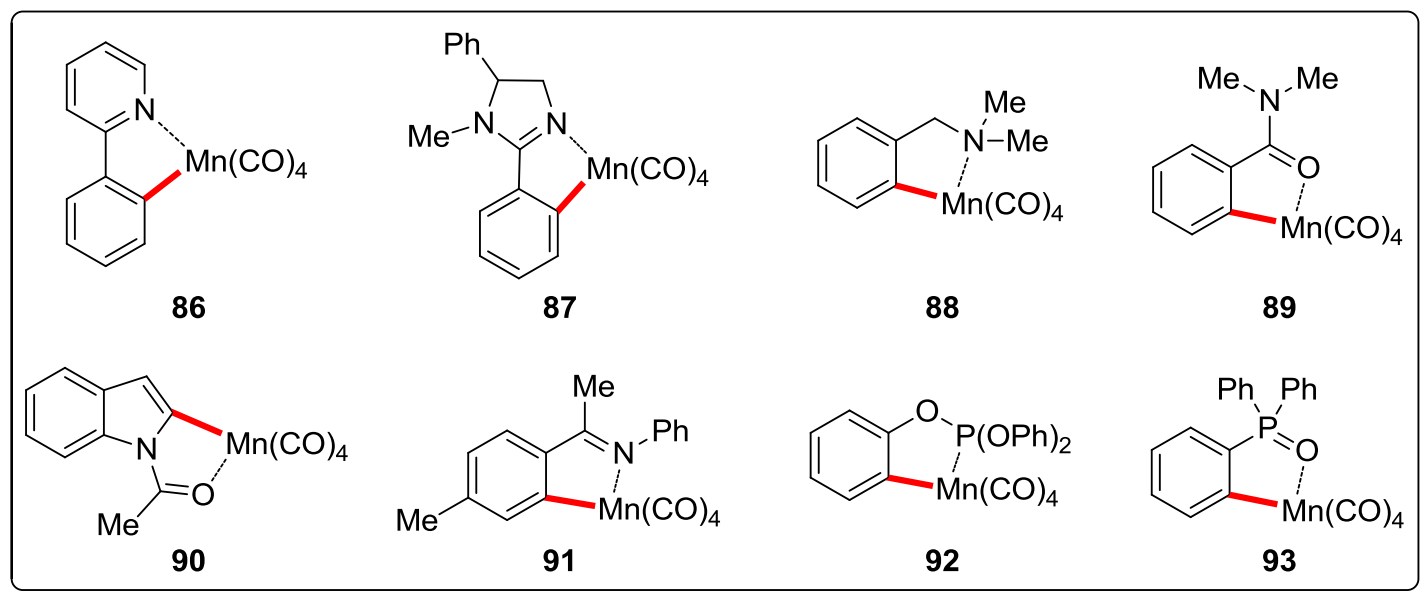

Scheme 1.3.2 Selected manganese complexes synthesized by $\mathrm{C}-\mathrm{H}$ activation from $\mathrm{MnR}(\mathrm{CO})_{5}$.

Although many years of research have passed since the initial synthesis of manganaycle complexes 
via $\mathrm{C}-\mathrm{H}$ activation, no directed manganese-catalyzed $\mathrm{C}-\mathrm{H}$ activation was developed until a reported by Kuninobu/Takai and coworkers in 2007. ${ }^{[95]}$ Here, the authors described the manganese(I)-catalyzed $\mathrm{C}-\mathrm{H}$ addition to aldehydes using imidazole as the directing group. In the course of their optimization studies, the stoichiometric reaction of 2-phenylimidazoles with $\mathrm{MnBr}(\mathrm{CO})_{5}$ was accomplished, followed by the addition to the $\mathrm{C}=\mathrm{O}$ bond of the aldehyde leading to the formation of alcohol. It was found that the catalytic reaction could only be achieved with the assistance of $\mathrm{Et}_{3} \mathrm{SiH}$. Remarkably, the authors demonstrated that stereoselective reactions of chiral imidazolines $\mathbf{9 4}$ with aldehydes $\mathbf{1 0}$ gave the desired products 95 in moderate to good yields with varying diastereomeric excesses of de: $30-95 \%$ (Scheme 1.3.3).

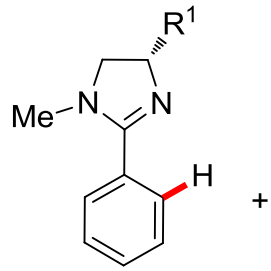

94

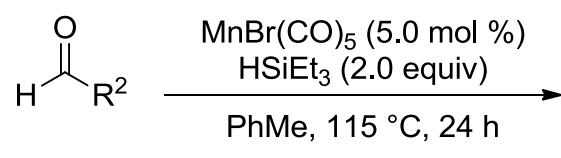

10

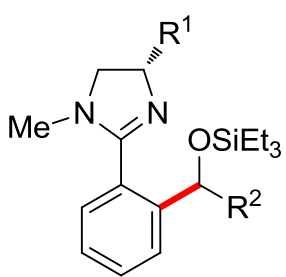

95

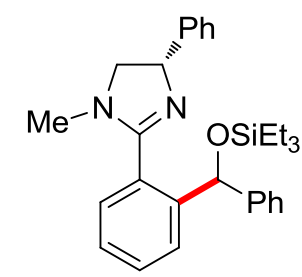

95a: $60 \%$ (de: $60 \%)$<smiles>CCOC(c1ccccc1)c1ccccc1C1=N[C@@H](Cc2ccccc2)CN1C</smiles>

95b: $72 \%(d e: 30 \%)$<smiles>CCOC(c1ccccc1)c1ccccc1C1=N[C@@H](C(C)C)CN1C</smiles>

95c: $80 \%(d e: 95 \%)$<smiles>CCOC(OCC)c1ccccc1C1=N[C@@H](C(C)C)CN1C</smiles>

95d: $68 \%(d e: 38 \%)$

Scheme 1.3.3 Manganese(I)-catalyzed hydroarylation of aldehydes by Kuninobu and Takai et al.

Moreover, a plausible mechanism was proposed by Kuninobu and Takai. First, the $\operatorname{MnBr}(\mathrm{CO})_{5}$ undergoes $\mathrm{C}-\mathrm{H}$ activation by oxidative addition, furnishing the $\mathrm{Mn}(\mathrm{III})$-hydride species $\mathbf{9 6}$. Then, a migratory insertion of the aldehyde into the manganese-carbon bond forms the intermediate $\mathbf{9 7}$. Finally, the desired product 95 is released along with $\mathrm{H}_{2}$ by treatment with $\mathrm{Et}_{3} \mathrm{SiH}$ (Scheme 1.3.4). 
<smiles>[R]C(OCC)c1ccccc1-c1nccn1C</smiles>

95

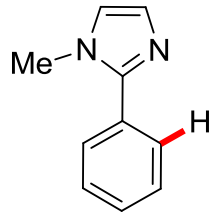

94a

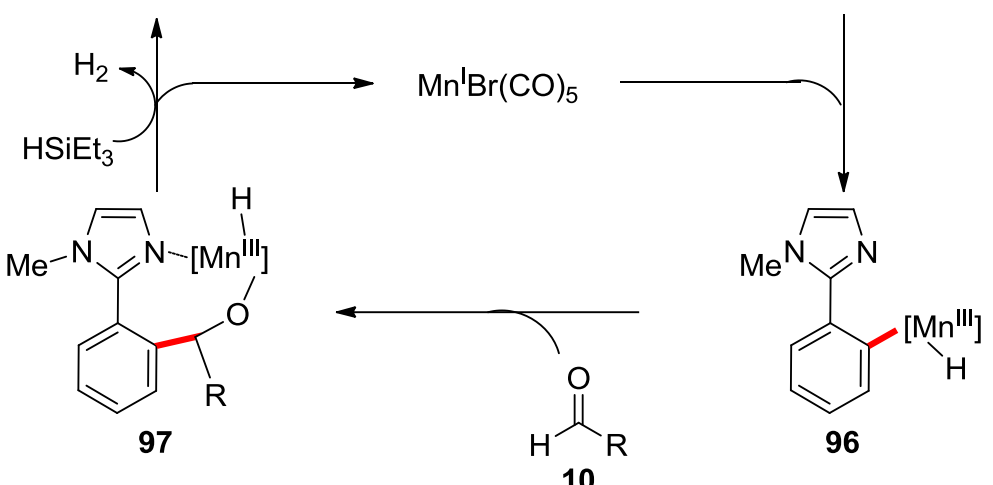

Scheme 1.3.4 Proposed mechanism for the hydroarylation of aldehydes.

\subsubsection{Examples of Manganese(I)-Catalyzed C-H Functionalizations}

\subsubsection{Manganese(I)-Catalyzed C-H Hydroarylations}

In 2013, Wang and coworkers reported the manganese-catalyzed $\mathrm{C}-\mathrm{H}$ alkenylation of 2-phenylpyridines 20 with terminal alkynes $\mathbf{8}$ in the presence of $\mathrm{Cy}_{2} \mathrm{NH}$ as the base (Scheme 1.3.5a). ${ }^{[96]}$ From the optimized conditions, weak organic bases showed better performance than strong bases. Moreover, this hydroarylation process exhibited high $(E)$-diastereo, regio-, and mono-selectivities. Various functional groups, such as fluoro, chloro, bromo, iodo, ester, and nitro groups were well tolerated under the optimized conditions.

Furthermore, Li and coworkers also reported in 2015 a similar manganese-catalyzed C-H alkenylation reaction of indoles 41 a using benzoic acid as the additive instead of the $\mathrm{Cy}_{2} \mathrm{NH}$ base. ${ }^{[97]}$ The authors proposed that the benzoic acid serves as the selectivity controlling element via a $H$-transfer process (Scheme 1.3.5b). Very recently, Fairlamb/Lynam and coworkers described a highly reactive seven-membered $\mathrm{Mn}(\mathrm{I})$ intermediate 100, which was shown to be effective for $H$-transfer to provide alkenylated products 101 (Scheme 1.3.5c). ${ }^{[98]}$ The detailed computational studies provided novel insights into the mechanism for manganese-catalyzed $\mathrm{C}-\mathrm{H}$ activation. 
a)<smiles>[R1]1ccccc1-c1ccccn1</smiles>

20

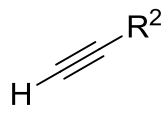

8

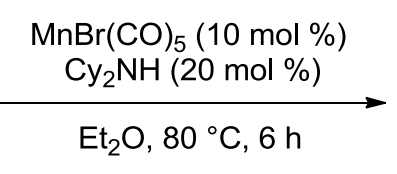

$\mathrm{Et}_{2} \mathrm{O}, 80^{\circ} \mathrm{C}, 6 \mathrm{~h}$

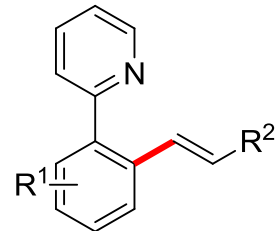

74<smiles>[R20]c1ccccc1/C=C/c1cccs1</smiles>

74d: $51 \%\left[{ }^{[a]}\right.$

$74 \mathrm{e}: 68 \%{ }^{[a]}$

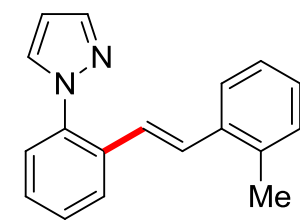

74f: $77 \%$

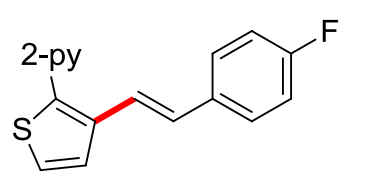

74g: $51 \%$

b)

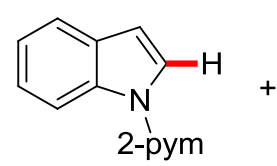

$41 a$

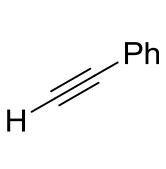

80

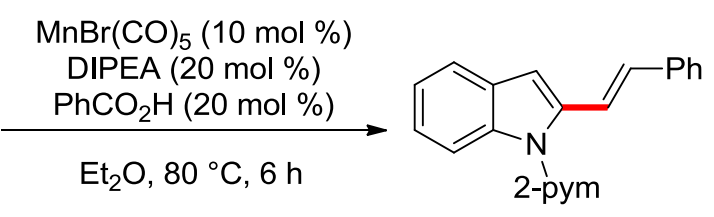

98

c)

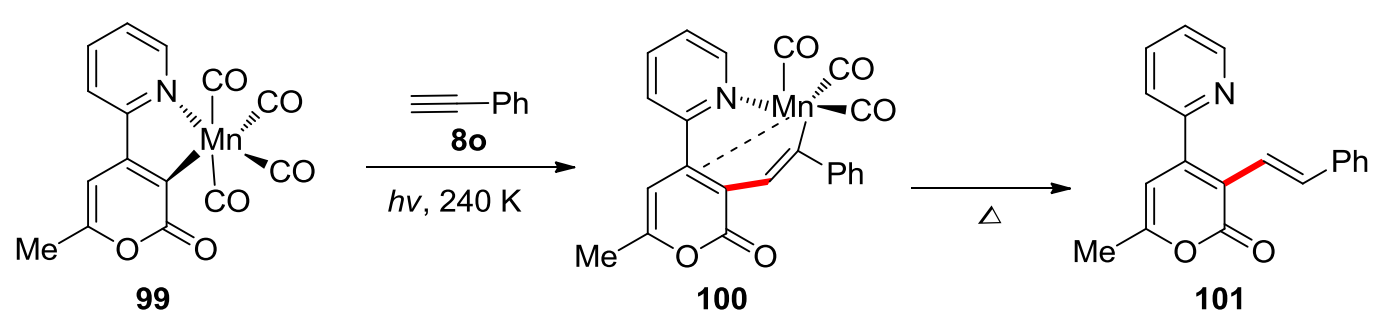

Scheme 1.3.5 Manganese(I)-catalyzed C-H hydroarylations with alkynes. ${ }^{[a]} 100{ }^{\circ} \mathrm{C}$.

The manganese-catalyzed hydroarylation-type $\mathrm{C}-\mathrm{H}$ activation strategy was further extended to the $\mathrm{C}=\mathrm{C}$ double bond. In 2014, Wang and coworkers developed the manganese-catalyzed direct aromatic $\mathrm{C}-\mathrm{H}$ addition reaction to $\alpha, \beta$-unsaturated carbonyls 11 as well (Scheme 1.3.6). ${ }^{[99]}$ This reaction featured a simple catalyst system, high chemo- and mono-selectivity, and a broad compatibility of functional groups. 


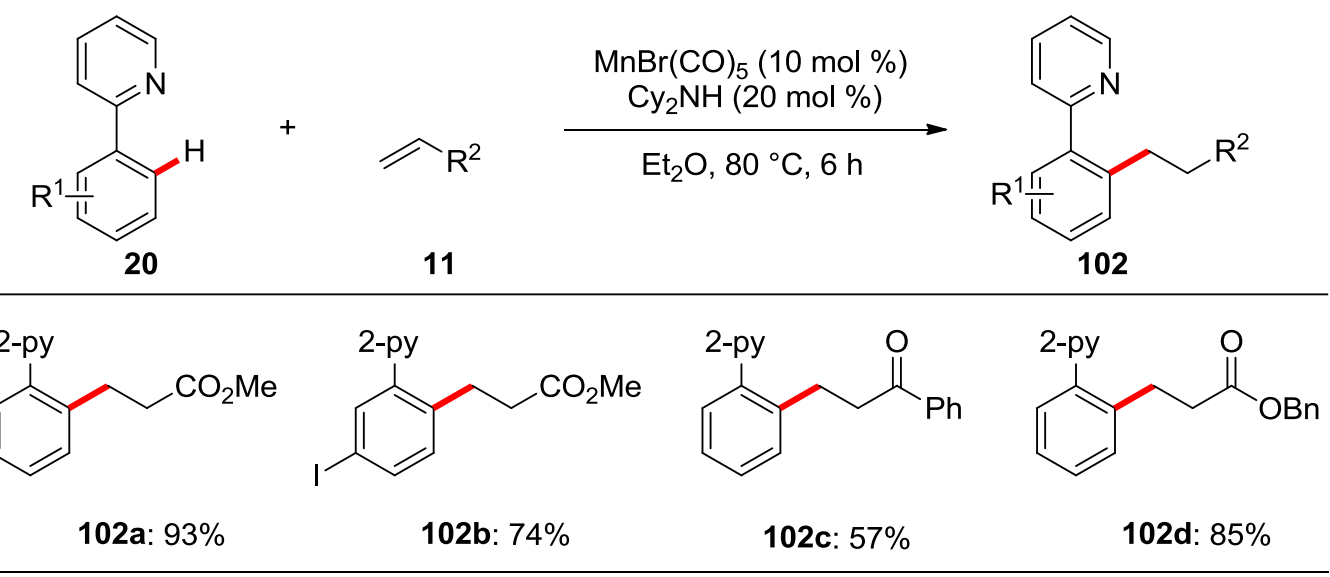

Scheme 1.3.6 Manganese(I)-catalyzed C-H alkylation with alkenes.

Furthermore, the manganese-catalyzed $\mathrm{C}-\mathrm{H}$ hydroarylation was not limited to carbon-carbon multiple bonds, but electrophilic $\mathrm{C}-\mathrm{Het}$ multiple bonds, such as $\mathrm{C}=\mathrm{O}$, and $\mathrm{C}=\mathrm{N}$ bonds, also proved to be viable. Wang and coworkers reported the manganese-catalyzed Grignard-type nucleophilic addition to aldehydes 10 , affording various alcohol products 103 . The reaction showed a broad substrate scope. Various aliphatic aldehydes, including primary, secondary, and tertiary ones and olefinic $\mathrm{C}-\mathrm{H}$ bonds all underwent the reaction smoothly, delivering the desired alcohols in good yields (Scheme 1.3.7a). ${ }^{[100]}$ In 2016, Ackermann and coworkers reported an unprecedented hydroarylation of $\mathrm{C}=\mathrm{O}$ double bonds by manganese catalysis under additive-free conditions (Scheme 1.3.7b). ${ }^{[101]}$ Challenging aldehydes and ketones were also successfully employed, delivering the corresponding products in good yields with high C-2 selectivities. Moreover, it is noteworthy that the first manganese-catalyzed $\mathrm{C}-\mathrm{H}$ hydroarylation with imines $\mathbf{1 0 6}$ was achieved (Scheme 1.3.7c). Thereafter, the similar works of manganese(I)-catalyzed $\mathrm{C}-\mathrm{H}$ hydroarylation of imines were reported by the same group ${ }^{[102]}$ and Wang, ${ }^{[103]}$ respectively. 
a)

)<smiles>[R]C=O</smiles>

20

10

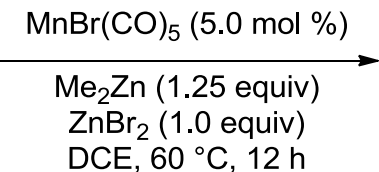

$\mathrm{R}^{1}$<smiles>[R]C(O)c1ccccc1-c1ccccn1</smiles><smiles>[R6]c1ccccc1C(O)c1ccccc1</smiles>

103a: $81 \%$<smiles>[R9]c1sccc1C(O)c1ccccc1</smiles>

103b: $78 \%$<smiles>[R6]c1ccccc1[C@H](O)c1ccco1</smiles>

103c: $66 \%$<smiles>[R6]c1ccccc1C(O)CCc1ccccc1</smiles>

103d: $65 \%$ [a]<smiles>[R6][13c]1ccccc1[C@H](O)CC=C</smiles><smiles>[R9]C1=C(C(O)c2ccccc2)CCC1</smiles>

103f: $76 \%$<smiles>[R6]/C=C\C(O)c1ccccc1</smiles>

103g: $83 \%$

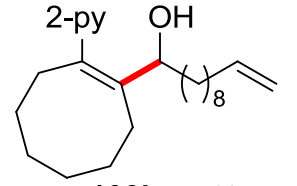

103h: $85 \%$

b)
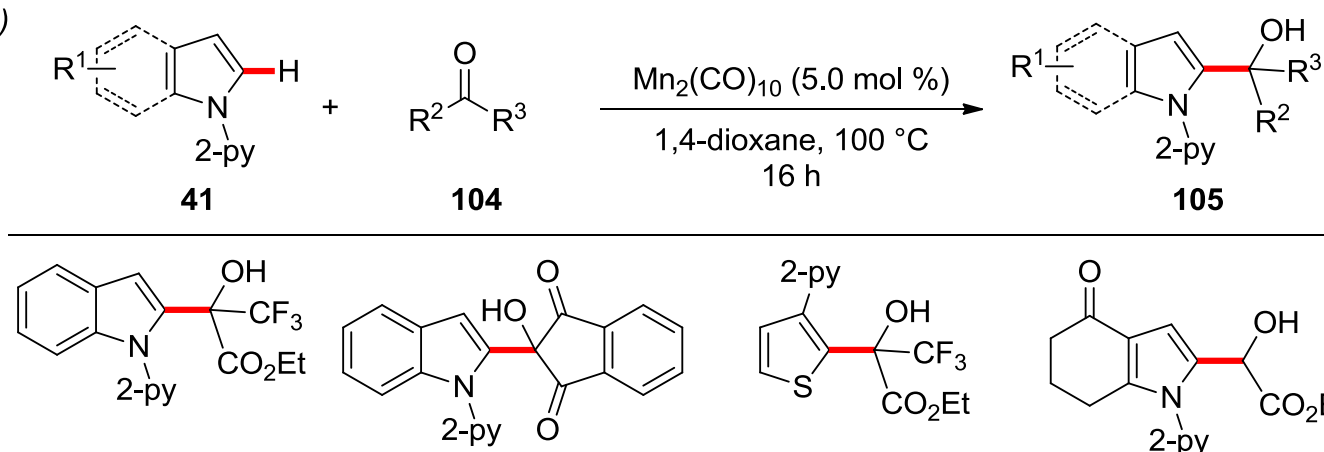

105a: $90 \%$

105b: $78 \%$<smiles>[R6]c1ccsc1C(O)(C(=O)OCC)C(F)(F)F</smiles>

105c: $91 \%$

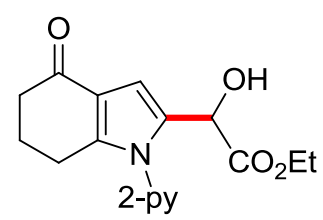

105d: $80 \%$

c)

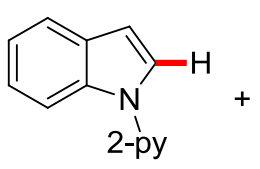

41<smiles>[N+]=Cc1ccccc1</smiles>

106<smiles>CCO[R10](=O)OCC(C)C(C)OC(C)=O</smiles>

$24 \mathrm{~h}$

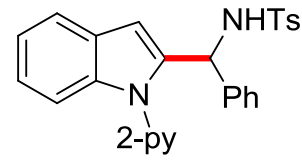

107: $88 \%$

Scheme 1.3.7 Manganese(I)-catalyzed $\mathrm{C}-\mathrm{H}$ addition onto $\mathrm{C}=\mathrm{Het}$ double bonds. ${ }^{[\mathrm{a}]} 80^{\circ} \mathrm{C}$.

\subsubsection{Manganese(I)-Catalyzed C-H Allylation}

In 2016, Ackermann and coworkers reported the first example of manganese(I)-catalyzed C-H allylations of arenes 34 with allyl carbonates 53 (Scheme 1.3.8). ${ }^{[104]}$ Both electron-rich and electron-withdrawing heterocycles, including various functional groups such as fluoro, chloro, bromide, iodo, cyano, aldehyde, and amine, could be employed in the reaction. The $\alpha$-substituted allyl carbonates 53c were also found to be suitable substrates and provided linear allylation products $108 \mathrm{c}$ with good yields. Mechanistic studies showed that electron-rich ketimines exhibited 
higher reactivity, and a significant H/D-scrambling in C-2 position of ketimines was observed as well. Both observations were in accordance with a base-assisted intramolecular electrophilic-type substitution (BIES) for manganese-catalyzed $\mathrm{C}-\mathrm{H}$ activation.

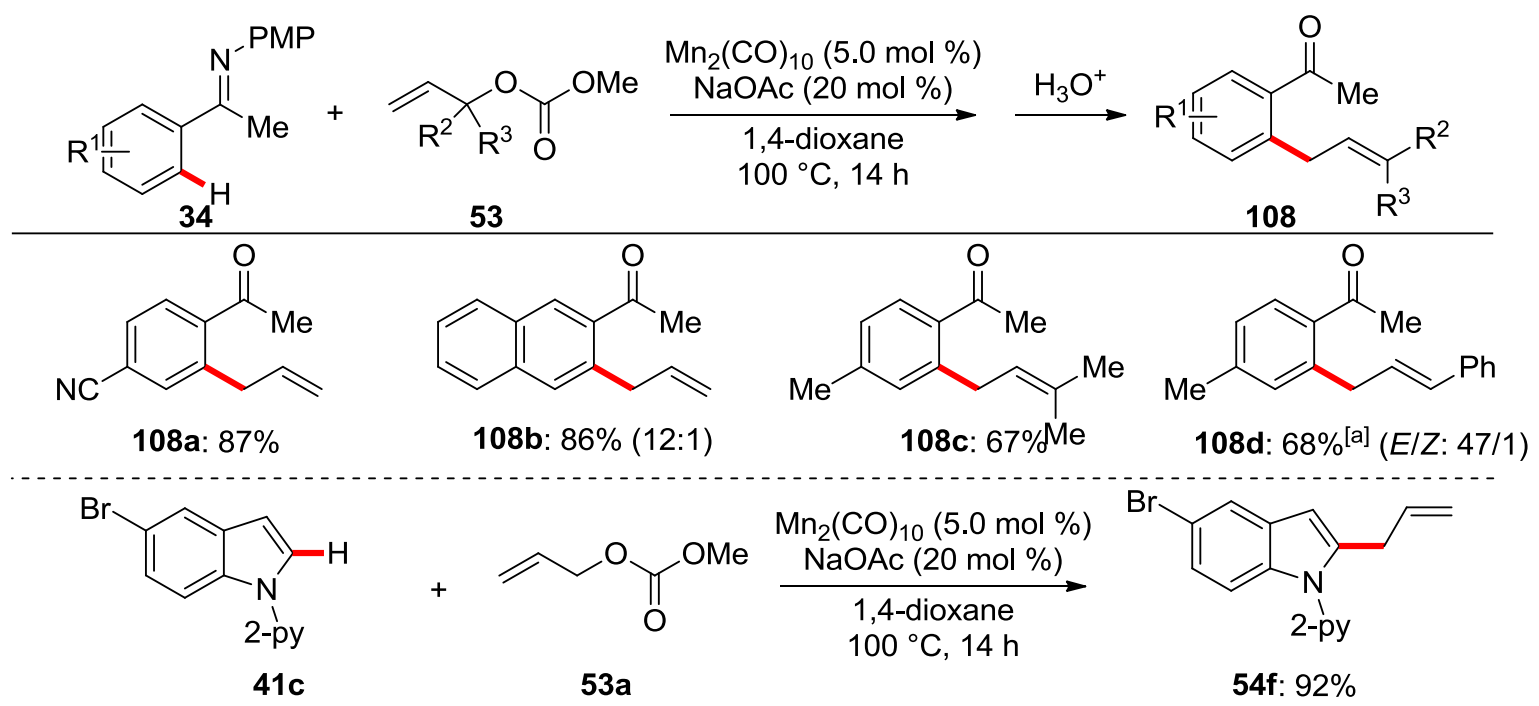

Scheme 1.3.8 Manganese(I)-catalyzed C-H allylation. ${ }^{[\mathrm{a}]} 120^{\circ} \mathrm{C}$

Afterwards, Glorius and coworkers also developed a similar manganese(I)-catalyzed C-H allylation reaction (Scheme 1.3.9a). ${ }^{[105]}$ New types of allyl coupling partners were employed in this reaction, affording allylic alcohols 111, allylated arenes $\mathbf{5 9}$ and functionalized cyclopentenes $\mathbf{1 1 2}$ in moderate to good yields and acceptable $E / Z$ ratios. In the same year, Zhang and coworkers also reported a manganese(I)-catalyzed $\mathrm{C}-\mathrm{H}$ 3,3-difluoroallylation using 3-bromo-3,3-difluoroprop-1-ene (114) as the allylating reagent (Scheme 1.3.9b). ${ }^{[106]}$ The reaction featured a broad substrate scope, and high functional group compatibility. Nevertheless the industrial applicability of such reaction was compromised by the high catalyst loading of $20 \mathrm{~mol} \%$. 
a)

b)<smiles>CCOC(=O)NN(NC(=O)OCC)C1CC=CC1c1ccccc1-c1ccccc1</smiles><smiles>CCOC(=O)N1C2C=CC(C2)N1C(=O)OCC</smiles><smiles>C=CC(F)(F)Br</smiles>
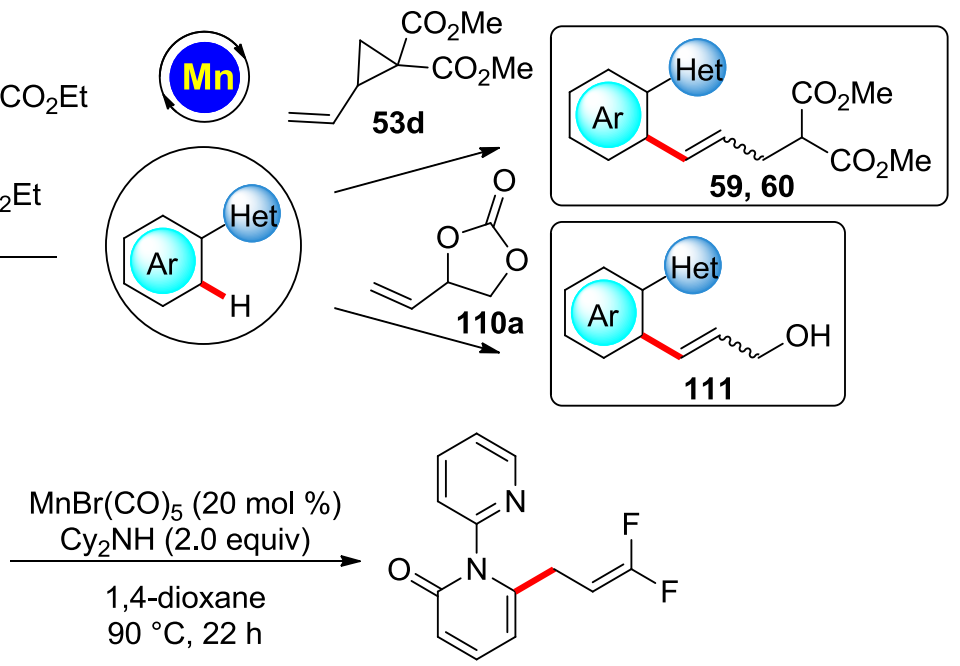

115: $90 \%$

Scheme 1.3.9 Manganese(I)-catalyzed C-H allylation with different coupling partners.

Moreover, Glorius and coworkers also reported manganese(I)-catalyzed allylation-type $\mathrm{C}-\mathrm{H}$ activation providing a direct access to 2-allenylindoles 117 (Scheme 1.3.10). ${ }^{[107]}$ The protocol provided an alternative method for the synthesis of fully substituted allenes 117 with high enantioselecties via chirality transfer (Scheme 1.3.10a and b). It is noteworthy that the ketone products 118 could be obtained in good yields when indole substrates bearing a 3-formyl group were employed in this $\mathrm{C}-\mathrm{H}$ activation in the presence of the PTSA and $\mathrm{H}_{2} \mathrm{O}$ as additives (Scheme 1.3.10c). 
a)

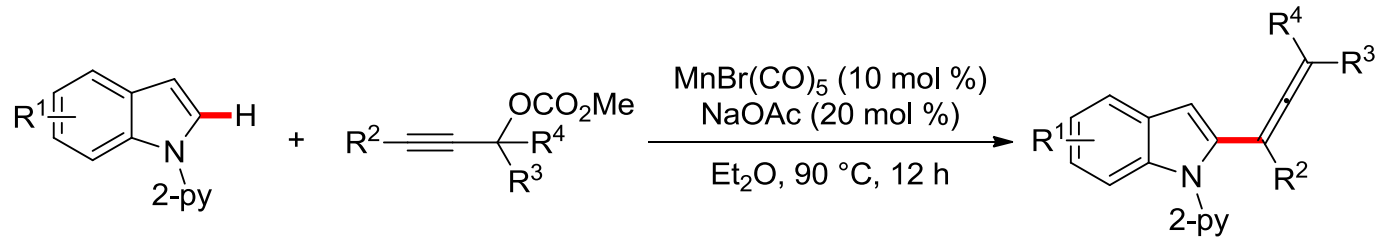<smiles>CC(C)=CC(=Cc1cc2ccccc2n1[18O])c1ccccc1</smiles>

116 117<smiles>CC(=O)c1ccc2c(c1)cc(C(=C=C(C)C)c1ccccc1)n2C(=O)O</smiles><smiles>O=C(C=C1CCCCC1)c1cc2ccccc2n1[O+]</smiles><smiles>CC(C)=C=Cc1cc2ccccc2n1[TeH]</smiles>
117c: $85 \%$ 117d: $65 \%$

b)

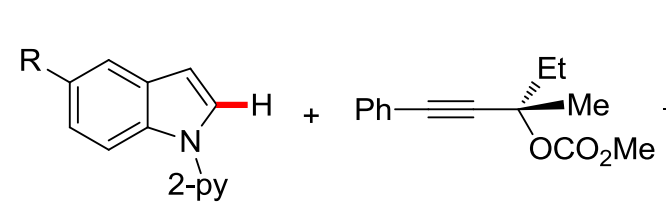

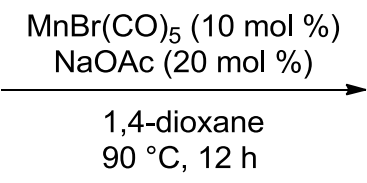

$$
\begin{aligned}
& \mathrm{R}=\mathrm{H}(41 \mathrm{~b}) \\
& \mathrm{R}=\mathrm{CO}_{2} \mathrm{Me}(41 \mathrm{~d})
\end{aligned}
$$

$90{ }^{\circ} \mathrm{C}, 12 \mathrm{~h}$
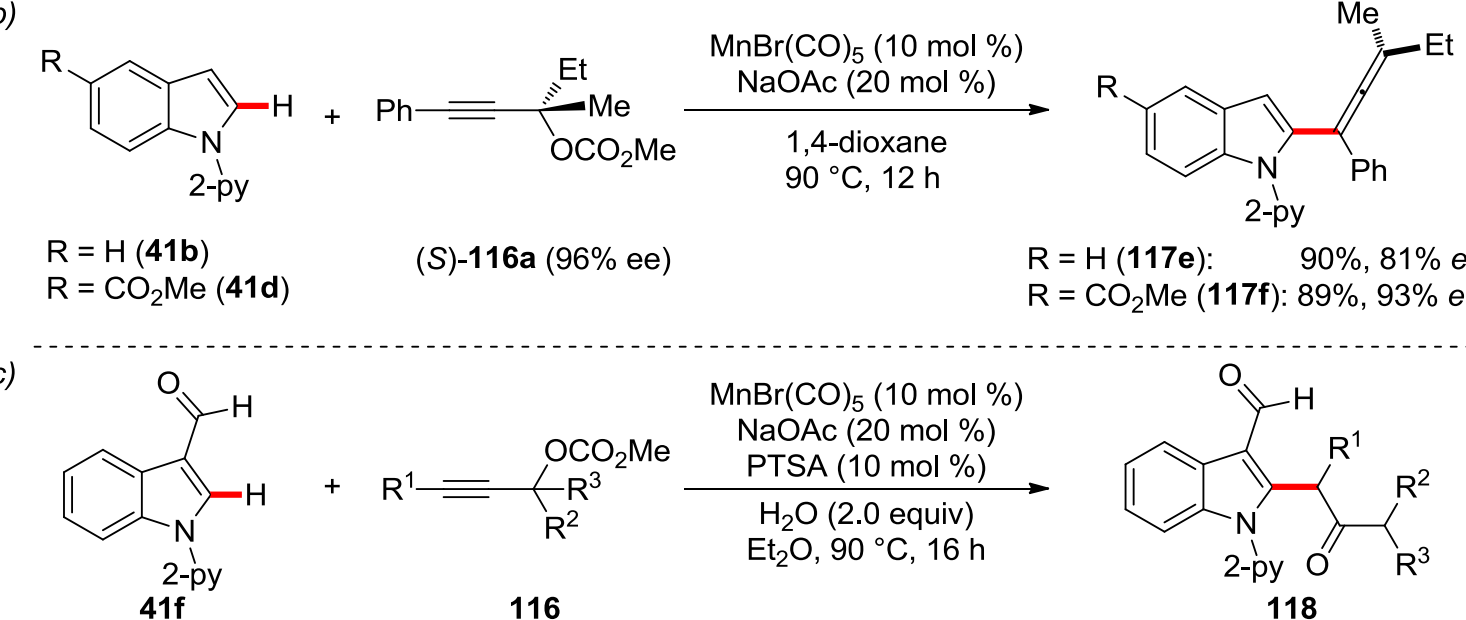

$\mathrm{R}=\mathrm{H}(\mathbf{1 1 7 e}): \quad 90 \%, 81 \%$ ee $\mathrm{R}=\mathrm{CO}_{2} \mathrm{Me}(\mathbf{1 1 7 f}): 89 \%, 93 \%$ ee

c)<smiles>[Y6]n1c(C(C(=O)C(C)C)c2ccccc2)c(C=O)c2ccccc21</smiles><smiles>[Y6]n1c(C(CCCC)C(=O)C(C)C)c(C=O)c2ccccc21</smiles><smiles>[Y6]n1c(CC(=O)C2CCCCCC2)c(C=O)c2ccccc21</smiles>

Scheme 1.3.10 Manganese(I)-catalyzed $\mathrm{C}-\mathrm{H}$ allylation for the synthesis of 2-allenylindoles.

\subsubsection{Manganese(I)-Catalyzed C-H Annulations}

Isoquinolines are among the most abundant and important classes of heterocycles found in natural products, agrochemicals, and pharmaceuticals. ${ }^{[108]}$ Many routes for the assembly of this heterocyclic skeleton have been developed during the last century. ${ }^{[109]}$ Recent advances in $\mathrm{C}-\mathrm{H}$ activation/annulation to access certain substituted isoquinolines have been developed by manganese(I) catalysis in this context. In 2014, Wang and coworkers disclosed a manganese(I)-catalyzed dehydrogenative [4+2] annulation of $\mathrm{N}-\mathrm{H}$ imines 16 and alkynes 8, which provided an expedient access to isoquinoline derivatives 119. ${ }^{[110]}$ Compared with other well known 
isoquinoline synthesis processes, ${ }^{[111]}$ this manganese-catalyzed $\mathrm{C}-\mathrm{H}$ annulation does not require any oxidants, external ligands, and additives, highlighting a unique and robust manganese catalyst. Detailed mechanistic studies suggested that the isolated five-membered manganacycle $\mathbf{1 2 0}$ is a key reaction intermediate in the catalytic cycle (Scheme 1.3.11a). Moreover, Glorius and coworkers also reported a manganese(I)-catalyzed $\mathrm{C}-\mathrm{H}$ annulation to the synthesis of isoquinolines using alkyne coupling partners with a traceless directing group very recently (Scheme 1.3.11b). ${ }^{[112]}$ Indeed, aliphatic, terminal, dialkyl- and monoalkyl-substitued alkynes were all compatible in this $\mathrm{C}-\mathrm{H}$ annulation and delivered the desired products $\mathbf{1 1 9 .}$

a)
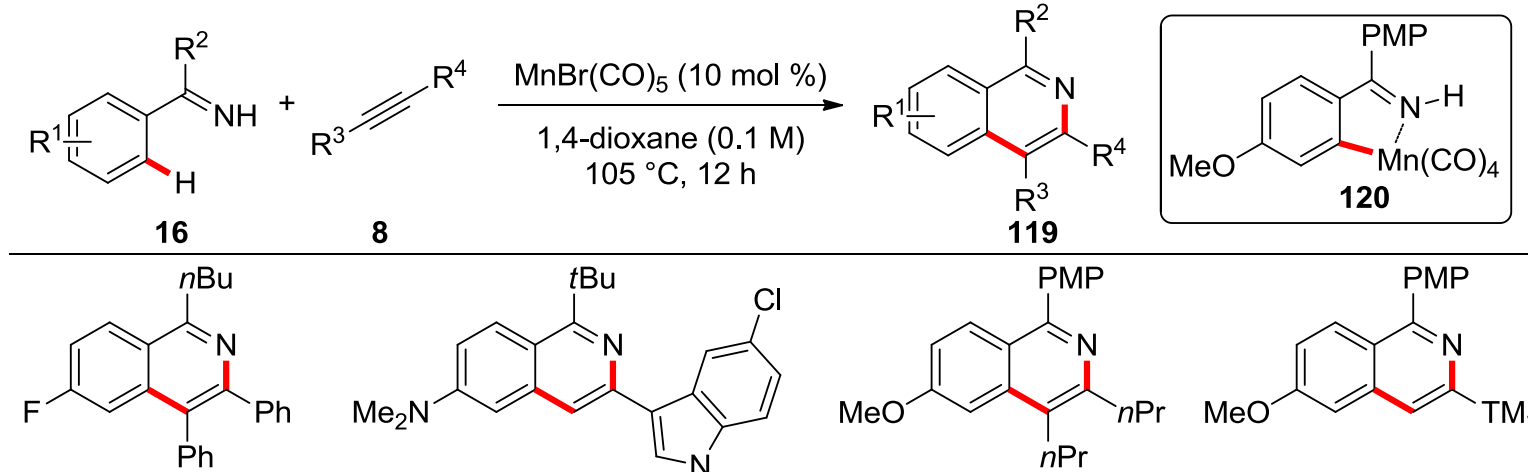

119a: $88 \%$
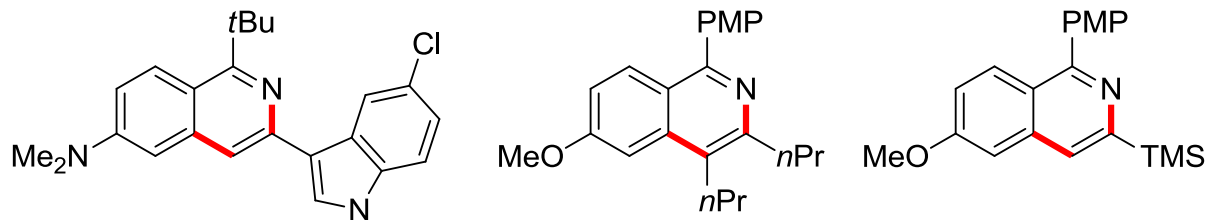

119b: $73 \%$ Boc

119c: $73 \%$

119d: $88 \%$

b)

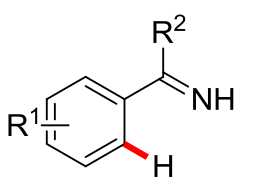

16

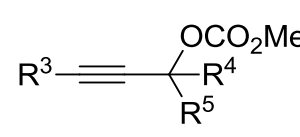

116

$$
\begin{gathered}
\mathrm{MnBr}(\mathrm{CO})_{5}(10 \mathrm{~mol} \%) \\
\mathrm{NaOAc}(20 \mathrm{~mol} \%)
\end{gathered}
$$
14-24 h<smiles>[R]c1nc([R])c2c#[R]ccc2c1[R9]</smiles><smiles>CCCc1nc(C(C)C)c(-c2ccccc2)c2ccccc12</smiles>

119e: $88 \%$<smiles>CCOc1nc(C(C)C)c(-c2ccccc2)c2sccc12</smiles>

119f: $95 \%$<smiles>CCCCc1nc(CC)c(C)c2ccccc12</smiles>

119g: $77 \%$<smiles>CCCCc1nc(C)c2ccccc2c1CC</smiles>

119h: $63 \%$<smiles>CCCCc1nc(C)cc2ccccc12</smiles>

119i: $65 \%$

Scheme 1.3.11 Manganese(l)-catalyzed $\mathrm{C}-\mathrm{H}$ annulations with alkynes. ${ }^{[\mathrm{a}]} \mathrm{BPh}_{3}(10 \mathrm{~mol} \%)$ and 1,2-dimethoxyethane (DME) were employed.

Manganese exhibits a lower electronegativity in comparison to $4 \mathrm{~d}$ transition metals such as rhodium, ruthenium, and iridium, which could form more nucleophilic intermediates leading to more significant reactions. Indeed, in 2015, Ackermann and coworkers developed the first manganese-catalyzed $\mathrm{C}-\mathrm{H}$ annulation of ketimines $\mathbf{3 4}$ with acrylates $\mathbf{1 1}$, providing expedient access to valuable $\beta$-amino acid esters (Scheme 1.3.12). ${ }^{[113]}$ The features of the reaction included high 
catalytic efficacy, good functional group tolerance, and an unusual cis stereo-selectivity. The catalytic cycle include a manganese nucleophilic intermediate which undergoes the intramolecular nucleophilic addition to the carbon atom of the imine moiety and then delivers the desired product 120.
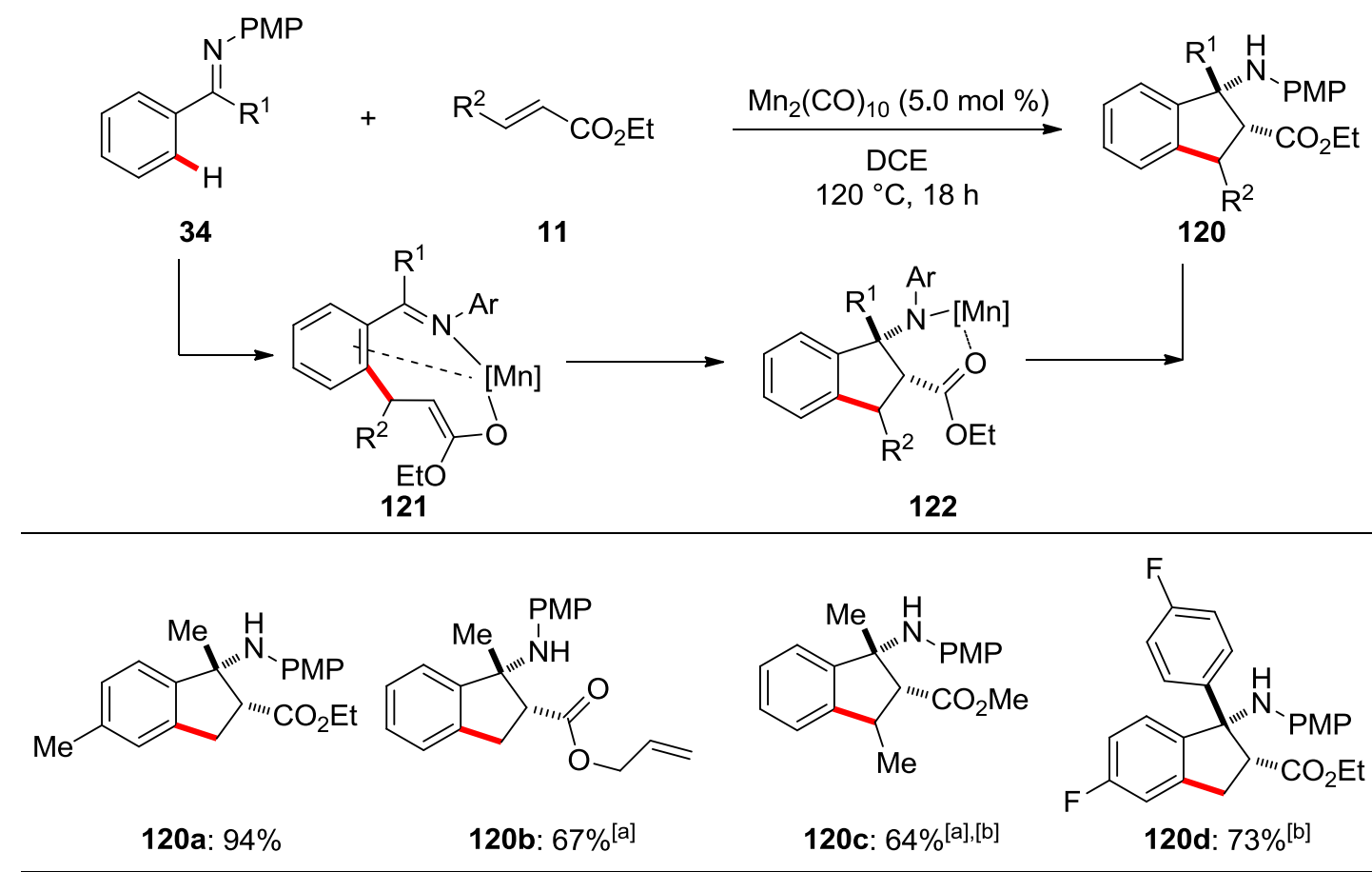

Scheme 1.3.12 Manganese(I)-catalyzed synthesis of cis- $\beta$-amino acid esters via $\mathrm{C}-\mathrm{H}$ activation. ${ }^{[\mathrm{a}]}$ In PhMe. ${ }^{[b]}$ With $\mathrm{Mn}_{2}(\mathrm{CO})_{10}(10 \mathrm{~mol} \%)$.

Thereafter, Rueping ${ }^{[114]}$ and $\mathrm{Wang} / \mathrm{Li}^{[115]}$ independently developed the unprecedented $\mathrm{C}-\mathrm{H} / \mathrm{C}-\mathrm{N}$ functionalization of pyrimidinyl-indoles 41 with allenes 121 . The optimized reactions showed that a high yield could be obtained when $\mathrm{NaOAc}$ was used as the additive. The use of disubstituted allenes 121b resulted in the selectively alkenylated C-2 indoles 124 under mild reaction conditions. However, when trisubstituted allenes were employed under similar reaction conditions, the unexpected annulation products 122 were obtained (Scheme 1.3.13a). In Wang/Li's system, the reaction proceeded under simple reaction conditions with no additives or even solvent-free conditions, but a high reaction temperature of $100{ }^{\circ} \mathrm{C}$ was necessary, providing the hydroarylation/cyclization products $\mathbf{1 2 2}$ in moderate to good yields with high stereo- and regio-selectivity. The decarboxylative ring-opening of the products $\mathbf{1 2 2}$ offered a series of vicinal biheteroaryl 123 by treatment with $\mathrm{K}_{2} \mathrm{CO}_{3}$ in methanol (Scheme 1.3.13b). 
a)
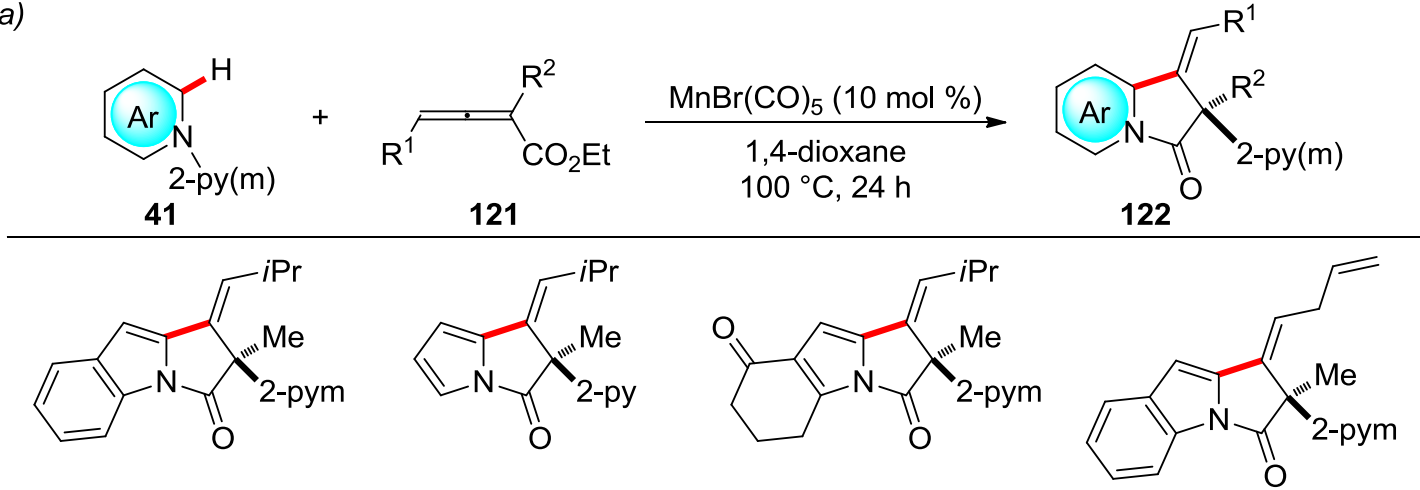

122a: $95 \%$

122b: $81 \%$

122c: $67 \%$

122d: $78 \%$

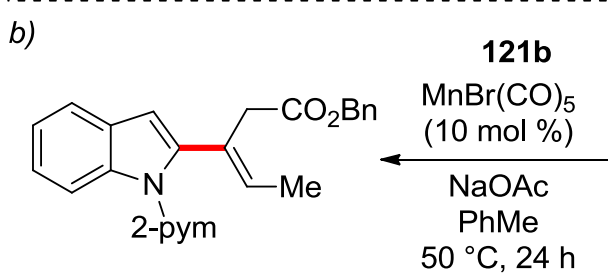

124: $98 \%$

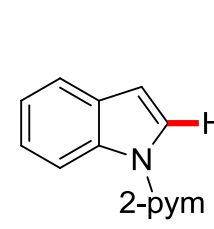

$41 a$

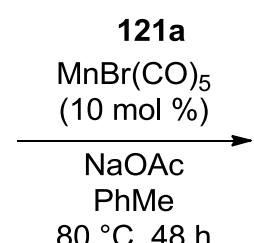

$80{ }^{\circ} \mathrm{C}, 48 \mathrm{~h}$

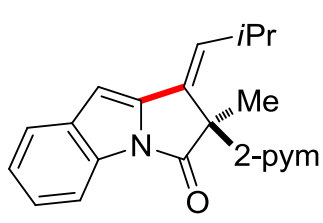

122a: $96 \%$

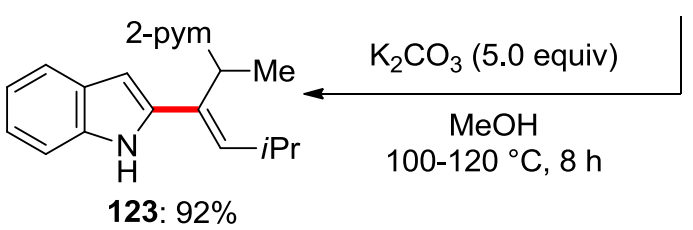

Scheme 1.3.13 Manganese(I)-catalyzed $\mathrm{C}-\mathrm{H} / \mathrm{C}-\mathrm{N}$ functionalization.

\subsubsection{Manganese(I)-Catalyzed C-H Cyanations}

In 2016, Ackermann and coworkers reported a manganese-catalyzed C-H cyanation of heteroarenes with NTCS (47a) as the cyanating reagent. ${ }^{[116]} \mathrm{A}$ combination of $\mathrm{MnBr}(\mathrm{CO})_{5}$ and $\mathrm{Cy}_{2} \mathrm{NH}$ gave the highest efficiency to provide cyanated products 49 with the assistance of $\mathrm{ZnCl}_{2}$. The intermolecular competition experiments showed that electron-rich substrates reacted preferentially. Moreover, this catalyst enabled $\mathrm{C}-\mathrm{H}$ cyanations on heterocycles, including pyrroles and thiophenes, with high mono- and C-2 selectivities (Scheme 1.3.14a). It is noteworthy that this cyanation strategy could be applied to tryptophan derivatives $\mathbf{1 2 5}$ and the authors showed that electron-deficient cyanating reagents could provide the desired products $\mathbf{1 2 6}$ in higher yields, presumably due to their enhanced electrophilic character (Scheme 1.3.14b). 
a)

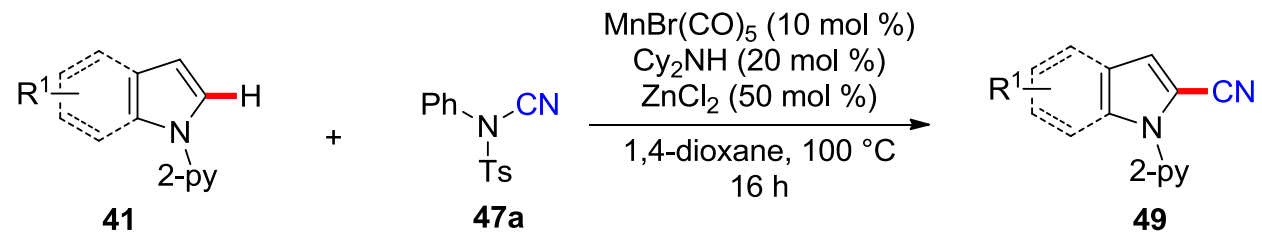<smiles>N#Cc1cc2ccccc2n1[17OH]</smiles>

49c: $70 \%$<smiles>N#Cc1cc2c(n1[18O])CCCC2=O</smiles>

49d: $83 \%$<smiles>Cc1c(C#N)n([Te])c2ccccc12</smiles>

49e: $90 \%$<smiles>N#Cc1cccn1P</smiles>

49f: $86 \%$

b)<smiles>[R]OC(=O)CCc1c(C)n([R20]#P)c2ccccc12</smiles>
125<smiles>N#CN([Te])[Te]</smiles>

47<smiles>[R]OC(N)Cc1c(C)n([R6])c2ccccc12</smiles>

126

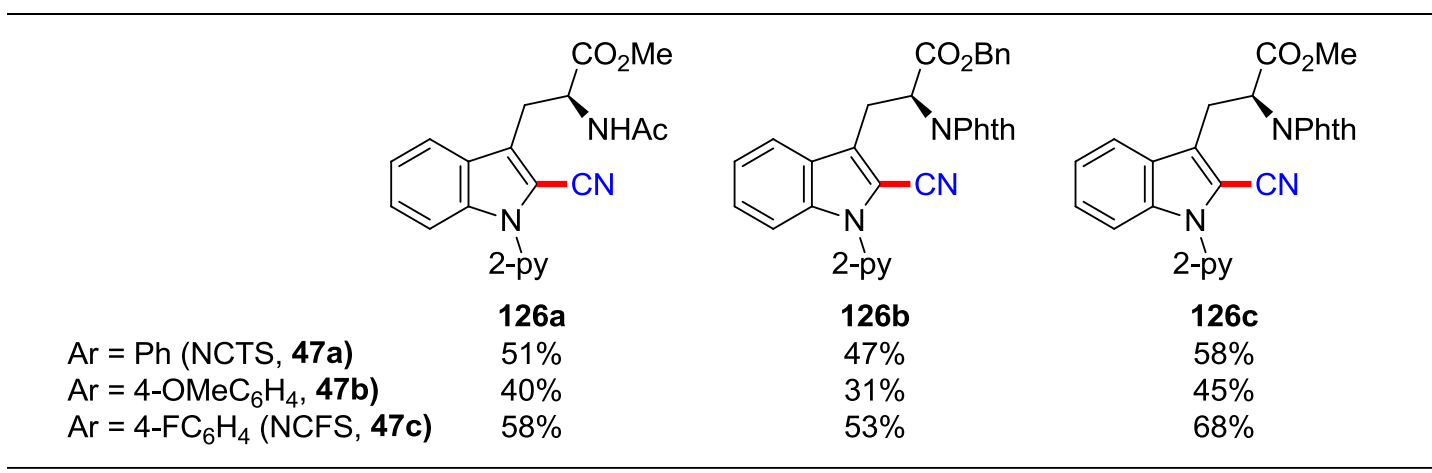

Scheme 1.3.14 Manganese(I)-catalyzed C-H cyanation.

Very recently, Bao and coworkers also described a manganese-catalyzed $\mathrm{C}-\mathrm{H}$ cyanation reaction of arenes by using $N$-cyano- $N$-(4-methoxy)phenyl- $p$-toluenesulfonamide (NMTS) (47b) as the cyanating reagent. ${ }^{[117]}$ The aromatic nitriles were obtained in $27-79 \%$ yields in the presence of 20 mol \% of $\mathrm{MnBr}(\mathrm{CO})_{5}$ catalyst (Scheme 1.3.15).<smiles>c1ccc(-c2ccccn2)cc1</smiles>

20a<smiles>COc1ccc(N([13S])C#N)cc1</smiles>

47b

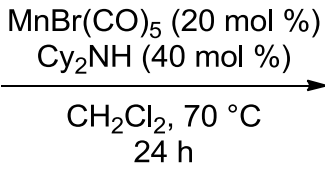

$24 \mathrm{~h}$<smiles>N#Cc1ccccc1-c1ccccn1</smiles>

48a: $68 \%$

Scheme 1.3.15 Manganese(I)-catalyzed C-H cyanation by using NMTS as the cyanating reagent. 


\subsubsection{Manganese(I)-Catalyzed C-H Alkynylation}

a)<smiles>[R20]n1c([2H])cc2c[R14]#ccc21</smiles>

41

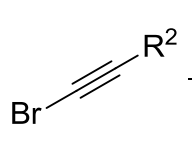

127
$\mathrm{MnBr}(\mathrm{CO})_{5}(5.0 \mathrm{~mol} \%)$

$\mathrm{Cy}_{2} \mathrm{NH}(20 \mathrm{~mol} \%)$

DCE, $80^{\circ} \mathrm{C}, 16 \mathrm{~h}$

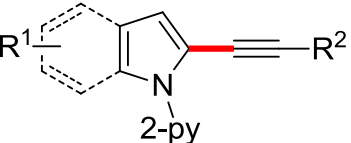

128<smiles>[R6]n1c(C#C[In]S)cc2ccccc21</smiles>

128a: $99 \%$<smiles></smiles>

128e: $69 \%$<smiles>C#Cc1c(C)cc(C)n1C#CC#C[In]</smiles>

128b: $92 \%$<smiles>[R6]n1c(C#CC#P)cc2ccccc21</smiles>

2-pym

128c: $95 \%$<smiles>[Z20]n1c(C#CC2=CCCCC2)cc2ccccc21</smiles>

128d: $79 \%$

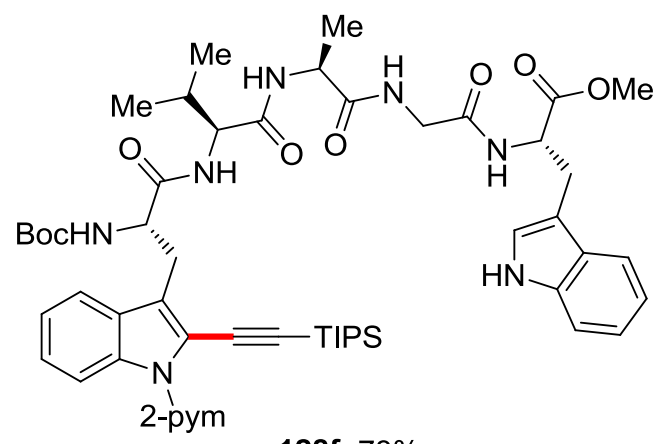

128f: $73 \%$

b)

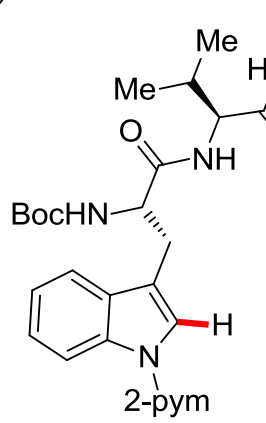<smiles>C=C(CCCCCCC)CNC(=O)CC</smiles><smiles>C1CCC2(CC1)OCCO2</smiles>

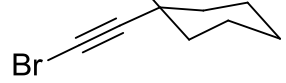

129

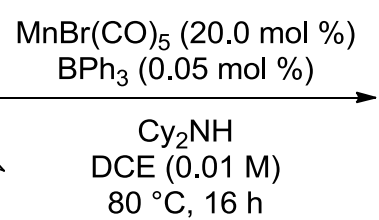
$80^{\circ} \mathrm{C}, 16 \mathrm{~h}$

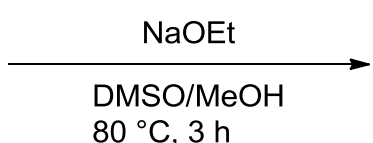

$80^{\circ} \mathrm{C}, 3 \mathrm{~h}$

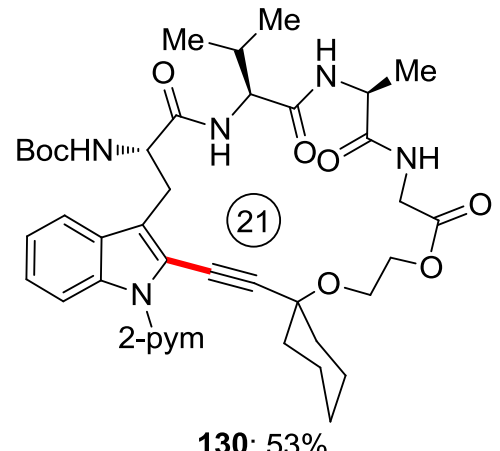

130: $53 \%$

c)

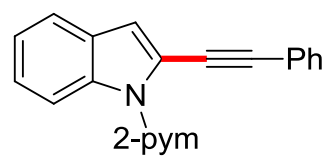

$128 \mathrm{c}$

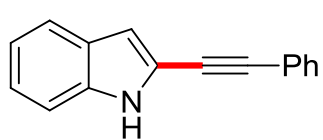

131: $81 \%$

Scheme 1.3.16 Manganese(I)-catalyzed C-H alkynylation.

In 2017, Ackermann and coworkers described the first manganese(I)-catalyzed substitutive alkynylation with bromoalkynes 127 (Scheme 1.3.16). ${ }^{[18]}$ The unique robustness of manganese catalyst was reflected by the unparalleled substrate scope, and valuable electrophilic functional group tolerance, including ester, cyano, halo, and nitro. Moreover, the substrate scope could be 
further extended to aryl, alkenyl, and alkyl alkynes using a combination of $\mathrm{MnBr}(\mathrm{CO})_{5}$ and triphenylborane as the key cocatalytic additive. It is worth noting that high efficiency was achieved, even with cocatalyst loadings as low as $0.05 \mathrm{~mol} \%$. More important, various acyclic peptides could also be employed as suitable substrates in this remarkable $\mathrm{C}-\mathrm{H}$ alkynylation approach, delivering the corresponding products 128 in $53-82 \%$ yields without any racemization (Scheme 1.3.16a). In addition, a highly challenging macrocyclization was accomplished to provide the 21-membered cyclic peptide 130 under high-dilution conditions (Scheme 1.3.16b). At last, the pyridine group could also be removed in a traceless fashion under mild conditions.

The detailed mechanistic studies, including H/D exchange, KIE, and kinetic experiments revealed a fast and reversible C-Mn bond formation. Thereafter, a plausible catalytic cycle was proposed to be initiated by a facile organometallic $\mathrm{C}-\mathrm{H}$ activation. Subsequently, the alkyne migratory insertion gives the seven-membered intermediate 133. The final alkynylation product $\mathbf{1 2 8}$ was most likely generated through $\beta$-elimination, although a mechanism involving oxidative addition and reductive elimination could not be ruled out (Scheme 1.3.17).

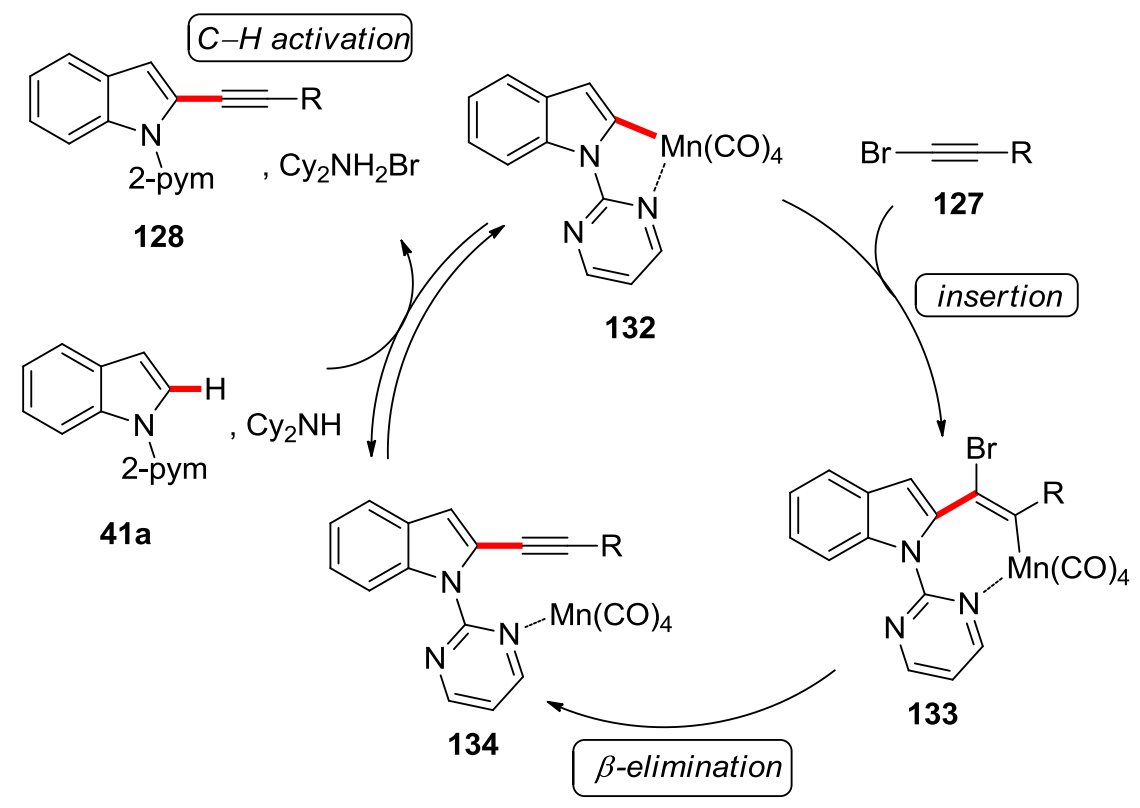

Scheme 1.3.17 Proposed catalytic cycle for manganese(I)-catalyzed $\mathrm{C}-\mathrm{H}$ alkynylation. 


\subsection{Transition Metal-Catalyzed C-C Functionalizations}

Selective transition metal-catalyzed carbon-carbon single bond functionalizations have recently been shown to be increasingly versatile tools for organic synthesis. Although numerous examples in this field have been disclosed in the past decade, ${ }^{[119]}$ the reported examples are still much fewer than the reports of transition metal-catalyzed $\mathrm{C}-\mathrm{H}$ functionalizations due to the intrinsic difficulties in activating $\mathrm{C}-\mathrm{C}$ bonds versus $\mathrm{C}-\mathrm{H}$ bonds in terms of thermodynamics and kinetics. The dissociation energy of $\mathrm{C}-\mathrm{C}$ bond is rather high of up to $375 \mathrm{kcal} \mathrm{mol}^{-1}{ }^{[120]}$ which results in a higher inertness of $\mathrm{C}-\mathrm{C}$ bond. Moreover, $\mathrm{C}-\mathrm{C}$-bond has a less favorable orbital directionality than $\mathrm{C}-\mathrm{H}$ bond, which makes the orbital interaction with transition metals more difficult. ${ }^{[121]}$ Therefore, selective $\mathrm{C}-\mathrm{C}$ activations often needed harsh reaction conditions. However, applying more forcing conditions may end up the reactions in side products. To date, many different strategies have been developed to solve these problems in order to achieve the $\mathrm{C}-\mathrm{C}$ bond cleaving transformations. The currently main methods for $\mathrm{C}-\mathrm{C}$ bond activation are restricted to the highly strained systems such as three- and four-membered rings, or more polarized $\mathrm{C}-\mathrm{C}$ bonds, for example, towards $\mathrm{C}-\mathrm{CN}$ bond activation (Scheme 1.4.1). The strain-release energy (cyclopropane is $\left.29.0 \mathrm{kcal} \mathrm{mol}^{-1}\right)^{[122]}$ facilitates the transition metal insertion leading to the formation of organometallic intermediate, which provides access to other organic molecules. ${ }^{[123]}$ In addition, the strong electron-withdrawing cyano group could weaken the $\mathrm{C}-\mathrm{CN}$ bond and coordinate to the transition metals that achieve the $\mathrm{C}-\mathrm{C}$ bond activation. ${ }^{[124]}$

a) strain-release substrates

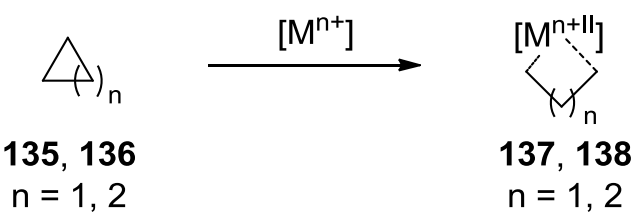

b) strong $M-C(s p)$ bond

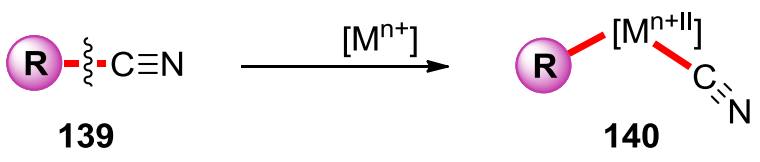

Scheme 1.4.1 $\mathrm{C}-\mathrm{C}$ bond activations of strained and polarized substrates. 
Besides these two transformations, other strategies have also been devised to enforce $\mathrm{C}-\mathrm{C}$ cleavages (Scheme 1.4.2), including: a) forming stable metallacycles via a chelation-assisted oxidative addition step; ${ }^{[125]}$ b) forming metallic aromatics; ${ }^{[126]}$ c) decarbonylation of unstrained ketones; ${ }^{[127]}$ d) forming the stable metal-carbon bond via a $\beta$-carbon elimination step; ${ }^{[128]}$ e) retro-allylation base on a 6-membered transition state. ${ }^{[119 a, 129]}$

a) forming stable metallocycle assisted by chelation

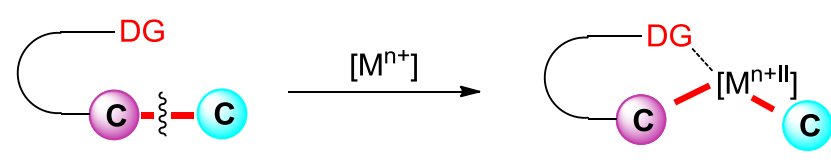

b) forming aromatics<smiles>[R]C1([R])C=CC=C1</smiles>

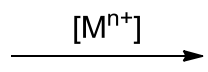

c) decarbonylation<smiles>[R]C([R])=O</smiles><smiles>CC1C(C)C1[13CH3]</smiles><smiles>[R]</smiles>

e) retro-allylation<smiles>[Y][Y10]1([H])cccc1</smiles><smiles></smiles>

d) $\beta$-carbon elimination<smiles>[R]C([R])=O</smiles><smiles>[R1][AlH][Y]([M])=C1C=CC=C1[R]</smiles>
$\mathrm{CO} \uparrow$

$\left[\mathrm{M}^{\mathrm{n}+11}\right]-\mathrm{CO}$

or 


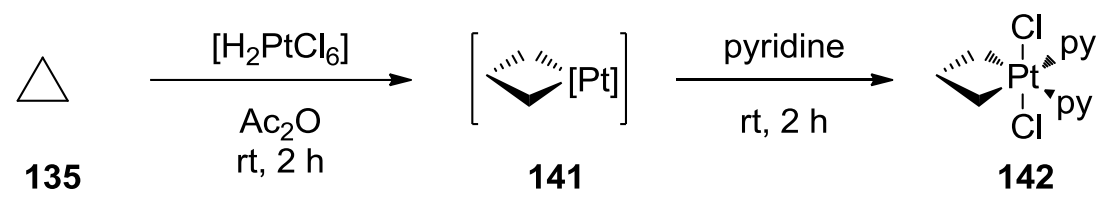

Scheme 1.4.3 Stoichiometric C-C cleavage cyclopropane via oxidative addition.

Inspired by the pioneering work of Tipper and Chatt, strained ring systems have thus emerged as role models for a number of $\mathrm{C}-\mathrm{C}$ cleaving transformations. ${ }^{[123]}$ For example, in 2013, Bower and coworkers developed rhodium-catalyzed multicomponent synthesis of $N$-heterobicyclic enones 144 and 145 by carbonylative $C-C$ bond activation of aminocyclopropanes 143 (Scheme 1.4.4). ${ }^{[132]} \mathrm{A}$ plausible pathway was postulated. Firstly, the rhodium catalyst activates the proximal C-C bond of cyclopropane with the aid of $\mathrm{N}$-protecting group, and then undergoes $\mathrm{CO}$ insertion generating the rhodacyclopentanone intermediate 146. Finally, the desired product was obtained by the alkyne insertion and $\mathrm{C}-\mathrm{C}$ bond reductive elimination.
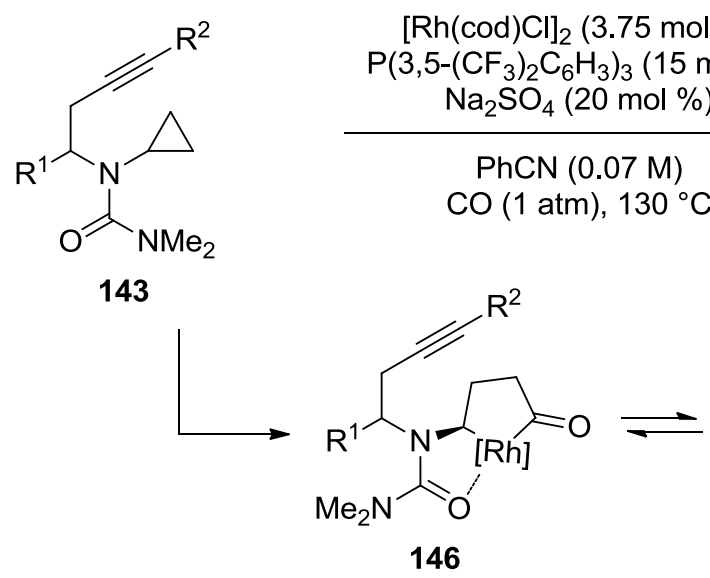
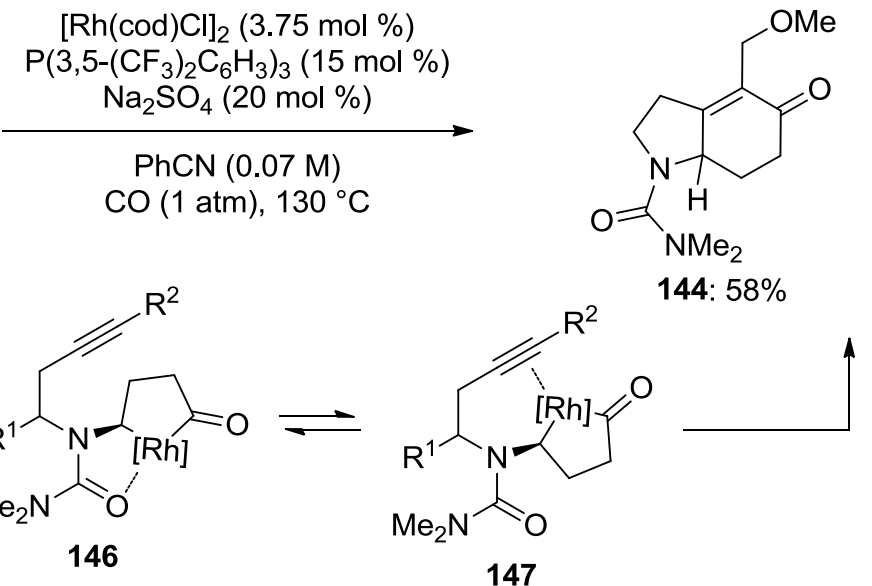
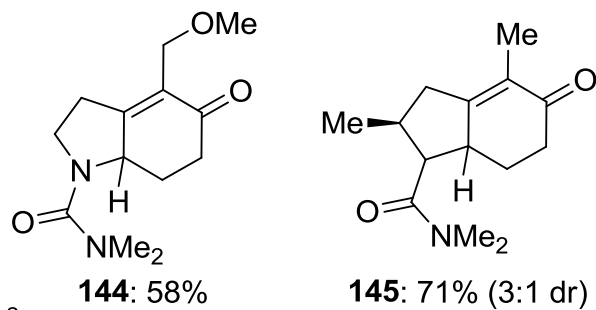

Scheme 1.4.4 Rhodium-catalyzed carbonylative C-C activation of aminocyclopropanes.

Meanwhile, other unstained substrates were also successfully employed for $\mathrm{C}-\mathrm{C}$ activations, such as $\mathrm{C}-\mathrm{C}$ bond cleavage assisted by chelation. Recently, Ackermann and coworkers reported an unprecedented ruthenium-catalyzed $\mathrm{C}-\mathrm{C}$ arylations as well as $\mathrm{C}-\mathrm{C}$ alkylations on decorated pyrazoles $148 .{ }^{[133]}$ The robust and unique ruthenium catalyst was reflected by fully tolerating valuable functional groups, including nitriles, cyano, free $\mathrm{NH}_{2}$, halides, alkenes, esters, and ketones. The leaving group for $\mathrm{C}-\mathrm{C}$ bond cleavage is not limited to the amide. Indeed, the decarboxylative $\mathrm{C}-\mathrm{C}$ arylations and $\mathrm{C}-\mathrm{C}$ alkylations were also successfully achieved under the optimal conditions. 
Detailed mechanistic studies indicated a facile and reversible $\mathrm{C}-\mathrm{C}$ metalation step (Scheme 1.4.5a). Moreover, the pyrazole group could be easily removed by ozonolysis, ${ }^{[134]}$ providing the arylated anilides 151 in moderate yields (Scheme 1.4.5b).

a)
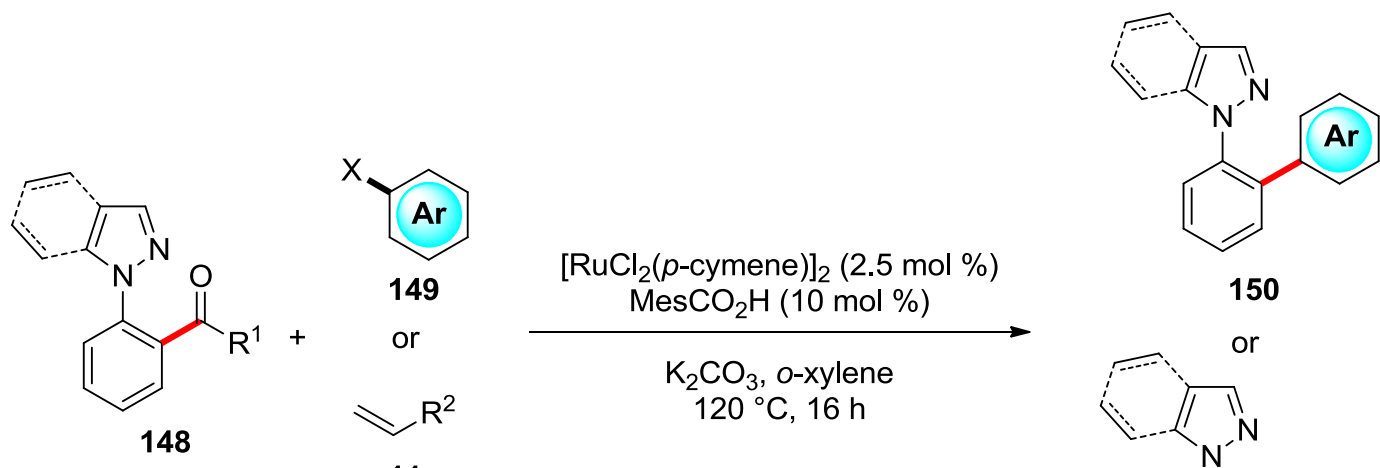

11

$\mathrm{R}^{1}=\mathrm{OH}$ or $\mathrm{ONHPh}$

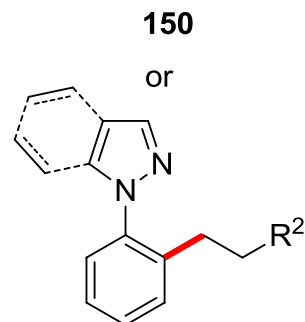

102

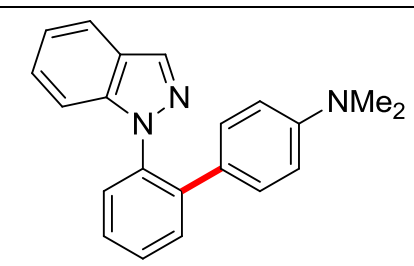

150a: $59 \%$

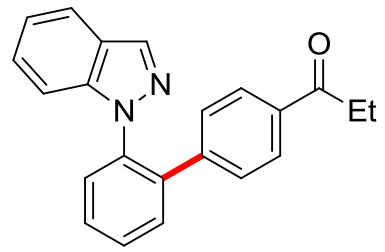

150b: $72 \%$<smiles>CCOC(=O)c1ccc(-c2ccccc2-n2nccc2C)cc1</smiles>

150c: $84 \%$<smiles>c1ccc(CCc2ccccc2-n2cccn2)cc1</smiles>

102e: $74 \%$

b)<smiles>CCOC(=O)c1ccc(-c2ccccc2-n2nccc2C)cc1</smiles>

$150 \mathrm{c}$

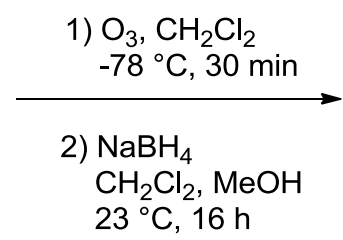

$23{ }^{\circ} \mathrm{C}, 16 \mathrm{~h}$<smiles>CCOC(=O)c1ccc(-c2ccccc2NC(C)=O)cc1</smiles>

151: $57 \%$

Scheme 1.4.5 Ruthenium(II)-catalyzed C-C functionalizations by Ackermann and coworkers.

In 2011, Shi and coworkers developed a rhodium-catalyzed selective C-C bond activation of secondary alcohols 152 with the aid of a pyridinyl group via $\beta$-carbon elimination. ${ }^{[135]}$ This C-C alkenylation features a broad reaction scope and highly functional group tolerance. Inter- and intra-molecular competition experiments both supported that $\mathrm{C}-\mathrm{C}$ bond activation was much faster than the direct $\mathrm{C}-\mathrm{H}$ activation under the optimal conditions. This strategy offered a mild and efficient process for $\mathrm{C}-\mathrm{C}$ cleavage (Scheme 1.4.6a). Thereafter, the same group also reported the rhodium-catalyzed $\mathrm{C}-\mathrm{C}$ arylation under an oxidative condition, and reductive cleavage of the $\mathrm{C}\left(s p^{2}\right)-\mathrm{C}\left(s p^{3}\right)$ bond in the presence of $\mathrm{H}_{2}$ as the reducing agent, respectively (Scheme 1.4.6b and c). ${ }^{[136]}$ 
a)
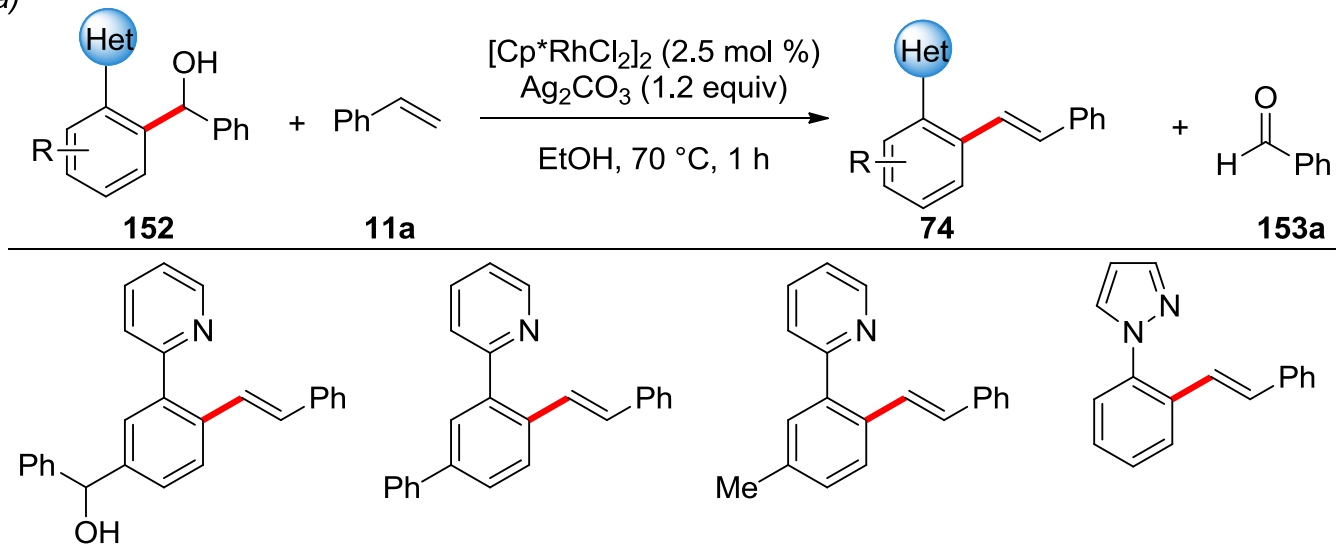<smiles>C(=C/c1ccc(-c2ccccc2)cc1-c1ccccn1)\c1ccccc1</smiles>

74i: $80 \%$<smiles>Cc1ccc(/C=C/c2ccccc2)c(-c2ccccn2)c1</smiles>

74j: $92 \%$

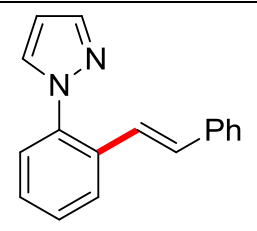

74a: $40 \%$

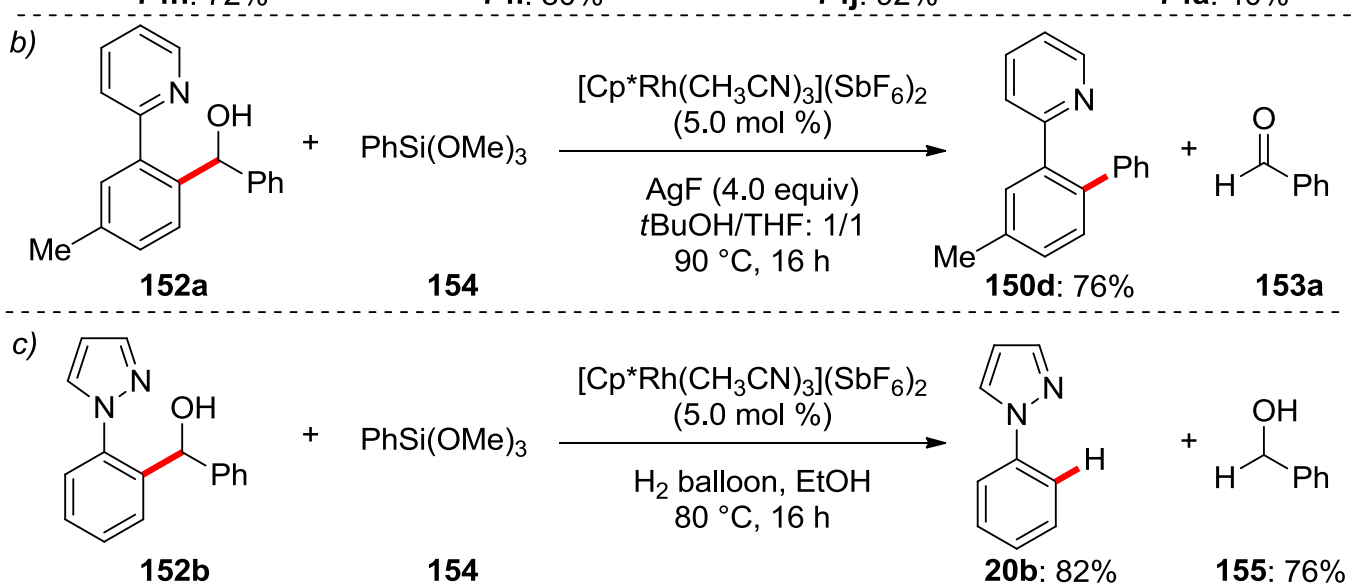

Scheme 1.4.6 C $-C$ bond activation via $\beta$-carbon elimination.

Compared to the noble metals, such as rhodium, cobalt is an alternative candidate for $\mathrm{C}-\mathrm{C}$ bond activation due to its benefits of Earth-abundant, nontoxic. In 2015, Morandi and coworkers developed the $\mathrm{C}-\mathrm{C}$ cleavage by using inexpensive cobalt as catalyst through a $\beta$-carbon elimination step. ${ }^{[137]}$ The electronic and steric effects of the substrates both had little influence on the transformation of $\mathrm{C}-\mathrm{C}$ cleavage. The secondary and tertiary alcohols underwent the reaction smoothly, but the primary alcohol could not achieve the $\mathrm{C}-\mathrm{C}$ bond activation (Scheme 1.4.7a). Moreover, when the cyanating reagent NCTS (47a) was selected as the reaction partner, the desired product was obtained in 91\% yield (Scheme 1.4.7b). Two possible pathways were proposed for the cobalt(III)-catalyzed C-C cyanation reaction. The cobalt intermediate $\mathbf{1 5 7}$ was firstly generated by the initial $\beta$-carbon elimination, and then underwent the cyanation directly, delivering the final product (Path $A$, direct $C-C$ activation). Alternatively, the intermediate 157 could be trapped by proton providing the phenylpyridine firstly, then underwent the $\mathrm{C}-\mathrm{H}$ functionalization and gave the desired product (Path $\mathrm{B}, \mathrm{C}-\mathrm{C}$ activation and then $\mathrm{C}-\mathrm{H}$ functionalization) (Scheme 
1.4.7c).

a)<smiles>[R]C([R])(O)c1ccc[R17]c1-c1ccccn1</smiles>

[Cp $\left.{ }^{*} \mathrm{Co}(\mathrm{CO}) \mathrm{I}_{2}\right](5.0 \mathrm{~mol} \%)$ $\mathrm{AgSbF}_{6}(10 \mathrm{~mol} \%)$

DCE, $100^{\circ} \mathrm{C}$

$16 \mathrm{~h}$<smiles>[R1]1:[R1]c(-c2ccccn2)ccc1</smiles>

$+{ }_{\mathrm{R}^{2}} \stackrel{\mathrm{O}}{\mathrm{R}^{3}}$

152<smiles>OC(c1ccccc1)c1ccccc1-c1ccccn1</smiles>

152c $(90 \%)$<smiles>OC(c1ccccc1)(c1ccc(C(F)(F)F)cc1)c1ccccc1-c1ccccn1</smiles>

152d (90\%)

b)<smiles>CC(C)(O)c1ccccc1-c1ccccn1</smiles>

$152 f$<smiles>OCC(O)c1ccccc1-c1ccccn1</smiles>

$152 e(82 \%)$

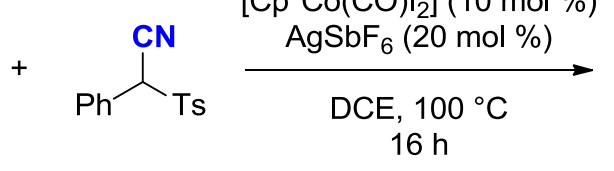
$47 a$<smiles>CC(C)(O)c1ccccc1-c1ccccn1</smiles>

$152 f(87 \%)$<smiles>OCc1ccccc1-c1ccccn1</smiles>

152g (trace)

c)

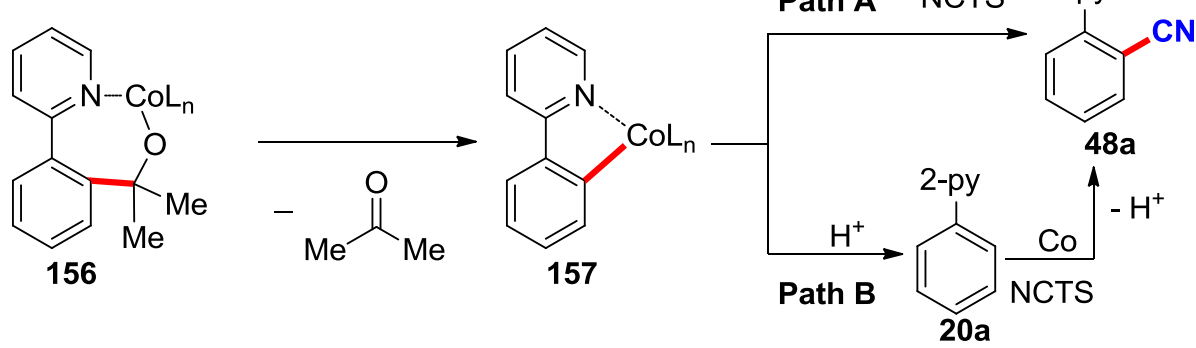

Scheme 1.4.7 Cobalt(III)-catalyzed C-C bond activation by Morandi and coworkers. 


\section{Objectives}

Transition metal-catalyzed $\mathrm{C}-\mathrm{H}$ functionalizations have emerged as increasingly powerful tools for sustainable organic syntheses. ${ }^{[81 b, 138]}$ Remarkable advances in this area have been achieved by Prof. Dr. Lutz Ackermann and coworkers, which is mainly focused on the development of chemo- and site-selective syntheses of valuable organic molecules, with applications to pharmaceutical chemistry, materials sciences and peptide assembly. ${ }^{[80,139]}$ Within this context, major efforts were made to develop novel $\mathrm{C}-\mathrm{H}$ or $\mathrm{C}-\mathrm{C}$ activation reactions by environmentally-benign, less expensive and Earth-abundant versatile cobalt(III)/manganese(I) catalysts.

In the past few years, alkyne annulations by $\mathrm{C}-\mathrm{H} / \mathrm{N}-\mathrm{O}$ functionalizations have proven to be instrumental for the step-economical assembly of various heterocycles with activities of relevance to medicinal chemistry and biology. ${ }^{[109 c, 140]}$ In addition, in light of the beneficial features of naturally abundant $3 d$ transition metals, focus has shifted in recent years to the use of environmentally-benign, less expensive base metal catalysts for the $\mathrm{C}-\mathrm{H}$ activation processes, such as cobalt catalyst. Therefore, it was of great interest to establish a novel approach for cobalt(III)-catalyzed $\mathrm{C}-\mathrm{H} / \mathrm{N}-\mathrm{O}$ functionalization for the redox-neutral preparation of isoquinolines (Scheme 2.1). ${ }^{[141]}$

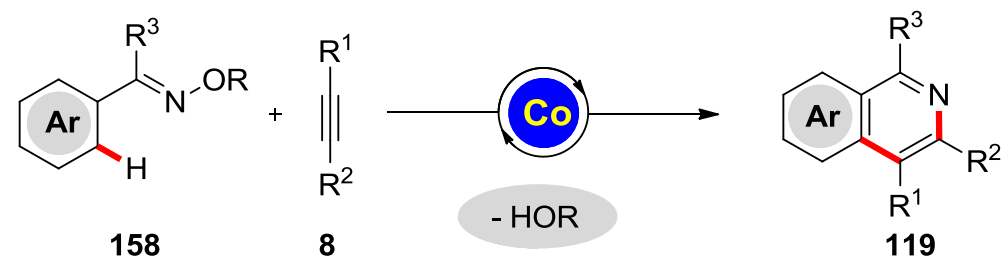

Scheme 2.1 Cobalt(III)-catalyzed $\mathrm{C}-\mathrm{H} / \mathrm{N}-\mathrm{O}$ functionalization of $\mathrm{O}$-acyl oximes 158.

Substituted indoles are important structural motifs widely found in compounds of relevance to medicinal chemistry, crop protection, and drug discovery, among others. ${ }^{[142]}$ Although the recent years have witnessed the emergence of $\mathrm{C}-\mathrm{H}$ functionalization as increasingly powerful tools for the direct synthesis of indoles, these protocols largely required precious $4 \mathrm{~d}$ and $5 \mathrm{~d}$ transition metals. ${ }^{[143]}$ In this regard, an Earth-abundant and environmentally-benign cobalt catalyst would be desired to be used for the synthesis of unprotected indoles by site-selective $\mathrm{C}-\mathrm{H}$ activation (Scheme 2.2). ${ }^{[144]}$ 


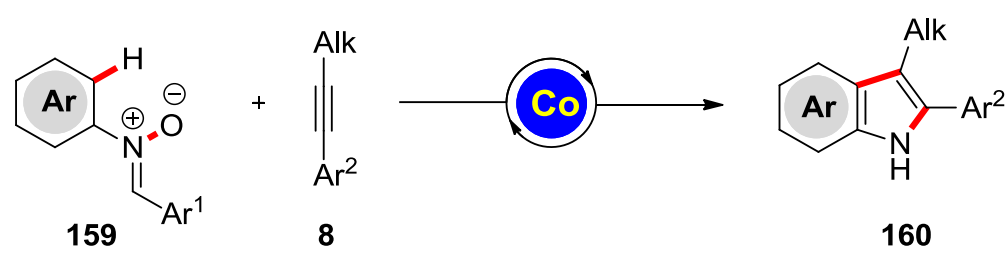

Scheme 2.2 Selective synthesis of indoles by cobalt(III)-catalyzed $\mathrm{C}-\mathrm{H} / \mathrm{N}-\mathrm{O}$ functionalization with nitrones 159.

Biologically relevant $N$-heterocycles, such as pyrazoles, oxazolines, pyrimidines, or pyridines, can strongly coordinate to the active transition metals, in some cases, resulting in $\mathrm{C}-\mathrm{H}$ activation at undesired position or catalyst poisoning, ${ }^{[145]}$ which severely limits the application of these reactions in material sciences or drug discovery. In 2014, Yu reported the palladium-catalyzed position-selective $\mathrm{C}-\mathrm{H}$ functionalizations of the substrates containing two different directing groups, which the $\mathrm{N}$-heterocycles, such as pyridine, quinolone, pyrazine, pyrimidine, pyrazole, thiazole, and oxazoline, are fully tolerant. ${ }^{[146]}$ Although major advances in cobalt(III)-catalyzed $\mathrm{C}-\mathrm{H}$ functionalizations have been accomplished in recent years, no example was reported for cobalt(III)-catalyzed $\mathrm{C}-\mathrm{H}$ activation fully tolerating strongly coordinating $\mathrm{N}$-heterocycles. Herein, we would plan to establish cobalt(III)-catalyzed $\mathrm{C}-\mathrm{H}$ amidation by the assistance of imidate that tolerated strongly coordinating $N$-heterocycles (Scheme 2.3). ${ }^{[147]}$<smiles>[R]C1=NOC(=O)C1</smiles>

161

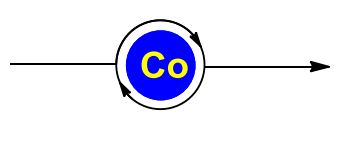

$162 a$<smiles>[R]c1nc(OCC)c2ccc([CH])cc2n1</smiles>

163<smiles></smiles>

Scheme 2.3 Strongly coordinating $\mathrm{N}$-heterocycles were fully tolerated in cobalt-catalyzed $\mathrm{C}-\mathrm{H}$ amidations.

Despite significant progress of $\mathrm{Cp} * \mathrm{Co}(\mathrm{III})$-catalyzed $\mathrm{C}-\mathrm{H}$ activation has been accomplished recently, large transformations still largely continue to simply mirror the activities and selectivities observed 
from their analogous $\mathrm{Cp} * \mathrm{Rh}(\mathrm{III})$ counterparts. Herein, a first cobalt(III)-catalyzed domino reaction comprising $\mathrm{C}-\mathrm{H} / \mathrm{N}-\mathrm{H}$ allylation for the direct synthesis of isoquinolines has been developed, which notably could not be achieved by $\mathrm{Rh}(\mathrm{III})$ catalysis (Scheme 2.4). ${ }^{[148]}$

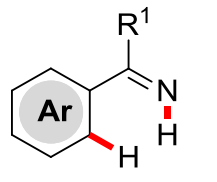

161<smiles>[R]C1OC(=O)OC1C=C</smiles>

110

\section{Co}

10

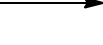
2

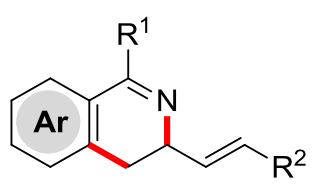

164

Scheme 2.4 Cobalt-catalyzed domino $\mathrm{C}-\mathrm{H} / \mathrm{N}-\mathrm{H}$ allylations of imidates 161.

In 2016, Ackermann and coworkers reported an unprecedented manganese(I)-catalyzed substitutive $\mathrm{C}-\mathrm{H}$ allylation with allyl carbontates 53. $^{[104]}$ Based on this work, further expansion for manganese-catalyzed $\mathrm{C}-\mathrm{H}$ allylation in water using dioxolanones $\mathbf{1 1 0}$ as the allyl source was investigated (Scheme 2.5). ${ }^{[149]}$

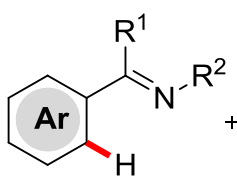

34, 41<smiles>[R]C1OC(=O)OC1C=C</smiles>

110

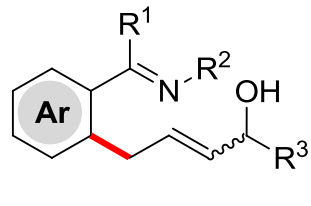

111,165

Scheme 2.5 Manganese(I)-catalyzed $\mathrm{C}-\mathrm{H}$ activation for decarboxylative $\mathrm{C}-\mathrm{H} / \mathrm{C}-\mathrm{O}$ cleavages.

Flow chemistry bears huge potential to address the needs of sustainable synthesis, facilitating challenging synthetic transformations and providing additional advantages, such as safer and faster reactions, clean products, and easy scale-up. ${ }^{[150]}$ In addition, remarkable advances have been achieved with the aid of less toxic manganese catalysis over the last decade. ${ }^{[83]}$ Nevertheless, all manganese(I)-catalyzed functionalization of substrates, bearing leaving groups in proximity to the C-C multiple bond, thus far resulted in $\beta$-heteroatom eliminations. ${ }^{[104-107,151]}$ Therefore, it is of great significance to develop a new versatile protocol, combining with continuous flow for manganese(I)-catalyzed $\mathrm{C}-\mathrm{H}$ alkenylations without concurrent $\beta$-O elimination (Scheme 2.6). ${ }^{[152]}$ 


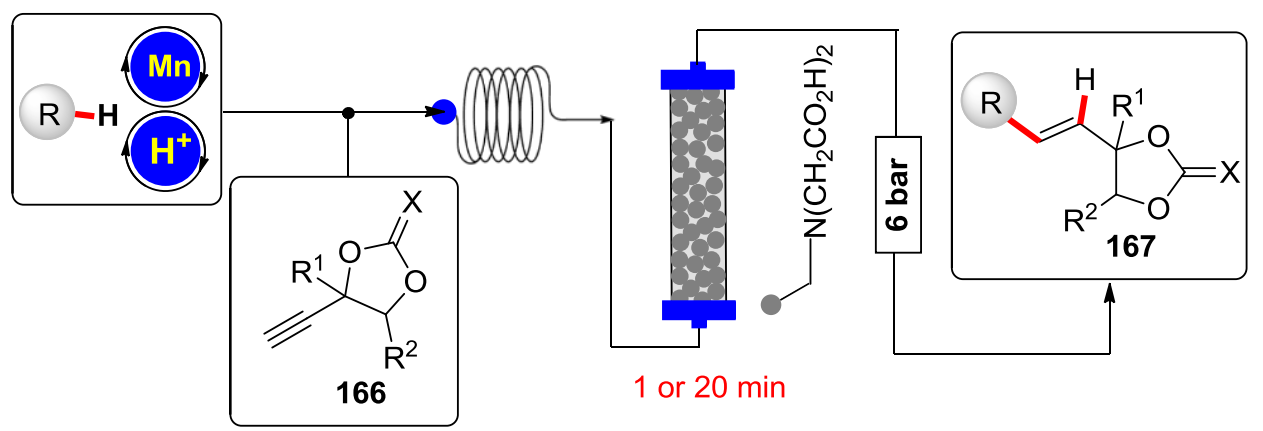

Scheme 2.6 Manganese(I)-catalyzed synergistic $\mathrm{C}-\mathrm{H}$ activation for chemoselective hydroarylation in flow.

Recent years have witnessed great sucssess in transition-metal-catalyzed C-C bond activations, offering new opportunities to the synthesis of valuable and novel organic moleculars. ${ }^{[119]}$ However, precious metals, such as rhodium, ruthenium and palladium, have always played a predominant role in this field, which limites their further application in synthetic chemistry due to the high cost and toxicity of these metals. In this regard, catalysts based on Earth-abundant metals, for example manganese, are highly desirable for $\mathrm{C}-\mathrm{C}$ bond functionalization. In addition, organic synthesis reactions catalyzed in water is consistent with the requirements of green chemistry. ${ }^{[29]}$ However, to date, transition-metal-catalyzed $\mathrm{C}-\mathrm{C}$ functionalizations in water have proven elusive. Within our program on sustainable $\mathrm{C}-\mathrm{C}$ functionalizations, ${ }^{[153]}$ herein, we disclosed the first versatile $\mathrm{C}-\mathrm{C}$ activation by inexpensive and less toxic manganese catalyst in water (Scheme 2.7). ${ }^{[154]}$

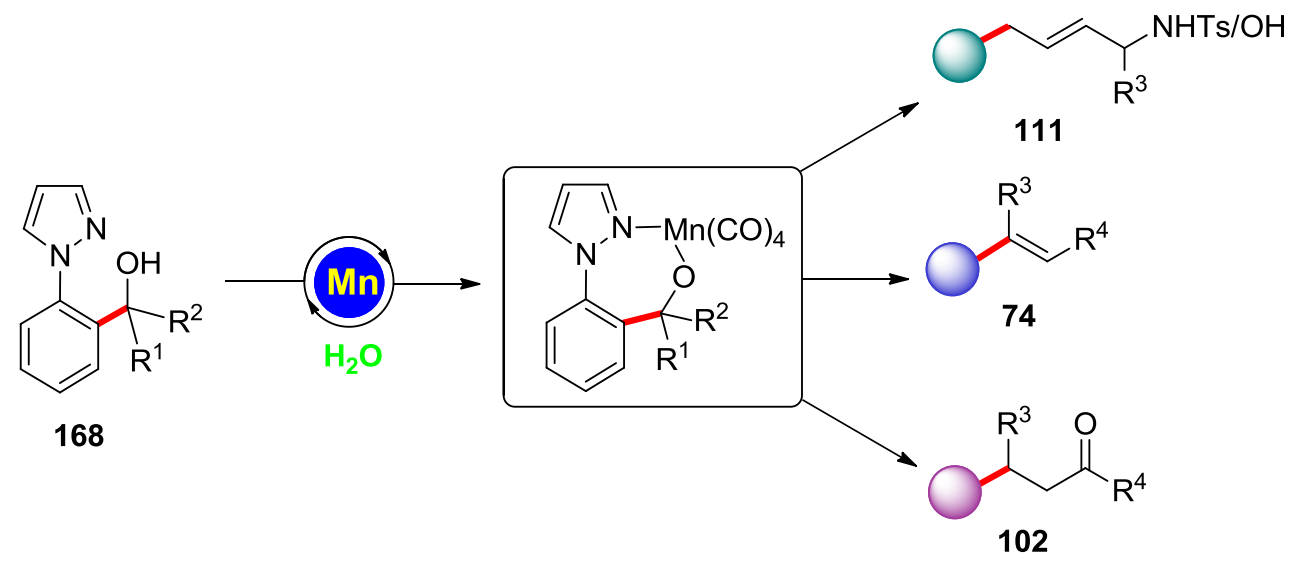

Scheme 2.7 Chelation-assisted manganese-catalyzed $\mathrm{C}-\mathrm{C}$ activations in $\mathrm{H}_{2} \mathrm{O}$. 


\section{Results and Discussion}

\subsection{Cobalt(III)-Catalyzed $\mathrm{C}-\mathrm{H} / \mathrm{N}-\mathrm{O}$ Functionalizations: Isohypsic Access to} Isoquinolines

Isoquinolines are versatile heterocycles that are widely used as a key structural moiety present in integrate molecules with medicinal benefits, natural products and diverse bioactivities. ${ }^{[108]}$ As a consequence, the development of efficient methods for the synthesis of isoquinolines continues to be of great interest. Over the past years, with advances in transition metal-catalyzed $\mathrm{C}-\mathrm{H}$ bond functionalizations, many effective methods have been developed to synthesize isoquinolines mainly using second- and third-row transition metals. ${ }^{[109 c, 140 \mathrm{~b}-\mathrm{d}, 155]}$ since the pioneering work of Matsunaga and $\mathrm{Kanai}^{\left[{ }^{[56]}\right.} \mathrm{Cp}^{*} \mathrm{Co}(\mathrm{III})$ catalysts have been shown as an inexpensive alternative to $\mathrm{Cp} * \mathrm{Rh}$ (III) catalysts for directed $\mathrm{C}-\mathrm{H}$ activation. Within our research program on cobalt(III)-catalyzed $\mathrm{C}-\mathrm{H}$ activation, ${ }^{[156]}$ we developed a novel cobalt(III)-catalyzed $\mathrm{C}-\mathrm{H} / \mathrm{N}-\mathrm{O}$ functionalizations for the redox-neutral preparation of isoquinolines.

\subsubsection{Optimization Studies for the Synthesis of Isoquinoline}

The cobalt(III)-catalyzed $\mathrm{C}-\mathrm{H}$ annulation was initiated using $(E)$-acetophenone $O$-acetyl oxime (158a) and 1,2-diphenylethyne (8a) in the presence of $\mathrm{Cp} * \mathrm{Co}(\mathrm{CO}) \mathrm{I}_{2}$ as the catalyst (Table 3.1.1). Preliminary experiments indicated DCE to be the solvent of choice, while low yields of the product 119aa were obtained in $\mathrm{MeOH}, \mathrm{H}_{2} \mathrm{O}, 1$,4-dioxane, and toluene (entries 1-5). Attempts to decrease the catalyst loading or reaction temperature of this annulation reaction resulted in a significant decrease in the product yields (entries 6-7). The desired product was isolated in only $48 \%$ yield when HOPiv was introduced as the additive (entry 8). It is worth noting that the cobalt(III)-catalyzed alkyne annulation proceeded efficiently under an atmosphere of air (entry 9). A significant decrease in reaction efficacy was observed when the $\left[\mathrm{Cp}^{*} \mathrm{Co}\left(\mathrm{C}_{6} \mathrm{H}_{6}\right)\right]\left(\mathrm{PF}_{6}\right)_{2}$ catalyst was employed for this reaction (entry 10). As anticipated, other cobalt catalysts did not afford the desired product 119aa under the otherwise identical conditions (entries 11-13). 
Table 3.1.1 Optimization studies for the synthesis of isoquinoline 119aa ${ }^{[a]}$

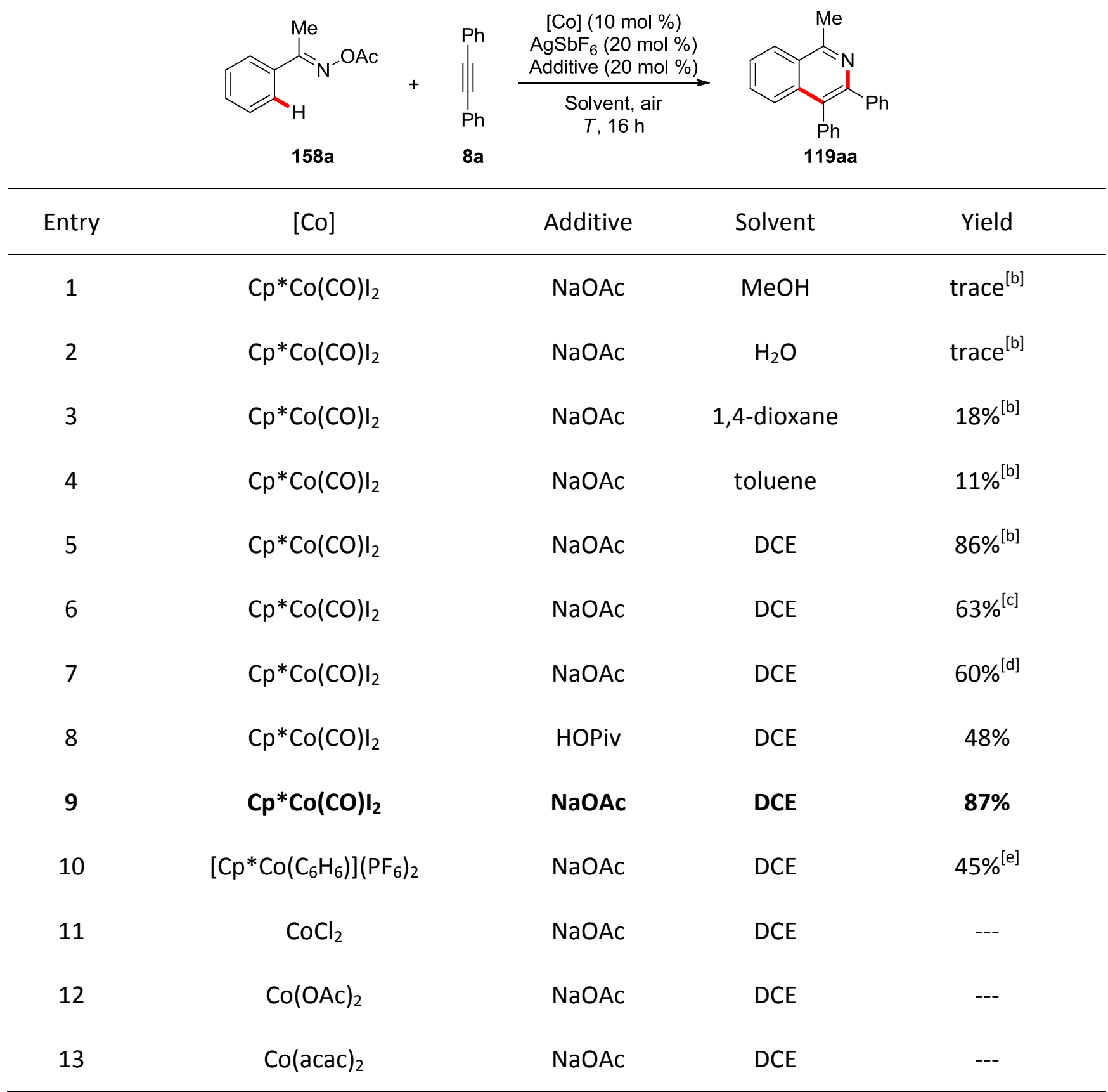

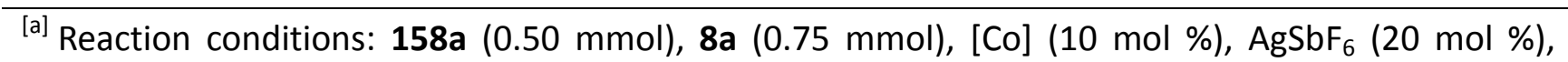
additive $(20 \mathrm{~mol} \%)$, solvent $(2.0 \mathrm{~mL})$, under air, $120{ }^{\circ} \mathrm{C}, 16 \mathrm{~h}$, isolated yield. ${ }^{[b]}$ Under $\mathrm{N}_{2} .{ }^{[c]}$ $\mathrm{Cp}^{*} \mathrm{Co}(\mathrm{CO}) \mathrm{I}_{2}(5.0 \mathrm{~mol} \%)$ was used. ${ }^{[\mathrm{d}]} T=100^{\circ} \mathrm{C} .{ }^{[\mathrm{e}]} 158 \mathrm{a}(0.25 \mathrm{mmol})$ was used. 


\subsubsection{Scope of Cobalt(III)-Catalyzed C-H/N-O Functionalization}

\subsubsection{Cobalt(III)-Catalyzed C-H/N-O Functionalization with Substituted Arenes 158}

With the optimized catalytic conditions in hand (Table 3.1.1, entry 9), we evaluated the reaction versatility by utilizing various substituted arenes 158 (Scheme 3.1.1).

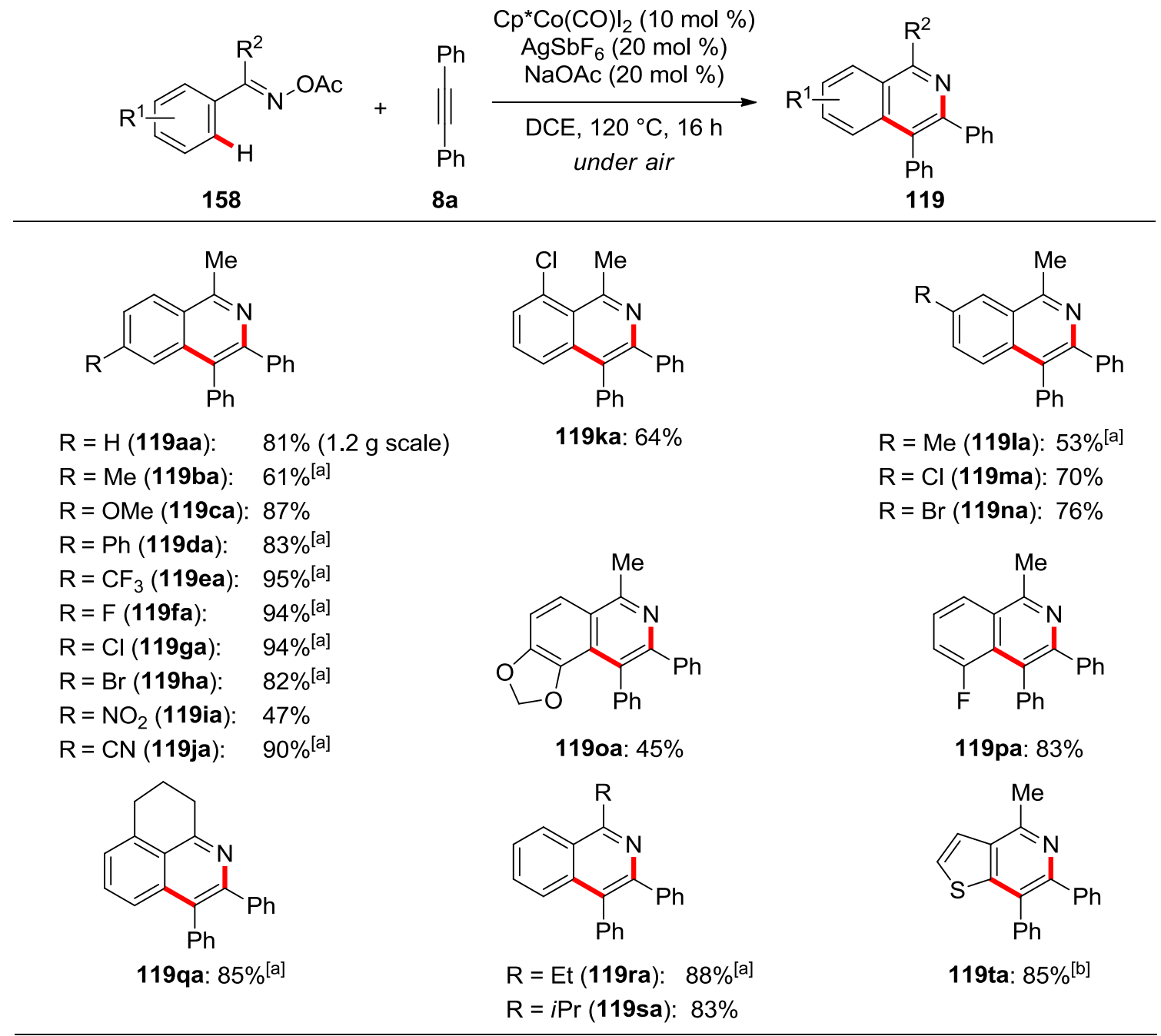

Scheme 3.1.1 Scope of cobalt(III)-catalyzed C-H/N-O functionalization with substituted arenes 158. ${ }^{[a]} 15$ min reaction time. ${ }^{[b]}$ In HFIP.

Both electron-donating and -withdrawing groups at the para-position, such as alky, methoxy, fluoro, trifluoromethyl, chloro, bromo, nitro, and cyano, were all well tolerated and afforded the desired products 119 in moderate to excellent yields. When $O$-acetyl oximes $158 \mathrm{l}-158 \mathrm{~m}$ bearing methyl, chloro and bromo groups at the meta-positions were chosen as the substrates, the $\mathrm{C}-\mathrm{H}$ activation occurred at the least hindered site and afforded the desired product in good yields with excellent 
selectivities, due to the small size of the cobalt. However, while the secondary interactions dominated in oxime derivatives, the totally opposite positions were selectively functionalized (119oa and 119pa). The $\mathrm{C}-\mathrm{H} / \mathrm{N}-\mathrm{O}$ annulation with substituted arene $\mathbf{1 5 8 q}$ set the stage for the assembly of the tricyclic product 119qa. In addition, the heterocyclic product 119ta was obtained in $85 \%$ yield with good regioselectivity when HFIP was employed as the reaction solvent. It is noteworthy that high catalytic activity of this cobalt(III) catalyst was showcased by obtaining the annulation products in high yields within only $15 \mathrm{~min}$.

\subsubsection{Isohypsic Annulation of Alkynes 8}

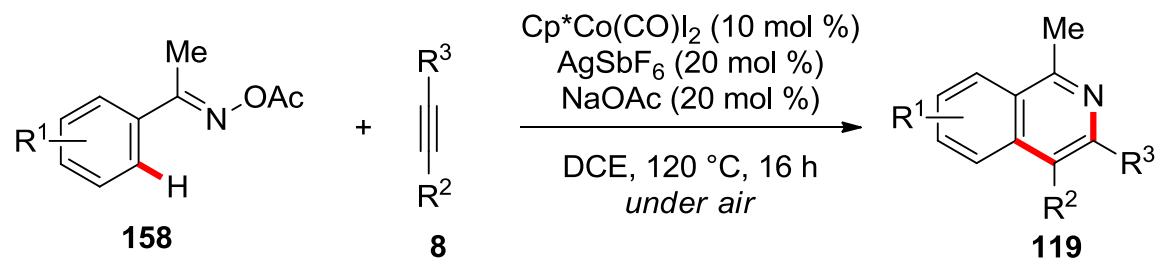

(i) aryl alkynes<smiles>[R]c1ccc(-c2nc(C)c3ccccc3c2-c2ccc([R])cc2)cc1</smiles>

$R=\operatorname{Me}(119 a b): 89 \%[a]$

$\mathrm{R}=\mathrm{CF}_{3}$ (119ae): $65 \%$

$\mathrm{R}=\mathrm{F}(119 \mathrm{af}): \quad 67 \%$

$\mathrm{R}=\mathrm{Cl}$ (119ag): $66 \%$

$\mathrm{R}=\mathrm{Br}$ (119ah): $\quad 71 \%$

(ii) alkyl alkynes<smiles>Cc1nc([Al])c([Al])c2cc(Cl)ccc12</smiles>

$\mathrm{R}=\mathrm{Et}(\mathbf{1 1 9} \mathbf{g k}): \quad$ 75\% ${ }^{[\mathrm{a}]}$

$\mathrm{R}=n \operatorname{Pr}(\mathbf{1 1 9} \mathrm{gl}): \quad 61 \%$

$\mathrm{R}=n \mathrm{Bu}(119 \mathrm{gm}): 85 \%$<smiles>Cc1nc(-c2cccc(Cl)c2)c(-c2cccc(Cl)c2)c2ccccc12</smiles>

119ai: $52 \%$

119aj: $84 \%$<smiles>Cc1nc(-c2cccs2)c(-c2cccs2)c2ccccc12</smiles>

(iii) unsymmetrical alkynes<smiles>Cc1nc(-c2ccccc2)c(C)c2ccccc12</smiles>

119an: $68 \%$<smiles>[R]c1cc2cc(Cl)ccc2c(C)n1</smiles>

$\mathrm{R}=\mathrm{Ph}(119 \mathrm{go}): 65 \%$

$\mathrm{R}=p$ Tol (119gp): $61 \%$

Scheme 3.1.2 Isohypsic annulation of alkynes $8 .{ }^{[a]} 15$ min reaction time.

Subsequently, we further explored the scope of this cobalt(III)-catalyzed $\mathrm{C}-\mathrm{H} / \mathrm{N}-\mathrm{O}$ functionalization 
by testing different alkynes 8 (Scheme 3.1.2). Various aryl- and alkyl-substituted alkynes were viable substrates, delivering the desired products in moderate to good yields $(\mathbf{8 b}-\mathbf{8 m})$. Unsymmetrical alkyne $8 \mathrm{n}$ underwent the reaction smoothly and provided the single products 119an with the phenyl substituent next to nitrogen in $68 \%$ yield. Terminal alkynes were also successfully applied for this annulation reaction, generating the desired products in good yields with excellent regio-selctivity (119go-119gp).

\subsubsection{Mechanistic Studies}

\subsubsection{Competition Experiments}

a) intermolecular competition experiment between arenes

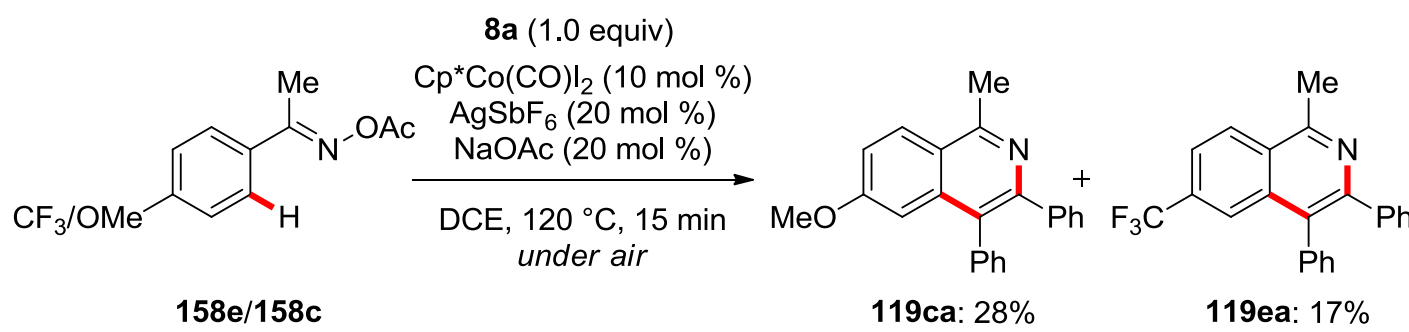

b) intramolecular competition experiment

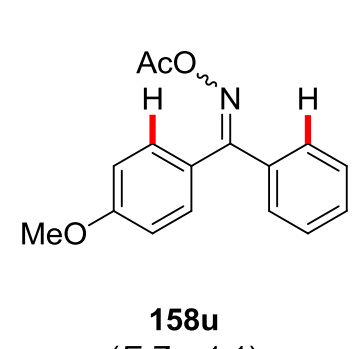

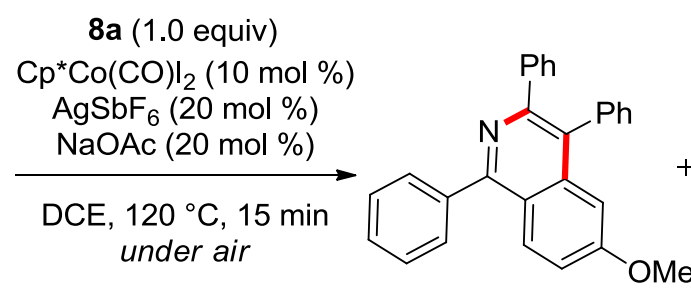

119ua: $63 \%$<smiles>COc1ccc(-c2nc(-c3ccccc3)c(-c3ccccc3)c3ccccc23)cc1</smiles>

119ua': $12 \%$

c) intermolecular competition experiment between alkynes 8

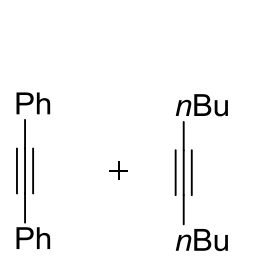

$8 \mathbf{a}$

$8 m$

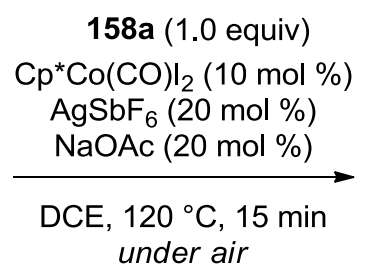

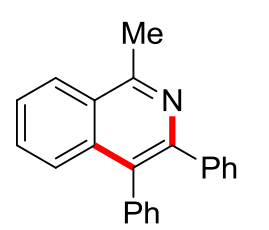

119aa: $36 \%$<smiles>CCCCOc1c(CCCC)nc(C)c2ccccc12</smiles>

119am: $15 \%$

Scheme 3.1.3 Intermolecular and intramolecular competition experiments.

Furthermore, intermolecular and intramolecular competition experiments between electron-rich 158c and electron-deficient arenes 158e under the optimized conditions were carried out (Scheme 
3.1.3a and b). As a result, the electron-rich arenes react preferentially, which possibly supports a base-assisted internal electrophilic-type substitution (BIES) $\mathrm{C}-\mathrm{H}$ activation by the cationic cobalt catalyst. It is noteworthy that the diastereomeric mixture of substrate $\mathbf{1 5 8} \mathbf{u}$ afforded the annulation product in high yield $(63 \%+12 \%)$. This result indicated that a $Z$-configuration of the $O$-acetyl oximes is not a prerequisite for this alkyne annulation reaction. ${ }^{[157]}$ Further, a competition experiment between different alkynes showed that aromatic substituents increased the inherent reaction rate (Scheme 3.1.3c).

\subsubsection{H/D-Exchange Experiments}

Moreover, in order to understand the mechanism of this $\mathrm{C}-\mathrm{H}$ activation reaction, the H/D-exchange experiment using substrate $(E)$-1-(4-methoxyphenyl)ethanone $O$-acetyl oxime $(\mathbf{1 5 8 c})$ with $\mathrm{D}_{2} \mathrm{O}$ as the co-solvent was conducted. Here, significant deuterium incorporation was observed in the ortho-position of reisolated substrate $[D]_{n}-\mathbf{1 5 8 c}$ as well as the product $[D]_{n}-119 c a$ (Scheme 3.1.4a), revealing the $\mathrm{C}-\mathrm{H}$ cobaltation process is reversible. Moreover, a $74 \% \mathrm{D}$ incorporation was observed at the $\mathrm{C}\left(s p^{3}\right)-\mathrm{H}$ bond of the product $[D]_{n}-119 c a$, suggesting that the cationic cobalt catalyst could enolize the product (Scheme 3.1.4b).

a) reversible $H / D$ exchange

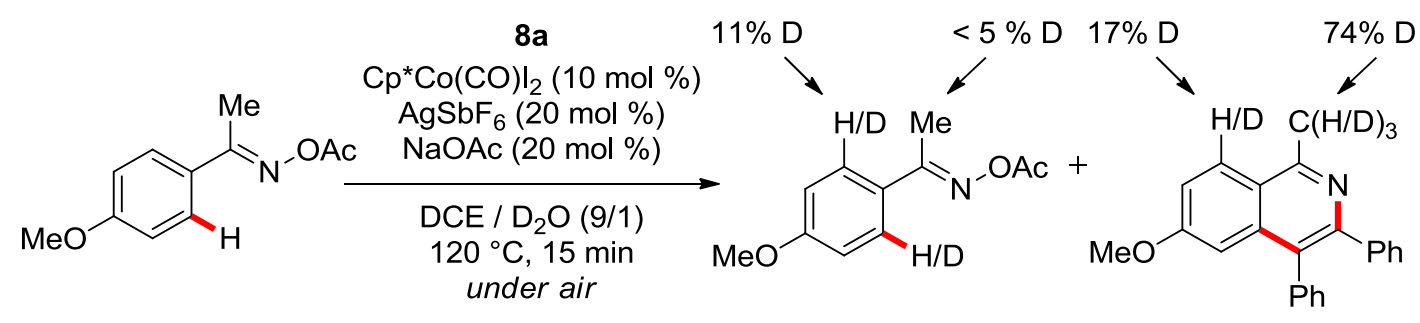

$158 c$

$[D]_{n}-158 c: 51 \%$

$[D]_{n}-119$ ca: $33 \%$

b) $H / D$ exchange experiment on product 119ca<smiles>COc1ccc2c(C)nc(-c3ccccc3)c(-c3ccccc3)c2c1</smiles>

119ca

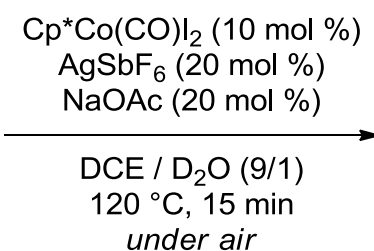

under air

under air<smiles>COc1ccc2c(C([14CH3])c3ccccc3)nc(-c3ccccc3)c(-c3ccccc3)c2c1</smiles>

$[D]_{n}-119 c a$

Scheme 3.1.4 H/D exchange experiments. 


\subsubsection{Kinetic Isotope Effect}

The kinetic isotope effect (KIE) of the cobalt(III)-catalyzed $\mathrm{C}-\mathrm{H}$ activation was determined by independent experiments of substrates $158 \mathrm{a}$ and $[\mathrm{D}]_{5}-158 \mathrm{a}$ to be $k_{\mathrm{H}} / k_{\mathrm{D}} \approx 1.5$ (Scheme 3.1.5). The result suggested that the reversible $\mathrm{C}-\mathrm{H}$ metalation is not the rate-determining step.

$8 \mathbf{a}$
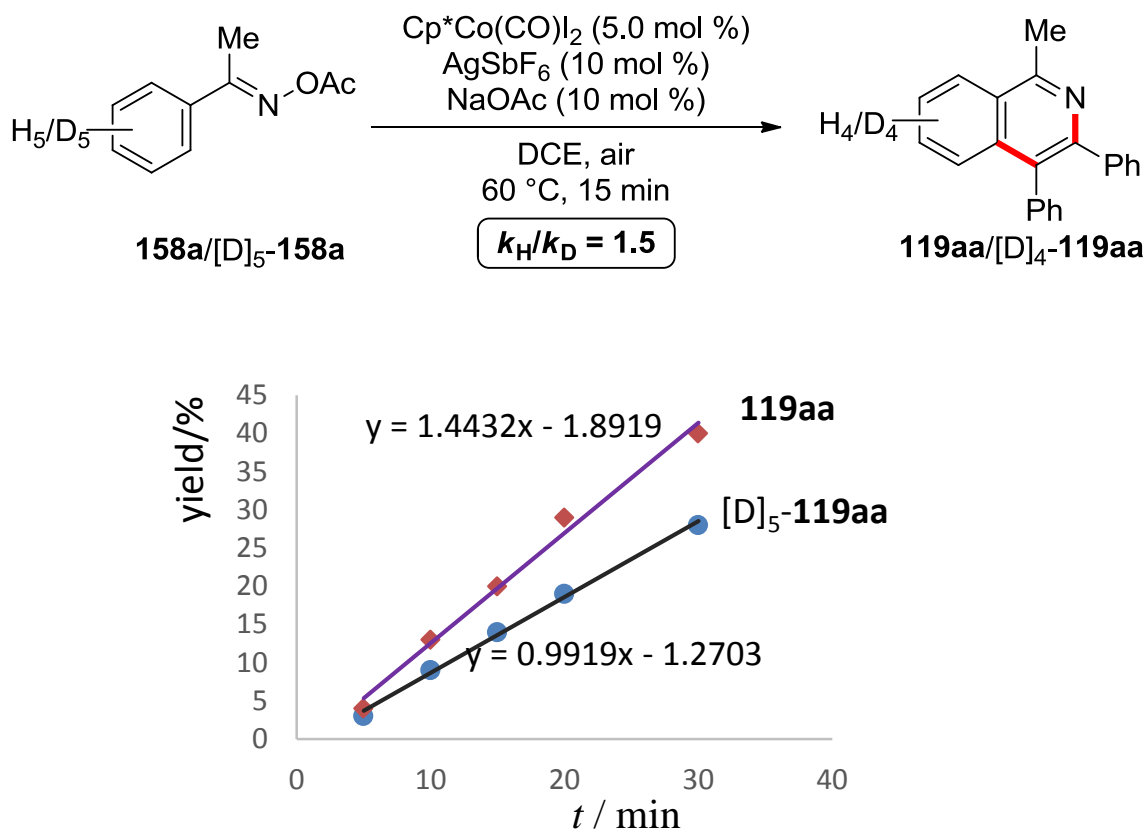

Scheme 3.1.5 Kinetic isotope effect experiment.

\subsubsection{Attempted Cyclization of ortho-Alkenylated Arene 169}

Additionally, the ortho-alkenylated intermediate 169 was separately prepared and subjected to the reaction conditions (Scheme 3.1.6). Notably, the cyclic product 119aa as not observed when the reaction was performed without $\mathrm{Cp}^{*} \mathrm{Co}(\mathrm{III})$ catalyst. Likewise, the attempted transformation of substrate 169 in the presence of $\mathrm{Cp}^{*} \mathrm{Co}$ (III) catalyst gave the isohypsic alkyne annulation product in only $15 \%$ yield, suggesting a hydroarylation/electrocyclization sequence unlikely to be operative. 


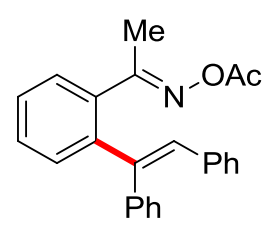

169

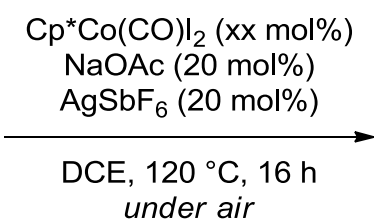

under air<smiles>Cc1nc(-c2ccccc2)c(-c2ccccc2)c2ccccc12</smiles>

$\mathrm{Cp}{ }^{*} \mathrm{Co}(\mathrm{CO}) \mathrm{I}_{2} \quad$ 119aa

$---:$

$10 \mathrm{~mol} \%$ :

$15 \%$

Scheme 3.1.6 Attempted cyclization of ortho-alkenylated arene $\mathbf{1 6 9 .}$

\subsubsection{Proposed Catalytic Cycle}

In summary, based on the mechanistic findings, a catalytic cycle was proposed for the cobalt(III)-catalyzed $\mathrm{C}-\mathrm{H} / \mathrm{N}-\mathrm{O}$ functionalization (Scheme 3.1.7). The catalytically active species might be a cationic cobalt(III)-acetate complex $\mathbf{5 0}$ formed by reaction of cobalt(III) precursor and $\mathrm{AgSbF}_{6}$. The reaction is initiated by reversible $\mathrm{C}-\mathrm{H}$ cobaltation of $\mathrm{O}$-acetyl oxime 158 , assisted by the acetate additive and presumably proceeds via a BIES-type pathway to furnish the intermediate 170. Then the key alkenyl intermediate $\mathbf{1 7 1}$ is generated by the alkyne migratory insertion, which subsequently undergoes the intramolecular cyclization by a $\mathrm{C}-\mathrm{N}$ bond formation. Finally, the desired product $\mathbf{1 1 9}$ was obtained along with the regeneration of the catalytic cobalt(III) complex $\mathbf{5 0}$ by a concerted acetate transfer process. 


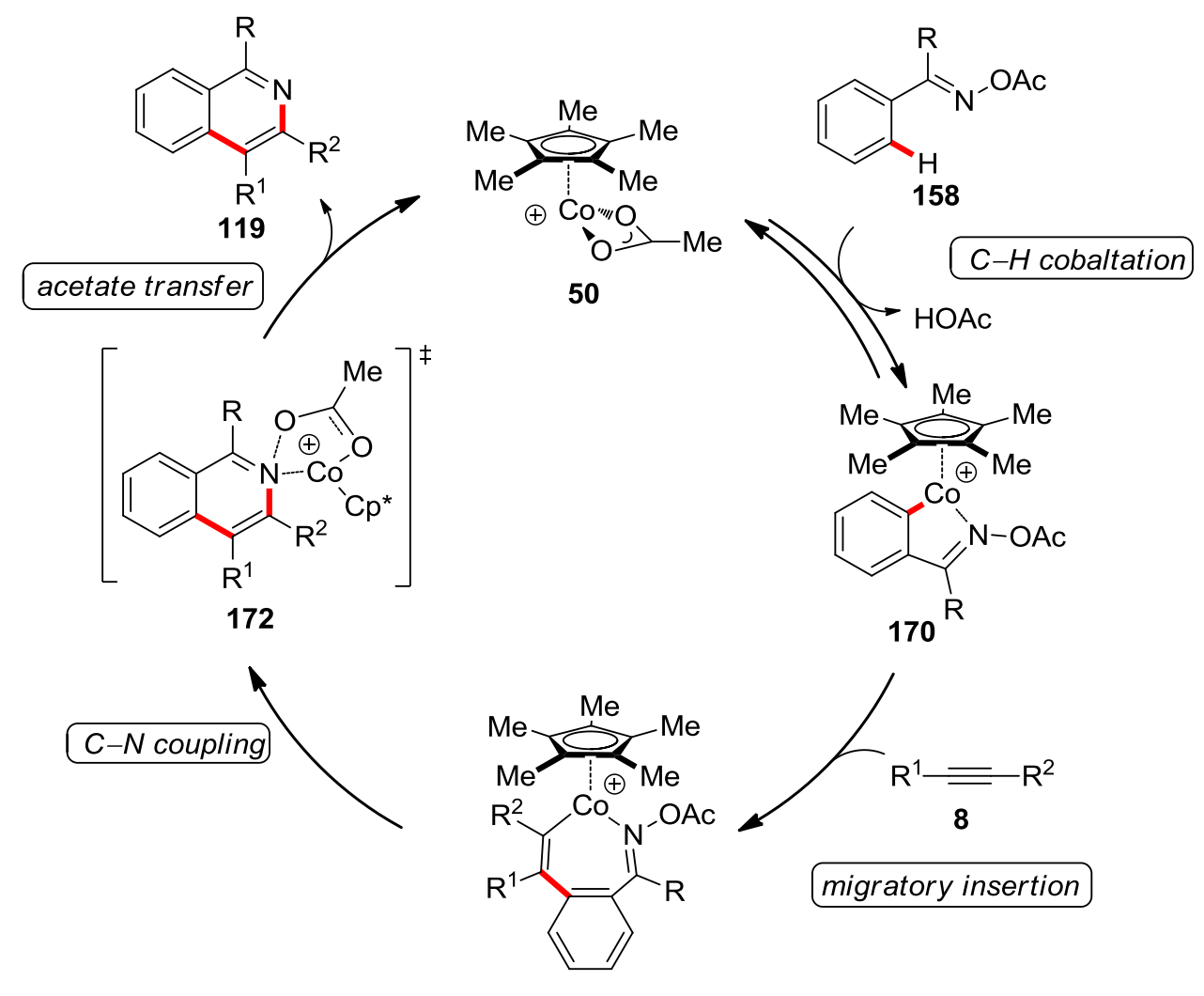

171

Scheme 3.1.7 Proposed catalytic cycle. 


\subsection{Selective Synthesis of Indoles by Cobalt(III)-Catalyzed $\mathrm{C}-\mathrm{H} / \mathrm{N}-\mathrm{O}$ Functionalization with Nitrones}

Substituted indoles are important building blocks abundantly found in natural products and pharmaceutically active compounds. ${ }^{[142 b]}$ Since Fischer and coworkers developed the new method for the synthesis of indole in 1883 from an arylhydrazine with a ketone or an aldehyde via the acid-mediated arylhydrazone formation, following by [3,3]-sigmatropic rearrangement (Scheme 3.2.1), ${ }^{[158]}$ indole synthese have become one of the most important topics in modern synthetic chemistry. Among those methods, $\mathrm{C}-\mathrm{H}$ activation has recently rapidly emerged as a robust tool for the synthesis of indole derivatives, avoiding the use of pre-functionalized substrates. ${ }^{[8,13 b]}$ In the past few years, significant progress has been achieved in $\mathrm{C}-\mathrm{H}$ activation using Earth-abundant and inexpensive first-row transition metals. ${ }^{[35 b]}$ While many routes for the synthesis of indoles have been reported, developing mild, environmentally-benign and atom-economical methods remains an important area. Herein, we became attracted to devise a protocol for cobalt(III)-catalyzed indole synthesis.

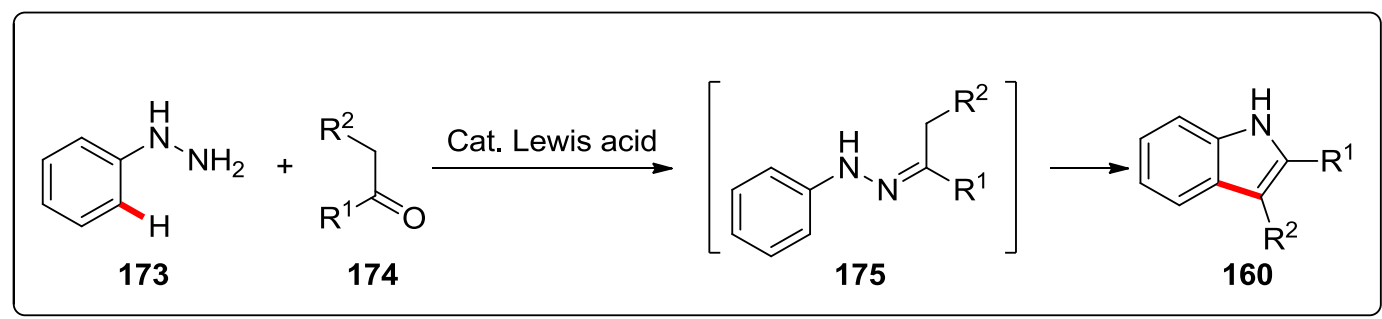

Scheme 3.2.1 Fischer indole synthesis.

\subsubsection{Optimization of Cobalt(III)-Catalyzed $\mathrm{C}-\mathrm{H} / \mathrm{N}-\mathrm{O}$ Alkyne Annulation}

We initiated our studies by testing the feasibility of the envisioned cobalt(III)-catalyzed $\mathrm{C}-\mathrm{H} / \mathrm{N}-\mathrm{O}$ functionalization with nitrone 159a and 1,2-diphenylethyne (8a) (Table 3.2.1). Preliminary experiments highlighted $\mathrm{Cp} * \mathrm{Co}(\mathrm{CO}) \mathrm{I}_{2}$ to be the catalyst of choice and indicated that TFE and HFIP were most suitable solvents (entries 1-7). A significant decrease in the product yields was observed when lower catalyst loadings or shorter reaction time were tested (entries 8-11). The isohypsic alkyne annulation proceeded at lower reaction temperatures, yet the best yield of the indole product 160aa was accomplished at $100{ }^{\circ} \mathrm{C}$ (entries 12-15). Moreover, the desired product was 
formed in $92 \%$ yield by a cationic single-component catalyst, thus avoiding the use of any silver salts (entry 16). It is noteworthy that only $13 \%$ yield of the annulation product 160 aa was observed in the presence of $\left[\mathrm{Cp}^{*} \mathrm{RhCl}_{2}\right]_{2}$ as the catalyst (entry 17$)$.

Table 3.2.1 Optimization of alkyne annulation ${ }^{[a]}$

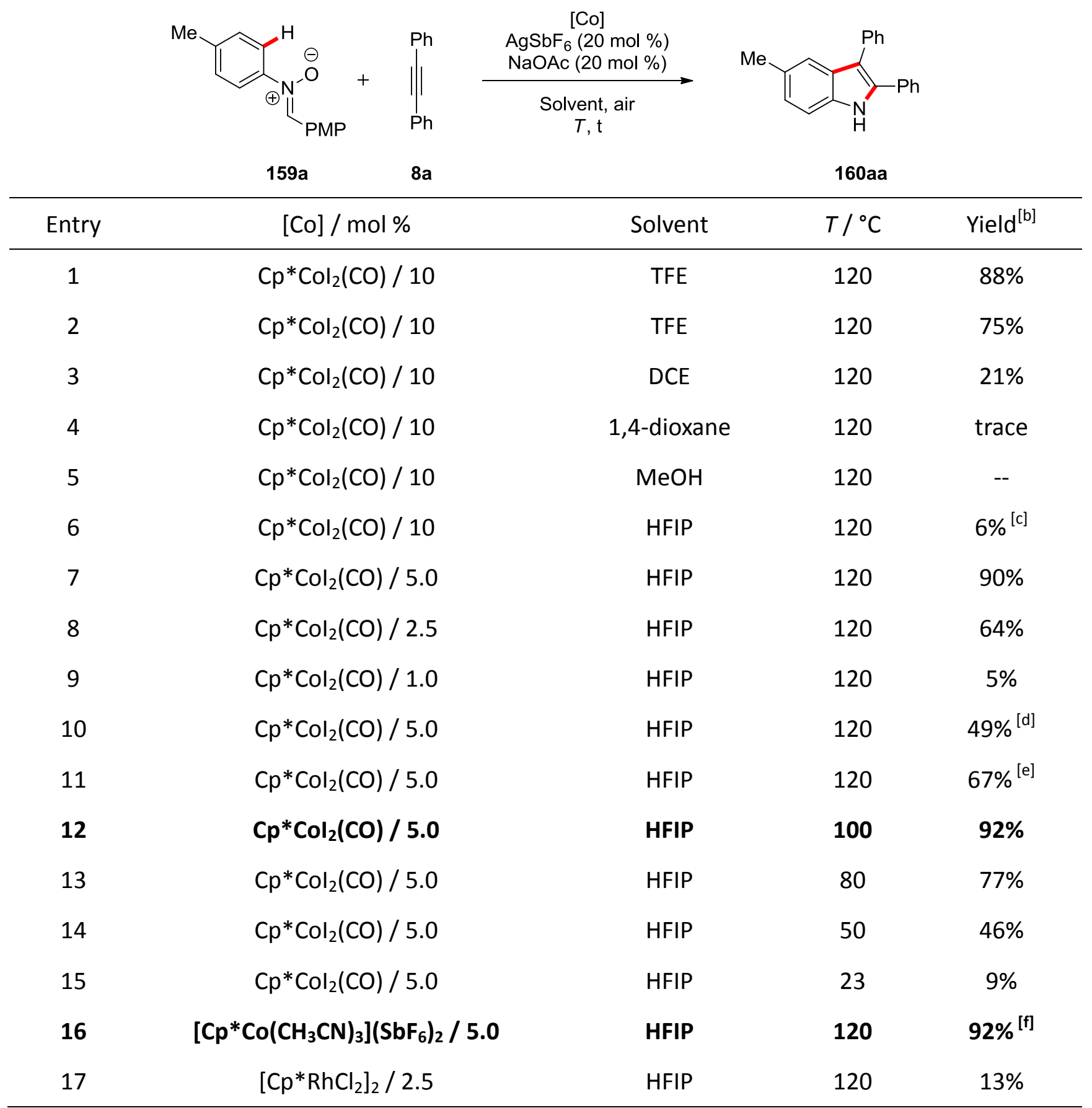

${ }^{[a]}$ Reaction conditions: 159a (0.50 mmol), 8a (0.75 mmol), AgSbF 6 (20 mol \%), NaOAc (20 mol \%), solvent $(2.0 \mathrm{~mL})$, under air, $100{ }^{\circ} \mathrm{C}, 16 \mathrm{~h} .{ }^{[b]}$ Yield of isolated product. ${ }^{[c]} \mathrm{Cu}(\mathrm{OAc})_{2}$ (1.0 equiv) was used. ${ }^{[\mathrm{d}]} 1 \mathrm{~h} .{ }^{[\mathrm{e}]} 3 \mathrm{~h} .{ }^{[\mathrm{fl}]}$ Without Ag salts. 
Table 3.2.2 Effect of additives ${ }^{[a]}$

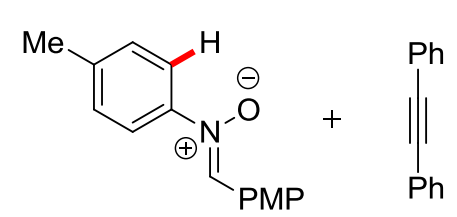

$159 a$

$8 \mathbf{a}$

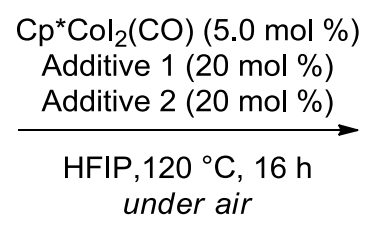<smiles>Cc1ccc2[nH]c(-c3ccccc3)c(-c3ccccc3)c2c1</smiles>

160aa

\begin{tabular}{|c|c|c|c|}
\hline Entry & Additive 1 & Additive 2 & Yield $^{[b]}$ \\
\hline 1 & $\mathrm{AgSbF}_{6}$ & $\mathrm{NaOAC}$ & $92 \%$ \\
\hline 2 & $\mathrm{AgPF}_{6}$ & $\mathrm{NaOAc}$ & $82 \%$ \\
\hline 3 & $\mathrm{AgBF}_{4}$ & $\mathrm{NaOAc}$ & $80 \%$ \\
\hline 4 & AgOTs & $\mathrm{NaOAc}$ & $82 \%$ \\
\hline 5 & AgOTf & $\mathrm{NaOAc}$ & $86 \%$ \\
\hline 6 & -- & $\mathrm{K}_{2} \mathrm{CO}_{3}$ & $10 \%$ \\
\hline 7 & $\mathrm{AgSbF}_{6}$ & KOAC & $86 \%$ \\
\hline 8 & $\mathrm{AgSbF}_{6}$ & $\mathrm{CsOAc}$ & $88 \%$ \\
\hline 9 & $\mathrm{AgSbF}_{6}$ & -- & $7 \%$ \\
\hline 10 & $\mathrm{AgSbF}_{6}$ & $\mathrm{NaOAc}$ & $--^{[c]}$ \\
\hline
\end{tabular}

[a] Reaction conditions: 159a (0.50 mmol), 8a (0.75 mmol), $\mathrm{Cp}^{*} \mathrm{Col}_{2}(\mathrm{CO})(5.0 \mathrm{~mol} \%)$, additive 1 (20 mol \%), additive $2(20 \mathrm{~mol} \%), \operatorname{HFIP}(2.0 \mathrm{~mL})$, under air, $120{ }^{\circ} \mathrm{C}, 16 \mathrm{~h} .{ }^{[\mathrm{b}]}$ Yield of isolated product. ${ }^{[\mathrm{c}]}$ Without $\mathrm{Cp}^{*} \mathrm{Col}_{2}(\mathrm{CO})$.

Furthermore, various additives were tested for the cobalt(III)-catalyzed $\mathrm{C}-\mathrm{H} / \mathrm{N}-\mathrm{O}$ functionalization (Table 3.2.2). Different silver salts were firstly employed for the reaction, delivering the desired product 160aa in satisfactory yields. $\mathrm{AgSbF}_{6}$ was optimal, presumably because hexafluoroantimonate is a weakly-coordinating and non-nucleophilic anion which stabilizes the cationic cobalt species (entries 1-5). Subsequently, the reactions with different bases or without base were examined, and these results suggested that NaOAc is the most effective (entries 6-9). A control experiment showed that there was no reaction in the absence of the cobalt(III) catalyst (entry 10).

The last few years have witnessed the significant progress of $\mathrm{N}$-acyl amino acids as powerful ligands in transition metal-catalyzed $\mathrm{C}-\mathrm{H}$ activation, as reported by $\mathrm{Yu}^{[159]}$ and Ackermann group. ${ }^{[160]}$ 
Therefore, with the previous optimization results in hand, we tested a series of amino acid ligands instead of $\mathrm{NaOAc}$ for the cobalt(III)-catalyzed $\mathrm{C}-\mathrm{H} / \mathrm{N}-\mathrm{O}$ functionalization with nitrone 159a (Table 3.2.3). Notably, Piv-Leu-OH proved to be a powerful ligand, delivering the desired indole 160aa in $88 \%$ yield (entry 4$)$.

Table 3.2.3 Effect of different amino acid ligands ${ }^{[a]}$

\begin{tabular}{ccc} 
Piv-lle-COONa & $\begin{array}{c}\mathrm{Cp}^{*} \mathrm{Col}_{2}(\mathrm{CO})(5.0 \mathrm{~mol} \%) \\
\text { AgSbF}(20 \mathrm{~mol} \%)\end{array}$ \\
\hline $159 a$ & Additive $(20 \mathrm{~mol} \%)$ \\
under air
\end{tabular}

Reaction conditions: $159 \mathrm{a}(0.50 \mathrm{mmol}), 8 \mathrm{a}(0.75 \mathrm{mmol}), \mathrm{Cp}^{*} \mathrm{Col}_{2}(\mathrm{CO})(5.0 \mathrm{~mol} \%), \mathrm{AgSbF}_{6}(20 \mathrm{~mol} \%)$, additive $(20 \mathrm{~mol} \%)$, HFIP $(2.0 \mathrm{~mL})$, under air, $100{ }^{\circ} \mathrm{C}, 16 \mathrm{~h} .{ }^{[\mathrm{b}]}$ Yield of isolated product.

\subsubsection{Influence of the C-Substitution Pattern}

Moreover, we also tested the dependence of the catalytic efficacy on the $C$-substitution pattern of the nitrones 159 (Scheme 3.2.2). These test reactions under the optimized reaction conditions 
verified the importance of the $C$-substitution pattern. Notably, the electron-donating PMP substituent afforded the desired product 160 aa in the highest yield of $92 \%$, presumably due to the fine tunning of electronic and steric factors.

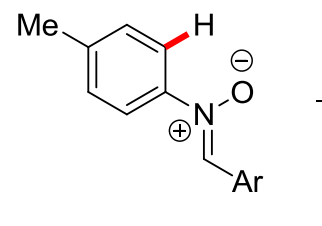

159

$\mathrm{Ar}=\mathrm{PMP}:$ 159a

$\mathrm{Ar}=\mathrm{Ph}: \quad 159 \mathrm{a}^{\prime}$

$\operatorname{Ar}=$ Mes: 159a"

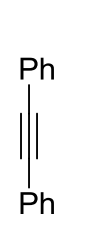

$8 \mathbf{a}$

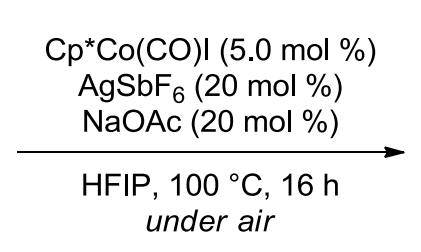

under air<smiles>Cc1ccc2[nH]c(-c3ccccc3)c(-c3ccccc3)c2c1</smiles>

160 aa

$92 \%$

$73 \%$

$57 \%$

Scheme 3.2.2 Influence of the $C$-substitution pattern on nitrones.

\subsubsection{Scope of Cobat-Catalyzed C-H/N-O Functionalization}

\subsubsection{C-H/N-O Functionalization with Nitrones 159}

With the optimized catalytst in hand (Table 3.2.1, entry 12 and Table 3.2.3, entry 4), the scope of the cobalt(III)-catalyzed $\mathrm{C}-\mathrm{H} / \mathrm{N}-\mathrm{O}$ annulation with various substituted nitrones 159 was examined (Scheme 3.2.3). A variation of substituents in para-position of the nitrones led to overall good to excellent yields. Moreover, valuable functional groups, such as fluoro, chloro, and bromo, were well tolerated under the optimal reaction conditions (160ca-160ea). The intramolecular competition experiment with meta-substituted nitrone $\mathbf{1 5 9 f}$ bearing two different ortho- $\mathrm{C}-\mathrm{H}$ bonds delivered site-selectively indole $\mathbf{1 6 0 f a}$ as the sole product. Moreover, there are no significant differences in the product yields between Piv-Leu-OH and $\mathrm{NaOAc}$ as the additives. 


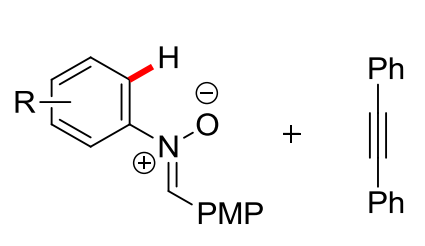

159<smiles>Cc1ccc2[nH]c(-c3ccccc3)c(-c3ccccc3)c2c1</smiles>

160 aa

NaOAc: $\quad 92 \%$

gram-scale: $82 \%$

Piv-Leu-OH: 88\%<smiles>Clc1ccc2[nH]c(-c3ccccc3)c(-c3ccccc3)c2c1</smiles>

$160 \mathrm{da}$

NaOAc: $\quad 70 \%$

Piv-Leu-OH: $76 \%$

$8 a$

$\mathrm{Cp}^{*} \mathrm{Co}(\mathrm{CO}) \mathrm{l}(5.0 \mathrm{~mol} \%)$

$\mathrm{AgSbF}_{6}(20 \mathrm{~mol} \%)$

additive $(20 \mathrm{~mol} \%)$

HFIP, $100^{\circ} \mathrm{C}, 16 \mathrm{~h}$ under air<smiles>c1ccc(-c2[nH]c3ccccc3c2-c2ccccc2)cc1</smiles>

$160 \mathrm{ba}$

NaOAc: $\quad 76 \%$

Piv-Leu-OH: $68 \%$<smiles>Brc1ccc2[nH]c(-c3ccccc3)c(-c3ccccc3)c2c1</smiles>

160ea

NaOAc: $\quad 91 \%$ Piv-Leu-OH: $80 \%$<smiles>[R]1ccc2c(-c3ccccc3)c(-c3ccccc3)[nH]c2c1</smiles>

160<smiles>CC(C)(C)OC(C)(C)O</smiles>

NaOAc: $\quad 70 \%$ Piv-Leu-OH: $67 \%$<smiles>Cc1ccc2c(-c3ccccc3)c(-c3ccccc3)[nH]c2c1</smiles>

$160 f a$

NaOAc: $\quad 78 \%$ Piv-Leu-OH: $89 \%$

Scheme 3.2.3 $\mathrm{C}-\mathrm{H} / \mathrm{N}-\mathrm{O}$ functionalization with nitrones 159.

\subsubsection{Cobalt(III)-Catalyzed Annulation of Tolanes}

Furthermore, the reaction was explored with differently substituted tolane derivatives $\mathbf{8}$, which also proved to be viable for the $\mathrm{C}-\mathrm{H}$ annulation reaction and afforded the 2,3-diaryl indoles 160 in moderate to good yields (Scheme 3.2.4). Notably, this cobalt(III)-catalyzed annulation reaction was shown tolerant for both electron-donating and electron-withdrawing groups, including Me (8b), OMe (8c), $\mathrm{Cl}(8 \mathrm{~g}, 8 \mathrm{~h})$ and $\mathrm{CF}_{3}(8 \mathrm{e})$. 


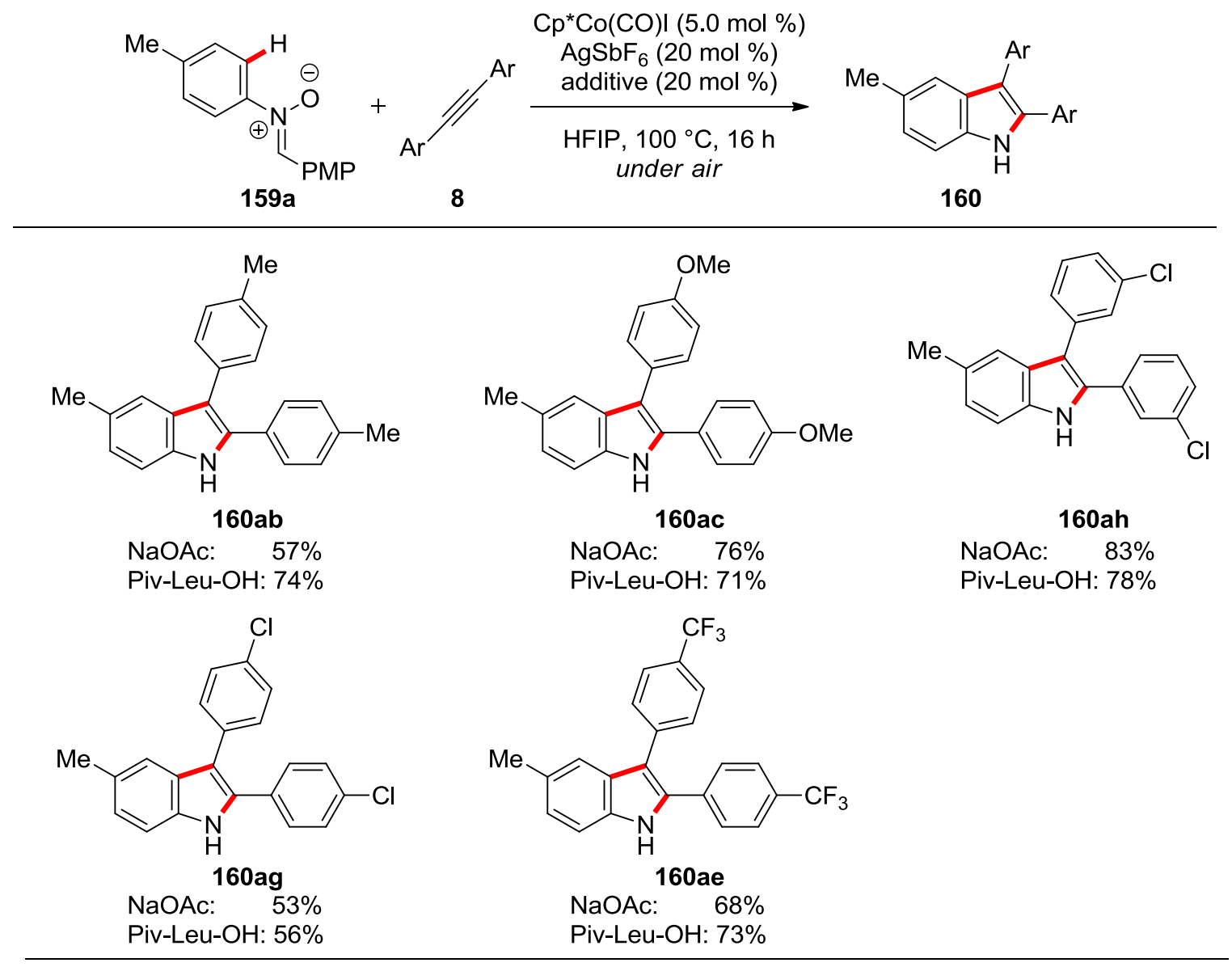

Scheme 3.2.4 Cobalt(III)-catalyzed annulation of tolanes 8 .

\subsubsection{Cobalt(III)-Catalyzed Annulation of Unsymmetrical Alkynes}

Particularly, when unsymmetrically substituted alkynes 8 were applied to this reaction using Piv-Leu-OH as the additive, the corresponding products 160ap-160ar was obtained in good yields and excellent regio-selectivities (Scheme 3.2.5). By comparison with a related rhodium(III)-catalyzed indole synthesis, ${ }^{[161]}$ higher regio-selectivities $(E / Z>15)$ were obtained, highlighting a more effective cobalt catalysis for this annulation reaction. 

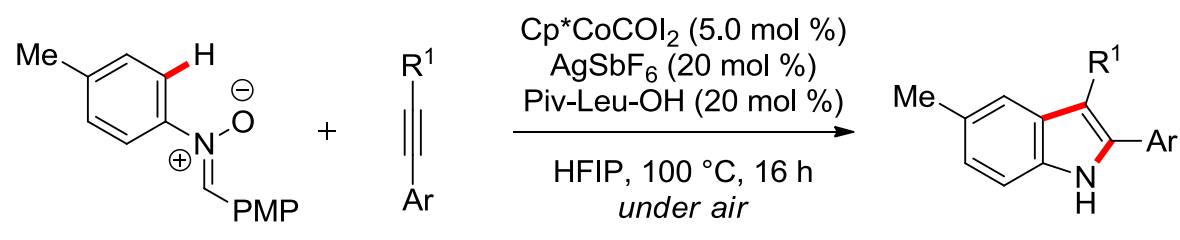

$159 a$

8

160

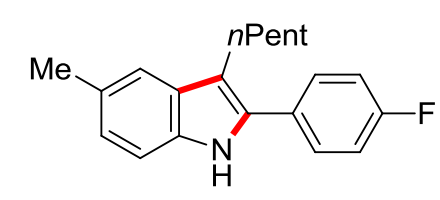

160ap: $77 \%$<smiles>CCOC(=O)c1c(-c2ccccc2)[nH]c2ccc(C)cc12</smiles>

160aq: $63 \%$<smiles>CCCCc1c(-c2ccc([N+](=O)[O-])cc2)[nH]c2ccc(C)cc12</smiles>

160ar: $54 \%$

Scheme 3.2.5 Cobalt(III)-catalyzed annulation of unsymmetrical alkynes 8.

\subsubsection{Formation of $3 H$-Indole and Cationic Cobalt(III) as the Catalyst}

a) formation of $3 H$-indole 161

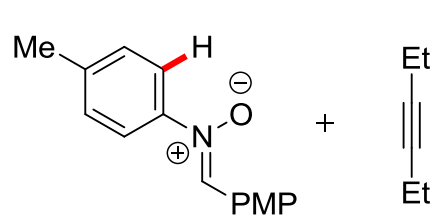

$159 a$

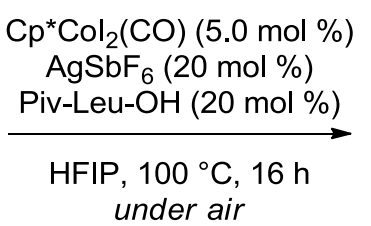

under air<smiles>[Y6]C1=Nc2ccc(C)cc2C1(CC)C(=O)CC</smiles>

161: $46 \%$

b) single-componeat catalyst<smiles>[R]C=Cc1ccccc1N([O-])C=[Y6]</smiles>

159

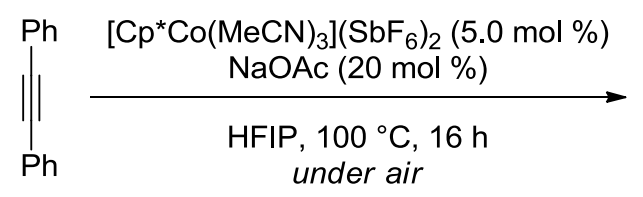

$8 a$

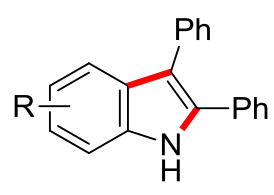

160<smiles>[R]c1ccc2[nH]c(-c3ccccc3)c(-c3ccccc3)c2c1</smiles>

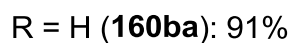

$\mathrm{R}=\mathrm{Me}(160 \mathrm{aa}): 92 \%$<smiles>[R]c1ccc2[nH]c(-c3ccccc3)c(-c3ccccc3)c2c1</smiles>

$R=F(160 \mathrm{ca}): 63 \%$ $\mathrm{R}=\mathrm{Br}$ (160ea): $89 \%$<smiles>Cc1ccc2c(-c3ccccc3)c(-c3ccccc3)[nH]c2c1</smiles>

160fa: $88 \%$

Scheme 3.2.6 Formation of $3 H$-indole 161 and cationic cobalt(III) as the catalyst.

Interestingly, when the dialkyl-substituted alkyne $\mathbf{8}$ was employed under the optimal reaction conditions, the unexpected 3,3-disubstituted $3 H$-indole 161 was obtained, which was in agreement 
with Chang's work ${ }^{[162]}$ reported on rhodium(III)-catalyzed $\mathrm{C}-\mathrm{H}$ activation for the synthesis of indolines (Scheme 3.2.6a) Moreover, the user-friendly nature of this $\mathrm{C}-\mathrm{H}$ activation strategy was reflected by using a cationic single-component cobalt catalyst, thus avoiding the use of additional silver salts (Scheme 3.2.6b).

\subsubsection{Mechanistic Studies}

\subsubsection{Competition Experiments}

Subsequently, an intermolecular competition experiment between electron-rich and electron-deficient para-substituted nitrones under the optimized conditions was carried out (Scheme 3.2.7a). As a result, the electron-rich nitrones 159a reacted preferentially, which supports a base (acetate)-assisted electrophilic-type (BIES) $\mathrm{C}-\mathrm{H}$ activation. Further competition experiments between electronically distinct alkynes $\mathbf{8 c}$ and $8 \mathrm{e}$ showed that electron-rich alkynes were found to be preferentially converted (Scheme 3.2.7b).

a) competition between nitrones

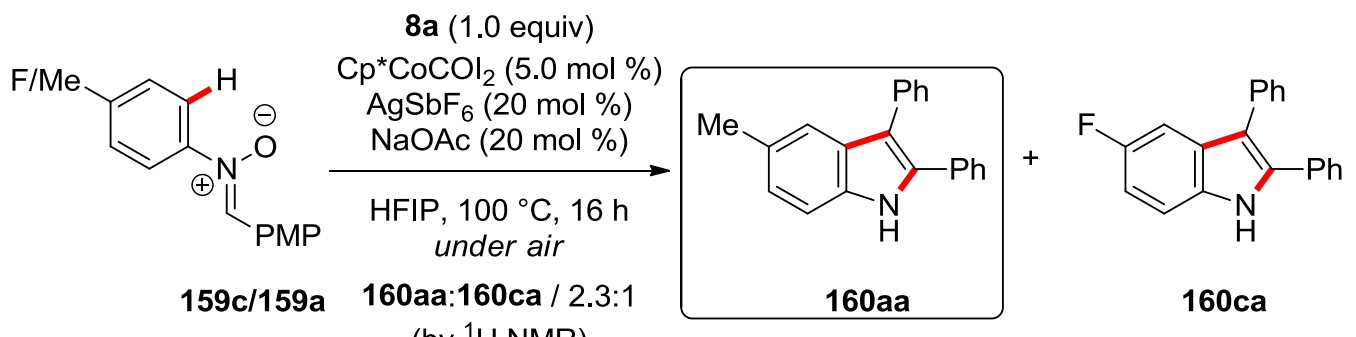

(by ${ }^{1} \mathrm{H}$ NMR)

b) competition between alkynes

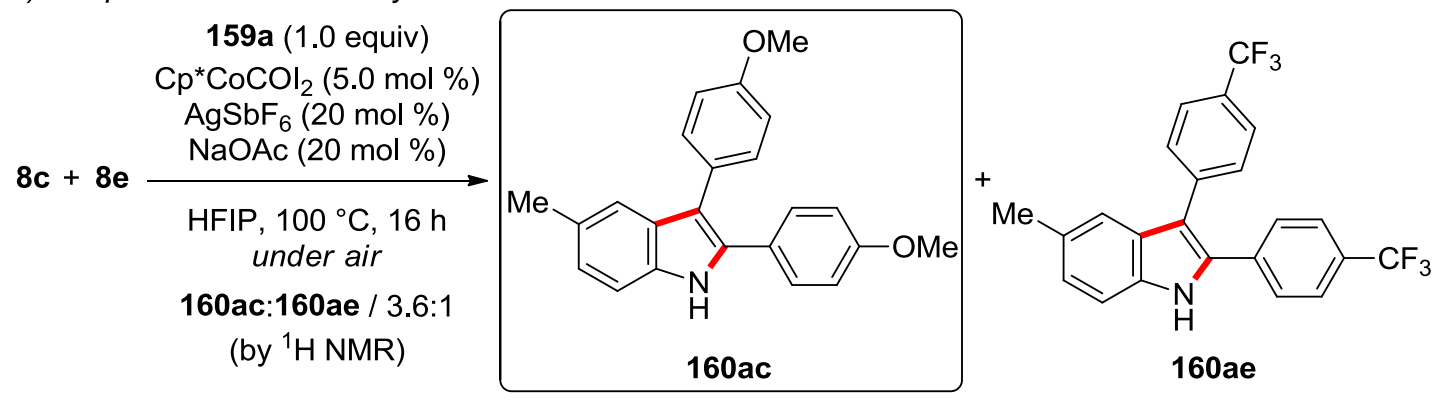

Scheme 3.2.7 Competition experiments. 


\subsubsection{H/D Exchange and Kinetic Isotope Effect Study}

When the reaction was performed in the presence of isotopically labelled $\mathrm{CD}_{3} \mathrm{OD}$ as co-solvent, we did not observe any H/D scrambling on both the reisolated starting material 159a and the desired product 160aa (Scheme 3.2.8a). Moreover, the KIE of the cobalt(III)-catalyzed $\mathrm{C}-\mathrm{H} / \mathrm{N}-\mathrm{O}$ annulation was determined by comparison of independent reaction rates of substrates $159 \mathrm{~b}$ and $[D]_{5}-159 b$, resulting in a value of $k_{H} / k_{D} \approx 2.7$ (Scheme 3.2.8b). These results suggested that the $\mathrm{C}-\mathrm{H}$ metalation is the rate-determining step.

a) attempted $H / D$ exchange experiment

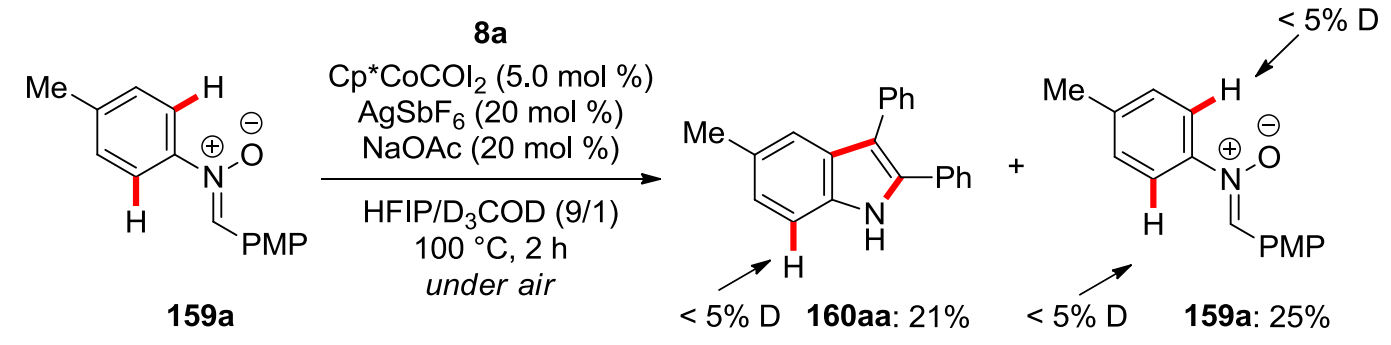

b) KIE by independent experiments
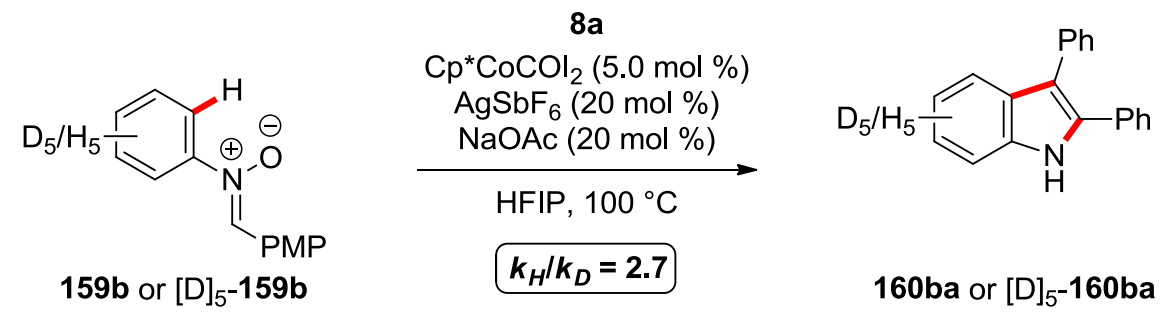

Scheme 3.2.8 H/D exchange and kinetic isotope effect study.

\subsubsection{Plausible Catalytic Cycle}

At last, a catalytic cycle for this cobalt(III)-catalyzed $\mathrm{C}-\mathrm{H}$ functionalization is proposed based on our mechanistic findings (Scheme 3.2.9). The BIES C-H activation is likely assisted by the carboxylate, which in situ forms the cationic cobalt(III)-carboxylate complex 50. After the metallacyle 176 is generated, coordination and insertion of alkyne 8 furnishes the key intermediate 177, then the following $\mathrm{N}-\mathrm{O}$ bond cleavage and $\mathrm{C}-\mathrm{O}$ bond formation generates the intermediate 178. Afterwards, the active cationic catalyst $\mathbf{5 0}$ is regenerated by a proto-demetalation, while the protected ortho-amino ketone $\mathbf{1 7 9}$ is also formed, which upon hydrolysis and subsequent intramolecular condensation provides the desired product 160. 


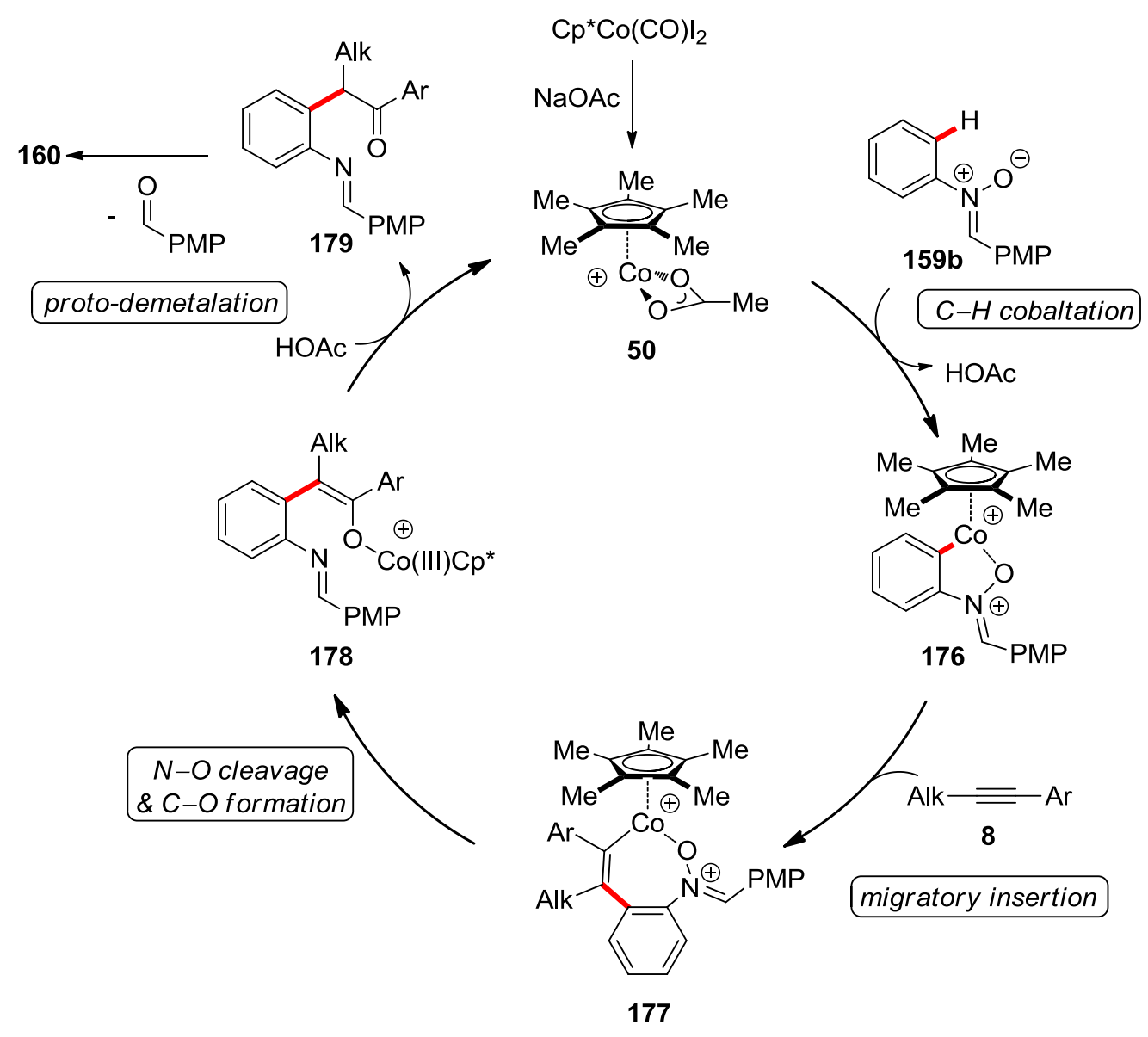

Scheme 3.2.9 Plausible catalytic cycle. 


\subsection{Overcoming the Limitations of $\mathrm{C}-\mathrm{H}$ Activation with Strongly Coordinating $\mathrm{N}$-Heterocycles by Cobalt Catalysis}

The synthesis of heterocycles has always attracted great attention in organic chemistry, because they widely exist in various pharmaceutical molecules and natural products. ${ }^{[163]}$ Over the past few decades, transition metal-catalyzed $\mathrm{C}-\mathrm{H}$ functionalization has emerged as one of the most powerful approaches for the synthesis and diversification of novel heterocycles. ${ }^{[164]}$ However, in direct $\mathrm{C}-\mathrm{H}$ activation, all nitrogen atoms present in heterocyclic substrates will strongly coordinate with metal catalysts, which in some cases could either activate an undesired $\mathrm{C}-\mathrm{H}$ bond or poison the catalyst. Thus, the solution to achieving the control of positional selectivity in $\mathrm{C}-\mathrm{H}$ activation will be a very meaningful topic in organic synthesis. But only one example was reported in 2014 by Yu and coworkers to achieve the position-selective $\mathrm{C}-\mathrm{H}$ activation on heterocycles with different $\mathrm{N}$-atoms. ${ }^{[146]}$ Despite great success in cobalt(III)-catalyzed $\mathrm{C}-\mathrm{H}$ functionalizations in recent years, ${ }^{[37 a-c \text {, }}$ ${ }^{37 e, 37 f]}$ there is no example for cobalt catalysis which achieves the control of positional selectivity on substrates with strongly coordinating $\mathrm{N}$-atoms. Therefore, the demand for a robust $\mathrm{C}-\mathrm{H}$ activation achieving the positional selectivity on heterocycles by cobalt catalysis is highly desirable.

\subsubsection{Optimization of the Cobalt(III)-Catalyzed C-H Amidation of Imidates}

We initiated our studies by testing a variety of reaction conditions for cobalt(III)-catalyzed $\mathrm{C}-\mathrm{H}$ amidation of ethyl benzimidate (161a) with 3-phenyl-1,4,2-dioxazol-5-one (162a) (Table 3.3.1). Firstly, the desired amidation product 163 aa could be obtained in good yields with $\mathrm{Cu}(\mathrm{OAc})_{2}$ and $\mathrm{NaOAc}$ as the additives (entries 1, 2). However, a quantitative yield of the product could be obtained without any additives (entry 3 ). The catalyst loading and reaction temperature could be significantly decreased, which still furnished the desired product 163aa in excellent yields (entries 3-6). Among a set of representative silver salts, $\mathrm{AgSbF}_{6}$ and $\mathrm{AgBF}_{4}$ provided the optimal results (entries 7-12). Moreover, the $\mathrm{C}-\mathrm{H}$ amidation was achieved with $\mathrm{Cp} * \mathrm{Co}(\mathrm{CO}) \mathrm{I}_{2}$ as the sole component catalyst in the absence of silver salts, albeit delivering the desired product 163aa in a lower yield (entry 13). Notably, no reactivity was observed using other typical cobalt catalysts or omitting the $\mathrm{Cp} * \mathrm{Co}(\mathrm{Co}) \mathrm{I}_{2}$ catalyst (entries 14-16). It is noteworthy that the well-defined complex 
$\left[\mathrm{Cp}^{*} \mathrm{Co}\left(\mathrm{CH}_{3} \mathrm{CN}\right)_{3}\right]\left(\mathrm{SbF}_{6}\right)_{2}(\mathbf{1 8 0})$ was identified as a user-friendly single component catalyst, which also provided the desired product 163aa with high efficiency (entries 17 and 18).

Table 3.3.1 Optimization of the Cobalt(III)-Catalyzed C-H Amidation of Imidate
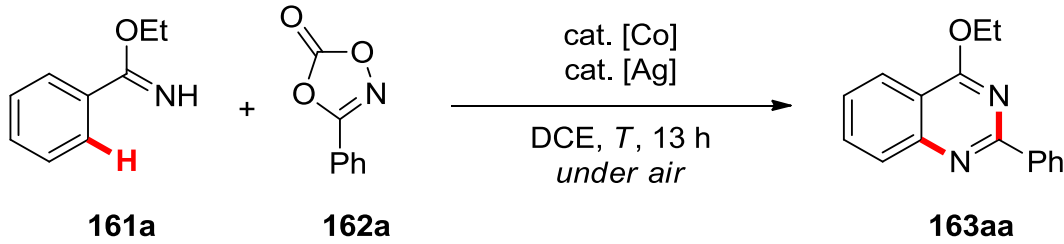

\begin{tabular}{|c|c|c|c|c|}
\hline Entry & {$[\mathrm{Co}] / \mathrm{mol} \%$} & Ag salt / mol \% & $T /{ }^{\circ} \mathrm{C}$ & Yield $^{[\mathrm{a}]}$ \\
\hline 1 & $\mathrm{Cp}^{*} \mathrm{Col}_{2}(\mathrm{CO}) / 10$ & $\mathrm{AgSbF}_{6} / 20$ & 120 & $81 \%^{[b, c, d]}$ \\
\hline 2 & $\mathrm{Cp}^{*} \mathrm{Col}_{2}(\mathrm{CO}) / 10$ & $\mathrm{AgSbF}_{6} / 20$ & 120 & $85 \%^{[c, d]}$ \\
\hline 3 & $\mathrm{Cp}^{*} \mathrm{Col}_{2}(\mathrm{CO}) / 10$ & $\mathrm{AgSbF}_{6} / 20$ & 120 & $99 \%^{[d]}$ \\
\hline 4 & $\mathrm{Cp} * \mathrm{Col}_{2}(\mathrm{CO}) / 5$ & $\mathrm{AgSbF}_{6} / 10$ & 120 & $99 \%^{[d]}$ \\
\hline 5 & $\mathrm{Cp} * \mathrm{Col}_{2}(\mathrm{CO}) / 5$ & $\mathrm{AgSbF}_{6} / 10$ & 100 & $99 \%^{[d]}$ \\
\hline 6 & $\mathrm{Cp}^{*} \mathrm{Col}_{2}(\mathrm{CO}) / 5$ & $\mathrm{AgSbF}_{6} / 10$ & 80 & $83 \%^{[\mathrm{d}]}$ \\
\hline 7 & $\mathrm{Cp} * \mathrm{Col}_{2}(\mathrm{CO}) / 5$ & $\mathrm{AgSbF}_{6} / 10$ & 100 & $99 \%$ \\
\hline 8 & $\mathrm{Cp}^{*} \mathrm{Col}_{2}(\mathrm{CO}) / 5$ & $\mathrm{AgBF}_{4} / 10$ & 100 & $96 \%$ \\
\hline 9 & $\mathrm{Cp}^{*} \mathrm{Col}_{2}(\mathrm{CO}) / 5$ & $\mathrm{AgPF}_{6} / 10$ & 100 & $99 \%$ \\
\hline 10 & $\mathrm{Cp}^{*} \mathrm{Col}_{2}(\mathrm{CO}) / 5$ & AgOTf / 10 & 100 & $80 \%$ \\
\hline 11 & $\mathrm{Cp}^{*} \mathrm{Col}_{2}(\mathrm{CO}) / 5$ & $\mathrm{AgN}(\mathrm{OTf})_{2}(10)$ & 100 & $88 \%$ \\
\hline 12 & $\mathrm{Cp}^{*} \mathrm{Col}_{2}(\mathrm{CO}) / 5$ & AgOTs / 10 & 100 & $19 \%$ \\
\hline 13 & $\mathrm{Cp}^{*} \mathrm{Col}_{2}(\mathrm{CO}) / 5$ & -- & 100 & $56 \%$ \\
\hline 14 & $\mathrm{Co}(\mathrm{OAc})_{2} / 5$ & $\mathrm{AgSbF}_{6} / 10$ & 100 & -- \\
\hline 15 & $\mathrm{Co}(\mathrm{acac})_{3} / 5$ & $\mathrm{AgSbF}_{6} / 10$ & 100 & -- \\
\hline 16 & -- & $\mathrm{AgSbF}_{6} / 10$ & 120 & -- \\
\hline 17 & {$\left[\mathrm{Cp} * \mathrm{Co}\left(\mathrm{CH}_{3} \mathrm{CN}\right)_{3}\right]\left(\mathrm{SbF}_{6}\right)_{2} / 5$} & -- & 100 & $94 \%{ }^{[\mathrm{e}]}$ \\
\hline 18 & {$\left[\mathrm{Cp} * \mathrm{Co}\left(\mathrm{CH}_{3} \mathrm{CN}\right)_{3}\right]\left(\mathrm{SbF}_{6}\right)_{2} / 5$} & -- & 100 & $96 \%$ \\
\hline
\end{tabular}


Under $\mathrm{N}_{2}$.

\subsubsection{Cobalt-Catalyzed C-H Amidation of Imidates}

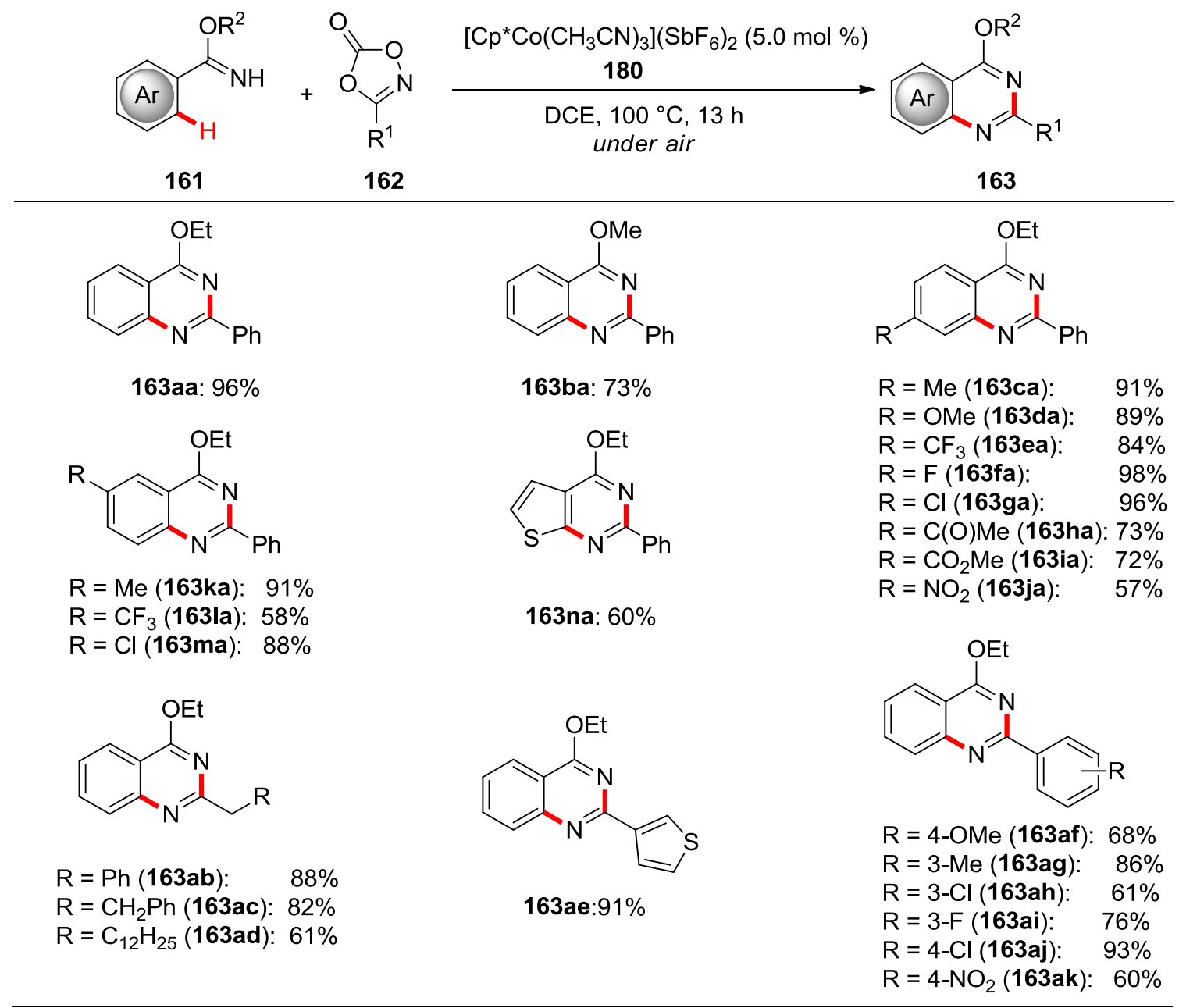

Scheme 3.3.1 Cobalt-catalyzed C-H amidation of imidates 161 .

The scope of substrates was surveyed using the single component catalyst 180 (Scheme 3.3.1). A variety of substituents on the aryl ring of benzimidates 161 could directly couple with 162 in moderate to good yields. Various valuable functional groups, such as trifluoromethyl, fluoro, chloro, ester, ketone, and nitro, were also well tolerated under the optimized conditions (163ea-163ja). The meta-substituted benzimidates delivered the corresponding products at the less hindered $\mathrm{C}-\mathrm{H}$ bond (163ka-163ma). It is worth mentioning that thiophene imidate $161 \mathrm{n}$ was also shown to be a suitable substrate and the desired product was obtained in 60\% yield with high regioselectivity (163na). Next, we explored the generality of this cobalt(III)-catalyzed $\mathrm{C}-\mathrm{H}$ amidation reaction with respect to dioxazolones 162. High yields were obtained with different alkyl- as well as heteroaryl-substituted 
dioxazolones (162c-162e). Likewise, both electron-donating and electron-withdrawing groups, such as methoxy, methyl, chloro, fluoro, and nitro, were all compatible to react with benzimidate 161a, delivering the desired products in good to excellent yields (163af-163ak).

\subsubsection{Overriding the Conventional Selectivity Dictated by Strongly Coordinating Heterocycles}

Encouraged by the success of above results, more challenging benzimidate substrates 161 containing strongly coordinating $N$-heterocyclic directing groups, were further investigated (Scheme 3.3.2). To our delight, various strongly coordinating heterocycles, such as pyrazole, pyrimidine, pyrazine, and even pyridine, were fully tolerated for the cobalt(III)-catalyzed $\mathrm{C}-\mathrm{H}$ amidation by imidate assistance, delivering the quinazolines $\mathbf{1 6 3}$ as the sole products. Moderate to good yields of the desired $\mathrm{C}-\mathrm{H}$ annulation products were obtained with excellent positional and regioselectivity when meta- and para-pyrazole substituted benzimidates were applied to react with different dioxazolones. Benzimidate bearing a meta-pyrazole group showed good reactivity towards the less sterically hindered $\mathrm{C}-\mathrm{H}$ bond (163la). Furthermore, we subsequently replaced the pyrazole by other groups, including the heterocylics adjacent to an $\mathrm{O}$-atom, amide and pyridines, and moderate to good yields of the desired products were obtained with excellent positional selectivity (163na-163te). Remarkably, the competition experiments were performed by Dr. M. M. Lorion with various directing groups for this cobalt(III)-catalyzed $\mathrm{C}-\mathrm{H}$ functionalization. The relative directing capabilities of $N$-heterocycles were found to decrease in the order: imidate $\geq$ pyridine $\approx$ pyrazole $>$ oxazoline > pyrimidine 


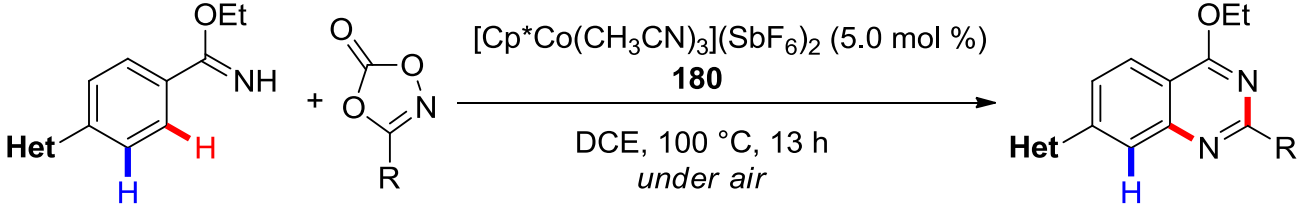

161

162

163<smiles>CCOc1nc(-c2cc[R]cc2)nc2cc(-n3cccn3)ccc12</smiles>

$\mathrm{R}=\mathrm{H}($ 163ka): $70 \%$

$\mathrm{R}=4-\mathrm{OMe}$ (163kf): $59 \%$

$\mathrm{R}=3-\mathrm{Me}(163 \mathrm{~kg}): \quad 63 \%$

$\mathrm{R}=3-\mathrm{F}$ (163ki): $\quad 59 \%$

$\mathrm{R}=3-\mathrm{Cl}$ (163kh): $\quad 64 \%$<smiles>CCOc1nc(-c2ccccc2)nc2ccccc12</smiles>

163la: $62 \%$<smiles>[R][X]c1cccc(-c2nc(OCC)c3ccc(Oc4cnccn4)cc3n2)c1</smiles>

$\mathrm{R}=\mathrm{H}$ (163oa): $\quad 89 \%$

$\mathrm{R}=4-\mathrm{Me}$ (163om): $75 \%$

$\mathrm{R}=3-\mathrm{Me}$ (163og): $\quad 84 \%$

$\mathrm{R}=4-\mathrm{Cl}$ (163oj): $\quad 87 \%$

$\mathrm{R}=4-\mathrm{NO}_{2}$ (163ok): $71 \%$<smiles>[R][X]C(=O)Nc1ccc2c(OCC)nc(-c3ccccc3)nc2c1</smiles>

$\mathrm{R}=3-\mathrm{Me}(163 \mathrm{pg}): \quad 85 \%$

$\mathrm{R}=4-\mathrm{OMe}(163 \mathrm{pf}): \quad 85 \%$

$\mathrm{R}=4-\mathrm{Cl}(163 \mathrm{pj}): \quad 90 \%$<smiles>CCOc1nc(-c2ccc(C)cc2)nc2cc(Oc3cc(C)ccn3)ccc12</smiles>

163rm: $83 \%$<smiles>CCOc1nc(CCc2ccccc2)nc2cc(-n3cccn3)ccc12</smiles>

163kc: $55 \%$<smiles>[R]c1ccc(-c2nc(OCC)c3ccc(-n4nccc4C)cc3n2)cc1</smiles>

$\mathrm{R}=\mathrm{Br}(163 \mathrm{ml}): \quad 64 \%$ $\mathrm{R}=\mathrm{NO}_{2}(163 \mathrm{mk}): 58 \%$<smiles>CCOc1nc([Al]c2ccccc2)nc2cc(Oc3cnccn3)ccc12</smiles>

$n=1$ (163ob): $78 \%$

$n=2$ (163oc): $87 \%$<smiles>CCOc1nc([Al])nc2cc(Oc3ccccn3)ccc12</smiles>

Alk $=\left(\mathrm{CH}_{2}\right)_{2} \mathrm{Ph}$ (163qc): $81 \%$ Alk $=n \mathrm{C}_{13} \mathrm{H}_{27}(163 q \mathrm{q}): \quad 86 \%$<smiles>[R]c1ccc(-c2nc(OCC)c3ccc(-c4ccccn4)cc3n2)cc1</smiles>

$\mathrm{R}=\mathrm{H}$ (163sa): $54 \%$ $\mathrm{R}=\mathrm{Cl}(163 \mathrm{sj}): 62 \%$<smiles>CCOc1nc(-c2ccsc2)nc2cc(-n3cccn3)ccc12</smiles>

163ke: $81 \%$<smiles>[R]c1ccc(-c2nc(OCC)c3ccc(-c4ncccn4)cc3n2)cc1</smiles>

$\mathrm{R}=\mathrm{H}$ (163na): $73 \%$

$\mathrm{R}=\mathrm{Cl}(163 \mathbf{n j}): \quad 71 \%$

$\mathrm{R}=\mathrm{Br}(163 \mathrm{nl}): \quad 85 \%$<smiles>CCOc1nc(-c2ccsc2)nc2cc(Oc3cnccn3)ccc12</smiles>

163oe: $86 \%$<smiles>[R][X]c1cccc(-c2nc(OCC)c3ccc(Oc4ccccn4)cc3n2)c1</smiles>

$\mathrm{R}=\mathrm{H}$ (163qa): $\quad 80 \%$

$\mathrm{R}=4$-OMe (163qf): $73 \%$

$R=3-F(163 q i): \quad 88 \%$<smiles>CCOc1nc(-c2ccsc2)nc2cc(-c3ccccn3)ccc12</smiles>

163te: $51 \%$

Scheme 3.3.2 Overriding the conventional selectivity dictated by strongly coordinating heterocycles. 


\subsubsection{Mechanistic Studies}

\subsubsection{Positional Selectivity in Stoichiometric C-H Cobaltation}

Subsequently, the $H / D$ exchange studies as to the positional selectivity of the key $\mathrm{C}-\mathrm{H}$ activation step were carried out using the stoichiometric single-component catalyst $\mathbf{1 8 0}$ and then quenched with $\mathrm{CD}_{3} \mathrm{CO}_{2} \mathrm{D}$ (Scheme 3.3.3). Similar amounts of deuterium incorporation at ortho-position of both directing groups were detected after the treatment with $\mathrm{CD}_{3} \mathrm{CO}_{2} \mathrm{D}$, when para-pyrazole, pyrimidine or pyridine substituted benzimidates were employed. These findings indicate that the positional selectivity is not determined in the $\mathrm{C}-\mathrm{H}$ metalation, but the $\mathrm{C}-\mathrm{N}$ bond-forming step is.<smiles>CCOC(=N)c1ccccc1</smiles>

161
1) $\left[\mathrm{Cp}{ }^{*} \mathrm{Co}\left(\mathrm{CH}_{3} \mathrm{CN}\right)_{3}\right]\left(\mathrm{SbF}_{6}\right)_{2}$ (1.0 equiv) 180

DCE, $100^{\circ} \mathrm{C}, 2 \mathrm{~h}$

2) $\mathrm{CD}_{3} \mathrm{COOD}$ (1.5 equiv)<smiles>[2H]c1c([2H])c(C(=N)OCC)c([18OH])c([18OH])c1[18OH]</smiles>

$[\mathrm{D}]_{\mathrm{n}}-161$

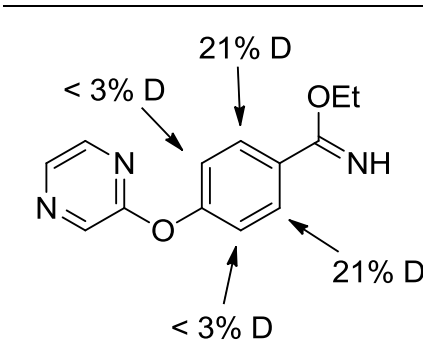

$19 \%$

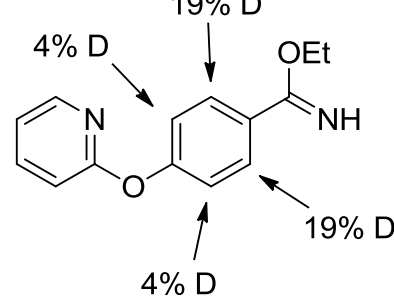

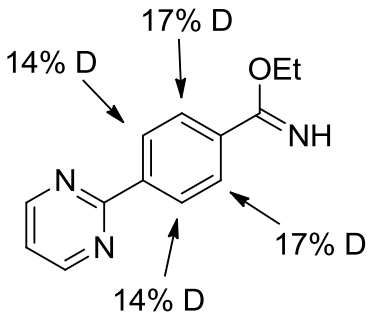

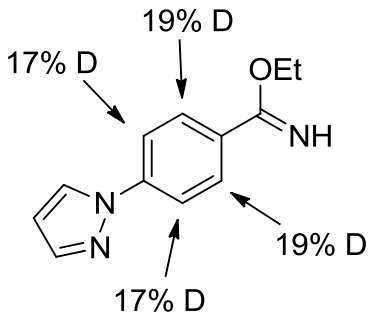

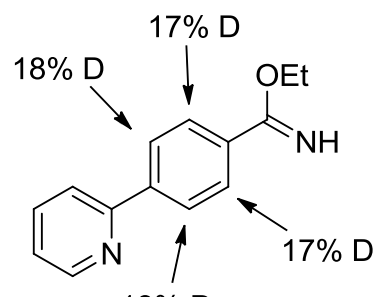

$18 \% \mathrm{D}$

Scheme 3.3.3 Positional selectivity in stoichiometric $\mathrm{C}-\mathrm{H}$ cobaltation.

\subsubsection{Intermolecular Competition Experiments}

Additionally, intermolecular competition experiments showed that the electron-rich imidate 161d

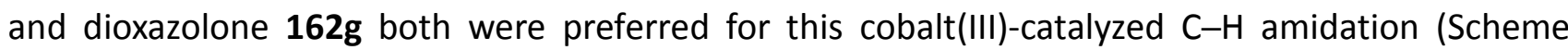
3.3.4). 
<smiles>CCOC(=N)c1ccc(C(C)=O)cc1</smiles>

161d / 161e

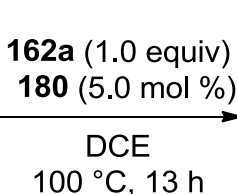

under air

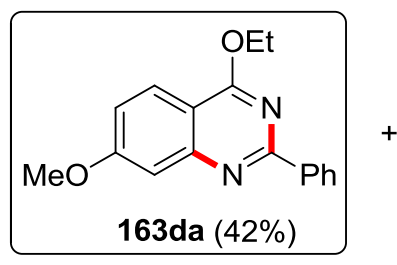<smiles>CCOc1nc(-c2ccccc2)nc2cc(C(F)(F)F)ccc12</smiles>

163da : 163ea / $1.75: 1$

(by ${ }^{1} \mathrm{H}$ NMR )

b)<smiles>Cc1cccc(-c2noc(=O)o2)c1</smiles>

161 a (1.0 equiv) $180(5.0 \mathrm{~mol} \%)$ $100^{\circ} \mathrm{C}, 13$ under air

163ag : 163ai / 2.6 :

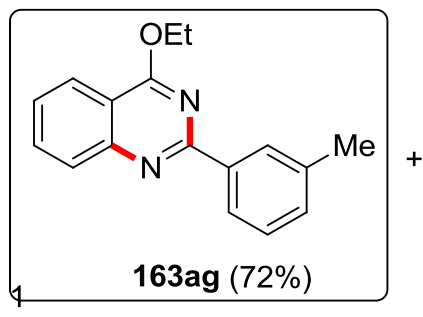<smiles>CCOc1nc(-c2cccc(F)c2)nc2ccccc12</smiles>

(by ${ }^{1} \mathrm{H}$ NMR )

Scheme 3.3.4 Intermolecular competition experiments.

\subsubsection{Kinetic Isotope Effect}

To gain deeper insight into the $\mathrm{C}-\mathrm{H}$ activation mechanism, a KIE study by comparison of initial rates of independent reactions with substrates $161 \mathrm{a}$ and $[\mathrm{D}]_{5}-161 \mathrm{a}$ was carried out (Scheme 3.3.5). A KIE of $k_{\mathrm{H}} / k_{\mathrm{D}} \approx 2.4$ suggested a rate-limiting step of the $\mathrm{C}-\mathrm{H}$ metalation likely to be operative.<smiles>CCOC(=N)c1ccc([AsH2])cc1</smiles><smiles>O=c1onc(-c2ccccc2)o1</smiles>

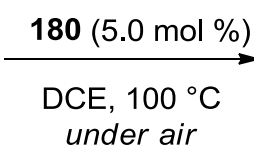
$162 a$<smiles>CCOC1=NC(c2ccccc2)=NC2=CC([AsH2])=[14CH][14CH]=[14CH][14CH]21</smiles>

Scheme 3.3.5 Kinetic isotope effect.

\subsubsection{Proposed Catalytic Cycle}

Based on our mechanistic findings and literature precedestes on cobalt(III)-catalyzed $\mathrm{C}-\mathrm{H}$ activation, ${ }^{[37 b]}$ a catalytic cycle of this reaction is proposed (Scheme 3.3.6). Presumably, the reaction involves a reversible and feasible $\mathrm{C}-\mathrm{H}$ activation step which is indicated by the significant $\mathrm{H} / \mathrm{D}$ exchange studies of positional selectivity. The elementary step of $\mathrm{C}-\mathrm{H}$ activation possibly proceeds by BIES mechanism based on the competition experiment, showing a preference for electron-rich substrates. Subsequently, the intermediate $\mathbf{1 8 2}$ is generated by the coordination and migratory 
insertion with dioxazolones 162 , resulting in the $\mathrm{C}-\mathrm{N}$ bond formation and $\mathrm{CO}_{2}$ extrusion. Finally, the desired product $\mathbf{1 6 3}$ is obtained through the intramolecular condensation following the amination product generation, along with the regeneration of the active cobalt(III) complex 181.

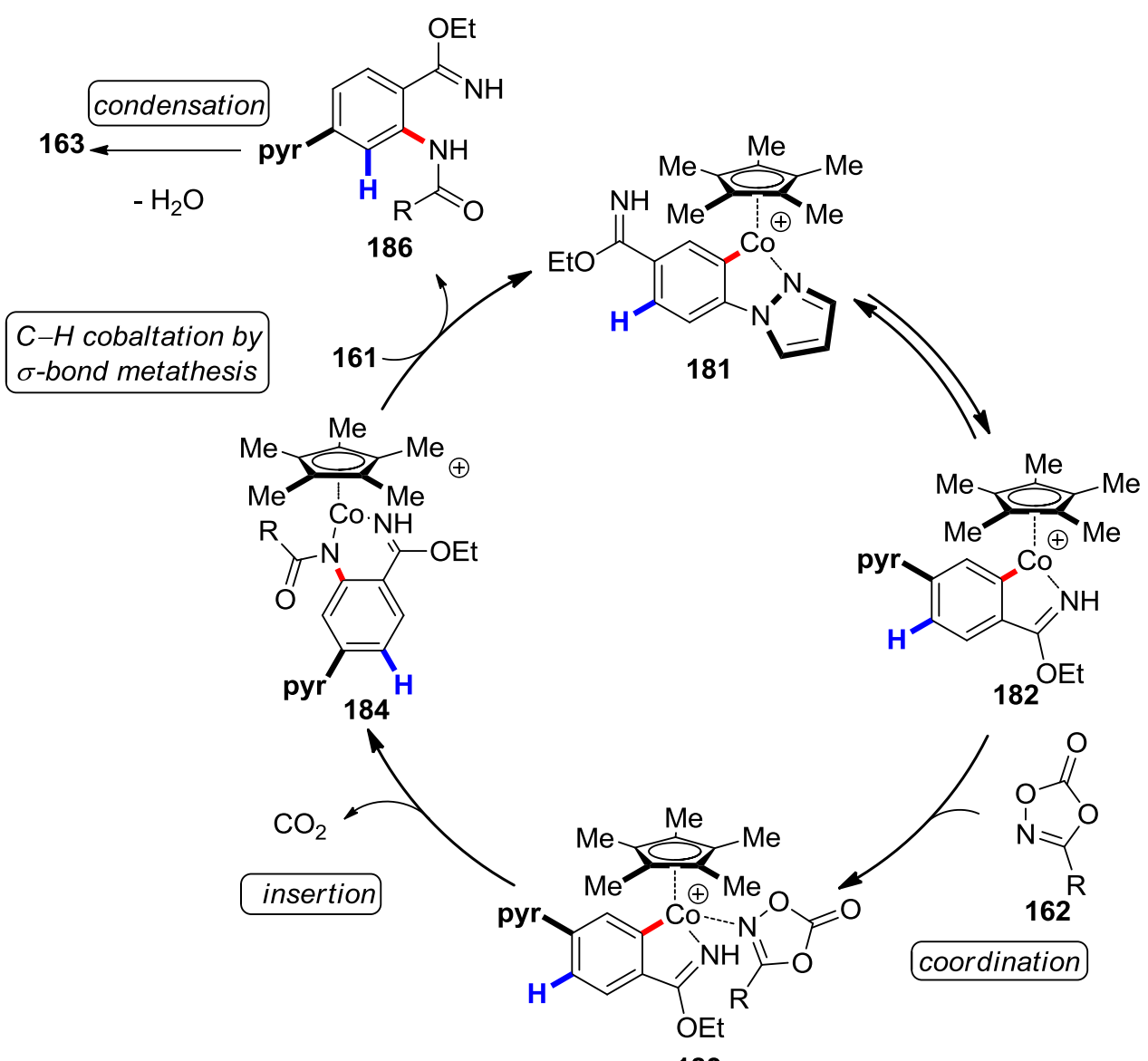

Scheme 3.3.6 Proposed catalytic cycle. 


\subsection{Domino $\mathrm{C}-\mathrm{H} / \mathrm{N}-\mathrm{H}$ Allylation of Imidates by Cobalt Catalysis}

In modern synthetic chemistry, a green reaction is an increasingly attractive option to all chemists, which aims to provide the products with efficiency, while minimizing the generation of waste and avoiding the use of toxic reagents or solvents. ${ }^{[165]}$ During the last few decades, the transition metal-catalyzed $\mathrm{C}-\mathrm{H}$ functionalization has made great success in such transformations, because of its practicality and high atom economy. ${ }^{[8 \mathrm{~b}, 166]}$ With the increasing attention to environmental issues, we have to face the question of how to synthesize the desired products in a green manner. In this regard, domino reactions have the potential to simplify reactions by forming several bonds in a one-pot fashion, which allows for minimization of waste compared to the stepwise reactions. ${ }^{[167]}$ Recent advances indicated that the direct $\mathrm{C}-\mathrm{H}$ activation in combination with domino reactions showed great promises in sustainable chemistry. ${ }^{[168]}$ However, precious metals such as palladium, rhodium, and iridium, have overwhelmingly dominated this field, which was inconsistent with the principles of green chemistry. With the advantages of Earth abundant metals, for example low price and low toxicity, we became interested in developing direct $\mathrm{C}-\mathrm{H}$ domino reactions with $3 \mathrm{~d}$ transition metals. Moreover, we had great success in cobalt(III)-catalyzed C-H annulation reactions recently. ${ }^{[37 e]}$ Therefore, we started to explore the possibility of developing direct cobalt(III)-catalyzed $\mathrm{C}-\mathrm{H}$ domino reactions.

\subsubsection{Optimization of the Domino $\mathrm{C}-\mathrm{H} / \mathrm{N}-\mathrm{H}$ Allylation of Imidate}

The optimization studies for the direct domino $\mathrm{C}-\mathrm{H} / \mathrm{N}-\mathrm{H}$ allylation reaction were initiated by testing various solvents, which delivered the desired vinyl-substituted heteroarene 164aa. Initially, no reactivity or unsatisfactory yields of the desired product 164aa were observed (Table 3.4.1, entries 1-5). In contrast, HFIP turned out to be the solvent of choice, resulting in the formation of the desired product in moderate yield (entry 6). Control experiments revealed that the $\mathrm{C}-\mathrm{H}$ functionalization did not occur without the cationic cobalt(III)-catalyst or with other typical cobalt complexes (entries 7-9). Only trace amounts of the desired product were obtained in the absence of $\mathrm{NaOAc}$ (entry 10). By investigating different additives, we found that NaOAc was the optimal additive for this domino $\mathrm{C}-\mathrm{H} / \mathrm{N}-\mathrm{H}$ allylation (entries $6,10-16)$. To our delight, the reaction efficacy 
could be improved by adding cocatalytic amounts of the Lewis acid $\mathrm{BPh}_{3}$ (entries 17, 18). Subsequently, several different cobalt(III) catalysts were tested for this domino reaction (entries 19-22), and it turned out that the new single-component complex $\left[\mathrm{Cp} * \mathrm{Co}\left(\mathrm{CH}_{3} \mathrm{CN}\right)_{3}\right]\left(\mathrm{PF}_{6}\right)_{2}$ provided the highest catalytic efficacy. The complex $\left[\mathrm{Cp}^{*} \mathrm{Rh}\left(\mathrm{CH}_{3} \mathrm{CN}\right)_{3}\right]\left(\mathrm{SbF}_{6}\right)_{2}$ failed in this domino $\mathrm{C}-\mathrm{H} / \mathrm{N}-\mathrm{H}$ allylation reaction (entries 23,24$)$.

Table 3.4.1 Optimization of the Domino $\mathrm{C}-\mathrm{H} / \mathrm{N}-\mathrm{H}$ Allylation of Imidate $161 \mathrm{a}^{[\mathrm{a}]}$<smiles>CCOC(=N)c1ccccc1P</smiles>

$161 \mathrm{a}$<smiles>C=CC1COC(=O)O1</smiles>

$110 \mathrm{a}$

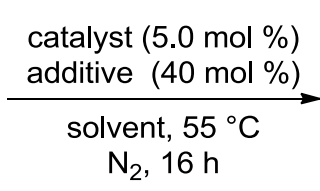

$\mathrm{N}_{2}, 16 \mathrm{~h}$

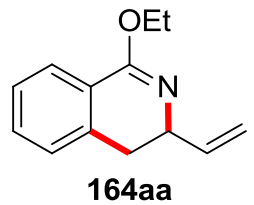

164aa

\begin{tabular}{|c|c|c|c|c|}
\hline Entry & Catalyst & Additive & Solvent & Yield $^{[b]}$ \\
\hline 1 & {$\left[\mathrm{Cp} * \mathrm{Co}\left(\mathrm{CH}_{3} \mathrm{CN}\right)_{3}\right]\left(\mathrm{SbF}_{6}\right)_{2}$} & $\mathrm{NaOAc}$ & $\mathrm{MeOH}$ & -- \\
\hline 2 & {$\left[\mathrm{Cp} * \mathrm{Co}\left(\mathrm{CH}_{3} \mathrm{CN}\right)_{3}\right]\left(\mathrm{SbF}_{6}\right)_{2}$} & $\mathrm{NaOAc}$ & GVL & -- \\
\hline 3 & {$\left[\mathrm{Cp} * \mathrm{Co}\left(\mathrm{CH}_{3} \mathrm{CN}\right)_{3}\right]\left(\mathrm{SbF}_{6}\right)_{2}$} & $\mathrm{NaOAc}$ & TFE & $13 \%$ \\
\hline 4 & {$\left[\mathrm{Cp} * \mathrm{Co}\left(\mathrm{CH}_{3} \mathrm{CN}\right)_{3}\right]\left(\mathrm{SbF}_{6}\right)_{2}$} & $\mathrm{NaOAC}$ & $\mathrm{PhCl}$ & $16 \%$ \\
\hline 5 & {$\left[\mathrm{Cp} * \mathrm{Co}\left(\mathrm{CH}_{3} \mathrm{CN}\right)_{3}\right]\left(\mathrm{SbF}_{6}\right)_{2}$} & $\mathrm{NaOAc}$ & DCE & $34 \%$ \\
\hline 6 & {$\left[\mathrm{Cp} * \mathrm{Co}\left(\mathrm{CH}_{3} \mathrm{CN}\right)_{3}\right]\left(\mathrm{SbF}_{6}\right)_{2}$} & $\mathrm{NaOAc}$ & HFIP & $50 \%$ \\
\hline 7 & -- & $\mathrm{NaOAC}$ & HFIP & -- \\
\hline 8 & $\mathrm{Co}(\mathrm{OAC})_{2}$ & $\mathrm{NaOAC}$ & HFIP & -- \\
\hline 9 & $\mathrm{CoC}_{2} \mathrm{O}_{4}$ & $\mathrm{NaOAC}$ & HFIP & -- \\
\hline 10 & {$\left[\mathrm{Cp} * \mathrm{Co}\left(\mathrm{CH}_{3} \mathrm{CN}\right)_{3}\right]\left(\mathrm{SbF}_{6}\right)_{2}$} & -- & HFIP & $<2 \%$ \\
\hline 11 & {$\left[\mathrm{Cp} * \mathrm{Co}\left(\mathrm{CH}_{3} \mathrm{CN}\right)_{3}\right]\left(\mathrm{SbF}_{6}\right)_{2}$} & NaOPiv & HFIP & $34 \%^{c}$ \\
\hline 12 & {$\left[\mathrm{Cp} * \mathrm{Co}\left(\mathrm{CH}_{3} \mathrm{CN}\right)_{3}\right]\left(\mathrm{SbF}_{6}\right)_{2}$} & $\mathrm{NaO}_{2} \mathrm{CAd}$ & HFIP & $30 \%$ \\
\hline 13 & {$\left[\mathrm{Cp} * \mathrm{Co}\left(\mathrm{CH}_{3} \mathrm{CN}\right)_{3}\right]\left(\mathrm{SbF}_{6}\right)_{2}$} & $\mathrm{CsOAc}$ & HFIP & trace \\
\hline 14 & {$\left[\mathrm{Cp} * \mathrm{Co}\left(\mathrm{CH}_{3} \mathrm{CN}\right)_{3}\right]\left(\mathrm{SbF}_{6}\right)_{2}$} & $\mathrm{Cu}(\mathrm{OAc})_{2}$ & HFIP & $26 \%$ \\
\hline 15 & {$\left[\mathrm{Cp} * \mathrm{Co}\left(\mathrm{CH}_{3} \mathrm{CN}\right)_{3}\right]\left(\mathrm{SbF}_{6}\right)_{2}$} & HOPiv & HFIP & $22 \%$ \\
\hline
\end{tabular}




\begin{tabular}{|c|c|c|c|c|}
\hline 16 & {$\left[\mathrm{Cp} * \mathrm{Co}\left(\mathrm{CH}_{3} \mathrm{CN}\right)_{3}\right]\left(\mathrm{SbF}_{6}\right)_{2}$} & $\mathrm{HO}_{2} \mathrm{CAd}$ & HFIP & $43 \%$ \\
\hline 17 & {$\left[\mathrm{Cp} * \mathrm{Co}\left(\mathrm{CH}_{3} \mathrm{CN}\right)_{3}\right]\left(\mathrm{SbF}_{6}\right)_{2}$} & $\mathrm{NaOAc}$ & HFIP & $36 \%{ }^{[c]}$ \\
\hline 18 & {$\left[\mathrm{Cp} * \mathrm{Co}\left(\mathrm{CH}_{3} \mathrm{CN}\right)_{3}\right]\left(\mathrm{SbF}_{6}\right)_{2}$} & $\mathrm{NaOAc}$ & HFIP & $62 \%{ }^{[\mathrm{d}]}$ \\
\hline 19 & $\mathrm{Cp} * \mathrm{Co}(\mathrm{CO}) \mathrm{I}_{2}$ & $\mathrm{NaOAc}$ & HFIP & $<2 \%^{[\mathrm{d}, \mathrm{e}]}$ \\
\hline 20 & {$\left[\mathrm{Cp} * \mathrm{Co}\left(\mathrm{CH}_{3} \mathrm{CN}\right)_{3}\right]\left(\mathrm{BF}_{4}\right)_{2}$} & $\mathrm{NaOAC}$ & HFIP & $50 \%^{[\mathrm{d}]}$ \\
\hline 21 & {$\left[\mathrm{Cp} * \mathrm{Co}\left(\mathrm{CH}_{3} \mathrm{CN}\right)_{3}\right]\left(\mathrm{PF}_{6}\right)_{2}$} & $\mathrm{NaOAC}$ & HFIP & $64 \%$ \\
\hline 22 & {$\left[\mathrm{Cp} * \mathrm{Co}\left(\mathrm{CH}_{3} \mathrm{CN}\right)_{3}\right]\left(\mathrm{PF}_{6}\right)_{2}$} & $\mathrm{NaOAc}$ & HFIP & $72 \%^{[\mathrm{d}]}$ \\
\hline 23 & {$\left[\mathrm{Cp} * \mathrm{Rh}\left(\mathrm{CH}_{3} \mathrm{CN}\right)_{3}\right]\left(\mathrm{SbF}_{6}\right)_{2}$} & $\mathrm{NaOAC}$ & DCE & $<2 \%$ \\
\hline 24 & {$\left[\mathrm{Cp} * \mathrm{Rh}\left(\mathrm{CH}_{3} \mathrm{CN}\right)_{3}\right]\left(\mathrm{SbF}_{6}\right)_{2}$} & $\mathrm{NaOAc}$ & HFIP & $<2 \%^{[\mathrm{d}]}$ \\
\hline
\end{tabular}

[a] Reaction conditions: 161a $(0.25 \mathrm{mmol}), 110 \mathrm{a}(0.75 \mathrm{mmol})$, catalyst $(5.0 \mathrm{~mol} \%)$, additive (40 mol \%), solvent $(1.0 \mathrm{~mL}), 55^{\circ} \mathrm{C}, 16 \mathrm{~h} .{ }^{[b]}$ Yields of isolated products. ${ }^{[c]} \ln (\mathrm{OTf})_{3}(40 \mathrm{~mol} \%) .{ }^{[\mathrm{d}]} \mathrm{BPh}_{3}$ (40 mol \%). ${ }^{[\mathrm{e}]} \mathrm{AgSbF}_{6}$ (15 mol \%).

\subsubsection{Scope of Cobalt(III)-Catalyzed Domino $\mathrm{C}-\mathrm{H} / \mathrm{N}-\mathrm{H}$ Allylation}

\subsubsection{Scope of Cobalt(III)-Catalyzed C-H Allylation}

With the optimized catalytic reaction conditions being identified, we tested the versatility of the cationic $\mathrm{CP}^{*} \mathrm{Co}(\mathrm{III})$-catalyzed $\mathrm{C}-\mathrm{H}$ allylation towards the synthesis of vinyl-substituted 3,4-dihydroisoquinolines 164 with various imidates 161 (Scheme 3.4.1). Thus, aryl-substituted imidates bearing various electron-donating and electron-withdrawing groups at different positions reacted smoothly with $\mathbf{1 1 0 a}$, affording the corresponding products in moderate to good yields. Moreover, the catalytic system also tolerated various functional groups on the arene part such as halides, ester, ketone and amide substituents, which can be easily transformed into other functionalities. Notably, an increased level of catalytic efficacy was achieved with the Lewis acid $\mathrm{BPh}_{3}$. The alkoxy-substituted benzimidates $\mathbf{1 1 0 b}$ and $\mathbf{1 1 0 w}$ were also well tolerated under the optimized conditions, delivering the allylation products in good yields. Likewise, the reaction system displayed a good reactivity when different substituted dioxolanones were examined (164ab-164ad). 

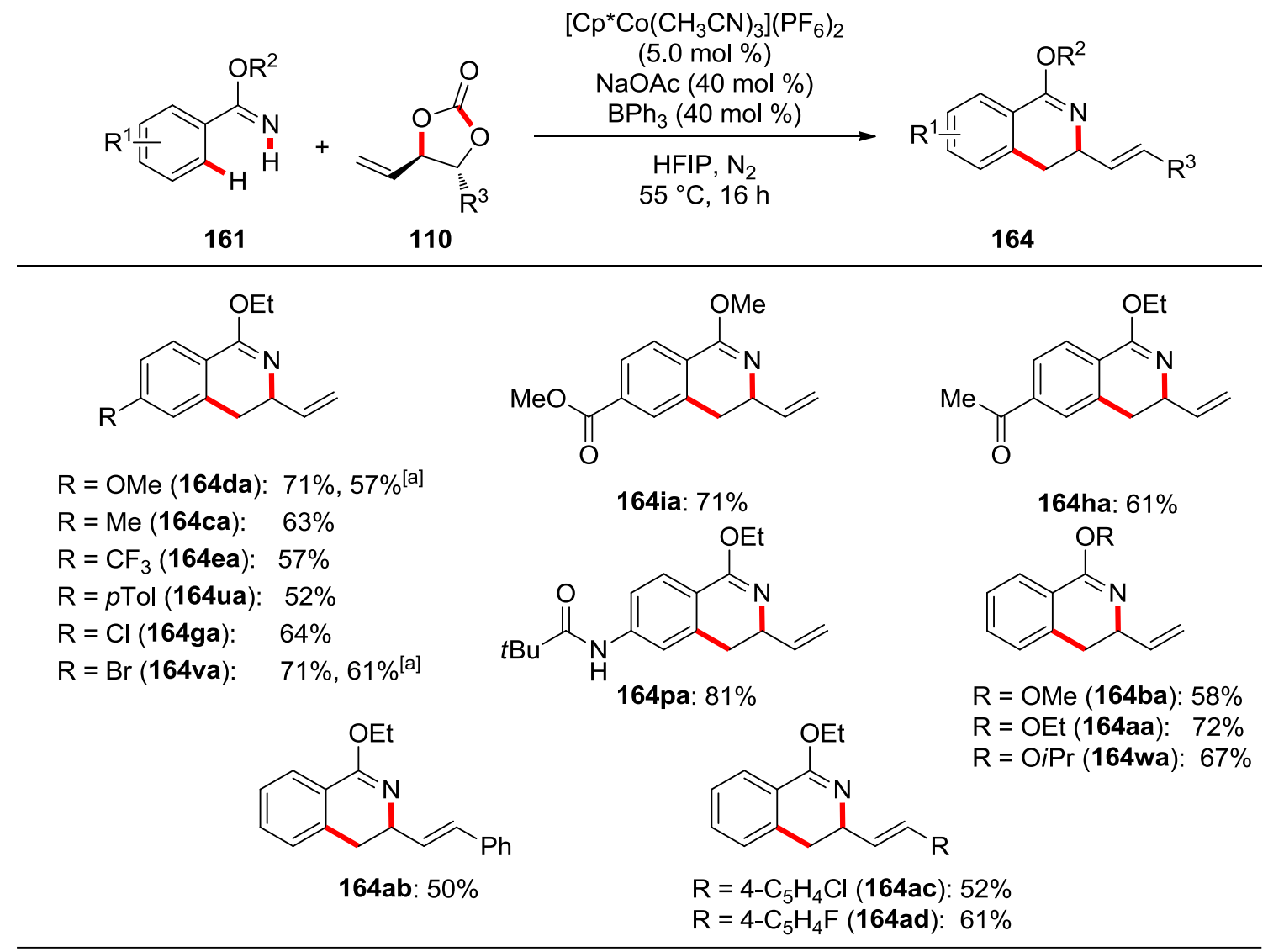

Scheme 3.4.1 Scope of the domino $\mathrm{C}-\mathrm{H} / \mathrm{N}-\mathrm{H}$ allylation. ${ }^{[\mathrm{a}]}$ Without $\mathrm{BPh}_{3}$.

\subsubsection{Scope of Cobalt(III)-Catalyzed C-H Allylation with meta-Substituted Imidates}
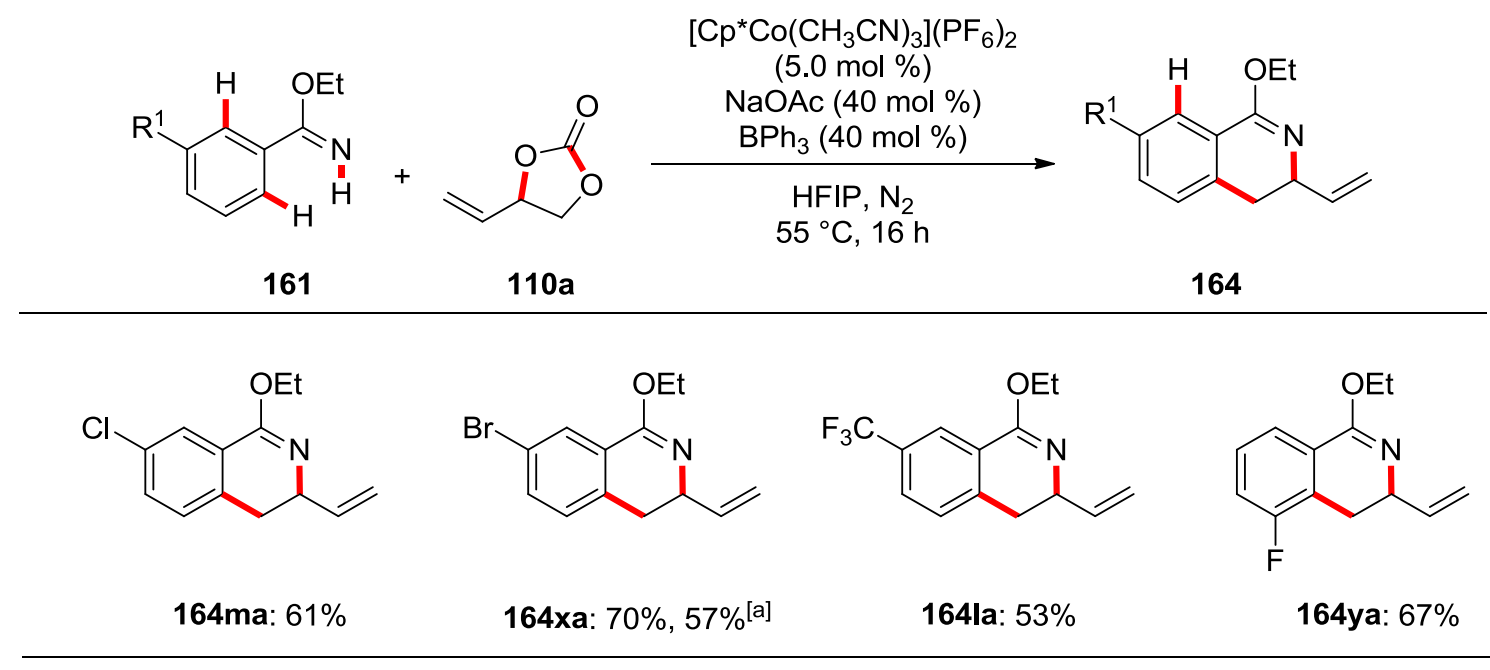

Scheme 3.4.2 Scope of cobalt(III)-catalyzed C-H allylation with meta-substituted imidates. ${ }^{\text {[a] }}$ Without $\mathrm{BPh}_{3}$.

The intramolecular competition experiments with meta-substituted arylimidates $161 \mathrm{~m}, 161 \mathrm{x}$ and 
161l bearing two different ortho- $\mathrm{C}-\mathrm{H}$ bonds showed excellent selectivity for the sterically less hindered position and delivered the products 164ma, 164xa and 164la in moderate yields. In contrast, the meta-fluoro substituted imidate $161 \mathrm{y}$ reacted preferentially at the more sterically hindered position, providing compound 164ya as the sole product in 67\% yield (Scheme 3.4.2).

\subsubsection{Key Mechanistic Findings}

\subsubsection{Intermolecular Competition Experiments}

Intermolecular competition experiments were performed between electron-rich and electron-deficient benzimidates under the optimal conditions (Scheme 3.4.3). As a result, the electron-rich substrates $161 \mathrm{~d}$ and $161 \mathrm{c}$ reacted preferrentally in this $\mathrm{C}-\mathrm{H} / \mathrm{N}-\mathrm{H}$ allylation reaction, which is in good agreement with a BIES-type $\mathrm{C}-\mathrm{H}$ activation.

a)

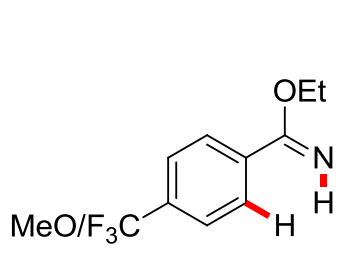

$161 \mathrm{~d} / 161 \mathrm{e}$

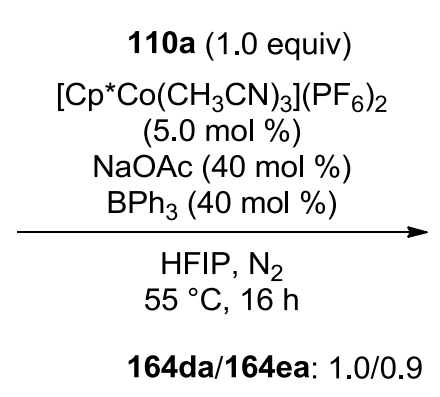

164da/164ea: $1.0 / 0.9$

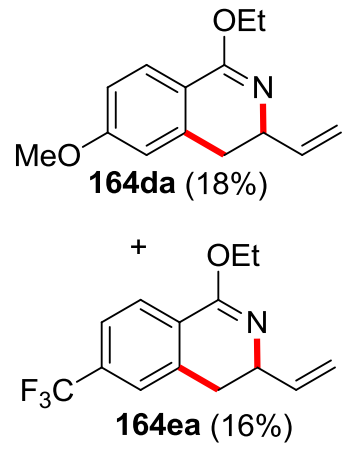

b)

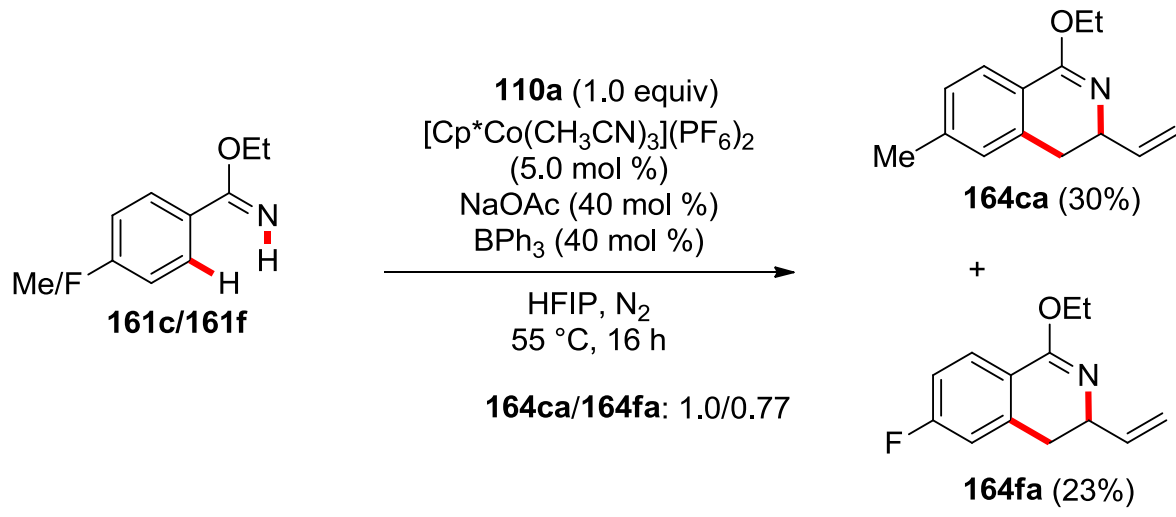

Scheme 3.4.3 Intermolecular competition experiments.

\subsubsection{H/D Exchange and KIE Studies}

In order to further investigate the reaction mechanism of the $\mathrm{C}-\mathrm{H}$ activation step, a series of important test reactions was thereafter conducted, including $H / D$ exchange, inter- and 
intra-molecular KIE experiments (Scheme 3.4.4).

a) $H / D$ exchange experiment

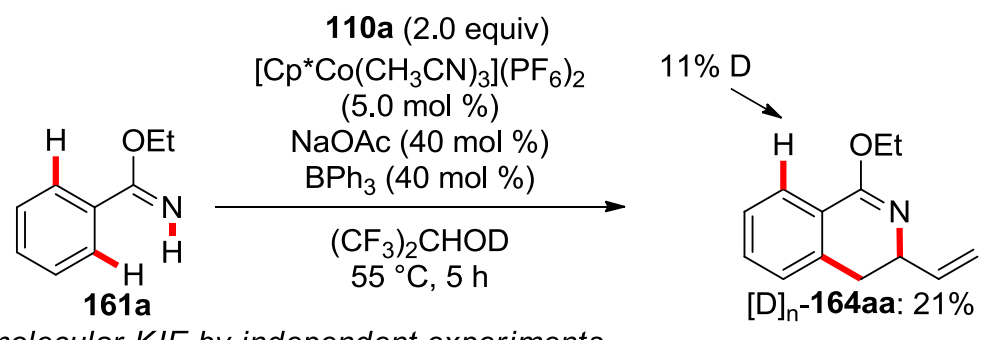

b) intermolecular KIE by independent experiments

$110 a$ (2.0 equiv)<smiles>CCO/C(=N/N)c1ccc(S)cc1</smiles>

$\left[\mathrm{Cp}{ }^{*} \mathrm{Co}\left(\mathrm{CH}_{3} \mathrm{CN}\right)_{3}\right]\left(\mathrm{PF}_{6}\right)_{2}$

$(5.0 \mathrm{~mol} \%)$

$\mathrm{NaOAc}(40 \mathrm{~mol} \%)$

$\mathrm{BPh}_{3}(40 \mathrm{~mol} \%)$

HFIP, $55^{\circ} \mathrm{C}$

$\mathrm{D}$<smiles></smiles>

$161 \mathrm{a}$ or $[D]_{5}-161 \mathrm{a}$

$k_{\mathrm{H}} / k_{\mathrm{D}}=2.9$

164aa or $[D]_{4}-164 a a$

c) intermolecular KIE by one-pot procedure

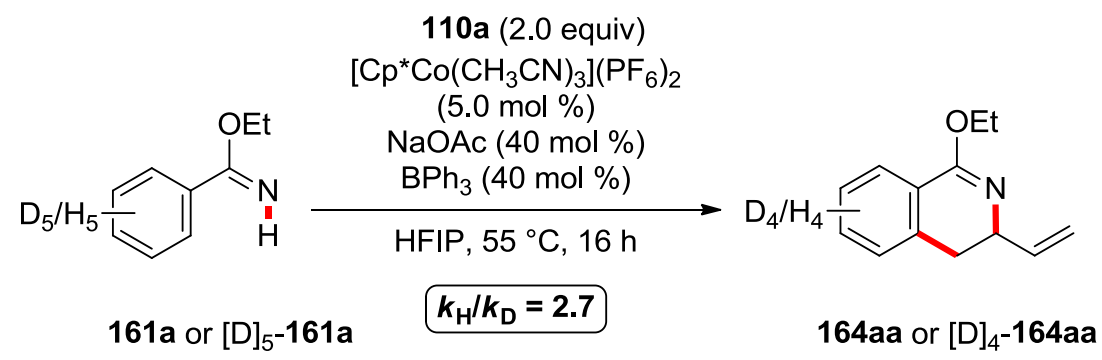

d) intramolecular KIE

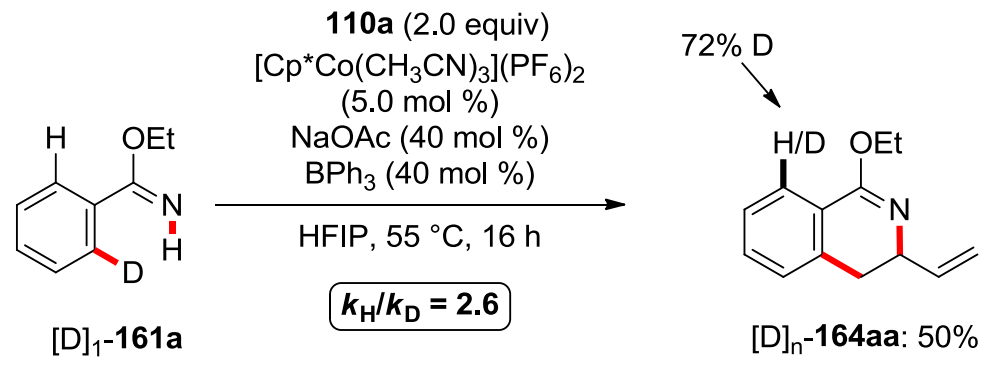

Scheme 3.4.4 H/D exchange and KIE studies.

The $\mathrm{H} / \mathrm{D}$ exchange experiment was performed in $\mathrm{CF}_{3} \mathrm{CHOD}$ as the reaction solvent under the optimal conditions. As a result, a minor H/D exchange in ortho-position of product 164aa was observed (a). The kinetic isotope effect of the cobalt(III)-catalyzed $\mathrm{C}-\mathrm{H} / \mathrm{N}-\mathrm{H}$ annulation was studied with labeled substrate $[D]_{5}-161 a$ by independent experiment, resulting in a value of $k_{H} / k_{D} \approx 2.9$ (b). In addition, a one-pot intermolecular KIE experiment showed a similar result of $k_{H} / k_{D} \approx 2.7$ (c). 
Furthermore, an intramolecular KIE of $k_{\mathrm{H}} / k_{\mathrm{D}} \approx 2.6$ was observed, which is in good agreement with the above mentioned results of the intermolecular KIE experiments (d). The mechanistic studies indicated that the $\mathrm{C}-\mathrm{H}$ activation step is the rate-limiting step of the catalytic cycle.

\subsubsection{Proposed Catalytic Cycle}

Based on the mechanistic observations, a plausible mechanism was proposed for the cobalt(III)-catalyzed C-H functionalization (Scheme 3.4.5). Initially, benzimdate 161 undergoes the $\mathrm{C}-\mathrm{H}$ metalation with single-component cationic cobalt(III) catalyst, forming intermediate $\mathbf{1 8 7}$. Then, coordination of 4-vinyl-1,3-dioxolan-2-one 110a and migratory insertion into the cobalt-carbon bond generates complex 188, which undergoes extrusion of $\mathrm{CO}_{2}$ to form intermediate 189 . Subsequently, the desired product 164 is obtained through an intramolecular cyclization by nucleophilic attack of the $\mathrm{N}$-atom with the help of cobalt(III) catalyst and $\mathrm{BPh}_{3}$. Finally, the active cationic cobalt(III) catalyst is regenerated by the reaction with acetic acid, which was formed in the initial C-H metalation step.

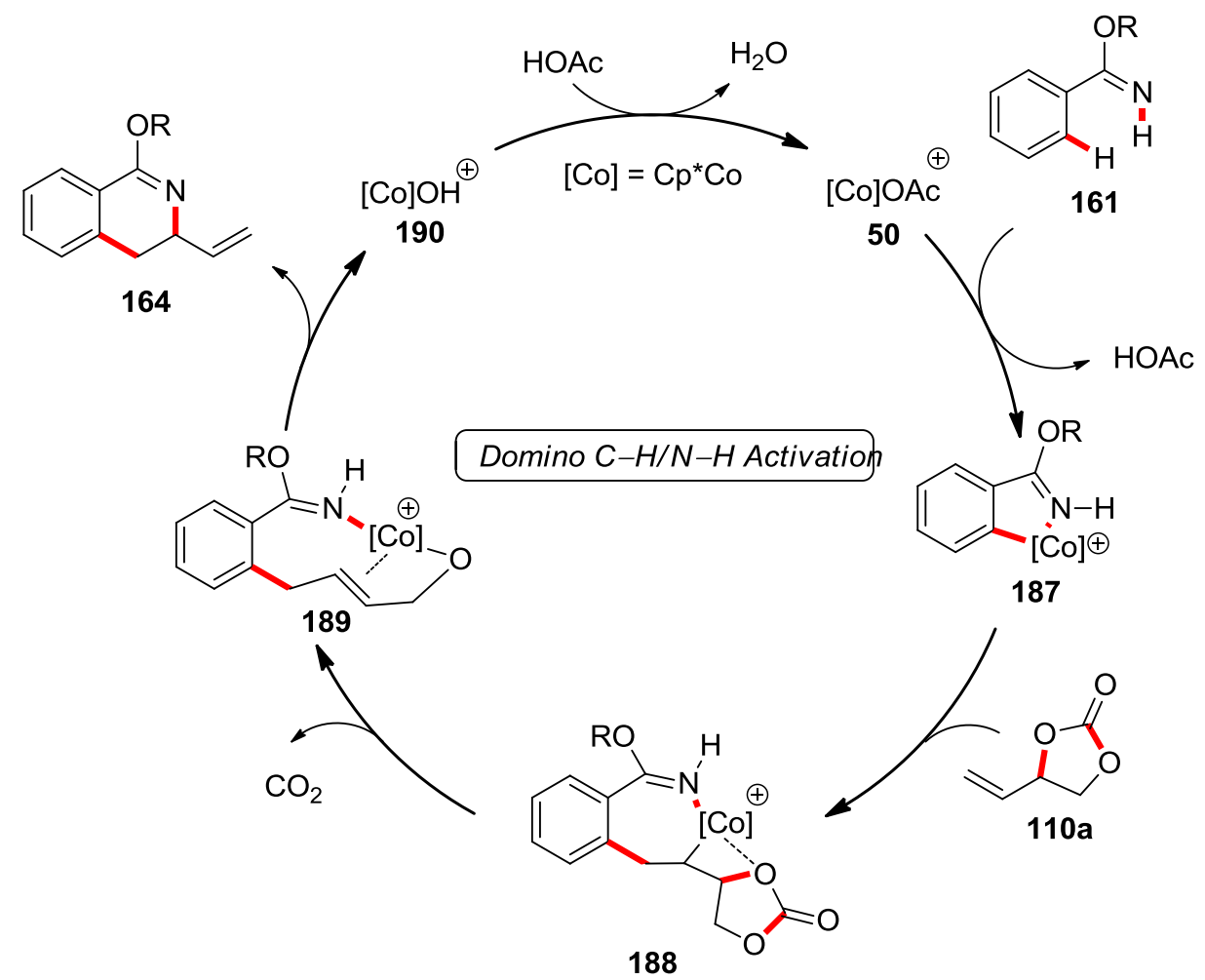

Scheme 3.4.5 Proposed catalytic cycle. 


\subsubsection{Diversification of Vinylated Heteroarenes}

Finally, the utility of the obtained vinyl-substituted heteroarenes 164 was investigated (Scheme 3.4.6). Hydrolysis of product 164aa provided access to vinyl-substituted dihydroisoquinolone derivatives 191. Furthemore, acetylated isoquinoline 192 was obtained in $76 \%$ yield through Wacker oxidation conditions. ${ }^{[169]}$

a) hydrolysis<smiles>C=CC1Cc2ccccc2C(OCC)=N1</smiles>

$164 a a$

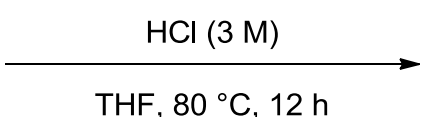

$\mathrm{THF}, 80^{\circ} \mathrm{C}, 12 \mathrm{~h}$

b) Wacker oxidation<smiles>C=CC1Cc2cc(OC)ccc2C(OCC)=N1</smiles>

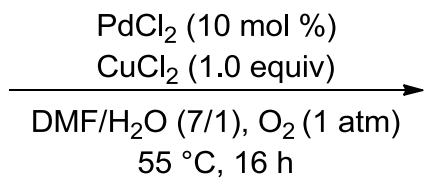

$55^{\circ} \mathrm{C}, 16 \mathrm{~h}$<smiles>C=CC1Cc2ccccc2C(=O)N1</smiles>

191: $91 \%$<smiles></smiles>

Scheme 3.4.6 Diversification of vinylated heteroarenes 164 . 


\subsection{Air-Stable Manganese(I)-Catalyzed C-H Activation for Decarboxylative C-H/C-O Cleavages in Water}

The allyl structural unit has proven to be a very useful building block in organic synthesis, which is widely found in natural products, pharmaceuticals and agrochemicals. ${ }^{[65]}$ Recent developments in transition metal-catalyzed $\mathrm{C}-\mathrm{H}$ allylation provided attractive approaches that streamlined the synthesis of allylic compounds without the need for pre-functionalizations. ${ }^{[170]}$ However, in most of these methods, expensive and rare $4 \mathrm{~d}$ or $5 \mathrm{~d}$ transition metals, such as rhodium, palladium, iridium, and ruthenium, are necessary. In contrast, $3 \mathrm{~d}$ metals, such as cobalt, manganese, nickel, and iron are typically cheap and Earth-abundant. ${ }^{[35 b]}$ In this regard, developing an alternative allylation reaction by replacing these noble metal catalysts by inexpensive ones is highly desirable. With the emergence of the concept of green chemistry, a mild and environmentally-benign reaction is considerably attractive. ${ }^{[29]}$ Consequently, a reaction explored in water, under air, and by using $3 d$ metal would be an ideal option. Based on our great achievement in manganese-catalyzed substitutive $\mathrm{C}-\mathrm{H}$ allylation of arenes, ${ }^{[83]}$ we now are interested in exploring the possibility of air-stable manganese-catalyzed decarboxylative $\mathrm{C}-\mathrm{H} / \mathrm{C}-\mathrm{O}$ cleavages in water.

\subsubsection{Optimization of Decarboxylative C-H/C-O Activation}

We initiated our studies with 1-(pyridin-2-yl)-1H-indole (41a) and 4-vinyl-1,3-dioxolan-2-one (110a) as model substrates and optimized the reaction conditions (Table 3.5.1). Initially, we probed various solvents for the envisioned manganese(I)-catalyzed $\mathrm{C}-\mathrm{H}$ activation. We found that the solvent plays a significant role in promoting the reaction efficiency. As a result, the polar solvents TFE and $\mathrm{H}_{2} \mathrm{O}$ displayed highest reactivities with good diastereoselectivities (entries 1-9). No reaction was observed in the absence of the manganese catalyst (entry 10). Moreover, other manganese sources, such as $\mathrm{MnCl}_{2}, \mathrm{MnBr}_{2}$, and $\mathrm{Mn}_{2}(\mathrm{CO})_{10}$, were also not applicable to this $\mathrm{C}-\mathrm{H} / \mathrm{C}-\mathrm{O}$ allylation reaction (entries $10-13)$. It should be noted that this manganese(I)-catalyzed $\mathrm{C}-\mathrm{H}$ activation was not only tolerant towards water, but also delivered good results under an atmosphere of air (entry 14). Next, the effect of different bases was explored for the reaction. Trace amounts of the product 111aa were observed when the strong base $\mathrm{K}_{2} \mathrm{CO}_{3}$ was used (entry 15). Organic bases like $\mathrm{Cy}_{2} \mathrm{NH}$ or 
monoprotected amino acid only provided the desired product in low yields (entries 16, 17). A lower catalyst loading $(2.5 \mathrm{~mol} \%)$ was tested for this reaction, affording the allylated product 111aa in $79 \%$ yield (entry 18). Importantly, a slight decrease of the catalytic activity was observed when the reaction temperature was decreased to $80^{\circ} \mathrm{C}$. Even at $60^{\circ} \mathrm{C}$, we could still obtain the desired product in $80 \%$ yield, reflecting the robustness of the manganese(I) catalysis system for this $\mathrm{C}-\mathrm{H}$ transformation (entries 19, 20).

Table 3.5.1 Optimization of decarboxylative $\mathrm{C}-\mathrm{H} / \mathrm{C}-\mathrm{O}$ activation.

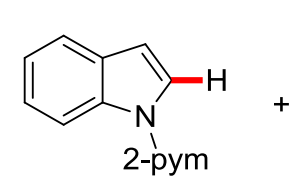

$41 a$

\begin{tabular}{|c|c|c|c|c|c|}
\hline Entry & Catalyst & Additive & Solvent & Yield $^{[\mathrm{a}]}$ & $E / Z$ \\
\hline 1 & $\mathrm{MnBr}(\mathrm{CO})_{5}$ & $\mathrm{NaOAC}$ & $\mathrm{Et}_{2} \mathrm{O}$ & $92 \%^{[b]}$ & 5.5 \\
\hline 2 & $\mathrm{MnBr}(\mathrm{CO})_{5}$ & $\mathrm{NaOAC}$ & $n \mathrm{Bu}_{2} \mathrm{O}$ & $85 \%^{[\mathrm{b}]}$ & 1.8 \\
\hline 3 & $\mathrm{MnBr}(\mathrm{CO})_{5}$ & --- & $n \mathrm{Bu}_{2} \mathrm{O}$ & $21 \%^{[b]}$ & 3.5 \\
\hline 4 & $\mathrm{MnBr}(\mathrm{CO})_{5}$ & $\mathrm{NaOAc}$ & $\mathrm{MeCN}$ & $21 \%^{[b]}$ & 1.9 \\
\hline 5 & $\mathrm{MnBr}(\mathrm{CO})_{5}$ & $\mathrm{NaOAc}$ & $\mathrm{CH}_{2} \mathrm{Cl}_{2}$ & $77 \%^{[\mathrm{b}]}$ & 2.4 \\
\hline 6 & $\mathrm{MnBr}(\mathrm{CO})_{5}$ & $\mathrm{NaOAC}$ & 1,4-dioxane & $90 \%{ }^{[b]}$ & 1.4 \\
\hline 7 & $\mathrm{MnBr}(\mathrm{CO})_{5}$ & $\mathrm{NaOAC}$ & TFE & $92 \%^{[b]}$ & 5.1 \\
\hline 8 & $\mathrm{MnBr}(\mathrm{CO})_{5}$ & $\mathrm{NaOAC}$ & DCE & $84 \%^{[b]}$ & 2.8 \\
\hline 9 & $\mathrm{MnBr}(\mathrm{CO})_{5}$ & $\mathrm{NaOAC}$ & $\mathrm{H}_{2} \mathrm{O}$ & $93 \%^{[\mathrm{b}]}$ & 6.4 \\
\hline 10 & -- & $\mathrm{NaOAc}$ & $\mathrm{H}_{2} \mathrm{O}$ & $--^{[b]}$ & -- \\
\hline 11 & $\mathrm{MnCl}_{2}$ & $\mathrm{NaOAC}$ & $\mathrm{H}_{2} \mathrm{O}$ & $--^{[b]}$ & -- \\
\hline 12 & $\mathrm{MnBr}_{2}$ & $\mathrm{NaOAc}$ & $\mathrm{H}_{2} \mathrm{O}$ & $--^{[b]}$ & -- \\
\hline 13 & $\mathrm{Mn}_{2}(\mathrm{CO})_{10}$ & $\mathrm{NaOAC}$ & $\mathrm{H}_{2} \mathrm{O}$ & $<5 \%^{[b, c, d]}$ & -- \\
\hline 14 & $\operatorname{MnBr}(\mathrm{CO})_{5}$ & $\mathrm{NaOAC}$ & $\mathrm{H}_{2} \mathrm{O}$ & $94 \%$ & 5.9 \\
\hline 15 & $\mathrm{MnBr}(\mathrm{CO})_{5}$ & $\mathrm{~K}_{2} \mathrm{CO}_{3}$ & $\mathrm{H}_{2} \mathrm{O}$ & $<10 \%{ }^{[\mathrm{d}]}$ & -- \\
\hline 16 & $\mathrm{MnBr}(\mathrm{CO})_{5}$ & $\mathrm{Cy}_{2} \mathrm{NH}$ & $\mathrm{H}_{2} \mathrm{O}$ & $24 \%$ & 6.4 \\
\hline 17 & $\mathrm{MnBr}(\mathrm{CO})_{5}$ & Piv-Val-OH & $\mathrm{H}_{2} \mathrm{O}$ & $46 \%$ & 5.7 \\
\hline
\end{tabular}
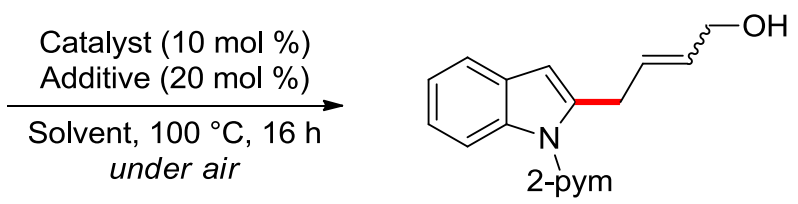

2-pym

$111 a a$ 


\begin{tabular}{|c|c|c|c|c|c|}
\hline 18 & $\mathrm{MnBr}(\mathrm{CO})_{5}$ & $\mathrm{NaOAc}$ & $\mathrm{H}_{2} \mathrm{O}$ & $79 \%^{[c, e]}$ & 5.7 \\
\hline 19 & $\mathrm{MnBr}(\mathrm{CO})_{5}$ & $\mathrm{NaOAc}$ & $\mathrm{H}_{2} \mathrm{O}$ & $84 \%^{[f]}$ & 5.9 \\
\hline 20 & $\mathrm{MnBr}(\mathrm{CO})_{5}$ & $\mathrm{NaOAc}$ & $\mathrm{H}_{2} \mathrm{O}$ & $80 \%^{[\mathrm{g}]}$ & 5.9 \\
\hline
\end{tabular}

\subsubsection{Scope of Manganese(I)-Catalyzed C-H/C-O Activation}

\subsubsection{Scope of Manganese(I)-Catalyzed Allylation of Indoles}

With the optimized reaction conditions in hand, we explored the scope of the manganese(I)-catalyzed $\mathrm{C}-\mathrm{H} / \mathrm{C}-\mathrm{O}$ activation on differently substituted indoles $\mathbf{4 1}$ in $\mathrm{H}_{2} \mathrm{O}$ or TFE (Scheme 3.5.1). Notably, various functional groups, such as halogens, hydroxyl, ester and ketone, were fully tolerated in the reaction conditions. Aryl-substituted indoles bearing electron-donating and electron-withdrawing groups at different positions all reacted smoothly with 4-vinyl-1,3-dioxolan-2-one 110a, delivering the allylated products in moderate to good yields with good E/Z ratio. Moreover, sterically demanding substituents in C-3 position were investigated. When TFE was chosen as the reaction solvent, the desired products were obtained in good yields (111la-111na, 111pa). However, the allylation of 3-methyl-substituted indole $41 \mathrm{~m}$ gave a lower yield of the desired product 111 ma in $\mathrm{H}_{2} \mathrm{O}$, probably due to the low solubility of the substrate $41 \mathrm{~m}$ in $\mathrm{H}_{2} \mathrm{O}$. In addition, 2-phenylpyridine was also shown to be a viable substrate and the desired product 111qa was obtained in $64 \%$ yield. 


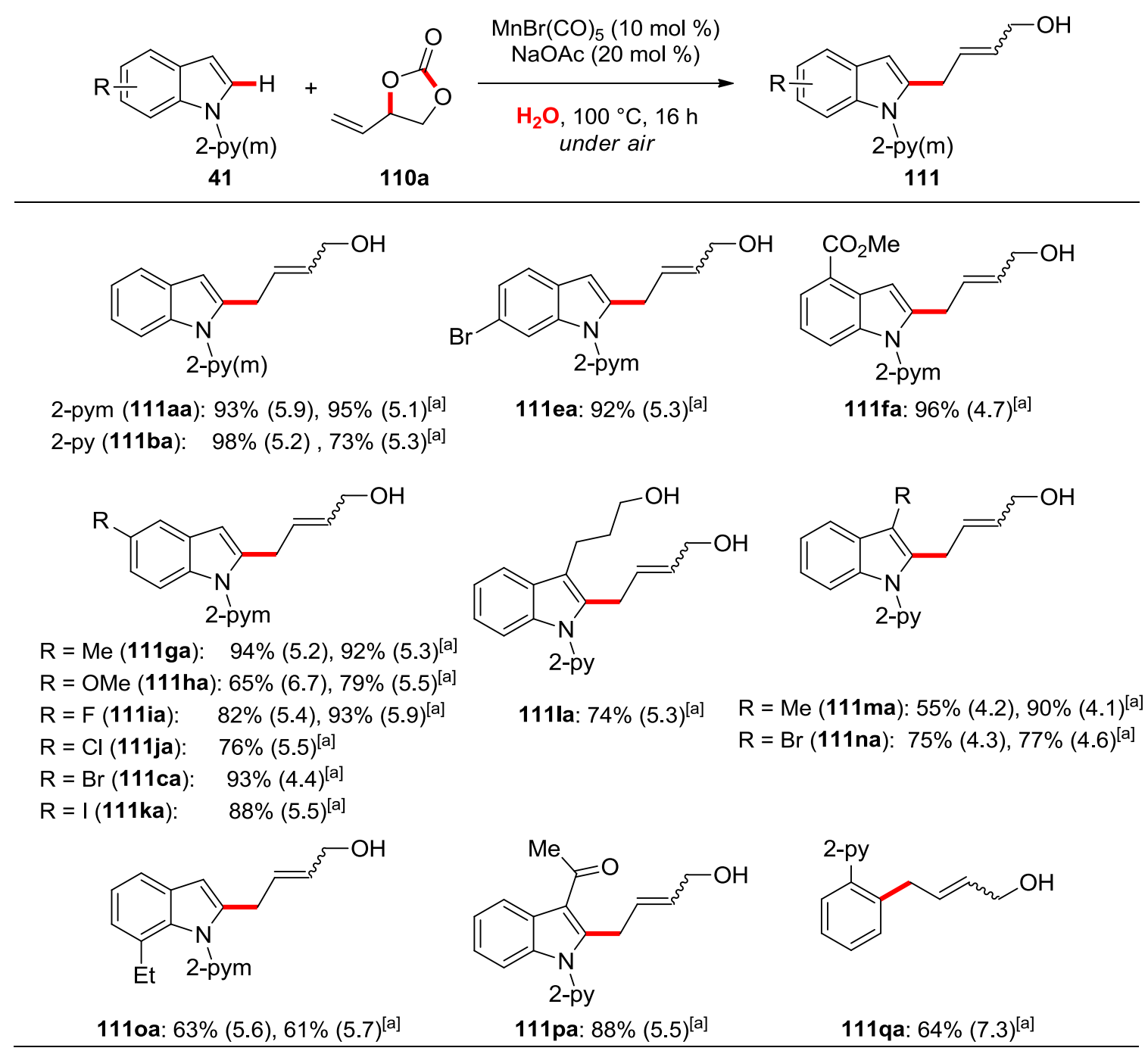

Scheme 3.5.1 Scope of manganese(I)-catalyzed allylation of indoles. $E / Z$ ratio in parentheses. ${ }^{[a]}$ TFE as the solvent.

\subsubsection{Scope of Manganese(I)-Catalyzed Allylation with Dioxolanones 110}

Subsequently, we also examined the applicability towards a representative set of vinylated dioxolanones 110 (Scheme 3.5.2). Notably, our method was compatible with different substitution pattern on dioxolanones and provided secondary and tertiary allylic alcohol products $\mathbf{1 1 1}$ in good yields with high diastereoselectivities. A variety of functional groups was also well tolerated, such as halogens, and even in case of the challenging nitro-substituent, a 79\% yield of the desired product 111ae was obtained. 

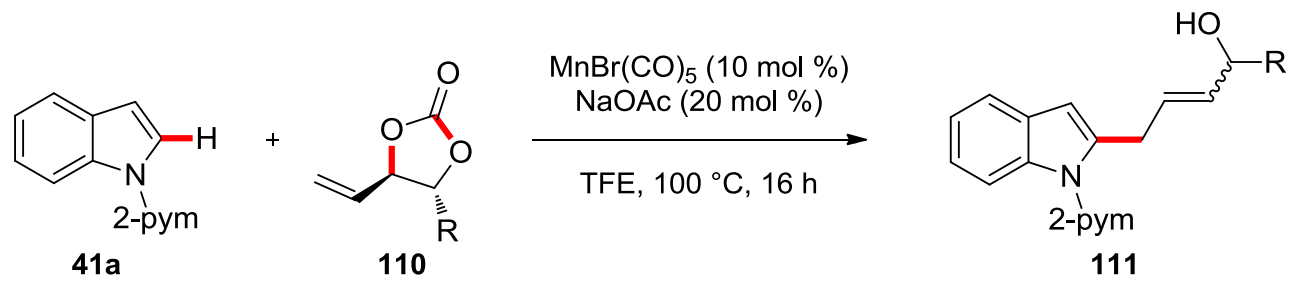

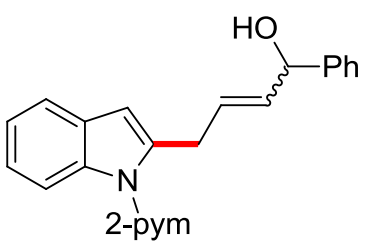

111ab: $80 \%(E / Z=20)$

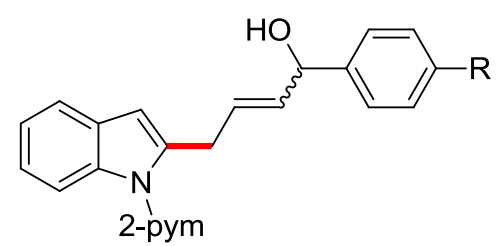

$\mathrm{R}=\mathrm{F}(111 \mathrm{ad}): \quad 77 \%(E / Z=2.8)$

$\mathrm{R}=\mathrm{Cl}(111 \mathrm{ac}): \quad 83 \% \quad(E / Z=3.0)$

$\mathrm{R}=\mathrm{NO}_{2}(111 \mathrm{ae}): 79 \%(E / Z=3.0)$

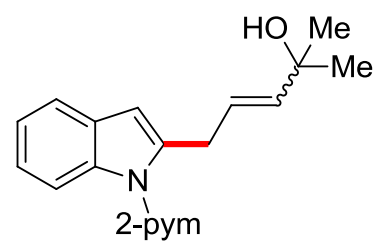

111af: $56 \%(E / Z>20)$

Scheme 3.5.2 Scope of manganese(I)-catalyzed C-H/C-O allylation with dioxolanones $\mathbf{1 1 0 .}$

\subsubsection{Manganese(I)-Catalyzed C-H/C-O Functionalization of Tryptophan and Ketimines}

Furthermore, the synthetic utility of the manganese(I)-catalyzed $\mathrm{C}-\mathrm{H}$ activation strategy was reflected by the direct modification of tryptophan $41 \mathrm{r}$ and $41 \mathrm{~s}$, delivering the desired products 111ra and 111sa in good yields without racemization (Scheme 3.5.3a). Motivated by the range of tolerated indoles and tryptophan derivatives, the applicability was further investigated by testing a variety of synthetically useful ketimines $\mathbf{3 4}$ (Scheme 3.5.3b). Remarkably, electron-rich as well as electron-deficient ketimines reacted smoothly and furnished the ketone products $\mathbf{1 6 5}$ in good yields with excellent diastereoselectivities. The position-selectivity of meta-substituted ketimines $\mathbf{3 4} \mathbf{i}$ and $\mathbf{3 4 k}$ was controlled by steric interactions, delivering the ketones $\mathbf{1 6 5 i a}$ and $\mathbf{1 6 5 k a}$ as sole products in $60 \%$, and $85 \%$ yields, respectively. These results highlighted a broad applicability and excellent functional group tolerance of this manganese(I) catalytic system. 
a) tryptophan $\mathrm{C}-\mathrm{H}$ functionalization<smiles>[R]OC(=O)[C@H](Cc1c([CH2+])n([R6])c2ccccc12)Nc1ccccc1</smiles>

2-pym (41r, 97\% ee) 110a 2-py $(41 s, 97 \%$ ee)

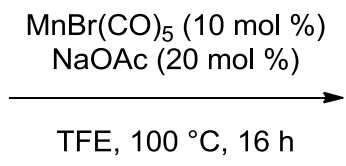

TFE, $100^{\circ} \mathrm{C}, 16 \mathrm{~h}$

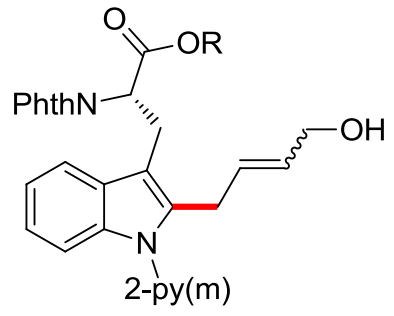

2-pym, $\mathrm{R}=\mathrm{Me}$ (111ra): $70 \%(E / Z=7.0,97 \%$ ee $)$ 2-py, $R=B n(111 \mathrm{sa}): \quad 90 \%(E / Z=6.4,96 \%$ ee $)$

b) ketimine $\mathrm{C}-\mathrm{H}$ functionalization<smiles>[Y6]N=C(C)c1cc[R1]cc1</smiles>

34<smiles>C=CC1COC(=O)O1</smiles>

$110 a$

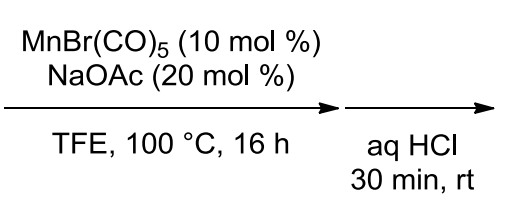

$30 \mathrm{~min}, \mathrm{rt}$

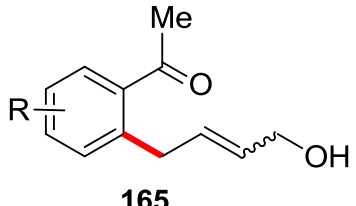

165<smiles>[R]c1ccc(C(C)=O)c(CC=CCO)c1</smiles>

$\mathrm{R}=\mathrm{CH}_{3}$ (165aa): $53 \%(E / Z>20)$

$\mathrm{R}=\mathrm{Ph}(165 \mathrm{ba}): \quad 66 \%(E / Z>20)$

$\mathrm{R}=\mathrm{CF}_{3}($ 165ca): $\quad 69 \%(E / Z=10)$

$\mathrm{R}=\mathrm{F}(\mathbf{1 6 5 d a}): \quad 71 \%(E / Z>20)$

$\mathrm{R}=\mathrm{Cl}$ (165ea): $\quad 73 \%(E / Z=12)$

$\mathrm{R}=\mathrm{Br}(\mathbf{1 6 5 f a}): \quad 82 \%(E / Z=9.0)$<smiles>[R]C(=O)c1ccccc1CC=CCO</smiles>

$\mathrm{R}=\mathrm{CH}_{3}$ (165ga): $70 \%(E / Z=12)$

$\mathrm{R}=\mathrm{Et}(165 \mathrm{ha}): \quad 64 \%(E / Z>20)$<smiles>CC(=O)c1cc2ccccc2cc1CC=CCO</smiles>

165ja: $68 \%(E / Z>20)$<smiles>CC(=O)c1ccc2c(c1C/C=C/CO)OCO2</smiles>

165ia: $60 \%(E / Z>20)$ $53 \%(E / Z>20)^{[a]}$<smiles>CC(=O)c1cccc(F)c1C/C=C/CO</smiles>

165ka: $85 \%(E / Z=7.3)$

Scheme 3.5.3 Manganese(I)-catalyzed $\mathrm{C}-\mathrm{H} / \mathrm{C}-\mathrm{O}$ functionalization of tryptophan $\mathbf{4 1}$ and ketimines $\mathbf{3 4}$. ${ }^{\text {[a] }}$ In $\mathrm{H}_{2} \mathrm{O}$.

\subsubsection{Key Mechanistic Findings}

\subsubsection{H/D Exchange Experiment}

In order to delineate the manganese catalyst's mode of action, a series of mechanistic studies was performed. Firstly, a H/D exchange experiment in the presence of isotopically labeled $\mathrm{D}_{2} \mathrm{O}$ was conducted (Scheme 3.5.4). A significant H/D exchange was observed in C-2 position of the re-isolated starting material $[D]_{n}-\mathbf{4 1 a}$, indicating a reversible $\mathrm{C}-\mathrm{H}$ activation elementary step to be operative. 


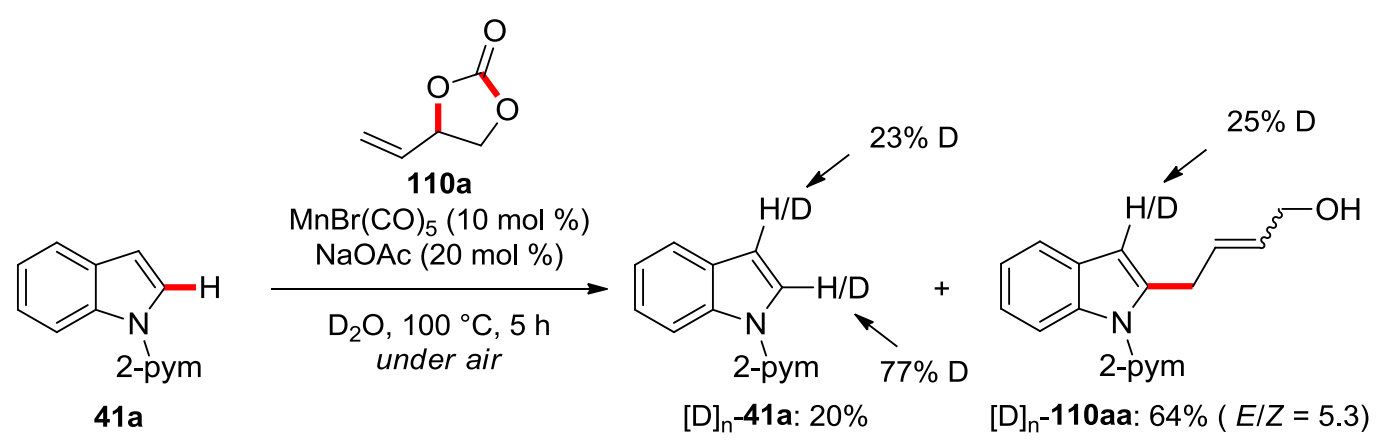

Scheme 3.5.4 H/D exchange experiment.

\subsubsection{Intermolecular Competition Experiment}

Then, an intermolecular competition experiment was carried out by comparing the reaction rates between electronically differentiated ketimines $\mathbf{3 4 a}$ and $\mathbf{3 4 d}$ (Scheme 3.5.5). This result showed a minor preference for the electron-deficient substrate under the optimized conditions.

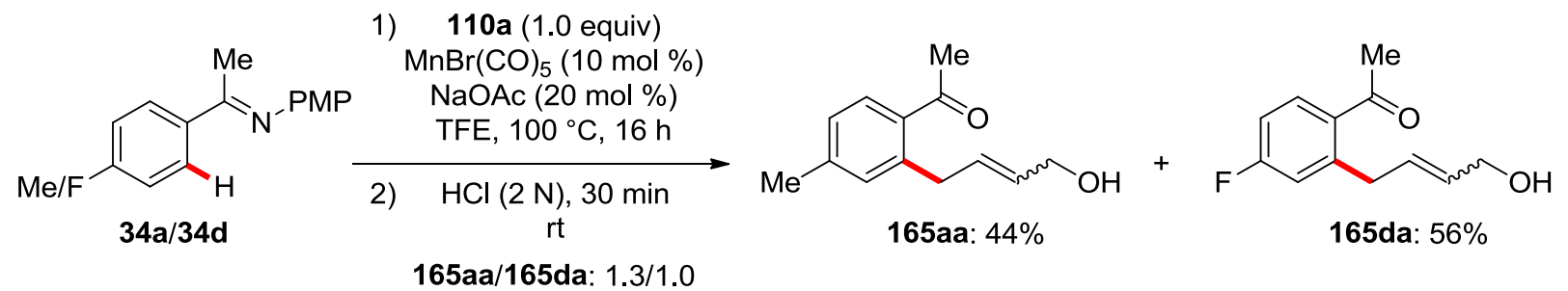

(by crude ${ }^{1} \mathrm{H}$ NMR)

Scheme 3.5.5 Intermolecular competition experiment.

\subsubsection{Decarboxylative C-H/C-O Activation with Cyclometalated Complex 193}

The organometallic complex 193 was independently prepared by the $\mathrm{C}-\mathrm{H}$ activation of stoichiometric amounts of $\mathrm{MnBr}(\mathrm{CO})_{5}$ with substrate 41a. Remarkably, complex 193 showed a high reaction efficiency to afford the allylic alcohol products $\mathbf{1 1 1}$ not only in a catalytic reaction, but also in a stoichiometric experiment (Scheme 3.5.6). Overall, these results showed that this manganese cyclometalated complex probably is a key intermedate in the catalytic cycle. 
a) synthesis of complex 193<smiles>[M]C(=O)ONC(=O)[O-]</smiles>

41a

b) catalytic reactions with complex 193<smiles></smiles><smiles>[R]c1ccc2c(c1)cc([18F])n2[12OH]</smiles>

41<smiles>C=CC1COC(=O)O1</smiles>

$110 \mathrm{a}$<smiles></smiles>

193: $43 \%$<smiles>[R]c1ccc2c(c1)cc(CC=CCO)n2[R6]</smiles>

$$
\begin{aligned}
& \mathrm{R}=\mathrm{H}(111 \mathrm{aa}): \quad 84 \% \quad(E / Z=5.5) \\
& \mathrm{R}=\mathrm{Me}(111 \mathrm{ga}): 86 \%(E / Z=5.3) \\
& \mathrm{R}=\mathrm{F}(111 \mathrm{ia}): \quad 82 \%(E / Z=5.1)
\end{aligned}
$$

c) stoichiometric reaction with complex 193

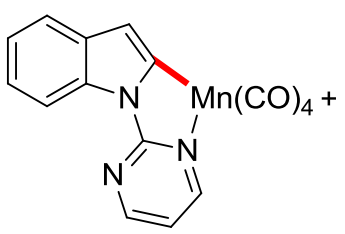

193<smiles>C=CC1COC(=O)O1</smiles>

$110 \mathrm{a}$<smiles>OCC=CCc1cc2ccccc2n1[Te]O</smiles>

111aa: $88 \%(E / Z=5.5)$

Scheme 3.5.6 Decarboxylative $\mathrm{C}-\mathrm{H} / \mathrm{C}-\mathrm{O}$ activation with cyclometalated complex 193. 


\subsection{Synergistic Manganese(I) C-H Activation Catalysis in Continuous Flow: Chemoselective Hydroarylation}

In recent years, the number and types of reactions performed in continuous flow have grown substantially, which were already widely applied to many fields, such as catalytic reactions, green chemistry, pharmaceutical and fine chemical industries due to the number of benefits, including: 1) improved process safety, 2) increased product quality and yield, 3) decreased reaction time, and 4) easy scale-up of chemical reactions. ${ }^{[150]}$ In addition, significant processes in transition metal-catalyzed $\mathrm{C}-\mathrm{H}$ activation also have been achieved during last few decades. ${ }^{[8,13 \mathrm{~b}]}$ However, metal-catalyzed $\mathrm{C}-\mathrm{H}$ activation in combination with continuous flow technology thus far has proven elusive. Only a few examples in this field have been very recently reported by Ackermann ${ }^{[171]}$ and Noë ${ }^{[172]}$. In addition, from a sustainable perspective, Earth abundant $3 d$ metals as the catalyst for $\mathrm{C}-\mathrm{H}$ activation would be highly desirable. Based on our previous studies on $\mathrm{C}-\mathrm{H}$ functionalizations, ${ }^{[160,173]}$ we hence became interested in developing a chemoselective manganese(I)-catalyzed C-H hydroarylation in continuous flow.

\subsubsection{Optimization of Synergistic Hydroarylation in Flow}

The optimization studies were commenced by probing the feasibility of the manganese(I)-catalyzed $\mathrm{C}-\mathrm{H}$ hydroarylation of substrate $\mathbf{4 1 b}$ with 4-ethynyl-4-methyl-1,3-dioxolan-2-one (166a) in continuous flow. Efforts towards the chemo-selective hydroarylation product 167ba, being fully tolerant of $\beta$-O leaving groups, were optimized (Table 3.6.1). No reaction took place at $60{ }^{\circ} \mathrm{C}$ in the presence of $\mathrm{NaOAc}$ (entry 1). However, when we increased the reaction temperature to $100{ }^{\circ} \mathrm{C}, 56 \%$ of the allene product was obtained (entry 2). Similar results were observed with $\mathrm{Cy}_{2} \mathrm{NH}$ as organic base or without additives (entries $3-4)$. When we chose $(n \mathrm{Bu})_{4} \mathrm{NOAc}$ as the additive, the desired product 167 ba was obtained in $26 \%$ yield (entry 5). A significant breakthrough was made by using acidic conditions. The use of pivalic acid furnished the desired hydroarylation product in good yield without formation of the allene product (194) (entry 6). Subsequently, we tried to optimize the flow rate with HOPiv as the additive. As a result, a longer residence time of the reaction in flow resulted in a slightly higher performance (entries 7-10). Notably, the reaction temperature played a major 
role in the reaction (entry 11). Moreover, the high yields of the hydroarylation product were obtained with HOAc as the additive (entries 12-15). Switching to toluene or DCE as the reaction solvent, reducing the catalyst loading or decreasing the reaction temperature resulted in a significant decrease in the yield of the desired product 167ba (entries 16-19). At last, the product was not observed in the absence of the manganese catalyst (entry 20).

Table 3.6.1 Optimization of synergistic hydroarylation of $41 \mathrm{~b}$ in flow

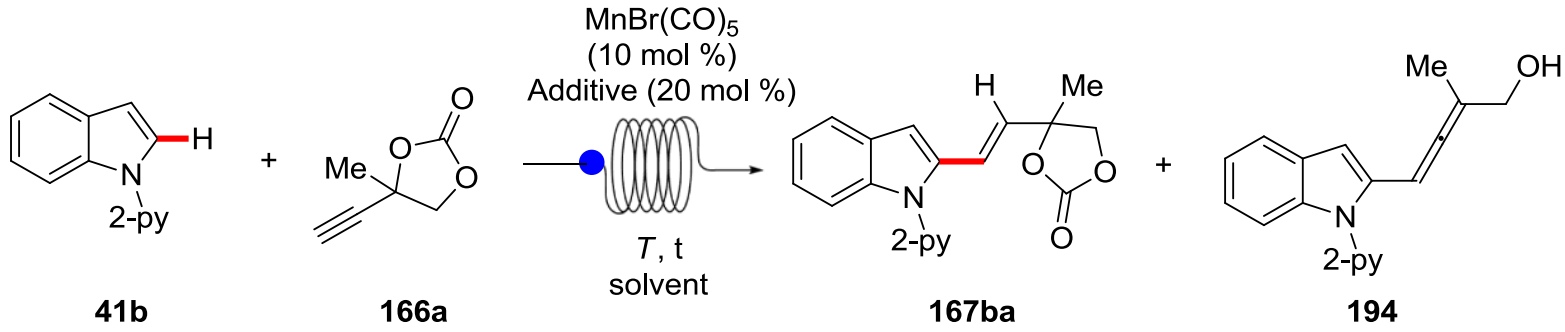

\begin{tabular}{|c|c|c|c|c|c|c|}
\hline \multirow{2}{*}{ Entry } & \multirow{2}{*}{ Additive } & \multirow{2}{*}{ Solvent } & \multirow{2}{*}{ Rate / ( $\mu \mathrm{L} / \mathrm{min})$} & \multirow{2}{*}{$T /{ }^{\circ} \mathrm{C}$} & \multicolumn{2}{|c|}{ Yield $^{[\mathrm{a}]}$} \\
\hline & & & & & $167 \mathrm{ba}$ & 194 \\
\hline 1 & $\mathrm{NaOAc}$ & 1,4-dioxane & 100 & 60 & -- & -- \\
\hline 2 & $\mathrm{NaOAc}$ & 1,4-dioxane & 500 & 100 & trace & $56 \%$ \\
\hline 3 & $\mathrm{Cy}_{2} \mathrm{NH}$ & 1,4-dioxane & 500 & 100 & -- & $32 \%$ \\
\hline 4 & -- & 1,4-dioxane & 500 & 100 & -- & $63 \%$ \\
\hline 5 & $(n \mathrm{Bu})_{4} \mathrm{NOAC}$ & 1,4-dioxane & 500 & 100 & $26 \%$ & $40 \%$ \\
\hline 6 & HOPiv & 1,4-dioxane & 500 & 100 & $71 \%$ & -- \\
\hline 7 & HOPiv & 1,4-dioxane & 150 & 100 & $85 \%$ & -- \\
\hline 8 & HOPiv & 1,4-dioxane & 200 & 100 & $87 \%$ & -- \\
\hline 9 & HOPiv & 1,4-dioxane & 250 & 100 & $80 \%$ & -- \\
\hline 10 & HOPiv & 1,4-dioxane & 300 & 100 & $75 \%$ & -- \\
\hline 11 & HOPiv & 1,4-dioxane & 500 & 80 & trace & -- \\
\hline 12 & HOAC & 1,4-dioxane & 200 & 100 & $93 \%$ & - \\
\hline
\end{tabular}




\begin{tabular}{ccccccc}
\hline 13 & HOAC & 1,4-dioxane & 300 & 100 & $92 \%$ & -- \\
14 & HOAc & 1,4-dioxane & 500 & 100 & $95 \%$ & -- \\
15 & HOAC & 1,4-dioxane & 1000 & 100 & $82 \%$ & -- \\
16 & HOAC & toluene & 500 & 100 & $25 \%$ & -- \\
17 & HOAC & DCE & 500 & 100 & $24 \%$ & -- \\
18 & HOAC & 1,4-dioxane & 500 & 80 & $57 \%$ & -- \\
$19^{[b]}$ & HOAC & 1,4-dioxane & 500 & 100 & $61 \%$ & -- \\
$20^{[c]}$ & HOAC & 1,4-dioxane & 500 & 100 & -- & -- \\
\hline
\end{tabular}

${ }^{[a]}$ Reaction conditions: $41 \mathrm{~b}(0.25 \mathrm{mmol}), 166 \mathrm{a}(0.50 \mathrm{mmol}), \mathrm{MnBr}(\mathrm{CO})_{5}(10.0 \mathrm{~mol} \%)$, additive (20.0 mol \%), solvent $(1.0 \mathrm{~mL})$, under air, $T$, isolated yield. ${ }^{[b]} \mathrm{MnBr}(\mathrm{CO})_{5}(5.0 \mathrm{~mol} \%)$ was used. ${ }^{[\mathrm{c}]}$ Without $\mathrm{MnBr}(\mathrm{CO})_{5}$.

\subsubsection{Scope of Synergistic C-H Activation in Flow}

\subsubsection{Scope of $\mathrm{C}-\mathrm{H}$ Activation of the Heteroarenes 41 in Flow}

Having established the optimized catalytic system, we explored the generality and scope of various indoles $\mathbf{4 1}$ for the manganese(I)-catalyzed $\mathrm{C}-\mathrm{H}$ hydroarylation in continuous flow (Scheme 3.6.1). Notably, these results showed a broad substrate applicability and excellent tolerance towards various functional groups, such as halogens, cyano, ester and carboxylic acid, which delivered the corresponding products in moderate to good yields. It should be noted that the C-3 substituted sterically hindered substrates $\mathbf{4 1 m}, \mathbf{4 1} \mathrm{n}$, and $\mathbf{4 1 t}$ were found to be suitable for this flow $\mathrm{C}-\mathrm{H}$ alkenylation and furnished the desired products 167ma, 167na, and 167ta in good yields. Moreover, the heterocyclic substrate $\mathbf{4 1} \mathbf{d}^{\prime}$ also underwent this process smoothly, affording the desired product 167d'a in good yield with high chemo- and regio-selectivity. Remarkably, this flow C-H hydroarylation reaction could be conducted within only one minute at $150{ }^{\circ} \mathrm{C}$, which demonstrated the major advantage of flow chemistry, avoiding the use of high-pressure sealed-tube equipment. 


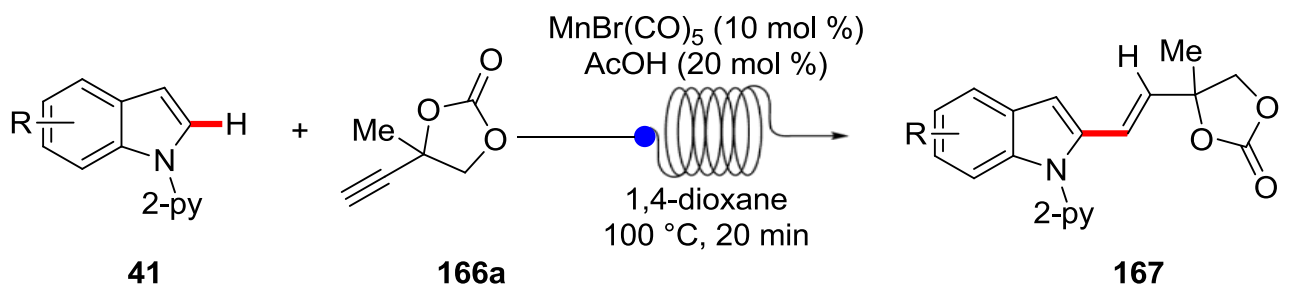

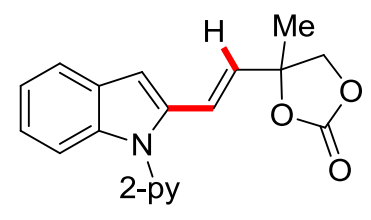

167ba: 95\%, 67\%[a]<smiles></smiles>

$R=I(167 w a):$

$\mathrm{R}=\mathrm{F}(167 \times a)$ :

$\mathrm{R}=\operatorname{Br}(167 y a)$

$\mathrm{R}=$ Me (167za):

$\mathrm{R}=\mathrm{CO}_{2} \mathrm{H}\left(167 \mathbf{a}^{\prime} \mathbf{a}\right): \quad 67 \%$

$\mathrm{R}=\mathrm{CO}_{2} \mathrm{Me}\left(167 \mathbf{b}^{\prime} \mathrm{a}\right): \quad 72 \%$<smiles>[R]c1c(/C=C/C2([Y4])COC(=O)O2)n([R20])c2ccccc12</smiles>

$\mathrm{R}=\mathrm{Me}(167 \mathrm{ma}): 86 \%$

$\mathrm{R}=\mathrm{Br}(167$ na): $63 \%$ $\mathrm{R}=\mathrm{CN}(167 \mathrm{ta}): 65 \%$<smiles>[Y60]N1OC(=O)OC=C1/C=C/c1cc2c(n1[13CH])CCCC2=O</smiles>

167c'a: $50 \%$<smiles>[R]c1ccc2cc(/C=C/C3([Y4])COC(=O)O3)n([R10])c2c1</smiles>

$\mathrm{R}=\mathrm{Br}(167 \mathrm{ua}): 81 \%$ $\mathrm{R}=\mathrm{Cl}(167 \mathrm{va}): 82 \%$<smiles>[R17]c1ccsc1/C=C/C1([M])COC(=O)O1</smiles>

167d'a: $88 \%$

Scheme 3.6.1 Synergistic $\mathrm{C}-\mathrm{H}$ activation of the heteroarenes 41 in flow. ${ }^{[\mathrm{a}]} 150^{\circ} \mathrm{C}, 1 \mathrm{~min}$.

\subsubsection{Scope of C-H Hydroarylation with Propargylic Alkynes 166 in Flow}

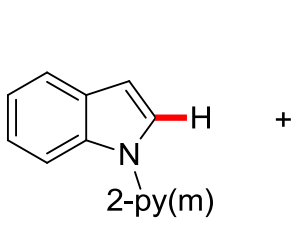

41

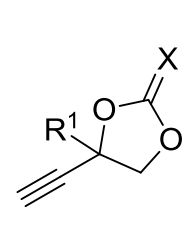

166

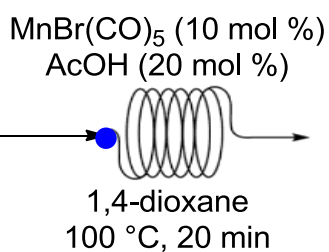

$100^{\circ} \mathrm{C}, 20 \mathrm{~min}$<smiles>[X]C1OCC([R])(/C(=C/c2cc3ccccc3n2[Y6])CC)O1</smiles>

167<smiles>CC1(/C=C/c2cc3ccccc3n2[PH2+])COC(=O)O1</smiles>

167aa: $95 \%$<smiles>[Y7]n1c(/C=C/C2COC(=O)O2)cc2ccccc21</smiles>

167bb: $83 \%$<smiles>CC1(/C=C/c2cc3ccccc3n2[18O])COC(C)(C)O1</smiles>

167bc: $71 \%$ (40 min)

Scheme 3.6.2 $\mathrm{C}-\mathrm{H}$ activation/hydroarylation with the propargylic alkynes 166 in flow.

Motivated by the success in the synergistic $\mathrm{C}-\mathrm{H}$ activation with a wide range of heteroarenes $\mathbf{4 1}$, we 
next tested the effect of propargylic alkynes 166 on the reaction process (Scheme 3.6.2). As expected, substituted propargylic alkynes 166 were also viable in this flow reaction, delivering the desired products in good yields with excellent levels of chemo-selectivity. Additional dioxolanone alkynes were tested by Dr. Pesciaioli. ${ }^{[152]}$

\subsubsection{Key Mechanistic Findings}

\subsubsection{Intermolecular Competition Experiment}

To further understand the mechanism of this unique manganese(I)-catalyzed $\mathrm{C}-\mathrm{H}$ hydroarylation, a set of experiments was carried out to delineate its mode of action. Firstly, an intermolecular competition experiment between electronically distinct substrates 41e'a and 41xa was performed (Scheme 3.6.3). The result showed that the electron-rich substrate 41e'a reacted preferentially under the reaction conditions (Scheme 3.6.3).

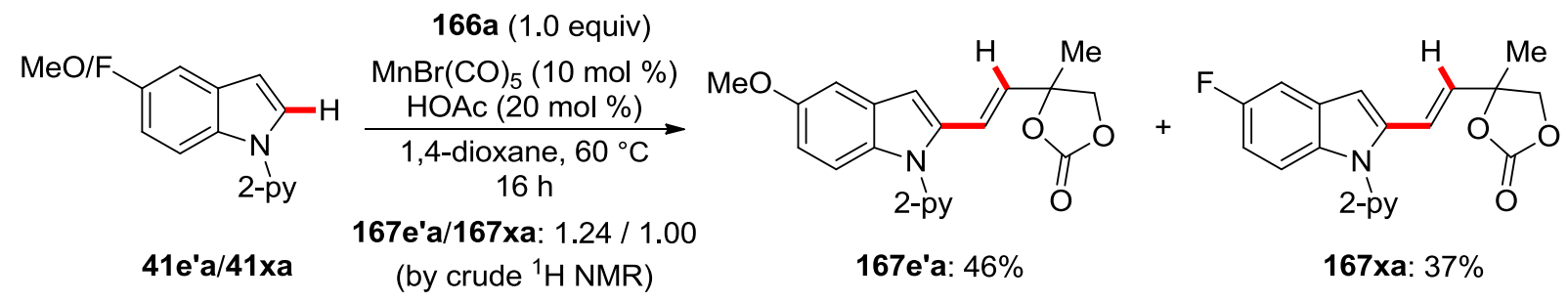

Scheme 3.6.3 Intermolecular competition experiment.

\subsubsection{H/D Exchange Experiments}

Furthermore, H/D exchange studies were conducted in the presence of isotopically labeled acetic acid as the additive. A notable H/D scrambling in C-2 position of the re-isolated starting material 41b was observed, indicating a reversible $\mathrm{C}-\mathrm{H}$ metalation to be operative. Importantly, a deuterium incorporation of $65 \%$ in the $\beta$-position of the product $[D]_{n}-167$ ba was also observed. In contrast, no $\mathrm{H} / \mathrm{D}$ exchange in the $\mathrm{C}-3$ position of the product $167 \mathrm{ba}$ as well as the re-isolated starting material was detected (Scheme 3.6.4a). The catalytic reaction of deuterated substrate $[D]_{1}-\mathbf{4 1 b}$ further supported that the $\beta$-proton source of the product $167 \mathrm{ba}$ is from the C-2 position of indole substrate $\mathbf{4 1 b}$, when catalytic amount of acetic acid was used (Scheme 3.6.4b). 
a) facile $H / D$ exchange

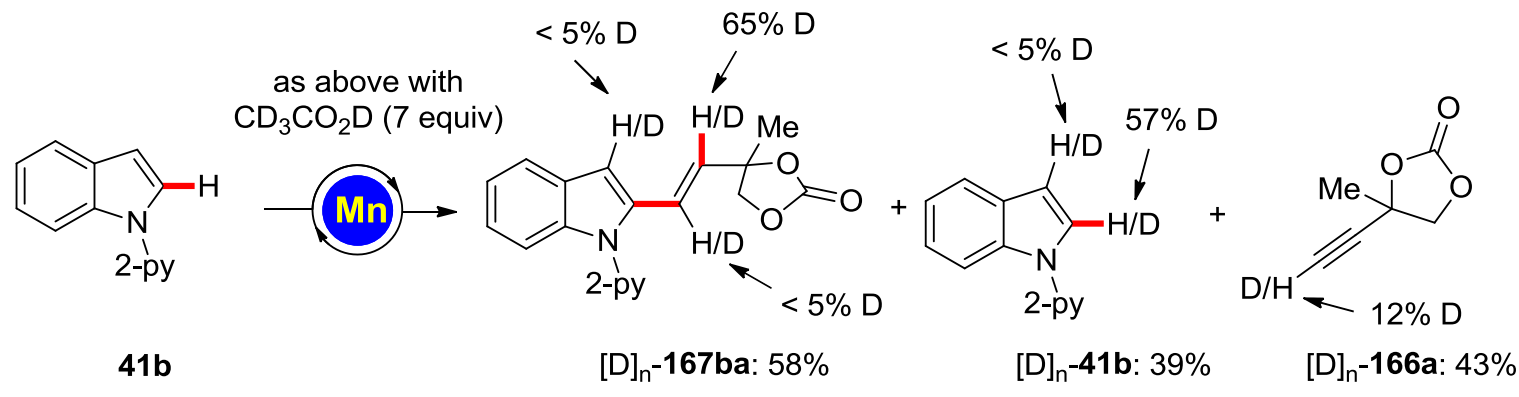

b) isotopically labeled substrate

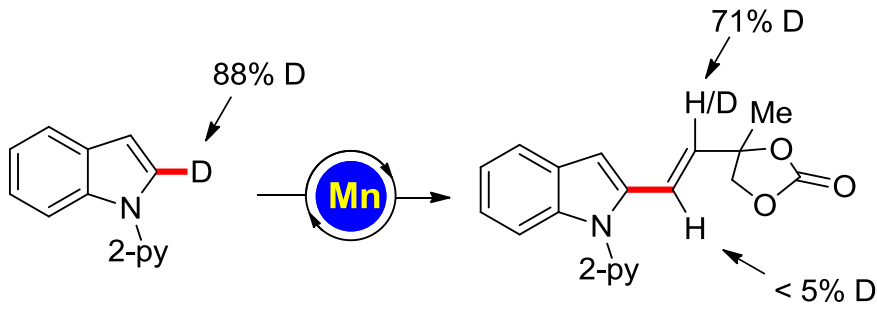

$[D]_{1}-41 b \quad[D]_{n}-167 b a: 86 \%$

Scheme 3.6.4 H/D exchange experiments.

\subsubsection{C-H Activation/Hydroarylation with Complex 195}

a) stoichiometric experiment without acetic acid<smiles>CC(C)n1c2ccccc2n2c3ccccc3cc12</smiles>

195

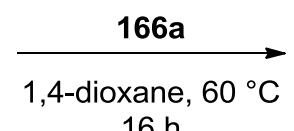

$16 \mathrm{~h}$

b) stoichiometric experiment with acetic acid<smiles>O=Cc1cc2ccccc2n1-c1ccccc1</smiles>

195

c) catalytic experiment with acetic acid

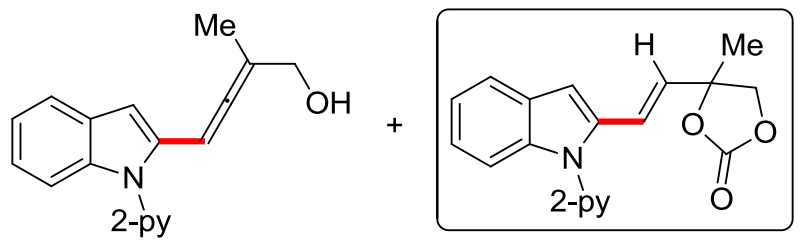

194: $46 \%$

167ba: n.d.

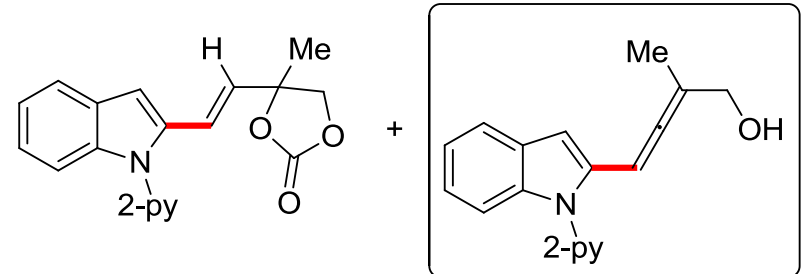

167ba: $48 \%$

194: n.d.<smiles>[R20]n1ccc2ccccc21</smiles>

41b<smiles>C#CC1(C)COC(=O)O1</smiles>

$166 a$<smiles>[R10]n1c(/C=C/C2(C)COC(=O)O2)cc2ccccc21</smiles>

167ba: $96 \%$

Scheme 3.6.5 C-H activation/hydroarylation with complex 195. n.d. = no reaction. 
At last, in order to elucidate the nature of the active manganese catalyst, the performance of cyclometalated complex 195 was investigated in stoichiometric and catalytic reactions (Scheme 3.6.5). Interestingly, the stoichiometric reaction was conducted in absence of acetic acid, delivering only allene 194 in $46 \%$ yield by $\beta-O$ elimination without any hydroarylation product being observed (Scheme 3.6.5a). In contrast, under acidic conditions, the cyclometalated complex 195 only afforded the hydroarylation product $167 \mathrm{ba}$ in $48 \%$ yield (Scheme 3.6.5b). Moreover, complex 195 showed a very high activity in the catalytic reaction in the presence of a catalytic amount of acetic acid and the desired product in almost quantitative yield (Scheme 3.6.5c). These results showed that this complex 195 could play a very important role in the manganese catalytic cycle.

\subsubsection{Continuous Flow Manganese-Catalyzed C-H Activation on Scale and Catalyst Separation}

a) continuous flow $\mathrm{C}-\mathrm{H}$ activation: on scale
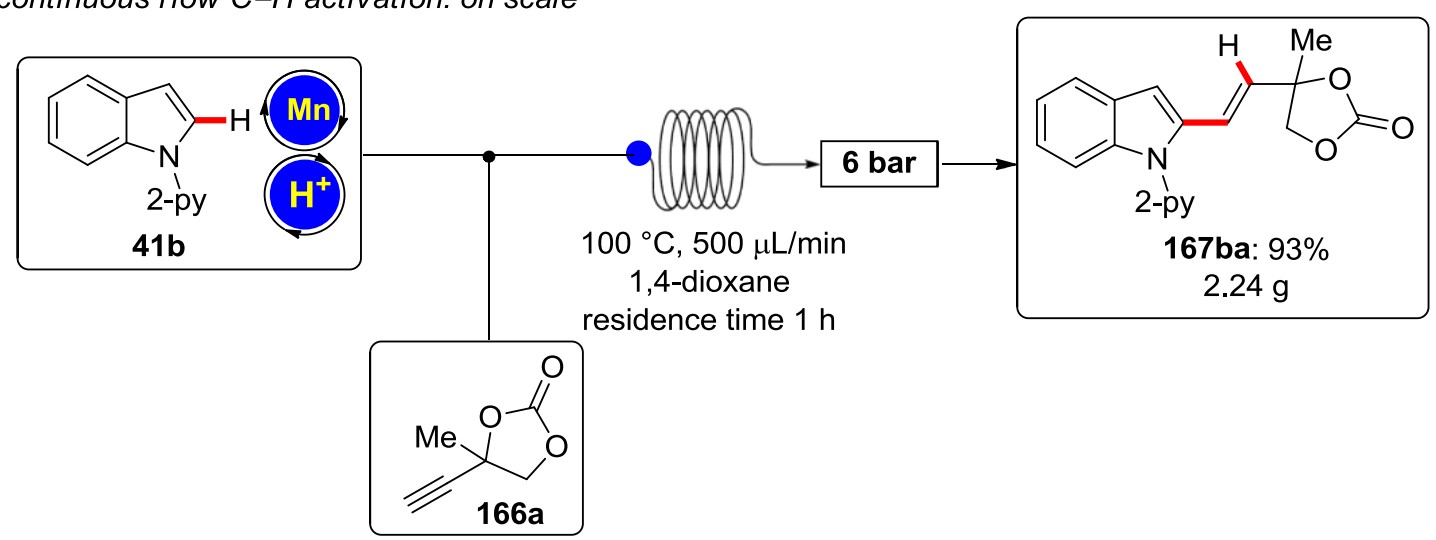

residence time $1 \mathrm{~h}$

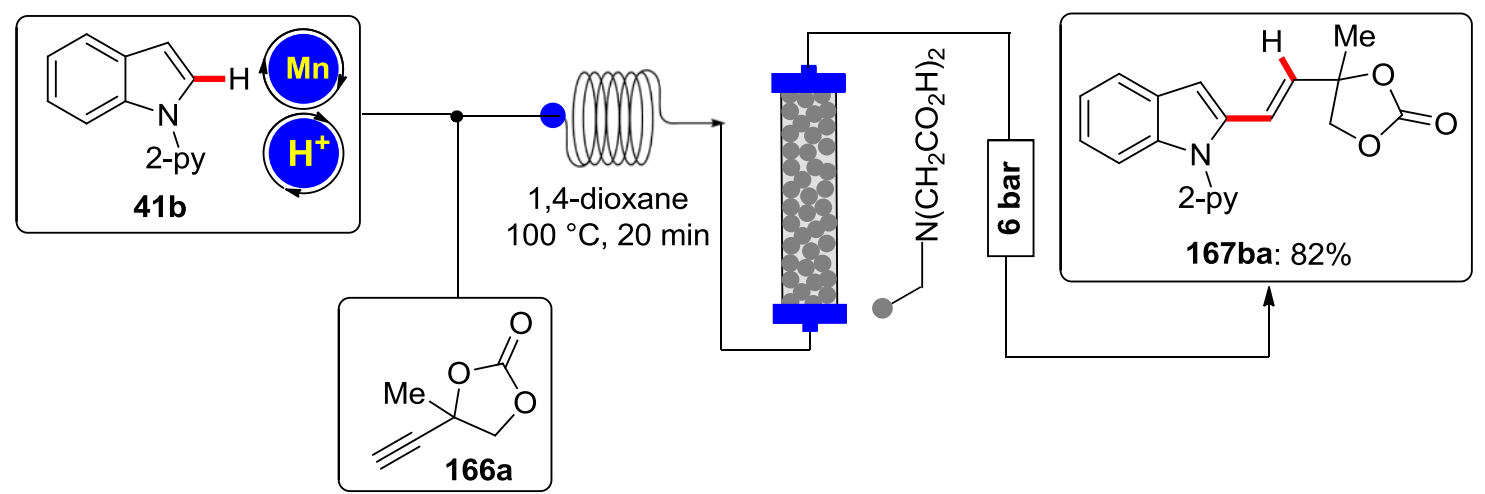

Scheme 3.6.6 Continuous flow manganese-catalyzed $\mathrm{C}-\mathrm{H}$ activation on scale and catalyst separation.

In addition, the continuous flow $\mathrm{C}-\mathrm{H}$ activation was conducted on a gram scale, and the desired 
product 167ba could be obtained in excellent yield with high chemo-selectivity, reflecting the robust and efficient manganese catalysis (Scheme 3.6.6a). Furthermore, we developed a convenient separation strategy for removing the manganese catalyst by using different types of resins (Scheme 3.6.6b). Further applications of this new technology in organic synthesis are still under investigation.

\subsubsection{Late-Stage Modifications of Product 167}

Finally, in order to demonstrate the unique synthetic utility of the obtained allylic carbonates 167, a large number of diversification reactions were carried out (Scheme 3.6.7). Notably, the hydroarylation product could be easily transformed into other useful compounds. Firsty, compound 167ba was hydrolyzed by treatment with sodium hydroxide in 1,4-dioxane to afford the 1,2-diol product 196 in near to quantitative yield (a). Additionally, decarboxylation of 167ba provided the product 197 in $88 \%$ yield with palladium as catalyst (b). ${ }^{[174]}$ Interestingly, when 167 ba was reacted with Grignard reagent under copper catalysis, 1,3-diene product 198 was obtained (c). ${ }^{[175]}$ Finally, nucleophilic substitution of compound 167 ba by aniline catalyzed by palladium with DPEphos as the ligand smoothly provided product 199 in good yield $(d),{ }^{[176]}$ which was performed by Dr. Pesciaioli.

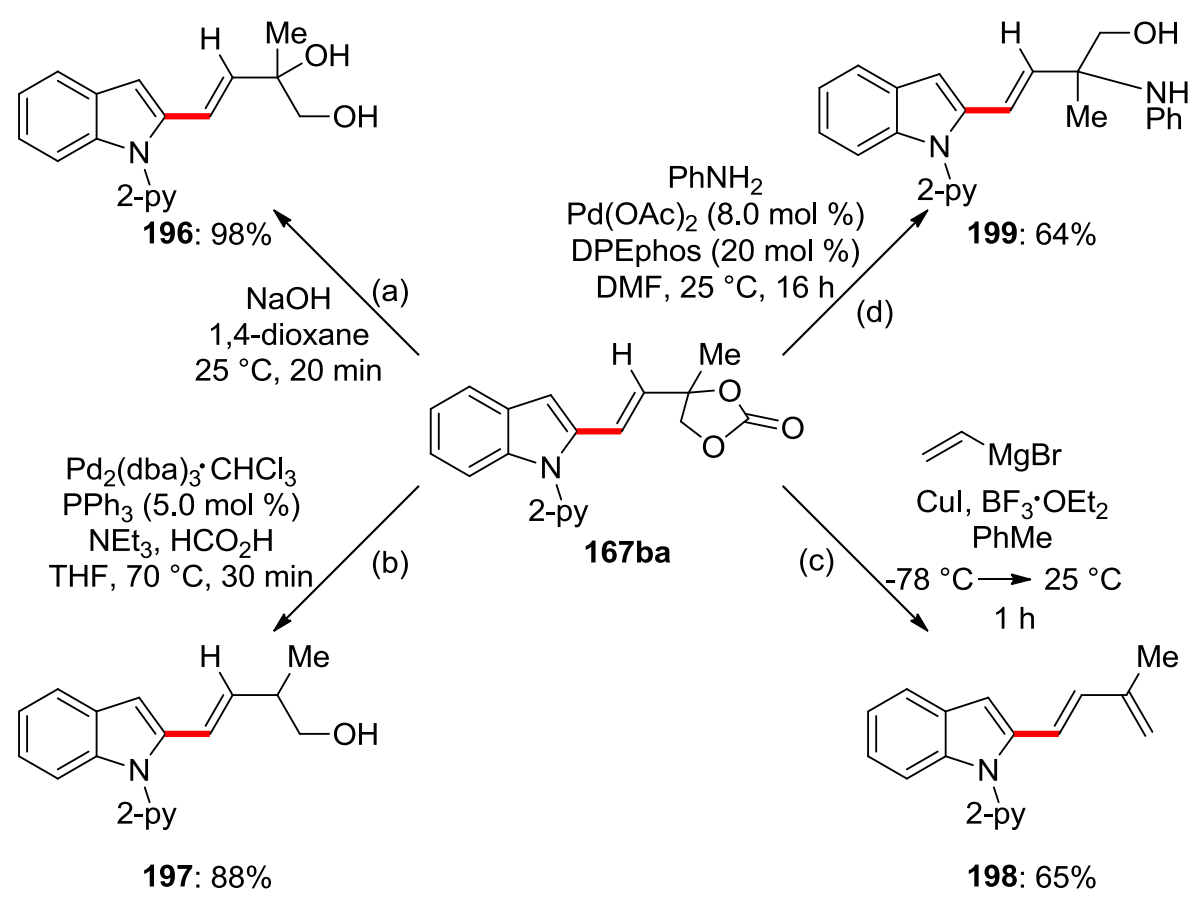

Scheme 3.6.7 Late-stage modifications of product 167ba. 


\subsection{Versatile and Robust C-C Activation by Chelation-Assisted Manganese-Catalysis}

Transition metal catalysis has emerged as an important and straightforward method for the syntheses of complex molecules, which are very useful in pharmaceutical and fine chemical industries. ${ }^{[119 d, 177]}$ Direct C-C bond cleavage by transition metal complexes has recently attracted considerable attention, in consequence of the potential applications to organic synthesis. ${ }^{[119 b-d]}$ An ideal reaction should be performed with high atom economy at low reaction temperature and pressure, minimizing the waste, and using Earth-abundant elements, such as water as the solvent and $3 \mathrm{~d}$ metal as the catalyst. Although great breakthroughs in direct $\mathrm{C}-\mathrm{C}$ functionalization have been achieved, there are still many challanges in this field, including 1) requirement of harsh conditions; 2) relying on the strained or polarized $C-C$ bonds; ${ }^{[178]} 3$ ) using noble metals as the catalysts, especially rhodium, ${ }^{[179]}$ ruthenium, ${ }^{[153]}$ and palladium; $\left.{ }^{[180]} 4\right)$ often the mechanism is not fully understood; and 5) limited substrate scopes. In this context, here we will focus on a distinct approach, which would carry out the $\mathrm{C}-\mathrm{C}$ functionalization in water with Earth-abundant manganese as the catalyst relying on a $\beta$-carbon elimination step. ${ }^{[135-136]}$

\subsubsection{Optimization of Manganese-Catalyzed C-C Cleavage}

Initially, we examined the reaction of 2-[2-(1H-pyrazol-1-yl)phenyl]propan-2-ol (168a) with 4-vinyl-1,3-dioxolan-2-one (110a) at $120{ }^{\circ} \mathrm{C}$ in the presence of $\mathrm{MnBr}(\mathrm{CO})_{5}$ as the catalyst by screening various solvents (Table 3.7.1, entries 1-6). Remarkably, nontoxic and nonflammable water turned out to be the optimal solvent for this manganese(I)-catalyzed C-C activation (entry 6). In contrast, other polar solvents, such as $n \mathrm{BuOH}$ and $\mathrm{GVL}$, shut down the reaction completely (entries 4 and 5). It was further shown that the addition of acid or base was not required for the reaction (entries 7 and 8). A decreased yield of the desired product was observed when lower or higher reaction temperature was employed (entries 9-11). It was found that attempts to lower the catalyst loading, led to a significant decrease in reactivity (entry 12). No reaction was observed without $\mathrm{MnBr}(\mathrm{CO})_{5}$ catalyst or with other manganese sources (entries 13-16). Furthermore, control experiments clearly showed that the manganese catalyst is unique and robust for this $\mathrm{C}-\mathrm{C}$ functionalization, while other metals, such as palladium, rhodium, ruthenium, copper, and iron 
complexes, failed to deliver the desired product 111aa (entries 17-23).

Table 3.7.1 Optimization of manganese-catalyzed C-C cleavage
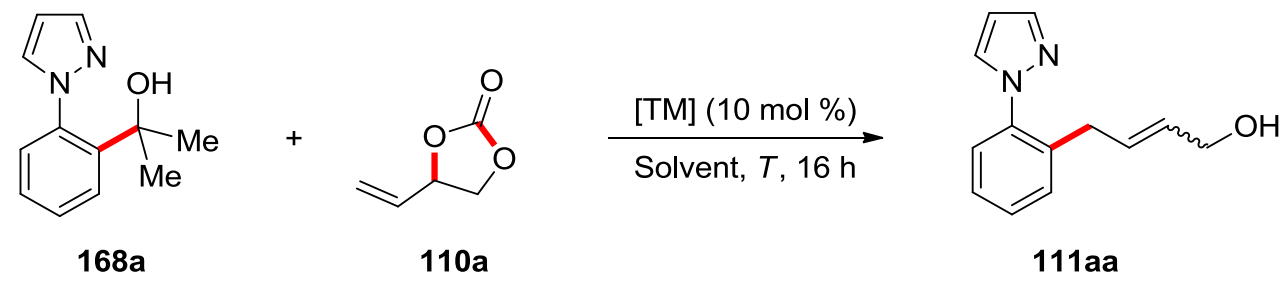

\begin{tabular}{|c|c|c|c|c|c|}
\hline Entry & $\mathrm{TM}$ & $T /{ }^{\circ} \mathrm{C}$ & Solvent & Yield $^{[\mathrm{a}]}$ & $E / Z$ \\
\hline 1 & $\mathrm{MnBr}(\mathrm{CO})_{5}$ & 120 & 1,4-dioxane & $65 \%$ & 2.6 \\
\hline 2 & $\mathrm{MnBr}(\mathrm{CO})_{5}$ & 120 & toluene & $63 \%$ & 2.1 \\
\hline 3 & $\mathrm{MnBr}(\mathrm{CO})_{5}$ & 120 & DCE & $71 \%$ & 3.5 \\
\hline 4 & $\mathrm{MnBr}(\mathrm{CO})_{5}$ & 120 & $n \mathrm{BuOH}$ & --- & --- \\
\hline 5 & $\mathrm{MnBr}(\mathrm{CO})_{5}$ & 120 & GVL & --- & --- \\
\hline 6 & $\operatorname{MnBr}(\mathrm{CO})_{5}$ & 120 & $\mathrm{H}_{2} \mathrm{O}$ & $75 \%$ & 4.9 \\
\hline 7 & $\mathrm{MnBr}(\mathrm{CO})_{5}$ & 120 & $\mathrm{H}_{2} \mathrm{O}$ & $17 \%^{[\mathrm{b}]}$ & 4.3 \\
\hline 8 & $\mathrm{MnBr}(\mathrm{CO})_{5}$ & 120 & $\mathrm{H}_{2} \mathrm{O}$ & $--{ }^{[c]}$ & --- \\
\hline 9 & $\mathrm{MnBr}(\mathrm{CO})_{5}$ & 100 & $\mathrm{H}_{2} \mathrm{O}$ & $62 \%$ & 4.5 \\
\hline 10 & $\mathrm{MnBr}(\mathrm{CO})_{5}$ & 140 & $\mathrm{H}_{2} \mathrm{O}$ & $65 \%$ & 5.1 \\
\hline 11 & $\mathrm{MnBr}(\mathrm{CO})_{5}$ & 80 & $\mathrm{H}_{2} \mathrm{O}$ & $45 \%$ & 4.6 \\
\hline 12 & $\mathrm{MnBr}(\mathrm{CO})_{5}$ & 120 & $\mathrm{H}_{2} \mathrm{O}$ & $59 \%{ }^{[\mathrm{d}]}$ & 4.1 \\
\hline 13 & --- & 120 & $\mathrm{H}_{2} \mathrm{O}$ & --- & --- \\
\hline 14 & $\mathrm{MnCl}_{2}$ & 120 & $\mathrm{H}_{2} \mathrm{O}$ & --- & --- \\
\hline 15 & $\mathrm{Mn}(\mathrm{OTf})_{2}$ & 120 & $\mathrm{H}_{2} \mathrm{O}$ & --- & --- \\
\hline 16 & $\mathrm{Mn}_{2}(\mathrm{CO})_{10}$ & 120 & $\mathrm{H}_{2} \mathrm{O}$ & --- & --- \\
\hline 17 & $\mathrm{Pd}(\mathrm{OAC})_{2}$ & 120 & $\mathrm{H}_{2} \mathrm{O}$ & --- & --- \\
\hline 18 & {$[\mathrm{Rh}(\mathrm{COD}) \mathrm{Cl}]_{2}$} & 120 & $\mathrm{H}_{2} \mathrm{O}$ & --- & --- \\
\hline 19 & {$\left[\mathrm{RuCl}_{2}(p \text {-cymene })\right]_{2}$} & 120 & $\mathrm{H}_{2} \mathrm{O}$ & trace & --- \\
\hline 20 & $\mathrm{Cu}(\mathrm{IPr}) \mathrm{Cl}$ & 120 & $\mathrm{H}_{2} \mathrm{O}$ & -- & -- \\
\hline 21 & $\mathrm{CpFe}(\mathrm{CO})_{2} \mathrm{I}$ & 120 & $\mathrm{H}_{2} \mathrm{O}$ & -- & -- \\
\hline 22 & {$\left[\mathrm{Cp} * \mathrm{RhCl}_{2}\right]_{2}$} & 120 & $\mathrm{H}_{2} \mathrm{O}$ & $-{ }_{--}^{[e]}$ & -- \\
\hline 23 & {$\left[\mathrm{Cp} * \mathrm{RhCl}_{2}\right]_{2}$} & 120 & 1,4-dioxane & $-{ }_{-}^{[\mathrm{e}]}$ & -- \\
\hline
\end{tabular}


$\operatorname{MnBr}(\mathrm{CO})_{5}(5.0 \mathrm{~mol} \%) .{ }^{[\mathrm{e}]}\left[\mathrm{Cp}^{*} \mathrm{RhCl}_{2}\right]_{2}(5.0 \mathrm{~mol} \%) . \mathrm{TM}=$ transition metal.

\subsubsection{Effect of Different Leaving Groups}

Subsequently, the effect of the leaving group at the substrate moiety under the optimized conditions was investigated (Scheme 3.7.1). As a result, the substrates 200 with arene groups reacted smoothly, delivering the desired products 111aa in moderate yields, while other secondary alcohols $200 \mathrm{e}-\mathbf{2 0 0} \mathrm{g}$ failed to achieve the $\mathrm{C}-\mathrm{C}$ functionalization. It proves that the arene group of the secondary alcohol substrates is essential for the manganese-catalyzed C $\mathrm{C}$ activation. It is noteworthy that ether $\mathbf{2 0 0} \mathbf{h}$, ketone $\mathbf{2 0 0} \mathbf{i}$, and acid $\mathbf{2 0 0} \mathbf{j}$ were not suitable leaving groups for the $\mathrm{C}-\mathrm{C}$ activation reaction.

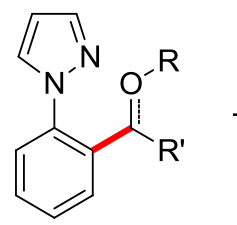

200

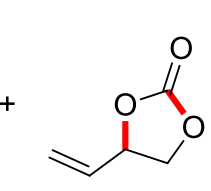

$110 a$

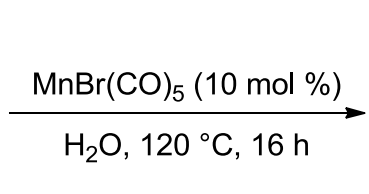

$\mathrm{H}_{2} \mathrm{O}, 120^{\circ} \mathrm{C}, 16 \mathrm{~h}$

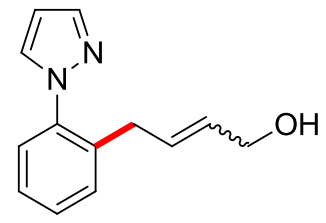

111 aa

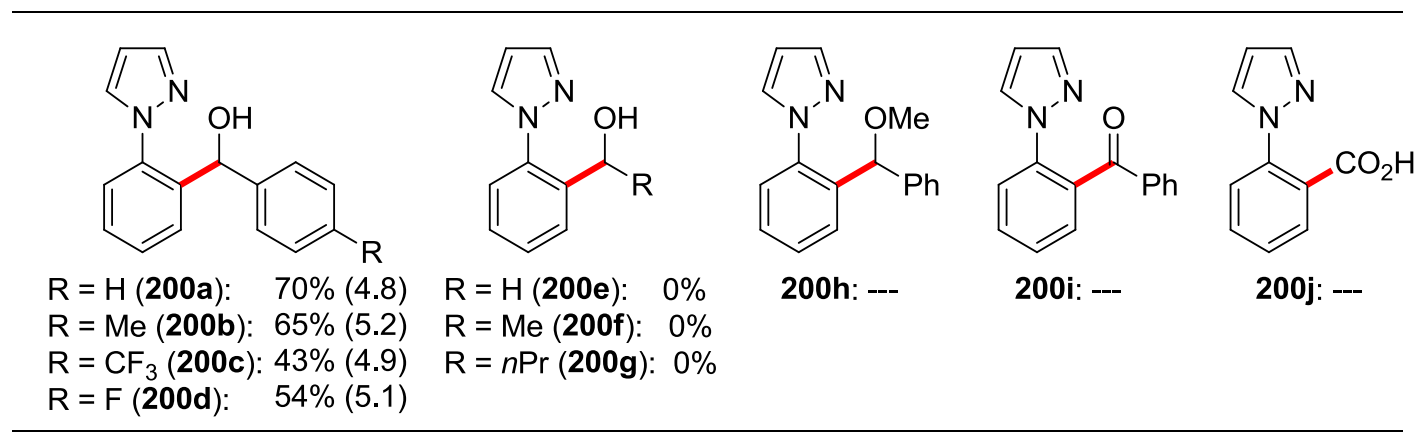

Scheme 3.7.1 Effect of leaving groups. E/Z ratio in parentheses.

\subsubsection{Substrate Scope of C-C Functionalization in Water}

\subsubsection{Scope of Manganese(I)-Catalyzed C-C Allylation in Water}

With the optimized catalytic system in hand, we evaluated the scope of the manganese(I)-catalyzed C-C functionalization with diversely decorated arenes 168 (Scheme 3.7.2). Notably, different directing groups, such as pyrazoles, pyridines and indazoles, could be smoothly converted in water. In addition, various valuable functional groups, such as bromo, amido and hydroxo, were well tolerated in this manganese catalytic system. Moreover, the manganese-catalyzed $\mathrm{C}-\mathrm{C}$ activation protocol was not limited to the allylic alcoholic products 111ca. Indeed, allylic amides could be also 
obtained in good yields (111cg, 111dg, 111gg and 111hg). The substituted propargylic alkene 110b was also shown to be efficient for this $\mathrm{C}-\mathrm{C}$ activation, delivering the desired product in $75 \%$ yield (111jb).
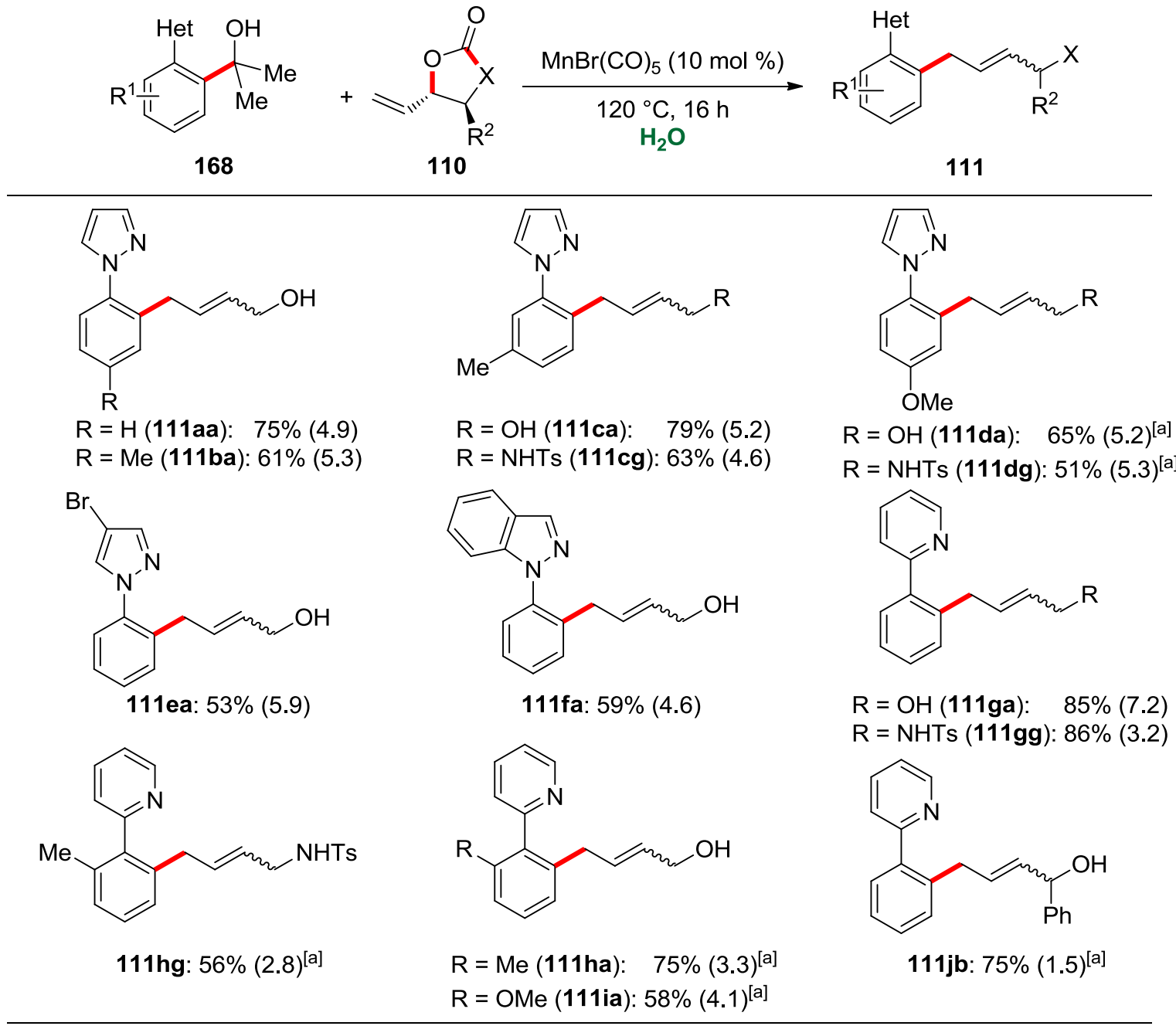

Scheme 3.7.2 Manganese(I)-catalyzed C-C allylation by chelation assistance. $E / Z$ ratio in parenthesis. ${ }^{[a]} \mathrm{PhCHO}$ as leaving group.

\subsubsection{Manganese(I)-Catalyzed C-C Activation for Additions of Alkynes in Water}

Likewise, the versatile C-C activation was accomplished with various alkynes 8 under otherwise identical reaction conditions (Scheme 3.7.3). At first, ortho- and para-substituted phenylacetylenes (8), including electron-donating and electron-withdrawing groups, were efficiently converted into the alkenylation products $\mathbf{7 4}$ with excellent diastereoselectivity. Importantly, the 3-ethynylthiophene (8t) and dec-1-yne $(\mathbf{8 u})$ underwent this catalytic process with good catalytic 
efficacy as well. It should be noted that the $\mathrm{C}-\mathrm{C}$ activation was not limited to the internal alkynes, but terminal alkynes were also shown to be viable substrates and furnished the thermodynamically more stable isomer in good yields (74ca-74cj). The reaction of 2-[2-(pyridin-2-yl)phenyl]propan-2-ol (168j) also gave the corresponding products 74jo and 74jv in good yields with high diastereoselectivities. Finally, the manganese(I)-catalyzed C-C activation was also applied to amino acid $(\mathbf{8 w})$ and steroid $(\mathbf{8 x})$, affording the desired products in good yields without any racemization (74jw and 74jx).<smiles>[M]C(C)(O)c1ccc[R1]c1Cl</smiles>

168<smiles>[R]C#[R][CH]</smiles>

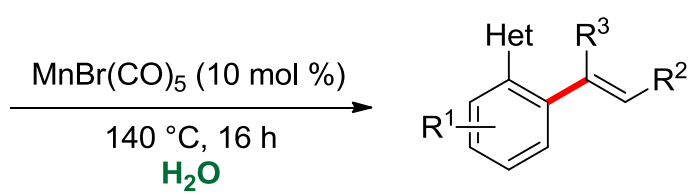

74<smiles>[R]c1ccc(/C=C/c2ccc(C)cc2-n2cccn2)cc1</smiles>

$\mathrm{R}=\mathrm{H}(\mathbf{7 4 \mathrm { co } )}: \quad 69 \%$

$\mathrm{R}=4-\mathrm{OMe}$ (74cq): $59 \%$

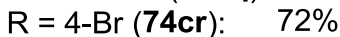

$\mathrm{R}=2-\mathrm{F}$ (74cs): $\quad 87 \%$<smiles>Cc1ccc(/C(=C/c2ccccc2)c2ccccc2)c(-n2cccn2)c1</smiles>

74ca: $72 \%$<smiles>Cc1ccc(/C=C/c2ccsc2)c(-n2cccn2)c1</smiles>

74ct: $60 \%$<smiles>CO/C=C/c1ccc(C)cc1-n1cccn1</smiles>

74cu: $56 \%$<smiles>CC(=O)[C@H](C)NC(=O)c1ccc(/C=C/c2ccccc2-c2ccccn2)cc1</smiles>

74jw: $62 \%\left(120^{\circ} \mathrm{C}\right)$<smiles>Cc1ccc(C(=Cc2cccs2)c2cccs2)c(-n2cccn2)c1</smiles>

74cj: $54 \%$

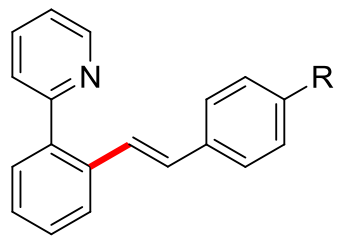

$\mathrm{R}=\mathrm{H}(\mathbf{7 4 j o}): \quad 72 \%$ $\mathrm{R}=t \mathrm{Bu}(\mathbf{7 4} \mathrm{jv}): 80 \%$

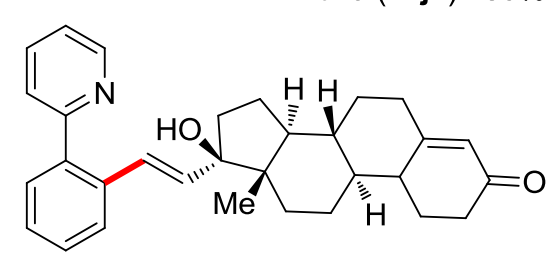

74jx: $55 \%\left(80^{\circ} \mathrm{C}\right)$

Scheme 3.7.3 Manganese(I)-catalyzed C-C activation for additions of alkynes $\mathbf{8}$ in water.

\subsubsection{Manganese(I)-Catalyzed C-C Activation with Alkenes in Water}

To our delight, the $\mathrm{C}-\mathrm{C}$ hydroarylation manifold was not restricted to the alkynes $\mathbf{8}$, but the alkenes 
11 were also identified as competent substrates, again featuring water as the ideal solvent. The manganese catalyst turned out to be efficient and widely applicable for this $\mathrm{C}-\mathrm{C}$ hydroarylation reaction, furnishing the corresponding products in good to excellent yields (Scheme 3.7.4). The reaction of substrates $168 \mathrm{k}$ and $\mathbf{1 6 8}$ l could be performed on $5.0 \mathrm{mmol}$ scale as well and provided the alkylated products in comparable yields (102kf and 102/f). Moreover, the reaction with $\alpha, \beta$-unsaturated ketone $11 \mathrm{~h}$ also proceeded to give the desired product $102 \mathrm{ch}$ in $76 \%$ yield.

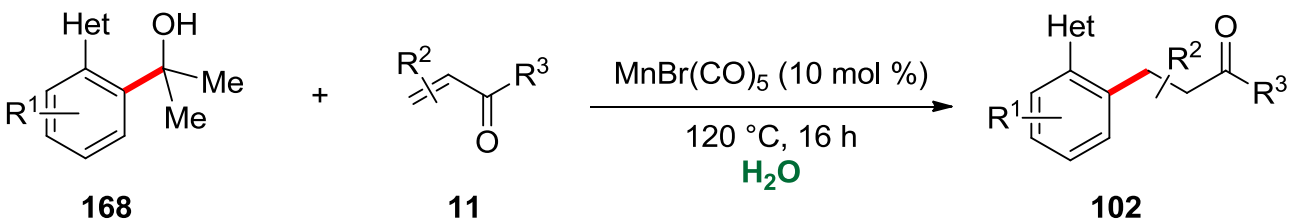<smiles>CN1C(=O)CC(c2ccccc2-n2cccn2)C1=O</smiles>

102af: $68 \%$<smiles>Cc1ccc(C2CC(=O)N(C)C2=O)c(-n2nc(C)cc2C)c1</smiles>

102kf: $85 \%(83 \%, 1.23 \mathrm{~g}$ scale $)$<smiles>CN1C(=O)CC(c2ccccc2-c2ccccn2)C1=O</smiles>

102jf: $91 \%$

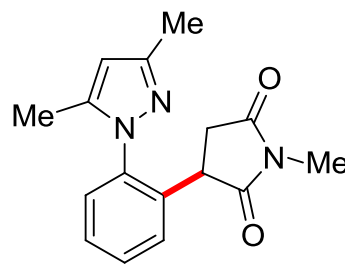

102If: $83 \%(79 \%, 1.1 \mathrm{~g}$ scale $)$<smiles>[R]N1C(=O)CC(c2ccc(C)cc2-n2cccn2)C1=O</smiles>

$R=\operatorname{Me~(102cf):~} 64 \%$ $\mathrm{R}=\mathrm{Et}(102 \mathrm{cg}): 62 \%$<smiles>CC(=O)CCc1ccc(C)cc1-n1cccn1</smiles>
102ch: $76 \%$

Scheme 3.7.4 Manganese(I)-catalyzed C-C activation with alkenes $\mathbf{1 1}$ in water.

\subsubsection{Scope of Manganese(I)-Catalyzed C-C Allylation to Synthesize $\alpha, \beta$-Unsaturated Esters}

Furthmore, we also developed a new allylation reaction using various allylic reagents that provided expedient access to useful $\alpha, \beta$-unsaturated esters 201 (Scheme 3.7.5). Notably, this transformation showed a good functional group tolerance and high regio-selectivity. It was demonstrated that the electron-withdrawing substrates $168 \mathrm{~m}$ and $168 \mathrm{n}$ could react smoothly to provide the allylation products in good yields (202ma and $202 \mathrm{na}$ ). The challenging substrate $\mathbf{2 0 1 b}$ was also found to be reactive under the newly developed conditions (202ab). This remarkable $C-C$ functionalization could be achieved by reacting with various alkenes 11, 201 and alkynes 8 in moderate to good yields 
with good diastereoselectivies.

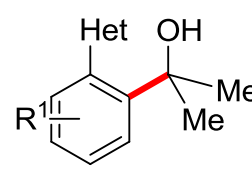

168<smiles>[R6]OCC(=O)O[R]</smiles>
201

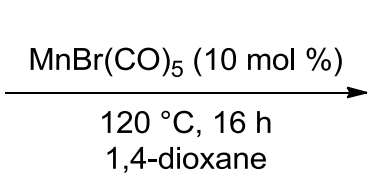

1,4-dioxane<smiles>[R]OC(=O)Cc1cc[R1]c1[CH]</smiles>
202<smiles>C=C(Cc1ccccc1-n1cccn1)C(C)=O</smiles>

202aa: $84 \%$<smiles>[R]c1ccc(CC(=C)C(C)=O)c(-n2cccn2)c1</smiles>

$\mathrm{R}=\mathrm{Me}(202 \mathrm{ca}): 72 \%$ $\mathrm{R}=\mathrm{Cl}(202 \mathrm{ma}): \quad 83 \%$

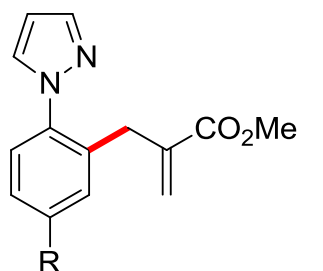

$\mathrm{R}=\mathrm{Me}$ (202ba): $85 \%$ $\mathrm{R}=\mathrm{CF}_{3}$ (202na): $57 \%$<smiles>C=C(Cc1ccccc1-n1nc(C)cc1C)C(C)OC</smiles>

202la: $73 \%$<smiles>C=C(Cc1ccccc1-n1cccn1)C(=O)O[C@H]1C[C@H](C)CC[C@H]1C(C)C</smiles>

202ab: $93 \%$

Scheme 3.7.5 Manganese(I)-catalyzed C-C allylation.

\subsubsection{Position-Selective Manganese(I)-Catalyzed C-C Activation Highlighting Unique Benefits over}

\section{C-H Activation}

\subsubsection{Position-Selective Manganese(I)-Catalyzed C-C Activation}

In order to overcome the limitations in the synthetic utility of the reaction, we here highlighted the unique $\mathrm{C}-\mathrm{C}$ activation strategy by achieving the position-selectivity for the synthesis of 1,2,3-tri-substituted arenes 204, 205 and 206 (Scheme 3.7.6). As we expected, these products could not be obtained by a $\mathrm{C}-\mathrm{H}$ activation process, instead the 1,2,5-tri-substituted isomers were formed by steric control in very low yields (Scheme 3.7.7). Both terminal and internal alkynes 8 afforded the 1,2,3-tri-substituted products in moderate to good yields (a). High yields of the position-selective allylic products 205aa and 205ab were obtained from the reaction with substrates 201a and 201b (b). The desired allylic alcohol product 206 also could be obtained in $46 \%$ yield with good diastereoselectivity (c). 
a)

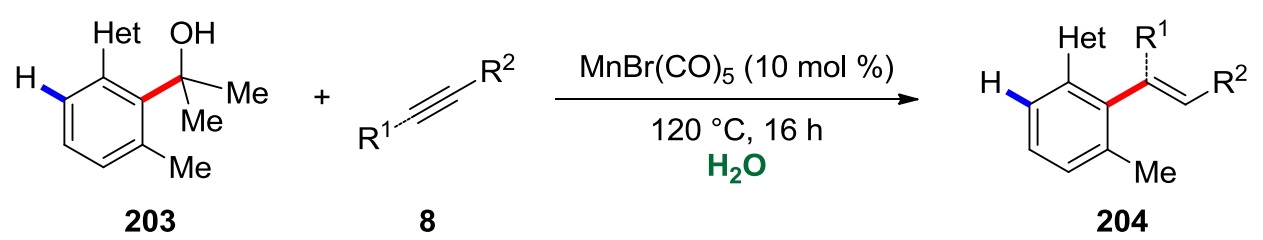<smiles>[R]C=Cc1c(C)cccc1-n1cccn1</smiles><smiles>Cc1cccc(-c2ccccn2)c1/C=C/c1ccccc1</smiles>

204bo: $55 \%$<smiles>Cc1cccc(-c2ccccn2)c1/C(=C/c1ccccc1)c1ccccc1</smiles>

204aa: $71 \%$

b)<smiles>Cc1cccc(-n2cccn2)c1C(C)(C)O</smiles>

203a

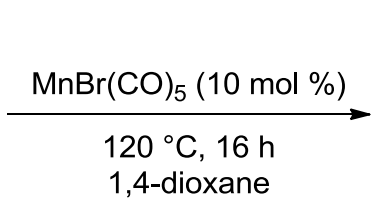

1,4-dioxane

201

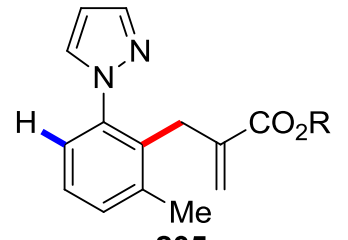

205<smiles></smiles>

205aa: $81 \%$<smiles>C=C(Cc1c(C)cccc1-n1cccn1)C(=O)O[C@H]1C[C@H](C)CC[C@H]1C(C)C</smiles>

205ab: $91 \%$

c)<smiles></smiles>

203

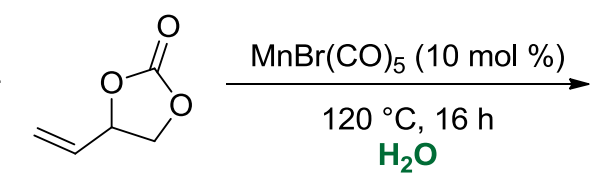

$110 a$

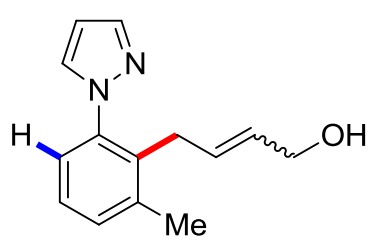

206: $46 \%(E / Z=6.2 / 1.0)$

Scheme3.7.6 Position-selective manganese(I)-catalyzed C-C activation.

\subsubsection{Manganese(I)-Catalyzed C-H Activation}

In contrast, the $\mathrm{C}-\mathrm{H}$ bond activation, which was performed in the presence of acetic acid, with phenylacetylene (80) and 4-vinyl-1,3-dioxolan-2-one (110a) furnished 1,2,5-tri-substituted products 74co, 74do, and 111ca in low yields without any observation of 1,2,3-tri-substituted products (Scheme 3.7.7). These results reflected the unique benefits of the $\mathrm{C}-\mathrm{C}$ activation strategy over the $\mathrm{C}-\mathrm{H}$ process. 


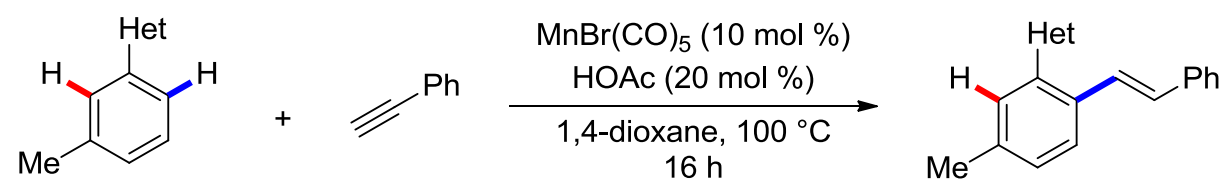

20

80

74
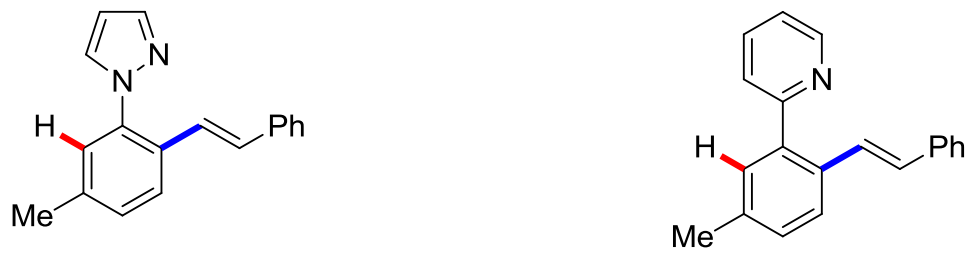

74co: $48 \%{ }^{[\mathrm{a}]}$ (sole product)

74do: $25 \%$ (sole product)<smiles>Cc1ccc(F)c(-n2cccn2)c1</smiles>

20c<smiles>C=CC1COC(=O)O1</smiles>

$110 a$

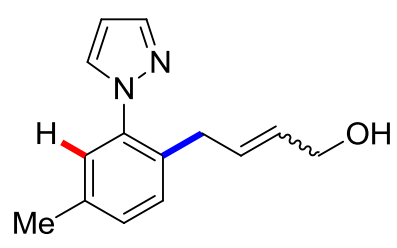

111ca: $37 \%$ (sole product)

Scheme 3.7.7 Manganese(I)-catalyzed C-H activation. ${ }^{[a]} 20 \mathrm{~mol} \%\left[\mathrm{MnBr}(\mathrm{CO})_{5}\right]$ was used.

\subsubsection{Key Mechanistic Findings}

\subsubsection{1 $\mathrm{C}-\mathrm{C}$ versus $\mathrm{C}-\mathrm{H}$ Activation Experiments}

In order to showcase the benefits of the position-selective manganese(I)-catalyzed C-C activation, a set of mechanistic study experiments was conducted (Scheme 3.7.8). Firstly, C-C hydroarylation with the labelled substrate $[D]_{1}-\mathbf{1 6 8 j}$ did not lead to $\mathrm{D} / \mathrm{H}$ scrambling, making a $\mathrm{C}-\mathrm{H}$ activation unlikely (a). When the labelled compound $[D]_{5}-\mathbf{2 0 b}$ was tested in the absence of substrate $\mathbf{1 1 f}$ under the optimized conditions, we could still get 92\% D incorporation at ortho-C-H position (b). When substrate 20a was reacted under the $\mathrm{C}-\mathrm{C}$ activation conditions, it failed to furnish the $\mathrm{C}-\mathrm{H}$ activation product 102jf (c). Lastly, an intermolecular competition experiment between substrate

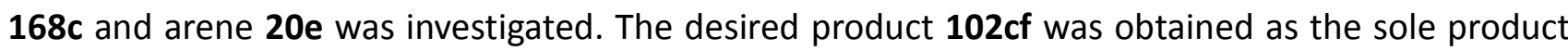
without any $\mathrm{C}-\mathrm{H}$ product formation (d), further demonstrating the unique manganese(I)-catalyzed $\mathrm{C}-\mathrm{C}$ activation process. 
a)

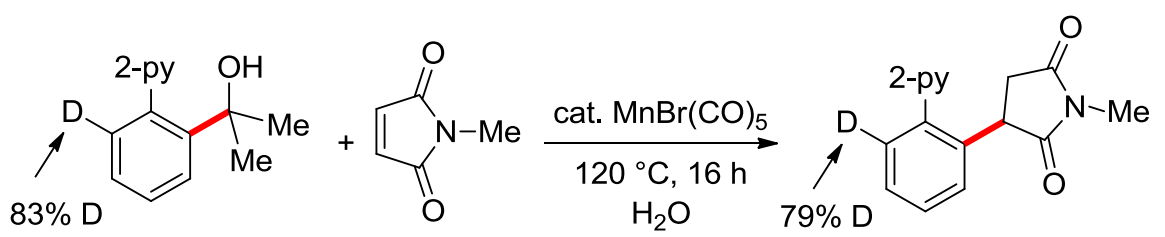

$[D]_{1}-168 j$

$11 f$

[D] $]_{n}-102$ jf: $90 \%$

b)

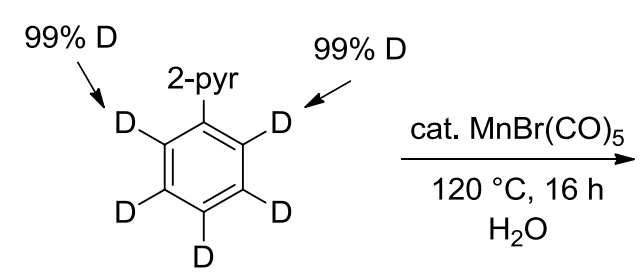

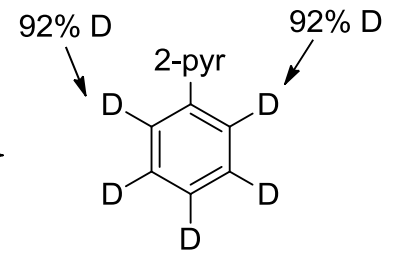

$[\mathrm{D}]_{5}-\mathbf{2 0 b}$

$[D]_{n}-20 b: 95 \%$

c)<smiles>[R9]c1ccccc1</smiles>

$20 a$<smiles>[M]N1C(=O)C=CC1=O</smiles>

$11 f$<smiles>O=C(O)OCCOC(=O)C(=O)O</smiles>
$\mathrm{H}_{2} \mathrm{O}$

d)<smiles>[R7]c1cc(CC)ccc1CC(C)(O)C(=O)O</smiles><smiles>[R7]c1ccccc1C1CC(=O)N(C)C1=O</smiles>

102jf: traces

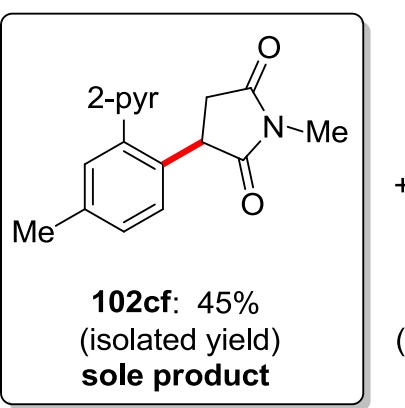<smiles>[R7]c1cccc(CC)c1</smiles>
(recovered: 86\%)

Scheme 3.7.8 $\mathrm{C}-\mathrm{C}$ versus $\mathrm{C}-\mathrm{H}$ activation experiments.

\subsubsection{H/D Exchange Experiments}

$\mathrm{H} / \mathrm{D}$ exchange experiments were also carried out to elucidate the mechanism of this $\mathrm{C}-\mathrm{C}$ activation (Scheme 3.7.9). Firstly, the reactions were conducted with substrate $168 \mathrm{a}$ and phenylacetylene 80 in the presence of isotopically labelled $\mathrm{D}_{2} \mathrm{O}$. A large amount of deuterium incorporation at both $\beta$-positions of the products $[D]_{n}-102 a f$ and $[D]_{n}-74 c o$ was observed (a and $b$ ). Moreover, the reactions of substrate $[D]_{1}-80$ were conducted in different solvents and no $H / D$ scrambling at $\beta$-position was observed in water, but a deuterium incorporation of $37 \%$ in 1,4-dioxane was determined ( $c$ and d). Importantly, when substrate $[D]_{1}-168 c$ reacted with phenylacetylene $(80)$ under the optimized conditions, no deuterium was detected in product $\mathbf{7 4 c o}$ (e). These findings clearly showed that the proto-demetalated step is caused by the vast excess of water. 
a)<smiles>CC(=O)c1ccccc1C(C)(C)O</smiles>

$11 f$

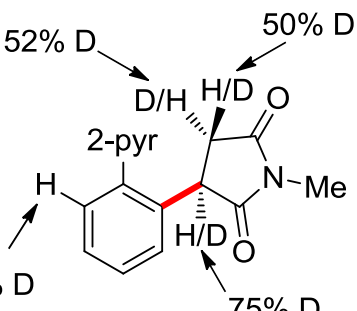

$168 a$

$[D]_{n}-102$ af: $61 \%$

b)<smiles>[Z6]c1cc(C)ccc1C(C)(O)c1ccc(C(C)(C)C)cc1</smiles><smiles>[R6]c1cc(C)ccc1C(=CC=[18O])c1ccccc1</smiles>

c)

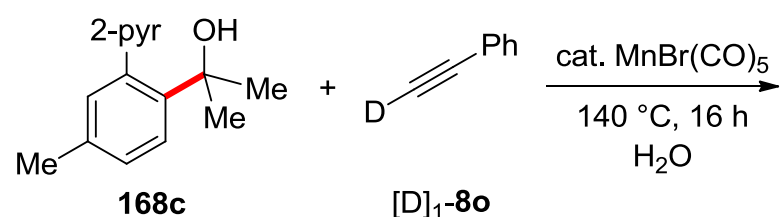

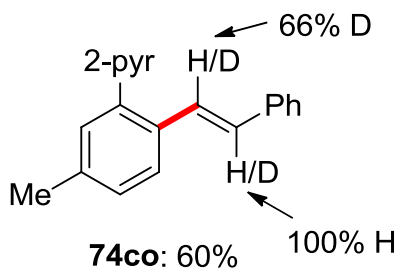

d)

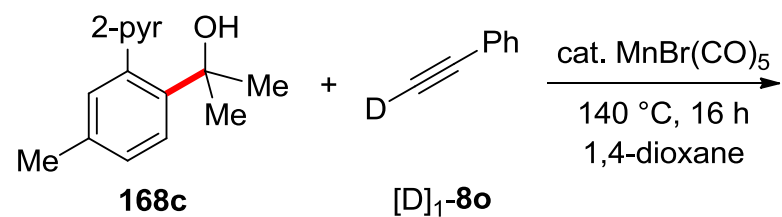

e)<smiles>[R6]c1cc(C)ccc1C(C)(C)c1ccc(Br)cc1</smiles>

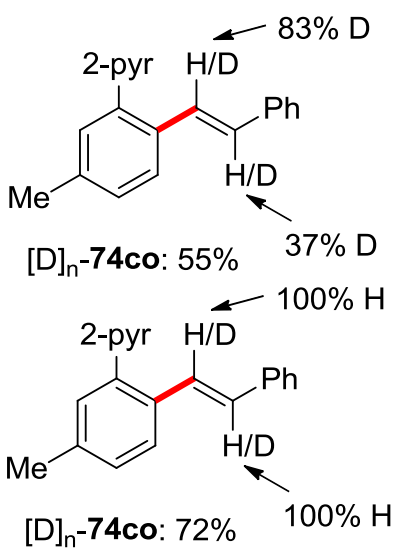

Scheme 3.7.9 H/D exchange experiments.

\subsubsection{Stoichiometric C-C Cleavage by X-ray and NMR Spectroscopy}

Thus, the stoichiometric $\mathrm{C}-\mathrm{C}$ activation of compound $168 \mathrm{a}$ by $\mathrm{BnMn}(\mathrm{CO})_{5}$ provided the intermediate 208, which was characterized by X-ray diffraction analysis. Further ${ }^{1} \mathrm{H} N M R$ experiments of the stoichiometric reaction provided strong evidence for the generation of complex 208 by the formation of equimolar amounts of toluene and acetone (Scheme 3.7.10).

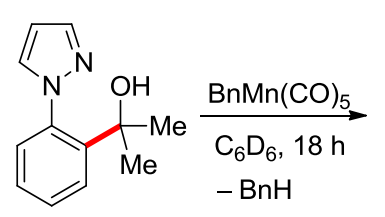

$168 \mathrm{a}$

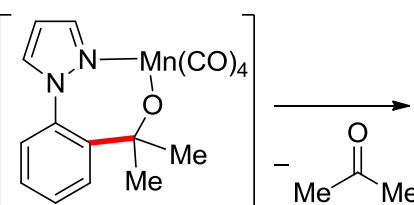

207<smiles>O=C(O)c1ccccc1-n1cccn1</smiles>

208

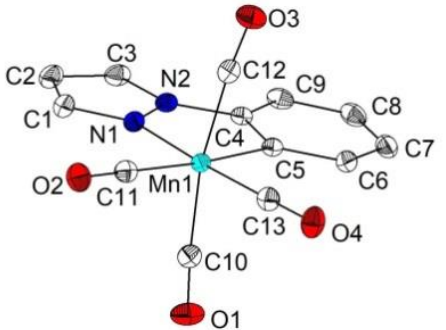




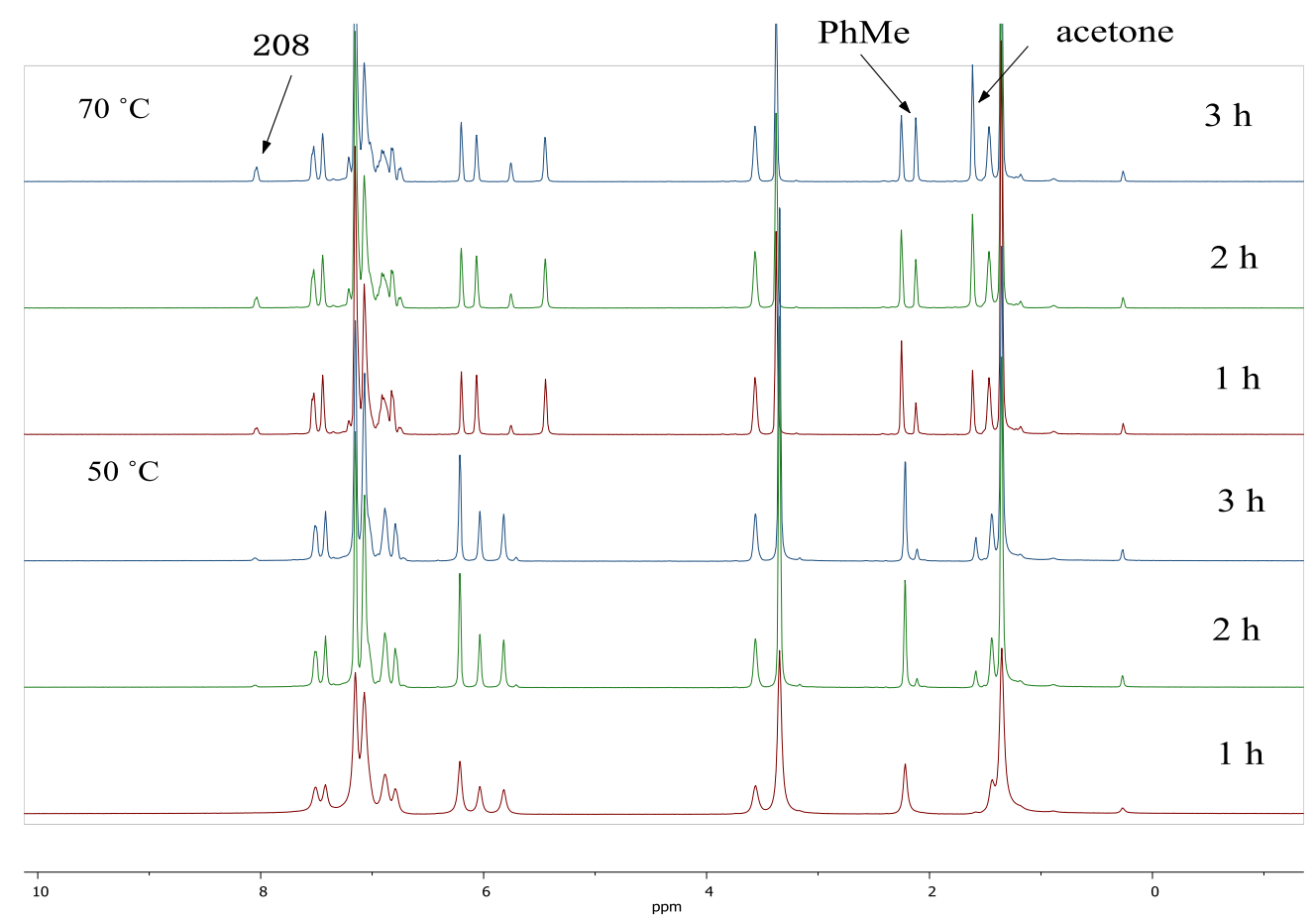

Scheme 3.7.10 Stoichiometric $\mathrm{C}-\mathrm{C}$ cleavage detected by $\mathrm{X}$-ray and ${ }^{1} \mathrm{H}$ NMR spectroscopy.

\subsubsection{Detection and Quantification of $\mathrm{CO}_{2}$}

Furthermore, in order to detect and quantify the generation of $\mathrm{CO}_{2}$. A volumetric analysis was perfomed (Scheme 3.7.11). The observed formation of $\mathrm{CO}_{2}$ is in good agreement with the results obtained from the $\mathrm{C}-\mathrm{C}$ allylation reaction.<smiles>COc1ccc(-n2cccn2)c(C(O)[PH2+]c2ccccc2)c1</smiles>

$168 \mathrm{~d}$<smiles>C=CC1COC(=O)O1</smiles>

$110 a$

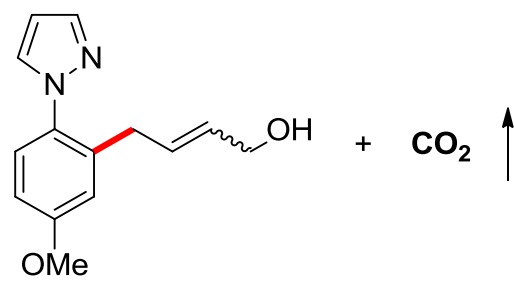

111da: $66 \%$ 


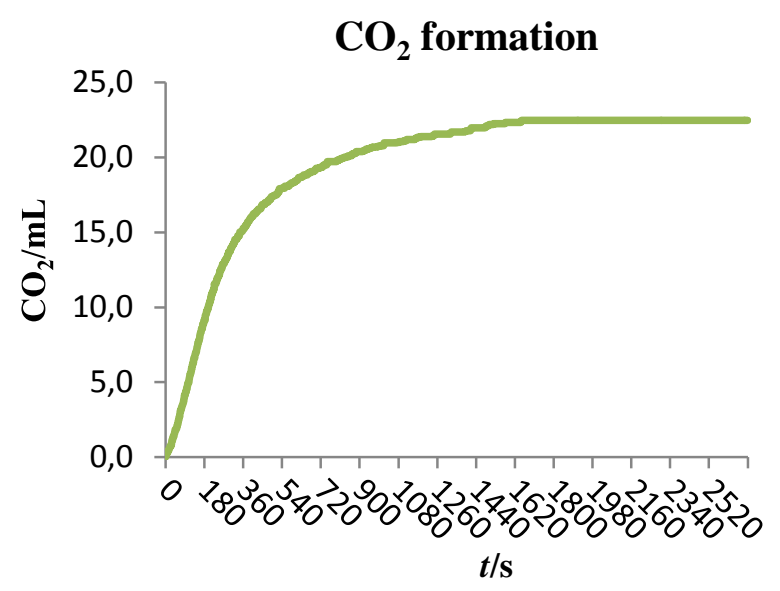

Scheme 3.7.11 Detection and quantification of $\mathrm{CO}_{2}$.

\subsubsection{Kinetic Reaction Orders}

The kinetic order of the reaction with respect to the concentration of 2-[2-(1H-pyrazol-1-yl)phenyl]propan-2-ol (168a) as well as the manganese catalyst showed a first order dependence, indicating that the substrate $168 \mathrm{a}$ and the catalyst $\mathrm{MnBr}(\mathrm{CO})_{5}$ both are part of the turnover-limiting step of the catalytic cycle (Scheme 3.7.12a and b). In sharp contrast, a zero order dependence on the concentration of the substrate $\mathbf{1 1 f}$ was observed, providing strong support for a rate-determining $\mathrm{C}-\mathrm{C}$ metalation (c). These results are also in good agreement with detailed DFT calculations performed by M.Sc. Rogge. ${ }^{[154]}$ 


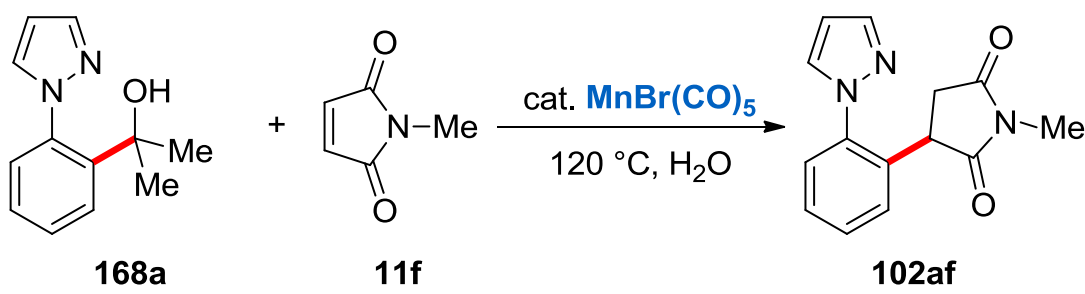

(a) order in 168a

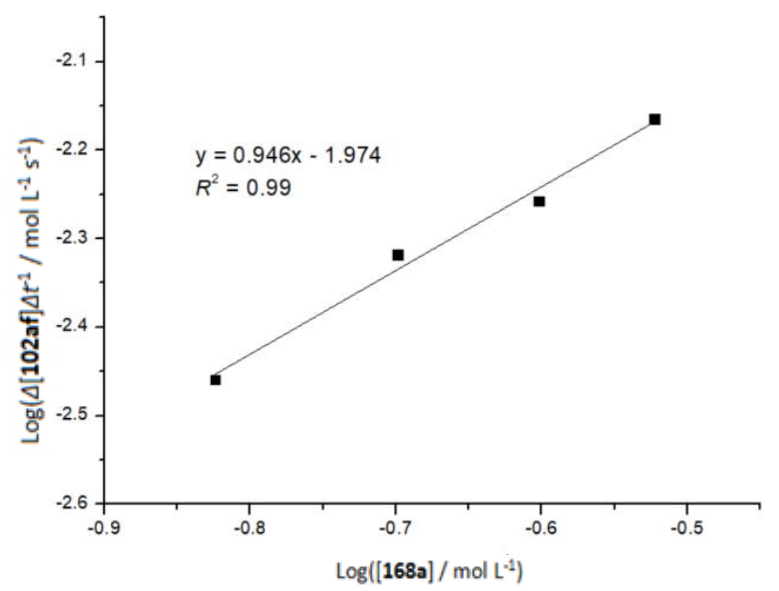

(b) order in $\mathrm{MnBr}(\mathrm{CO})_{5}$

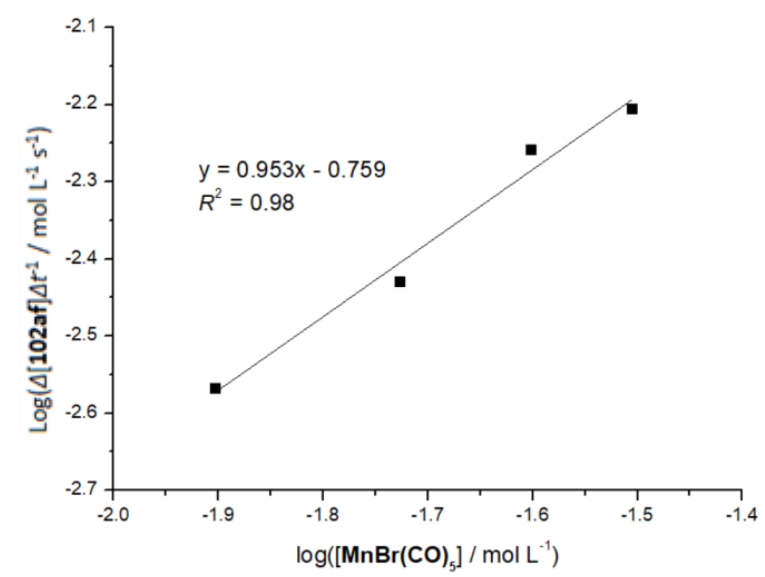

(c) order in $11 f$

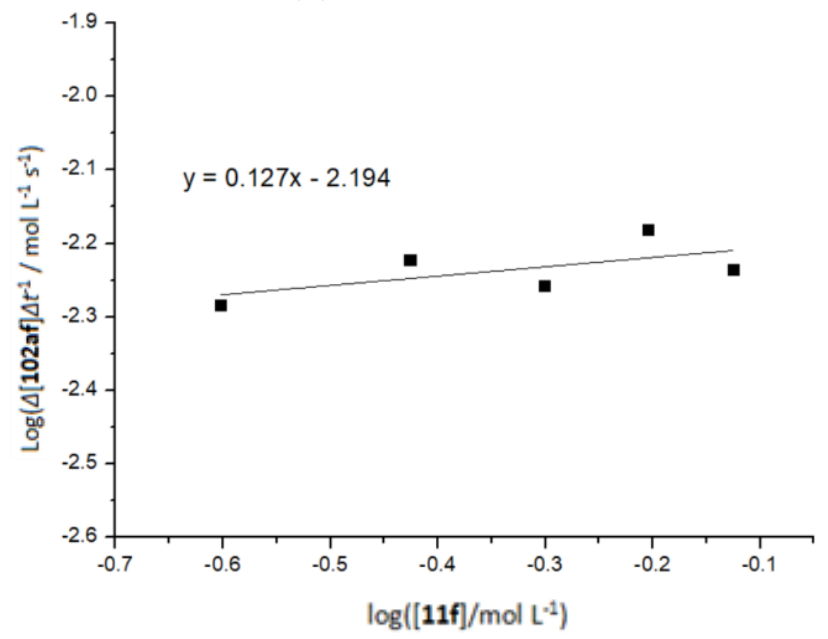

Scheme 3.7.12 Kinetic order of coumpounds 168a, 11f and manganese catalyst.

\subsubsection{Traceless Removal of the Pyrazole Group}

Finally, the synthetic utility of this C-C activation strategy was investigated by the traceless removal of the pyrazole group, delivering the corresponding anilines $\mathbf{2 0 9}$ in moderate to good yields, which could be easily transformed into other useful compounds (Scheme 3.7.13). 
<smiles>[R]C=C([R1])c1ccc(C)cc1-n1cccn1</smiles>

74

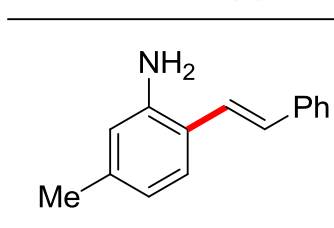

209a: $72 \%$
1) $\mathrm{TMSCl}$, TMPMgCl$\cdot \mathrm{LiCl}$ $36 \mathrm{~h}, 0^{\circ} \mathrm{C}$

2) aq. $\mathrm{HCl}, \mathrm{MeOH}$ $40^{\circ} \mathrm{C}, 90 \mathrm{~min}$<smiles>[R]C=C([R1])c1ccc(C)cc1N</smiles>

209<smiles>Cc1ccc(/C(=C/c2ccccc2)c2ccccc2)c(N)c1</smiles>

209c: $59 \%$

Scheme 3.7.13 Traceless removal of the pyrazole group. 


\section{Summary and Outlook}

Metal-catalyzed $\mathrm{C}-\mathrm{H}$ and $\mathrm{C}-\mathrm{C}$ functionalizations have become an increasingly viable approach, which allows the direct formation of $\mathrm{C}-\mathrm{C}$ and $\mathrm{C}-$ heteroatom bonds in an atom- and step-economical manner. However, the significant accomplishments in this field have heavily relied on the use of precious transition metals, such as rhodium, palladium, ruthenium, and iridium, over the last few decades. The high cost and potential toxicity of these metals limit the applications in pharmaceutical and fine chemical industries. Therefore, developing efficient and economic $\mathrm{C}-\mathrm{H}$ and C-C functionalization by inexpensive and Earth-abundant metals is highly desirable. In this thesis, we summarize our recent achievements in direct $\mathrm{C}-\mathrm{H}$ and $\mathrm{C}-\mathrm{C}$ bond transformations by cobalt(III)and manganese(I)-catalysis.

In the first project, a cobalt(III)-catalyzed $\mathrm{C}-\mathrm{H} / \mathrm{N}-\mathrm{O}$ functionalization was achieved for the synthesis of substituted isoquinolines derivatives (Scheme 3.8.1). Notable features of this developed annulation reaction were a wide substrate scope applicable and tolerance of various functional groups. The $\mathrm{N}-\mathrm{O}$ bond of the oxime was successfully utilized as the internal oxidant in this process. Importantly, the reaction was not limited to the symmetrical alkynes, but also unsymmetrical and terminal alkynes could be employed in the reaction to afford the isoquinolines in good yields with high regio-selectivities. In many cases, the annulation products were obtained high yields within only 15 min. The mechanistic findings, including H/D exchange, competition experiments and KIE studies, revealed a reversible and facile BIES-type $\mathrm{C}-\mathrm{H}$ metalation pathway was involved.

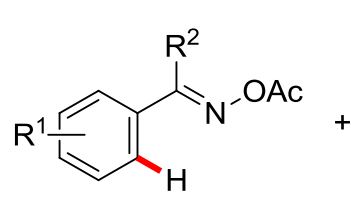

158

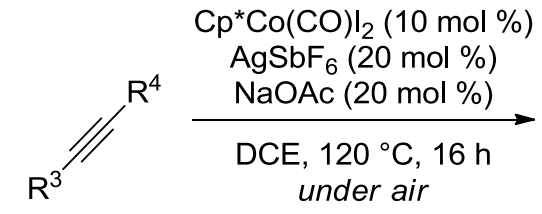

8

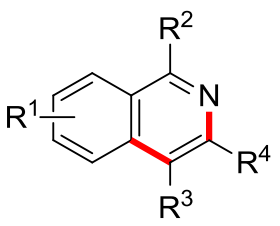

119

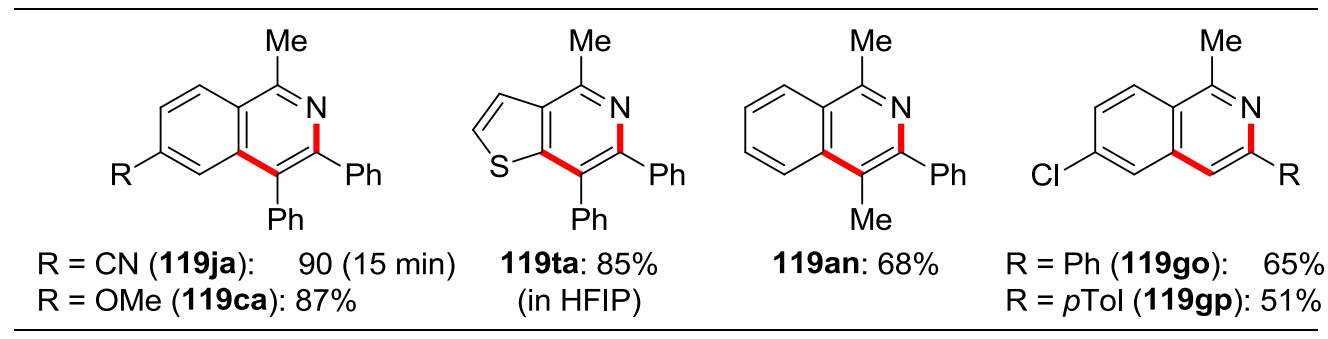

Scheme 3.8.1 Cobalt(III)-catalyzed $\mathrm{C}-\mathrm{H} / \mathrm{N}-\mathrm{O}$ functionalization for the synthesis of isoquinolines. 
In the second project, a good site- and regio-selective cobalt(III)-catalyzed $\mathrm{C}-\mathrm{H}$ annulation of various nitrones approached the novel and useful indole synthesis (Scheme 3.8.2). The versatile cobalt(III) catalyst proved to be particularly effective for challenging unsymmetrically substituted alkynes, when employing a catalytic amounts of Piv-Leu-OH as ligand, delivering unprotected indoles in good yields with excellent levels of regioselectivity. Detailed mechanistic studies, such as H/D exchange and KIE experiments, provided strong support for a rate-determining $\mathrm{C}-\mathrm{H}$ metalation step.

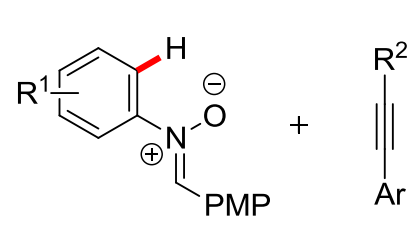

159

8

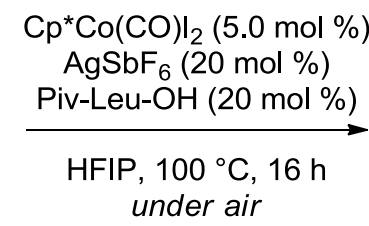

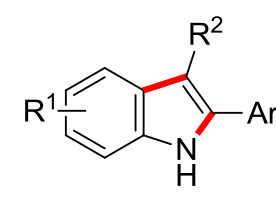

160

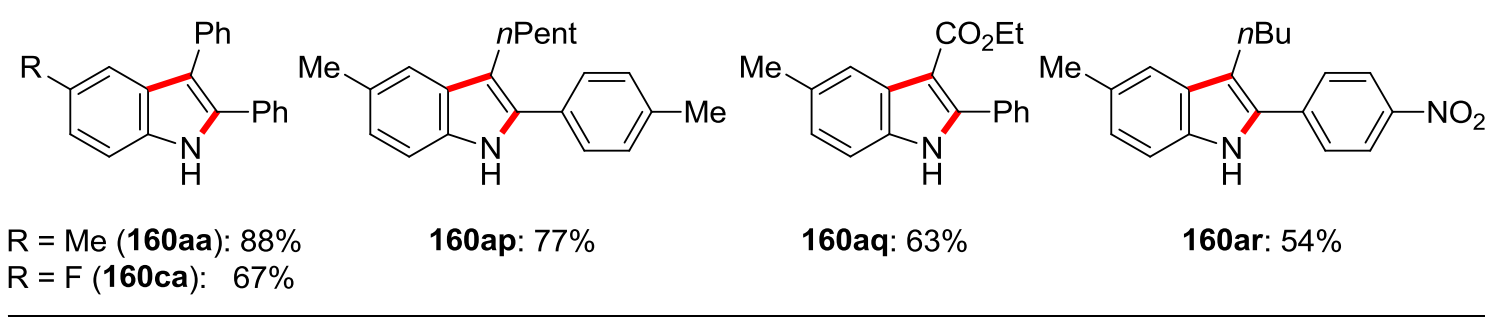

Scheme 3.8.2 Cobalt(III)-catalyzed $\mathrm{C}-\mathrm{H} / \mathrm{N}-\mathrm{O}$ functionalization for the synthesis of indoles.

In the third project, we developed the first cobalt(III)-catalyzed position-selective $\mathrm{C}-\mathrm{H}$ functionalization, which fully tolerated strongly coordinating heterocycles, such as pyridines, pyrimidines, and pyrazoles (Scheme 3.8.3). This reaction was showed a wide substrate scope with various functional groups tolerance, such as chloro, fluoro, ester, ketone, nitro, and thiophene. The preliminary mechanistic studies, especially the H/D exchange experiments, indicated that the positional selectivity of this $\mathrm{C}-\mathrm{H}$ amination is determined in the $\mathrm{C}-\mathrm{N}$ bond forming step. 


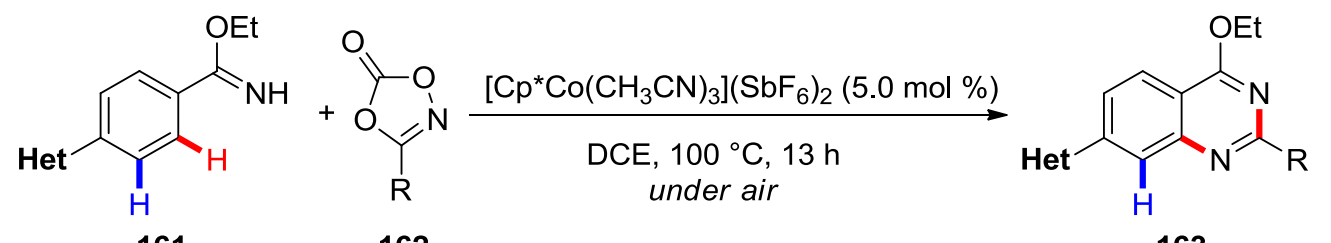<smiles>[R]c1ccc(-c2nc(OCC)c3ccc(-n4nccc4C)cc3n2)cc1</smiles>

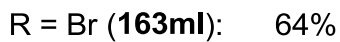
$\mathrm{R}=\mathrm{NO}_{2}(163 \mathrm{mk}): 58 \%$<smiles>[R]c1ccc(-c2nc(OCC)c3ccc(-c4ncccn4)cc3n2)cc1</smiles>

$\mathrm{R}=\mathrm{H}($ (163na): $73 \%$ $\mathrm{R}=\mathrm{Cl}(\mathbf{1 6 3 n j}): 71 \%$<smiles>CCOc1nc(-c2ccsc2)nc2cc(-c3ccccn3)ccc12</smiles>

163oe: $51 \%$

Scheme 3.8.3 Cobalt(III)-catalyzed position-selective $\mathrm{C}-\mathrm{H}$ functionalization.

In the fourth project, a cobalt(III)-catalyzed domino $\mathrm{C}-\mathrm{H} / \mathrm{N}-\mathrm{H}$ allylation reaction of aryl imidates with dioxolanones was accomplished (Scheme 3.8.4). The reaction was performed under mild reaction conditions with water and generated $\mathrm{CO}_{2}$ as the only byproducts. This step-economic method using an earth-abundant cobalt catalyst provided expedient access to decorated vinyl 3,4-dihydroisoquinolines, which could not be obtained using a rhodium catalysis. ${ }^{[181]}$ Aryl-substituted imidates bearing various electron-donating and electron-withdrawing groups are compatible with the reaction conditions, delivering the cyclization products 164 in good yields with high levels of regio-selectivity. Furthermore, the obtained product $\mathbf{1 6 4}$ could be easily transformed to dihydroisoquinolone 191 and acetylated isoquinoline 192.

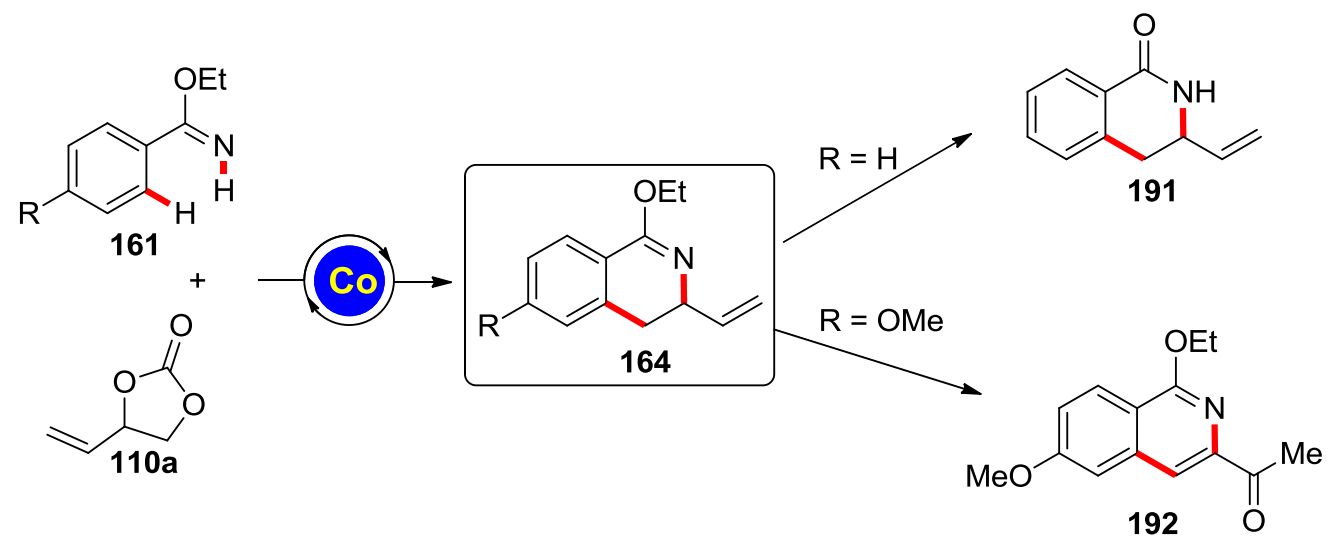

Scheme 3.8.4 Cobalt(III)-catalyzed domino $\mathrm{C}-\mathrm{H} / \mathrm{N}-\mathrm{H}$ allylation.

In the fifth project, a manganese(I)-catalyzed decarboxylative $\mathrm{C}-\mathrm{H} / \mathrm{N}-\mathrm{O}$ allylation in water was 
developed (Scheme 3.8.5). When indole substrates were employed, the reaction features a broad substrate scope and good functional group tolerance. This organometallic $\mathrm{C}-\mathrm{H}$ activation was also tolerant to air and water. The organomanganese intermediate 193 could be isolated and showed high catalytic efficiency in both catalytic and stoichiometric experiments. The detailed mechanistic findings including competition experiments, H/D exchange and KIE studies strongly support a facile and reversible $\mathrm{C}-\mathrm{H}$ metalation step. At last, this versatile $\mathrm{C}-\mathrm{H}$ allylation was also successfully applied to the amino acids and aryl ketimines, delivering the allylation products in good yields with high levels of chemo- and regio-selectivities.

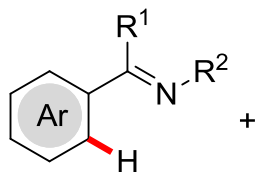

34,41<smiles>[R]C1OC(=O)OC1C=C</smiles>

110

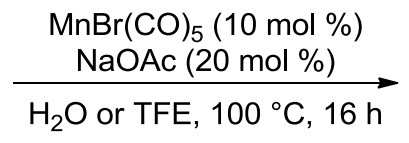

$\mathrm{H}_{2} \mathrm{O}$ or TFE, $100^{\circ} \mathrm{C}, 16 \mathrm{~h}$

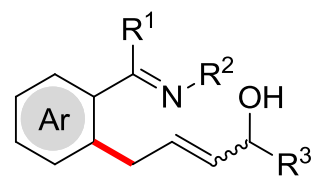

111,165

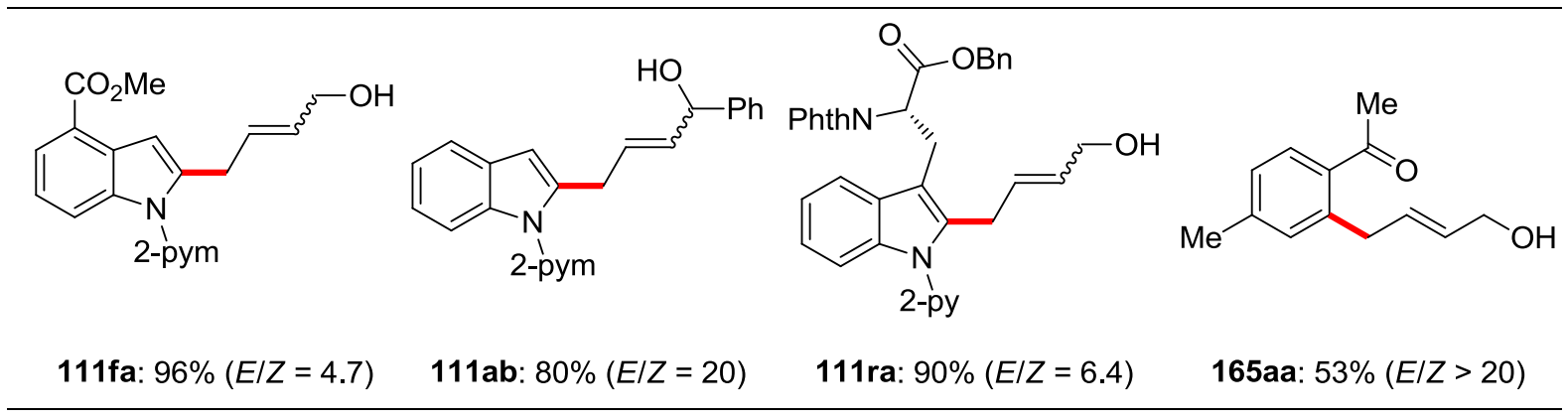

Scheme 3.8.5 Manganese(I)-catalyzed decarboxylative $\mathrm{C}-\mathrm{H} / \mathrm{N}-\mathrm{O}$ functionalization.

In the sixth project, a synergistic Brønsted acid/manganese(I)-catalyzed $\mathrm{C}-\mathrm{H}$ hydroarylation with high chemo- and regio-selectivities in continuous flow was accomplished (Scheme 3.8.6). With the assistance of carboxylic acid, the undesired $\beta-O$ elimination could be avoided and provided a robust access to allylic carbonates in high yields with excellent chemo- and regio-selectivities. Moreover, this catalytic system tolerated a variety of valuable functional groups, including chloro, bromo, iodo, ether, carboxylic acid, and ester. The first manganese(I)-catalyzed $\mathrm{C}-\mathrm{H}$ activation in continuous flow could be conducted within only 20 minutes under an atmosphere of air. Mechanistic findings indicated that a fast organometallic $\mathrm{C}-\mathrm{H}$ metalation step, as well as an intramolecular proton transfer were involved. ${ }^{[152]}$ Furthermore, late-stage diversification of the allylic carbonates $167 \mathrm{ba}$ could be achieved, giving rise to a plethora of valuable building blocks. 


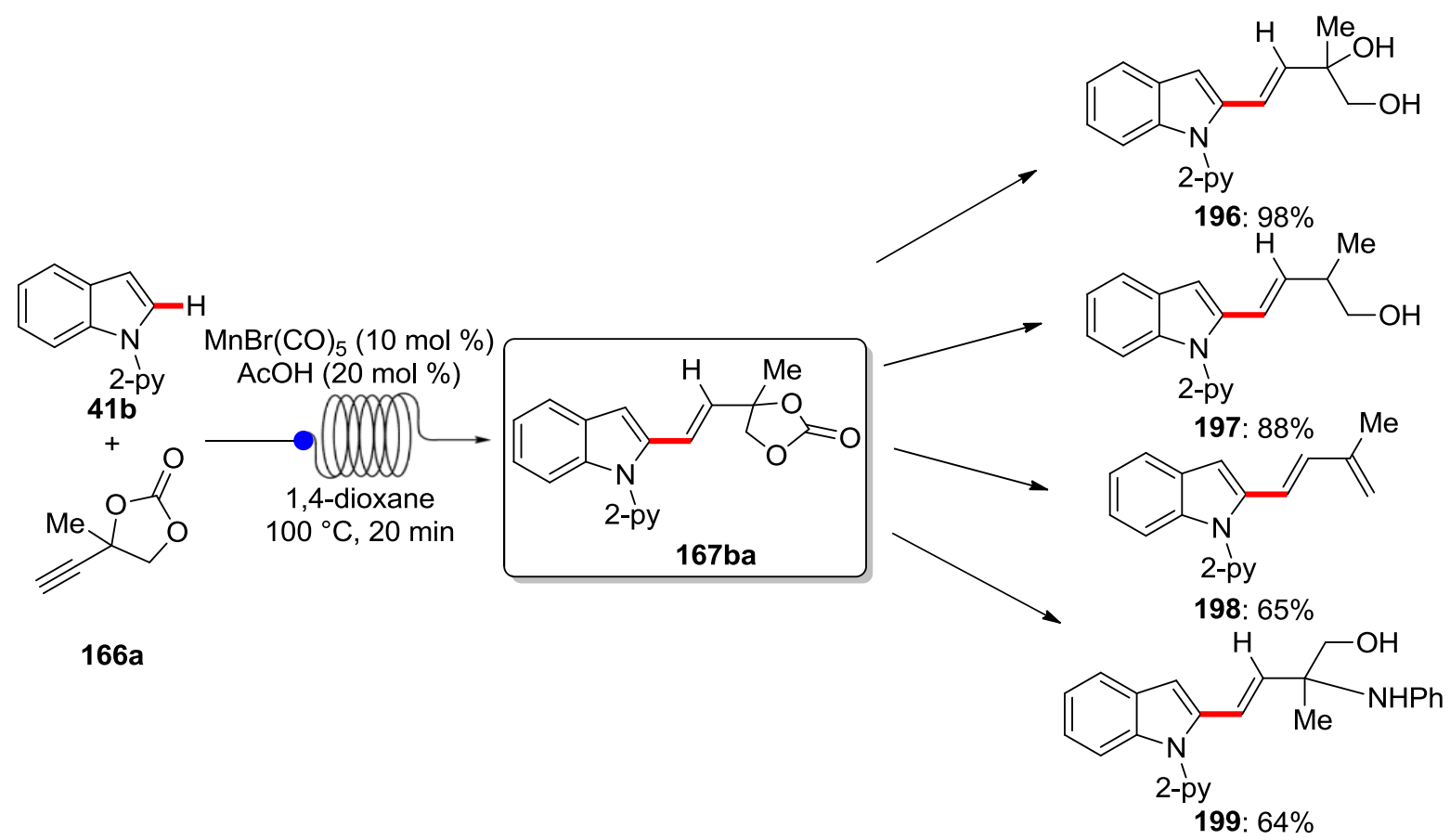

Scheme 3.8.6 Synergistic manganese(I)-catalyzed C-H hydroarylation in continuous flow.

In the last project, we have developed versatile $\mathrm{C}-\mathrm{C}$ activations in water by inexpensive and Earth-abundant manganese catalysis (Scheme 3.8.7). The organometallic C-C functionalizations, including $\mathrm{C}-\mathrm{C}$ allylations, $\mathrm{C}-\mathrm{C}$ alkenylations, and $\mathrm{C}-\mathrm{C}$ alkylations, occurred efficiently in environmentally-benign solvent with excellent levels of chemo-, regio-, and position-selectivities. The unique manganese(I)-catalyzed C-C activation was characterized by a broad substrate scopes, functional group tolerance and position-selective synthesis. Competition and H/D exchange experiments clearly showed that the $\mathrm{C}-\mathrm{C}$ cleavage is much faster than the $\mathrm{C}-\mathrm{H}$ activation under the optimal condition. This result was showcased by the synthesis of 1,2,3-tri-substituted arenes, which could not be achieved by $\mathrm{C}-\mathrm{H}$ activation. Importantly, the pyrazole group could be easily removed, furnishing the synthetically useful anilines 209. 


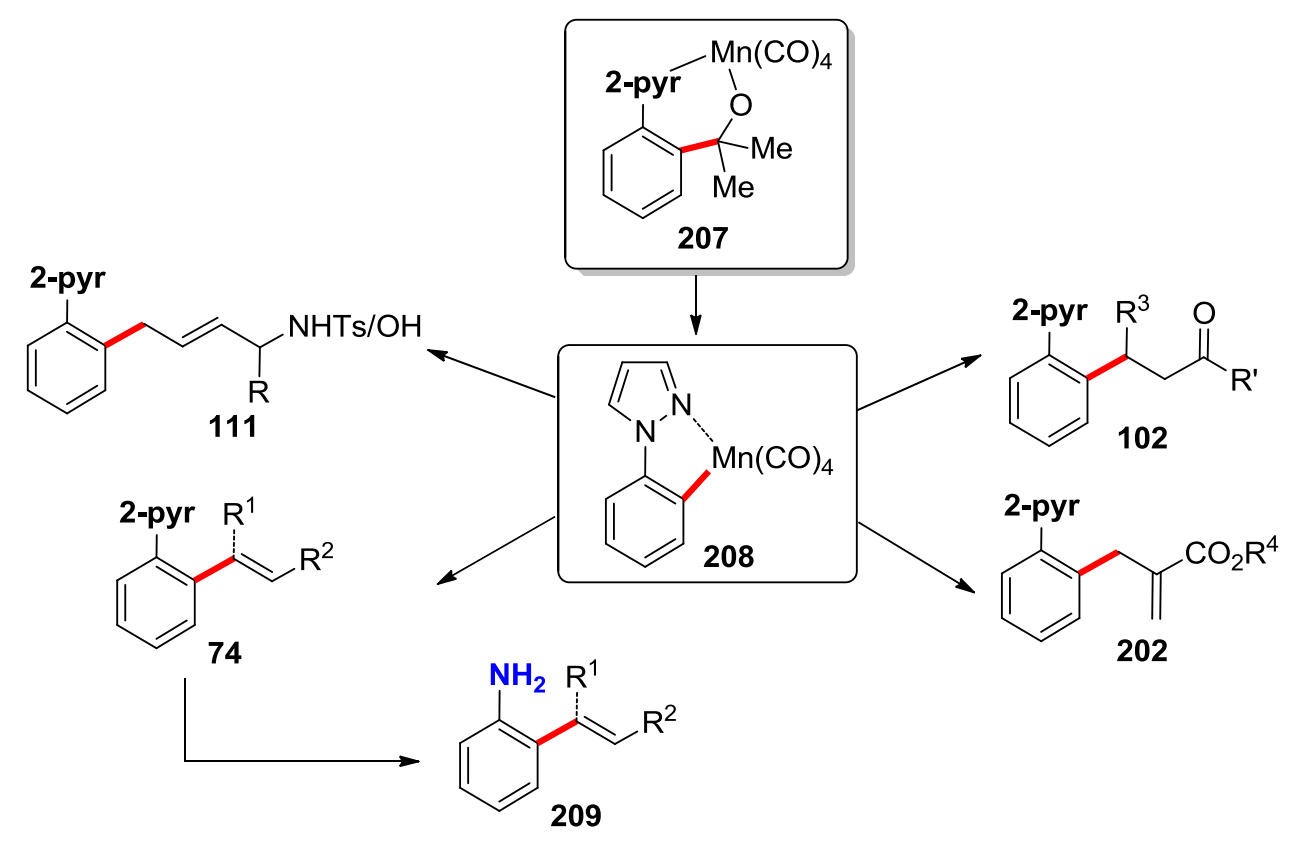

Scheme 3.8.7 Manganese(I)-catalyzed C-C functionalizations in water. 


\section{Experimental Section}

\subsection{General Remarks}

The catalysis in water or under an atmosphere of air use the sealed tubes or Schlenk tubes. Unless otherwise noted, other reactions were performed under $\mathrm{N}_{2}$ atmosphere using pre-dried glassware and standard Schlenk techniques.

If not otherwise noted, yields refer to isolated compounds, estimated to be $>95 \%$ pure as determined by ${ }^{1} \mathrm{H}-\mathrm{NMR}$.

\section{Vacuum}

The following pressures were measured on the used vacuum pump and were not corrected: membrane pump vacuum (MPV): 0.5 mbar, oil pump vacuum (OPV): 0.1 mbar.

\section{Melting Points (M.p.)}

Melting points were measured using a Stuart ${ }^{\circledR}$ Melting Point Apparatus SMP3 from BARLOWORLD SCIENTIFIC. The reported values are uncorrected.

$\mathrm{CO}_{2}$

The $\mathrm{CO}_{2}$ was detected and quantified by a GM5-KONT instrument from MesSen Nord.

\section{Chromatography}

Analytical thin layer chromatography (TLC) was performed on $0.25 \mathrm{~mm}$ silica gel 60F-plates (MACHEREY-NAGEL) with $254 \mathrm{~nm}$ fluorescent indicator from MERCK. Plates were visualized under UV-light or developed by treatment with a $\mathrm{KMnO}_{4}$ solution followed by careful applying a heat gun. Chromatographic purification of products was accomplished by flash column chromatography on MERCK silica gel, grade $60(0.040-0.063 \mathrm{~mm}$ and $0.063-0.200 \mathrm{~mm})$. 


\section{Gas Chromatograpgy (GC)}

The conversion of the reactions was monitored applying coupled gas chromatography/mass spectrometry using G1760C GCDplus with mass detector HP 5971, 5890 Series // with mass detector HP 5972 from HEWLETT-PACKARD and 7890A GC-System with mass detector 5975C (Triplex-Axis-Detector) from AGILENT TECHNOLOGIES equipped with HP-5MS columns (30 m $\times 0.25$ $\mathrm{mm} \times 0.25 \mathrm{~m}$ ) were used.

\section{Gel permeation chromatography (GPC)}

GPC purifications were performed on a JAI system (JAI-LC-9260 /I NEXT) equipped with two sequential columns (JAIGEL-2HR, gradient rate: 5.000; JAIGEL-2.5HR, gradient rate: 20.000; internal diameter $=20 \mathrm{~mm}$; length $=600 \mathrm{~mm}$; Flush rate $=10.0 \mathrm{~mL} / \mathrm{min}$ and chloroform (HPLC-quality with $0.6 \%$ ethanol as stabilizer) was used as the eluent.

\section{Infrared Spectroscopy}

Infrared spectra were recorded at a BRUKER Alpha-P ATR FT-IR spectrometer. Liquid samples were measured as a film, solid samples neat. The analysis of the spectra was carried out using the software from BRUKER OPUS 6. The absorption is given in wave numbers $\left(\mathrm{cm}^{-1}\right)$ and the spectra were recorded in the range of $4000-400 \mathrm{~cm}^{-1}$. In situ-IR studies were performed on METTLER TOLEDO ReactIR ${ }^{\text {TM }} 15$ with an iC IR 4.3 software.

\section{Mass Spectrometry}

Electron ionization (EI) and EI high resolution mass spectra (HR-MS) were measured on a time-of-flight mass spectrometer AccuTOF from JOEL. Electrospray ionization (ESI) mass spectra were recorded on an Ion-Trap mass spectrometer LCQ from FINNIGAN, a quadrupole time-of-flight maXis from BRUKER DALTONIC or on a time-of-flight mass spectrometer microTOF from BRUKER DALTONIC. ESI-HRMS spectra were recorded on a BRUKER Apex IV or a BRUKER Daltonic 7T, fourier transform ion cyclotron resonance (FTICR) mass spectrometer. The ratios of mass to charge $(\mathrm{m} / \mathrm{z})$ are indicated and intensities relative to the base peak $(I=100)$ are written in parentheses. 


\section{Nuclear Magnetic Resonance Spectroscopy (NMR)}

Nuclear magnetic resonance (NMR) spectra were recorded on VARIAN Inova 500, 600, VARIAN Mercury 300, VX 300, VARIAN Avance 300, VARIAN VNMRS 300 and BRUKER Avance III 300, 400 and HD 500 spectrometers. All chemical shifts are given as $\delta$-values in ppm relative to the residual proton peak of the deuterated solvent or its carbon atom, respectively. ${ }^{1} \mathrm{H}$ and ${ }^{13} \mathrm{C} N M R$ spectra were referenced using the residual proton or solvent carbon peak (see table), respectively. ${ }^{13} \mathrm{C}$ and ${ }^{19} \mathrm{~F}$ NMR were measured as proton-decoupled spectra.

\begin{tabular}{ccc} 
& ${ }^{1} \mathrm{H}-\mathrm{NMR}$ & ${ }^{13} \mathrm{C}-\mathrm{NMR}$ \\
\hline $\mathrm{CDCl}_{3}$ & 7.26 & 77.16 \\
{$[\mathrm{D}]_{6}-\mathrm{DMSO}$} & 2.50 & 39.52
\end{tabular}

The observed resonance-multiplicities were described by the following abbreviations: $s$ (singlet), $d$ (doublet), t (triplet), q (quartet), hept (heptet), m (multiplet) or analogous representations. The coupling constants $J$ are reported in Hertz $(\mathrm{Hz})$. Analysis of the recorded spectra was carried out with MestReNova 10 software.

\section{Solvents}

All solvents for reactions involving moisture-sensitive reagents were dried, distilled and stored under an inert atmosphere ( $\operatorname{Ar}$ or $\mathrm{N}_{2}$ ) according to the following standard procedures.

1,2-Dichloroethane (DCE), $N, N$-dimethylformamide (DMF) and $\boldsymbol{\gamma}$-Valerolactone (GVL) were dried over $\mathrm{CaH}_{2}$ for $8 \mathrm{~h}$, degassed and distilled under reduced pressure.

1,1,1,3,3,3-Hexafluoropropan-2-ol (HFIP) and Chlorobenzene (PhCl) were distilled from $3 \AA$ molecular sieves.

Methanol (MeOH) was stirred over magnesium turnings at $65{ }^{\circ} \mathrm{C}$ for $3 \mathrm{~h}$ prior to distillation from $\mathrm{Mg}(\mathrm{OMe})_{2}$.

Toluene (PhMe), Tetrahydrofuran (THF), Dichloromethane (DCM) and ethyl ether (Et ${ }_{2} \mathrm{O}$ ) were purified using a solvent purification system (SPS-800) from M. BRAUN.

Acetonitrile (MeCN) was dried over $\mathrm{P}_{2} \mathrm{O}_{5}$ for $24 \mathrm{~h}$ degassed and distilled under reduced pressure.

2,2,2-Trifluoroethanol (TFE) was stirred over $\mathrm{CaSO}_{4}$ and distilled under reduced pressure.

Water $\left(\mathbf{H}_{\mathbf{2}} \mathbf{O}\right)$ was degassed by repeated Freeze-Pump-Thaw degassing procedure. 
1,4-Dioxane and $\mathrm{Di}$-(n-butyl)-ether $\left(n \mathrm{Bu}_{2} \mathrm{O}\right)$ were distilled from sodium benzophenone ketyl.

\section{Reagents}

Chemicals obtained from commercial sources with purity above $95 \%$ were used without further purification. The following compounds are known and were synthesized according to previously described methods:

$\mathrm{Cp}^{*} \mathrm{Col}_{2}(\mathrm{CO}),{ }^{[56]}$ O-acyloximes $\mathbf{1 5 8 a - 1 5 8 n},{ }^{[182]}[\mathrm{D}]_{1}-\mathbf{1 5 8 a},{ }^{[113]}[\mathrm{D}]_{5}-\mathbf{1 5 8 a}$, alkynes $\mathbf{8 b - 8 \mathbf { j } ^ { [ 1 8 3 ] }}$ $(E)-1-\left\{2-\left[(E)-1,2-\right.\right.$ diphenylvinyl] phenyl\}ethanone $O$-acetyl oxime $158 \mathbf{u}^{[184]}$, nitrones $159{ }^{[185]}$ aryl alkyl alkynes 8p-8r. ${ }^{[186]} \quad\left[\mathrm{Cp}^{*} \mathrm{Co}\left(\mathrm{CH}_{3} \mathrm{CN}\right)_{3}\right]\left(\mathrm{PF}_{6}\right)_{2}, \quad\left[\mathrm{Cp}^{*} \mathrm{Co}\left(\mathrm{CH}_{3} \mathrm{CN}\right)_{3}\right]\left(\mathrm{BF}_{4}\right)_{2}$, and $\left[\mathrm{Cp} * \mathrm{Co}(\mathrm{MeCN})_{3}\right]\left[\mathrm{SbF}_{6}\right]_{2},{ }^{[136 a]}$ Benzimidates $161 \mathrm{a}-161 \mathbf{n},{ }^{[187]}$ dioxazolones $\mathbf{1 6 2 a - 1 6 2 k}{ }^{[188]}$ substrates 41a $,{ }^{[57,189]} 41 b-41 e,{ }^{[190]} 20 a,{ }^{[191]} 110 b-110 f,{ }^{[192]} 168 a-168 g,{ }^{[135]} 110 g,{ }^{[137]}$ and complex $193 .{ }^{[193]}$

The following compounds were obtained by the generous courtesy of the following persons:

M. Sc. Julian Koeller: $(E)-1-(2-[(E)-1,2$-diphenylvinyl)phenyl]ethanone $O$-acetyl oxime 158u.

Dr. Mélanie M. Lorion: 3-tosyl-5-vinyloxazolidin-2-one 110g.

Dr. Weiping Liu: (E)-N-[1-(4-fluorophenyl) ethylidene]-4-methoxyaniline 34d, (E)-N-\{1-[(1,1'-biphenyl)-4-yl]ethylidene\}-4- methoxyaniline 34b.

M. Sc. Issac Choi: [2-(1H-pyrazol-1-yl)phenyl)(phenyl)methanol 200a.

M. Sc. Nikolaos Kaplaneris: methyl 2-\{[(tert-butoxycarbonyl)oxy]methyl\}acrylate 201. 


\subsection{General Procedures}

General Procedure A: Cobalt(III)-Catalyzed C-H/N-O Functionalization for the Synthesis of Isoquinolines 119

A suspension of $O$-acetyl oxime 158 ( $0.50 \mathrm{mmol}, 1.0$ equiv), alkynes 8 (0.75 mmol, 1.5 equiv), $\mathrm{Cp}^{*} \mathrm{Col}_{2}(\mathrm{CO})(24.0 \mathrm{mg}, 10.0 \mathrm{~mol} \%), \mathrm{AgSbF}_{6}(34.4 \mathrm{mg}, 20.0 \mathrm{~mol} \%)$ and $\mathrm{NaOAc}(8.2 \mathrm{mg}, 20.0 \mathrm{~mol} \%)$ in DCE $(2.0 \mathrm{~mL})$ was stirred at $120{ }^{\circ} \mathrm{C}$ for $15 \mathrm{~min}$ or $16 \mathrm{~h}$ under air. After cooling to ambient temperature, the solvent was evaporated in vacuo and the remaining residue was purified by column chromatography on silica gel to afford the desired products $\mathbf{1 1 9}$.

General Procedure B: Cobalt(III)-Catalyzed C-H/N-O Functionalization for the Synthesis of Indoles 160

A suspension of nitrone 159 ( $0.50 \mathrm{mmol}, 1.0$ equiv), alkyne 8 (0.75 mmol, 1.5 equiv), $\mathrm{Cp}^{*} \mathrm{Col}_{2}(\mathrm{CO})$ (12.0 mg, $5.0 \mathrm{~mol} \%), \mathrm{AgSbF}_{6}(34.4 \mathrm{mg}, 20.0 \mathrm{~mol} \%)$, NaOAc (8.2 mg, $20.0 \mathrm{~mol} \%$ ) or Piv-Leu-OH (22.1 mg, $20.0 \mathrm{~mol} \%$ ) was stirred at $100^{\circ} \mathrm{C}$ for $16 \mathrm{~h}$ under air. After cooling to ambient temperature, the mixture was transferred into a round bottom flask with $\mathrm{CH}_{2} \mathrm{Cl}_{2}(20 \mathrm{~mL})$ and concentrated in vacuo. Purification by column chromatography on silica gel and optionally by GPC afforded the desired products 160 .

General Procedure C: Cobalt(III)-Catalyzed C-H Functionalization for the Synthesis of Quinazolines 163

A suspension of benzimidates 161 ( $0.25 \mathrm{mmol}, 1.0$ equiv), dioxazolones 162 (0.30 mmol, 1.2 equiv), $\left[\mathrm{Cp}^{*} \mathrm{Co}\left(\mathrm{CH}_{3} \mathrm{CN}\right)_{3}\right]\left(\mathrm{SbF}_{6}\right)_{2}(\mathbf{1 8 0})(6.9 \mathrm{mg}, 5.0 \mathrm{~mol} \%)$ in DCE $(1.0 \mathrm{~mL})$ was stirred at $100{ }^{\circ} \mathrm{C}$ for $13 \mathrm{~h}$ under air. After cooling to ambient temperature, the mixture was transferred into a round bottom flask with $\mathrm{CH}_{2} \mathrm{Cl}_{2}(20 \mathrm{~mL})$ and concentrated in vacuo. Purification by column chromatography on silica gel afforded the desired products 163.

General Procedure D: Cobalt-Catalyzed C-H/N-H Activation for the Synthesis of Vinyl-Substituted Dihydroisoquinolines 164 
A suspension of benzimidates 161 ( $0.25 \mathrm{mmol}, 1.0$ equiv), dioxolanone 110 (0.75 mmol, 3.0 equiv), $\mathrm{NaOAC}(8.2 \mathrm{mg}, 40.0 \mathrm{~mol} \%), \mathrm{BPh}_{3}(24.2 \mathrm{mg}, 40.0 \mathrm{~mol} \%),\left[\mathrm{Cp}{ }^{*} \mathrm{Co}\left(\mathrm{CH}_{3} \mathrm{CN}\right)_{3}\right]\left(\mathrm{PF}_{6}\right)_{2}(7.6 \mathrm{mg}, 5.0 \mathrm{~mol} \%)$ in HFIP $(1.0 \mathrm{~mL})$ was stirred at $55{ }^{\circ} \mathrm{C}$ for $16 \mathrm{~h}$ under $\mathrm{N}_{2}$. After cooling to ambient temperature, the mixture was transferred into a round bottom flask with $\mathrm{CH}_{2} \mathrm{Cl}_{2}(20 \mathrm{~mL})$ and concentrated in vacuo. Purification by column chromatography on silica gel afforded the desired products 164 .

\section{General Procedure E: Manganese(I)-Catalyzed C-H/C-O Activation with Heteroarenes}

A suspension of heteroarenes 41 ( $0.25 \mathrm{mmol}, 1.0$ equiv), dioxolanones 110 (0.75 mmol, 3.0 equiv), $\left[\mathrm{MnBr}(\mathrm{CO})_{5}\right](6.9 \mathrm{mg}, 10.0 \mathrm{~mol} \%)$ and $\mathrm{NaOAc}(4.1 \mathrm{mg}, 20.0 \mathrm{~mol} \%)$ in $\mathrm{H}_{2} \mathrm{O}$ or TFE $(1.0 \mathrm{~mL})$ was stirred at $100{ }^{\circ} \mathrm{C}$ for $16 \mathrm{~h}$ under air (or under $\mathrm{N}_{2}$ when specified). After cooling to ambient temperature, the mixture was transferred into a round bottom flask with $\mathrm{CH}_{2} \mathrm{Cl}_{2}(20 \mathrm{~mL})$ and concentrated in vacuo. Purification by column chromatography on silica gel afforded the desired products 111

\section{General Procedure F: Manganese(I)-Catalyzed C-H/C-O Activation with Ketimines 34}

A suspension of ketimines 34 ( $0.25 \mathrm{mmol}, 1.0$ equiv), dioxolanones 110 (0.75 mmol, 3.0 equiv), $\left[\mathrm{MnBr}(\mathrm{CO})_{5}\right](6.9 \mathrm{mg}, 10.0 \mathrm{~mol} \%)$ and $\mathrm{NaOAc}(4.1 \mathrm{mg}, 20.0 \mathrm{~mol} \%)$ in TFE $(1.0 \mathrm{~mL})$ was stirred at $100{ }^{\circ} \mathrm{C}$ for $16 \mathrm{~h}$ under $\mathrm{N}_{2}$. After cooling to ambient temperature, $\mathrm{HCl}(2 \mathrm{~N}, 3.0 \mathrm{~mL}$ ) was added. The resulting mixture was stirred for $30 \mathrm{~min}$ at $25^{\circ} \mathrm{C}$ and extracted with $\mathrm{Et}_{2} \mathrm{O}(3 \times 20 \mathrm{~mL})$. The combined organic layers were dried over $\mathrm{Na}_{2} \mathrm{SO}_{4}$ and concentrated in vacuo. Purification by column chromatography on silica gel afforded the desired products 165.

\section{General procedure G: Manganese(I)-Catalyzed C-H Hydroarylation in Flow}

A $10 \mathrm{~mL}$ oven-dried volumetric flask was charged with heteroarenes $\mathbf{4 1}$ (0.25 mmol, 1.0 equiv), propargylic alkynes 166 (0.50 mmol, 2.0 equiv), [ $\left.\mathrm{MnBr}(\mathrm{CO})_{5}\right](6.9 \mathrm{mg}, 10.0 \mathrm{~mol} \%)$, HOAc (2.8 $\mu \mathrm{L}$, $20.0 \mathrm{~mol} \%)$ and 1,4-dioxane $(1.0 \mathrm{~mL})$ under air. Subsequently, the solution was connected to the inlet of the $10 \mathrm{~mL}$ standard heated reactor by a syringe pump (Vapourtec $\mathrm{V}-3$ ). The syringe pump was operated at a flow rate of $500 \mu \mathrm{L} / \min (20$ min residence time). The back pressure was set up around 8.0 bar and the temperature of the standard heated reactor was set at $100{ }^{\circ} \mathrm{C}$. Using the Flow Wizard system, the solution was collected automatically. Next, the mixture was concentrated 
in vacuo. Purification by column chromatography on silica gel afforded the desired products 167.

\section{General Procedure H: Manganese(I)-Catalyzed C-C Allylation with Dioxolanones 110}

A suspension of heteroarenes 168 ( $0.25 \mathrm{mmol}, 1.0$ equiv), dioxolanones 110 (0.50 mmol, 2.0 equiv), $\left[\mathrm{MnBr}(\mathrm{CO})_{5}\right](6.9 \mathrm{mg}, 10.0 \mathrm{~mol} \%)$ in $\mathrm{H}_{2} \mathrm{O}(1.0 \mathrm{~mL})$ was stirred at $120{ }^{\circ} \mathrm{C}$ for $16 \mathrm{~h}$ under $\mathrm{N}_{2}$. After cooling to ambient temperature, EtOAc $(10 \mathrm{~mL})$ was added and the mixture was dried over $\mathrm{Na}_{2} \mathrm{SO}_{4}$, washed with EtOAc ( $30 \mathrm{~mL}$ ) and concentrated in vacuo. Purification by column chromatography on silica gel afforded the desired products 111.

\section{General Procedure I: Manganese(I)-Catalyzed C-C Alkenylation with Alkynes 8}

A suspension of heteroarenes 168 ( $0.25 \mathrm{mmol}, 1.0$ equiv), alkynes 8 (0.50 mmol, 2.0 equiv), $\left[\mathrm{MnBr}(\mathrm{CO})_{5}\right](6.9 \mathrm{mg}, 10.0 \mathrm{~mol} \%)$ in $\mathrm{H}_{2} \mathrm{O}(1.0 \mathrm{~mL})$ was stirred at $140{ }^{\circ} \mathrm{C}$ for $16 \mathrm{~h}$ under $\mathrm{N}_{2}$. After cooling to ambient temperature, EtOAc $(10 \mathrm{~mL})$ was added and the mixture was dried over $\mathrm{Na}_{2} \mathrm{SO}_{4}$, washed with EtOAc ( $30 \mathrm{~mL}$ ) and concentrated in vacuo. Purification by column chromatography on silica gel afforded the desired products 74 .

\section{General procedure J: Manganese(I)-Catalyzed C-C Alkylation with Alkenes 11}

A suspension of heteroarenes 168 ( $0.25 \mathrm{mmol}, 1.0$ equiv), alkenes 11 (0.50 mmol, 2.0 equiv), [ $\left.\mathrm{MnBr}(\mathrm{CO})_{5}\right](6.9 \mathrm{mg}, 10.0 \mathrm{~mol} \%)$ in $\mathrm{H}_{2} \mathrm{O}(1.0 \mathrm{~mL})$ was stirred at $120{ }^{\circ} \mathrm{C}$ for $16 \mathrm{~h}$ under $\mathrm{N}_{2}$. After cooling to ambient temperature, EtOAc $(10 \mathrm{~mL})$ was added and the mixture was dried over $\mathrm{Na}_{2} \mathrm{SO}_{4}$, washed with EtOAc $(30 \mathrm{~mL})$ and concentrated in vacuo. Purification by column chromatography on silica gel afforded the desired products 102.

General procedure K: Manganese(I)-Catalyzed C-C Allylation with Morita-Baylis-Hillman Adducts 201

A suspension of heteroarenes 168 (0.25 mmol, 1.0 equiv), Morita-Baylis-Hillman adducts 201 (0.50 mmol, 2.0 equiv), $\left[\mathrm{MnBr}(\mathrm{CO})_{5}\right](6.9 \mathrm{mg}, 10.0 \mathrm{~mol} \%)$ in 1,4-dioxane $(1.0 \mathrm{~mL})$ was stirred at $120^{\circ} \mathrm{C}$ for $16 \mathrm{~h}$ under $\mathrm{N}_{2}$. After cooling to ambient temperature, the mixture was transferred into a round bottom flask with $\mathrm{CH}_{2} \mathrm{Cl}_{2}(20 \mathrm{~mL})$ and concentrated in vacuo. Purification by column chromatography on silica gel afforded the desired products 202 . 


\subsection{Experimental and Analytical Data}

\subsubsection{Data for Cobalt(III)-Catalyzed C-H/N-O Functionalizations: Isohypsic Access to Isoquinolines}

\section{Characterization Data}<smiles>Cc1nc(-c2ccccc2)c(-c2ccccc2)c2ccccc12</smiles>

1-Methyl-3,4-diphenylisoquinoline (119aa): The general procedure A was followed using (E)-acetophenone $O$-acetyl oxime (158a) $(89 \mathrm{mg}, 0.50 \mathrm{mmol}$ ) and diphenylacetylene (8a) (134 mg, $0.75 \mathrm{mmol}$ ). Purification by column chromatography on silica gel ( $n$-hexane/EtOAc: $25 / 1 \rightarrow 20 / 1$ ) yielded 119aa (129 mg, 87\%) as a pale yellow solid.

M.p. $=153-155^{\circ} \mathrm{C}^{1}{ }^{1} \mathrm{H}$ NMR $\left(500 \mathrm{MHz}, \mathrm{CDCl}_{3}\right): \delta=8.23-8.19(\mathrm{~m}, 1 \mathrm{H}), 7.71-7.67(\mathrm{~m}, 1 \mathrm{H}), 7.62-7.57$ (m, 2H), 7.42-7.31 (m, 5H), 7.27-7.16 (m, 5H), 3.10 (s, 3H). ${ }^{13} \mathrm{C}$ NMR $\left(125 \mathrm{MHz}, \mathrm{CDCl}_{3}\right): \delta=157.7$ $\left(\mathrm{C}_{\mathrm{q}}\right), 149.4\left(\mathrm{C}_{\mathrm{q}}\right), 141.0\left(\mathrm{C}_{\mathrm{q}}\right), 137.6\left(\mathrm{C}_{\mathrm{q}}\right), 136.0\left(\mathrm{C}_{\mathrm{q}}\right), 131.4(\mathrm{CH}), 130.2(\mathrm{CH}), 130.0(\mathrm{CH}), 129.1\left(\mathrm{C}_{\mathrm{q}}\right)$, $128.2(\mathrm{CH}), 127.6(\mathrm{CH}), 127.1(\mathrm{CH}), 126.9(\mathrm{CH}), 126.5(\mathrm{CH}), 126.2(\mathrm{CH}), 126.1\left(\mathrm{C}_{\mathrm{q}}\right), 125.5(\mathrm{CH}), 22.7$ $\left(\mathrm{CH}_{3}\right)$. IR $(\mathrm{ATR}) v=1567,1389,1334,1072,1026,765,695,612,563,496 \mathrm{~cm}^{-1} . \mathrm{MS}$ (ESI) m/z (relative intensity): $296(100)[M+H]^{+}$. HR-MS (ESI) m/z calcd for $\mathrm{C}_{22} \mathrm{H}_{18} \mathrm{~N}[\mathrm{M}+\mathrm{H}]^{+}:$296.1434, found: 296.1434.

The analytical data were in accordance with those reported in the literature. ${ }^{[109 c]}$<smiles>Cc1ccc2c([N+](=O)[O-])nc(-c3ccccc3)c(-c3ccccc3)c2c1</smiles>

1,6-Dimethyl-3,4-diphenylisoquinoline (119ba): The general procedure A was followed using (E)-1-(p-tolyl)ethanone $O$-acetyl oxime (158b) $(96 \mathrm{mg}, 0.50 \mathrm{mmol}$ ) and diphenylacetylene (8a) (134 $\mathrm{mg}, 0.75 \mathrm{mmol}$ ). Purification by column chromatography on silica gel ( $n$-hexane/EtOAc: $40 / 1 \rightarrow$ 20/1) yielded 119ba (94 $\mathrm{mg}, 61 \%$ ) as a white solid.

M.p. $=168-169^{\circ} \mathrm{C}^{1}{ }^{1} \mathrm{H}$ NMR $\left(500 \mathrm{MHz}, \mathrm{CDCl}_{3}\right): \delta=8.08(\mathrm{~d}, J=8.9 \mathrm{~Hz}, 1 \mathrm{H}), 7.43-7.39(\mathrm{~m}, 2 \mathrm{H}), 7.37-$ $7.30(\mathrm{~m}, 5 \mathrm{H}), 7.23-7.14(\mathrm{~m}, 5 \mathrm{H}), 3.04(\mathrm{~s}, 3 \mathrm{H}), 2.42(\mathrm{~s}, 3 \mathrm{H}) .{ }^{13} \mathrm{C} \mathrm{NMR}\left(125 \mathrm{MHz}, \mathrm{CDCl}_{3}\right): \delta=157.3\left(\mathrm{C}_{\mathrm{q}}\right)$, $149.6\left(\mathrm{C}_{\mathrm{q}}\right), 141.2\left(\mathrm{C}_{\mathrm{q}}\right), 140.1\left(\mathrm{C}_{\mathrm{q}}\right), 137.7\left(\mathrm{C}_{\mathrm{q}}\right), 136.2\left(\mathrm{C}_{\mathrm{q}}\right), 131.4(\mathrm{CH}), 130.2(\mathrm{CH}), 128.7\left(\mathrm{C}_{\mathrm{q}}\right), 128.6(\mathrm{CH})$, 
$128.1(\mathrm{CH}), 127.5(\mathrm{CH}), 127.0(\mathrm{CH}), 126.8(\mathrm{CH}), 125.4(\mathrm{CH}), 125.0(\mathrm{CH}), 124.5\left(\mathrm{C}_{\mathrm{q}}\right), 22.6\left(\mathrm{CH}_{3}\right), 22.1$ $\left(\mathrm{CH}_{3}\right)$. IR (ATR) $v=3061,2917,1621,1566,1493,1384,1335,1070,1028,796,696,612 \mathrm{~cm}^{-1}$. MS (ESI) $\mathrm{m} / \mathrm{z}$ (relative intensity): $310(100)[\mathrm{M}+\mathrm{H}]^{+}$. HR-MS (ESI) $\mathrm{m} / \mathrm{z}$ calcd for $\mathrm{C}_{23} \mathrm{H}_{20} \mathrm{~N}[\mathrm{M}+\mathrm{H}]^{+}: 310.1590$, found: 310.1593.

The analytical data were in accordance with those reported in the literature. ${ }^{[109 c]}$<smiles>COc1ccc2c(C)c3cc(-c4ccccc4)c(-c4ccccc4)c(-c4ccccc4)nc-3c2c1</smiles>

6-Methoxy-1-methyl-3,4-diphenylisoquinoline (119ca): The general procedure A was followed using (E)-1-(4-methoxyphenyl)ethanone O-acetyl oxime (158c) (104 mg, $0.50 \mathrm{mmol})$ and diphenylacetylene $(8 \mathrm{a})(134 \mathrm{mg}, 0.75 \mathrm{mmol})$. Purification by column chromatography on silica gel ( $n$-hexane/EtOAc: $15 / 1 \rightarrow 10 / 1$ ) yielded 119ca (141 mg, 87\%) as a pale yellow solid.

M.p. $=180-182{ }^{\circ} \mathrm{C} .{ }^{1} \mathrm{H}$ NMR $\left(500 \mathrm{MHz}, \mathrm{CDCl}_{3}\right): \delta=8.11(\mathrm{dd}, J=9.2,0.5 \mathrm{~Hz}, 1 \mathrm{H}), 7.37-7.27(\mathrm{~m}, 5 \mathrm{H})$, 7.25-7.12 (m, 6H), $6.92(\mathrm{~d}, J=2.5 \mathrm{~Hz}, 1 \mathrm{H}), 3.73(\mathrm{~s}, 3 \mathrm{H}), 3.02(\mathrm{~s}, 3 \mathrm{H}) .{ }^{13} \mathrm{C}$ NMR $\left(125 \mathrm{MHz}, \mathrm{CDCl}_{3}\right): \delta=$ 160.7 $\left(\mathrm{C}_{\mathrm{q}}\right), 157.1\left(\mathrm{C}_{\mathrm{q}}\right), 150.3\left(\mathrm{C}_{\mathrm{q}}\right), 141.4\left(\mathrm{C}_{\mathrm{q}}\right), 138.2\left(\mathrm{C}_{\mathrm{q}}\right), 138.1\left(\mathrm{C}_{\mathrm{q}}\right), 131.5(\mathrm{CH}), 130.4(\mathrm{CH}), 128.7\left(\mathrm{C}_{\mathrm{q}}\right)$, $128.4(\mathrm{CH}), 127.7(\mathrm{CH}), 127.6(\mathrm{CH}), 127.2(\mathrm{CH}), 127.0(\mathrm{CH}), 122.0\left(\mathrm{C}_{\mathrm{q}}\right), 118.8(\mathrm{CH}), 104.7(\mathrm{CH}), 55.4$ $\left(\mathrm{CH}_{3}\right), 22.8\left(\mathrm{CH}_{3}\right)$. IR (ATR) $v=3059,1500,1410,1273,1229,1205,1070,1024,853,696 \mathrm{~cm}^{-1}$. MS (ESI) $\mathrm{m} / \mathrm{z}$ (relative intensity): $326(100)[\mathrm{M}+\mathrm{H}]^{+}$. HR-MS (ESI) $\mathrm{m} / \mathrm{z}$ calcd for $\mathrm{C}_{23} \mathrm{H}_{20} \mathrm{NO}[\mathrm{M}+\mathrm{H}]^{+}$: 326.1539 , found: 326.1538 .

The analytical data were in accordance with those reported in the literature. ${ }^{[194]}$<smiles>Cc1nc(-c2ccccc2)c(-c2ccccc2)c2cc(-c3ccccc3)ccc12</smiles>

1-Methyl-3,4,6-triphenylisoquinoline (119da): The general procedure A was followed using (E)-1-[(1,1'-biphenyl)-4-yl]ethanone O-acetyl oxime $(\mathbf{1 5 8 d}) \quad(127 \mathrm{mg}, \quad 0.50 \mathrm{mmol})$ and diphenylacetylene (8a) (134 mg, $0.75 \mathrm{mmol})$. Purification by column chromatography on silica gel ( $n$-hexane/EtOAc: $40 / 1 \rightarrow 20 / 1$ ) yielded 119da (154 mg, 83\%) as a pale yellow solid.

M.p. $=178-179^{\circ} \mathrm{C} .{ }^{1} \mathrm{H}$ NMR $\left(500 \mathrm{MHz}, \mathrm{CDCl}_{3}\right): \delta=8.27(\mathrm{dd}, J=8.7,0.7 \mathrm{~Hz}, 1 \mathrm{H}), 7.89(\mathrm{dd}, J=1.8,0.7$ 
$\mathrm{Hz}, 1 \mathrm{H}), 7.85(\mathrm{dd}, J=8.7,1.8 \mathrm{~Hz}, 1 \mathrm{H}), 7.59-7.55(\mathrm{~m}, 2 \mathrm{H}), 7.46-7.39(\mathrm{~m}, 4 \mathrm{H}), 7.39-7.32(\mathrm{~m}, 4 \mathrm{H})$, 7.31-7.27 (m, 2H), 7.25-7.18 (m, 3H), $3.11(\mathrm{~s}, 3 \mathrm{H}) .{ }^{13} \mathrm{C}$ NMR (125 MHz, CDCl $): \delta=157.5\left(\mathrm{C}_{\mathrm{q}}\right), 149.9$ $\left(C_{q}\right), 142.4\left(C_{q}\right), 141.0\left(C_{q}\right), 140.4\left(C_{q}\right), 137.5\left(C_{q}\right), 136.3\left(C_{q}\right), 131.4(C H), 130.2(C H), 129.3\left(C_{q}\right), 128.8$ $(\mathrm{CH}), 128.2(\mathrm{CH}), 127.9(\mathrm{CH}), 127.6(\mathrm{CH}), 127.4(\mathrm{CH}), 127.1(\mathrm{CH}), 127.0(\mathrm{CH}), 126.9(\mathrm{CH}), 126.1(\mathrm{CH})$, $125.1\left(\mathrm{C}_{\mathrm{q}}\right), 123.9(\mathrm{CH}), 22.7\left(\mathrm{CH}_{3}\right)$. IR (ATR) $v=3058$, 3025, 1611, 1567, 1434, 1340, 1158, 1073, 1029, 955, 894, 760, 751, 691, $611 \mathrm{~cm}^{-1}$. MS (ESI) m/z (relative intensity): 372 (100) [M+H] $]^{+}$HR-MS (ESI) $\mathrm{m} / \mathrm{z}$ calcd for $\mathrm{C}_{28} \mathrm{H}_{22} \mathrm{~N}[\mathrm{M}+\mathrm{H}]^{+}: 372.1747$, found: 372.1751 .<smiles>Cc1nc(-c2ccccc2)c(-c2ccccc2)c2cc(C(F)(F)F)ccc12</smiles>

6-(Trifluoromethyl)-1-methyl-3,4-diphenylisoquinoline (119ea): The general procedure A was followed using (E)-1-(4-(trifluoromethyl)phenyl)ethanone $O$-acetyl oxime (158e) (123 mg, 0.50 $\mathrm{mmol}$ ) and diphenylacetylene $(8 \mathrm{a})(134 \mathrm{mg}, 0.75 \mathrm{mmol})$. Purification by column chromatography on silica gel ( $n$-hexane/EtOAc 30:1 $\rightarrow$ 20:1 $\rightarrow$ 15:1) yielded 119ea (173 mg, 95\%) as a pale yellow solid. M.p. $=112-113{ }^{\circ} \mathrm{C} .{ }^{1} \mathrm{H}-\mathrm{NMR}\left(500 \mathrm{MHz}, \mathrm{CDCl}_{3}\right): \delta=8.33(\mathrm{dt}, J=8.7,0.8 \mathrm{~Hz}, 1 \mathrm{H}), 7.98-7.97(\mathrm{~m}, 1 \mathrm{H})$, $7.76(\mathrm{dd}, J=8.7,1.8 \mathrm{~Hz}, 1 \mathrm{H}), 7.41-7.34(\mathrm{~m}, 5 \mathrm{H}), 7.25-7.18(\mathrm{~m}, 5 \mathrm{H}), 3.12(\mathrm{~s}, 3 \mathrm{H}) .{ }^{13} \mathrm{C}$ NMR $(125 \mathrm{MHz}$, $\left.\mathrm{CDCl}_{3}\right): \delta=158.0\left(\mathrm{C}_{\mathrm{q}}\right), 151.1\left(\mathrm{C}_{\mathrm{q}}\right), 140.6\left(\mathrm{C}_{\mathrm{q}}\right), 136.6\left(\mathrm{C}_{\mathrm{q}}\right), 135.6\left(\mathrm{C}_{\mathrm{q}}\right), 131.5\left(\mathrm{q},{ }^{2} \mathrm{~J}_{\mathrm{C}-\mathrm{F}}=32 \mathrm{~Hz}, \mathrm{C}_{\mathrm{q}}\right), 131.4$ $(\mathrm{CH}), 130.4(\mathrm{CH}), 129.9\left(\mathrm{C}_{\mathrm{q}}\right), 128.7(\mathrm{CH}), 127.9(\mathrm{CH}), 127.8(\mathrm{CH}), 127.5(\mathrm{CH}), 127.1\left(\mathrm{C}_{\mathrm{q}}\right), 127.0(\mathrm{CH})$, $124.0\left(q,{ }^{3} J_{C-F}=5 \mathrm{~Hz}, \mathrm{CH}\right), 123.8\left(q,{ }^{1} J_{\mathrm{C}-\mathrm{F}}=273 \mathrm{~Hz}, \mathrm{C}_{\mathrm{q}}\right), 122.2\left(\mathrm{q},{ }^{4} J_{\mathrm{C}-\mathrm{F}}=3 \mathrm{~Hz}, \mathrm{CH}\right), 23.0\left(\mathrm{CH}_{3}\right) .{ }^{19} \mathrm{~F} \mathrm{NMR}$ $\left(282 \mathrm{MHz}, \mathrm{CDCl}_{3}\right): \delta=-63.3$ (s). IR (ATR) $v=2958,1555,1336,1305,1177,1156,1135,1082,909$, $696 \mathrm{~cm}^{-1}$. MS (ESI) $\mathrm{m} / \mathrm{z}$ (relative intensity): 364 (100) $[\mathrm{M}+\mathrm{H}]^{+}$. HR-MS (ESI) $\mathrm{m} / z$ calcd for $\mathrm{C}_{23} \mathrm{H}_{16} \mathrm{~F}_{3} \mathrm{~N}$ $[\mathrm{M}+\mathrm{H}]^{+}: 364.1308$, found: 364.1315 .

The analytical data were in accordance with those reported in the literature. ${ }^{[109 c]}$<smiles>Cc1nc(-c2ccccc2)c(-c2ccccc2)c2cc(F)ccc12</smiles>

6-Fluoro-1-methyl-3,4-diphenylisoquinoline (119fa): The general procedure A was followed using 6-fluoro-1-methyl-3,4-diphenylisoquinoline (158f) (98 mg, $0.50 \mathrm{mmol}$ ) and diphenylacetylene (8a) 
(134 mg, $0.75 \mathrm{mmol}$ ). Purification by column chromatography on silica gel ( $n$-hexane/EtOAc: 30:1 $\rightarrow$ 20:1) yielded $119 \mathrm{fa}$ (147 $\mathrm{mg}, 94 \%$ ) as a pale yellow solid.

M.p. $=139-140{ }^{\circ} \mathrm{C} .{ }^{1} \mathrm{H}$ NMR $\left(500 \mathrm{MHz}, \mathrm{CDCl}_{3}\right): \delta=8.22(\mathrm{ddd}, J=9.2,5.7,0.5 \mathrm{~Hz}, 1 \mathrm{H}), 7.39-7.31(\mathrm{~m}$, $6 \mathrm{H}), 7.28-7.25(\mathrm{~m}, 1 \mathrm{H}), 7.23-7.15(\mathrm{~m}, 5 \mathrm{H}), 3.06(\mathrm{~s}, 3 \mathrm{H}) .{ }^{13} \mathrm{C}$ NMR $\left(125 \mathrm{MHz}, \mathrm{CDCl}_{3}\right): \delta=163.3(\mathrm{~d}$, $\left.{ }^{1} J_{C-F}=251 \mathrm{~Hz}, C_{q}\right), 157.7\left(C_{q}\right), 150.6\left(C_{q}\right), 140.8\left(C_{q}\right), 138.2\left(d,{ }^{3} J_{C-F}=10 \mathrm{~Hz}, C_{q}\right), 137.3\left(C_{q}\right), 131.4(C H)$, $130.4(\mathrm{CH}), 129.1\left(\mathrm{~d},{ }^{4} J_{\mathrm{C}-\mathrm{F}}=5.2 \mathrm{~Hz}, \mathrm{C}_{\mathrm{q}}\right), 128.8\left(\mathrm{~d},{ }^{3} \mathrm{~J}_{\mathrm{C}-\mathrm{F}}=10 \mathrm{~Hz}, \mathrm{CH}\right), 128.6(\mathrm{CH}), 127.8(\mathrm{CH}), 127.5$ $(\mathrm{CH}), 127.3(\mathrm{CH}), 123.6\left(\mathrm{C}_{\mathrm{q}}\right), 116.8\left(\mathrm{~d},{ }^{2} \mathrm{~J}_{\mathrm{C}-\mathrm{F}}=25.2 \mathrm{~Hz}, \mathrm{CH}\right), 110.0\left(\mathrm{~d},{ }^{2} \mathrm{~J}_{\mathrm{C}-\mathrm{F}}=22.2 \mathrm{~Hz}, \mathrm{CH}\right), 23.0\left(\mathrm{CH}_{3}\right)$.

${ }^{19}$ F NMR $\left(282 \mathrm{MHz}_{\mathrm{CDCl}}\right.$ ) $: \delta=-108.0$ (ddd, $\left.J=10.9,8.0,5.6 \mathrm{~Hz}\right)$. IR (ATR) $v=1623,1571,1504$, 1398, 1260, 1183, 874, 830, $704 \mathrm{~cm}^{-1}$. MS (ESI) m/z (relative intensity): 314 (100) [M+H] $]^{+}$HR-MS (ESI) $\mathrm{m} / \mathrm{z}$ calcd for $\mathrm{C}_{22} \mathrm{H}_{17} \mathrm{~N}_{19} \mathrm{~F}[\mathrm{M}+\mathrm{H}]^{+}$: 314.1340, found: 314.1339 .

The analytical data were in accordance with those reported in the literature. ${ }^{[195]}$<smiles>Cc1nc(-c2ccccc2)c(-c2ccccc2)c2cc(Cl)ccc12</smiles>

6-Chloro-1-methyl-3,4-diphenylisoquinoline (119ga): The general procedure $\mathbf{A}$ was followed using (E)-1-(4-chlorophenyl)ethanone $O$-acetyl oxime (158g) $(106 \mathrm{mg}, 0.50 \mathrm{mmol})$ and diphenylacetylene (8a) (134 mg, $0.75 \mathrm{mmol}$ ). Purification by column chromatography on silica gel ( $n$-hexane/EtOAc: $40 / 1 \rightarrow 20 / 1$ ) yielded 119ga (156 mg, 94\%) as a pale yellow solid.

M.p. $=177-178{ }^{\circ} \mathrm{C} .{ }^{1} \mathrm{H}-\mathrm{NMR}\left(500 \mathrm{MHz}, \mathrm{CDCl}_{3}\right): \delta=8.11(\mathrm{dd}, J=8.9,0.5 \mathrm{~Hz}, 1 \mathrm{H}), 7.64(\mathrm{dd}, J=2.2,0.5$ $\mathrm{Hz}, 1 \mathrm{H}), 7.51(\mathrm{dd}, J=8.9,2.2 \mathrm{~Hz}, 1 \mathrm{H}), 7.39-7.32(\mathrm{~m}, 5 \mathrm{H}), 7.22-7.17(\mathrm{~m}, 5 \mathrm{H}), 3.04(\mathrm{~s}, 3 \mathrm{H}) .{ }^{13} \mathrm{C}$ NMR $\left(125 \mathrm{MHz}, \mathrm{CDCl}_{3}\right): \delta=157.6\left(\mathrm{C}_{\mathrm{q}}\right), 150.5\left(\mathrm{C}_{\mathrm{q}}\right), 140.6\left(\mathrm{C}_{\mathrm{q}}\right), 137.0\left(\mathrm{C}_{\mathrm{q}}\right), 136.8\left(\mathrm{C}_{\mathrm{q}}\right), 136.3\left(\mathrm{C}_{\mathrm{q}}\right), 131.2(\mathrm{CH})$, $130.1(\mathrm{CH}), 128.4(\mathrm{CH}), 127.6(\mathrm{CH}), 127.4(\mathrm{CH}), 127.3(\mathrm{CH}), 127.3(\mathrm{CH}), 127.1(\mathrm{CH}), 125.0(\mathrm{CH}), 124.3$ $\left(\mathrm{C}_{\mathrm{q}}\right), 22.7\left(\mathrm{CH}_{3}\right)$. IR (ATR) $v=3064,3026,1602,1548,1493,1446,1386,1329,1098,957,752,698$, $626 \mathrm{~cm}^{-1}$. MS (ESI) m/z (relative intensity): $330(100)[\mathrm{M}+\mathrm{H}]^{+}$. HR-MS (ESI) m/z calcd for $\mathrm{C}_{22} \mathrm{H}_{17} \mathrm{CIN}$ $[\mathrm{M}+\mathrm{H}]^{+}: 330.1044$, found: 330.1043 .

The analytical data were in accordance with those reported in the literature. ${ }^{[195]}$ 
<smiles>Cc1nc(-c2ccccc2)c(-c2ccccc2)c2cc(Br)ccc12</smiles>

6-Bromo-1-methyl-3,4-diphenylisoquinoline (119ha): The general procedure A was followed using (E)-1-(4-bromophenyl)ethanone $O$-acetyl oxime (158h) $(128 \mathrm{mg}, 0.50 \mathrm{mmol})$ and diphenylacetylene (8a) (134 mg, $0.75 \mathrm{mmol}$ ). Purification by column chromatography on silica gel ( $n$-hexane/EtOAc: $30 / 1 \rightarrow 20 / 1 \rightarrow 10 / 1$ ) yielded $119 \mathrm{ha}(154 \mathrm{mg}, 82 \%$ ) as a slightly yellow solid.

M.p. $=193-195{ }^{\circ} \mathrm{C} .{ }^{1} \mathrm{H}$ NMR $\left(500 \mathrm{MHz}, \mathrm{CDCl}_{3}\right): \delta=8.06(\mathrm{dd}, J=8.9,0.5 \mathrm{~Hz}, 1 \mathrm{H}), 7.81(\mathrm{~d}, J=2.0 \mathrm{~Hz}$, 1H), 7.67 (dd, J = 8.9, $2.0 \mathrm{~Hz}, 1 \mathrm{H}), 7.39-7.32(\mathrm{~m}, 5 \mathrm{H}), 7.22-7.15(\mathrm{~m}, 5 \mathrm{H}), 3.05(\mathrm{~s}, 3 \mathrm{H}) .{ }^{13} \mathrm{C}$ NMR $(125$ $\left.\mathrm{MHz}, \mathrm{CDCl}_{3}\right): \delta=157.6\left(\mathrm{C}_{\mathrm{q}}\right), 150.5\left(\mathrm{C}_{\mathrm{q}}\right), 140.6\left(\mathrm{C}_{\mathrm{q}}\right), 137.4\left(\mathrm{C}_{\mathrm{q}}\right), 136.8\left(\mathrm{C}_{\mathrm{q}}\right), 131.2(\mathrm{CH}), 130.3(\mathrm{CH})$, $130.1(\mathrm{CH}), 128.4(\mathrm{CH}), 128.4(\mathrm{CH}) 128.3\left(\mathrm{C}_{\mathrm{q}}\right), 127.6(\mathrm{CH}), 127.4(\mathrm{CH}), 127.3(\mathrm{CH}), 127.1(\mathrm{CH}), 125.0$ $\left(\mathrm{C}_{\mathrm{q}}\right), 124.3\left(\mathrm{C}_{\mathrm{q}}\right), 22.7\left(\mathrm{CH}_{3}\right)$. IR (ATR) $v=3064,1597,1561,1481,1445,1386,1329,1071,1029,697$ $\mathrm{cm}^{-1}$. MS (ESI) m/z (relative intensity): $374(100)[\mathrm{M}+\mathrm{H}]^{+}, 296$ (55). HR-MS (ESI) m/z calcd for $\mathrm{C}_{22} \mathrm{H}_{17} \mathrm{BrN}[\mathrm{M}+\mathrm{H}]^{+}:$374.0539, found: 374.0539 .

The analytical data were in accordance with those reported in the literature. ${ }^{[109 c]}$<smiles>Cc1nc(-c2ccccc2)c(-c2ccccc2)c2cc([N+](=O)[O-])ccc12</smiles>

1-Methyl-6-nitro-3,4-diphenylisoquinoline (119ia): The general procedure $\mathbf{A}$ was followed using (E)-1-(4-nitrophenyl)ethanone $O$-acetyl oxime (158i) $(111 \mathrm{mg}, 0.50 \mathrm{mmol})$ and diphenylacetylene (8a) (134 mg, $0.75 \mathrm{mmol}$ ). Purification by column chromatography on silica gel ( $n$-hexane/EtOAc $10: 1 \rightarrow 8: 1 \rightarrow 5: 1$ ) yielded 119ia ( $80 \mathrm{mg}, 47 \%$ ) as a yellow solid.

M.p. $=170-173{ }^{\circ} \mathrm{C}^{1}{ }^{1} \mathrm{H}$ NMR $\left(300 \mathrm{MHz}, \mathrm{CDCl}_{3}\right): \delta=8.59(\mathrm{dd}, J=2.1,0.8 \mathrm{~Hz}, 1 \mathrm{H}), 8.35(\mathrm{~d}, J=0.8 \mathrm{~Hz}$, $1 \mathrm{H}), 8.33(\mathrm{~d}, J=2.1 \mathrm{~Hz}, 1 \mathrm{H}), 7.50-7.29(\mathrm{~m}, 5 \mathrm{H}), 7.26-7.18(\mathrm{~m}, 5 \mathrm{H}), 3.14(\mathrm{~s}, 3 \mathrm{H}) .{ }^{13} \mathrm{C}$ NMR $(125 \mathrm{MHz}$, $\left.\mathrm{CDCl}_{3}\right): \delta=158.2\left(\mathrm{C}_{\mathrm{q}}\right), 151.8\left(\mathrm{C}_{\mathrm{q}}\right), 148.4\left(\mathrm{C}_{\mathrm{q}}\right), 140.1\left(\mathrm{C}_{\mathrm{q}}\right), 136.1\left(\mathrm{C}_{\mathrm{q}}\right), 136.0\left(\mathrm{C}_{\mathrm{q}}\right), 131.3(\mathrm{CH}), 130.6\left(\mathrm{C}_{\mathrm{q}}\right)$, $130.3(\mathrm{CH}), 128.9(\mathrm{CH}), 128.2(\mathrm{CH}), 127.9\left(\mathrm{C}_{q}\right), 127.9(\mathrm{CH}), 127.8(\mathrm{CH}), 127.7(\mathrm{CH}), 122.9(\mathrm{CH}), 120.0$ (CH), $23.1\left(\mathrm{CH}_{3}\right)$. IR (ATR) $v=1531,1343,1326,1312,902,832,767,738,698,623 \mathrm{~cm}^{-1}$. MS (ESI) $m / z$ (relative intensity): $341(100)[\mathrm{M}+\mathrm{H}]^{+}$. HR-MS (ESI) $m / z$ calcd for $\mathrm{C}_{22} \mathrm{H}_{17} \mathrm{~N}_{2} \mathrm{O}_{2}[\mathrm{M}+\mathrm{H}]^{+}: 341.1285$, found: 341.1285 . 
The analytical data were in accordance with those reported in the literature. ${ }^{[194]}$<smiles>Cc1nc(-c2ccccc2)c(-c2ccccc2)c2cc(C#N)ccc12</smiles>

1-Methyl-3,4-diphenylisoquinoline-6-carbonitrile (119ja): The general procedure A was followed using (E)-4-(1-(acetoxyimino)ethyl)benzonitrile (158j) $(101 \mathrm{mg}, 0.50 \mathrm{mmol})$ and diphenylacetylene (8a) (134 mg, $0.75 \mathrm{mmol})$. Purification by column chromatography on silica gel ( $n$-hexane/EtOAc: $30 / 1 \rightarrow 10 / 1$ ) yielded $119 \mathrm{ja}$ (144 $\mathrm{mg}, 90 \%$ ) as a pale yellow solid.

M.p. $=171-172{ }^{\circ} \mathrm{C} .{ }^{1} \mathrm{H}$ NMR $\left(500 \mathrm{MHz}, \mathrm{CDCl}_{3}\right): \delta=8.27(\mathrm{dd}, J=8.6,0.7 \mathrm{~Hz}, 1 \mathrm{H}), 8.03(\mathrm{dd}, J=1.6,0.7$ $\mathrm{Hz}, 1 \mathrm{H}), 7.71(\mathrm{dd}, J=8.6,1.6 \mathrm{~Hz}, 1 \mathrm{H}), 7.41-7.32(\mathrm{~m}, 5 \mathrm{H}), 7.22-7.15(\mathrm{~m}, 5 \mathrm{H}), 3.08(\mathrm{~s}, 3 \mathrm{H}) .{ }^{13} \mathrm{C}$ NMR $\left(125 \mathrm{MHz}, \mathrm{CDCl}_{3}\right): \delta=158.0\left(\mathrm{C}_{\mathrm{q}}\right), 151.3\left(\mathrm{C}_{\mathrm{q}}\right), 140.1\left(\mathrm{C}_{\mathrm{q}}\right), 136.1\left(\mathrm{C}_{\mathrm{q}}\right), 135.5\left(\mathrm{C}_{\mathrm{q}}\right), 132.5(\mathrm{CH}), 131.2(\mathrm{CH})$, $130.2(\mathrm{CH}), 129.0\left(\mathrm{C}_{\mathrm{q}}\right), 128.6(\mathrm{CH}), 127.9(\mathrm{CH}), 127.8(\mathrm{CH}), 127.5(\mathrm{CH}), 127.1(\mathrm{CH}), 126.9(\mathrm{CH}), 126.7$ $\left(C_{q}\right), 118.5\left(C_{q}\right), 113.5\left(C_{q}\right), 22.7\left(C_{3}\right)$. IR (ATR) $v=3067,2229,1612,1564,1493,1441,1385,1330$, 900, 823, 799, 696, $608 \mathrm{~cm}^{-1}$. MS (ESI) $\mathrm{m} / \mathrm{z}$ (relative intensity): 321 (100) [M+H] ${ }^{+}$. HR-MS (ESI) $\mathrm{m} / z$ calcd for $\mathrm{C}_{23} \mathrm{H}_{17} \mathrm{~N}_{2}[\mathrm{M}+\mathrm{H}]^{+}: 321.1392$, found: 321.1386 .<smiles>Cc1nc(-c2ccccc2)c(-c2ccccc2)c2cccc(Cl)c12</smiles>

8-Chloro-1-methyl-3,4-diphenylisoquinoline (119ka): The general procedure A was followed using (E)-1-(2-chlorophenyl)ethanone $O$-acetyl oxime $(\mathbf{1 5 8 k})(106 \mathrm{mg}, 0.50 \mathrm{mmol})$ and diphenylacetylene (8a) (134 mg, $0.75 \mathrm{mmol}$ ). Purification by column chromatography on silica gel ( $n$-hexane/EtOAc: $60 / 1 \rightarrow 30 / 1$ ) yielded 119ka (106 mg, 64\%) as a pale green solid.

M.p. $=139-141^{\circ} \mathrm{C} .{ }^{1} \mathrm{H}$ NMR $\left(400 \mathrm{MHz}, \mathrm{CDCl}_{3}\right): \delta=7.62(\mathrm{dd}, J=7.4,1.2 \mathrm{~Hz}, 1 \mathrm{H}), 7.56(\mathrm{dd}, J=8.5,1.2$ $\mathrm{Hz}, 1 \mathrm{H}), 7.39-7.31(\mathrm{~m}, 6 \mathrm{H}), 7.22-7.15(\mathrm{~m}, 5 \mathrm{H}), 3.39(\mathrm{~s}, 3 \mathrm{H}) .{ }^{13} \mathrm{C}$ NMR $\left(100 \mathrm{MHz}, \mathrm{CDCl}_{3}\right): \delta=157.1$ $\left(C_{q}\right), 149.3\left(C_{q}\right), 140.2\left(C_{q}\right), 139.2\left(C_{q}\right), 137.5\left(C_{q}\right), 132.2\left(C_{q}\right), 131.3(\mathrm{CH}), 130.1(\mathrm{CH}), 129.5(\mathrm{CH})$, $129.2(\mathrm{CH}), 129.0\left(\mathrm{C}_{\mathrm{q}}\right), 128.3(\mathrm{CH}), 127.6(\mathrm{CH}), 127.3(\mathrm{CH}), 127.2(\mathrm{CH}), 125.8(\mathrm{CH}), 124.5\left(\mathrm{C}_{\mathrm{q}}\right), 29.9$ $\left(\mathrm{CH}_{3}\right)$. IR (ATR) $v=3022,1601,1432,1382,1260,1087,1027,819,787,762,695,572 \mathrm{~cm}^{-1}$. MS (EI) $m / z$ (relative intensity): $330[\mathrm{M}+\mathrm{H}]^{+}$. HR-MS (ESI) $m / z$ calcd for $\mathrm{C}_{22} \mathrm{H}_{17} \mathrm{CIN}[\mathrm{M}+\mathrm{H}]^{+}: 330.1050$, found: 
330.1044 .<smiles>COc1ccc2c(-c3ccccc3)c(-c3ccccc3)nc([N+](=O)[O-])c2c1</smiles>

1,7-Dimethyl-3,4-diphenylisoquinoline (119la): The general procedure A was followed using (E)-1-(m-tolyl)ethanone $O$-acetyl oxime (158I) $(96 \mathrm{mg}, 0.50 \mathrm{mmol})$ and diphenylacetylene (8a) (134 $\mathrm{mg}, 0.75 \mathrm{mmol}$ ). Purification by column chromatography on silica gel ( $n$-hexane/EtOAc: $40 / 1 \rightarrow 20: 1$ ) yielded 119la (82 $\mathrm{mg}, 53 \%$ ) as a pale yellow solid.

M.p. $=132-134{ }^{\circ} \mathrm{C} .{ }^{1} \mathrm{H}$ NMR $\left(400 \mathrm{MHz}, \mathrm{CDCl}_{3}\right): \delta=7.95(\mathrm{t}, J=2.0 \mathrm{~Hz}, 1 \mathrm{H}), 7.56(\mathrm{~d}, J=8.8 \mathrm{~Hz}, 1 \mathrm{H})$, $7.41(\mathrm{dd}, J=8.8,2.0 \mathrm{~Hz}, 1 \mathrm{H}), 7.38-7.26(\mathrm{~m}, 5 \mathrm{H}), 7.24-7.10(\mathrm{~m}, 5 \mathrm{H}), 3.05(\mathrm{~s}, 3 \mathrm{H}), 2.57(\mathrm{~s}, 3 \mathrm{H}) .{ }^{13} \mathrm{C}$ $\operatorname{NMR}\left(100 \mathrm{MHz}, \mathrm{CDCl}_{3}\right): \delta=157.0\left(\mathrm{C}_{\mathrm{q}}\right), 148.6\left(\mathrm{C}_{\mathrm{q}}\right), 141.1\left(\mathrm{C}_{\mathrm{q}}\right), 137.7\left(\mathrm{C}_{\mathrm{q}}\right), 136.3\left(\mathrm{C}_{\mathrm{q}}\right), 134.1\left(\mathrm{C}_{\mathrm{q}}\right), 132.0$ $(\mathrm{CH}), 131.4(\mathrm{CH}), 130.2(\mathrm{CH}), 129.0\left(\mathrm{C}_{\mathrm{q}}\right), 128.1(\mathrm{CH}), 127.5(\mathrm{CH}), 127.0(\mathrm{CH}), 126.7(\mathrm{CH}), 126.3\left(\mathrm{C}_{\mathrm{q}}\right)$, $126.1(\mathrm{CH}), 124.5(\mathrm{CH}), 22.7\left(\mathrm{CH}_{3}\right), 21.8\left(\mathrm{CH}_{3}\right)$. IR (ATR) $v=3055,3023,2916,1553,1505,1443,1387$, 1322, 1073, 1028, 905, 831, 767, $699 \mathrm{~cm}^{-1}$. MS (ESI) $\mathrm{m} / z$ (relative intensity): 310 (100) $[\mathrm{M}+\mathrm{H}]^{+}$. HR-MS (ESI) $m / z$ calcd for $\mathrm{C}_{23} \mathrm{H}_{20} \mathrm{~N}[\mathrm{M}+\mathrm{H}]^{+}: 310.1590$, found: 310.1588 .

The analytical data were in accordance with those reported in the literature. ${ }^{[109 c]}$<smiles>O=[W]c1nc(-c2ccccc2)c(-c2ccccc2)c2ccc(Cl)cc12</smiles>

7-Chloro-1-methyl-3,4-diphenylisoquinoline (119ma): The general procedure $\mathbf{A}$ was followed using (E)-1-(3-chlorophenyl)ethanone $O$-acetyl oxime $(158 \mathrm{~m})(106 \mathrm{mg}, 0.50 \mathrm{mmol})$ and diphenylacetylene (8a) (134 mg, $0.75 \mathrm{mmol}$ ). Purification by column chromatography on silica gel ( $n$-hexane/EtOAc: $20 / 1 \rightarrow 15 / 1$ ) yielded $119 m a$ (115 $\mathrm{mg}, 70 \%$ ) as an off-white solid.

M.p. $=145-147^{\circ} \mathrm{C} .{ }^{1} \mathrm{H}$ NMR $\left(500 \mathrm{MHz}, \mathrm{CDCl}_{3}\right): \delta=8.17(\mathrm{dd}, J=2.2,0.6 \mathrm{~Hz}, 1 \mathrm{H}), 7.61(\mathrm{dd}, J=9.0,0.6$ $\mathrm{Hz}, 1 \mathrm{H}), 7.51(\mathrm{dd}, J=9.0,2.2 \mathrm{~Hz}, 1 \mathrm{H}), 7.38-7.31(\mathrm{~m}, 5 \mathrm{H}), 7.23-7.15(\mathrm{~m}, 5 \mathrm{H}), 3.04(\mathrm{~s}, 3 \mathrm{H}) .{ }^{13} \mathrm{C}$ NMR $\left(125 \mathrm{MHz}, \mathrm{CDCl}_{3}\right): \delta=157.0\left(\mathrm{C}_{\mathrm{q}}\right), 150.0\left(\mathrm{C}_{\mathrm{q}}\right), 140.8\left(\mathrm{C}_{\mathrm{q}}\right), 137.2\left(\mathrm{C}_{\mathrm{q}}\right), 134.6\left(\mathrm{C}_{\mathrm{q}}\right), 132.4\left(\mathrm{C}_{\mathrm{q}}\right), 131.4(\mathrm{CH})$, $130.8(\mathrm{CH}), 130.4(\mathrm{CH}), 129.2\left(\mathrm{C}_{\mathrm{q}}\right), 128.5(\mathrm{CH}), 128.3(\mathrm{CH}), 127.8(\mathrm{CH}), 127.5(\mathrm{CH}), 127.3(\mathrm{CH}), 127.0$ $\left(\mathrm{C}_{\mathrm{q}}\right), 124.7(\mathrm{CH}), 22.9\left(\mathrm{CH}_{3}\right)$. IR (ATR) $v=2956,1544,1498,1444,1409,880,868,794,701,568 \mathrm{~cm}^{-1}$. 
MS (ESI) $m / z$ (relative intensity): $330(100)[\mathrm{M}+\mathrm{H}]^{+}$. HR-MS (ESI) $m / z$ calcd for $\mathrm{C}_{22} \mathrm{H}_{17} \mathrm{CIN}[\mathrm{M}+\mathrm{H}]^{+}$: 330.1044, found: 330.1048 .<smiles>O=[N+]([O-])c1nc(-c2ccccc2)c(-c2ccccc2)c2ccc(Br)cc12</smiles>

7-Bromo-1-methyl-3,4-diphenylisoquinoline (119na): The general procedure A was followed using (E)-1-(3-bromophenyl)ethanone $O$-acetyl oxime (158n) (128 mg, $0.50 \mathrm{mmol})$ and diphenylacetylene (8a) (134 mg, $0.75 \mathrm{mmol}$ ). Purification by column chromatography on silica gel ( $n$-hexane/EtOAc: 20/1) yielded 119na (142 $\mathrm{mg}, 76 \%$ ) as a yellow solid.

M.p. $=133-135{ }^{\circ} \mathrm{C} .{ }^{1} \mathrm{H}$ NMR $\left(300 \mathrm{MHz}, \mathrm{CDCl}_{3}\right): \delta=8.34(\mathrm{~d}, J=2.0 \mathrm{~Hz}, 1 \mathrm{H}), 7.64$ (dd, $J=9.0,2.0 \mathrm{~Hz}$, $1 \mathrm{H}), 7.54(\mathrm{~d}, J=9.0 \mathrm{~Hz}, 1 \mathrm{H}), 7.39-7.31(\mathrm{~m}, 5 \mathrm{H}), 7.24-7.16(\mathrm{~m}, 5 \mathrm{H}), 3.04(\mathrm{~s}, 3 \mathrm{H}) .{ }^{13} \mathrm{C}$ NMR $(125 \mathrm{MHz}$, $\left.\mathrm{CDCl}_{3}\right): \delta=156.9\left(\mathrm{C}_{\mathrm{q}}\right), 150.0\left(\mathrm{C}_{\mathrm{q}}\right), 140.7\left(\mathrm{C}_{\mathrm{q}}\right), 137.1\left(\mathrm{C}_{\mathrm{q}}\right), 134.8\left(\mathrm{C}_{\mathrm{q}}\right), 133.4(\mathrm{CH}), 131.4(\mathrm{CH}), 130.3$ $(\mathrm{CH}), 129.2\left(\mathrm{C}_{\mathrm{q}}\right), 128.5(\mathrm{CH}), 128.4(\mathrm{CH}), 128.0(\mathrm{CH}), 127.8(\mathrm{CH}), 127.5(\mathrm{CH}), 127.4\left(\mathrm{C}_{\mathrm{q}}\right), 127.3(\mathrm{CH})$, $120.7\left(\mathrm{C}_{\mathrm{q}}\right), 22.8\left(\mathrm{CH}_{3}\right)$. IR (ATR) $v=3052,3023,1544,1496,1434,1407,1380,868,766,700 \mathrm{~cm}^{-1}$. MS (ESI) $m / z$ (relative intensity): $374(100)[M+H]^{+}$. HR-MS (ESI) $m / z$ calcd for $\mathrm{C}_{22} \mathrm{H}_{17} \mathrm{BrN}[\mathrm{M}+\mathrm{H}]^{+}$: 374.0539, found: 374.0541 .

The analytical data were in accordance with those reported in the literature. ${ }^{[182]}$<smiles>Cc1nc(-c2ccccc2)c(-c2ccccc2)c2c3c(ccc12)OCO3</smiles>

5,6-(Methylenedioxy)-1-methyl-3,4-diphenylisoquinoline (119oa): The general procedure A was followed using (E)-1-(benzo[d][1,3]dioxol-5-yl)ethanone $O$-acetyl oxime (1580) (111 mg, $0.50 \mathrm{mmol})$ and diphenylacetylene $(8 \mathrm{a})(134 \mathrm{mg}, 0.75 \mathrm{mmol})$. Purification by column chromatography on silica gel ( $n$-hexane/EtOAc: $10 / 1 \rightarrow 8 / 1 \rightarrow 5 / 1$ ) yielded 1190 a (76 $\mathrm{mg}, 45 \%$ ) as a white solid.

M.p. $=250-253^{\circ} \mathrm{C} .{ }^{1} \mathrm{H}$ NMR $\left(500 \mathrm{MHz}, \mathrm{CDCl}_{3}\right): \delta=7.82(\mathrm{~d}, J=8.8 \mathrm{~Hz}, 1 \mathrm{H}), 7.29-7.26(\mathrm{~m}, 2 \mathrm{H}), 7.25-$ $7.10(\mathrm{~m}, 9 \mathrm{H}), 5.83(\mathrm{~s}, 2 \mathrm{H}), 2.99(\mathrm{~s}, 3 \mathrm{H}) .{ }^{13} \mathrm{C} \mathrm{NMR}\left(125 \mathrm{MHz}, \mathrm{CDCl}_{3}\right): \delta=157.9\left(\mathrm{C}_{\mathrm{q}}\right), 150.3\left(\mathrm{C}_{\mathrm{q}}\right), 147.8$ $\left(\mathrm{C}_{\mathrm{q}}\right) 141.8\left(\mathrm{C}_{\mathrm{q}}\right), 141.0\left(\mathrm{C}_{\mathrm{q}}\right), 138.6\left(\mathrm{C}_{\mathrm{q}}\right), 131.3(\mathrm{CH}), 130.3(\mathrm{CH}), 127.6(\mathrm{CH}), 127.2(\mathrm{CH}), 127.0(\mathrm{CH})$, $126.9(\mathrm{CH}), 124.9\left(\mathrm{C}_{\mathrm{q}}\right), 123.4\left(\mathrm{C}_{\mathrm{q}}\right), 122.7\left(\mathrm{C}_{\mathrm{q}}\right), 121.1(\mathrm{CH}), 111.0(\mathrm{CH}), 101.6\left(\mathrm{CH}_{2}\right), 23.6\left(\mathrm{CH}_{3}\right) . \operatorname{IR}(\operatorname{ATR})$ 
$v=1431,1384,1353,1279,1049,1031,794,767,698,644 \mathrm{~cm}^{-1}$. MS (ESI) $\mathrm{m} / z$ (relative intensity): 340 (100) $[\mathrm{M}+\mathrm{H}]^{+}$. HR-MS (ESI) $\mathrm{m} / z$ calcd for $\mathrm{C}_{23} \mathrm{H}_{18} \mathrm{NO}_{2}[\mathrm{M}+\mathrm{H}]^{+}: 340.1332$, found: 340.1335 .

The analytical data were in accordance with those reported in the literature. ${ }^{[109 c]}$<smiles>Cc1nc(-c2ccccc2)c(-c2ccccc2)c2c(F)cccc12</smiles>

5-Fluoro-1-methyl-3,4-diphenylisoquinoline (119pa): The general procedure A was followed using (E)-1-(3-fluorophenyl)ethanone $O$-acetyl oxime (158p) $(98 \mathrm{mg}, 0.50 \mathrm{mmol}$ ) and diphenylacetylene (8a) (134 mg, $0.75 \mathrm{mmol}$ ). Purification by column chromatography on silica gel ( $n$-hexane/EtOAc: $30 / 1 \rightarrow 15: 1$ ) yielded $119 \mathrm{pa} \mathrm{(130} \mathrm{mg}, 83 \%$ ) as a pale yellow solid.

M.p. $=123-125{ }^{\circ} \mathrm{C} .{ }^{1} \mathbf{H}$ NMR $\left(400 \mathrm{MHz}, \mathrm{CDCl}_{3}\right): \delta=8.01(\mathrm{ddd}, J=8.4,1.2,0.5 \mathrm{~Hz}, 1 \mathrm{H}), 7.53(\mathrm{ddd}, J=$ 8.4, 7.7, 4.6 Hz, 1H), 7.32-7.12 (m, 11H), $3.08(\mathrm{~s}, 3 \mathrm{H}) .{ }^{13} \mathrm{C} \mathrm{NMR}\left(100 \mathrm{MHz}, \mathrm{CDCl}_{3}\right): \delta=159.0\left(\mathrm{~d},{ }^{1} J_{\mathrm{C}-\mathrm{F}}=\right.$ $\left.258 \mathrm{~Hz}, \mathrm{C}_{\mathrm{q}}\right), 157.4\left(\mathrm{~d},{ }^{4} \mathrm{~J}_{\mathrm{C}-\mathrm{F}}=2 \mathrm{~Hz}, \mathrm{Cq}\right), 151.4(\mathrm{Cq}), 140.71(\mathrm{Cq}), 139.3\left(\mathrm{~d},{ }^{3} \mathrm{~J}_{\mathrm{C}-\mathrm{F}}=4 \mathrm{~Hz}, \mathrm{Cq}\right), 130.4(\mathrm{~d}$, $\left.{ }^{4} J_{\mathrm{C}-\mathrm{F}}=3 \mathrm{~Hz}, \mathrm{CH}\right), 130.1(\mathrm{CH}), 128.0\left(\mathrm{~d},{ }^{4} J_{\mathrm{C}-\mathrm{F}}=3 \mathrm{~Hz}, \mathrm{Cq}\right), 127.3\left(\mathrm{~d},{ }^{2} \mathrm{~J}_{\mathrm{C}-\mathrm{F}}=22 \mathrm{~Hz}, \mathrm{CH}\right), 126.83(\mathrm{CH})$, $126.76(\mathrm{CH}), 126.66(\mathrm{CH}), 125.9\left(\mathrm{~d},{ }^{3} J_{\mathrm{C}-\mathrm{F}}=9 \mathrm{~Hz}, \mathrm{Cq}\right), 125.6\left(\mathrm{~d},{ }^{4} J_{\mathrm{C}-\mathrm{F}}=3 \mathrm{~Hz}, \mathrm{Cq}\right), 121.8\left(\mathrm{~d},{ }^{3} \mathrm{~J}_{\mathrm{C}-\mathrm{F}}=5 \mathrm{~Hz}\right.$, $\mathrm{CH}), 115.5\left(\mathrm{~d},{ }^{2} \mathrm{~J}_{\mathrm{C}-\mathrm{F}}=22.1 \mathrm{~Hz}, \mathrm{CH}\right), 23.21\left(\mathrm{CH}_{3}\right) .{ }^{19} \mathrm{~F} \mathrm{NMR}\left(376 \mathrm{MHz}, \mathrm{CDCl}_{3}\right): \delta=-105.64(\mathrm{dd}, J=12.7$, $4.5 \mathrm{~Hz}$ ). IR (ATR) $v=3087,3056,1552,1502,1430,1391,1326,1245,1028,904,769 \mathrm{~cm}^{-1}$. MS (ESI) $m / z$ (relative intensity): $314.1(100)[\mathrm{M}+\mathrm{H}]^{+}$. HR-MS (ESI) $\mathrm{m} / z$ calcd for $\mathrm{C}_{22} \mathrm{H}_{17} \mathrm{FN}[\mathrm{M}+\mathrm{H}]^{+}: 314.1340$, found: 314.1342 .<smiles>c1ccc(-c2nc3c4c(cccc4c2-c2ccccc2)CCC3)cc1</smiles>

2,3-Diphenyl-8,9-dihydro-7H-benzo[de]quinolone (119qa): The general procedure A was followed using (E)-3,4-dihydronaphthalen-1(2H)-one $O$-acetyl oxime (158q) (102 mg, $0.50 \mathrm{mmol}$ ) and diphenylacetylene (8a) (134 mg, $0.75 \mathrm{mmol})$. Purification by column chromatography on silica gel ( $n$-hexane/EtOAc: $30 / 1 \rightarrow 20 / 1 \rightarrow 15 / 1$ ) yielded 119qa (144 mg, 85\%) as a light brown solid.

M.p. $=148-150{ }^{\circ} \mathrm{C} .{ }^{1} \mathbf{H}$ NMR $\left(500 \mathrm{MHz}, \mathrm{CDCl}_{3}\right): \delta=7.52-7.45(\mathrm{~m}, 2 \mathrm{H}), 7.38-7.28(\mathrm{~m}, 6 \mathrm{H}), 7.24-7.14$ $(\mathrm{m}, 5 \mathrm{H}), 3.39(\mathrm{t}, J=6.4 \mathrm{~Hz}, 2 \mathrm{H}), 3.21(\mathrm{t}, J=6.2 \mathrm{~Hz}, 2 \mathrm{H}), 2.32-2.25(\mathrm{~m}, 2 \mathrm{H}) .{ }^{13} \mathrm{C} \mathrm{NMR}\left(125 \mathrm{MHz}, \mathrm{CDCl}_{3}\right)$ : 
$\delta=159.4\left(C_{q}\right), 149.6\left(C_{q}\right), 141.3\left(C_{q}\right), 138.6\left(C_{q}\right), 138.0\left(C_{q}\right), 136.4\left(C_{q}\right), 131.5(C H), 130.4(C H), 130.1$ $(\mathrm{CH}), 129.2\left(\mathrm{C}_{\mathrm{q}}\right), 128.3(\mathrm{CH}), 127.7(\mathrm{CH}), 127.2(\mathrm{CH}), 127.0(\mathrm{CH}) 124.9(\mathrm{CH}), 124.0\left(\mathrm{C}_{\mathrm{q}}\right), 123.7(\mathrm{CH})$, $35.0\left(\mathrm{CH}_{2}\right), 31.0\left(\mathrm{CH}_{2}\right), 23.6\left(\mathrm{CH}_{2}\right)$. IR (ATR) $v=2934,1577,1551,1496,1444,1387,1372,765,695$, $625 \mathrm{~cm}^{-1}$. MS (ESI) $\mathrm{m} / z$ (relative intensity): $322(100)[\mathrm{M}+\mathrm{H}]^{+}$. HR-MS (ESI) $\mathrm{m} / z$ calcd for $\mathrm{C}_{24} \mathrm{H}_{20} \mathrm{~N}$ $[\mathrm{M}+\mathrm{H}]^{+}: 322.1590$, found: 322.1588 .

The analytical data were in accordance with those reported in the literature. ${ }^{[182]}$<smiles>CCc1nc(-c2ccccc2)c(-c2ccccc2)c2ccccc12</smiles>

1-Ethyl-3,4-diphenylisoquinoline (119ra): The general procedure A was followed using (E)-propiophenone $O$-acetyl oxime (158r) $(96 \mathrm{mg}, 0.50 \mathrm{mmol}$ ) and diphenylacetylene (8a) (134 $\mathrm{mg}$, $0.75 \mathrm{mmol}$ ). Purification by column chromatography on silica gel ( $n$-hexane/EtOAc: 30/1 $\rightarrow$ 20/1) yielded 119ra (136 $\mathrm{mg}, 88 \%$ ) as a colorless solid.

M.p. $=114-116{ }^{\circ} \mathrm{C} .{ }^{1} \mathbf{H}$ NMR $\left(500 \mathrm{MHz}, \mathrm{CDCl}_{3}\right): \delta=8.28-8.24(\mathrm{~m}, 1 \mathrm{H}), 7.70-7.65(\mathrm{~m}, 1 \mathrm{H}), 7.61-7.55$ $(m, 2 H), 7.42-7.31(m, 5 H), 7.26-7.15(m, 5 H), 3.46(q, J=7.6 \mathrm{~Hz}, 2 \mathrm{H}), 1.55(\mathrm{t}, J=7.6 \mathrm{~Hz}, 3 \mathrm{H}) .{ }^{13} \mathrm{C}$ NMR $\left(125 \mathrm{MHz}, \mathrm{CDCl}_{3}\right): \delta=162.4\left(\mathrm{C}_{\mathrm{q}}\right), 149.4\left(\mathrm{C}_{\mathrm{q}}\right), 141.3\left(\mathrm{C}_{\mathrm{q}}\right), 137.9\left(\mathrm{C}_{\mathrm{q}}\right), 136.5\left(\mathrm{C}_{\mathrm{q}}\right), 131.5(\mathrm{CH})$, $130.5(\mathrm{CH}), 129.8(\mathrm{CH}), 129.1\left(\mathrm{C}_{\mathrm{q}}\right), 128.4(\mathrm{CH}), 127.7(\mathrm{CH}), 127.3(\mathrm{CH}), 127.0(\mathrm{CH}), 126.6(\mathrm{CH}), 125.4$ $\left(\mathrm{C}_{\mathrm{q}}\right), 125.3(\mathrm{CH}), 29.0\left(\mathrm{CH}_{2}\right), 14.1\left(\mathrm{CH}_{3}\right)$. IR (ATR) $v=3025,2981,2937,1553,1504,1422,1316,762$, $704,597 \mathrm{~cm}^{-1}$. MS (ESI) $\mathrm{m} / z$ (relative intensity): $310(100)[\mathrm{M}+\mathrm{H}]^{+}$. HR-MS (ESI) $\mathrm{m} / z$ calcd for $\mathrm{C}_{23} \mathrm{H}_{20} \mathrm{~N}$ $[\mathrm{M}+\mathrm{H}]^{+}: 310.1590$, found: 310.1597 .

The analytical data were in accordance with those reported in the literature. ${ }^{[109 c]}$<smiles>CC(C)c1nc(-c2ccccc2)c(-c2ccccc2)c2ccccc12</smiles>

1-Isopropyl-3,4-diphenylisoquinoline (119sa): The general procedure A was followed using acetophenone $O$-acetyl oxime (158s) $(103 \mathrm{mg}, 0.50 \mathrm{mmol}$ ) and diphenylacetylene (8a) (134 mg, $0.75 \mathrm{mmol}$ ). Purification by column chromatography on silica gel ( $n$-hexane/EtOAc: 30/1 $\rightarrow$ 20/1) yielded 119sa (135 $\mathrm{mg}, 83 \%$ ) as a colorless solid. 
M.p. $=142-144{ }^{\circ} \mathrm{C} .{ }^{1} \mathbf{H}$ NMR $\left(400 \mathrm{MHz}, \mathrm{CDCl}_{3}\right): \delta=8.33-8.29(\mathrm{~m}, 1 \mathrm{H}), 7.70-7.65(\mathrm{~m}, 1 \mathrm{H}), 7.61-7.53$ $(\mathrm{m}, 2 \mathrm{H}), 7.49-7.44(\mathrm{~m}, 2 \mathrm{H}), 7.42-7.33(\mathrm{~m}, 3 \mathrm{H}), 7.29-7.24(\mathrm{~m}, 2 \mathrm{H}), 7.24-7.16(\mathrm{~m}, 3 \mathrm{H}), 4.05$ (sept, $J=$ $6.8 \mathrm{~Hz}, 1 \mathrm{H}), 1.55(\mathrm{~d}, J=6.8 \mathrm{~Hz}, 6 \mathrm{H}) .{ }^{13} \mathrm{C} \mathrm{NMR}\left(100 \mathrm{MHz}, \mathrm{CDCl}_{3}\right): \delta=165.1\left(\mathrm{C}_{\mathrm{q}}\right), 148.7\left(\mathrm{C}_{\mathrm{q}}\right), 141.4\left(\mathrm{C}_{\mathrm{q}}\right)$, $138.3\left(\mathrm{C}_{\mathrm{q}}\right), 136.7\left(\mathrm{C}_{\mathrm{q}}\right), 131.6(\mathrm{CH}), 130.7(\mathrm{CH}), 129.5(\mathrm{CH}), 128.5\left(\mathrm{C}_{\mathrm{q}}\right), 128.4(\mathrm{CH}), 127.5(\mathrm{CH}), 127.2$ $(\mathrm{CH}), 127.0(\mathrm{CH}), 126.6(\mathrm{CH}), 126.4(\mathrm{CH}), 124.9\left(\mathrm{C}_{\mathrm{q}}\right), 124.7(\mathrm{CH}), 31.5(\mathrm{CH}), 22.4\left(\mathrm{CH}_{3}\right)$. IR (ATR) $v=$ 2969, 1551, 1381, 1032, 761, 703, 678, 633, 596, $569 \mathrm{~cm}^{-1}$. MS (ESI) $\mathrm{m} / \mathrm{z}$ (re:lative intensity): 324 (100) $[\mathrm{M}+\mathrm{H}]^{+}$. HR-MS (ESI) $\mathrm{m} / \mathrm{z}$ calcd for $\mathrm{C}_{23} \mathrm{H}_{20} \mathrm{~N}[\mathrm{M}+\mathrm{H}]^{+}: 324.1747$, found: 324.1748 .

The analytical data were in accordance with those reported in the literature. ${ }^{[194]}$<smiles>Cc1nc(-c2ccccc2)c(-c2ccccc2)c2sccc12</smiles>

4-Methyl-6,7-diphenylthieno[3,2-c]pyridine (119ta): The general procedure A was followed using (E)-1-(thiophen-3-yl)ethanone $O$-acetyl oxime (158t) $(92 \mathrm{mg}, 0.50 \mathrm{mmol}$ ) and diphenylacetylene (8a) (134 mg, $0.75 \mathrm{mmol}$ ). Purification by column chromatography on silica gel ( $n$-hexane/EtOAc: $30 / 1 \rightarrow$ 20/1) yielded 119ta (127 mg, 72\%) as a pale solid.

M.p. $=147-149{ }^{\circ} \mathrm{C} .{ }^{1} \mathrm{H}$ NMR $\left(400 \mathrm{MHz}, \mathrm{CDCl}_{3}\right): \delta=7.51(\mathrm{~d}, J=5.5 \mathrm{~Hz}, 1 \mathrm{H}), 7.45(\mathrm{~d}, J=5.5 \mathrm{~Hz}, 1 \mathrm{H})$, 7.41-7.36 (m, 2H), 7.34-7.29 (m, 5H), 7.23-7.17 (m, 3H), $2.93(\mathrm{~s}, 3 \mathrm{H}) .{ }^{13} \mathrm{C} \mathrm{NMR}\left(100 \mathrm{MHz}, \mathrm{CDCl}_{3}\right): \delta$ $=152.5\left(C_{q}\right), 149.9\left(C_{q}\right), 149.6\left(C_{q}\right), 140.2\left(C_{q}\right), 138.5\left(C_{q}\right), 133.8\left(C_{q}\right), 130.3(C H), 129.7(C H), 128.6$ (CH), $127.71(\mathrm{CH}), 127.68(\mathrm{CH}), 127.64\left(\mathrm{C}_{\mathrm{q}}\right), 127.60(\mathrm{CH}), 127.2(\mathrm{CH}), 122.5(\mathrm{CH}), 22.8\left(\mathrm{CH}_{3}\right)$. IR (ATR) $v=3060,1544,1414,1387,1073,1028,898,754,728,696,619 \mathrm{~cm}^{-1}$. MS (EI) m/z (relative intensity): $302[\mathrm{M}+\mathrm{H}]^{+}$. HR-MS (ESI) $\mathrm{m} / \mathrm{z}$ calcd for $\mathrm{C}_{20} \mathrm{H}_{16} \mathrm{NS}[\mathrm{M}+\mathrm{H}]^{+}: 302.1003$, found: 302.0998 .<smiles>Cc1ccc(-c2nc(C)c3ccccc3c2-c2ccc(C)cc2)cc1</smiles>

Methyl-3,4-di-p-tolylisoquinoline (119ab): The general procedure A was followed using (E)-acetophenone $O$-acetyl oxime (158a) $(89 \mathrm{mg}, 0.50 \mathrm{mmol}$ ) and 1,2-di-p-tolylethyne (8b) (155 mg, 
$0.75 \mathrm{mmol}$ ). Purification by column chromatography on silica gel ( $n$-hexane/EtOAc: $40 / 1 \rightarrow 20 / 1)$ yielded 119ab (145 $\mathrm{mg}, 89 \%)$ as a pale yellow solid.

M.p. $=151-153{ }^{\circ} \mathrm{C}^{1}{ }^{1} \mathbf{H}$ NMR $\left(500 \mathrm{MHz}, \mathrm{CDCl}_{3}\right): \delta=8.20-8.14(\mathrm{~m}, 1 \mathrm{H}), 7.70-7.64(\mathrm{~m}, 1 \mathrm{H})$, 7.59-7.53 $(\mathrm{m}, 2 \mathrm{H}), 7.31(\mathrm{~d}, J=8.2 \mathrm{~Hz}, 2 \mathrm{H}), 7.17(\mathrm{~d}, J=8.0 \mathrm{~Hz}, 2 \mathrm{H}), 7.13(\mathrm{~d}, J=8.1 \mathrm{~Hz}, 2 \mathrm{H}), 7.03(\mathrm{~d}, J=7.6 \mathrm{~Hz}$, 1H), $3.07(\mathrm{~s}, 3 \mathrm{H}), 2.40(\mathrm{~s}, 3 \mathrm{H}), 2.29(\mathrm{~s}, 3 \mathrm{H}) .{ }^{13} \mathrm{C} \mathrm{NMR}\left(125 \mathrm{MHz}, \mathrm{CDCl}_{3}\right): \delta=157.3\left(\mathrm{C}_{\mathrm{q}}\right), 149.3\left(\mathrm{C}_{\mathrm{q}}\right)$, $138.2\left(\mathrm{C}_{\mathrm{q}}\right), 136.5\left(\mathrm{C}_{\mathrm{q}}\right), 136.4\left(\mathrm{C}_{\mathrm{q}}\right), 136.2\left(\mathrm{C}_{\mathrm{q}}\right), 134.6\left(\mathrm{C}_{\mathrm{q}}\right), 131.1(\mathrm{CH}), 130.1(\mathrm{CH}), 129.6(\mathrm{CH}), 128.9$ $(\mathrm{CH}), 128.8\left(\mathrm{C}_{\mathrm{q}}\right), 128.3(\mathrm{CH}), 126.2(\mathrm{CH}), 126.0\left(\mathrm{C}_{\mathrm{q}}\right), 125.4(\mathrm{CH}), 22.7\left(\mathrm{CH}_{3}\right), 21.2\left(\mathrm{CH}_{3}\right), 21.1\left(\mathrm{CH}_{3}\right) . \mathbf{I R}$ (ATR) $v=3024,3000,2918,1607,1569,1546,1510,1430,1389,1370,1329,1261,1182,1106$, 1022, 817, 756, 728, 595, $564 \mathrm{~cm}^{-1}$. MS (ESI) m/z (relative intensity): 324 (100) [M+H] $]^{+}$HR-MS (ESI) $m / z$ calcd for $\mathrm{C}_{24} \mathrm{H}_{22} \mathrm{~N}[\mathrm{M}+\mathrm{H}]^{+}: 324.1747$, found: 324.1751 .

The analytical data were in accordance with those reported in the literature. ${ }^{[195]}$<smiles>O=[N+]([O-])c1nc(-c2ccc(C(F)(F)F)cc2)c(-c2ccc(C(F)(F)F)cc2)c2ccccc12</smiles>

1-Methyl-3,4-bis(4-(trifluoromethyl)phenyl)isoquinoline (119ae): The general procedure A was followed using (E)-acetophenone $O$-acetyl oxime (158a) $(89 \mathrm{mg}, 0.50 \mathrm{mmol})$ and 1,2-bis(4-(trifluoromethyl)phenyl)ethyne (8e) $(236 \mathrm{mg}, 0.75 \mathrm{mmol}$ ). Purification by column chromatography on silica gel ( $n$-hexane/EtOAc: $40 / 1 \rightarrow 20 / 1)$ yielded 119 ae $(140 \mathrm{mg}, 65 \%)$ as a pale yellow solid.

M.p. $=151-152{ }^{\circ} \mathrm{C}^{1}{ }^{1} \mathrm{H}$ NMR $\left(300 \mathrm{MHz}, \mathrm{CDCl}_{3}\right): \delta=8.26-8.21(\mathrm{~m}, 1 \mathrm{H}), 7.68-7.61(\mathrm{~m}, 4 \mathrm{H}), 7.58-7.54$ $(\mathrm{m}, 1 \mathrm{H}), 7.46(\mathrm{~m}, 4 \mathrm{H}), 7.36(\mathrm{~d}, J=7.8 \mathrm{~Hz}, 2 \mathrm{H}), 3.08(\mathrm{~s}, 3 \mathrm{H}) .{ }^{13} \mathrm{C} \mathrm{NMR}\left(125 \mathrm{MHz}, \mathrm{CDCl}_{3}\right): \delta=158.9\left(\mathrm{C}_{\mathrm{q}}\right)$, $148.0\left(C_{q}\right), 144.1\left(C_{q}\right), 141.1\left(C_{q}\right), 135.4\left(C_{q}\right), 131.7(C H), 130.6(C H), 130.5(C H), 129.8\left(q,{ }^{2} J_{C-F}=32\right.$ $\left.\mathrm{Hz}, \mathrm{C}_{\mathrm{q}}\right), 129.3\left(\mathrm{q},{ }^{2} \mathrm{~J}_{\mathrm{C}-\mathrm{F}}=32 \mathrm{~Hz}, \mathrm{C}_{\mathrm{q}}\right), 128.3\left(\mathrm{C}_{\mathrm{q}}\right), 127.3(\mathrm{CH}), 126.4\left(\mathrm{C}_{\mathrm{q}}\right), 125.8\left(\mathrm{C}_{\mathrm{q}}\right), 125.4\left(\mathrm{q},{ }^{3} J_{\mathrm{C}-\mathrm{F}}=4 \mathrm{~Hz}\right.$, $\mathrm{CH}), 124.8\left(\mathrm{q},{ }^{3} \mathrm{~J}_{\mathrm{C}-\mathrm{F}}=4 \mathrm{~Hz}, \mathrm{CH}\right), 124.0\left(\mathrm{~d},{ }^{1} \mathrm{~J}_{\mathrm{C}-\mathrm{F}}=272 \mathrm{~Hz}, \mathrm{C}_{\mathrm{q}}\right), 124.0\left(\mathrm{~d},{ }^{1} \mathrm{~J}_{\mathrm{C}-\mathrm{F}}=272 \mathrm{~Hz}, \mathrm{C}_{\mathrm{q}}\right), 22.74\left(\mathrm{CH}_{3}\right)$. ${ }^{19} \mathrm{~F}$ NMR $\left(376 \mathrm{MHz} \mathrm{CDCl}_{3}\right): \delta=62.5,62.6$. IR (ATR) $v=3063,2985,1618,1556,1411,1394,1320$, 1160, 1104, 1064, 1017, 951, 848, 834, $\mathrm{cm}^{-1}$. MS (ESI) $\mathrm{m} / \mathrm{z}$ (relative intensity): $432[\mathrm{M}+\mathrm{H}]^{+}$. HR-MS (ESI) $\mathrm{m} / \mathrm{z}$ calcd for $\mathrm{C}_{24} \mathrm{H}_{16} \mathrm{~F}_{6} \mathrm{~N}[\mathrm{M}+\mathrm{H}]^{+}:$432.1181, found: 432.1182 . 
<smiles>Cc1nc(-c2ccc(F)cc2)c(-c2ccc(F)cc2)c2ccccc12</smiles>

3,4-Bis(4-fluorophenyl)-1-methylisoquinoline (119af): The general procedure A was followed using (E)-acetophenone $O$-acetyl oxime (158a) $(89 \mathrm{mg}, 0.50 \mathrm{mmol}$ ) and 1,2-bis(4-fluorophenyl)ethyne (8f) (161 mg, $0.75 \mathrm{mmol}$ ). Purification by column chromatography on silica gel ( $n$-hexane/EtOAc: 40/1 $\rightarrow$ 20/1) yielded 119af (111 mg, 67\%) as a pale yellow solid.

M.p. $=138-140{ }^{\circ} \mathrm{C} .{ }^{1} \mathbf{H}$ NMR $\left(400 \mathrm{MHz}, \mathrm{CDCl}_{3}\right): \delta=8.23-8.14(\mathrm{~m}, 1 \mathrm{H}), 7.65-7.55(\mathrm{~m}, 3 \mathrm{H}), 7.37-7.28$ $(\mathrm{m}, 2 \mathrm{H}), 7.21-7.13(\mathrm{~m}, 2 \mathrm{H}), 7.11-7.01(\mathrm{~m}, 2 \mathrm{H}), 6.95-6.86(\mathrm{~m}, 2 \mathrm{H}), 3.05(\mathrm{~s}, 3 \mathrm{H}) .{ }^{13} \mathrm{C}$ NMR $(100 \mathrm{MHz}$, $\left.\mathrm{CDCl}_{3}\right): \delta=162.0\left(\mathrm{~d},{ }^{1} J_{\mathrm{C}-\mathrm{F}}=248 \mathrm{~Hz}, \mathrm{C}_{\mathrm{q}}\right), 162.0\left(\mathrm{~d},{ }^{1} \mathrm{~J}_{\mathrm{C}-\mathrm{F}}=247 \mathrm{~Hz}, \mathrm{C}_{\mathrm{q}}\right), 158.0\left(\mathrm{C}_{\mathrm{q}}\right), 148.6\left(\mathrm{C}_{\mathrm{q}}\right), 136.9(\mathrm{~d}$, $\left.{ }^{4} J_{C-F}=4 \mathrm{~Hz}, C_{q}\right), 135.9\left(C_{q}\right), 133.3\left(d,{ }^{4} J_{C-F}=4 \mathrm{~Hz}, C_{q}\right), 132.9\left(d,{ }^{3} J_{C-F}=8 \mathrm{~Hz}, C H\right), 131.9\left(d,{ }^{3} J_{C-F}=8 \mathrm{~Hz}\right.$, $\mathrm{CH}), 130.1(\mathrm{CH}), 128.0\left(\mathrm{C}_{\mathrm{q}}\right), 126.7(\mathrm{CH}), 126.2\left(\mathrm{C}_{\mathrm{q}}\right), 125.9(\mathrm{CH}), 125.6(\mathrm{CH}), 115.4\left(\mathrm{~d},{ }^{2} \mathrm{~J}_{\mathrm{C}-\mathrm{F}}=21 \mathrm{~Hz}, \mathrm{CH}\right)$, $114.6\left(\mathrm{~d},{ }^{2} \mathrm{~J}_{\mathrm{C}-\mathrm{F}}=21 \mathrm{~Hz}, \mathrm{CH}\right), 22.7\left(\mathrm{CH}_{3}\right) .{ }^{19} \mathrm{~F} \mathrm{NMR}\left(376 \mathrm{MHz}, \mathrm{CDCl}_{3}\right): \delta=114.6(\mathrm{tt}, J=8.8,5.6 \mathrm{~Hz})$, $-115.2(\mathrm{tt}, J=8.7,5.5 \mathrm{~Hz}$ ). IR (ATR) $v=3071,3035,1603,1572,1507,1437,1391,1222,1093,837$, 759, $728 \mathrm{~cm}^{-1}$. MS (ESI) m/z (relative intensity): 332 (100) [M+H] ${ }^{+}$. HR-MS (ESI) $\mathrm{m} / z$ calcd for $\mathrm{C}_{22} \mathrm{H}_{16} \mathrm{~F}_{2} \mathrm{~N}[\mathrm{M}+\mathrm{H}]^{+}: 332.1245$, found: 332.1246.

The analytical data were in accordance with those reported in the literature. ${ }^{[109 c]}$<smiles>Cc1nc(-c2ccc(Cl)cc2)c(-c2ccc(Cl)cc2)c2ccccc12</smiles>

3,4-Bis(4-chlorophenyl)-1-methylisoquinoline (119ag): The general procedure A was followed using (E)-acetophenone $O$-acetyl oxime (158a) $(89 \mathrm{mg}, 0.50 \mathrm{mmol}$ ) and 1,2-bis(4-chlorophenyl)ethyne (8g) (185 mg, $0.75 \mathrm{mmol}$ ). Purification by column chromatography on silica gel ( $n$-hexane/EtOAc: 40/1 $\rightarrow$ 20/1) yielded 119ag (120 mg, 66\%) as a pale yellow solid.

M.p. $=149-151{ }^{\circ} \mathrm{C} .{ }^{1} \mathbf{H}$ NMR $\left(500 \mathrm{MHz}, \mathrm{CDCl}_{3}\right): \delta=8.22-8.16(\mathrm{~m}, 1 \mathrm{H}), 7.62-7.57(\mathrm{~m}, 3 \mathrm{H}), 7.37-7.33$ 
(m, 2H), 7.31-7.27 (m, 2H), 7.21-7.17 (m, 2H), 7.16-7.12 (m, 2H), 3.06 (s, 3H). ${ }^{13} \mathrm{C}$ NMR (125 MHz, $\left.\mathrm{CDCl}_{3}\right) \delta=158.3\left(\mathrm{C}_{\mathrm{q}}\right), 148.1\left(\mathrm{C}_{\mathrm{q}}\right), 139.2\left(\mathrm{C}_{\mathrm{q}}\right), 135.8\left(\mathrm{C}_{\mathrm{q}}\right), 135.7\left(\mathrm{C}_{\mathrm{q}}\right), 133.4\left(\mathrm{C}_{\mathrm{q}}\right), 133.2\left(\mathrm{C}_{\mathrm{q}}\right), 132.6(\mathrm{CH})$, $131.5(\mathrm{CH}), 130.2(\mathrm{CH}), 128.7(\mathrm{CH}), 128.0\left(\mathrm{C}_{\mathrm{q}}\right), 127.9(\mathrm{CH}), 126.9(\mathrm{CH}), 126.2\left(\mathrm{C}_{\mathrm{q}}\right), 125.8(\mathrm{CH}), 125.6$ (CH), $22.6\left(\mathrm{CH}_{3}\right)$. IR (ATR) $v=3070,1568,1552,1488,1431,1333,1084,1013,796,460 \mathrm{~cm}^{-1}$. MS (ESI) $m / z$ (relative intensity): $364(100)[\mathrm{M}+\mathrm{H}]^{+}$. HR-MS (ESI) $m / z$ calcd for $\mathrm{C}_{22} \mathrm{H}_{16} \mathrm{Cl}{ }_{2} \mathrm{~N}[\mathrm{M}+\mathrm{H}]^{+}$: 364.0654, found: 364.0652 .

The analytical data were in accordance with those reported in the literature. ${ }^{[195]}$<smiles>Cc1nc(-c2ccc(Br)cc2)c(-c2ccc(Br)cc2)c2ccccc12</smiles>

3,4-Bis(4-bromophenyl)-1-methylisoquinoline (119ah): The general procedure A was followed using $(E)$-acetophenone $O$-acetyl oxime $(\mathbf{1 5 8 a}) \quad(89 \quad \mathrm{mg}, \quad 0.50 \mathrm{mmol})$ and 1,2-bis(4-bromophenyl)ethyne $(8 \mathrm{~h})(252 \mathrm{mg}, 0.75 \mathrm{mmol})$. Purification by column chromatography on silica gel ( $n$-hexane/EtOAc: 40/1 $\rightarrow$ 20/1) yielded 119ah (161 mg, 71\%) as a pale yellow solid.

M.p. $=176-178{ }^{\circ} \mathrm{C}^{1}{ }^{1} \mathrm{H}$ NMR $\left(500 \mathrm{MHz}, \mathrm{CDCl}_{3}\right): \delta=8.22-8.13(\mathrm{~m}, 1 \mathrm{H}), 7.65-7.55(\mathrm{~m}, 3 \mathrm{H}), 7.54-7.46$ $(\mathrm{m}, 2 \mathrm{H}), 7.36-7.32(\mathrm{~m}, 2 \mathrm{H}), 7.24-7.20(\mathrm{~m}, 2 \mathrm{H}), 7.10-7.06(\mathrm{~m}, 2 \mathrm{H}), 3.04(\mathrm{~s}, 3 \mathrm{H}) .{ }^{13} \mathrm{C}$ NMR (125 MHz, $\left.\mathrm{CDCl}_{3}\right): \delta=158.4\left(\mathrm{C}_{\mathrm{q}}\right), 148.1\left(\mathrm{C}_{\mathrm{q}}\right), 139.6\left(\mathrm{C}_{\mathrm{q}}\right), 136.2\left(\mathrm{C}_{\mathrm{q}}\right), 135.6\left(\mathrm{C}_{\mathrm{q}}\right), 132.9(\mathrm{CH}), 131.9(\mathrm{CH}), 131.7$ $(\mathrm{CH}), 130.9(\mathrm{CH}), 130.3(\mathrm{CH}), 127.9\left(\mathrm{C}_{\mathrm{q}}\right), 126.9(\mathrm{CH}), 126.2\left(\mathrm{C}_{\mathrm{q}}\right), 125.8(\mathrm{CH}), 125.7(\mathrm{CH}), 121.6\left(\mathrm{C}_{\mathrm{q}}\right)$, $121.5\left(\mathrm{C}_{\mathrm{q}}\right), 22.7\left(\mathrm{CH}_{3}\right)$. IR (ATR) $v=3060,1544,1414,1387,1073,1028,898,754,728,696 \mathrm{~cm}^{-1}$. MS (ESI) $m / z$ (relative intensity): $454[\mathrm{M}+\mathrm{H}]^{+}$. HR-MS (ESI) $m / z$ calcd for $\mathrm{C}_{22} \mathrm{H}_{16} \mathrm{Br}_{2} \mathrm{~N}[\mathrm{M}+\mathrm{H}]^{+}: 451.9649$, found: 451.9643.

The analytical data were in accordance with those reported in the literature. ${ }^{[195]}$ 
<smiles>Cc1nc(-c2cccc(Cl)c2)c(-c2cccc(Cl)c2)c2ccccc12</smiles>

3,4-Bis(3-chlorophenyl)-1-methylisoquinoline (119ai): The general procedure $\mathbf{A}$ was followed using (E)-acetophenone $O$-acetyl oxime (158a) $(89 \mathrm{mg}, 0.50 \mathrm{mmol}$ ) and 1,2-bis(3-chlorophenyl)ethyne (8i) (185 mg, $0.75 \mathrm{mmol}$ ). Purification by column chromatography on silica gel ( $n$-hexane/EtOAc: 40/1 $\rightarrow$ 20/1) yielded 119ai (95 $\mathrm{mg}, 52 \%$ ) as a pale yellow solid.

M.p. $=107-109{ }^{\circ} \mathrm{C}^{1}{ }^{1} \mathrm{H}$ NMR $\left(500 \mathrm{MHz}, \mathrm{CDCl}_{3}\right): \delta=8.23-8.17(\mathrm{~m}, 1 \mathrm{H}), 7.66-7.57(\mathrm{~m}, 3 \mathrm{H}), 7.47-7.46$ $(\mathrm{m}, 1 \mathrm{H}), 7.36-7.23(\mathrm{~m}, 3 \mathrm{H}), 7.19-7.14(\mathrm{~m}, 1 \mathrm{H}), 7.14-7.06(\mathrm{~m}, 3 \mathrm{H}), 3.06(\mathrm{~s}, 3 \mathrm{H}) .{ }^{13} \mathrm{C}$ NMR $(125 \mathrm{MHz}$, $\left.\mathrm{CDCl}_{3}\right): \delta=158.5\left(\mathrm{C}_{\mathrm{q}}\right), 147.9\left(\mathrm{C}_{\mathrm{q}}\right), 142.4\left(\mathrm{C}_{\mathrm{q}}\right), 139.1\left(\mathrm{C}_{\mathrm{q}}\right), 135.6\left(\mathrm{C}_{\mathrm{q}}\right), 134.3\left(\mathrm{C}_{\mathrm{q}}\right), 133.8\left(\mathrm{C}_{\mathrm{q}}\right), 131.2(\mathrm{CH})$, $130.4(\mathrm{CH}), 130.3(\mathrm{CH}), 129.7(\mathrm{CH}), 129.6(\mathrm{CH}), 128.8(\mathrm{CH}), 128.3(\mathrm{CH}), 128.1\left(\mathrm{C}_{\mathrm{q}}\right), 127.7(\mathrm{CH}), 127.4$ (CH), $127.0(\mathrm{CH}), 126.3\left(\mathrm{C}_{\mathrm{q}}\right), 125.9(\mathrm{CH}), 125.7(\mathrm{CH}), 22.7\left(\mathrm{CH}_{3}\right)$. IR (ATR) $v=3065,1593,1565,1434$, 1390, 1330, 1078, 783, 760, 703, $631 \mathrm{~cm}^{-1}$. MS (ESI) m/z (relative intensity): $364[\mathrm{M}+\mathrm{H}]^{+}$. HR-MS (ESI) $\mathrm{m} / \mathrm{z}$ calcd for $\mathrm{C}_{22} \mathrm{H}_{16} \mathrm{Cl}_{2} \mathrm{~N}[\mathrm{M}+\mathrm{H}]^{+}: 364.0654$, found: 364.0656 .<smiles>Cc1nc(-c2cccs2)c(-c2cccs2)c2ccccc12</smiles>

1-Methyl-3,4-di(thiophen-3-yl)isoquinoline (119aj): The general procedure A was followed using (E)-acetophenone $\quad O$-acetyl oxime $\quad(158 \mathrm{a}) \quad(89 \quad \mathrm{mg}, \quad 0.50 \quad \mathrm{mmol})$ and 2-(thiophen-3-ylethynyl)thiophene (8j) (143 mg, $0.75 \mathrm{mmol})$. Purification by column chromatography on silica gel ( $n$-hexane/EtOAc: $60 / 1 \rightarrow 30 / 1$ ) yielded 119aj (129 mg, 84\%) as a pale yellow solid.

M.p. $=120-122{ }^{\circ} \mathrm{C}^{1}{ }^{1} \mathrm{H}$ NMR $\left(500 \mathrm{MHz}, \mathrm{CDCl}_{3}\right): \delta=8.09(\mathrm{dd}, J=8.2,1.1 \mathrm{~Hz}, 1 \mathrm{H}), 7.63-7.55(\mathrm{~m}, 3 \mathrm{H})$, 7.52 (ddd, $J=8.1,6.5,1.5 \mathrm{~Hz}, 1 \mathrm{H}$ ), 7.30 (dd, $J=5.0,1.1 \mathrm{~Hz}, 1 \mathrm{H}$ ), 7.26 (dd, $J=5.2,3.4 \mathrm{~Hz}, 1 \mathrm{H}$ ), 7.09 (dd, $J=3.4,1.1 \mathrm{~Hz}, 1 \mathrm{H}), 6.91(\mathrm{dd}, J=5.0,3.8 \mathrm{~Hz}, 1 \mathrm{H}), 6.75(\mathrm{dd}, J=3.8,1.1 \mathrm{~Hz}, 1 \mathrm{H}), 3.03(\mathrm{~s}, 3 \mathrm{H}) .{ }^{13} \mathrm{C}$ NMR $\left(125 \mathrm{MHz}, \mathrm{CDCl}_{3}\right): \delta=158.7\left(\mathrm{C}_{\mathrm{q}}\right), 144.9\left(\mathrm{C}_{\mathrm{q}}\right), 144.2\left(\mathrm{C}_{\mathrm{q}}\right), 137.9\left(\mathrm{C}_{\mathrm{q}}\right), 137.7\left(\mathrm{C}_{\mathrm{q}}\right), 130.3(\mathrm{CH})$, $129.1(\mathrm{CH}), 127.8(\mathrm{CH}), 127.6(\mathrm{CH}), 127.4(\mathrm{CH}), 127.2(\mathrm{CH}), 126.4(\mathrm{CH}), 125.9(\mathrm{CH}), 125.7\left(\mathrm{C}_{\mathrm{q}}\right), 125.3$ 
(CH), $118.7\left(\mathrm{C}_{\mathrm{q}}\right), 22.6\left(\mathrm{CH}_{3}\right)$. IR (ATR) $v=3097,3066,1609,1558,1530,1433,1382,1233,1063,904$, 843, 816, 756, 702, 611, $541 \mathrm{~cm}^{-1}$. MS (ESI) $\mathrm{m} / z$ (relative intensity): $308[\mathrm{M}+\mathrm{H}]^{+}$. HR-MS (ESI) $\mathrm{m} / z$ calcd for $\mathrm{C}_{18} \mathrm{H}_{14} \mathrm{NS}_{2}[\mathrm{M}+\mathrm{H}]^{+}: 308.0562$, found: 308.0565 .

The analytical data were in accordance with those reported in the literature. ${ }^{[140 a]}$<smiles>CCc1nc([N+](=O)[O-])c2ccc(Cl)cc2c1CC</smiles>

6-Chloro-3,4-diethyl-1-methylisoquinoline (119gk): The general procedure A was followed using (E)-1-(4-chlorophenyl)ethanone O-acetyl oxime (158g) (106 mg, $0.50 \mathrm{mmol}$ ) and hex-3-yne (8k) (66 $\mathrm{mg}, 0.75 \mathrm{mmol}$ ). Purification by column chromatography on silica gel ( $n$-hexane/EtOAc: 30/1 $\rightarrow 15 / 1$ ) yielded 119gk (88 $\mathrm{mg}, 75 \%$ ) as a pale yellow solid.

M.p. $=34-36{ }^{\circ} \mathrm{C}^{1}{ }^{1} \mathrm{H}$ NMR $\left(400 \mathrm{MHz}, \mathrm{CDCl}_{3}\right): \delta=7.97(\mathrm{dd}, J=8.9,0.5 \mathrm{~Hz}, 1 \mathrm{H}), 7.90(\mathrm{dd}, J=2.1,0.5 \mathrm{~Hz}$, $1 \mathrm{H}), 7.39(\mathrm{dd}, J=8.9,2.1 \mathrm{~Hz}, 1 \mathrm{H}), 2.94(\mathrm{q}, J=7.6 \mathrm{~Hz}, 4 \mathrm{H}), 2.86(\mathrm{~s}, 3 \mathrm{H}), 1.31(\mathrm{t}, J=7.6 \mathrm{~Hz}, 3 \mathrm{H}), 1.25(\mathrm{t}$, $J=7.6 \mathrm{~Hz}, 3 \mathrm{H}) .{ }^{13} \mathrm{C}$ NMR $\left(100 \mathrm{MHz}, \mathrm{CDCl}_{3}\right): \delta=155.7\left(\mathrm{C}_{\mathrm{q}}\right), 153.9\left(\mathrm{C}_{\mathrm{q}}\right), 136.2\left(\mathrm{C}_{\mathrm{q}}\right), 135.8\left(\mathrm{C}_{\mathrm{q}}\right), 127.9$ $(\mathrm{CH}), 126.5\left(\mathrm{C}_{\mathrm{q}}\right), 126.1(\mathrm{CH}), 124.3\left(\mathrm{C}_{\mathrm{q}}\right), 122.5(\mathrm{CH}), 28.5\left(\mathrm{CH}_{2}\right), 22.3\left(\mathrm{CH}_{3}\right), 20.6\left(\mathrm{CH}_{2}\right), 15.1\left(\mathrm{CH}_{3}\right)$, $14.7\left(\mathrm{CH}_{3}\right)$. IR (ATR) $v=2963,2931,2870,1606,1565,1448,1387,1308,1164,1097,1001,875,817$, $805 \mathrm{~cm}^{-1}$. MS (ESI) $\mathrm{m} / z$ (relative intensity): $234[\mathrm{M}+\mathrm{H}]^{+}$. HR-MS (ESI) $\mathrm{m} / z$ calcd for $\mathrm{C}_{14} \mathrm{H}_{17} \mathrm{CIN}[\mathrm{M}+\mathrm{H}]^{+}$: 234.1044, found: 234.1049 .<smiles>Cc1nc(C(C)C)c(C(C)C)c2cc(Cl)ccc12</smiles>

6-Chloro-1-methyl-3,4-dipropylisoquinoline (119gl): The general procedure $A$ was followed using (E)-1-(4-chlorophenyl)ethanone $O$-acetyl oxime (158g) $(106 \mathrm{mg}, 0.50 \mathrm{mmol})$ and oct-4-yne (8I) (83 $\mathrm{mg}, 0.75 \mathrm{mmol}$ ). Purification by column chromatography on silica gel ( $n$-hexane/EtOAc: 30/1 $\rightarrow 15 / 1$ ) yielded $119 \mathrm{gl}$ ( $80 \mathrm{mg}, 61 \%$ ) as a pale yellow oil.

${ }^{1} \mathrm{H}$ NMR $\left(400 \mathrm{MHz}, \mathrm{CDCl}_{3}\right): \delta=7.97(\mathrm{dd}, J=8.9,0.5 \mathrm{~Hz}, 1 \mathrm{H}), 7.87(\mathrm{dd}, J=2.1,0.5 \mathrm{~Hz}, 1 \mathrm{H}), 7.39(\mathrm{dd}, J$ = 8.9, $2.0 \mathrm{~Hz}, 1 \mathrm{H}), 2.93-2.83(\mathrm{~m}, 7 \mathrm{H}), 1.82-1.69(\mathrm{~m}, 2 \mathrm{H}), 1.68-1.56(\mathrm{~m}, 2 \mathrm{H}), 1.07(\mathrm{t}, J=7.4 \mathrm{~Hz}, 3 \mathrm{H})$, $1.01(t, J=7.4 \mathrm{~Hz}, 3 \mathrm{H}) .{ }^{13} \mathrm{C}$ NMR $\left(100 \mathrm{MHz}, \mathrm{CDCl}_{3}\right): \delta=155.5\left(\mathrm{C}_{\mathrm{q}}\right), 153.0\left(\mathrm{C}_{\mathrm{q}}\right), 136.4\left(\mathrm{C}_{\mathrm{q}}\right), 135.7\left(\mathrm{C}_{\mathrm{q}}\right)$, 
$127.8(\mathrm{CH}), 126.1(\mathrm{CH}), 125.5\left(\mathrm{C}_{\mathrm{q}}\right), 124.2\left(\mathrm{C}_{\mathrm{q}}\right), 122.7(\mathrm{CH}), 37.4\left(\mathrm{CH}_{2}\right), 29.7\left(\mathrm{CH}_{2}\right), 24.1\left(\mathrm{CH}_{2}\right), 23.6$ $\left(\mathrm{CH}_{2}\right), 22.3\left(\mathrm{CH}_{3}\right), 14.5\left(\mathrm{CH}_{3}\right), 14.3\left(\mathrm{CH}_{3}\right)$. IR (ATR) $v=2958,2870,1606,1567,1455,1393,1329$, 1102, 991, 870, 812, $625 \mathrm{~cm}^{-1}$. MS (ESI) $\mathrm{m} / z$ (relative intensity): $262[\mathrm{M}+\mathrm{H}]^{+}$. HR-MS (ESI) $\mathrm{m} / z$ calcd for $\mathrm{C}_{16} \mathrm{H}_{21} \mathrm{CIN}[\mathrm{M}+\mathrm{H}]^{+}:$262.1357, found: 262.1358 .<smiles>CCCCc1nc(CCCC)c2cc(Cl)ccc2c1CCCC</smiles>

3,4-Dibutyl-6-chloro-1-methylisoquinoline (119gm): The general procedure $A$ was followed using (E)-1-(4-chlorophenyl)ethanone $O$-acetyl oxime $(\mathbf{1 5 8 g})(106 \mathrm{mg}, 0.50 \mathrm{mmol})$ and dec-5-yne $(\mathbf{8 m})$ (104 mg, $0.75 \mathrm{mmol}$ ). Purification by column chromatography on silica gel ( $n$-hexane/EtOAc: 40/1 $\rightarrow$ 20/1) yielded 119gm (123 mg, 85\%) as a pale yellow solid.

M.p. $=41-42{ }^{\circ} \mathrm{C}^{1}{ }^{1} \mathrm{H}$ NMR $\left(400 \mathrm{MHz} \mathrm{CDCl}_{3}\right): \delta=7.97(\mathrm{dd}, J=8.9,0.5 \mathrm{~Hz}, 1 \mathrm{H}), 7.88(\mathrm{dd}, J=2.1,0.5 \mathrm{~Hz}$, $1 \mathrm{H}), 7.39(\mathrm{dd}, J=8.9,2.0 \mathrm{~Hz}, 1 \mathrm{H}), 2.93-2.86(\mathrm{~m}, 4 \mathrm{H}), 2.85(\mathrm{~s}, 3 \mathrm{H}), 1.76-1.66(\mathrm{~m}, 2 \mathrm{H}), 1.62-1.38(\mathrm{~m}$, $6 \mathrm{H}), 0.99(\mathrm{t}, J=7.6 \mathrm{~Hz}, 3 \mathrm{H}), 0.95(\mathrm{t}, J=7.6 \mathrm{~Hz}, 3 \mathrm{H}) .{ }^{13} \mathrm{C} \mathrm{NMR}\left(100 \mathrm{MHz}, \mathrm{CDCl}_{3}\right): \delta=155.5\left(\mathrm{C}_{\mathrm{q}}\right), 153.2$ $\left(\mathrm{C}_{q}\right), 136.4\left(\mathrm{C}_{\mathrm{q}}\right), 135.7\left(\mathrm{C}_{\mathrm{q}}\right), 127.8(\mathrm{CH}), 126.0(\mathrm{CH}), 125.5\left(\mathrm{C}_{\mathrm{q}}\right), 124.2\left(\mathrm{C}_{\mathrm{q}}\right), 122.6(\mathrm{CH}), 35.3\left(\mathrm{CH}_{2}\right), 33.0$ $\left(\mathrm{CH}_{2}\right), 32.7\left(\mathrm{CH}_{2}\right), 27.4\left(\mathrm{CH}_{2}\right), 23.1\left(\mathrm{CH}_{2}\right), 23.0\left(\mathrm{CH}_{2}\right), 22.3\left(\mathrm{CH}_{3}\right), 14.1\left(\mathrm{CH}_{3}\right), 13.9\left(\mathrm{CH}_{3}\right)$. IR (ATR) $v=$ 2951, 2926, 2870, 1605, 1565, 1490, 1392, 1332, 1101, 991, 896, 877, 810, 773, $616 \mathrm{~cm}^{-1}$. MS (ESI) $m / z$ (relative intensity): $290[\mathrm{M}+\mathrm{H}]^{+}$. HR-MS (ESI) $m / z$ calcd for $\mathrm{C}_{18} \mathrm{H}_{25} \mathrm{CIN}[\mathrm{M}+\mathrm{H}]^{+}: 290.1670$, found: 290.1677 .<smiles>Cc1nc(-c2ccccc2)c(C)c2ccccc12</smiles>

1,4-Dimethyl-3-phenylisoquinoline (119an): The general procedure A was followed using (E)-acetophenone $O$-acetyl oxime (158a) $(89 \mathrm{mg}, 0.50 \mathrm{mmol}$ ) and prop-1-yn-1-ylbenzene (8n) (88 $\mathrm{mg}, 0.75 \mathrm{mmol}$ ). Purification by column chromatography on silica gel ( $n$-hexane/EtOAc: 40/1 $\rightarrow 20 / 1$ ) yielded 119an (79 $\mathrm{mg}, 68 \%$ ) as a pale yellow solid.

M.p. $=95-97{ }^{\circ} \mathrm{C} .{ }^{1} \mathbf{H}$ NMR $\left(500 \mathrm{MHz}, \mathrm{CDCl}_{3}\right): \delta=8.17-8.13(\mathrm{~m}, 1 \mathrm{H}), 8.04$ (ddd, $J=7.5,4.2,3.4 \mathrm{~Hz}$, $1 \mathrm{H}), 7.73(\mathrm{ddd}, J=8.3,6.9,1.3 \mathrm{~Hz}, 1 \mathrm{H}), 7.62-7.54(\mathrm{~m}, 3 \mathrm{H}), 7.48-7.43(\mathrm{~m}, 2 \mathrm{H}), 7.40-7.34(\mathrm{~m}, 1 \mathrm{H})$, 
$2.98(\mathrm{~d}, J=0.4 \mathrm{~Hz}, 3 \mathrm{H}), 2.59(\mathrm{~d}, J=0.4 \mathrm{~Hz}, 3 \mathrm{H}) .{ }^{13} \mathrm{C}$ NMR $\left(125 \mathrm{MHz}, \mathrm{CDCl}_{3}\right): \delta=155.8\left(\mathrm{C}_{\mathrm{q}}\right), 150.6\left(\mathrm{C}_{\mathrm{q}}\right)$, $141.6\left(\mathrm{C}_{\mathrm{q}}\right), 136.2\left(\mathrm{C}_{\mathrm{q}}\right), 129.8(\mathrm{CH}), 129.8(\mathrm{CH}), 128.1(\mathrm{CH}), 127.4(\mathrm{CH}), 126.2(\mathrm{CH}), 126.1\left(\mathrm{C}_{\mathrm{q}}\right), 126.0$ (CH), $124.1(\mathrm{CH}), 122.1(\mathrm{Cq}), 22.5\left(\mathrm{CH}_{3}\right), 15.4\left(\mathrm{CH}_{3}\right)$. IR (ATR) $v=2948,1568,1501,1431,1333,1084$, 1013, 837, 757, $561 \mathrm{~cm}^{-1}$. MS (ESI) $\mathrm{m} / z$ (relative intensity): $234[\mathrm{M}+\mathrm{H}]^{+}$. HR-MS (ESI) $\mathrm{m} / z$ calcd for $\mathrm{C}_{17} \mathrm{H}_{16} \mathrm{~N}[\mathrm{M}+\mathrm{H}]^{+}: 234.1277$, found: 234.1281 .

The analytical data were in accordance with those reported in the literature. ${ }^{[194]}$<smiles>Cc1nc(-c2ccccc2)cc2cc(Cl)ccc12</smiles>

6-Chloro-1-methyl-3-phenylisoquinoline (119go): The general procedure A was followed using (E)-1-(4-chlorophenyl)ethanone $O$-acetyl oxime $(\mathbf{1 5 8 g})(106 \mathrm{mg}, 0.50 \mathrm{mmol})$ and ethynylbenzene (80) $(77 \mathrm{mg}, 0.75 \mathrm{mmol})$. Purification by column chromatography on silica gel ( $n$-hexane/EtOAc: $60 / 1 \rightarrow 30 / 1$ ) yielded 119go ( $82 \mathrm{mg}, 65 \%$ ) as a pale yellow solid.

M.p. $=90-92{ }^{\circ} \mathrm{C} .{ }^{1} \mathrm{H}$ NMR $\left(500 \mathrm{MHz}, \mathrm{CDCl}_{3}\right): \delta=8.12-8.07(\mathrm{~m}, 2 \mathrm{H}), 8.01(\mathrm{~d}, J=10 \mathrm{~Hz}, 1 \mathrm{H}), 7.78(\mathrm{t}, J=$ $5 \mathrm{~Hz}, 2 \mathrm{H}), 7.51-7.44(\mathrm{~m}, 3 \mathrm{H}), 7.40(\mathrm{t}, J=10 \mathrm{~Hz}, 1 \mathrm{H}), 2.98(\mathrm{~s}, 3 \mathrm{H}) \cdot{ }^{13} \mathrm{C} \mathbf{N M R}\left(125 \mathrm{MHz}, \mathrm{CDCl}_{3}\right): \delta=$ $158.5\left(\mathrm{C}_{\mathrm{q}}\right), 151.1\left(\mathrm{C}_{\mathrm{q}}\right), 139.3\left(\mathrm{C}_{\mathrm{q}}\right), 137.6\left(\mathrm{C}_{\mathrm{q}}\right), 136.1\left(\mathrm{C}_{\mathrm{q}}\right), 128.7(\mathrm{CH}), 128.6(\mathrm{CH}), 127.6(\mathrm{CH}), 127.3$ (CH), $127.0(\mathrm{CH}), 126.2(\mathrm{CH}), 124.7\left(\mathrm{C}_{\mathrm{q}}\right), 114.2(\mathrm{CH}), 22.6\left(\mathrm{CH}_{3}\right)$. IR (ATR) $v=3068,3032,2922,1615$, 1566, 1489, 1385, 1361, 1086, 912, 886, 814, 772, $688 \mathrm{~cm}^{-1}$. MS (ESI) $\mathrm{m} / \mathrm{z}$ (relative intensity): 254 $[\mathrm{M}+\mathrm{H}]^{+}$. HR-MS (ESI) $\mathrm{m} / \mathrm{z}$ calcd for $\mathrm{C}_{16} \mathrm{H}_{13} \mathrm{CIN}[\mathrm{M}+\mathrm{H}]^{+}: 254.0731$, found: 254.0736 .<smiles>Cc1ccc(-c2cc3cc(Cl)ccc3c([N+](=O)[O-])n2)cc1</smiles>

6-Chloro-1-methyl-3-(p-tolyl)isoquinoline (119gp): The general procedure A was followed using (E)-1-(4-chlorophenyl)ethanone $O$-acetyl oxime $\quad(\mathbf{1 5 8 g}) \quad(106 \quad \mathrm{mg}, \quad 0.50 \mathrm{mmol})$ and 1-ethynyl-4-methylbenzene $(\mathbf{8 p})(87 \mathrm{mg}, 0.75 \mathrm{mmol})$. Purification by column chromatography on silica gel ( $n$-hexane/EtOAc: 60/1 $\rightarrow$ 30/1) yielded 119gp (68 mg, 51\%) as a pale yellow solid.

M.p. $=92-93{ }^{\circ} \mathrm{C} .{ }^{1} \mathrm{H}$ NMR $\left(500 \mathrm{MHz}, \mathrm{CDCl}_{3}\right): \delta=8.04-7.97(\mathrm{~m}, 3 \mathrm{H}), 7.78(\mathrm{~d}, J=2.1 \mathrm{~Hz}, 1 \mathrm{H}), 7.76(\mathrm{~s}$, $1 \mathrm{H}), 7.44(\mathrm{dd}, J=8.9,2.1 \mathrm{~Hz}, 1 \mathrm{H}), 7.29-7.27(\mathrm{~m}, 2 \mathrm{H}), 2.98(\mathrm{~d}, J=0.4 \mathrm{~Hz}, 3 \mathrm{H}), 2.41(\mathrm{~s}, 3 \mathrm{H}) .{ }^{13} \mathrm{C}$ NMR 
$\left(100 \mathrm{MHz}, \mathrm{CDCl}_{3}\right): \delta=158.4\left(\mathrm{C}_{\mathrm{q}}\right), 151.1\left(\mathrm{C}_{\mathrm{q}}\right), 138.6\left(\mathrm{C}_{\mathrm{q}}\right), 137.7\left(\mathrm{C}_{\mathrm{q}}\right), 136.5\left(\mathrm{C}_{\mathrm{q}}\right), 136.0\left(\mathrm{C}_{\mathrm{q}}\right), 129.5(\mathrm{CH})$, $127.4(\mathrm{CH}), 126.8(\mathrm{CH}), 126.2(\mathrm{CH}), 124.6\left(\mathrm{C}_{\mathrm{q}}\right), 113.6(\mathrm{CH}), 22.6\left(\mathrm{CH}_{3}\right), 21.3\left(\mathrm{CH}_{3}\right)$. IR $(\mathrm{ATR}) v=3063$, 2918, 1613, 1568, 1439, 1178, 1085, 914, 881, $818 \mathrm{~cm}^{-1}$. MS (ESI) $\mathrm{m} / \mathrm{z}$ (relative intensity): 268 $[\mathrm{M}+\mathrm{H}]^{+}$. HR-MS (ESI) $\mathrm{m} / \mathrm{z}$ calcd for $\mathrm{C}_{17} \mathrm{H}_{15} \mathrm{CIN}[\mathrm{M}+\mathrm{H}]^{+}: 268.0888$, found: 268.0888 .

\section{Intermolecular Competition Experiment}

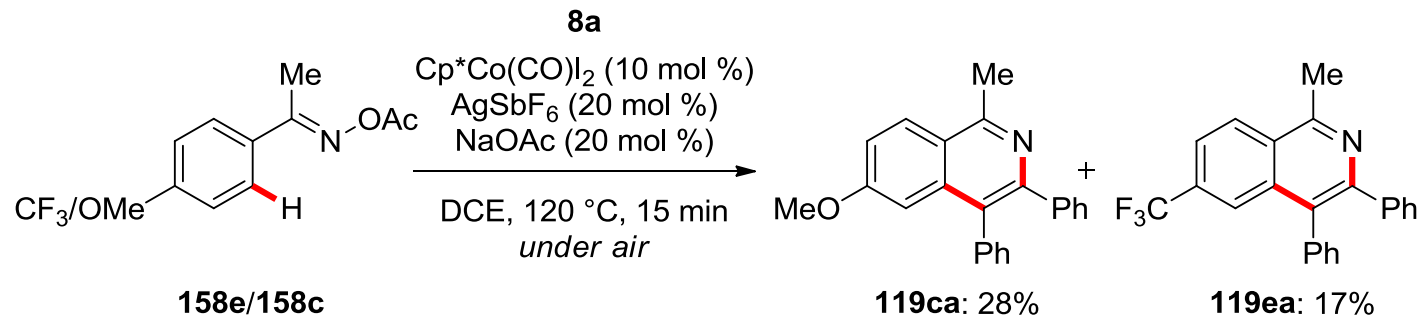

A suspension of (E)-1-(4-methoxyphenyl)ethanone $O$-acetyl oxime (158c) (104 mg, $0.5 \mathrm{mmol}$ ), (E)-1-[4-(trifluoromethyl)phenyl]ethanone O-acetyl oxime (158e) (123 $\mathrm{mg}, 0.5 \mathrm{mmol})$, diphenylacetylene (8a) $(89 \mathrm{mg}, 0.5 \mathrm{mmol}), \mathrm{Cp}^{*} \mathrm{Co}(\mathrm{CO}) \mathrm{I}_{2}(24 \mathrm{mg}, 10 \mathrm{~mol} \%), \mathrm{AgSbF}_{6}(34.4 \mathrm{mg}, 20$ $\mathrm{mol} \%)$ and $\mathrm{NaOAC}(8.2 \mathrm{mg}, 20 \mathrm{~mol} \%)$ in DCE $(2.0 \mathrm{~mL})$ was stirred at $120{ }^{\circ} \mathrm{C}$ for $15 \mathrm{~min}$ under air. After cooling to ambient temperature, the mixture was transferred into a round bottom flask with DCM $(20 \mathrm{~mL})$ and concentrated under reduced pressure, purified by flash column chromatography on silica gel ( $n$-hexane/EtOAc: $30 / 1 \rightarrow 20 / 1 \rightarrow 10 / 1$ ) yielded the products $119 \mathrm{ca} \mathrm{(45} \mathrm{mg,} 28 \%$ ) and 119ea (31 mg, 17\%).

\section{Intramolecular Competition Experiment}

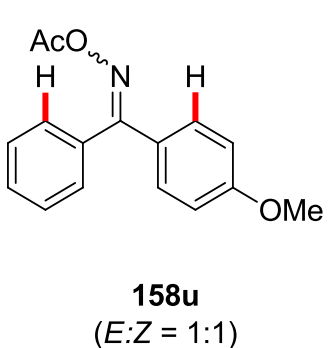

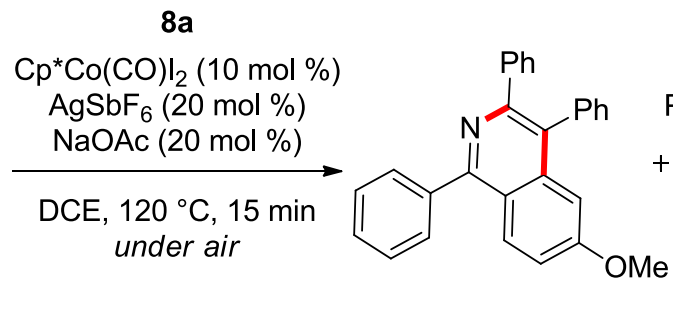

119ua: $63 \%$

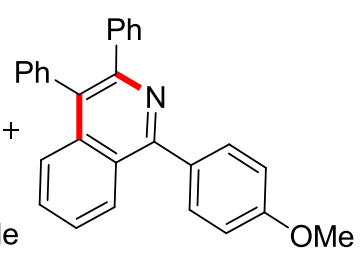

119ua': $12 \%$

A suspension of (4-methoxyphenyl)(phenyl)methanone $O$-acetyl oxime (158u) (135mg, $0.5 \mathrm{mmol}$ ), diphenylacetylene (8a) (89 mg, 0.5 mmol), $\mathrm{Cp}^{*} \mathrm{Co}(\mathrm{CO}) \mathrm{I}_{2}(24 \mathrm{mg}, 10 \mathrm{~mol} \%), \mathrm{AgSbF}_{6}(34.4 \mathrm{mg}, 20$ $\mathrm{mol} \%)$ and $\mathrm{NaOAC}(8.2 \mathrm{mg}, 20 \mathrm{~mol} \%)$ in DCE $(2.0 \mathrm{~mL})$ was stirred at $120^{\circ} \mathrm{C}$ for $15 \mathrm{~min}$ under air. After cooling to ambient temperature, the mixture was transferred into a round bottom flask with 
DCM $(20 \mathrm{~mL})$ and concentrated under reduced pressure, purified by flash column chromatography on silica gel ( $n$-hexane/EtOAc: $60 / 1 \rightarrow 40 / 1$ ) to afford the product 119ua (122 mg, 63\%) and 119ua' (23mg, 12\%).

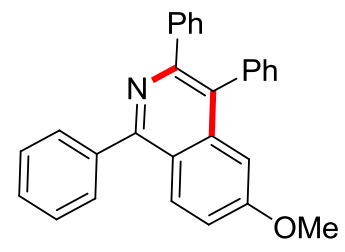

6-Methoxy-1,3,4-triphenylisoquinoline (119ua): A white solid.

M.p. $=183-185^{\circ} \mathrm{C} .{ }^{1} \mathrm{H}$ NMR $\left(300 \mathrm{MHz}, \mathrm{CDCl}_{3}\right): \delta=8.09(\mathrm{~d}, J=9.2 \mathrm{~Hz}, 1 \mathrm{H}), 7.86-7.73(\mathrm{~m}, 2 \mathrm{H}), 7.58-$ $7.47(\mathrm{~m}, 3 \mathrm{H}), 7.45-7.28(\mathrm{~m}, 7 \mathrm{H}), 7.22-7.10(\mathrm{~m}, 4 \mathrm{H}), 6.98(\mathrm{~d}, J=2.6 \mathrm{~Hz}, 1 \mathrm{H}), 3.73(\mathrm{~s}, 3 \mathrm{H}) .{ }^{13} \mathrm{C}$ NMR $\left(125 \mathrm{MHz}, \mathrm{CDCl}_{3}\right): \delta=160.5\left(\mathrm{C}_{\mathrm{q}}\right), 159.1\left(\mathrm{C}_{\mathrm{q}}\right), 150.3\left(\mathrm{C}_{\mathrm{q}}\right), 141.1\left(\mathrm{C}_{\mathrm{q}}\right), 139.9\left(\mathrm{C}_{\mathrm{q}}\right), 139.0\left(\mathrm{C}_{\mathrm{q}}\right), 137.8\left(\mathrm{C}_{\mathrm{q}}\right)$, $131.2(\mathrm{CH}), 130.4(\mathrm{CH}), 130.1(\mathrm{CH}), 129.4(\mathrm{CH}), 129.0\left(\mathrm{C}_{q}\right), 128.4(\mathrm{CH}), 128.4(\mathrm{CH}), 128.2(\mathrm{CH}), 127.4$ (CH), $127.2(\mathrm{CH}), 126.9(\mathrm{CH}), 121.2\left(\mathrm{C}_{\mathrm{q}}\right), 118.8(\mathrm{CH}), 104.2(\mathrm{CH}), 55.2\left(\mathrm{CH}_{3}\right)$. IR (ATR) $v=1407,1374$, 1220, 1029, 833, 775, 752, 702, 694, $666 \mathrm{~cm}^{-1}$. MS (ESI) m/z (relative intensity): 388 (100) [M+H] ${ }^{+}$ HR-MS (ESI) $m / z$ calcd for $\mathrm{C}_{28} \mathrm{H}_{22} \mathrm{NO}[\mathrm{M}+\mathrm{H}]^{+}: 388.1696$, found: 388.1699 .<smiles>COc1ccc(-c2nc(-c3ccccc3)c(-c3ccccc3)c3ccccc23)cc1</smiles>

1-(4-Methoxyphenyl)-3,4-diphenylisoquinoline (119ua'): A white solid.

M.p. $=155-157^{\circ} \mathrm{C} .{ }^{1} \mathrm{H}$ NMR $\left(400 \mathrm{MHz}, \mathrm{CDCl}_{3}\right): \delta=8.22(\mathrm{ddd}, J=8.3,1.4,0.7 \mathrm{~Hz}, 1 \mathrm{H}), 7.84-7.75(\mathrm{~m}$, $2 \mathrm{H}$ ), 7.70 (ddd, $J=8.5,1.3,0.7 \mathrm{~Hz}, 1 \mathrm{H}$ ), 7.57 (ddd, $J=8.4,6.7,1.4 \mathrm{~Hz}, 1 \mathrm{H}$ ), 7.51 (ddd, $J=8.1,6.7$, $1.3 \mathrm{~Hz}, 1 \mathrm{H}), 7.45-7.32(\mathrm{~m}, 5 \mathrm{H}), 7.31-7.27(\mathrm{~m}, 2 \mathrm{H}), 7.21-7.14(\mathrm{~m}, 3 \mathrm{H}), 7.08(\mathrm{~d}, J=8.7 \mathrm{~Hz}, 2 \mathrm{H}), 3.90$ (s, $3 \mathrm{H}) .{ }^{13} \mathrm{C}$ NMR $\left(100 \mathrm{MHz}, \mathrm{CDCl}_{3}\right): \delta=160.0\left(\mathrm{C}_{\mathrm{q}}\right), 159.4\left(\mathrm{C}_{\mathrm{q}}\right), 149.6\left(\mathrm{C}_{\mathrm{q}}\right), 141.0\left(\mathrm{C}_{\mathrm{q}}\right), 137.6\left(\mathrm{C}_{\mathrm{q}}\right)$, $137.0\left(\mathrm{C}_{\mathrm{q}}\right), 132.4\left(\mathrm{C}_{\mathrm{q}}\right), 131.6(\mathrm{CH}), 131.4(\mathrm{CH}), 130.4(\mathrm{CH}), 129.8(\mathrm{CH}), 129.3\left(\mathrm{C}_{\mathrm{q}}\right), 128.3(\mathrm{CH}), 127.5$ (CH), $127.5(\mathrm{CH}), 127.2(\mathrm{CH}), 126.9(\mathrm{CH}), 126.4(\mathrm{CH}), 126.0\left(\mathrm{C}_{\mathrm{q}}\right), 125.4(\mathrm{CH}), 113.8(\mathrm{CH}), 55.4\left(\mathrm{CH}_{3}\right) . \mathbf{I R}$ (ATR) $v=3055,2928,1736,1606,1540,1501,1384,1245,1170,1028,980,841,768,700 \mathrm{~cm}^{-1}$. MS (ESI) $m / z$ (relative intensity): $388(100)[\mathrm{M}+\mathrm{H}]^{+}$. HR-MS (ESI) $\mathrm{m} / z$ calcd for $\mathrm{C}_{28} \mathrm{H}_{22} \mathrm{NO}[\mathrm{M}+\mathrm{H}]^{+}$: 388.1696, found: 388.1699 . 
The analytical data were in accordance with those reported in the literature. ${ }^{[196]}$ Intermolecular Competition Experiment between Alkynes

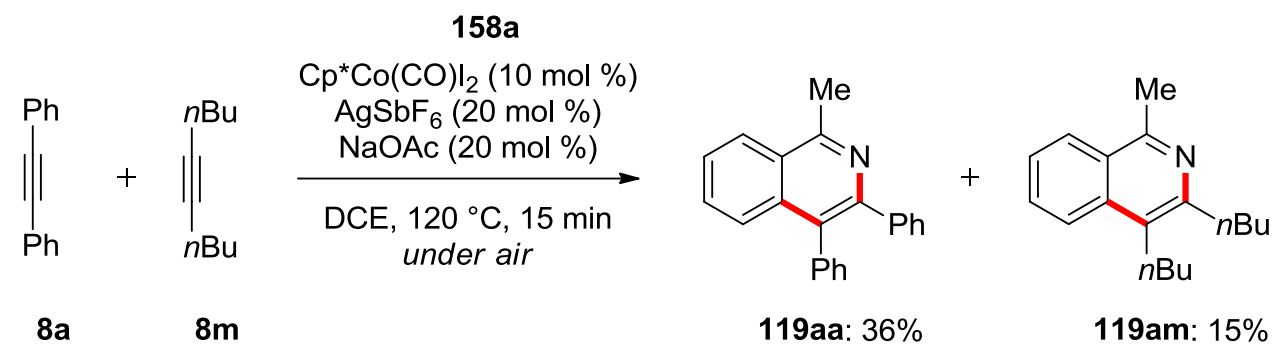

To a solution of $(E)$-acetophenone $O$-acetyl oxime (158a) (89 mg, $0.5 \mathrm{mmol}$ ), diphenylacetylene (8a) (89 mg, 0.5 mmol), dec-5-yne (8m) (69 mg, 0.5 mmol), Cp*Co(CO)I 2 (24 mg, 10 mol \%), AgSbF 6 (34.4 $\mathrm{mg}, 20 \mathrm{~mol} \%)$ and $\mathrm{NaOAC}(8.2 \mathrm{mg}, 20 \mathrm{~mol} \%)$ in DCE $(2.0 \mathrm{~mL})$ was stirred at $120{ }^{\circ} \mathrm{C}$ for $15 \mathrm{~min}$ under air. After cooling to ambient temperature, the mixture was transferred into a round bottom flask with DCM $(20 \mathrm{~mL})$ and concentrated under reduced pressure, purified by flash column chromatography on silica gel ( $n$-hexane/EtOAc: 20/1) to afford the products (119aa + 119am: $73 \mathrm{mg}$ ) and the yields were determined by ${ }^{1} \mathrm{H}$ NMR spectroscopy.

\section{$H / D$ Exchange Experiment}

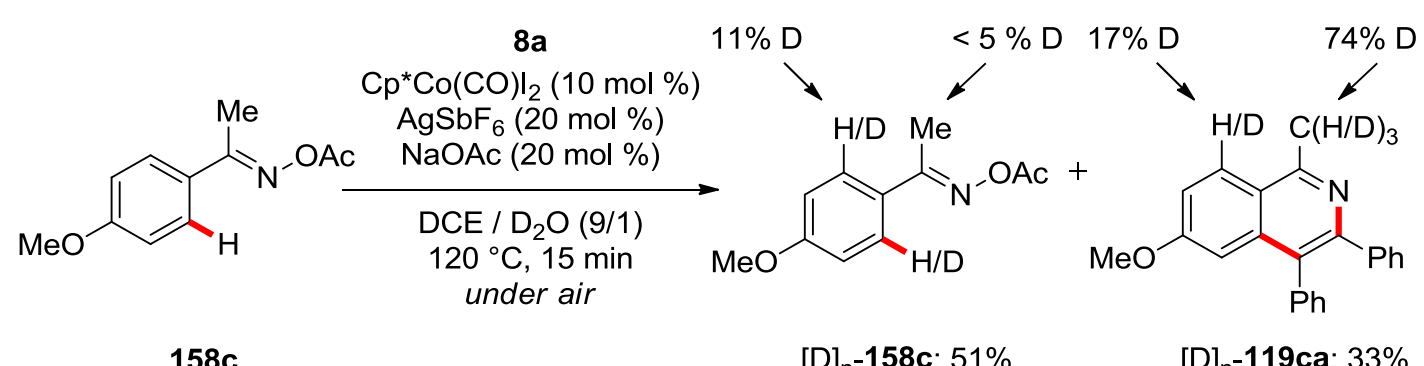

(E)-1-(4-Methoxyphenyl)ethanone $O$-acetyl oxime (158c) (104 mg, $0.5 \mathrm{mmol})$, diphenylacetylene (8a) (89 mg, $0.50 \mathrm{mmol}$ ), Cp*Co(CO)I 2 (24 mg, 10 mol \%), AgSbF 6 (34.4 mg, $20 \mathrm{~mol} \%$ ), NaOAc (8.2 mg, $20 \mathrm{~mol} \%)$, DCE $(1.8 \mathrm{~mL})$ and $\mathrm{D}_{2} \mathrm{O}(0.2 \mathrm{ml})$ were placed in a $25 \mathrm{~mL}$ Schlenk tube under air and then were stirred at $120{ }^{\circ} \mathrm{C}$ for $15 \mathrm{~min}$. At ambient temperature, the reaction mixture was diluted with $\mathrm{H}_{2} \mathrm{O}(10 \mathrm{~mL})$ and extracted with EtOAc $(3 \times 15 \mathrm{~mL})$. The combined organic layers were dried over $\mathrm{Na}_{2} \mathrm{SO}_{4}$ and concentrated under reduced pressure. Purification by flash column chromatography on silica gel ( $n$-hexane/EtOAc: $40 / 1 \rightarrow 15 / 1)$ yielded $[D]_{n}-158 c(53 \mathrm{mg}, 51 \%)$ and $[D]_{n}-119 c a(54 \mathrm{mg}$, 33\%). The $H / D$ exchange results of this reaction were determined by ${ }^{1} \mathrm{H}$ NMR spectroscopy. 

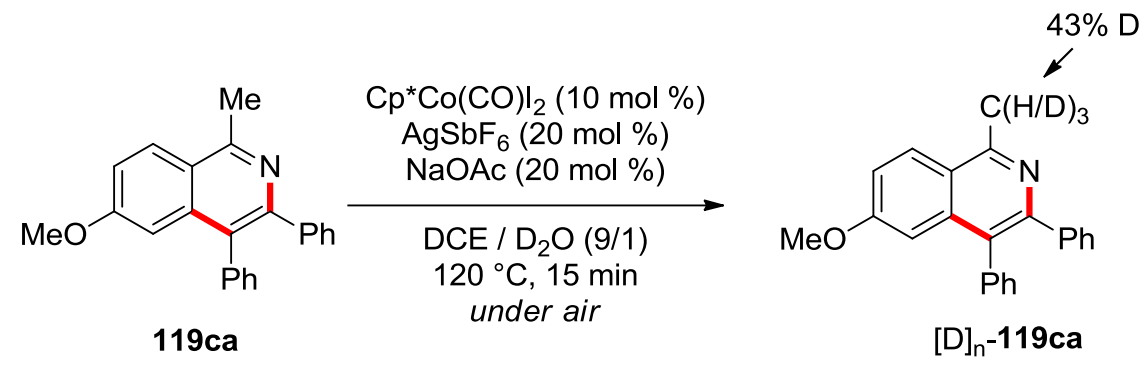

6-Methoxy-1-methyl-3,4-diphenylisoquinoline (119ca) (163mg, $0.5 \mathrm{mmol}), \mathrm{Cp}{ }^{*} \mathrm{Co}(\mathrm{CO}) \mathrm{I}_{2}(24 \mathrm{mg}, 10$ mol \%), $\operatorname{AgSbF}_{6}(34.4 \mathrm{mg}, 20 \mathrm{~mol} \%), \mathrm{NaOAc}(8.2 \mathrm{mg}, 20 \mathrm{~mol} \%), \mathrm{DCE}(1.8 \mathrm{~mL})$ and $\mathrm{D}_{2} \mathrm{O}(0.2 \mathrm{ml})$ were placed in a $25 \mathrm{~mL}$ Schlenk tube under air and were then stirred at $120{ }^{\circ} \mathrm{C}$ for $15 \mathrm{~min}$. At ambient temperature, the reaction mixture was filtered over a short plug of silica and the result of $H / D$ exchange experiment was determined by crude ${ }^{1} \mathrm{H}$ NMR. Then the reaction mixture was transferred into a round bottom flask with DCM $(20 \mathrm{~mL})$ and concentrated under reduced pressure, purified by flash column chromatography on silica gel ( $n$-hexane/EtOAc: $15 / 1$ ) yielded $[D]_{n}-119$ ca (155 mg, 95\%).

\section{Kinetic Isotope Effect Experiment}
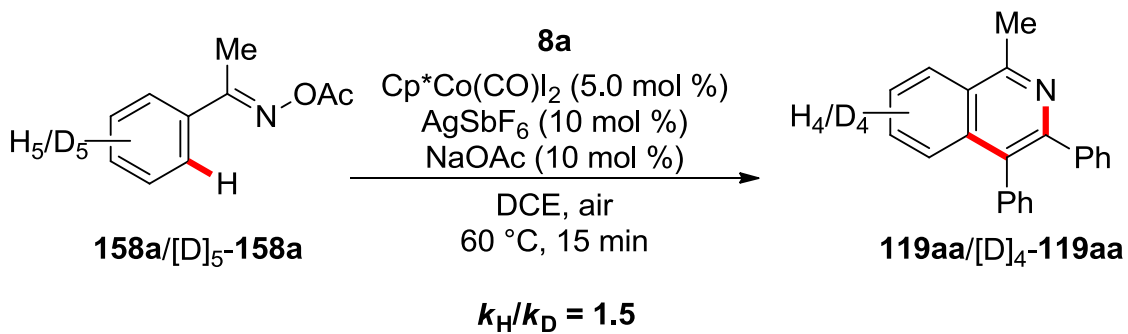

Two parallel reactions of $\mathbf{8 a}$ with $158 \mathrm{a}$ and $[\mathrm{D}]_{5}-\mathbf{1 5 8 a}$ respectively were performed to determine the corresponding KIE value: $158 \mathrm{a}\left(89 \mathrm{mg}, 0.5 \mathrm{mmol}\right.$ ) or $[\mathrm{D}]_{5}-158 \mathrm{a}$ (93 mg, $0.5 \mathrm{mmol}$ ), diphenylacetylene (8a) (134 mg, $0.75 \mathrm{mmol}), \mathrm{Cp}^{*} \mathrm{Co}(\mathrm{CO}) \mathrm{I}_{2}(12 \mathrm{mg}, 5 \mathrm{~mol} \%), \mathrm{AgSbF}_{6}(17.2 \mathrm{mg}, 10$ $\mathrm{mol} \%), \mathrm{NaOAc}(4 \mathrm{mg}, 20 \mathrm{~mol} \%)$, 1,3,5-trimethoxybenzene (28 mg, 0.5/3 mmol) and DCE (2.0 mL) were placed in a $25 \mathrm{~mL}$ Schlenk tube. The mixture was stirred at $60^{\circ} \mathrm{C}$, a periodic aliquot $(0.05 \mathrm{~mL})$ was taking out by syringe and analyzed by GC to provide the following conversions: 


\begin{tabular}{|c|c|c|c|c|c|}
\hline$t / \min$ & 5 & 10 & 15 & 20 & 30 \\
\hline yield / \% & & & & & \\
\hline$[D]_{5}-119 a a$ & 3 & 9 & 14 & 19 & 28 \\
\hline
\end{tabular}

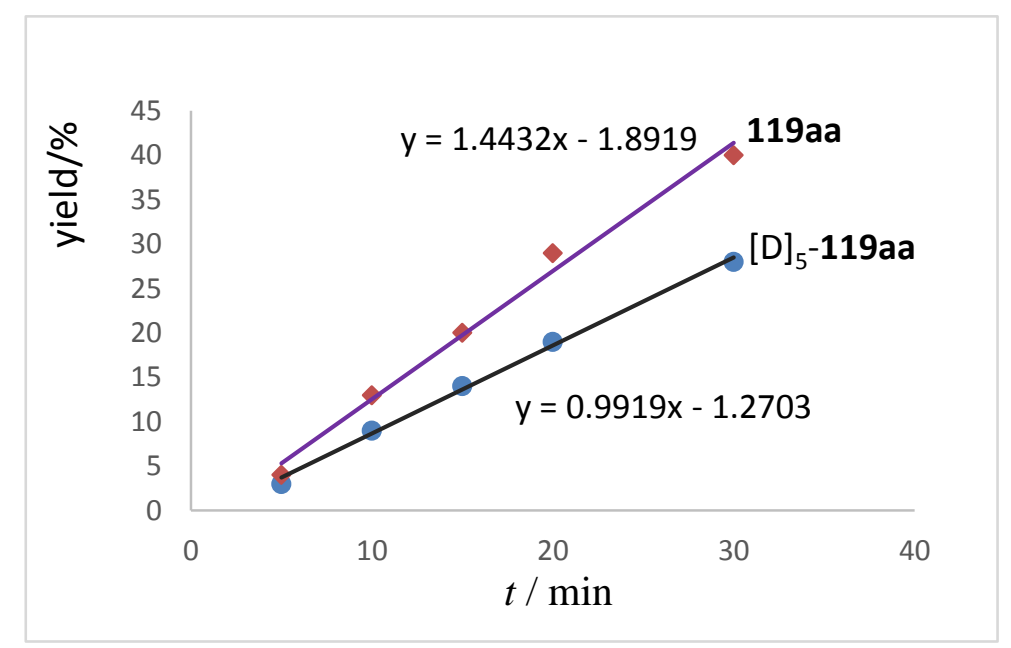

\section{Attempted Cyclization of ortho-Alkenylated Arene 119aa}
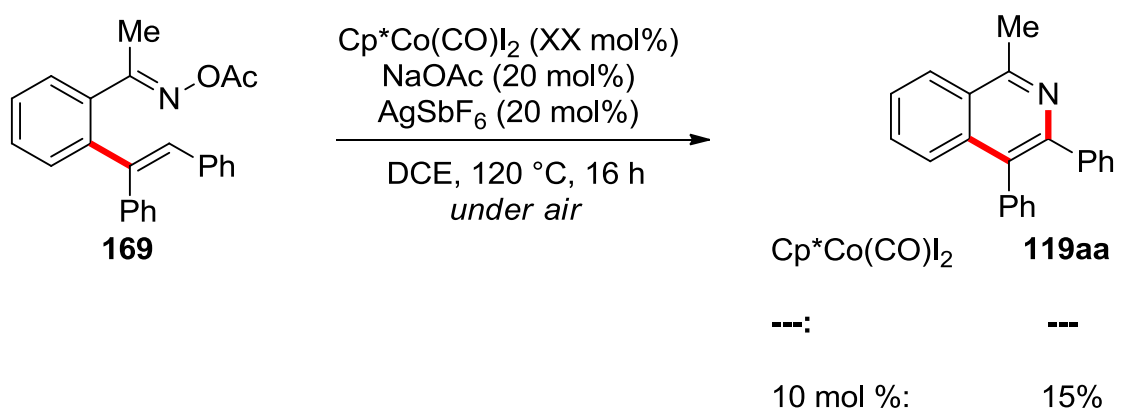

$(E)-1-\left\{2-\left[(E)-1,2-\right.\right.$ diphenylvinyl]phenyl\}ethanone $O$-acetyl oxime (169) (25mg, 70 umol), Cp*Co(CO) $I_{2}$ (3.4 mg, $10 \mathrm{~mol} \%), \mathrm{AgSbF}_{6}(5 \mathrm{mg}, 20 \mathrm{~mol} \%), \mathrm{NaOAc}(2 \mathrm{mg}, 20 \mathrm{~mol} \%)$, DCE $(0.3 \mathrm{~mL}$ ) were placed in a $25 \mathrm{~mL}$ Schlenk tube under air and were then stirred at $120{ }^{\circ} \mathrm{C}$ for $16 \mathrm{~h}$. After cooling to ambient temperature, the reaction mixture was transferred into a round bottom flask with $\mathrm{DCM}(10 \mathrm{~mL})$ and concentrated under reduced pressure, purified by flash column chromatography on silica gel (n-hexane/EtOAc: 25/1) yielded 119aa (15\%). In the absence of the Co-catalyst no reaction was observed and only starting material was recovered. 
<smiles>CC(=O)O/N=C(\C)c1ccccc1/C(=C/c1ccccc1)c1ccccc1</smiles>

(E)-1-\{2-[(E)-1,2-Diphenylvinyl]phenyl\}ethanone $O$-acetyl oxime (169): A white solid.

M.p. $=110-114{ }^{\circ} \mathrm{C} .{ }^{1} \mathrm{H}$ NMR $\left(500 \mathrm{MHz}, \mathrm{CDCl}_{3}\right): \delta=7.46-7.38(\mathrm{~m}, 3 \mathrm{H}), 7.35-7.23(\mathrm{~m}, 5 \mathrm{H})$, 7.19-7.09 $(\mathrm{m}, 3 \mathrm{H}), 7.04-6.99(\mathrm{~m}, 3 \mathrm{H}), 2.01(\mathrm{~s}, 3 \mathrm{H}), 1.89(\mathrm{~s}, 3 \mathrm{H}) .{ }^{13} \mathrm{C} \mathrm{NMR}\left(125 \mathrm{MHz}, \mathrm{CDCl}_{3}\right): \delta=170.8\left(\mathrm{C}_{\mathrm{q}}\right)$, $163.5\left(C_{q}\right), 142.7\left(C_{q}\right), 141.2\left(C_{q}\right), 139.4\left(C_{q}\right), 137.1\left(C_{q}\right), 136.4\left(C_{q}\right), 132.0(C H), 130.0(C H), 129.5(C H)$, $129.4(\mathrm{CH}), 129.1(\mathrm{CH}), 128.4(\mathrm{CH}), 128.2(\mathrm{CH}), 128.1(\mathrm{CH}), 127.8(\mathrm{CH}), 127.5(\mathrm{CH}), 127.2(\mathrm{CH}), 20.1$ $\left(\mathrm{CH}_{3}\right), 16.6\left(\mathrm{CH}_{3}\right)$. IR (ATR) $v=1772,1317,1210,924,762,750,697,644 \mathrm{~cm}^{-1}$. MS (ESI) $\mathrm{m} / \mathrm{z}$ (relative intensity): 378 (100) [M+Na] $]^{+}, 296$ (70) [M-OAc] ${ }^{+}$. HR-MS (ESI) $\mathrm{m} / z$ calcd for $\mathrm{C}_{24} \mathrm{H}_{21} \mathrm{~N}_{2} \mathrm{NaO}[\mathrm{M}+\mathrm{Na}]^{+}$: 378.1465, found: 378.1466 .

The analytical data were in accordance with those reported in the literature. ${ }^{[182]}$

\subsubsection{Data for the Products of Indoles by Cobalt(III)-Catalyzed $\mathrm{C}-\mathrm{H} / \mathrm{N}-\mathrm{O}$ Functionalizations with} Nitrones

\section{Characterization Data}<smiles>Cc1ccc2[nH]c(-c3ccccc3)c(-c3ccccc3)c2c1</smiles>

5-Methyl-2,3-diphenyl-1H-indole (160aa): The general procedure B was followed using $\mathrm{N}$-(4-methoxybenzylidene)-4-methylaniline oxide $\quad(159 \mathrm{a}) \quad(121 \mathrm{mg}, \quad 0.50 \mathrm{mmol})$ and 1,2-diphenylethyne (8a) (134 mg, $0.75 \mathrm{mmol}$ ). Purification by coloumn chromatography on silica gel ( $n$-hexane $/ \mathrm{CH}_{2} \mathrm{Cl}_{2}: 3 / 1$ ) yielded 160aa (130 mg, 92\%) as a white solid.

M. p. $=143-145{ }^{\circ} \mathrm{C}^{1}{ }^{1} \mathbf{H}$ NMR $\left(300 \mathrm{MHz}, \mathrm{CDCl}_{3}\right): \delta=8.11(\mathrm{~s}, 1 \mathrm{H}), 7.58-7.37(\mathrm{~m}, 7 \mathrm{H}), 7.36-7.19(\mathrm{~m}$, $5 \mathrm{H}), 7.09(\mathrm{dd}, J=8.3,1.6 \mathrm{~Hz}, 1 \mathrm{H}), 2.46(\mathrm{~s}, 3 \mathrm{H}) .{ }^{13} \mathrm{C}$ NMR $\left(75 \mathrm{MHz}, \mathrm{CDCl}_{3}\right): \delta=135.2\left(\mathrm{C}_{\mathrm{q}}\right), 134.2\left(\mathrm{C}_{\mathrm{q}}\right)$, $134.2\left(\mathrm{C}_{\mathrm{q}}\right), 132.8\left(\mathrm{C}_{\mathrm{q}}\right), 130.2(\mathrm{CH}), 129.7\left(\mathrm{C}_{\mathrm{q}}\right), 129.0\left(\mathrm{C}_{\mathrm{q}}\right), 128.6(\mathrm{CH}), 128.5(\mathrm{CH}), 128.1(\mathrm{CH}), 127.5$ (CH), $126.1(\mathrm{CH}), 124.3(\mathrm{CH}), 119.2(\mathrm{CH}), 114.6\left(\mathrm{C}_{\mathrm{q}}\right), 110.5(\mathrm{CH}), 21.5\left(\mathrm{CH}_{3}\right)$. IR (ATR) $v=3368,3056$, 1600, 1448, 1316, 1030, 780, 760, $696 \mathrm{~cm}^{-1}$. MS (ESI) m/z (relative intensity): 282 (100) [M-H] 
HR-MS (ESI) m/z calcd for $\mathrm{C}_{21} \mathrm{H}_{17} \mathrm{~N}[\mathrm{M}-\mathrm{H}]^{-}: 282.1288$, found: 282.1292.

The analytical data were in accordance with those reported in the literature. ${ }^{[161]}$<smiles>c1ccc(-c2[nH]c3ccccc3c2-c2ccccc2)cc1</smiles>

2,3-Diphenyl-1H-indole (160ba): The general procedure B was followed using $\mathrm{N}$-(4-methoxybenzylidene)aniline oxide (159b) (113.6 mg, $0.50 \mathrm{mmol}$ ) and 1,2-diphenylethyne (8a) (134 mg, $0.75 \mathrm{mmol}$ ). Purification by coloumn chromatography on silica gel $\left(n\right.$-hexane $\left./ \mathrm{CH}_{2} \mathrm{Cl}_{2}: 3 / 1\right)$ yielded 160ba (102.3 mg, 76\%) as a white solid.

M. p. $=98-100{ }^{\circ} \mathrm{C} .{ }^{1} \mathrm{H}$ NMR $\left(300 \mathrm{MHz}, \mathrm{CDCl}_{3}\right): \delta=8.18(\mathrm{~s}, 1 \mathrm{H}), 7.71(\mathrm{~d}, J=7.9 \mathrm{~Hz}, 1 \mathrm{H}), 7.55-7.38(\mathrm{~m}$, 7H), 7.38-7.22 (m, 5H), $7.17(\mathrm{t}, J=7.5 \mathrm{~Hz}, 1 \mathrm{H}) .{ }^{13} \mathrm{C}$ NMR $\left(75 \mathrm{MHz}, \mathrm{CDCl}_{3}\right): \delta=135.8\left(\mathrm{C}_{\mathrm{q}}\right), 135.0\left(\mathrm{C}_{\mathrm{q}}\right)$, $134.0\left(\mathrm{C}_{\mathrm{q}}\right), 132.6\left(\mathrm{C}_{\mathrm{q}}\right), 130.1(\mathrm{CH}), 128.7\left(\mathrm{C}_{\mathrm{q}}\right), 128.6(\mathrm{CH}), 128.5(\mathrm{CH}), 128.1(\mathrm{CH}), 127.7(\mathrm{CH}), 126.2$ (CH), $122.7(\mathrm{CH}), 120.4(\mathrm{CH}), 119.7(\mathrm{CH}), 115.0\left(\mathrm{C}_{\mathrm{q}}\right), 110.7(\mathrm{CH})$. IR (ATR) $v=3389,3039,1601,1455$, 1151, 1008, 748, 694, 606, $515 \mathrm{~cm}^{-1}$. MS (ESI) m/z (relative intensity): 269 (100), 296 (85), 381 (20) $[M]^{+}$. HR-MS (ESI) m/z calcd for $\mathrm{C}_{20} \mathrm{H}_{15} \mathrm{~N}[\mathrm{M}]^{+}:$269.1199, found: 269.1197.

The analytical data were in accordance with those reported in the literature. ${ }^{[161]}$<smiles>Fc1ccc2[nH]c(-c3ccccc3)c(-c3ccccc3)c2c1</smiles>

5-Fluoro-2,3-diphenyl-1H-indole (160ca): The general procedure B was followed using 4-fluoro- $N$-(4-methoxybenzylidene)aniline oxide $\quad(159 \mathrm{c}) \quad(122.6 \quad \mathrm{mg}, \quad 0.50 \mathrm{mmol})$ and 1,2-diphenylethyne (8a) (134 mg, $0.75 \mathrm{mmol}$ ). Purification by coloumn chromatography on silica gel ( $n$-hexane $/ \mathrm{CH}_{2} \mathrm{Cl}_{2}: 3 / 1$ ) yielded $160 \mathrm{ca}(101 \mathrm{mg}, 70 \%$ ) as a white solid.

M. p. $=124-126{ }^{\circ} \mathrm{C}^{1}{ }^{1} \mathbf{H}$ NMR $\left(300 \mathrm{MHz}, \mathrm{CDCl}_{3}\right): \delta=8.13(\mathrm{~s}, 1 \mathrm{H}), 7.50-7.37(\mathrm{~m}, 7 \mathrm{H}), 7.36-7.26(\mathrm{~m}$, $5 \mathrm{H}), 7.01(\mathrm{td}, J=9.0,2.5 \mathrm{~Hz}, 1 \mathrm{H}) .{ }^{13} \mathrm{C}$ NMR $\left(75 \mathrm{MHz}, \mathrm{CDCl}_{3}\right): \delta=158.4\left(\mathrm{~d},{ }^{1} J_{\mathrm{C}-\mathrm{F}}=235.3 \mathrm{~Hz}, \mathrm{C}_{\mathrm{q}}\right), 135.8$ $\left(C_{q}\right), 134.6\left(C_{q}\right), 132.3\left(C_{q}\right), 132.3\left(C_{q}\right), 129.9(C H), 129.2\left(d,{ }^{3} J_{C-F}=10.1 \mathrm{~Hz}, C_{q}\right), 128.7(C H), 128.6(C H)$, $128.1(\mathrm{CH}), 127.9(\mathrm{CH}), 126.4(\mathrm{CH}), 115.2\left(\mathrm{~d},{ }^{4} \mathrm{~J}_{\mathrm{C}-\mathrm{F}}=4.7 \mathrm{~Hz}, \mathrm{C}_{\mathrm{q}}\right), 111.6\left(\mathrm{~d},{ }^{3} \mathrm{~J}_{\mathrm{C}-\mathrm{F}}=9.8 \mathrm{~Hz}, \mathrm{CH}\right), 111.0(\mathrm{~d}$, $\left.{ }^{2} J_{C-F}=26.5 \mathrm{~Hz}, \mathrm{CH}\right), 104.6\left(\mathrm{~d},{ }^{2} J_{\mathrm{C}-\mathrm{F}}=24.1 \mathrm{~Hz}, \mathrm{CH}\right) .{ }^{19} \mathrm{~F}$ NMR $\left(283 \mathrm{MHz}, \mathrm{CDCl}_{3}\right): \delta=-123.44(\mathrm{td}, J=9.5$, 
$4.4 \mathrm{~Hz}$ ). IR (ATR) $v=3423,1600,1474,1069,951,859,754,692 \mathrm{~cm}^{-1} . \mathrm{MS}$ (ESI) m/z (relative intensity): 286 (100) [M-H] . HR-MS (ESI) m/z calcd for $\mathrm{C}_{20} \mathrm{H}_{14} \mathrm{NF}[\mathrm{M}-\mathrm{H}]^{-}: 286.1038$, found: 286.1040. The analytical data were in accordance with those reported in the literature. ${ }^{[161]}$<smiles>Clc1ccc2[nH]c(-c3ccccc3)c(-c3ccccc3)c2c1</smiles>

5-Chloro-2,3-diphenyl-1H-indole (160da): The general procedure B was followed using 4-chloro- $N$-(4-methoxybenzylidene)aniline oxide $\quad(159 \mathrm{~d}) \quad(131 \mathrm{mg}, \quad 0.50 \mathrm{mmol})$ and 1,2-diphenylethyne (8a) (134 mg, $0.75 \mathrm{mmol}$ ). Purification by coloumn chromatography on silica gel ( $n$-hexane $/ \mathrm{CH}_{2} \mathrm{Cl}_{2}: 3 / 1$ ) yielded $160 \mathrm{da}$ (115 $\mathrm{mg}, 76 \%$ ) as a pale yellow solid.

M. p. $=110-112^{\circ} \mathrm{C}^{1}{ }^{1} \mathrm{H}$ NMR $\left(300 \mathrm{MHz}, \mathrm{CDCl}_{3}\right): \delta=8.20(\mathrm{~s}, 1 \mathrm{H}), 7.63(\mathrm{~d}, J=2.0 \mathrm{~Hz}, 1 \mathrm{H}), 7.50-7.34$ $(\mathrm{m}, 6 \mathrm{H}), 7.34-7.25(\mathrm{~m}, 5 \mathrm{H}), 7.18(\mathrm{dd}, J=8.6,2.0 \mathrm{~Hz}, 1 \mathrm{H}) .{ }^{13} \mathrm{C} \mathrm{NMR}\left(76 \mathrm{MHz}, \mathrm{CDCl}_{3}\right): \delta=135.4\left(\mathrm{C}_{\mathrm{q}}\right)$, $134.3\left(\mathrm{C}_{\mathrm{q}}\right), 134.2\left(\mathrm{C}_{\mathrm{q}}\right), 132.1\left(\mathrm{C}_{\mathrm{q}}\right), 130.0(\mathrm{CH}), 129.9\left(\mathrm{C}_{\mathrm{q}}\right), 128.7(\mathrm{CH}), 128.6(\mathrm{CH}), 128.1(\mathrm{CH}), 128.0$ (CH), $126.5(\mathrm{CH}), 126.1\left(\mathrm{C}_{\mathrm{q}}\right), 122.9(\mathrm{CH}), 119.1(\mathrm{CH}), 114.7\left(\mathrm{C}_{\mathrm{q}}\right), 111.9(\mathrm{CH})$. IR (ATR) $v=3438,3420$, 1506, 1458, 762, 694, $607 \mathrm{~cm}^{-1}$. MS (ESI) m/z (relative intensity): 302 (100), 304 (30) [M-H]'. HR-MS (ESI) $\mathrm{m} / \mathrm{z}$ calcd for $\mathrm{C}_{20} \mathrm{H}_{14} \mathrm{NCl}[\mathrm{M}-\mathrm{H}]^{-}: 302.0742$, found: 302.0743 .

The analytical data were in accordance with those reported in the literature. ${ }^{[161]}$<smiles>Brc1ccc2[nH]c(-c3ccccc3)c(-c3ccccc3)c2c1</smiles>

5-Bromo-2,3-diphenyl-1H-indole (160ea): The general procedure B was followed using 4-bromo- $N$-(4-methoxybenzylidene)aniline oxide $\quad(159 \mathrm{e}) \quad(153 \mathrm{mg}, \quad 0.50 \mathrm{mmol})$ and 1,2-diphenylethyne (8a) (134 mg, $0.75 \mathrm{mmol})$. Purification by coloumn chromatography on silica gel ( $n$-hexane/ $\mathrm{CH}_{2} \mathrm{Cl}_{2}: 3 / 1$ ) yielded 160 ea (158 $\mathrm{mg}, 91 \%$ ) as a pale yellow solid.

M. p. $=133-135^{\circ} \mathrm{C}^{1}{ }^{1} \mathrm{H}$ NMR $\left(300 \mathrm{MHz}, \mathrm{CDCl}_{3}\right): \delta=8.19(\mathrm{~s}, 1 \mathrm{H}), 7.78(\mathrm{~d}, \mathrm{~J}=1.8 \mathrm{~Hz}, 1 \mathrm{H}), 7.49-7.36(\mathrm{~m}$, $6 \mathrm{H}), 7.35-7.21(\mathrm{~m}, 6 \mathrm{H}) .{ }^{13} \mathrm{C}$ NMR $\left(75 \mathrm{MHz}, \mathrm{CDCl}_{3}\right): \delta=135.2\left(\mathrm{C}_{\mathrm{q}}\right), 134.4\left(\mathrm{C}_{\mathrm{q}}\right), 134.3\left(\mathrm{C}_{\mathrm{q}}\right), 132.0\left(\mathrm{C}_{\mathrm{q}}\right)$, $130.5\left(\mathrm{C}_{\mathrm{q}}\right), 130.0(\mathrm{CH}), 128.7(\mathrm{CH}), 128.6(\mathrm{CH}), 128.1(\mathrm{CH}), 128.0(\mathrm{CH}), 126.5(\mathrm{CH}), 125.4(\mathrm{CH}), 122.1$ (CH), $114.6\left(\mathrm{C}_{\mathrm{q}}\right), 113.7\left(\mathrm{C}_{\mathrm{q}}\right), 112.3(\mathrm{CH}) . \mathrm{IR}(\mathrm{ATR}) v=3451,1449,1306,1286,760,696,648,586,508$, 
$445 \mathrm{~cm}^{-1}$. MS (ESI) m/z (relative intensity): 346 (100) [M-H]- HR-MS (ESI) m/z calcd for $\mathrm{C}_{20} \mathrm{H}_{14} \mathrm{NBr}$ $[\mathrm{M}-\mathrm{H}]:$ : 346.0237, found: 346.0231 .

The analytical data were in accordance with those reported in the literature. ${ }^{[161]}$<smiles>Cc1ccc2c(-c3ccccc3)c(-c3ccccc3)[nH]c2c1</smiles>

6-Methyl-2,3-diphenyl-1H-indole (160fa): The general procedure B was followed using $\mathrm{N}$-(4-methoxybenzylidene)-3-methylaniline oxide $\quad(159 \mathrm{f}) \quad(121 \mathrm{mg}, \quad 0.50 \mathrm{mmol})$ and 1,2-diphenylethyne (8a) (134 mg, $0.75 \mathrm{mmol}$ ). Purification by coloumn chromatography on silica gel ( $n$-hexane $/ \mathrm{CH}_{2} \mathrm{Cl}_{2}: 3 / 1$ ) yielded $160 \mathrm{fa}$ (126 mg, 89\%) as a white solid.

M. p. $=95-97{ }^{\circ} \mathrm{C}^{1}{ }^{1} \mathrm{H}$ NMR $\left(300 \mathrm{MHz}, \mathrm{CDCl}_{3}\right): \delta=8.07(\mathrm{~s}, 1 \mathrm{H}), 7.56(\mathrm{~d}, \mathrm{~J}=8.2 \mathrm{~Hz}, 1 \mathrm{H}), 7.48-7.36(\mathrm{~m}$, 5H), 7.35-7.24 (m, 5H), 7.22-7.19 (m, 1H), $6.99(\mathrm{dd}, J=8.2,0.9 \mathrm{~Hz}, 1 \mathrm{H}), 2.49(\mathrm{~s}, 3 \mathrm{H}) .{ }^{13} \mathrm{C}$ NMR $(75$ $\left.\mathrm{MHz}, \mathrm{CDCl}_{3}\right): \delta=136.3\left(\mathrm{C}_{\mathrm{q}}\right), 135.2\left(\mathrm{C}_{\mathrm{q}}\right), 133.3\left(\mathrm{C}_{\mathrm{q}}\right), 132.8\left(\mathrm{C}_{\mathrm{q}}\right), 132.6\left(\mathrm{C}_{\mathrm{q}}\right), 130.1(\mathrm{CH}), 128.6(\mathrm{CH})$, $128.5(\mathrm{CH}), 128.0(\mathrm{CH}), 127.5(\mathrm{CH}), 126.6\left(\mathrm{C}_{\mathrm{q}}\right), 126.1(\mathrm{CH}), 122.2(\mathrm{CH}), 119.3(\mathrm{CH}), 114.9\left(\mathrm{C}_{\mathrm{q}}\right), 110.8$ (CH), $21.7\left(\mathrm{CH}_{3}\right)$. IR (ATR) $v=3406,1601,1502,1449,1439,1250,914,804,763,697 \mathrm{~cm}^{-1}$. MS (ESI)

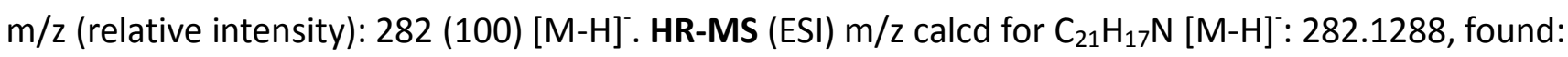
282.1289.

The analytical data were in accordance with those reported in the literature. ${ }^{[161]}$

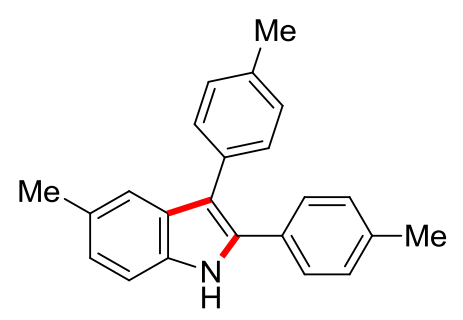

5-Methyl-2,3-di-p-tolyl-1H-indole (160ab): The general procedure B was followed using $\mathrm{N}$-(4-methoxybenzylidene)-4-methylaniline oxide $\quad(159 \mathrm{a}) \quad(121 \mathrm{mg}, \quad 0.50 \mathrm{mmol})$ and 1,2-di-p-tolylethyne (8b) (155 mg, $0.75 \mathrm{mmol})$. Purification by coloumn chromatography on silica gel ( $n$-pentane/EtOAc: $30 / 1$ ) yielded 160ab (115.2 mg, 74\%) as a white solid.

M. p. $=157-160{ }^{\circ} \mathrm{C} .{ }^{1} \mathbf{H}$ NMR $\left(300 \mathrm{MHz}, \mathrm{CDCl}_{3}\right): \delta=8.05(\mathrm{~s}, 1 \mathrm{H}), 7.44(\mathrm{~s}, 1 \mathrm{H}), 7.35-7.28(\mathrm{~m}, 5 \mathrm{H})$, 7.23-7.17 (m, 2H), 7.16-7.09 (m, 2H), $7.05(\mathrm{dd}, J=8.4,1.6 \mathrm{~Hz}, 1 \mathrm{H}), 2.44(\mathrm{~s}, 3 \mathrm{H}), 2.41(\mathrm{~s}, 3 \mathrm{H}), 2.35$ (s, 
3H). ${ }^{13} \mathrm{C}$ NMR $\left(125 \mathrm{MHz}, \mathrm{CDCl}_{3}\right): \delta=137.2\left(\mathrm{C}_{\mathrm{q}}\right), 135.5\left(\mathrm{C}_{\mathrm{q}}\right), 134.0\left(\mathrm{C}_{\mathrm{q}}\right), 132.2\left(\mathrm{C}_{\mathrm{q}}\right), 130.0\left(\mathrm{C}_{\mathrm{q}}\right), 129.9$ $(\mathrm{CH}), 129.9\left(\mathrm{C}_{\mathrm{q}}\right) 129.4\left(\mathrm{C}_{\mathrm{q}}\right), 129.2(\mathrm{CH}), 129.1(\mathrm{CH}), 129.1\left(\mathrm{C}_{\mathrm{q}}\right), 127.8(\mathrm{CH}), 123.9(\mathrm{CH}), 119.1(\mathrm{CH})$, $114.1\left(\mathrm{C}_{\mathrm{q}}\right), 110.4(\mathrm{CH}), 21.6\left(\mathrm{CH}_{3}\right), 21.3\left(\mathrm{CH}_{3}\right), 21.3\left(\mathrm{CH}_{3}\right)$. IR (ATR) $v=3379,2917,1510,1439,821$, 798, 723, $517 \mathrm{~cm}^{-1}$. MS (EI) m/z (relative intensity): 327 (17), 311 (100) [M] ${ }^{+}$. HR-MS (ESI) m/z calcd for $\mathrm{C}_{23} \mathrm{H}_{21} \mathrm{~N}[\mathrm{M}]^{+}:$311.1674, found: 311.1665 .

The analytical data were in accordance with those reported in the literature. ${ }^{[197]}$<smiles>COc1ccc(-c2[nH]c3ccc(C)cc3c2-c2ccc(OC)cc2)cc1</smiles>

2,3-Bis(4-methoxyphenyl)-5-methyl-1H-indole (160ac): The general procedure B was followed using $\quad \mathrm{N}$-(4-methoxybenzylidene)-4-methylaniline oxide (159a) (121 mg, $0.50 \mathrm{mmol})$ and 1,2-bis(4-methoxyphenyl)ethyne (8c) $(178 \mathrm{mg}, 0.75 \mathrm{mmol})$. Purification by coloumn chromatography on silica gel ( $n$-pentane/EtOAc: $10 / 1$ ) yielded $160 \mathrm{ac}$ (122 mg, 71\%) as a yellow solid.

M. p. $=147-150{ }^{\circ} \mathrm{C}^{1}{ }^{1} \mathrm{H}$ NMR $\left(500 \mathrm{MHz}, \mathrm{CDCl}_{3}\right): \delta=8.03(\mathrm{~s}, 1 \mathrm{H}), 7.40(\mathrm{~s}, 1 \mathrm{H}), 7.37-7.30(\mathrm{~m}, 4 \mathrm{H}), 7.27$ (d, J = 8.2 Hz, 1H), $7.03(\mathrm{~s}, 1 \mathrm{H}), 6.93(\mathrm{~d}, J=8.7 \mathrm{~Hz}, 2 \mathrm{H}), 6.84$ (d, J = 8.9 Hz, 2H), 3.85 (s, 3H), 3.80 (s, 3H), $2.43(\mathrm{~s}, 3 \mathrm{H}) .{ }^{13} \mathrm{C}$ NMR $\left(125 \mathrm{MHz}, \mathrm{CDCl}_{3}\right): \delta=159.0\left(\mathrm{C}_{\mathrm{q}}\right), 157.9\left(\mathrm{C}_{\mathrm{q}}\right), 134.0\left(\mathrm{C}_{\mathrm{q}}\right), 133.8\left(\mathrm{C}_{\mathrm{q}}\right), 131.1$ $(\mathrm{CH}), 129.4\left(\mathrm{C}_{q}\right), 129.2(\mathrm{CH}), 127.7\left(\mathrm{C}_{q}\right), 125.4\left(\mathrm{C}_{\mathrm{q}}\right), 123.8(\mathrm{CH}), 119.0(\mathrm{CH}), 114.3\left(\mathrm{C}_{\mathrm{q}}\right), 114.1(\mathrm{CH})$, $114.0(\mathrm{CH}), 113.3\left(\mathrm{C}_{\mathrm{q}}\right) 110.4(\mathrm{CH}), 55.2\left(\mathrm{CH}_{3}\right), 55.2\left(\mathrm{CH}_{3}\right), 21.5\left(\mathrm{CH}_{3}\right)$. IR (ATR) $v=3362,2928,2835$, 1510, 1455, 1231, 1172, 1023, 829, $791 \mathrm{~cm}^{-1}$. MS (EI) $\mathrm{m} / \mathrm{z}$ (relative intensity): 343 (100) [M] ${ }^{+}, 328$ (50). HR-MS (ESI) $m / z$ calcd for $\mathrm{C}_{23} \mathrm{H}_{21} \mathrm{NO}_{2}[\mathrm{M}]^{+}: 343.1572$, found: 343.1572 .<smiles>Cc1ccc2[nH]c(-c3cccc(Cl)c3)c(-c3cccc(Cl)c3)c2c1</smiles>

2,3-Bis(3-chlorophenyl)-5-methyl-1H-indole (160ah): The general procedure B was followed using $\mathrm{N}$-(4-methoxybenzylidene)-4-methylaniline oxide $\quad(159 \mathrm{a}) \quad(121 \mathrm{mg}, \quad 0.50 \mathrm{mmol})$ and 
1,2-bis(3-chlorophenyl)ethyne $(8 \mathrm{~h})$ (185 $\mathrm{mg}, 0.75 \mathrm{mmol})$. Purification by coloumn chromatography on silica gel ( $n$-hexane $/ \mathrm{CH}_{2} \mathrm{Cl}_{2}: 3 / 1$ ) yielded 160ah (146 mg, 83\%) as a yellow oil.

${ }^{1} \mathrm{H}$ NMR $\left(400 \mathrm{MHz}, \mathrm{CDCl}_{3}\right): \delta=8.10(\mathrm{~s}, 1 \mathrm{H}), 7.46-7.39(\mathrm{~m}, 3 \mathrm{H}), 7.34-7.28(\mathrm{~m}, 3 \mathrm{H}), 7.28-7.18(\mathrm{~m}, 4 \mathrm{H})$, $7.10(\mathrm{dd}, J=8.5,1.4 \mathrm{~Hz}, 1 \mathrm{H}), 2.45(\mathrm{~s}, 3 \mathrm{H}) .{ }^{13} \mathrm{C} \mathrm{NMR}\left(100 \mathrm{MHz}, \mathrm{CDCl}_{3}\right): \delta=136.7\left(\mathrm{C}_{\mathrm{q}}\right), 134.6\left(\mathrm{C}_{\mathrm{q}}\right)$, $134.3\left(\mathrm{C}_{\mathrm{q}}\right), 134.2\left(\mathrm{C}_{\mathrm{q}}\right), 134.1\left(\mathrm{C}_{\mathrm{q}}\right) 132.9\left(\mathrm{C}_{\mathrm{q}}\right), 130.3\left(\mathrm{C}_{\mathrm{q}}\right), 129.9(\mathrm{CH}), 129.8(\mathrm{CH}), 129.8(\mathrm{CH}), 128.5\left(\mathrm{C}_{\mathrm{q}}\right)$, $128.3(\mathrm{CH}), 127.8(\mathrm{CH}), 127.7(\mathrm{CH}), 126.5(\mathrm{CH}), 126.4(\mathrm{CH}), 125.0(\mathrm{CH}), 119.0(\mathrm{CH}), 114.1\left(\mathrm{C}_{\mathrm{q}}\right), 110.7$ (CH), $21.5\left(\mathrm{CH}_{3}\right)$. IR (ATR) $v=3399,2917,1594,1562,1485,1458,1077,883,784,733 \mathrm{~cm}^{-1}$. MS (EI) m/z (relative intensity): 351 (100), 315 (11), 381 (10), 178 (7). HR-MS (ESI) m/z calcd for $\mathrm{C}_{23} \mathrm{H}_{21} \mathrm{NO}_{2}$ $[\mathrm{M}]^{+}:$351.0582, found: 351.0588 .

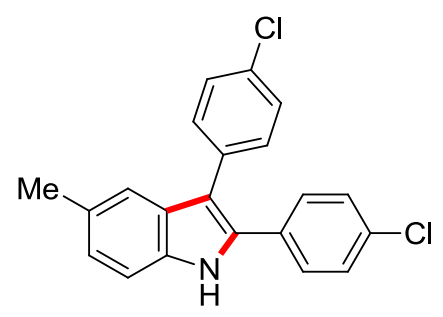

2,3-Bis(4-chlorophenyl)-5-methyl-1H-indole (160ag): The general procedure B was followed using nitrone (159a) (121 mg, $0.50 \mathrm{mmol}$ ) and 1,2-bis(4-chlorophenyl)ethyne (8g) (185 mg, $0.75 \mathrm{mmol}$ ). Purification by coloumn chromatography on silica gel ( $n$-hexane $/ \mathrm{CH}_{2} \mathrm{Cl}_{2}: 3 / 1$ ) yielded 160ag (99 mg, $56 \%)$ as a pale yellow solid.

M. p. $=131-132{ }^{\circ} \mathrm{C}^{1}{ }^{1} \mathrm{H}$ NMR $\left(300 \mathrm{MHz}, \mathrm{CDCl}_{3}\right): \delta=8.08(\mathrm{~s}, 1 \mathrm{H}), 7.40(\mathrm{~s}, 1 \mathrm{H}), 7.39-7.31(\mathrm{~m}, 9 \mathrm{H}), 7.08$ $(\mathrm{d}, J=9.4 \mathrm{~Hz}, 1 \mathrm{H}), 2.43(\mathrm{~s}, 3 \mathrm{H}) .{ }^{13} \mathrm{C}$ NMR $\left(125 \mathrm{MHz}, \mathrm{CDCl}_{3}\right): \delta=134.2\left(\mathrm{C}_{\mathrm{q}}\right), 133.6\left(\mathrm{C}_{\mathrm{q}}\right), 133.3\left(\mathrm{C}_{\mathrm{q}}\right)$, $133.1\left(\mathrm{C}_{\mathrm{q}}\right), 132.1\left(\mathrm{C}_{\mathrm{q}}\right), 131.2(\mathrm{CH}), 130.9\left(\mathrm{C}_{\mathrm{q}}\right), 130.1\left(\mathrm{C}_{\mathrm{q}}\right), 129.2(\mathrm{CH}), 128.9(\mathrm{CH}), 128.8(\mathrm{CH}), 128.6$ $\left(\mathrm{C}_{\mathrm{q}}\right), 124.7(\mathrm{CH}), 118.9(\mathrm{CH}), 113.8\left(\mathrm{C}_{\mathrm{q}}\right), 110.6(\mathrm{CH}), 21.6\left(\mathrm{CH}_{3}\right)$. IR (ATR) $v=3452,3390,1498,1471$, 1086, 1013, 833, $784 \mathrm{~cm}^{-1}$. MS (ESI) m/z (relative intensity): 350 (100), 351 (20), 352 (60) [M-H]. HR-MS (ESI) m/z calcd for $\mathrm{C}_{21} \mathrm{H}_{15} \mathrm{NCl}_{2}$ [M-H]': 350.0509, found: 350.0508 .<smiles>Cc1ccc2[nH]c(-c3ccc(C(F)(F)F)cc3)c(-c3ccc(C(F)(F)F)cc3)c2c1</smiles>

5-Methyl-2,3-bis[4-(trifluoromethyl)phenyl]-1H-indole (160ae): The general procedure B was 155 
followed using $\mathrm{N}$-(4-methoxybenzylidene)-4-methylaniline oxide (159a) (121 mg, $0.50 \mathrm{mmol}$ ) and 1,2-bis[4-(trifluoromethyl)phenyl]ethyne $(8 \mathrm{e})(236 \mathrm{mg}, 0.75 \mathrm{mmol})$. Purification by coloumn chromatography on silica gel ( $n$-hexane $/ \mathrm{CH}_{2} \mathrm{Cl}_{2}: 3 / 1$ ) yielded $160 \mathrm{ae}(153 \mathrm{mg}, 73 \%$ ) as a yellow solid. M. p. $=149-150{ }^{\circ} \mathrm{C} .{ }^{1} \mathrm{H}$ NMR $\left(300 \mathrm{MHz}, \mathrm{CDCl}_{3}\right): \delta=8.21(\mathrm{~s}, 1 \mathrm{H}), 7.68-7.54(\mathrm{~m}, 4 \mathrm{H}), 7.49(\mathrm{t}, J=8.7 \mathrm{~Hz}$, $4 \mathrm{H}), 7.42(\mathrm{~s}, 1 \mathrm{H}), 7.35(\mathrm{~d}, J=8.3 \mathrm{~Hz}, 1 \mathrm{H}), 7.13(\mathrm{dd}, J=8.3,1.6 \mathrm{~Hz}, 1 \mathrm{H}), 2.45(\mathrm{~s}, 3 \mathrm{H}) .{ }^{13} \mathrm{C} \mathrm{NMR}(75 \mathrm{MHz}$, $\left.\mathrm{CDCl}_{3}\right): \delta=138.7\left(\mathrm{C}_{\mathrm{q}}\right), 135.8\left(\mathrm{C}_{\mathrm{q}}\right), 134.6\left(\mathrm{C}_{\mathrm{q}}\right), 133.1\left(\mathrm{C}_{\mathrm{q}}\right), 130.7\left(\mathrm{C}_{\mathrm{q}}\right), 129.8\left(\mathrm{q},{ }^{2} \mathrm{~J}_{\mathrm{C}-\mathrm{F}}=33.1 \mathrm{~Hz}, \mathrm{C}_{\mathrm{q}}\right), 130.3$ $(\mathrm{CH}), 128.5\left(\mathrm{q},{ }^{2} \mathrm{~J}_{\mathrm{C}-\mathrm{F}}=31.9 \mathrm{~Hz}, \mathrm{C}_{\mathrm{q}}\right), 128.5\left(\mathrm{C}_{\mathrm{q}}\right), 128.3(\mathrm{CH}), 125.9\left(\mathrm{q},{ }^{3} J_{\mathrm{C}-\mathrm{F}}=3.8 \mathrm{~Hz}, \mathrm{CH}\right), 125.6\left(\mathrm{q},{ }^{3} J_{\mathrm{C}-\mathrm{F}}=\right.$ $3.8 \mathrm{~Hz}, \mathrm{CH}), 125.4(\mathrm{CH}), 124.3\left(\mathrm{q},{ }^{1} \mathrm{~J}_{\mathrm{C}-\mathrm{F}}=272.0 \mathrm{~Hz}, \mathrm{C}_{\mathrm{q}}\right.$ ), $124.0\left(\mathrm{q},{ }^{1} \mathrm{~J}_{\mathrm{C}-\mathrm{F}}=273.0 \mathrm{~Hz}, \mathrm{C}_{\mathrm{q}}\right), 119.1(\mathrm{CH}), 114.7$ $\left(\mathrm{C}_{\mathrm{q}}\right), 111.0(\mathrm{CH}), 21.5\left(\mathrm{CH}_{3}\right) .{ }^{19} \mathrm{~F}$ NMR $\left(282 \mathrm{MHz}, \mathrm{CDCl}_{3}\right): \delta=-62.34,-62.67$. IR (ATR) $v=3474,2922$, 1617, 1319, 1154, 1090, 1060, 840, $793 \mathrm{~cm}^{-1}$. MS (EI) m/z (relative intensity): 343 (100), 328 (50), 268 (9) 171 (5). HR-MS (ESI) $m / z$ calcd for $\mathrm{C}_{23} \mathrm{H}_{15} \mathrm{~F}_{6} \mathrm{~N}[\mathrm{M}]^{+}:$419.1109, found: 419.1120.

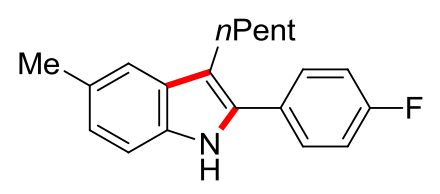

2-(4-Fluorophenyl)-5-methyl-3-pentyl-1H-indole (160as): The general procedure B was followed using nitrone (159a) (121 mg, $0.50 \mathrm{mmol}, 1.0$ equiv) and 1-fluoro-4-(hept-1-yn-1-yl)benzene (8s) (143 mg, $0.75 \mathrm{mmol}$ ). Purification by coloumn chromatography on silica gel ( $n$-hexane/EtOAc: 10/1) and GPC yielded 160as (114 mg, 77\%) as a pale yellow solid.

M. p. $=118-120{ }^{\circ} \mathrm{C} .{ }^{1} \mathrm{H}$ NMR $\left(300 \mathrm{MHz}, \mathrm{DMSO}-d_{6}\right): \delta=10.98(\mathrm{~s}, 1 \mathrm{H}), 7.65-7.58(\mathrm{~m}, 2 \mathrm{H}), 7.35(\mathrm{~d}, J=$ $8.9 \mathrm{~Hz}, 2 \mathrm{H}), 7.31(\mathrm{~d}, J=1.8 \mathrm{~Hz}, 1 \mathrm{H}), 7.24(\mathrm{~d}, J=8.1 \mathrm{~Hz}, 1 \mathrm{H}), 6.92(\mathrm{dd}, J=8.2,1.6 \mathrm{~Hz}, 1 \mathrm{H}), 2.78(\mathrm{t}, J=$ $7.8 \mathrm{~Hz}, 2 \mathrm{H}), 2.39(\mathrm{~s}, 3 \mathrm{H}), 1.62(\mathrm{p}, J=7.2 \mathrm{~Hz}, 2 \mathrm{H}), 1,35-1.25(\mathrm{~m}, 4 \mathrm{H}), 0.83(\mathrm{t}, J=7.1 \mathrm{~Hz}, 3 \mathrm{H}) .{ }^{13} \mathrm{C}$ NMR $\left(75 \mathrm{MHz}, \mathrm{DMSO}-d_{6}\right): \delta=161.3\left(\mathrm{~d},{ }^{1} \mathrm{~J}_{\mathrm{C}-\mathrm{F}}=245 \mathrm{~Hz}, \mathrm{C}_{\mathrm{q}}\right), 134.3\left(\mathrm{C}_{\mathrm{q}}\right), 132.9\left(\mathrm{C}_{\mathrm{q}}\right), 129.5\left(\mathrm{~d},{ }^{3} \mathrm{~J}_{\mathrm{C}-\mathrm{F}}=8.1 \mathrm{~Hz}\right.$, $\mathrm{CH}), 128.9\left(\mathrm{C}_{\mathrm{q}}\right), 127.0\left(\mathrm{C}_{\mathrm{q}}\right), 123.0(\mathrm{CH}), 119.9\left(\mathrm{C}_{\mathrm{q}}\right), 118.1(\mathrm{CH}), 115.6\left(\mathrm{~d},{ }^{2} \mathrm{~J}_{\mathrm{C}-\mathrm{F}}=21.5 \mathrm{~Hz}, \mathrm{CH}\right), 111.7\left(\mathrm{C}_{\mathrm{q}}\right)$, 110.8 (CH), $31.4\left(\mathrm{CH}_{3}\right), 30.3\left(\mathrm{CH}_{2}\right), 24.0\left(\mathrm{CH}_{2}\right), 22.0\left(\mathrm{CH}_{3}\right), 21.3\left(\mathrm{CH}_{2}\right), 13.9\left(\mathrm{CH}_{2}\right) .{ }^{19} \mathrm{~F}$ NMR $(282 \mathrm{MHz}$, DMSO- $\left.d_{6}\right): \delta=115.01$. IR (ATR) $v=3381,2923,2857,1506,1441,1225,838,797,516,477 \mathrm{~cm}^{-1}$. MS (ESI) $m / z$ (relative intensity): 295 (6) [M] ${ }^{+}, 312$ (100), 334 (34), 350 (24). HR-MS (ESI) m/z calcd for $\mathrm{C}_{20} \mathrm{H}_{22} \mathrm{FN}[\mathrm{M}]^{+}:$295.1736, found: 295.1727. 
<smiles>CCOC(=O)c1c(-c2ccccc2)[nH]c2ccc(C)cc12</smiles>

Ethyl 5-methyl-2-phenyl-1H-indole-3-carboxylate (160at): The general procedure B was followed using nitrone (159a) (121 mg, $0.50 \mathrm{mmol}, 1.0$ equiv) and ethyl 3-phenylpropiolate (8t) (131 mg, 0.75 mmol, 1.5 equiv). Purification by coloumn chromatography on silica gel ( $n$-hexane/EtOAc: $10 / 1)$ and GPC yielded 160at ( $86.6 \mathrm{mg}, 63 \%$ ) as a colorless solid.

M. p. $=145-147^{\circ} \mathrm{C} .{ }^{1} \mathrm{H}$ NMR $\left(300 \mathrm{MHz}, \mathrm{DMSO}-d_{6}\right): \delta=11.97(\mathrm{~s}, 1 \mathrm{H}), 7.86(\mathrm{~d}, J=1.0 \mathrm{~Hz}, 1 \mathrm{H})$, 7.68-7.65 (m, 2H), 7.52-7.45 (m, 3H), $7.33(\mathrm{~d}, J=8.2 \mathrm{~Hz}, 1 \mathrm{H}), 7.44(\mathrm{dd}, J=8.2,1.1 \mathrm{~Hz}, 1 \mathrm{H}), 4.19(\mathrm{q}, J$ $=7.1 \mathrm{~Hz}, 2 \mathrm{H}), 2.43(\mathrm{~s}, 3 \mathrm{H}), 1.21(\mathrm{t}, J=7.1 \mathrm{~Hz}, 3 \mathrm{H}) .{ }^{13} \mathrm{C}$ NMR $\left(125 \mathrm{MHz}, \mathrm{DMSO}-d_{6}\right): \delta=164.5\left(\mathrm{C}_{\mathrm{q}}\right)$, $144.3\left(\mathrm{C}_{\mathrm{q}}\right), 133.9\left(\mathrm{C}_{\mathrm{q}}\right), 132.0\left(\mathrm{C}_{\mathrm{q}}\right), 129.9\left(\mathrm{C}_{\mathrm{q}}\right), 129.8(\mathrm{CH}), 128.6(\mathrm{CH}), 127.7(\mathrm{CH}), 127.5\left(\mathrm{C}_{\mathrm{q}}\right), 124.0$ (CH), $120.8(\mathrm{CH}), 111.4(\mathrm{CH}), 102.4\left(\mathrm{C}_{\mathrm{q}}\right), 58.8\left(\mathrm{CH}_{2}\right), 21.4\left(\mathrm{CH}_{3}\right), 14.1\left(\mathrm{CH}_{3}\right)$. IR $(\mathrm{ATR}) v=3232,1652$, 1476, 1451, 1268, 1218, 1145, 1049, 777, $696 \mathrm{~cm}^{-1}$. MS (ESI) $\mathrm{m} / \mathrm{z}$ (relative intensity): 280 (6) [M+H] , 302 (100) [M+Na] $]^{+}$. HR-MS (ESI) $\mathrm{m} / z$ calcd for $\mathrm{C}_{18} \mathrm{H}_{17} \mathrm{NNaO}_{2}[\mathrm{M}+\mathrm{Na}]^{+}: 302.1157$, found: 302.1159 .

The analytical data were in accordance with those reported in the literature. ${ }^{[198]}$<smiles>CCCCc1c(-c2ccc([N+](=O)[O-])cc2)[nH]c2ccc(C)cc12</smiles>

3-Butyl-5-methyl-2-(4-nitrophenyl)-1H-indole (160au): The general procedure B was followed using nitrone (159a) (121 mg, 0.50 mmol, 1.0 equiv) and 1-(hex-1-yn-1-yl)-4-nitrobenzene (8u) (152 $\mathrm{mg}, 0.75 \mathrm{mmol}, 1.5$ equiv). Purification by coloumn chromatography on silica gel ( $n$-hexane/EtOAc: 30/1) and GPC yielded 160au (84 mg, 54\%) as a yellow solid.

M. p. $=126-128^{\circ} \mathrm{C} .{ }^{1} \mathrm{H}$ NMR $\left(300 \mathrm{MHz}, \mathrm{DMSO}-d_{6}\right): \delta=11.23(\mathrm{~s}, 1 \mathrm{H}), 8.34(\mathrm{~d}, J=8.9 \mathrm{~Hz}, 2 \mathrm{H}), 7.87(\mathrm{~d}$, $J=8.9 \mathrm{~Hz}, 2 \mathrm{H}), 7.37(\mathrm{~d}, J=1.6 \mathrm{~Hz}, 1 \mathrm{H}), 7.29$ (d, $J=8.2 \mathrm{~Hz}, 1 \mathrm{H}), 7.00$ (dd, $J=8.4,1.5 \mathrm{~Hz}, 1 \mathrm{H}$ ), 2.89 (dd, $J=8.7,6.8 \mathrm{~Hz}, 2 \mathrm{H}), 2.40(\mathrm{~s}, 3 \mathrm{H}), 1.62(\mathrm{tt}, J=8.0,6.2 \mathrm{~Hz}, 2 \mathrm{H}), 1.39(\mathrm{tt}, J=7.3,7.3 \mathrm{~Hz}, 2 \mathrm{H}), 0.90(\mathrm{t}, J=$ $7.3 \mathrm{~Hz}, 3 \mathrm{H}) .{ }^{13} \mathrm{C}$ NMR $\left(75 \mathrm{MHz}, \mathrm{DSMO}-d_{6}\right): \delta=145.5\left(\mathrm{C}_{\mathrm{q}}\right), 139.7\left(\mathrm{C}_{\mathrm{q}}\right), 135.1\left(\mathrm{C}_{\mathrm{q}}\right), 131.3\left(\mathrm{C}_{\mathrm{q}}\right), 128.3\left(\mathrm{C}_{\mathrm{q}}\right)$, $127.7(\mathrm{CH}), 127.5\left(\mathrm{C}_{\mathrm{q}}\right), 124.5(\mathrm{CH}), 123.9(\mathrm{CH}), 118.5(\mathrm{CH}), 115.2\left(\mathrm{C}_{\mathrm{q}}\right), 111.1(\mathrm{CH}), 32.6\left(\mathrm{CH}_{2}\right), 23.9$ $\left(\mathrm{CH}_{2}\right), 22.0\left(\mathrm{CH}_{2}\right), 21.2\left(\mathrm{CH}_{3}\right), 13.7\left(\mathrm{CH}_{3}\right)$. IR (ATR) $v=3313,1684,1306,1234,1106,755,693,654$, 608, $590 \mathrm{~cm}^{-1}$. MS (ESI) m/z (relative intensity): 331.2 (100) [M+Na] $]^{+}, 356.2$ (25). HR-MS (ESI) m/z 
calcd for $\mathrm{C}_{19} \mathrm{H}_{20} \mathrm{~N}_{2} \mathrm{O}_{2} \mathrm{Na}[\mathrm{M}+\mathrm{Na}]^{+}: 331.1422$, found: 331.1410 .<smiles>CCC(=O)C1(CC)C([N+]#N)=Nc2ccc(C)cc21</smiles>

1-[3-Ethyl-2-(4-methoxyphenyl)-5-methyl-3H-indol-3-yl]propan-1-one (161): The general procedure B was followed using nitrone (159a) $(121 \mathrm{mg}, 0.50 \mathrm{mmol}, 1.0$ equiv) and 3-hexyne (8r) (61.6 mg, $0.75 \mathrm{mmol}, 1.5$ equiv). Purification by coloumn chromatography on silica gel (n-hexane/EtOAc: 10/1) and GPC yielded 161 (74 mg, 46\%) as a colorless solid.

M. p. $=96-98{ }^{\circ} \mathrm{C}^{1}{ }^{1} \mathrm{H}$ NMR $\left(300 \mathrm{MHz}, \mathrm{CDCl}_{3}\right): \delta=7.87(\mathrm{~d}, J=8.9 \mathrm{~Hz}, 2 \mathrm{H}), 7.60(\mathrm{~d}, J=7.9 \mathrm{~Hz}, 1 \mathrm{H}), 7.24$ (ddd, $J=8.0,1.7,0.8 \mathrm{~Hz}, 1 \mathrm{H}), 6.99(\mathrm{~d}, J=0.8 \mathrm{~Hz}, 1 \mathrm{H}), 6.96(\mathrm{~d}, J=9.0 \mathrm{~Hz}, 2 \mathrm{H}), 3.86(\mathrm{~s}, 3 \mathrm{H}), 2.53-2.27$ $(\mathrm{m}, 2 \mathrm{H}), 2.40(\mathrm{~s}, 3 \mathrm{H}), 2.03-1.75(\mathrm{~m}, 2 \mathrm{H}), 0.8(\mathrm{t}, J=7.2 \mathrm{~Hz}, 3 \mathrm{H}), 0.24(\mathrm{t}, J=7.4 \mathrm{~Hz}, 3 \mathrm{H}) .{ }^{13} \mathrm{C}$ NMR $(75$ $\left.\mathrm{MHz}, \mathrm{CDCl}_{3}\right): \delta=207.3\left(\mathrm{C}_{\mathrm{q}}\right), 175.8\left(\mathrm{C}_{\mathrm{q}}\right), 162.2\left(\mathrm{C}_{\mathrm{q}}\right), 155.0\left(\mathrm{C}_{\mathrm{q}}\right), 139.1\left(\mathrm{C}_{\mathrm{q}}\right), 136.3\left(\mathrm{C}_{\mathrm{q}}\right), 129.9(\mathrm{CH})$, $129.7(\mathrm{CH}), 125.7\left(\mathrm{C}_{\mathrm{q}}\right), 122.7(\mathrm{CH}), 120.4(\mathrm{CH}), 114.6(\mathrm{CH}), 75.4\left(\mathrm{C}_{\mathrm{q}}\right), 55.6\left(\mathrm{CH}_{3}\right), 31.3\left(\mathrm{CH}_{3}\right), 26.6$ $\left(\mathrm{CH}_{2}\right), 21.7\left(\mathrm{CH}_{2}\right), 8.3\left(\mathrm{CH}_{3}\right), 7.3\left(\mathrm{CH}_{3}\right)$. IR $(\mathrm{ATR}) v=2967,3935,1706,1603,1505,1459,1254,1174$, 1033, $836 \mathrm{~cm}^{-1}$. MS (ESI) m/z (relative intensity): 306.2 (70) [M-Me] $]^{+}, 322.2(41)[\mathrm{M}+\mathrm{H}]^{+}, 344.2(100)$ $[\mathrm{M}+\mathrm{Na}]^{+}$. HR-MS (ESI) m/z calcd for $\mathrm{C}_{21} \mathrm{H}_{23} \mathrm{NO}_{2} \mathrm{Na}[\mathrm{M}+\mathrm{Na}]^{+}:$344.1626, found: 344.1624.

\section{Intermolecular Competition Experiment}
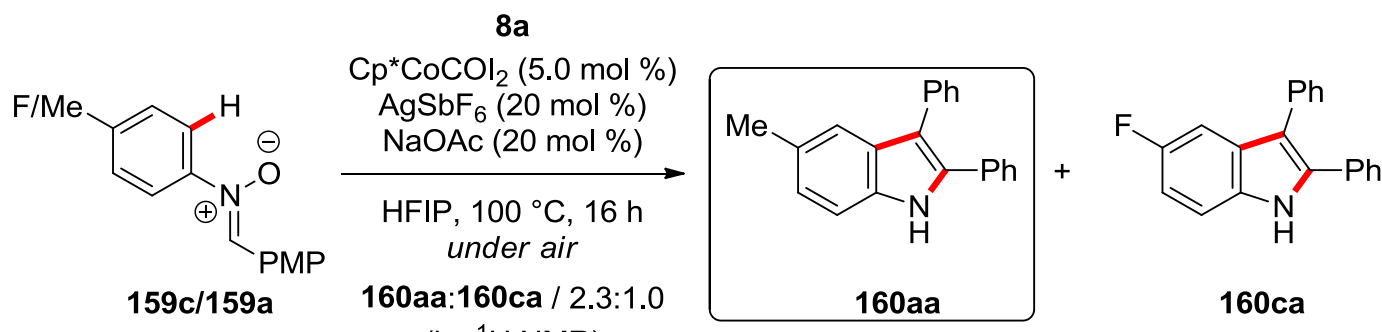

(by ${ }^{1} \mathrm{H}$ NMR)

A suspension of $\mathrm{N}$-(4-methoxybenzylidene)-4-methylaniline oxide (159a) (121 mg, $0.5 \mathrm{mmol}$ ), 4-fluoro- $N$-(4-methoxybenzylidene)aniline oxide (159c) (123 mg, $0.5 \mathrm{mmol}$ ), diphenylacetylene (8a) (89 mg, $0.5 \mathrm{mmol}$ ), $\mathrm{Cp}^{*} \mathrm{Col}_{2}(\mathrm{CO})(12 \mathrm{mg}, 5.0 \mathrm{~mol} \%), \mathrm{AgSbF}_{6}(34.4 \mathrm{mg}, 20 \mathrm{~mol} \%$ ) and $\mathrm{NaOAc}(8.2 \mathrm{mg}$, $20 \mathrm{~mol} \%)$ in HFIP $(2.0 \mathrm{~mL})$ was stirred under air at $100{ }^{\circ} \mathrm{C}$ for $16 \mathrm{~h}$. After cooling to ambient temperature, the mixture was transferred into a round bottom flask with $\mathrm{CH}_{2} \mathrm{Cl}_{2}(20 \mathrm{~mL})$ and 
concentrated in vacuo. Purification by flash column chromatography on silica gel ( $n$-hexane $/ \mathrm{CH}_{2} \mathrm{Cl}_{2}$ : $3 / 1$ ) yielded the products $160 \mathrm{aa}$ and $160 \mathrm{ca}(120 \mathrm{mg})$ and the conversions were determined by ${ }^{1} \mathrm{H}$ NMR spectroscopy.
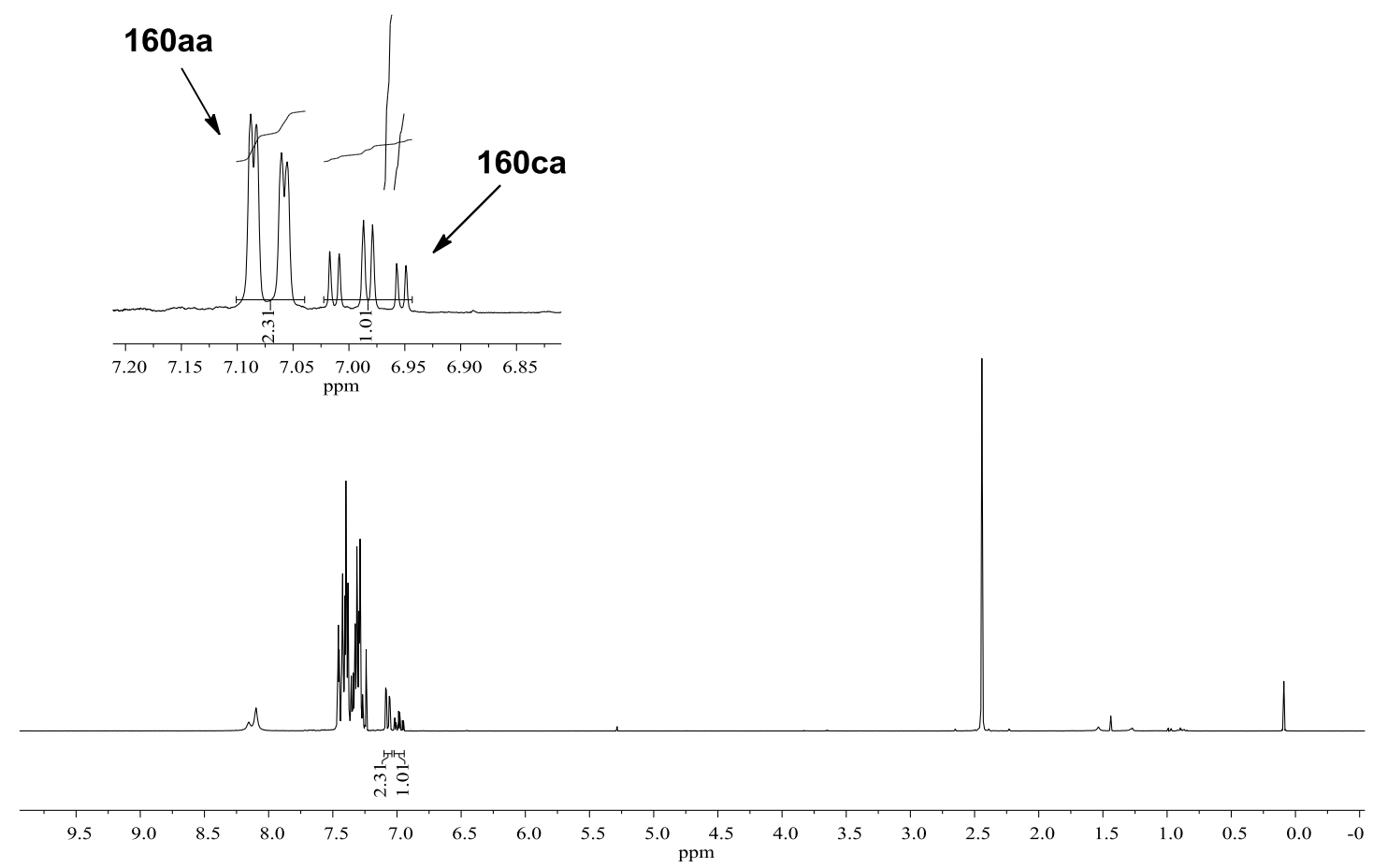

\section{Competition Experiment between Alkynes 8}

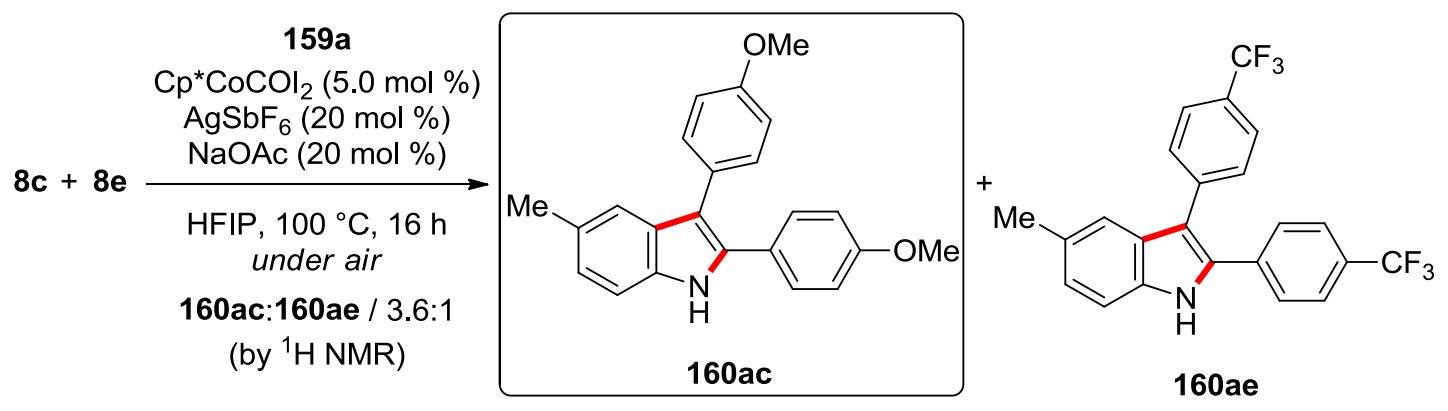

A suspension of 1,2-bis(4-methoxyphenyl)ethyne (8a) (119 $\mathrm{mg}, 0.5 \mathrm{mmol})$, 1,2-bis[4-(trifluoromethyl)phenyl]ethyne $\quad(8 \mathbf{e}) \quad(157 \quad \mathrm{mg}, \quad 0.5 \quad \mathrm{mmol})$, $\mathrm{N}$-(4-methoxybenzylidene)-4-methylaniline oxide (159a) (121 mg, $0.5 \mathrm{mmol}), \mathrm{Cp}^{*} \mathrm{Col}_{2}(\mathrm{CO})(12 \mathrm{mg}$, $5.0 \mathrm{~mol} \%), \mathrm{AgSbF}_{6}(34.4 \mathrm{mg}, 20 \mathrm{~mol} \%)$ and $\mathrm{NaOAc}(8.2 \mathrm{mg}, 20 \mathrm{~mol} \%)$ in HFIP $(2.0 \mathrm{~mL})$ was stirred at $100{ }^{\circ} \mathrm{C}$ for $16 \mathrm{~h}$ under air. After cooling to ambient temperature, the mixture was filtered through a short pad of celite, rinsed with $\mathrm{CH}_{2} \mathrm{Cl}_{2}(20 \mathrm{~mL})$ and concentrated in vacuo. The crude ${ }^{1} \mathrm{H}$ NMR was 
measured to determine the conversions to the products $160 \mathrm{ac}(62 \%)$ and $160 \mathrm{ae}(17 \%)$ using the 1,3,5-trimethoxybenzene as the internal standard.
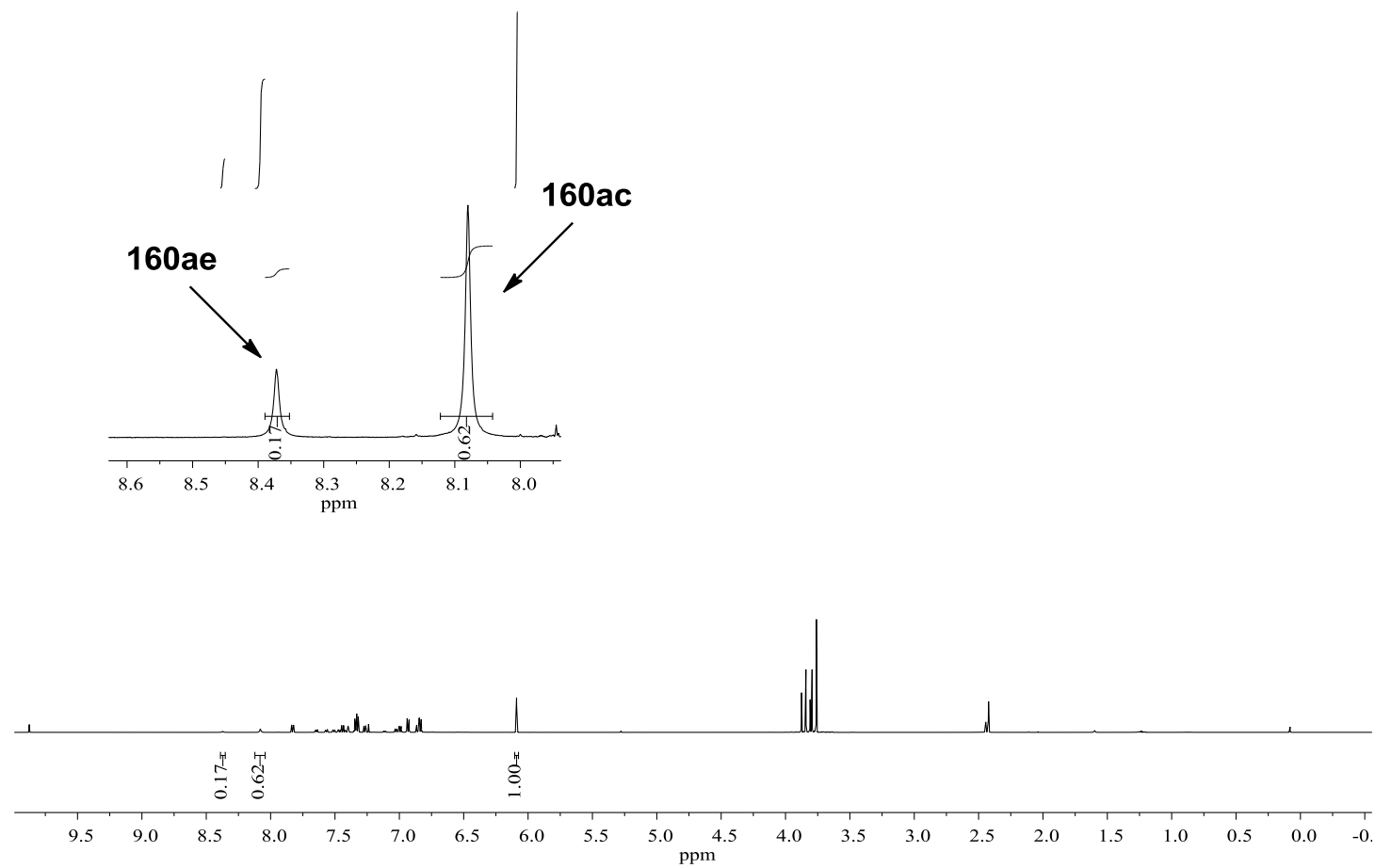

\section{H/D Exchange Experiments}

$8 \mathbf{a}$<smiles>Cc1ccc([N+](=[O+])[O-])c([O-])c1</smiles>

$159 a$

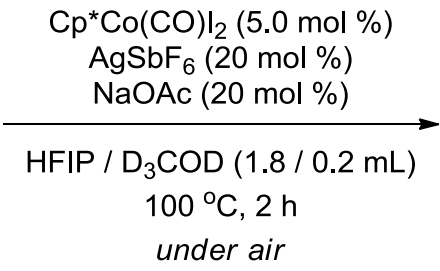

under air<smiles>CCCc1cc(C)cc2c(-c3ccccc3)c(-c3ccccc3)[nH]c12</smiles>

$<5 \%$ D 160aa: $21 \%$

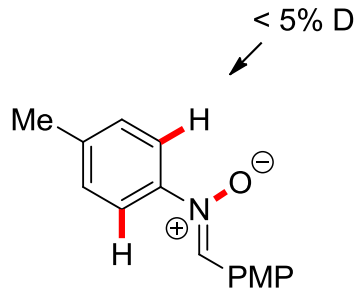

159a: $25 \%$

$\mathrm{N}$-(4-methoxybenzylidene)-4-methylaniline oxide (159a) (121 mg, $0.5 \mathrm{mmol}$ ), diphenylacetylene (8a) (89 mg, $0.5 \mathrm{mmol}), \mathrm{Cp}^{*} \mathrm{Col}_{2}(\mathrm{CO})(12 \mathrm{mg}, 5.0 \mathrm{~mol} \%), \mathrm{AgSbF}_{6}(34.4 \mathrm{mg}, 20 \mathrm{~mol} \%$ ) and NaOAc (8.2 mg, $20 \mathrm{~mol} \%), \mathrm{HFIP}(1.8 \mathrm{~mL})$ and $\mathrm{D}_{3} \mathrm{COD}(0.2 \mathrm{ml})$ were placed in a $25 \mathrm{~mL}$ Schlenk tube under air and the mixture was stirred at $100{ }^{\circ} \mathrm{C}$ for $2 \mathrm{~h}$. After cooling to ambient temperature, the mixture was transferred into a round bottom flask with $\mathrm{CH}_{2} \mathrm{Cl}_{2}(20 \mathrm{~mL})$ and concentrated in vacuo. Purification by flash column chromatography on silica gel ( $n$-hexane $/ \mathrm{CH}_{2} \mathrm{Cl}_{2}: 3 / 1$ ) yielded the product 160aa (80 mg, 
21\%) and 159a (31 mg, 25\%) (n-hexane/EtOAc: 3/1).

\section{Kinetic Isotope Effect Experiment}

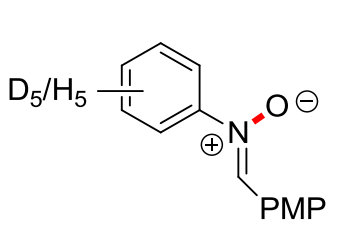

$159 b$ or $[D]_{5}-159 b$

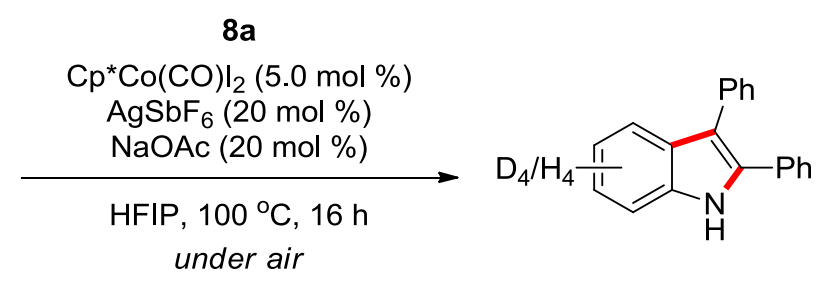

$160 \mathrm{ba}$ or $[\mathrm{D}]_{5}-160 \mathrm{ba}$

Two parallel reactions of $8 a$ with $159 a$ or $[D]_{5}-159 a$ were performed to determine the corresponding KIE value. 159a (113.6 mg, $0.5 \mathrm{mmol})$ or $[\mathrm{D}]_{5}-159 \mathrm{a}(116.2 \mathrm{mg}, 0.5 \mathrm{mmol}$ ), diphenylacetylene (8a) (134 mg, 0.75 mmol), Cp*Col 2 (CO) (12 mg, 5.0 mol \%), AgSbF 6 (34.4 mg, 20 mol \%), NaOAc (8.2 mg, $20 \mathrm{~mol} \%)$, 1,3,5-trimethoxybenzene (28 mg, $0.17 \mathrm{mmol}$ ) as internal standard and HFIP $(2.0 \mathrm{~mL})$ were placed in a $25 \mathrm{~mL}$ Schlenk tube. The mixture was stirred at $100{ }^{\circ} \mathrm{C}$, a periodic aliquot $(0.05 \mathrm{~mL})$ was removed by syringe and analyzed by $\mathrm{GC}$ to determine the following conversions:

\begin{tabular}{|c|c|c|c|c|c|c|}
\hline yield /\% & 10 & 20 & 30 & 40 & 50 & 60 \\
\hline 160 ba & 3 & 14.5 & 24.8 & 37.3 & 44.6 & 50.2 \\
\hline$[D]_{5}-160$ ba & 0.4 & 3.4 & 7.5 & 13.8 & 44.6 & 50.2 \\
\hline
\end{tabular}

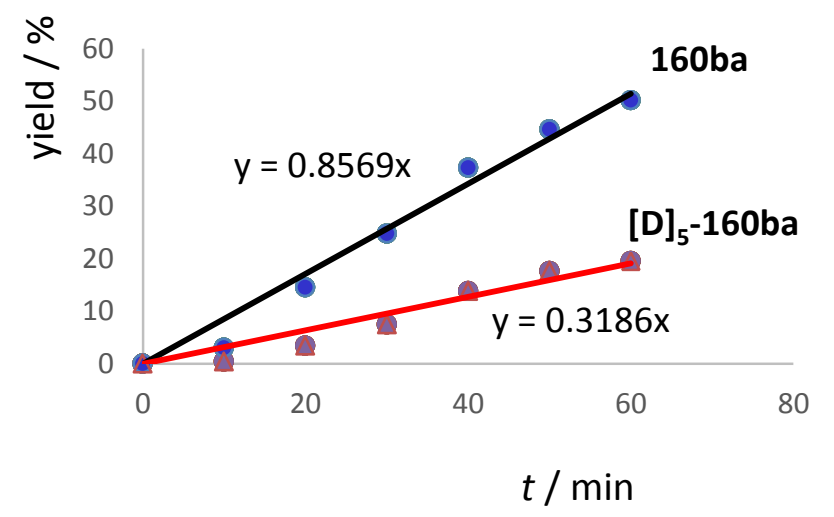




\subsubsection{Data for the Products of Quinazolines by Cobalt(III)-Catalyzed $\mathrm{C}-\mathrm{H} / \mathrm{N}-\mathrm{O}$ Functionalizations with Benzimidates}

\section{Characterization Data}<smiles>CCOc1nc(-c2ccccc2)nc2ccccc12</smiles>

4-Ethoxy-2-phenylquinazoline (163aa): The general procedure C was followed using ethyl benzimidate (161a) (37.3 mg, $0.25 \mathrm{mmol}$ ) and 5-phenyloxazol-2(5H)-one (162a) (48.9 mg, 0.30 mmol). Purification by coloumn chromatography on silica gel ( $n$-hexane/EtOAc: $30 / 1$ ) yielded 163aa (60 mg, 96\%) as a white solid.

M. p. $=64-65{ }^{\circ} \mathrm{C}^{1}{ }^{\mathrm{H}} \mathrm{NMR}\left(300 \mathrm{MHz}, \mathrm{CDCl}_{3}\right) \delta=8.58(\mathrm{dd}, J=7.3,2.3 \mathrm{~Hz}, 2 \mathrm{H}), 8.15(\mathrm{~d}, J=8.8 \mathrm{~Hz}, 1 \mathrm{H})$, $7.97(\mathrm{~d}, J=8.4 \mathrm{~Hz}, 1 \mathrm{H}), 7.79(\mathrm{t}, J=7.7 \mathrm{~Hz}, 1 \mathrm{H}), 7.58-7.40(\mathrm{~m}, 4 \mathrm{H}), 4.76(\mathrm{q}, J=7.1 \mathrm{~Hz}, 2 \mathrm{H}), 1.56(\mathrm{t}, J=$ $7.1 \mathrm{~Hz}, 3 \mathrm{H}) .{ }^{13} \mathrm{C}$ NMR $\left(75 \mathrm{MHz}, \mathrm{CDCl}_{3}\right) \delta=166.6\left(\mathrm{C}_{\mathrm{q}}\right), 160.0\left(\mathrm{C}_{\mathrm{q}}\right), 151.8\left(\mathrm{C}_{\mathrm{q}}\right), 138.2\left(\mathrm{C}_{\mathrm{q}}\right), 133.3(\mathrm{CH})$, $130.4(\mathrm{CH}), 128.4(\mathrm{CH}), 128.3(\mathrm{CH}), 127.9(\mathrm{CH}), 126.2(\mathrm{CH}), 123.5(\mathrm{CH}), 115.3\left(\mathrm{C}_{\mathrm{q}}\right), 62.8\left(\mathrm{CH}_{2}\right), 14.4$ $\left(\mathrm{CH}_{3}\right)$. IR (ATR) $v=3056,2973,1575,1557,1422,1324,1045,1020,763,693 \mathrm{~cm}^{-1} . \mathrm{MS}(\mathrm{ESI}) \mathrm{m} / \mathrm{z}$ (relative intensity): 224 (40), 251 (100) $[\mathrm{M}+\mathrm{H}]^{+}, 273$ (10) [M+Na] $]^{+}$HR-MS (ESI) m/z calcd for $\mathrm{C}_{16} \mathrm{H}_{15} \mathrm{~N}_{2} \mathrm{O}[\mathrm{M}+\mathrm{H}]^{+}: 251.1179$, found: 251.1183 .

The analytical data were in accordance with those reported in the literature. ${ }^{[199]}$<smiles>COc1nc(-c2ccccc2)nc2ccccc12</smiles>

4-Methoxy-2-phenylquinazoline (163ba): The general procedure $\mathrm{C}$ was followed using methyl benzimidate (161b) (33.8 mg, $0.25 \mathrm{mmol}$ ) and 5-phenyloxazol-2(5H)-one (162a) (48.9 mg, 0.30 mmol). Purification by coloumn chromatography on silica gel ( $n$-hexane/EtOAc: $40 / 1$ ) yielded 163 ba (43.0 $\mathrm{mg}, 73 \%)$ as a white solid.

M. p. $=49-50{ }^{\circ} \mathrm{C} .{ }^{1} \mathrm{H}$ NMR $\left(300 \mathrm{MHz}, \mathrm{CDCl}_{3}\right) \delta=8.63-8.60(\mathrm{~m}, 2 \mathrm{H}), 8.16(\mathrm{ddd}, J=8.2,1.5,0.7 \mathrm{~Hz}$, 1H), 8.00 (ddd, $J=8.4,1.2,0.7 \mathrm{~Hz}, 1 \mathrm{H}), 7.81$ (ddd, $J=8.5,7.0,1.5 \mathrm{~Hz}, 1 \mathrm{H}), 7.55-7.48(\mathrm{~m}, 4 \mathrm{H}), 4.29$ (s, 3H). ${ }^{13} \mathrm{C}$ NMR $\left(100 \mathrm{MHz}, \mathrm{CDCl}_{3}\right) \delta=167.2\left(\mathrm{C}_{\mathrm{q}}\right), 160.2\left(\mathrm{C}_{\mathrm{q}}\right), 152.0\left(\mathrm{C}_{\mathrm{q}}\right), 138.3\left(\mathrm{C}_{\mathrm{q}}\right), 133.6(\mathrm{CH}), 130.6$ 
$(\mathrm{CH}), 128.6(\mathrm{CH}), 128.5(\mathrm{CH}), 128.1(\mathrm{CH}), 126.5(\mathrm{CH}), 123.6(\mathrm{CH}), 115.4\left(\mathrm{C}_{\mathrm{q}}\right), 54.2\left(\mathrm{CH}_{3}\right)$. IR $(\mathrm{ATR}) v=$ 3058, 1620, 1557, 1501, 1444, 1375, 1103, 911, 759, $672 \mathrm{~cm}^{-1}$. MS (ESI) m/z (relative intensity): 237 (100) $[\mathrm{M}+\mathrm{H}]^{+}$. HR-MS (ESI) $\mathrm{m} / \mathrm{z}$ calcd for $\mathrm{C}_{15} \mathrm{H}_{13} \mathrm{~N}_{2} \mathrm{O}[\mathrm{M}+\mathrm{H}]^{+}:$: 237.1022, found: 237.1026.

The analytical data were in accordance with those reported in the literature. ${ }^{[199]}$<smiles>CCOc1nc(-c2ccccc2)nc2cc(C)ccc12</smiles>

4-Ethoxy-7-methyl-2-phenylquinazoline (163ca): The general procedure C was followed using ethyl 4-methylbenzimidate (161c) $(40.8 \mathrm{mg}, 0.25 \mathrm{mmol})$ and 5-phenyloxazol-2(5H)-one (162a) (48.9 mg, $0.30 \mathrm{mmol}$ ). Purification by coloumn chromatography on silica gel ( $n$-hexane/EtOAc: $40 / 1$ ) yielded 163ca (60.0 mg, 91\%) as a white solid.

M. p. $=92-93{ }^{\circ} \mathrm{C} .{ }^{1} \mathrm{H}$ NMR $\left(300 \mathrm{MHz}, \mathrm{CDCl}_{3}\right) \delta=8.56(\mathrm{dd}, J=7.5,2.3 \mathrm{~Hz}, 2 \mathrm{H}), 8.03(\mathrm{~d}, J=8.3 \mathrm{~Hz}, 1 \mathrm{H})$, $7.76(\mathrm{~s}, 1 \mathrm{H}), 7.58-7.40(\mathrm{~m}, 3 \mathrm{H}), 7.30(\mathrm{dd}, J=8.3,1.6 \mathrm{~Hz}, 1 \mathrm{H}), 4.74(\mathrm{q}, J=7.1 \mathrm{~Hz}, 2 \mathrm{H}), 2.53(\mathrm{~s}, 3 \mathrm{H})$, $1.55(\mathrm{t}, J=7.1 \mathrm{~Hz}, 3 \mathrm{H}) .{ }^{13} \mathrm{C} \mathrm{NMR}\left(75 \mathrm{MHz}, \mathrm{CDCl}_{3}\right) \delta=166.5\left(\mathrm{C}_{\mathrm{q}}\right), 160.1\left(\mathrm{C}_{\mathrm{q}}\right), 152.1\left(\mathrm{C}_{\mathrm{q}}\right), 144.1\left(\mathrm{C}_{\mathrm{q}}\right)$, $138.4\left(\mathrm{C}_{\mathrm{q}}\right), 130.3(\mathrm{CH}), 128.4(\mathrm{CH}), 128.3(\mathrm{CH}), 128.2(\mathrm{CH}), 127.1(\mathrm{CH}), 123.2(\mathrm{CH}), 113.2\left(\mathrm{C}_{\mathrm{q}}\right), 62.6$ $\left(\mathrm{CH}_{2}\right), 22.1\left(\mathrm{CH}_{3}\right), 14.4\left(\mathrm{CH}_{3}\right)$. IR $($ ATR $) v=2958,1622,1553,148.95,1414,1326,1018,927,799,679$ $\mathrm{cm}^{-1}$. MS (ESI) m/z (relative intensity): 237 (25), 265 (100) [M+H] $]^{+}, 287$ (10) [M+Na $]^{+}$. HR-MS (ESI) $\mathrm{m} / \mathrm{z}$ calcd for $\mathrm{C}_{17} \mathrm{H}_{17} \mathrm{~N}_{2} \mathrm{O}[\mathrm{M}+\mathrm{H}]^{+}:$: 265.1335, found: 265.1339 .

The analytical data were in accordance with those reported in the literature. ${ }^{[199]}$<smiles>CCOc1nc(-c2ccccc2)nc2cc(OC)ccc12</smiles>

4-Ethoxy-7-methoxy-2-phenylquinazoline (163da): The general procedure C was followed using ethyl 4-methoxybenzimidate (161d) $(44.8 \mathrm{mg}, 0.25 \mathrm{mmol})$ and 5-phenyloxazol-2(5H)-one (162a) (48.9 mg, $0.30 \mathrm{mmol})$. Purification by coloumn chromatography on silica gel ( $n$-hexane/EtOAc: $40 / 1$ ) yielded $163 \mathrm{da}$ (62.2 $\mathrm{mg}, 89 \%$ ) as a white solid.

M. p. $=131-132{ }^{\circ} \mathrm{C} .{ }^{1} \mathrm{H}$ NMR $\left(400 \mathrm{MHz}, \mathrm{CDCl}_{3}\right) \delta=8.55(\mathrm{dd}, J=7.8,1.9 \mathrm{~Hz}, 2 \mathrm{H}), 8.02(\mathrm{~d}, J=9.3 \mathrm{~Hz}$, $1 \mathrm{H}), 7.63-7.41(\mathrm{~m}, 3 \mathrm{H}), 7.29(\mathrm{~d}, J=2.5 \mathrm{~Hz}, 1 \mathrm{H}), 7.08(\mathrm{dd}, J=9.0,2.5 \mathrm{~Hz}, 1 \mathrm{H}), 4.72(\mathrm{q}, J=7.1 \mathrm{~Hz}, 2 \mathrm{H})$, 
$3.94(\mathrm{~s}, 3 \mathrm{H}), 1.53(\mathrm{t}, J=7.1 \mathrm{~Hz}, 3 \mathrm{H}) .{ }^{13} \mathrm{C} \mathrm{NMR}\left(100 \mathrm{MHz}, \mathrm{CDCl}_{3}\right) \delta=166.3\left(\mathrm{C}_{\mathrm{q}}\right), 163.7\left(\mathrm{C}_{\mathrm{q}}\right), 160.7\left(\mathrm{C}_{\mathrm{q}}\right)$, $154.2\left(\mathrm{C}_{\mathrm{q}}\right), 138.3\left(\mathrm{C}_{\mathrm{q}}\right), 130.3(\mathrm{CH}), 128.4(\mathrm{CH}), 128.3(\mathrm{CH}), 124.8(\mathrm{CH}), 118.5(\mathrm{CH}), 109.7\left(\mathrm{C}_{\mathrm{q}}\right), 106.5$ (CH), $62.5\left(\mathrm{CH}_{2}\right), 55.6\left(\mathrm{CH}_{3}\right), 14.4\left(\mathrm{CH}_{3}\right)$. IR $(\mathrm{ATR}) v=2982,1622,1584,1438,1348,1210,1158$, 1019, 768, $703 \mathrm{~cm}^{-1}$. MS (ESI) m/z (relative intensity): $253(25), 281(100)[\mathrm{M}+\mathrm{H}]^{+}, 203(10)[\mathrm{M}+\mathrm{Na}]^{+}$. HR-MS (ESI) m/z calcd for $\mathrm{C}_{17} \mathrm{H}_{17} \mathrm{~N}_{2} \mathrm{O}_{2}[\mathrm{M}+\mathrm{H}]^{+}:$: 281.1285, found: 282.1281 .

The analytical data were in accordance with those reported in the literature. ${ }^{[199]}$<smiles>CCOc1nc(-c2ccccc2)nc2cc(C(F)(F)F)ccc12</smiles>

4-Ethoxy-2-phenyl-7-(trifluoromethyl)quinazoline (163ea): The general procedure C was followed using ethyl 4-(trifluoromethyl)benzimidate $(161 \mathrm{e}) \quad(54.3 \quad \mathrm{mg}, \quad 0.25 \mathrm{mmol})$ and 5-phenyloxazol-2(5H)-one (162a) $(48.9 \mathrm{mg}, 0.30 \mathrm{mmol})$. Purification by coloumn chromatography on silica gel ( $n$-hexane/EtOAc: $40 / 1$ ) yielded $163 e a(66.9 \mathrm{mg}, 84 \%)$ as a white solid.

M. p. $=101-103{ }^{\circ} \mathrm{C} .{ }^{1} \mathrm{H}$ NMR $\left(300 \mathrm{MHz}, \mathrm{CDCl}_{3}\right) \delta=8.56(\mathrm{dd}, J=6.5,3.3 \mathrm{~Hz}, 2 \mathrm{H}), 8.23(\mathrm{~d}, J=7.9 \mathrm{~Hz}$, $2 \mathrm{H}), 7.64(\mathrm{dd}, J=8.6,1.6 \mathrm{~Hz}, 1 \mathrm{H}), 7.57-7.44(\mathrm{~m}, 3 \mathrm{H}), 4.76(\mathrm{q}, J=7.1 \mathrm{~Hz}, 2 \mathrm{H}), 1.57(\mathrm{t}, J=7.1 \mathrm{~Hz}, 3 \mathrm{H})$. ${ }^{13} \mathrm{C}$ NMR $\left(75 \mathrm{MHz}, \mathrm{CDCl}_{3}\right) \delta=166.5\left(\mathrm{C}_{\mathrm{q}}\right), 161.3\left(\mathrm{C}_{\mathrm{q}}\right), 151.3\left(\mathrm{C}_{\mathrm{q}}\right), 137.5\left(\mathrm{C}_{\mathrm{q}}\right), 134.9\left(\mathrm{q},{ }^{2} \mathrm{~J}_{\mathrm{C}-\mathrm{F}}=32.9 \mathrm{~Hz}\right.$, $\mathrm{C}_{\mathrm{q}}$ ), $130.9(\mathrm{CH}), 128.5(\mathrm{CH}), 128.4(\mathrm{CH}), 125.6\left(\mathrm{q},{ }^{3} \mathrm{~J}_{\mathrm{C}-\mathrm{F}}=4.1 \mathrm{~Hz}, \mathrm{CH}\right), 124.9(\mathrm{CH}), 121.9\left(\mathrm{q},{ }^{3} \mathrm{~J}_{\mathrm{C}-\mathrm{F}}=3.2\right.$ $\mathrm{Hz}, \mathrm{CH}), 123.6\left(\mathrm{q},{ }^{1} J_{\mathrm{C}-\mathrm{F}}=273.3 \mathrm{~Hz}, \mathrm{C}_{\mathrm{q}}\right), 117.0\left(\mathrm{C}_{\mathrm{q}}\right), 63.3\left(\mathrm{CH}_{2}\right), 14.3\left(\mathrm{CH}_{3}\right) .{ }^{19} \mathrm{~F} \mathrm{NMR}\left(283 \mathrm{MHz}, \mathrm{CDCl}_{3}\right) \delta$ $=-63.20$. IR (ATR) $v=2995,1581,1557,1450,1327,1176,1119,895,715 \mathrm{~cm}^{-1} . \mathrm{MS}$ (ESI) m/z (relative intensity): $319(100)[\mathrm{M}+\mathrm{H}]^{+}$. HR-MS (ESI) m/z calcd for $\mathrm{C}_{17} \mathrm{H}_{14} \mathrm{~N}_{2} \mathrm{OF}_{3}[\mathrm{M}+\mathrm{H}]^{+}: 319.1053$, found: 319.1055 .<smiles>CCOc1nc(-c2ccccc2)nc2cc(F)ccc12</smiles>

4-Ethoxy-7-fluoro-2-phenylquinazoline (163fa): The general procedure $\mathrm{C}$ was followed using ethyl 4-fluorobenzimidate (161f) $(41.8 \mathrm{mg}, 0.25 \mathrm{mmol}$ ) and 5-phenyloxazol-2(5H)-one (162a) (48.9 mg, $0.30 \mathrm{mmol}$ ). Purification by coloumn chromatography on silica gel ( $n$-hexane/EtOAc: $40 / 1)$ yielded $163 \mathrm{fa}(66.9 \mathrm{mg}, 98 \%)$ as a white solid. 
M. p. $=93-94{ }^{\circ} \mathrm{C} .{ }^{1} \mathrm{H}$ NMR $\left(300 \mathrm{MHz}, \mathrm{CDCl}_{3}\right) \delta=8.55(\mathrm{dd}, J=6.6,3.2 \mathrm{~Hz}, 2 \mathrm{H}), 8.13(\mathrm{dd}, J=9.0,6.2 \mathrm{~Hz}$, 1H), 7.57 (dd, $J=10.1,2.5 \mathrm{~Hz}, 1 \mathrm{H}), 7.52-7.47(\mathrm{~m}, 3 \mathrm{H}), 7.21$ (td, $J=8.7,2.5 \mathrm{~Hz}, 1 \mathrm{H}), 4.73(\mathrm{q}, J=7.1 \mathrm{~Hz}$, 2H), $1.54(\mathrm{t}, J=7.1 \mathrm{~Hz}, 3 \mathrm{H}) .{ }^{13} \mathrm{C}$ NMR $\left(75 \mathrm{MHz}, \mathrm{CDCl}_{3}\right) \delta=166.4\left(\mathrm{C}_{\mathrm{q}}\right), 165.7\left(\mathrm{~d},{ }^{1} \mathrm{~J}_{\mathrm{C}-\mathrm{F}}=253.1 \mathrm{~Hz}, \mathrm{C}_{\mathrm{q}}\right)$, $161.2\left(\mathrm{C}_{\mathrm{q}}\right), 153.7\left(\mathrm{~d},{ }^{3} \mathrm{~J}_{\mathrm{C}-\mathrm{F}}=13.9 \mathrm{~Hz}, \mathrm{C}_{\mathrm{q}}\right), 137.8\left(\mathrm{C}_{\mathrm{q}}\right), 130.7(\mathrm{CH}), 128.5(\mathrm{CH}), 128.4(\mathrm{CH}), 126.2\left(\mathrm{~d},{ }^{3} \mathrm{~J}_{\mathrm{C}-\mathrm{F}}\right.$ $=11.1 \mathrm{~Hz}, \mathrm{CH}), 116.0\left(\mathrm{~d},{ }^{2} J_{\mathrm{C}-\mathrm{F}}=24.9 \mathrm{~Hz}, \mathrm{CH}\right), 112.2\left(\mathrm{~d},{ }^{4} J_{\mathrm{C}-\mathrm{F}}=3.7 \mathrm{~Hz}, \mathrm{C}_{\mathrm{q}}\right), 112.0\left(\mathrm{~d},{ }^{2} \mathrm{~J}_{\mathrm{C}-\mathrm{F}}=20.4 \mathrm{~Hz}, \mathrm{CH}\right)$, $62.9\left(\mathrm{CH}_{2}\right), 14.3\left(\mathrm{CH}_{3}\right) .{ }^{19} \mathrm{~F} \mathrm{NMR}\left(283 \mathrm{MHz}, \mathrm{CDCl}_{3}\right) \delta=-104.33$ (ddd, $\left.J=10.1,8.4,6.2 \mathrm{~Hz}\right)$. IR (ATR) $v=$ 2975, 1626, 1562, 1416, 1340, 1156, 1018, 861, 770, $676 \mathrm{~cm}^{-1}$. MS (ESI) m/z (relative intensity): 241 (30), 269 (100) $[\mathrm{M}+\mathrm{H}]^{+}, 291(100)[\mathrm{M}+\mathrm{Na}]^{+}$. HR-MS (ESI) m/z calcd for $\mathrm{C}_{16} \mathrm{H}_{14} \mathrm{~N}_{2} \mathrm{OF}[\mathrm{M}+\mathrm{H}]^{+}: 269.1085$, found: 269.1086 .<smiles>CCOc1nc(-c2ccccc2)nc2cc(Cl)ccc12</smiles>

7-Chloro-4-ethoxy-2-phenylquinazoline (163ga): The general procedure $\mathbf{C}$ was followed using ethyl 4-chlorobenzimidate (161g) (45.9 mg, $0.25 \mathrm{mmol}$ ) and 5-phenyloxazol-2(5H)-one (162a) (48.9 mg, $0.30 \mathrm{mmol}$ ). Purification by coloumn chromatography on silica gel ( $n$-hexane/EtOAc: $40 / 1$ ) yielded 163ga (68.0 mg, 96\%) as a white solid.

M. p. $=104-105^{\circ} \mathrm{C} .{ }^{1} \mathrm{H}$ NMR $\left(400 \mathrm{MHz}, \mathrm{CDCl}_{3}\right) \delta=8.56-8.52(\mathrm{~m}, 2 \mathrm{H}), 8.05(\mathrm{dd}, J=8.7,0.5 \mathrm{~Hz}, 1 \mathrm{H})$, $7.94(\mathrm{dd}, J=2.0,0.5 \mathrm{~Hz}, 1 \mathrm{H}), 7.63-7.44(\mathrm{~m}, 3 \mathrm{H}), 7.41(\mathrm{dd}, J=8.7,2.0 \mathrm{~Hz}, 1 \mathrm{H}), 4.73(\mathrm{q}, J=7.1 \mathrm{~Hz}, 2 \mathrm{H})$, $1.54(\mathrm{t}, J=7.1 \mathrm{~Hz}, 3 \mathrm{H}) .{ }^{13} \mathrm{C}$ NMR $\left(100 \mathrm{MHz}, \mathrm{CDCl}_{3}\right) \delta=166.5\left(\mathrm{C}_{\mathrm{q}}\right), 161.1\left(\mathrm{C}_{\mathrm{q}}\right), 152.6\left(\mathrm{C}_{\mathrm{q}}\right), 139.4\left(\mathrm{C}_{\mathrm{q}}\right)$, $137.8\left(\mathrm{C}_{\mathrm{q}}\right), 130.7(\mathrm{CH}), 128.5(\mathrm{CH}), 128.4(\mathrm{CH}), 127.1(\mathrm{CH}), 127.1(\mathrm{CH}), 124.9(\mathrm{CH}), 113.7\left(\mathrm{C}_{\mathrm{q}}\right), 63.0$ $\left(\mathrm{CH}_{2}\right), 14.3\left(\mathrm{CH}_{3}\right)$. IR (ATR) $v=2975,1615,1556,1431,1340,1317,1018,871,772,704 \mathrm{~cm}^{-1}$. MS (ESI) m/z (relative intensity): 257 (30), $285(100)[M+H]^{+}, 307(20)\left[M+N_{a}\right]^{+}$. HR-MS (ESI) m/z calcd for $\mathrm{C}_{16} \mathrm{H}_{14} \mathrm{~N}_{2} \mathrm{OCl}[\mathrm{M}+\mathrm{H}]^{+}:$285.0789, found: 285.0792.

The analytical data were in accordance with those reported in the literature. ${ }^{[199]}$ 
<smiles>CCOc1nc(-c2ccccc2)nc2cc(C(C)=O)ccc12</smiles>

1-(4-Ethoxy-2-phenylquinazolin-7-yl)ethanone (163ha): The general procedure C was followed using ethyl 4-acetylbenzimidate $(\mathbf{1 6 1 h})(47.8 \mathrm{mg}, 0.25 \mathrm{mmol})$ and 5-phenyloxazol-2(5H)-one (162a) (48.9 mg, $0.30 \mathrm{mmol}$ ). Purification by coloumn chromatography on silica gel ( $n$-hexane/EtOAc: $40 / 1)$ yielded $163 \mathrm{ha}(53.4 \mathrm{mg}, 73 \%$ ) as a pale yellow solid.

M. p. $=139-140{ }^{\circ} \mathrm{C} .{ }^{1} \mathrm{H}$ NMR $\left(300 \mathrm{MHz}, \mathrm{CDCl}_{3}\right) \delta=8.56(\mathrm{dd}, J=6.7,3.2 \mathrm{~Hz}, 2 \mathrm{H}), 8.49(\mathrm{~d}, J=1.6 \mathrm{~Hz}$, $1 \mathrm{H}), 8.20(\mathrm{~d}, J=8.5 \mathrm{~Hz}, 1 \mathrm{H}), 8.03(\mathrm{dd}, J=8.5,1.6 \mathrm{~Hz}, 1 \mathrm{H}), 7.59-7.42(\mathrm{~m}, 3 \mathrm{H}), 4.77(\mathrm{q}, J=7.1 \mathrm{~Hz}, 2 \mathrm{H})$, $2.74(\mathrm{~s}, 3 \mathrm{H}), 1.57(\mathrm{t}, J=7.1 \mathrm{~Hz}, 3 \mathrm{H}) .{ }^{13} \mathrm{C} \operatorname{NMR}\left(75 \mathrm{MHz}, \mathrm{CDCl}_{3}\right) \delta=197.8\left(\mathrm{C}_{\mathrm{q}}\right), 166.6\left(\mathrm{C}_{\mathrm{q}}\right), 161.0\left(\mathrm{C}_{\mathrm{q}}\right)$, $151.8\left(\mathrm{C}_{\mathrm{q}}\right), 140.8\left(\mathrm{C}_{\mathrm{q}}\right), 137.7\left(\mathrm{C}_{\mathrm{q}}\right), 130.8(\mathrm{CH}), 129.3(\mathrm{CH}), 128.5(\mathrm{CH}), 128.5(\mathrm{CH}), 124.2(\mathrm{CH}), 124.1$ (CH), $117.8\left(\mathrm{C}_{\mathrm{q}}\right), 63.3\left(\mathrm{CH}_{2}\right), 26.9\left(\mathrm{CH}_{3}\right), 14.3\left(\mathrm{CH}_{3}\right)$. IR (ATR) $v=2974,1686,1551,1384,1318,1221$, 1019, 777, 714, $676 \mathrm{~cm}^{-1}$. MS (ESI) m/z (relative intensity): 293 (95) [M+H] $]^{+}, 315$ (100) [M+Na] $]^{+}$ HR-MS (ESI) m/z calcd for $\mathrm{C}_{18} \mathrm{H}_{17} \mathrm{~N}_{2} \mathrm{O}_{2}[\mathrm{M}+\mathrm{H}]^{+}: 293.1285$, found: 293.1280 .<smiles>COC(=O)c1ccc2c(OC)nc(-c3ccccc3)nc2c1</smiles>

Methyl 4-methoxy-2-phenylquinazoline-7-carboxylate (163ia): The general procedure C was followed using methyl 4-[imino(methoxy)methyl]benzoate (161i) $(48.3 \mathrm{mg}, 0.25 \mathrm{mmol})$ and 5-phenyloxazol-2(5H)-one (162a) $(48.9 \mathrm{mg}, 0.30 \mathrm{mmol})$. Purification by coloumn chromatography on silica gel ( $n$-hexane/EtOAc: $20 / 1$ ) yielded 163ia (48.0 mg, 72\%) as a white solid.

M. p. $=124-125^{\circ} \mathrm{C} .{ }^{1} \mathrm{H}$ NMR $\left(400 \mathrm{MHz}, \mathrm{CDCl}_{3}\right) \delta=8.62(\mathrm{~d}, J=2.1 \mathrm{~Hz}, 1 \mathrm{H}), 8.60-8.54(\mathrm{~m}, 2 \mathrm{H}), 8.14$ (dd, $J=8.5,0.7 \mathrm{~Hz}, 1 \mathrm{H}), 8.07-8.03(\mathrm{~m}, 1 \mathrm{H}), 7.55-7.45(\mathrm{~m}, 3 \mathrm{H}), 4.26(\mathrm{~s}, 3 \mathrm{H}), 3.97(\mathrm{~s}, 3 \mathrm{H}) .{ }^{13} \mathrm{C}$ NMR $\left(100 \mathrm{MHz}, \mathrm{CDCl}_{3}\right) \delta=166.9\left(\mathrm{C}_{\mathrm{q}}\right), 166.3\left(\mathrm{C}_{\mathrm{q}}\right), 160.7\left(\mathrm{C}_{\mathrm{q}}\right), 151.4\left(\mathrm{C}_{\mathrm{q}}\right), 137.7\left(\mathrm{C}_{\mathrm{q}}\right), 134.5\left(\mathrm{C}_{\mathrm{q}}\right), 130.7(\mathrm{CH})$, $130.1(\mathrm{CH}), 128.5(\mathrm{CH}), 128.4(\mathrm{CH}), 125.9(\mathrm{CH}), 123.7(\mathrm{CH}), 117.6\left(\mathrm{C}_{\mathrm{q}}\right), 54.3\left(\mathrm{CH}_{3}\right), 52.5\left(\mathrm{CH}_{3}\right)$. IR (ATR) $v=2945,1718,1556,148.99,1373,1267,909,753,713 \mathrm{~cm}^{-1}$. MS (ESI) m/z (relative intensity): 295 (100) $[\mathrm{M}+\mathrm{H}]^{+}, 317(95)[\mathrm{M}+\mathrm{Na}]^{+}$. HR-MS (ESI) m/z calcd for $\mathrm{C}_{17} \mathrm{H}_{15} \mathrm{~N}_{2} \mathrm{O}_{3}[\mathrm{M}+\mathrm{H}]^{+}:$295.1077, found: 295.1080 . 
<smiles>CCOc1nc(-c2ccccc2)nc2cc([N+](=O)[O-])ccc12</smiles>

4-Ethoxy-7-nitro-2-phenylquinazoline (163ja): The general procedure C was followed using ethyl 4-nitrobenzimidate $(\mathbf{1 6 1 j})(48.9 \mathrm{mg}, 0.25 \mathrm{mmol})$ and 5-phenyloxazol-2(5H)-one (162a) (48.9 mg, $0.30 \mathrm{mmol}$ ). Purification by coloumn chromatography on silica gel ( $n$-hexane/EtOAc: $40 / 1$ ) yielded 163ja (42.0 mg, 57\%) as a white solid.

M. p. $=151-153{ }^{\circ} \mathrm{C} .{ }^{1} \mathrm{H}$ NMR $\left(400 \mathrm{MHz}, \mathrm{CDCl}_{3}\right) \delta=8.74(\mathrm{dd}, J=2.2,0.6 \mathrm{~Hz}, 1 \mathrm{H}), 8.62-8.48(\mathrm{~m}, 2 \mathrm{H})$, $8.24(\mathrm{dd}, J=8.9,0.6 \mathrm{~Hz}, 1 \mathrm{H}), 8.17(\mathrm{dd}, J=8.9,2.2 \mathrm{~Hz}, 1 \mathrm{H}), 7.41-6.70(\mathrm{~m}, 3 \mathrm{H}), 4.76(\mathrm{q}, J=7.1 \mathrm{~Hz}, 2 \mathrm{H})$, $1.57(\mathrm{t}, J=7.1 \mathrm{~Hz}, 3 \mathrm{H}) .{ }^{13} \mathrm{C}$ NMR $\left(100 \mathrm{MHz}, \mathrm{CDCl}_{3}\right) \delta=166.4\left(\mathrm{C}_{\mathrm{q}}\right), 162.0\left(\mathrm{C}_{\mathrm{q}}\right), 151.7\left(\mathrm{C}_{\mathrm{q}}\right), 150.9\left(\mathrm{C}_{\mathrm{q}}\right)$, $137.1\left(\mathrm{C}_{\mathrm{q}}\right), 131.2(\mathrm{CH}), 128.6(\mathrm{CH}), 128.5(\mathrm{CH}), 125.5(\mathrm{CH}), 123.7(\mathrm{CH}), 119.5(\mathrm{CH}), 118.5\left(\mathrm{C}_{\mathrm{q}}\right), 63.7$ $\left(\mathrm{CH}_{2}\right), 14.2\left(\mathrm{CH}_{3}\right)$. IR (ATR) $v=2982,1565,1531,1337,1068,1012,892,821,739,670 \mathrm{~cm}^{-1}$. MS (ESI) m/z (relative intensity): $296(95)[\mathrm{M}+\mathrm{H}]^{+}, 318(100)[\mathrm{M}+\mathrm{Na}]^{+}$. HR-MS (ESI) m/z calcd for $\mathrm{C}_{16} \mathrm{H}_{13} \mathrm{~N}_{3} \mathrm{O}_{3}$ $[\mathrm{M}+\mathrm{H}]^{+}:$296.1030, found: 296.1027.<smiles>CCOc1nc(-c2ccccc2)nc2ccc(C)cc12</smiles>

4-Ethoxy-6-methyl-2-phenylquinazoline (163ka): The general procedure $\mathrm{C}$ was followed using ethyl 3-methylbenzimidate (161k) $(41.0 \mathrm{mg}, 0.25 \mathrm{mmol})$ and 5-phenyloxazol-2(5H)-one (162a) (48.9 mg, $0.30 \mathrm{mmol}$ ). Purification by coloumn chromatography on silica gel ( $n$-hexane/EtOAc: $40 / 1$ ) yielded 163ka (60.0 mg, 91\%) as a white solid.

M. p. $=89-91{ }^{\circ} \mathrm{C} .{ }^{1} \mathrm{H}$ NMR $\left(500 \mathrm{MHz}, \mathrm{CDCl}_{3}\right) \delta=8.56(\mathrm{dd}, J=8.1,1.6 \mathrm{~Hz}, 2 \mathrm{H}), 7.92(\mathrm{~s}, 1 \mathrm{H}), 7.87(\mathrm{~d}, J=$ $8.5 \mathrm{~Hz}, 1 \mathrm{H}), 7.61(\mathrm{dd}, J=8.5,1.9 \mathrm{~Hz}, 1 \mathrm{H}), 7.54-7.40(\mathrm{~m}, 3 \mathrm{H}), 4.75(\mathrm{q}, J=7.1 \mathrm{~Hz}, 2 \mathrm{H}), 2.51(\mathrm{~s}, 3 \mathrm{H})$, $1.56(\mathrm{t}, J=7.1 \mathrm{~Hz}, 3 \mathrm{H}) .{ }^{13} \mathrm{C} \operatorname{NMR}\left(125 \mathrm{MHz}, \mathrm{CDCl}_{3}\right) \delta=166.2\left(\mathrm{C}_{\mathrm{q}}\right), 159.2\left(\mathrm{C}_{\mathrm{q}}\right), 150.2\left(\mathrm{C}_{\mathrm{q}}\right), 138.3\left(\mathrm{C}_{\mathrm{q}}\right)$, $136.3\left(\mathrm{C}_{\mathrm{q}}\right), 135.3(\mathrm{CH}), 130.2(\mathrm{CH}), 128.3(\mathrm{CH}), 128.3(\mathrm{CH}), 127.6(\mathrm{CH}), 122.4(\mathrm{CH}), 115.1\left(\mathrm{C}_{\mathrm{q}}\right), 62.6$ $\left(\mathrm{CH}_{2}\right), 21.6\left(\mathrm{CH}_{3}\right), 14.4\left(\mathrm{CH}_{3}\right)$. IR (ATR) $v=2976,1562,1383,1312,1108,1023,780,707 \mathrm{~cm}^{-1}$. MS (ESI) $\mathrm{m} / \mathrm{z}$ (relative intensity): 265 (100) $[\mathrm{M}+\mathrm{H}]^{+}$. HR-MS (ESI) $\mathrm{m} / \mathrm{z}$ calcd for $\mathrm{C}_{17} \mathrm{H}_{17} \mathrm{~N}_{2} \mathrm{O}[\mathrm{M}+\mathrm{H}]^{+}$: 265.1335 , found: 265.1338 .

The analytical data were in accordance with those reported in the literature. ${ }^{[199]}$ 
<smiles>CCOc1nc(-c2ccccc2)nc2ccc(C(F)(F)F)cc12</smiles>

4-Ethoxy-2-phenyl-6-(trifluoromethyl)quinazoline (163la): The general procedure C was followed using ethyl 3-(trifluoromethyl)benzimidate $\quad$ (161l) $\quad(54.3 \quad \mathrm{mg}, \quad 0.25 \mathrm{mmol})$ and 5-phenyloxazol-2(5H)-one (162a) $(48.9 \mathrm{mg}, 0.30 \mathrm{mmol})$. Purification by coloumn chromatography on silica gel ( $n$-hexane/EtOAc: $40 / 1$ ) yielded 163 la (46.0 mg, 58\%) as a white solid.

M. p. $=129-130{ }^{\circ} \mathrm{C}^{1}{ }^{1} \mathrm{H}$ NMR $\left(300 \mathrm{MHz}, \mathrm{CDCl}_{3}\right) \delta=8.62-8.52(\mathrm{~m}, 2 \mathrm{H}), 8.45(\mathrm{t}, J=0.9 \mathrm{~Hz}, 1 \mathrm{H}), 8.05(\mathrm{~d}$, $J=8.8 \mathrm{~Hz}, 1 \mathrm{H}), 7.95(\mathrm{dd}, J=8.8,2.1 \mathrm{~Hz}, 1 \mathrm{H}), 7.57-7.46(\mathrm{~m}, 3 \mathrm{H}), 4.80(\mathrm{q}, J=7.1 \mathrm{~Hz}, 2 \mathrm{H}), 1.58(\mathrm{t}, J=$ $7.1 \mathrm{~Hz}, 3 \mathrm{H}) .{ }^{13} \mathrm{C}$ NMR $\left(75 \mathrm{MHz}, \mathrm{CDCl}_{3}\right) \delta=167.0\left(\mathrm{C}_{\mathrm{q}}\right), 162.0\left(\mathrm{C}_{\mathrm{q}}\right), 153.3\left(\mathrm{C}_{\mathrm{q}}\right), 137.6\left(\mathrm{C}_{\mathrm{q}}\right), 131.1(\mathrm{CH})$, $129.2\left(q,{ }^{3} J_{C-F}=3.6 \mathrm{~Hz}, \mathrm{CH}\right), 128.9(\mathrm{CH}), 128.7(\mathrm{CH}), 128.5(\mathrm{CH}), 127.9\left(\mathrm{q},{ }^{2} \mathrm{~J}_{\mathrm{C}-\mathrm{F}}=33.0 \mathrm{~Hz}, \mathrm{C} q\right) 123.8(\mathrm{q}$, $\left.{ }^{1} J_{\mathrm{C}-\mathrm{F}}=271.9 \mathrm{~Hz}, \mathrm{C}_{\mathrm{q}}\right), 121.8\left(\mathrm{q},{ }^{3} \mathrm{~J}_{\mathrm{C}-\mathrm{F}}=4.5 \mathrm{~Hz}, \mathrm{CH}\right), 114.7\left(\mathrm{C}_{\mathrm{q}}\right), 63.4\left(\mathrm{CH}_{2}\right), 14.3\left(\mathrm{CH}_{3}\right) .{ }^{19} \mathrm{~F} \mathrm{NMR}(283 \mathrm{MHz}$, $\left.\mathrm{CDCl}_{3}\right) \delta=-62.27$. IR (ATR) $v=2992,1634,1575,1443,1320,1107,873,686 \mathrm{~cm}^{-1}$. MS (ESI) m/z (relative intensity): 295 (90), $319(100)[\mathrm{M}+\mathrm{H}]^{+}$. HR-MS (ESI) m/z calcd for $\mathrm{C}_{17} \mathrm{H}_{14} \mathrm{~N}_{2} \mathrm{OF}{ }_{3}[\mathrm{M}+\mathrm{H}]^{+}$: 319.1053, found: 319.1049 .<smiles>CCOc1nc(-c2ccccc2)nc2ccc(Cl)cc12</smiles>

6-Chloro-4-ethoxy-2-phenylquinazoline (163ma): The general procedure $\mathrm{C}$ was followed using ethyl 3-chlorobenzimidate $(\mathbf{1 6 1 \mathrm { m } )}$ (46 $\mathrm{mg}, 0.25 \mathrm{mmol}$ ) and 5-phenyloxazol-2(5H)-one (162a) (48.9 mg, $0.30 \mathrm{mmol}$ ). Purification by coloumn chromatography on silica gel ( $n$-hexane/EtOAc: $40 / 1$ ) yielded 163ma (62.3 mg, 88\%) as a white solid.

M. p. $=132-133{ }^{\circ} \mathrm{C} .{ }^{1} \mathrm{H}$ NMR $\left(300 \mathrm{MHz}, \mathrm{CDCl}_{3}\right) \delta=8.53(\mathrm{dd}, J=6.7,3.2 \mathrm{~Hz}, 2 \mathrm{H}), 8.09(\mathrm{~d}, J=2.4 \mathrm{~Hz}$, $1 \mathrm{H}), 7.87(\mathrm{~d}, J=8.9 \mathrm{~Hz}, 1 \mathrm{H}), 7.69(\mathrm{dd}, J=8.9,2.4 \mathrm{~Hz}, 1 \mathrm{H}), 7.53-7.43(\mathrm{~m}, 3 \mathrm{H}), 4.73(\mathrm{q}, J=7.1 \mathrm{~Hz}, 2 \mathrm{H})$, $1.55(t, J=7.1 \mathrm{~Hz}, 3 \mathrm{H}) .{ }^{13} \mathrm{C}$ NMR $\left(75 \mathrm{MHz}, \mathrm{CDCl}_{3}\right) \delta=165.8\left(\mathrm{C}_{\mathrm{q}}\right), 160.2\left(\mathrm{C}_{\mathrm{q}}\right), 150.3\left(\mathrm{C}_{\mathrm{q}}\right), 137.8\left(\mathrm{C}_{\mathrm{q}}\right)$, $134.1(\mathrm{CH}), 131.7\left(\mathrm{C}_{\mathrm{q}}\right), 130.6(\mathrm{CH}), 129.5(\mathrm{CH}), 128.4(\mathrm{CH}), 128.4(\mathrm{CH}), 122.7(\mathrm{CH}), 115.9\left(\mathrm{C}_{\mathrm{q}}\right), 63.1$ $\left(\mathrm{CH}_{2}\right), 14.3\left(\mathrm{CH}_{3}\right)$. IR (ATR) $v=2975,1555,1488,1412,1306,1022,834,670,547 \mathrm{~cm}^{-1} . \mathrm{MS}(\mathrm{ESI}) \mathrm{m} / \mathrm{z}$ (relative intensity): $285(100)[\mathrm{M}+\mathrm{H}]^{+}, 287$ (30). HR-MS (ESI) m/z calcd for $\mathrm{C}_{16} \mathrm{H}_{14} \mathrm{~N}_{2} \mathrm{OCl}[\mathrm{M}+\mathrm{H}]^{+}$: 285.0789, found: 285.0789 . 
<smiles>CCOc1nc(-c2ccccc2)nc2sccc12</smiles>

4-Ethoxy-2-phenylthieno[2,3-d]pyrimidine (163na): The general procedure $C$ was followed using ethyl thiophene-3-carbimidate (161n) (39 mg, $0.25 \mathrm{mmol}$ ) and 5-phenyloxazol-2(5H)-one (162a) (48.9 mg, $0.30 \mathrm{mmol})$. Purification by coloumn chromatography on silica gel ( $n$-hexane/EtOAc: $15 / 1)$ yielded 163na (38.0 $\mathrm{mg}, 60 \%$ ) as a white solid.

M. p. $=51-53{ }^{\circ} \mathrm{C} .{ }^{1} \mathbf{H}$ NMR $\left(300 \mathrm{MHz}, \mathrm{CDCl}_{3}\right) \delta=8.54-8.51(\mathrm{~m}, 2 \mathrm{H}), 7.53-7.46(\mathrm{~m}, 3 \mathrm{H}), 7.38(\mathrm{~d}, J=$ $5.9 \mathrm{~Hz}, 1 \mathrm{H}), 7.33(\mathrm{~d}, J=5.9 \mathrm{~Hz}, 1 \mathrm{H}), 4.75(\mathrm{q}, J=7.1 \mathrm{~Hz}, 2 \mathrm{H}), 1.54(\mathrm{t}, J=7.1 \mathrm{~Hz}, 3 \mathrm{H}) .{ }^{13} \mathrm{C} \mathrm{NMR}(75 \mathrm{MHz}$, $\left.\mathrm{CDCl}_{3}\right) \delta=169.7\left(\mathrm{C}_{\mathrm{q}}\right), 163.8\left(\mathrm{C}_{\mathrm{q}}\right), 159.9\left(\mathrm{C}_{\mathrm{q}}\right), 137.8\left(\mathrm{C}_{\mathrm{q}}\right), 130.5(\mathrm{CH}), 128.6(\mathrm{CH}), 128.5(\mathrm{CH}), 124.1$ (CH), $118.8(\mathrm{CH}), 117.5\left(\mathrm{C}_{\mathrm{q}}\right), 62.7\left(\mathrm{CH}_{2}\right), 14.7\left(\mathrm{CH}_{3}\right)$. IR (ATR) $v=2982,1618,1567,1535,1468,1381$, 1319, 1038, 889, 686, $664 \mathrm{~cm}^{-1}$. MS (ESI) m/z (relative intensity): 257 (100) $[\mathrm{M}+\mathrm{H}]^{+}, 279$ (23) $[\mathrm{M}+\mathrm{Na}]^{+}$. HR-MS (ESI) m/z calcd for $\mathrm{C}_{14} \mathrm{H}_{13} \mathrm{~N}_{2} \mathrm{OS}[\mathrm{M}+\mathrm{H}]^{+}: 257.0749$, found: 257.0745 .<smiles>CCOc1nc(Cc2ccccc2)nc2ccccc12</smiles>

2-Benzyl-4-ethoxyquinazoline (163ab): The general procedure $\mathrm{C}$ was followed using ethyl benzimidate (161a) (37.3 mg, $0.25 \mathrm{mmol}$ ) and 5-benzyloxazol-2(5H)-one (162b) (52.6 mg, 0.30 mmol). Purification by coloumn chromatography on silica gel ( $n$-hexane/EtOAc: $15 / 1$ ) yielded 163ab (56.9 $\mathrm{mg}, 88 \%)$ as a yellow oil.

${ }^{1} \mathrm{H}$ NMR $\left(300 \mathrm{MHz}_{\mathrm{CDCl}}\right) \delta=8.11(\mathrm{ddd}, J=8.2,1.5,0.7 \mathrm{~Hz}, 1 \mathrm{H}), 7.88(\mathrm{ddd}, J=8.4,1.2,0.6 \mathrm{~Hz}, 1 \mathrm{H})$, 7.77 (ddd, $J=8.5,7.0,1.5 \mathrm{~Hz}, 1 \mathrm{H}), 7.50-7.44(\mathrm{~m}, 3 \mathrm{H}), 7.32-7.27(\mathrm{~m}, 2 \mathrm{H}), 7.23-7.17(\mathrm{~m}, 1 \mathrm{H}), 4.59$ (q, $J=7.1 \mathrm{~Hz}, 2 \mathrm{H}), 4.26(\mathrm{~s}, 2 \mathrm{H}), 1.45(\mathrm{t}, J=7.1 \mathrm{~Hz}, 3 \mathrm{H}) .{ }^{13} \mathrm{C} \mathrm{NMR}\left(75 \mathrm{MHz}, \mathrm{CDCl}_{3}\right) \delta=166.8\left(\mathrm{C}_{\mathrm{q}}\right), 165.3$ $\left(\mathrm{C}_{\mathrm{q}}\right), 151.1\left(\mathrm{C}_{\mathrm{q}}\right), 138.9\left(\mathrm{C}_{\mathrm{q}}\right), 133.3(\mathrm{CH}), 129.5(\mathrm{CH}), 128.3(\mathrm{CH}), 127.4(\mathrm{CH}), 126.4(\mathrm{CH}), 126.2(\mathrm{CH})$, $123.5(\mathrm{CH}), 115.1\left(\mathrm{C}_{q}\right), 63.0\left(\mathrm{CH}_{2}\right), 46.5\left(\mathrm{CH}_{2}\right), 14.4\left(\mathrm{CH}_{3}\right)$. IR (ATR) $v=2926,1619,1573,148.97,1457$, 1420, 1325, 1105, 770, $696 \mathrm{~cm}^{-1}$. MS (EI) m/z (relative intensity): 265 (100) $[\mathrm{M}+\mathrm{H}]^{+}, 237$ (29), 287 (15) $[\mathrm{M}+\mathrm{Na}]^{+}$. HRMS (ESI) calcd for $\mathrm{C}_{17} \mathrm{H}_{17} \mathrm{~N}_{2} \mathrm{O}\left([\mathrm{M}+\mathrm{H}]^{+}\right)$: 265.1335; found 265.1337.

The analytical data were in accordance with those reported in the literature. ${ }^{[199]}$ 
<smiles>CCOc1nc(Cc2ccccc2)nc2ccccc12</smiles>

4-Ethoxy-2-phenethylquinazoline (163ac): The general procedure C was followed using ethyl benzimidate (161c) $(37.3 \mathrm{mg}, 0.25 \mathrm{mmol})$ and 5-phenethyloxazol-2(5H)-one (162a) (56.8 mg, 0.30 mmol). Purification by coloumn chromatography on silica gel ( $n$-hexane/EtOAc: $20 / 1$ ) yielded 163ac (56.9 $\mathrm{mg}, 82 \%)$ as a colorless oil.

${ }^{1} \mathrm{H}$ NMR $\left(300 \mathrm{MHz}_{\mathrm{CDCl}}\right) \delta=8.12(\mathrm{ddd}, J=8.2,1.6,0.7 \mathrm{~Hz}, 1 \mathrm{H}), 7.86(\mathrm{ddd}, J=8.4,1.3,0.7 \mathrm{~Hz}, 1 \mathrm{H})$, 7.76 (ddd, $J=8.4,6.9,1.4 \mathrm{~Hz}, 1 \mathrm{H}$ ), 7.47 (ddd, $J=8.2,6.9,1.3 \mathrm{~Hz}, 1 \mathrm{H}), 7.32-7.24(\mathrm{~m}, 4 \mathrm{H}), 7.20-7.14$ $(\mathrm{m}, 1 \mathrm{H}), 4.63(\mathrm{q}, J=7.1 \mathrm{~Hz}, 2 \mathrm{H}), 3.31-3.29(\mathrm{~m}, 4 \mathrm{H}), 1.50(\mathrm{t}, J=7.1 \mathrm{~Hz}, 3 \mathrm{H}) .{ }^{13} \mathrm{C} \mathrm{NMR}\left(125 \mathrm{MHz}, \mathrm{CDCl}_{3}\right)$ $\delta=166.6\left(\mathrm{C}_{\mathrm{q}}\right), 166.1\left(\mathrm{C}_{\mathrm{q}}\right), 151.4\left(\mathrm{C}_{\mathrm{q}}\right), 141.9\left(\mathrm{C}_{\mathrm{q}}\right), 133.3(\mathrm{CH}), 128.5(\mathrm{CH}), 128.4(\mathrm{CH}), 127.2(\mathrm{CH})$, $126.0(\mathrm{CH}), 125.9(\mathrm{CH}), 123.5(\mathrm{CH}), 115.0\left(\mathrm{C}_{\mathrm{q}}\right), 62.9\left(\mathrm{CH}_{2}\right), 41.5\left(\mathrm{CH}_{2}\right), 35.0\left(\mathrm{CH}_{2}\right), 14.6\left(\mathrm{CH}_{3}\right) . \mathrm{MS}(\mathrm{ESI})$ m/z (relative intensity): $279(100)[\mathrm{M}+\mathrm{H}]^{+}$. IR (ATR) $v=2979,1620,1572,1496,1419,1322,1103$, $769,683 \mathrm{~cm}^{-1}$. HR-MS (ESI) m/z calcd for $\mathrm{C}_{18} \mathrm{H}_{18} \mathrm{~N}_{2} \mathrm{O}[\mathrm{M}+\mathrm{H}]^{+}:$279.1492, found: 279.1497.

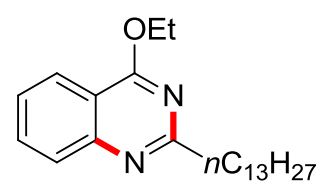

4-Ethoxy-2-tridecylquinazoline (163ad): The general procedure C was followed using ethyl benzimidate (161a) $(37.3 \mathrm{mg}, 0.25 \mathrm{mmol}$ ) and 5-tridecyloxazol-2(5H)-one (162d) $(80.8 \mathrm{mg}, 0.30$ mmol). Purification by coloumn chromatography on silica gel ( $n$-hexane/EtOAc: $30 / 1$ ) yielded 163ad (54.0 $\mathrm{mg}, 61 \%)$ as a colorless oil.

${ }^{1} \mathrm{H}$ NMR $\left.\left(300 \mathrm{MHz}^{\mathrm{CDCl}}\right)_{3}\right) \delta=8.12(\mathrm{dd}, J=8.2,1.4 \mathrm{~Hz}, 1 \mathrm{H}), 7.84(\mathrm{~d}, J=8.4 \mathrm{~Hz}, 1 \mathrm{H}), 7.75(\mathrm{ddd}, J=8.4$, 6.9, $1.5 \mathrm{~Hz}, 1 \mathrm{H}), 7.46$ (ddd, $J=8.2,6.8,1.3 \mathrm{~Hz}, 1 \mathrm{H}), 4.63(\mathrm{q}, J=7.1 \mathrm{~Hz}, 2 \mathrm{H}), 2.94-2.89(\mathrm{~m}, 2 \mathrm{H})$, $1.91-1.81(\mathrm{~m}, 2 \mathrm{H}), 1.50(\mathrm{t}, J=7.1 \mathrm{~Hz}, 3 \mathrm{H}), 1.42-1.14(\mathrm{~m}, 20 \mathrm{H}), 0.89-0.85(\mathrm{~m}, 3 \mathrm{H}) .{ }^{13} \mathrm{C}$ NMR $(75 \mathrm{MHz}$, $\left.\mathrm{CDCl}_{3}\right) \delta=167.5\left(\mathrm{C}_{\mathrm{q}}\right), 166.6\left(\mathrm{C}_{\mathrm{q}}\right), 151.5\left(\mathrm{C}_{\mathrm{q}}\right), 133.3(\mathrm{CH}), 127.2(\mathrm{CH}), 125.9(\mathrm{CH}), 125.5(\mathrm{CH}), 115.0$ $\left(\mathrm{C}_{\mathrm{q}}\right), 62.8\left(\mathrm{CH}_{2}\right), 40.1\left(\mathrm{CH}_{2}\right), 32.1\left(\mathrm{CH}_{2}\right), 29.8\left(\mathrm{CH}_{2}\right), 29.8\left(\mathrm{CH}_{2}\right), 29.8\left(\mathrm{CH}_{2}\right), 29.8\left(\mathrm{CH}_{2}\right), 29.7\left(\mathrm{CH}_{2}\right), 29.7$ $\left(\mathrm{CH}_{2}\right), 29.6\left(\mathrm{CH}_{2}\right), 29.5\left(\mathrm{CH}_{2}\right), 28.8\left(\mathrm{CH}_{2}\right), 22.8\left(\mathrm{CH}_{2}\right), 14.5\left(\mathrm{CH}_{3}\right), 14.3\left(\mathrm{CH}_{3}\right)$. IR (ATR) $v=2922,2852$, 1621, 1571, 1496, 1419, 1325, 1102, $768 \mathrm{~cm}^{-1}$. MS (ESI) m/z (relative intensity): 357 (100) [M+H] ${ }^{+}$ HR-MS (ESI) m/z calcd for $\mathrm{C}_{23} \mathrm{H}_{36} \mathrm{~N}_{2} \mathrm{O}[\mathrm{M}+\mathrm{H}]^{+}: 357.2900$, found: 357.2905 . 
<smiles>CCOc1nc(-c2ccsc2)nc2ccccc12</smiles>

4-Ethoxy-2-(thiophen-3-yl)quinazoline (163ae): The general procedure C was followed using ethyl benzimidate (161a) $(37.3 \mathrm{mg}, 0.25 \mathrm{mmol})$ and 5-(thiophen-3-yl)oxazol-2(5H)-one (162e) $(50.7 \mathrm{mg}$, $0.30 \mathrm{mmol}$ ). Purification by coloumn chromatography on silica gel ( $n$-hexane/EtOAc: $40 / 1$ ) yielded 163ae (58.1 mg, 91\%) as a colorless oil.

${ }^{1} \mathrm{H}$ NMR $\left(300 \mathrm{MHz} \mathrm{CDCl}_{3}\right) \delta=8.12(\mathrm{dd}, J=8.2,1.4 \mathrm{~Hz}, 1 \mathrm{H}), 8.08(\mathrm{dd}, J=3.7,1.3 \mathrm{~Hz}, 1 \mathrm{H}), 7.91(\mathrm{~d}, J=$ 8.4 Hz, 1H), 7.77 (ddd, J = 8.5, 6.9, $1.5 \mathrm{~Hz}, 1 \mathrm{H}), 7.48-7.43(\mathrm{~m}, 2 \mathrm{H}), 7.16(\mathrm{dd}, J=5.0,3.7 \mathrm{~Hz}, 1 \mathrm{H}), 4.73$ $(q, J=7.1 \mathrm{~Hz}, 2 \mathrm{H}), 1.56(\mathrm{t}, J=7.1 \mathrm{~Hz}, 3 \mathrm{H}) .{ }^{13} \mathrm{C} \mathbf{N M R}\left(75 \mathrm{MHz}, \mathrm{CDCl}_{3}\right) \delta=166.6\left(\mathrm{C}_{\mathrm{q}}\right), 157.0\left(\mathrm{C}_{\mathrm{q}}\right), 151.2$ $\left(\mathrm{C}_{\mathrm{q}}\right), 144.4\left(\mathrm{C}_{\mathrm{q}}\right), 133.6(\mathrm{CH}), 129.6(\mathrm{CH}), 128.9(\mathrm{CH}), 128.2(\mathrm{CH}), 127.6(\mathrm{CH}), 126.1(\mathrm{CH}), 123.7(\mathrm{CH})$, $115.4\left(\mathrm{C}_{\mathrm{q}}\right), 63.1\left(\mathrm{CH}_{2}\right), 14.5\left(\mathrm{CH}_{3}\right)$. IR (ATR) $v=2980,1618,1560,1494,1417,1339,1104,845,767$ $\mathrm{cm}^{-1}$. MS (ESI) m/z (relative intensity): 229 (40), $257(100)[\mathrm{M}+\mathrm{H}]^{+}, 279(20)[\mathrm{M}+\mathrm{Na}]^{+}$. HR-MS (ESI) $\mathrm{m} / \mathrm{z}$ calcd for $\mathrm{C}_{14} \mathrm{H}_{12} \mathrm{~N}_{2} \mathrm{OS}[\mathrm{M}+\mathrm{H}]^{+}: 257.0743$, found: 257.0744 .<smiles>CCOc1nc(-c2ccc(OC)cc2)nc2ccccc12</smiles>

4-Ethoxy-2-(4-methoxyphenyl)quinazoline (163af): The general procedure $\mathrm{C}$ was followed using ethyl benzimidate (161a) (37.3 mg, $0.25 \mathrm{mmol}$ ) and 5-(4-methoxyphenyl)oxazol-2(5H)-one (162f) (57.9 mg, $0.30 \mathrm{mmol}$ ). Purification by coloumn chromatography on silica gel ( $n$-hexane/EtOAc: 20/1) yielded 163af (46.9 $\mathrm{mg}, 68 \%$ ) as a white solid.

M. p. $=70-71^{\circ} \mathrm{C} .{ }^{1} \mathrm{H}$ NMR $\left(300 \mathrm{MHz}, \mathrm{CDCl}_{3}\right) \delta=8.54(\mathrm{~d}, J=9.0 \mathrm{~Hz}, 2 \mathrm{H}), 8.14$ (ddd, J=8.2, 1.5, 0.7 Hz, 1H), 7.94 (ddd, $J=8.5,1.2,0.7 \mathrm{~Hz}, 1 \mathrm{H}$ ), 7.78 (ddd, $J=8.5,1.2,1.6 \mathrm{~Hz}, 1 \mathrm{H}$ ), 7.46 (ddd, $J=8.2,7.0,1.2$ $\mathrm{Hz}, 1 \mathrm{H}), 7.02(\mathrm{~d}, J=9.0 \mathrm{~Hz}, 2 \mathrm{H}), 4.76(\mathrm{q}, J=7.1 \mathrm{~Hz}, 2 \mathrm{H}), 3.89(\mathrm{~s}, 3 \mathrm{H}), 1.57(\mathrm{t}, J=7.1 \mathrm{~Hz}, 3 \mathrm{H}) .{ }^{13} \mathrm{C} \mathbf{N M R}$ $\left(125 \mathrm{MHz}, \mathrm{CDCl}_{3}\right) \delta=165.5\left(\mathrm{C}_{\mathrm{q}}\right), 161.7\left(\mathrm{C}_{\mathrm{q}}\right), 159.9\left(\mathrm{C}_{\mathrm{q}}\right), 152.0\left(\mathrm{C}_{\mathrm{q}}\right), 133.3(\mathrm{CH}), 131.1\left(\mathrm{C}_{\mathrm{q}}\right), 130.1(\mathrm{CH})$, 127.7 (CH), $125.8(\mathrm{CH}), 123.5(\mathrm{CH}), 115.2\left(\mathrm{C}_{\mathrm{q}}\right), 113.8(\mathrm{CH}), 62.8\left(\mathrm{CH}_{2}\right), 55.5\left(\mathrm{CH}_{3}\right), 14.7\left(\mathrm{CH}_{3}\right)$. IR (ATR) $v=3047,1603,1574,1497,1328,1249,1151,765,680,542 \mathrm{~cm}^{-1}$. MS (ESI) m/z (relative intensity): 281 (100) $[\mathrm{M}+\mathrm{H}]^{+}$. HRMS (ESI) $\mathrm{m} / z$ calcd for $\mathrm{C}_{17} \mathrm{H}_{17} \mathrm{~N}_{2} \mathrm{O}_{2}[\mathrm{M}+\mathrm{H}]^{+}: 281.1290$ found 281.1285. 
The analytical data were in accordance with those reported in the literature. ${ }^{[200]}$<smiles>CCOc1nc(-c2cccc(C)c2)nc2ccccc12</smiles>

4-Ethoxy-2-(m-tolyl)quinazoline (163ag): The general procedure C was followed using ethyl benzimidate (161a) (37.3 mg, $0.25 \mathrm{mmol})$ and 5-( $m$-tolyl)oxazol-2(5H)-one (162g) (53.2 mg, 0.30 mmol). Purification by coloumn chromatography on silica gel ( $n$-hexane/EtOAc: 40/1) yielded 163ag (56.9 $\mathrm{mg}, 86 \%)$ as a white solid.

M. p. $=72-74{ }^{\circ} \mathrm{C} .{ }^{1} \mathbf{H}$ NMR $\left(400 \mathrm{MHz}, \mathrm{CDCl}_{3}\right) \delta=8.42-8.34(\mathrm{~m}, 2 \mathrm{H}), 8.15$ (ddd, $J=8.2,1.5,0.6 \mathrm{~Hz}$, 1H), 7.97 (ddd, $J=8.4,0.7 \mathrm{~Hz}, 1 \mathrm{H}), 7.78$ (ddd, $J=8.5,7.0,1.5 \mathrm{~Hz}, 1 \mathrm{H}), 7.48$ (ddd, $J=8.1,7.0,1.1 \mathrm{~Hz}$, 1H), 7.39 (t, $J=7.6 \mathrm{~Hz}, 1 \mathrm{H}), 7.29(\mathrm{~d}, J=8.2 \mathrm{~Hz}, 1 \mathrm{H}), 4.77(\mathrm{q}, J=7.1 \mathrm{~Hz}, 2 \mathrm{H}), 2.48(\mathrm{~s}, 3 \mathrm{H}), 1.56(\mathrm{t}, J=$ $7.1 \mathrm{~Hz}, 3 \mathrm{H}) .{ }^{13} \mathrm{C}$ NMR $\left(100 \mathrm{MHz}, \mathrm{CDCl}_{3}\right) \delta=166.6\left(\mathrm{C}_{\mathrm{q}}\right), 160.2\left(\mathrm{C}_{\mathrm{q}}\right), 151.8\left(\mathrm{C}_{\mathrm{q}}\right), 138.2\left(\mathrm{C}_{\mathrm{q}}\right), 137.9\left(\mathrm{C}_{\mathrm{q}}\right)$, $133.3(\mathrm{CH}), 131.2(\mathrm{CH}), 128.9(\mathrm{CH}), 128.3(\mathrm{CH}), 127.8(\mathrm{CH}), 126.1(\mathrm{CH}), 125.7(\mathrm{CH}), 123.5(\mathrm{CH}), 115.3$ $\left(\mathrm{C}_{\mathrm{q}}\right), 62.8\left(\mathrm{CH}_{2}\right), 21.5\left(\mathrm{CH}_{3}\right), 14.4\left(\mathrm{CH}_{3}\right)$. IR (ATR) $v=2982,1620,1561,1498,1418,1323,1161,1104$, 1018, $765 \mathrm{~cm}^{-1}$. MS (ESI) m/z (relative intensity): $265(100)[\mathrm{M}+\mathrm{H}]^{+}, 287[\mathrm{M}+\mathrm{Na}]^{+}$. HR-MS (ESI) m/z calcd for $\mathrm{C}_{17} \mathrm{H}_{17} \mathrm{~N}_{2} \mathrm{O}[\mathrm{M}+\mathrm{H}]^{+}:$265.1335, found: 265.1332.<smiles>CCOc1nc(-c2cccc(Cl)c2)nc2ccccc12</smiles>

2-(3-Chlorophenyl)-4-ethoxyquinazoline (163ah): The general procedure $\mathbf{C}$ was followed using ethyl benzimidate (161a) $(37.3 \mathrm{mg}, 0.25 \mathrm{mmol}$ ) and 5-(3-chlorophenyl)oxazol-2(5H)-one (162h) $(59.3 \mathrm{mg}$, $0.30 \mathrm{mmol}$ ). Purification by coloumn chromatography on silica gel ( $n$-hexane/EtOAc: $40 / 1)$ yielded 163ah (43.4 mg, 61\%) as a white solid.

M. p. $=85-87^{\circ} \mathrm{C}^{1}{ }^{1} \mathrm{H}$ NMR $\left(400 \mathrm{MHz}, \mathrm{CDCl}_{3}\right) \delta=8.54(\mathrm{td}, J=1.7,0.7 \mathrm{~Hz}, 1 \mathrm{H}), 8.48 .9-8.38(\mathrm{~m}, 1 \mathrm{H})$, 8.15 (ddd, $J=8.2,1.5,0.7 \mathrm{~Hz}, 1 \mathrm{H}$ ), 7.95 (ddd, $J=8.4,1.1,0.7 \mathrm{~Hz}, 1 \mathrm{H}$ ), 7.79 (ddd, $J=8.5,7.0,1.5 \mathrm{~Hz}$, 1H), 7.50 (ddd, J = 8.2, 7.0, 1.2 Hz, 1H), 7.45-7.36 (m, 2H), 4.74 (q, J = 7.1 Hz, 2H), 1.56 (t, J = 7.1 Hz, 3H). ${ }^{13} \mathrm{C}$ NMR $\left(100 \mathrm{MHz}, \mathrm{CDCl}_{3}\right) \delta=166.8\left(\mathrm{C}_{\mathrm{q}}\right), 158.6\left(\mathrm{C}_{\mathrm{q}}\right), 151.7\left(\mathrm{C}_{\mathrm{q}}\right), 140.1\left(\mathrm{C}_{\mathrm{q}}\right), 134.5\left(\mathrm{C}_{\mathrm{q}}\right), 133.5$ 
(CH), $130.3(\mathrm{CH}), 129.6(\mathrm{CH}), 128.5(\mathrm{CH}), 127.9(\mathrm{CH}), 126.6(\mathrm{CH}), 126.5(\mathrm{CH}), 123.5(\mathrm{CH}), 115.5\left(\mathrm{C}_{\mathrm{q}}\right)$, $63.0\left(\mathrm{CH}_{2}\right), 14.4\left(\mathrm{CH}_{3}\right)$. IR (ATR) $v=2975,1620,1575,1499,1418,1325,1171,1015,764,672 \mathrm{~cm}^{-1}$. MS (ESI) m/z (relative intensity): $285(100)[\mathrm{M}+\mathrm{H}]^{+}, 307(30)[\mathrm{M}+\mathrm{Na}]^{+}$. HR-MS (ESI) m/z calcd for $\mathrm{C}_{16} \mathrm{H}_{14} \mathrm{~N}_{2} \mathrm{OCl}[\mathrm{M}+\mathrm{H}]^{+}:$285.0789, found: 285.0788 .

The analytical data were in accordance with those reported in the literature. ${ }^{[199]}$<smiles>CCOc1nc(-c2cccc(F)c2)nc2ccccc12</smiles>

4-Ethoxy-2-(3-fluorophenyl)quinazoline (163ai): The general procedure $\mathbf{C}$ was followed using ethyl benzimidate (161a) (37.3 mg, $0.25 \mathrm{mmol}$ ) and 3-(3-fluorophenyl)-1,4,2-dioxazol-5H-one (162i) (54.3 $\mathrm{mg}, 0.30 \mathrm{mmol}$ ). Purification by coloumn chromatography on silica gel ( $n$-hexane/EtOAc: 40/1) yielded 163ai (51.3 $\mathrm{mg}, 76 \%$ ) as a white solid.

M. p. $=84-86{ }^{\circ} \mathrm{C} .{ }^{1} \mathrm{H}$ NMR $\left(400 \mathrm{MHz}, \mathrm{CDCl}_{3}\right) \delta=8.36$ (ddd, $\left.J=7.8,1.5,1.0 \mathrm{~Hz}, 1 \mathrm{H}\right), 8.26$ (ddd, $J=$ 10.5, 2.5, 1.4 Hz, 1H), 8.14 (ddd, $J=8.2,1.5,0.7 \mathrm{~Hz}, 1 \mathrm{H}$ ), 7.95 (ddd, $J=8.4,1.1,0.7 \mathrm{~Hz}, 1 \mathrm{H}$ ), 7.79 (ddd, $J=8.5,7.0,1.5 \mathrm{~Hz}, 1 \mathrm{H}), 7.58-7.37(\mathrm{~m}, 2 \mathrm{H}), 7.16$ (ddd, $J=8.3,2.7,1.0 \mathrm{~Hz}, 1 \mathrm{H}), 4.74(\mathrm{q}, J=7.1$ $\mathrm{Hz}, 2 \mathrm{H}), 1.55(\mathrm{t}, J=7.1 \mathrm{~Hz}, 3 \mathrm{H}) .{ }^{13} \mathrm{C}$ NMR $\left(100 \mathrm{MHz}, \mathrm{CDCl}_{3}\right) \delta=166.7\left(\mathrm{C}_{\mathrm{q}}\right), 163.1\left(\mathrm{~d},{ }^{1} \mathrm{~J}=246.3 \mathrm{~Hz}, \mathrm{C}_{\mathrm{q}}\right)$, $168.8\left(d,{ }^{4} J=3.8 \mathrm{~Hz}, \mathrm{C}_{q}\right), 151.7\left(\mathrm{C}_{\mathrm{q}}\right), 140.7\left(\mathrm{~d},{ }^{3} \mathrm{~J}=7.8 \mathrm{~Hz}, \mathrm{C}_{\mathrm{q}}\right), 133.5(\mathrm{CH}), 130.0\left(\mathrm{~d},{ }^{3} \mathrm{~J}=7.8 \mathrm{~Hz}, \mathrm{CH}\right)$, $127.9(\mathrm{CH}), 126.5(\mathrm{CH}), 124.0\left(\mathrm{~d},{ }^{4} \mathrm{~J}=2.9 \mathrm{~Hz}, \mathrm{CH}\right), 123.5(\mathrm{CH}), 117.2\left(\mathrm{~d},{ }^{2} \mathrm{~J}=21.4 \mathrm{~Hz}, \mathrm{CH}\right), 115.5\left(\mathrm{C}_{\mathrm{q}}\right)$, $115.3\left(\mathrm{~d},{ }^{2} \mathrm{~J}=22.2 \mathrm{~Hz}, \mathrm{CH}\right), 62.9\left(\mathrm{CH}_{2}\right), 14.4\left(\mathrm{CH}_{3}\right) .{ }^{19} \mathrm{~F}$ NMR $\left(376 \mathrm{MHz}, \mathrm{CDCl}_{3}\right) \delta=-113.58$ (ddd, $J=$ 10.3, 8.4, $5.9 \mathrm{~Hz}$ ). IR (ATR) $v=2984,1622,1575,1499,1424,1325,1167,1018,902,770 \mathrm{~cm}^{-1}$. MS (ESI) $\mathrm{m} / \mathrm{z}$ (relative intensity): $265(100)[\mathrm{M}+\mathrm{H}]^{+}, 287[\mathrm{M}+\mathrm{Na}]^{+}$. HR-MS (ESI) m/z calcd for $\mathrm{C}_{16} \mathrm{H}_{14} \mathrm{FN}_{2} \mathrm{O}$ $[\mathrm{M}+\mathrm{H}]^{+}: 269.1085$, found: 269.1086 .<smiles>CCOc1nc(-c2ccc(Cl)cc2)nc2ccccc12</smiles>

2-(4-Chlorophenyl)-4-ethoxyquinazoline (163aj): The general procedure $\mathrm{C}$ was followed using ethyl benzimidate (161a) (37.3 mg, $0.25 \mathrm{mmol})$ and 5-(4-chlorophenyl)oxazol-2(5H)-one (162j) (59.3 mg, 
$0.30 \mathrm{mmol}$ ). Purification by coloumn chromatography on silica gel ( $n$-hexane/EtOAc: $30 / 1)$ yielded 163aj (66.0 mg, 93\%) as a white solid.

M. p. $=119-120{ }^{\circ} \mathrm{C} .{ }^{1} \mathrm{H}$ NMR $\left(300 \mathrm{MHz}, \mathrm{CDCl}_{3}\right) \delta=8.57(\mathrm{~d}, J=8.6 \mathrm{~Hz}, 2 \mathrm{H}), 8.15(\mathrm{~d}, J=7.1 \mathrm{~Hz}, 1 \mathrm{H})$, $7.95(\mathrm{~d}, J=8.3 \mathrm{~Hz}, 1 \mathrm{H}), 7.79(\mathrm{ddd}, J=8.5,6.9,1.6 \mathrm{~Hz}, 1 \mathrm{H}), 7.53-7.49(\mathrm{~m}, 1 \mathrm{H}), 7.46(\mathrm{~d}, J=8.6 \mathrm{~Hz}, 2 \mathrm{H})$, $4.73(\mathrm{q}, J=7.1 \mathrm{~Hz}, 2 \mathrm{H}), 1.56(\mathrm{t}, J=7.1 \mathrm{~Hz}, 3 \mathrm{H}) .{ }^{13} \mathrm{C} \mathrm{NMR}\left(75 \mathrm{MHz}, \mathrm{CDCl}_{3}\right) \delta=166.8\left(\mathrm{C}_{\mathrm{q}}\right), 159.1\left(\mathrm{C}_{\mathrm{q}}\right)$, $151.8\left(\mathrm{C}_{\mathrm{q}}\right), 138.8\left(\mathrm{C}_{\mathrm{q}}\right), 136.6\left(\mathrm{C}_{\mathrm{q}}\right), 133.6(\mathrm{CH}), 129.9(\mathrm{CH}), 128.7(\mathrm{CH}), 128.0(\mathrm{CH}), 126.6(\mathrm{CH}), 123.6$ (CH), $115.5\left(\mathrm{C}_{\mathrm{q}}\right), 63.0\left(\mathrm{CH}_{2}\right), 14.5\left(\mathrm{CH}_{3}\right)$. IR (ATR) $v=2979,1620,1575,1501,1325,1088,937,837$, 763, $539 \mathrm{~cm}^{-1}$. MS (ESI) m/z (relative intensity): 285 (100) $[M+H]^{+}$. HR-MS (ESI) m/z calcd for $\mathrm{C}_{16} \mathrm{H}_{14} \mathrm{~N}_{2} \mathrm{OCl}[\mathrm{M}+\mathrm{H}]^{+}:$285.0789, found: 285.0789.

The analytical data were in accordance with those reported in the literature. ${ }^{[199]}$<smiles>CCOc1nc(-c2ccc([N+](=O)[O-])cc2)nc2ccccc12</smiles>

4-Ethoxy-2-(4-nitrophenyl)quinazoline (163ak): The general procedure $C$ was followed using ethyl benzimidate (161a) $(37.3 \mathrm{mg}, 0.25 \mathrm{mmol})$ and 5-(4-nitrophenyl)oxazol-2(5H)-one (162k) (62.4 mg, $0.30 \mathrm{mmol}$ ). Purification by coloumn chromatography on silica gel ( $n$-hexane/EtOAc: $20 / 1$ ) yielded 163ak (44.8 $\mathrm{mg}, 60 \%)$ as a pale yellow solid.

M. p. $=154-155^{\circ} \mathrm{C} .{ }^{1} \mathrm{H}$ NMR $\left(300 \mathrm{MHz}, \mathrm{CDCl}_{3}\right) \delta=8.74(\mathrm{~d}, J=9.0 \mathrm{~Hz}, 2 \mathrm{H}), 8.33(\mathrm{~d}, J=9.0 \mathrm{~Hz}, 2 \mathrm{H})$, $8.21(\mathrm{~d}, J=8.3 \mathrm{~Hz}, 1 \mathrm{H}$ ), 8.00 (d, $J=8.4 \mathrm{~Hz}, 1 \mathrm{H}$ ), 7.86 (ddd, $J=8.5,7.0,1.5 \mathrm{~Hz}, 1 \mathrm{H}$ ), 7.58 (ddd, $J=8.2$, 7.0, $1.2 \mathrm{~Hz}, 1 \mathrm{H}), 4.79(\mathrm{q}, J=7.1 \mathrm{~Hz}, 2 \mathrm{H}), 1.60(\mathrm{t}, J=7.1 \mathrm{~Hz}, 3 \mathrm{H}) .{ }^{13} \mathrm{C}$ NMR $\left(75 \mathrm{MHz}, \mathrm{CDCl}_{3}\right) \delta=167.1$ $\left(\mathrm{C}_{q}\right), 157.9\left(\mathrm{C}_{q}\right), 151.7\left(\mathrm{C}_{q}\right), 148.9\left(\mathrm{C}_{q}\right), 144.3\left(\mathrm{C}_{q}\right), 134.0(\mathrm{CH}), 129.3(\mathrm{CH}), 128.3(\mathrm{CH}), 127.5(\mathrm{CH})$, $123.8(\mathrm{CH}), 123.7(\mathrm{CH}), 115.7\left(\mathrm{C}_{\mathrm{q}}\right), 63.3\left(\mathrm{CH}_{2}\right), 14.5\left(\mathrm{CH}_{3}\right)$. IR (ATR) $v=2987,1622,1576,1501,1343$, 1331, 1081, 765, 715, $670 \mathrm{~cm}^{-1}$. MS (EI) m/z (relative intensity): 268 (15), $296(100)[\mathrm{M}+\mathrm{H}]^{+}, 318(60)$ $[\mathrm{M}+\mathrm{Na}]^{+}$. HRMS (ESI) $\mathrm{m} / \mathrm{z}$ calcd for $\mathrm{C}_{16} \mathrm{H}_{14} \mathrm{~N}_{3} \mathrm{O}_{3}[\mathrm{M}+\mathrm{H}]^{+}:$296.1030, found 296.1030. 
<smiles>CCOc1nc(-c2ccccc2)nc2cc(-n3cccn3)ccc12</smiles>

4-Ethoxy-2-phenyl-7-(1H-pyrazol-1-yl)quinazoline (163ka): The general procedure C was followed using ethyl 4-(1H-pyrazol-1-yl)benzimidate $(\mathbf{1 6 1 k}) \quad(53.8 \quad \mathrm{mg}, \quad 0.25 \quad \mathrm{mmol})$ and 5-phenyloxazol-2(5H)-one (162a) $(48.9 \mathrm{mg}, 0.30 \mathrm{mmol})$. Purification by coloumn chromatography on silica gel ( $n$-hexane/EtOAc: $25 / 1$ ) yielded 163ka (55.4 mg, 70\%) as a white solid.

M. p. $=129-130{ }^{\circ} \mathrm{C} .{ }^{1} \mathrm{H} N M R\left(400 \mathrm{MHz}, \mathrm{CDCl}_{3}\right) \delta=8.62-8.50(\mathrm{~m}, 2 \mathrm{H}), 8.21(\mathrm{dd}, J=8.9,0.5 \mathrm{~Hz}, 1 \mathrm{H})$, $8.12(\mathrm{dd}, J=2.6,0.6 \mathrm{~Hz}, 1 \mathrm{H}), 8.10$ (dd, $J=2.2,0.4 \mathrm{~Hz}, 1 \mathrm{H}), 8.04$ (dd, $J=8.9,2.2 \mathrm{~Hz}, 1 \mathrm{H}$ ), 7.79 (dd, $J=$ 1.7, $0.6 \mathrm{~Hz}, 1 \mathrm{H}), 7.55-7.45(\mathrm{~m}, 3 \mathrm{H}), 6.53(\mathrm{dd}, J=2.6,1.7 \mathrm{~Hz}, 1 \mathrm{H}), 4.75(\mathrm{q}, J=7.1 \mathrm{~Hz}, 2 \mathrm{H}), 1.56(\mathrm{t}, J=$ $7.1 \mathrm{~Hz}, 3 \mathrm{H}) .{ }^{13} \mathrm{C}$ NMR $\left(100 \mathrm{MHz}, \mathrm{CDCl}_{3}\right) \delta=166.5\left(\mathrm{C}_{\mathrm{q}}\right), 161.2\left(\mathrm{C}_{\mathrm{q}}\right), 152.8\left(\mathrm{C}_{\mathrm{q}}\right), 143.7\left(\mathrm{C}_{\mathrm{q}}\right), 142.0(\mathrm{CH})$, $138.0\left(\mathrm{C}_{\mathrm{q}}\right), 130.6(\mathrm{CH}), 128.5(\mathrm{CH}), 128.4(\mathrm{CH}), 127.1(\mathrm{CH}), 125.3(\mathrm{CH}), 118.4(\mathrm{CH}), 115.1(\mathrm{CH}), 113.3$ $\left(\mathrm{C}_{\mathrm{q}}\right), 108.6(\mathrm{CH}), 63.0\left(\mathrm{CH}_{2}\right), 14.4\left(\mathrm{CH}_{3}\right)$. IR (ATR) $v=2974,1713,1626,1565,1472,1394,1333,1025$, 740, $698 \mathrm{~cm}^{-1}$. MS (ESI) m/z (relative intensity): $317(100)[\mathrm{M}+\mathrm{H}]^{+}, 339(75)[\mathrm{M}+\mathrm{Na}]^{+}$. HR-MS (ESI) $\mathrm{m} / \mathrm{z}$ calcd for $\mathrm{C}_{19} \mathrm{H}_{17} \mathrm{~N}_{4} \mathrm{O}[\mathrm{M}+\mathrm{H}]^{+}:$317.1397, found: 317.1400 .<smiles>CCOc1nc(-c2ccc(OC)cc2)nc2cc(-n3cccn3)ccc12</smiles>

4-Ethoxy-2-(4-methoxyphenyl)-7-(1H-pyrazol-1-yl)quinazoline (163kf): The general procedure C was followed using ethyl 4-(1H-pyrazol-1-yl)benzimidate (161k) $(53.8 \mathrm{mg}, 0.25 \mathrm{mmol})$ and 3-(4-methoxyphenyl)-1,4,2-dioxazol-5-one (162f) $(58.0 \mathrm{mg}, 0.30 \mathrm{mmol})$. Purification by coloumn chromatography on silica gel ( $n$-hexane/EtOAc: 6/1) yielded 163kf (51.0 mg, 59\%) as a white solid. M. p. $=138-140{ }^{\circ} \mathrm{C} .{ }^{1} \mathrm{H}$ NMR $\left(400 \mathrm{MHz}, \mathrm{CDCl}_{3}\right) \delta=8.51(\mathrm{~d}, J=9.0 \mathrm{~Hz}, 2 \mathrm{H}), 8.19$ (dd, J = 8.9, $0.6 \mathrm{~Hz}$, $1 \mathrm{H}), 8.11(\mathrm{~d}, J=3.0 \mathrm{~Hz}, 1 \mathrm{H}), 8.06(\mathrm{~d}, J=1.8 \mathrm{~Hz}, 1 \mathrm{H}), 8.00(\mathrm{dd}, J=8.8,2.2 \mathrm{~Hz}, 1 \mathrm{H}), 7.78(\mathrm{~d}, J=1.4 \mathrm{~Hz}$, 1H), $7.00(\mathrm{~d}, J=9.0 \mathrm{~Hz}, 2 \mathrm{H}), 6.52(\mathrm{dd}, J=2.5,1.7 \mathrm{~Hz}, 1 \mathrm{H}), 4.73(\mathrm{q}, J=7.1 \mathrm{~Hz}, 2 \mathrm{H}), 3.87(\mathrm{~s}, 3 \mathrm{H}), 1.55$ (t, $J=7.1 \mathrm{~Hz}, 3 \mathrm{H}) .{ }^{13} \mathrm{C}$ NMR $\left(100 \mathrm{MHz}, \mathrm{CDCl}_{3}\right) \delta=166.3\left(\mathrm{C}_{\mathrm{q}}\right), 161.8\left(\mathrm{C}_{\mathrm{q}}\right), 161.0\left(\mathrm{C}_{\mathrm{q}}\right), 152.9\left(\mathrm{C}_{\mathrm{q}}\right), 143.7$ $\left(\mathrm{C}_{\mathrm{q}}\right), 141.9(\mathrm{CH}), 130.7\left(\mathrm{C}_{\mathrm{q}}\right), 130.1(\mathrm{CH}), 127.1(\mathrm{CH}), 125.3(\mathrm{CH}), 117.9(\mathrm{CH}), 114.8(\mathrm{CH}), 113.7(\mathrm{CH})$, $113.1\left(\mathrm{C}_{\mathrm{q}}\right), 108.5(\mathrm{CH}), 62.8\left(\mathrm{CH}_{2}\right), 55.4\left(\mathrm{CH}_{3}\right), 14.4\left(\mathrm{CH}_{3}\right)$. IR $(\mathrm{ATR}) v=2983,2834,1626,1579,1512$, 
1422, 1331, 1159, 1018, $749 \mathrm{~cm}^{-1}$. MS (ESI) m/z (relative intensity): 236 (20), $347(100)[\mathrm{M}+\mathrm{H}]^{+}, 369$ (20) $[\mathrm{M}+\mathrm{Na}]^{+}, 715(10)[2 \mathrm{M}+\mathrm{Na}]^{+}$. HR-MS (ESI) m/z calcd for $\mathrm{C}_{20} \mathrm{H}_{19} \mathrm{~N}_{4} \mathrm{O}_{2}[\mathrm{M}+\mathrm{H}]^{+}: 347.1503$, found: 347.1504 .<smiles>CCOc1nc(-c2cccc(C)c2)nc2cc(-n3cccn3)ccc12</smiles>

4-Ethoxy-7-(1H-pyrazol-1-yl)-2-( $m$-tolyl)quinazoline (163kg): The general procedure C was followed using ethyl 4-(1H-pyrazol-1-yl)benzimidate $(\mathbf{1 6 1 k}) \quad(53.8 \quad \mathrm{mg}, \quad 0.25 \quad \mathrm{mmol})$ and 3-(m-tolyl)-1,4,2-dioxazol-5-one $\quad(\mathbf{1 6 2} \mathbf{g}) \quad(53.2 \mathrm{mg}, \quad 0.30 \mathrm{mmol})$. Purification by coloumn chromatography on silica gel ( $n$-hexane/EtOAc: $20 / 1)$ yielded $163 \mathrm{~kg}(51.8 \mathrm{mg}, 63 \%)$ as a white solid. M. p. $=149-151{ }^{\circ} \mathrm{C} .{ }^{1} \mathrm{H}$ NMR $\left(400 \mathrm{MHz}, \mathrm{CDCl}_{3}\right) \delta=8.38-8.33(\mathrm{~m}, 2 \mathrm{H}), 8.23(\mathrm{dd}, J=8.9,0.6 \mathrm{~Hz}, 1 \mathrm{H})$, $8.13(\mathrm{dd}, J=2.6,0.6 \mathrm{~Hz}, 1 \mathrm{H}), 8.11(\mathrm{dd}, J=2.2,0.6 \mathrm{~Hz}, 1 \mathrm{H}), 8.05(\mathrm{dd}, J=8.9,2.2 \mathrm{~Hz}, 1 \mathrm{H}), 7.79(\mathrm{dd}, J=$ 1.7, $0.6 \mathrm{~Hz}, 1 \mathrm{H}), 7.39(\mathrm{td}, J=7.5,0.8 \mathrm{~Hz}, 1 \mathrm{H}), 7.32-7.28(\mathrm{~m}, 1 \mathrm{H}), 6.53(\mathrm{dd}, J=2.6,1.7 \mathrm{~Hz}, 1 \mathrm{H}), 4.76(\mathrm{q}$, $J=7.1 \mathrm{~Hz}, 2 \mathrm{H}), 2.47(\mathrm{~s}, 3 \mathrm{H}), 1.57(\mathrm{t}, J=7.1 \mathrm{~Hz}, 3 \mathrm{H}) .{ }^{13} \mathrm{C} \mathbf{N M R}\left(100 \mathrm{MHz}, \mathrm{CDCl}_{3}\right) \delta=166.5\left(\mathrm{C}_{\mathrm{q}}\right), 161.4$ $\left(\mathrm{C}_{q}\right), 152.8\left(\mathrm{C}_{q}\right), 143.7\left(\mathrm{C}_{\mathrm{q}}\right), 142.0(\mathrm{CH}), 138.0\left(\mathrm{C}_{\mathrm{q}}\right), 137.9\left(\mathrm{C}_{\mathrm{q}}\right), 131.5(\mathrm{CH}), 129.0(\mathrm{CH}), 128.3(\mathrm{CH})$, $127.1(\mathrm{CH}), 125.7(\mathrm{CH}), 125.4(\mathrm{CH}), 118.4(\mathrm{CH}), 115.0(\mathrm{CH}), 113.3\left(\mathrm{C}_{\mathrm{q}}\right), 108.6(\mathrm{CH}), 63.0\left(\mathrm{CH}_{2}\right), 21.6$ $\left(\mathrm{CH}_{3}\right), 14.4\left(\mathrm{CH}_{3}\right)$. IR (ATR) $v=3127,2977,1625,1579,1435,1333,1017,870,767,600 \mathrm{~cm}^{-1} . \mathrm{MS}$ (ESI) $\mathrm{m} / \mathrm{z}$ (relative intensity): $331(100)[\mathrm{M}+\mathrm{H}]^{+}, 353(20)[\mathrm{M}+\mathrm{Na}]^{+}, 683(20)[2 \mathrm{M}+\mathrm{Na}]^{+}$. HR-MS (ESI) m/z calcd for $\mathrm{C}_{20} \mathrm{H}_{19} \mathrm{~N}_{4} \mathrm{O}[\mathrm{M}+\mathrm{H}]^{+}$: 331.1553, found: 331.1557 .<smiles>CCOc1nc(-c2cccc(F)c2)nc2cc(-n3cccn3)ccc12</smiles>

4-Ethoxy-2-(3-fluorophenyl)-7-(1H-pyrazol-1-yl)quinazoline (163ki): The general procedure C was followed using ethyl 4-(1H-pyrazol-1-yl)benzimidate $(\mathbf{1 6 1 k}) \quad(53.8 \mathrm{mg}, 0.25 \mathrm{mmol})$ and 3-(3-fluorophenyl)-1,4,2-dioxazol-5-one (162i) (54.4 mg, $0.30 \mathrm{mmol}$ ). Purification by coloumn chromatography on silica gel ( $n$-hexane/EtOAc: 15/1) yielded 163ki (49.1 mg, 59\%) as a white solid. M. p. $=154-155^{\circ} \mathrm{C} .{ }^{1} \mathrm{H}$ NMR $\left(300 \mathrm{MHz}, \mathrm{CDCl}_{3}\right) \delta=8.39(\mathrm{dt}, J=7.8,1.1 \mathrm{~Hz}, 1 \mathrm{H}), 8.34-8.23(\mathrm{~m}, 2 \mathrm{H})$, 
$8.16(\mathrm{dd}, J=2.6,0.4 \mathrm{~Hz}, 1 \mathrm{H}), 8.15-8.07(\mathrm{~m}, 2 \mathrm{H}), 7.83(\mathrm{~d}, J=1.6 \mathrm{~Hz}, 1 \mathrm{H}), 7.49(\mathrm{td}, J=8.0,5.8 \mathrm{~Hz}, 1 \mathrm{H})$, 7.21 (tdd $J=8.3,2.7,1.0 \mathrm{~Hz}, 1 \mathrm{H}), 6.58(\mathrm{dd}, J=2.6,1.6 \mathrm{~Hz}, 1 \mathrm{H}), 4.79(\mathrm{q}, J=7.1 \mathrm{~Hz}, 2 \mathrm{H}), 1.60(\mathrm{t}, J=$ $7.1 \mathrm{~Hz}, 3 \mathrm{H}) .{ }^{13} \mathrm{C}$ NMR $\left(100 \mathrm{MHz}, \mathrm{CDCl}_{3}\right) \delta=166.5\left(\mathrm{C}_{\mathrm{q}}\right), 163.1\left(\mathrm{~d},{ }^{1} \mathrm{~J}=244.4 \mathrm{~Hz}, \mathrm{C}_{\mathrm{q}}\right), 160.0\left(\mathrm{~d},{ }^{4} \mathrm{~J}=3.4\right.$ $\left.\mathrm{Hz}, \mathrm{C}_{\mathrm{q}}\right), 152.6\left(\mathrm{C}_{\mathrm{q}}\right), 143.8\left(\mathrm{C}_{\mathrm{q}}\right), 142.1(\mathrm{CH}), 140.4\left(\mathrm{~d},{ }^{3} \mathrm{~J}=7.8 \mathrm{~Hz}, \mathrm{C}_{\mathrm{q}}\right), 129.8\left(\mathrm{~d},{ }^{3} \mathrm{~J}=7.8 \mathrm{~Hz}, \mathrm{CH}\right), 127.1$ (CH), $125.4(\mathrm{CH}), 124.1\left(\mathrm{~d},{ }^{4} \mathrm{~J}=2.8 \mathrm{~Hz}, \mathrm{CH}\right), 118.7(\mathrm{CH}), 117.4\left(\mathrm{~d},{ }^{2} \mathrm{~J}=21.5 \mathrm{~Hz}, \mathrm{CH}\right), 115.3\left(\mathrm{~d},{ }^{2} \mathrm{~J}=23.2\right.$ $\mathrm{Hz}, \mathrm{CH}), 115.0(\mathrm{CH}), 113.4\left(\mathrm{C}_{\mathrm{q}}\right), 108.7(\mathrm{CH}), 63.1\left(\mathrm{CH}_{2}\right), 14.4\left(\mathrm{CH}_{3}\right) .{ }^{19} \mathbf{F} \mathrm{NMR}\left(376 \mathrm{MHz}, \mathrm{CDCl}_{3}\right) \delta=$ -113.44 (ddd, $J=10.5,8.5,5.9 \mathrm{~Hz}$ ). IR (ATR) $v=3129,2979,1624,1578,1564,1333,956,875,778$, $676 \mathrm{~cm}^{-1} . \mathrm{MS}(\mathrm{ESI}) \mathrm{m} / \mathrm{z}$ (relative intensity): $335(100)[\mathrm{M}+\mathrm{H}]^{+}, 357(80), 691[2 \mathrm{M}+\mathrm{Na}]^{+}$. HR-MS (ESI) $\mathrm{m} / \mathrm{z}$ calcd for $\mathrm{C}_{19} \mathrm{H}_{16} \mathrm{FN}_{4} \mathrm{O}[\mathrm{M}+\mathrm{H}]^{+}$: 335.1303, found: 335.1305 .<smiles>CCOc1nc(-c2cccc(Cl)c2)nc2cc(-n3cccn3)ccc12</smiles>

2-(3-Chlorophenyl)-4-ethoxy-7-(1H-pyrazol-1-yl)quinazoline (163kh): The general procedure C was followed using ethyl 4-(1H-pyrazol-1-yl)benzimidate $(\mathbf{1 6 1 k}) \quad(53.8 \mathrm{mg}, 0.25 \mathrm{mmol})$ and 3-(3-chlorophenyl)-1,4,2-dioxazol-5-one (162h) (59.3 mg, $0.30 \mathrm{mmol}$ ). Purification by coloumn chromatography on silica gel ( $n$-hexane/EtOAc: 20/1) yielded 163kh (56.3 mg, 64\%) as a white solid. M. p. $=168-170{ }^{\circ} \mathrm{C} .{ }^{1} \mathrm{H}$ NMR $\left(300 \mathrm{MHz}, \mathrm{CDCl}_{3}\right) \delta=8.56(\mathrm{~d}, J=1.8 \mathrm{~Hz}, 1 \mathrm{H}), 8.46(\mathrm{dt}, J=6.8,1.8 \mathrm{~Hz}$, $1 \mathrm{H}), 8.24(\mathrm{dd}, J=8.7,0.6 \mathrm{~Hz}, 1 \mathrm{H}), 8.15(\mathrm{~d}, J=2.6 \mathrm{~Hz}, 1 \mathrm{H}), 8.12-8.00(\mathrm{~m}, 2 \mathrm{H}), 7.82(\mathrm{~d}, J=1.5 \mathrm{~Hz}, 1 \mathrm{H})$, 7.56-7.37 (m, 2H), 6.57 (dd, J = 2.5, $1.8 \mathrm{~Hz}, 1 \mathrm{H}), 4.77(\mathrm{q}, J=7.1 \mathrm{~Hz}, 2 \mathrm{H}), 1.59(\mathrm{t}, J=7.1 \mathrm{~Hz}, 3 \mathrm{H}) .{ }^{13} \mathrm{C}$ $\operatorname{NMR}\left(75 \mathrm{MHz}, \mathrm{CDCl}_{3}\right) \delta=166.6\left(\mathrm{C}_{\mathrm{q}}\right), 159.8\left(\mathrm{C}_{\mathrm{q}}\right), 152.6\left(\mathrm{C}_{\mathrm{q}}\right), 143.8\left(\mathrm{C}_{\mathrm{q}}\right), 142.1(\mathrm{CH}), 139.9\left(\mathrm{C}_{\mathrm{q}}\right), 134.5$ $\left(\mathrm{C}_{q}\right), 130.5(\mathrm{CH}), 129.6(\mathrm{CH}), 128.5(\mathrm{CH}), 127.1(\mathrm{CH}), 126.6(\mathrm{CH}), 125.4(\mathrm{CH}), 118.7(\mathrm{CH}), 115.0(\mathrm{CH})$, $113.4\left(\mathrm{C}_{\mathrm{q}}\right), 108.7(\mathrm{CH}), 63.2\left(\mathrm{CH}_{2}\right), 14.4\left(\mathrm{CH}_{3}\right)$. IR $(\mathrm{ATR}) v=2979,1626,1578,1381,1333,875,745$, $676,603 \mathrm{~cm}^{-1}$. MS (ESI) m/z (relative intensity): $351(100)[\mathrm{M}+\mathrm{H}]^{+}, 732(60)[2 \mathrm{M}+\mathrm{Na}]^{+}$. HR-MS (ESI) $\mathrm{m} / \mathrm{z}$ calcd for $\mathrm{C}_{19} \mathrm{H}_{16} \mathrm{CIN}_{4} \mathrm{O}[\mathrm{M}+\mathrm{H}]^{+}:$351.1007, found: 351.1007 . 
<smiles>CCOc1nc(Nc2ccccc2)nc2cc(-n3cccn3)ccc12</smiles>

4-Ethoxy-2-phenethyl-7-(1H-pyrazol-1-yl)quinazoline (163kc): The general procedure C was followed using ethyl 4-(1H-pyrazol-1-yl)benzimidate (161k) $(53.8 \mathrm{mg}, 0.25 \mathrm{mmol})$ and 3-phenethyl-1,4,2-dioxazol-5-one (162c) $(57.4 \mathrm{mg}, 0.30 \mathrm{mmol})$. Purification by coloumn chromatography on silica gel ( $n$-hexane/EtOAc: 6/1) yielded 163kc (47.2 mg, 55\%) as a white solid.

M. p. $=92-93{ }^{\circ} \mathrm{C}^{1}{ }^{1} \mathrm{H}$ NMR $\left(400 \mathrm{MHz}, \mathrm{CDCl}_{3}\right) \delta=8.20(\mathrm{dd}, J=8.9,0.6 \mathrm{~Hz}, 1 \mathrm{H}), 8.09(\mathrm{dd}, J=2.6,0.6$ $\mathrm{Hz}, 1 \mathrm{H}), 8.05(\mathrm{dd}, J=8.9,2.2 \mathrm{~Hz}, 1 \mathrm{H}), 7.99(\mathrm{dd}, J=2.2,0.5 \mathrm{~Hz}, 1 \mathrm{H}), 7.78(\mathrm{dd}, J=1.8,0.6 \mathrm{~Hz}, 1 \mathrm{H})$, 7.31-7.24 (m, 4H), 7.20-7.13 (m, 1H), $6.52(\mathrm{dd}, J=2.6,1.7 \mathrm{~Hz}, 1 \mathrm{H}), 4.62(\mathrm{q}, J=7.1 \mathrm{~Hz}, 2 \mathrm{H})$, 3.31-3.17 (m, 4H), $1.50(\mathrm{t}, J=7.1 \mathrm{~Hz}, 3 \mathrm{H}) .{ }^{13} \mathrm{C}$ NMR $\left(100 \mathrm{MHz}, \mathrm{CDCl}_{3}\right) \delta=167.4\left(\mathrm{C}_{\mathrm{q}}\right), 166.4\left(\mathrm{C}_{\mathrm{q}}\right)$, $152.3\left(\mathrm{C}_{\mathrm{q}}\right), 143.6\left(\mathrm{C}_{\mathrm{q}}\right), 142.0(\mathrm{CH}), 141.7\left(\mathrm{C}_{\mathrm{q}}\right), 128.5(\mathrm{CH}), 128.3(\mathrm{CH}), 127.0(\mathrm{CH}), 125.9(\mathrm{CH}), 125.3$ $(\mathrm{CH}), 118.2(\mathrm{CH}), 114.3(\mathrm{CH}), 112.9\left(\mathrm{C}_{\mathrm{q}}\right), 108.7(\mathrm{CH}), 62.9\left(\mathrm{CH}_{2}\right), 41.3\left(\mathrm{CH}_{2}\right), 34.3\left(\mathrm{CH}_{2}\right), 14.4\left(\mathrm{CH}_{3}\right) . \mathbf{I R}$ (ATR) $v=3118,3027,2932,1622,1573,1474,1338,1107,863,695 \mathrm{~cm}^{-1}$. MS (ESI) m/z (relative intensity): 117 (40), 345 (100) $[\mathrm{M}+\mathrm{H}]^{+}$. HR-MS (ESI) m/z calcd for $\mathrm{C}_{21} \mathrm{H}_{21} \mathrm{~N}_{4} \mathrm{O}[\mathrm{M}+\mathrm{H}]^{+}: 345.1710$, found: 345.1713 .<smiles>CCOc1nc(-c2ccsc2)nc2cc(-n3cccn3)ccc12</smiles>

4-Ethoxy-7-(1H-pyrazol-1-yl)-2-(thiophen-3-yl)quinazoline (163ke): The general procedure C was followed using ethyl 4-(1H-pyrazol-1-yl)benzimidate $(\mathbf{1 6 1 k}) \quad(53.8 \mathrm{mg}, 0.25 \mathrm{mmol})$ and 3-(thiophen-3-yl)-1,4,2-dioxazol-5-one (162e) (51.8 mg, $0.30 \mathrm{mmol}$ ). Purification by coloumn chromatography on silica gel ( $n$-hexane/EtOAc: 6/1) yielded 163ke $(65.0 \mathrm{mg}, 81 \%)$ as a white solid. M. p. $=167-169^{\circ} \mathrm{C} .{ }^{1} \mathrm{H}$ NMR $\left(400 \mathrm{MHz}, \mathrm{CDCl}_{3}\right) \delta=8.20-8.11(\mathrm{~m}, 1 \mathrm{H}), 8.09(\mathrm{~d}, J=2.6 \mathrm{~Hz}, 1 \mathrm{H}), 8.04$ (dd, $J=3.7,1.2 \mathrm{~Hz}, 1 \mathrm{H}), 8.02-7.96(\mathrm{~m}, 2 \mathrm{H}), 7.77(\mathrm{~d}, J=1.4 \mathrm{~Hz}, 1 \mathrm{H}), 7.46(\mathrm{dd}, J=5.0,1.2 \mathrm{~Hz}, 1 \mathrm{H}), 7.13$ (dd, $J=5.0,3.7 \mathrm{~Hz}, 1 \mathrm{H}), 6.50(\mathrm{dd}, J=2.6,1.8 \mathrm{~Hz}, 1 \mathrm{H}), 4.68(\mathrm{q}, J=7.1 \mathrm{~Hz}, 2 \mathrm{H}), 1.53(\mathrm{t}, J=7.1 \mathrm{~Hz}, 3 \mathrm{H})$. ${ }^{13} \mathrm{C}$ NMR $\left(100 \mathrm{MHz}, \mathrm{CDCl}_{3}\right) \delta=166.2\left(\mathrm{C}_{\mathrm{q}}\right), 157.8\left(\mathrm{C}_{\mathrm{q}}\right), 152.6\left(\mathrm{C}_{\mathrm{q}}\right), 144.0\left(\mathrm{C}_{\mathrm{q}}\right), 143.7\left(\mathrm{C}_{\mathrm{q}}\right), 141.9(\mathrm{CH})$, $129.8(\mathrm{CH}), 129.1(\mathrm{CH}), 128.0(\mathrm{CH}), 127.0(\mathrm{CH}), 125.3(\mathrm{CH}), 118.0(\mathrm{CH}), 114.5(\mathrm{CH}), 113.1\left(\mathrm{C}_{\mathrm{q}}\right), 108.6$ 
(CH), $63.1\left(\mathrm{CH}_{2}\right), 14.3\left(\mathrm{CH}_{3}\right)$. IR (ATR) $v=3115,2979,1624,1565,1414,1330,1167,875,779,704$ $\mathrm{cm}^{-1}$. MS (ESI) m/z (relative intensity): $323(100)[\mathrm{M}+\mathrm{H}]^{+}, 345(55)[\mathrm{M}+\mathrm{Na}]^{+}, 667$ (45) $[2 \mathrm{M}+\mathrm{Na}]^{+}$. HR-MS (ESI) m/z calcd for $\mathrm{C}_{17} \mathrm{H}_{15} \mathrm{~N}_{4} \mathrm{OS}[\mathrm{M}+\mathrm{H}]^{+}$: 323.0961, found: 323.0960 .<smiles>CCOc1nc(-c2ccccc2)nc2ccc(-n3cccn3)cc12</smiles>

4-Ethoxy-2-phenyl-6-(1H-pyrazol-1-yl)quinazoline (163la): The general procedure $\mathrm{C}$ was followed using ethyl 3-(1H-pyrazol-1-yl)benzimidate $\quad(161) \quad(53.8 \quad \mathrm{mg}, \quad 0.25 \quad \mathrm{mmol})$ and 5-phenyloxazol-2(5H)-one (162a) $(48.9 \mathrm{mg}, 0.30 \mathrm{mmol})$. Purification by coloumn chromatography on silica gel ( $n$-hexane/EtOAc: $10 / 1$ to $6 / 1$ ) yielded 163 la $(48.9 \mathrm{mg}, 62 \%)$ as a white solid.

M. p. $=130-131^{\circ} \mathrm{C} .{ }^{1} \mathbf{H}$ NMR $\left(300 \mathrm{MHz}, \mathrm{CDCl}_{3}\right) \delta=8.61-8.50(\mathrm{~m}, 2 \mathrm{H}), 8.35(\mathrm{~d}, J=2.5 \mathrm{~Hz}, 1 \mathrm{H}), 8.19$ (dd, $J=9.1,2.6 \mathrm{~Hz}, 1 \mathrm{H}), 8.07-7.95(\mathrm{~m}, 2 \mathrm{H}), 7.77(\mathrm{~d}, J=1.7 \mathrm{~Hz}, 1 \mathrm{H}), 7.53-7.44(\mathrm{~m}, 3 \mathrm{H}), 6.51(\mathrm{dd}, J=$ 2.5, $1.8 \mathrm{~Hz}, 1 \mathrm{H}), 4.76(\mathrm{~d}, J=7.1 \mathrm{~Hz}, 2 \mathrm{H}), 1.56(\mathrm{t}, J=7.1 \mathrm{~Hz}, 3 \mathrm{H}) .{ }^{13} \mathrm{C}$ NMR $\left(75 \mathrm{MHz}, \mathrm{CDCl}_{3}\right) \delta=166.5$ $\left(\mathrm{C}_{q}\right), 159.9\left(\mathrm{C}_{\mathrm{q}}\right), 150.2\left(\mathrm{C}_{\mathrm{q}}\right), 141.6(\mathrm{CH}), 137.9\left(\mathrm{C}_{\mathrm{q}}\right), 137.7\left(\mathrm{C}_{\mathrm{q}}\right), 130.5(\mathrm{CH}), 129.5(\mathrm{CH}), 128.7(\mathrm{CH})$, $128.3(\mathrm{CH}), 126.9(\mathrm{CH}), 125.4(\mathrm{CH}), 115.6\left(\mathrm{C}_{\mathrm{q}}\right), 112.0(\mathrm{CH}), 108.1(\mathrm{CH}), 63.1\left(\mathrm{CH}_{2}\right), 14.4\left(\mathrm{CH}_{3}\right)$. IR (ATR) $v=2983,1579,1507,1391,1312,1019,774,701,560 \mathrm{~cm}^{-1}$. MS (ESI) m/z (relative intensity): $345(100)[\mathrm{M}+\mathrm{H}]^{+}, 367(20)[\mathrm{M}+\mathrm{Na}]^{+}$. HR-MS (ESI) m/z calcd for $\mathrm{C}_{20} \mathrm{H}_{17} \mathrm{~N}_{4} \mathrm{O}_{2}[\mathrm{M}+\mathrm{H}]^{+}: 345.1346$, found: 345.1347 .<smiles>CCOc1nc(-c2ccc(Br)cc2)nc2cc(-n3nccc3C)ccc12</smiles>

2-(4-Bromophenyl)-4-ethoxy-7-(5-methyl-1H-pyrazol-1-yl)quinazoline $\quad(163 \mathrm{ml}): \quad$ The general procedure C was followed using ethyl 4-(5-methyl-1H-pyrazol-1-yl)benzimidate (161m) (57.3 mg, $0.25 \mathrm{mmol}$ ) and 3-(4-bromophenyl)-1,4,2-dioxazol-5-one (162l) $(72.6 \mathrm{mg}, 0.30 \mathrm{mmol})$. Purification by coloumn chromatography on silica gel ( $n$-hexane/EtOAc: $15 / 1)$ yielded $163 \mathrm{ml}(63.1 \mathrm{mg}, 64 \%)$ as a white solid.

M. p. $=184-186^{\circ} \mathrm{C} .{ }^{1} \mathrm{H}$ NMR $\left(400 \mathrm{MHz}, \mathrm{CDCl}_{3}\right) \delta=8.39(\mathrm{~d}, J=8.6 \mathrm{~Hz}, 2 \mathrm{H}), 8.15(\mathrm{~d}, J=9.7 \mathrm{~Hz}, 1 \mathrm{H})$, 8.05-7.94 (m, 3H), $7.59(\mathrm{~d}, J=8.5 \mathrm{~Hz}, 2 \mathrm{H}), 6.30(\mathrm{~d}, J=2.5 \mathrm{~Hz}, 1 \mathrm{H}), 4.70(\mathrm{q}, J=7.1 \mathrm{~Hz}, 2 \mathrm{H}), 2.39(\mathrm{~s}$, 
3H), $1.54(\mathrm{t}, J=7.1 \mathrm{~Hz}, 3 \mathrm{H}) .{ }^{13} \mathrm{C}$ NMR $\left(100 \mathrm{MHz}, \mathrm{CDCl}_{3}\right) \delta=166.5\left(\mathrm{C}_{\mathrm{q}}\right), 160.0\left(\mathrm{C}_{\mathrm{q}}\right), 152.7\left(\mathrm{C}_{\mathrm{q}}\right), 151.6$ $\left(\mathrm{C}_{\mathrm{q}}\right), 143.8\left(\mathrm{C}_{\mathrm{q}}\right), 137.0\left(\mathrm{C}_{\mathrm{q}}\right), 131.5(\mathrm{CH}), 130.0(\mathrm{CH}), 127.6(\mathrm{CH}), 125.3\left(\mathrm{C}_{\mathrm{q}}\right), 125.2(\mathrm{CH}), 118.2(\mathrm{CH})$, $114.1(\mathrm{CH}), 112.9\left(\mathrm{C}_{\mathrm{q}}\right), 108.8(\mathrm{CH}), 63.0\left(\mathrm{CH}_{2}\right), 14.4\left(\mathrm{CH}_{3}\right), 13.8\left(\mathrm{CH}_{3}\right)$. IR (ATR) $v=2974,1628,1579$, 1536, 1426, 1337, 1010, 935, $754 \mathrm{~cm}^{-1} . \mathrm{MS}(\mathrm{ESI}) \mathrm{m} / \mathrm{z}$ (relative intensity): $372(15), 409(100)[\mathrm{M}+\mathrm{H}]^{+}$, 411 (100), 431 (15) [M+Na] $]^{+}$. HR-MS (ESI) m/z calcd for $\mathrm{C}_{20} \mathrm{H}_{18} \mathrm{~N}_{4} \mathrm{OBr}[\mathrm{M}+\mathrm{H}]^{+}:$409.0659, found: 409.0649.<smiles>CCOc1nc(-c2ccc([N+](=O)[O-])cc2)nc2cc(-n3nccc3C(C)([O-])O)ccc12</smiles>

4-Ethoxy-7-(5-methyl-1H-pyrazol-1-yl)-2-(4-nitrophenyl)quinazoline (163mk): The general procedure C was followed using ethyl 4-(5-methyl-1H-pyrazol-1-yl)benzimidate (161m) (57.3 mg, $0.25 \mathrm{mmol}$ ) and 5-(4-nitrophenyl)oxazol-2(5H)-one (162k) $(62.4 \mathrm{mg}, 0.30 \mathrm{mmol})$. Purification by column chromatography on silica gel ( $n$-hexane/EtOAc: $10 / 1$ to $4 / 1$ ) yielded $163 \mathrm{mk}$ (54.4 mg, 58\%) as a yellow solid.

M. p. $=182-184{ }^{\circ} \mathrm{C} .{ }^{1} \mathbf{H}$ NMR $\left(300 \mathrm{MHz}, \mathrm{CDCl}_{3}\right) \delta=8.70(\mathrm{~d}, J=8.9 \mathrm{~Hz}, 2 \mathrm{H}), 8.31(\mathrm{~d}, J=8.9 \mathrm{~Hz}, 2 \mathrm{H})$, $8.21(\mathrm{dd}, J=8.3,1.2 \mathrm{~Hz}, 1 \mathrm{H}), 8.06-8.03(\mathrm{~m}, 2 \mathrm{H}), 8.01(\mathrm{~d}, J=2.5 \mathrm{~Hz}, 1 \mathrm{H}), 6.34(\mathrm{~d}, J=2.5 \mathrm{~Hz}, 1 \mathrm{H}), 4.75$ (q, $J=7.1 \mathrm{~Hz}, 2 \mathrm{H}), 2.42(\mathrm{~s}, 3 \mathrm{H}), 1.59$ (t, $J=7.1 \mathrm{~Hz}, 3 \mathrm{H}) .{ }^{13} \mathrm{C} \mathrm{NMR}\left(100 \mathrm{MHz}, \mathrm{CDCl}_{3}\right) \delta=166.8\left(\mathrm{C}_{\mathrm{q}}\right)$, $158.9\left(\mathrm{C}_{\mathrm{q}}\right), 152.7\left(\mathrm{C}_{\mathrm{q}}\right), 152.0\left(\mathrm{C}_{\mathrm{q}}\right), 149.3\left(\mathrm{C}_{\mathrm{q}}\right), 144.1\left(\mathrm{C}_{\mathrm{q}}\right), 144.0\left(\mathrm{C}_{\mathrm{q}}\right), 129.4(\mathrm{CH}), 127.8(\mathrm{CH}), 125.5(\mathrm{CH})$, 123.7 (CH), $119.7(\mathrm{CH}), 114.5(\mathrm{CH}), 113.2\left(\mathrm{C}_{\mathrm{q}}\right), 109.2(\mathrm{CH}), 63.4\left(\mathrm{CH}_{2}\right), 14.5\left(\mathrm{CH}_{3}\right), 14.0\left(\mathrm{CH}_{3}\right)$. IR (ATR) $v=2985,1622,1577,1539,1512,1427,1340,1319,1038,867 \mathrm{~cm}^{-1}$. MS (ESI) m/z (relative intensity): 376 (100) $[\mathrm{M}+\mathrm{H}]^{+}, 398(58)[\mathrm{M}+\mathrm{Na}]^{+}$. HR-MS (ESI) $\mathrm{m} / \mathrm{z}$ calcd for $\mathrm{C}_{20} \mathrm{H}_{18} \mathrm{~N}_{5} \mathrm{O}_{3}[\mathrm{M}+\mathrm{H}]^{+}$: 376,1410 , found: 376.1404 .<smiles>CCOc1nc(-c2ccccc2)nc2cc(-c3ncccn3)ccc12</smiles>

4-Ethoxy-2-phenyl-7-(pyrimidin-2-yl)quinazoline (163na): The general procedure C was followed using ethyl 4-(pyrimidin-2-yl)benzimidate $(161 \mathrm{n}) \quad(56.9 \quad \mathrm{mg}, \quad 0.25 \quad \mathrm{mmol})$ and 
5-phenyloxazol-2(5H)-one (162a) $(48.9 \mathrm{mg}, 0.30 \mathrm{mmol})$. Purification by coloumn chromatography on silica gel ( $n$-hexane/EtOAc: $5 / 1$ ) yielded 163na (60 mg, 73\%) as a white solid.

M. p. $=145-146{ }^{\circ} \mathrm{C} .{ }^{1} \mathrm{H}$ NMR $\left(300 \mathrm{MHz}, \mathrm{CDCl}_{3}\right) \delta=9.08(\mathrm{~d}, J=1.1 \mathrm{~Hz}, 1 \mathrm{H}), 8.86(\mathrm{~d}, J=4.8 \mathrm{~Hz}, 2 \mathrm{H})$, 8.67-8.57 (m, 2H), 8.54 (dd, $J=8.6,1.6 \mathrm{~Hz}, 1 \mathrm{H}), 8.23(\mathrm{dd}, J=8.6,0.6 \mathrm{~Hz}, 1 \mathrm{H}), 7.70-7.41(\mathrm{~m}, 3 \mathrm{H})$, $7.24(\mathrm{t}, J=4.8 \mathrm{~Hz}, 1 \mathrm{H}), 4.77(\mathrm{q}, J=7.1 \mathrm{~Hz}, 2 \mathrm{H}), 1.57(\mathrm{t}, J=7.1 \mathrm{~Hz}, 3 \mathrm{H}) .{ }^{13} \mathrm{C} \mathbf{N M R}\left(125 \mathrm{MHz}, \mathrm{CDCl}_{3}\right) \delta=$ $166.5\left(\mathrm{C}_{\mathrm{q}}\right), 163.8\left(\mathrm{C}_{\mathrm{q}}\right), 160.2\left(\mathrm{C}_{\mathrm{q}}\right), 157.2(\mathrm{CH}), 152.1\left(\mathrm{C}_{\mathrm{q}}\right), 142.1\left(\mathrm{C}_{\mathrm{q}}\right), 138.1\left(\mathrm{C}_{\mathrm{q}}\right), 130.3(\mathrm{CH}), 128.4(\mathrm{CH})$, $128.3(\mathrm{CH}), 128.0(\mathrm{CH}), 125.4(\mathrm{CH}), 123.7(\mathrm{CH}), 119.7(\mathrm{CH}), 116.5\left(\mathrm{C}_{\mathrm{q}}\right), 62.9\left(\mathrm{CH}_{2}\right), 14.5\left(\mathrm{CH}_{3}\right)$. IR (ATR) $v=2974,1623,1562,1431,1324,1163,1025,756,708 \mathrm{~cm}^{-1}$. MS (ESI) m/z (relative intensity): 329 (100) $[\mathrm{M}+\mathrm{H}]^{+}, 351(40)[\mathrm{M}+\mathrm{Na}]^{+}$. HR-MS (ESI) m/z calcd for $\mathrm{C}_{20} \mathrm{H}_{17} \mathrm{~N}_{4} \mathrm{O}[\mathrm{M}+\mathrm{H}]^{+}:$: 329.1397, found: 329.1397.<smiles>CCOc1nc(-c2ccc(Cl)cc2)nc2cc(-c3ncccn3)ccc12</smiles>

2-(4-Chlorophenyl)-4-ethoxy-7-(pyrimidin-2-yl)quinazoline (163nj): The general procedure C was followed using ethyl 4-(pyrimidin-2-yl)benzimidate (161n) $(56.8 \mathrm{mg}, 0.25 \mathrm{mmol})$ and 3-(4-chlorophenyl)-1,4,2-dioxazol-5-one (162j) (59.3 mg, $0.30 \mathrm{mmol})$. Purification by coloumn chromatography on silica gel ( $n$-hexane/EtOAc: $6 / 1$ ) yielded $163 \mathrm{nj}(64.4 \mathrm{mg}, 71 \%)$ as a yellow solid. M. p. $=198-190{ }^{\circ} \mathrm{C} .{ }^{1} \mathrm{H}$ NMR $\left(300 \mathrm{MHz}, \mathrm{CDCl}_{3}\right) \delta=9.02(\mathrm{~d}, J=1.2 \mathrm{~Hz}, 1 \mathrm{H}), 8.85(\mathrm{~d}, J=4.8 \mathrm{~Hz}, 2 \mathrm{H})$, 8.56-8.46 (m, 3H), $8.18(\mathrm{~d}, J=8.6 \mathrm{~Hz}, 1 \mathrm{H}), 7.49-7.39(\mathrm{~m}, 2 \mathrm{H}), 7.27-7.18(\mathrm{~m}, 1 \mathrm{H}), 4.71(\mathrm{q}, J=7.1 \mathrm{~Hz}$, $2 \mathrm{H}), 1.55(\mathrm{t}, J=7.1 \mathrm{~Hz}, 3 \mathrm{H}) .{ }^{13} \mathrm{C}$ NMR $\left(75 \mathrm{MHz}, \mathrm{CDCl}_{3}\right) \delta=166.6\left(\mathrm{C}_{\mathrm{q}}\right), 163.7\left(\mathrm{C}_{\mathrm{q}}\right), 159.2\left(\mathrm{C}_{\mathrm{q}}\right), 157.3$ $(\mathrm{CH}), 152.0\left(\mathrm{C}_{\mathrm{q}}\right), 142.2\left(\mathrm{C}_{\mathrm{q}}\right), 136.6\left(\mathrm{C}_{\mathrm{q}}\right), 136.5\left(\mathrm{C}_{\mathrm{q}}\right), 129.7(\mathrm{CH}), 128.5(\mathrm{CH}), 128.0(\mathrm{CH}), 125.6(\mathrm{CH})$, $123.7(\mathrm{CH}), 119.8(\mathrm{CH}), 116.5\left(\mathrm{C}_{\mathrm{q}}\right), 63.0\left(\mathrm{CH}_{2}\right), 14.4\left(\mathrm{CH}_{3}\right)$. IR (ATR) $v=2982,1623,1560,1494,1415$, 1325, 1012, 840, $787 \mathrm{~cm}^{-1}$. MS (ESI) m/z (relative intensity): $363(100)[\mathrm{M}+\mathrm{H}]^{+}, 364$ (20), 365 (30), $385(10)[\mathrm{M}+\mathrm{Na}]^{+}, 747(10)[2 \mathrm{M}+\mathrm{Na}]^{+}$. HR-MS (ESI) m/z calcd for $\mathrm{C}_{20} \mathrm{H}_{16} \mathrm{ClN}_{4} \mathrm{O}[\mathrm{M}+\mathrm{H}]^{+}: 363.1007$, found: 363.1010 . 
<smiles>CCOc1nc(-c2ccc(Br)cc2)nc2cc(-c3ncccn3)ccc12</smiles>

2-(4-Bromophenyl)-4-ethoxy-7-(pyrimidin-2-yl)quinazoline (163nl): The general procedure C was followed using ethyl 4-(pyrimidin-2-yl)benzimidate (161n) $(56.8 \mathrm{mg}, 0.25 \mathrm{mmol})$ and 3-(4-bromophenyl)-1,4,2-dioxazol-5-one (162l) (72.6 mg, $0.30 \mathrm{mmol}$ ). Purification by coloumn chromatography on silica gel ( $n$-hexane/EtOAc: $5 / 1$ ) yielded $163 \mathrm{nl}(87.0 \mathrm{mg}, 85 \%)$ as a white solid. M. p. $=191-193{ }^{\circ} \mathrm{C} .{ }^{1} \mathrm{H}$ NMR $\left(300 \mathrm{MHz}, \mathrm{CDCl}_{3}\right) \delta=9.03(\mathrm{~d}, J=1.3 \mathrm{~Hz}, 1 \mathrm{H}), 8.85(\mathrm{~d}, J=4.8 \mathrm{~Hz}, 2 \mathrm{H})$, $8.53(\mathrm{dd}, J=8.6,1.7 \mathrm{~Hz}, 1 \mathrm{H}), 8.43(\mathrm{~d}, J=8.6 \mathrm{~Hz}, 2 \mathrm{H}), 8.20(\mathrm{~d}, J=8.6 \mathrm{~Hz}, 1 \mathrm{H}), 7.59(\mathrm{~d}, J=8.6 \mathrm{~Hz}, 2 \mathrm{H})$, $7.24(\mathrm{t}, J=4.8 \mathrm{~Hz}, 1 \mathrm{H}), 4.72(\mathrm{q}, J=7.1 \mathrm{~Hz}, 2 \mathrm{H}), 1.55(\mathrm{t}, J=7.1 \mathrm{~Hz}, 3 \mathrm{H}) .{ }^{13} \mathrm{C} \mathrm{NMR}\left(75 \mathrm{MHz}, \mathrm{CDCl}_{3}\right) \delta=$ $166.7\left(\mathrm{C}_{\mathrm{q}}\right), 163.7\left(\mathrm{C}_{\mathrm{q}}\right), 159.3\left(\mathrm{C}_{\mathrm{q}}\right), 157.4(\mathrm{CH}), 152.0\left(\mathrm{C}_{\mathrm{q}}\right), 142.3\left(\mathrm{C}_{\mathrm{q}}\right), 137.1\left(\mathrm{C}_{\mathrm{q}}\right), 131.5(\mathrm{CH}), 130.0(\mathrm{CH})$, $128.0(\mathrm{CH}), 125.7(\mathrm{CH}), 125.1\left(\mathrm{C}_{\mathrm{q}}\right), 123.7(\mathrm{CH}), 119.8(\mathrm{CH}), 116.5\left(\mathrm{C}_{\mathrm{q}}\right), 63.0\left(\mathrm{CH}_{2}\right), 14.4\left(\mathrm{CH}_{3}\right)$. IR (ATR) $v=2976,1625,1560,1414,1325,1160,1011,837,785,738 \mathrm{~cm}^{-1}$. MS (ESI) m/z (relative intensity): 301 (10), 360 (10), 407 (100) [M+H] , 409 (100). HR-MS (ESI) m/z calcd for $\mathrm{C}_{20} \mathrm{H}_{16} \mathrm{~N}_{4} \mathrm{OBr}[\mathrm{M}+\mathrm{H}]^{+}$: 407.0502, found: 407.0499 .<smiles>CCOc1nc(-c2ccccc2)nc2cc(Oc3cnccn3)ccc12</smiles>

4-Ethoxy-2-phenyl-7-(pyrazin-2-yloxy)quinazoline (1630a): The general procedure C was followed using ethyl 4-(pyrazin-2-yloxy)benzimidate (1610) $(60.8 \quad \mathrm{mg}, \quad 0.25 \mathrm{mmol})$ and 5-phenyloxazol-2(5H)-one (162a) $(48.9 \mathrm{mg}, 0.30 \mathrm{mmol})$. Purification by coloumn chromatography on silica gel ( $n$-hexane/EtOAc: 10/1) yielded $1630 a(76.9 \mathrm{mg}, 89 \%)$ as a white solid.

M. p. $=129-130{ }^{\circ} \mathrm{C} .{ }^{1} \mathrm{H}$ NMR $\left(300 \mathrm{MHz}, \mathrm{CDCl}_{3}\right) \delta=8.60-8.45(\mathrm{~m}, 3 \mathrm{H}), 8.33(\mathrm{~d}, J=2.7 \mathrm{~Hz}, 1 \mathrm{H}), 8.20$ $(\mathrm{dd}, J=8.9,0.4 \mathrm{~Hz}, 1 \mathrm{H}), 8.13(\mathrm{dd}, J=2.7,1.4 \mathrm{~Hz}, 1 \mathrm{H}), 7.70(\mathrm{dd}, J=2.3,0.4 \mathrm{~Hz}, 1 \mathrm{H}), 7.53-7.42(\mathrm{~m}, 3 \mathrm{H})$, $7.29(\mathrm{dd}, J=8.9,2.3 \mathrm{~Hz}, 1 \mathrm{H}), 4.76(\mathrm{q}, J=7.1 \mathrm{~Hz}, 2 \mathrm{H}), 1.55(\mathrm{t}, J=7.1 \mathrm{~Hz}, 3 \mathrm{H}) .{ }^{13} \mathrm{C} \mathrm{NMR}(125 \mathrm{MHz}$, $\left.\mathrm{CDCl}_{3}\right) \delta=166.3\left(\mathrm{C}_{\mathrm{q}}\right), 160.8\left(\mathrm{C}_{\mathrm{q}}\right), 159.3\left(\mathrm{C}_{\mathrm{q}}\right), 157.2\left(\mathrm{C}_{\mathrm{q}}\right), 153.3\left(\mathrm{C}_{\mathrm{q}}\right), 141.1(\mathrm{CH}), 139.3(\mathrm{CH}), 137.9\left(\mathrm{C}_{\mathrm{q}}\right)$, $136.3(\mathrm{CH}), 130.5(\mathrm{CH}), 128.4(\mathrm{CH}), 128.3(\mathrm{CH}), 125.4(\mathrm{CH}), 120.6(\mathrm{CH}), 117.6(\mathrm{CH}), 112.7\left(\mathrm{C}_{\mathrm{q}}\right), 62.9$ 
$\left(\mathrm{CH}_{2}\right), 14.5\left(\mathrm{CH}_{3}\right)$. IR $($ ATR $) v=2975,1623,1579,1405,1343,1285,1150,1107,848,706 \mathrm{~cm}^{-1}$. MS (ESI) $\mathrm{m} / \mathrm{z}$ (relative intensity): $317(100)[\mathrm{M}+\mathrm{H}]^{+}, 339$ (40) $[\mathrm{M}+\mathrm{Na}]^{+}$. HR-MS (ESI) m/z calcd for $\mathrm{C}_{19} \mathrm{H}_{17} \mathrm{~N}_{4} \mathrm{O}[\mathrm{M}+\mathrm{H}]^{+}:$317.1397, found: 317.1397.<smiles>CCOc1nc(-c2ccc(C)cc2)nc2cc(Oc3cnccn3)ccc12</smiles>

4-Ethoxy-7-(pyrazin-2-yloxy)-2-(p-tolyl)quinazoline (1630m): The general procedure C was followed using ethyl 4-(pyridin-2-yloxy)benzimidate (1610) $\quad(60.8 \quad \mathrm{mg}, \quad 0.25 \mathrm{mmol})$ and 3-(p-tolyl)-1,4,2-dioxazol-5-one $\quad(\mathbf{1 6 2 m}) \quad(53.1 \mathrm{mg}, \quad 0.30 \mathrm{mmol})$. Purification by column chromatography on silica gel ( $n$-hexane/EtOAc: $10 / 1$ ) yielded $1630 \mathrm{~m}$ (67.2 $\mathrm{mg}, 75 \%$ ) as a white solid.

M. p. $=151-153{ }^{\circ} \mathrm{C} .{ }^{1} \mathrm{H}$ NMR $\left(300 \mathrm{MHz}, \mathrm{CDCl}_{3}\right) \delta=8.54(\mathrm{~d}, J=1.4 \mathrm{~Hz}, 1 \mathrm{H}), 8.45(\mathrm{~d}, J=8.2 \mathrm{~Hz}, 2 \mathrm{H})$, $8.35(\mathrm{~d}, J=2.7 \mathrm{~Hz}, 1 \mathrm{H}), 8.22(\mathrm{~d}, J=8.9 \mathrm{~Hz}, 1 \mathrm{H}), 8.16(\mathrm{dd}, J=2.7,1.4 \mathrm{~Hz}, 1 \mathrm{H}), 7.70(\mathrm{~d}, J=2.3 \mathrm{~Hz}, 1 \mathrm{H})$, 7.35-7.24 (m, 3H), (dd, J=8.8, 2.3 Hz, 1H), $4.78(\mathrm{q}, J=7.1 \mathrm{~Hz}, 2 \mathrm{H}), 2.43(\mathrm{~s}, 3 \mathrm{H}), 1.57$ (t, J = $7.1 \mathrm{~Hz}$, 3H). ${ }^{13} \mathrm{C}$ NMR $\left(75 \mathrm{MHz}, \mathrm{CDCl}_{3}\right) \delta=166.6\left(\mathrm{C}_{\mathrm{q}}\right), 161.3\left(\mathrm{C}_{\mathrm{q}}\right), 159.7\left(\mathrm{C}_{\mathrm{q}}\right), 157.5\left(\mathrm{C}_{\mathrm{q}}\right), 153.7\left(\mathrm{C}_{\mathrm{q}}\right), 141.4(\mathrm{CH})$, $141.0\left(\mathrm{C}_{\mathrm{q}}\right), 139.6(\mathrm{CH}), 136.5(\mathrm{CH}), 135.5\left(\mathrm{C}_{\mathrm{q}}\right), 129.3(\mathrm{CH}), 128.7(\mathrm{CH}), 125.7(\mathrm{CH}), 120.6(\mathrm{CH}), 117.8$ (CH), $112.9\left(\mathrm{C}_{\mathrm{q}}\right), 63.0\left(\mathrm{CH}_{2}\right), 21.7\left(\mathrm{CH}_{3}\right), 14.6\left(\mathrm{CH}_{3}\right)$. IR (ATR) $v=2981,1623,1575,1558,1419,1399$, $1381,1275,1177,1160 \mathrm{~cm}^{-1} . \mathrm{MS}(\mathrm{ESI}) \mathrm{m} / \mathrm{z}$ (relative intensity): $359(100)[\mathrm{M}+\mathrm{H}]^{+}, 376(4)[\mathrm{M}+\mathrm{Na}]^{+}$. HR-MS (ESI) $\mathrm{m} / \mathrm{z}$ calcd for $\mathrm{C}_{21} \mathrm{H}_{19} \mathrm{~N}_{4} \mathrm{O}_{2}[\mathrm{M}+\mathrm{H}]^{+}: 359.1508$, found: 359.1503 .<smiles>CCOc1nc(-c2cccc([N+](=O)[O-])c2)nc2cc(Oc3cnccn3)ccc12</smiles>

4-Ethoxy-7-(pyrazin-2-yloxy)-2-(thiophen-3-yl)quinazoline (163og): The general procedure C was followed using ethyl 4-(pyrazin-2-yloxy)benzimidate (1610) $(60.8 \mathrm{mg}, 0.25 \mathrm{mmol})$ and 5-(m-tolyl)oxazol-2(5H)-one (162g) $(53.1 \mathrm{mg}, 0.30 \mathrm{mmol})$. Purification by column chromatography on silica gel ( $n$-hexane/EtOAc: $4 / 1$ ) yielded 1630 (75.3 $\mathrm{mg}, 84 \%)$ as a white solid. 
M. p. $=114-116{ }^{\circ} \mathrm{C} .{ }^{1} \mathrm{H}$ NMR $\left(300 \mathrm{MHz}, \mathrm{CDCl}_{3}\right) \delta=8.55(\mathrm{~s}, 1 \mathrm{H}), 8.37-8.34(\mathrm{~m}, 3 \mathrm{H}), 8.23(\mathrm{dd}, \mathrm{J}=8.8$, $0.5 \mathrm{~Hz}, 1 \mathrm{H}), 8.16(\mathrm{dd}, J=2.7,1.4 \mathrm{~Hz}, 1 \mathrm{H}), 7.72(\mathrm{~d}, J=2.3 \mathrm{~Hz}, 1 \mathrm{H}), 7.39(\mathrm{t}, J=7.9 \mathrm{~Hz}, 1 \mathrm{H}), 7.34-7.29$ $(\mathrm{m}, 2 \mathrm{H}), 4.79(\mathrm{q}, J=7.1 \mathrm{~Hz}, 2 \mathrm{H}), 2.47(\mathrm{~s}, 3 \mathrm{H}), 1.57(\mathrm{t}, J=7.1 \mathrm{~Hz}, 3 \mathrm{H}) .{ }^{13} \mathrm{C} \mathbf{N M R}\left(75 \mathrm{MHz}, \mathrm{CDCl}_{3}\right) \delta=$ 166.7 $\left(\mathrm{C}_{\mathrm{q}}\right), 166.6\left(\mathrm{C}_{\mathrm{q}}\right), 161.4\left(\mathrm{C}_{\mathrm{q}}\right), 159.7\left(\mathrm{C}_{\mathrm{q}}\right), 157.5\left(\mathrm{C}_{\mathrm{q}}\right), 153.6\left(\mathrm{C}_{\mathrm{q}}\right), 141.4(\mathrm{CH}), 139.6(\mathrm{CH}), 138.2\left(\mathrm{C}_{\mathrm{q}}\right)$, $136.6(\mathrm{CH}), 131.5(\mathrm{CH}), 129.2(\mathrm{CH}), 128.4(\mathrm{CH}), 125.9(\mathrm{CH}), 125.7(\mathrm{CH}), 120.8(\mathrm{CH}), 117.8(\mathrm{CH}), 112.9$ $\left(\mathrm{C}_{\mathrm{q}}\right), 63.1\left(\mathrm{CH}_{2}\right), 21.7\left(\mathrm{CH}_{3}\right), 14.6\left(\mathrm{CH}_{3}\right)$. IR (ATR) $v=2923,1623,1576,1497,1419,1325,1106 \mathrm{~cm}^{-1}$. MS (ESI) m/z (relative intensity): $359(100)[\mathrm{M}+\mathrm{H}]^{+}, 739$ (11) $[2 \mathrm{M}+\mathrm{Na}]^{+}$. HR-MS (ESI) m/z calcd for $\mathrm{C}_{21} \mathrm{H}_{19} \mathrm{~N}_{4} \mathrm{O}_{2}[\mathrm{M}+\mathrm{H}]^{+}:$359.1508, found: 359.1505 .

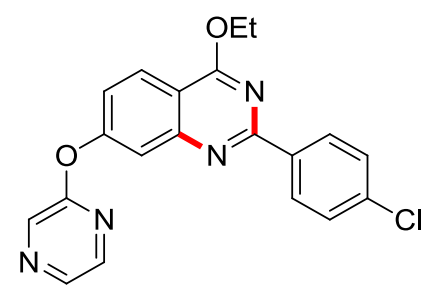

2-(4-Chlorophenyl)-4-ethoxy-7-(pyrazin-2-yloxy)quinazoline (163oj): The general procedure C was followed using ethyl 4-(pyrazin-2-yloxy)benzimidate (1610) $(60.8 \mathrm{mg}, 0.25 \mathrm{mmol})$ and 5-(4-chlorophenyl)oxazol-2(5H)-one $\quad(\mathbf{1 6 2 j}) \quad(59.3 \mathrm{mg}, 0.30 \mathrm{mmol})$. Purification by column chromatography on silica gel ( $n$-hexane/EtOAc: $10 / 1)$ yielded 1630 j $(82.3 \mathrm{mg}, 87 \%)$ as a white solid. M. p. $=167-169^{\circ} \mathrm{C} .{ }^{1} \mathrm{H} N M R\left(300 \mathrm{MHz}, \mathrm{CDCl}_{3}\right) \delta=8.54(\mathrm{dd}, J=1.4,0.5 \mathrm{~Hz}, 1 \mathrm{H}), 8.53-8.47(\mathrm{~m}, 2 \mathrm{H})$, $8.36(\mathrm{dd}, J=2.7,0.5 \mathrm{~Hz}, 1 \mathrm{H}), 8.23(\mathrm{dd}, J=8.9,0.5 \mathrm{~Hz}, 1 \mathrm{H}), 8.16(\mathrm{dd}, J=2.7,1.4 \mathrm{~Hz}, 1 \mathrm{H}$ ), 7.70 (dd, $J=$ 2.3, 0.5 Hz, 1H), 7.56-7.40 (m, 2H), $7.33(\mathrm{dd}, J=8.9,2.4 \mathrm{~Hz}, 1 \mathrm{H}), 4.77(\mathrm{q}, J=7.1 \mathrm{~Hz}, 2 \mathrm{H}), 1.57(\mathrm{t}, J=$ $7.1 \mathrm{~Hz}, 3 \mathrm{H}) .{ }^{13} \mathrm{C}$ NMR $\left(75 \mathrm{MHz}, \mathrm{CDCl}_{3}\right) \delta=166.7\left(\mathrm{C}_{\mathrm{q}}\right), 160.1\left(\mathrm{C}_{\mathrm{q}}\right), 159.5\left(\mathrm{C}_{\mathrm{q}}\right), 157.6\left(\mathrm{C}_{\mathrm{q}}\right), 153.5\left(\mathrm{C}_{\mathrm{q}}\right)$, $141.3(\mathrm{CH}), 139.6(\mathrm{CH}), 136.9\left(\mathrm{C}_{\mathrm{q}}\right), 136.6\left(\mathrm{C}_{\mathrm{q}}\right), 136.5(\mathrm{CH}), 130.0(\mathrm{CH}), 128.7(\mathrm{CH}), 125.7(\mathrm{CH}), 121.0$ (CH), $117.8(\mathrm{CH}), 112.9\left(\mathrm{C}_{\mathrm{q}}\right), 63.1\left(\mathrm{CH}_{2}\right), 14.5\left(\mathrm{CH}_{3}\right)$. IR (ATR) $v=2984,1623,1576,1499,1444,1403$, 1285, 1108, $937 \mathrm{~cm}^{-1}$. MS (ESI) m/z (relative intensity): 379 (100) $[\mathrm{M}+\mathrm{H}]^{+}, 779$ (19) [2M+Na] . HR-MS (ESI) $\mathrm{m} / \mathrm{z}$ calcd for $\mathrm{C}_{20} \mathrm{H}_{16} \mathrm{CIN}_{4} \mathrm{O}_{2}[\mathrm{M}+\mathrm{H}]^{+}: 379.0962$, found: 379.0957 . 
<smiles>CCOc1nc(-c2ccc([N+](=O)[O-])cc2)nc2cc(Oc3cnccn3)ccc12</smiles>

4-Ethoxy-2-(4-nitrophenyl)-7-(pyrazin-2-yloxy)quinazoline (163ok): The general procedure C was followed using ethyl 4-(pyridin-2-yloxy)benzimidate (1610) $(60.8 \mathrm{mg}, 0.25 \mathrm{mmol})$ and 5-(4-nitrophenyl)oxazol-2(5H)-one $\quad(\mathbf{1 6 2 k}) \quad(62.4 \mathrm{mg}, 0.30 \mathrm{mmol})$. Purification by column chromatography on silica gel ( $n$-hexane/EtOAc: $10 / 1$ to $4 / 1$ ) yielded 163 ok $(69.1 \mathrm{mg}, 71 \%$ ) as a yellow solid.

M. p. $=188-190{ }^{\circ} \mathrm{C} .{ }^{1} \mathrm{H}$ NMR $\left(300 \mathrm{MHz}, \mathrm{CDCl}_{3}\right) \delta=8.73(\mathrm{~d}, J=9.1 \mathrm{~Hz}, 2 \mathrm{H}), 8.57(\mathrm{dd}, J=1.4,0.5 \mathrm{~Hz}$, $1 \mathrm{H}), 8.38(\mathrm{dd}, J=2.7,0.5 \mathrm{~Hz}, 1 \mathrm{H}), 8.33(\mathrm{~d}, J=9.1 \mathrm{~Hz}, 2 \mathrm{H}), 8.27(\mathrm{dd}, J=8.9,0.5 \mathrm{~Hz}, 1 \mathrm{H}), 8.17(\mathrm{dd}, J=$ 2.7, $1.4 \mathrm{~Hz}, 1 \mathrm{H}), 7.76(\mathrm{dd}, J=2.3,0.5 \mathrm{~Hz}, 1 \mathrm{H}), 7.40(\mathrm{dd}, J=8.9,2.3 \mathrm{~Hz}, 1 \mathrm{H}), 4.80(\mathrm{q}, J=7.1 \mathrm{~Hz}, 2 \mathrm{H})$, $1.59(\mathrm{t}, J=7.1 \mathrm{~Hz}, 3 \mathrm{H}) .{ }^{13} \mathrm{C} \operatorname{NMR}\left(100 \mathrm{MHz}, \mathrm{CDCl}_{3}\right) \delta=166.9\left(\mathrm{C}_{\mathrm{q}}\right), 159.5\left(\mathrm{C}_{\mathrm{q}}\right), 158.9\left(\mathrm{C}_{\mathrm{q}}\right), 157.8\left(\mathrm{C}_{\mathrm{q}}\right)$, $153.3\left(\mathrm{C}_{\mathrm{q}}\right), 149.3\left(\mathrm{C}_{\mathrm{q}}\right), 144.0\left(\mathrm{C}_{\mathrm{q}}\right), 141.3(\mathrm{CH}), 139.8(\mathrm{CH}), 136.6(\mathrm{CH}), 129.5(\mathrm{CH}), 125.8(\mathrm{CH}), 123.7$ (CH), $121.9(\mathrm{CH}), 118.0(\mathrm{CH}), 113.1\left(\mathrm{C}_{\mathrm{q}}\right), 63.5\left(\mathrm{CH}_{2}\right), 14.5\left(\mathrm{CH}_{3}\right)$. IR (ATR) $v=2987,1621,1576,1520$, 1401, 1345, 1280, 1167, $1082 \mathrm{~cm}^{-1}$. MS (ESI) m/z (relative intensity): 412 (100) [M+Na] $]^{+}$HR-MS (ESI) $\mathrm{m} / \mathrm{z}$ calcd for $\mathrm{C}_{20} \mathrm{H}_{15} \mathrm{~N}_{5} \mathrm{O}_{4} \mathrm{Na}[\mathrm{M}+\mathrm{Na}]^{+}:$412.1022, found: 412.1016 .

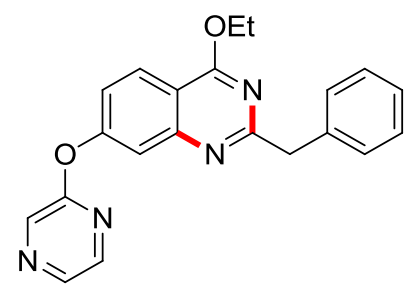

2-Benzyl-4-ethoxy-7-(pyrazin-2-yloxy)quinazoline (163ob): The general procedure C was followed using ethyl 4-(pyrazin-2-yloxy)benzimidate $(1610) \quad(60.8 \quad \mathrm{mg}, \quad 0.25 \mathrm{mmol})$ and 5-benzyloxazol-2(5H)-one (162b) $(53.1 \mathrm{mg}, 0.30 \mathrm{mmol})$. Purification by column chromatography on silica gel ( $n$-hexane/EtOAc: $3 / 2$ ) yielded 1630 b $(69.9 \mathrm{mg}, 78 \%)$ as a white solid.

M. p. $=122-124{ }^{\circ} \mathrm{C} .{ }^{1} \mathrm{H}$ NMR $\left(300 \mathrm{MHz}, \mathrm{CDCl}_{3}\right) \delta=8.54(\mathrm{~d}, J=1.4 \mathrm{~Hz}, 1 \mathrm{H}), 8.36(\mathrm{~d}, J=2.7 \mathrm{~Hz}, 1 \mathrm{H})$, $8.18(\mathrm{~d}, J=8.9 \mathrm{~Hz}, 1 \mathrm{H}), 8.16(\mathrm{dd}, J=2.8,1.4 \mathrm{~Hz}, 1 \mathrm{H}), 7.64(\mathrm{dd}, J=2.4,0.5 \mathrm{~Hz}, 1 \mathrm{H}), 7.48-7.45(\mathrm{~m}, 2 \mathrm{H})$, 7.33-7.28 (m, 3H), 7.25-7.19 (m, 1H), $4.62(\mathrm{q}, J=7.1 \mathrm{~Hz}, 2 \mathrm{H}), 4.25(\mathrm{~s}, 2 \mathrm{H}), 1.46(\mathrm{t}, J=7.1 \mathrm{~Hz}, 3 \mathrm{H}) .{ }^{13} \mathrm{C}$ NMR $\left(75 \mathrm{MHz}, \mathrm{CDCl}_{3}\right) \delta=166.6\left(\mathrm{C}_{\mathrm{q}}\right), 166.5\left(\mathrm{C}_{\mathrm{q}}\right), 159.5\left(\mathrm{C}_{\mathrm{q}}\right), 157.4\left(\mathrm{C}_{\mathrm{q}}\right), 153.2\left(\mathrm{C}_{\mathrm{q}}\right), 141.4(\mathrm{CH}), 139.6$ 
$(\mathrm{CH}), 138.7\left(\mathrm{C}_{\mathrm{q}}\right), 136.6(\mathrm{CH}), 129.4(\mathrm{CH}), 128.4(\mathrm{CH}), 126.5(\mathrm{CH}), 125.5(\mathrm{CH}), 120.7(\mathrm{CH}), 117.2(\mathrm{CH})$, $112.4\left(\mathrm{C}_{\mathrm{q}}\right), 63.1\left(\mathrm{CH}_{2}\right), 46.5\left(\mathrm{CH}_{2}\right), 14.4\left(\mathrm{CH}_{3}\right)$. IR (ATR) $v=2981,1623,1575,1421,1344,1278,1136$ $\mathrm{cm}^{-1}$. MS (ESI) m/z (relative intensity): $359(100)[\mathrm{M}+\mathrm{H}]^{+}, 381$ (5) $[\mathrm{M}+\mathrm{Na}]^{+}$. HR-MS (ESI) m/z calcd for $\mathrm{C}_{21} \mathrm{H}_{19} \mathrm{~N}_{4} \mathrm{O}_{2}[\mathrm{M}+\mathrm{H}]^{+}:$359.1508, found: 359.1503 .<smiles>CCOc1nc(Nc2ccccc2)nc2cc(Oc3cnccn3)ccc12</smiles>

4-Ethoxy-2-phenethyl-7-(pyrazin-2-yloxy)quinazoline (1630c): The general procedure C was followed using ethyl 4-(pyrazin-2-yloxy)benzimidate (1610) $(60.6 \mathrm{mg}, 0.25 \mathrm{mmol})$ and 5-phenethyloxazol-2(5H)-one (162c) $(57.3 \mathrm{mg}, 0.30 \mathrm{mmol})$. Purification by column chromatography on silica gel ( $n$-hexane/EtOAc: $4 / 1$ ) yielded $1630 c(81.0 \mathrm{mg}, 87 \%)$ as a white solid.

M. p. $=94-96{ }^{\circ} \mathrm{C} .{ }^{1} \mathrm{H}$ NMR $\left(300 \mathrm{MHz}, \mathrm{CDCl}_{3}\right) \delta=8.52(\mathrm{~d}, J=1.4 \mathrm{~Hz}, 1 \mathrm{H}), 8.35(\mathrm{~d}, J=2.6 \mathrm{~Hz}, 1 \mathrm{H}), 8.20$ $(\mathrm{d}, J=8.9 \mathrm{~Hz}, 1 \mathrm{H}), 8.14(\mathrm{dd}, J=2.6,1.4 \mathrm{~Hz}, 1 \mathrm{H}), 7.60(\mathrm{~d}, J=2.3 \mathrm{~Hz}, 1 \mathrm{H}), 7.32-7.24(\mathrm{~m}, 5 \mathrm{H}), 7.22-7.15$ $(\mathrm{m}, 1 \mathrm{H}), 4.64(\mathrm{q}, J=7.1 \mathrm{~Hz}, 2 \mathrm{H}), 3.28-3.19(\mathrm{~m}, 4 \mathrm{H}), 1.50(\mathrm{t}, J=7.1 \mathrm{~Hz}, 3 \mathrm{H}) .{ }^{13} \mathrm{C} \mathrm{NMR}\left(75 \mathrm{MHz}, \mathrm{CDCl}_{3}\right)$ $\delta=167.4\left(C_{q}\right), 166.5\left(C_{q}\right), 159.5\left(C_{q}\right), 157.4\left(C_{q}\right), 153.1\left(C_{q}\right), 141.9\left(C_{q}\right), 141.4(C H), 139.6(C H), 136.6$ $(\mathrm{CH}), 128.6(\mathrm{CH}), 128.5(\mathrm{CH}), 126.0(\mathrm{CH}), 125.6(\mathrm{CH}), 120.5(\mathrm{CH}), 117.0(\mathrm{CH}), 112.5\left(\mathrm{C}_{\mathrm{q}}\right), 63.6\left(\mathrm{CH}_{2}\right)$, $41.4\left(\mathrm{CH}_{2}\right), 34.5\left(\mathrm{CH}_{2}\right), 14.5\left(\mathrm{CH}_{3}\right)$. IR (ATR) $v=2980,1623,1574,1495,1420,1278,1136 \mathrm{~cm}^{-1} . \mathrm{MS}$ (ESI) $\mathrm{m} / \mathrm{z}$ (relative intensity): $373(100)[\mathrm{M}+\mathrm{H}]^{+}, 395(10)[\mathrm{M}+\mathrm{Na}]^{+}$. HR-MS (ESI) m/z calcd for $\mathrm{C}_{22} \mathrm{H}_{21} \mathrm{~N}_{4} \mathrm{O}_{2}[\mathrm{M}+\mathrm{H}]^{+}:$373.1665, found: 373.1659 .<smiles>CCOc1nc(-c2ccsc2)nc2cc(Oc3cnccn3)ccc12</smiles>

4-Ethoxy-7-(pyrazin-2-yloxy)-2-(thiophen-3-yl)quinazoline (163oe): The general procedure C was followed using ethyl 4-(pyrazin-2-yloxy)benzimidate (1610) $(60.8 \mathrm{mg}, 0.25 \mathrm{mmol})$ and 5-(thiophen-3-yl)oxazol-2(5H)-one (162e) $\quad(50.7 \mathrm{mg}, 0.30 \mathrm{mmol})$. Purification by column chromatography on silica gel ( $n$-hexane/EtOAc: $4 / 1$ ) yielded 1630 ( $75.3 \mathrm{mg}, 86 \%$ ) as a white solid. 
M. p. $=145-147^{\circ} \mathrm{C}^{1}{ }^{1} \mathrm{H}$ NMR $\left(300 \mathrm{MHz}, \mathrm{CDCl}_{3}\right) \delta=8.53(\mathrm{dd}, J=1.4,0.4 \mathrm{~Hz}, 1 \mathrm{H}), 8.36(\mathrm{dd}, J=2.7,0.4$ $\mathrm{Hz}, 1 \mathrm{H}), 8.19(\mathrm{dd}, J=8.9,0.5 \mathrm{~Hz}, 1 \mathrm{H}), 8.16(\mathrm{dd}, J=2.7,1.4 \mathrm{~Hz}, 1 \mathrm{H}), 8.07$ (dd, $J=3.7,1.3 \mathrm{~Hz}, 1 \mathrm{H}), 7.64$ (dd, $J=2.3,0.5 \mathrm{~Hz}, 1 \mathrm{H}), 7.48(\mathrm{dd}, J=5.0,1.3 \mathrm{~Hz}, 1 \mathrm{H}), 7.28(\mathrm{dd}, J=8.9,2.3 \mathrm{~Hz}, 1 \mathrm{H}), 7.15(\mathrm{~d}, J=5.0$, $3.7 \mathrm{~Hz}, 1 \mathrm{H}), 4.74(\mathrm{q}, J=7.1 \mathrm{~Hz}, 2 \mathrm{H}), 1.55(\mathrm{t}, J=7.1 \mathrm{~Hz}, 3 \mathrm{H}) .{ }^{13} \mathrm{C} \mathbf{N M R}\left(75 \mathrm{MHz}, \mathrm{CDCl}_{3}\right) \delta=166.5\left(\mathrm{C}_{\mathrm{q}}\right)$, $159.6\left(\mathrm{C}_{\mathrm{q}}\right), 157.9\left(\mathrm{C}_{\mathrm{q}}\right), 157.7\left(\mathrm{C}_{\mathrm{q}}\right), 153.5\left(\mathrm{C}_{\mathrm{q}}\right), 144.2\left(\mathrm{C}_{\mathrm{q}}\right), 141.4(\mathrm{CH}), 139.6(\mathrm{CH}), 136.6(\mathrm{CH}), 129.9$ $(\mathrm{CH}), 129.3(\mathrm{CH}), 128.2(\mathrm{CH}), 125.7(\mathrm{CH}), 120.5(\mathrm{CH}), 117.4(\mathrm{CH}), 112.8\left(\mathrm{C}_{\mathrm{q}}\right), 63.3\left(\mathrm{CH}_{2}\right), 14.5\left(\mathrm{CH}_{3}\right) . \mathbf{I R}$ (ATR) $v=2981,1621,1575,1496,1452,1400,1343,1318,1150 \mathrm{~cm}^{-1}$. MS (ESI) m/z (relative intensity): 351 (100) $[\mathrm{M}+\mathrm{H}]^{+}, 723$ (11) $[2 \mathrm{M}+\mathrm{Na}]^{+}$. HR-MS (ESI) m/z calcd for $\mathrm{C}_{18} \mathrm{H}_{15} \mathrm{~N}_{4} \mathrm{O}_{2} \mathrm{~S}[\mathrm{M}+\mathrm{H}]^{+}$: 351.0916, found: 351.0914 .

(me

$N$-[4-Ethoxy-2-(m-tolyl)quinazolin-7-yl]pivalamide (163pg): The general procedure C was followed using ethyl 4-pivalamidobenzimidate (161p) $(62.1 \quad \mathrm{mg}, 0.25 \mathrm{mmol})$ and 3-(m-tolyl)-1,4,2-dioxazol-5-one (162g) $\quad(53.2 \mathrm{mg}, 0.30 \mathrm{mmol})$. Purification by coloumn chromatography on silica gel ( $n$-hexane/EtOAc: 6/1) yielded $163 \mathrm{pg}$ (77.0 mg, 85\%) as a white solid.

M. p. $=199-201{ }^{\circ} \mathrm{C} .{ }^{1} \mathrm{H}$ NMR $\left(300 \mathrm{MHz}, \mathrm{CDCl}_{3}\right) \delta=8.39(\mathrm{~s}, 1 \mathrm{H}), 8.36(\mathrm{~s}, 1 \mathrm{H}), 8.08(\mathrm{~d}, J=8.9 \mathrm{~Hz}, 1 \mathrm{H})$, $8.02(\mathrm{~d}, J=2.1 \mathrm{~Hz}, 1 \mathrm{H}), 7.83(\mathrm{dd}, J=8.9,2.1 \mathrm{~Hz}, 1 \mathrm{H}), 7.65(\mathrm{~s}, 1 \mathrm{H}), 7.40(\mathrm{t}, J=7.6 \mathrm{~Hz}, 1 \mathrm{H}), 7.31(\mathrm{~d}, J=$ $7.4 \mathrm{~Hz}, 1 \mathrm{H}), 4.75(\mathrm{q}, J=7.1 \mathrm{~Hz}, 2 \mathrm{H}), 2.49(\mathrm{~s}, 3 \mathrm{H}), 1.57(\mathrm{t}, J=7.1 \mathrm{~Hz}, 3 \mathrm{H}), 1.38(\mathrm{~s}, 9 \mathrm{H}) .{ }^{13} \mathrm{C}$ NMR $(75$ $\left.\mathrm{MHz}, \mathrm{CDCl}_{3}\right) \delta=176.8\left(\mathrm{C}_{\mathrm{q}}\right), 166.2\left(\mathrm{C}_{\mathrm{q}}\right), 160.7\left(\mathrm{C}_{\mathrm{q}}\right), 152.8\left(\mathrm{C}_{\mathrm{q}}\right), 142.6\left(\mathrm{C}_{\mathrm{q}}\right), 138.2\left(\mathrm{C}_{\mathrm{q}}\right), 137.9\left(\mathrm{C}_{\mathrm{q}}\right), 131.2$ $(\mathrm{CH}), 129.0(\mathrm{CH}), 128.2(\mathrm{CH}), 125.7(\mathrm{CH}), 124.5(\mathrm{CH}), 119.5(\mathrm{CH}), 116.0(\mathrm{CH}), 111.8\left(\mathrm{C}_{\mathrm{q}}\right), 62.7\left(\mathrm{CH}_{2}\right)$, $39.9\left(\mathrm{C}_{\mathrm{q}}\right), 27.6\left(\mathrm{CH}_{3}\right), 21.6\left(\mathrm{CH}_{3}\right), 14.4\left(\mathrm{CH}_{3}\right)$. IR (ATR) $v=3333,2958,1665,1572,1436,1326,1028$, 1169, 1110, $788 \mathrm{~cm}^{-1}$. MS (ESI) m/z (relative intensity): $364(100)[\mathrm{M}+\mathrm{H}]^{+}, 386(10)[\mathrm{M}+\mathrm{Na}]^{+}, 727$ (10) $[2 \mathrm{M}+\mathrm{Na}]^{+}$. HR-MS (ESI) m/z calcd for $\mathrm{C}_{22} \mathrm{H}_{26} \mathrm{~N}_{3} \mathrm{O}_{2}[\mathrm{M}+\mathrm{H}]^{+}: 364.2020$, found: 364.2025. 
<smiles>CCOc1ccc(NC(=O)C(C)(C)C)cc2nc(-c3ccc(OC)cc3)nc1-2</smiles>

$\mathrm{N}$-[4-Ethoxy-2-(4-methoxyphenyl)quinazolin-7-yl]pivalamide (163pf): The general procedure C was followed using ethyl 4-pivalamidobenzimidate (161p) $(62.1 \mathrm{mg}, 0.25 \mathrm{mmol})$ and 3-(4-methoxyphenyl)-1,4,2-dioxazol-5-one (162f) $(57.9 \mathrm{mg}, 0.30 \mathrm{mmol})$. Purification by coloumn chromatography on silica gel ( $n$-hexane/EtOAc: 6/1) yielded $163 \mathrm{pf}(81.0 \mathrm{mg}, 85 \%)$ as a white solid. M. p. $=211-213{ }^{\circ} \mathrm{C} .{ }^{1} \mathrm{H}$ NMR $\left(400 \mathrm{MHz}, \mathrm{CDCl}_{3}\right) \delta=8.48(\mathrm{~d}, J=9.0 \mathrm{~Hz}, 2 \mathrm{H}), 8.01(\mathrm{~d}, J=8.8 \mathrm{~Hz}, 1 \mathrm{H})$, $7.95(\mathrm{~d}, J=2.1 \mathrm{~Hz}, 1 \mathrm{H}), 7.73(\mathrm{dd}, J=8.9,2.1 \mathrm{~Hz}, 1 \mathrm{H}), 7.61(\mathrm{~s}, 1 \mathrm{H}), 6.97(\mathrm{~d}, J=9.0 \mathrm{~Hz}, 2 \mathrm{H}), 4.68(\mathrm{q}, J=$ $7.1 \mathrm{~Hz}, 2 \mathrm{H}), 3.85(\mathrm{~s}, 3 \mathrm{H}), 1.51(\mathrm{t}, J=7.1 \mathrm{~Hz}, 3 \mathrm{H}), 1.33(\mathrm{~s}, 9 \mathrm{H}) .{ }^{13} \mathrm{C}$ NMR $\left(100 \mathrm{MHz}, \mathrm{CDCl}_{3}\right) \delta=176.8$ $\left(C_{q}\right), 166.0\left(C_{q}\right), 161.6\left(C_{q}\right), 160.3\left(C_{q}\right), 152.9\left(C_{q}\right), 142.4\left(C_{q}\right), 130.9\left(C_{q}\right), 130.0(C H), 124.4(C H), 119.1$ $(\mathrm{CH}), 115.8\left(\mathrm{C}_{\mathrm{q}}\right), 113.6(\mathrm{CH}), 111.5(\mathrm{CH}), 62.5\left(\mathrm{CH}_{2}\right), 55.3\left(\mathrm{CH}_{3}\right), 39.8\left(\mathrm{C}_{\mathrm{q}}\right), 27.5\left(\mathrm{CH}_{3}\right), 14.4\left(\mathrm{CH}_{3}\right) . \mathbf{I R}$ (ATR) $v=3351,2969,1662,1579,1442,1326,1251,1164,1027,845,791 \mathrm{~cm}^{-1}$. MS (ESI) m/z (relative intensity): $380(100)[\mathrm{M}+\mathrm{H}]^{+}$. HR-MS (ESI) m/z calcd for $\mathrm{C}_{22} \mathrm{H}_{26} \mathrm{~N}_{3} \mathrm{O}_{3}[\mathrm{M}+\mathrm{H}]^{+}: 380.1969$, found: 380.1970 .<smiles>CCOc1nc(-c2ccc(Cl)cc2)nc2cc(NC(=O)C(C)(C)C)ccc12</smiles>

$\mathbf{N}$-[2-(4-Chlorophenyl)-4-ethoxyquinazolin-7-yl]pivalamide (163pj): The general procedure C was followed using ethyl 4-pivalamidobenzimidate $(161 \mathrm{p}) \quad(62.1 \mathrm{mg}, \quad 0.25 \mathrm{mmol})$ and 3-(4-chlorophenyl)-1,4,2-dioxazol-5-one (162j) $(59.3 \mathrm{mg}, 0.30 \mathrm{mmol})$. Purification by coloumn chromatography on silica gel ( $n$-hexane/EtOAc: 6/1) yielded 163pj (86.0 mg, 90\%) as a white solid. M. p. $=228-230{ }^{\circ} \mathrm{C} .{ }^{1} \mathrm{H}$ NMR $\left(300 \mathrm{MHz}, \mathrm{CDCl}_{3}\right) \delta=8.48(\mathrm{~d}, J=8.6 \mathrm{~Hz}, 2 \mathrm{H}), 8.06(\mathrm{~d}, J=8.9 \mathrm{~Hz}, 1 \mathrm{H})$, $8.02(\mathrm{~d}, J=2.1 \mathrm{~Hz}, 1 \mathrm{H}), 7.79(\mathrm{dd}, J=8.9,2.1 \mathrm{~Hz}, 1 \mathrm{H}), 7.66(\mathrm{~s}, 1 \mathrm{H}), 7.45(\mathrm{~d}, J=8.6 \mathrm{~Hz}, 2 \mathrm{H}), 4.70(\mathrm{q}, J=$ $7.1 \mathrm{~Hz}, 2 \mathrm{H}), 1.55$ (t, J = $7.1 \mathrm{~Hz}, 3 \mathrm{H}), 1.39(\mathrm{~s}, 9 \mathrm{H}) .{ }^{13} \mathrm{C}$ NMR $\left(75 \mathrm{MHz}, \mathrm{CDCl}_{3}\right) \delta=176.8\left(\mathrm{C}_{\mathrm{q}}\right), 166.3\left(\mathrm{C}_{\mathrm{q}}\right)$, $159.5\left(\mathrm{C}_{\mathrm{q}}\right), 152.8\left(\mathrm{C}_{\mathrm{q}}\right), 142.7\left(\mathrm{C}_{\mathrm{q}}\right), 136.8\left(\mathrm{C}_{\mathrm{q}}\right), 136.5\left(\mathrm{C}_{\mathrm{q}}\right), 129.8(\mathrm{CH}), 128.5(\mathrm{CH}), 124.5\left(\mathrm{C}_{\mathrm{q}}\right), 119.7(\mathrm{CH})$, $115.9(\mathrm{CH}), 111.8(\mathrm{CH}), 62.8\left(\mathrm{CH}_{2}\right), 39.9\left(\mathrm{C}_{\mathrm{q}}\right), 27.6\left(\mathrm{CH}_{3}\right), 14.4\left(\mathrm{CH}_{3}\right)$. IR (ATR) $v=3323,2984,1659$, 
1579, 1437, 1324, 1205, 1089, 1014, $789 \mathrm{~cm}^{-1}$. MS (ESI) m/z (relative intensity): 384 (100) [M+H] , 406 (10) $[\mathrm{M}+\mathrm{Na}]^{+}$. HR-MS (ESI) m/z calcd for $\mathrm{C}_{21} \mathrm{H}_{23} \mathrm{~N}_{3} \mathrm{O}_{2}[\mathrm{M}+\mathrm{H}]^{+}:$384.1473, found: 384.1476.<smiles>CCOc1nc(Nc2ccccc2)nc2cc(Oc3ccccn3)ccc12</smiles>

4-Ethoxy-2-phenethyl-7-(pyridin-2-yloxy)quinazoline (163qc): The general procedure C was followed using ethyl 4-(pyridin-2-yloxy)benzimidate (161q) $(60.8 \mathrm{mg}, 0.25 \mathrm{mmol})$ and 5-phenethyloxazol-2(5H)-one (162c) $(57.3 \mathrm{mg}, 0.30 \mathrm{mmol})$. Purification by column chromatography on silica gel ( $n$-hexane/EtOAc: $10 / 1)$ yielded $163 q c(75.2 \mathrm{mg}, 81 \%)$ as a colorless oil.

${ }^{1} \mathbf{H}$ NMR $\left(300 \mathrm{MHz} \mathrm{CDCl}_{3}\right) \delta=8.25$ (ddd, $\left.J=5.0,2.0,0.8 \mathrm{~Hz}, 1 \mathrm{H}\right), 8.15(\mathrm{dd}, J=8.9,0.4 \mathrm{~Hz}, 1 \mathrm{H})$, 7.78-7.72 (m, 1H), $7.51(\mathrm{dd}, J=2.4,0.6 \mathrm{~Hz}, 1 \mathrm{H}), 7.34-7.24(\mathrm{~m}, 5 \mathrm{H}), 7.22-7.15(\mathrm{~m}, 1 \mathrm{H}), 7.08(\mathrm{dd}, J=$ 7.3, $5.0 \mathrm{~Hz}, 1 \mathrm{H}), 7.04$ (d, $J=8.4 \mathrm{~Hz}, 1 \mathrm{H}), 4.63(\mathrm{q}, J=7.1 \mathrm{~Hz}, 2 \mathrm{H}), 3.28-3.18(\mathrm{~m}, 4 \mathrm{H}), 1.49(\mathrm{t}, J=7.1 \mathrm{~Hz}$, 3H). ${ }^{13} \mathrm{C} \mathrm{NMR}\left(75 \mathrm{MHz}, \mathrm{CDCl}_{3}\right) \delta=167.0\left(\mathrm{C}_{\mathrm{q}}\right), 166.5\left(\mathrm{C}_{\mathrm{q}}\right), 162.8\left(\mathrm{C}_{\mathrm{q}}\right), 158.9\left(\mathrm{C}_{\mathrm{q}}\right), 153.2\left(\mathrm{C}_{\mathrm{q}}\right), 148.1(\mathrm{CH})$, $141.9\left(\mathrm{C}_{\mathrm{q}}\right), 139.9(\mathrm{CH}), 128.6(\mathrm{CH}), 128.4(\mathrm{CH}), 125.9(\mathrm{CH}), 125.3(\mathrm{CH}), 120.6(\mathrm{CH}), 119.7(\mathrm{CH}), 115.9$ (CH), $112.9(\mathrm{CH}), 111.8\left(\mathrm{C}_{\mathrm{q}}\right), 62.8\left(\mathrm{CH}_{2}\right), 41.4\left(\mathrm{CH}_{2}\right), 34.5\left(\mathrm{CH}_{2}\right), 14.5\left(\mathrm{CH}_{3}\right)$. IR (ATR) $v=2979,1622$, 1569, 1416, 1340, 1238, 1135, $1104 \mathrm{~cm}^{-1}$. MS (ESI) m/z (relative intensity): 372 (100) [M+H], 394 (10) $[\mathrm{M}+\mathrm{Na}]^{+}$. HR-MS (ESI) $\mathrm{m} / \mathrm{z}$ calcd for $\mathrm{C}_{23} \mathrm{H}_{22} \mathrm{~N}_{3} \mathrm{O}_{2}[\mathrm{M}+\mathrm{H}]^{+}:$372.1712, found: 372.1707.

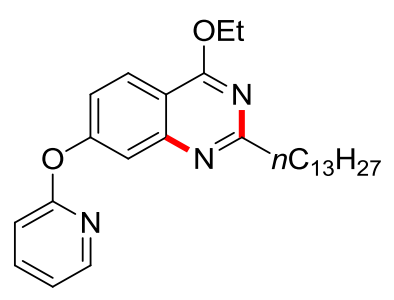

4-Ethoxy-7-(pyridin-2-yloxy)-2-n-tridecylquinazoline (163qd): The general procedure C was followed using ethyl 4-(pyridin-2-yloxy)benzimidate (161q) $(60.6 \mathrm{mg}, 0.25 \mathrm{mmol})$, 5-tridecyloxazol-2(5H)-one (162d) $(80.8 \mathrm{mg}, 0.30 \mathrm{mmol})$. Purification by column chromatography on silica gel ( $n$-hexane/EtOAc: $4 / 1$ ) yielded $163 q d(96.7 \mathrm{mg}, 86 \%)$ as a colorless oil.

${ }^{1} \mathrm{H}$ NMR $\left(300 \mathrm{MHz}, \mathrm{CDCl}_{3}\right) \delta=8.23(\mathrm{ddd}, J=4.9,2.0,0.6 \mathrm{~Hz}, 1 \mathrm{H}), 8.14(\mathrm{~d}, J=8.9 \mathrm{~Hz}, 1 \mathrm{H}), 7.77-7.71$ $(\mathrm{m}, 1 \mathrm{H}), 7.53(\mathrm{~s}, 1 \mathrm{H}), 7.28(\mathrm{dd}, J=8.9,2.3 \mathrm{~Hz}, 1 \mathrm{H}), 7.06(\mathrm{dd}, J=7.4,4.9,0.6 \mathrm{~Hz}, 1 \mathrm{H}), 7.02(\mathrm{~d}, J=8.2$ 
$\mathrm{Hz}, 1 \mathrm{H}), 4.63(\mathrm{q}, J=7.1 \mathrm{~Hz}, 2 \mathrm{H}), 2.90(\mathrm{t}, J=7.7 \mathrm{~Hz}, 2 \mathrm{H}), 1.84(\mathrm{q}, J=7.6 \mathrm{~Hz}, 2 \mathrm{H}), 1.48(\mathrm{t}, J=7.1 \mathrm{~Hz}, 3 \mathrm{H})$, 1.41-1.24 (m, 20H), 0.89-0.84 (m, 3H). ${ }^{13} \mathrm{C}$ NMR (75 MHz, $\left.\mathrm{CDCl}_{3}\right) \delta=168.3\left(\mathrm{C}_{\mathrm{q}}\right), 166.6\left(\mathrm{C}_{\mathrm{q}}\right), 162.7$ $\left(\mathrm{C}_{\mathrm{q}}\right), 159.1\left(\mathrm{C}_{\mathrm{q}}\right), 148.1(\mathrm{CH}), 139.9(\mathrm{CH}), 125.3(\mathrm{CH}), 120.6(\mathrm{CH}), 119.7(\mathrm{CH}), 115.7\left(\mathrm{C}_{\mathrm{q}}\right), 115.6(\mathrm{CH})$, $112.9(\mathrm{CH}), 111.6\left(\mathrm{C}_{\mathrm{q}}\right), 62.9\left(\mathrm{CH}_{2}\right), 39.8\left(\mathrm{CH}_{2}\right), 32.0\left(\mathrm{CH}_{2}\right), 29.8\left(\mathrm{CH}_{2}\right), 29.8\left(\mathrm{CH}_{2}\right), 29.7\left(\mathrm{CH}_{2}\right), 29.7$ $\left(\mathrm{CH}_{2}\right), 29.7\left(\mathrm{CH}_{2}\right), 29.6\left(\mathrm{CH}_{2}\right), 29.6\left(\mathrm{CH}_{2}\right), 29.5\left(\mathrm{CH}_{2}\right), 28.7\left(\mathrm{CH}_{2}\right), 22.8\left(\mathrm{CH}_{2}\right), 14.5\left(\mathrm{CH}_{3}\right), 14.2\left(\mathrm{CH}_{3}\right)$. IR (ATR) $v=2922,2852,1623,1571,1464,1341,1241,1137,779 \mathrm{~cm}^{-1}$. MS (ESI) m/z (relative intensity): 450 (100) $[\mathrm{M}+\mathrm{H}]^{+}$. HR-MS (ESI) m/z calcd for $\mathrm{C}_{28} \mathrm{H}_{39} \mathrm{~N}_{3} \mathrm{O}_{2} \mathrm{Na}[\mathrm{M}+\mathrm{Na}]^{+}:$472.2940, found: 472.2934 .<smiles>CCOc1nc(-c2ccccc2)nc2cc(Oc3ccccn3)ccc12</smiles>

4-Ethoxy-2-phenyl-7-(pyridin-2-yloxy)quinazoline (163qa): The general procedure C was followed using ethyl 4-(pyridin-2-yloxy)benzimidate (161q) $(60.6 \quad \mathrm{mg}, 0.25 \mathrm{mmol})$ and 5-phenyloxazol-2(5H)-one (162a) $(48.9 \mathrm{mg}, 0.30 \mathrm{mmol})$. Purification by coloumn chromatography on silica gel ( $n$-hexane/EtOAc: $15 / 1$ ) yielded $163 q$ a $(69.1 \mathrm{mg}, 80 \%)$ as a colorless oil.

${ }^{1} \mathbf{H}$ NMR $\left(300 \mathrm{MHz}, \mathrm{CDCl}_{3}\right) \delta=8.63-8.46(\mathrm{~m}, 2 \mathrm{H}), 8.24(\mathrm{dd}, J=4.9,1.9 \mathrm{~Hz}, 1 \mathrm{H}), 8.18(\mathrm{~d}, J=8.9 \mathrm{~Hz}$, $1 \mathrm{H}), 7.73$ (ddd, $J=8.3,7.4,1.9 \mathrm{~Hz}, 1 \mathrm{H}), 7.63(\mathrm{~d}, J=2.3 \mathrm{~Hz}, 1 \mathrm{H}), 7.54-7.43(\mathrm{~m}, 3 \mathrm{H}), 7.30$ (dd, $J=8.9$, $2.3 \mathrm{~Hz}, 1 \mathrm{H}), 7.11-6.97(\mathrm{~m}, 2 \mathrm{H}), 4.76(\mathrm{q}, J=7.1 \mathrm{~Hz}, 2 \mathrm{H}), 1.54(\mathrm{t}, J=7.1 \mathrm{~Hz}, 3 \mathrm{H}) .{ }^{13} \mathrm{C} \mathrm{NMR}(75 \mathrm{MHz}$, $\left.\mathrm{CDCl}_{3}\right) \delta=166.4\left(\mathrm{C}_{\mathrm{q}}\right), 162.7\left(\mathrm{C}_{\mathrm{q}}\right), 160.7\left(\mathrm{C}_{\mathrm{q}}\right), 158.8\left(\mathrm{C}_{\mathrm{q}}\right), 153.5\left(\mathrm{C}_{\mathrm{q}}\right), 147.9(\mathrm{CH}), 139.7(\mathrm{CH}), 138.1\left(\mathrm{C}_{\mathrm{q}}\right)$, $130.4(\mathrm{CH}), 128.4(\mathrm{CH}), 128.3(\mathrm{CH}), 125.2(\mathrm{CH}), 120.8(\mathrm{CH}), 119.5(\mathrm{CH}), 116.7(\mathrm{CH}), 112.6(\mathrm{CH}), 112.1$ $\left(\mathrm{C}_{\mathrm{q}}\right), 62.7\left(\mathrm{CH}_{2}\right), 14.4\left(\mathrm{CH}_{3}\right)$. IR (ATR) $v=2980,1620,1573,148.95,1417,1343,1242,969,774,710$ $\mathrm{cm}^{-1}$. MS (ESI) m/z (relative intensity): $344(100)[\mathrm{M}+\mathrm{H}]^{+}, 366(45)[\mathrm{M}+\mathrm{Na}]^{+}$. HR-MS (ESI) m/z calcd for $\mathrm{C}_{21} \mathrm{H}_{18} \mathrm{~N}_{3} \mathrm{O}_{2}[\mathrm{M}+\mathrm{H}]^{+}: 344.1394$, found: 344.1396 .<smiles>CCOc1nc(-c2ccc(OC)cc2)nc2cc(Oc3ccccn3)ccc12</smiles>

4-Ethoxy-2-(4-methoxyphenyl)-7-(pyridin-2-yloxy)quinazoline (163qf): The general procedure C 190 
was followed using ethyl 4-(pyridin-2-yloxy)benzimidate (161q) $(60.6 \mathrm{mg}, 0.25 \mathrm{mmol})$ and 5-(4-methoxyphenyl)oxazol-2(5H)-one (162f) (57.9 $\mathrm{mg}, 0.30 \mathrm{mmol}$ ). Purification by column chromatography on silica gel ( $n$-hexane/EtOAc: $8 / 2$ ) yielded $163 q f(68.1 \mathrm{mg}, 73 \%)$ as a white solid. M. p. $=118-119{ }^{\circ} \mathrm{C}^{1}{ }^{1} \mathrm{H}$ NMR $\left(300 \mathrm{MHz}, \mathrm{CDCl}_{3}\right) \delta=8.51(\mathrm{~d}, J=9.0 \mathrm{~Hz}, 2 \mathrm{H}), 8.26$ (ddd, $J=5.0,2.0,0.8$ $\mathrm{Hz}, 1 \mathrm{H}), 8.17(\mathrm{dd}, J=8.9,0.5 \mathrm{~Hz}, 1 \mathrm{H}), 7.76(\mathrm{ddd}, J=8.2,7.3,2.0 \mathrm{~Hz}, 1 \mathrm{H}), 7.59(\mathrm{~d}, J=2.3 \mathrm{~Hz}, 1 \mathrm{H}), 7.28$ (dd, $J=9.2,2.3 \mathrm{~Hz}, 1 \mathrm{H}$ ), 7.08 (ddd, $J=7.3,5.0,0.9 \mathrm{~Hz}, 1 \mathrm{H}), 7.04(\mathrm{~d}, J=8.2 \mathrm{~Hz}, 1 \mathrm{H}), 6.99(\mathrm{~d}, J=9.0 \mathrm{~Hz}$, $2 \mathrm{H}), 4.76(\mathrm{q}, J=7.1 \mathrm{~Hz}, 2 \mathrm{H}), 3.88(\mathrm{~s}, 3 \mathrm{H}), 1.56(\mathrm{t}, J=7.1 \mathrm{~Hz}, 3 \mathrm{H}) .{ }^{13} \mathrm{C} \mathrm{NMR}\left(100 \mathrm{MHz}, \mathrm{CDCl}_{3}\right) \delta=166.5$ $\left(C_{q}\right), 162.9\left(C_{q}\right), 161.8\left(C_{q}\right), 160.7\left(C_{q}\right), 158.9\left(C_{q}\right), 153.8\left(C_{q}\right), 148.2(C H), 139.7(C H), 131.0\left(C_{q}\right), 130.3$ $(\mathrm{CH}), 125.4(\mathrm{CH}), 120.5(\mathrm{CH}), 119.7(\mathrm{CH}), 116.7(\mathrm{CH}), 113.8(\mathrm{CH}), 112.8(\mathrm{CH}), 112.1\left(\mathrm{C}_{\mathrm{q}}\right), 62.8\left(\mathrm{CH}_{2}\right)$, $55.5\left(\mathrm{CH}_{3}\right), 14.6\left(\mathrm{CH}_{3}\right)$. IR (ATR) $v=2977,1624,1577,1497,1445,1344,1250,1106 \mathrm{~cm}^{-1} . \mathrm{MS}$ (ESI) $\mathrm{m} / \mathrm{z}$ (relative intensity): $374(100)[\mathrm{M}+\mathrm{H}]^{+}, 396(7)[\mathrm{M}+\mathrm{Na}]^{+}$. HR-MS (ESI) m/z calcd for $\mathrm{C}_{22} \mathrm{H}_{19} \mathrm{~N}_{3} \mathrm{NaO}_{3}$ $[\mathrm{M}+\mathrm{Na}]^{+}:$396.1324, found: 396.1321 .

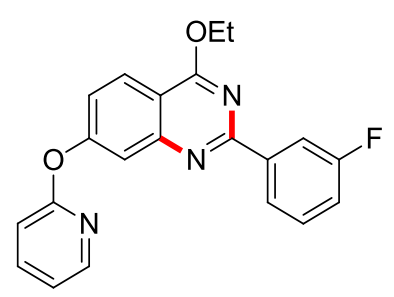

4-Ethoxy-2-(3-fluorophenyl)-7-(pyridin-2-yloxy)quinazoline (163qi): The general procedure C was followed using ethyl 4-(pyridin-2-yloxy)benzimidate (161q) $(60.6 \mathrm{mg}, 0.25 \mathrm{mmol})$ and 3-(3-fluorophenyl)-1,4,2-dioxazol-5H-one (162i) (54.3 mg, $0.30 \mathrm{mmol}$ ). Purification by column chromatography on silica gel ( $n$-hexane/EtOAc: 10/1) yielded $163 q i(79.5 \mathrm{mg}, 88 \%)$ as a white solid. M. p. $=101-104{ }^{\circ} \mathrm{C} .{ }^{1} \mathrm{H}$ NMR $\left(300 \mathrm{MHz}, \mathrm{CDCl}_{3}\right) \delta=8.34(\mathrm{dt}, J=7.9,1.2 \mathrm{~Hz}, 1 \mathrm{H}), 8.27-8.26(\mathrm{~m}, 2 \mathrm{H})$, $8.20(\mathrm{dd}, J=8.9,0.5 \mathrm{~Hz}, 1 \mathrm{H}), 7.78(\mathrm{ddd}, J=8.2,7.3,2.0 \mathrm{~Hz}, 1 \mathrm{H}), 7.63(\mathrm{~d}, J=2.3 \mathrm{~Hz}, 1 \mathrm{H}), 7.44(\mathrm{td}, J=$ 8.0, $5.8 \mathrm{~Hz}, 1 \mathrm{H}$ ), 7.34 (dd, $J=8.9,2.4 \mathrm{~Hz}, 1 \mathrm{H}$ ), 7.16 (tdd, $J=8.3,2.7,1.0 \mathrm{~Hz}, 1 \mathrm{H}$ ), 7.10 (ddd, $J=7.4$, 5.0, $1.0 \mathrm{~Hz}, 1 \mathrm{H}), 7.06(\mathrm{dt}, J=8.3,0.9 \mathrm{~Hz}, 1 \mathrm{H}) 4.77(\mathrm{q}, J=7.1 \mathrm{~Hz}, 2 \mathrm{H}), 1.57(\mathrm{t}, J=7.1 \mathrm{~Hz}, 3 \mathrm{H}) .{ }^{13} \mathrm{C} \mathrm{NMR}$ $\left(125 \mathrm{MHz} \mathrm{CDCl}_{3}\right) \delta=166.6\left(\mathrm{C}_{\mathrm{q}}\right), 163.1\left(\mathrm{~d},{ }^{1} \mathrm{~J}=243.9 \mathrm{~Hz}, \mathrm{C}_{\mathrm{q}}\right), 162.7\left(\mathrm{C}_{\mathrm{q}}\right), 160.0\left(\mathrm{~d},{ }^{4} \mathrm{~J}=3.3 \mathrm{~Hz}, \mathrm{C}_{\mathrm{q}}\right)$ $159.0\left(\mathrm{C}_{\mathrm{q}}\right), 153.5\left(\mathrm{C}_{\mathrm{q}}\right), 148.0(\mathrm{CH}), 140.7\left(\mathrm{~d},{ }^{3} \mathrm{~J}=7.8 \mathrm{~Hz}, \mathrm{C}_{\mathrm{q}}\right), 139.9(\mathrm{CH}), 129.8\left(\mathrm{~d},{ }^{3} \mathrm{~J}=7.8 \mathrm{~Hz}, \mathrm{CH}\right)$, $125.3(\mathrm{CH}), 124.1\left(\mathrm{~d},{ }^{4} \mathrm{~J}=2.8 \mathrm{~Hz}, \mathrm{CH}\right), 121.3(\mathrm{CH}), 119.7(\mathrm{CH}), 117.3\left(\mathrm{~d},{ }^{2} \mathrm{~J}=21.4 \mathrm{~Hz}, \mathrm{CH}\right), 116.9(\mathrm{CH})$, $115.4\left(\mathrm{~d},{ }^{2} \mathrm{~J}=23.0 \mathrm{~Hz}, \mathrm{CH}\right), 112.8(\mathrm{CH}), 112.4\left(\mathrm{C}_{\mathrm{q}}\right), 63.1\left(\mathrm{CH}_{2}\right), 14.7\left(\mathrm{CH}_{3}\right) .{ }^{19} \mathrm{~F} \mathrm{NMR}\left(282 \mathrm{MHz}, \mathrm{CDCl}_{3}\right) \delta$ $=-113.58$ (ddd, $J=10.5,8.4,5.8 \mathrm{~Hz}$ ). IR (ATR) $v=2981,1622,1592,1577,1427,1325,1245,1141$ 
$\mathrm{cm}^{-1} . \mathrm{MS}(\mathrm{ESI}) \mathrm{m} / \mathrm{z}$ (relative intensity): $362(100)[\mathrm{M}+\mathrm{H}]^{+}, 745(10)[2 \mathrm{M}+\mathrm{Na}]^{+}$. HR-MS (ESI) m/z calcd for $\mathrm{C}_{21} \mathrm{H}_{17} \mathrm{FN}_{3} \mathrm{O}_{2}[\mathrm{M}+\mathrm{H}]^{+}: 362.1305$, found: 362.1299 .<smiles>CCOc1nc(-c2ccc(C)cc2)nc2cc(Oc3cc(C)ccn3)ccc12</smiles>

4-Ethoxy-7-[(4-methylpyridin-2-yl)oxy]-2-(p-tolyl)quinazoline (163rm): The general procedure C was followed using ethyl 4-[(4-methylpyridin-2-yl)oxy]benzimidate (161r) (64.1 mg, $0.25 \mathrm{mmol})$ and 3-(p-tolyl)-1,4,2-dioxazol-5-one $\quad(\mathbf{1 6 2 m}) \quad(53.2 \mathrm{mg}, 0.30 \mathrm{mmol})$. Purification by coloumn chromatography on silica gel ( $n$-hexane/EtOAc: $10 / 1)$ yielded $163 \mathrm{rm}(77.2 \mathrm{mg}, 83 \%)$ as a white solid. M. p. $=102-104{ }^{\circ} \mathrm{C} .{ }^{1} \mathrm{H}$ NMR $\left(300 \mathrm{MHz}, \mathrm{CDCl}_{3}\right) \delta=8.42(\mathrm{~d}, J=8.2 \mathrm{~Hz}, 2 \mathrm{H}), 8.14(\mathrm{~d}, J=8.9 \mathrm{~Hz}, 1 \mathrm{H})$, $8.07(\mathrm{~d}, J=2.4 \mathrm{~Hz}, 1 \mathrm{H}), 7.59-7.50(\mathrm{~m}, 2 \mathrm{H}), 7.30-7.20(\mathrm{~m}, 3 \mathrm{H}), 6.93(\mathrm{~d}, J=8.3 \mathrm{~Hz}, 1 \mathrm{H}), 4.74(\mathrm{q}, J=7.1$ $\mathrm{Hz}, 2 \mathrm{H}), 2.41(\mathrm{~s}, 3 \mathrm{H}), 2.31(\mathrm{~s}, 3 \mathrm{H}), 1.54(\mathrm{t}, J=7.1 \mathrm{~Hz}, 3 \mathrm{H}) .{ }^{13} \mathrm{C} \mathrm{NMR}\left(75 \mathrm{MHz}, \mathrm{CDCl}_{3}\right) \delta=166.3\left(\mathrm{C}_{\mathrm{q}}\right)$, $160.8\left(\mathrm{C}_{\mathrm{q}}\right), 160.7\left(\mathrm{C}_{\mathrm{q}}\right), 159.5\left(\mathrm{C}_{\mathrm{q}}\right), 153.5\left(\mathrm{C}_{\mathrm{q}}\right), 147.8(\mathrm{CH}), 140.6\left(\mathrm{C}_{\mathrm{q}}\right), 140.5(\mathrm{CH}), 135.4\left(\mathrm{C}_{\mathrm{q}}\right), 129.1\left(\mathrm{C}_{\mathrm{q}}\right)$, $129.1(\mathrm{CH}), 128.4(\mathrm{CH}), 125.2(\mathrm{CH}), 120.2(\mathrm{CH}), 115.7(\mathrm{CH}), 112.4(\mathrm{CH}), 111.8\left(\mathrm{C}_{\mathrm{q}}\right), 62.7\left(\mathrm{CH}_{2}\right), 21.5$ $\left(\mathrm{CH}_{3}\right), 17.6\left(\mathrm{CH}_{3}\right), 14.4\left(\mathrm{CH}_{3}\right)$. IR (ATR) $v=2976,2921,1603,1568,1470,1341,1279,1156,890,788$ $\mathrm{cm}^{-1}$. MS (ESI) m/z (relative intensity): $372(100)[\mathrm{M}+\mathrm{H}]^{+}, 394(5)[\mathrm{M}+\mathrm{Na}]^{+}$. HR-MS (ESI) m/z calcd for $\mathrm{C}_{23} \mathrm{H}_{22} \mathrm{~N}_{3} \mathrm{O}_{2}[\mathrm{M}+\mathrm{H}]^{+}:$372.1707, found: 372.1706 .<smiles>CCOc1nc(-c2ccccc2)nc2cc(-c3ccccn3)ccc12</smiles>

4-Ethoxy-2-phenyl-7-(pyridin-2-yl)quinazoline (163sa): The general procedure $\mathbf{C}$ was followed using ethyl 4-(pyridin-2-yl)benzimidate (161s) $(56.9 \mathrm{mg}, 0.25 \mathrm{mmol}$ ) and 5-phenyloxazol-2(5H)-one (162a) (48.9 mg, $0.30 \mathrm{mmol}$ ). Purification by coloumn chromatography on silica gel ( $n$-hexane/EtOAc: $15 / 1)$ yielded 163sa (44.2 $\mathrm{mg}, 54 \%$ ) as a white solid.

M. p. $=130-131{ }^{\circ} \mathrm{C}^{1}{ }^{1} \mathrm{H}$ NMR $\left(400 \mathrm{MHz}, \mathrm{CDCl}_{3}\right) \delta=8.76(\mathrm{ddd}, J=4.8,1.8,0.9 \mathrm{~Hz}, 1 \mathrm{H}), 8.64-8.55(\mathrm{~m}$, $2 \mathrm{H}), 8.50(\mathrm{dd}, J=1.5,0.7 \mathrm{~Hz}, 1 \mathrm{H}), 8.30-8.20(\mathrm{~m}, 2 \mathrm{H}), 7.93(\mathrm{dt}, J=8.0,1.0 \mathrm{~Hz}, 1 \mathrm{H}), 7.85-7.73(\mathrm{~m}, 1 \mathrm{H})$, 7.57-7.42 (m, 3H), 7.29 (ddd, J = 7.5, 4.8, $1.1 \mathrm{~Hz}, 1 \mathrm{H}), 4.78(\mathrm{q}, J=7.1 \mathrm{~Hz}, 2 \mathrm{H}), 1.58(\mathrm{t}, J=7.1 \mathrm{~Hz}, 3 \mathrm{H})$. 
${ }^{13} \mathrm{C}$ NMR $\left(100 \mathrm{MHz}, \mathrm{CDCl}_{3}\right) \delta=166.7\left(\mathrm{C}_{\mathrm{q}}\right), 160.5\left(\mathrm{C}_{\mathrm{q}}\right), 156.3\left(\mathrm{C}_{\mathrm{q}}\right), 152.3\left(\mathrm{C}_{\mathrm{q}}\right), 148.9(\mathrm{CH}), 144.1\left(\mathrm{C}_{\mathrm{q}}\right)$, $138.3\left(\mathrm{C}_{\mathrm{q}}\right), 136.9(\mathrm{CH}), 130.4(\mathrm{CH}), 128.5(\mathrm{CH}), 128.4(\mathrm{CH}), 125.8(\mathrm{CH}), 125.2(\mathrm{CH}), 124.0(\mathrm{CH}), 122.9$ (CH), $121.3(\mathrm{CH}), 115.4\left(\mathrm{C}_{\mathrm{q}}\right), 62.9\left(\mathrm{CH}_{2}\right), 14.4\left(\mathrm{CH}_{3}\right)$. IR (ATR) $v=2968,1703,1621,1553,1431,1321$, 1261, 1106, 1016, $769 \mathrm{~cm}^{-1}$. MS (ESI) m/z (relative intensity): $328(100)[\mathrm{M}+\mathrm{H}]^{+}, 350$ (30) $[\mathrm{M}+\mathrm{Na}]^{+}$. HR-MS (ESI) $\mathrm{m} / \mathrm{z}$ calcd for $\mathrm{C}_{21} \mathrm{H}_{17} \mathrm{~N}_{3} \mathrm{O}[\mathrm{M}+\mathrm{H}]^{+}:$328.1444, found: 328.1446 .<smiles>CCOc1nc(-c2ccc(Cl)cc2)nc2cc(-c3ccccn3)ccc12</smiles>

2-(4-Chlorophenyl)-4-ethoxy-7-(pyridin-2-yl)quinazoline (163sj): The general procedure C was followed using ethyl 4-(pyridin-2-yl)benzimidate (161s) $(56.6 \mathrm{mg}, 0.25 \mathrm{mmol})$ and 3-(4-chlorophenyl)-1,4,2-dioxazol-5-one (162j) (59.3 mg, $0.30 \mathrm{mmol})$. Purification by coloumn chromatography on silica gel ( $n$-hexane/EtOAc: $5 / 1$ ) yielded $163 \mathrm{sj}(56.0 \mathrm{mg}, 62 \%)$ as a white solid. M. p. $=192-194{ }^{\circ} \mathrm{C} .{ }^{1} \mathrm{H}$ NMR $\left(300 \mathrm{MHz}, \mathrm{CDCl}_{3}\right) \delta=8.78(\mathrm{~d}, J=4.8 \mathrm{~Hz}, 1 \mathrm{H}), 8.53(\mathrm{~d}, J=8.7 \mathrm{~Hz}, 2 \mathrm{H})$, $8.48(\mathrm{~s}, 1 \mathrm{H}), 8.32-8.19(\mathrm{~m}, 2 \mathrm{H}), 7.93(\mathrm{~d}, J=8.0 \mathrm{~Hz}, 1 \mathrm{H}), 7.82(\mathrm{dd}, J=7.7,1.8 \mathrm{~Hz}, 1 \mathrm{H}), 7.47(\mathrm{~d}, J=8.6$ $\mathrm{Hz}, 2 \mathrm{H}), 7.38-7.25(\mathrm{~m}, 1 \mathrm{H}), 4.76(\mathrm{q}, J=7.1 \mathrm{~Hz}, 2 \mathrm{H}), 1.59$ (t, $J=7.1 \mathrm{~Hz}, 3 \mathrm{H}) .{ }^{13} \mathrm{C}$ NMR $\left(75 \mathrm{MHz}, \mathrm{CDCl}_{3}\right)$ $\delta=166.7\left(C_{q}\right), 159.4\left(C_{q}\right), 156.1\left(C_{q}\right), 152.1\left(C_{q}\right), 149.9(C H), 144.2\left(C_{q}\right), 136.9(C H), 136.7\left(C_{q}\right), 136.6$ $\left(\mathrm{C}_{\mathrm{q}}\right), 129.8(\mathrm{CH}), 128.6(\mathrm{CH}), 125.7(\mathrm{CH}), 125.4(\mathrm{CH}), 124.0(\mathrm{CH}), 123.0(\mathrm{CH}), 121.2(\mathrm{CH}), 115.4\left(\mathrm{C}_{\mathrm{q}}\right)$, $63.0\left(\mathrm{CH}_{2}\right), 14.4\left(\mathrm{CH}_{3}\right)$. IR (ATR) $v=2978,1624,1566,1379,1327,1089,1013,990,770,738 \mathrm{~cm}^{-1}$. MS (ESI) m/z (relative intensity): $362(100)[\mathrm{M}+\mathrm{H}]^{+}, 384(10)[\mathrm{M}+\mathrm{Na}]^{+}, 745(10)[2 \mathrm{M}+\mathrm{Na}]^{+}$. HR-MS (ESI) $\mathrm{m} / \mathrm{z}$ calcd for $\mathrm{C}_{21} \mathrm{H}_{17} \mathrm{CIN}_{3} \mathrm{O}[\mathrm{M}+\mathrm{H}]^{+}: 362.1055$, found: 362.1056 .<smiles>CCOc1nc(-c2ccsc2)nc2cc(-c3ccccn3)ccc12</smiles>

4-Ethoxy-7-(pyridin-2-yl)-2-(thiophen-3-yl)quinazoline (163te): The general procedure C was followed using ethyl 4-(pyridin-2-yl)benzimidate (161t) $(56.6 \mathrm{mg}, 0.25 \mathrm{mmol})$ and 3-(thiophen-3-yl)-1,4,2-dioxazol-5-one (162e) (50.7 mg, $0.30 \mathrm{mmol}$ ). Purification by coloumn chromatography on silica gel ( $n$-hexane/EtOAc: $6 / 1$ ) yielded 163 te $(43.2 \mathrm{mg}, 51 \%)$ as a white solid. 
M. p. $=109-111^{\circ} \mathrm{C} .{ }^{1} \mathrm{H}$ NMR $\left(300 \mathrm{MHz}, \mathrm{CDCl}_{3}\right) \delta=8.75$ (ddd, $\left.J=4.8,1.9,1.0 \mathrm{~Hz}, 1 \mathrm{H}\right), 8.41$ (dd, $J=$ 1.6, $0.7 \mathrm{~Hz}, 1 \mathrm{H}), 8.30-8.15(\mathrm{~m}, 2 \mathrm{H}), 8.07(\mathrm{dd}, J=3.7,1.3 \mathrm{~Hz}, 1 \mathrm{H}), 7.92(\mathrm{dd}, J=8.0,1.1 \mathrm{~Hz}, 1 \mathrm{H}), 7.80$ (ddd, $J=8.0,7.5,1.8 \mathrm{~Hz}, 1 \mathrm{H}$ ), 7.46 (dd, $J=5.0,1.3 \mathrm{~Hz}, 1 \mathrm{H}$ ), 7.29 (ddd, $J=7.4,4.8,1.2 \mathrm{~Hz}, 1 \mathrm{H}$ ), 7.15 $(\mathrm{dd}, J=5.0,3.7 \mathrm{~Hz}, 1 \mathrm{H}), 4.73(\mathrm{q}, J=7.1 \mathrm{~Hz}, 2 \mathrm{H}), 1.56(\mathrm{t}, J=7.1 \mathrm{~Hz}, 3 \mathrm{H}) .{ }^{13} \mathrm{C} \mathrm{NMR}\left(125 \mathrm{MHz}, \mathrm{CDCl}_{3}\right) \delta$ $=166.4\left(\mathrm{C}_{\mathrm{q}}\right), 157.1\left(\mathrm{C}_{\mathrm{q}}\right), 156.1\left(\mathrm{C}_{\mathrm{q}}\right), 152.0\left(\mathrm{C}_{\mathrm{q}}\right), 149.7(\mathrm{CH}), 144.2\left(\mathrm{C}_{\mathrm{q}}\right), 144.1\left(\mathrm{C}_{\mathrm{q}}\right), 136.8(\mathrm{CH}), 129.5$ $(\mathrm{CH}), 128.8(\mathrm{CH}), 128.0(\mathrm{CH}), 125.3(\mathrm{CH}), 124.9(\mathrm{CH}), 124.0(\mathrm{CH}), 122.9(\mathrm{CH}), 121.2(\mathrm{CH}), 115.2\left(\mathrm{C}_{\mathrm{q}}\right)$, $63.1\left(\mathrm{CH}_{2}\right), 14.5\left(\mathrm{CH}_{3}\right)$. IR (ATR) $v=3069,2977,1623,1555,1416,1319,1110,846,774,703 \mathrm{~cm}^{-1}$. MS (ESI) m/z (relative intensity): $306(10), 334(100)[\mathrm{M}+\mathrm{H}]^{+}, 356(10)[\mathrm{M}+\mathrm{Na}]^{+}, 689(10)[2 \mathrm{M}+\mathrm{Na}]^{+}$. HR-MS (ESI) m/z calcd for $\mathrm{C}_{19} \mathrm{H}_{16} \mathrm{~N}_{3} \mathrm{OS}[\mathrm{M}+\mathrm{H}]^{+}: 334.1009$, found: 334.1013.

Intermolecular competition experiments between different benzimidates 161<smiles>CCOC(=N)c1ccc(C(F)(F)F)cc1</smiles>

$161 \mathrm{~d} / 161 \mathrm{e}$

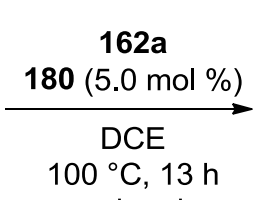

under air

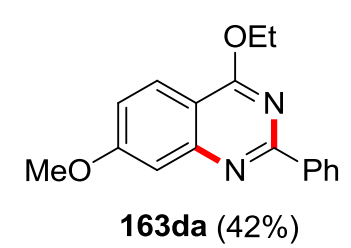

163da (42\%)<smiles>CCOc1nc(-c2ccccc2)nc2cc(C(F)(F)F)ccc12</smiles>

163ea $(24 \%)$

163da : 163ea / $1.75: 1$

(by ${ }^{1} \mathrm{H}$ NMR )

A suspension of ethyl 4-methoxybenzimidate (161d) $(53.8 \mathrm{mg}, 0.3 \mathrm{mmol})$, ethyl 4-(trifluoromethyl)benzimidate (161e) $(65.2 \mathrm{mg}, 0.3 \mathrm{mmol}), 5$-phenyloxazol-2(5H)-one (162a) $(40.8$ $\mathrm{mg}, 0.25 \mathrm{mmol})$ and $\left[\mathrm{Cp}^{*} \mathrm{Co}\left(\mathrm{CH}_{3} \mathrm{CN}\right)_{3}\right]\left(\mathrm{SbF}_{6}\right)_{2}(\mathbf{1 8 0})(6.9 \mathrm{mg}, 5.0 \mathrm{~mol} \%)$ in DCE $(1.0 \mathrm{~mL})$ was stirred under air at $100^{\circ} \mathrm{C}$ for $13 \mathrm{~h}$. After cooling to ambient temperature, the mixture was filtered through a short pad of celite, rinsed with $\mathrm{CH}_{2} \mathrm{Cl}_{2}(20 \mathrm{~mL})$ and concentrated in vacuo. The crude ${ }^{1} \mathrm{H}$ NMR was measured to determine the conversions to the products $163 \mathrm{da}(42 \%)$ and 163ea (24\%) using 1,3,5-trimethoxybenzene $(13.9 \mathrm{mg}, 0.083 \mathrm{mmol})$ as the internal standard. 


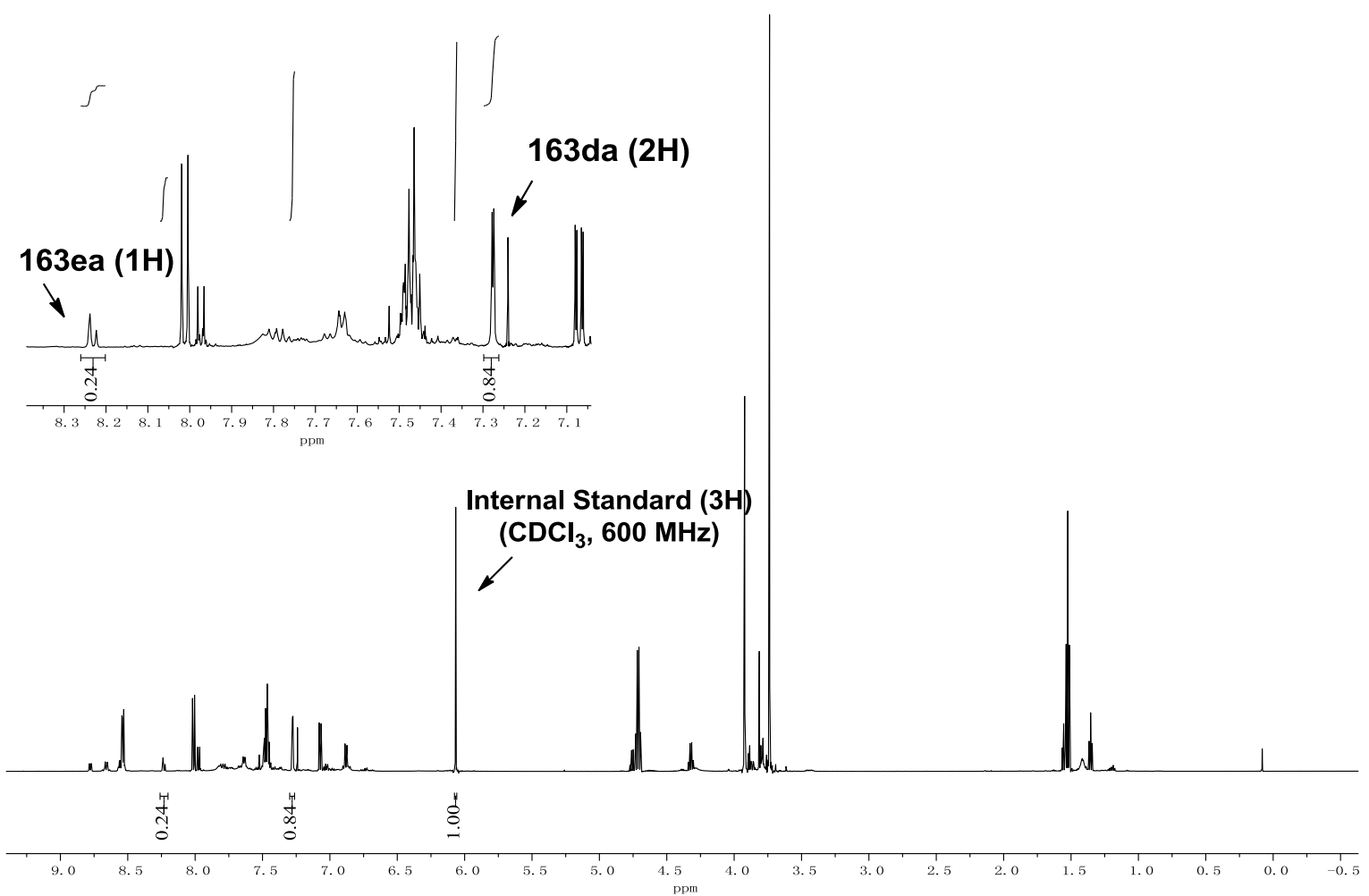

Intermolecular competition experiment between different dioxazolones 162<smiles>COc1cccc(-c2noc(=O)o2)c1</smiles>

$162 \mathrm{~g} / 162 \mathrm{i}$

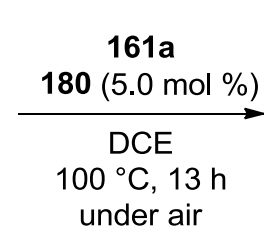

163ag : 163ai / $2.6: 1$

(by ${ }^{1} \mathrm{H}$ NMR)<smiles>CCOc1nc(-c2cccc([N+](=O)[O-])c2)nc2ccccc12</smiles>

163ag (72\%)<smiles>CCOc1nc(-c2cccc(F)c2)nc2ccccc12</smiles>

163ai $(27 \%)$

A suspension of ethyl benzimidate (161a) $(37.3 \mathrm{mg}, 0.25 \mathrm{mmol}), 3$-( $m$-tolyl)-1,4,2-dioxazol-5H-one (162g) (53.2 mg, $0.3 \mathrm{mmol}), 3-(3-f l u o r o p h e n y l)-1,4,2-d i o x a z o l-5 H$-one (162i) (54.4 mg, $0.3 \mathrm{mmol})$ and $\left[\mathrm{Cp}^{*} \mathrm{Co}\left(\mathrm{CH}_{3} \mathrm{CN}\right)_{3}\right]\left(\mathrm{SbF}_{6}\right)_{2}(\mathbf{1 8 0})(6.9 \mathrm{mg}, 5.0 \mathrm{~mol} \%)$ in DCE $(1.0 \mathrm{~mL})$ was stirred under air at $100{ }^{\circ} \mathrm{C}$ for $13 \mathrm{~h}$. After cooling to ambient temperature, the mixture was filtered through a short pad of celite, rinsed with $\mathrm{CH}_{2} \mathrm{Cl}_{2}(20 \mathrm{~mL})$ and concentrated in vacuo. The crude ${ }^{1} \mathrm{H} N M R$ was measured to determine the conversions to the products 163ag (72\%) and 163ai (27\%) using 1,3,5-trimethoxybenzene $(13.9 \mathrm{mg}, 0.083 \mathrm{mmol})$ as the internal standard. 


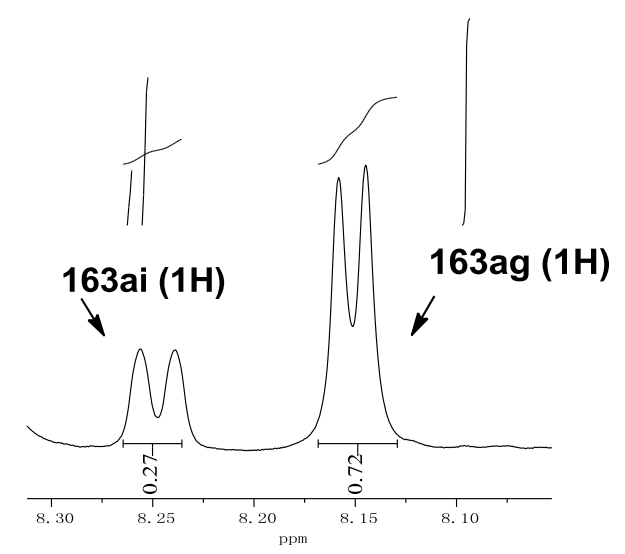

Kinetic Isotope Effect Experiment
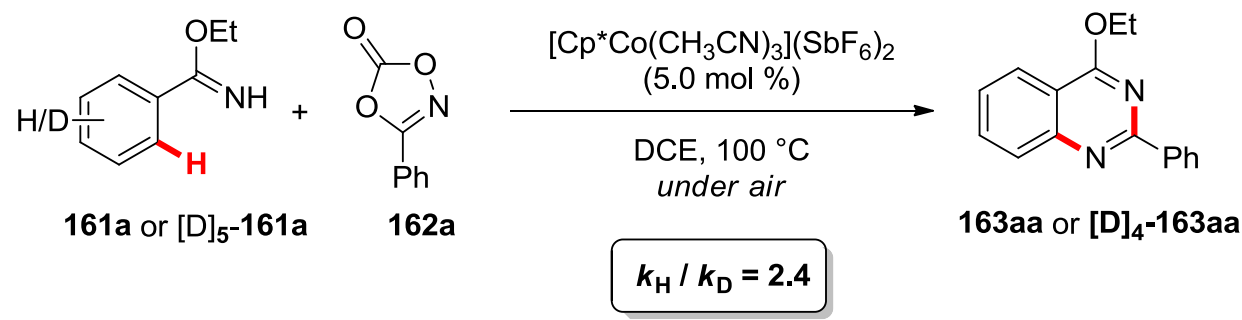

163aa or $[D]_{4}-163 a a$

Two parallel reactions of $162 a$ with $161 a$ or $[D]_{5}-161 a$ were performed to determine the corresponding KIE value. 161a $(37.3 \mathrm{mg}, 0.25 \mathrm{mmol})$ or $[\mathrm{D}]_{5}-161 \mathrm{a}(38.6 \mathrm{mg}, 0.25 \mathrm{mmol})$, 3-phenyl-1,4,2-dioxazol-5H-one (162a) $(48.9 \mathrm{mg}, 0.30 \mathrm{mmol}),\left[\mathrm{Cp}^{*} \mathrm{Co}\left(\mathrm{CH}_{3} \mathrm{CN}\right)_{3}\right]\left(\mathrm{SbF}_{6}\right)_{2}(\mathbf{1 8 0})(6.9 \mathrm{mg}$, $5.0 \mathrm{~mol} \%)$ and 1,3,5-trimethoxybenzene $(42.0 \mathrm{mg}, 0.25 \mathrm{mmol})$ as internal standard and DCE (1.0 mL) were placed in a $25 \mathrm{~mL}$ Schlenk tube. The mixture was stirred at $100{ }^{\circ} \mathrm{C}$, a periodic aliquot $(0.05 \mathrm{~mL})$ was removed by syringe and analyzed by GC to determine the following conversions: 


\begin{tabular}{|c|c|c|c|c|c|}
\hline $\mathrm{t} / \mathrm{min}$ & 5 & 10 & 15 & 20 & 25 \\
\hline yield /\% & 10 & 38 & 56 & 75 & 81 \\
\hline$[\mathrm{D}]_{4}-163 a \mathrm{a}$ & 5 & 17 & 21 & 30 & 34 \\
\hline
\end{tabular}

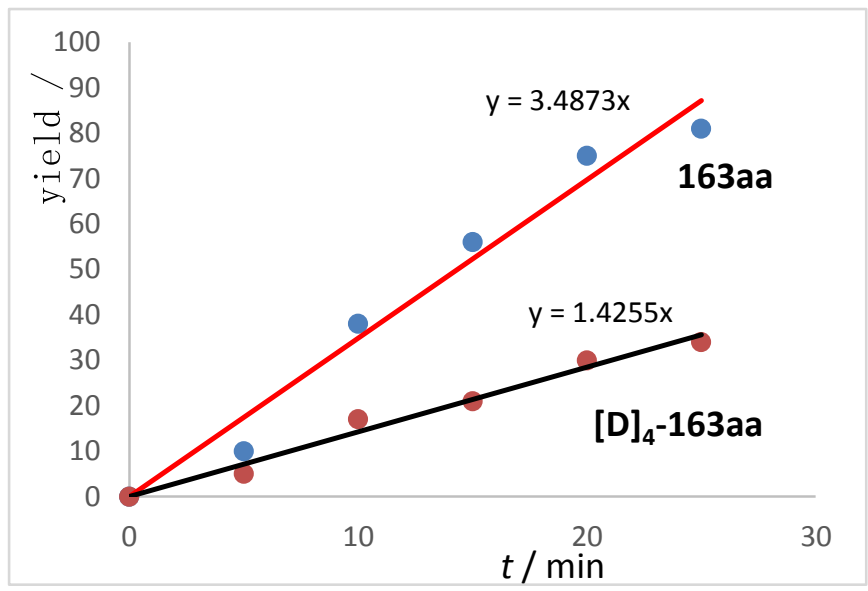

\subsubsection{Data for Cobalt(III)-Catalyzed Domino $\mathrm{C}-\mathrm{H} / \mathrm{N}-\mathrm{H}$ Allylations of Imidates}

\section{Characterization Data}<smiles>C=CC1Cc2cc(OC)ccc2C(OCC)=N1</smiles>

1-Ethoxy-6-methoxy-3-vinyl-3,4-dihydroisoquinoline (164da): The general procedure D was followed using ethyl 4-methoxybenzimidate (161d) $(44.8 \mathrm{mg}, \quad 0.25 \mathrm{mmol})$ and 4-vinyl-1,3-dioxolan-2-one (110a) $(72.0 \mu \mathrm{L}, 0.75 \mathrm{mmol})$. Purification by column chromatography on silica gel ( $n$-pentane/Et 2 O: 20/1) yielded $164 \mathrm{da} \mathrm{(41} \mathrm{mg,} \mathrm{71 \% )} \mathrm{as} \mathrm{a} \mathrm{colorless} \mathrm{oil.}$

${ }^{1} \mathrm{H}$ NMR $\left(300 \mathrm{MHz}, \mathrm{CDCl}_{3}\right) \delta=7.61(\mathrm{~d}, J=8.5 \mathrm{~Hz}, 1 \mathrm{H}), 6.75(\mathrm{dd}, J=8.5,2.5 \mathrm{~Hz}, 1 \mathrm{H}), 6.68(\mathrm{~d}, J=2.5 \mathrm{~Hz}$, 1H), 5.95 (ddd, $J=17.1,10.3,5.9 \mathrm{~Hz}, 1 \mathrm{H}), 5.26(\mathrm{dt}, J=17.1,1.7 \mathrm{~Hz}, 1 \mathrm{H}), 5.07(\mathrm{dt}, J=10.3,1.6 \mathrm{~Hz}, 1 \mathrm{H}$ ), 4.35-4.14 (m, 3H), $3.80(\mathrm{~s}, 3 \mathrm{H}), 2.87$ (dd, J = 15.6, $5.5 \mathrm{~Hz}, 1 \mathrm{H}), 2.62$ (dd, J = 15.6, $9.5 \mathrm{~Hz}, 1 \mathrm{H}), 1.36$ (t, $J=7.1 \mathrm{~Hz}, 3 \mathrm{H}) .{ }^{13} \mathrm{C} \mathrm{NMR}\left(75 \mathrm{MHz}, \mathrm{CDCl}_{3}\right) \delta=161.5\left(\mathrm{C}_{\mathrm{q}}\right), 159.6\left(\mathrm{C}_{\mathrm{q}}\right), 140.3(\mathrm{CH}), 140.2\left(\mathrm{C}_{\mathrm{q}}\right), 126.4(\mathrm{CH})$, $118.8\left(\mathrm{C}_{\mathrm{q}}\right), 114.4\left(\mathrm{CH}_{2}\right), 112.6(\mathrm{CH}), 111.9(\mathrm{CH}), 60.8\left(\mathrm{CH}_{2}\right), 57.0(\mathrm{CH}), 55.3\left(\mathrm{CH}_{3}\right), 33.1\left(\mathrm{CH}_{2}\right), 14.4$ $\left(\mathrm{CH}_{3}\right)$. IR (ATR) $v=2977,2936,1636,1606,1298,1254,1150,1034,918,675 \mathrm{~cm}^{-1}$. MS (ESI) m/z 
(relative intensity): $232(100)[\mathrm{M}+\mathrm{H}]^{+}, 204(40)$. HR-MS (ESI) $\mathrm{m} / \mathrm{z}$ calcd for $\mathrm{C}_{14} \mathrm{H}_{18} \mathrm{NO}_{2}[\mathrm{M}+\mathrm{H}]^{+}$: 232.1332, found: 232.1339 .<smiles>C=CC1Cc2cc(C)ccc2C(OCC)=N1</smiles>

1-Ethoxy-6-methyl-3-vinyl-3,4-dihydroisoquinoline (164ca): The general procedure D was followed using ethyl 4-methylbenzimidate (164c) $(40.8 \mathrm{mg}, 0.25 \mathrm{mmol})$ and 4-vinyl-1,3-dioxolan-2-one (110a) (72.0 $\mu \mathrm{L}, 0.75 \mathrm{mmol})$. Purification by column chromatography on silica gel ( $n$-pentane/Et $\left.{ }_{2} \mathrm{O}: 20 / 1\right)$

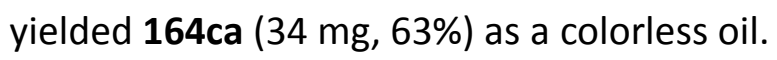

${ }^{1} \mathrm{H}$ NMR $\left(300 \mathrm{MHz}, \mathrm{CDCl}_{3}\right) \delta=7.56(\mathrm{~d}, J=7.8 \mathrm{~Hz}, 1 \mathrm{H}), 7.05(\mathrm{~d}, J=7.8 \mathrm{~Hz}, 1 \mathrm{H}), 6.97(\mathrm{~s}, 1 \mathrm{H}), 5.95$ (ddd, $J=17.0,10.3,5.8 \mathrm{~Hz}, 1 \mathrm{H}), 5.26(\mathrm{dt}, J=17.1,1.7 \mathrm{~Hz}, 1 \mathrm{H}), 5.07(\mathrm{dt}, J=10.3,1.6 \mathrm{~Hz}, 1 \mathrm{H}), 4.42-4.10(\mathrm{~m}$, $3 \mathrm{H}), 2.86(\mathrm{dd}, J=15.6,5.5 \mathrm{~Hz}, 1 \mathrm{H}), 2.61(\mathrm{dd}, J=15.6,9.6 \mathrm{~Hz}, 1 \mathrm{H}), 2.34(\mathrm{~s}, 3 \mathrm{H}), 1.37(\mathrm{t}, J=7.1 \mathrm{~Hz}, 3 \mathrm{H})$. ${ }^{13} \mathrm{C}$ NMR $\left(75 \mathrm{MHz}, \mathrm{CDCl}_{3}\right) \delta=159.8\left(\mathrm{C}_{\mathrm{q}}\right), 141.1\left(\mathrm{C}_{\mathrm{q}}\right), 140.3(\mathrm{CH}), 138.1\left(\mathrm{C}_{\mathrm{q}}\right), 128.0(\mathrm{CH}), 127.4(\mathrm{CH})$, 124.6 (CH), $123.1\left(\mathrm{C}_{\mathrm{q}}\right), 114.4\left(\mathrm{CH}_{2}\right), 60.8\left(\mathrm{CH}_{2}\right), 57.1(\mathrm{CH}), 32.7\left(\mathrm{CH}_{2}\right), 21.5\left(\mathrm{CH}_{3}\right), 14.4\left(\mathrm{CH}_{3}\right)$. IR (ATR) $v=2977,1648,1637,1575,1298,1168,1099,918,827,674 \mathrm{~cm}^{-1}$. MS (ESI) m/z (relative intensity): $216(100)[\mathrm{M}+\mathrm{H}]^{+}, 188$ (40). HR-MS (ESI) m/z calcd for $\mathrm{C}_{14} \mathrm{H}_{18} \mathrm{NO}[\mathrm{M}+\mathrm{H}]^{+}:$216.1383, found: 216.1387.<smiles>C=CC1Cc2cc(C(F)(F)F)ccc2C(OCC)=N1</smiles>

1-Ethoxy-6-(trifluoromethyl)-3-vinyl-3,4-dihydroisoquinoline (164ea): The general procedure D was followed using ethyl 4-(trifluoromethyl)benzimidate (161e) (54.3 mg, $0.25 \mathrm{mmol}$ ) and 4-vinyl-1,3-dioxolan-2-one (110a) $(72.0 \mu \mathrm{L}, 0.75 \mathrm{mmol})$. Purification by column chromatography on silica gel (n-pentane/Et ${ }_{2} \mathrm{O}: 20 / 1$ ) yielded 164 ea (38 mg, 57\%) as a colorless oil.

${ }^{1} \mathrm{H}$ NMR $\left(400 \mathrm{MHz}, \mathrm{CDCl}_{3}\right) \delta=7.77(\mathrm{~d}, J=8.0 \mathrm{~Hz}, 1 \mathrm{H}), 7.51(\mathrm{~d}, J=8.1 \mathrm{~Hz}, 1 \mathrm{H}), 7.42(\mathrm{~s}, 1 \mathrm{H}), 5.93$ (ddd, $J=17.1,10.3,5.8 \mathrm{~Hz}, 1 \mathrm{H}), 5.27(\mathrm{dt}, J=17.1,1.6 \mathrm{~Hz}, 1 \mathrm{H}), 5.10(\mathrm{dt}, J=10.3,1.5 \mathrm{~Hz}, 1 \mathrm{H}), 4.48-4.10(\mathrm{~m}$, 3H), $2.96(\mathrm{dd}, J=15.8,5.6 \mathrm{~Hz}, 1 \mathrm{H}), 2.70(\mathrm{dd}, J=15.8,9.6 \mathrm{~Hz}, 1 \mathrm{H}), 1.38(\mathrm{t}, J=7.1 \mathrm{~Hz}, 3 \mathrm{H}) .{ }^{13} \mathrm{C} \mathrm{NMR}$ $\left(100 \mathrm{MHz} \mathrm{CDCl}_{3}\right) \delta=158.4\left(\mathrm{C}_{\mathrm{q}}\right), 139.5(\mathrm{CH}), 138.8\left(\mathrm{C}_{\mathrm{q}}\right), 132.5\left(\mathrm{q},{ }^{2} \mathrm{~J}=32.1 \mathrm{~Hz}, \mathrm{C}_{\mathrm{q}}\right), 128.5\left(\mathrm{C}_{\mathrm{q}}\right), 125.1$ $(\mathrm{CH}), 124.2\left(q,{ }^{3} \mathrm{~J}=3.7 \mathrm{~Hz}, \mathrm{CH}\right), 123.8\left(q,{ }^{1} \mathrm{~J}=273.3 \mathrm{~Hz}, \mathrm{C}_{\mathrm{q}}\right), 123.7\left(q,{ }^{3} \mathrm{~J}=4.0 \mathrm{~Hz}, \mathrm{CH}\right), 115.0\left(\mathrm{CH}_{2}\right)$, 
$61.3\left(\mathrm{CH}_{2}\right), 56.7(\mathrm{CH}), 32.5\left(\mathrm{CH}_{2}\right), 14.3\left(\mathrm{CH}_{3}\right) .{ }^{19} \mathrm{~F} \mathrm{NMR}\left(376 \mathrm{MHz}, \mathrm{CDCl}_{3}\right) \delta=-62.90$. IR (ATR) $v=2981$, 1651, 1297, 1167, 1125, 1101, 1070, 920, 844, $679 \mathrm{~cm}^{-1}$. MS (ESI) m/z (relative intensity): 270 (100) $[\mathrm{M}+\mathrm{H}]^{+}, 242$ (40). HR-MS (ESI) m/z calcd for $\mathrm{C}_{14} \mathrm{H}_{15} \mathrm{~F}_{3} \mathrm{NO}[\mathrm{M}+\mathrm{H}]^{+}:$270.1100, found: 270.1110 .<smiles>C=CC1Cc2cc(-c3ccc(C)cc3)ccc2C(OCC)=N1</smiles>

1-Ethoxy-6-(p-tolyl)-3-vinyl-3,4-dihydroisoquinoline (164ua): The general procedure D was followed using ethyl 4'-methyl-(1,1'-biphenyl)-4-carbimidate (161u) (59.8 mg, $0.25 \mathrm{mmol}$ ) and 4-vinyl-1,3-dioxolan-2-one (110a) $(72.0 \mu \mathrm{L}, 0.75 \mathrm{mmol})$. Purification by column chromatography on silica gel ( $n$-pentane/Et ${ }_{2} \mathrm{O}: 20 / 1$ ) yielded $164 \mathrm{ua} \mathrm{(37.9} \mathrm{mg,52 \% )} \mathrm{as} \mathrm{a} \mathrm{white} \mathrm{solid.}$

M.p. $=64-66{ }^{\circ} \mathrm{C} .{ }^{1} \mathrm{H}$ NMR $\left(300 \mathrm{MHz}, \mathrm{CDCl}_{3}\right) \delta=7.73(\mathrm{~d}, J=8.0 \mathrm{~Hz}, 1 \mathrm{H}), 7.55-7.44(\mathrm{~m}, 3 \mathrm{H}), 7.38(\mathrm{~s}$, 1H), $7.24(\mathrm{~d}, J=7.9 \mathrm{~Hz}, 2 \mathrm{H}), 5.99(\mathrm{ddd}, J=17.0,10.3,5.9 \mathrm{~Hz}, 1 \mathrm{H}), 5.30(\mathrm{dt}, J=17.0,1.6 \mathrm{~Hz}, 1 \mathrm{H}), 5.10$ (dt, $J=10.3,1.6 \mathrm{~Hz}, 1 \mathrm{H}), 4.65-4.12(\mathrm{~m}, 3 \mathrm{H}), 2.97(\mathrm{dd}, J=15.7,5.6 \mathrm{~Hz}, 1 \mathrm{H}), 2.72(\mathrm{dd}, J=15.7,9.6 \mathrm{~Hz}$, $1 \mathrm{H}), 2.39(\mathrm{~s}, 3 \mathrm{H}), 1.40(\mathrm{t}, J=7.1 \mathrm{~Hz}, 3 \mathrm{H}) .{ }^{13} \mathrm{C} \mathbf{N M R}\left(75 \mathrm{MHz}, \mathrm{CDCl}_{3}\right) \delta=159.7\left(\mathrm{C}_{\mathrm{q}}\right), 143.7\left(\mathrm{C}_{\mathrm{q}}\right), 140.1$ $(\mathrm{CH}), 138.6\left(\mathrm{C}_{\mathrm{q}}\right), 137.7\left(\mathrm{C}_{\mathrm{q}}\right), 137.4\left(\mathrm{C}_{\mathrm{q}}\right), 129.5(\mathrm{CH}), 127.0(\mathrm{CH}), 125.8(\mathrm{CH}), 125.3(\mathrm{CH}), 125.2(\mathrm{CH})$, $124.2\left(\mathrm{C}_{\mathrm{q}}\right), 114.7\left(\mathrm{CH}_{2}\right), 61.2\left(\mathrm{CH}_{2}\right), 57.0(\mathrm{CH}), 32.9\left(\mathrm{CH}_{2}\right), 21.1\left(\mathrm{CH}_{3}\right), 14.4\left(\mathrm{CH}_{3}\right)$. IR (ATR) $v=2977$, 1634, 1314, 1291, 1100, 919, 814, $674 \mathrm{~cm}^{-1}$. MS (ESI) m/z (relative intensity): 292 (100) [M+H] ${ }^{+}, 264$ (20). HR-MS (ESI) m/z calcd for $\mathrm{C}_{20} \mathrm{H}_{22} \mathrm{NO}[\mathrm{M}+\mathrm{H}]^{+}: 292.1696$, found: 292.1697.<smiles>C=CC1Cc2cc(Cl)ccc2C(OCC)=N1</smiles>

6-Chloro-1-ethoxy-3-vinyl-3,4-dihydroisoquinoline (164ga): The general procedure D was followed using ethyl 4-chlorobenzimidate (161g) $(45.9 \mathrm{mg}, 0.25 \mathrm{mmol}$ ) and 4-vinyl-1,3-dioxolan-2-one (110a) $(72.0 \mu \mathrm{L}, 0.75 \mathrm{mmol})$. Purification by column chromatography on silica gel ( $n$-pentane/Et $\left.{ }_{2} \mathrm{O}: 30 / 1\right)$ yielded 164ga (38 $\mathrm{mg}, 64 \%$ ) as a colorless oil.

${ }^{1} \mathrm{H}$ NMR $\left(400 \mathrm{MHz}^{\mathrm{CDCl}}{ }_{3}\right) \delta=7.60(\mathrm{~d}, J=8.2 \mathrm{~Hz}, 1 \mathrm{H}), 7.22(\mathrm{dt}, J=8.2,2.1 \mathrm{~Hz}, 1 \mathrm{H}), 7.15(\mathrm{~d}, J=2.1 \mathrm{~Hz}$, 1H), 5.92 (ddd, $J=17.1,10.3,5.8 \mathrm{~Hz}, 1 \mathrm{H}$ ), 5.25 (dt, $J=17.1,1.6 \mathrm{~Hz}, 1 \mathrm{H}$ ), 5.08 (dt, $J=10.3,1.6 \mathrm{~Hz}, 1 \mathrm{H}$ ), 4.49-4.06 (m, 3H), 2.87 (dd, $J=15.8,5.6 \mathrm{~Hz}, 1 \mathrm{H}), 2.62(\mathrm{dd}, J=15.8,9.6 \mathrm{~Hz}, 1 \mathrm{H}), 1.36(\mathrm{t}, J=7.1 \mathrm{~Hz}$, 
3H). ${ }^{13} \mathrm{C}$ NMR $\left(100 \mathrm{MHz}, \mathrm{CDCl}_{3}\right) \delta=158.8\left(\mathrm{C}_{\mathrm{q}}\right), 140.0\left(\mathrm{C}_{\mathrm{q}}\right), 139.7(\mathrm{CH}), 136.6\left(\mathrm{C}_{\mathrm{q}}\right), 127.4(\mathrm{CH}), 126.9$ (CH), $126.1(\mathrm{CH}), 124.1\left(\mathrm{C}_{\mathrm{q}}\right), 114.8\left(\mathrm{CH}_{2}\right), 61.1\left(\mathrm{CH}_{2}\right), 56.8(\mathrm{CH}), 32.5\left(\mathrm{CH}_{2}\right), 14.3\left(\mathrm{CH}_{3}\right)$. IR (ATR) $v=$ 2978, 1638, 1595, 1294, 1103, 920, 830, $665 \mathrm{~cm}^{-1}$. MS (ESI) m/z (relative intensity): 236 (100) $[\mathrm{M}+\mathrm{H}]^{+}, 208$ (60). HR-MS (ESI) m/z calcd for $\mathrm{C}_{13} \mathrm{H}_{15} \mathrm{NOCl}[\mathrm{M}+\mathrm{H}]^{+}:$236.0837, found: 236.0840.<smiles>C=CC1Cc2cc(Br)ccc2C(OCC)=N1</smiles>

6-Bromo-1-ethoxy-3-vinyl-3,4-dihydroisoquinoline (164va): The general procedure D was followed using ethyl 4-bromobenzimidate (161v) (57.1 mg, $0.25 \mathrm{mmol}$ ) and 4-vinyl-1,3-dioxolan-2-one (110a) $(72.0 \mu \mathrm{L}, 0.75 \mathrm{mmol})$. Purification by column chromatography on silica gel ( $n$-pentane/Et $\left.{ }_{2} \mathrm{O}: 20 / 1\right)$ yielded $164 \mathrm{va} \mathrm{(50} \mathrm{mg}, 71 \%$ ) as a colorless oil.

${ }^{1} \mathrm{H}$ NMR $\left(300 \mathrm{MHz}, \mathrm{CDCl}_{3}\right) \delta=7.52(\mathrm{~d}, J=8.2 \mathrm{~Hz}, 1 \mathrm{H}), 7.38(\mathrm{dd}, J=8.2,2.0 \mathrm{~Hz}, 1 \mathrm{H}), 7.31(\mathrm{~d}, J=2.0 \mathrm{~Hz}$, 1H), 5.92 (ddd, $J=17.1,10.3,5.8 \mathrm{~Hz}, 1 \mathrm{H}), 5.25(\mathrm{dt}, J=17.1,1.6 \mathrm{~Hz}, 1 \mathrm{H}), 5.08(\mathrm{dt}, J=10.3,1.6 \mathrm{~Hz}, 1 \mathrm{H}$ ), 4.46-4.12 (m, 3H), 2.87 (dd, $J=15.8,5.6 \mathrm{~Hz}, 1 \mathrm{H}), 2.62$ (dd, $J=15.8,9.5 \mathrm{~Hz}, 1 \mathrm{H}), 1.36$ (t, J = 7.1 Hz, 3H). ${ }^{13} \mathrm{C}$ NMR $\left(75 \mathrm{MHz}, \mathrm{CDCl}_{3}\right) \delta=158.9\left(\mathrm{C}_{\mathrm{q}}\right), 140.1\left(\mathrm{C}_{\mathrm{q}}\right), 139.7(\mathrm{CH}), 130.3(\mathrm{CH}), 129.9(\mathrm{CH}), 126.3$ (CH), $125.0\left(\mathrm{C}_{\mathrm{q}}\right), 124.5\left(\mathrm{C}_{\mathrm{q}}\right), 114.8\left(\mathrm{CH}_{2}\right), 61.1\left(\mathrm{CH}_{2}\right), 56.8(\mathrm{CH}), 32.3\left(\mathrm{CH}_{2}\right), 14.3\left(\mathrm{CH}_{3}\right)$. IR (ATR) $v=$ 2938, 2898, 1638, 1588, 1366, 1273, 1101, 918, 828, $665 \mathrm{~cm}^{-1}$. MS (ESI) m/z (relative intensity): 282 (98) $[\mathrm{M}+\mathrm{H}]^{+}\left({ }^{81} \mathrm{Br}\right), 280(100)[\mathrm{M}+\mathrm{H}]{ }^{+}\left({ }^{79} \mathrm{Br}\right), 254(48)\left({ }^{81} \mathrm{Br}\right), 252(50)\left({ }^{79} \mathrm{Br}\right)$. HR-MS (ESI) m/z calcd for $\mathrm{C}_{13} \mathrm{H}_{15} \mathrm{NO}^{79} \mathrm{Br} \quad[\mathrm{M}+\mathrm{H}]^{+}$: 280.0332, found: 280.0333, $\mathrm{C}_{13} \mathrm{H}_{15} \mathrm{NO}^{81} \mathrm{Br}[\mathrm{M}+\mathrm{H}]^{+}$: 282.0311, found: 282.0313 .<smiles>C=CC1Cc2cc(C(=O)OC)ccc2C(OC)=N1</smiles>

Methyl 1-methoxy-3-vinyl-3,4-dihydroisoquinoline-6-carboxylate (164ia): The general procedure D was followed using methyl 4-[imino(methoxy)methyl]benzoate (161i) $(48.3 \mathrm{mg}, 0.25 \mathrm{mmol}$ ) and 4-vinyl-1,3-dioxolan-2-one (110a) $(72.0 \mu \mathrm{L}, 0.75 \mathrm{mmol})$. Purification by column chromatography on silica gel ( $n$-pentane/Et ${ }_{2} \mathrm{O}: 20 / 1$ ) yielded 164ia (38 mg, 71\%) as a white solid.

M.p. $=56-58{ }^{\circ} \mathrm{C}^{1}{ }^{\mathrm{H}} \mathrm{NMR}\left(300 \mathrm{MHz}, \mathrm{CDCl}_{3}\right) \delta=7.92(\mathrm{dd}, J=8.0,1.6 \mathrm{~Hz}, 1 \mathrm{H}), 7.84(\mathrm{~s}, 1 \mathrm{H}), 7.70(\mathrm{~d}, J=$ 
$8.0 \mathrm{~Hz}, 1 \mathrm{H}$ ), 5.94 (ddd, $J=17.1,10.3,5.7 \mathrm{~Hz}, 1 \mathrm{H}$ ), 5.27 (dt, $J=17.1,1.6 \mathrm{~Hz}, 1 \mathrm{H}), 5.09$ (dt, $J=10.3,1.6$ $\mathrm{Hz}, 1 \mathrm{H}$ ), 4.25 (ddd, J = 9.5, 5.7, $1.5 \mathrm{~Hz}, 1 \mathrm{H}), 3.90(\mathrm{~s}, 3 \mathrm{H}), 3.88(\mathrm{~s}, 3 \mathrm{H}), 2.96(\mathrm{dd}, J=15.8,5.7 \mathrm{~Hz}, 1 \mathrm{H}$ ), $2.69(\mathrm{dd}, J=15.7,9.7 \mathrm{~Hz}, 1 \mathrm{H}) .{ }^{13} \mathrm{C}$ NMR $\left(75 \mathrm{MHz}, \mathrm{CDCl}_{3}\right) \delta=166.5\left(\mathrm{C}_{\mathrm{q}}\right), 159.3\left(\mathrm{C}_{\mathrm{q}}\right), 139.6(\mathrm{CH}), 138.2$ $\left(\mathrm{C}_{\mathrm{q}}\right), 132.0\left(\mathrm{C}_{\mathrm{q}}\right), 129.0\left(\mathrm{C}_{\mathrm{q}}\right), 128.4(\mathrm{CH}), 128.1(\mathrm{CH}), 124.6(\mathrm{CH}), 114.9\left(\mathrm{CH}_{2}\right), 56.8(\mathrm{CH}), 52.9\left(\mathrm{CH}_{3}\right)$, $52.3\left(\mathrm{CH}_{3}\right), 32.5\left(\mathrm{CH}_{2}\right)$. IR (ATR) $v=2947,1724,1651,1433,1289,1266,1197,1114,906,736 \mathrm{~cm}^{-1}$. MS (ESI) m/z (relative intensity): $246(100)[M+H]^{+}$. HR-MS (ESI) m/z calcd for $\mathrm{C}_{14} \mathrm{H}_{16} \mathrm{NO}_{3}[\mathrm{M}+\mathrm{H}]^{+}$: 246.1125, found: 246.1125 .<smiles>C=CC1Cc2cc(C(C)=O)ccc2C(OCC)=N1</smiles>

1-(1-Ethoxy-3-vinyl-3,4-dihydroisoquinolin-6-yl)ethanone (164ha): The general procedure D was followed using ethyl 4-acetylbenzimidate $(161 \mathrm{~h}) \quad(47.8 \mathrm{mg}, 0.25 \mathrm{mmol})$ and 4-vinyl-1,3-dioxolan-2-one (110a) $(72.0 \mu \mathrm{L}, 0.75 \mathrm{mmol})$. Purification by column chromatography on silica gel ( $n$-pentane/Et ${ }_{2} \mathrm{O}: 20 / 1 \rightarrow 10 / 1$ ) yielded $164 \mathrm{ha}(37 \mathrm{mg}, 61 \%)$ as a colorless oil.

${ }^{1} \mathbf{H}$ NMR $\left(300 \mathrm{MHz}, \mathrm{CDCl}_{3}\right) \delta=7.82(\mathrm{dd}, J=8.1,1.7 \mathrm{~Hz}, 1 \mathrm{H}), 7.77-7.68(\mathrm{~m}, 2 \mathrm{H}), 5.92(\mathrm{ddd}, J=17.1$, 10.3, $5.7 \mathrm{~Hz}, 1 \mathrm{H}), 5.25(\mathrm{dt}, J=17.1,1.6 \mathrm{~Hz}, 1 \mathrm{H}), 5.08(\mathrm{dt}, J=10.3,1.5 \mathrm{~Hz}, 1 \mathrm{H}), 4.50-4.10(\mathrm{~m}, 3 \mathrm{H})$, $2.96(\mathrm{dd}, J=15.7,5.6 \mathrm{~Hz}, 1 \mathrm{H}), 2.69(\mathrm{dd}, J=15.7,9.5 \mathrm{~Hz}, 1 \mathrm{H}), 2.58(\mathrm{~s}, 3 \mathrm{H}), 1.38(\mathrm{t}, J=7.1 \mathrm{~Hz}, 3 \mathrm{H}) .{ }^{13} \mathrm{C}$ $\operatorname{NMR}\left(75 \mathrm{MHz}, \mathrm{CDCl}_{3}\right) \delta=197.6\left(\mathrm{C}_{\mathrm{q}}\right), 158.7\left(\mathrm{C}_{\mathrm{q}}\right), 139.6(\mathrm{CH}), 138.6\left(\mathrm{C}_{\mathrm{q}}\right), 138.4\left(\mathrm{C}_{\mathrm{q}}\right), 129.2\left(\mathrm{C}_{\mathrm{q}}\right), 127.0$ (CH), $126.9(\mathrm{CH}), 124.8(\mathrm{CH}), 114.8\left(\mathrm{CH}_{2}\right), 61.2\left(\mathrm{CH}_{2}\right), 56.8(\mathrm{CH}), 32.5\left(\mathrm{CH}_{2}\right), 26.7\left(\mathrm{CH}_{3}\right), 14.3\left(\mathrm{CH}_{3}\right)$. IR (ATR) $v=2978,1685,1637,1421,1359,1300,1280,1105,918,671 \mathrm{~cm}^{-1}$. MS (ESI) m/z (relative intensity): $266(60)[\mathrm{M}+\mathrm{Na}]^{+}, 244(100)[\mathrm{M}+\mathrm{H}]^{+}, 216$ (50). HR-MS (ESI) m/z calcd for $\mathrm{C}_{15} \mathrm{H}_{18} \mathrm{NO}_{2}$ $[\mathrm{M}+\mathrm{H}]^{+}:$244.1332, found: 244.1334 .<smiles>C=CC1Cc2cc(NC(=O)C(C)(C)C)ccc2C(OCC)=N1</smiles>

N-(1-Ethoxy-3-vinyl-3,4-dihydroisoquinolin-6-yl)pivalamide (164pa): The general procedure D was followed using ethyl 4-pivalamidobenzimidate (161p) $(62.1 \mathrm{mg}, \quad 0.25 \mathrm{mmol})$ and 
4-vinyl-1,3-dioxolan-2-one (110a) $(72.0 \mu \mathrm{L}, 0.75 \mathrm{mmol})$. Purification by column chromatography on silica gel ( $n$-pentane/Et ${ }_{2} \mathrm{O}: 4 / 1$ ) yielded $164 \mathrm{pa} \mathrm{(61} \mathrm{mg,} \mathrm{81 \% )} \mathrm{as} \mathrm{a} \mathrm{white} \mathrm{solid.}$

M.p. $=54-56{ }^{\circ} \mathrm{C}^{1}{ }^{1} \mathrm{H}$ NMR $\left(400 \mathrm{MHz}, \mathrm{CDCl}_{3}\right) \delta=7.61(\mathrm{~d}, J=8.4 \mathrm{~Hz}, 1 \mathrm{H}), 7.57(\mathrm{~d}, J=2.3 \mathrm{~Hz}, 1 \mathrm{H}), 7.37$ (brs, 1H), 7.25 (dd, $J=8.4,2.3 \mathrm{~Hz}, 1 \mathrm{H}$ ), 5.91 (ddd, $J=17.1,10.3,5.8 \mathrm{~Hz}, 1 \mathrm{H}$ ), 5.23 (dt, J=17.1, $1.7 \mathrm{~Hz}$, 1H), $5.05(\mathrm{dt}, J=10.3,1.7 \mathrm{~Hz}, 1 \mathrm{H}), 4.43-4.08(\mathrm{~m}, 3 \mathrm{H}), 2.88(\mathrm{dd}, J=15.7,5.6 \mathrm{~Hz}, 1 \mathrm{H}), 2.62(\mathrm{dd}, J=$ 15.7, $9.2 \mathrm{~Hz}, 1 \mathrm{H}), 1.36(\mathrm{t}, J=7.1 \mathrm{~Hz}, 3 \mathrm{H}), 1.29(\mathrm{~s}, 9 \mathrm{H}) .{ }^{13} \mathrm{C}$ NMR $\left(100 \mathrm{MHz}, \mathrm{CDCl}_{3}\right) \delta=176.7\left(\mathrm{C}_{\mathrm{q}}\right), 159.3$ $\left(\mathrm{C}_{\mathrm{q}}\right), 140.2\left(\mathrm{C}_{\mathrm{q}}\right), 140.0(\mathrm{CH}), 139.5\left(\mathrm{C}_{\mathrm{q}}\right), 125.6(\mathrm{CH}), 121.6\left(\mathrm{C}_{\mathrm{q}}\right), 118.2(\mathrm{CH}), 117.4(\mathrm{CH}), 114.6\left(\mathrm{CH}_{2}\right)$, $60.9\left(\mathrm{CH}_{2}\right), 56.9(\mathrm{CH}), 39.7\left(\mathrm{C}_{\mathrm{q}}\right), 32.9\left(\mathrm{CH}_{2}\right), 27.6\left(\mathrm{CH}_{3}\right), 14.4\left(\mathrm{CH}_{3}\right)$. IR (ATR) $v=3331,2973,1650$, 1636, 1585, 1520, 1302, 1166, 917, $732 \mathrm{~cm}^{-1}$. MS (ESI) m/z (relative intensity): 323 (25) [M+Na] , 301 (100) $[\mathrm{M}+\mathrm{H}]^{+}, 273$ (10). HR-MS (ESI) m/z calcd for $\mathrm{C}_{18} \mathrm{H}_{25} \mathrm{~N}_{2} \mathrm{O}_{2}[\mathrm{M}+\mathrm{H}]^{+}: 301.1911$, found: 301.1914.<smiles>C=CC1Cc2ccccc2C(OC)=N1</smiles>

1-Methoxy-3-vinyl-3,4-dihydroisoquinoline (164ba): The general procedure D was followed using methyl benzimidate (161b) (33.8 mg, $0.25 \mathrm{mmol}$ ) and 4-vinyl-1,3-dioxolan-2-one (110a) (72.0 $\mu \mathrm{L}$, $0.75 \mathrm{mmol}$ ). Purification by column chromatography on silica gel (n-pentane/Et $\left.{ }_{2} \mathrm{O}: 20 / 1\right)$ yielded 164ba (27 mg, 58\%) as a colorless oil.

${ }^{1} \mathrm{H}$ NMR $\left(300 \mathrm{MHz}, \mathrm{CDCl}_{3}\right) \delta=7.65(\mathrm{dd}, J=7.5,1.5 \mathrm{~Hz}, 1 \mathrm{H}), 7.35$ (td, $\left.J=7.4,1.5 \mathrm{~Hz}, 1 \mathrm{H}\right), 7.29-7.21$ (m, 1H), $7.17(\mathrm{~d}, J=8.0 \mathrm{~Hz}, 1 \mathrm{H}), 5.97$ (ddd $J=17.1,10.3,5.8 \mathrm{~Hz}, 1 \mathrm{H}), 5.29(\mathrm{dt}, J=17.1,1.7 \mathrm{~Hz}, 1 \mathrm{H})$, 5.09 (dt, $J=10.3,1.7 \mathrm{~Hz}, 1 \mathrm{H}), 4.22$ (ddd, $J=9.9,5.7,1.5 \mathrm{~Hz}, 1 \mathrm{H}), 3.88(\mathrm{~s}, 3 \mathrm{H}), 2.91$ (dd, $J=15.7,5.7$ $\mathrm{Hz}, 1 \mathrm{H}), 2.66(\mathrm{dd}, J=15.7,9.9 \mathrm{~Hz}, 1 \mathrm{H}) .{ }^{13} \mathrm{C}$ NMR $\left(75 \mathrm{MHz}, \mathrm{CDCl}_{3}\right) \delta=160.0\left(\mathrm{C}_{\mathrm{q}}\right), 140.1(\mathrm{CH}), 138.1$ $\left(\mathrm{C}_{\mathrm{q}}\right), 130.9(\mathrm{CH}), 127.3(\mathrm{CH}), 126.7(\mathrm{CH}), 125.5\left(\mathrm{C}_{\mathrm{q}}\right), 124.6(\mathrm{CH}), 114.6\left(\mathrm{CH}_{2}\right), 57.0(\mathrm{CH}), 52.7\left(\mathrm{CH}_{3}\right)$, $32.7\left(\mathrm{CH}_{2}\right)$. IR (ATR) $v=2942,1650,1638,1436,1310,1901,919,738,671 \mathrm{~cm}^{-1} . \mathrm{MS}$ (ESI) m/z (relative intensity): $188(100)[\mathrm{M}+\mathrm{H}]^{+}$. HR-MS (ESI) m/z calcd for $\mathrm{C}_{12} \mathrm{H}_{14} \mathrm{NO}[\mathrm{M}+\mathrm{H}]^{+}: 188.1070$, found: 188.1071. 
<smiles>C=CC1Cc2ccccc2C(OCC)=N1</smiles>

1-Ethoxy-3-vinyl-3,4-dihydroisoquinoline (164aa): The general procedure D was followed using ethyl benzimidate (161a) (37.3 mg, $0.25 \mathrm{mmol}$ ) and 4-vinyl-1,3-dioxolan-2-one (110a) $(72.0 \mu \mathrm{L}, 0.75$ mmol). Purification by column chromatography on silica gel ( $n$-pentane/Et ${ }_{2} \mathrm{O}: 20 / 1$ ) yielded 164aa (36 mg, 72\%) as a colorless oil.

${ }^{1} \mathrm{H}$ NMR $\left(500 \mathrm{MHz}, \mathrm{CDCl}_{3}\right) \delta=7.68(\mathrm{dd}, J=7.7,1.4 \mathrm{~Hz}, 1 \mathrm{H}), 7.34(\mathrm{td}, J=7.5,1.4 \mathrm{~Hz}, 1 \mathrm{H}), 7.25(\mathrm{~d}, J=$ $7.2 \mathrm{~Hz}, 1 \mathrm{H}), 7.16$ (d, J = 7.4 Hz, 1H), 5.96 (ddd, $J=17.1,10.3,5.8 \mathrm{~Hz}, 1 \mathrm{H}), 5.28(\mathrm{dt}, J=17.1,1.6 \mathrm{~Hz}$, 1H), 5.08 (dt, $J=10.3,1.6 \mathrm{~Hz}, 1 \mathrm{H}), 4.45-4.07(\mathrm{~m}, 3 \mathrm{H}), 2.90$ (dd, $J=15.6,5.5 \mathrm{~Hz}, 1 \mathrm{H}), 2.65$ (dd, $J=$ 15.6, $9.8 \mathrm{~Hz}, 1 \mathrm{H}), 1.38(\mathrm{t}, J=7.1 \mathrm{~Hz}, 3 \mathrm{H}) .{ }^{13} \mathrm{C} \mathrm{NMR}\left(75 \mathrm{MHz}, \mathrm{CDCl}_{3}\right) \delta=159.5\left(\mathrm{C}_{\mathrm{q}}\right), 140.2(\mathrm{CH}), 138.1$ $\left(\mathrm{C}_{\mathrm{q}}\right), 130.8(\mathrm{CH}), 127.2(\mathrm{CH}), 126.7(\mathrm{CH}), 125.7\left(\mathrm{C}_{\mathrm{q}}\right), 124.6(\mathrm{CH}), 114.5\left(\mathrm{CH}_{2}\right), 60.9\left(\mathrm{CH}_{2}\right), 57.0(\mathrm{CH})$, $32.7\left(\mathrm{CH}_{2}\right), 14.4\left(\mathrm{CH}_{3}\right)$. IR (ATR) $v=2978,1649,1638,1366,1300,1093,917,738,680 \mathrm{~cm}^{-1}$. MS (ESI) m/z (relative intensity): $202(100)[\mathrm{M}+\mathrm{H}]^{+}, 174(75)$. HR-MS (ESI) m/z calcd for $\mathrm{C}_{13} \mathrm{H}_{16} \mathrm{NO}[\mathrm{M}+\mathrm{H}]^{+}$: 202.1226, found: 202.1230 .<smiles>C=CC1Cc2ccccc2C(OC(C)C)=N1</smiles>

1-Isopropoxy-3-vinyl-3,4-dihydroisoquinoline (164wa): The general procedure D was followed using isopropyl benzimidate (161w) (40.8 mg, $0.25 \mathrm{mmol}$ ) and 4-vinyl-1,3-dioxolan-2-one (110a) (72.0 $\mu \mathrm{L}, 0.75 \mathrm{mmol})$. Purification by column chromatography on silica gel ( $n$-pentane/Et $\left.{ }_{2} \mathrm{O}: 20 / 1\right)$ yielded 164wa (36 mg, 67\%) as a colorless oil.

${ }^{1} \mathrm{H}$ NMR $\left(300 \mathrm{MHz}, \mathrm{CDCl}_{3}\right) \delta=7.67(\mathrm{dd}, J=7.5,1.5 \mathrm{~Hz}, 1 \mathrm{H}), 7.33$ (ddd, $\left.J=7.7,7.5,1.5 \mathrm{~Hz}, 1 \mathrm{H}\right), 7.25$ (ddd, $J=7.7,7.5,1.5 \mathrm{~Hz}, 1 \mathrm{H}$ ), $7.15(\mathrm{~d}, J=7.3 \mathrm{~Hz}, 1 \mathrm{H}$ ), 5.96 (ddd, $J=17.2,10.3,5.7 \mathrm{~Hz}, 1 \mathrm{H}$ ), 5.42-5.20 (m, 2H), $5.07(\mathrm{dt}, J=10.3,1.7 \mathrm{~Hz}, 1 \mathrm{H}), 4.27-4.16(\mathrm{~m}, 1 \mathrm{H}), 2.90(\mathrm{dd}, J=15.6,5.5 \mathrm{~Hz}, 1 \mathrm{H}), 2.64(\mathrm{dd}, J=$ 15.6, 9.7 Hz, 1H), $1.34(\mathrm{~d}, J=6.2 \mathrm{~Hz}, 6 \mathrm{H}) .{ }^{13} \mathrm{C} \mathrm{NMR}\left(75 \mathrm{MHz}, \mathrm{CDCl}_{3}\right) \delta=158.7\left(\mathrm{C}_{\mathrm{q}}\right), 140.4(\mathrm{CH}), 138.2$ $\left(\mathrm{C}_{\mathrm{q}}\right), 130.7(\mathrm{CH}), 127.2(\mathrm{CH}), 126.6(\mathrm{CH}), 126.1\left(\mathrm{C}_{\mathrm{q}}\right), 124.7(\mathrm{CH}), 114.4\left(\mathrm{CH}_{2}\right), 67.0(\mathrm{CH}), 56.9(\mathrm{CH})$, $32.7\left(\mathrm{CH}_{2}\right), 22.0\left(\mathrm{CH}_{3}\right), 21.8\left(\mathrm{CH}_{3}\right)$. IR (ATR) $v=2975,1637,1359,1298,1114,1089,918,778,739$, $682 \mathrm{~cm}^{-1} . \mathrm{MS}(\mathrm{ESI}) \mathrm{m} / \mathrm{z}$ (relative intensity): $238(10)[\mathrm{M}+\mathrm{Na}]^{+}, 216(10)[\mathrm{M}+\mathrm{H}]^{+}, 196(20), 174(100)$. HR-MS (ESI) $\mathrm{m} / \mathrm{z}$ calcd for $\mathrm{C}_{14} \mathrm{H}_{18} \mathrm{NO}[\mathrm{M}+\mathrm{H}]^{+}: 216.1383$, found: 216.1385 . 
<smiles>CCOC1=NC(/C=C/c2ccccc2)Cc2ccccc21</smiles>

(E)-1-Ethoxy-3-styryl-3,4-dihydroisoquinoline (164ab): The general procedure D was followed using ethyl benzimidate (161a) (37.3 mg, $0.25 \mathrm{mmol}$ ) and (trans)-4-phenyl-5-vinyl-1,3-dioxolan-2-one (110b) (142.7 mg, $0.75 \mathrm{mmol}$ ). Purification by column chromatography on silica gel ( $n$-pentane/ $\mathrm{Et}_{2} \mathrm{O}$ : 20/1) yielded $164 \mathrm{ab}(34.7 \mathrm{mg}, 50 \%)$ as a colorless oil.

${ }^{1} \mathbf{H}$ NMR $\left(300 \mathrm{MHz}, \mathrm{CDCl}_{3}\right) \delta=7.71(\mathrm{dd}, J=7.4,1.3 \mathrm{~Hz}, 1 \mathrm{H}), 7.43-7.32(\mathrm{~m}, 3 \mathrm{H}), 7.31-7.23(\mathrm{~m}, 3 \mathrm{H})$, 7.22-7.12 (m, 2H), $6.66(\mathrm{dd}, J=15.8,1.4 \mathrm{~Hz}, 1 \mathrm{H}), 6.31(\mathrm{dd}, J=15.8,6.3 \mathrm{~Hz}, 1 \mathrm{H}), 4.50-4.25(\mathrm{~m}, 3 \mathrm{H})$, $2.98(\mathrm{dd}, J=15.7,5.4 \mathrm{~Hz}, 1 \mathrm{H}), 2.74(\mathrm{dd}, J=15.7,9.8 \mathrm{~Hz}, 1 \mathrm{H}), 1.41(\mathrm{t}, J=7.1 \mathrm{~Hz}, 3 \mathrm{H}) .{ }^{13} \mathrm{C}$ NMR $(125$ $\left.\mathrm{MHz}, \mathrm{CDCl}_{3}\right) \delta=159.6\left(\mathrm{C}_{\mathrm{q}}\right), 138.1\left(\mathrm{C}_{\mathrm{q}}\right), 137.3\left(\mathrm{C}_{\mathrm{q}}\right), 131.9(\mathrm{CH}), 130.8(\mathrm{CH}), 129.8(\mathrm{CH}), 128.3(\mathrm{CH})$, $127.2(\mathrm{CH}), 127.1(\mathrm{CH}), 126.7(\mathrm{CH}), 126.3(\mathrm{CH}), 125.7\left(\mathrm{C}_{\mathrm{q}}\right), 124.7(\mathrm{CH}), 61.1\left(\mathrm{CH}_{2}\right), 56.9(\mathrm{CH}), 33.3$ $\left(\mathrm{CH}_{2}\right), 14.5\left(\mathrm{CH}_{3}\right)$. IR (ATR) $v=2977,1639,1493,1367,1298,1095,964,731,691 \mathrm{~cm}^{-1} . \mathrm{MS}(\mathrm{ESI}) \mathrm{m} / \mathrm{z}$ (relative intensity): $278(100)[\mathrm{M}+\mathrm{H}]^{+}$. HR-MS (ESI) m/z calcd for $\mathrm{C}_{19} \mathrm{H}_{20} \mathrm{NO}[\mathrm{M}+\mathrm{H}]^{+}:$278.1539, found: 278.1542 .<smiles>CCOC1=NC(/C=C/c2ccc(Cl)cc2)Cc2ccccc21</smiles>

(E)-3-(4-Chlorostyryl)-1-ethoxy-3,4-dihydroisoquinoline (164ac): The general procedure D was followed using ethyl benzimidate (161a) $(37.3 \mathrm{mg}, 0.25 \mathrm{mmol})$ and (trans)-4-(4-chlorophenyl)-5-vinyl-1,3-dioxolan-2-one (110c) (168.5 mg, $0.75 \mathrm{mmol})$. Purification by column chromatography on silica gel ( $n$-hexane/EtOAc: $20 / 1)$ yielded $164 a c(41.2 \mathrm{mg}, 53 \%)$ as a white solid.

M.p. $=120-123{ }^{\circ} \mathrm{C} .{ }^{1} \mathrm{H}$ NMR $\left(500 \mathrm{MHz}, \mathrm{CDCl}_{3}\right) \delta=7.70(\mathrm{~d}, J=7.7 \mathrm{~Hz}, 1 \mathrm{H}), 7.36(\mathrm{dd}, J=7.5,1.4 \mathrm{~Hz}$, 1H), 7.29-7.17 (m, 6H), 6.62 (dd, $J=15.8,1.4 \mathrm{~Hz}, 1 \mathrm{H}), 6.29$ (dd, $J=15.8,10.3 \mathrm{~Hz}, 1 \mathrm{H}), 4.38-4.28$ (m, 3H), 2.96 (dd, J = 15.6, $5.4 \mathrm{~Hz}, 1 \mathrm{H}), 2.72(\mathrm{dd}, J=15.6,10.3 \mathrm{~Hz}, 1 \mathrm{H}), 1.39(\mathrm{t}, J=7.1 \mathrm{~Hz}, 3 \mathrm{H}) .{ }^{13} \mathrm{C}$ NMR $\left(100 \mathrm{MHz}, \mathrm{CDCl}_{3}\right) \delta=160.0\left(\mathrm{C}_{\mathrm{q}}\right), 138.2\left(\mathrm{C}_{\mathrm{q}}\right), 136.0\left(\mathrm{C}_{\mathrm{q}}\right), 132.9\left(\mathrm{C}_{\mathrm{q}}\right), 132.8(\mathrm{CH}), 131.2(\mathrm{CH}), 128.9(\mathrm{CH})$, $128.7(\mathrm{CH}), 127.8(\mathrm{CH}), 127.5(\mathrm{CH}), 127.0(\mathrm{CH}), 125.8\left(\mathrm{C}_{\mathrm{q}}\right), 125.0(\mathrm{CH}), 61.4\left(\mathrm{CH}_{2}\right), 56.9(\mathrm{CH}), 33.2$ $\left(\mathrm{CH}_{2}\right), 14.5\left(\mathrm{CH}_{3}\right)$. IR (ATR) $v=2972,1640,1488,1366,1217,1160,1011,779,504 \mathrm{~cm}^{-1}$. MS (ESI) 
m/z (relative intensity): $312(100)[\mathrm{M}+\mathrm{H}]^{+}, 240(20)$. HR-MS (ESI) m/z calcd for $\mathrm{C}_{19} \mathrm{H}_{19} \mathrm{CINO}[\mathrm{M}+\mathrm{H}]^{+}$: 312.1150, found: 312.1153 .<smiles>CCOC1=NC(/C=C/c2ccc(F)cc2)Cc2ccccc21</smiles>

(E)-1-Ethoxy-3-(4-fluorostyryl)-3,4-dihydroisoquinoline (164ad): The general procedure D was followed using ethyl benzimidate (161a) $(37.3 \mathrm{mg}, 0.25 \mathrm{mmol})$ and (trans)-4-(4-fluorophenyl)-5-vinyl-1,3-dioxolan-2-one (110d) (156.2 mg, $0.75 \mathrm{mmol})$. Purification by column chromatography on silica gel (n-pentane/Et $\left.{ }_{2} \mathrm{O}: 20 / 1\right)$ yielded $164 \mathrm{ad}(45.0 \mathrm{mg}, 61 \%)$ as a white solid.

M.p. $=89-90{ }^{\circ} \mathrm{C} .{ }^{1} \mathrm{H}$ NMR $\left(300 \mathrm{MHz}, \mathrm{CDCl}_{3}\right) \delta=7.71(\mathrm{dd}, J=7.6,1.2 \mathrm{~Hz}, 1 \mathrm{H}), 7.42-7.25(\mathrm{~m}, 4 \mathrm{H}), 7.19$ (dd, $J=7.4,1.5 \mathrm{~Hz}, 1 \mathrm{H}), 7.05-6.88(\mathrm{~m}, 2 \mathrm{H}), 6.63(\mathrm{dd}, J=15.8,1.4 \mathrm{~Hz}, 1 \mathrm{H}), 6.23$ (dd, J = 15.8, $6.4 \mathrm{~Hz}$, 1H), 4.50-4.22 (m, 3H), 2.97 (dd, $J=15.7,5.4 \mathrm{~Hz}, 1 \mathrm{H}), 2.73(\mathrm{dd}, J=15.7,10.0 \mathrm{~Hz}, 1 \mathrm{H}), 1.40(\mathrm{t}, J=7.1$ $\mathrm{Hz}, 3 \mathrm{H}) .{ }^{13} \mathrm{C}$ NMR $\left(125 \mathrm{MHz}, \mathrm{CDCl}_{3}\right) \delta=162.0\left(\mathrm{~d},{ }^{1} \mathrm{~J}_{\mathrm{C}-\mathrm{F}}=247.0 \mathrm{~Hz}, \mathrm{C}_{\mathrm{q}}\right), 159.6\left(\mathrm{C}_{\mathrm{q}}\right), 138.0\left(\mathrm{C}_{\mathrm{q}}\right), 133.4(\mathrm{~d}$, $\left.{ }^{4} J_{\mathrm{C}-\mathrm{F}}=3.2 \mathrm{~Hz}, \mathrm{C}_{\mathrm{q}}\right), 131.7(\mathrm{CH}), 130.9(\mathrm{CH}), 128.6(\mathrm{CH}), 127.8\left(\mathrm{~d},{ }^{3} J_{\mathrm{C}-\mathrm{F}}=8.0 \mathrm{~Hz}, \mathrm{CH}\right), 127.2(\mathrm{CH}), 126.7$ $(\mathrm{CH}), 125.6\left(\mathrm{C}_{\mathrm{q}}\right), 124.7(\mathrm{CH}), 115.3\left(\mathrm{~d},{ }^{2} \mathrm{~J}_{\mathrm{C}-\mathrm{F}}=21.6 \mathrm{~Hz}, \mathrm{CH}\right), 61.1\left(\mathrm{CH}_{2}\right), 56.9(\mathrm{CH}), 33.3\left(\mathrm{CH}_{2}\right), 14.5$ $\left(\mathrm{CH}_{3}\right) \cdot{ }^{19} \mathrm{~F}$ NMR $\left(282 \mathrm{MHz}, \mathrm{CDCl}_{3}\right) \delta=-115.23$ (ddd, $J=14.0,8.7,5.4 \mathrm{~Hz}$ ). IR (ATR) $v=1638,1508$, 1365, 1296, 1224, 1160, 1097, 730, $677 \mathrm{~cm}^{-1}$. MS (ESI) m/z (relative intensity): 296 (100) [M+H] $]^{+}$ HR-MS (ESI) $\mathrm{m} / \mathrm{z}$ calcd for $\mathrm{C}_{19} \mathrm{H}_{19} \mathrm{FNO}[\mathrm{M}+\mathrm{H}]^{+}:$: 296.1445, found: 296.1450.<smiles>C=CC1Cc2ccc(Cl)cc2C(OCC)=N1</smiles>

7-Chloro-1-ethoxy-3-vinyl-3,4-dihydroisoquinoline (164ma): The general procedure D was followed using ethyl 3-chlorobenzimidate (161m) (45.9 mg, $0.25 \mathrm{mmol}$ ) and 4-vinyl-1,3-dioxolan-2-one (110a) $(72.0 \mu \mathrm{L}, 0.75 \mathrm{mmol})$. Purification by column chromatography on silica gel ( $n$-pentane/Et $\left.{ }_{2} \mathrm{O}: 20 / 1\right)$ yielded $164 \mathrm{mq}$ (36 $\mathrm{mg}, 61 \%$ ) as a colorless oil.

${ }^{1} \mathrm{H}$ NMR $\left(500 \mathrm{MHz}, \mathrm{CDCl}_{3}\right) \delta=7.65(\mathrm{~d}, J=2.2 \mathrm{~Hz}, 1 \mathrm{H}), 7.31(\mathrm{dd}, J=8.0,2.2 \mathrm{~Hz}, 1 \mathrm{H}), 7.10(\mathrm{~d}, J=8.0 \mathrm{~Hz}$, 1H), $5.92(\mathrm{ddd}, J=17.1,10.3,5.8 \mathrm{~Hz}, 1 \mathrm{H}), 5.25(\mathrm{dt}, J=17.1,1.6 \mathrm{~Hz}, 1 \mathrm{H}), 5.08(\mathrm{dt}, J=10.3,1.5 \mathrm{~Hz}, 1 \mathrm{H})$, 
4.53-3.99 (m, 3H), $2.87(\mathrm{dd}, J=15.7,5.6 \mathrm{~Hz}, 1 \mathrm{H}), 2.61(\mathrm{dd}, J=15.7,9.6 \mathrm{~Hz}, 1 \mathrm{H}), 1.38(\mathrm{t}, J=7.1 \mathrm{~Hz}$, 3H). ${ }^{13} \mathrm{C}$ NMR $\left(100 \mathrm{MHz}, \mathrm{CDCl}_{3}\right) \delta=158.5\left(\mathrm{C}_{\mathrm{q}}\right), 139.8(\mathrm{CH}), 136.4\left(\mathrm{C}_{\mathrm{q}}\right), 132.4\left(\mathrm{C}_{\mathrm{q}}\right), 130.7(\mathrm{CH}), 128.6$ (CH), $127.0\left(\mathrm{C}_{\mathrm{q}}\right) 124.9(\mathrm{CH}), 114.8\left(\mathrm{CH}_{2}\right), 61.2\left(\mathrm{CH}_{2}\right), 56.9(\mathrm{CH}), 32.0\left(\mathrm{CH}_{2}\right), 14.3\left(\mathrm{CH}_{3}\right)$. IR (ATR) $v=$ 2977, 1650, 1482, 1302, 1258, 1106, 1019, 792, $512 \mathrm{~cm}^{-1}$. MS (ESI) m/z (relative intensity): 236 (100) $[\mathrm{M}+\mathrm{H}]^{+}, 208$ (60). HR-MS (ESI) m/z calcd for $\mathrm{C}_{13} \mathrm{H}_{15} \mathrm{CINO}[\mathrm{M}+\mathrm{H}]^{+}:$236.0837, found: 236.0838.<smiles>C=CC1Cc2ccc(Br)cc2C(OCC)=N1</smiles>

7-Bromo-1-ethoxy-3-vinyl-3,4-dihydroisoquinoline (164xa): The general procedure D was followed using ethyl 3-bromobenzimidate (161x) $(57.0 \mathrm{mg}, 0.25 \mathrm{mmol})$ and 4-vinyl-1,3-dioxolan-2-one (110a) (72.0 $\mu \mathrm{L}, 0.75 \mathrm{mmol})$. Purification by column chromatography on silica gel ( $n$-pentane/Et $\left.{ }_{2} \mathrm{O}: 20 / 1\right)$ yielded 164xa (49 $\mathrm{mg}, 70 \%$ ) as a colorless oil.

${ }^{1} \mathrm{H}$ NMR $\left(400 \mathrm{MHz} \mathrm{CDCl}_{3}\right) \delta=7.81(\mathrm{~d}, J=2.0 \mathrm{~Hz}, 1 \mathrm{H}), 7.46(\mathrm{dd}, J=8.0,2.0 \mathrm{~Hz}, 1 \mathrm{H}), 7.04(\mathrm{~d}, J=8.0 \mathrm{~Hz}$, 1H), 5.91 (ddd, $J=17.1,10.3,5.8 \mathrm{~Hz}, 1 \mathrm{H}$ ), 5.25 (dt, $J=17.1,1.6 \mathrm{~Hz}, 1 \mathrm{H}$ ), 5.08 (dt, $J=10.3,1.5 \mathrm{~Hz}, 1 \mathrm{H}$ ), 4.61-4.06 (m, 3H), 2.86 (dd, $J=15.8,5.6 \mathrm{~Hz}, 1 \mathrm{H}), 2.59$ (dd, $J=15.8,9.5 \mathrm{~Hz}, 1 \mathrm{H}), 1.38$ (t, J = 7.1 Hz, 3H). ${ }^{13} \mathrm{C}$ NMR (75 MHz, CDCl $) \delta=158.4\left(\mathrm{C}_{\mathrm{q}}\right), 139.5(\mathrm{CH}), 136.9\left(\mathrm{C}_{\mathrm{q}}\right), 133.8(\mathrm{CH}), 128.9(\mathrm{CH}), 127.8$ $(\mathrm{CH}), 127.1\left(\mathrm{C}_{\mathrm{q}}\right), 120.3\left(\mathrm{C}_{\mathrm{q}}\right), 114.9\left(\mathrm{CH}_{2}\right), 61.5\left(\mathrm{CH}_{2}\right), 56.7(\mathrm{CH}), 32.0\left(\mathrm{CH}_{2}\right), 14.3\left(\mathrm{CH}_{3}\right)$. IR (ATR) $v=$ 2977, 1650, 1567, 1479, 1303, 1258, 1101, 919, $815 \mathrm{~cm}^{-1}$. MS (ESI) m/z (relative intensity): 282 (98) $\left({ }^{81} \mathrm{Br}\right), 280(100)[\mathrm{M}+\mathrm{H}]{ }^{+}\left({ }^{79} \mathrm{Br}\right), 254(50)\left({ }^{81} \mathrm{Br}\right), 252(48)\left({ }^{79} \mathrm{Br}\right)$. HR-MS (ESI) m/z calcd for $\mathrm{C}_{13} \mathrm{H}_{15} \mathrm{NO}^{79} \mathrm{Br}[\mathrm{M}+\mathrm{H}]^{+}$: 280.0332, found: 280.0334, $\mathrm{C}_{13} \mathrm{H}_{15} \mathrm{NO}^{81} \mathrm{Br}[\mathrm{M}+\mathrm{H}]^{+}$: 282.0311, found: 282.0314 .<smiles>C=CC1Cc2ccc(C(F)(F)F)cc2C(OCC)=N1</smiles>

1-Ethoxy-7-(trifluoromethyl)-3-vinyl-3,4-dihydroisoquinoline (164la): The general procedure D was followed using ethyl 3-(trifluoromethyl)benzimidate (161) $(54.3 \mathrm{mg}, 0.25 \mathrm{mmol}$ ) and 4-vinyl-1,3-dioxolan-2-one (110a) $(72.0 \mu \mathrm{L}, 0.75 \mathrm{mmol})$. Purification by column chromatography on silica gel ( $n$-pentane/Et ${ }_{2} \mathrm{O}: 20 / 1$ ) yielded 164la (36 mg, 53\%) as a colorless oil. 
${ }^{1} \mathbf{H}$ NMR $\left(400 \mathrm{MHz}_{\mathrm{CDCl}}\right) \delta=7.92(\mathrm{~s}, 1 \mathrm{H}), 7.59(\mathrm{dd}, J=7.9,1.3 \mathrm{~Hz}, 1 \mathrm{H}), 7.28(\mathrm{~d}, J=7.9 \mathrm{~Hz}, 1 \mathrm{H}), 5.93$ (ddd, $J=17.1,10.3,5.7 \mathrm{~Hz}, 1 \mathrm{H}$ ), 5.27 (dt, $J=17.1,1.6 \mathrm{~Hz}, 1 \mathrm{H}$ ), 5.10 (dt, $J=10.3,1.6 \mathrm{~Hz}, 1 \mathrm{H}$ ), 4.46-4.16 (m, 3H), $2.96(\mathrm{dd}, J=15.9,5.6 \mathrm{~Hz}, 1 \mathrm{H}), 2.70(\mathrm{dd}, J=15.9,9.6 \mathrm{~Hz}, 1 \mathrm{H}), 1.40(\mathrm{t}, J=7.1 \mathrm{~Hz}$, 3H). ${ }^{13} \mathrm{C}$ NMR $\left(100 \mathrm{MHz}, \mathrm{CDCl}_{3}\right) \delta=158.3\left(\mathrm{C}_{\mathrm{q}}\right), 142.0\left(\mathrm{C}_{\mathrm{q}}\right), 139.6(\mathrm{CH}), 129.3\left(\mathrm{q},{ }^{2} \mathrm{~J}_{\mathrm{C}-\mathrm{F}}=32.4 \mathrm{~Hz}, \mathrm{C}_{\mathrm{q}}\right)$, $127.8(\mathrm{CH}), 127.3\left(\mathrm{q},{ }^{3} J_{\mathrm{C}-\mathrm{F}}=3.7 \mathrm{~Hz}, \mathrm{CH}\right), 126.2\left(\mathrm{C}_{\mathrm{q}}\right), 123.9\left(\mathrm{q},{ }^{1} \mathrm{~J}_{\mathrm{C}-\mathrm{F}}=272.8 \mathrm{~Hz}, \mathrm{C}_{\mathrm{q}}\right), 121.7\left(\mathrm{q},{ }^{3} \mathrm{~J}_{\mathrm{C}-\mathrm{F}}=3.9\right.$ $\mathrm{Hz}, \mathrm{CH}), 114.9\left(\mathrm{CH}_{2}\right), 61.3\left(\mathrm{CH}_{2}\right), 56.6(\mathrm{CH}), 32.5\left(\mathrm{CH}_{2}\right), 14.3\left(\mathrm{CH}_{3}\right) .{ }^{19} \mathrm{~F}$ NMR $\left(376 \mathrm{MHz}, \mathrm{CDCl}_{3}\right) \delta=$ -62.50. IR (ATR) $v=2981,1653,1336,1301,1259,1167,1124,1101,917 \mathrm{~cm}^{-1}$. MS (ESI) m/z (relative intensity): $270(100)[\mathrm{M}+\mathrm{H}]^{+}, 242(50)$. HR-MS (ESI) m/z calcd for $\mathrm{C}_{14} \mathrm{H}_{15} \mathrm{NOF} \mathrm{F}_{3}[\mathrm{M}+\mathrm{H}]^{+}$: 270.1100, found: 2270.1101.<smiles>C=CC1Cc2c(F)cccc2C(OCC)=N1</smiles>

1-Ethoxy-5-fluoro-3-vinyl-3,4-dihydroisoquinoline (164ya): The general procedure D was followed using ethyl 3-fluorobenzimidate (161y) $(41.8 \mathrm{mg}, 0.25 \mathrm{mmol})$ and 4-vinyl-1,3-dioxolan-2-one (110a) (72.0 $\mu \mathrm{L}, 0.75 \mathrm{mmol})$. Purification by column chromatography on silica gel ( $n$-pentane/Et $\left.{ }_{2} \mathrm{O}: 20 / 1\right)$ yielded 164ya (37 mg, 67\%) as a colorless oil.

${ }^{1} \mathrm{H}$ NMR $\left(300 \mathrm{MHz}, \mathrm{CDCl}_{3}\right) \delta=7.48(\mathrm{dd}, J=7.6,0.8 \mathrm{~Hz}, 1 \mathrm{H}), 7.31-7.16(\mathrm{~m}, 1 \mathrm{H}), 7.09(\mathrm{dd}, J=8.6,1.2$ $\mathrm{Hz}, 1 \mathrm{H}), 5.96(\mathrm{ddd}, J=17.1,10.3,5.7 \mathrm{~Hz}, 1 \mathrm{H}), 5.28(\mathrm{dt}, J=17.1,1.6 \mathrm{~Hz}, 1 \mathrm{H}), 5.10(\mathrm{dt}, J=10.3,1.6 \mathrm{~Hz}$, $1 \mathrm{H}), 4.50-4.10(\mathrm{~m}, 3 \mathrm{H}), 2.98(\mathrm{dd}, J=16.1,5.7 \mathrm{~Hz}, 1 \mathrm{H}), 2.60(\mathrm{dd}, J=16.2,9.7 \mathrm{~Hz}, 1 \mathrm{H}), 1.37(\mathrm{t}, J=7.1$ $\mathrm{Hz}, 3 \mathrm{H}) .{ }^{13} \mathrm{C}$ NMR $\left(125 \mathrm{MHz}, \mathrm{CDCl}_{3}\right) \delta=159.1\left(\mathrm{~d},{ }^{1} J_{\mathrm{C}-\mathrm{F}}=243.9 \mathrm{~Hz}, \mathrm{C}_{\mathrm{q}}\right), 158.5\left(\mathrm{~d},{ }^{4} \mathrm{~J}_{\mathrm{C}-\mathrm{F}}=4.3 \mathrm{~Hz}, \mathrm{C}_{\mathrm{q}}\right)$, $139.8(\mathrm{CH}), 127.3\left(\mathrm{~d},{ }^{3} J_{\mathrm{C}-\mathrm{F}}=6.1 \mathrm{~Hz}, \mathrm{C}_{\mathrm{q}}\right), 127.2\left(\mathrm{~d},{ }^{3} \mathrm{~J}_{\mathrm{C}-\mathrm{F}}=8.0 \mathrm{~Hz}, \mathrm{CH}\right), 124.8\left(\mathrm{~d},{ }^{2} \mathrm{~J}_{\mathrm{C}-\mathrm{F}}=19.4 \mathrm{~Hz}, \mathrm{C}_{\mathrm{q}}\right), 120.4$ $\left(d,{ }^{4} J_{C-F}=3.3 \mathrm{~Hz}, \mathrm{CH}\right), 117.5\left(\mathrm{~d},{ }^{2} J_{\mathrm{C}-\mathrm{F}}=21.7 \mathrm{~Hz}, \mathrm{CH}\right), 114.6\left(\mathrm{CH}_{2}\right), 61.1\left(\mathrm{CH}_{2}\right), 56.3(\mathrm{CH}), 24.9\left(\mathrm{~d},{ }^{3} J_{\mathrm{C}-\mathrm{F}}=\right.$ $\left.1.4 \mathrm{~Hz}, \mathrm{CH}_{2}\right), 14.4\left(\mathrm{CH}_{3}\right) .{ }^{19} \mathrm{~F} \mathrm{NMR}\left(282 \mathrm{MHz}, \mathrm{CDCl}_{3}\right) \delta=-120.72$ (dd, $\left.J=8.9,5.5 \mathrm{~Hz}\right)$. IR (ATR) $v=2979$, 1651, 1583, 1467, 1293, 1040, 920, 798, $732 \mathrm{~cm}^{-1}$. MS (ESI) m/z (relative intensity): 220 (100) $[\mathrm{M}+\mathrm{H}]^{+}, 192$ (80). HR-MS (ESI) m/z calcd for $\mathrm{C}_{13} \mathrm{H}_{15} \mathrm{NOF}[\mathrm{M}+\mathrm{H}]^{+}:$:220.1132, found: 220.1134 . 


\section{Intermolecular Competition Experiments}

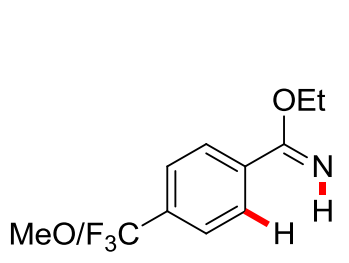

$161 \mathrm{~d} / 161 \mathrm{e}$

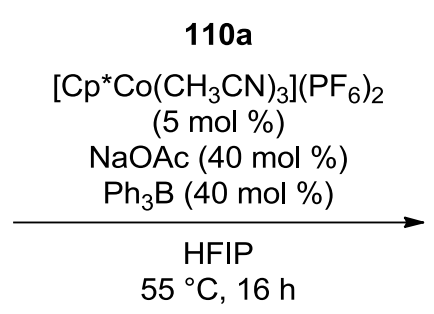

164da/164ea: 1/0.82

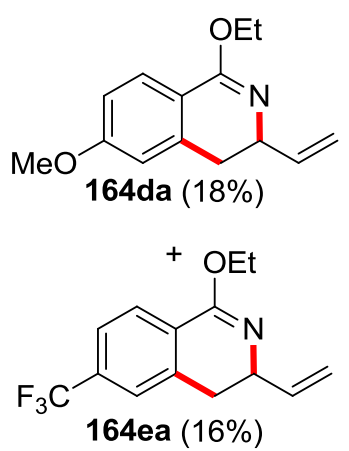

164ea $(16 \%)$

A suspension of ethyl 4-methoxybenzimidate (161d) $(44.8 \mathrm{mg}, 0.25 \mathrm{mmol})$, ethyl 4-(trifluoromethyl)benzimidate (161e) (54.3 mg, $0.25 \mathrm{mmol}$ ), 4-vinyl-1,3-dioxolan-2-one (110a) (28.6 mg, $0.25 \mathrm{mmol}), \mathrm{NaOAc}(8.2 \mathrm{mg}, 40 \mathrm{~mol} \%), \mathrm{Ph}_{3} \mathrm{~B}(24.2 \mathrm{mg}, 40 \mathrm{~mol} \%$ ) and $\left[\mathrm{Cp}^{*} \mathrm{Co}\left(\mathrm{CH}_{3} \mathrm{CN}\right)_{3}\right]\left(\mathrm{PF}_{6}\right)_{2}(\mathbf{1 8 0})(7.6 \mathrm{mg}, 5.0 \mathrm{~mol} \%)$ in HFIP $(1.0 \mathrm{~mL})$ was stirred under $\mathrm{N}_{2}$ at $55^{\circ} \mathrm{C}$ for 5 h. After cooling to ambient temperature, the mixture was transferred into a round bottom flask with $\mathrm{CH}_{2} \mathrm{Cl}_{2}(20 \mathrm{~mL})$ and concentrated in vacuo. Purification by column chromatography on silica gel ( $n$-pentane/Et 2 O: 20/1 $\rightarrow 10 / 1$ ) afforded product 164da (10 mg, 18\%) and 164ea (11 mg, 16\%).

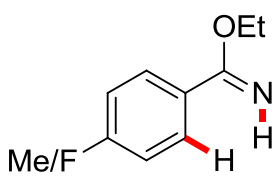

$161 \mathrm{c} / 161 \mathrm{f}$

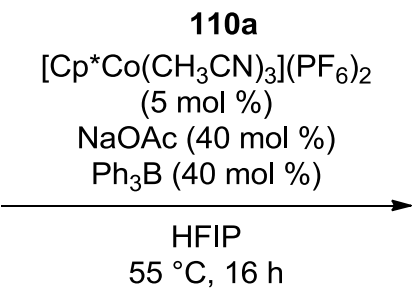

164ca/164fa: $1 / 0.76$

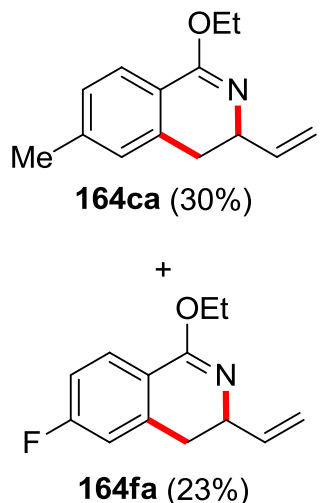

$164 \mathrm{fa}(23 \%)$

A suspension of ethyl 4-methylbenzimidate (161c) $(40.8 \mathrm{mg}, 0.25 \mathrm{mmol})$, ethyl 4-fluorobenzimidate (161f) (41.8 mg, $0.25 \mathrm{mmol}), 4$-vinyl-1,3-dioxolan-2-one (110a) (28.6 mg, $0.25 \mathrm{mmol}), \mathrm{NaOAc}(8.2$ $\mathrm{mg}, 40 \mathrm{~mol} \%), \mathrm{Ph}_{3} \mathrm{~B}(24.2 \mathrm{mg}, 40 \mathrm{~mol} \%)$ and $\left[\mathrm{Cp}^{*} \mathrm{Co}\left(\mathrm{CH}_{3} \mathrm{CN}\right)_{3}\right]\left(\mathrm{PF}_{6}\right)_{2}(\mathbf{1 8 0})(7.6 \mathrm{mg}, 5.0 \mathrm{~mol} \%)$ in HFIP $(1.0 \mathrm{~mL})$ was stirred under $\mathrm{N}_{2}$ at $55{ }^{\circ} \mathrm{C}$ for $5 \mathrm{~h}$. After cooling to ambient temperature, the mixture was transferred into a round bottom flask with $\mathrm{CH}_{2} \mathrm{Cl}_{2}(20 \mathrm{~mL})$ and concentrated in vacuo. Purification by column chromatography on silica gel ( $n$-pentane/ $\mathrm{Et}_{2} \mathrm{O}: 20 / 1 \rightarrow 10 / 1$ ) afforded product 164ca (16.2 mg, 30\%) and 164fa (12.3 mg, 23\%). 


\section{H/D Exchange Experiment}

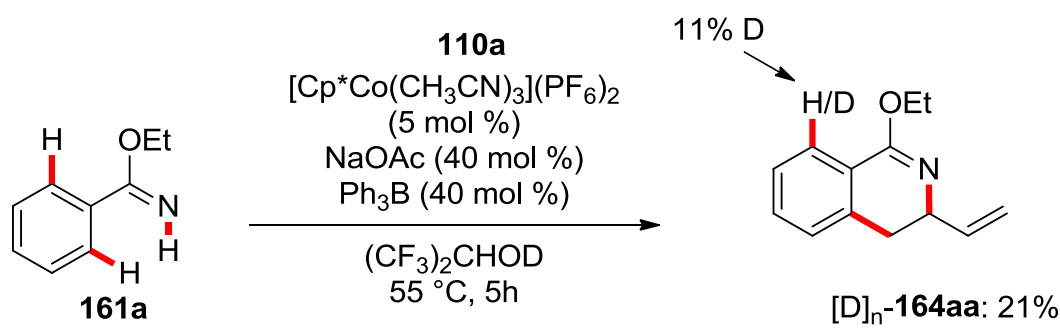

A suspension of benzimidate (161a) $(37.3 \mathrm{mg}, 0.25 \mathrm{mmol})$, 4-vinyl-1,3-dioxolan-2-one (110a) (72.0 $\mu \mathrm{L}, 0.75 \mathrm{mmol}), \mathrm{NaOAc}(8.2 \mathrm{mg}, 40 \mathrm{~mol} \%), \mathrm{Ph}_{3} \mathrm{~B}(24.2 \mathrm{mg}, 40 \mathrm{~mol} \%)$ and $\left[\mathrm{Cp}^{*} \mathrm{Co}\left(\mathrm{CH}_{3} \mathrm{CN}\right)_{3}\right]\left(\mathrm{PF}_{6}\right)_{2}$ (180) $(7.6 \mathrm{mg}, 5.0 \mathrm{~mol} \%)$ in $\left(\mathrm{CF}_{3}\right)_{2} \mathrm{CHOD}(1.0 \mathrm{~mL})$ was stirred under $\mathrm{N}_{2}$ at $55^{\circ} \mathrm{C}$ for $5 \mathrm{~h}$. After cooling to ambient temperature, the mixture was transferred into a round bottom flask with $\mathrm{CH}_{2} \mathrm{Cl}_{2}(20 \mathrm{~mL})$ and concentrated in vacuo. Purification by column chromatography on silica gel ( $n$-pentane/Et $\mathrm{O}_{2} \mathrm{O}$ 20/1) afforded product $[D]_{n}-164 a a(11 \mathrm{mg}, 21 \%)$. The $H / D$ exchange result was determined by ${ }^{1} \mathrm{H}$ NMR spectroscopy.

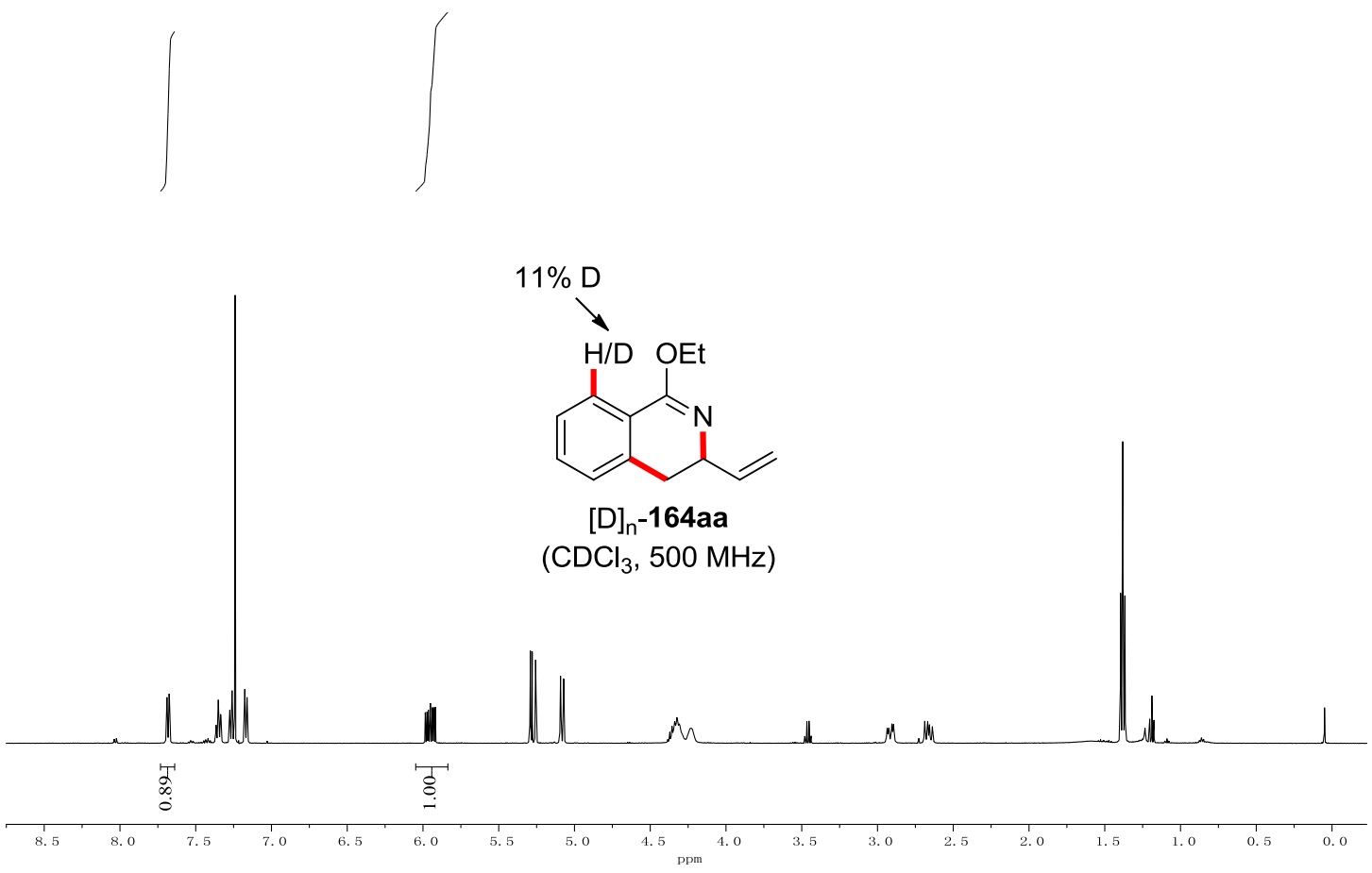




\section{Intermolecular KIE Experiment}

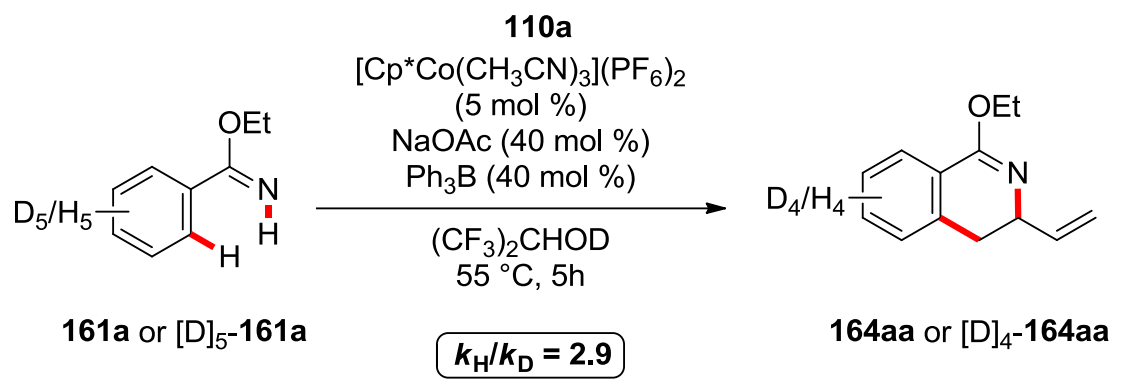

Two parallel reactions of $110 \mathrm{a}$ with $161 \mathrm{a}$ or $[\mathrm{D}]_{5}-161 \mathrm{a}$ were performed to determine the corresponding KIE value. 164aa $(37.3 \mathrm{mg}, 0.25 \mathrm{mmol})$ or $[\mathrm{D}]_{5}-164 \mathrm{aa}(38.6 \mathrm{mg}, 0.25 \mathrm{mmol})$, 4-vinyl-1,3-dioxolan-2-one (110a) $(72.0 \mu \mathrm{L}, 0.75 \mathrm{mmol}), \mathrm{NaOAc}(8.2 \mathrm{mg}, 40 \mathrm{~mol} \%), \mathrm{Ph}_{3} \mathrm{~B}(24.2 \mathrm{mg}$, $40 \mathrm{~mol} \%)$, and $\left[\mathrm{Cp}^{*} \mathrm{Co}\left(\mathrm{CH}_{3} \mathrm{CN}\right)_{3}\right]\left(\mathrm{PF}_{6}\right)_{2}(7.6 \mathrm{mg}, 5.0 \mathrm{~mol} \%)$, 1,3,5-trimethoxybenzene (42.0 mg, 0.25 mmol) as internal standard and HFIP $(1.0 \mathrm{~mL})$ were placed in a $25 \mathrm{~mL}$ Schlenk tube. The mixture was stirred at $55{ }^{\circ} \mathrm{C}$, and a periodic aliquot $(0.05 \mathrm{~mL})$ was removed by syringe and analyzed by $\mathrm{GC}$ to determine the following conversions:

\begin{tabular}{|c|c|c|c|c|c|c|}
\hline $\begin{array}{c}\mathrm{t} / \mathrm{min} \\
\text { yield / \% }\end{array}$ & 30 & 60 & 90 & 120 & 150 & 180 \\
\hline 164aa & 3.1 & 9.2 & 13.5 & 17.5 & 21.6 & 24.0 \\
\hline$[\mathrm{D}]_{4}-164 a a$ & 1.3 & 3.4 & 5.2 & 6.6 & 7.4 & 8.7 \\
\hline
\end{tabular}

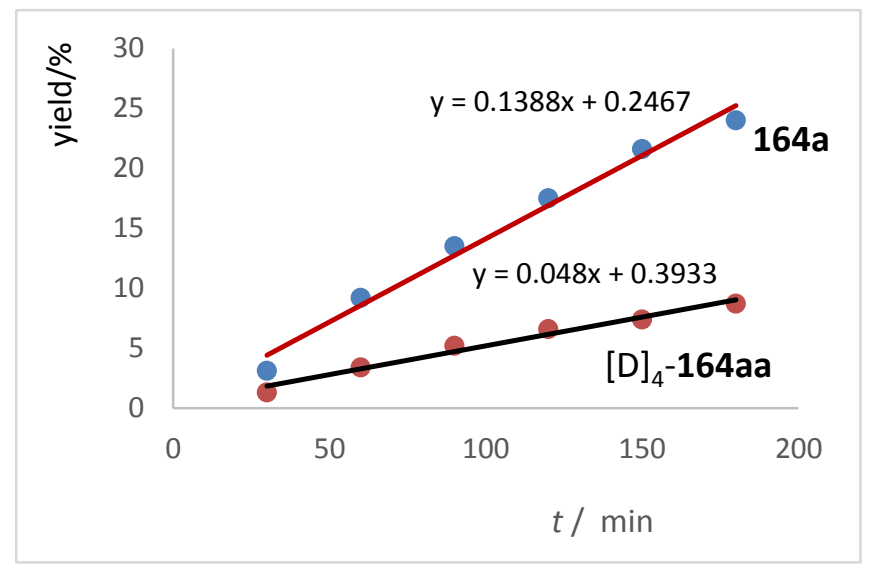




\section{Intramolecular KIE Experiment}

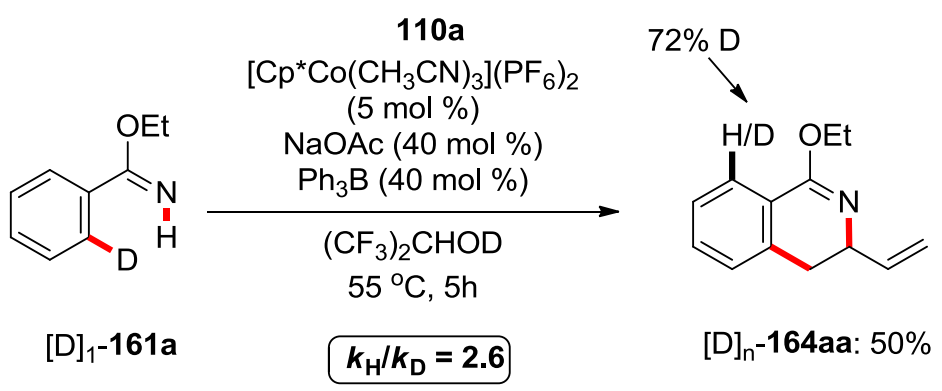

A suspension of $[D]_{1}$-161a (37.6 mg $\left.0.25 \mathrm{mmol}\right)$, 4-vinyl-1,3-dioxolan-2-one (110a) (72.0 $\mu \mathrm{L}, 0.75$ mmol), $\mathrm{NaOAc}(8.2 \mathrm{mg}, 40 \mathrm{~mol} \%), \mathrm{Ph}_{3} \mathrm{~B}(24.2 \mathrm{mg}, 40 \mathrm{~mol} \%)$, and $\left[\mathrm{Cp}^{*} \mathrm{Co}\left(\mathrm{CH}_{3} \mathrm{CN}\right)_{3}\right]\left(\mathrm{PF}_{6}\right)_{2}(\mathbf{1 8 0})(7.6$ $\mathrm{mg}, 5.0 \mathrm{~mol} \%)$ in HFIP $(1.0 \mathrm{~mL})$ was stirred for $16 \mathrm{~h}$ at $55^{\circ} \mathrm{C}$. After cooling to ambient temperature, the reaction mixture was transferred into a round flask with $\mathrm{CH}_{2} \mathrm{Cl}_{2}(20 \mathrm{~mL})$ and concentrated under reduced pressure, purified by column chromatography on silica gel ( $n$-hexane/EtOAc: $20 / 1$ ) to afford $[D]_{n}-164 a a(25.3 \mathrm{mg}, 50 \%)$. The kinetic isotope effect of this reaction was determined to be $k_{H} / k_{D}=$ 2.6 as estimated by ${ }^{1} \mathrm{H}$ NMR spectroscopy.

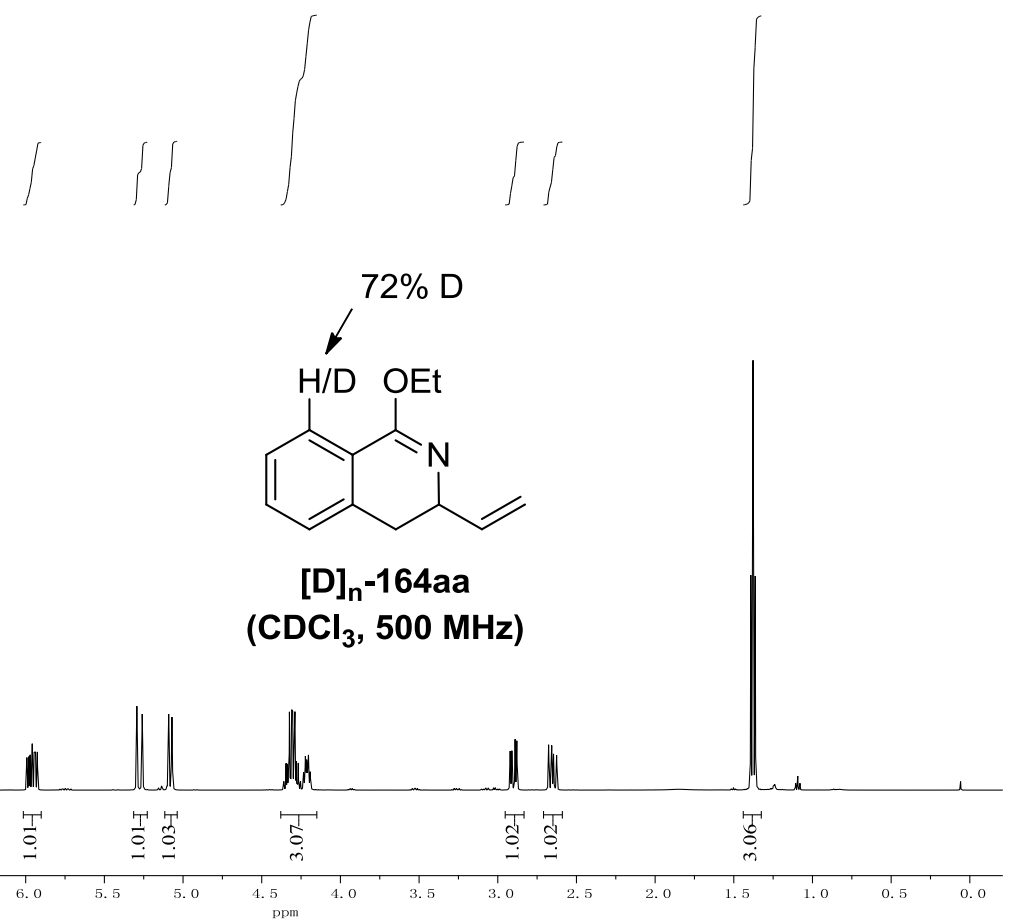




\section{Diversification of Vinylated Heteroarenes 164}

a) Synthesis of Dihydroisoquinolone 191

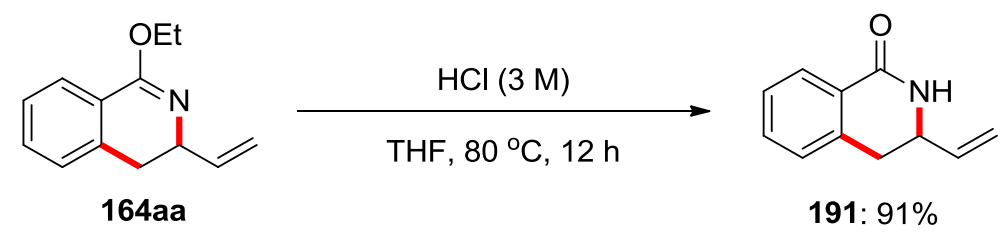

To a solution of 164aa (50.4 mg $0.25 \mathrm{mmol})$ in THF $(2.0 \mathrm{~mL})$ was added aqueous $\mathrm{HCl}(3 \mathrm{M}, 2.0 \mathrm{~mL})$, and the mixture was stirred at $80{ }^{\circ} \mathrm{C}$ for $12 \mathrm{~h}$. After cooling to ambient temperature, the solution was neutralized with a saturated $\mathrm{NaHCO}_{3}$ solution and extracted with EtOAc $(3 \times 20 \mathrm{~mL})$. The combined organic layers were washed with brine $(40 \mathrm{~mL})$, dried over $\mathrm{Na}_{2} \mathrm{SO}_{4}$, and evaporated in vacuo. Purification by column chromatography (EtOAc/n-hexane: 4/1) afforded product 191 (39.4 $\mathrm{mg}, 91 \%)$ as a white solid.<smiles>C=CC1Cc2ccccc2C(=O)N1</smiles>

\section{3-Vinyl-3,4-dihydroisoquinolin-1(2H)-one (191)}

M.p.: 90-92 ${ }^{\circ} \mathrm{C} .{ }^{1} \mathrm{H}$ NMR $\left(300 \mathrm{MHz}, \mathrm{CDCl}_{3}\right) \delta=8.04$ (dd, $\left.J=7.6,1.5 \mathrm{~Hz}, 1 \mathrm{H}\right), 7.42$ (td, $J=7.5,1.5 \mathrm{~Hz}$, 1H), 7.32 (t, $J=7.3 \mathrm{~Hz}, 1 \mathrm{H}$ ), $7.16(\mathrm{~d}, J=7.4 \mathrm{~Hz}, 1 \mathrm{H}$ ), 6.34 (brs, $1 \mathrm{H}$ ), 5.88 (ddd, $J=17.0,10.2,6.6 \mathrm{~Hz}$, 1H), 5.29 (dd, $J=17.0,1.5 \mathrm{~Hz}, 1 \mathrm{H}), 5.18(\mathrm{dd}, J=10.3,1.5 \mathrm{~Hz}, 1 \mathrm{H}), 4.31-4.17(\mathrm{~m}, 1 \mathrm{H}), 3.05(\mathrm{dd}, J=$ 15.6, $5.0 \mathrm{~Hz}, 1 \mathrm{H}), 2.91(\mathrm{dd}, J=15.6,9.3 \mathrm{~Hz}, 1 \mathrm{H}) .{ }^{13} \mathrm{C} \mathrm{NMR}\left(75 \mathrm{MHz} \mathrm{CDCl}_{3}\right) \delta=166.0\left(\mathrm{C}_{\mathrm{q}}\right), 137.3(\mathrm{CH})$, $132.3(\mathrm{CH}), 128.4\left(\mathrm{C}_{\mathrm{q}}\right), 127.9(\mathrm{CH}), 127.4(\mathrm{CH}), 127.1(\mathrm{CH}), 117.2\left(\mathrm{C}_{\mathrm{q}}\right), 117.1\left(\mathrm{CH}_{2}\right), 53.9(\mathrm{CH}), 34.4$ $\left(\mathrm{CH}_{2}\right)$. IR (ATR) $v=3188,3039,2925,1659,1470,1406,1346,915,740,535 \mathrm{~cm}^{-1}$. MS (ESI) m/z (relative intensity) $296(60)[\mathrm{M}+\mathrm{Na}]^{+}, 174(100)[\mathrm{M}+\mathrm{H}]^{+}$. HR-MS (ESI) m/z calcd for $\mathrm{C}_{11} \mathrm{H}_{12} \mathrm{NO}[\mathrm{M}+\mathrm{H}]^{+}$: 174.0913, found: 174.0916 . 


\section{b) Synthesis of Acetylated Isoquinoline 192 by Wacker-Type Oxidation}
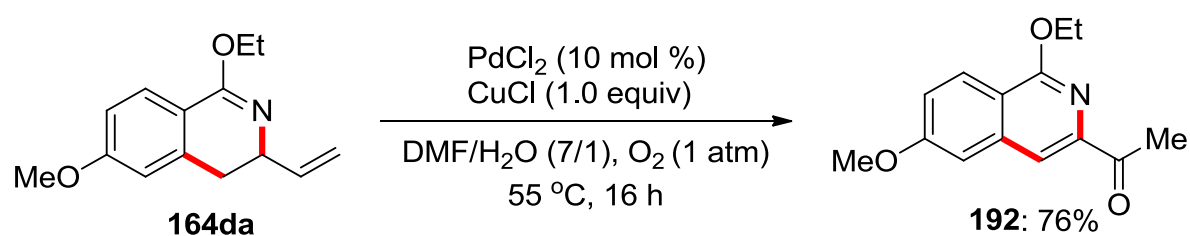

To a stirred solution of $\mathrm{PdCl}_{2}(4.4 \mathrm{mg}, 0.025 \mathrm{mmol})$ and $\mathrm{CuCl}(24.8 \mathrm{mg}, 0.25 \mathrm{mmol})$ in $\mathrm{DMF}$ and $\mathrm{H}_{2} \mathrm{O}$ $(7: 1,2 \mathrm{~mL})$ was added $164 \mathrm{da}(57.8 \mathrm{mg}, 0.25 \mathrm{mmol})$ under ambient $\mathrm{O}_{2}$ atmosphere. The reaction mixture was stirred at ambient temperature for $12 \mathrm{~h}$ and extracted with $\mathrm{Et}_{2} \mathrm{O}$. The organic layer was dried over $\mathrm{Na}_{2} \mathrm{SO}_{4}$ and evaporated in vacuo. The crude product was separated by column chromatography (EtOAc/n-hexane: 10/1) to afford product 192 (46.6 mg, 76\%) as a white solid.<smiles>CCOc1nc(C(C)=O)cc2cc(OC)ccc12</smiles>

\section{1-(1-Ethoxy-6-methoxyisoquinolin-3-yl)ethanone (192)}

M.p. $=127-129^{\circ} \mathrm{C}^{1}{ }^{1} \mathrm{H}$ NMR $\left(300 \mathrm{MHz}, \mathrm{CDCl}_{3}\right) \delta=8.16(\mathrm{~d}, J=9.1 \mathrm{~Hz}, 1 \mathrm{H}), 7.91(\mathrm{~s}, 1 \mathrm{H}), 7.21(\mathrm{dd}, J=$ 9.1, $2.5 \mathrm{~Hz}, 1 \mathrm{H}), 7.12(\mathrm{~d}, J=2.5 \mathrm{~Hz}, 1 \mathrm{H}), 4.60(\mathrm{q}, J=7.1 \mathrm{~Hz}, 2 \mathrm{H}), 3.91(\mathrm{~s}, 3 \mathrm{H}), 2.71(\mathrm{~s}, 3 \mathrm{H}), 1.50(\mathrm{t}, J=$ $7.1 \mathrm{~Hz}, 3 \mathrm{H}) .{ }^{13} \mathrm{C}$ NMR $\left(125 \mathrm{MHz}, \mathrm{CDCl}_{3}\right) \delta=200.5\left(\mathrm{C}_{\mathrm{q}}\right), 161.2\left(\mathrm{C}_{\mathrm{q}}\right), 159.7\left(\mathrm{C}_{\mathrm{q}}\right), 145.4\left(\mathrm{C}_{\mathrm{q}}\right), 139.4\left(\mathrm{C}_{\mathrm{q}}\right)$, $125.9(\mathrm{CH}), 120.5(\mathrm{CH}), 116.4\left(\mathrm{C}_{\mathrm{q}}\right), 113.8(\mathrm{CH}), 106.7(\mathrm{CH}), 62.1\left(\mathrm{CH}_{2}\right), 55.5\left(\mathrm{CH}_{3}\right), 26.5\left(\mathrm{CH}_{3}\right), 14.6$ $\left(\mathrm{CH}_{3}\right)$. IR (ATR) $v=3076,2937,1685,1574,1412,1327,1236,1160,910,630 \mathrm{~cm}^{-1} . \mathrm{MS}(\mathrm{ESI}) \mathrm{m} / \mathrm{z}$ (relative intensity) $268(100)[\mathrm{M}+\mathrm{Na}]^{+}, 246(95)[\mathrm{M}+\mathrm{H}]^{+}, 218$ (60). HR-MS (ESI) m/z calcd for $\mathrm{C}_{14} \mathrm{H}_{16} \mathrm{NO}_{3}[\mathrm{M}+\mathrm{H}]^{+}: 246.1125$, found: 246.1127. 


\subsubsection{Data for Maganese(I)-Catalyzed C-H Activation for Decarboxylative C-H/C-O} Functionalization in Water

\section{Characterization Data}

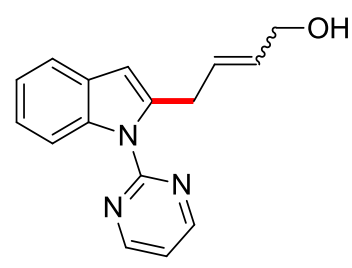

(E/Z)-4-[1-(Pyrimidin-2-yl)-1H-indol-2-yl]but-2-en-1-ol (111aa): The general procedure E was followed using 1-(pyrimidin-2-yl)-1H-indole (41a) $(48.8 \quad \mathrm{mg}, \quad 0.25 \mathrm{mmol})$ and 4-vinyl-1,3-dioxolan-2-one (110a) $(72.0 \mu \mathrm{L}, 0.75 \mathrm{mmol})$. Purification by column chromatography on silica gel ( $n$-hexane/EtOAc: $1 / 1$ ) yielded 111aa $\left(61.7 \mathrm{mg}, 93 \%, E / Z=5.9 / 1.0\right.$ by ${ }^{1} \mathrm{H}$ NMR) as a colorless oil.

${ }^{1} \mathrm{H}$ NMR $\left(300 \mathrm{MHz}, \mathrm{CDCl}_{3}\right) \delta=8.75(\mathrm{~d}, J=4.8 \mathrm{~Hz}, 2 \mathrm{H}), 8.22(\mathrm{~d}, J=7.7 \mathrm{~Hz}, 1 \mathrm{H}), 7.52(\mathrm{dd}, J=6.5,1.5 \mathrm{~Hz}$, 1H), 7.31-7.07 (m, 2H), $7.10(t, J=4.8 \mathrm{~Hz}, 1 \mathrm{H}), 6.46(\mathrm{~s}, 1 \mathrm{H}), 6.00-5.52(\mathrm{~m}, 2 \mathrm{H}), 4.22(\mathrm{~d}, J=5.3 \mathrm{~Hz}$, $0.35 \mathrm{H}), 4.00$ (dd, $J=5.8,1.2 \mathrm{~Hz}, 1.65 \mathrm{H}), 3.98-3.85(\mathrm{~m}, 2 \mathrm{H}), 1.54$ (brs, $1 \mathrm{H}) .{ }^{13} \mathrm{C} \mathrm{NMR}\left(75 \mathrm{MHz}, \mathrm{CDCl}_{3}\right)$ Major isomer: $\delta=158.1(\mathrm{CH}), 158.1\left(\mathrm{C}_{\mathrm{q}}\right), 139.6\left(\mathrm{C}_{\mathrm{q}}\right), 137.0\left(\mathrm{C}_{\mathrm{q}}\right), 131.0(\mathrm{CH}), 129.4(\mathrm{CH}), 129.1\left(\mathrm{C}_{\mathrm{q}}\right)$, 122.7 (CH), $121.8(\mathrm{CH}), 119.8(\mathrm{CH}), 117.1(\mathrm{CH}), 113.7(\mathrm{CH}), 106.4(\mathrm{CH}), 63.3\left(\mathrm{CH}_{2}\right), 32.4\left(\mathrm{CH}_{2}\right)$. Minor isomer: $\delta=139.6\left(\mathrm{C}_{\mathrm{q}}\right), 130.1(\mathrm{CH}), 129.0(\mathrm{CH}), 122.7(\mathrm{CH}), 121.9(\mathrm{CH}), 113.8(\mathrm{CH}), 106.2(\mathrm{CH}), 58.5$ $\left(\mathrm{CH}_{2}\right), 28.1\left(\mathrm{CH}_{2}\right)$. (Due to overlap, five peaks are missing). IR (ATR) $v=3376,2862,1562,1454,1425$, 1348, 1207, 973, 802, $746 \mathrm{~cm}^{-1}$. MS (ESI) m/z (relative intensity): 288 (100) [M+Na] $]^{+}, 266(20)$ $[\mathrm{M}+\mathrm{H}]^{+}, 248$ (40). HR-MS (ESI) m/z calcd for $\mathrm{C}_{16} \mathrm{H}_{16} \mathrm{~N}_{3} \mathrm{O}[\mathrm{M}+\mathrm{H}]^{+}: 266.1288$, found: 266.1288 .

The analytical data were in accordance with those reported in the literature. ${ }^{[69]}$

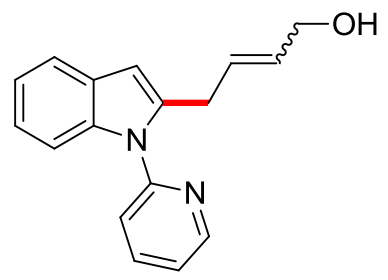

(E/Z)-4-[1-(Pyridin-2-yl)-1H-indol-2-yl]but-2-en-1-ol (111ba): The general procedure E was followed using methyl 1-(pyridin-2-yl)-1H-indole (41b) $(48.6 \mathrm{mg}, 0.25 \mathrm{mmol}$ ) and 4-vinyl-1,3-dioxolan-2-one 
(110a) $(72.0 \mu \mathrm{L}, 0.75 \mathrm{mmol})$. Purification by column chromatography on silica gel ( $n$-hexane/EtOAc: 1/1) yielded 111 ba ( $64.8 \mathrm{mg}, 98 \%, E / Z=5.2 / 1.0$ by ${ }^{1} \mathrm{H}$ NMR) as a colorless oil.

${ }^{1} \mathbf{H}$ NMR $\left(600 \mathrm{MHz}, \mathrm{CDCl}_{3}\right) \delta=8.62(\mathrm{dd}, J=4.9,2.0 \mathrm{~Hz}, 1 \mathrm{H}), 7.89-7.81(\mathrm{~m}, 1 \mathrm{H}), 7.58-7.50(\mathrm{~m}, 1 \mathrm{H})$, $7.43(\mathrm{~d}, J=8.0 \mathrm{~Hz}, 0.17 \mathrm{H}), 7.40$ (d, J=8.0 Hz, 0.83H), 7.34-7.27 (m, 2H), 7.17-7.08 (m, 2H), 6.43 (s, 1H), 5.73-5.38 (m, 2H), 4.06 (d, J = 4.7 Hz, 0.32H), 3.93 (d, J=6.5 Hz, 1.68H), 3.63 (d, J = $5.3 \mathrm{~Hz}$, $0.32 \mathrm{H}), 3.60(\mathrm{~d}, J=6.6 \mathrm{~Hz}, 1.68 \mathrm{H}), 1.77$ (brs, $1 \mathrm{H}) .{ }^{13} \mathrm{C}$ NMR $\left(75 \mathrm{MHz}, \mathrm{CDCl}_{3}\right.$ ) Major isomer: $\delta=151.2$ $\left(\mathrm{C}_{\mathrm{q}}\right), 149.5(\mathrm{CH}), 138.9\left(\mathrm{C}_{\mathrm{q}}\right), 138.3(\mathrm{CH}), 137.3\left(\mathrm{C}_{\mathrm{q}}\right), 131.1(\mathrm{CH}), 128.5(\mathrm{CH}), 128.4\left(\mathrm{C}_{\mathrm{q}}\right), 122.1(\mathrm{CH})$, $121.8(\mathrm{CH}), 121.1(\mathrm{CH}), 120.7(\mathrm{CH}), 120.0(\mathrm{CH}), 110.0(\mathrm{CH}), 103.1(\mathrm{CH}), 63.1\left(\mathrm{CH}_{2}\right), 30.6\left(\mathrm{CH}_{2}\right)$. Minor isomer: $\delta=151.2\left(\mathrm{C}_{\mathrm{q}}\right), 149.5(\mathrm{CH}), 139.2\left(\mathrm{C}_{\mathrm{q}}\right), 138.4(\mathrm{CH}), 130.3(\mathrm{CH}), 128.2(\mathrm{CH}), 120.7(\mathrm{CH}), 110.0$ (CH), $102.9(\mathrm{CH}), 58.2\left(\mathrm{CH}_{2}\right), 26.1\left(\mathrm{CH}_{2}\right)$. (Due to overlap, six peaks are missing). IR (ATR) $v=3355$, 2862, 1587, 1469, 1456, 1437, 1348, 1212, 972, 782, $754 \mathrm{~cm}^{-1}$. MS (ESI) m/z (relative intensity): 287 (60) $[\mathrm{M}+\mathrm{Na}]^{+}, 265(80)[\mathrm{M}+\mathrm{H}]^{+}, 247(100)$. HR-MS (ESI) m/z calcd for $\mathrm{C}_{17} \mathrm{H}_{17} \mathrm{~N}_{2} \mathrm{O}[\mathrm{M}+\mathrm{H}]^{+}: 265.1335$, found: 265.1337.

The analytical data were in accordance with those reported in the literature. ${ }^{[66 c]}$

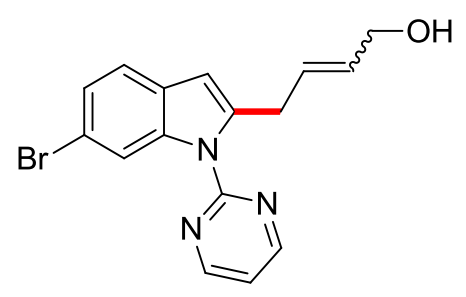

(E/Z)-1-[2-(4-Hydroxybut-2-en-1-yl)-1-(pyridin-2-yl)-1H-indol-3-yl]ethanone (111ea): The general procedure E was followed using 6-bromo-1-(pyrimidin-2-yl)-1H-indole (41e) (68.5 mg, $0.25 \mathrm{mmol}$ ) and 4-vinyl-1,3-dioxolan-2-one (110a) $(72.0 \mu \mathrm{L}, 0.75 \mathrm{mmol})$. Purification by column chromatography on silica gel ( $n$-hexane/EtOAc: $1 / 1$ ) yielded 111 ea $\left(79.2 \mathrm{mg}, 92 \%, E / Z=5.3 / 1.0\right.$ by ${ }^{1} \mathrm{H}$ NMR) as a yellow oil.

${ }^{1} \mathrm{H}$ NMR $\left(300 \mathrm{MHz}, \mathrm{CDCl}_{3}\right) \delta=8.76(\mathrm{~d}, J=4.8 \mathrm{~Hz}, 2 \mathrm{H}), 8.48-8.44(\mathrm{~m}, 1 \mathrm{H}), 7.37(\mathrm{~d}, J=8.3 \mathrm{~Hz}, 1 \mathrm{H})$, $7.28(\mathrm{dd}, J=8.3,1.7 \mathrm{~Hz}, 1 \mathrm{H}), 7.14(\mathrm{t}, J=4.8 \mathrm{~Hz}, 1 \mathrm{H}), 6.43(\mathrm{~s}, 1 \mathrm{H}), 5.87-5.59(\mathrm{~m}, 2 \mathrm{H}), 4.23(\mathrm{~d}, J=4.9$ $\mathrm{Hz}, 0.26 \mathrm{H}), 4.02$ (dd, J = 5.7, $1.2 \mathrm{~Hz}, 1.74 \mathrm{H}), 3.95-3.89(\mathrm{~m}, 2 \mathrm{H}), 1.67$ (brs, $1 \mathrm{H}) .{ }^{13} \mathrm{C}$ NMR $(75 \mathrm{MHz}$, $\mathrm{CDCl}_{3}$ ) Major Isomer: $\delta=158.1(\mathrm{CH}), 157.7\left(\mathrm{C}_{\mathrm{q}}\right), 140.4\left(\mathrm{C}_{\mathrm{q}}\right), 137.6\left(\mathrm{C}_{\mathrm{q}}\right), 131.2(\mathrm{CH}), 128.9(\mathrm{CH}), 127.9$ $\left(\mathrm{C}_{\mathrm{q}}\right), 124.9(\mathrm{CH}), 120.8(\mathrm{CH}), 117.4(\mathrm{CH}), 116.9(\mathrm{CH}), 116.2\left(\mathrm{C}_{\mathrm{q}}\right), 106.2(\mathrm{CH}), 63.2\left(\mathrm{CH}_{2}\right), 32.5\left(\mathrm{CH}_{2}\right)$. Minor Isomer: $\delta=137.6\left(\mathrm{C}_{\mathrm{q}}\right), 130.4(\mathrm{CH}), 128.6(\mathrm{CH}), 125.0(\mathrm{CH}), 117.4(\mathrm{CH}), 117.0(\mathrm{CH}), 116.3\left(\mathrm{C}_{\mathrm{q}}\right)$, 
$106.0(\mathrm{CH}), 58.5\left(\mathrm{CH}_{2}\right), 28.1\left(\mathrm{CH}_{2}\right)$. (Due to overlap, five peaks are missing). IR (ATR) $v=3347,2917$, $1575,1422,1343,973,815,736 \mathrm{~cm}^{-1}$. MS (ESI) m/z (relative intensity): $368(100)[\mathrm{M}+\mathrm{Na}]^{+}\left({ }^{81} \mathrm{Br}\right.$ ), $\left.366(98)[\mathrm{M}+\mathrm{Na}]^{+}\left({ }^{79} \mathrm{Br}\right), 346(50)[\mathrm{M}+\mathrm{H}]^{+}\left({ }^{81} \mathrm{Br}\right), 344(50)[\mathrm{M}+\mathrm{H}]\right]^{+}\left({ }^{79} \mathrm{Br}\right), 328(45)\left({ }^{81} \mathrm{Br}\right), 326(45)$ $\left({ }^{79} \mathrm{Br}\right)$. HR-MS (ESI) m/z calcd for $\mathrm{C}_{16} \mathrm{H}_{14} \mathrm{BrN}_{3} \mathrm{ONa}[\mathrm{M}+\mathrm{Na}]^{+}: 366.0212$, found: 366.0223 .

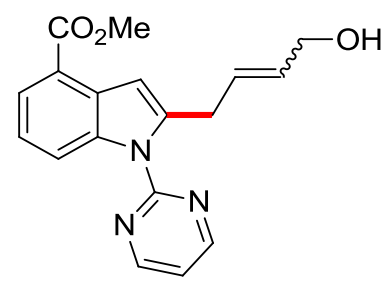

(E/Z)-Methyl 2-(4-hydroxybut-2-en-1-yl)-1-(pyrimidin-2-yl)-1H-indole-4-carboxylate (111fa): The general procedure E was followed using methyl 1-(pyrimidin-2-yl)-1H-indole-4-carboxylate (41f) (63.3 $\mathrm{mg}, 0.25 \mathrm{mmol}$ ) and 4-vinyl-1,3-dioxolan-2-one (110a) $(72.0 \mu \mathrm{L}, 0.75 \mathrm{mmol})$. Purification by column chromatography on silica gel ( $n$-hexane/EtOAc: $1 / 1)$ yielded $111 \mathrm{fa}(77.6 \mathrm{mg}, 96 \%, E / Z=$ 4.7/1.0 by ${ }^{1} \mathrm{H}$ NMR) as a colorless oil.

${ }^{1} \mathrm{H}$ NMR $\left(300 \mathrm{MHz}, \mathrm{CDCl}_{3}\right) \delta=8.77(\mathrm{~d}, J=4.8 \mathrm{~Hz}, 2 \mathrm{H}), 8.38(\mathrm{~d}, J=8.3 \mathrm{~Hz}, 1 \mathrm{H}), 7.91(\mathrm{dd}, J=7.6,1.0 \mathrm{~Hz}$, 1H), 7.37-7.00 (m, 3H), 5.96-5.50 (m, 2H), $4.24(\mathrm{~d}, J=5.2 \mathrm{~Hz}, 0.34 \mathrm{H}), 4.06-3.85(\mathrm{~m}, 6.66 \mathrm{H}), 1.63(\mathrm{~s}$, 1H). ${ }^{13} \mathrm{C} \mathrm{NMR}\left(75 \mathrm{MHz}, \mathrm{CDCl}_{3}\right)$ Major isomer: $\delta=167.8\left(\mathrm{C}_{\mathrm{q}}\right), 158.2(\mathrm{CH}), 157.7\left(\mathrm{C}_{\mathrm{q}}\right), 142.0\left(\mathrm{C}_{\mathrm{q}}\right), 137.7$ $\left(\mathrm{C}_{\mathrm{q}}\right), 131.4(\mathrm{CH}), 129.1\left(\mathrm{C}_{\mathrm{q}}\right), 128.9(\mathrm{CH}), 124.8(\mathrm{CH}), 121.9(\mathrm{CH}), 120.5\left(\mathrm{C}_{\mathrm{q}}\right), 118.2(\mathrm{CH}), 117.6(\mathrm{CH})$, $106.9(\mathrm{CH}), 63.3\left(\mathrm{CH}_{2}\right), 51.7\left(\mathrm{CH}_{3}\right), 32.4\left(\mathrm{CH}_{2}\right)$. Minor isomer: $\delta=142.0\left(\mathrm{C}_{\mathrm{q}}\right), 130.4(\mathrm{CH}), 128.5(\mathrm{CH})$, $124.8(\mathrm{CH}), 118.3(\mathrm{CH}), 106.8(\mathrm{CH}), 58.5\left(\mathrm{CH}_{2}\right), 28.1\left(\mathrm{CH}_{2}\right)$. (Due to overlap, nine peaks are missing). IR (ATR) $v=3439,2950,1708,1566,1420,1258,1137,973,804,753 \mathrm{~cm}^{-1}$. MS (ESI) m/z (relative intensity): 346 (100) $[\mathrm{M}+\mathrm{Na}]^{+}, 324(40)[\mathrm{M}+\mathrm{H}]^{+}, 306$ (60). HR-MS (ESI) m/z calcd for $\mathrm{C}_{18} \mathrm{H}_{18} \mathrm{~N}_{3} \mathrm{O}_{3}$ $[\mathrm{M}+\mathrm{H}]^{+}: 324.1343$, found: 324.1353 .

The analytical data were in accordance with those reported in the literature. ${ }^{[69]}$<smiles>Cc1ccc2c(c1)cc(C/C=C/CO)n2-c1ncccn1</smiles>

(E/Z)-4-[5-Methyl-1-(pyrimidin-2-yl)-1H-indol-2-yl]but-2-en-1-ol (111ga): The general procedure E 
was followed using 5-methyl-1-(pyrimidin-2-yl)-1H-indole $(41 \mathrm{~g})(52.3 \mathrm{mg}, 0.25 \mathrm{mmol})$ and 4-vinyl-1,3-dioxolan-2-one (110a) $(72.0 \mu \mathrm{L}, 0.75 \mathrm{mmol})$. Purification by column chromatography on silica gel ( $n$-hexane/EtOAc: $1 / 1$ ) yielded 111ga (65.4 mg, 94\%, $E / Z=5.2 / 1.0$ by ${ }^{1} \mathrm{H}$ NMR) as a yellow oil.

${ }^{1} \mathrm{H}$ NMR $\left(300 \mathrm{MHz}^{\mathrm{CDCl}}{ }_{3}\right) \delta=8.76(\mathrm{~d}, J=4.8 \mathrm{~Hz}, 2 \mathrm{H}), 8.16(\mathrm{~d}, J=8.5 \mathrm{~Hz}, 1 \mathrm{H}), 7.31(\mathrm{~s}, 1 \mathrm{H}), 7.12(\mathrm{t}, J=$ $4.8 \mathrm{~Hz}, 1 \mathrm{H}), 7.04(\mathrm{dd}, J=8.5,1.6 \mathrm{~Hz}, 1 \mathrm{H}), 6.40(\mathrm{~s}, 1 \mathrm{H}), 5.92-5.62(\mathrm{~m}, 2 \mathrm{H}), 4.27(\mathrm{~d}, J=5.5 \mathrm{~Hz}, 0.32 \mathrm{H})$, $4.05(\mathrm{~d}, J=5.7 \mathrm{~Hz}, 1.68 \mathrm{H}), 4.00-3.94(\mathrm{~m}, 2 \mathrm{H}), 2.44$ (s, 3H), 1.60 (brs, $1 \mathrm{H}) .{ }^{13} \mathrm{C} \mathrm{NMR}\left(75 \mathrm{MHz}, \mathrm{CDCl}_{3}\right)$ Major Isomer: $\delta=158.2\left(\mathrm{C}_{q}\right), 158.1(\mathrm{CH}), 139.7\left(\mathrm{C}_{\mathrm{q}}\right), 135.3\left(\mathrm{C}_{\mathrm{q}}\right), 131.2\left(\mathrm{C}_{\mathrm{q}}\right), 130.9(\mathrm{CH}), 129.6(\mathrm{CH})$, $129.4\left(\mathrm{C}_{\mathrm{q}}\right), 124.1(\mathrm{CH}), 119.8(\mathrm{CH}), 116.9(\mathrm{CH}), 113.6(\mathrm{CH}), 106.3(\mathrm{CH}), 66.4\left(\mathrm{CH}_{2}\right), 32.7\left(\mathrm{CH}_{2}\right), 21.4$ $\left(\mathrm{CH}_{3}\right)$. Minor Isomer: $\delta=158.2(\mathrm{CH}), 139.8\left(\mathrm{C}_{\mathrm{q}}\right), 135.4\left(\mathrm{C}_{\mathrm{q}}\right), 131.3\left(\mathrm{C}_{\mathrm{q}}\right), 130.2(\mathrm{CH}), 129.6(\mathrm{CH}), 129.4$ $\left(\mathrm{C}_{q}\right), 129.1(\mathrm{CH}), 124.2(\mathrm{CH}), 116.9(\mathrm{CH}), 113.8(\mathrm{CH}), 106.2(\mathrm{CH}), 58.6\left(\mathrm{CH}_{2}\right), 28.3\left(\mathrm{CH}_{2}\right)$. (Due to overlap, two peaks are missing). IR (ATR) $v=3315,2924,1646,1429,1137,1027,924,661 \mathrm{~cm}^{-1}$. MS (ESI) $\mathrm{m} / \mathrm{z}$ (relative intensity): $302(100)[\mathrm{M}+\mathrm{Na}]^{+}, 280(43)[\mathrm{M}+\mathrm{H}]^{+}$. HR-MS (ESI) $\mathrm{m} / \mathrm{z}$ calcd for $\mathrm{C}_{17} \mathrm{H}_{17} \mathrm{~N}_{3} \mathrm{ONa}[\mathrm{M}+\mathrm{Na}]^{+}: 302.1264$, found: 302.1265 .

The analytical data were in accordance with those reported in the literature. ${ }^{[69]}$

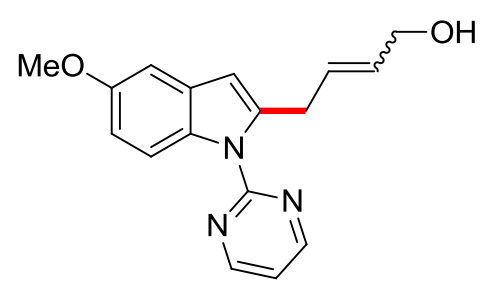

(E/Z)-4-[5-Methoxy-1-(pyrimidin-2-yl)-1H-indol-2-yl]but-2-en-1-ol (111ha): The general procedure E was followed using 5-methoxy-1-(pyrimidin-2-yl)-1H-indole (41h) $(56.3 \mathrm{mg}, 0.25 \mathrm{mmol}$ ) and 4-vinyl-1,3-dioxolan-2-one (110a) $(72.0 \mu \mathrm{L}, 0.75 \mathrm{mmol})$. Purification by column chromatography on silica gel ( $n$-hexane/EtOAc: $1 / 1$ ) yielded 111 ha $\left(48.0 \mathrm{mg}, 65 \%, E / Z=6.7 / 1.0\right.$ by ${ }^{1} \mathrm{H}$ NMR) as a colorless oil.

${ }^{1} \mathrm{H}$ NMR $\left(400 \mathrm{MHz}^{\mathrm{CDCl}}{ }_{3}\right) \delta=8.70(\mathrm{~d}, J=4.8 \mathrm{~Hz}, 2 \mathrm{H}), 8.18(\mathrm{~d}, J=9.1 \mathrm{~Hz}, 1 \mathrm{H}), 7.05(\mathrm{t}, J=4.8 \mathrm{~Hz}, 1 \mathrm{H})$, $6.98(\mathrm{~d}, J=2.5 \mathrm{~Hz}, 1 \mathrm{H}), 6.84(\mathrm{dd}, J=9.1,2.5 \mathrm{~Hz}, 1 \mathrm{H}), 6.38(\mathrm{~d}, J=0.9 \mathrm{~Hz}, 1 \mathrm{H}), 5.93-5.57(\mathrm{~m}, 2 \mathrm{H}), 4.22$ $(\mathrm{d}, J=5.5 \mathrm{~Hz}, 0.31 \mathrm{H}), 4.00(\mathrm{dd}, J=5.8,1.1 \mathrm{~Hz}, 1.69 \mathrm{H}), 3.98-3.88(\mathrm{~m}, 2 \mathrm{H}), 3.83(\mathrm{~s}, 3 \mathrm{H}), 1.68(\mathrm{brs}, 1 \mathrm{H})$. ${ }^{13} \mathrm{C}$ NMR $\left(100 \mathrm{MHz}, \mathrm{CDCl}_{3}\right)$ Major isomer: $\delta=158.0\left(\mathrm{C}_{\mathrm{q}}\right), 157.9(\mathrm{CH}), 155.3\left(\mathrm{C}_{\mathrm{q}}\right), 140.3\left(\mathrm{C}_{\mathrm{q}}\right), 131.9\left(\mathrm{C}_{\mathrm{q}}\right)$, $130.9(\mathrm{CH}), 129.9\left(\mathrm{C}_{\mathrm{q}}\right), 129.5(\mathrm{CH}), 116.7(\mathrm{CH}), 114.9(\mathrm{CH}), 111.5(\mathrm{CH}), 106.4(\mathrm{CH}), 102.3(\mathrm{CH}), 63.3$ 
$\left(\mathrm{CH}_{2}\right)$, $55.6\left(\mathrm{CH}_{3}\right), 32.7\left(\mathrm{CH}_{2}\right)$. Minor isomer: $\delta=155.3\left(\mathrm{C}_{\mathrm{q}}\right), 130.1(\mathrm{CH}), 129.0(\mathrm{CH}), 116.7(\mathrm{CH}), 115.1$ $(\mathrm{CH}), 111.6(\mathrm{CH}), 106.3(\mathrm{CH}), 58.5\left(\mathrm{CH}_{2}\right), 28.4\left(\mathrm{CH}_{2}\right)$. (Due to overlap, seven peaks are missing). IR (ATR) $v=3389,2995,2832,1613,1561,1422,1204,801 \mathrm{~cm}^{-1}$. MS (ESI) m/z (relative intensity): 318 (100) $[\mathrm{M}+\mathrm{Na}]^{+}, 296(56)[\mathrm{M}+\mathrm{H}]^{+}$. HR-MS (ESI) m/z calcd for $\mathrm{C}_{17} \mathrm{H}_{18} \mathrm{~N}_{3} \mathrm{O}_{2}[\mathrm{M}+\mathrm{H}]^{+}:$: 296.1394, found: 296.1405.

The analytical data were in accordance with those reported in the literature. ${ }^{[69]}$

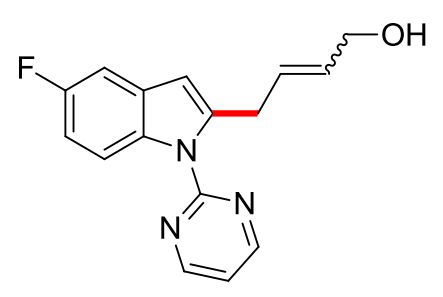

(E/Z)-4-[5-Fluoro-1-(pyrimidin-2-yl)-1H-indol-2-yl]but-2-en-1-ol (111ia): The general procedure E was followed using 5-fluoro-1-(pyrimidin-2-yl)-1H-indole (41i) $(53.3 \mathrm{mg}, 0.25 \mathrm{mmol})$ and 4-vinyl-1,3-dioxolan-2-one (110a) $(72.0 \mu \mathrm{L}, 0.75 \mathrm{mmol})$. Purification by column chromatography on silica gel ( $n$-hexane/EtOAc: $1 / 1$ ) yielded 111 ia $\left(58.7 \mathrm{mg}, 82 \%, E / Z=5.4 / 1\right.$ by ${ }^{1} \mathrm{H} N M R$ ) as a white solid.

M.p. $=93-96{ }^{\circ} \mathrm{C} .{ }^{1} \mathrm{H}$ NMR $\left(400 \mathrm{MHz}, \mathrm{CDCl}_{3}\right) \delta=8.74(\mathrm{~d}, \mathrm{~J}=4.8 \mathrm{~Hz}, 2 \mathrm{H}), 8.25-8.16(\mathrm{~m}, 1 \mathrm{H}), 7.18-7.05$ (m, 2H), $6.92(\mathrm{td}, J=9.2,2.6 \mathrm{~Hz}, 1 \mathrm{H}), 6.41(\mathrm{~d}, J=0.9 \mathrm{~Hz}, 1 \mathrm{H}), 5.97-5.53(\mathrm{~m}, 2 \mathrm{H}), 4.23(\mathrm{~d}, J=5.4 \mathrm{~Hz}$, $0.29 \mathrm{H}), 4.02(\mathrm{dd}, J=5.8,1.2 \mathrm{~Hz}, 1.71 \mathrm{H}), 3.98-3.85(\mathrm{~m}, 2 \mathrm{H}), 1.46(\mathrm{brs}, 1 \mathrm{H}) .{ }^{13} \mathrm{C} \mathrm{NMR}\left(100 \mathrm{MHz}, \mathrm{CDCl}_{3}\right)$ Major isomer: $\delta=158.9\left(\mathrm{~d},{ }^{1} \mathrm{~J}_{\mathrm{C}-\mathrm{F}}=237.9 \mathrm{~Hz}, \mathrm{C}_{\mathrm{q}}\right), 158.1(\mathrm{CH}), 157.9\left(\mathrm{C}_{\mathrm{q}}\right), 141.4\left(\mathrm{C}_{\mathrm{q}}\right), 133.4\left(\mathrm{C}_{\mathrm{q}}\right), 131.2$ (CH), $129.9\left(\mathrm{~d},{ }^{3} \mathrm{~J}_{\mathrm{C}-\mathrm{F}}=9.6 \mathrm{~Hz}, \mathrm{C}_{\mathrm{q}}\right), 129.1(\mathrm{CH}), 117.2(\mathrm{CH}), 114.9\left(\mathrm{~d},{ }^{3} \mathrm{~J}_{\mathrm{C}-\mathrm{F}}=8.9 \mathrm{~Hz}, \mathrm{CH}\right), 110.3\left(\mathrm{~d},{ }^{2} \mathrm{~J}_{\mathrm{C}-\mathrm{F}}=\right.$ $25.3 \mathrm{~Hz}, \mathrm{CH}), 106.3\left(\mathrm{~d},{ }^{4} J_{\mathrm{C}-\mathrm{F}}=3.4 \mathrm{~Hz}, \mathrm{CH}\right), 105.0\left(\mathrm{~d},{ }^{2} \mathrm{~J}_{\mathrm{C}-\mathrm{F}}=23.5 \mathrm{~Hz}, \mathrm{CH}\right), 63.3\left(\mathrm{CH}_{2}\right), 32.7\left(\mathrm{CH}_{2}\right)$. Minor isomer: $\delta=130.3(\mathrm{CH}), 128.8(\mathrm{CH}), 117.2(\mathrm{CH}), 115.0\left(\mathrm{~d},{ }^{3} J_{\mathrm{C}-\mathrm{F}}=8.9 \mathrm{~Hz}, \mathrm{CH}\right), 110.3\left(\mathrm{~d},{ }^{2} \mathrm{~J}_{\mathrm{C}-\mathrm{F}}=25.3 \mathrm{~Hz}\right.$, $\mathrm{CH}), 106.1\left(\mathrm{~d},{ }^{4} J_{\mathrm{C}-\mathrm{F}}=3.4 \mathrm{~Hz}, \mathrm{CH}\right), 58.5\left(\mathrm{CH}_{2}\right), 28.3\left(\mathrm{CH}_{2}\right)$. (Due to overlap, seven peaks are missing). ${ }^{19} \mathrm{~F}$ NMR $\left(376 \mathrm{MHz}, \mathrm{CDCl}_{3}\right.$ ) Major isomer: $\delta=-122.33(\mathrm{td}, J=9.2,4.7 \mathrm{~Hz})$. Minor isomer: -122.42 (td, $J=9.1,4.7 \mathrm{~Hz}$ ). IR (ATR) $v=3272,1562,1431,1174,1109,978,782,592 \mathrm{~cm}^{-1}$. MS (ESI) $\mathrm{m} / \mathrm{z}$ (relative intensity): $306(100)[\mathrm{M}+\mathrm{Na}]^{+}, 284(40)[\mathrm{M}+\mathrm{H}]^{+}, 266$ (90). HR-MS (ESI) m/z calcd for $\mathrm{C}_{16} \mathrm{H}_{15} \mathrm{FN}_{3} \mathrm{O}$ $[\mathrm{M}+\mathrm{H}]^{+}:$284.1194, found: 284.1195 .

The analytical data were in accordance with those reported in the literature. ${ }^{[69]}$ 


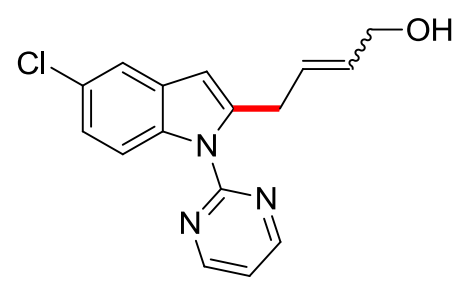

(E/Z)-4-[5-Chloro-1-(pyrimidin-2-yl)-1H-indol-2-yl]but-2-en-1-ol (111ja): The general procedure E was followed using 5-chloro-1-(pyrimidin-2-yl)-1H-indole (41j) (57.4 mg, $0.25 \mathrm{mmol})$ and 4-vinyl-1,3-dioxolan-2-one (110a) $(72.0 \mu \mathrm{L}, 0.75 \mathrm{mmol})$. Purification by column chromatography on silica gel ( $n$-hexane/EtOAc: $1 / 1$ ) yielded 111 ja $\left(57.0 \mathrm{mg}, 76 \%, E / Z=5.5 / 1.0\right.$ by $\left.{ }^{1} \mathrm{H} \mathrm{NMR}\right)$ as a colorless oil.

${ }^{1} \mathrm{H}$ NMR $\left(400 \mathrm{MHz}^{\mathrm{CDCl}}{ }_{3}\right) \delta=8.75(\mathrm{~d}, J=4.8 \mathrm{~Hz}, 2 \mathrm{H}), 8.16(\mathrm{~d}, J=8.9 \mathrm{~Hz}, 1 \mathrm{H}), 7.45(\mathrm{~d}, J=2.2 \mathrm{~Hz}, 1 \mathrm{H})$, 7.19-7.01 (m, 2H), $6.39(\mathrm{~s}, 1 \mathrm{H}), 5.99-5.48(\mathrm{~m}, 2 \mathrm{H}), 4.23(\mathrm{dd}, J=4.6,0.7 \mathrm{~Hz}, 0.23 \mathrm{H}), 4.02(\mathrm{dd}, J=5.7$, $1.2 \mathrm{~Hz}, 1.77 \mathrm{H}), 3.97-3.88(\mathrm{~m}, 2 \mathrm{H}), 1.50$ (brs, $1 \mathrm{H}) .{ }^{13} \mathrm{C} \mathrm{NMR}\left(100 \mathrm{MHz}, \mathrm{CDCl}_{3}\right)$ Major isomer: $\delta=158.1$ $(\mathrm{CH}), 157.8\left(\mathrm{C}_{\mathrm{q}}\right), 141.2\left(\mathrm{C}_{\mathrm{q}}\right), 135.3\left(\mathrm{C}_{\mathrm{q}}\right), 131.3(\mathrm{CH}), 130.3\left(\mathrm{C}_{\mathrm{q}}\right), 129.0(\mathrm{CH}), 127.3\left(\mathrm{C}_{\mathrm{q}}\right), 122.7(\mathrm{CH})$, $119.3(\mathrm{CH}), 117.3(\mathrm{CH}), 115.0(\mathrm{CH}), 105.8(\mathrm{CH}), 63.3\left(\mathrm{CH}_{2}\right), 32.6\left(\mathrm{CH}_{2}\right)$. Minor isomer: $\delta=130.4(\mathrm{CH})$, $128.7(\mathrm{CH}), 127.3\left(\mathrm{C}_{\mathrm{q}}\right), 122.8(\mathrm{CH}), 119.2(\mathrm{CH}), 117.3(\mathrm{CH}), 115.2(\mathrm{CH}), 105.6(\mathrm{CH}), 58.5\left(\mathrm{CH}_{2}\right), 28.2$ $\left(\mathrm{CH}_{2}\right)$. (Due to overlap, five peaks are missing). IR (ATR) $v=3357,2918,1574,1561,1242,1200$, 1069, 974, $802 \mathrm{~cm}^{-1}$. MS (ESI) m/z (relative intensity): $322(100)[\mathrm{M}+\mathrm{Na}]^{+}, 300(40)[\mathrm{M}+\mathrm{H}]^{+}, 282(85)$. HR-MS (ESI) m/z calcd for $\mathrm{C}_{16} \mathrm{H}_{15} \mathrm{ClN}_{3} \mathrm{O}[\mathrm{M}+\mathrm{H}]^{+}: 300.0898$, found: 300.0890 .

The analytical data were in accordance with those reported in the literature. ${ }^{[69]}$<smiles>OC/C=C/Cc1cc2cc(Br)ccc2n1-c1ncccn1</smiles>

(E/Z)-4-[5-Bromo-1-(pyrimidin-2-yl)-1H-indol-2-yl]but-2-en-1-ol (111ca): The general procedure E was followed using 5-bromo-1-(pyrimidin-2-yl)-1H-indole (41c) $(68.5 \mathrm{mg}, 0.25 \mathrm{mmol})$ and 4-vinyl-1,3-dioxolan-2-one (110a) $(72.0 \mu \mathrm{L}, 0.75 \mathrm{mmol})$. Purification by column chromatography on silica gel ( $n$-hexane/EtOAc: $1 / 1$ ) yielded $111 \mathrm{ca}\left(80 \mathrm{mg}, 93 \%, E / Z=4.4 / 1.0\right.$ by ${ }^{1} \mathrm{H}$ NMR) as a colorless oil.

${ }^{1} \mathrm{H}$ NMR $\left(300 \mathrm{MHz}^{\mathrm{CDCl}}{ }_{3}\right) \delta=8.75(\mathrm{~d}, J=4.8 \mathrm{~Hz}, 2 \mathrm{H}), 8.11(\mathrm{~d}, J=8.8 \mathrm{~Hz}, 1 \mathrm{H}), 7.61(\mathrm{~d}, J=2.0 \mathrm{~Hz}, 1 \mathrm{H})$, 
7.32-7.21 (m, 1H), $7.14(\mathrm{t}, J=4.8 \mathrm{~Hz}, 1 \mathrm{H}), 6.38(\mathrm{~s}, 1 \mathrm{H}), 5.89-5.75(\mathrm{~m}, 1 \mathrm{H}), 5.74-5.52(\mathrm{~m}, 1 \mathrm{H}), 4.23(\mathrm{~d}$, $J=4.8 \mathrm{~Hz}, 0.35 \mathrm{H}), 4.02(\mathrm{~d}, J=5.6 \mathrm{~Hz}, 1.65 \mathrm{H}), 3.98-5.85(\mathrm{~m}, 2 \mathrm{H}), 1.41$ (brs, $1 \mathrm{H}) .{ }^{13} \mathrm{C}$ NMR $(75 \mathrm{MHz}$, $\left.\mathrm{CDCl}_{3}\right)$ Major isomer: $\delta=158.1(\mathrm{CH}), 157.8\left(\mathrm{C}_{\mathrm{q}}\right), 141.0\left(\mathrm{C}_{\mathrm{q}}\right), 135.7\left(\mathrm{C}_{\mathrm{q}}\right), 131.3(\mathrm{CH}), 130.9\left(\mathrm{C}_{\mathrm{q}}\right), 129.0$ $(\mathrm{CH}), 125.3(\mathrm{CH}), 122.3(\mathrm{CH}), 117.4(\mathrm{CH}), 115.4(\mathrm{CH}), 115.0\left(\mathrm{C}_{\mathrm{q}}\right), 105.7(\mathrm{CH}), 63.3\left(\mathrm{CH}_{2}\right), 32.5\left(\mathrm{CH}_{2}\right)$. Minor isomer: $\delta=130.4(\mathrm{CH}), 128.7(\mathrm{CH}), 125.4(\mathrm{CH}), 115.6(\mathrm{CH}), 115.0\left(\mathrm{C}_{\mathrm{q}}\right), 58.5\left(\mathrm{CH}_{2}\right), 28.2\left(\mathrm{CH}_{2}\right)$. (Due to overlap, seven peaks are missing). IR (ATR) $v=3357,2863,1560,1420,1198,973,799 \mathrm{~cm}^{-1}$. MS (ESI) m/z (relative intensity): $368(98)[\mathrm{M}+\mathrm{Na}]^{+}\left({ }^{81} \mathrm{Br}\right), 366(98)[\mathrm{M}+\mathrm{Na}]^{+}\left({ }^{79} \mathrm{Br}\right), 356(95)[\mathrm{M}+\mathrm{H}]^{+}$ $\left.\left({ }^{81} \mathrm{Br}\right), 344(95)[\mathrm{M}+\mathrm{H}]\right]^{+}\left({ }^{79} \mathrm{Br}\right), 328(100)\left({ }^{81} \mathrm{Br}\right), 326(100)\left({ }^{79} \mathrm{Br}\right)$. HR-MS (ESI) $\mathrm{m} / \mathrm{z}$ calcd for $\mathrm{C}_{16} \mathrm{H}_{15} \mathrm{BrN}_{3} \mathrm{O}[\mathrm{M}+\mathrm{H}]^{+}:$344.0393, found: 344.0394 .

The analytical data were in accordance with those reported in the literature. ${ }^{[201]}$

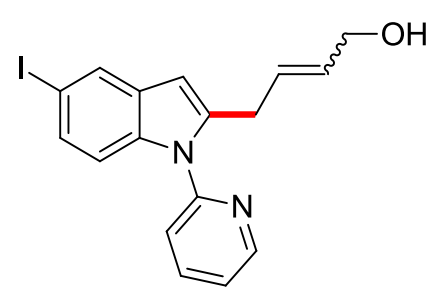

(E/Z)-4-[5-lodo-1-(pyrimidin-2-yl)-1H-indol-2-yl]but-2-en-1-ol (111ka): The general procedure E was followed using 5-iodo-1-(pyridin-2-yl)-1H-indole $(\mathbf{4 1 k})(80.0 \mathrm{mg}, 0.25 \mathrm{mmol})$ and 4-vinyl-1,3-dioxolan-2-one (110a) $(72.0 \mu \mathrm{L}, 0.75 \mathrm{mmol})$. Purification by column chromatography on silica gel ( $n$-hexane/EtOAc: $1 / 1$ ) yielded 111ka ( $85.8 \mathrm{mg}, 88 \%, E / Z=5.5 / 1.0$ by ${ }^{1} \mathrm{H}$ NMR) as a yellow oil.

${ }^{1} \mathrm{H}$ NMR $\left(300 \mathrm{MHz}, \mathrm{CDCl}_{3}\right) \delta=8.62(\mathrm{ddd}, J=4.9,1.9,0.9 \mathrm{~Hz}, 1 \mathrm{H}), 7.89-7.84(\mathrm{~m}, 2 \mathrm{H}), 7.39-7.30(\mathrm{~m}$, $3 \mathrm{H}), 7.07(\mathrm{dt}, J=8.6,0.7 \mathrm{~Hz}, 1 \mathrm{H}), 6.34(\mathrm{~d}, J=0.9 \mathrm{~Hz}, 1 \mathrm{H}), 5.72-5.42(\mathrm{~m}, 2 \mathrm{H}), 4.07(\mathrm{~d}, J=5.6 \mathrm{~Hz}, 0.31$ H), 3.95 (dd, $J=5.7,1.2 \mathrm{~Hz}, 1.69 \mathrm{H}), 3.62-3.55(\mathrm{~m}, 2 \mathrm{H}), 1.71$ (brs, $1 \mathrm{H}) .{ }^{13} \mathrm{C} \mathrm{NMR}\left(125 \mathrm{MHz}, \mathrm{CDCl}_{3}\right)$ Major Isomer: $\delta=150.8\left(\mathrm{C}_{\mathrm{q}}\right), 149.5(\mathrm{CH}), 139.8\left(\mathrm{C}_{\mathrm{q}}\right), 138.3(\mathrm{CH}), 136.4\left(\mathrm{C}_{\mathrm{q}}\right), 131.4(\mathrm{CH}), 130.8\left(\mathrm{C}_{\mathrm{q}}\right)$, $130.0(\mathrm{CH}), 128.7(\mathrm{CH}), 128.0(\mathrm{CH}), 122.3(\mathrm{CH}), 120.9(\mathrm{CH}), 112.0(\mathrm{CH}), 102.2(\mathrm{CH}), 84.1\left(\mathrm{C}_{\mathrm{q}}\right), 63.1$ $\left(\mathrm{CH}_{2}\right), 30.5\left(\mathrm{CH}_{2}\right)$. Minor Isomer: $\delta=150.7\left(\mathrm{C}_{\mathrm{q}}\right), 149.6(\mathrm{CH}), 140.1\left(\mathrm{C}_{\mathrm{q}}\right), 138.4(\mathrm{CH}), 130.4(\mathrm{CH}), 130.1$ $(\mathrm{CH}), 128.8(\mathrm{CH}), 127.8(\mathrm{CH}), 122.4(\mathrm{CH}), 120.9(\mathrm{CH}), 111.9(\mathrm{CH}), 102.0(\mathrm{CH}), 84.2\left(\mathrm{C}_{\mathrm{q}}\right), 58.3\left(\mathrm{CH}_{2}\right)$, $26.1\left(\mathrm{CH}_{2}\right)$. (Due to overlap, two peaks are missing). IR (ATR) $v=3321,2913,2860,1586,1470,1439$, 1274, 782, $580 \mathrm{~cm}^{-1}$. MS (ESI) m/z (relative intensity): $391(100)[\mathrm{M}+\mathrm{H}]^{+}, 413(67)[\mathrm{M}+\mathrm{H}]^{+} . \mathbf{H R}-\mathrm{MS}$ (ESI) $\mathrm{m} / \mathrm{z}$ calcd for $\mathrm{C}_{17} \mathrm{H}_{16} \mathrm{~N}_{2} \mathrm{OI}[\mathrm{M}+\mathrm{H}]^{+}$: 391.0302, found: 391.0315 . 


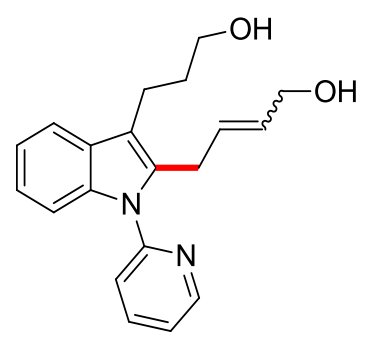

(E/Z)-4-[3-(3-Hydroxypropyl)-1-(pyridin-2-yl)-1H-indol-2-yl]but-2-en-1-ol (111la): The general procedure E was followed using 3-[1-(pyridin-2-yl)-1H-indol-3-yl]propan-1-ol (41I) (63.1 mg, 0.25 mmol) and 4-vinyl-1,3-dioxolan-2-one (110a) (72.0 $\mu \mathrm{L}, 0.75 \mathrm{mmol})$. Purification by column chromatography on silica gel ( $n$-hexane/EtOAc: $1 / 1)$ yielded 111la $(59.6 \mathrm{mg}, 74 \%, E / Z=5.3 / 1.0$ by $\left.{ }^{1} \mathrm{H} N M R\right)$ as a yellow oil.

${ }^{1} \mathrm{H}$ NMR $\left(300 \mathrm{MHz} \mathrm{CDCl}_{3}\right) \delta=8.50(\mathrm{~d}, J=4.9 \mathrm{~Hz}, 1 \mathrm{H}), 7.74(\mathrm{td}, J=7.7,2.0 \mathrm{~Hz}, 1 \mathrm{H}), 7.48-7.44(\mathrm{~m}, 1 \mathrm{H})$, 7.32-7.26 (m, 1H), 7.21-7.15 (m, 2H), 7.06-7.01 (m, 2H), 5.51-5.18 (m, 2H), $3.92(\mathrm{~d}, J=6.1 \mathrm{~Hz}, 0.32$ $\mathrm{Hz}), 3.72(\mathrm{~d}, J=5.9 \mathrm{~Hz}, 1.68 \mathrm{H}), 3.57-3.48(\mathrm{~m}, 4 \mathrm{H}), 2.97$ (brs, 2H), 2.74-2.69 (m, 2H), 1.86-1.68 (m, 2H). ${ }^{13} \mathrm{C}$ NMR (100 MHz, CDCl $)$ Major Isomer: $\delta=151.4\left(\mathrm{C}_{\mathrm{q}}\right), 149.5(\mathrm{CH}), 138.3(\mathrm{CH}), 136.7\left(\mathrm{C}_{\mathrm{q}}\right)$, $133.9\left(\mathrm{C}_{\mathrm{q}}\right), 130.2(\mathrm{CH}), 128.9(\mathrm{CH}), 128.7(\mathrm{CH}), 128.5\left(\mathrm{C}_{\mathrm{q}}\right), 121.9(\mathrm{CH}), 121.3(\mathrm{CH}), 120.2(\mathrm{CH}), 118.4$ $(\mathrm{CH}), 114.8\left(\mathrm{C}_{\mathrm{q}}\right), 110.0(\mathrm{CH}), 62.8\left(\mathrm{CH}_{2}\right), 61.9\left(\mathrm{CH}_{2}\right), 33.0\left(\mathrm{CH}_{2}\right), 27.8\left(\mathrm{CH}_{2}\right), 20.4\left(\mathrm{CH}_{2}\right)$. Minor Isomer: $\delta=151.3\left(\mathrm{C}_{\mathrm{q}}\right), 149.3(\mathrm{CH}), 138.3(\mathrm{CH}), 136.6\left(\mathrm{C}_{\mathrm{q}}\right), 134.7\left(\mathrm{C}_{\mathrm{q}}\right), 129.0(\mathrm{CH}), 128.7(\mathrm{CH}), 128.5\left(\mathrm{C}_{\mathrm{q}}\right)$, $121.9(\mathrm{CH}), 121.2(\mathrm{CH}), 120.3(\mathrm{CH}), 118.3(\mathrm{CH}), 114.6\left(\mathrm{C}_{\mathrm{q}}\right), 109.9(\mathrm{CH}), 61.7\left(\mathrm{CH}_{2}\right), 57.6\left(\mathrm{CH}_{2}\right), 32.8$ $\left(\mathrm{CH}_{2}\right), 23.5\left(\mathrm{CH}_{2}\right), 20.3\left(\mathrm{CH}_{2}\right)$. (Due to overlap, one peak is missing). IR (ATR) $v=3315,2928,2857$, 1588, 1471, 1458, 1437, 1060, $742 \mathrm{~cm}^{-1}$. MS (ESI) m/z (relative intensity): 345 (87) [M+Na] ${ }^{+}, 323$ (100) $[\mathrm{M}+\mathrm{H}]^{+}$. HR-MS (ESI) m/z calcd for $\mathrm{C}_{20} \mathrm{H}_{22} \mathrm{~N}_{2} \mathrm{O}_{2} \mathrm{Na}[\mathrm{M}+\mathrm{H}]^{+}$: 345.1573, found: 345.1586 .

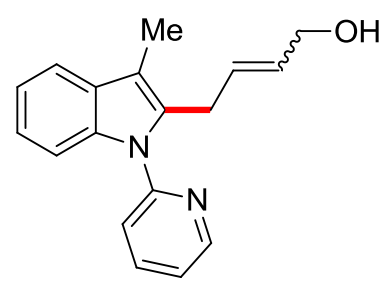

(E/Z)-4-[3-Methyl-1-(pyridin-2-yl)-1H-indol-2-yl]but-2-en-1-ol (111ma): The general procedure E was followed using 3-methyl-1-(pyridin-2-yl)-1H-indole $(41 \mathrm{~m})(52.1 \mathrm{mg}, 0.25 \mathrm{mmol})$ and 4-vinyl-1,3-dioxolan-2-one (110a) $(72.0 \mu \mathrm{L}, 0.75 \mathrm{mmol})$. Purification by column chromatography on silica gel ( $n$-hexane/EtOAc: $1 / 1$ ) yielded $111 \mathrm{ma}$ (38.2 $\mathrm{mg}, 55 \%, E / Z=4.2 / 1.0$ by ${ }^{1} \mathrm{H} \mathrm{NMR}$ ) as a yellow 
oil.

${ }^{1} \mathbf{H}$ NMR $\left(400 \mathrm{MHz}, \mathrm{CDCl}_{3}\right) \delta=8.61(\mathrm{~d}, J=4.0 \mathrm{~Hz}, 1 \mathrm{H}), 7.87-7.81(\mathrm{~m}, 1 \mathrm{H}), 7.55-7.53(\mathrm{~m}, 1 \mathrm{H})$, 7.41-7.37 (m, 1H), 7.33-7.24 (m, 2H), 7.15-7.12 (m, 2H), 5.61-5.28 (m, 2H), $3.97(\mathrm{~d}, J=6.1 \mathrm{~Hz}$, $0.39 \mathrm{H}), 3.87(\mathrm{~d}, J=5.9 \mathrm{~Hz}, 1.61 \mathrm{H}), 3.68(\mathrm{~d}, J=6.1 \mathrm{~Hz}, 0.39 \mathrm{H}), 3.63(\mathrm{~d}, J=6.2 \mathrm{~Hz}, 1.61 \mathrm{H}), 2.32(\mathrm{~s}$, 0.59H), $2.30(\mathrm{~s}, 2.41 \mathrm{H}), 1.59$ (brs, $1 \mathrm{H}) .{ }^{13} \mathrm{C}$ NMR (100 MHz, CDCl 3 ) Major Isomer: $\delta=151.6\left(\mathrm{C}_{\mathrm{q}}\right), 149.4$ $(\mathrm{CH}), 138.1(\mathrm{CH}), 136.5\left(\mathrm{C}_{\mathrm{q}}\right), 133.7\left(\mathrm{C}_{\mathrm{q}}\right), 130.1(\mathrm{CH}), 129.3\left(\mathrm{C}_{\mathrm{q}}\right), 129.0(\mathrm{CH}), 122.0(\mathrm{CH}), 121.7(\mathrm{CH})$, $121.0(\mathrm{CH}), 120.2(\mathrm{CH}), 118.3(\mathrm{CH}), 110.7\left(\mathrm{C}_{\mathrm{q}}\right), 109.9(\mathrm{CH}), 63.2\left(\mathrm{CH}_{2}\right), 27.8\left(\mathrm{CH}_{2}\right), 8.7\left(\mathrm{CH}_{3}\right)$. Minor Isomer: $\delta=151.6\left(\mathrm{C}_{\mathrm{q}}\right), 149.9(\mathrm{CH}), 139.3(\mathrm{CH}), 134.4,129.4\left(\mathrm{C}_{\mathrm{q}}\right), 122.1(\mathrm{CH}), 121.7(\mathrm{CH}), 121.1(\mathrm{CH})$, $120.3(\mathrm{CH}), 118.3(\mathrm{CH}), 110.3\left(\mathrm{C}_{\mathrm{q}}\right), 109.8(\mathrm{CH}), 58.1\left(\mathrm{CH}_{2}\right), 23.8\left(\mathrm{CH}_{2}\right), 8.8\left(\mathrm{CH}_{3}\right)$. (Due to overlap, four peaks are missing). IR (ATR) $v=3349,3054,2916,1587,1471,1457,1381,1315,1087,740 \mathrm{~cm}^{-1}$. MS (ESI) m/z (relative intensity): $301(85)[\mathrm{M}+\mathrm{Na}]^{+}, 279(100)[\mathrm{M}+\mathrm{H}]^{+}$. HR-MS (ESI) m/z calcd for $\mathrm{C}_{18} \mathrm{H}_{19} \mathrm{~N}_{2} \mathrm{O}[\mathrm{M}+\mathrm{H}]^{+}:$279.1497, found: 279.1492 .

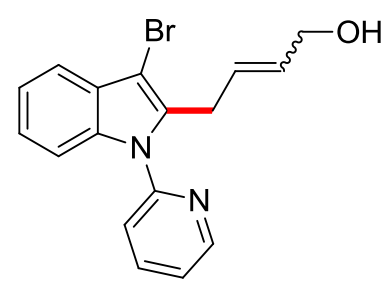

(E/Z)-4-[3-Bromo-1-(pyridin-2-yl)-1H-indol-2-yl]but-2-en-1-ol (111na): The general procedure E was followed using 3-bromo-1-(pyridin-2-yl)-1H-indole (41n) (68.3 mg, $0.25 \mathrm{mmol}$ ) and 4-vinyl-1,3-dioxolan-2-one (110a) $(72.0 \mu \mathrm{L}, 0.75 \mathrm{mmol})$. Purification by column chromatography on silica gel ( $n$-hexane/EtOAc: $1 / 1$ ) yielded 111 na $\left(64.4 \mathrm{mg}, 75 \%, E / Z=4.3 / 1\right.$ by ${ }^{1} \mathrm{H} \mathrm{NMR}$ ) as a yellow oil.

${ }^{1} \mathrm{H}$ NMR $\left(300 \mathrm{MHz}, \mathrm{CDCl}_{3}\right) \delta=8.61(\mathrm{ddd}, J=4.9,2.0,0.9 \mathrm{~Hz}, 1 \mathrm{H}), 7.85(\mathrm{ddd}, J=7.9,7.4,2.0 \mathrm{~Hz}, 1 \mathrm{H})$, 7.57-7.53 (m, 1H), 7.40-7.14 (m, 5H), 5.58-5.27 (m, 2H), $3.99(\mathrm{~d}, J=6.2 \mathrm{~Hz}, 0.36 \mathrm{H}), 3.83(\mathrm{dd}, J=5.7$, $1.3 \mathrm{~Hz}, 1.64 \mathrm{H}$ ), 3.72 (d, $J=6.2 \mathrm{~Hz}, 0.36 \mathrm{H}), 3.68$ (dd, $J=6.2,1.3 \mathrm{~Hz}, 1.64 \mathrm{H}), 2.03$ (brs, $1 \mathrm{H}) .{ }^{13} \mathrm{C}$ NMR $\left(100 \mathrm{MHz}, \mathrm{CDCl}_{3}\right)$ Major Isomer: $\delta=150.6\left(\mathrm{C}_{\mathrm{q}}\right), 149.5(\mathrm{CH}), 138.3(\mathrm{CH}), 136.1\left(\mathrm{C}_{\mathrm{q}}\right), 135.7\left(\mathrm{C}_{\mathrm{q}}\right), 131.0$ $(\mathrm{CH}), 127.3\left(\mathrm{C}_{\mathrm{q}}\right), 127.0(\mathrm{CH}), 123.1(\mathrm{CH}), 122.5(\mathrm{CH}), 121.3(\mathrm{CH}), 121.1(\mathrm{CH}), 118.8(\mathrm{CH}), 110.3(\mathrm{CH})$, $94.2\left(\mathrm{C}_{\mathrm{q}}\right), 62.9\left(\mathrm{CH}_{2}\right), 28.6\left(\mathrm{CH}_{2}\right)$. Minor Isomer: $\delta=150.6\left(\mathrm{C}_{\mathrm{q}}\right), 149.6(\mathrm{CH}), 138.5(\mathrm{CH}), 136.0\left(\mathrm{C}_{\mathrm{q}}\right)$, $135.7\left(\mathrm{C}_{\mathrm{q}}\right), 135.2\left(\mathrm{C}_{\mathrm{q}}\right), 129.8(\mathrm{CH}), 127.3\left(\mathrm{C}_{\mathrm{q}}\right), 123.2(\mathrm{CH}), 122.5(\mathrm{CH}), 121.4(\mathrm{CH}), 110.2(\mathrm{CH}), 93.9$ $\left(\mathrm{C}_{\mathrm{q}}\right), 58.2\left(\mathrm{CH}_{2}\right), 24.7\left(\mathrm{CH}_{2}\right)$. (Due to overlap, two peaks are missing). IR (ATR) $v=3355,3053,2918$, 
1588, 1452, 1436, 1213, 994, $741 \mathrm{~cm}^{-1}$. MS (ESI) m/z (relative intensity): 367 (98) [M+Na] ${ }^{+}\left({ }^{81} \mathrm{Br}\right.$ ), $365(100)[\mathrm{M}+\mathrm{Na}]^{+}\left({ }^{79} \mathrm{Br}\right), 345(88)[\mathrm{M}+\mathrm{H}]^{+}\left({ }^{81} \mathrm{Br}\right), 343(90)[\mathrm{M}+\mathrm{H}]^{+}\left({ }^{79} \mathrm{Br}\right)$. HR-MS (ESI) m/z calcd for $\mathrm{C}_{17} \mathrm{H}_{16} \mathrm{~N}_{2} \mathrm{OBr}[\mathrm{M}+\mathrm{H}]^{+}: 343.0446$, found: 343.0441 .

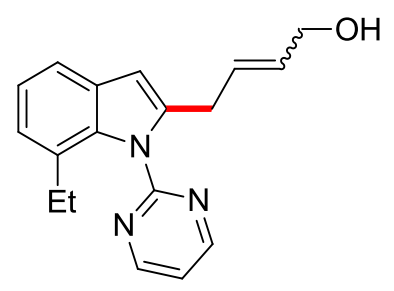

(E/Z)-4-[7-Ethyl-1-(pyrimidin-2-yl)-1H-indol-2-yl]but-2-en-1-ol (1110a): The general procedure E was followed using 7-ethyl-1-(pyrimidin-2-yl)-1H-indole (410) $(55.8 \mathrm{mg}, 0.25 \mathrm{mmol}$ ) and 4-vinyl-1,3-dioxolan-2-one (110a) $(72.0 \mu \mathrm{L}, 0.75 \mathrm{mmol})$. Purification by column chromatography on silica gel ( $n$-hexane/EtOAc: $1 / 1$ ) yielded 1110 a $\left(46.2 \mathrm{mg}, 63 \%, E / Z=5.6 / 1.0\right.$ by ${ }^{1} \mathrm{H} N M R$ ) as a yellow oil.

${ }^{1} \mathrm{H}$ NMR $\left(300 \mathrm{MHz}, \mathrm{CDCl}_{3}\right) \delta=8.85(\mathrm{~d}, J=4.8,2 \mathrm{H}), 7.43(\mathrm{dd}, J=7.7,1.3 \mathrm{~Hz}, 1 \mathrm{H}), 7.32(\mathrm{t}, J=4.8 \mathrm{~Hz}$, 1H), $7.12(\mathrm{t}, J=7.5 \mathrm{~Hz}, 1 \mathrm{H}), 7.02(\mathrm{~d}, J=7.3 \mathrm{~Hz}, 1 \mathrm{H}), 6.44(\mathrm{~s}, 1 \mathrm{H}), 5.72-5.38(\mathrm{~m}, 2 \mathrm{H}), 4.11(\mathrm{~d}, J=5.4 \mathrm{~Hz}$, $0.30 \mathrm{H}$ ), $3.94(\mathrm{~d}, J=5.6 \mathrm{~Hz}, 1.70 \mathrm{H}), 3.51$ (d, J =6.4 Hz, 2H), 2.31 (q, J= $7.4 \mathrm{~Hz}, 2 \mathrm{H}), 1.60$ (brs, $1 \mathrm{H}), 0.96$ $(\mathrm{t}, J=7.4 \mathrm{~Hz}, 3 \mathrm{H}) .{ }^{13} \mathrm{C}$ NMR $\left(75 \mathrm{MHz}, \mathrm{CDCl}_{3}\right)$ Major Isomer: $\delta=159.1\left(\mathrm{C}_{\mathrm{q}}\right), 158.2(\mathrm{CH}), 139.5\left(\mathrm{C}_{\mathrm{q}}\right)$, $135.8\left(\mathrm{C}_{\mathrm{q}}\right), 130.8(\mathrm{CH}), 129.6\left(\mathrm{C}_{\mathrm{q}}\right), 128.6(\mathrm{CH}), 127.9\left(\mathrm{C}_{\mathrm{q}}\right), 122.9(\mathrm{CH}), 121.4(\mathrm{CH}), 119.2(\mathrm{CH}), 118.0$ $(\mathrm{CH}), 104.2(\mathrm{CH}), 63.2\left(\mathrm{CH}_{2}\right), 30.8\left(\mathrm{CH}_{2}\right), 25.8\left(\mathrm{CH}_{2}\right), 14.0\left(\mathrm{CH}_{3}\right)$. Minor Isomer: $\delta=159.1\left(\mathrm{C}_{\mathrm{q}}\right), 158.3$ $(\mathrm{CH}), 139.8\left(\mathrm{C}_{\mathrm{q}}\right), 136.0\left(\mathrm{C}_{\mathrm{q}}\right), 130.2(\mathrm{CH}), 127.9\left(\mathrm{C}_{\mathrm{q}}\right), 121.4(\mathrm{CH}), 119.2(\mathrm{CH}), 104.0(\mathrm{CH}), 58.3\left(\mathrm{CH}_{2}\right)$, $26.3\left(\mathrm{CH}_{2}\right), 25.8\left(\mathrm{CH}_{2}\right)$. (Due to overlap, four peaks are missing). IR (ATR) $v=3312,2966,1561,1416$, 1265, 1092, $743 \mathrm{~cm}^{-1}$. MS (ESI) m/z (relative intensity): 316 (100) [M+Na] ${ }^{+}$HR-MS (ESI) m/z calcd for $\mathrm{C}_{18} \mathrm{H}_{19} \mathrm{~N}_{3} \mathrm{ONa}[\mathrm{M}+\mathrm{Na}]^{+}: 316.1420$, found: 316.1432 .

The analytical data were in accordance with those reported in the literature. ${ }^{[69]}$

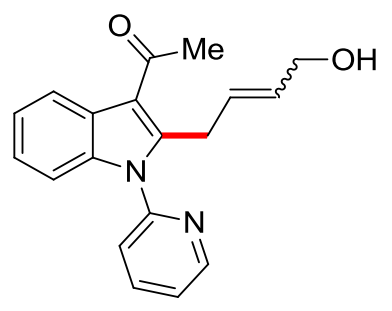

(E/Z)-1-[2-(4-Hydroxybut-2-en-1-yl)-1-(pyridin-2-yl)-1H-indol-3-yl]ethanone (111pa): The general 
procedure E was followed using 1-[1-(pyridin-2-yl)-1H-indol-3-yl]ethanone (41p) $(59.1 \mathrm{mg}, 0.25$ $\mathrm{mmol}$ ) and 4-vinyl-1,3-dioxolan-2-one (110a) (72.0 $\mu \mathrm{L}, 0.75 \mathrm{mmol})$. Purification by column chromatography on silica gel ( $n$-hexane/EtOAc: $1 / 1)$ yielded 111 pa $\left(67.4 \mathrm{mg}, 88 \%, E / Z=5.7 / 1\right.$ by ${ }^{1} \mathrm{H}$ NMR) as a yellow oil.

${ }^{1} \mathrm{H}$ NMR $\left(300 \mathrm{MHz}^{\mathrm{CDCl}}{ }_{3}\right) \delta=8.65(\mathrm{dd}, J=4.9,2.0 \mathrm{~Hz}, 1 \mathrm{H}), 7.96(\mathrm{dt}, J=8.1,1.0 \mathrm{~Hz}, 1 \mathrm{H}), 7.88(\mathrm{td}, J=$ 7.8, 1.9 Hz, 1H), 7.42-7.34 (m, 2H), 7.26-7.20 (m, 1H), 7.16-7.05 (m, 2H), 5.69-5.22 (m, 2H), 3.99 (d, $J=7.3 \mathrm{~Hz}, 0.3 \mathrm{H}), 3.89-3.85(\mathrm{~m}, 3.7 \mathrm{H}), 2.69(\mathrm{~s}, 0.45 \mathrm{H}), 2.67(\mathrm{~s}, 2.55 \mathrm{H}), 1.60$ (brs, $1 \mathrm{H}) .{ }^{13} \mathrm{C}$ NMR $(75$ MHz, $\left.\mathrm{CDCl}_{3}\right)$ Major Isomer: $\delta=194.8\left(\mathrm{C}_{\mathrm{q}}\right), 150.1(\mathrm{CH}), 149.8\left(\mathrm{C}_{\mathrm{q}}\right), 145.4\left(\mathrm{C}_{\mathrm{q}}\right), 138.7(\mathrm{CH}), 137.2\left(\mathrm{C}_{\mathrm{q}}\right)$, $131.0(\mathrm{CH}), 127.8(\mathrm{CH}), 126.2\left(\mathrm{C}_{\mathrm{q}}\right), 123.8(\mathrm{CH}), 123.0(\mathrm{CH}), 122.7(\mathrm{CH}), 122.5(\mathrm{CH}), 120.9(\mathrm{CH}), 115.6$ $\left(\mathrm{C}_{\mathrm{q}}\right), 110.9(\mathrm{CH}), 63.2\left(\mathrm{CH}_{2}\right), 31.8\left(\mathrm{CH}_{3}\right), 29.2\left(\mathrm{CH}_{2}\right)$. Minor Isomer: $\delta=195.3\left(\mathrm{C}_{\mathrm{q}}\right), 150.3(\mathrm{CH}), 149.9$ $\left(\mathrm{C}_{\mathrm{q}}\right), 146.5(\mathrm{CH}), 138.9(\mathrm{CH}), 137.1\left(\mathrm{C}_{\mathrm{q}}\right), 129.9(\mathrm{CH}), 127.2(\mathrm{CH}), 126.1\left(\mathrm{C}_{\mathrm{q}}\right), 124.0(\mathrm{CH}), 122.8(\mathrm{CH})$, 122.7 (CH), $120.7(\mathrm{CH}), 111.0(\mathrm{CH}), 57.8\left(\mathrm{CH}_{2}\right), 31.9\left(\mathrm{CH}_{3}\right), 25.3\left(\mathrm{CH}_{2}\right)$. (Due to overlap, two peaks are missing). IR (ATR) $v=3377,3032,2922,1640,1588,1509,1393,1192,743 \mathrm{~cm}^{-1}$. MS (ESI) m/z (relative intensity): $329(100)[\mathrm{M}+\mathrm{Na}]^{+}, 307(26)[\mathrm{M}+\mathrm{H}]^{+}$. HR-MS (ESI) m/z calcd for $\mathrm{C}_{19} \mathrm{H}_{18} \mathrm{~N}_{2} \mathrm{O}_{2} \mathrm{Na}$ $[\mathrm{M}+\mathrm{Na}]^{+}:$329.1260, found: 329.1262 .

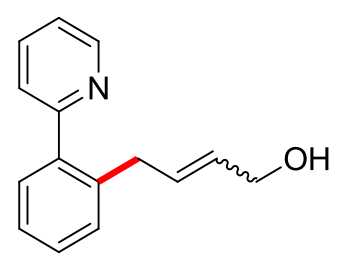

(E/Z)-4-[2-(Pyridin-2-yl)phenyl]but-2-en-1-ol (111qa): The general procedure $E$ was followed using 2-phenylpyridine (20a) (38.8 mg, $0.25 \mathrm{mmol}$ ) and 4-vinyl-1,3-dioxolan-2-one (110a) (72.0 $\mu \mathrm{L}, 0.75$ mmol). Purification by column chromatography on silica gel ( $n$-hexane/EtOAc: $4 / 1$ to $1 / 1$ ) yielded 111qa (36.0 mg, 64\%, $E / Z=7.3 / 1.0$ by ${ }^{1} \mathrm{H} \mathrm{NMR}$ ) as a yellow oil.

${ }^{1} \mathrm{H}$ NMR $\left(300 \mathrm{MHz}, \mathrm{CDCl}_{3}\right) \delta=8.69(\mathrm{brs}, 1 \mathrm{H}), 7.74(\mathrm{t}, J=7.7 \mathrm{~Hz}, 1 \mathrm{H}), 7.41-7.24(\mathrm{~m}, 6 \mathrm{H}), 5.74-5.42(\mathrm{~m}$, $2 \mathrm{H}), 4.03(\mathrm{~d}, J=5.1 \mathrm{~Hz}, 0.25 \mathrm{~Hz}), 3.99$ (d, J = 5.4 Hz, 1.75H), 3.54 (d, J=5.4 Hz, $0.25 \mathrm{~Hz}$ ), 3.49 (d, $J=$ $6.4 \mathrm{~Hz}, 1.75 \mathrm{H}), 1.67$ (brs, $1 \mathrm{H}) .{ }^{13} \mathrm{C}$ NMR $\left(75 \mathrm{MHz}, \mathrm{CDCl}_{3}\right)$ Major Isomer: $\delta=159.9\left(\mathrm{C}_{\mathrm{q}}\right), 149.1(\mathrm{CH})$, $140.3\left(\mathrm{C}_{\mathrm{q}}\right), 137.8\left(\mathrm{C}_{\mathrm{q}}\right), 136.3(\mathrm{CH}), 131.3(\mathrm{CH}), 130.2(\mathrm{CH}), 130.0(\mathrm{CH}), 129.9(\mathrm{CH}), 128.5(\mathrm{CH}), 126.4$ $(\mathrm{CH}), 124.2(\mathrm{CH}), 121.9(\mathrm{CH}), 63.4\left(\mathrm{CH}_{2}\right), 36.0\left(\mathrm{CH}_{2}\right)$. Minor Isomer: $\delta=138.3\left(\mathrm{C}_{\mathrm{q}}\right), 136.6(\mathrm{CH}), 131.2$ (CH), $130.0(\mathrm{CH}), 129.8(\mathrm{CH}), 129.1(\mathrm{CH}), 128.6(\mathrm{CH}), 128.4(\mathrm{CH}), 126.3(\mathrm{CH}), 126.4(\mathrm{CH}), 124.4(\mathrm{CH})$, 
$58.1\left(\mathrm{CH}_{2}\right), 31.1\left(\mathrm{CH}_{2}\right)$. (Due to overlap, two peaks are missing). IR (ATR) $v=3308,2853,1586,1468$, 1425, 1023, 995, 795, $751 \mathrm{~cm}^{-1}$. MS (ESI) m/z (relative intensity): 248 (13) [M+Na], 226 (100) $[M+H]^{+}$. HR-MS (ESI) m/z calcd for $\mathrm{C}_{15} \mathrm{H}_{16} \mathrm{NO}[\mathrm{M}+\mathrm{H}]^{+}:$: 226.1226, found: 226.1226.

The analytical data were in accordance with those reported in the literature. ${ }^{[69]}$

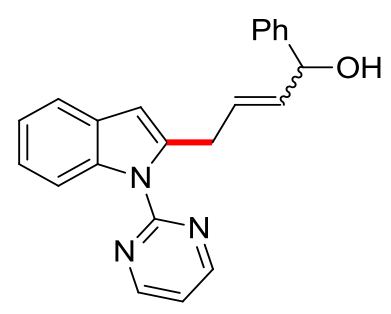

(E/Z)-1-Phenyl-4-[1-(pyrimidin-2-yl)-1H-indol-2-yl]but-2-en-1-ol (111ab): The general procedure E was followed using 1-(pyrimidin-2-yl)-1H-indole (41a) $(48.8 \mathrm{mg}, 0.25 \mathrm{mmol})$ and (trans)-4-phenyl-5-vinyl-1,3-dioxolan-2-one (110b) (142.6 mg, $0.75 \mathrm{mmol}$ ). Purification by column chromatography on silica gel $\left(\mathrm{CH}_{2} \mathrm{Cl}_{2} / \mathrm{Et}_{2} \mathrm{O}: 20 / 1\right)$ yielded $111 \mathrm{ab}\left(68.3 \mathrm{mg}, 80 \%, \mathrm{E} / \mathrm{Z}>20 / 1\right.$ by ${ }^{1} \mathrm{H}$ NMR) as a colorless oil.

${ }^{1} \mathrm{H}$ NMR $\left(500 \mathrm{MHz}, \mathrm{CDCl}_{3}\right) \delta=8.68(\mathrm{~d}, J=4.8 \mathrm{~Hz}, 2 \mathrm{H}), 8.20(\mathrm{dd}, J=8.4,0.9 \mathrm{~Hz}, 1 \mathrm{H}), 7.52(\mathrm{dd}, J=7.6$, $1.5 \mathrm{~Hz}, 1 \mathrm{H}), 7.39-7.09(\mathrm{~m}, 7 \mathrm{H}), 7.01(\mathrm{t}, J=4.8 \mathrm{~Hz}, 1 \mathrm{H}), 6.46(\mathrm{~s}, 1 \mathrm{H}), 5.87$ (ddt, $J=15.3,6.5,1.1 \mathrm{~Hz}$, $1 \mathrm{H}), 5.63(\mathrm{ddt}, J=15.3,6.9,1.5 \mathrm{~Hz}, 1 \mathrm{H}), 5.08(\mathrm{dd}, J=7.0,3.0 \mathrm{~Hz}, 1 \mathrm{H}), 3.97(\mathrm{~d}, J=6.6 \mathrm{~Hz}, 2 \mathrm{H}), 1.81(\mathrm{~d}$, $J=3.5 \mathrm{~Hz}, 1 \mathrm{H}) .{ }^{13} \mathrm{C}$ NMR $\left(75 \mathrm{MHz}, \mathrm{CDCl}_{3}\right) \delta=158.0\left(\mathrm{C}_{\mathrm{q}}\right), 157.9(\mathrm{CH}), 142.9\left(\mathrm{C}_{\mathrm{q}}\right), 139.3\left(\mathrm{C}_{\mathrm{q}}\right), 137.0\left(\mathrm{C}_{\mathrm{q}}\right)$, $134.2(\mathrm{CH}), 129.1\left(\mathrm{C}_{\mathrm{q}}\right), 129.0(\mathrm{CH}), 128.4(\mathrm{CH}), 127.4(\mathrm{CH}), 126.0(\mathrm{CH}), 122.7(\mathrm{CH}), 121.8(\mathrm{CH}), 119.8$ (CH), $117.1(\mathrm{CH}), 113.6(\mathrm{CH}), 106.5(\mathrm{CH}), 74.8(\mathrm{CH}), 32.4\left(\mathrm{CH}_{2}\right)$. IR (ATR) $v=3385,1561,1453,1424$, 1348, 1205, 971, 908, 802, 744, $699 \mathrm{~cm}^{-1}$. MS (ESI) m/z (relative intensity): 364 (40) [M+Na] $]^{+}, 342$ (10) $[\mathrm{M}+\mathrm{H}]^{+}, 324$ (100). HR-MS (ESI) m/z calcd for $\mathrm{C}_{22} \mathrm{H}_{20} \mathrm{~N}_{3} \mathrm{O}[\mathrm{M}+\mathrm{H}]^{+}: 342.1601$, found: 342.1598 .

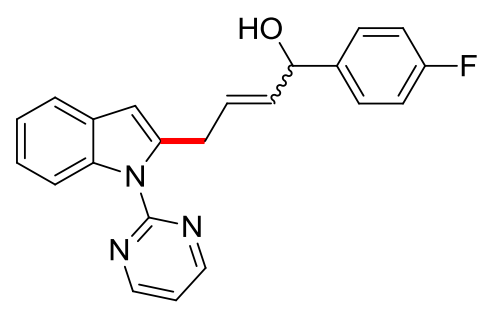

(E/Z)-1-(4-Fluorophenyl)-4-[1-(pyrimidin-2-yl)-1H-indol-2-yl]but-2-en-1-ol (111ad): The general procedure E was followed using 1-(pyrimidin-2-yl)-1H-indole (41a) (48.8 mg, $0.25 \mathrm{mmol}$ ) and (trans)-4-(4-fluorophenyl)-5-vinyl-1,3-dioxolan-2-one (110d) (156.2 mg, 0.75 mmol). Purification by 
column chromatography on silica gel $\left(\mathrm{CH}_{2} \mathrm{Cl}_{2} / \mathrm{Et}_{2} \mathrm{O}: 20 / 1\right)$ yielded $111 \mathrm{ad}(69.2 \mathrm{mg}, 77 \%, \mathrm{E} / \mathrm{Z}=2.8 / 1.0$ by ${ }^{1} \mathrm{H} N \mathrm{NMR}$ ) as a yellow oil.

${ }^{1} \mathrm{H}$ NMR $\left(400 \mathrm{MHz}, \mathrm{CDCl}_{3}\right) \delta=8.75(\mathrm{~d}, J=4.8 \mathrm{~Hz}, 0.44 \mathrm{H}), 8.68(\mathrm{~d}, J=4.8 \mathrm{~Hz}, 1.56 \mathrm{H}), 8.35-8.24(\mathrm{~m}$, $0.28 \mathrm{H}), 8.20(\mathrm{dd}, J=8.2,1.4 \mathrm{~Hz}, 0.72 \mathrm{H}), 7.54-7.48(\mathrm{~m}, 1 \mathrm{H}), 7.37-7.09(\mathrm{~m}, 4 \mathrm{H}), 7.08-6.90(\mathrm{~m}, 3 \mathrm{H})$, $6.45(\mathrm{~d}, J=0.9 \mathrm{~Hz}, 1 \mathrm{H}), 5.93-5.53(\mathrm{~m}, 2 \mathrm{H}), 5.04(\mathrm{~d}, J=6.9 \mathrm{~Hz}, 1 \mathrm{H}), 4.24-3.90(\mathrm{~m}, 2 \mathrm{H}), 2.05$ (brs, $0.22 \mathrm{H}), 1.90$ (brs, 0.78H). ${ }^{13} \mathrm{C}$ NMR $\left(100 \mathrm{MHz}, \mathrm{CDCl}_{3}\right)$ Major isomer: $\delta=162.2\left(\mathrm{~d},{ }^{1} J_{\mathrm{C}-\mathrm{F}}=245.3 \mathrm{~Hz}, \mathrm{C}_{\mathrm{q}}\right)$, $158.0\left(\mathrm{C}_{\mathrm{q}}\right), 158.0(\mathrm{CH}), 139.2\left(\mathrm{C}_{\mathrm{q}}\right), 138.8\left(\mathrm{~d},{ }^{4} \mathrm{~J}_{\mathrm{C}-\mathrm{F}}=3.2 \mathrm{~Hz}, \mathrm{C}_{\mathrm{q}}\right), 137.0\left(\mathrm{C}_{\mathrm{q}}\right), 134.0(\mathrm{CH}), 129.1\left(\mathrm{C}_{\mathrm{q}}\right), 129.2$ (CH), $127.7\left(\mathrm{~d},{ }^{3} \mathrm{~J}_{\mathrm{C}-\mathrm{F}}=8.1 \mathrm{~Hz}, \mathrm{CH}\right), 122.8(\mathrm{CH}), 121.9(\mathrm{CH}), 119.8(\mathrm{CH}), 117.0(\mathrm{CH}), 115.2\left(\mathrm{~d},{ }^{2} \mathrm{~J}_{\mathrm{C}-\mathrm{F}}=21.4\right.$ $\mathrm{Hz}, \mathrm{CH}), 113.7(\mathrm{CH}), 106.6(\mathrm{CH}), 74.1(\mathrm{CH}), 32.4\left(\mathrm{CH}_{2}\right)$. Minor isomer: $\delta=162.2\left(\mathrm{~d},{ }^{1} J_{\mathrm{C}-\mathrm{F}}=245.3 \mathrm{~Hz}\right.$, $\left.\mathrm{C}_{\mathrm{q}}\right), 158.1(\mathrm{CH}), 158.0\left(\mathrm{C}_{\mathrm{q}}\right), 139.3\left(\mathrm{C}_{\mathrm{q}}\right), 138.8\left(\mathrm{~d},{ }^{4} \mathrm{~J}_{\mathrm{C}-\mathrm{F}}=3.2 \mathrm{~Hz}, \mathrm{C}_{\mathrm{q}}\right), 137.0\left(\mathrm{C}_{\mathrm{q}}\right), 133.4 .0(\mathrm{CH}), 129.1\left(\mathrm{C}_{\mathrm{q}}\right)$, $128.6(\mathrm{CH}), 127.7\left(\mathrm{~d},{ }^{3} J_{\mathrm{C}-\mathrm{F}}=8.1 \mathrm{~Hz}, \mathrm{CH}\right), 122.9(\mathrm{CH}), 122.0(\mathrm{CH}), 119.9(\mathrm{CH}), 117.1(\mathrm{CH}), 115.3\left(\mathrm{~d},{ }^{2} \mathrm{~J}_{\mathrm{C}-\mathrm{F}}\right.$ $=21.4 \mathrm{~Hz}, \mathrm{CH}), 114.0(\mathrm{CH}), 106.6(\mathrm{CH}), 69.0(\mathrm{CH}), 28.4\left(\mathrm{CH}_{2}\right) \cdot{ }^{19} \mathrm{~F}$ NMR $\left(376 \mathrm{MHz}, \mathrm{CDCl}_{3}\right)$ Major isomer: $\delta=-115.2(\mathrm{tt}, J=8.7,5.4 \mathrm{~Hz})$. Minor isomer: $\delta=-115.1(\mathrm{tt}, J=8.8,5.4 \mathrm{~Hz})$. IR (ATR) $v=3373$, 3047, 1562, 1507, 1454, 1425, 1349, 1218, 972, 803, $745 \mathrm{~cm}^{-1}$. MS (ESI) m/z (relative intensity): 382 (30) $[\mathrm{M}+\mathrm{Na}]^{+}, 360(5)[\mathrm{M}+\mathrm{H}]^{+}, 342$ (100). HR-MS (ESI) m/z calcd for $\mathrm{C}_{22} \mathrm{H}_{19} \mathrm{FN}_{3} \mathrm{O}_{3}[\mathrm{M}+\mathrm{H}]^{+}: 360.1507$, found: 360.1508 .

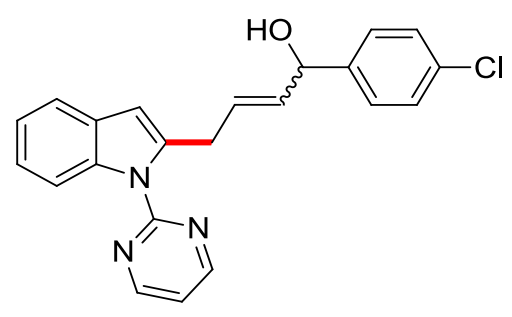

(E/Z)-1-(4-Chlorophenyl)-4-[1-(pyrimidin-2-yl)-1H-indol-2-yl]but-2-en-1-ol (111ac): The general procedure E was followed using 1-(pyrimidin-2-yl)-1H-indole (41a) $(48.8 \mathrm{mg}, 0.25 \mathrm{mmol}$ ) and (trans)-4-(4-chlorophenyl)-5-vinyl-1,3-dioxolan-2-one (110c) (168.5 mg, $0.75 \mathrm{mmol})$. Purification by column chromatography on silica gel $\left(\mathrm{CH}_{2} \mathrm{Cl}_{2} / \mathrm{Et}_{2} \mathrm{O}: 20 / 1\right)$ yielded 111ac $(78.1 \mathrm{mg}, 83 \%, E / Z=3.0 / 1.0$ by ${ }^{1} \mathrm{H}$ NMR) as a colorless oil.

${ }^{1} \mathbf{H}$ NMR $\left(300 \mathrm{MHz}, \mathrm{CDCl}_{3}\right) \delta=8.71(\mathrm{~d}, J=4.8 \mathrm{~Hz}, 0.44 \mathrm{H}), 8.63(\mathrm{~d}, J=4.8 \mathrm{~Hz}, 1.56 \mathrm{H}), 8.30-8.23(\mathrm{~m}$, 0.22H), 8.19-8.11 (m, 0.78H), 7.58-7.40 (m, 1H), 7.24-7.11 (m, 4H), 7.11-7.04 (m, 2H), $6.97(\mathrm{t}, J=$ $4.8 \mathrm{~Hz}, 1 \mathrm{H}), 6.42(\mathrm{~s}, 1 \mathrm{H}), 5.87-5.40(\mathrm{~m}, 2 \mathrm{H}), 4.96(\mathrm{~d}, J=6.9 \mathrm{~Hz}, 1 \mathrm{H}), 4.16-3.81(\mathrm{~m}, 2 \mathrm{H}), 2.23$ (brs, $0.22 \mathrm{H}), 2.11$ (brs, 0.78H). ${ }^{13} \mathrm{C}$ NMR (125 MHz, $\mathrm{CDCl}_{3}$ ) Major isomer: $\delta=158.0\left(\mathrm{C}_{\mathrm{q}}\right), 157.8(\mathrm{CH}), 141.3$ 
$\left(\mathrm{C}_{\mathrm{q}}\right), 139.0\left(\mathrm{C}_{\mathrm{q}}\right), 137.0\left(\mathrm{C}_{\mathrm{q}}\right), 133.7(\mathrm{CH}), 132.9\left(\mathrm{C}_{\mathrm{q}}\right), 129.3(\mathrm{CH}), 128.9\left(\mathrm{C}_{\mathrm{q}}\right), 128.4(\mathrm{CH}), 127.3(\mathrm{CH})$, $122.8(\mathrm{CH}), 121.8(\mathrm{CH}), 119.8(\mathrm{CH}), 117.0(\mathrm{CH}), 113.6(\mathrm{CH}), 106.6(\mathrm{CH}), 74.1(\mathrm{CH}), 32.4\left(\mathrm{CH}_{2}\right)$. Minor isomer: $\delta=158.0(\mathrm{CH}), 141.7\left(\mathrm{C}_{\mathrm{q}}\right), 139.1\left(\mathrm{C}_{\mathrm{q}}\right), 136.9\left(\mathrm{C}_{\mathrm{q}}\right), 133.1(\mathrm{CH}), 133.0\left(\mathrm{C}_{\mathrm{q}}\right), 129.0\left(\mathrm{C}_{\mathrm{q}}\right), 128.7$ $(\mathrm{CH}), 128.4(\mathrm{CH}), 127.2(\mathrm{CH}), 122.7(\mathrm{CH}), 121.9(\mathrm{CH}), 119.8(\mathrm{CH}), 117.0(\mathrm{CH}), 113.9(\mathrm{CH}), 106.5(\mathrm{CH})$, $68.9(\mathrm{CH}), 28.4\left(\mathrm{CH}_{2}\right)$. (Due to overlap, one peak is missing). IR (ATR) $v=3375,3046,1562,1454$, $1424,1348,1088,1013,907,802,730 \mathrm{~cm}^{-1}$. MS (ESI) m/z (relative intensity): 398 (30) [M+Na], 376 (10) $[\mathrm{M}+\mathrm{H}]^{+}, 358$ (100). HR-MS (ESI) m/z calcd for $\mathrm{C}_{22} \mathrm{H}_{19} \mathrm{ClN}_{3} \mathrm{O}[\mathrm{M}+\mathrm{H}]^{+}: 376.1211$, found: 376.1211 .

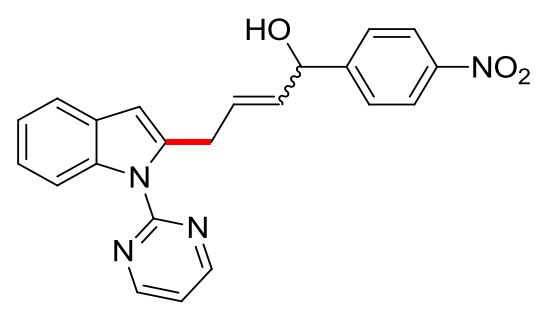

(E/Z)-1-(4-Nitrophenyl)-4-[1-(pyrimidin-2-yl)-1H-indol-2-yl]but-2-en-1-ol (111ae): The general procedure E was followed using 1-(pyrimidin-2-yl)-1H-indole (41a) $(48.8 \mathrm{mg}, 0.25 \mathrm{mmol}$ ) and (trans)-4-(4-nitrophenyl)-5-vinyl-1,3-dioxolan-2-one (110e) (176.4 mg, $0.75 \mathrm{mmol})$. Purification by column chromatography on silica gel ( $n$-hexane/EtOAc: $1 / 1)$ yielded 111ae $(76.4 \mathrm{mg}, 79 \%, E / Z=$ 3.0/1 by $\left.{ }^{1} \mathrm{H} N M R\right)$ as a yellow solid.

M.p. $=128-130{ }^{\circ} \mathrm{C} .{ }^{1} \mathrm{H}$ NMR $\left(300 \mathrm{MHz}, \mathrm{CDCl}_{3}\right) \delta=8.77(\mathrm{~d}, J=4.7 \mathrm{~Hz}, 0.66 \mathrm{H}), 8.67(\mathrm{~d}, J=4.8 \mathrm{~Hz}$, $1.34 \mathrm{H}), 8.27(\mathrm{~d}, J=8.0 \mathrm{~Hz}, 0.29 \mathrm{H}), 8.19(\mathrm{~d}, J=7.4 \mathrm{~Hz}, 0.71 \mathrm{H}), 8.16-8.03(\mathrm{~m}, 2 \mathrm{H}), 7.58-7.42(\mathrm{~m}, 2 \mathrm{H})$, $7.33(\mathrm{~d}, J=8.9 \mathrm{~Hz}, 1 \mathrm{H}), 7.29-7.09(\mathrm{~m}, 2 \mathrm{H}), 7.03(\mathrm{t}, J=4.8 \mathrm{~Hz}, 1 \mathrm{H}), 6.45(\mathrm{~d}, J=5.9 \mathrm{~Hz}, 1 \mathrm{H}), 6.02-5.79$ $(\mathrm{m}, 1 \mathrm{H}), 5.70-5.43(\mathrm{~m}, 1 \mathrm{H}), 5.11(\mathrm{~d}, J=7.2 \mathrm{~Hz}, 1 \mathrm{H}), 4.27-3.84(\mathrm{~m}, 2 \mathrm{H}), 2.26(\mathrm{brs}, 1 \mathrm{H}) .{ }^{13} \mathrm{C}$ NMR $(75$ $\left.\mathrm{MHz}, \mathrm{CDCl}_{3}\right)$ Major isomer: $\delta=158.0\left(\mathrm{C}_{\mathrm{q}}\right), 158.0(\mathrm{CH}), 150.0\left(\mathrm{C}_{\mathrm{q}}\right), 147.0\left(\mathrm{C}_{\mathrm{q}}\right), 138.7\left(\mathrm{C}_{\mathrm{q}}\right), 137.0\left(\mathrm{C}_{\mathrm{q}}\right)$, $132.9(\mathrm{CH}), 130.8(\mathrm{CH}), 129.0\left(\mathrm{C}_{\mathrm{q}}\right), 126.6(\mathrm{CH}), 123.5(\mathrm{CH}), 122.9(\mathrm{CH}), 122.0(\mathrm{CH}), 119.9(\mathrm{CH}), 117.1$ $(\mathrm{CH}), 113.8(\mathrm{CH}), 106.8(\mathrm{CH}), 73.9(\mathrm{CH}), 32.3\left(\mathrm{CH}_{2}\right)$. Minor isomer: $\delta=158.2(\mathrm{CH}), 150.3\left(\mathrm{C}_{\mathrm{q}}\right), 147.1$ $\left(\mathrm{C}_{\mathrm{q}}\right), 138.8\left(\mathrm{C}_{\mathrm{q}}\right), 137.0\left(\mathrm{C}_{\mathrm{q}}\right), 132.4(\mathrm{CH}), 129.8(\mathrm{CH}), 129.0\left(\mathrm{C}_{\mathrm{q}}\right), 126.6(\mathrm{CH}), 123.6(\mathrm{CH}), 123.0(\mathrm{CH})$, $122.1(\mathrm{CH}), 119.9(\mathrm{CH}), 117.2(\mathrm{CH}), 114.0(\mathrm{CH}), 106.6(\mathrm{CH}), 68.6(\mathrm{CH}), 28.4\left(\mathrm{CH}_{2}\right)$. (Due to overlap, one peak is missing). IR (ATR) $v=3377,2917,1562,1515,1474,1422,1342,1208,972,804,745$ $\mathrm{cm}^{-1}$. MS (ESI) m/z (relative intensity): 409 (40) $[\mathrm{M}+\mathrm{Na}]^{+}, 387$ (35) [M+H] $]^{+}, 369$ (100). HR-MS (ESI) $\mathrm{m} / \mathrm{z}$ calcd for $\mathrm{C}_{22} \mathrm{H}_{19} \mathrm{~N}_{4} \mathrm{O}_{3}[\mathrm{M}+\mathrm{H}]^{+}: 387.1452$, found: 387.1458. 


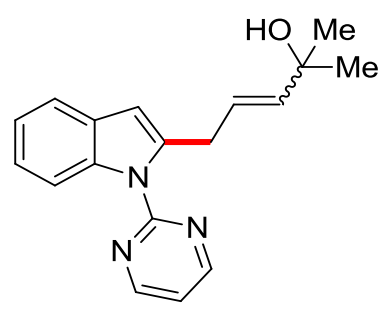

(E/Z)-2-Methyl-5-[1-(pyrimidin-2-yl)-1H-indol-2-yl]pent-3-en-2-ol (111af): The general procedure E was followed using 1-(pyrimidin-2-yl)-1H-indole (41a) $(48.8 \mathrm{mg}, \quad 0.25 \mathrm{mmol})$ and 4,4-dimethyl-5-vinyl-1,3-dioxolan-2-one (110f) (106.6. $\mathrm{mg}, 0.75 \mathrm{mmol}$ ). Purification by column chromatography on silica gel ( $n$-hexane/EtOAc: $1 / 1$ ) yielded 111 af $\left(41.1 \mathrm{mg}, 56 \%, E / Z>20 / 1.0\right.$ by ${ }^{1} \mathrm{H}$ NMR) as a colorless oil.

${ }^{1} \mathbf{H}$ NMR $\left(300 \mathrm{MHz}, \mathrm{CDCl}_{3}\right) \delta=8.76(\mathrm{~d}, J=4.8 \mathrm{~Hz}, 2 \mathrm{H}), 8.25-8.16(\mathrm{~m}, 1 \mathrm{H}), 7.56-7.48(\mathrm{~m}, 1 \mathrm{H})$, 7.23-7.07 (m, 3H), $6.45(\mathrm{q}, J=0.9 \mathrm{~Hz}, 1 \mathrm{H}), 5.74(\mathrm{dt}, J=15.6,6.4 \mathrm{~Hz}, 1 \mathrm{H}), 5.56(\mathrm{dt}, J=15.6,1.3 \mathrm{~Hz}$, $1 \mathrm{H}), 3.92(\mathrm{dt}, J=6.3,1.2 \mathrm{~Hz}, 2 \mathrm{H}), 1.31(\mathrm{bs}, 1 \mathrm{H}), 1.18(\mathrm{~s}, 6 \mathrm{H}) .{ }^{13} \mathrm{C} \mathrm{NMR}\left(125 \mathrm{MHz}, \mathrm{CDCl}_{3}\right) \delta=158.1\left(\mathrm{C}_{\mathrm{q}}\right)$, $158.0(\mathrm{CH}), 139.8\left(\mathrm{C}_{\mathrm{q}}\right), 139.8(\mathrm{CH}), 137.0\left(\mathrm{C}_{\mathrm{q}}\right), 129.1\left(\mathrm{C}_{\mathrm{q}}\right), 123.9(\mathrm{CH}), 122.6(\mathrm{CH}), 121.7(\mathrm{CH}), 119.7$ (CH), $117.0(\mathrm{CH}), 113.5(\mathrm{CH}), 106.4(\mathrm{CH}), 70.6\left(\mathrm{C}_{\mathrm{q}}\right), 32.4\left(\mathrm{CH}_{2}\right), 29.7\left(\mathrm{CH}_{3}\right)$. IR $(\operatorname{ATR}) v=3426,2971$, 1562, 1454, 1424, 1349, 1151, 974, 802, $745 \mathrm{~cm}^{-1}$. MS (ESI) m/z (relative intensity): 316 (40) $[\mathrm{M}+\mathrm{Na}]^{+}, 294(15)[\mathrm{M}+\mathrm{H}]^{+}, 276$ (100). HR-MS (ESI) m/z calcd for $\mathrm{C}_{18} \mathrm{H}_{20} \mathrm{~N}_{3} \mathrm{O}[\mathrm{M}+\mathrm{H}]^{+}:$294.1601, found: 294.1608.<smiles>COC(=O)[C@H](Cc1c(C/C=C/CO)n(-c2ccccn2)c2ccccc12)Nc1ccccc1</smiles>

$(S, E)-$ Methyl 2-(1,3-dioxoisoindolin-2-yl)-3-[2-(4-hydroxybut-2-en-1-yl)-1-(pyrimidin-2-yl)-1Hindol-3-yl]propanoate (111ra): The general procedure $\mathbf{E}$ was followed using (S)-methyl 2-(1,3-dioxoisoindolin-2-yl)-3-[1-(pyrimidin-2-yl)-1H-indol-3-yl]propanoate (41r) (42.6 mg, $0.1 \mathrm{mmol})$ and 4-vinyl-1,3-dioxolan-2-one (110a) $(34.2 \mathrm{mg}, 0.3 \mathrm{mmol})$. Purification by column chromatography on silica gel ( $n$-hexane/EtOAc: $1 / 2$ ) yielded 111ra (34.8 mg, 70\%, $E / Z=7.0 / 1.0$ by ${ }^{1} \mathrm{H} N M R$ ) as a pale yellow solid. 
$[\alpha]_{\mathrm{D}}=+38.8^{\circ}$. M. p. $=71-73^{\circ} \mathrm{C}^{1}{ }^{1} \mathrm{H}$ NMR $\left(300 \mathrm{MHz}, \mathrm{CDCl}_{3}\right) \delta=8.73(\mathrm{~d}, J=4.8 \mathrm{~Hz}, 2 \mathrm{H}), 8.06(\mathrm{ddd}, J=$ 8.3, 1.3, 0.7 Hz, 1H), 7.77-7.71 (m, 2H), 7.67-7.63 (m, 2H), 7.53-7.49 (m, 1H), 7.16-7.03 (m, 3H), 5.70-5.27 (m, 3H), 4.09-3.89 (m, 2H), 3.80 (s, 3H), 3.73 (dd, J = 5.9, $1.1 \mathrm{~Hz}, 2 \mathrm{H}), 3.76-3.71(\mathrm{~m}, 2 \mathrm{H})$, 1.53 (brs, 1H). ${ }^{13} \mathrm{C}$ NMR $\left(75 \mathrm{MHz}, \mathrm{CDCl}_{3}\right) \delta=169.6\left(\mathrm{C}_{\mathrm{q}}\right), 167.8\left(\mathrm{C}_{\mathrm{q}}\right), 158.3(\mathrm{CH}), 158.0\left(\mathrm{C}_{\mathrm{q}}\right), 136.3\left(\mathrm{C}_{\mathrm{q}}\right)$, $136.1\left(\mathrm{C}_{\mathrm{q}}\right), 134.2(\mathrm{CH}), 131.9\left(\mathrm{C}_{\mathrm{q}}\right), 130.3(\mathrm{CH}), 130.2(\mathrm{CH}), 129.3\left(\mathrm{C}_{\mathrm{q}}\right), 123.6(\mathrm{CH}), 123.2(\mathrm{CH}), 121.9$ $(\mathrm{CH}), 118.1(\mathrm{CH}), 117.4(\mathrm{CH}), 113.3(\mathrm{CH}), 113.1\left(\mathrm{C}_{\mathrm{q}}\right), 63.4\left(\mathrm{CH}_{2}\right), 53.1(\mathrm{CH}), 52.7\left(\mathrm{CH}_{3}\right), 28.9\left(\mathrm{CH}_{2}\right)$, $24.2\left(\mathrm{CH}_{2}\right)$. IR (ATR) $v=3349,2926,2854,1744,1714,1427,1104,721 \mathrm{~cm}^{-1}$. MS (ESI) m/z (relative intensity): $519(100)[\mathrm{M}+\mathrm{Na}]^{+}, 497(28)[\mathrm{M}+\mathrm{H}]^{+}$. HR-MS (ESI) m/z calcd for $\mathrm{C}_{28} \mathrm{H}_{24} \mathrm{~N}_{4} \mathrm{O}{ }_{5} \mathrm{Na}[\mathrm{M}+\mathrm{Na}]^{+}$: 519.1639, found: 519.1639 .

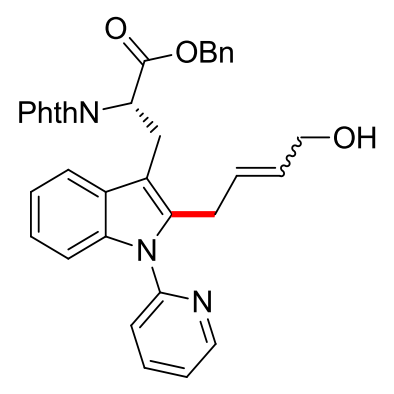

(S,E)-Benzyl 2-(1,3-dioxoisoindolin-2-yl)-3-[2-(4-hydroxybut-2-en-1-yl)-1-(pyrimidin-2-yl)-1H-indol3-yl]propanoate (111sa): The general procedure $\mathbf{E}$ was followed using (S)-benzyl 2-(1,3-dioxo-2,3-dihydro-1H-inden-2-yl)-3-[1-(pyridin-2-yl)-1H-indol-3-yl]propanoate (41s) (50.2 mg, $0.1 \mathrm{mmol}$ ) and 4-vinyl-1,3-dioxolan-2-one (110a) (34.2 $\mathrm{mg}, 0.3 \mathrm{mmol}$ ). Purification by column chromatography on silica gel ( $n$-hexane/EtOAc: $3 / 1$ ) yielded 111 sa $\left(51.4 \mathrm{mg}, 90 \%, E / Z=6.4 / 1\right.$ by ${ }^{1} \mathrm{H}$ NMR) as a yellow solid.

M. p. $=59-61{ }^{\circ} \mathrm{C} .{ }^{1} \mathrm{H}$ NMR $\left(300 \mathrm{MHz}, \mathrm{CDCl}_{3}\right) \delta=8.58(\mathrm{~d}, J=4.8 \mathrm{~Hz}, 1 \mathrm{H}), 7.82(\mathrm{td}, J=7.7,1.9 \mathrm{~Hz}, 1 \mathrm{H})$, 7.77-7.72 (m, 2H), 7.67-7.64 (m, 2H), 7.59-7.63 (m, 1H), 7.34-7.25 (m, 7H), 7.23-7.20 (m, 1H), 7.08-6.99 (m, 2H), 5.51-5.21 (m, 5H), 3.88-3.80 (m, 2H), 3.68 (dd, J = 14.0, $5.7 \mathrm{~Hz}, 4 \mathrm{H}), 1.55$ (brs, 1H). ${ }^{13} \mathrm{C}$ NMR $\left(125 \mathrm{MHz}, \mathrm{CDCl}_{3}\right)$ Major Isomer: $\delta=169.1\left(\mathrm{C}_{\mathrm{q}}\right), 167.9\left(\mathrm{C}_{\mathrm{q}}\right), 151.4\left(\mathrm{C}_{\mathrm{q}}\right), 149.6(\mathrm{CH})$, $138.3(\mathrm{CH}), 136.7\left(\mathrm{C}_{\mathrm{q}}\right), 135.8\left(\mathrm{C}_{\mathrm{q}}\right), 135.4\left(\mathrm{C}_{\mathrm{q}}\right), 134.2(\mathrm{CH}), 131.9\left(\mathrm{C}_{\mathrm{q}}\right), 130.7(\mathrm{CH}), 129.1(\mathrm{CH}), 128.7$ $(\mathrm{CH}), 128.4\left(\mathrm{C}_{\mathrm{q}}\right), 128.3(\mathrm{CH}), 128.2(\mathrm{CH}), 123.6(\mathrm{CH}), 122.2(\mathrm{CH}), 122.1(\mathrm{CH}), 121.4(\mathrm{CH}), 120.7(\mathrm{CH})$, $118.3(\mathrm{CH}), 110.2\left(\mathrm{C}_{\mathrm{q}}\right), 110.1(\mathrm{CH}), 67.7\left(\mathrm{CH}_{2}\right), 63.2\left(\mathrm{CH}_{2}\right), 53.1(\mathrm{CH}), 27.9\left(\mathrm{CH}_{2}\right), 24.4\left(\mathrm{CH}_{2}\right)$. Minor Isomer: $\delta=169.2\left(\mathrm{C}_{\mathrm{q}}\right), 167.6\left(\mathrm{C}_{\mathrm{q}}\right), 151.4\left(\mathrm{C}_{\mathrm{q}}\right), 149.7(\mathrm{CH}), 138.5(\mathrm{CH}), 136.8\left(\mathrm{C}_{\mathrm{q}}\right), 136.7\left(\mathrm{C}_{\mathrm{q}}\right), 135.3\left(\mathrm{C}_{\mathrm{q}}\right)$, $134.4(\mathrm{CH}), 131.9\left(\mathrm{C}_{\mathrm{q}}\right), 129.6(\mathrm{CH}), 128.5(\mathrm{CH}), 128.4(\mathrm{CH}), 118.3\left(\mathrm{C}_{\mathrm{q}}\right), 123.7(\mathrm{CH}), 122.4(\mathrm{CH}), 121.5$ 
$(\mathrm{CH}), 120.8(\mathrm{CH}), 118.1(\mathrm{CH}), 109.8\left(\mathrm{C}_{\mathrm{q}}\right), 67.8\left(\mathrm{CH}_{2}\right), 58.3\left(\mathrm{CH}_{2}\right), 52.7(\mathrm{CH}), 29.8\left(\mathrm{CH}_{2}\right), 24.6\left(\mathrm{CH}_{2}\right)$. (Due to overlap, four peaks are missing). IR (ATR) $v=3318,2926,1775,1743,1588,1470,1438$, 1388, 906, $722 \mathrm{~cm}^{-1}$. MS (ESI) m/z (relative intensity): 1143 (5) $[2 \mathrm{M}+\mathrm{H}]^{+}, 572(100)[\mathrm{M}+\mathrm{H}]^{+}$. HR-MS (ESI) $\mathrm{m} / \mathrm{z}$ calcd for $\mathrm{C}_{35} \mathrm{H}_{30} \mathrm{~N}_{3} \mathrm{O}_{5}[\mathrm{M}+\mathrm{H}]^{+}:$572.2180, found: 572. 2186.

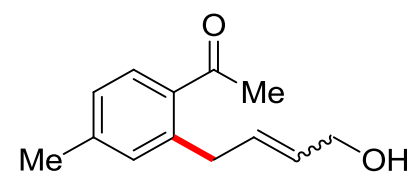

(E/Z)-1-[2-(4-hydroxybut-2-en-1-yl)-4-methylphenyl]ethanone (165aa): The general procedure F was followed using (E)-4-methoxy- $N$-[1-( $p$-tolyl)ethylidene]aniline (34a) (59.8 mg, $0.25 \mathrm{mmol}$ ) and 4-vinyl-1,3-dioxolan-2-one (110a) $(72.0 \mu \mathrm{L}, 0.75 \mathrm{mmol})$. Purification by column chromatography on silica gel ( $n$-hexane/EtOAc: $2 / 1$ ) yielded 165aa $\left(27.0 \mathrm{mg}, 53 \%, E / Z>20 / 1.0\right.$ by $\left.{ }^{1} \mathrm{H} \mathrm{NMR}\right)$ as a colorless oil.

${ }^{1} \mathrm{H}$ NMR $\left(400 \mathrm{MHz}, \mathrm{CDCl}_{3}\right) \delta=7.59(\mathrm{~d}, J=7.9 \mathrm{~Hz}, 1 \mathrm{H}), 7.15-6.99(\mathrm{~m}, 2 \mathrm{H}), 5.85(\mathrm{dtt}, J=15.7,6.5,1.4$ $\mathrm{Hz}, 1 \mathrm{H}), 5.62(\mathrm{dtt}, J=15.3,5.9,1.5 \mathrm{~Hz}, 1 \mathrm{H}), 4.07$ (dd, $J=5.9,1.2 \mathrm{~Hz}, 2 \mathrm{H}), 3.62(\mathrm{dd}, J=6.5,1.4 \mathrm{~Hz}, 2 \mathrm{H})$, $2.53(\mathrm{~s}, 3 \mathrm{H}), 2.34(\mathrm{~s}, 3 \mathrm{H}), 1.53$ (brs, 1H). ${ }^{13} \mathrm{C}$ NMR (100 MHz, CDCl 3 ) $\delta=201.2\left(\mathrm{C}_{\mathrm{q}}\right), 142.4\left(\mathrm{C}_{\mathrm{q}}\right), 140.4$ $\left(\mathrm{C}_{\mathrm{q}}\right), 134.6\left(\mathrm{C}_{\mathrm{q}}\right), 132.1(\mathrm{CH}), 131.8(\mathrm{CH}), 129.9(\mathrm{CH}), 129.9(\mathrm{CH}), 126.8(\mathrm{CH}), 63.6\left(\mathrm{CH}_{2}\right), 36.8\left(\mathrm{CH}_{2}\right)$, $29.5\left(\mathrm{CH}_{3}\right), 21.4\left(\mathrm{CH}_{3}\right)$. IR (ATR) $v=3406,2920,1678,1608,1431,1356,1259,971,817 \mathrm{~cm}^{-1}$. MS (ESI) m/z (relative intensity): $227(100)[\mathrm{M}+\mathrm{Na}]^{+}, 187$ (80). HR-MS (ESI) m/z calcd for $\mathrm{C}_{13} \mathrm{H}_{16} \mathrm{O}_{2} \mathrm{Na}[\mathrm{M}+\mathrm{Na}]^{+}$: 227.1043, found: 227.1044 .<smiles>CC(=O)c1ccc(-c2ccccc2)cc1CC=CCO</smiles>

(E/Z)-1-\{3-(4-Hydroxybut-2-en-1-yl)-[1,1'-biphenyl]-4-yl\}ethanone (165ba): The general procedure

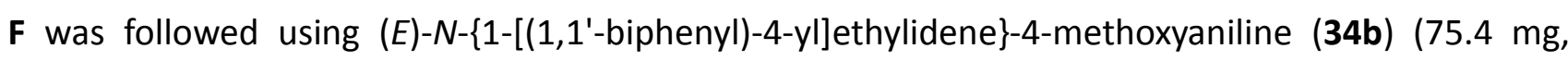
$0.25 \mathrm{mmol}$ ) and 4-vinyl-1,3-dioxolan-2-one (110a) $(72.0 \mu \mathrm{L}, 0.75 \mathrm{mmol})$. Purification by column chromatography on silica gel ( $n$-hexane/EtOAc: $2 / 1$ ) yielded 165 ba $(44.0 \mathrm{mg}, 66 \%, E / Z>20 / 1.0$ by $\left.{ }^{1} \mathrm{H} N M R\right)$ as a yellow oil. 
${ }^{1} \mathbf{H}$ NMR $\left(300 \mathrm{MHz}, \mathrm{CDCl}_{3}\right) \delta=7.76(\mathrm{dd}, J=8.0,0.5 \mathrm{~Hz}, 1 \mathrm{H}), 7.68-7.55(\mathrm{~m}, 2 \mathrm{H}), 7.52-7.31(\mathrm{~m}, 5 \mathrm{H})$, $5.90(\mathrm{dtt}, J=15.5,6.4,1.3 \mathrm{~Hz}, 1 \mathrm{H}), 5.66(\mathrm{dtt}, J=15.4,5.8,1.4 \mathrm{~Hz}, 1 \mathrm{H}), 4.08(\mathrm{dd}, J=5.8,1.2 \mathrm{~Hz}, 2 \mathrm{H})$, $3.72(\mathrm{dd}, J=6.5,1.4 \mathrm{~Hz}, 2 \mathrm{H}), 2.59(\mathrm{~s}, 3 \mathrm{H}), 1.68$ (bs, $1 \mathrm{H}) .{ }^{13} \mathrm{C} \mathrm{NMR}\left(125 \mathrm{MHz}, \mathrm{CDCl}_{3}\right) \delta=201.1\left(\mathrm{C}_{\mathrm{q}}\right)$, $144.3\left(\mathrm{C}_{\mathrm{q}}\right), 140.7\left(\mathrm{C}_{\mathrm{q}}\right), 139.7\left(\mathrm{C}_{\mathrm{q}}\right), 136.0\left(\mathrm{C}_{\mathrm{q}}\right), 131.4(\mathrm{CH}), 130.2(\mathrm{CH}), 130.0(\mathrm{CH}), 30.0(\mathrm{CH}), 128.8$ (CH), $128.0(\mathrm{CH}), 127.1(\mathrm{CH}), 124.7(\mathrm{CH}), 63.5\left(\mathrm{CH}_{2}\right), 36.9\left(\mathrm{CH}_{2}\right), 29.7\left(\mathrm{CH}_{3}\right)$. IR (ATR) $v=3384,2918$, 2860, 1677, 1605, 1430, 1250, 971, 764, $697 \mathrm{~cm}^{-1}$. MS (ESI) m/z (relative intensity): 289 (100) $[\mathrm{M}+\mathrm{Na}]^{+}, 249$ (95). HR-MS (ESI) m/z calcd for $\mathrm{C}_{18} \mathrm{H}_{19} \mathrm{O}_{2}[\mathrm{M}+\mathrm{H}]^{+}:$267.1380, found: 267.1376.<smiles>CC(=O)c1ccc(C(F)(F)F)cc1C/C=C/CO</smiles>

(E/Z)-1-[2-(4-Hydroxybut-2-en-1-yl)-4-(trifluoromethyl)phenyl]ethanone (165ca): The general procedure $\mathbf{F}$ was followed using (E)-4-methoxy- $N$-\{1-[4-(trifluoromethyl)phenyl]ethylidene\}aniline (34c) (73.3 mg, $0.25 \mathrm{mmol})$ and 4-vinyl-1,3-dioxolan-2-one (110a) $(72.0 \mu \mathrm{L}, 0.75 \mathrm{mmol})$. Purification by column chromatography on silica gel ( $n$-hexane/EtOAc: $2 / 1)$ yielded $165 \mathrm{ca}(44.5 \mathrm{mg}, 69 \%, E / Z=$ $10 / 1$ by ${ }^{1} \mathrm{H}$ NMR) as a colorless oil.

${ }^{1} \mathrm{H}$ NMR $\left(300 \mathrm{MHz}^{\mathrm{CDCl}}{ }_{3}\right) \delta=7.68(\mathrm{~d}, J=8.0 \mathrm{~Hz}, 1 \mathrm{H}), 7.59-7.44(\mathrm{~m}, 2 \mathrm{H}), 5.81(\mathrm{dtt}, J=15.5,6.4,1.4$ $\mathrm{Hz}, 1 \mathrm{H}), 5.62(\mathrm{dtt}, J=15.4,5.7,1.4 \mathrm{~Hz}, 1 \mathrm{H}), 4.25(\mathrm{dd}, J=11.5,3.2 \mathrm{~Hz}, 0.18 \mathrm{H}), 4.08(\mathrm{~d}, J=5.6 \mathrm{~Hz}$, $1.82 \mathrm{H}), 3.76(\mathrm{~d}, J=3.0 \mathrm{~Hz}, 0.19 \mathrm{H}), 3.62(\mathrm{~d}, J=7.0 \mathrm{~Hz}, 1.81), 2.56(\mathrm{~s}, 3 \mathrm{H}), 1.53$ (brs, $1 \mathrm{H}) .{ }^{13} \mathrm{C} \mathrm{NMR}(75$ $\left.\mathrm{MHz}, \mathrm{CDCl}_{3}\right) \delta=201.5\left(\mathrm{C}_{\mathrm{q}}\right), 141.2\left(\mathrm{C}_{\mathrm{q}}\right), 140.3\left(\mathrm{C}_{\mathrm{q}}\right), 133.0\left(\mathrm{q},{ }^{2} \mathrm{~J}=32.0 \mathrm{~Hz}, \mathrm{C}_{\mathrm{q}}\right), 132.2(\mathrm{CH}), 130.0(\mathrm{CH})$, $128.9(\mathrm{CH}), 127.9\left(\mathrm{q},{ }^{3} \mathrm{~J}=3.6 \mathrm{~Hz}, \mathrm{CH}\right), 123.5\left(\mathrm{q},{ }^{1} \mathrm{~J}=273.6 \mathrm{~Hz}, \mathrm{C}_{\mathrm{q}}\right), 123.2\left(\mathrm{~d},{ }^{3} \mathrm{~J}=4.0 \mathrm{~Hz}, \mathrm{CH}\right), 63.3\left(\mathrm{CH}_{2}\right)$, $36.2\left(\mathrm{CH}_{2}\right), 30.0\left(\mathrm{CH}_{3}\right) .{ }^{19} \mathrm{~F} \mathrm{NMR}\left(283 \mathrm{MHz}, \mathrm{CDCl}_{3}\right) \delta=-63.07$. IR (ATR) $v=3373,2918,1691,1359$, 1164, 1122, 1088, 970, $831 \mathrm{~cm}^{-1}$. MS (ESI) m/z (relative intensity): 281 (100) [M+Na] $]^{+}, 241$ (90). HR-MS (ESI) $\mathrm{m} / \mathrm{z}$ calcd for $\mathrm{C}_{13} \mathrm{H}_{13} \mathrm{~F}_{3} \mathrm{O}_{2} \mathrm{Na}[\mathrm{M}+\mathrm{Na}]^{+}:$281.0760, found: 281.0764 .

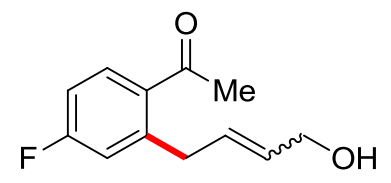

(E/Z)-1-[4-Fluoro-2-(4-hydroxybut-2-en-1-yl)phenyl]ethanone (165da): The general procedure F was followed using (E)-N-[1-(4-fluorophenyl)ethylidene]-4-methoxyaniline (34d) (60.8 mg, 0.25 
$\mathrm{mmol}$ ) and 4-vinyl-1,3-dioxolan-2-one (110a) (72.0 $\mu \mathrm{L}, 0.75 \mathrm{mmol})$. Purification by column chromatography on silica gel ( $n$-hexane/EtOAc: $2 / 1$ ) yielded $165 \mathrm{da}(37.0 \mathrm{mg}, 71 \%, E / Z>20 / 1.0$ by ${ }^{1} \mathrm{H}$ NMR) as a colorless oil.

${ }^{1} \mathbf{H}$ NMR $\left(300 \mathrm{MHz}, \mathrm{CDCl}_{3}\right) \delta=7.75-7.64(\mathrm{~m}, 1 \mathrm{H}), 7.01-6.87(\mathrm{~m}, 2 \mathrm{H}), 5.94-5.74(\mathrm{~m}, 1 \mathrm{H}), 5.72-5.55$ $(\mathrm{m}, 1 \mathrm{H}), 4.08(\mathrm{~d}, J=5.6 \mathrm{~Hz}, 2 \mathrm{H}), 3.64(\mathrm{~d}, J=5.3 \mathrm{~Hz}, 2 \mathrm{H}), 2.54(\mathrm{~s}, 3 \mathrm{H}), 1.58$ (brs, 1H). ${ }^{13} \mathrm{C}$ NMR $(75$ $\left.\mathrm{MHz}_{\mathrm{CDCl}}\right) \delta=200.1\left(\mathrm{C}_{\mathrm{q}}\right), 164.2\left(\mathrm{~d},{ }^{1} \mathrm{~J}=254.1 \mathrm{~Hz}, \mathrm{C}_{\mathrm{q}}\right) 144.1\left(\mathrm{~d},{ }^{3} \mathrm{~J}=7.9 \mathrm{~Hz}, \mathrm{C}_{\mathrm{q}}\right), 133.6\left(\mathrm{~d},{ }^{4} \mathrm{~J}=3.2 \mathrm{~Hz}\right.$, $\left.\mathrm{C}_{\mathrm{q}}\right), 132.0\left(\mathrm{~d},{ }^{3} \mathrm{~J}=9.2 \mathrm{~Hz}, \mathrm{CH}\right), 130.9(\mathrm{CH}), 130.4(\mathrm{CH}), 118.1\left(\mathrm{~d},{ }^{2} \mathrm{~J}=21.5 \mathrm{~Hz}, \mathrm{CH}\right), 113.1\left(\mathrm{~d},{ }^{2} \mathrm{~J}=21.5\right.$ $\mathrm{Hz}, \mathrm{CH}), 63.4\left(\mathrm{CH}_{2}\right), 36.6\left(\mathrm{CH}_{2}\right), 29.6\left(\mathrm{CH}_{3}\right) .{ }^{19} \mathrm{~F}$ NMR $\left(283 \mathrm{MHz}, \mathrm{CDCl}_{3}\right) \delta=-107.21$ (ddd, J = 9.6, 7.9, $5.7 \mathrm{~Hz}$ ). IR (ATR) $v=3393,2861,1680,1581,1356,1233,972,817,578 \mathrm{~cm}^{-1}$. MS (ESI) m/z (relative intensity): 231 (90) $[\mathrm{M}+\mathrm{Na}]^{+}, 191$ (100). HR-MS (ESI) m/z calcd for $\mathrm{C}_{12} \mathrm{H}_{14} \mathrm{FO}_{2}[\mathrm{M}+\mathrm{H}]^{+}:$209.0972, found: 209.0966 .

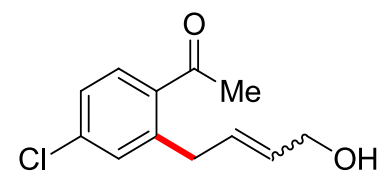

(E/Z)-1-[4-Chloro-2-(4-hydroxybut-2-en-1-yl)phenyl]ethanone (165ea): The general procedure $\mathrm{F}$ was followed using (E)-N-[1-(4-chlorophenyl)ethylidene]-4-methoxyaniline (34e) (64.9 mg, 0.25 mmol) and 4-vinyl-1,3-dioxolan-2-one (110a) (72.0 $\mu \mathrm{L}, 0.75 \mathrm{mmol})$. Purification by column chromatography on silica gel ( $n$-hexane/EtOAc: $2 / 1)$ yielded 165 ea $(41.0 \mathrm{mg}, 73 \%, E / Z=11.5 / 1.0$ by ${ }^{1} \mathrm{H}$ NMR) as a colorless oil.

${ }^{1} \mathbf{H}$ NMR $\left(300 \mathrm{MHz}, \mathrm{CDCl}_{3}\right) \delta=7.59(\mathrm{~d}, J=9.0 \mathrm{~Hz}, 1 \mathrm{H}), 7.34-7.12(\mathrm{~m}, 2 \mathrm{H}), 5.81(\mathrm{dtt}, J=15.5,6.3,1.3$ $\mathrm{Hz}, 1 \mathrm{H}), 5.63(\mathrm{dtt}, J=15.4,5.7,1.4 \mathrm{~Hz}, 1 \mathrm{H}), 4.08(\mathrm{dd}, J=5.6,1.2 \mathrm{~Hz}, 2 \mathrm{H}), 3.60(\mathrm{dd}, J=6.4,1.3 \mathrm{~Hz}, 2 \mathrm{H})$, $2.53(\mathrm{~s}, 3 \mathrm{H}), 1.52$ (brs, $1 \mathrm{H}) .{ }^{13} \mathrm{C}$ NMR $\left(125 \mathrm{MHz}, \mathrm{CDCl}_{3}\right) \delta=200.4\left(\mathrm{C}_{\mathrm{q}}\right), 142.2\left(\mathrm{C}_{\mathrm{q}}\right), 137.6\left(\mathrm{C}_{\mathrm{q}}\right), 135.8$ $\left(\mathrm{C}_{\mathrm{q}}\right), 131.2(\mathrm{CH}), 130.9(\mathrm{CH}), 130.6(\mathrm{CH}), 130.3(\mathrm{CH}), 126.3(\mathrm{CH}), 63.4\left(\mathrm{CH}_{2}\right), 36.4\left(\mathrm{CH}_{2}\right), 29.7\left(\mathrm{CH}_{3}\right)$. IR (ATR) $v=3378,2860,1681,1590,1557,1356,1248,1102,970,816 \mathrm{~cm}^{-1}$. MS (ESI) m/z (relative intensity): 247 (100) $[\mathrm{M}+\mathrm{Na}]^{+}, 207$ (95). HR-MS (ESI) m/z calcd for $\mathrm{C}_{12} \mathrm{H}_{14} \mathrm{ClO}_{2}[\mathrm{M}+\mathrm{H}]^{+}: 225.0677$, found: 225.0690 . 
<smiles>CC(=O)c1ccc(Br)cc1C/C=C/CO</smiles>

(E/Z)-1-[4-Bromo-2-(4-hydroxybut-2-en-1-yl)phenyl]ethanone (165fa): The general procedure $\mathrm{F}$ was followed using (E)-N-[1-(4-bromophenyl)ethylidene]-4-methoxyaniline (34f) (76.1 mg, 0.25 mmol) and 4-vinyl-1,3-dioxolan-2-one (110a) (72.0 $\mu \mathrm{L}, 0.75 \mathrm{mmol})$. Purification by column chromatography on silica gel ( $n$-hexane/EtOAc: $2 / 1)$ yielded $165 \mathrm{fa}(55.2 \mathrm{mg}, 82 \%, E / Z=9.0 / 1.0$ by ${ }^{1} \mathrm{H}$ NMR) as a colorless oil.

${ }^{1} \mathbf{H}$ NMR $\left(300 \mathrm{MHz}_{\mathrm{CDCl}}\right) \delta=7.51(\mathrm{~d}, J=8.8 \mathrm{~Hz}, 1 \mathrm{H}), 7.46-7.33(\mathrm{~m}, 2 \mathrm{H}), 5.81(\mathrm{dtt}, J=15.5,6.4,1.3$ $\mathrm{Hz}, 1 \mathrm{H}), 5.62(\mathrm{dtt}, J=15.4,5.7,1.3 \mathrm{~Hz}, 1 \mathrm{H}), 4.08(\mathrm{dd}, J=5.7,1.2 \mathrm{~Hz}, 2 \mathrm{H}), 3.59$ (dd, $J=6.4,1.3 \mathrm{~Hz}, 2 \mathrm{H}$ ), 2.53 (s, 3H), 1.51 (brs, 1H). ${ }^{13} \mathrm{C}$ NMR (125 MHz, $\left.\mathrm{CDCl}_{3}\right) \delta=200.6\left(\mathrm{C}_{\mathrm{q}}\right), 142.2\left(\mathrm{C}_{\mathrm{q}}\right), 136.2\left(\mathrm{C}_{\mathrm{q}}\right), 134.1$ (CH), $130.9(\mathrm{CH}), 130.6(\mathrm{CH}), 130.3(\mathrm{CH}), 129.3(\mathrm{CH}), 126.1\left(\mathrm{C}_{\mathrm{q}}\right), 63.4\left(\mathrm{CH}_{2}\right), 36.4\left(\mathrm{CH}_{2}\right), 29.7\left(\mathrm{CH}_{3}\right) . \mathbf{I R}$ (ATR) $v=3379,2861,1681,1584,1554,1355,1250,1092,971,814 \mathrm{~cm}^{-1}$. MS (ESI) m/z (relative intensity): 293 (100) [M+Na] ${ }^{+}\left({ }^{81} \mathrm{Br}\right), 291(100)[\mathrm{M}+\mathrm{Na}]^{+}\left({ }^{79} \mathrm{Br}\right), 253(90)\left({ }^{81} \mathrm{Br}\right), 251$ (90) $\left({ }^{79} \mathrm{Br}\right) . \mathbf{H R}-\mathrm{MS}$ (ESI) $\mathrm{m} / \mathrm{z}$ calcd for $\mathrm{C}_{12} \mathrm{H}_{13} \mathrm{BrO}_{2} \mathrm{Na}[\mathrm{M}+\mathrm{Na}]^{+}: 290.9991$, found: 290.9999 .<smiles>CC(=O)c1ccccc1C/C=C/CO</smiles>

(E/Z)-1-[2-(4-Hydroxybut-2-en-1-yl)phenyl]ethanone (165ga): The general procedure $\mathbf{F}$ was followed using (E)-4-methoxy- $N$-(1-phenylethylidene)aniline $(34 \mathrm{~g})(63.8 \mathrm{mg}, 0.25 \mathrm{mmol}$ ) and 4-vinyl-1,3-dioxolan-2-one (110a) $(72.0 \mu \mathrm{L}, 0.75 \mathrm{mmol})$. Purification by column chromatography on silica gel ( $n$-hexane/EtOAc: $2 / 1$ ) yielded $165 \mathrm{ga}\left(33.3 \mathrm{mg}, 70 \%, E / Z=12 / 1.0\right.$ by ${ }^{1} \mathrm{H} N M R$ ) as a colorless oil.

${ }^{1} \mathbf{H}$ NMR $\left(400 \mathrm{MHz}, \mathrm{CDCl}_{3}\right) \delta=7.64(\mathrm{dd}, J=7.6,1.3 \mathrm{~Hz}, 1 \mathrm{H}), 7.39(\mathrm{td}, J=7.5,1.4 \mathrm{~Hz}, 1 \mathrm{H}), 7.34-7.19$ $(\mathrm{m}, 2 \mathrm{H}), 5.85(\mathrm{dtt}, J=15.4,6.5,1.4 \mathrm{~Hz}, 1 \mathrm{H}), 5.61(\mathrm{dtt}, J=15.3,5.9,1.5 \mathrm{~Hz}, 1 \mathrm{H}), 4.24(\mathrm{dd}, J=7.1,1.1$ $\mathrm{Hz}, 0.16 \mathrm{H}), 4.06(\mathrm{dd}, J=5.8,1.3 \mathrm{~Hz}, 0.84 \mathrm{H}), 3.62(\mathrm{dd}, J=6.5,1.3 \mathrm{~Hz}, 2 \mathrm{H}), 2.55(\mathrm{~s}, 3 \mathrm{H}), 1.56$ (brs, 1H). ${ }^{13} \mathrm{C}$ NMR $\left(75 \mathrm{MHz}, \mathrm{CDCl}_{3}\right) \delta=202.0\left(\mathrm{C}_{\mathrm{q}}\right), 139.8\left(\mathrm{C}_{\mathrm{q}}\right), 137.7\left(\mathrm{C}_{\mathrm{q}}\right), 131.6(\mathrm{CH}), 131.5(\mathrm{CH}), 131.3(\mathrm{CH})$, $130.2(\mathrm{CH}), 129.1(\mathrm{CH}), 126.2(\mathrm{CH}), 63.5\left(\mathrm{CH}_{2}\right), 36.5\left(\mathrm{CH}_{2}\right), 29.7\left(\mathrm{CH}_{3}\right)$. IR (ATR) $v=3381,2860,1680$, 
1429, 1356, 1252, 1089, 972, 759, $601 \mathrm{~cm}^{-1}$. MS (ESI) m/z (relative intensity): 213 (100) [M+Na] 210 (40), 173 (80). HR-MS (ESI) m/z calcd for $\mathrm{C}_{12} \mathrm{H}_{14} \mathrm{O}_{2} \mathrm{Na}[\mathrm{M}+\mathrm{Na}]^{+}: 213.0886$, found: 213.0891.<smiles>CCC(=O)c1ccccc1C/C=C/CO</smiles>

(E/Z)-1-[2-(4-Hydroxybut-2-en-1-yl)phenyl]propan-1-one (165ga): The general procedure $F$ was followed using (E)-4-methoxy- $N$-(1-phenylpropylidene)aniline (34h) (59.8 mg, $0.25 \mathrm{mmol}$ ) and 4-vinyl-1,3-dioxolan-2-one (110a) $(72.0 \mu \mathrm{L}, 0.75 \mathrm{mmol})$. Purification by column chromatography on silica gel ( $n$-hexane/EtOAc: $2 / 1$ ) yielded 165ga (32.7 mg, 64\%, E/Z > 20/1.0 by ${ }^{1} \mathrm{H} \mathrm{NMR}$ ) as a colorless oil.

${ }^{1} \mathbf{H}$ NMR $\left(400 \mathrm{MHz}, \mathrm{CDCl}_{3}\right) \delta=7.56(\mathrm{dd}, J=7.2,1.7 \mathrm{~Hz}, 1 \mathrm{H}), 7.42-7.35(\mathrm{~m}, 1 \mathrm{H}), 7.33-7.19(\mathrm{~m}, 2 \mathrm{H})$, $5.84(\mathrm{dtt}, J=15.7,6.5,1.4 \mathrm{~Hz}, 1 \mathrm{H}), 5.60(\mathrm{dtt}, J=15.4,5.9,1.5 \mathrm{~Hz}, 1 \mathrm{H}), 4.06(\mathrm{dd}, J=5.9,1.2 \mathrm{~Hz}, 2 \mathrm{H})$, $3.56(\mathrm{dd}, J=6.6,1.4 \mathrm{~Hz}, 2 \mathrm{H}), 2.88(\mathrm{q}, J=7.3 \mathrm{~Hz}, 2 \mathrm{H}), 1.49$ (brs, $3 \mathrm{H}), 1.16(\mathrm{t}, J=7.3 \mathrm{~Hz}, 3 \mathrm{H}) .{ }^{13} \mathrm{C}$ NMR $\left(100 \mathrm{MHz}, \mathrm{CDCl}_{3}\right) \delta=205.4\left(\mathrm{C}_{\mathrm{q}}\right), 139.3\left(\mathrm{C}_{\mathrm{q}}\right), 138.4\left(\mathrm{C}_{\mathrm{q}}\right), 131.6(\mathrm{CH}), 131.1(\mathrm{CH}), 131.1(\mathrm{CH}), 130.2$ (CH), $128.1(\mathrm{CH}), 126.2(\mathrm{CH}), 63.5\left(\mathrm{CH}_{2}\right), 36.4\left(\mathrm{CH}_{2}\right), 35.0\left(\mathrm{CH}_{2}\right), 8.3\left(\mathrm{CH}_{3}\right)$. IR (ATR) $v=3407,2937$, 1685, 1445, 1220, 1089, 973, $755 \mathrm{~cm}^{-1}$. MS (ESI) m/z (relative intensity): 227 (100) [M+Na] $]^{+}, 187$ (80). HR-MS (ESI) m/z calcd for $\mathrm{C}_{13} \mathrm{H}_{16} \mathrm{O}_{2} \mathrm{Na}[\mathrm{M}+\mathrm{Na}]^{+}:$: 227.1043, found: 227.1043 .<smiles>CC(=O)c1ccc2c(c1C/C=C/CO)OCO2</smiles>

(E/Z)-1-\{4-(4-Hydroxybut-2-en-1-yl)benzo[d][1,3]dioxol-5-yl\}ethanone (165ia): The general procedure $\mathbf{F}$ was followed using $(E)-N$-\{1-(benzo[d][1,3]dioxol-5-yl)ethylidene $\}-4-m e t h o x y a n i l i n e ~(34 i)$ (67.3 $\mathrm{mg}, 0.25 \mathrm{mmol}$ ) and 4-vinyl-1,3-dioxolan-2-one (110a) $(72.0 \mu \mathrm{L}, 0.75 \mathrm{mmol})$. Purification by column chromatography on silica gel (n-hexane/EtOAc: $2 / 1$ ) yielded $165 i a$ (35.2 mg, 60\%, E/Z > 20/1.0 by ${ }^{1} \mathrm{H}$ NMR) as a white solid.

M.p. $=78-80{ }^{\circ} \mathrm{C} .{ }^{1} \mathrm{H}$ NMR $\left(400 \mathrm{MHz}, \mathrm{CDCl}_{3}\right) \delta=7.36(\mathrm{~d}, J=8.2 \mathrm{~Hz}, 1 \mathrm{H}), 6.69(\mathrm{~d}, J=8.2 \mathrm{~Hz}, 1 \mathrm{H}), 6.00$ (s, 2H), $5.85(\mathrm{dtt}, J=15.4,6.3,1.3 \mathrm{~Hz}, 1 \mathrm{H}), 5.64(\mathrm{dtt}, J=15.4,5.9,1.4 \mathrm{~Hz}, 1 \mathrm{H}), 4.03(\mathrm{dq}, J=5.9,1.2$ $\mathrm{Hz}, 2 \mathrm{H}), 3.63(\mathrm{dd}, J=6.3,1.3 \mathrm{~Hz}, 2 \mathrm{H}), 2.50(\mathrm{~s}, 3 \mathrm{H}), 1.56$ (brs, $1 \mathrm{H}) .{ }^{13} \mathrm{C} \mathrm{NMR}\left(100 \mathrm{MHz}, \mathrm{CDCl}_{3}\right) \delta=$ 
$199.2\left(\mathrm{C}_{\mathrm{q}}\right), 149.9\left(\mathrm{C}_{\mathrm{q}}\right), 147.3\left(\mathrm{C}_{\mathrm{q}}\right), 131.3\left(\mathrm{C}_{\mathrm{q}}\right), 130.0(\mathrm{CH}), 129.9(\mathrm{CH}), 126.1(\mathrm{CH}), 122.4\left(\mathrm{C}_{\mathrm{q}}\right), 105.6$ (CH), $101.5\left(\mathrm{CH}_{2}\right), 63.6\left(\mathrm{CH}_{2}\right), 29.4\left(\mathrm{CH}_{2}\right), 29.2\left(\mathrm{CH}_{3}\right)$. IR (ATR) $v=3408,2906,1671,1596,1448,1263$, 1050, 982, 807. MS (ESI) m/z (relative intensity): 257 (70) [M+Na] $]^{+}, 217$ (100). HR-MS (ESI) m/z calcd for $\mathrm{C}_{13} \mathrm{H}_{14} \mathrm{O}_{4} \mathrm{Na}[\mathrm{M}+\mathrm{H}]^{+}:$257.0784, found: 257.0784 .

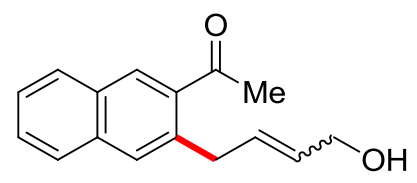

(E/Z)-1-[3-(4-Hydroxybut-2-en-1-yl)naphthalen-2-yl]ethanone (165ja): The general procedure F was followed using (E)-4-methoxy-N-(1-(naphthalen-2-yl)ethylidene)aniline (34j) (68.8 mg, 0.25 mmol) and 4-vinyl-1,3-dioxolan-2-one (110a) (72.0 $\mu \mathrm{L}, 0.75 \mathrm{mmol})$. Purification by column chromatography on silica gel ( $n$-hexane/EtOAc: $2 / 1$ ) yielded $165 j a\left(41.0 \mathrm{mg}, 68 \%, E / Z>20 / 1.0\right.$ by ${ }^{1} \mathrm{H}$ NMR) as a colorless oil.

${ }^{1} \mathbf{H}$ NMR $\left(400 \mathrm{MHz}, \mathrm{CDCl}_{3}\right) \delta=8.18(\mathrm{~s}, 1 \mathrm{H}), 7.85(\mathrm{~d}, J=8.7 \mathrm{~Hz}, 1 \mathrm{H}), 7.77(\mathrm{~d}, J=8.7 \mathrm{~Hz}, 1 \mathrm{H}), 7.65(\mathrm{~s}$, 1H), 7.59-7.40 (m, 2H), $5.92(\mathrm{dtt}, J=15.6,6.5,1.4 \mathrm{~Hz}, 1 \mathrm{H}), 5.63(\mathrm{dtt}, J=15.3,5.9,1.5 \mathrm{~Hz}, 1 \mathrm{H}), 4.08$ (dd, $J=5.9,1.3 \mathrm{~Hz}, 2 \mathrm{H}), 3.79(\mathrm{~d}, J=6.5 \mathrm{~Hz}, 2 \mathrm{H}), 2.67$ (s, 3H), 1.55 (brs, 1H). ${ }^{13} \mathrm{C}$ NMR (100 MHz, $\left.\mathrm{CDCl}_{3}\right) \delta=201.7\left(\mathrm{C}_{\mathrm{q}}\right), 136.3\left(\mathrm{C}_{\mathrm{q}}\right), 136.2\left(\mathrm{C}_{\mathrm{q}}\right), 134.7\left(\mathrm{C}_{\mathrm{q}}\right), 131.8(\mathrm{CH}), 131.1\left(\mathrm{C}_{\mathrm{q}}\right), 130.5(\mathrm{CH}), 130.3(\mathrm{CH})$, $129.6(\mathrm{CH}), 128.4(\mathrm{CH}), 128.2(\mathrm{CH}), 127.2(\mathrm{CH}), 126.3(\mathrm{CH}), 63.6\left(\mathrm{CH}_{2}\right), 36.7\left(\mathrm{CH}_{2}\right), 29.6\left(\mathrm{CH}_{3}\right)$. IR (ATR) $v=3401,2862,1678,1460,1356,1271,1200,974,750 \mathrm{~cm}^{-1}$. MS (ESI) m/z (relative intensity): 263 (95) $[\mathrm{M}+\mathrm{Na}]^{+}, 223$ (100). HR-MS (ESI) m/z calcd for $\mathrm{C}_{16} \mathrm{H}_{16} \mathrm{O}_{2} \mathrm{Na}[\mathrm{M}+\mathrm{H}]^{+}:$: 263.1043, found: 263.1046.<smiles>CC(=O)c1cccc(F)c1C/C=C/CO</smiles>

(E/Z)-1-[3-Fluoro-2-(4-hydroxybut-2-en-1-yl)phenyl]ethanone (165ka): The general procedure $\mathbf{F}$ was followed using (E)-N-[1-(3-fluorophenyl)ethylidene]-4-methoxyaniline (34k) (60.8 mg, 0.25 $\mathrm{mmol}$ ) and 4-vinyl-1,3-dioxolan-2-one (110a) $(72.0 \mu \mathrm{L}, 0.75 \mathrm{mmol})$. Purification by column chromatography on silica gel ( $n$-hexane/EtOAc: $1 / 1)$ yielded $165 \mathrm{ka}\left(44.2 \mathrm{mg}, 85 \%, E / Z=7.3 / 1\right.$ by ${ }^{1} \mathrm{H}$ NMR) as a brown oil.

${ }^{1} \mathrm{H}$ NMR $\left(300 \mathrm{MHz}, \mathrm{CDCl}_{3}\right) \delta=7.42(\mathrm{dd}, J=7.6,1.4 \mathrm{~Hz}, 1 \mathrm{H}), 7.29-7.22(\mathrm{~m}, 1 \mathrm{H}), 7.15$ (ddd, J = 9.6, 8.2, 
$1.4 \mathrm{~Hz}, 1 \mathrm{H}), 5.87-5.57(\mathrm{~m}, 2 \mathrm{H}), 4.27(\mathrm{~d}, J=7.1 \mathrm{~Hz}, 0.17 \mathrm{H}), 4.04(\mathrm{dd}, J=5.8,1.3 \mathrm{~Hz}, 1.83 \mathrm{H}), 3.62-3.58$ (m, 2H), $2.55(\mathrm{~s}, 3 \mathrm{H}), 1.83$ (brs, 1H). ${ }^{13} \mathrm{C}$ NMR $\left(125 \mathrm{MHz}, \mathrm{CDCl}_{3}\right)$ Major isomer: $\delta=201.4\left(\mathrm{~d},{ }^{4} \mathrm{~J}_{\mathrm{C}-\mathrm{F}}=2.6\right.$ $\left.\mathrm{Hz}, \mathrm{C}_{\mathrm{q}}\right), 161.7\left(\mathrm{~d},{ }^{1} \mathrm{~J}=246.7 \mathrm{~Hz}, \mathrm{C}_{\mathrm{q}}\right), 140.1\left(\mathrm{~d},{ }^{3} \mathrm{~J}_{\mathrm{C}-\mathrm{F}}=4.1 \mathrm{~Hz}, \mathrm{C}_{\mathrm{q}}\right), 130.4(\mathrm{CH}), 129.9(\mathrm{CH}), 127.6\left(\mathrm{~d},{ }^{3} J_{C-F}\right.$ $=8.7 \mathrm{~Hz}, \mathrm{CH}), 126.8\left(\mathrm{~d},{ }^{2} \mathrm{~J}_{\mathrm{C}-\mathrm{F}}=16.8 \mathrm{~Hz}, \mathrm{C}_{\mathrm{q}}\right), 124.6\left(\mathrm{~d},{ }^{4} \mathrm{~J}_{\mathrm{C}-\mathrm{F}}=3.4 \mathrm{~Hz}, \mathrm{CH}\right), 118.6\left(\mathrm{~d},{ }^{2} \mathrm{~J}_{\mathrm{C}-\mathrm{F}}=23.8 \mathrm{~Hz}, \mathrm{CH}\right)$, $63.5\left(\mathrm{CH}_{2}\right), 30.1\left(\mathrm{CH}_{3}\right), 28.1\left(\mathrm{~d},{ }^{3} \mathrm{~J}_{\mathrm{C}-\mathrm{F}}=3.9, \mathrm{CH}_{2}\right)$. Minor isomer: $\delta=201.9\left(\mathrm{~d},{ }^{4} \mathrm{~J}=2.4 \mathrm{~Hz}, \mathrm{C} \mathrm{q}\right), 161.6(\mathrm{~d}$, $\left.{ }^{1} J_{C-F}=240.1 \mathrm{~Hz}, C_{q}\right), 139.9\left(d,{ }^{3} J_{C-F}=4.0 \mathrm{~Hz}, C_{q}\right), 130.6(\mathrm{CH}), 130.2(\mathrm{CH}), 127.6\left(\mathrm{~d},{ }^{3} \mathrm{~J}_{\mathrm{C}-\mathrm{F}}=9.0 \mathrm{~Hz}, \mathrm{CH}\right)$, $127.4\left(\mathrm{~d},{ }^{2} \mathrm{~J}_{\mathrm{C}-\mathrm{F}}=16.3 \mathrm{~Hz}, \mathrm{C}_{\mathrm{q}}\right), 125.0\left(\mathrm{~d},{ }^{4} \mathrm{~J}_{\mathrm{C}-\mathrm{F}}=3.3 \mathrm{~Hz}, \mathrm{CH}\right), 118.8\left(\mathrm{~d},{ }^{2} \mathrm{~J}_{\mathrm{C}-\mathrm{F}}=23.9 \mathrm{~Hz}, \mathrm{CH}\right), 58.2\left(\mathrm{CH}_{2}\right)$, $29.7\left(\mathrm{CH}_{3}\right), 23.9\left(\mathrm{~d},{ }^{3} \mathrm{~J}=4.0 \mathrm{~Hz}, \mathrm{CH}_{2}\right) .{ }^{19} \mathrm{~F} \mathrm{NMR}\left(376 \mathrm{MHz}, \mathrm{CDCl}_{3}\right)$ Major isomer: $\delta=-115.82(\mathrm{t}, J=6.8$ Hz). Minor isomer: $\delta=-115.95$ (dd, $J=9.3,6.0$ Hz). IR (ATR) $v=3419,2925,1687,1576,1452,1259$, $792 \mathrm{~cm}^{-1}$. MS (ESI) m/z (relative intensity): 231 (100) $[\mathrm{M}+\mathrm{Na}]^{+}$. HR-MS (ESI) $\mathrm{m} / \mathrm{z}$ calcd for $\mathrm{C}_{12} \mathrm{H}_{13} \mathrm{O}{ }_{2} \mathrm{FNa}[\mathrm{M}+\mathrm{Na}]^{+}:$231.0792, found: 231.0792 .

\section{H/D Exchange Experiment}

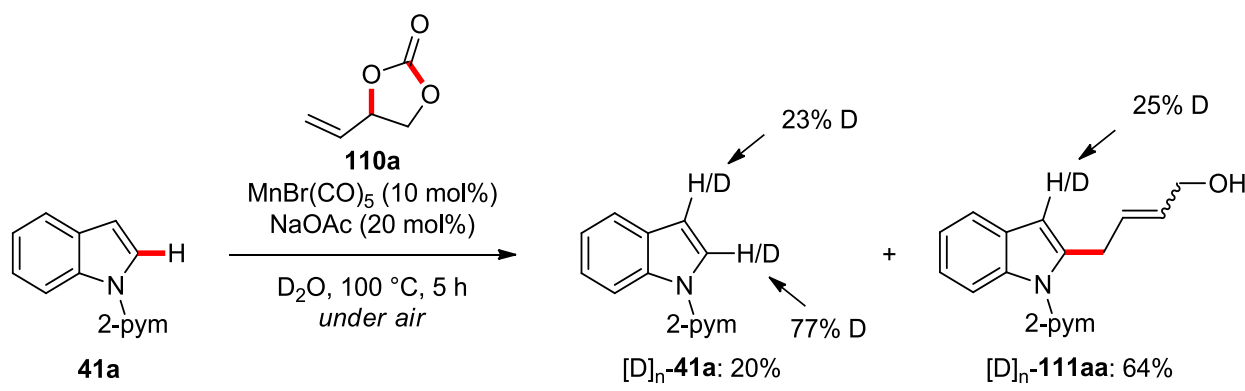

Substrates 41a (48.8 mg, $0.25 \mathrm{mmol}), 110 \mathrm{a}(85.5 \mathrm{mg}, 0.75 \mathrm{mmol}),\left[\mathrm{MnBr}(\mathrm{CO})_{5}\right](6.9 \mathrm{mg}, 10.0 \mathrm{~mol} \%)$, $\mathrm{NaOAc}(4.1 \mathrm{mg}, 20.0 \mathrm{~mol} \%)$ and $\mathrm{D}_{2} \mathrm{O}(1.0 \mathrm{~mL})$ were placed in a $25 \mathrm{~mL}$ Schlenk tube under ambient air and stirred at $100{ }^{\circ} \mathrm{C}$ for $5 \mathrm{~h}$. After cooling to ambient temperature, the mixture was transferred into a round bottom flask with $\mathrm{CH}_{2} \mathrm{Cl}_{2}(20 \mathrm{~mL})$ and concentrated in vacuo. Purification by column chromatography on silica gel ( $n$-hexane/EtOAc: $10 / 1$ to $1 / 1)$ yielded $[D]_{n}-41 a(9.8 \mathrm{mg}, 20 \%)$ and $[D]_{n}-111 a a(42.4 \mathrm{mg}, 64 \%)$. The $D$ incorporation was determined by ${ }^{1} \mathrm{H}-\mathrm{NMR}$ spectroscopy. 

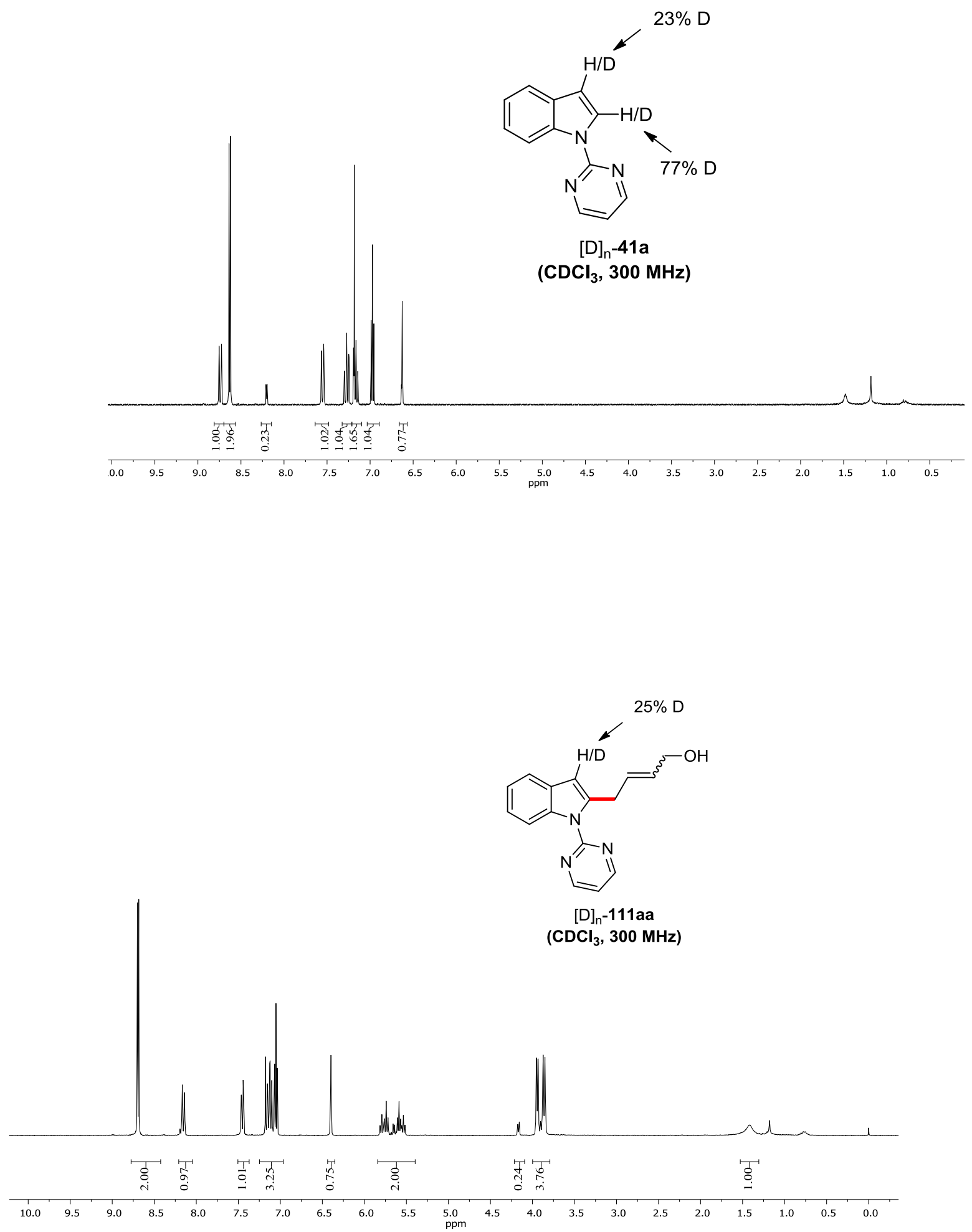


\section{Intermolecular Competition Experiment}

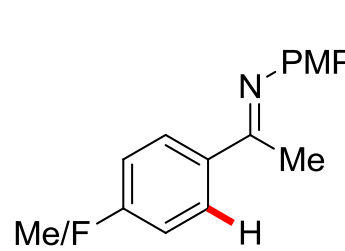

$34 a / 34 d$

(each $0.25 \mathrm{mmol}$ )
1) $110 \mathbf{a}$ (1.0 equiv) $\operatorname{MnBr}(\mathrm{CO})_{5}(10 \mathrm{~mol} \%)$ $\mathrm{NaOAc}(20 \mathrm{~mol} \%)$ TFE, $100^{\circ} \mathrm{C}, 16 \mathrm{~h}$

2) $\mathrm{HCl}(2 \mathrm{~N}), 30 \mathrm{~min}$

165aa/165da: 1.3/1.0

(by crude ${ }^{1} \mathrm{H}$ NMR)<smiles>CC(=O)c1ccc(C)cc1CC=CCO</smiles><smiles>CC(=O)c1ccc(F)cc1C/C=C/CO</smiles>

165da: $56 \%$

A suspension of (E)-4-methoxy- $N$-[1-(p-tolyl)ethylidene]aniline (34a) (59.8 mg, $0.25 \mathrm{mmol}$ ), (E)- $N$-[1-(4-fluorophenyl)ethylidene]-4-methoxyaniline $\quad$ (34d) $\quad(60.8 \quad \mathrm{mg}, \quad 0.25 \quad \mathrm{mmol})$, 4-vinyl-1,3-dioxolan-2-one (110a) (72.0 $\mu \mathrm{L}, 0.75 \mathrm{mmol}), \mathrm{NaOAc}(4.1 \mathrm{mg}, 20.0 \mathrm{~mol} \%$ ) and $\left[\mathrm{MnBr}(\mathrm{CO})_{5}\right](6.9 \mathrm{mg}, 10.0 \mathrm{~mol} \%)$ in TFE $(1.0 \mathrm{~mL})$ was stirred at $100{ }^{\circ} \mathrm{C}$ for $16 \mathrm{~h}$ under $\mathrm{N}_{2}$. After cooling to ambient temperature, $\mathrm{HCl}(2 \mathrm{~N}, 3.0 \mathrm{~mL})$ was added. The resulting mixture was stirred for $30 \mathrm{~min}$ at $25^{\circ} \mathrm{C}$ and extracted with $\mathrm{Et}_{2} \mathrm{O}(3 \times 20 \mathrm{~mL})$. The combined organic layers were dried over $\mathrm{Na}_{2} \mathrm{SO}_{4}$ and concentrated in vacuo. The crude ${ }^{1} \mathrm{H}$ NMR was measured to determine the conversions to the products $165 \mathrm{aa}(44 \%)$ and $165 \mathrm{da}$ (56\%) using 1,3,5-trimethoxybenzene as the internal standard.

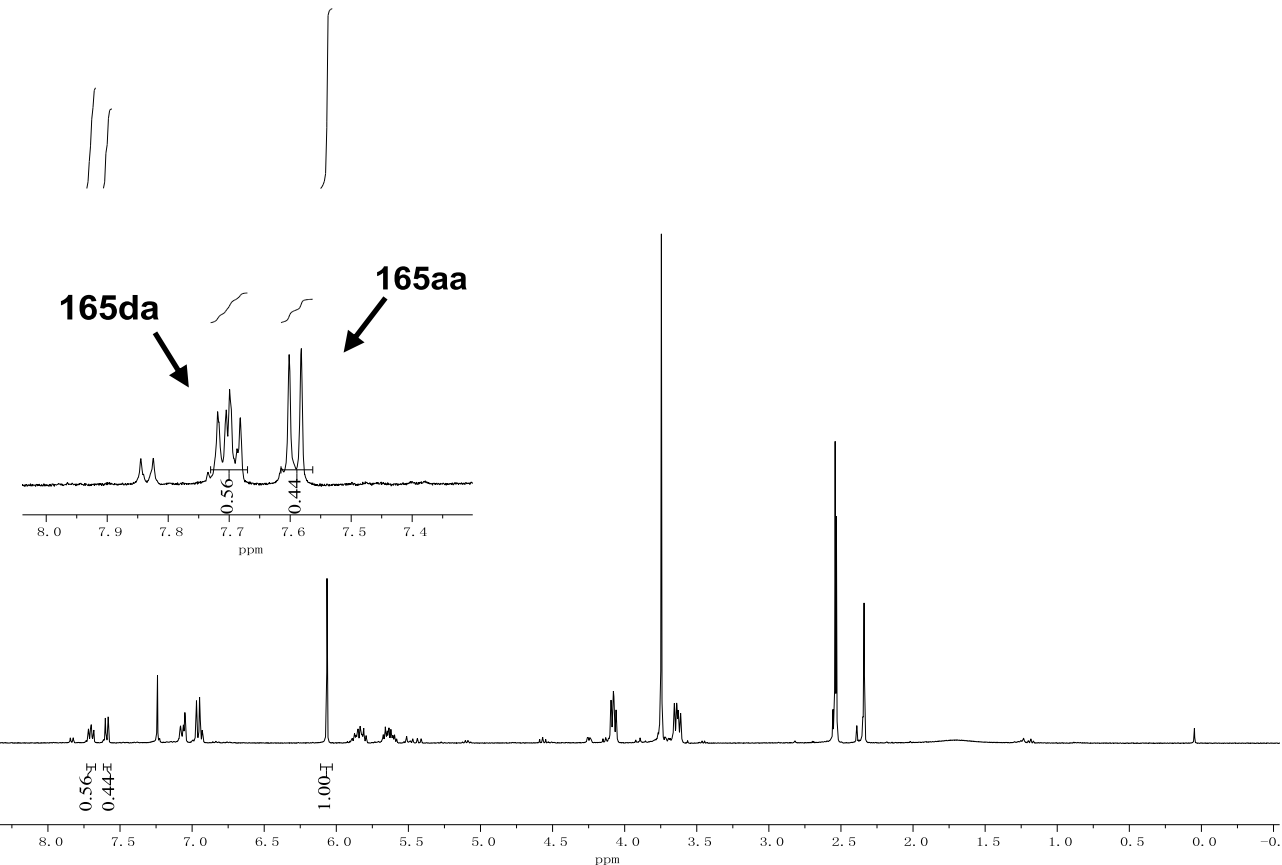




\section{Decarboxylative $\mathrm{C}-\mathrm{H} / \mathrm{C}-\mathrm{O}$ Activation with Cyclometalated Complex 4 in catalytic reactions}

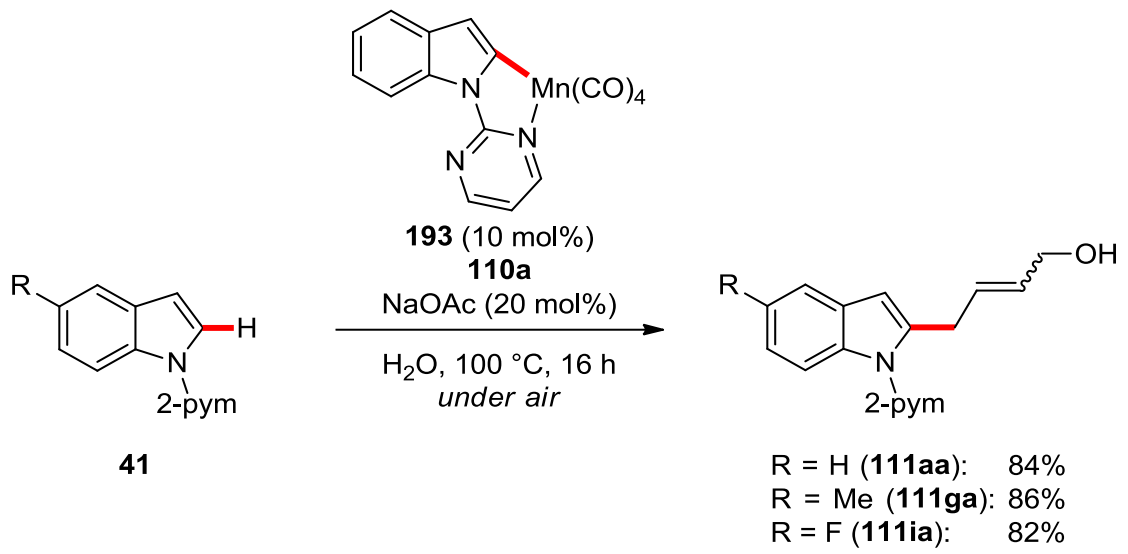

The general procedure $\mathbf{F}$ was followed using 1-(pyrimidin-2-yl)- $1 H$-indole (41a) (48.8 mg, 0.25 mmol), 4-vinyl-1,3-dioxolan-2-one (110a) (72.0 $\mu \mathrm{L}, 0.75 \mathrm{mmol}), \mathrm{NaOAc}(4.1 \mathrm{mg}, 20.0 \mathrm{~mol} \%$ ) and complex 193 (9.0 mg, $10.0 \mathrm{~mol} \%)$. Purification by column chromatography on silica gel ( $n$-hexane/EtOAc: $1 / 1)$ yielded 111aa $(61.3 \mathrm{mg}, 84 \%$ based on $0.275 \mathrm{mmol}$ )

The general procedure $\mathbf{F}$ was followed using 5-methyl-1-(pyrimidin-2-yl)-1H-indole (41g) (52.3 mg, $0.25 \mathrm{mmol}$ ) 4-vinyl-1,3-dioxolan-2-one (110a) (72.0 $\mu \mathrm{L}, 0.75 \mathrm{mmol}), \mathrm{NaOAc}(4.1 \mathrm{mg}, 20.0 \mathrm{~mol} \%)$ and complex 193 (9.0 mg, $10.0 \mathrm{~mol} \%$ ). Purification by column chromatography on silica gel ( $n$-hexane/EtOAc: $1 / 1)$ afforded $64.1 \mathrm{mg}$ of a 9.4/1 mixture of 111ga $(0.215 \mathrm{mmol}, 86 \%)$ and 111ga' (0.014 mmol, 56\%)

The general procedure $\mathbf{F}$ was followed using 5-fluoro-1-(pyrimidin-2-yl)-1H-indole (41i) (53.3 mg, $0.25 \mathrm{mmol}$ ) 4-vinyl-1,3-dioxolan-2-one (110a) (72.0 $\mathrm{LL}, 0.75 \mathrm{mmol}), \mathrm{NaOAc}(4.1 \mathrm{mg}, 20.0 \mathrm{~mol} \%)$ and complex 193 (9.0 mg, $10.0 \mathrm{~mol} \%)$. Purification by column chromatography on silica gel (n-hexane/EtOAc: 1/1) afforded $62.5 \mathrm{mg}$ of a 9.2/1 mixture of 111ia (0.205 mmol, 82\%) and 111ia' (0.016 mmol, 64\%). 


\section{Decarboxylative C-H/C-O Activation with Cyclometalated Complex 193 in stoichiometric reaction}

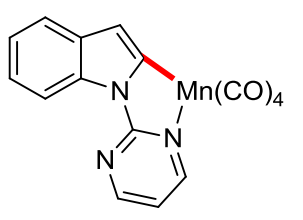

193

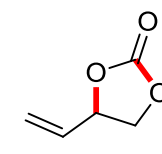

$110 \mathrm{a}$

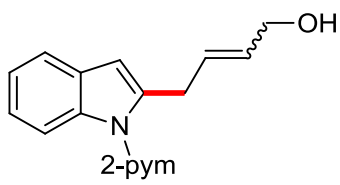

111aa: $88 \%$

Complex 193 (54.2 mg, $0.15 \mathrm{mmol})$, dioxolanone 110a (51.3 mg, $0.45 \mathrm{mmol}$ ) and TFE (1.0 mL) were placed in a $25 \mathrm{~mL}$ Schlenk tube under ambient air and stirred at $100{ }^{\circ} \mathrm{C}$ for $16 \mathrm{~h}$. After cooling to ambient temperature, the mixture was transferred into a round bottom flask with $\mathrm{CH}_{2} \mathrm{Cl}_{2}(20 \mathrm{~mL})$ and concentrated in vacuo. Purification by column chromatography on silica gel ( $n$-hexane/EtOAc: $1 / 1$ ) yielded 111 aa $\left(35.0 \mathrm{mg}, 88 \%, E / Z=5.5 / 1\right.$ by ${ }^{1} \mathrm{H} N M R$ ).

\subsubsection{Data for Synergistic Manganese(I)-Catalyzed Chem-Selective C-H Hydroarylation in Continous Flow}

\section{Characterization Data}<smiles>CC1(C=Cc2cc3ccccc3n2-c2ccccn2)COC(=O)O1</smiles>

(E)-4-Methyl-4-\{2-[1-(pyridin-2-yl)-1H-indol-2-yl]vinyl\}-1,3-dioxolan-2-one (167ba): The general procedure $\mathbf{G}$ was followed using 1-(pyridin-2-yl)-1H-indole (41b) (48.6 mg, $0.25 \mathrm{mmol})$ and 4-ethynyl-4-methyl-1,3-dioxolan-2-one (166a) (58.0 $\mu \mathrm{L}, 0.5 \mathrm{mmol})$. Purification by column chromatography on silica gel ( $n$-hexane/EtOAc: 3/2) yielded 167ba (76.1 mg, 95\%) as colorless oil. ${ }^{1} \mathrm{H}$ NMR $\left(400 \mathrm{MHz} \mathrm{CDCl}_{3}\right) \delta=8.66(\mathrm{dd}, J=4.9,1.9 \mathrm{~Hz}, 1 \mathrm{H}), 7.89(\mathrm{ddd}, J=8.0,7.5,2.0 \mathrm{~Hz}, 1 \mathrm{H}), 7.67-$ $7.57(\mathrm{~m}, 1 \mathrm{H}), 7.49-7.41(\mathrm{~m}, 1 \mathrm{H}), 7.37(\mathrm{dt}, J=8.0,1.0 \mathrm{~Hz}, 1 \mathrm{H}), 7.34$ (ddd, $J=7.5,4.9,1.0 \mathrm{~Hz}, 1 \mathrm{H})$, 7.22-7.12 (m, 2H), $6.87(\mathrm{~s}, 1 \mathrm{H}), 6.77(\mathrm{~d}, J=16.0 \mathrm{~Hz}, 1 \mathrm{H}), 6.17(\mathrm{~d}, J=16.0 \mathrm{~Hz}, 1 \mathrm{H}), 4.29$ (d, J = 8.4 Hz, 1H), $4.19(\mathrm{~d}, J=8.4 \mathrm{~Hz}, 1 \mathrm{H}), 1.62(\mathrm{~s}, 3 \mathrm{H}) .{ }^{13} \mathrm{C}$ NMR $\left(125 \mathrm{MHz}, \mathrm{CDCl}_{3}\right) \delta=154.2\left(\mathrm{C}_{\mathrm{q}}\right), 150.7\left(\mathrm{C}_{\mathrm{q}}\right), 149.7$ 
$(\mathrm{CH}), 138.5(\mathrm{CH}), 137.7\left(\mathrm{C}_{\mathrm{q}}\right), 135.5\left(\mathrm{C}_{\mathrm{q}}\right), 128.7(\mathrm{CH}), 128.2\left(\mathrm{C}_{\mathrm{q}}\right), 123.4(\mathrm{CH}), 122.3(\mathrm{CH}), 121.9(\mathrm{CH})$, $121.5(\mathrm{CH}), 121.1(\mathrm{CH}), 120.8(\mathrm{CH}), 110.8(\mathrm{CH}), 103.6(\mathrm{CH}), 82.6\left(\mathrm{C}_{\mathrm{q}}\right), 74.6\left(\mathrm{CH}_{2}\right), 24.4\left(\mathrm{CH}_{3}\right)$. IR (ATR) $v=2922,1779,1586,1468,1340,1213,1044,969,793,754 \mathrm{~cm}^{-1}$. MS (ESI) m/z (relative intensity): 369 (20), $337(100)[\mathrm{M}+\mathrm{Na}]^{+}, 321(80)[\mathrm{M}+\mathrm{H}]^{+}, 299(20), 277$ (20). HR-MS (ESI) m/z calcd for $\mathrm{C}_{19} \mathrm{H}_{17} \mathrm{~N}_{2} \mathrm{O}_{3}[\mathrm{M}+\mathrm{H}]^{+}:$321.1234, found: 321.1233 .

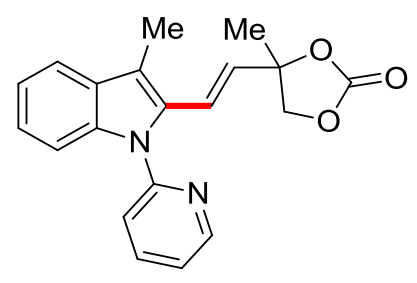

(E)-4-Methyl-4-\{2-[3-methyl-1-(pyridin-2-yl)-1H-indol-2-yl]vinyl\}-1,3-dioxolan-2-one (167ma): The general procedure $\mathbf{G}$ was followed using 3-methyl-1-(pyridin-2-yl)- $1 H$-indole $(41 \mathrm{~m})(52.1 \mathrm{mg}, 0.25$ mmol) and 4-ethynyl-4-methyl-1,3-dioxolan-2-one (166a). Purification by column chromatography on silica gel ( $n$-hexane/EtOAc: $3 / 2$ ) yielded $167 \mathrm{ma}(72.0 \mathrm{mg}, 86 \%)$ as colorless oil.

${ }^{1} \mathrm{H}$ NMR $\left(400 \mathrm{MHz}_{\mathrm{CDCl}}\right) \delta=8.63(\mathrm{ddd}, J=4.8,2.0,1.0 \mathrm{~Hz}, 1 \mathrm{H}), 7.85$ (ddd, $\left.J=8.0,7.4,2.0 \mathrm{~Hz}, 1 \mathrm{H}\right)$, $7.59(\mathrm{dd}, J=6.5,1.2 \mathrm{~Hz}, 1 \mathrm{H}), 7.45(\mathrm{dd}, J=7.0,1.2 \mathrm{~Hz}, 1 \mathrm{H}), 7.36-7.25(\mathrm{~m}, 2 \mathrm{H}), 7.24-7.14(\mathrm{~m}, 2 \mathrm{H})$, $6.79(\mathrm{~d}, J=16.3 \mathrm{~Hz}, 1 \mathrm{H}), 5.69(\mathrm{~d}, J=16.3 \mathrm{~Hz}, 1 \mathrm{H}), 4.22(\mathrm{~d}, J=8.4 \mathrm{~Hz}, 1 \mathrm{H}), 4.17(\mathrm{~d}, J=8.4 \mathrm{~Hz}, 1 \mathrm{H})$, $2.43(\mathrm{~s}, 3 \mathrm{H}), 1.60(\mathrm{~s}, 3 \mathrm{H}) .{ }^{13} \mathrm{C} \mathrm{NMR}\left(100 \mathrm{MHz} \mathrm{CDCl}_{3}\right) \delta=154.2\left(\mathrm{C}_{\mathrm{q}}\right), 151.6\left(\mathrm{C}_{\mathrm{q}}\right), 149.5(\mathrm{CH}), 138.3(\mathrm{CH})$, $137.4\left(\mathrm{C}_{\mathrm{q}}\right), 130.9\left(\mathrm{C}_{\mathrm{q}}\right), 130.0(\mathrm{CH}), 129.3\left(\mathrm{C}_{\mathrm{q}}\right), 124.0(\mathrm{CH}), 122.0(\mathrm{CH}), 121.3(\mathrm{CH}), 121.2(\mathrm{CH}), 120.9$ $(\mathrm{CH}), 119.2(\mathrm{CH}), 115.0\left(\mathrm{C}_{\mathrm{q}}\right), 110.7(\mathrm{CH}), 82.8\left(\mathrm{C}_{\mathrm{q}}\right), 74.7\left(\mathrm{CH}_{2}\right), 24.3\left(\mathrm{CH}_{3}\right), 10.0\left(\mathrm{CH}_{3}\right)$. IR (ATR) $v=$ 2978, 1801, 1588, 1470, 1455, 1227, 1056, $743 \mathrm{~cm}^{-1}$. MS (ESI) m/z (relative intensity): 691 (70) $[2 \mathrm{M}+\mathrm{Na}]^{+}, 357(100)[\mathrm{M}+\mathrm{Na}]^{+}, 335(40)[\mathrm{M}+\mathrm{H}]^{+}, 313(35), 291$ (30). HR-MS (ESI) m/z calcd for $\mathrm{C}_{20} \mathrm{H}_{19} \mathrm{~N}_{2} \mathrm{O}_{3}[\mathrm{M}+\mathrm{H}]^{+}:$335.1390, found: 335.1387 .

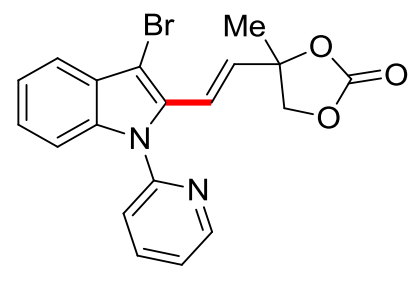

(E)-4-\{2-[3-Bromo-1-(pyridin-2-yl)-1H-indol-2-yl]vinyl\}-4-methyl-1,3-dioxolan-2-one (167na): The general procedure $\mathbf{G}$ was followed using 3-bromo-1-(pyridin-2-yl)-1H-indole (41n) (68.3 mg, 0.25 mmol) and 4-ethynyl-4-methyl-1,3-dioxolan-2-one (110a) (58.0 $\mu \mathrm{L}, 0.5 \mathrm{mmol})$. Purification by 
column chromatography on silica gel ( $n$-hexane/EtOAc: $2 / 1$ ) yielded 167 na $(62.9 \mathrm{mg}, 63 \%$ ) as colorless oil.

${ }^{1} \mathrm{H}$ NMR $\left(300 \mathrm{MHz}^{\mathrm{CDCl}}{ }_{3}\right) \delta=8.67(\mathrm{dd}, J=4.9,2.0 \mathrm{~Hz}, 1 \mathrm{H}), 7.91(\mathrm{ddd}, J=7.9,7.5,2.0 \mathrm{~Hz}, 1 \mathrm{H}), 7.67-$ $7.56(\mathrm{~m}, 1 \mathrm{H}), 7.48-7.31(\mathrm{~m}, 3 \mathrm{H}), 7.31-7.21(\mathrm{~m}, 2 \mathrm{H}), 6.71(\mathrm{~d}, J=16.4 \mathrm{~Hz}, 1 \mathrm{H}), 6.30(\mathrm{~d}, J=16.4 \mathrm{~Hz}, 1 \mathrm{H})$, $4.27(\mathrm{~d}, J=8.4 \mathrm{~Hz}, 1 \mathrm{H}), 4.20(\mathrm{~d}, J=8.4 \mathrm{~Hz}, 1 \mathrm{H}), 1.63(\mathrm{~s}, 3 \mathrm{H}) .{ }^{13} \mathrm{C} \mathrm{NMR}\left(125 \mathrm{MHz}, \mathrm{CDCl}_{3}\right) \delta=154.0\left(\mathrm{C}_{\mathrm{q}}\right)$, $150.5\left(\mathrm{C}_{\mathrm{q}}\right), 149.7(\mathrm{CH}), 138.5(\mathrm{CH}), 136.8\left(\mathrm{C}_{\mathrm{q}}\right), 132.3(\mathrm{CH}), 130.9\left(\mathrm{C}_{\mathrm{q}}\right), 127.8\left(\mathrm{C}_{\mathrm{q}}\right), 124.8(\mathrm{CH}), 122.8$ (CH), $122.0(\mathrm{CH}), 121.5(\mathrm{CH}), 119.7(\mathrm{CH}), 119.5(\mathrm{CH}), 110.9(\mathrm{CH}), 96.3\left(\mathrm{C}_{\mathrm{q}}\right), 82.5\left(\mathrm{C}_{\mathrm{q}}\right), 74.6\left(\mathrm{CH}_{2}\right), 24.4$ $\left(\mathrm{CH}_{3}\right)$. IR (ATR) $v=2981,1796,1587,1466,1435,1343,1214,1054,739 \mathrm{~cm}^{-1}$. MS (ESI) m/z (relative intensity): $\left.\left.423(10)\left({ }^{81} \mathrm{Br}\right)[\mathrm{M}+\mathrm{H}]\right]^{+}, 421(10)\left({ }^{79} \mathrm{Br}\right)[\mathrm{M}+\mathrm{H}]\right]^{+}, 401(100)\left({ }^{81} \mathrm{Br}\right)[\mathrm{M}+\mathrm{H}]+, 399(100)\left({ }^{79} \mathrm{Br}\right)$ $[\mathrm{M}+\mathrm{H}]^{+}, 342$ (10). HR-MS (ESI) $\mathrm{m} / \mathrm{z}$ calcd for $\mathrm{C}_{19} \mathrm{H}_{16} \mathrm{~N}_{2} \mathrm{O}_{3}{ }^{81} \mathrm{Br}[\mathrm{M}+\mathrm{H}]^{+}:$401.0319, found: 401.0322, $\mathrm{C}_{19} \mathrm{H}_{16} \mathrm{~N}_{2} \mathrm{O}_{3}{ }^{79} \mathrm{Br}[\mathrm{M}+\mathrm{H}]^{+}:$399.0339, found: 399.0341 .

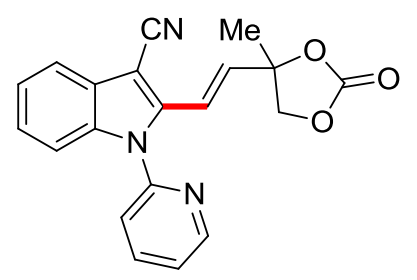

(E)-2-[2-(4-Methyl-2-oxo-1,3-dioxolan-4-yl)vinyl]-1-(pyridin-2-yl)-1H-indole-3-carbonitrile (167ta): The general procedure $\mathbf{G}$ was followed using 1-(pyridin-2-yl)-1H-indole-3-carbonitrile (41t) (54.8 mg, $0.25 \mathrm{mmol}$ ) and 4-ethynyl-4-methyl-1,3-dioxolan-2-one (110a) (58.0 $\mu \mathrm{L}, 0.5 \mathrm{mmol})$. Purification by column chromatography on silica gel ( $n$-hexane/EtOAc: $3 / 2$ ) yielded 167 ta $(56.1 \mathrm{mg}, 65 \%)$ as white solid.

M.p. $=151-153{ }^{\circ} \mathrm{C} .{ }^{1} \mathrm{H}$ NMR $\left(400 \mathrm{MHz}, \mathrm{CDCl}_{3}\right) \delta=8.70(\mathrm{dd}, J=4.9,1.9 \mathrm{~Hz}, 1 \mathrm{H}), 7.97$ (td, $J=7.7,1.9$ $\mathrm{Hz}, 1 \mathrm{H}), 7.85-7.68(\mathrm{~m}, 1 \mathrm{H}), 7.46(\mathrm{ddd}, J=7.6,4.9,1.0 \mathrm{~Hz}, 1 \mathrm{H}), 7.43-7.36(\mathrm{~m}, 2 \mathrm{H}), 7.35-7.26(\mathrm{~m}, 2 \mathrm{H})$, $6.84(\mathrm{~d}, J=16.2 \mathrm{~Hz}, 1 \mathrm{H}), 6.70(\mathrm{~d}, J=16.2 \mathrm{~Hz}, 1 \mathrm{H}), 4.37(\mathrm{~d}, J=8.5 \mathrm{~Hz}, 1 \mathrm{H}), 4.25(\mathrm{~d}, J=8.5 \mathrm{~Hz}, 1 \mathrm{H})$, $1.67(\mathrm{~s}, 3 \mathrm{H}) .{ }^{13} \mathrm{C}$ NMR $\left(100 \mathrm{MHz}, \mathrm{CDCl}_{3}\right) \delta=153.8\left(\mathrm{C}_{\mathrm{q}}\right), 150.2(\mathrm{CH}), 148.9\left(\mathrm{C}_{\mathrm{q}}\right), 141.2\left(\mathrm{C}_{\mathrm{q}}\right), 139.1(\mathrm{CH})$, $136.2\left(\mathrm{C}_{q}\right), 135.4(\mathrm{CH}), 127.5\left(\mathrm{C}_{\mathrm{q}}\right), 125.3(\mathrm{CH}), 124.0(\mathrm{CH}), 123.5(\mathrm{CH}), 121.5(\mathrm{CH}), 119.6(\mathrm{CH}), 118.0$ $(\mathrm{CH}), 116.3\left(\mathrm{C}_{\mathrm{q}}\right), 111.6(\mathrm{CH}), 86.6\left(\mathrm{C}_{\mathrm{q}}\right), 82.2\left(\mathrm{C}_{\mathrm{q}}\right), 74.5\left(\mathrm{CH}_{2}\right), 24.7\left(\mathrm{CH}_{3}\right)$. IR (ATR) $v=2923,2215,1788$, 1612, 1467, 1392, 1220, 1144, 1065, $760 \mathrm{~cm}^{-1}$. MS (ESI) m/z (relative intensity): 713 (30) [2M+Na], $368(60)[\mathrm{M}+\mathrm{Na}]^{+}, 346(100)[\mathrm{M}+\mathrm{H}]^{+}$. HR-MS (ESI) m/z calcd for $\mathrm{C}_{20} \mathrm{H}_{16} \mathrm{~N}_{3} \mathrm{O}_{3}[\mathrm{M}+\mathrm{H}]^{+}: 346.1186$, found: 346.1188. 
<smiles>[M]OC1(/C=C/c2cc3ccc(Br)cc3n2-c2ccccn2)COC(=O)O1</smiles>

(E)-4-\{2-[6-Bromo-1-(pyridin-2-yl)-1H-indol-2-yl]vinyl\}-4-methyl-1,3-dioxolan-2-one (167ua): The general procedure $\mathbf{G}$ was followed using 6-bromo-1-(pyridin-2-yl)-1H-indole (41u) $(68.3 \mathrm{mg}, 0.25$ mmol) and 4-ethynyl-4-methyl-1,3-dioxolan-2-one (110a) (58.0 $\mu \mathrm{L}, 0.5 \mathrm{mmol})$. Purification by column chromatography on silica gel ( $n$-hexane/EtOAc: $3 / 2$ ) yielded 167 ua $(80.8 \mathrm{mg}, 81 \%)$ as colorless oil.

${ }^{1} \mathrm{H}$ NMR $\left(400 \mathrm{MHz}, \mathrm{CDCl}_{3}\right) \delta=8.66(\mathrm{dd}, J=4.9,2.0 \mathrm{~Hz}, 1 \mathrm{H}), 7.91(\mathrm{td}, J=7.7,2.0 \mathrm{~Hz}, 1 \mathrm{H}), 7.59(\mathrm{~d}, J=$ $1.9 \mathrm{~Hz}, 1 \mathrm{H}), 7.45(\mathrm{~d}, J=8.4 \mathrm{~Hz}, 1 \mathrm{H}), 7.36(\mathrm{ddd}, J=7.5,4.9,1.0 \mathrm{~Hz}, 1 \mathrm{H}), 7.32(\mathrm{dt}, J=7.9,1.0 \mathrm{~Hz}, 1 \mathrm{H})$, 7.28-7.22 (m, 1H), $6.81(\mathrm{~s}, 1 \mathrm{H}), 6.70(\mathrm{~d}, J=16.0 \mathrm{~Hz}, 1 \mathrm{H}), 6.17(\mathrm{~d}, J=16.0 \mathrm{~Hz}, 1 \mathrm{H}), 4.27(\mathrm{~d}, J=8.4 \mathrm{~Hz}$, $1 \mathrm{H}), 4.18(\mathrm{~d}, J=8.4 \mathrm{~Hz}, 1 \mathrm{H}), 1.61(\mathrm{~s}, 3 \mathrm{H}) .{ }^{13} \mathrm{C}$ NMR $\left(100 \mathrm{MHz}, \mathrm{CDCl}_{3}\right) \delta=154.1\left(\mathrm{C}_{\mathrm{q}}\right), 150.2\left(\mathrm{C}_{\mathrm{q}}\right), 149.8$ $(\mathrm{CH}), 138.7(\mathrm{CH}), 138.4\left(\mathrm{C}_{\mathrm{q}}\right), 136.1\left(\mathrm{C}_{\mathrm{q}}\right), 129.5(\mathrm{CH}), 126.9\left(\mathrm{C}_{\mathrm{q}}\right), 124.8(\mathrm{CH}), 122.7(\mathrm{CH}), 122.0(\mathrm{CH})$, $121.3(\mathrm{CH}), 121.1(\mathrm{CH}), 117.0\left(\mathrm{C}_{\mathrm{q}}\right), 113.9(\mathrm{CH}), 103.4(\mathrm{CH}), 82.5\left(\mathrm{C}_{\mathrm{q}}\right), 74.5\left(\mathrm{CH}_{2}\right), 24.3\left(\mathrm{CH}_{3}\right)$. IR $(\operatorname{ATR}) v$ $=2981,1798,1587,1470,1441,1340,1229,1057,948 \mathrm{~cm}^{-1}$. MS (ESI) m/z (relative intensity): 423 (95) $\left.\left({ }^{81} \mathrm{Br}\right)[\mathrm{M}+\mathrm{H}]^{+}, 421(100)\left({ }^{79} \mathrm{Br}\right)[\mathrm{M}+\mathrm{H}]\right]^{+}, 401(30)\left({ }^{81} \mathrm{Br}\right)[\mathrm{M}+\mathrm{H}]^{+}, 399(30)\left({ }^{79} \mathrm{Br}\right)[\mathrm{M}+\mathrm{H}]^{+}, 357(30)$ $\left({ }^{81} \mathrm{Br}\right), 355$ (30) $\left({ }^{79} \mathrm{Br}\right)$. HR-MS (ESI) m/z calcd for $\mathrm{C}_{19} \mathrm{H}_{16} \mathrm{~N}_{2} \mathrm{O}_{3}{ }^{81} \mathrm{Br}[\mathrm{M}+\mathrm{H}]{ }^{+}$: 401.0321, found: 401.0314, $\mathrm{C}_{19} \mathrm{H}_{16} \mathrm{~N}_{2} \mathrm{O}_{3}{ }^{79} \mathrm{Br}[\mathrm{M}+\mathrm{H}]^{+}:$399.0339, found: 399.0335 .<smiles>COC1(/C=C/c2cc3ccc(Cl)cc3n2-c2ccccn2)COC(=O)O1</smiles>

(E)-4-\{2-[6-Chloro-1-(pyridin-2-yl)-1H-indol-2-yl]vinyl\}-4-methyl-1,3-dioxolan-2-one (167va): The general procedure $\mathbf{G}$ was followed using 6-chloro-1-(pyridin-2-yl)-1H-indole (41v) (57.2 mg, 0.25 mmol) and 4-ethynyl-4-methyl-1,3-dioxolan-2-one (110a) $(58.0 \mu \mathrm{L}, 0.5 \mathrm{mmol})$. Purification by column chromatography on silica gel ( $n$-hexane/EtOAc: $3 / 2$ ) yielded $167 \mathrm{va}(73.0 \mathrm{mg}, 82 \%)$ as colorless oil.

${ }^{1} \mathbf{H}$ NMR $\left(400 \mathrm{MHz} \mathrm{CDCl}_{3}\right) \delta=8.66(\mathrm{dd}, J=4.9,2.0 \mathrm{~Hz}, 1 \mathrm{H}), 7.91(\mathrm{ddd}, J=8.0,7.5,2.0 \mathrm{~Hz}, 1 \mathrm{H}), 7.49$ 
(d, $J=8.5 \mathrm{~Hz}, 1 \mathrm{H}), 7.44(\mathrm{dt}, J=1.9,0.7 \mathrm{~Hz}, 1 \mathrm{H}), 7.36(\mathrm{ddd}, J=7.5,4.9,1.0 \mathrm{~Hz}, 1 \mathrm{H}), 7.32(\mathrm{dt}, J=7.9$, $0.9 \mathrm{~Hz}, 1 \mathrm{H}), 7.11(\mathrm{dd}, J=8.4,1.8 \mathrm{~Hz}, 1 \mathrm{H}), 6.81(\mathrm{~s}, 1 \mathrm{H}), 6.70(\mathrm{~d}, J=16.0 \mathrm{~Hz}, 1 \mathrm{H}), 6.16(\mathrm{~d}, J=16.0 \mathrm{~Hz}$, $1 \mathrm{H}), 4.27(\mathrm{~d}, J=8.4 \mathrm{~Hz}, 1 \mathrm{H}), 4.18(\mathrm{~d}, J=8.4 \mathrm{~Hz}, 1 \mathrm{H}), 1.61(\mathrm{~s}, 3 \mathrm{H}) .{ }^{13} \mathrm{C} \mathrm{NMR}\left(100 \mathrm{MHz}, \mathrm{CDCl}_{3}\right) \delta=154.1$ $\left(\mathrm{C}_{\mathrm{q}}\right), 150.2\left(\mathrm{C}_{\mathrm{q}}\right), 149.8(\mathrm{CH}), 138.7(\mathrm{CH}), 138.0\left(\mathrm{C}_{\mathrm{q}}\right), 136.2\left(\mathrm{C}_{\mathrm{q}}\right), 129.3\left(\mathrm{C}_{\mathrm{q}}\right), 129.3(\mathrm{CH}), 126.6\left(\mathrm{C}_{\mathrm{q}}\right)$, 122.7 (CH), $122.2(\mathrm{CH}), 121.6(\mathrm{CH}), 121.4(\mathrm{CH}), 121.0(\mathrm{CH}), 111.0(\mathrm{CH}), 103.4(\mathrm{CH}), 82.5\left(\mathrm{C}_{\mathrm{q}}\right), 74.6$ $\left(\mathrm{CH}_{2}\right), 24.3\left(\mathrm{CH}_{3}\right)$. IR (ATR) $v=2982,1799,1587,1471,1442,1342,1230,1057,956 \mathrm{~cm}^{-1}$. MS (ESI) m/z (relative intensity): $377(100)[\mathrm{M}+\mathrm{Na}]^{+}, 355(30)[\mathrm{M}+\mathrm{H}]^{+}, 333(25), 311$ (30). HR-MS (ESI) m/z calcd for $\mathrm{C}_{19} \mathrm{H}_{16} \mathrm{ClN}_{2} \mathrm{O}_{3}[\mathrm{M}+\mathrm{H}]^{+}: 355.0844$, found: 355.0845 .

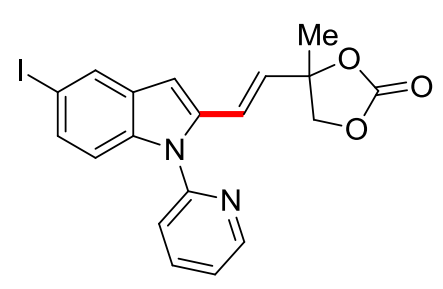

(E)-4-\{2-[5-lodo-1-(pyridin-2-yl)-1H-indol-2-yl]vinyl\}-4-methyl-1,3-dioxolan-2-one (167wa): The general procedure $\mathbf{G}$ was followed using 5-iodo-1-(pyridin-2-yl)-1H-indole (41w) (80.1 mg, 0.25 mmol) and 4-ethynyl-4-methyl-1,3-dioxolan-2-one (110a) (58.0 $\mu \mathrm{L}, 0.5 \mathrm{mmol})$. Purification by column chromatography on silica gel ( $n$-hexane/EtOAc: $3 / 2$ ) yielded 167 wa $(104.9 \mathrm{mg}$, 94\%) as white solid.

M.p. $=49-51{ }^{\circ} \mathrm{C} .{ }^{1} \mathrm{H}$ NMR $\left(400 \mathrm{MHz}, \mathrm{CDCl}_{3}\right) \delta=8.66(\mathrm{dd}, J=4.9,2.0 \mathrm{~Hz}, 1 \mathrm{H}), 7.99-7.83(\mathrm{~m}, 2 \mathrm{H}), 7.41$ (dd, $J=8.7,1.6 \mathrm{~Hz}, 1 \mathrm{H}), 7.36(\mathrm{ddd}, J=7.5,4.9,1.0 \mathrm{~Hz}, 1 \mathrm{H}), 7.32(\mathrm{~d}, J=8.0 \mathrm{~Hz}, 1 \mathrm{H}), 7.21(\mathrm{~d}, J=8.7 \mathrm{~Hz}$, 1H), $6.76(\mathrm{~s}, 1 \mathrm{H}), 6.72(\mathrm{~d}, J=16.0 \mathrm{~Hz}, 1 \mathrm{H}), 6.19(\mathrm{~d}, J=16.0 \mathrm{~Hz}, 1 \mathrm{H}), 4.29(\mathrm{~d}, J=8.4 \mathrm{~Hz}, 1 \mathrm{H}), 4.19$ (d, J $=8.4 \mathrm{~Hz}, 1 \mathrm{H}), 1.62(\mathrm{~s}, 3 \mathrm{H}) .{ }^{13} \mathrm{C}$ NMR $\left(100 \mathrm{MHz} \mathrm{CDCl}_{3}\right) \delta=154.1\left(\mathrm{C}_{\mathrm{q}}\right), 150.2\left(\mathrm{C}_{\mathrm{q}}\right), 149.8(\mathrm{CH}), 138.6$ $(\mathrm{CH}), 136.8\left(\mathrm{C}_{\mathrm{q}}\right), 136.2\left(\mathrm{C}_{\mathrm{q}}\right), 131.7(\mathrm{CH}), 130.6\left(\mathrm{C}_{\mathrm{q}}\right), 129.7(\mathrm{CH}), 129.5(\mathrm{CH}), 122.7(\mathrm{CH}), 121.3(\mathrm{CH})$, $121.1(\mathrm{CH}), 112.9(\mathrm{CH}), 102.3(\mathrm{CH}), 85.0\left(\mathrm{C}_{\mathrm{q}}\right), 82.5\left(\mathrm{C}_{\mathrm{q}}\right), 74.6\left(\mathrm{CH}_{2}\right), 24.4\left(\mathrm{CH}_{3}\right)$. IR $($ ATR $) v=2978$, 1791, 1586, 1469, 1439, 1373, 1209, 1051, 956, $786 \mathrm{~cm}^{-1}$. MS (ESI) m/z (relative intensity): 915 (40) $[2 \mathrm{M}+\mathrm{Na}]^{+}, 469(35)[\mathrm{M}+\mathrm{Na}]^{+}, 447(100)[\mathrm{M}+\mathrm{H}]^{+}, 425$ (30), 314 (25). HR-MS (ESI) m/z calcd for $\mathrm{C}_{19} \mathrm{H}_{15} \mathrm{IN}_{2} \mathrm{O}_{3}[\mathrm{M}+\mathrm{H}]^{+}:$447.0200, found: 447.0195 . 
<smiles>COC1(/C=C/c2cc3cc(F)ccc3n2-c2ccccn2)COC(=O)O1</smiles>

(E)-4-\{2-[5-Fluoro-1-(pyridin-2-yl)-1H-indol-2-yl]vinyl\}-4-methyl-1,3-dioxolan-2-one (167xa): The general procedure $\mathbf{G}$ was followed using 5-fluoro-1-(pyridin-2-yl)- $1 H$-indole (41x) (53.1 mg, 0.25 $\mathrm{mmol}$ ) and 4-ethynyl-4-methyl-1,3-dioxolan-2-one (110a) $(58.0 \mu \mathrm{L}, 0.5 \mathrm{mmol})$. Purification by column chromatography on silica gel (n-hexane/EtOAc: $3 / 2$ ) yielded $167 \times a$ (76.0 mg, 90\%) as colorless oil.

${ }^{1} \mathrm{H}$ NMR $\left(300 \mathrm{MHz}_{\mathrm{CDCl}}\right) \delta=8.66(\mathrm{dd}, J=4.9,2.0 \mathrm{~Hz}, 1 \mathrm{H}), 7.90(\mathrm{ddd}, J=8.0,7.5,2.0 \mathrm{~Hz}, 1 \mathrm{H}), 7.46-$ $7.30(\mathrm{~m}, 3 \mathrm{H}), 7.23(\mathrm{dd}, J=9.1,2.5 \mathrm{~Hz}, 1 \mathrm{H}), 6.92(\mathrm{td}, J=9.1,2.5 \mathrm{~Hz}, 1 \mathrm{H}), 6.81(\mathrm{~s}, 1 \mathrm{H}), 6.73(\mathrm{~d}, J=16.0$ $\mathrm{Hz}, 1 \mathrm{H}), 6.19(\mathrm{~d}, J=16.0 \mathrm{~Hz}, 1 \mathrm{H}), 4.29(\mathrm{~d}, J=8.4 \mathrm{~Hz}, 1 \mathrm{H}), 4.20(\mathrm{~d}, J=8.4 \mathrm{~Hz}, 1 \mathrm{H}), 1.62(\mathrm{~s}, 3 \mathrm{H}) .{ }^{13} \mathrm{C}$ $\operatorname{NMR}\left(125 \mathrm{MHz}, \mathrm{CDCl}_{3}\right) \delta=158.6\left(\mathrm{~d},{ }^{1} J_{\mathrm{C}-\mathrm{F}}=237.6 \mathrm{~Hz}, \mathrm{C}_{\mathrm{q}}\right), 154.0\left(\mathrm{C}_{\mathrm{q}}\right), 150.4\left(\mathrm{C}_{\mathrm{q}}\right), 149.6(\mathrm{CH}), 138.5$ (CH), $136.8\left(\mathrm{C}_{\mathrm{q}}\right), 134.2\left(\mathrm{C}_{\mathrm{q}}\right), 129.4(\mathrm{CH}), 128.6\left(\mathrm{~d},{ }^{3} \mathrm{~J}_{\mathrm{C}-\mathrm{F}}=9.9 \mathrm{~Hz}, \mathrm{C}_{\mathrm{q}}\right), 122.5(\mathrm{CH}), 121.5(\mathrm{CH}), 121.0$ $(\mathrm{CH}), 111.8\left(\mathrm{~d},{ }^{3} \mathrm{~J}_{\mathrm{C}-\mathrm{F}}=9.2 \mathrm{~Hz}, \mathrm{CH}\right), 111.7\left(\mathrm{~d},{ }^{2} \mathrm{~J}_{\mathrm{C}-\mathrm{F}}=26.3 \mathrm{~Hz}, \mathrm{CH}\right), 105.5\left(\mathrm{~d},{ }^{2} \mathrm{~J}_{\mathrm{C}-\mathrm{F}}=24.0 \mathrm{~Hz}, \mathrm{CH}\right), 103.3(\mathrm{~d}$, $\left.{ }^{4} J_{C-F}=4.5 \mathrm{~Hz}, \mathrm{CH}\right), 82.5\left(\mathrm{C}_{\mathrm{q}}\right), 74.6\left(\mathrm{CH}_{2}\right), 24.5\left(\mathrm{CH}_{3}\right) .{ }^{19} \mathrm{~F} \mathrm{NMR}\left(282 \mathrm{MHz}, \mathrm{CDCl}_{3}\right) \delta=-122.51(\mathrm{td}, J=9.2$, $4.4 \mathrm{~Hz}$ ). IR (ATR) $v=2982,1796,1586,1467,1386,1236,1185,1054,958,782 \mathrm{~cm}^{-1} . \mathrm{MS}$ (ESI) m/z (relative intensity): $699(20)[2 \mathrm{M}+\mathrm{Na}]^{+}, 361(20)[\mathrm{M}+\mathrm{Na}]^{+}, 339(100)[\mathrm{M}+\mathrm{H}]^{+}, 317$ (30). HR-MS (ESI) $\mathrm{m} / \mathrm{z}$ calcd for $\mathrm{C}_{19} \mathrm{H}_{16} \mathrm{~N}_{2} \mathrm{O}_{3} \mathrm{~F}[\mathrm{M}+\mathrm{H}]^{+}$: 339.1139, found: 339.1140 .

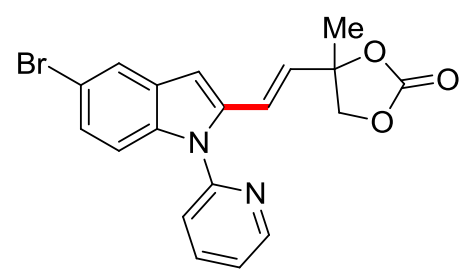

(E)-4-\{2-[5-Bromo-1-(pyridin-2-yl)-1H-indol-2-yl]vinyl\}-4-methyl-1,3-dioxolan-2-one (167ya): The general procedure $\mathbf{G}$ was followed using 5-bromo-1-(pyridin-2-yl)-1H-indole (41y) (68.3 mg, 0.25 mmol) and 4-ethynyl-4-methyl-1,3-dioxolan-2-one (110a) $(58.0 \mu \mathrm{L}, 0.5 \mathrm{mmol})$. Purification by column chromatography on silica gel ( $n$-hexane/EtOAc: $3 / 2$ ) yielded 167ya $(91.2 \mathrm{mg}, 91 \%)$ as pale yellow solid.

M.p. $=45-47^{\circ} \mathrm{C} .{ }^{1} \mathrm{H}$ NMR $\left(300 \mathrm{MHz}, \mathrm{CDCl}_{3}\right) \delta=8.65$ (dd, $\left.J=4.9,1.9 \mathrm{~Hz}, 1 \mathrm{H}\right), 7.90$ (ddd, $J=7.9,7.5$, 
$1.9 \mathrm{~Hz}, 1 \mathrm{H}), 7.71(\mathrm{~d}, J=1.9 \mathrm{~Hz}, 1 \mathrm{H}), 7.47-7.16(\mathrm{~m}, 4 \mathrm{H}), 6.77(\mathrm{~s}, 1 \mathrm{H}), 6.72(\mathrm{~d}, J=16.0 \mathrm{~Hz}, 1 \mathrm{H}), 6.19(\mathrm{~d}$, $J=16.0 \mathrm{~Hz}, 1 \mathrm{H}), 4.28(\mathrm{~d}, J=8.4 \mathrm{~Hz}, 1 \mathrm{H}), 4.19(\mathrm{~d}, J=8.4 \mathrm{~Hz}, 1 \mathrm{H}), 1.62(\mathrm{~s}, 3 \mathrm{H}) .{ }^{13} \mathrm{C} \mathrm{NMR}(125 \mathrm{MHz}$, $\left.\mathrm{CDCl}_{3}\right) \delta=154.0\left(\mathrm{C}_{\mathrm{q}}\right), 150.2\left(\mathrm{C}_{\mathrm{q}}\right), 149.7(\mathrm{CH}), 138.5(\mathrm{CH}), 136.5\left(\mathrm{C}_{\mathrm{q}}\right), 136.3\left(\mathrm{C}_{\mathrm{q}}\right), 129.7\left(\mathrm{C}_{\mathrm{q}}\right), 129.7(\mathrm{CH})$, $126.1(\mathrm{CH}), 123.1(\mathrm{CH}), 122.6(\mathrm{CH}), 121.3(\mathrm{CH}), 121.0(\mathrm{CH}), 114.5\left(\mathrm{C}_{\mathrm{q}}\right), 112.4(\mathrm{CH}), 102.6(\mathrm{CH}), 82.4$ $\left(\mathrm{C}_{\mathrm{q}}\right), 74.6\left(\mathrm{CH}_{2}\right), 24.5\left(\mathrm{CH}_{3}\right)$. IR $(\mathrm{ATR}) v=2981,1791,1586,1440,1382,1228,1209,1050,957,786$ $\mathrm{cm}^{-1} . \mathrm{MS}(\mathrm{ESI}) \mathrm{m} / \mathrm{z}$ (relative intensity): $401(100)\left({ }^{81} \mathrm{Br}\right)[\mathrm{M}+\mathrm{H}]^{+}, 399(100)\left({ }^{79} \mathrm{Br}\right)[\mathrm{M}+\mathrm{H}]^{+}, 357(15)$ $\left({ }^{81} \mathrm{Br}\right), 355$ (15) $\left({ }^{79} \mathrm{Br}\right)$. HR-MS (ESI) m/z calcd for $\mathrm{C}_{19} \mathrm{H}_{16} \mathrm{~N}_{2} \mathrm{O}_{3}{ }^{81} \mathrm{Br}[\mathrm{M}+\mathrm{H}]^{+}:$401.0319, found: 401.0315, $\mathrm{C}_{19} \mathrm{H}_{16} \mathrm{~N}_{2} \mathrm{O}_{3}{ }^{79} \mathrm{Br}[\mathrm{M}+\mathrm{H}]^{+}:$399.0339, found: 399.0334 .

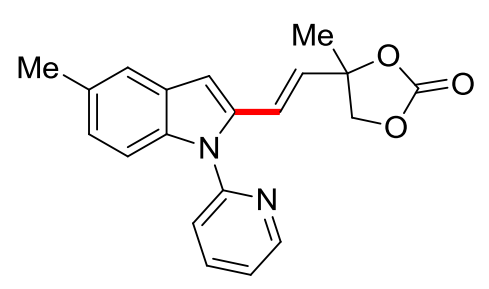

(E)-4-Methyl-4-\{2-[5-methyl-1-(pyridin-2-yl)-1H-indol-2-yl]vinyl\}-1,3-dioxolan-2-one (167za): The general procedure $\mathbf{G}$ was followed using 5-methyl-1-(pyridin-2-yl)-1H-indole (41z) (52.1 mg, 0.25 mmol) and 4-ethynyl-4-methyl-1,3-dioxolan-2-one (110a) (58.0 $\mathrm{LL}, 0.5 \mathrm{mmol})$. Purification by column chromatography on silica gel ( $n$-hexane/EtOAc: $3 / 2$ ) yielded $167 z a ~(65.2 \mathrm{mg}, 78 \%$ ) as colorless oil.

${ }^{1} \mathrm{H}$ NMR $\left(400 \mathrm{MHz} \mathrm{CDCl}_{3}\right) \delta=8.65(\mathrm{dd}, J=5.1,2.1 \mathrm{~Hz}, 1 \mathrm{H}), 7.88(\mathrm{ddd}, J=8.0,7.4,2.0, \mathrm{~Hz}, 1 \mathrm{H}), 7.42-$ $7.28(\mathrm{~m}, 4 \mathrm{H}), 7.01(\mathrm{dd}, J=8.5,1.7 \mathrm{~Hz}, 1 \mathrm{H}), 6.79(\mathrm{~s}, 1 \mathrm{H}), 6.77$ (d, J = $16.1 \mathrm{~Hz}, 1 \mathrm{H}), 6.15$ (d, J = $16.1 \mathrm{~Hz}$, $1 \mathrm{H}), 4.29(\mathrm{~d}, J=8.4 \mathrm{~Hz}, 1 \mathrm{H}), 4.19(\mathrm{dd}, J=8.4 \mathrm{~Hz}, 1 \mathrm{H}), 2.42(\mathrm{~s}, 3 \mathrm{H}), 1.62(\mathrm{~s}, 3 \mathrm{H}) .{ }^{13} \mathrm{C} \mathrm{NMR}(100 \mathrm{MHz}$, $\left.\mathrm{CDCl}_{3}\right) \delta=154.3\left(\mathrm{C}_{\mathrm{q}}\right), 150.9\left(\mathrm{C}_{\mathrm{q}}\right), 149.6(\mathrm{CH}), 138.5(\mathrm{CH}), 136.2\left(\mathrm{C}_{\mathrm{q}}\right), 135.5\left(\mathrm{C}_{\mathrm{q}}\right), 130.9\left(\mathrm{C}_{\mathrm{q}}\right), 128.5\left(\mathrm{C}_{\mathrm{q}}\right)$, $128.4(\mathrm{CH}), 125.2(\mathrm{CH}), 122.2(\mathrm{CH}), 122.1(\mathrm{CH}), 121.0(\mathrm{CH}), 120.5(\mathrm{CH}), 110.6(\mathrm{CH}), 103.4(\mathrm{CH}), 82.7$ $\left(\mathrm{C}_{\mathrm{q}}\right), 74.7\left(\mathrm{CH}_{2}\right), 24.4\left(\mathrm{CH}_{3}\right), 21.4\left(\mathrm{CH}_{3}\right)$. IR (ATR) $v=2924,1800,1588,1470,1437,1384,1301,1187$, $1057 \mathrm{~cm}^{-1}$. MS (ESI) m/z (relative intensity): 335 (100) [M+H] $]^{+}, 313$ (40), 271 (40). HR-MS (EI) m/z calcd for $\mathrm{C}_{20} \mathrm{H}_{19} \mathrm{~N}_{2} \mathrm{O}_{3}[\mathrm{M}+\mathrm{H}]^{+}:$335.1390, found: 335.1393 .

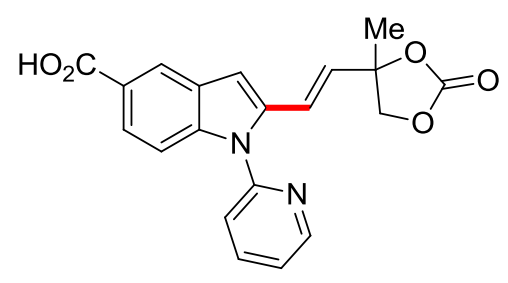




\section{(E)-2-[2-(4-Methyl-2-oxo-1,3-dioxolan-4-yl)vinyl]-1-(pyridin-2-yl)-1H-indole-5-carboxylic}

acid

(167a'a): The general procedure $\mathbf{G}$ was followed using 1-(pyridin-2-yl)-1H-indole-5-carboxylic acid (41a') (59.6 mg, $0.25 \mathrm{mmol}$ ) and 4-ethynyl-4-methyl-1,3-dioxolan-2-one (110a) (58.0 $\mu \mathrm{L}, 0.5 \mathrm{mmol})$. Purification by column chromatography on silica gel (EtOAc/MeOH: 20/1) yielded 167a'a (61.1 mg, $67 \%)$ as white solid.

M.p. $=135-137^{\circ} \mathrm{C} .{ }^{1} \mathrm{H}$ NMR $\left(300 \mathrm{MHz}, \mathrm{CDCl}_{3}\right) \delta=8.70(\mathrm{dd}, J=4.9,2.0 \mathrm{~Hz}, 1 \mathrm{H}), 8.45(\mathrm{~s}, 1 \mathrm{H}), 8.11-$ $7.84(\mathrm{~m}, 2 \mathrm{H}), 7.53-7.37(\mathrm{~m}, 3 \mathrm{H}), 6.96(\mathrm{~s}, 1 \mathrm{H}), 6.74(\mathrm{dd}, J=16.0 \mathrm{~Hz}, 1 \mathrm{H}), 6.23(\mathrm{~d}, J=16.0 \mathrm{~Hz}, 1 \mathrm{H}), 4.31$ $(\mathrm{d}, J=8.4 \mathrm{~Hz}, 1 \mathrm{H}), 4.21(\mathrm{~d}, J=8.4 \mathrm{~Hz}, 1 \mathrm{H}), 1.64(\mathrm{~s}, 3 \mathrm{H}) .{ }^{13} \mathrm{C} \mathrm{NMR}\left(125 \mathrm{MHz}, \mathrm{CDCl}_{3}\right) \delta=171.8\left(\mathrm{C}_{\mathrm{q}}\right)$, $154.0\left(\mathrm{C}_{\mathrm{q}}\right), 150.9\left(\mathrm{C}_{\mathrm{q}}\right), 149.8(\mathrm{CH}), 140.5\left(\mathrm{C}_{\mathrm{q}}\right), 138.7(\mathrm{CH}), 137.1\left(\mathrm{C}_{\mathrm{q}}\right), 130.0(\mathrm{CH}), 127.7\left(\mathrm{C}_{\mathrm{q}}\right), 125.1$ $(\mathrm{CH}), 124.5(\mathrm{CH}), 123.0(\mathrm{CH}), 122.5\left(\mathrm{C}_{\mathrm{q}}\right), 121.3(\mathrm{CH}), 121.1(\mathrm{CH}), 110.7(\mathrm{CH}), 104.3(\mathrm{CH}), 82.4\left(\mathrm{C}_{\mathrm{q}}\right)$, $74.6\left(\mathrm{CH}_{2}\right), 24.6\left(\mathrm{CH}_{3}\right)$. IR (ATR) $v=2924,1796,1678,1470,1228,1053,905,767,726 \mathrm{~cm}^{-1}$. MS (ESI) $\mathrm{m} / \mathrm{z}$ (relative intensity): $751(50)[2 \mathrm{M}+\mathrm{Na}]^{+}, 387(70)[\mathrm{M}+\mathrm{Na}]^{+}, 365(100)[\mathrm{M}+\mathrm{H}]^{+}, 343(55)$. HR-MS (ESI) $\mathrm{m} / \mathrm{z}$ calcd for $\mathrm{C}_{20} \mathrm{H}_{17} \mathrm{~N}_{2} \mathrm{O}_{5}[\mathrm{M}+\mathrm{H}]^{+}$: 365.1132, found: 365.1124 .

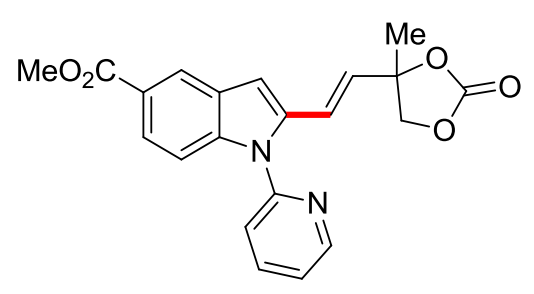

(E)-Methyl 2-[2-(4-methyl-2-oxo-1,3-dioxolan-4-yl)vinyl]-1-(pyridin-2-yl)-1H-indole-5-carboxylate (167b'a): The general procedure $G$ was followed using methyl 1-(pyridin-2-yl)-1H-indole-5-carboxylate (416') $\quad(63.1 \quad \mathrm{mg}, \quad 0.25 \quad \mathrm{mmol})$ and 4-ethynyl-4-methyl-1,3-dioxolan-2-one (110a) (58.0 $\mu \mathrm{L}, 0.5 \mathrm{mmol})$. Purification by column chromatography on silica gel ( $n$-hexane/EtOAc: $3 / 2$ ) yielded 167b'a (68.1 mg, $72 \%$ ) as colorless oil. ${ }^{1} \mathrm{H}$ NMR $\left(400 \mathrm{MHz}, \mathrm{CDCl}_{3}\right) \delta=8.67(\mathrm{dd}, J=4.9,1.9 \mathrm{~Hz}, 1 \mathrm{H}), 8.34(\mathrm{~d}, J=1.7 \mathrm{~Hz}, 1 \mathrm{H}), 7.92$ (ddd, $J=8.0$, 7.5, 1.9 Hz, 1H), 7.86 (dd, J = 8.8, 1.7 Hz, 1H), 7.42 (dt, J = 8.7, 0.8 Hz, 1H), 7.40-7.31 (m, 2H), 6.92 (s, 1H), $6.72(\mathrm{~d}, J=16.0 \mathrm{~Hz}, 1 \mathrm{H}), 6.21(\mathrm{~d}, J=16.0 \mathrm{~Hz}, 1 \mathrm{H}), 4.29(\mathrm{~d}, J=8.4 \mathrm{~Hz}, 1 \mathrm{H}), 4.19(\mathrm{~d}, J=8.4 \mathrm{~Hz}, 1 \mathrm{H})$, $3.91(\mathrm{~s}, 3 \mathrm{H}), 1.61(\mathrm{~s}, 3 \mathrm{H}) .{ }^{13} \mathrm{C} \mathrm{NMR}\left(100 \mathrm{MHz}, \mathrm{CDCl}_{3}\right) \delta=167.6\left(\mathrm{C}_{\mathrm{q}}\right), 154.1\left(\mathrm{C}_{\mathrm{q}}\right), 150.2\left(\mathrm{C}_{\mathrm{q}}\right), 149.8(\mathrm{CH})$, $140.0\left(\mathrm{C}_{\mathrm{q}}\right), 138.7(\mathrm{CH}), 137.0\left(\mathrm{C}_{\mathrm{q}}\right), 129.9(\mathrm{CH}), 127.7\left(\mathrm{C}_{\mathrm{q}}\right), 124.6(\mathrm{CH}), 123.7(\mathrm{CH}), 123.5\left(\mathrm{C}_{\mathrm{q}}\right), 122.9$ (CH), $121.2(\mathrm{CH}), 121.2(\mathrm{CH}), 110.6(\mathrm{CH}), 104.2(\mathrm{CH}), 82.4\left(\mathrm{C}_{\mathrm{q}}\right), 74.6\left(\mathrm{CH}_{2}\right), 51.9\left(\mathrm{CH}_{3}\right), 24.4\left(\mathrm{CH}_{3}\right)$. IR (ATR) $v=2951,1795,1706,1588,1469,1434,1309,1253,1089,1053 \mathrm{~cm}^{-1}$. MS (ESI) m/z (relative 
intensity): $779(30)[2 \mathrm{M}+\mathrm{Na}]^{+}, 757(30)[2 \mathrm{M}+\mathrm{H}]^{+}, 401(10)[\mathrm{M}+\mathrm{Na}]^{+}, 379(100)[\mathrm{M}+\mathrm{H}]^{+}, 357(30), 335$ (35). HR-MS (ESI) m/z calcd for $\mathrm{C}_{21} \mathrm{H}_{19} \mathrm{~N}_{2} \mathrm{O}_{3}[\mathrm{M}+\mathrm{H}]^{+}: 379.1288$, found: 379.1289 .<smiles>[M]C1(/C=C/c2cc3c(n2-c2ccccn2)CCCC3=O)COC(=O)O1</smiles>

(E)-2-[2-(4-Methyl-2-oxo-1,3-dioxolan-4-yl)vinyl]-1-(pyridin-2-yl)-6,7-dihydro-1 $H$-indol-4(5H)-one (167c'a): The general procedure $\mathbf{G}$ was followed using 1-(pyridin-2-yl)-6,7-dihydro-1H-indol-4(5H)-one $\quad\left(41 c^{\prime}\right) \quad(53.1 \quad \mathrm{mg}, \quad 0.25 \quad \mathrm{mmol})$ and 4-ethynyl-4-methyl-1,3-dioxolan-2-one (110a) (58.0 $\mu \mathrm{L}, 0.5 \mathrm{mmol})$. Purification by column chromatography on silica gel ( $n$-hexane/EtOAc: $1 / 3$ ) yielded $167 c^{\prime a}(42.3 \mathrm{mg}, 50 \%)$ as a white solid. M.p. $=149-151{ }^{\circ} \mathrm{C} .{ }^{1} \mathrm{H}$ NMR $\left(300 \mathrm{MHz}, \mathrm{CDCl}_{3}\right) \delta=8.59(\mathrm{dd}, J=4.9,1.9 \mathrm{~Hz}, 1 \mathrm{H}), 7.87$ (td, $J=7.7,1.9$ $\mathrm{Hz}, 1 \mathrm{H}$ ), 7.38 (ddd, $J=7.6,4.9,1.0 \mathrm{~Hz}, 1 \mathrm{H}), 7.19$ (d, $J=8.0 \mathrm{~Hz}, 1 \mathrm{H}), 6.79(\mathrm{~s}, 1 \mathrm{H}), 6.31(\mathrm{~d}, J=16.0 \mathrm{~Hz}$, $1 \mathrm{H}), 5.89(\mathrm{~d}, J=16.0 \mathrm{~Hz}, 1 \mathrm{H}), 4.17(\mathrm{~d}, J=8.4 \mathrm{~Hz}, 1 \mathrm{H}), 4.11(\mathrm{~d}, J=8.4 \mathrm{~Hz}, 1 \mathrm{H}), 2.66(\mathrm{td}, J=6.1,2.7 \mathrm{~Hz}$, $2 \mathrm{H}), 2.49-2.37(\mathrm{~m}, 2 \mathrm{H}), 2.14-1.97(\mathrm{~m}, 2 \mathrm{H}), 1.51(\mathrm{~s}, 3 \mathrm{H}) .{ }^{13} \mathrm{C} \mathrm{NMR}\left(125 \mathrm{MHz}, \mathrm{CDCl}_{3}\right) \delta=194.1\left(\mathrm{C}_{\mathrm{q}}\right)$, $154.0\left(\mathrm{C}_{\mathrm{q}}\right), 149.7(\mathrm{CH}), 149.4\left(\mathrm{C}_{\mathrm{q}}\right), 145.5\left(\mathrm{C}_{\mathrm{q}}\right), 138.6(\mathrm{CH}), 131.2\left(\mathrm{C}_{\mathrm{q}}\right), 126.8(\mathrm{CH}), 123.7(\mathrm{CH}), 121.6$ $(\mathrm{CH}), 121.4\left(\mathrm{C}_{\mathrm{q}}\right), 120.1(\mathrm{CH}), 105.0(\mathrm{CH}), 82.5\left(\mathrm{C}_{\mathrm{q}}\right), 74.7\left(\mathrm{CH}_{2}\right), 37.9\left(\mathrm{CH}_{2}\right), 24.5\left(\mathrm{CH}_{3}\right), 23.6\left(\mathrm{CH}_{2}\right), 23.0$ $\left(\mathrm{CH}_{2}\right)$. IR (ATR) $v=2930,1796,1656,1460,1438,1220,1134,1093,1054,733 \mathrm{~cm}^{-1} . \mathrm{MS}(\mathrm{ESI}) \mathrm{m} / \mathrm{z}$ (relative intensity): $699(70)[2 \mathrm{M}+\mathrm{Na}]^{+}, 361(40)[\mathrm{M}+\mathrm{Na}]^{+}, 339(100)[\mathrm{M}+\mathrm{H}]^{+}, 317(80) . \mathrm{HR}-\mathrm{MS}(\mathrm{ESI})$ $\mathrm{m} / \mathrm{z}$ calcd for $\mathrm{C}_{19} \mathrm{H}_{19} \mathrm{~N}_{2} \mathrm{O}_{4}[\mathrm{M}+\mathrm{H}]^{+}: 339.1339$, found: 339.1340 .

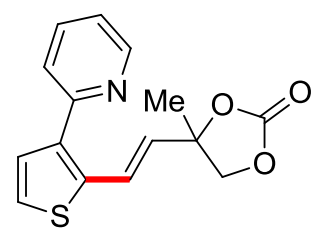

(E)-4-Methyl-4-\{2-[3-(pyridin-2-yl)thiophen-2-yl]vinyl\}-1,3-dioxolan-2-one (167d'a): The general procedure G was followed using 2-(thiophen-3-yl)pyridine (41d') (40.3 mg, $0.25 \mathrm{mmol}$ ) and 4-ethynyl-4-methyl-1,3-dioxolan-2-one (110a) (58.0 $\mu \mathrm{L}, 0.5 \mathrm{mmol})$. Purification by column chromatography on silica gel ( $n$-hexane/EtOAc: $3 / 1$ ) yielded $167 \mathrm{~d}$ 'a (63.2 mg, $88 \%$ ) as colorless oil. 
${ }^{1} \mathrm{H}$ NMR $\left(300 \mathrm{MHz}, \mathrm{C}_{6} \mathrm{D}_{6}\right) \delta=8.62(\mathrm{dt}, J=4.8,1.5 \mathrm{~Hz}, 1 \mathrm{H}), 7.89(\mathrm{~d}, J=16.1 \mathrm{~Hz}, 1 \mathrm{H}), 7.32-7.08(\mathrm{~m}, 3 \mathrm{H})$, $6.88(\mathrm{~d}, J=5.3 \mathrm{~Hz}, 1 \mathrm{H}), 6.72(\mathrm{ddd}, J=5.7,4.8,2.9 \mathrm{~Hz}, 1 \mathrm{H}), 5.93(\mathrm{~d}, J=16.1 \mathrm{~Hz}, 1 \mathrm{H}), 3.54(\mathrm{~d}, J=8.4 \mathrm{~Hz}$, $1 \mathrm{H}), 3.34(\mathrm{~d}, J=8.4 \mathrm{~Hz}, 1 \mathrm{H}), 1.06(\mathrm{~s}, 3 \mathrm{H}) .{ }^{13} \mathrm{C} \mathrm{NMR}\left(75 \mathrm{MHz}, \mathrm{C}_{6} \mathrm{D}_{6}\right) \delta=154.5\left(\mathrm{C}_{\mathrm{q}}\right), 154.0\left(\mathrm{C}_{\mathrm{q}}\right), 149.7$ $(\mathrm{CH}), 139.9\left(\mathrm{C}_{\mathrm{q}}\right), 138.1\left(\mathrm{C}_{\mathrm{q}}\right), 136.2(\mathrm{CH}), 129.5(\mathrm{CH}), 128.5(\mathrm{CH}), 125.4(\mathrm{CH}), 124.1(\mathrm{CH}), 122.9(\mathrm{CH})$, $121.7(\mathrm{CH}), 81.8\left(\mathrm{C}_{\mathrm{q}}\right), 73.8\left(\mathrm{CH}_{2}\right), 23.4\left(\mathrm{CH}_{3}\right)$. IR (ATR) $v=1800,1585,1474,1439,1265,1230,1095$, 1057, 958, $772 \mathrm{~cm}^{-1}$. MS (ESI) m/z (relative intensity): 266 (70), $288(100)[\mathrm{M}+\mathrm{H}]^{+}, 310(80)[\mathrm{M}+\mathrm{Na}]^{+}$, $597(40)[2 \mathrm{M}+\mathrm{Na}]^{+}$. HR-MS (ESI) m/z calcd for $\mathrm{C}_{15} \mathrm{H}_{13} \mathrm{NO}_{3} \mathrm{~S}[\mathrm{M}+\mathrm{H}]^{+}:$:288.0689, found: 288.0691 .

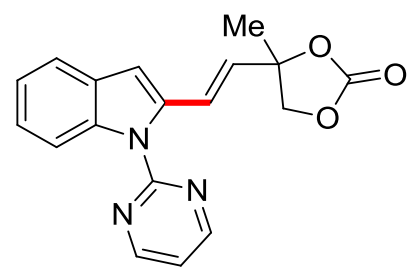

(E)-4-Methyl-4-\{2-[1-(pyrimidin-2-yl)-1H-indol-2-yl]vinyl\}-1,3-dioxolan-2-one (167aa): The general procedure $\mathbf{G}$ was followed using 1-(pyrimidin-2-yl)-1H-indole (41a) (48.8 mg, $0.25 \mathrm{mmol}$ ) and 4-ethynyl-4-methyl-1,3-dioxolan-2-one (110a) (58.0 $\mu \mathrm{L}, 0.5 \mathrm{mmol})$. Purification by column chromatography on silica gel ( $n$-hexane/EtOAc: $3 / 2$ ) yielded 167 aa $(57.8 \mathrm{mg}, 72 \%$ ) as colorless oil. ${ }^{1} \mathrm{H}$ NMR $\left(400 \mathrm{MHz}, \mathrm{CDCl}_{3}\right) \delta=8.78(\mathrm{~d}, J=4.7 \mathrm{~Hz}, 2 \mathrm{H}), 8.35(\mathrm{~d}, J=8.3 \mathrm{~Hz}, 1 \mathrm{H}), 7.57(\mathrm{~d}, J=7.7 \mathrm{~Hz}, 1 \mathrm{H})$, $7.36(\mathrm{~d}, J=15.9 \mathrm{~Hz}, 1 \mathrm{H}), 7.32-7.04(\mathrm{~m}, 3 \mathrm{H}), 6.85(\mathrm{~s}, 1 \mathrm{H}), 6.19(\mathrm{~d}, J=15.9 \mathrm{~Hz}, 1 \mathrm{H}), 4.39(\mathrm{~d}, J=8.2 \mathrm{~Hz}$, $1 \mathrm{H}), 4.24(\mathrm{~d}, J=8.2 \mathrm{~Hz}, 1 \mathrm{H}), 1.70(\mathrm{~s}, 3 \mathrm{H}) .{ }^{13} \mathrm{C} \mathrm{NMR}\left(100 \mathrm{MHz}^{\mathrm{C}} \mathrm{CDCl}_{3}\right) \delta=158.2(\mathrm{CH}), 157.8\left(\mathrm{C}_{\mathrm{q}}\right), 154.5$ $\left(\mathrm{C}_{q}\right), 137.2\left(\mathrm{C}_{\mathrm{q}}\right), 136.4\left(\mathrm{C}_{\mathrm{q}}\right), 128.9\left(\mathrm{C}_{\mathrm{q}}\right), 127.6(\mathrm{CH}), 124.6(\mathrm{CH}), 124.1(\mathrm{CH}), 122.4(\mathrm{CH}), 120.6(\mathrm{CH})$, $117.3(\mathrm{CH}), 114.5(\mathrm{CH}), 106.5(\mathrm{CH}), 82.8\left(\mathrm{C}_{\mathrm{q}}\right), 74.8\left(\mathrm{CH}_{2}\right), 24.5\left(\mathrm{CH}_{3}\right)$. IR (ATR) $v=2981,1791,1562$, 1419, 1344, 1233, 1210, 1091, 947, $746 \mathrm{~cm}^{-1}$. MS (ESI) m/z (relative intensity): 665 (70) [2M+Na] , $344(10)[\mathrm{M}+\mathrm{Na}]^{+}, 322(100)[\mathrm{M}+\mathrm{H}]^{+}, 300(20), 278(60), 260$ (20). HR-MS (ESI) m/z calcd for $\mathrm{C}_{18} \mathrm{H}_{16} \mathrm{~N}_{3} \mathrm{O}_{3}[\mathrm{M}+\mathrm{H}]^{+}:$322.1186, found: 322.1195 .

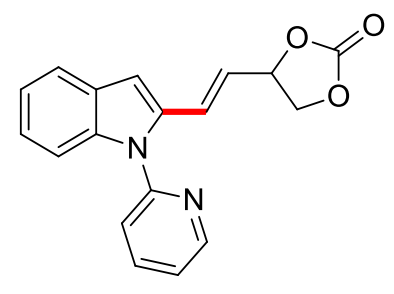

(E)-4-\{2-[1-(Pyridin-2-yl)-1H-indol-2-yl]vinyl\}-1,3-dioxolan-2-one (167bb): The general procedure G 
was followed using 1-(pyridin-2-yl)-1H-indole (41b) $\quad(48.6 \quad \mathrm{mg}, \quad 0.25 \mathrm{mmol})$ and 4-ethynyl-1,3-dioxolan-2-one (110b) $(56.1 \mathrm{mg}, 0.5 \mathrm{mmol})$. Purification by column chromatography on silica gel ( $n$-hexane/EtOAc: $3 / 2$ ) yielded $167 \mathrm{bb}(63.6 \mathrm{mg}, 83 \%)$ as colorless oil.

${ }^{1} \mathrm{H}$ NMR $\left(300 \mathrm{MHz}^{\mathrm{CDCl}}{ }_{3}\right) \delta=8.66(\mathrm{dd}, J=4.9,2.0 \mathrm{~Hz}, 1 \mathrm{H}), 7.91(\mathrm{ddd}, J=8.0,7.5,2.0 \mathrm{~Hz}, 1 \mathrm{H}), 7.70-$ $7.59(\mathrm{~m}, 1 \mathrm{H}), 7.48-7.31(\mathrm{~m}, 3 \mathrm{H}), 7.23-7.06(\mathrm{~m}, 2 \mathrm{H}), 6.94(\mathrm{~s}, 1 \mathrm{H}), 6.83(\mathrm{~d}, J=15.8 \mathrm{~Hz}, 1 \mathrm{H}), 6.10(\mathrm{dd}, J$ $=15.8,7.9 \mathrm{~Hz}, 1 \mathrm{H}$ ), 5.19 (qd, $J=7.9,0.9 \mathrm{~Hz}, 1 \mathrm{H}$ ), 4.57 (ddd, $J=8.7,8.0,0.9 \mathrm{~Hz}, 1 \mathrm{H}$ ), 4.17 (ddd, $J=8.7$, 8.0, 0.9 Hz, 1H). ${ }^{13} \mathrm{C}$ NMR (125 MHz, $\left.\mathrm{CDCl}_{3}\right) \delta=154.5\left(\mathrm{C}_{\mathrm{q}}\right), 150.6\left(\mathrm{C}_{\mathrm{q}}\right), 149.6(\mathrm{CH}), 138.5(\mathrm{CH}), 137.8$ $\left(\mathrm{C}_{\mathrm{q}}\right), 135.0\left(\mathrm{C}_{\mathrm{q}}\right), 128.0\left(\mathrm{C}_{\mathrm{q}}\right), 126.7(\mathrm{CH}), 123.7(\mathrm{CH}), 123.2(\mathrm{CH}), 122.4(\mathrm{CH}), 121.5(\mathrm{CH}), 121.2(\mathrm{CH})$, $121.0(\mathrm{CH}), 110.7(\mathrm{CH}), 104.4(\mathrm{CH}), 77.7(\mathrm{CH}), 69.2\left(\mathrm{CH}_{2}\right)$. IR (ATR) $v=3055,1794,1586,1467,1436$, 1160, 1149, 1047, 933, $743 \mathrm{~cm}^{-1}$. MS (ESI) m/z (relative intensity): 329 (10) [M+Na], 307 (100) $[\mathrm{M}+\mathrm{H}]^{+}, 285$ (15), 245 (10). HR-MS (ESI) m/z calcd for $\mathrm{C}_{18} \mathrm{H}_{15} \mathrm{~N}_{2} \mathrm{O}_{3}[\mathrm{M}+\mathrm{H}]^{+}:$307.1077, found: 307.1075.

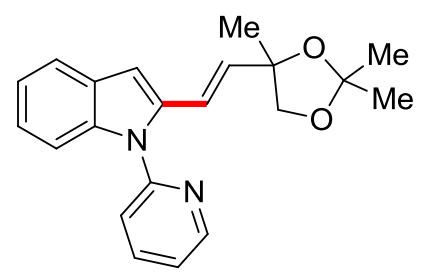

(E)-1-(Pyridin-2-yl)-2-[2-(2,2,4-trimethyl-1,3-dioxolan-4-yl)vinyl]-1H-indole (167bc): The general procedure $\mathbf{G}$ was followed using 1-(pyridin-2-yl)-1H-indole (41b) (48.6 mg, $0.25 \mathrm{mmol}$ ) and 4-ethynyl-2,2,4-trimethyl-1,3-dioxolane (110c) (70.1 mg, $0.5 \mathrm{mmol})$ for $40 \mathrm{~min}$. Purification by column chromatography on silica gel ( $n$-hexane/EtOAc: 6/1) yielded $167 \mathrm{bc}(59.4 \mathrm{mg}, 71 \%)$ as colorless oil.

${ }^{1} \mathrm{H}$ NMR $\left(400 \mathrm{MHz}_{\mathrm{CDCl}}\right) \delta=8.66(\mathrm{dd}, J=4.9,2.0 \mathrm{~Hz}, 1 \mathrm{H}), 7.84(\mathrm{ddd}, J=8.0,7.4,2.0 \mathrm{~Hz}, 1 \mathrm{H}), 7.62-$ $7.55(\mathrm{~m}, 1 \mathrm{H}), 7.52-7.42(\mathrm{~m}, 1 \mathrm{H}), 7.34(\mathrm{dt}, J=8.0,1.0 \mathrm{~Hz}, 1 \mathrm{H}), 7.30$ (ddd, $J=7.5,4.9,1.0 \mathrm{~Hz}, 1 \mathrm{H})$, 7.22-7.07 (m, 2H), $6.81(\mathrm{~s}, 1 \mathrm{H}), 6.66(\mathrm{~d}, J=15.9 \mathrm{~Hz}, 1 \mathrm{H}), 6.25(\mathrm{~d}, J=15.9 \mathrm{~Hz}, 1 \mathrm{H}), 3.91(\mathrm{~d}, J=8.4 \mathrm{~Hz}$, 1H), $3.82(\mathrm{~d}, J=8.4 \mathrm{~Hz}, 1 \mathrm{H}), 1.42(\mathrm{~d}, J=0.7 \mathrm{~Hz}, 3 \mathrm{H}), 1.39(\mathrm{~s}, 3 \mathrm{H}), 1.36(\mathrm{~d}, J=0.7 \mathrm{~Hz}, 3 \mathrm{H}) .{ }^{13} \mathrm{C}$ NMR $\left(100 \mathrm{MHz}, \mathrm{CDCl}_{3}\right) \delta=151.2\left(\mathrm{C}_{\mathrm{q}}\right), 149.5(\mathrm{CH}), 138.1(\mathrm{CH}), 137.6\left(\mathrm{C}_{\mathrm{q}}\right), 137.2\left(\mathrm{C}_{\mathrm{q}}\right), 135.3(\mathrm{CH}), 128.5\left(\mathrm{C}_{\mathrm{q}}\right)$, $122.7(\mathrm{CH}), 121.9(\mathrm{CH}), 121.4(\mathrm{CH}), 121.2(\mathrm{CH}), 120.4(\mathrm{CH}), 118.8(\mathrm{CH}), 110.8(\mathrm{CH}), 109.9\left(\mathrm{C}_{\mathrm{q}}\right), 102.3$ (CH), $80.7\left(\mathrm{C}_{\mathrm{q}}\right), 74.6\left(\mathrm{CH}_{2}\right), 27.1\left(\mathrm{CH}_{3}\right), 26.5\left(\mathrm{CH}_{3}\right), 25.4\left(\mathrm{CH}_{3}\right)$. IR (ATR) $v=2982,1386,1468,1452$, 1212, 1103, 1057, 972, $745 \mathrm{~cm}^{-1}$. MS (ESI) m/z (relative intensity): 357 (100) [M+Na] $]^{+}, 335$ (50) 
$[\mathrm{M}+\mathrm{H}]^{+}, 277$ (20). HR-MS (ESI) m/z calcd for $\mathrm{C}_{21} \mathrm{H}_{23} \mathrm{~N}_{2} \mathrm{O}_{2}[\mathrm{M}+\mathrm{H}]^{+}:$335.1754, found: 335.1749.

\section{Intermolecular Competition Experiment}<smiles>COCc1ccc2c(c1)cc([18F])n2[18OH]</smiles>

41e'a / 41xa (each $0.25 \mathrm{mmol})$

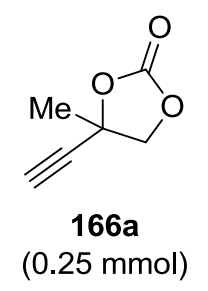

167e'a / 167xa:1.24 / 1.0

(by ${ }^{1} \mathrm{H}$ NMR)

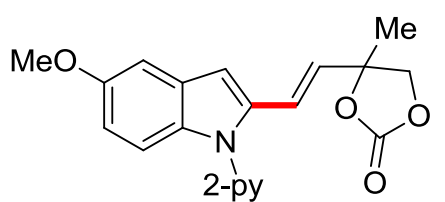

167e'a: $46 \%$<smiles>CC1(/C=C/c2cc3cc(F)ccc3n2[18O])COC(=O)O1</smiles>

167xa: $37 \%$

A suspension of 5-methoxy-1-(pyridin-2-yl)-1H-indole (41e'a) (56.1 mg, $0.25 \mathrm{mmol}$ ), 5-fluoro-1-(pyridin-2-yl)-1H-indole (41xa) 160.8 $\mathrm{mg}$, 0.25 $\mathrm{mmol})$, 4-ethynyl-4-methyl-1,3-dioxolan-2-one (166a) (58.0 $\mu \mathrm{L}, 0.5 \mathrm{mmol}), \mathrm{HOAc}(2.8 \mu \mathrm{L}, 20.0 \mathrm{~mol} \%)$ and $\left[\mathrm{MnBr}(\mathrm{CO})_{5}\right](6.9 \mathrm{mg}, 10.0 \mathrm{~mol} \%)$ in 1,4-dioxane $(1.0 \mathrm{~mL})$ was stirred at $60{ }^{\circ} \mathrm{C}$ for $16 \mathrm{~h}$ under $\mathrm{N}_{2}$. After cooling to ambient temperature, the mixture was transferred into a round bottom flask with $\mathrm{CH}_{2} \mathrm{Cl}_{2}(20 \mathrm{~mL})$ and concentrated in vacuo. Purification by column chromatography on silica gel afforded the products (167e'a + 167xa: $71.6 \mathrm{mg}$ ) and the ratio were determined by ${ }^{1} \mathrm{H}$ NMR spectroscopy. 


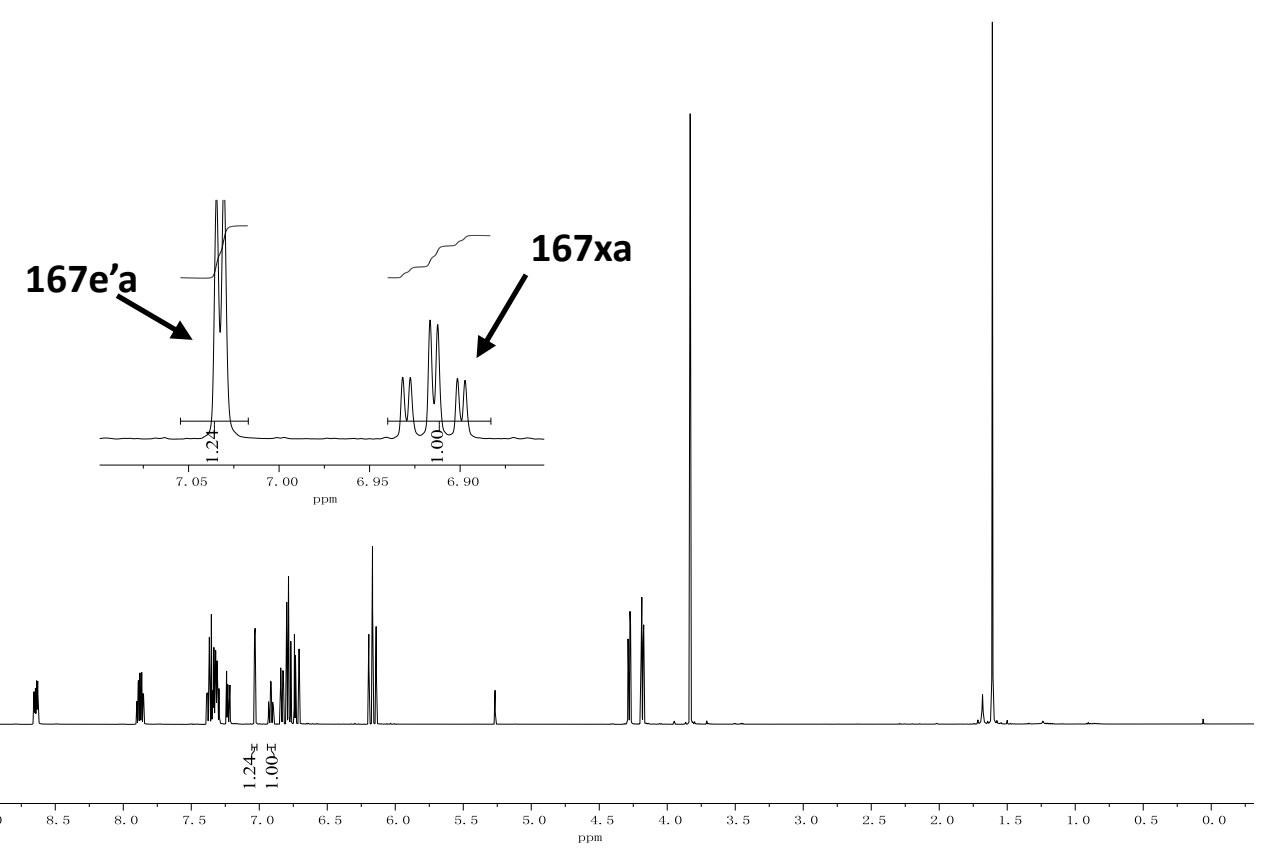

\section{$H / D$ Exchange Experiments}

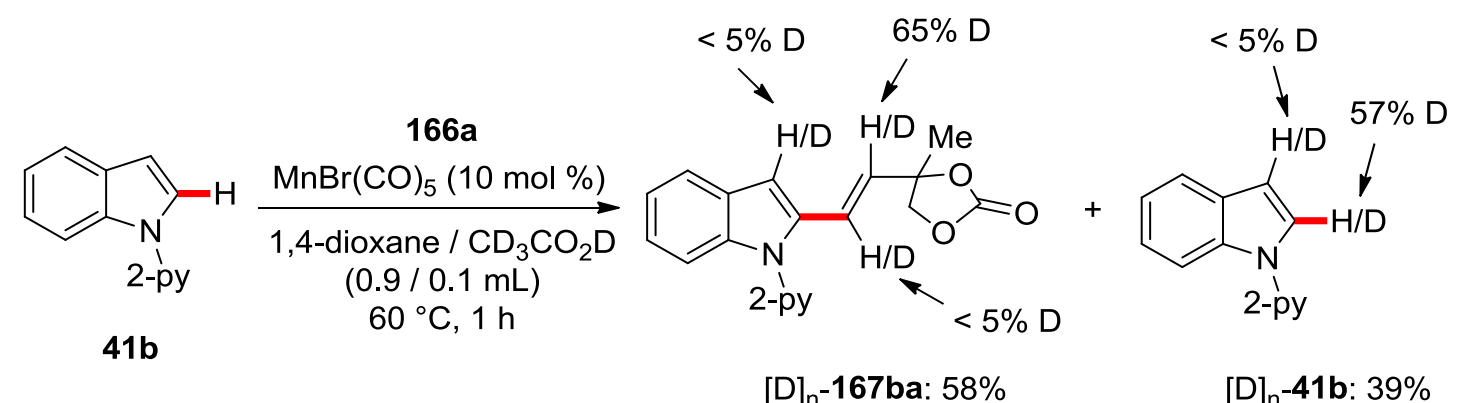

Substrates 41b (48.6 mg, $0.25 \mathrm{mmol}), 166 \mathrm{a}(58 \mu \mathrm{L}, 0.50 \mathrm{mmol}),\left[\mathrm{MnBr}(\mathrm{CO})_{5}\right](6.9 \mathrm{mg}, 10.0 \mathrm{~mol} \%)$, 1,4-dioxane $(0.9 \mathrm{~mL})$ and $\mathrm{CD}_{3} \mathrm{CO}_{2} \mathrm{D}\left(0.1 \mathrm{~mL}, 7.0\right.$ equiv) were placed in a $25 \mathrm{~mL}$ Schlenk tube under $\mathrm{N}_{2}$ and stirred at $60^{\circ} \mathrm{C}$ for $1 \mathrm{~h}$. After cooling to ambient temperature, the mixture was transferred into a round bottom flask with $\mathrm{CH}_{2} \mathrm{Cl}_{2}(20 \mathrm{~mL})$ and concentrated in vacuo. Purification by column chromatography on silica gel ( $n$-hexane/EtOAc: $10 / 1$ to $3 / 2$ ) yielded $[D]_{n}-167$ ba $(46.5 \mathrm{mg}, 58 \%$ ), $[D]_{n}-41 b(18.9 \mathrm{mg}, 39 \%)$ and $[D]_{n}-166 a(27.0 \mathrm{mg}, 43 \%)$. The $D$ incorporation was determined by ${ }^{1} \mathrm{H}$ NMR spectroscopy. 


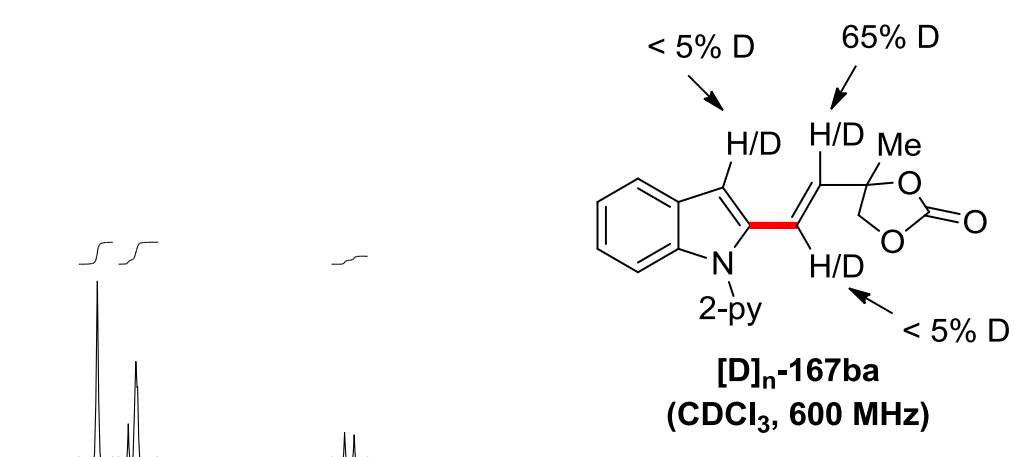

$\iiint \iint_{1} \int$
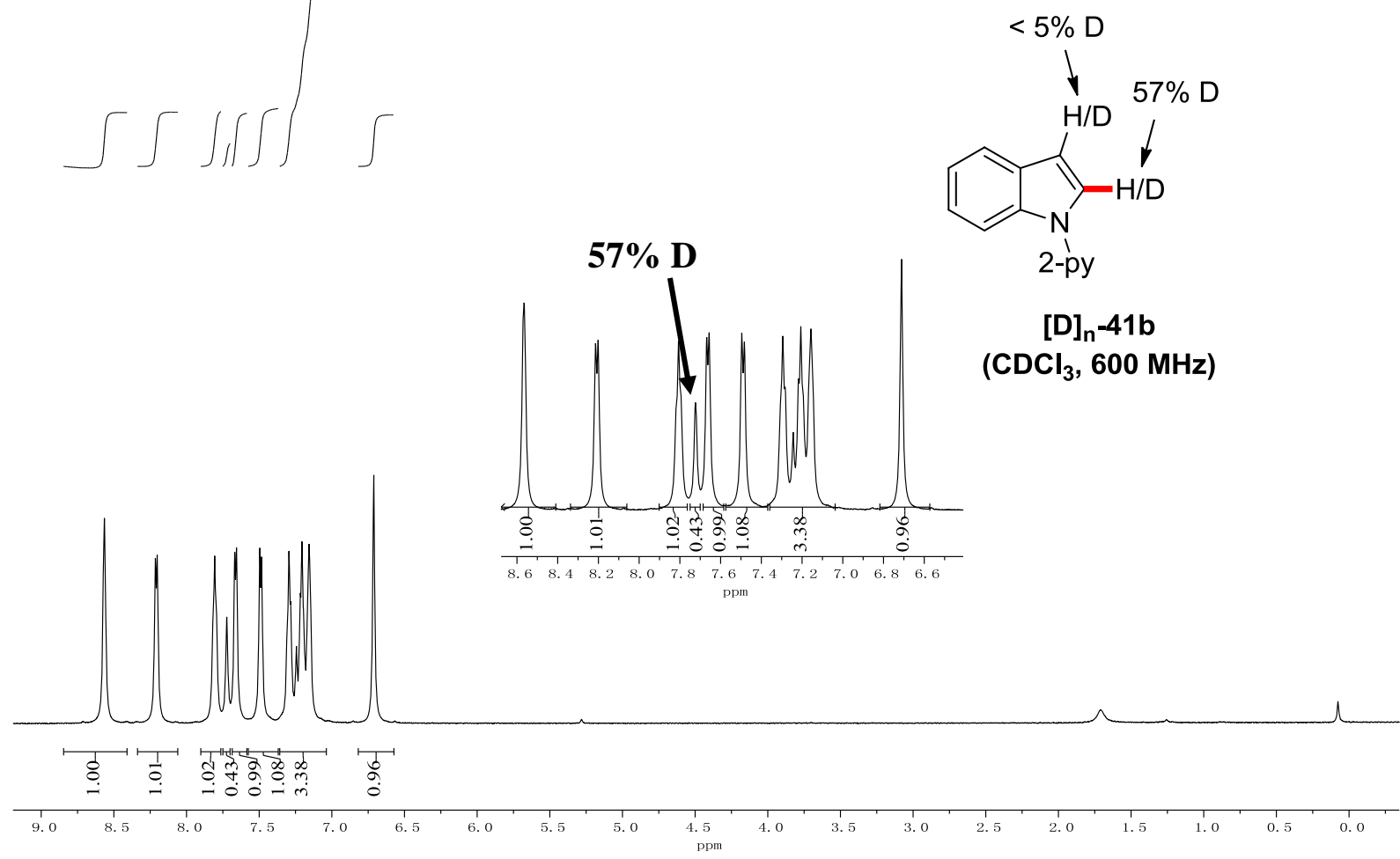


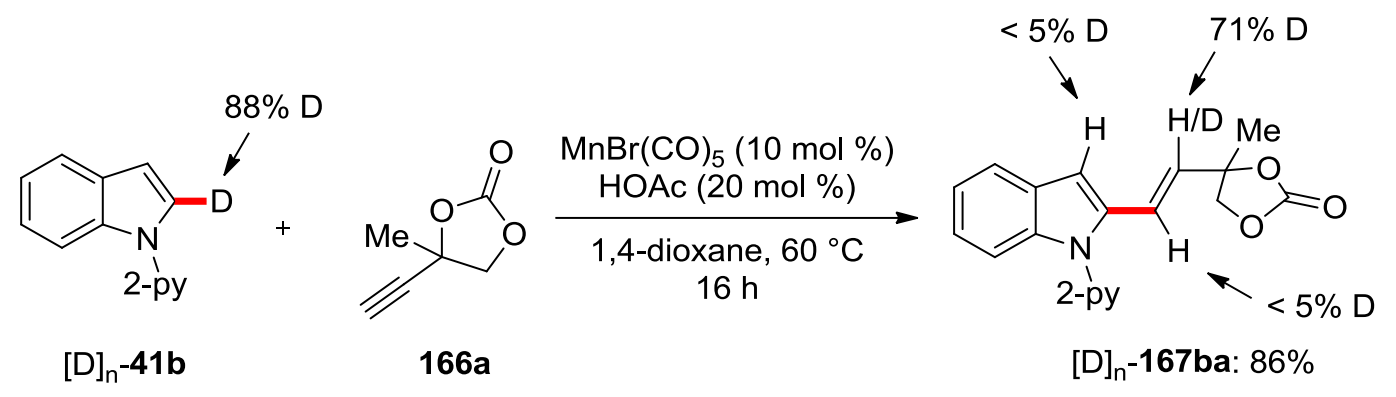

Substrates $[D]_{1}-41 b(48.8 \mathrm{mg}, 0.25 \mathrm{mmol}), 166 \mathrm{a}(58 \mu \mathrm{L}, 0.50 \mathrm{mmol}),\left[\mathrm{MnBr}(\mathrm{CO})_{5}\right](6.9 \mathrm{mg}, 10.0$ mol \%), HOAc (2.8 $\mu \mathrm{L}, 20.0 \mathrm{~mol} \%)$ and 1,4-dioxane $(1.0 \mathrm{~mL})$ were placed in a $25 \mathrm{~mL}$ Schlenk tube under $\mathrm{N}_{2}$ and stirred at $60{ }^{\circ} \mathrm{C}$ for $16 \mathrm{~h}$. After cooling to ambient temperature, the mixture was transferred into a round bottom flask with $\mathrm{CH}_{2} \mathrm{Cl}_{2}(20 \mathrm{~mL})$ and concentrated in vacuo. Purification by column chromatography on silica gel ( $n$-hexane/EtOAc: $3 / 2$ ) yielded $[D]_{n}-167 b a(68.9 \mathrm{mg}, 86 \%)$. The D incorporation was determined by ${ }^{1} \mathrm{H}-\mathrm{NMR}$ spectroscopy.
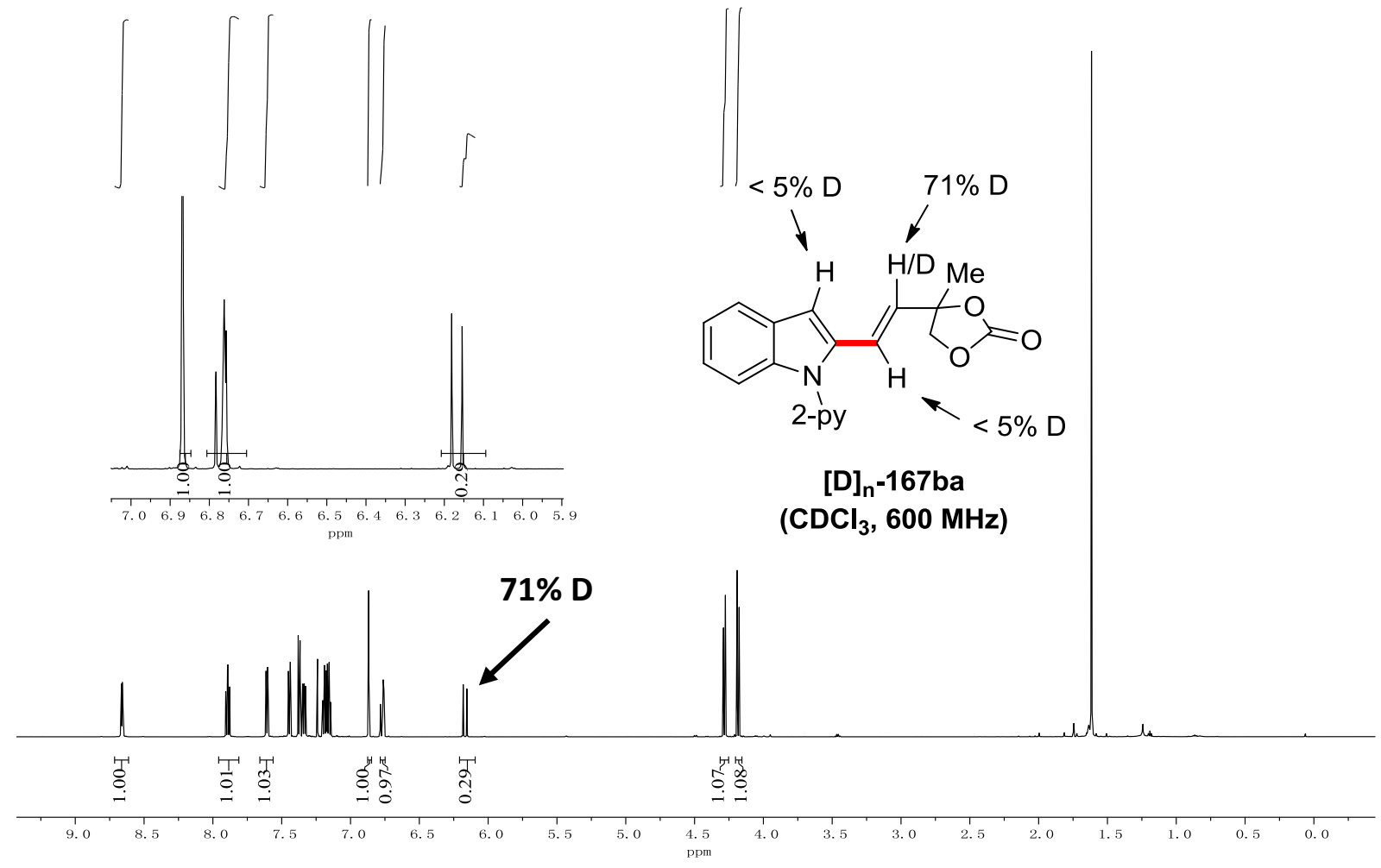


\section{Synergistic hydroarylation with cyclometalated complex 195}

\section{a) Stoichiometric reaction without HOAC}

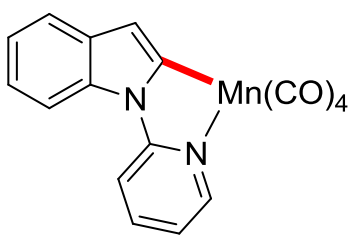

195

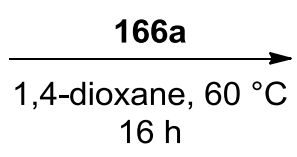

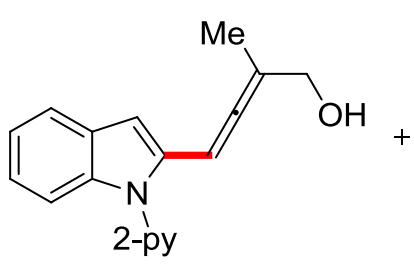

194: $46 \%$

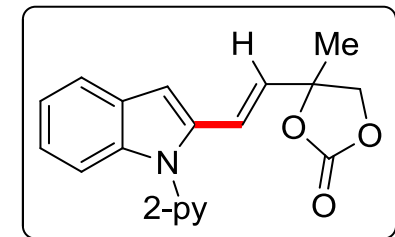

167ba: --

Complex 195 (36.0 mg, 0.10 mmol), 4-ethynyl-4-methyl-1,3-dioxolan-2-one (166a) (25.3 mg, 0.2 mmol) and 1,4-dioxane $(0.5 \mathrm{~mL})$ were placed in a $10 \mathrm{~mL}$ Schlenk tube under $\mathrm{N}_{2}$ and stirred at $60^{\circ} \mathrm{C}$ for $16 \mathrm{~h}$. After cooling to ambient temperature, the mixture was transferred into a round bottom flask with $\mathrm{CH}_{2} \mathrm{Cl}_{2}(20 \mathrm{~mL})$ and concentrated in vacuo. Purification by column chromatography on silica gel ( $n$-hexane/EtOAc: 3/2) yielded 194 (32.0 mg, 46\%) as colorless oil, the desired compound 167ba was not detected by coupled gas chromatography-mass spectrometry.

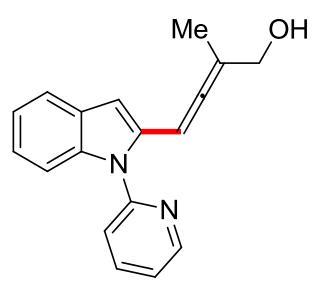

2-Methyl-4-[1-(pyridin-2-yl)-1H-indol-2-yl]buta-2,3-dien-1-ol (194)

${ }^{1} \mathrm{H}$ NMR $\left(400 \mathrm{MHz}, \mathrm{CDCl}_{3}\right) \delta=8.64(\mathrm{~d}, J=4.1 \mathrm{~Hz}, 1 \mathrm{H}), 7.86(\mathrm{td}, J=7.7,1.5 \mathrm{~Hz}, 1 \mathrm{H}), 7.59-7.50(\mathrm{~m}, 1 \mathrm{H})$, $7.39(\mathrm{dd}, J=8.0,1.0 \mathrm{~Hz}, 1 \mathrm{H}), 7.31(\mathrm{ddd}, J=7.6,4.8,1.0 \mathrm{~Hz}, 1 \mathrm{H}), 7.24-7.16(\mathrm{~m}, 1 \mathrm{H}), 7.15-7.02(\mathrm{~m}$, $2 \mathrm{H}), 6.63(\mathrm{~s}, 1 \mathrm{H}), 6.42(\mathrm{q}, J=3.1 \mathrm{~Hz}, 1 \mathrm{H}), 3.84(\mathrm{~s}, 2 \mathrm{H}), 2.08(\mathrm{brs}, 1 \mathrm{H}), 1.51(\mathrm{~d}, J=3.0 \mathrm{~Hz}, 3 \mathrm{H}) .{ }^{13} \mathrm{C} \mathrm{NMR}$ $\left(100 \mathrm{MHz}, \mathrm{CDCl}_{3}\right) \delta=201.4\left(\mathrm{C}_{\mathrm{q}}\right), 151.5\left(\mathrm{C}_{\mathrm{q}}\right), 149.6(\mathrm{CH}), 138.7\left(\mathrm{C}_{\mathrm{q}}\right), 138.3(\mathrm{CH}), 133.2\left(\mathrm{C}_{\mathrm{q}}\right), 128.4\left(\mathrm{C}_{\mathrm{q}}\right)$, $122.6(\mathrm{CH}), 122.5(\mathrm{CH}), 122.1(\mathrm{CH}), 121.0(\mathrm{CH}), 120.2(\mathrm{CH}), 110.2(\mathrm{CH}), 104.4(\mathrm{CH}), 104.3\left(\mathrm{C}_{\mathrm{q}}\right), 88.2$ (CH), $63.6\left(\mathrm{CH}_{2}\right), 15.2\left(\mathrm{CH}_{3}\right)$. IR (ATR) $v=3346,2857,1587,1470,1437,1345,1023,780,744 \mathrm{~cm}^{-1}$. MS (ESI) m/z (relative intensity): $575(100)[2 \mathrm{M}+\mathrm{Na}]^{+}, 431(10), 299(60)[\mathrm{M}+\mathrm{Na}]^{+}, 276(55)[\mathrm{M}+\mathrm{H}]^{+}$. HR-MS (ESI) $\mathrm{m} / \mathrm{z}$ calcd for $\mathrm{C}_{18} \mathrm{H}_{17} \mathrm{~N}_{2} \mathrm{O}[\mathrm{M}+\mathrm{H}]^{+}: 277.1335$, found: 277.1334 . 


\section{b) Stoichiometric reaction with HOAC}<smiles>Cc1cc2ccccc2n2c1nn2C(C)C</smiles>

195

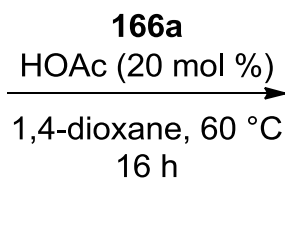

$16 \mathrm{~h}$<smiles>CC1(/C=C/c2cc3ccccc3n2[18O])COC(=O)O1</smiles>

167ba: $48 \%$

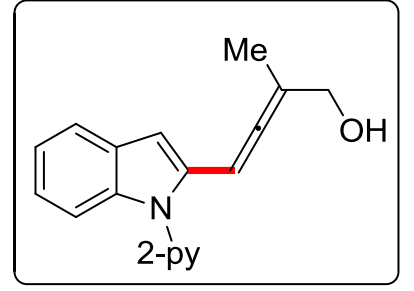

194: --

Complex 195 (36.0 mg, 0.10 mmol), 4-ethynyl-4-methyl-1,3-dioxolan-2-one (166a) (25.3 mg, 0.2 $\mathrm{mmol}), \mathrm{HOAc}(1.2 \mu \mathrm{L}, 20.0 \mathrm{~mol} \%)$ and 1,4-dioxane $(0.5 \mathrm{~mL})$ were placed in a $10 \mathrm{~mL}$ Schlenk tube under $\mathrm{N}_{2}$ and stirred at $60{ }^{\circ} \mathrm{C}$ for $16 \mathrm{~h}$. After cooling to ambient temperature, the mixture was transferred into a round bottom flask with $\mathrm{CH}_{2} \mathrm{Cl}_{2}(20 \mathrm{~mL})$ and concentrated in vacuo. Purification by column chromatography on silica gel ( $n$-hexane/EtOAc: $3 / 2$ ) yielded $167 \mathrm{ba}(38.5 \mathrm{mg}, 48 \%)$, the allene 194 was not detected coupled gas chromatography-mass spectrometry.

\section{c) Complex 195 as catalyst}

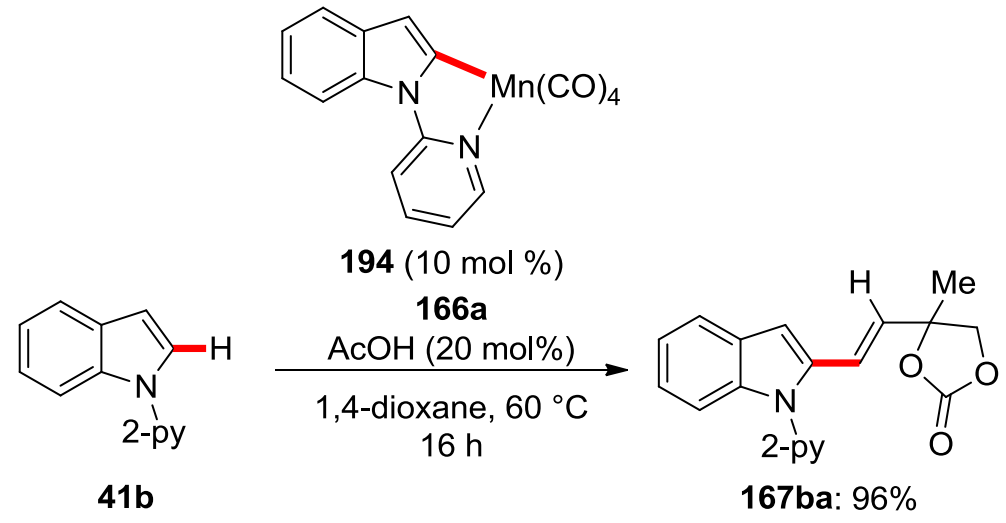

The general procedure $\mathbf{G}$ was followed using 1 -(pyrimidin-2-yl)- $1 H$-indole $(\mathbf{4 1 b})$ (46.6 mg, 0.24 mmol), 4-ethynyl-4-methyl-1,3-dioxolan-2-one (166a) (58.0 $\mu \mathrm{L}, 0.5 \mathrm{mmol}), \mathrm{HOAc}(2.8 \mu \mathrm{L}, 20.0 \mathrm{~mol} \%)$ and complex 195 (9.0 mg, $10.0 \mathrm{~mol} \%)$. Purification by column chromatography on silica gel ( $n$-hexane/EtOAc: $3 / 2$ ) yielded 167 ba (76.9 mg, 96\%) as colorless oil. 


\section{Evaluation of the Mxing Effect}

a) Continuous Flow C-H Activation: On Scale

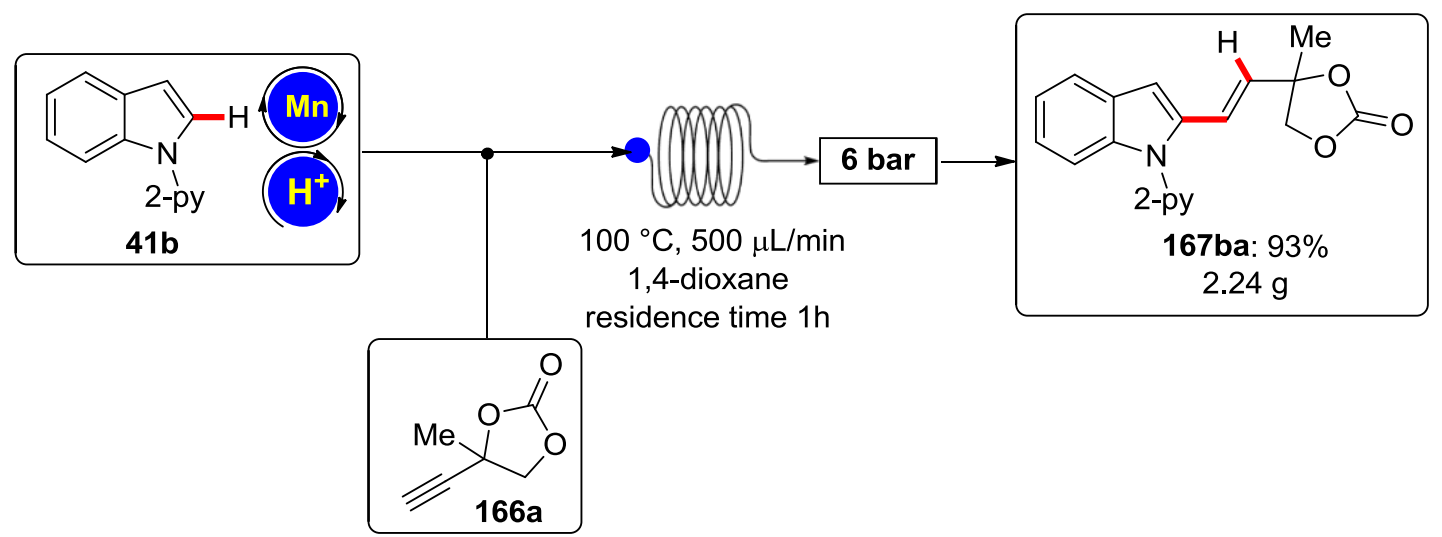

A solution of $41 \mathrm{~b}$ (7.5 mmol, 1.0 equiv), $\left[\mathrm{MnBr}(\mathrm{CO})_{5}\right](206 \mathrm{mg}, 10.0 \mathrm{~mol} \%)$ and $\mathrm{HOAc}(85 \mu \mathrm{L}, 20.0$ mol \%) in 1,4-dioxane was prepared in vial 1 and brought to a volume of $15 \mathrm{~mL}$. A solution of $166 \mathrm{a}$ $(1.75 \mathrm{~mL}, 15 \mathrm{mmol})$ in dioxane was prepared in vial 2 and brought to a final volume of $15 \mathrm{~mL}$. The solutions were taken into separate syringes and operated at a flow rate of $250 \mu \mathrm{L} / \mathrm{min}$. The two solutions were mixed at a T-joint connection and subsequently reacted in a $10 \mathrm{~mL}$ reactor for $1 \mathrm{~h}$ residence time. Using the Flow Wizard system, the solution was collected automatically. Next, the mixture was concentrated in vacuo. Purification by column chromatography on silica gel yielded the desired product 167ba (2.24 g mg, 93\%).

\section{b) Continuous Flow C-H Activation: Catalyst Separation}

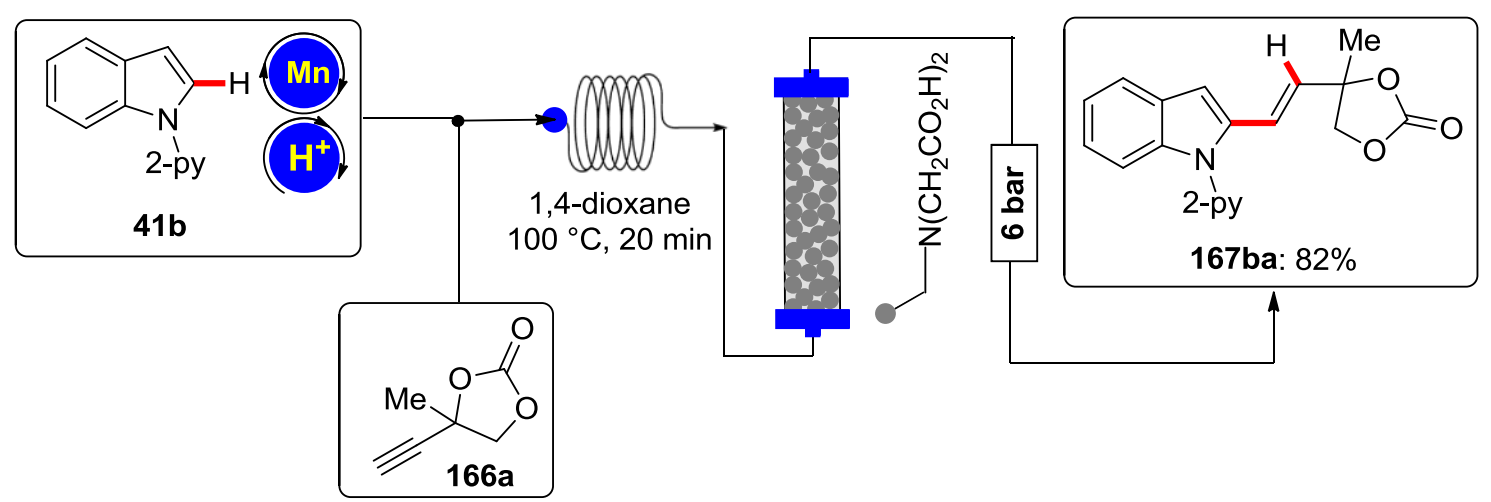

A solution of $41 \mathrm{~b}\left(0.50 \mathrm{mmol}, 1.0\right.$ equiv), $\left[\mathrm{MnBr}(\mathrm{CO})_{5}\right](13.8 \mathrm{mg}, 10.0 \mathrm{~mol} \%)$ and HOAc (5.6 $\mu \mathrm{L}, 20.0$ $\mathrm{mol} \%$ ) in 1,4-dioxane was prepared in vial 1 and brought to a volume of $1.0 \mathrm{~mL}$. A solution of $166 \mathrm{a}$ 
$(116.0 \mu \mathrm{L}, 1.0 \mathrm{mmol})$ in dioxane was prepared in vial 2 and brought to a final volume of $1.0 \mathrm{~mL}$. The solutions were taken into separate syringes and operated at a flow rate of $250 \mu \mathrm{L} / \mathrm{min}$ and the two solutions were mixed at a T-joint connection. Subsequently, the reaction media was connected to the inlet of $10 \mathrm{~mL}$ standard heated reactor coupled with a column reactor $(\varnothing=8 \mathrm{~mm})$ packed with $500 \mathrm{mg}$ of QuadraPure ${ }^{\circledR}$ IDA ( $=2.5 \mathrm{~mL}$ ). Using the Flow Wizard system, the solution was collected automatically. Next, the mixture was concentrated in vacuo. Purification by column chromatography on silica gel yielded the desired product $167 \mathrm{ba}$ (132.0 mg, 82\%).

\section{Diversification of 167ba}
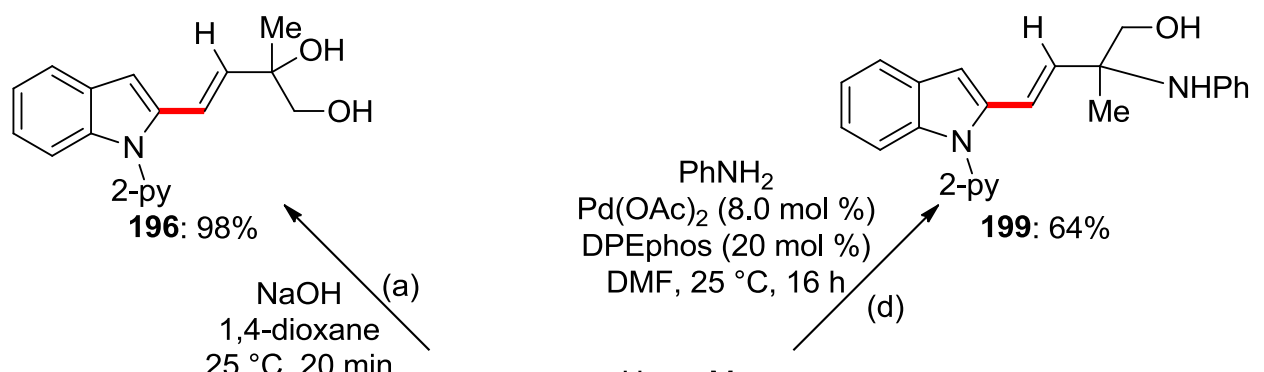

$25^{\circ} \mathrm{C}, 20 \mathrm{~min}$<smiles>Cn1c(/C=C/c2cc3ccccc3n2C)coc1=O</smiles>

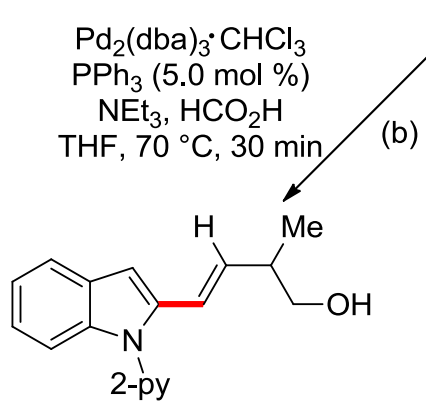

197: $88 \%$

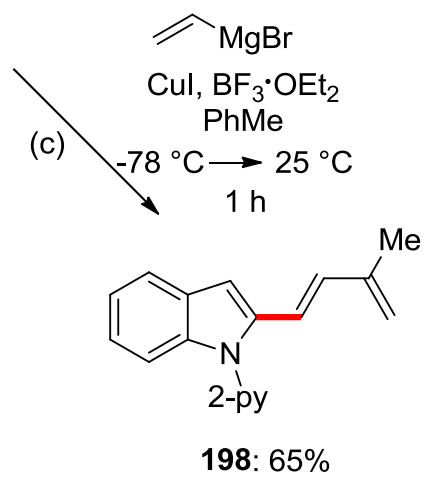

198: $65 \%$

Reaction (a): The product 167ba $(64.1 \mathrm{mg}, 0.20 \mathrm{mmol})$ was dissolved in 1,4-dioxane $(2.0 \mathrm{~mL})$, followed by $\mathrm{NaOH}(1 \mathrm{~N}, 2.0 \mathrm{~mL})$. The resulting solution was allowed to stir for $30 \mathrm{~min}$ at $25^{\circ} \mathrm{C}$. The mixture was transferred into a round bottom flask with $\mathrm{CH}_{2} \mathrm{Cl}_{2}(20.0 \mathrm{~mL})$ and concentrated in vacuo. Purification by column chromatography on silica gel (EtOAc: 100\%) afforded the desired products 196 (57.7 mg, 98\%) as colorless oil. 


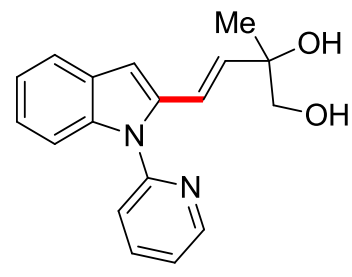

(E)-2-Methyl-4-(1-(pyridin-2-yl)-1H-indol-2-yl)but-3-ene-1,2-diol (196)

${ }^{1} \mathrm{H}$ NMR $\left(400 \mathrm{MHz}_{\mathrm{CDCl}}\right) \delta=8.62(\mathrm{dd}, J=4.9,2.0 \mathrm{~Hz}, 1 \mathrm{H}), 7.86(\mathrm{ddd}, J=8.0,7.5,2.0 \mathrm{~Hz}, 1 \mathrm{H}), 7.66-$ $7.52(\mathrm{~m}, 1 \mathrm{H}), 7.45-7.37(\mathrm{~m}, 2 \mathrm{H}), 7.30(\mathrm{ddd}, J=7.5,4.9,1.0 \mathrm{~Hz}, 1 \mathrm{H}), 7.19-7.10(\mathrm{~m}, 2 \mathrm{H}), 6.76(\mathrm{~s}, 1 \mathrm{H})$, $6.62(\mathrm{~d}, J=16.0 \mathrm{~Hz}, 1 \mathrm{H}), 6.14(\mathrm{~d}, J=16.0 \mathrm{~Hz}, 1 \mathrm{H}), 3.50$ (d, $J=11.1 \mathrm{~Hz}, 1 \mathrm{H}), 3.40(\mathrm{~d}, J=11.1 \mathrm{~Hz}, 1 \mathrm{H})$, 2.58 (brs, 2H), 1.25 (s, 3H). ${ }^{13} \mathrm{C}$ NMR $\left(100 \mathrm{MHz} \mathrm{CDCl}_{3}\right) \delta=151.0\left(\mathrm{C}_{\mathrm{q}}\right), 149.5(\mathrm{CH}), 138.4(\mathrm{CH}), 137.5$ $\left(\mathrm{C}_{\mathrm{q}}\right), 137.2\left(\mathrm{C}_{\mathrm{q}}\right), 135.7(\mathrm{CH}), 128.5\left(\mathrm{C}_{\mathrm{q}}\right), 122.8(\mathrm{CH}), 122.1(\mathrm{CH}), 121.4(\mathrm{CH}), 121.3(\mathrm{CH}), 120.5(\mathrm{CH})$, $119.9(\mathrm{CH}), 110.6(\mathrm{CH}), 102.3(\mathrm{CH}), 73.5\left(\mathrm{C}_{\mathrm{q}}\right), 69.8\left(\mathrm{CH}_{2}\right), 24.1\left(\mathrm{CH}_{3}\right)$. IR $(\mathrm{ATR}) v=3352$, 2929, 1587, 1451, 1436, 1347, 1347, 1044, 907, 780, $730 \mathrm{~cm}^{-1}$. MS (ESI) m/z (relative intensity): 311 (100) $[\mathrm{M}+\mathrm{Na}]^{+}, 295(80)[\mathrm{M}+\mathrm{H}]^{+}, 277$ (70). HR-MS (ESI) m/z calcd for $\mathrm{C}_{18} \mathrm{H}_{19} \mathrm{~N}_{2} \mathrm{O}_{2}[\mathrm{M}+\mathrm{H}]^{+}: 295.1441$, found: 295.1440 .

Reaction (b): To $167 \mathrm{ba}(64.1 \mathrm{mg}, 0.20 \mathrm{mmol})$ in THF $(10 \mathrm{~mL})$ was added $\mathrm{Pd}_{2}(\mathrm{dba})_{3} \cdot \mathrm{CHCl}_{3}(10.2 \mathrm{mg}$, $5.0 \mathrm{~mol} \%), \mathrm{PPh}_{3}(2.6 \mathrm{mg}, 5.0 \mathrm{~mol} \%), \mathrm{Et}_{3} \mathrm{~N}$ (101.2 mg, 5.0 equiv) and $\mathrm{HCO}_{2} \mathrm{H}$ (38.0 $\mu \mathrm{L}, 5.0$ equiv). The reaction was stirred at $70{ }^{\circ} \mathrm{C}$ for $30 \mathrm{~min}$. The reaction was then allowed to cool to $25{ }^{\circ} \mathrm{C}$, diluted with $\mathrm{Et}_{2} \mathrm{O}(10.0 \mathrm{~mL})$ and filtered through a plug of silica gel. After concentration in vacuo the crude mixture was purified by silica gel column chromatography ( $n$-hexane/EtOAc: 3/2) to yield 197 (49.0 $\mathrm{mg}, 88 \%)$ as colorless oil.

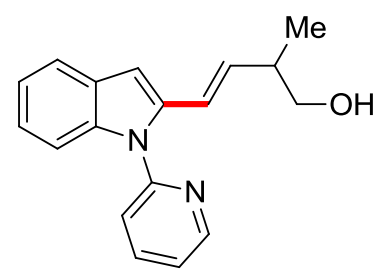

(E)-2-Methyl-4-[1-(pyridin-2-yl)-1H-indol-2-yl]but-3-en-1-ol (197)

${ }^{1} \mathrm{H}$ NMR $\left(400 \mathrm{MHz}^{\mathrm{CDCl}}{ }_{3}\right) \delta=8.64(\mathrm{dd}, J=4.9,2.0 \mathrm{~Hz}, 1 \mathrm{H}), 7.86(\mathrm{ddd}, J=8.1,7.5,2.0 \mathrm{~Hz}, 1 \mathrm{H}), 7.65-$ $7.53(\mathrm{~m}, 1 \mathrm{H}), 7.48-7.37(\mathrm{~m}, 2 \mathrm{H}), 7.30(\mathrm{ddd}, J=7.5,4.9,1.1 \mathrm{~Hz}, 1 \mathrm{H}), 7.17-7.10(\mathrm{~m}, 2 \mathrm{H}), 6.76(\mathrm{~s}, 1 \mathrm{H})$, $6.41(\mathrm{dt}, J=15.9,1.0 \mathrm{~Hz}, 1 \mathrm{H}), 6.03$ (dd, $J=15.9,8.0 \mathrm{~Hz}, 1 \mathrm{H}$ ), 3.51 (dd, $J=10.7,5.5 \mathrm{~Hz}, 1 \mathrm{H}$ ), 3.42 (dd, $J=10.7,8.0 \mathrm{~Hz}, 1 \mathrm{H}$ ), 2.44 (qdd, $J=8.0,6.8,5.5 \mathrm{~Hz}, 1 \mathrm{H}$ ), 2.08 (brs, $1 \mathrm{H}), 1.02(\mathrm{~d}, J=6.8 \mathrm{~Hz}, 3 \mathrm{H}) .{ }^{13} \mathrm{C}$ 
NMR $\left(100 \mathrm{MHz}, \mathrm{CDCl}_{3}\right) \delta=151.1\left(\mathrm{C}_{\mathrm{q}}\right), 149.4(\mathrm{CH}), 138.3(\mathrm{CH}), 137.8\left(\mathrm{C}_{\mathrm{q}}\right), 137.3\left(\mathrm{C}_{\mathrm{q}}\right), 135.3(\mathrm{CH})$, $128.6\left(\mathrm{C}_{\mathrm{q}}\right), 122.5(\mathrm{CH}), 122.0(\mathrm{CH}), 121.3(\mathrm{CH}), 121.2(\mathrm{CH}), 121.2(\mathrm{CH}), 120.4(\mathrm{CH}), 110.5(\mathrm{CH}), 101.7$ (CH), $67.1\left(\mathrm{CH}_{2}\right), 40.2(\mathrm{CH}), 16.1\left(\mathrm{CH}_{3}\right)$. IR (ATR) $v=3364,2868,1586,1468,1451,1344,1026,783$, $744 \mathrm{~cm}^{-1} . \mathrm{MS}(\mathrm{ESI}) \mathrm{m} / \mathrm{z}$ (relative intensity): $301(20)[\mathrm{M}+\mathrm{Na}]^{+}, 279(100)[\mathrm{M}+\mathrm{H}]^{+}$. HR-MS (ESI) m/z calcd for $\mathrm{C}_{18} \mathrm{H}_{19} \mathrm{~N}_{2} \mathrm{O}[\mathrm{M}+\mathrm{H}]^{+}: 279.1492$, found: 279.1492 .

Reaction (c): To a stirred solution of Cul $(57.1 \mathrm{mg}, 3.0$ equiv) in dry THF ( $1 \mathrm{~mL})$ at $-78{ }^{\circ} \mathrm{C}$ under $\mathrm{N}_{2}$ was added vinylmagnesium bromide (1.0 M in THF, $1.2 \mathrm{~mL}, 6.0$ equiv) and $\mathrm{BF}_{3} \cdot \mathrm{OEt}_{2}(0.3 \mathrm{~mL}, 1.2$ equiv). Then, $167 \mathrm{ba}(64.1 \mathrm{mg}, 0.20 \mathrm{mmol})$ in dry THF $(0.5 \mathrm{~mL})$ was added and the mixture was allowed to warm to $25{ }^{\circ} \mathrm{C}$ for $1 \mathrm{~h}$. To the reaction mixture was added a saturated aqueous $\mathrm{NH}_{4} \mathrm{Cl}$ solution $(2.0 \mathrm{~mL})$ and extracted with $\mathrm{Et}_{2} \mathrm{O}(20.0 \mathrm{~mL} \times 3)$. The organic layer was dried over $\mathrm{Na}_{2} \mathrm{SO}_{4}$ and evaporated in vacuo. Purification by column chromatography ( $n$-hexane/EtOAc: $10 / 1$ ) yielded 198 (34.0 mg, 65\%) as colorless oil.

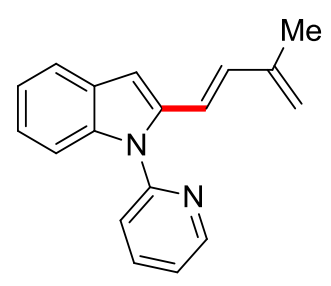

(E)-2-(3-Methylbuta-1,3-dien-1-yl)-1-(pyridin-2-yl)-1H-indole (198)

${ }^{1} \mathrm{H}$ NMR $\left(400 \mathrm{MHz}, \mathrm{CDCl}_{3}\right) \delta=8.69$ (ddd, $\left.J=4.9,2.0,0.9 \mathrm{~Hz}, 1 \mathrm{H}\right), 7.86$ (ddd, $J=8.0,7.5,2.0 \mathrm{~Hz}, 1 \mathrm{H}$ ), 7.63-7.57 (m, 1H), 7.52-7.44 (m, 1H), 7.37 (dt, J = 8.0, 0.9 Hz, 1H), 7.32 (ddd, J = 7.4, 4.9, $1.0 \mathrm{~Hz}, 1 \mathrm{H}$ ), 7.19-7.10 (m, 2H), $6.88(\mathrm{~s}, 1 \mathrm{H}), 6.87(\mathrm{~d}, J=16.1 \mathrm{~Hz}, 1 \mathrm{H}), 6.50(\mathrm{~d}, J=16.1 \mathrm{~Hz}, 1 \mathrm{H}), 5.08(\mathrm{~d}, J=2.1 \mathrm{~Hz}$, $1 \mathrm{H}), 5.04(\mathrm{~d}, J=2.1 \mathrm{~Hz}, 1 \mathrm{H}), 1.83(\mathrm{~s}, 3 \mathrm{H}) .{ }^{13} \mathrm{C} \mathrm{NMR}\left(100 \mathrm{MHz}, \mathrm{CDCl}_{3}\right) \delta=151.3\left(\mathrm{C}_{\mathrm{q}}\right), 149.5(\mathrm{CH}), 141.9$ $\left(\mathrm{C}_{q}\right), 138.1(\mathrm{CH}), 138.0\left(\mathrm{C}_{\mathrm{q}}\right), 137.8\left(\mathrm{C}_{\mathrm{q}}\right), 133.6(\mathrm{CH}), 128.7\left(\mathrm{C}_{\mathrm{q}}\right), 122.7(\mathrm{CH}), 122.0(\mathrm{CH}), 121.4(\mathrm{CH})$, $121.2(\mathrm{CH}), 120.4(\mathrm{CH}), 118.4(\mathrm{CH}), 117.7\left(\mathrm{CH}_{2}\right), 110.8(\mathrm{CH}), 102.1(\mathrm{CH}), 18.3\left(\mathrm{CH}_{3}\right)$. IR (ATR) $v=3051$, 1585, 1467, 1450, 1435, 1335, 1213, 956, 784, $744 \mathrm{~cm}^{-1}$. MS (ESI) m/z (relative intensity): 261 (100) $[\mathrm{M}+\mathrm{H}]^{+}, 207$ (30). HR-MS (ESI) m/z calcd for $\mathrm{C}_{18} \mathrm{H}_{17} \mathrm{~N}_{2}[\mathrm{M}+\mathrm{H}]^{+}:$: 261.1386, found: 261.1387.

Reaction (d): An oven-dired Schlenk tube, equipped with a stirring bar and a septum, was charged with $167 \mathrm{ba}(64 \mathrm{mg}, 0.2 \mathrm{mmol}), \mathrm{Pd}(\mathrm{OAC})_{2} \cdot \mathrm{CHCl}_{3}(3.6 \mathrm{mg}, 8.0 \mathrm{~mol} \%$ ) and DPEPhos (21.5 mg, 40.0 
$\mathrm{mol} \%)$. Then, DMF $(0.4 \mathrm{~mL})$ and aniline $(27.5 \mathrm{mg}, 0.3 \mathrm{mmol})$ were added. The reaction mixture was stirred at $25{ }^{\circ} \mathrm{C}$ for $16 \mathrm{~h}$. Then the mixture was transferred into a round bottom flask with $\mathrm{CH}_{2} \mathrm{Cl}_{2}$ $(20.0 \mathrm{~mL})$ and concentrated in vacuo. Purification by column chromatography on silica gel ( $n$-hexane/EtOAc: $1 / 1)$ yielded 199 (47.8 mg, 64\%) as colorless oil.

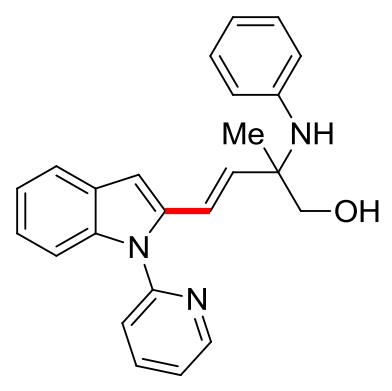

(E)-2-Methyl-2-(phenylamino)-4-[1-(pyridin-2-yl)-1H-indol-2-yl]but-3-en-1-ol (199)

${ }^{1} \mathbf{H}$ NMR $\left(400 \mathrm{MHz}, \mathrm{CDCl}_{3}\right) \delta=8.51(\mathrm{dd}, J=4.8,1.9 \mathrm{~Hz}, 1 \mathrm{H}), 7.68-7.55(\mathrm{~m}, 2 \mathrm{H}), 7.50-7.42(\mathrm{~m}, 1 \mathrm{H})$, 7.23-7.04 (m, 6H), $6.79(\mathrm{~s}, 1 \mathrm{H}), 6.74-6.61(\mathrm{~m}, 3 \mathrm{H}), 6.49(\mathrm{~d}, J=16.1 \mathrm{~Hz}, 1 \mathrm{H}), 6.19(\mathrm{~d}, J=16.1 \mathrm{~Hz}, 1 \mathrm{H})$, $3.60(\mathrm{~d}, J=11.0 \mathrm{~Hz}, 1 \mathrm{H}), 3.50(\mathrm{~d}, J=11.0 \mathrm{~Hz}, 1 \mathrm{H}), 2.79$ (brs, 1H), $1.40(\mathrm{~s}, 3 \mathrm{H}) .{ }^{13} \mathrm{C}$ NMR (100 MHz, $\left.\mathrm{CDCl}_{3}\right) \delta=150.9\left(\mathrm{C}_{\mathrm{q}}\right), 149.3(\mathrm{CH}), 145.6\left(\mathrm{C}_{\mathrm{q}}\right), 138.8\left(\mathrm{C}_{\mathrm{q}}\right), 138.3(\mathrm{CH}), 137.3\left(\mathrm{C}_{\mathrm{q}}\right), 134.3(\mathrm{CH}), 128.8$ $(\mathrm{CH}), 128.6\left(\mathrm{C}_{\mathrm{q}}\right), 122.8(\mathrm{CH}), 122.1(\mathrm{CH}), 121.8(\mathrm{CH}), 121.3(\mathrm{CH}), 121.1(\mathrm{CH}), 120.5(\mathrm{CH}), 117.7(\mathrm{CH})$, $116.1(\mathrm{CH}), 110.9(\mathrm{CH}), 102.3(\mathrm{CH}), 69.5\left(\mathrm{CH}_{2}\right), 58.4\left(\mathrm{C}_{\mathrm{q}}\right), 22.1\left(\mathrm{CH}_{3}\right)$. IR (ATR) $v=3500,3052,2928$, 1600, 1468, 1452, 1348, 1051, 783, $747 \mathrm{~cm}^{-1}$. MS (ESI) m/z (relative intensity): 383 (20) [M+Na] , 381 (100). HR-MS (ESI) m/z calcd for $\mathrm{C}_{24} \mathrm{H}_{23} \mathrm{~N}_{3} \mathrm{O}[\mathrm{M}]^{+}: 369.1836$, found: 369.1828 .

5.3.7 Data for the Products of Quinazolines by Cobalt(III)-Catalyzed C-H/N-O Functionalizations with Benzimidates

\section{Characterization Data}<smiles>OC/C=C/Cc1ccccc1-n1cccn1</smiles>

4-[2-(1H-Pyrazol-1-yl)phenyl]but-2-en-1-ol (111aa): The general procedure $\mathbf{H}$ was followed using 
2-[2-(1H-pyrazol-1-yl)phenyl]propan-2-ol (168a) $\quad(50.6 \quad \mathrm{mg}, \quad 0.25 \quad \mathrm{mmol})$ and 4-vinyl-1,3-dioxolan-2-one (110a). Purification by column chromatography on silica gel (n-hexane/EtOAc: $1 / 1$ ) yielded $111 \mathrm{aa}\left(45.3 \mathrm{mg}, 75 \%, E / Z=4.9 / 1.0\right.$ by ${ }^{1} \mathrm{H}$ NMR) as a colorless oil.

${ }^{1} \mathrm{H}$ NMR $\left(300 \mathrm{MHz}^{\mathrm{CDCl}}{ }_{3}\right) \delta=7.68(\mathrm{dd}, J=1.9,0.7 \mathrm{~Hz}, 0.17 \mathrm{H}), 7.66(\mathrm{dd}, J=1.9,0.7 \mathrm{~Hz}, 0.83 \mathrm{H}), 7.57-$ $7.49(\mathrm{~m}, 1 \mathrm{H}), 7.40-7.16(\mathrm{~m}, 4 \mathrm{H}), 6.40(\mathrm{dd}, J=2.4,1.9 \mathrm{~Hz}, 0.17 \mathrm{H}), 6.38(\mathrm{dd}, J=2.4,1.9 \mathrm{~Hz}, 0.83 \mathrm{H})$, $5.58(\mathrm{dtt}, J=15.4,6.4,1.4 \mathrm{~Hz}, 1 \mathrm{H}), 5.40(\mathrm{dtt}, J=15.4,5.6,1.4 \mathrm{~Hz}, 1 \mathrm{H}), 3.97(\mathrm{~d}, J=5.8 \mathrm{~Hz}, 0.33 \mathrm{H}$ ), $3.91(\mathrm{~d}, J=5.8 \mathrm{~Hz}, 1.67 \mathrm{H}), 3.30(\mathrm{~d}, J=5.8 \mathrm{~Hz}, 0.33 \mathrm{H}), 3.25(\mathrm{~d}, J=5.8 \mathrm{~Hz}, 1.67 \mathrm{H}), 2.68(\mathrm{~s}, 0.17 \mathrm{H}), 2.57$ (s, 0.83H). ${ }^{13} \mathrm{C}$ NMR (125 MHz, $\left.\mathrm{CDCl}_{3}\right)$ Major isomer: $\delta=140.2(\mathrm{CH}), 139.5\left(\mathrm{C}_{\mathrm{q}}\right), 136.0\left(\mathrm{C}_{\mathrm{q}}\right), 130.9$ (CH), $130.9(\mathrm{CH}), 130.6(\mathrm{CH}), 129.7(\mathrm{CH}), 128.7(\mathrm{CH}), 127.0(\mathrm{CH}), 126.6(\mathrm{CH}), 106.2(\mathrm{CH}), 63.0\left(\mathrm{CH}_{2}\right)$, $34.3\left(\mathrm{CH}_{2}\right)$. Minor isomer: $\delta=140.4(\mathrm{CH}), 139.3\left(\mathrm{C}_{\mathrm{q}}\right), 136.5\left(\mathrm{C}_{\mathrm{q}}\right), 130.9(\mathrm{CH}), 130.3(\mathrm{CH}), 130.0(\mathrm{CH})$, $129.5(\mathrm{CH}), 128.9(\mathrm{CH}), 126.9(\mathrm{CH}), 126.6(\mathrm{CH}), 106.4(\mathrm{CH}), 58.0\left(\mathrm{CH}_{2}\right), 29.5\left(\mathrm{CH}_{2}\right)$. IR $(\mathrm{ATR}) v=3347$, 2855, 1517, 1395, 1328, 1100, 972, 916, 755, $597 \mathrm{~cm}^{-1}$. MS (ESI) m/z (relative intensity): 237 (50) $[\mathrm{M}+\mathrm{Na}]^{+}, 215(30)[\mathrm{M}+\mathrm{H}]^{+}, 197$ (100). HR-MS (ESI) m/z calcd for $\mathrm{C}_{13} \mathrm{H}_{15} \mathrm{~N}_{2} \mathrm{O}[\mathrm{M}+\mathrm{H}]^{+}: 215.1179$, found: 215.1181.

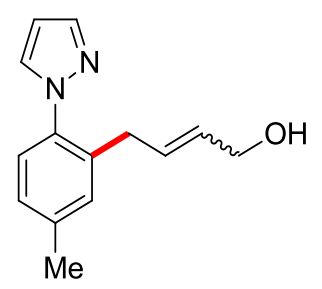

4-[5-Methyl-2-(1H-pyrazol-1-yl)phenyl]but-2-en-1-ol (111ba): The general procedure $\mathrm{H}$ was followed using 2-[5-methyl-2-(1H-pyrazol-1-yl)phenyl]propan-2-ol (168b) (54.1 mg, 0.25 mmol) and 4-vinyl-1,3-dioxolan-2-one (110a) $(48.0 \mu \mathrm{L}, 0.50 \mathrm{mmol})$. Purification by column chromatography on silica gel ( $n$-hexane/EtOAc: $2 / 1$ ) yielded 111 ba $\left(35.0 \mathrm{mg}, 61 \%, E / Z=5.3 / 1.0\right.$ by ${ }^{1} \mathrm{H}$ NMR) as a colorless oil.

${ }^{1} \mathbf{H}$ NMR $\left(400 \mathrm{MHz}, \mathrm{CDCl}_{3}\right) \delta=7.69(\mathrm{~d}, J=1.9 \mathrm{~Hz}, 0.16 \mathrm{H}), 7.66(\mathrm{~d}, J=1.9 \mathrm{~Hz}, 0.84 \mathrm{H}), 7.55-7.50(\mathrm{~m}$, 1H), 7.21-7.05 (m, 3H), $6.40(\mathrm{t}, J=2.1 \mathrm{~Hz}, 0.16 \mathrm{H}), 6.38(\mathrm{t}, J=2.1 \mathrm{~Hz}, 0.84 \mathrm{H}), 5.61(\mathrm{dtt}, J=15.4,6.5$, $1.2 \mathrm{~Hz}, 1 \mathrm{H}), 5.45(\mathrm{dtt}, J=15.4,5.8,1.4 \mathrm{~Hz}, 1 \mathrm{H}), 4.01$ (d, J = 6.0 Hz, 0.31H), $3.97(\mathrm{~d}, J=6.0 \mathrm{~Hz}, 1.69 \mathrm{H})$, $3.30(\mathrm{dd}, J=6.8,1.4 \mathrm{~Hz}, 0.31 \mathrm{H}), 3.25$ (dd, $J=6.8,1.4 \mathrm{~Hz}, 1.69 \mathrm{H}), 2.36(\mathrm{~s}, 3 \mathrm{H}), 1.79$ (brs, $0.16 \mathrm{H}), 1.71$ (brs, 0.84H). ${ }^{13} \mathrm{C}$ NMR (100 MHz, $\left.\mathrm{CDCl}_{3}\right)$ Major isomer: $\delta=140.1(\mathrm{CH}), 138.7\left(\mathrm{C}_{\mathrm{q}}\right), 137.2\left(\mathrm{C}_{\mathrm{q}}\right), 135.7$ $\left(\mathrm{C}_{\mathrm{q}}\right), 131.1(\mathrm{CH}), 130.8(\mathrm{CH}), 130.5(\mathrm{CH}), 130.3(\mathrm{CH}), 127.7(\mathrm{CH}), 126.4(\mathrm{CH}), 106.0(\mathrm{CH}), 63.3\left(\mathrm{CH}_{2}\right)$, 
$34.3\left(\mathrm{CH}_{2}\right), 21.1\left(\mathrm{CH}_{3}\right)$. Minor isomer: $\delta=140.3(\mathrm{CH}), 138.9\left(\mathrm{C}_{\mathrm{q}}\right), 137.0\left(\mathrm{C}_{\mathrm{q}}\right), 136.2\left(\mathrm{C}_{\mathrm{q}}\right), 131.0(\mathrm{CH})$, $130.9(\mathrm{CH}), 130.1(\mathrm{CH}), 129.5(\mathrm{CH}), 127.6(\mathrm{CH}), 126.5(\mathrm{CH}), 106.2(\mathrm{CH}), 58.0\left(\mathrm{CH}_{2}\right), 29.3\left(\mathrm{CH}_{2}\right), 21.1$ $\left(\mathrm{CH}_{3}\right)$. IR (ATR) $v=3352,2918,1518,1395,1101,972,945,820,753,626 \mathrm{~cm}^{-1} . \mathrm{MS}$ (ESI) m/z (relative intensity): $479(100)[2 \mathrm{M}+\mathrm{Na}]^{+}, 263(40), 251(100)[\mathrm{M}+\mathrm{Na}]^{+}, 229(30)[\mathrm{M}+\mathrm{H}]^{+} . \mathrm{HR}-\mathrm{MS}(\mathrm{ESI})$ $\mathrm{m} / \mathrm{z}$ calcd for $\mathrm{C}_{14} \mathrm{H}_{18} \mathrm{~N}_{2} \mathrm{O}[\mathrm{M}+\mathrm{H}]^{+}:$229.1335, found: 229.1334 .<smiles>Cc1ccc(CC=CCO)c(-n2cccn2)c1</smiles>

4-[4-Methyl-2-(1H-pyrazol-1-yl)phenyl]but-2-en-1-ol (111ca): The general procedure $\mathbf{H}$ was followed using 2-[4-methyl-2-(1H-pyrazol-1-yl)phenyl]propan-2-ol (168c) (54.1 mg, $0.25 \mathrm{mmol})$ and 4-vinyl-1,3-dioxolan-2-one (110a) $(48.0 \mu \mathrm{L}, 0.50 \mathrm{mmol})$. Purification by column chromatography on silica gel ( $n$-hexane/EtOAc: $3 / 2$ ) yielded $111 \mathrm{ca}\left(45.1 \mathrm{mg}, 79 \%, E / Z=5.2 / 1.0\right.$ by ${ }^{1} \mathrm{H} \mathrm{NMR}$ ) as a colorless oil.

${ }^{1} \mathrm{H}$ NMR $\left(400 \mathrm{MHz}, \mathrm{CDCl}_{3}\right) \delta=7.69(\mathrm{~d}, J=1.9 \mathrm{~Hz}, 0.16 \mathrm{H}), 7.66(\mathrm{~d}, J=1.9 \mathrm{~Hz}, 0.84 \mathrm{H}), 7.55(\mathrm{dd}, J=2.3$, $0.6 \mathrm{~Hz}, 0.16 \mathrm{H}), 7.54(\mathrm{dd}, J=2.3,0.6 \mathrm{~Hz}, 0.84 \mathrm{H}), 7.21-7.07(\mathrm{~m}, 3 \mathrm{H}), 6.41(\mathrm{t}, J=1.9 \mathrm{~Hz}, 0.16 \mathrm{H}), 6.38(\mathrm{t}$, $J=1.9 \mathrm{~Hz}, 0.84 \mathrm{H}), 5.59(\mathrm{dtt}, J=15.3,6.4,1.4 \mathrm{~Hz}, 1 \mathrm{H}), 5.58(\mathrm{dtt}, J=15.3,5.7,1.6 \mathrm{~Hz}, 1 \mathrm{H}), 4.00(\mathrm{~d}, J=$ $6.8 \mathrm{~Hz}, 0.32 \mathrm{H}), 3.95(\mathrm{dd}, J=6.8 \mathrm{~Hz}, 1.68 \mathrm{H}), 3.29(\mathrm{~d}, J=6.4 \mathrm{~Hz}, 0.32 \mathrm{H}), 3.25(\mathrm{~d}, J=6.4 \mathrm{~Hz}, 1.68 \mathrm{H})$, $2.33(\mathrm{~s}, 3 \mathrm{H}), 2.11$ (brs, $0.16 \mathrm{H}), 1.85$ (brs, 0.84H). ${ }^{13} \mathrm{C}$ NMR $\left(100 \mathrm{MHz}, \mathrm{CDCl}_{3}\right.$ ) Major isomer: $\delta=140.2$ $(\mathrm{CH}), 139.4\left(\mathrm{C}_{\mathrm{q}}\right), 137.0\left(\mathrm{C}_{\mathrm{q}}\right), 132.6\left(\mathrm{C}_{\mathrm{q}}\right), 130.7(\mathrm{CH}), 130.5(\mathrm{CH}), 130.4(\mathrm{CH}), 130.4(\mathrm{CH}), 129.4(\mathrm{CH})$, $127.1(\mathrm{CH}), 106.1(\mathrm{CH}), 63.2\left(\mathrm{CH}_{2}\right), 33.9\left(\mathrm{CH}_{2}\right), 20.7\left(\mathrm{CH}_{3}\right)$. Minor isomer: $\delta=140.3(\mathrm{CH}), 139.2\left(\mathrm{C}_{\mathrm{q}}\right)$, $136.9\left(\mathrm{C}_{q}\right), 133.2\left(\mathrm{C}_{q}\right), 130.9(\mathrm{CH}), 130.2(\mathrm{CH}), 130.1(\mathrm{CH}), 129.6(\mathrm{CH}), 129.5(\mathrm{CH}), 127.2(\mathrm{CH}), 106.2$ (CH), $57.9\left(\mathrm{CH}_{2}\right), 29.0\left(\mathrm{CH}_{2}\right), 20.7\left(\mathrm{CH}_{3}\right)$. IR (ATR) $v=3356,1516,1392,1327,1191,1100,1041,970$, $752 \mathrm{~cm}^{-1} . \mathrm{MS}(\mathrm{ESI}) \mathrm{m} / \mathrm{z}$ (relative intensity): $479(100)[2 \mathrm{M}+\mathrm{Na}]^{+}, 251(50)[\mathrm{M}+\mathrm{Na}]^{+}, 229(30)[\mathrm{M}+\mathrm{H}]^{+}$. HR-MS (ESI) m/z calcd for $\mathrm{C}_{14} \mathrm{H}_{17} \mathrm{~N}_{2} \mathrm{O}[\mathrm{M}+\mathrm{H}]^{+}:$:229.1335, found: 229.1332 . 
<smiles>Cc1ccc(CC=CCNCCS)c(-n2cccn2)c1</smiles>

4-Methyl-N-\{4-[4-methyl-2-(1H-pyrazol-1-yl)phenyl]but-2-en-1-yl\}benzenesulfonamide

$(111 \mathrm{cg})$ :

The general procedure $\mathbf{H}$ was followed using 2-[4-methyl-2-(1H-pyrazol-1-yl)phenyl]propan-2-ol (168c) (54.1 mg, $0.25 \mathrm{mmol}$ ) and 3-tosyl-5-vinyloxazolidin-2-one (110g) (133.7 $\mathrm{mg}, 0.50 \mathrm{mmol})$. Purification by column chromatography on silica gel (DCM: $100 \% \rightarrow n$-hexane/EtOAc: $2 / 1$ ) yielded $111 \mathrm{cg}\left(60.1 \mathrm{mg}, 63 \%, E / Z=4.6 / 1.0\right.$ by ${ }^{1} \mathrm{H}$ NMR) as a colorless oil.

${ }^{1} \mathbf{H}$ NMR $\left(600 \mathrm{MHz}, \mathrm{CDCl}_{3}\right) \delta=7.74-7.58(\mathrm{~m}, 3 \mathrm{H}), 7.49(\mathrm{~d}, J=2.4 \mathrm{~Hz}, 0.18 \mathrm{H}), 7.48(\mathrm{~d}, J=2.4 \mathrm{~Hz}$, 0.82H), 7.29-7.22 (m, 2H), 7.13-7.03 (m, 3H), $6.37(\mathrm{t}, J=2.1 \mathrm{~Hz}, 1 \mathrm{H}), 5.47(\mathrm{dtt}, J=15.6,6.3,1.3 \mathrm{~Hz}$, $0.82 \mathrm{H}), 5.40(\mathrm{dtt}, J=10.7,7.3,1.2 \mathrm{~Hz}, 0.18 \mathrm{H}), 5.24(\mathrm{dtt}, J=10.7,6.9,1.8 \mathrm{~Hz}, 0.18 \mathrm{H}), 5.13(\mathrm{dtt}, J=$ 15.6, 6.3, $1.6 \mathrm{~Hz}, 0.82 \mathrm{H}), 4.76(\mathrm{t}, J=6.3 \mathrm{~Hz}, 0.18 \mathrm{H}), 4.56(\mathrm{t}, J=6.3 \mathrm{~Hz}, 0.82 \mathrm{H}), 3.44(\mathrm{t}, J=6.9 \mathrm{~Hz}$, $0.34 \mathrm{H}), 3.39(\mathrm{t}, J=6.6 \mathrm{~Hz}, 1.66 \mathrm{H}), 3.19(\mathrm{~d}, J=6.6 \mathrm{~Hz}, 0.34 \mathrm{H}), 3.16(\mathrm{~d}, J=6.6 \mathrm{~Hz}, 1.66 \mathrm{H}), 2.40(\mathrm{~s}$, $0.51 \mathrm{H}), 2.38(\mathrm{~s}, 2.49 \mathrm{H}), 2.32(\mathrm{~s}, 2.49 \mathrm{H}), 2.31(\mathrm{~s}, 0.51 \mathrm{H}) .{ }^{13} \mathrm{C} \mathrm{NMR}\left(125 \mathrm{MHz}, \mathrm{CDCl}_{3}\right)$ Major isomer: $\delta=$ $143.2\left(\mathrm{C}_{\mathrm{q}}\right), 140.1(\mathrm{CH}), 139.3\left(\mathrm{C}_{\mathrm{q}}\right), 137.1\left(\mathrm{C}_{\mathrm{q}}\right), 136.9\left(\mathrm{C}_{\mathrm{q}}\right), 132.3(\mathrm{CH}), 132.0\left(\mathrm{C}_{\mathrm{q}}\right), 130.5(\mathrm{CH}), 130.3$ (CH), $129.5(\mathrm{CH}), 129.3(\mathrm{CH}), 127.0(\mathrm{CH}), 127.0(\mathrm{CH}), 125.7(\mathrm{CH}), 106.1(\mathrm{CH}), 45.0\left(\mathrm{CH}_{2}\right), 34.0\left(\mathrm{CH}_{2}\right)$, $21.5\left(\mathrm{CH}_{3}\right), 20.8\left(\mathrm{CH}_{3}\right)$. Minor isomer: $\delta=143.2\left(\mathrm{C}_{\mathrm{q}}\right), 140.2(\mathrm{CH}), 139.1\left(\mathrm{C}_{\mathrm{q}}\right), 137.0\left(\mathrm{C}_{\mathrm{q}}\right), 137.0\left(\mathrm{C}_{\mathrm{q}}\right)$, $132.5\left(\mathrm{C}_{\mathrm{q}}\right), 131.8(\mathrm{CH}), 130.6(\mathrm{CH}), 130.0(\mathrm{CH}), 129.5(\mathrm{CH}), 129.5(\mathrm{CH}), 127.1(\mathrm{CH}), 127.0(\mathrm{CH}), 124.9$ (CH), $106.2(\mathrm{CH}), 39.8\left(\mathrm{CH}_{2}\right), 29.1\left(\mathrm{CH}_{2}\right), 21.5\left(\mathrm{CH}_{3}\right), 20.8\left(\mathrm{CH}_{3}\right)$. IR (ATR) $v=3278,1516,1405,1326$, 1157, 1094, 1043, 911, 732, $663 \mathrm{~cm}^{-1}$. MS (ESI) m/z (relative intensity): 785 (40) [2M+Na] $]^{+}, 404(70)$ $[\mathrm{M}+\mathrm{Na}]^{+}, 382(100)[\mathrm{M}+\mathrm{H}]^{+}$. HR-MS (ESI) m/z calcd for $\mathrm{C}_{21} \mathrm{H}_{24} \mathrm{~N}_{3} \mathrm{O}_{2} \mathrm{~S}[\mathrm{M}+\mathrm{H}]^{+}:$382.1584, found: 382.1582 .

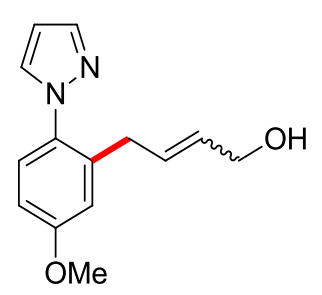

4-[5-Methoxy-2-(1H-pyrazol-1-yl)phenyl)but-2-en-1-ol (111da): The general procedure $\mathbf{H}$ was followed using 2-[5-methoxy-2-(1H-pyrazol-1-yl)phenyl]propan-2-ol (168d) (58.1 mg, $0.25 \mathrm{mmol})$ 
and 4-vinyl-1,3-dioxolan-2-one (110a) $(48.0 \mu \mathrm{L}, 0.50 \mathrm{mmol})$. Purification by column chromatography on silica gel ( $n$-hexane/EtOAc: $1 / 1$ ) yielded $111 \mathrm{da}\left(40.0 \mathrm{mg}, 65 \%, E / Z=3.8 / 1.0\right.$ by ${ }^{1} \mathrm{H}$ NMR) as a colorless oil.

${ }^{1} \mathrm{H}$ NMR $\left(300 \mathrm{MHz} \mathrm{CDCl}_{3}\right) \delta=7.67(\mathrm{dd}, J=1.9,0.7 \mathrm{~Hz}, 0.21 \mathrm{H}), 7.65(\mathrm{dd}, J=1.9,0.7 \mathrm{~Hz}, 0.79 \mathrm{H}), 7.53-$ $7.45(\mathrm{~m}, 1 \mathrm{H}), 7.23-7.14(\mathrm{~m}, 1 \mathrm{H}), 6.86-6.72(\mathrm{~m}, 2 \mathrm{H}), 6.39$ (dd, $J=2.3,1.9 \mathrm{~Hz}, 0.21 \mathrm{H}), 6.37$ (dd, J = 2.3, $1.9 \mathrm{~Hz}, 0.79 \mathrm{H}), 5.60(\mathrm{dtt}, J=15.3,6.5,1.1 \mathrm{~Hz}, 1 \mathrm{H}), 5.45(\mathrm{dtt}, J=15.3,5.7,1.3 \mathrm{~Hz}, 1 \mathrm{H}), 4.08-3.93(\mathrm{~m}$, $2 \mathrm{H}), 3.81(\mathrm{~s}, 3 \mathrm{H}), 3.25(\mathrm{dd}, J=6.8,1.4 \mathrm{~Hz}, 0.42 \mathrm{H}), 3.20(\mathrm{dd}, J=6.8,1.4 \mathrm{~Hz}, 1.58 \mathrm{H}), 2.14(\mathrm{~s}, 0.21 \mathrm{H})$, $1.90(\mathrm{~s}, 0.79 \mathrm{H}) .{ }^{13} \mathrm{C}$ NMR $\left(100 \mathrm{MHz}, \mathrm{CDCl}_{3}\right)$ Major isomer: $\delta=159.6\left(\mathrm{C}_{\mathrm{q}}\right), 140.0(\mathrm{CH}), 137.8\left(\mathrm{C}_{\mathrm{q}}\right)$, $132.9\left(\mathrm{C}_{\mathrm{q}}\right), 131.1(\mathrm{CH}), 130.9(\mathrm{CH}), 129.7(\mathrm{CH}), 127.9(\mathrm{CH}), 115.7(\mathrm{CH}), 111.8(\mathrm{CH}), 105.9(\mathrm{CH}), 63.1$ $\left(\mathrm{CH}_{2}\right), 55.5\left(\mathrm{CH}_{3}\right), 34.3\left(\mathrm{CH}_{2}\right)$. Minor isomer: $\delta=159.7\left(\mathrm{C}_{\mathrm{q}}\right), 140.2(\mathrm{CH}), 138.2\left(\mathrm{C}_{\mathrm{q}}\right), 132.7\left(\mathrm{C}_{\mathrm{q}}\right), 131.2$ $(\mathrm{CH}), 130.0(\mathrm{CH}), 129.5(\mathrm{CH}), 127.9(\mathrm{CH}), 115.4(\mathrm{CH}), 111.8(\mathrm{CH}), 106.1(\mathrm{CH}), 57.8\left(\mathrm{CH}_{2}\right), 55.5\left(\mathrm{CH}_{3}\right)$, $29.4\left(\mathrm{CH}_{2}\right)$. IR (ATR) $v=3370,2839,1608,1500,1241,1043,756,624 \mathrm{~cm}^{-1}$. MS (ESI) m/z (relative intensity): $511(100)[2 \mathrm{M}+\mathrm{Na}]^{+}, 267(60)[\mathrm{M}+\mathrm{Na}]^{+}, 245(70)[\mathrm{M}+\mathrm{H}]^{+}, 227$ (20). HR-MS (ESI) m/z calcd for $\mathrm{C}_{14} \mathrm{H}_{17} \mathrm{~N}_{2} \mathrm{O}_{2}[\mathrm{M}+\mathrm{H}]^{+}:$245.1285, found: 245.1282 .

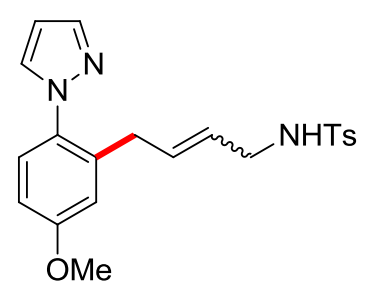

$N$-\{4-[5-Methoxy-2-(1H-pyrazol-1-yl)phenyl]but-2-en-1-yl\}-4-methylbenzenesulfonamide (111dg): The general procedure $\mathbf{H}$ was followed using 2-[5-methoxy-2-(1H-pyrazol-1-yl)phenyl]propan-2-ol (168d) (58.1 mg, $0.25 \mathrm{mmol})$ and 3-tosyl-5-vinyloxazolidin-2-one (110g) (133.7 $\mathrm{mg}, 0.50 \mathrm{mmol})$. Purification by column chromatography on silica gel (Hexane/EtOAc/Et ${ }_{3} \mathrm{~N}: 3 / 1 / 0.3 \rightarrow$ $n$-hexane/EtOAc: $1 / 1)$ yielded $111 \mathrm{dg}\left(51.0 \mathrm{mg}, 51 \%, E / Z=5.3 / 1.0\right.$ by ${ }^{1} \mathrm{H}$ NMR) as a colorless oil.

${ }^{1} \mathbf{H}$ NMR $\left(400 \mathrm{MHz}, \mathrm{CDCl}_{3}\right) \delta=7.75-7.65(\mathrm{~m}, 2 \mathrm{H}), 7.63(\mathrm{~d}, J=1.9 \mathrm{~Hz}, 0.84 \mathrm{H}), 7.59(\mathrm{~d}, J=1.9 \mathrm{~Hz}$, 0.16H), 7.47-7.41 (m, 1H), 7.32-7.22 (m, 2H), $7.17(\mathrm{~d}, J=8.6 \mathrm{~Hz}, 0.84 \mathrm{H}), 7.13(\mathrm{~d}, J=8.6 \mathrm{~Hz}, 0.16 \mathrm{H})$, 6.84-6.73 (m, 1.16H), $6.71(\mathrm{~d}, J=2.9 \mathrm{~Hz}, 0.84 \mathrm{H}), 6.36$ (dd, $J=2.3,1.8 \mathrm{~Hz}, 1 \mathrm{H}), 5.47(\mathrm{dtt}, J=15.3,6.6$, $1.4 \mathrm{~Hz}, 1 \mathrm{H}), 5.27(\mathrm{dtt}, J=10.5,7.1,1.7 \mathrm{~Hz}, 0.16 \mathrm{H}), 5.15(\mathrm{dtt}, J=15.3,6.3,1.5 \mathrm{~Hz}, 0.84 \mathrm{H}), 4.72(\mathrm{t}, J=$ $6.0 \mathrm{~Hz}, 0.16 \mathrm{H}), 4.51(\mathrm{t}, J=6.0 \mathrm{~Hz}, 0.84 \mathrm{H}), 3.80(\mathrm{~s}, 3 \mathrm{H}), 3.45-3.37(\mathrm{~m}, 2 \mathrm{H}), 3.19-3.08(\mathrm{~m}, 2 \mathrm{H}), 2.40(\mathrm{~s}$, $0.52 \mathrm{H}), 2.38(\mathrm{~s}, 2.48 \mathrm{H}) .{ }^{13} \mathrm{C} \mathrm{NMR}\left(100 \mathrm{MHz}, \mathrm{CDCl}_{3}\right)$ Major isomer: $\delta=159.6\left(\mathrm{C}_{\mathrm{q}}\right), 143.3\left(\mathrm{C}_{\mathrm{q}}\right), 140.1$ 
$(\mathrm{CH}), 137.2\left(\mathrm{C}_{\mathrm{q}}\right), 136.9\left(\mathrm{C}_{\mathrm{q}}\right), 132.9\left(\mathrm{C}_{\mathrm{q}}\right), 131.9(\mathrm{CH}), 131.0(\mathrm{CH}), 129.6(\mathrm{CH}), 127.9(\mathrm{CH}), 127.1(\mathrm{CH})$, $126.2(\mathrm{CH}), 115.7(\mathrm{CH}), 111.9(\mathrm{CH}), 106.0(\mathrm{CH}), 55.5\left(\mathrm{CH}_{3}\right), 45.0\left(\mathrm{CH}_{2}\right), 34.4\left(\mathrm{CH}_{2}\right), 21.5\left(\mathrm{CH}_{3}\right)$. Minor isomer: $\delta=159.7\left(\mathrm{C}_{\mathrm{q}}\right), 143.4\left(\mathrm{C}_{\mathrm{q}}\right), 140.2(\mathrm{CH}), 137.6\left(\mathrm{C}_{\mathrm{q}}\right), 137.1\left(\mathrm{C}_{\mathrm{q}}\right), 132.7\left(\mathrm{C}_{\mathrm{q}}\right), 131.3(\mathrm{CH}), 131.1$ $(\mathrm{CH}), 129.6(\mathrm{CH}), 127.9(\mathrm{CH}), 126.4(\mathrm{CH}), 125.4(\mathrm{CH}), 115.4(\mathrm{CH}), 111.9(\mathrm{CH}), 106.1(\mathrm{CH}), 65.8\left(\mathrm{CH}_{3}\right)$, $39.8\left(\mathrm{CH}_{2}\right), 29.5\left(\mathrm{CH}_{2}\right), 15.2\left(\mathrm{CH}_{3}\right)$. IR (ATR) $v=3274,2918,1599,1518,1324,1156,1093,1041,813$, $661 \mathrm{~cm}^{-1} . \mathrm{MS}(\mathrm{ESI}) \mathrm{m} / \mathrm{z}$ (relative intensity): $817(10)[2 \mathrm{M}+\mathrm{Na}]^{+}, 420(20)[\mathrm{M}+\mathrm{Na}]^{+}, 398(100)[\mathrm{M}+\mathrm{H}]^{+}$. HR-MS (ESI) m/z calcd for $\mathrm{C}_{21} \mathrm{H}_{24} \mathrm{~N}_{3} \mathrm{O}_{3} \mathrm{~S}[\mathrm{M}+\mathrm{H}]^{+}:$398.1533, found: 398.1537.

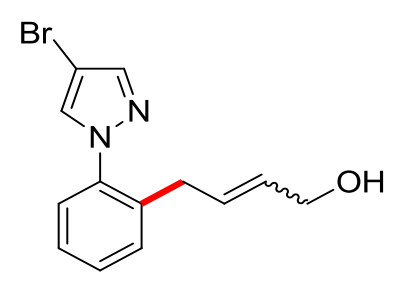

4-[2-(4-Bromo-1H-pyrazol-1-yl)phenyl]but-2-en-1-ol (111ea): The general procedure $\mathbf{H}$ was followed using 2-[2-(4-bromo-1H-pyrazol-1-yl)phenyl]propan-2-ol (168e) (70.3 mg, $0.25 \mathrm{mmol}$ ) and 4-vinyl-1,3-dioxolan-2-one (110a) $(48.0 \mu \mathrm{L}, 0.50 \mathrm{mmol})$. Purification by column chromatography on silica gel ( $n$-hexane/EtOAc: $2 / 1$ ) yielded 111 ea $\left(39.0 \mathrm{mg}, 53 \%, E / Z=5.9 / 1.0\right.$ by ${ }^{1} \mathrm{H} \mathrm{NMR}$ ) as a colorless oil.

${ }^{1} \mathbf{H}$ NMR $\left(400 \mathrm{MHz}, \mathrm{CDCl}_{3}\right) \delta=7.67(\mathrm{~d}, J=0.7 \mathrm{~Hz}, 0.15 \mathrm{H}), 7.64(\mathrm{~d}, J=0.7 \mathrm{~Hz}, 0.85 \mathrm{H}), 7.60(\mathrm{~d}, J=0.7$ $\mathrm{Hz}, 0.15 \mathrm{H}), 7.59(\mathrm{~d}, J=0.7 \mathrm{~Hz}, 0.85 \mathrm{H}), 7.43-7.34(\mathrm{~m}, 1 \mathrm{H}), 7.43-7.21(\mathrm{~m}, 3 \mathrm{H}), 5.66(\mathrm{dtt}, J=15.2,6.5$, $1.2 \mathrm{~Hz}, 1 \mathrm{H}), 5.49(\mathrm{dtt}, J=15.2,5.8,1.5 \mathrm{~Hz}, 1 \mathrm{H}), 4.09$ (d, J = 6.5 Hz, 0.29H), $4.02(\mathrm{~d}, J=6.5 \mathrm{~Hz}, 1.71 \mathrm{H})$, 3.35 (dd, $J=6.5,1.5 \mathrm{~Hz}, 0.29 \mathrm{H}$ ), 3.31 (dd, $J=6.5,1.5 \mathrm{~Hz}, 1.71 \mathrm{H}$ ), 1.62 (brs, 0.15H), 1.41 (brs, 0.85H). ${ }^{13} \mathrm{C}$ NMR (100 MHz, CDCl $)_{3}$ Major isomer: $\delta=140.9(\mathrm{CH}), 139.1\left(\mathrm{C}_{\mathrm{q}}\right), 135.8\left(\mathrm{C}_{\mathrm{q}}\right), 130.9(\mathrm{CH}), 130.8$ $(\mathrm{CH}), 129.8(\mathrm{CH}), 129.8(\mathrm{CH}), 129.2(\mathrm{CH}), 127.3(\mathrm{CH}), 126.4(\mathrm{CH}), 94.5\left(\mathrm{C}_{\mathrm{q}}\right), 63.3\left(\mathrm{CH}_{2}\right), 34.2\left(\mathrm{CH}_{2}\right)$. Minor isomer: $\delta=141.0(\mathrm{CH}), 138.9\left(\mathrm{C}_{\mathrm{q}}\right), 136.3\left(\mathrm{C}_{\mathrm{q}}\right), 130.8(\mathrm{CH}), 130.5(\mathrm{CH}), 129.9(\mathrm{CH}), 129.8(\mathrm{CH})$, $129.4(\mathrm{CH}), 127.2(\mathrm{CH}), 126.5(\mathrm{CH}), 94.3\left(\mathrm{C}_{\mathrm{q}}\right), 58.2\left(\mathrm{CH}_{2}\right), 29.4\left(\mathrm{CH}_{2}\right)$. IR (ATR) $v=3357,2916,1494$, $1405,1328,954,764,614 \mathrm{~cm}^{-1}$. MS (ESI) m/z (relative intensity): $317(100)[\mathrm{M}+\mathrm{Na}]^{+}\left({ }^{81} \mathrm{Br}\right), 315(100)$ $[\mathrm{M}+\mathrm{Na}]^{+}\left({ }^{79} \mathrm{Br}\right), 295(20)[\mathrm{M}+\mathrm{H}]^{+}\left({ }^{81} \mathrm{Br}\right), 293(20)[\mathrm{M}+\mathrm{H}]^{+}\left({ }^{79} \mathrm{Br}\right)$. HR-MS (ESI) $\mathrm{m} / \mathrm{z}$ calcd for $\mathrm{C}_{13} \mathrm{H}_{14}{ }^{81} \mathrm{BrN}_{2} \mathrm{O}[\mathrm{M}+\mathrm{H}]^{+}:$295.0265, found: 295.0260; $\mathrm{C}_{13} \mathrm{H}_{14}{ }^{79} \mathrm{BrN}_{2} \mathrm{O}[\mathrm{M}+\mathrm{H}]^{+}:$293.0284, found: 293.0280 . 
<smiles>OC/C=C/Cc1ccccc1-n1ncc2ccccc21</smiles>

4-[2-(1H-Indazol-1-yl)phenyl]but-2-en-1-ol (111fa): The general procedure $\mathbf{H}$ was followed using 2-[2-(1H-indazol-1-yl)phenyl]propan-2-ol

(168f) $\quad(63.1 \quad \mathrm{mg}, \quad 0.25 \quad \mathrm{mmol}) \quad$ and 4-vinyl-1,3-dioxolan-2-one (110a) $(48.0 \mu \mathrm{L}, 0.50 \mathrm{mmol})$. Purification by column chromatography on silica gel ( $n$-hexane/EtOAc: $2 / 1$ ) yielded $111 \mathrm{fa}\left(39.2 \mathrm{mg}, 59 \%, E / Z=4.6 / 1.0\right.$ by ${ }^{1} \mathrm{H} \mathrm{NMR}$ ) as a colorless oil.

${ }^{1} \mathrm{H}$ NMR $\left(400 \mathrm{MHz}, \mathrm{CDCl}_{3}\right) \delta=8.20(\mathrm{~d}, J=0.9 \mathrm{~Hz}, 0.18 \mathrm{H}), 8.18(\mathrm{~d}, J=0.9 \mathrm{~Hz}, 0.82 \mathrm{H}), 7.83-7.7(\mathrm{~m}, 1 \mathrm{H})$, 7.52-7.30 (m, 5H), 7.23-7.11 (m, 2H), $5.46(\mathrm{dtt}, J=15.3,6.7,1.2 \mathrm{~Hz}, 1 \mathrm{H}), 5.43-5.38(\mathrm{~m}, 0.18 \mathrm{H}), 5.20$ (dtt, $J=15.3,5.9,1.4 \mathrm{~Hz}, 0.82 \mathrm{H}), 3.81(\mathrm{~d}, J=5.6 \mathrm{~Hz}, 0.36 \mathrm{H}), 3.75(\mathrm{~d}, J=5.6 \mathrm{~Hz}, 1.64 \mathrm{H}), 3.34-3.19(\mathrm{~m}$, $2 \mathrm{H}), 1.73$ (brs, 0.18H), 1.13 (brs, 0.82H). ${ }^{13} \mathrm{C}$ NMR (100 MHz, $\mathrm{CDCl}_{3}$ ) Major isomer: $\delta=140.6\left(\mathrm{C}_{\mathrm{q}}\right)$, $138.1\left(\mathrm{C}_{\mathrm{q}}\right), 137.8\left(\mathrm{C}_{\mathrm{q}}\right), 134.5(\mathrm{CH}), 130.9(\mathrm{CH}), 130.4(\mathrm{CH}), 129.8(\mathrm{CH}), 129.1(\mathrm{CH}), 127.8(\mathrm{CH}), 127.3$ $(\mathrm{CH}), 126.8(\mathrm{CH}), 123.9\left(\mathrm{C}_{\mathrm{q}}\right), 121.1(\mathrm{CH}), 121.0(\mathrm{CH}), 110.0(\mathrm{CH}), 63.2\left(\mathrm{CH}_{2}\right), 34.6\left(\mathrm{CH}_{2}\right)$. Minor isomer: $\delta=140.6\left(\mathrm{C}_{\mathrm{q}}\right), 138.2\left(\mathrm{C}_{\mathrm{q}}\right), 137.6\left(\mathrm{C}_{\mathrm{q}}\right), 134.6(\mathrm{CH}), 130.5(\mathrm{CH}), 129.7(\mathrm{CH}), 129.5(\mathrm{CH}), 129.2(\mathrm{CH})$, $127.9(\mathrm{CH}), 127.2(\mathrm{CH}), 126.9(\mathrm{CH}), 123.9\left(\mathrm{C}_{\mathrm{q}}\right), 121.2(\mathrm{CH}), 121.0(\mathrm{CH}), 110.0(\mathrm{CH}), 58.0\left(\mathrm{CH}_{2}\right), 29.5$ $\left(\mathrm{CH}_{2}\right)$. IR (ATR) $v=3372,2917,1615,1500,1414,1200,984,744 \mathrm{~cm}^{-1}$. MS (ESI) $\mathrm{m} / \mathrm{z}$ (relative intensity): $287(100)[\mathrm{M}+\mathrm{Na}]^{+}, 265(30)[\mathrm{M}+\mathrm{H}]^{+}, 247$ (80). HR-MS (ESI) m/z calcd for $\mathrm{C}_{17} \mathrm{H}_{17} \mathrm{~N}_{2} \mathrm{O}$ $[\mathrm{M}+\mathrm{H}]^{+}: 265.1335$, found: 265.1336 .<smiles>OC/C=C/Cc1ccccc1-c1ccccn1</smiles>

4-[2-(Pyridin-2-yl)phenyl]but-2-en-1-ol (111ga): The general procedure $\mathbf{H}$ was followed using 2-[2-(pyridin-2-yl)phenyl]propan-2-ol (168g) (53.4 mg, $0.25 \mathrm{mmol}$ ) and 4-vinyl-1,3-dioxolan-2-one (110a). Purification by column chromatography on silica gel ( $n$-hexane/EtOAc: $2 / 1$ ) yielded 111ga (47.9 mg, 85\%, E/Z = 7.2/1.0 by ${ }^{1} \mathrm{H} N M R$ ) as a colorless oil.

${ }^{1} \mathrm{H}$ NMR $\left(400 \mathrm{MHz}, \mathrm{CDCl}_{3}\right) \delta=8.71-8.61(\mathrm{~m}, 1 \mathrm{H}), 7.84-7.65(\mathrm{~m}, 1 \mathrm{H}), 7.43-7.15(\mathrm{~m}, 6 \mathrm{H}), 5.67(\mathrm{dtt}, J=$ $15.3,6.6,1.4 \mathrm{~Hz}, 0.87 \mathrm{H}), 5.61-5.54(\mathrm{~m}, 0.26 \mathrm{H}), 5.40(\mathrm{dtt}, J=15.3,5.9,1.6 \mathrm{~Hz}, 0.87 \mathrm{H}), 4.02-3.98(\mathrm{~m}$, 
$0.24 \mathrm{H}), 3.94(\mathrm{dq}, J=5.9,1.2 \mathrm{~Hz}, 1.76 \mathrm{H}), 3.53-3.48(\mathrm{~m}, 0.24 \mathrm{H}), 3.45(\mathrm{dt}, J=6.6,1.2 \mathrm{~Hz}, 1.76 \mathrm{H}), 1.82$ (brs, $1 \mathrm{H}) .{ }^{13} \mathrm{C}$ NMR (100 MHz, $\left.\mathrm{CDCl}_{3}\right)$ Major isomer: $\delta=159.8\left(\mathrm{C}_{\mathrm{q}}\right), 149.0(\mathrm{CH}), 140.3\left(\mathrm{C}_{\mathrm{q}}\right), 137.7\left(\mathrm{C}_{\mathrm{q}}\right)$, $136.2(\mathrm{CH}), 131.4(\mathrm{CH}), 130.1(\mathrm{CH}), 130.0(\mathrm{CH}), 129.8(\mathrm{CH}), 128.5(\mathrm{CH}), 126.3(\mathrm{CH}), 124.1(\mathrm{CH}), 121.8$ $(\mathrm{CH}), 63.3\left(\mathrm{CH}_{2}\right), 35.9\left(\mathrm{CH}_{2}\right)$. Minor isomer: $\delta=159.9\left(\mathrm{C}_{\mathrm{q}}\right), 148.9(\mathrm{CH}), 140.0\left(\mathrm{C}_{\mathrm{q}}\right), 138.2\left(\mathrm{C}_{\mathrm{q}}\right), 136.5$ (CH), $131.3(\mathrm{CH}), 130.0(\mathrm{CH}), 129.7(\mathrm{CH}), 129.0(\mathrm{CH}), 128.6(\mathrm{CH}), 126.3(\mathrm{CH}), 124.3(\mathrm{CH}), 121.8(\mathrm{CH})$, $58.0\left(\mathrm{CH}_{2}\right), 31.1\left(\mathrm{CH}_{2}\right)$. IR (ATR) $v=3321,2851,1586,1468,1426,1092,972,753 \mathrm{~cm}^{-1} . \mathrm{MS}(\mathrm{ESI}) \mathrm{m} / \mathrm{z}$ (relative intensity): $248(100)[\mathrm{M}+\mathrm{Na}]^{+}, 226(70)[\mathrm{M}+\mathrm{H}]^{+}$. HR-MS (ESI) m/z calcd for $\mathrm{C}_{15} \mathrm{H}_{16} \mathrm{NO}[\mathrm{M}+\mathrm{H}]^{+}$: 226.1226, found: 226.1226 .

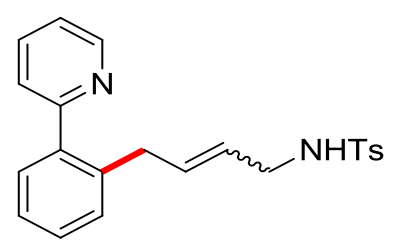

4-Methyl-N-[4-(2-(pyridin-2-yl)phenyl)but-2-en-1-yl)benzenesulfonamide (111gg): The general procedure $\mathbf{H}$ was followed using 2-[2-(pyridin-2-yl)phenyl]propan-2-ol (168g) $(53.4 \mathrm{mg}, 0.25 \mathrm{mmol})$ and 3-tosyl-5-vinyloxazolidin-2-one $(\mathbf{1 1 0 g})(133.7 \mathrm{mg}, 0.50 \mathrm{mmol})$. Purification by column chromatography on silica gel (Hexane/EtOAc/Et $\left.{ }_{3} \mathrm{~N}: 3 / 1 / 0.3\right)$ yielded 111gg $(81.4 \mathrm{mg}, 86 \%, E / Z=$ 3.2/1.0 by ${ }^{1} \mathrm{H}$ NMR) as a colorless oil.

${ }^{1} \mathbf{H}$ NMR $\left(300 \mathrm{MHz}^{\mathrm{CDCl}}{ }_{3}\right) \delta=8.68-8.52(\mathrm{~m}, 1 \mathrm{H}), 7.85-7.61(\mathrm{~m}, 3 \mathrm{H}), 7.43-7.09(\mathrm{~m}, 8 \mathrm{H}), 5.09(\mathrm{dtt}, J=$ 15.2, 6.3, $1.5 \mathrm{~Hz}, 1 \mathrm{H}), 5.21$ (dtt, $J=10.4,7.0,1.5 \mathrm{~Hz}, 0.24 \mathrm{H}), 5.53(\mathrm{dtt}, J=15.2,6.7,1.3 \mathrm{~Hz}, 0.76 \mathrm{H})$, $4.99(\mathrm{t}, J=6.0 \mathrm{~Hz}, 0.24 \mathrm{H}), 4.59(\mathrm{t}, J=6.0 \mathrm{~Hz}, 0.76 \mathrm{H}), 3.65-3.26(\mathrm{~m}, 4 \mathrm{H}), 2.39(\mathrm{~s}, 0.71 \mathrm{H}), 2.38(\mathrm{~s}$, 2.29H). ${ }^{13} \mathrm{C}$ NMR (125 MHz, $\left.\mathrm{CDCl}_{3}\right)$ Major isomer: $\delta=159.6\left(\mathrm{C}_{\mathrm{q}}\right), 148.9(\mathrm{CH}), 143.1\left(\mathrm{C}_{\mathrm{q}}\right), 140.2\left(\mathrm{C}_{\mathrm{q}}\right)$, $137.2\left(\mathrm{C}_{\mathrm{q}}\right), 136.9\left(\mathrm{C}_{\mathrm{q}}\right), 136.1(\mathrm{CH}), 133.3(\mathrm{CH}), 129.9(\mathrm{CH}), 129.7(\mathrm{CH}), 129.5(\mathrm{CH}), 128.3(\mathrm{CH}), 127.0$ (CH), $126.3(\mathrm{CH}), 125.5(\mathrm{CH}), 124.0(\mathrm{CH}), 121.7(\mathrm{CH}), 45.1\left(\mathrm{CH}_{2}\right), 35.9\left(\mathrm{CH}_{2}\right), 21.5\left(\mathrm{CH}_{3}\right)$. Minor isomer: $\delta=159.7\left(\mathrm{C}_{\mathrm{q}}\right), 148.9(\mathrm{CH}), 143.1\left(\mathrm{C}_{\mathrm{q}}\right), 140.0\left(\mathrm{C}_{\mathrm{q}}\right), 137.6\left(\mathrm{C}_{\mathrm{q}}\right), 137.1\left(\mathrm{C}_{\mathrm{q}}\right), 136.4(\mathrm{CH}), 132.7(\mathrm{CH}), 129.9$ $(\mathrm{CH}), 129.6(\mathrm{CH}), 129.5(\mathrm{CH}), 128.5(\mathrm{CH}), 127.0(\mathrm{CH}), 126.3(\mathrm{CH}), 124.5(\mathrm{CH}), 124.1(\mathrm{CH}), 121.8(\mathrm{CH})$, $39.9\left(\mathrm{CH}_{2}\right), 31.2\left(\mathrm{CH}_{2}\right), 21.5\left(\mathrm{CH}_{3}\right)$. IR (ATR) $v=3274,2922,1587,1426,1325,1156,1093,754,661$, $550 \mathrm{~cm}^{-1} . \mathrm{MS}(\mathrm{ESI}) \mathrm{m} / \mathrm{z}$ (relative intensity): $779(10)[2 \mathrm{M}+\mathrm{Na}]^{+}, 401(40)[\mathrm{M}+\mathrm{Na}]^{+}, 379(100)[\mathrm{M}+\mathrm{H}]^{+}$. HR-MS (ESI) $\mathrm{m} / \mathrm{z}$ calcd for $\mathrm{C}_{22} \mathrm{H}_{22} \mathrm{~N}_{2} \mathrm{O}_{2} \mathrm{~S}[\mathrm{M}+\mathrm{H}]^{+}: 379.1475$, found: 379.1478 . 
<smiles>Cc1cccc(CC=CCNS)c1-c1ccccn1</smiles>

4-Methyl-N-\{4-[3-methyl-2-(pyridin-2-yl)phenyl]but-2-en-1-yl\}benzenesulfon-amide (111hg): The general procedure $\mathbf{H}$ was followed using 2-[3-methyl-2-(pyridin-2-yl)phenyl]propan-2-ol (168h) (56.8 $\mathrm{mg}, 0.25 \mathrm{mmol})$ and 3-tosyl-5-vinyloxazolidin-2-one $(\mathbf{1 1 0 g})(133.7 \mathrm{mg}, 0.50 \mathrm{mmol})$. Purification by column chromatography on silica gel (Hexane/EtOAc/Et $\left.{ }_{3} \mathrm{~N}: 3 / 1 / 0.3\right)$ yielded $111 \mathrm{hg}(55.0 \mathrm{mg}, 56 \%$, $E / Z=2.8 / 1.0$ by $^{1} \mathrm{H}$ NMR) as a colorless oil.

${ }^{1} \mathbf{H}$ NMR $\left(300 \mathrm{MHz}, \mathrm{CDCl}_{3}\right) \delta=9.06-8.55(\mathrm{~m}, 1 \mathrm{H}), 7.72(\mathrm{td}, J=7.7,1.8 \mathrm{~Hz}, 1 \mathrm{H}), 7.68-7.60(\mathrm{~m}, 2 \mathrm{H})$, 7.35-7.13 (m, 5H), 7.13-7.03 (m, 1H), 7.03-6.93 (m, 1H), $5.45(\mathrm{dtt}, J=15.3,6.9,1.3 \mathrm{~Hz}, 1 \mathrm{H}), 5.16$ (dtt, $J=10.6,7.1,1.7 \mathrm{~Hz}, 0.26 \mathrm{H}), 4.98(\mathrm{dtt}, J=15.3,6.4,1.5 \mathrm{~Hz}, 0.74 \mathrm{H}), 4.89(\mathrm{t}, J=6.0 \mathrm{~Hz}, 0.26 \mathrm{H})$, $4.59(\mathrm{t}, J=6.0 \mathrm{~Hz}, 0.74 \mathrm{H}), 3.35(\mathrm{t}, J=6.0 \mathrm{~Hz}, 1.47 \mathrm{H}), 3.25(\mathrm{t}, J=6.0 \mathrm{~Hz}, 0.53 \mathrm{H}), 3.06-2.95(\mathrm{~m}, 2 \mathrm{H})$, $2.40(\mathrm{~s}, 0.79 \mathrm{H}), 2.38(\mathrm{~s}, 2.21 \mathrm{H}), 1.99(\mathrm{~s}, 2.21 \mathrm{H}), 1.97(\mathrm{~s}, 0.79 \mathrm{H}) .{ }^{13} \mathrm{C}$ NMR $\left(125 \mathrm{MHz}, \mathrm{CDCl}_{3}\right)$ Major isomer: $\delta=159.1\left(\mathrm{C}_{\mathrm{q}}\right), 149.4(\mathrm{CH}), 143.1\left(\mathrm{C}_{\mathrm{q}}\right), 140.1\left(\mathrm{C}_{\mathrm{q}}\right), 137.1\left(\mathrm{C}_{\mathrm{q}}\right), 136.9\left(\mathrm{C}_{\mathrm{q}}\right), 136.1\left(\mathrm{C}_{\mathrm{q}}\right), 136.1(\mathrm{CH})$, $133.1(\mathrm{CH}), 129.5(\mathrm{CH}), 128.1(\mathrm{CH}), 128.0(\mathrm{CH}), 127.0(\mathrm{CH}), 126.8(\mathrm{CH}), 125.3(\mathrm{CH}), 124.6(\mathrm{CH}), 121.8$ $(\mathrm{CH}), 45.1\left(\mathrm{CH}_{2}\right), 36.5\left(\mathrm{CH}_{2}\right), 21.5\left(\mathrm{CH}_{3}\right), 20.3\left(\mathrm{CH}_{3}\right)$. Minor isomer: $\delta=159.1\left(\mathrm{C}_{\mathrm{q}}\right), 149.5(\mathrm{CH}), 143.1$ $\left(\mathrm{C}_{q}\right), 139.9\left(\mathrm{C}_{q}\right), 137.4\left(\mathrm{C}_{q}\right), 137.1\left(\mathrm{C}_{q}\right), 136.2(\mathrm{CH}), 136.1\left(\mathrm{C}_{\mathrm{q}}\right), 132.4(\mathrm{CH}), 129.5(\mathrm{CH}), 128.2(\mathrm{CH})$, $128.0(\mathrm{CH}), 126.9(\mathrm{CH}), 126.5(\mathrm{CH}), 124.7(\mathrm{CH}), 124.3(\mathrm{CH}), 121.8(\mathrm{CH}), 39.7\left(\mathrm{CH}_{2}\right), 31.7\left(\mathrm{CH}_{2}\right), 21.5$ $\left(\mathrm{CH}_{3}\right), 20.3\left(\mathrm{CH}_{3}\right)$. IR (ATR) $v=3275,3063,1570,1459,1324,1155,1092,970,660 \mathrm{~cm}^{-1} . \mathrm{MS}$ (ESI) m/z (relative intensity): $415(20)[\mathrm{M}+\mathrm{Na}]^{+}, 393(100)[\mathrm{M}+\mathrm{H}]^{+}$. HR-MS (ESI) m/z calcd for $\mathrm{C}_{23} \mathrm{H}_{24} \mathrm{~N}_{2} \mathrm{O}_{2} \mathrm{~S}$ $[\mathrm{M}+\mathrm{H}]^{+}:$393.1631, found: 393.1634 .<smiles>Cc1cccc(C/C=C/CO)c1-c1ccccn1</smiles>

4-[3-Methyl-2-(pyridin-2-yl)phenyl]but-2-en-1-ol (111ha): The general procedure $\mathrm{H}$ was followed using 2-[3-methyl-2-(pyridin-2-yl)phenyl]propan-2-ol $\quad(168 \mathrm{~h}) \quad(56.8 \quad \mathrm{mg}, \quad 0.25 \mathrm{mmol})$ and 4-vinyl-1,3-dioxolan-2-one (110a) $(48.0 \mu \mathrm{L}, 0.50 \mathrm{mmol})$. Purification by column chromatography on 
silica gel ( $n$-hexane/EtOAc: $1 / 3$ ) yielded 111 ha $\left(44.9 \mathrm{mg}, 75 \%, E / Z=3.3 / 1.0\right.$ by ${ }^{1} \mathrm{H} \mathrm{NMR}$ ) as a colorless oil.

${ }^{1} \mathbf{H}$ NMR $\left(300 \mathrm{MHz}, \mathrm{CDCl}_{3}\right) \delta=8.72-8.64(\mathrm{~m}, 1 \mathrm{H}), 8.79-8.69(\mathrm{~m}, 1 \mathrm{H}), 7.34-7.18(\mathrm{~m}, 3 \mathrm{H}), 7.15-7.04$ (m, 2H), $5.53(\mathrm{dtt}, J=15.2,6.6,1.4 \mathrm{~Hz}, 0.77 \mathrm{H}), 5.52-5.43(\mathrm{~m}, 0.46 \mathrm{H}), 5.09(\mathrm{dtt}, J=15.2,6.6,1.4 \mathrm{~Hz}$, 0.77H), 3.91 (ddd, $J=5.8,1.1,1.1 \mathrm{~Hz}, 1.53 \mathrm{H}$ ), 3.83 (d, $J=5.8 \mathrm{~Hz}, 0.47 \mathrm{H}$ ), 3.15-3.00 (m, 2H), 2.06 (brs, 1H), $2.01(\mathrm{~s}, 3 \mathrm{H}) .{ }^{13} \mathrm{C}$ NMR (125 MHz, $\left.\mathrm{CDCl}_{3}\right)$ Major isomer: $\delta=159.2\left(\mathrm{C}_{\mathrm{q}}\right), 149.3(\mathrm{CH}), 140.0\left(\mathrm{C}_{\mathrm{q}}\right)$, $137.7\left(\mathrm{C}_{\mathrm{q}}\right), 136.1(\mathrm{CH}), 136.0\left(\mathrm{C}_{\mathrm{q}}\right), 131.1(\mathrm{CH}), 129.9(\mathrm{CH}), 128.1(\mathrm{CH}), 128.0(\mathrm{CH}), 126.8(\mathrm{CH}), 124.7$ $(\mathrm{CH}), 121.8(\mathrm{CH}), 63.3\left(\mathrm{CH}_{2}\right), 36.6\left(\mathrm{CH}_{2}\right), 20.3\left(\mathrm{CH}_{3}\right)$. Minor isomer: $\delta=159.3\left(\mathrm{C}_{\mathrm{q}}\right), 149.5(\mathrm{CH}), 139.9$ $\left(\mathrm{C}_{\mathrm{q}}\right), 137.9\left(\mathrm{C}_{\mathrm{q}}\right), 136.2(\mathrm{CH}), 136.1\left(\mathrm{C}_{\mathrm{q}}\right), 130.8(\mathrm{CH}), 128.8(\mathrm{CH}), 128.2(\mathrm{CH}), 128.0(\mathrm{CH}), 126.5(\mathrm{CH})$, $124.8(\mathrm{CH}), 121.8(\mathrm{CH}), 58.0\left(\mathrm{CH}_{2}\right), 31.7\left(\mathrm{CH}_{2}\right), 20.3\left(\mathrm{CH}_{3}\right)$. IR (ATR) $v=3306,2917,1720,1585,1459$, 1424, 970, $751 \mathrm{~cm}^{-1} . \mathrm{MS}$ (ESI) m/z (relative intensity): $501(50)[2 \mathrm{M}+\mathrm{Na}]^{+}, 262(45)[\mathrm{M}+\mathrm{Na}]^{+}, 240$ (100) $[\mathrm{M}+\mathrm{H}]^{+}, 222$ (30). HR-MS (ESI) m/z calcd for $\mathrm{C}_{16} \mathrm{H}_{18} \mathrm{NO}[\mathrm{M}+\mathrm{H}]^{+}:$240.1383, found: 240.1383.<smiles>COc1cccc(C/C=C/CO)c1-c1ccccn1</smiles>

4-[3-Methoxy-2-(pyridin-2-yl)phenyl]but-2-en-1-ol (111ia): The general procedure $\mathbf{H}$ was followed using 2-[3-methoxy-2-(pyridin-2-yl)phenyl]propan-2-ol (168i) $\quad(60.8 \mathrm{mg}, \quad 0.25 \mathrm{mmol})$ and 4-vinyl-1,3-dioxolan-2-one (110a) $(48.0 \mu \mathrm{L}, 0.50 \mathrm{mmol})$. Purification by column chromatography on silica gel (Hexane/EtOAc/Et ${ }_{3} \mathrm{~N}: 3 / 1 / 0.3$ ) yielded 111 ia $\left(37.0 \mathrm{mg}, 58 \%, E / Z=4.1 / 1.0\right.$ by ${ }^{1} \mathrm{H} \mathrm{NMR}$ ) as a colorless oil.

${ }^{1} \mathbf{H}$ NMR $\left(300 \mathrm{MHz}, \mathrm{CDCl}_{3}\right) \delta=8.72-8.58(\mathrm{~m}, 1 \mathrm{H}), 7.76-7.62(\mathrm{~m}, 1 \mathrm{H}), 7.44-7.12(\mathrm{~m}, 3 \mathrm{H}), 6.97-6.74$ $(\mathrm{m}, 2 \mathrm{H}), 5.53(\mathrm{dtt}, J=15.2,6.8,1.5 \mathrm{~Hz}, 0.82 \mathrm{H}), 5.50-5.45(\mathrm{~m}, 0.36 \mathrm{H}), 5.29(\mathrm{dtt}, J=15.2,5.8,1.3 \mathrm{~Hz}$, $0.82 \mathrm{H}), 3.88(\mathrm{dq}, J=5.9,1.1 \mathrm{~Hz}, 1.62 \mathrm{H}), 3.84(\mathrm{dq}, J=5.9,1.1 \mathrm{~Hz}, 0.38 \mathrm{H}), 3.67(\mathrm{~s}, 3 \mathrm{H}), 3.16(\mathrm{~d}, J=6.2$ $\mathrm{Hz}, 0.38 \mathrm{H}), 3.12(\mathrm{~d}, J=6.2 \mathrm{~Hz}, 1.62 \mathrm{H}), 2.38$ (brs, $1 \mathrm{H}) .{ }^{13} \mathrm{C} \mathrm{NMR}\left(125 \mathrm{MHz}, \mathrm{CDCl}_{3}\right)$ Major isomer: $\delta=$ $156.9\left(\mathrm{C}_{\mathrm{q}}\right), 156.5\left(\mathrm{C}_{\mathrm{q}}\right), 149.0(\mathrm{CH}), 139.7\left(\mathrm{C}_{\mathrm{q}}\right), 135.6(\mathrm{CH}), 130.7(\mathrm{CH}), 130.0(\mathrm{CH}), 129.5\left(\mathrm{C}_{\mathrm{q}}\right), 129.1$ (CH), $125.8(\mathrm{CH}), 121.8(\mathrm{CH}), 121.7(\mathrm{CH}), 108.9(\mathrm{CH}), 63.2\left(\mathrm{CH}_{2}\right), 55.8\left(\mathrm{CH}_{3}\right), 36.1\left(\mathrm{CH}_{2}\right)$. Minor isomer: $\delta=156.9\left(\mathrm{C}_{\mathrm{q}}\right), 156.5\left(\mathrm{C}_{\mathrm{q}}\right), 149.1(\mathrm{CH}), 140.0\left(\mathrm{C}_{\mathrm{q}}\right), 135.8(\mathrm{CH}), 130.5(\mathrm{CH}), 129.5\left(\mathrm{C}_{\mathrm{q}}\right), 129.2(\mathrm{CH})$, 129.0 (CH), $126.0(\mathrm{CH}), 121.7(\mathrm{CH}), 121.5(\mathrm{CH}), 108.9(\mathrm{CH}), 63.2\left(\mathrm{CH}_{2}\right), 57.8\left(\mathrm{CH}_{3}\right), 31.2\left(\mathrm{CH}_{2}\right)$. IR (ATR) 
$v=3306,2835,1579,1466,1255,1061,971,780,745 \mathrm{~cm}^{-1}$. MS (ESI) m/z (relative intensity): 533 (40) $[2 \mathrm{M}+\mathrm{Na}]^{+}, 278(30)[\mathrm{M}+\mathrm{Na}]^{+}, 272(40), 256(100)[\mathrm{M}+\mathrm{H}]^{+}$. HR-MS (ESI) m/z calcd for $\mathrm{C}_{16} \mathrm{H}_{18} \mathrm{NO}_{2}$ $[\mathrm{M}+\mathrm{H}]^{+}: 256.1332$, found: 256.1334 .

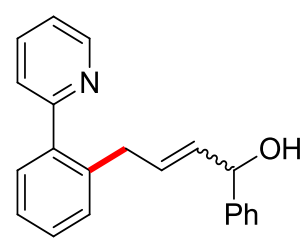

1-Phenyl-4-[2-(pyridin-2-yl)phenyl]but-2-en-1-ol (111jb): The general procedure $\mathbf{H}$ was followed using phenyl [2-(pyridin-2-yl)phenyl]methanol $\quad(\mathbf{1 6 8 j}) \quad(65.3 \quad \mathrm{mg}, \quad 0.25 \mathrm{mmol})$ and (trans)-4-phenyl-5-vinyl-1,3-dioxolan-2-one (110b) $(95.1 \mathrm{mg}, 0.50 \mathrm{mmol})$. Purification by column chromatography on silica gel ( $n$-hexane/EtOAc: $3 / 1$ ) yielded $111 \mathrm{jb}(56.7 \mathrm{mg}, 75 \%, E / Z=1.5 / 1.0$ by ${ }^{1} \mathrm{H}$ NMR) as a colorless oil.

${ }^{1} \mathrm{H}$ NMR $\left(400 \mathrm{MHz}, \mathrm{CDCl}_{3}\right) \delta=8.67$ (ddd, $\left.J=4.9,1.9,1.0 \mathrm{~Hz}, 0.4 \mathrm{H}\right), 8.61$ (ddd, $J=4.9,1.9,1.0 \mathrm{~Hz}$, $0.6 \mathrm{H}), 7.73(\mathrm{td}, J=7.7,1.8 \mathrm{~Hz}, 0.4 \mathrm{H}), 7.62(\mathrm{td}, J=7.7,1.8 \mathrm{~Hz}, 0.6 \mathrm{H}), 7.44-7.13(\mathrm{~m}, 11 \mathrm{H}), 5.73(\mathrm{dtd}, J$ $=15.2,6.6,1.1 \mathrm{~Hz}, 0.6 \mathrm{H}), 5.67-5.56(\mathrm{~m}, 0.8 \mathrm{H}), 5.40$ (ddt, $J=15.2,7.0,1.5 \mathrm{~Hz}, 1 \mathrm{H}), 5.01(\mathrm{~d}, J=6.9 \mathrm{~Hz}$, 0.6H), 3.85-3.73 (m, 0.4H), 3.57-3.44 (m, 1.6H), 2.45 (brs, 1H). ${ }^{13} \mathrm{C}$ NMR (100 MHz, $\left.\mathrm{CDCl}_{3}\right)$ Major isomer: $\delta=159.6\left(\mathrm{C}_{\mathrm{q}}\right), 148.9(\mathrm{CH}), 143.1\left(\mathrm{C}_{\mathrm{q}}\right), 140.3\left(\mathrm{C}_{\mathrm{q}}\right), 137.6\left(\mathrm{C}_{\mathrm{q}}\right), 136.2(\mathrm{CH}), 133.5(\mathrm{CH}), 130.8$ (CH), $130.1(\mathrm{CH}), 129.8(\mathrm{CH}), 128.5(\mathrm{CH}), 128.3(\mathrm{CH}), 127.3(\mathrm{CH}), 126.4(\mathrm{CH}), 126.1(\mathrm{CH}), 124.1(\mathrm{CH})$, $121.7(\mathrm{CH}), 74.7(\mathrm{CH}), 36.0\left(\mathrm{CH}_{2}\right)$. Minor isomer: $\delta=159.9\left(\mathrm{C}_{\mathrm{q}}\right), 148.9(\mathrm{CH}), 143.5\left(\mathrm{C}_{\mathrm{q}}\right), 140.0\left(\mathrm{C}_{\mathrm{q}}\right)$, $138.1\left(\mathrm{C}_{\mathrm{q}}\right), 136.6(\mathrm{CH}), 132.7(\mathrm{CH}), 130.4(\mathrm{CH}), 130.0(\mathrm{CH}), 129.8(\mathrm{CH}), 128.7(\mathrm{CH}), 128.4(\mathrm{CH}), 127.2$ (CH), $126.3(\mathrm{CH}), 125.9(\mathrm{CH}), 124.4(\mathrm{CH}), 121.9(\mathrm{CH}), 69.0(\mathrm{CH}), 31.4\left(\mathrm{CH}_{2}\right)$. IR (ATR) $v=3311,3024$, 1586, 1468, 1443, 1023, 969, 750, $699 \mathrm{~cm}^{-1}$. MS (ESI) m/z (relative intensity): 625 (30) [2M+Na], 324 (20) $[\mathrm{M}+\mathrm{Na}]^{+}, 318$ (40), $302(45)[\mathrm{M}+\mathrm{H}]^{+}, 300$ (70), 284 (100). HR-MS (ESI) m/z calcd for $\mathrm{C}_{21} \mathrm{H}_{20} \mathrm{NO}[\mathrm{M}+\mathrm{H}]^{+}: 302.1539$, found: 302.1540 . 
<smiles>Cc1ccc(/C=C/c2ccccc2)c(-n2cccn2)c1</smiles>

(E)-1-(5-Methyl-2-styrylphenyl)-1H-pyrazole (74co): The general procedure I was followed using phenyl 2-[4-methyl-2-(1H-pyrazol-1-yl)phenyl]propan-2-ol (168c) (54.1 mg, $0.25 \mathrm{mmol})$ and ethynylbenzene $(80)(51.1 \mathrm{mg}, 0.50 \mathrm{mmol})$. Purification by column chromatography on silica gel ( $n$-hexane/EtOAc: $20 / 1)$ yielded 74 co $(45.0 \mathrm{mg}, 69 \%)$ as a colorless oil.

${ }^{1} \mathbf{H}$ NMR $\left(300 \mathrm{MHz}, \mathrm{CDCl}_{3}\right) \delta=7.76(\mathrm{~d}, J=1.8 \mathrm{~Hz}, 1 \mathrm{H}), 7.67-7.58(\mathrm{~m}, 2 \mathrm{H}), 7.47-7.34(\mathrm{~m}, 2 \mathrm{H}), 7.34-$ $7.13(\mathrm{~m}, 5 \mathrm{H}), 7.00(\mathrm{~d}, J=16.3 \mathrm{~Hz}, 1 \mathrm{H}), 6.90(\mathrm{~d}, J=16.3 \mathrm{~Hz}, 1 \mathrm{H}), 6.45$ (d, J=2.1 Hz, 1H), $2.39(\mathrm{~s}, 3 \mathrm{H})$. ${ }^{13} \mathrm{C}$ NMR $\left(125 \mathrm{MHz}, \mathrm{CDCl}_{3}\right) \delta=140.5(\mathrm{CH}), 138.5\left(\mathrm{C}_{\mathrm{q}}\right), 138.3\left(\mathrm{C}_{\mathrm{q}}\right), 137.1\left(\mathrm{C}_{\mathrm{q}}\right), 131.4(\mathrm{CH}), 130.3\left(\mathrm{C}_{\mathrm{q}}\right)$, $129.9(\mathrm{CH}), 129.1(\mathrm{CH}), 128.5(\mathrm{CH}), 127.6(\mathrm{CH}), 126.8(\mathrm{CH}), 126.5(\mathrm{CH}), 126.3(\mathrm{CH}), 123.8(\mathrm{CH}), 106.4$ (CH), $21.1\left(\mathrm{CH}_{3}\right)$. IR (ATR) $v=3024,1515,1449,1391,1097,1042,951,813,753,691 \mathrm{~cm}^{-1}$. MS (ESI) $\mathrm{m} / \mathrm{z}$ (relative intensity): $283(70)[\mathrm{M}+\mathrm{Na}]^{+}, 261(100)[\mathrm{M}+\mathrm{H}]^{+}$. HR-MS (ESI) m/z calcd for $\mathrm{C}_{18} \mathrm{H}_{17} \mathrm{~N}_{2}$ $[\mathrm{M}+\mathrm{H}]^{+}:$261.1386, found: 261.1385 .

The analytical data were in accordance with those reported in the literature. ${ }^{[202]}$<smiles>COc1ccc(/C=C/c2ccc(C)cc2-n2cccn2)cc1</smiles>

(E)-1-[2-(4-Methoxystyryl)-5-methylphenyl]-1H-pyrazole (74cq): The general procedure I was followed using phenyl2-[4-methyl-2-(1H-pyrazol-1-yl)phenyl]propan-2-ol (168c) (54.1 mg, 0.25 $\mathrm{mmol}$ ) and 1-ethynyl-4-methoxybenzene $(\mathbf{8 q})(66.1 \mathrm{mg}, 0.50 \mathrm{mmol})$. Purification by column chromatography on silica gel ( $n$-hexane/EtOAc: $10 / 1)$ yielded $\mathbf{7 4 c q}(43.0 \mathrm{mg}, 59 \%)$ as a white solid. M.p. $=70-72{ }^{\circ} \mathrm{C}^{1}{ }^{1} \mathrm{H}$ NMR $\left(300 \mathrm{MHz} \mathrm{CDCl}_{3}\right) \delta=7.75(\mathrm{~d}, J=1.8 \mathrm{~Hz}, 1 \mathrm{H}), 7.66-7.57(\mathrm{~m}, 2 \mathrm{H}), 7.35-7.27$ $(\mathrm{m}, 2 \mathrm{H}), 7.26-7.14(\mathrm{~m}, 2 \mathrm{H}), 6.94(\mathrm{~d}, J=16.3 \mathrm{~Hz}, 1 \mathrm{H}), 6.88-6.80(\mathrm{~m}, 2 \mathrm{H}), 6.75(\mathrm{~d}, J=16.3 \mathrm{~Hz}, 1 \mathrm{H})$, $6.44(\mathrm{dd}, J=2.4,1.8 \mathrm{~Hz}, 1 \mathrm{H}), 3.79(\mathrm{~s}, 3 \mathrm{H}), 2.38(\mathrm{~s}, 3 \mathrm{H}) .{ }^{13} \mathrm{C} \mathrm{NMR}\left(125 \mathrm{MHz}, \mathrm{CDCl}_{3}\right) \delta=159.3\left(\mathrm{C}_{\mathrm{q}}\right)$, $140.4(\mathrm{CH}), 138.3\left(\mathrm{C}_{\mathrm{q}}\right), 137.9\left(\mathrm{C}_{\mathrm{q}}\right), 131.4(\mathrm{CH}), 130.3\left(\mathrm{C}_{\mathrm{q}}\right), 130.0\left(\mathrm{C}_{\mathrm{q}}\right), 129.8(\mathrm{CH}), 129.1(\mathrm{CH}), 127.7$ (CH), $126.7(\mathrm{CH}), 126.1(\mathrm{CH}), 121.6(\mathrm{CH}), 114.0(\mathrm{CH}), 106.3(\mathrm{CH}), 55.3\left(\mathrm{CH}_{3}\right), 21.0\left(\mathrm{CH}_{3}\right)$. IR $(\mathrm{ATR}) v=$ 2916, 1603, 1511, 1457, 1248, 1174, 1033, 951, 826, $754 \mathrm{~cm}^{-1}$. MS (ESI) m/z (relative intensity): 313 
(100) $[\mathrm{M}+\mathrm{Na}]^{+}, 291(50)[\mathrm{M}+\mathrm{H}]^{+}$. HR-MS (ESI) m/z calcd for $\mathrm{C}_{19} \mathrm{H}_{19} \mathrm{~N}_{2} \mathrm{O}[\mathrm{M}+\mathrm{H}]^{+}:$: 291.1492, found: 291.1491.<smiles>COc1ccc(/C=C/c2ccc(Br)cc2)c(-n2cccn2)c1</smiles>

(E)-1-[2-(4-Bromostyryl)-5-methylphenyl]-1H-pyrazole (74cr): The general procedure I was followed using 2-[4-methyl-2-(1H-pyrazol-1-yl)phenyl]propan-2-ol (168c) (54.1 mg, $0.25 \mathrm{mmol})$ and 1-bromo-4-ethynylbenzene (8r) $(90.5 \mathrm{mg}, 0.50 \mathrm{mmol})$. Purification by column chromatography on silica gel ( $n$-hexane/EtOAc: $20 / 1)$ yielded $74 \mathrm{cr}(61.1 \mathrm{mg}, 72 \%)$ as a colorless oil.

${ }^{1} \mathbf{H}$ NMR $\left(300 \mathrm{MHz}^{\mathrm{CDCl}}{ }_{3}\right) \delta=7.76(\mathrm{~s}, 1 \mathrm{H}), 7.67-7.54(\mathrm{~m}, 2 \mathrm{H}), 7.45-7.37(\mathrm{~m}, 2 \mathrm{H}), 7.27-7.18(\mathrm{~m}, 4 \mathrm{H})$, $6.92(\mathrm{~d}, J=16.3 \mathrm{~Hz}, 1 \mathrm{H}), 6.86(\mathrm{~d}, J=16.3 \mathrm{~Hz}, 1 \mathrm{H}), 6.45(\mathrm{~d}, J=2.1 \mathrm{~Hz}, 1 \mathrm{H}), 2.39(\mathrm{~s}, 3 \mathrm{H}) .{ }^{13} \mathrm{C}$ NMR $(125$ $\left.\mathrm{MHz}, \mathrm{CDCl}_{3}\right) \delta=140.6\left(\mathrm{C}_{\mathrm{q}}\right), 138.6\left(\mathrm{C}_{\mathrm{q}}\right), 138.5\left(\mathrm{C}_{\mathrm{q}}\right), 136.0(\mathrm{CH}), 131.6(\mathrm{CH}), 131.3(\mathrm{CH}), 129.6\left(\mathrm{C}_{\mathrm{q}}\right)$, $129.1(\mathrm{CH}), 128.8(\mathrm{CH}), 127.9(\mathrm{CH}), 126.8(\mathrm{CH}), 126.2(\mathrm{CH}), 124.5(\mathrm{CH}), 121.3\left(\mathrm{C}_{\mathrm{q}}\right), 106.5(\mathrm{CH}), 21.0$ $\left(\mathrm{CH}_{3}\right)$. IR (ATR) $v=3026,2918,1613,1515,1485,1390,1191,1071,950,750 \mathrm{~cm}^{-1}$. MS (ESI) m/z (relative intensity): $363(30)[\mathrm{M}+\mathrm{Na}]^{+}\left({ }^{81} \mathrm{Br}\right), 361(30)[\mathrm{M}+\mathrm{Na}]^{+}\left({ }^{79} \mathrm{Br}\right), 341(100)[\mathrm{M}+\mathrm{H}]^{+}\left({ }^{81} \mathrm{Br}\right), 339$ (100) $[\mathrm{M}+\mathrm{H}]^{+}\left({ }^{79} \mathrm{Br}\right)$. HR-MS (ESI) $\mathrm{m} / \mathrm{z}$ calcd for $\mathrm{C}_{18} \mathrm{H}_{16} \mathrm{~N}_{2}{ }^{81} \mathrm{Br}[\mathrm{M}+\mathrm{H}]^{+}$: 341.0472, found: 341.0474, $\mathrm{C}_{18} \mathrm{H}_{16} \mathrm{~N}_{2}{ }^{79} \mathrm{Br}[\mathrm{M}+\mathrm{H}]^{+}:$339.0491, found: 339.0491 .<smiles>Cc1ccc(/C=C/c2ccccc2F)c(-n2cccn2)c1</smiles>

(E)-1-[2-(2-Fluorostyryl)-5-methylphenyl]-1H-pyrazole (74cs): The general procedure I was followed using 2-[4-methyl-2-(1H-pyrazol-1-yl)phenyl]propan-2-ol $(168 \mathrm{c}) \quad(54.1 \mathrm{mg}, \quad 0.25 \mathrm{mmol})$ and 1-ethynyl-2-fluorobenzene $(8 \mathrm{~s})(60.1 \mathrm{mg}, 0.50 \mathrm{mmol})$. Purification by column chromatography on silica gel ( $n$-hexane/EtOAc: 20/1) yielded 74cs (60.5 mg, 87\%) as a colorless oil.

${ }^{1} \mathrm{H}$ NMR $\left(400 \mathrm{MHz} \mathrm{CDCl}_{3}\right) \delta=7.68(\mathrm{~s}, 1 \mathrm{H}), 7.63-7.53(\mathrm{~m}, 2 \mathrm{H}), 7.33(\mathrm{td}, J=7.7,1.7 \mathrm{~Hz}, 1 \mathrm{H}), 7.22-7.07$ $(\mathrm{m}, 4 \mathrm{H}), 7.01-6.87(\mathrm{~m}, 3 \mathrm{H}), 6.38(\mathrm{~s}, 1 \mathrm{H}), 2.32(\mathrm{~s}, 3 \mathrm{H}) .{ }^{13} \mathrm{C} \mathrm{NMR}\left(100 \mathrm{MHz}, \mathrm{CDCl}_{3}\right) \delta=160.3\left(\mathrm{~d},{ }^{1} \mathrm{~J}_{\mathrm{C}-\mathrm{F}}=\right.$ $\left.251.3 \mathrm{~Hz}, \mathrm{C}_{\mathrm{q}}\right), 138.8\left(\mathrm{C}_{\mathrm{q}}\right), 138.7\left(\mathrm{C}_{\mathrm{q}}\right), 129.8\left(\mathrm{C}_{\mathrm{q}}\right), 125.1\left(\mathrm{~d},{ }^{2} \mathrm{~J}_{\mathrm{C}-\mathrm{F}}=12.0 \mathrm{~Hz}, \mathrm{C}_{\mathrm{q}}\right), 129.2(\mathrm{CH}), 129.2(\mathrm{CH})$, 
$128.9\left(\mathrm{~d},{ }^{3} J_{\mathrm{C}-\mathrm{F}}=8.4 \mathrm{~Hz}, \mathrm{CH}\right), 126.9\left(\mathrm{~d},{ }^{4} \mathrm{~J}_{\mathrm{C}-\mathrm{F}}=3.6 \mathrm{~Hz}, \mathrm{CH}\right), 126.7(\mathrm{CH}), 126.4(\mathrm{CH}), 126.4(\mathrm{CH}), 125.9(\mathrm{~d}$, $\left.{ }^{3} J_{C-F}=4.8 \mathrm{~Hz}, \mathrm{CH}\right), 124.1\left(\mathrm{~d},{ }^{4} J_{\mathrm{C}-\mathrm{F}}=3.7 \mathrm{~Hz}, \mathrm{CH}\right), 122.2\left(\mathrm{~d},{ }^{3} J_{\mathrm{C}-\mathrm{F}}=3.8 \mathrm{~Hz}, \mathrm{CH}\right), 115.6\left(\mathrm{~d},{ }^{2} \mathrm{~J}_{\mathrm{C}-\mathrm{F}}=22.2 \mathrm{~Hz}\right.$, $\mathrm{CH}), 106.5(\mathrm{CH}), 20.9\left(\mathrm{CH}_{3}\right) .{ }^{19} \mathrm{~F}$ NMR (282 MHz, $\left.\mathrm{CDCl}_{3}\right) \delta=-118.13$ (ddd, $J=10.8,7.7,5.3 \mathrm{~Hz}$ ). IR (ATR) $v=3065,1615,1516,1455,1230,1095,1038,950,751 \mathrm{~cm}^{-1}$. MS (ESI) m/z (relative intensity): 301 (30) $[\mathrm{M}+\mathrm{Na}]^{+}, 279$ (100) $[\mathrm{M}+\mathrm{H}]^{+}$. HR-MS (ESI) m/z calcd for $\mathrm{C}_{18} \mathrm{H}_{16} \mathrm{~N}_{2} \mathrm{~F}[\mathrm{M}+\mathrm{H}]^{+}:$279.1292, found: 279.1293.<smiles>COc1ccc(/C=C/c2ccsc2)c(-n2cccn2)c1</smiles>

(E)-1-\{5-Methyl-2-[2-(thiophen-3-yl)vinyl]phenyl\}-1H-pyrazole (74ct): The general procedure I was followed using 2-[4-methyl-2-(1H-pyrazol-1-yl)phenyl]propan-2-ol (168c) (54.1 mg, $0.25 \mathrm{mmol})$ and 3-ethynylthiophene $(\mathbf{8 t})(54.1 \mathrm{mg}, 0.50 \mathrm{mmol})$. Purification by column chromatography on silica gel ( $n$-hexane/EtOAc: $20 / 1)$ yielded $74 c t(40.2 \mathrm{mg}, 60 \%)$ as a colorless oil.

${ }^{1} \mathrm{H}$ NMR $\left(300 \mathrm{MHz}, \mathrm{CDCl}_{3}\right) \delta=7.75(\mathrm{~s}, 1 \mathrm{H}), 7.63(\mathrm{~d}, J=2.3 \mathrm{~Hz}, 1 \mathrm{H}), 7.60(\mathrm{~d}, J=8.0 \mathrm{~Hz}, 1 \mathrm{H}), 7.28-7.17$ (m, 4H), 7.14 (dd, $J=5.0,1.3 \mathrm{~Hz}, 1 \mathrm{H}), 7.00(\mathrm{~d}, J=16.2 \mathrm{~Hz}, 1 \mathrm{H}), 6.73(\mathrm{~d}, J=16.2 \mathrm{~Hz}, 1 \mathrm{H}), 6.44(\mathrm{~d}, J=$ 2.3, $1.8 \mathrm{~Hz}, 1 \mathrm{H}), 2.38(\mathrm{~s}, 3 \mathrm{H}) .{ }^{13} \mathrm{C}$ NMR $\left(125 \mathrm{MHz}, \mathrm{CDCl}_{3}\right) \delta=140.6(\mathrm{CH}), 140.1\left(\mathrm{C}_{\mathrm{q}}\right), 138.5\left(\mathrm{C}_{\mathrm{q}}\right), 138.3$ $\left(\mathrm{C}_{\mathrm{q}}\right), 131.5(\mathrm{CH}), 130.1\left(\mathrm{C}_{\mathrm{q}}\right), 129.3(\mathrm{CH}), 126.9(\mathrm{CH}), 126.2(\mathrm{CH}), 126.1(\mathrm{CH}), 125.0(\mathrm{CH}), 124.5(\mathrm{CH})$, $123.9(\mathrm{CH}), 122.7(\mathrm{CH}), 106.5(\mathrm{CH}), 21.2\left(\mathrm{CH}_{3}\right)$. IR (ATR) $v=3104,2918,1677,1517,1401,1044,951$, 755, $623 \mathrm{~cm}^{-1}$. MS (ESI) m/z (relative intensity): 289 (20) [M+Na] $]^{+}, 267$ (100) [M+H] $]^{+}$HR-MS (ESI) $\mathrm{m} / \mathrm{z}$ calcd for $\mathrm{C}_{16} \mathrm{H}_{15} \mathrm{~N}_{2} \mathrm{~S}[\mathrm{M}+\mathrm{H}]^{+}:$267.0950, found: 267.0949 .<smiles>CCOC=Cc1ccc(C)cc1-n1cccn1</smiles>

(E)-1-[2-(dec-1-En-1-yl)-5-methylphenyl]-1H-pyrazole (74cu): The general procedure I was followed using 2-[4-methyl-2-(1H-pyrazol-1-yl)phenyl]propan-2-ol (168c) (54.1 mg, 0.25 mmol) and dec-1-yne (8u) $(69.1 \mathrm{mg}, 0.50 \mathrm{mmol})$. Purification by column chromatography on silica gel ( $n$-hexane/EtOAc: $20 / 1$ ) yielded $\mathbf{7 4 c u}(39.5 \mathrm{mg}, 56 \%)$ as a colorless oil. 
${ }^{1} \mathrm{H}$ NMR $\left(400 \mathrm{MHz}, \mathrm{CDCl}_{3}\right) \delta=7.65(\mathrm{~d}, J=2.2 \mathrm{~Hz}, 1 \mathrm{H}), 7.53(\mathrm{~d}, J=2.2 \mathrm{~Hz}, 1 \mathrm{H}), 7.40(\mathrm{~d}, J=8.0 \mathrm{~Hz}, 1 \mathrm{H})$, $7.14(\mathrm{~s}, 1 \mathrm{H}), 7.08(\mathrm{~d}, J=8.0 \mathrm{~Hz}, 1 \mathrm{H}), 6.36(\mathrm{t}, J=2.1 \mathrm{~Hz}, 1 \mathrm{H}), 6.09(\mathrm{~d}, J=15.7 \mathrm{~Hz}, 1 \mathrm{H}), 6.08-6.03(\mathrm{~m}$, 1H), $2.29(\mathrm{~s}, 3 \mathrm{H}), 2.05(\mathrm{td}, J=7.3,5.4 \mathrm{~Hz}, 2 \mathrm{H}), 1.51(\mathrm{~s}, 1 \mathrm{H}), 1.33(\mathrm{t}, J=7.3 \mathrm{~Hz}, 2 \mathrm{H}), 1.28-1.07(\mathrm{~m}, 9 \mathrm{H})$, $0.80(\mathrm{~d}, J=7.1 \mathrm{~Hz}, 3 \mathrm{H}) .{ }^{13} \mathrm{C}$ NMR $\left(100 \mathrm{MHz}, \mathrm{CDCl}_{3}\right) \delta=140.3(\mathrm{CH}), 137.8\left(\mathrm{C}_{\mathrm{q}}\right), 137.4\left(\mathrm{C}_{\mathrm{q}}\right), 133.2(\mathrm{CH})$, $131.3(\mathrm{CH}), 130.5\left(\mathrm{C}_{\mathrm{q}}\right), 129.0(\mathrm{CH}), 126.7(\mathrm{CH}), 126.5(\mathrm{CH}), 124.8(\mathrm{CH}), 106.1(\mathrm{CH}), 33.1\left(\mathrm{CH}_{2}\right), 31.8$ $\left(\mathrm{CH}_{2}\right)$, $29.4\left(\mathrm{CH}_{2}\right), 29.2\left(\mathrm{CH}_{2}\right), 29.2\left(\mathrm{CH}_{2}\right), 29.1\left(\mathrm{CH}_{2}\right), 22.6\left(\mathrm{CH}_{2}\right), 20.8\left(\mathrm{CH}_{3}\right), 14.0\left(\mathrm{CH}_{3}\right)$. IR (ATR) $v=$ 2923, 2853, 1517, 1457, 1042, 950, 748, $624 \mathrm{~cm}^{-1}$. MS (ESI) m/z (relative intensity): 319 (20) $[\mathrm{M}+\mathrm{Na}]^{+}, 297(100)[\mathrm{M}+\mathrm{H}]^{+}$. HR-MS (ESI) m/z calcd for $\mathrm{C}_{20} \mathrm{H}_{29} \mathrm{~N}_{2}[\mathrm{M}+\mathrm{H}]^{+}:$: 297.2325, found: 297.2328.

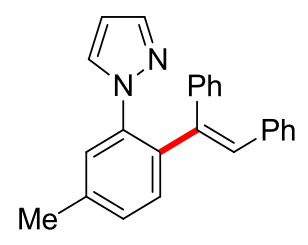

(E)-1-[2-(1,2-Diphenylvinyl)-5-methylphenyl]-1H-pyrazole (74ca): The general procedure I was followed using 2-[4-methyl-2-(1H-pyrazol-1-yl)phenyl]propan-2-ol (168c) (54.1 mg, $0.25 \mathrm{mmol})$ and 1,2-diphenylethyne $(8 \mathrm{a})(89.1 \mathrm{mg}, 0.50 \mathrm{mmol})$. Purification by column chromatography on silica gel ( $n$-hexane/EtOAc: $20 / 1)$ yielded $\mathbf{7 4 c a ~}(60.6 \mathrm{mg}, 72 \%)$ as a colorless oil.

${ }^{1} \mathrm{H}$ NMR $\left(600 \mathrm{MHz}, \mathrm{CDCl}_{3}\right) \delta=7.40(\mathrm{~d}, J=2.4 \mathrm{~Hz}, 1 \mathrm{H}), 7.34(\mathrm{~d}, J=1.8 \mathrm{~Hz}, 1 \mathrm{H}), 7.25(\mathrm{~d}, J=7.8 \mathrm{~Hz}, 1 \mathrm{H})$, $7.19(\mathrm{~d}, J=1.3 \mathrm{~Hz}, 1 \mathrm{H}), 7.12(\mathrm{dd}, J=7.7,1.8, \mathrm{~Hz}, 1 \mathrm{H}), 7.04-6.91(\mathrm{~m}, 8 \mathrm{H}), 6.89-6.84(\mathrm{~m}, 2 \mathrm{H}), 6.54(\mathrm{~s}$, $1 \mathrm{H}), 6.02(\mathrm{dd}, J=2.4,1.8 \mathrm{~Hz}, 1 \mathrm{H}), 2.32(\mathrm{~s}, 3 \mathrm{H}) .{ }^{13} \mathrm{C} \mathrm{NMR}\left(125 \mathrm{MHz}, \mathrm{CDCl}_{3}\right) \delta=140.0(\mathrm{CH}), 139.9\left(\mathrm{C}_{\mathrm{q}}\right)$, $139.2\left(\mathrm{C}_{\mathrm{q}}\right), 139.0\left(\mathrm{C}_{\mathrm{q}}\right), 138.6\left(\mathrm{C}_{\mathrm{q}}\right), 137.2\left(\mathrm{C}_{\mathrm{q}}\right), 137.0\left(\mathrm{C}_{\mathrm{q}}\right), 131.5(\mathrm{CH}), 130.8(\mathrm{CH}), 130.6(\mathrm{CH}), 129.6$ (CH), $129.3(\mathrm{CH}), 128.8(\mathrm{CH}), 127.9(\mathrm{CH}), 127.8(\mathrm{CH}), 127.2(\mathrm{CH}), 127.1(\mathrm{CH}), 126.8(\mathrm{CH}), 106.2(\mathrm{CH})$, $21.1\left(\mathrm{CH}_{3}\right)$. IR (ATR) $v=3022,1517,1445,1400,1100,952,826,747,695 \mathrm{~cm}^{-1} . \mathrm{MS}$ (ESI) m/z (relative intensity): $359(10)[\mathrm{M}+\mathrm{Na}]^{+}, 337(100)[\mathrm{M}+\mathrm{H}]^{+}$. HR-MS (ESI) m/z calcd for $\mathrm{C}_{24} \mathrm{H}_{21} \mathrm{~N}_{2}[\mathrm{M}+\mathrm{H}]^{+}$: 337.1699, found: 337.1700 .

The analytical data were in accordance with those reported in the literature. ${ }^{[203]}$ 
<smiles>Cc1ccc(C(=Cc2cccs2)c2cccs2)c(-n2cccn2)c1</smiles>

(Z)-1-\{2-[1,2-Di(thiophen-2-yl)vinyl]-5-methylphenyl\}-1H-pyrazole (74cj): The general procedure I was followed using 2-[4-methyl-2-(1H-pyrazol-1-yl)phenyl]propan-2-ol (168c) $(54.1 \mathrm{mg}, 0.25 \mathrm{mmol})$ and 1,2-di(thiophen-2-yl)ethyne $(8 \mathrm{j})(95.1 \mathrm{mg}, 0.50 \mathrm{mmol})$. Purification by column chromatography on silica gel ( $n$-hexane/EtOAc: $20 / 1$ ) yielded $74 \mathrm{cj}(47.1 \mathrm{mg}, 54 \%)$ as a colorless oil.

${ }^{1} \mathbf{H}$ NMR $\left(400 \mathrm{MHz}, \mathrm{CDCl}_{3}\right) \delta=7.60(\mathrm{~d}, J=1.8 \mathrm{~Hz}, 1 \mathrm{H}), 7.56(\mathrm{dd}, J=2.4 \mathrm{~Hz}, 1 \mathrm{H}), 7.33(\mathrm{~d}, J=7.9 \mathrm{~Hz}$, 1H), 7.31-7.27 (m, 2H), 7.20 (dd, $J=7.9,1.8 \mathrm{~Hz}, 1 \mathrm{H}), 7.11$ (dd, $J=5.0,1.2 \mathrm{~Hz}, 1 \mathrm{H}), 6.92-6.86(\mathrm{~m}, 3 \mathrm{H})$, $6.83(\mathrm{dd}, J=3.5,1.2 \mathrm{~Hz}, 1 \mathrm{H}), 6.68(\mathrm{~s}, 1 \mathrm{H}), 6.26(\mathrm{dd}, J=2.4,1.8 \mathrm{~Hz}, 1 \mathrm{H}), 2.40(\mathrm{~s}, 3 \mathrm{H}) .{ }^{13} \mathrm{C}$ NMR $(100$ $\left.\mathrm{MHz}, \mathrm{CDCl}_{3}\right) \delta=140.4\left(\mathrm{C}_{\mathrm{q}}\right), 140.1\left(\mathrm{C}_{\mathrm{q}}\right), 140.0(\mathrm{CH}), 139.0\left(\mathrm{C}_{\mathrm{q}}\right), 138.7\left(\mathrm{C}_{\mathrm{q}}\right), 135.9\left(\mathrm{C}_{\mathrm{q}}\right), 131.0(\mathrm{CH})$, 130.7 (CH), $130.3\left(\mathrm{C}_{\mathrm{q}}\right), 129.7(\mathrm{CH}), 129.0(\mathrm{CH}), 128.6(\mathrm{CH}), 127.5(\mathrm{CH}), 127.0(\mathrm{CH}), 126.6(\mathrm{CH}), 126.5$ (CH), $126.4(\mathrm{CH}), 121.5(\mathrm{CH}), 106.7(\mathrm{CH}), 21.1\left(\mathrm{CH}_{3}\right)$. IR (ATR) $v=3098,1518,1400,1036,950,841$, 750, $699 \mathrm{~cm}^{-1}$. MS (ESI) m/z (relative intensity): $371(30)[\mathrm{M}+\mathrm{Na}]^{+}, 349(100)[\mathrm{M}+\mathrm{H}]^{+}, 252(10)$. HR-MS (ESI) m/z calcd for $\mathrm{C}_{20} \mathrm{H}_{17} \mathrm{~N}_{2} \mathrm{~S}_{2}[\mathrm{M}+\mathrm{H}]^{+}: 349.0828$, found: 349.0831 .<smiles>C(=Cc1ccccc1-c1ccccn1)c1ccccc1</smiles>

(E)-2-(2-Styrylphenyl)pyridine (74jo): The general procedure I was followed using phenyl 2-[2-(pyridin-2-yl)phenyl]propan-2-ol (168j) (53.3 mg, $0.25 \mathrm{mmol})$ and ethynylbenzene (80) (51.1 $\mathrm{mg}, 0.50 \mathrm{mmol}$ ). Purification by column chromatography on silica gel (DCM: $100 \% \rightarrow$ $n$-hexane/EtOAc: $8 / 1$ ) yielded 74 jo $(46.3 \mathrm{mg}, 72 \%)$ as a colorless oil.

${ }^{1} \mathbf{H}$ NMR $\left(400 \mathrm{MHz}, \mathrm{CDCl}_{3}\right) \delta=8.75(\mathrm{dt}, J=4.1,1.2 \mathrm{~Hz}, 1 \mathrm{H}), 7.91-7.68(\mathrm{~m}, 2 \mathrm{H}), 7.56(\mathrm{dd}, J=7.6,1.6$ $\mathrm{Hz}, 1 \mathrm{H}), 7.50-7.34(\mathrm{~m}, 5 \mathrm{H}), 7.34-7.16(\mathrm{~m}, 5 \mathrm{H}), 7.05(\mathrm{~d}, J=16.2 \mathrm{~Hz}, 1 \mathrm{H}) .{ }^{13} \mathrm{C} \mathbf{N M R}\left(100 \mathrm{MHz} \mathrm{CDCl}_{3}\right) \delta$ $=158.9\left(\mathrm{C}_{\mathrm{q}}\right), 149.5(\mathrm{CH}), 139.6\left(\mathrm{C}_{\mathrm{q}}\right), 137.5\left(\mathrm{C}_{\mathrm{q}}\right), 135.9(\mathrm{CH}), 135.7\left(\mathrm{C}_{\mathrm{q}}\right), 130.2(\mathrm{CH}), 130.0(\mathrm{CH}), 128.6$ $(\mathrm{CH}), 128.6(\mathrm{CH}), 127.6(\mathrm{CH}), 127.5(\mathrm{CH}), 127.5(\mathrm{CH}), 126.5(\mathrm{CH}), 126.2(\mathrm{CH}), 125.0(\mathrm{CH}), 121.8(\mathrm{CH})$. IR (ATR) v = 3056, 1583, 1459, 1424, 1150, 962, 761, 750, $692 \mathrm{~cm}^{-1}$. MS (ESI) m/z (relative intensity): 
$537(20)[2 \mathrm{M}+\mathrm{Na}]^{+}, 515(30)[2 \mathrm{M}+\mathrm{H}]^{+}, 280(30)[\mathrm{M}+\mathrm{Na}]^{+}, 258(100)[\mathrm{M}+\mathrm{H}]^{+}$. HR-MS (ESI) m/z calcd for $\mathrm{C}_{19} \mathrm{H}_{16} \mathrm{~N}[\mathrm{M}+\mathrm{H}]^{+}:$258.1277, found: 258.1277.

The analytical data were in accordance with those reported in the literature. ${ }^{[77]}$<smiles>CC(C)(C)c1ccc(/C=C/c2ccccc2-c2ccccn2)cc1</smiles>

(E)-2-\{2-[4-(tert-Butyl)styryl]phenyl\}pyridine (74jv): The general procedure I was followed using phenyl 2-(2-(pyridin-2-yl)phenyl)propan-2-ol $\quad(\mathbf{1 6 8 j}) \quad(53.3 \quad \mathrm{mg}, \quad 0.25 \quad \mathrm{mmol})$ and 1-(tert-butyl)-4-ethynylbenzene (8v) $(79.2 \mathrm{mg}, 0.50 \mathrm{mmol})$. Purification by column chromatography on silica gel ( $n$-hexane/EtOAc: $10 / 1)$ yielded 74 jv $(62.7 \mathrm{mg}, 80 \%)$ as a colorless oil.

${ }^{1} \mathbf{H}$ NMR $\left(400 \mathrm{MHz}, \mathrm{CDCl}_{3}\right) \delta=8.75(\mathrm{ddd}, J=4.8,1.9,1.0 \mathrm{~Hz}, 1 \mathrm{H}), 7.70(\mathrm{dd}, J=7.7,1.6 \mathrm{~Hz}, 1 \mathrm{H}), 7.75$ $(\mathrm{dd}, J=7.7,1.2 \mathrm{~Hz}, 1 \mathrm{H}), 7.55(\mathrm{dd}, J=7.4,1.6 \mathrm{~Hz}, 1 \mathrm{H}), 7.44(\mathrm{ddd}, J=7.8,1.2,1.0 \mathrm{~Hz}, 1 \mathrm{H}), 7.41(\mathrm{dd}, J=$ 7.6, $1.6 \mathrm{~Hz}, 1 \mathrm{H}), 7.37$ (dd, J = 7.4, 1.6 Hz, 1H), 7.34-7.31 (m, 4H), 7.26 (ddd, J = 7.4, 4.8, 1.2 Hz, 1H), $7.20(\mathrm{~d}, J=16.2 \mathrm{~Hz}, 1 \mathrm{H}), 7.04(\mathrm{~d}, J=16.2 \mathrm{~Hz}, 1 \mathrm{H}), 1.31(\mathrm{~s}, 9 \mathrm{H}) .{ }^{13} \mathrm{C}$ NMR $\left(100 \mathrm{MHz}, \mathrm{CDCl}_{3}\right) \delta=158.9$ $\left(\mathrm{C}_{\mathrm{q}}\right), 150.7\left(\mathrm{C}_{\mathrm{q}}\right), 149.5(\mathrm{CH}), 139.5\left(\mathrm{C}_{\mathrm{q}}\right), 135.9(\mathrm{CH}), 135.9\left(\mathrm{C}_{\mathrm{q}}\right), 135.0\left(\mathrm{C}_{\mathrm{q}}\right), 130.2(\mathrm{CH}), 129.9(\mathrm{CH})$, $128.6(\mathrm{CH}), 127.5(\mathrm{CH}), 126.8(\mathrm{CH}), 126.3(\mathrm{CH}), 126.2(\mathrm{CH}), 125.5(\mathrm{CH}), 125.1(\mathrm{CH}), 121.8(\mathrm{CH}), 34.6$ $\left(\mathrm{C}_{\mathrm{q}}\right), 31.2\left(\mathrm{CH}_{3}\right)$. IR (ATR) $v=2961,1584,1460,1424,1268,965,818,750 \mathrm{~cm}^{-1} . \mathrm{MS}$ (ESI) $\mathrm{m} / \mathrm{z}$ (relative intensity): $336(10)[\mathrm{M}+\mathrm{Na}]^{+}, 314(100)[\mathrm{M}+\mathrm{H}]^{+}$. HR-MS (ESI) m/z calcd for $\mathrm{C}_{23} \mathrm{H}_{24} \mathrm{~N}[\mathrm{M}+\mathrm{H}]^{+}: 314.1903$, found: 314.1906 .<smiles>CC(=O)C(C)NC(=O)c1ccc(/C=C/c2ccccc2-c2ccccn2)cc1</smiles>

(S,E)-Methyl 2-\{4-[2-(pyridin-2-yl)styryl]benzamido\}propanoate (74jw): The general procedure I was followed at $120{ }^{\circ} \mathrm{C}$ using phenyl 2-(2-(pyridin-2-yl)phenyl)propan-2-ol (168j) (53.3 mg, 0.25 $\mathrm{mmol}$ ) and (S)-methyl 2-(4-ethynylbenzamido)propanoate $(8 \mathrm{w})(115.6 \mathrm{mg}, 0.50 \mathrm{mmol})$. Purification by column chromatography on silica gel ( $n$-hexane/EtOAc: $4 / 1)$ yielded $74 j w(60.0 \mathrm{mg}, 62 \%)$ as a colorless oil. 
${ }^{1} \mathrm{H}$ NMR $\left(300 \mathrm{MHz}, \mathrm{CDCl}_{3}\right) \delta=8.73(\mathrm{ddd}, J=4.9,1.8,1.0 \mathrm{~Hz}, 1 \mathrm{H}), 7.90-7.67(\mathrm{~m}, 4 \mathrm{H}), 7.64-7.50(\mathrm{~m}$, 1H), 7.49-7.32 (m, 5H), 7.32-7.20 (m, 2H), $7.04(\mathrm{~d}, J=16.2 \mathrm{~Hz}, 1 \mathrm{H}), 6.76(\mathrm{~d}, J=7.2 \mathrm{~Hz}, 1 \mathrm{H}), 4.77$ (dt, $J=14.4,7.2 \mathrm{~Hz}, 1 \mathrm{H}), 3.76(\mathrm{~s}, 3 \mathrm{H}), 1.49(\mathrm{~d}, J=7.2 \mathrm{~Hz}, 3 \mathrm{H}) .{ }^{13} \mathrm{C} \mathrm{NMR}\left(125 \mathrm{MHz}, \mathrm{CDCl}_{3}\right) \delta=173.5\left(\mathrm{C}_{\mathrm{q}}\right)$, $166.2\left(\mathrm{C}_{q}\right), 158.6\left(\mathrm{C}_{\mathrm{q}}\right), 149.4(\mathrm{CH}), 140.9\left(\mathrm{C}_{\mathrm{q}}\right), 139.7\left(\mathrm{C}_{\mathrm{q}}\right), 136.0(\mathrm{CH}), 135.1\left(\mathrm{C}_{\mathrm{q}}\right), 132.4\left(\mathrm{C}_{\mathrm{q}}\right), 130.2(\mathrm{CH})$, $129.6(\mathrm{CH}), 128.7(\mathrm{CH}), 128.6(\mathrm{CH}), 128.0(\mathrm{CH}), 127.3(\mathrm{CH}), 126.5(\mathrm{CH}), 126.2(\mathrm{CH}), 124.8(\mathrm{CH}), 121.9$ (CH), $52.5(\mathrm{CH}), 48.5\left(\mathrm{CH}_{3}\right), 18.7\left(\mathrm{CH}_{3}\right)$. IR (ATR) $v=3323,2951,1742,1641,1536,1501,1458,1213$, 1167, $752 \mathrm{~cm}^{-1}$. MS (ESI) m/z (relative intensity): 795 (10) $[2 \mathrm{M}+\mathrm{Na}]^{+}, 773(30)[\mathrm{M}+\mathrm{H}]^{+}, 409$ (10) $[\mathrm{M}+\mathrm{Na}]^{+}, 387(100)[\mathrm{M}+\mathrm{H}]^{+}$. HR-MS (ESI) $\mathrm{m} / \mathrm{z}$ calcd for $\mathrm{C}_{24} \mathrm{H}_{23} \mathrm{~N}_{2} \mathrm{O}_{3}[\mathrm{M}+\mathrm{H}]^{+}:$: 387.1703, found: 387.1702 .

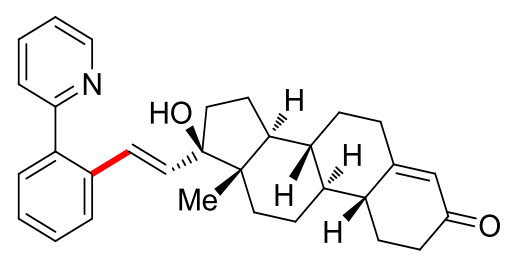

(8R,9S,10R,13S,14S,17R)-17-Hydroxy-13-methyl-17-[(E)-2-(pyridin-2-yl)styryl]-6,7,8,9,10,11,12,13, 14,15,16,17-dodecahydro-1H-cyclopenta[a]phenanthren-3(2H)-one $(\mathbf{7 4 j x )}$ : The general procedure I was followed at $80{ }^{\circ} \mathrm{C}$ using phenyl 2-(2-(pyridin-2-yl)phenyl)propan-2-ol (168j) (53.3 mg, 0.25 $\mathrm{mmol})$ and (8R,9S,10R,13S,14S,17R)-17-ethynyl-17-hydroxy-13-methyl-6,7,8,9,10,11,12,13,14,15,16,17dodecahydro- $1 H$-cyclopenta[a]phenanthren-3(2H)-one $(8 x)(149.2 \mathrm{mg}, 0.50 \mathrm{mmol})$. Purification by column chromatography on silica gel ( $n$-hexane/EtOAc: $1 / 1)$ yielded $74 j \mathbf{j x}(62.4 \mathrm{mg}, 55 \%)$ as a colorless oil.

${ }^{1} \mathrm{H}$ NMR $\left(400 \mathrm{MHz}^{\mathrm{CDCl}}{ }_{3}\right) \delta=8.65(\mathrm{dd}, J=4.9,1.8 \mathrm{~Hz}, 1 \mathrm{H}), 7.68(\mathrm{td}, J=7.9,1.8 \mathrm{~Hz}, 1 \mathrm{H}), 7.54(\mathrm{dd}, J=$ 7.5, $1.8 \mathrm{~Hz}, 1 \mathrm{H}), 7.46(\mathrm{dd}, J=7.5,1.8 \mathrm{~Hz}, 1 \mathrm{H}), 7.39(\mathrm{dt}, J=7.9,1.2 \mathrm{~Hz}, 1 \mathrm{H}), 7.37-7.27(\mathrm{~m}, 2 \mathrm{H}), 7.22$ (ddd, J = 7.5, 4.9, 1.2 Hz, 1H), 6.57 (d, J = 16.0 Hz, 1H), 6.26 (d, J = 16.0 Hz, 1H), $5.80(\mathrm{~s}, 1 \mathrm{H}), 2.50$ $2.32(\mathrm{~m}, 2 \mathrm{H}), 2.30-2.15(\mathrm{~m}, 3 \mathrm{H}), 2.10-2.00(\mathrm{~m}, 1 \mathrm{H}), 1.97-1.75(\mathrm{~m}, 5 \mathrm{H}), 1.62-1.43(\mathrm{~m}, 3 \mathrm{H}), 1.41-1.15$ $(\mathrm{m}, 5 \mathrm{H}), 1.07-0.97(\mathrm{~m}, 1 \mathrm{H}), 0.94(\mathrm{~s}, 3 \mathrm{H}), 0.84-0.70(\mathrm{~m}, 1 \mathrm{H}) .{ }^{13} \mathrm{C} \mathrm{NMR}\left(100 \mathrm{MHz}, \mathrm{CDCl}_{3}\right) \delta=199.8\left(\mathrm{C}_{\mathrm{q}}\right)$, $166.5\left(\mathrm{C}_{\mathrm{q}}\right), 159.0\left(\mathrm{C}_{\mathrm{q}}\right), 149.3(\mathrm{CH}), 139.2\left(\mathrm{C}_{\mathrm{q}}\right), 136.4(\mathrm{CH}), 135.9(\mathrm{CH}), 135.6\left(\mathrm{C}_{\mathrm{q}}\right), 130.0(\mathrm{CH}), 128.5$ $(\mathrm{CH}), 127.4(\mathrm{CH}), 127.1(\mathrm{CH}), 126.6(\mathrm{CH}), 124.7(\mathrm{CH}), 124.5(\mathrm{CH}), 121.8(\mathrm{CH}), 84.0\left(\mathrm{C}_{\mathrm{q}}\right), 49.2(\mathrm{CH})$, $48.7(\mathrm{CH}), 47.2\left(\mathrm{C}_{\mathrm{q}}\right), 42.5(\mathrm{CH}), 41.1(\mathrm{CH}), 36.5\left(\mathrm{CH}_{2}\right), 36.2\left(\mathrm{CH}_{2}\right), 35.5\left(\mathrm{CH}_{2}\right), 32.1\left(\mathrm{CH}_{2}\right), 30.8\left(\mathrm{CH}_{2}\right)$, 
$26.5\left(\mathrm{CH}_{2}\right), 26.1\left(\mathrm{CH}_{2}\right), 23.3\left(\mathrm{CH}_{2}\right), 14.1\left(\mathrm{CH}_{3}\right)$. IR (ATR) $v=3436,2927,2867,1660,1461,1425,1260$, 1014, 910, $730 \mathrm{~cm}^{-1}$. MS (ESI) m/z (relative intensity): 907 (30) $[2 \mathrm{M}+\mathrm{H}]^{+}, 476(15)[\mathrm{M}+\mathrm{Na}]^{+}, 454(100)$ $[\mathrm{M}+\mathrm{H}]^{+}, 436$ (30). HR-MS (ESI) m/z calcd for $\mathrm{C}_{31} \mathrm{H}_{36} \mathrm{NO}_{2}[\mathrm{M}+\mathrm{H}]^{+}:$454.2741, found: 454.2747 .<smiles>CC(=O)N1CC(=O)C(c2ccccc2-n2cccn2)C1=O</smiles>

3-[2-(1H-Pyrazol-1-yl)phenyl]-1-methylpyrrolidine-2,5-dione (102af): The general procedure J was followed using 2-[2-(1H-pyrazol-1-yl)phenyl]propan-2-ol (168a) $(50.6 \mathrm{mg}, 0.25 \mathrm{mmol})$ and 1-methyl-1H-pyrrole-2,5-dione (11f) $(55.6 \mathrm{mg}, 0.50 \mathrm{mmol})$. Purification by column chromatography on silica gel ( $n$-hexane/EtOAc: $3 / 2$ ) yielded 102af (43.4 mg, 68\%) as a colorless oil.

${ }^{1} \mathbf{H}$ NMR $\left(400 \mathrm{MHz}, \mathrm{CDCl}_{3}\right) \delta=7.70(\mathrm{~d}, J=2.4 \mathrm{~Hz}, 1 \mathrm{H}), 7.61(\mathrm{~d}, J=1.8 \mathrm{~Hz}, 1 \mathrm{H}), 7.43-7.36(\mathrm{~m}, 2 \mathrm{H})$, 7.34-7.29 (m, 1H), 7.29-7.23 (m, 1H), $6.41(\mathrm{dd}, J=2.4,1.8 \mathrm{~Hz}, 1 \mathrm{H}), 4.12(\mathrm{dd}, J=9.6,5.6 \mathrm{~Hz}, 1 \mathrm{H})$, $3.07(\mathrm{dd}, J=18.4,9.6 \mathrm{~Hz}, 1 \mathrm{H}), 2.92(\mathrm{~s}, 3 \mathrm{H}), 2.82(\mathrm{dd}, J=18.4,5.6 \mathrm{~Hz}, 1 \mathrm{H}) .{ }^{13} \mathrm{C} \mathrm{NMR}\left(100 \mathrm{MHz}, \mathrm{CDCl}_{3}\right)$ $\delta=177.5\left(\mathrm{C}_{\mathrm{q}}\right), 176.2\left(\mathrm{C}_{\mathrm{q}}\right), 140.8(\mathrm{CH}), 139.6\left(\mathrm{C}_{\mathrm{q}}\right), 133.0\left(\mathrm{C}_{\mathrm{q}}\right), 131.2(\mathrm{CH}), 129.9(\mathrm{CH}), 129.0(\mathrm{CH})$, $128.7(\mathrm{CH}), 126.6(\mathrm{CH}), 107.1(\mathrm{CH}), 43.3(\mathrm{CH}), 37.8\left(\mathrm{CH}_{2}\right), 25.1\left(\mathrm{CH}_{3}\right)$. IR (ATR) $v=3136,1694,1518$, 1435, 1382, 1280,1144, 1003, $760 \mathrm{~cm}^{-1}$. MS (ESI) m/z (relative intensity): 533 (100) [2M+Na] $]^{+}, 278$ (70) $[\mathrm{M}+\mathrm{Na}]^{+}, 256(40)[\mathrm{M}+\mathrm{H}]^{+}$. HR-MS (ESI) m/z calcd for $\mathrm{C}_{14} \mathrm{H}_{14} \mathrm{~N}_{3} \mathrm{O}_{2}[\mathrm{M}+\mathrm{H}]^{+}:$:256.1081, found: 256.1077 .

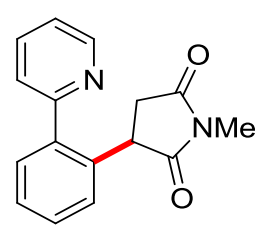

1-Methyl-3-[2-(pyridin-2-yl)phenyl]pyrrolidine-2,5-dione (102jf): The general procedure J was followed using phenyl 2-(2-(pyridin-2-yl)phenyl)propan-2-ol (168j) $(53.3 \mathrm{mg}, 0.25 \mathrm{mmol}$ ) and 1-methyl-1H-pyrrole-2,5-dione (11f) $(55.6 \mathrm{mg}, 0.50 \mathrm{mmol})$. Purification by column chromatography on silica gel ( $n$-hexane/EtOAc: $1 / 1)$ yielded $102 j f(60.6 \mathrm{mg}, 91 \%)$ as a colorless oil.

${ }^{1} \mathbf{H}$ NMR $\left(600 \mathrm{MHz}, \mathrm{CDCl}_{3}\right) \delta=8.52(\mathrm{~d}, J=4.8 \mathrm{~Hz}, 1 \mathrm{H}), 7.75(\mathrm{t}, J=7.8 \mathrm{~Hz}, 1 \mathrm{H}), 7.54(\mathrm{dd}, J=7.8,1.0 \mathrm{~Hz}$, 1H), 7.47-7.43 (m, 1H), 7.41-7.35 (m, 2H), 7.29-7.15 (m, 2H), $4.34(\mathrm{dd}, J=9.6,5.6 \mathrm{~Hz}, 1 \mathrm{H}), 3.14$ (dd, 
$J=18.4,9.6 \mathrm{~Hz}, 1 \mathrm{H}), 2.92(\mathrm{~s}, 3 \mathrm{H}), 2.89(\mathrm{dd}, J=18.4,9.6 \mathrm{~Hz}, 1 \mathrm{H}) .{ }^{13} \mathrm{C}$ NMR $\left(125 \mathrm{MHz}, \mathrm{CDCl}_{3}\right) \delta=178.3$ $\left(\mathrm{C}_{\mathrm{q}}\right), 176.5\left(\mathrm{C}_{\mathrm{q}}\right), 158.9\left(\mathrm{C}_{\mathrm{q}}\right), 148.4(\mathrm{CH}), 140.0\left(\mathrm{C}_{\mathrm{q}}\right), 136.8(\mathrm{CH}), 135.4\left(\mathrm{C}_{\mathrm{q}}\right), 130.5(\mathrm{CH}), 129.4(\mathrm{CH})$, $129.0(\mathrm{CH}), 127.9(\mathrm{CH}), 124.1(\mathrm{CH}), 122.0(\mathrm{CH}), 44.9(\mathrm{CH}), 38.6\left(\mathrm{CH}_{2}\right), 25.0\left(\mathrm{CH}_{3}\right)$. IR (ATR) $v=3057$, 1696, 1436, 1382, 1282, 1120, 953, $757 \mathrm{~cm}^{-1}$. MS (ESI) m/z (relative intensity): 555 (100) [2M+Na] $]^{+}$ $289(70)[\mathrm{M}+\mathrm{Na}]^{+}, 267(90)[\mathrm{M}+\mathrm{H}]^{+}$. HR-MS (ESI) m/z calcd for $\mathrm{C}_{16} \mathrm{H}_{15} \mathrm{~N}_{2} \mathrm{O}_{2}[\mathrm{M}+\mathrm{H}]^{+}:$: 267.1128, found: 267.1126.

The analytical data were in accordance with those reported in the literature. ${ }^{[204]}$<smiles>CC(=O)N1CC(=O)C(c2ccc(C)cc2-n2cccn2)C1</smiles>

1-Methyl-3-[4-methyl-2-(1H-pyrazol-1-yl)phenyl]pyrrolidine-2,5-dione (102cf): The general procedure J was followed using 2-[4-methyl-2-(1H-pyrazol-1-yl)phenyl]propan-2-ol (168c) (54.1 mg, $0.25 \mathrm{mmol}$ ) and 1-methyl-1H-pyrrole-2,5-dione (11f) $(55.6 \mathrm{mg}, 0.50 \mathrm{mmol})$. Purification by column chromatography on silica gel ( $n$-hexane/EtOAc: 2/1) yielded 102cf (43.1 mg, 64\%) as a colorless oil. ${ }^{1} \mathrm{H}$ NMR $\left(300 \mathrm{MHz} \mathrm{CDCl}_{3}\right) \delta=7.73(\mathrm{~d}, J=2.2 \mathrm{~Hz}, 1 \mathrm{H}), 7.64(\mathrm{~d}, J=1.8 \mathrm{~Hz}, 1 \mathrm{H}), 7.24(\mathrm{dd}, J=7.8,1.3 \mathrm{~Hz}$, $1 \mathrm{H}), 7.20-7.14(\mathrm{~m}, 2 \mathrm{H}), 6.44(\mathrm{dd}, J=2.2,1.8 \mathrm{~Hz}, 1 \mathrm{H}), 4.10$ (dd, J = 9.6, $5.6 \mathrm{~Hz}, 1 \mathrm{H}), 3.09$ (dd, $J=18.4$, $9.6 \mathrm{~Hz}, 1 \mathrm{H}), 2.96(\mathrm{~s}, 3 \mathrm{H}), 2.83(\mathrm{dd}, J=18.4,5.6 \mathrm{~Hz}, 1 \mathrm{H}), 2.40(\mathrm{~s}, 3 \mathrm{H}) .{ }^{13} \mathrm{C} \mathbf{N M R}\left(100 \mathrm{MHz}, \mathrm{CDCl}_{3}\right) \delta=$ $177.7\left(\mathrm{C}_{\mathrm{q}}\right), 176.3\left(\mathrm{C}_{\mathrm{q}}\right), 140.7(\mathrm{CH}), 139.4\left(\mathrm{C}_{\mathrm{q}}\right), 139.0\left(\mathrm{C}_{\mathrm{q}}\right), 131.1(\mathrm{CH}), 129.9\left(\mathrm{C}_{\mathrm{q}}\right), 129.7(\mathrm{CH}), 129.6$ (CH), $127.2(\mathrm{CH}), 106.9(\mathrm{CH}), 42.9(\mathrm{CH}), 37.8\left(\mathrm{CH}_{2}\right), 25.1\left(\mathrm{CH}_{3}\right), 20.8\left(\mathrm{CH}_{3}\right)$. IR (ATR) $v=3118,2924$, 1694, 1434, 1381, 1279, 1118, 950, $757 \mathrm{~cm}^{-1}$. MS (ESI) m/z (relative intensity): 561 (30) [2M+Na] , $292(100)[\mathrm{M}+\mathrm{Na}]^{+}, 270(80)[\mathrm{M}+\mathrm{H}]^{+}$. HR-MS (ESI) m/z calcd for $\mathrm{C}_{15} \mathrm{H}_{16} \mathrm{~N}_{3} \mathrm{O}_{2}[\mathrm{M}+\mathrm{H}]^{+}: 270.1237$, found: 270.1239 .<smiles>CCN1C(=O)CC(c2ccc(C)cc2-n2cccn2)C1=O</smiles>

1-Ethyl-3-[4-methyl-2-(1H-pyrazol-1-yl)phenyl]pyrrolidine-2,5-dione $\quad(102 \mathrm{cg}): \quad$ The general procedure J was followed using 2-[4-methyl-2-(1H-pyrazol-1-yl)phenyl]propan-2-ol (168c) (54.1 mg, 
$0.25 \mathrm{mmol}$ ) and 1-ethyl-1H-pyrrole-2,5-dione $(\mathbf{1 1 g})(62.6 \mathrm{mg}, 0.50 \mathrm{mmol})$. Purification by column chromatography on silica gel ( $n$-hexane/EtOAc: $2 / 1$ ) yielded $102 \mathrm{cg}(44.0 \mathrm{mg}, 62 \%)$ as a colorless oil. ${ }^{1} \mathrm{H}$ NMR $\left(300 \mathrm{MHz}, \mathrm{CDCl}_{3}\right) \delta=7.76(\mathrm{~d}, J=2.4 \mathrm{~Hz}, 1 \mathrm{H}), 7.66(\mathrm{~d}, J=1.8 \mathrm{~Hz}, 1 \mathrm{H}), 7.24(\mathrm{dd}, J=7.8,1.8 \mathrm{~Hz}$, 1H), $7.19(\mathrm{~d}, J=1.3 \mathrm{~Hz}, 1 \mathrm{H}), 7.15(\mathrm{~d}, J=7.8 \mathrm{~Hz}, 1 \mathrm{H}), 6.45(\mathrm{dd}, J=2.4,1.8 \mathrm{~Hz}, 1 \mathrm{H}), 4.09$ (dd, $J=9.6$, $5.6 \mathrm{~Hz}, 1 \mathrm{H}), 3.55(\mathrm{qd}, J=7.2,3.7 \mathrm{~Hz}, 2 \mathrm{H}), 3.07(\mathrm{dd}, J=18.4,9.6 \mathrm{~Hz}, 1 \mathrm{H}), 2.76(\mathrm{dd}, J=18.4,5.6 \mathrm{~Hz}$, $1 \mathrm{H}), 2.40(\mathrm{~s}, 3 \mathrm{H}), 1.19(\mathrm{t}, J=7.2 \mathrm{~Hz}, 3 \mathrm{H}) .{ }^{13} \mathrm{C}$ NMR $\left(125 \mathrm{MHz}, \mathrm{CDCl}_{3}\right) \delta=177.4\left(\mathrm{C}_{\mathrm{q}}\right), 175.9\left(\mathrm{C}_{\mathrm{q}}\right), 140.7$ $(\mathrm{CH}), 139.4\left(\mathrm{C}_{\mathrm{q}}\right), 138.8\left(\mathrm{C}_{\mathrm{q}}\right), 131.1(\mathrm{CH}), 129.9\left(\mathrm{C}_{\mathrm{q}}\right), 129.7(\mathrm{CH}), 129.1(\mathrm{CH}), 127.1(\mathrm{CH}), 106.9(\mathrm{CH})$, $42.7(\mathrm{CH}), 37.8\left(\mathrm{CH}_{2}\right), 34.0\left(\mathrm{CH}_{2}\right), 20.9\left(\mathrm{CH}_{3}\right), 13.0\left(\mathrm{CH}_{3}\right)$. IR (ATR) $v=3119,2939,1698,1402,1351$, 1222, 1126, 1044, $752 \mathrm{~cm}^{-1}$. MS (ESI) m/z (relative intensity): 589 (40) [2M+Na] $]^{+}, 306$ (98) [M+Na] , $284(100)[\mathrm{M}+\mathrm{H}]^{+}$. HR-MS (ESI) m/z calcd for $\mathrm{C}_{16} \mathrm{H}_{18} \mathrm{~N}_{3} \mathrm{O}_{2}[\mathrm{M}+\mathrm{H}]^{+}:$284.1394, found: 284.1395.<smiles>Cc1ccc(C2CC(=O)N(C)C2=O)c(-n2nc(C)cc2C)c1</smiles>

3-[2-(3,5-Dimethyl-1H-pyrazol-1-yl)-4-methylphenyl]-1-methylpyrrolidine-2,5-dione (102kf): The general procedure J was followed using 2-[2-(3,5-dimethyl-1H-pyrazol-1-yl)-4-methylphenyl]propan-2-ol (168k) (61.1 mg, $0.25 \mathrm{mmol}$ ) and 1-methyl-1H-pyrrole-2,5-dione (11f) $(55.5 \mathrm{mg}, 0.50 \mathrm{mmol})$. Purification by column chromatography on silica gel ( $n$-hexane/EtOAc: $1 / 1)$ yielded $102 \mathrm{kf}(60.0 \mathrm{mg}, 85 \%)$ as a white solid.

M.p. $=127-129^{\circ} \mathrm{C}^{1}{ }^{1} \mathrm{H}$ NMR $\left(300 \mathrm{MHz}, \mathrm{CDCl}_{3}\right) \delta=7.23-7.12(\mathrm{~m}, 2 \mathrm{H}), 7.00(\mathrm{dt}, J=1.5,0.7 \mathrm{~Hz}, 1 \mathrm{H})$, $5.87(\mathrm{~s}, 1 \mathrm{H}), 3.83(\mathrm{dd}, J=8.6,6.5 \mathrm{~Hz}, 1 \mathrm{H}), 3.00(\mathrm{~s}, 1 \mathrm{H}), 2.98(\mathrm{~d}, J=3.3 \mathrm{~Hz}, 1 \mathrm{H}), 2.81(\mathrm{~s}, 3 \mathrm{H}), 2.34(\mathrm{~s}$, 3H), $2.16(\mathrm{~s}, 3 \mathrm{H}), 2.09(\mathrm{~s}, 3 \mathrm{H}) .{ }^{13} \mathrm{C}$ NMR $\left(125 \mathrm{MHz}, \mathrm{CDCl}_{3}\right) \delta=177.3\left(\mathrm{C}_{\mathrm{q}}\right), 176.1\left(\mathrm{C}_{\mathrm{q}}\right), 148.8\left(\mathrm{C}_{\mathrm{q}}\right), 141.3$ $\left(\mathrm{C}_{q}\right), 138.6\left(\mathrm{C}_{q}\right), 137.9\left(\mathrm{C}_{q}\right), 132.6\left(\mathrm{C}_{\mathrm{q}}\right), 130.2(\mathrm{CH}), 130.0(\mathrm{CH}), 129.2(\mathrm{CH}), 105.6(\mathrm{CH}), 43.4(\mathrm{CH}), 37.9$ $\left(\mathrm{CH}_{2}\right), 25.0\left(\mathrm{CH}_{3}\right), 20.9\left(\mathrm{CH}_{3}\right), 13.4\left(\mathrm{CH}_{3}\right), 11.5\left(\mathrm{CH}_{3}\right)$. IR (ATR) $v=2925,1693,1433,1283,1119,835$, $778,689 \mathrm{~cm}^{-1} . \mathrm{MS}(\mathrm{ESI}) \mathrm{m} / \mathrm{z}$ (relative intensity): $320(40)[\mathrm{M}+\mathrm{Na}]^{+}, 298(100)[\mathrm{M}+\mathrm{H}]^{+}$. HR-MS (ESI) $\mathrm{m} / \mathrm{z}$ calcd for $\mathrm{C}_{17} \mathrm{H}_{20} \mathrm{~N}_{3} \mathrm{O}_{2}[\mathrm{M}+\mathrm{H}]^{+}: 298.1550$, found: 298.1547 . 
<smiles>CCN1C(=O)CC(c2ccccc2-n2nc(C)cc2C)C1=O</smiles>

3-[2-(3,5-Dimethyl-1H-pyrazol-1-yl)phenyl]-1-methylpyrrolidine-2,5-dione (102lf): The general procedure J was followed using 2-[2-(3,5-dimethyl-1H-pyrazol-1-yl)phenyl]propan-2-ol (168I) (57.6 $\mathrm{mg}, 0.25 \mathrm{mmol}$ ) and 1-methyl-1H-pyrrole-2,5-dione (11f) $(55.5 \mathrm{mg}, 0.50 \mathrm{mmol})$. Purification by column chromatography on silica gel ( $n$-hexane/EtOAc: $1 / 1)$ yielded 102 lf $(58.1 \mathrm{mg}, 82 \%)$ as a white solid.

M.p. $=100-102{ }^{\circ} \mathrm{C} .{ }^{1} \mathrm{H}$ NMR $\left(400 \mathrm{MHz}, \mathrm{CDCl}_{3}\right) \delta=7.43-7.33(\mathrm{~m}, 2 \mathrm{H}), 7.32-7.13(\mathrm{~m}, 2 \mathrm{H}), 5.88(\mathrm{~s}, 1 \mathrm{H})$, $3.88(\mathrm{dd}, J=9.0,6.1 \mathrm{~Hz}, 1 \mathrm{H}), 3.15-2.89(\mathrm{~m}, 2 \mathrm{H}), 2.80(\mathrm{~s}, 3 \mathrm{H}), 2.15(\mathrm{~s}, 3 \mathrm{H}), 2.08(\mathrm{~s}, 3 \mathrm{H}) .{ }^{13} \mathrm{C}$ NMR $(100$ $\left.\mathrm{MHz}, \mathrm{CDCl}_{3}\right) \delta=177.2\left(\mathrm{C}_{\mathrm{q}}\right), 176.1\left(\mathrm{C}_{\mathrm{q}}\right), 148.9\left(\mathrm{C}_{\mathrm{q}}\right), 141.4\left(\mathrm{C}_{\mathrm{q}}\right), 138.1\left(\mathrm{C}_{\mathrm{q}}\right), 135.8\left(\mathrm{C}_{\mathrm{q}}\right), 130.6(\mathrm{CH}), 129.3$ $(\mathrm{CH}), 128.6(\mathrm{CH}), 128.5(\mathrm{CH}), 105.8(\mathrm{CH}), 43.8(\mathrm{CH}), 37.7\left(\mathrm{CH}_{2}\right), 24.9\left(\mathrm{CH}_{3}\right), 13.3\left(\mathrm{CH}_{3}\right), 11.4\left(\mathrm{CH}_{3}\right) . \mathrm{IR}$ (ATR) $v=1691,1508,1436,1380,1279,1121,951,766 \mathrm{~cm}^{-1}$. MS (ESI) m/z (relative intensity): 306 (70) $[\mathrm{M}+\mathrm{Na}]^{+}, 284(100)[\mathrm{M}+\mathrm{H}]^{+}$. HR-MS (ESI) m/z calcd for $\mathrm{C}_{16} \mathrm{H}_{18} \mathrm{~N}_{3} \mathrm{O}_{2}[\mathrm{M}+\mathrm{H}]^{+}:$: 284.1394, found: 284.1386.<smiles>COc1ccc(CCC(C)=O)c(-n2cccn2)c1</smiles>

4-[4-Methyl-2-(1H-pyrazol-1-yl)phenyl]butan-2-one (102ch): The general procedure J was followed using 2-[4-methyl-2-(1H-pyrazol-1-yl)phenyl]propan-2-ol $(168 \mathrm{c}) \quad(54.1 \mathrm{mg}, \quad 0.25 \mathrm{mmol})$ and but-3-en-2-one $(\mathbf{1 1 h})(35.1 \mathrm{mg}, 0.50 \mathrm{mmol})$. Purification by column chromatography on silica gel (n-hexane/EtOAc: $4 / 1$ ) yielded $102 \mathrm{ch}(43.4 \mathrm{mg}, 76 \%)$ as a colorless oil.

${ }^{1} \mathbf{H}$ NMR $\left(300 \mathrm{MHz}, \mathrm{CDCl}_{3}\right) \delta=7.67(\mathrm{~d}, J=1.3 \mathrm{~Hz}, 1 \mathrm{H}), 7.57(\mathrm{~d}, J=1.8 \mathrm{~Hz}, 1 \mathrm{H}), 7.20-7.07(\mathrm{~m}, 3 \mathrm{H})$, $6.40(\mathrm{t}, J=2.1 \mathrm{~Hz}, 1 \mathrm{H}), 2.75(\mathrm{t}, J=7.6 \mathrm{~Hz}, 2 \mathrm{H}), 2.53(\mathrm{t}, J=7.6 \mathrm{~Hz}, 2 \mathrm{H}), 2.33(\mathrm{~s}, 3 \mathrm{H}), 2.02(\mathrm{~s}, 3 \mathrm{H}) .{ }^{13} \mathrm{C}$ NMR $\left(125 \mathrm{MHz}, \mathrm{CDCl}_{3}\right) \delta=207.6\left(\mathrm{C}_{\mathrm{q}}\right), 140.1(\mathrm{CH}), 139.3\left(\mathrm{C}_{\mathrm{q}}\right), 136.8\left(\mathrm{C}_{\mathrm{q}}\right), 133.7\left(\mathrm{C}_{\mathrm{q}}\right), 130.4(\mathrm{CH})$, 130.2 (CH), $129.3(\mathrm{CH}), 127.0(\mathrm{CH}), 106.2(\mathrm{CH}), 44.4\left(\mathrm{CH}_{2}\right), 29.8\left(\mathrm{CH}_{3}\right), 25.5\left(\mathrm{CH}_{2}\right), 20.7\left(\mathrm{CH}_{3}\right)$. IR (ATR) $v=2923,1713,1516,1405,1162,1044,951,817,754,623 \mathrm{~cm}^{-1}$. MS (ESI) m/z (relative intensity): $251(50)[\mathrm{M}+\mathrm{Na}]^{+}, 229(100)[\mathrm{M}+\mathrm{H}]^{+}, 171$ (30). HR-MS (ESI) m/z calcd for $\mathrm{C}_{14} \mathrm{H}_{17} \mathrm{~N}_{2} \mathrm{O}[\mathrm{M}+\mathrm{H}]^{+}$: 
229.1335, found: 229.1344 .<smiles>C=C(Cc1ccccc1-n1cccn1)C(C)=O</smiles>

Methyl 2-[2-(1H-pyrazol-1-yl)benzyl]acrylate (202aa): The general procedure $\mathrm{K}$ was followed using 2-[2-(1H-pyrazol-1-yl)phenyl]propan-2-ol $\quad$ (168a) $\quad(50.6 \quad \mathrm{mg}, \quad 0.25 \quad \mathrm{mmol})$ and methyl 2-\{[(tert-butoxycarbonyl)oxy]methyl\}acrylate (201a) (108.1 mg, $0.50 \mathrm{mmol})$. Purification by column chromatography on silica gel ( $n$-hexane/EtOAc: $4 / 1$ ) yielded 202aa (48.3 mg, 80\%) as a colorless oil. ${ }^{1} \mathbf{H}$ NMR $\left(300 \mathrm{MHz}, \mathrm{CDCl}_{3}\right) \delta=7.68(\mathrm{dd}, J=1.9,0.7 \mathrm{~Hz}, 1 \mathrm{H}), 7.57(\mathrm{dd}, J=2.4,0.7 \mathrm{~Hz}, 1 \mathrm{H}), 7.38-7.28$ $(\mathrm{m}, 4 \mathrm{H}), 6.39(\mathrm{dd}, J=2.4,1.9 \mathrm{~Hz}, 1 \mathrm{H}), 6.13(\mathrm{td}, J=1.2,1.0 \mathrm{~Hz}, 1 \mathrm{H}), 5.20(\mathrm{td}, J=1.5,1.3 \mathrm{~Hz}, 1 \mathrm{H}), 3.67$ $(\mathrm{s}, 3 \mathrm{H}), 3.62(\mathrm{dd}, J=1.5,1.0 \mathrm{~Hz}, 2 \mathrm{H}) .{ }^{13} \mathrm{C}$ NMR $\left(125 \mathrm{MHz}, \mathrm{CDCl}_{3}\right) \delta=166.9\left(\mathrm{C}_{\mathrm{q}}\right), 140.3(\mathrm{CH}), 139.8\left(\mathrm{C}_{\mathrm{q}}\right)$, $138.7\left(\mathrm{C}_{\mathrm{q}}\right), 134.4\left(\mathrm{C}_{\mathrm{q}}\right), 130.9(\mathrm{CH}), 130.6(\mathrm{CH}), 128.5(\mathrm{CH}), 127.3(\mathrm{CH}), 126.6(\mathrm{CH}), 126.5\left(\mathrm{CH}_{2}\right), 106.2$ (CH), $51.9\left(\mathrm{CH}_{3}\right), 33.5\left(\mathrm{CH}_{2}\right)$. IR (ATR) $v=2950,1716,1517,1394,1194,1138,1045,939,751 \mathrm{~cm}^{-1}$. MS (ESI) m/z (relative intensity): $265(75)[\mathrm{M}+\mathrm{Na}]^{+}, 243(100)[\mathrm{M}+\mathrm{H}]^{+}, 211$ (15). HR-MS (ESI) m/z calcd for $\mathrm{C}_{14} \mathrm{H}_{15} \mathrm{~N}_{2} \mathrm{O}_{2}[\mathrm{M}+\mathrm{H}]^{+}: 243.1128$, found: 243.1126 .<smiles>C=C(Cc1ccc(C)cc1-n1cccn1)C(C)=O</smiles>

Methyl 2-[4-methyl-2-(1H-pyrazol-1-yl)benzyl]acrylate (202ca): The general procedure K was followed using 2-[4-methyl-2-(1H-pyrazol-1-yl)phenyl]propan-2-ol (168c) (53.8 mg, $0.25 \mathrm{mmol})$ and methyl 2-\{[(tert-butoxycarbonyl)oxy]methyl\}acrylate (201a) (108.1 mg, $0.50 \mathrm{mmol})$. Purification by column chromatography on silica gel ( $n$-hexane/EtOAc: 6/1) yielded 202 ca $(46.1 \mathrm{mg}, 72 \%$ ) as a colorless oil.

${ }^{1} \mathbf{H}$ NMR $\left(400 \mathrm{MHz}, \mathrm{CDCl}_{3}\right) \delta=7.67(\mathrm{dd}, J=1.9,0.7 \mathrm{~Hz}, 1 \mathrm{H}), 7.56(\mathrm{dd}, J=2.3,0.7 \mathrm{~Hz}, 1 \mathrm{H}), 7.20-7.11$ (m, 3H), $6.37(\mathrm{dd}, J=2.3,1.9 \mathrm{~Hz}, 1 \mathrm{H}), 6.11(\mathrm{td}, J=1.9,0.5 \mathrm{~Hz}, 1 \mathrm{H}), 5.20(\mathrm{td}, J=1.5,1.4 \mathrm{~Hz}, 1 \mathrm{H}), 3.66$ $(\mathrm{s}, 3 \mathrm{H}), 3.57$ (dd, $J=1.5,1.1 \mathrm{~Hz}, 2 \mathrm{H}) .{ }^{13} \mathrm{C}$ NMR $\left(100 \mathrm{MHz}, \mathrm{CDCl}_{3}\right) \delta=167.1\left(\mathrm{C}_{\mathrm{q}}\right), 140.3(\mathrm{CH}), 139.7\left(\mathrm{C}_{\mathrm{q}}\right)$, $139.1\left(\mathrm{C}_{\mathrm{q}}\right), 137.3\left(\mathrm{C}_{\mathrm{q}}\right), 131.1\left(\mathrm{C}_{\mathrm{q}}\right), 130.8(\mathrm{CH}), 130.6(\mathrm{CH}), 129.3(\mathrm{CH}), 127.2(\mathrm{CH}), 126.4\left(\mathrm{CH}_{2}\right), 106.2$ (CH), $51.8\left(\mathrm{CH}_{3}\right), 33.1\left(\mathrm{CH}_{2}\right), 20.8\left(\mathrm{CH}_{3}\right)$. IR (ATR) $v=2950,1718,1516,1436,1196,1174,1136,952$, 
$753 \mathrm{~cm}^{-1} . \mathrm{MS}(\mathrm{ESI}) \mathrm{m} / \mathrm{z}$ (relative intensity): $279(100)[\mathrm{M}+\mathrm{Na}]^{+}, 257(50)[\mathrm{M}+\mathrm{H}]^{+}, 225$ (45), 197 (10). HR-MS (ESI) m/z calcd for $\mathrm{C}_{15} \mathrm{H}_{17} \mathrm{~N}_{2} \mathrm{O}_{2}[\mathrm{M}+\mathrm{H}]^{+}: 257.1285$, found: 257.1280 .<smiles>C=C(Cc1ccc(Cl)cc1-n1cccn1)C(C)=O</smiles>

Methyl 2-[4-chloro-2-(1H-pyrazol-1-yl)benzyl]acrylate (202ma): The general procedure $\mathrm{K}$ was followed using 2-[4-chloro-2-(1H-pyrazol-1-yl)phenyl]propan-2-ol (168m) (59.2 mg, 0.25 mmol) and methyl 2-\{[(tert-butoxycarbonyl)oxy]methyl\}acrylate (201a) $(108.1 \mathrm{mg}, 0.50 \mathrm{mmol})$. Purification by column chromatography on silica gel ( $n$-hexane/EtOAc: 6/1) yielded $202 \mathrm{ma}(57.3 \mathrm{mg}, 83 \%)$ as a colorless oil.

${ }^{1} \mathbf{H}$ NMR $\left(300 \mathrm{MHz}, \mathrm{CDCl}_{3}\right) \delta=7.68(\mathrm{dd}, J=1.9,0.7 \mathrm{~Hz}, 1 \mathrm{H}), 7.56(\mathrm{dd}, J=2.4,0.7 \mathrm{~Hz}, 1 \mathrm{H}), 7.30-7.28$ (m, 1H), 7.27-7.21 (m, 2H), $6.39(\mathrm{dd}, J=2.4,1.9 \mathrm{~Hz}, 1 \mathrm{H}), 6.16(\mathrm{td}, J=1.9,0.5 \mathrm{~Hz}, 1 \mathrm{H}), 5.27(\mathrm{td}, J=$ 1.5, $1.2 \mathrm{~Hz}, 1 \mathrm{H}), 3.67(\mathrm{~s}, 3 \mathrm{H}), 3.59(\mathrm{~s}, 2 \mathrm{H}) .{ }^{13} \mathrm{C}$ NMR $\left(125 \mathrm{MHz}, \mathrm{CDCl}_{3}\right) \delta=166.6\left(\mathrm{C}_{\mathrm{q}}\right), 140.6(\mathrm{CH})$, $138.3\left(\mathrm{C}_{q}\right), 138.0\left(\mathrm{C}_{\mathrm{q}}\right), 136.4\left(\mathrm{C}_{\mathrm{q}}\right), 134.1\left(\mathrm{C}_{\mathrm{q}}\right), 130.7(\mathrm{CH}), 130.6(\mathrm{CH}), 127.8(\mathrm{CH}), 127.4(\mathrm{CH}), 127.2$ $\left(\mathrm{CH}_{2}\right), 106.6(\mathrm{CH}), 52.0\left(\mathrm{CH}_{3}\right), 33.4\left(\mathrm{CH}_{2}\right)$. IR (ATR) $v=2932,1717,1517,1490,1394,1195,1142,939$, 819, $753 \mathrm{~cm}^{-1}$. MS (ESI) m/z (relative intensity): $299(70)[\mathrm{M}+\mathrm{Na}]^{+}, 277(100)[\mathrm{M}+\mathrm{H}]^{+}, 245(10)$. HR-MS (ESI) $\mathrm{m} / \mathrm{z}$ calcd for $\mathrm{C}_{14} \mathrm{H}_{14} \mathrm{ClN}_{2} \mathrm{O}_{2}[\mathrm{M}+\mathrm{H}]^{+}: 277.0738$, found: 277.0742 .

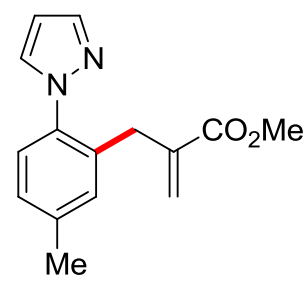

Methyl 2-[5-methyl-2-(1H-pyrazol-1-yl)benzyl]acrylate (202ba): The general procedure $\mathrm{K}$ was followed using 2-[5-methyl-2-(1H-pyrazol-1-yl)phenyl]propan-2-ol (168b) (54.1 mg, $0.25 \mathrm{mmol})$ and methyl 2-\{[(tert-butoxycarbonyl)oxy]methyl\}acrylate (201a) (108.1 mg, $0.50 \mathrm{mmol})$. Purification by column chromatography on silica gel ( $n$-hexane/EtOAc: 6/1) yielded 202 ba $(54.4 \mathrm{mg}, 85 \%$ ) as a colorless oil.

${ }^{1} \mathbf{H}$ NMR $\left(400 \mathrm{MHz}, \mathrm{CDCl}_{3}\right) \delta=7.66(\mathrm{dd}, J=1.9,0.7 \mathrm{~Hz}, 1 \mathrm{H}), 7.53(\mathrm{dd}, J=2.3,0.7 \mathrm{~Hz}, 1 \mathrm{H}), 7.22-7.16$ 
(m, 1H), 7.13-7.07 (m, 2H), $6.36(\mathrm{dd}, J=2.3,1.9 \mathrm{~Hz}, 1 \mathrm{H}), 6.13(\mathrm{td}, J=2.0,0.5 \mathrm{~Hz}, 1 \mathrm{H}), 5.21(\mathrm{td}, J=$ 1.5, $1.3 \mathrm{~Hz}, 1 \mathrm{H}), 3.67(\mathrm{~s}, 3 \mathrm{H}), 3.56(\mathrm{~m}, 2 \mathrm{H}), 2.35(\mathrm{~s}, 3 \mathrm{H}) .{ }^{13} \mathrm{C} \mathrm{NMR}\left(100 \mathrm{MHz}, \mathrm{CDCl}_{3}\right) \delta=167.1\left(\mathrm{C}_{\mathrm{q}}\right)$, $140.2(\mathrm{CH}), 138.9\left(\mathrm{C}_{\mathrm{q}}\right), 138.5\left(\mathrm{C}_{\mathrm{q}}\right), 137.6\left(\mathrm{C}_{\mathrm{q}}\right), 134.2\left(\mathrm{C}_{\mathrm{q}}\right), 131.5(\mathrm{CH}), 130.7(\mathrm{CH}), 128.0(\mathrm{CH}), 126.6$ $\left(\mathrm{CH}_{2}\right), 126.5(\mathrm{CH}), 106.1(\mathrm{CH}), 51.8\left(\mathrm{CH}_{3}\right), 33.3\left(\mathrm{CH}_{2}\right), 21.1\left(\mathrm{CH}_{3}\right)$. IR (ATR) $v=2949,1717,1519,1436$, 1395, 1201, 1143, 819, $752 \mathrm{~cm}^{-1}$. MS (ESI) m/z (relative intensity): 279 (45) [M+Na], 257 (100) $[\mathrm{M}+\mathrm{H}]^{+}, 225$ (10). HR-MS (ESI) m/z calcd for $\mathrm{C}_{15} \mathrm{H}_{17} \mathrm{~N}_{2} \mathrm{O}_{2}[\mathrm{M}+\mathrm{H}]^{+}:$257.1285, found: 257.1294.

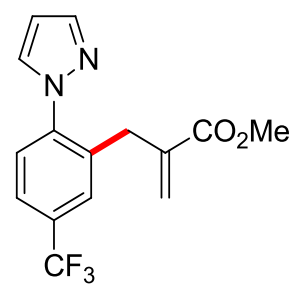

Methyl 2-[2-(1H-pyrazol-1-yl)-5-(trifluoromethyl)benzyl]acrylate (202na): The general procedure K was followed using 2-[2-(1H-pyrazol-1-yl)-5-(trifluoromethyl)phenyl]propan-2-ol (168n) (53.8 mg, $0.25 \mathrm{mmol}$ ) and methyl 2-\{[(tert-butoxycarbonyl)oxy]methyl\}acrylate (201a) (108.1 mg, $0.50 \mathrm{mmol}$ ). Purification by column chromatography on silica gel ( $n$-hexane/EtOAc: 10/1) yielded 202na (34.3 mg, $57 \%)$ as a colorless oil.

${ }^{1} \mathbf{H}$ NMR $\left(300 \mathrm{MHz}, \mathrm{CDCl}_{3}\right) \delta=7.72(\mathrm{dd}, J=1.8,0.6 \mathrm{~Hz}, 1 \mathrm{H}), 7.63(\mathrm{dd}, J=2.4,0.6 \mathrm{~Hz}, 1 \mathrm{H}), 7.60-7.55$ (m, 2H), 7.47-7.41 (m, 1H), $6.44(\mathrm{dd}, J=2.4,1.8 \mathrm{~Hz}, 1 \mathrm{H}), 6.17(\mathrm{td}, J=1.9,0.5 \mathrm{~Hz}, 1 \mathrm{H}), 5.25(\mathrm{td}, J=$ 1.5, $1.1 \mathrm{~Hz}, 1 \mathrm{H}), 3.73(\mathrm{dd}, J=1.5,1.0 \mathrm{~Hz}, 2 \mathrm{H}), 3.68(\mathrm{~s}, 3 \mathrm{H}) .{ }^{13} \mathrm{C} \mathrm{NMR}\left(125 \mathrm{MHz}, \mathrm{CDCl}_{3}\right) \delta=166.5\left(\mathrm{C}_{\mathrm{q}}\right)$, $142.5\left(\mathrm{C}_{\mathrm{q}}\right), 141.0(\mathrm{CH}), 137.9\left(\mathrm{C}_{\mathrm{q}}\right), 135.2\left(\mathrm{C}_{\mathrm{q}}\right), 130.6(\mathrm{CH}), 130.4\left(\mathrm{q},{ }^{2} \mathrm{~J}_{\mathrm{C}-\mathrm{F}}=32.7 \mathrm{~Hz}, \mathrm{C}_{\mathrm{q}}\right), 128.1\left(\mathrm{q},{ }^{3} \mathrm{~J}_{\mathrm{C}-\mathrm{F}}\right.$ $=3.6 \mathrm{~Hz}, \mathrm{CH}), 127.2\left(\mathrm{CH}_{2}\right), 126.8(\mathrm{CH}), 124.4\left(\mathrm{q},{ }^{3} J_{\mathrm{C}-\mathrm{F}}=3.6 \mathrm{~Hz}, \mathrm{CH}\right), 123.6\left(\mathrm{q},{ }^{1} \mathrm{~J}_{\mathrm{C}-\mathrm{F}}=273.5 \mathrm{~Hz}, \mathrm{C}_{\mathrm{q}}\right)$, $107.0(\mathrm{CH}), 52.0\left(\mathrm{CH}_{3}\right), 33.7\left(\mathrm{CH}_{2}\right) .{ }^{19} \mathrm{~F} \mathrm{NMR}\left(282 \mathrm{MHz}, \mathrm{CDCl}_{3}\right) \delta=-62.58$ (s). IR (ATR) $v=2953,1718$, $1522,1395,1335,1126,940,753 \mathrm{~cm}^{-1}$. MS (ESI) m/z (relative intensity): $333(100)[\mathrm{M}+\mathrm{Na}]^{+}, 311(70)$ $[\mathrm{M}+\mathrm{H}]^{+}, 291$ (15), 279 (35), 251 (10). HR-MS (ESI) m/z calcd for $\mathrm{C}_{15} \mathrm{H}_{14} \mathrm{~N}_{2} \mathrm{O}_{2} \mathrm{~F}_{3}[\mathrm{M}+\mathrm{H}]^{+}: 311.1002$, found: 311.1000 . 
<smiles>C=C(Cc1ccccc1-n1nc(C)cc1C)C(C)OC</smiles>

Methyl 2-[2-(3,5-dimethyl-1H-pyrazol-1-yl)benzyl]acrylate (202la): The general procedure $\mathrm{K}$ was followed using 2-[2-(3,5-dimethyl-1H-pyrazol-1-yl)phenyl]propan-2-ol (168I) (57.6 mg, $0.25 \mathrm{mmol})$ and methyl 2-\{[(tert-butoxycarbonyl)oxy]methyl\}acrylate (201a) (108.1 mg, $0.50 \mathrm{mmol})$. Purification by column chromatography on silica gel ( $n$-hexane/EtOAc: $4 / 1$ ) yielded 202la (49.1 mg, 73\%) as a colorless oil.

${ }^{1} \mathbf{H}$ NMR $\left(300 \mathrm{MHz}^{\mathrm{CDCl}}{ }_{3}\right) \delta=7.35-7.23(\mathrm{~m}, 3 \mathrm{H}), 7.16$ (ddd, $\left.J=7.5,7.5,1.2 \mathrm{~Hz}, 1 \mathrm{H}\right), 6.09$ (td, $J=1.4$, $0.7 \mathrm{~Hz}, 1 \mathrm{H}), 5.91(\mathrm{~s}, 1 \mathrm{H}), 5.20(\mathrm{td}, J=1.4,1.4 \mathrm{~Hz}, 1 \mathrm{H}), 3.64(\mathrm{~s}, 3 \mathrm{H}), 3.47(\mathrm{~m}, 2 \mathrm{H}), 2.25(\mathrm{~s}, 3 \mathrm{H}), 2.02(\mathrm{~d}$, $J=0.7 \mathrm{~Hz}, 3 \mathrm{H}) .{ }^{13} \mathrm{C}$ NMR $\left(125 \mathrm{MHz}, \mathrm{CDCl}_{3}\right) \delta=166.9\left(\mathrm{C}_{\mathrm{q}}\right), 148.3\left(\mathrm{C}_{\mathrm{q}}\right), 140.2\left(\mathrm{C}_{\mathrm{q}}\right), 138.5\left(\mathrm{C}_{\mathrm{q}}\right), 138.1\left(\mathrm{C}_{\mathrm{q}}\right)$, $137.1\left(\mathrm{C}_{\mathrm{q}}\right), 130.5(\mathrm{CH}), 128.8(\mathrm{CH}), 128.0(\mathrm{CH}), 127.0(\mathrm{CH}), 126.8\left(\mathrm{CH}_{2}\right), 105.1(\mathrm{CH}), 51.8\left(\mathrm{CH}_{3}\right), 33.4$ $\left(\mathrm{CH}_{2}\right), 13.6\left(\mathrm{CH}_{3}\right), 11.5\left(\mathrm{CH}_{3}\right)$. IR (ATR) $v=2950,1719,1502,1437,1204,1142,948,780 \mathrm{~cm}^{-1}$. MS (ESI) $\mathrm{m} / \mathrm{z}$ (relative intensity): 293 (20) $[\mathrm{M}+\mathrm{Na}]^{+}, 271$ (100) $[\mathrm{M}+\mathrm{H}]^{+}$. HR-MS (ESI) m/z calcd for $\mathrm{C}_{16} \mathrm{H}_{19} \mathrm{~N}_{2} \mathrm{O}_{2}[\mathrm{M}+\mathrm{H}]^{+}:$271.1441, found: 271.1450 .

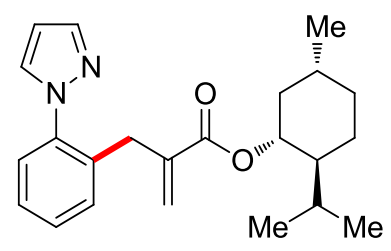

(1R,2S,5R)-2-Isopropyl-5-methylcyclohexyl 2-[2-(1H-pyrazol-1-yl)benzyl]acrylate (202ab): The general procedure $\mathbf{K}$ was followed using 2-[2-(1H-pyrazol-1-yl)phenyl]propan-2-ol (168a) (50.6 mg, $0.25 \mathrm{mmol})$ and $(1 R, 2 S, 5 R)$-2-isopropyl-5-methylcyclohexyl 2-\{[(tert-butoxycarbonyl)oxy]methyl)\} acrylate (201b) (136.2 mg, $0.50 \mathrm{mmol}$ ). Purification by column chromatography on silica gel ( $n$-hexane/EtOAc: $9 / 1 \rightarrow 4 / 1$ ) yielded 202ab (83.4 mg, 91\%) as a colorless oil.

${ }^{1} \mathrm{H}$ NMR $\left(400 \mathrm{MHz}, \mathrm{CDCl}_{3}\right) \delta=7.67(\mathrm{dd}, J=1.9,0.7 \mathrm{~Hz}, 1 \mathrm{H}), 7.56(\mathrm{dd}, J=2.4,0.7 \mathrm{~Hz}, 1 \mathrm{H}), 7.38-7.25$ $(\mathrm{m}, 4 \mathrm{H}), 6.38(\mathrm{dd}, J=2.4,1.9 \mathrm{~Hz}, 1 \mathrm{H}), 6.12(\mathrm{td}, J=1.4,1.3 \mathrm{~Hz}, 1 \mathrm{H}), 5.21(\mathrm{td}, J=1.5,1.4 \mathrm{~Hz}, 1 \mathrm{H}), 4.64$ $(\mathrm{td}, J=10.9,4.4 \mathrm{~Hz}, 1 \mathrm{H}), 3.60(\mathrm{~m}, 2 \mathrm{H}), 1.93-1.85(\mathrm{~m}, 1 \mathrm{H}), 1.72-1.53(\mathrm{~m}, 3 \mathrm{H}), 1.50-1.36(\mathrm{~m}, 2 \mathrm{H})$, 1.34-1.25 (m, 1H), 1.07-0.93 (m, 1H), 0.89-082 (m, 4H), $0.79(\mathrm{~d}, J=7.0 \mathrm{~Hz}, 3 \mathrm{H}), 0.64(\mathrm{~d}, J=7.0 \mathrm{~Hz}$, 3H). ${ }^{13} \mathrm{C}$ NMR $\left(100 \mathrm{MHz}, \mathrm{CDCl}_{3}\right) \delta=166.1\left(\mathrm{C}_{\mathrm{q}}\right), 140.3(\mathrm{CH}), 139.9\left(\mathrm{C}_{\mathrm{q}}\right), 139.3\left(\mathrm{C}_{\mathrm{q}}\right), 134.7\left(\mathrm{C}_{\mathrm{q}}\right), 130.7$ 
(CH), $130.6(\mathrm{CH}), 128.4(\mathrm{CH}), 127.2(\mathrm{CH}), 126.5(\mathrm{CH}), 126.2\left(\mathrm{CH}_{2}\right), 106.2(\mathrm{CH}), 74.6(\mathrm{CH}), 47.0(\mathrm{CH})$, $40.7\left(\mathrm{CH}_{2}\right), 34.2\left(\mathrm{CH}_{2}\right), 33.6\left(\mathrm{CH}_{2}\right), 31.3(\mathrm{CH}), 26.1(\mathrm{CH}), 23.4\left(\mathrm{CH}_{2}\right), 22.0\left(\mathrm{CH}_{3}\right), 20.8\left(\mathrm{CH}_{3}\right), 16.2\left(\mathrm{CH}_{3}\right)$. IR (ATR) $v=2953,2924,2868,1709,1517,1454,1393,1252,1141,939,759 \mathrm{~cm}^{-1}$. MS (ESI) m/z (relative intensity): 389 (30) $[\mathrm{M}+\mathrm{Na}]^{+}, 367(100)[\mathrm{M}+\mathrm{H}]^{+}, 229$ (35). HR-MS (ESI) m/z calcd for $\mathrm{C}_{23} \mathrm{H}_{31} \mathrm{~N}_{2} \mathrm{O}_{2}[\mathrm{M}+\mathrm{H}]^{+}:$367.2380, found: 367.2377 .

Postion-selective Manganese(I)-Catalyzed C-C Activation Highlighting benefits over C-H Activation

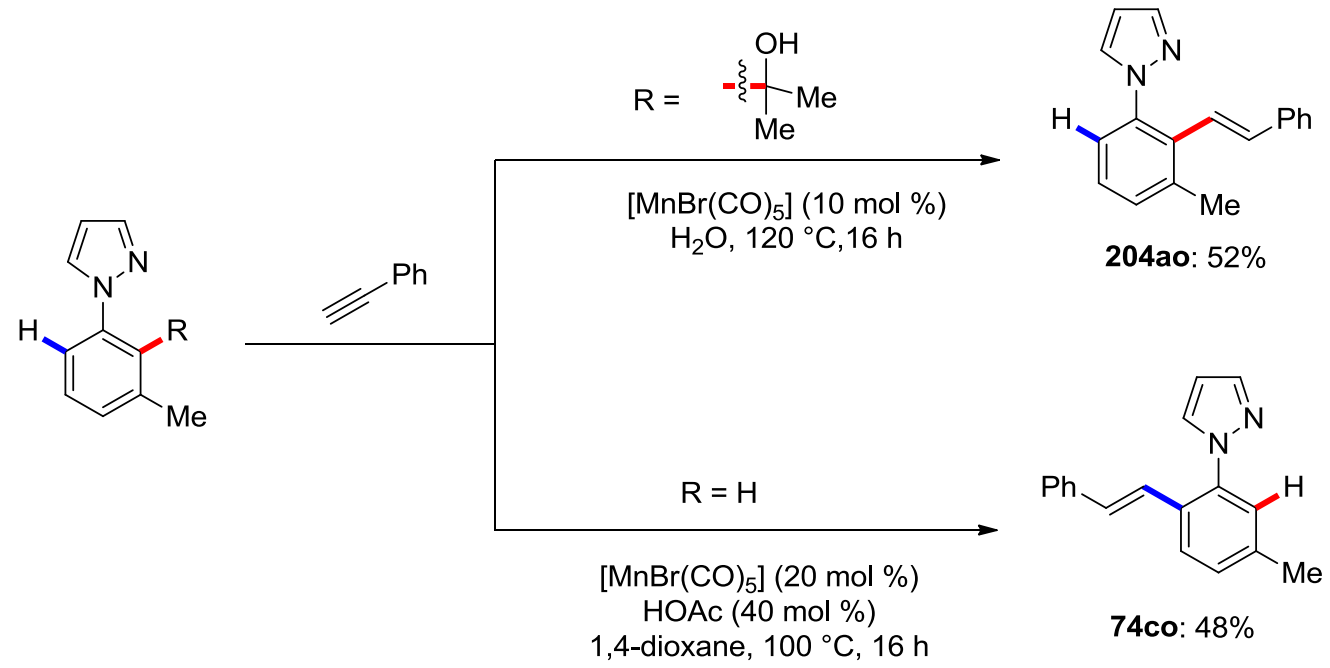

A suspension of 2-[2-methyl-6-(1H-pyrazol-1-yl)phenyl]propan-2-ol (203a) (54.1 mg, $0.25 \mathrm{mmol}$ ), ethynylbenzene (8o) $(66.1 \mathrm{mg}, 0.50 \mathrm{mmol}),\left[\mathrm{MnBr}(\mathrm{CO})_{5}\right](6.9 \mathrm{mg}, 10.0 \mathrm{~mol} \%)$ in $\mathrm{H}_{2} \mathrm{O}(1.0 \mathrm{~mL})$ was stirred at $120^{\circ} \mathrm{C}$ for $16 \mathrm{~h}$ under $\mathrm{N}_{2}$. After cooling to ambient temperature, EtOAc $(10 \mathrm{~mL})$ was added and the mixture was dried over $\mathrm{Na}_{2} \mathrm{SO}_{4}$, washed with EtOAc $(30 \mathrm{~mL})$ and concentrated in vacuo. Purification by column chromatography on silica gel ( $n$-hexane/EtOAc: $20 / 1$ ) yielded 204ao (33.9 mg, $52 \%)$ as a colorless oil.<smiles></smiles>

(E)-1-(3-Methyl-2-styrylphenyl)-1H-pyrazole (204ao) ${ }^{1} \mathrm{H}$ NMR $\left(600 \mathrm{MHz}, \mathrm{CDCl}_{3}\right) \delta=7.70(\mathrm{~d}, J=1.9$ $\mathrm{Hz}, 1 \mathrm{H}), 7.58(\mathrm{~d}, J=2.1 \mathrm{~Hz}, 1 \mathrm{H}), 7.36-7.20(\mathrm{~m}, 8 \mathrm{H}), 6.88(\mathrm{~d}, J=16.7 \mathrm{~Hz}, 1 \mathrm{H}), 6.36(\mathrm{dd}, J=2.1,1.9 \mathrm{~Hz}$, $1 \mathrm{H}), 6.29(\mathrm{~d}, J=16.7 \mathrm{~Hz}, 1 \mathrm{H}), 2.49(\mathrm{~s}, 3 \mathrm{H}) .{ }^{13} \mathrm{C}$ NMR $\left(125 \mathrm{MHz}, \mathrm{CDCl}_{3}\right) \delta=140.0(\mathrm{CH}), 139.1\left(\mathrm{C}_{\mathrm{q}}\right)$, 
$137.6\left(\mathrm{C}_{\mathrm{q}}\right), 137.1\left(\mathrm{C}_{\mathrm{q}}\right), 134.3(\mathrm{CH}), 133.0\left(\mathrm{C}_{\mathrm{q}}\right), 131.3(\mathrm{CH}), 130.5(\mathrm{CH}), 128.5(\mathrm{CH}), 127.7(\mathrm{CH}), 127.2$ (CH), $126.3(\mathrm{CH}), 124.5(\mathrm{CH}), 123.1(\mathrm{CH}), 106.3(\mathrm{CH}), 21.2\left(\mathrm{CH}_{3}\right)$. IR (ATR) $v=3024,1473,1393,1043$, $970,953,752 \mathrm{~cm}^{-1} . \mathrm{MS}(\mathrm{ESI}) \mathrm{m} / \mathrm{z}$ (relative intensity): $363(10), 283(30)[\mathrm{M}+\mathrm{Na}]^{+}, 261(100)[\mathrm{M}+\mathrm{H}]^{+}$. HR-MS (ESI) $\mathrm{m} / \mathrm{z}$ calcd for $\mathrm{C}_{18} \mathrm{H}_{17} \mathrm{~N}_{2}[\mathrm{M}+\mathrm{H}]^{+}:$261.1386, found: 261.1384 .

A suspension of 1-( $m$-tolyl)-1H-pyrazole (20c) $(39.6 \mathrm{mg}, 0.25 \mathrm{mmol})$, ethynylbenzene (8o) $(66.1 \mathrm{mg}$, $0.50 \mathrm{mmol}), \mathrm{HOAC}(6.0 \mu \mathrm{L}, 40 \mathrm{~mol} \%),\left[\mathrm{MnBr}(\mathrm{CO})_{5}\right](13.7 \mathrm{mg}, 20.0 \mathrm{~mol} \%)$ in 1,4-dioxane $(1.0 \mathrm{~mL})$ was stirred at $100{ }^{\circ} \mathrm{C}$ for $16 \mathrm{~h}$ under $\mathrm{N}_{2}$. After cooling to ambient temperature, the mixture was transferred into a round bottom flask with $\mathrm{CH}_{2} \mathrm{Cl}_{2}(20 \mathrm{~mL})$ and concentrated in vacuo. Purification by column chromatography on silica gel ( -hexane/EtOAc: $20 / 1)$ yielded 74 co $(31.3 \mathrm{mg}, 48 \%$ ) as a colorless oil. The data has been reported above.

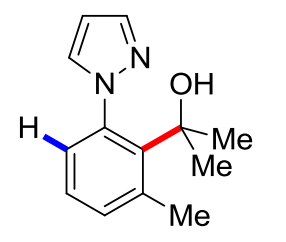

$203 a$

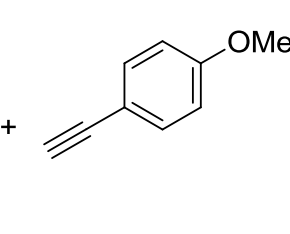

$8 q$

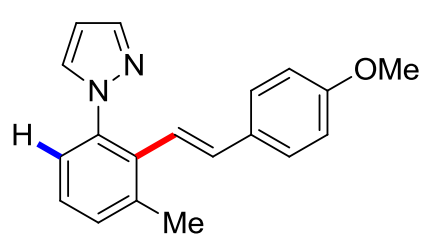

204aq: $59 \%$

A suspension of 2-[2-methyl-6-(1H-pyrazol-1-yl)phenyl]propan-2-ol (203a) (54.1 mg, $0.25 \mathrm{mmol})$, 1-ethynyl-4-methoxybenzene (8q) $(66.1 \mathrm{mg}, 0.50 \mathrm{mmol}),\left[\mathrm{MnBr}(\mathrm{CO})_{5}\right](6.9 \mathrm{mg}, 10.0 \mathrm{~mol} \%)$ in $\mathrm{H}_{2} \mathrm{O}$ $(1.0 \mathrm{~mL})$ was stirred at $120^{\circ} \mathrm{C}$ for $16 \mathrm{~h}$ under $\mathrm{N}_{2}$. After cooling to ambient temperature, EtOAc (10 $\mathrm{mL}$ ) was added and the mixture was dried over $\mathrm{Na}_{2} \mathrm{SO}_{4}$, washed with EtOAc $(30 \mathrm{~mL})$ and concentrated in vacuo. Purification by column chromatography on silica gel ( $n$-hexane/EtOAc: 10/1) yielded 204aq (43.0 mg, 59\%) as a colorless oil.<smiles>COc1ccc(/C=C/c2c(C)cccc2-n2cccn2)cc1</smiles>

(E)-1-[2-(4-Methoxystyryl)-3-methylphenyl]-1H-pyrazole (204aq) ${ }^{1} \mathrm{H}$ NMR $\left(600 \mathrm{MHz}, \mathrm{CDCl}_{3}\right) \delta=$ $7.70(\mathrm{dd}, J=1.9,0.7 \mathrm{~Hz}, 1 \mathrm{H}), 7.58(\mathrm{dd}, J=2.4,0.7 \mathrm{~Hz}, 1 \mathrm{H}), 7.35-7.27(\mathrm{~m}, 2 \mathrm{H}), 7.26-7.20(\mathrm{~m}, 3 \mathrm{H})$, 6.89-6.82 (m, 2H), $6.74(\mathrm{~d}, J=16.7 \mathrm{~Hz}, 1 \mathrm{H}), 6.36(\mathrm{dd}, J=2.4,1.9 \mathrm{~Hz}, 1 \mathrm{H}), 6.23(\mathrm{~d}, J=16.7 \mathrm{~Hz}, 1 \mathrm{H})$, 
$3.80(\mathrm{~s}, 3 \mathrm{H}), 2.48(\mathrm{~s}, 3 \mathrm{H}) .{ }^{13} \mathrm{C}$ NMR $\left(125 \mathrm{MHz}, \mathrm{CDCl}_{3}\right) \delta=159.3\left(\mathrm{C}_{\mathrm{q}}\right), 140.0(\mathrm{CH}), 139.1\left(\mathrm{C}_{\mathrm{q}}\right), 137.5\left(\mathrm{C}_{\mathrm{q}}\right)$, $133.8(\mathrm{CH}), 133.3\left(\mathrm{C}_{\mathrm{q}}\right), 131.3(\mathrm{CH}), 130.4(\mathrm{CH}), 130.0\left(\mathrm{C}_{\mathrm{q}}\right), 127.5(\mathrm{CH}), 126.9(\mathrm{CH}), 124.5(\mathrm{CH}), 120.9$ (CH), $114.0(\mathrm{CH}), 106.2(\mathrm{CH}), 55.3\left(\mathrm{CH}_{3}\right), 21.3\left(\mathrm{CH}_{3}\right)$. IR (ATR) $v=2835,1605,1509,1472,1393,1247$, 1173, 1031, $752 \mathrm{~cm}^{-1}$. MS (ESI) m/z (relative intensity): $313(10)[\mathrm{M}+\mathrm{Na}]^{+}, 291(100)[\mathrm{M}+\mathrm{H}]^{+} . \mathbf{H R}-\mathbf{M S}$ (ESI) $\mathrm{m} / \mathrm{z}$ calcd for $\mathrm{C}_{19} \mathrm{H}_{19} \mathrm{~N}_{2} \mathrm{O}[\mathrm{M}+\mathrm{H}]^{+}:$291.1492, found: 291.1486.
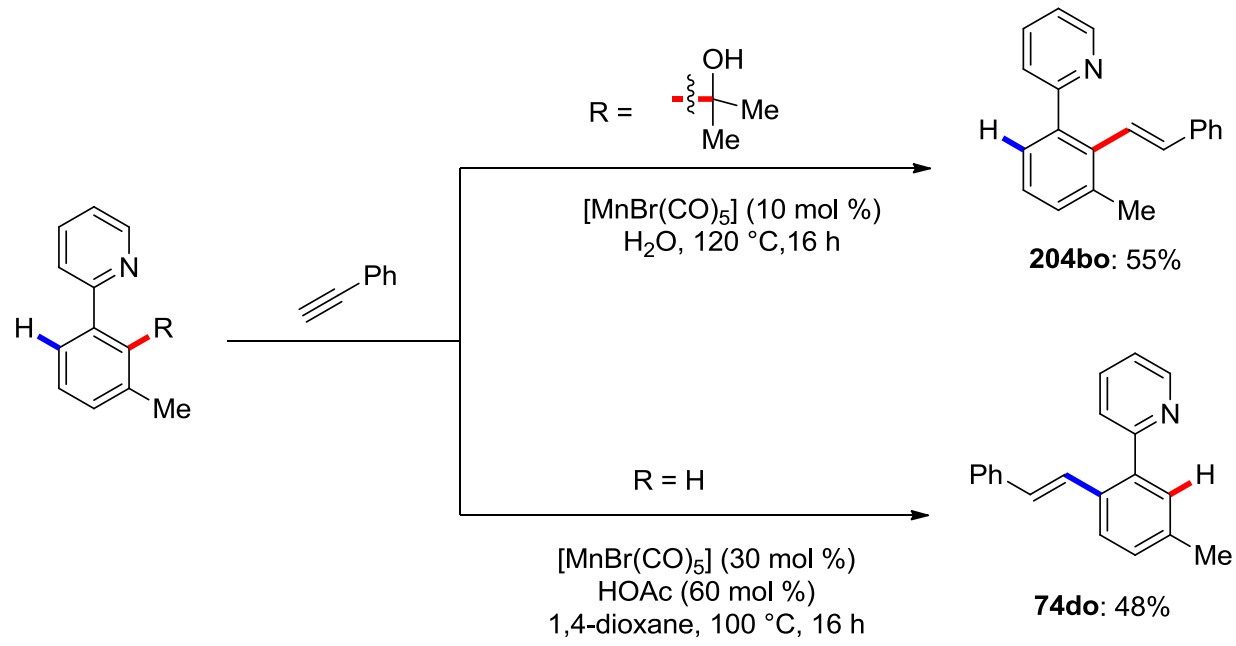

74do: $48 \%$

A suspension of 2-[2-methyl-6-(pyridin-2-yl)phenyl]propan-2-ol (203b) (56.8 mg, $0.25 \mathrm{mmol}$ ), ethynylbenzene (8o) (66.1 mg, $0.50 \mathrm{mmol}),\left[\mathrm{MnBr}(\mathrm{CO})_{5}\right](6.9 \mathrm{mg}, 10.0 \mathrm{~mol} \%)$ in $\mathrm{H}_{2} \mathrm{O}(1.0 \mathrm{~mL})$ was stirred at $120^{\circ} \mathrm{C}$ for $16 \mathrm{~h}$ under $\mathrm{N}_{2}$. After cooling to ambient temperature, EtOAc $(10 \mathrm{~mL})$ was added and the mixture was dried over $\mathrm{Na}_{2} \mathrm{SO}_{4}$, washed with EtOAc $(30 \mathrm{~mL})$ and concentrated in vacuo. Purification by column chromatography on silica gel ( $n$-hexane/EtOAc: $20 / 1$ ) yielded 204bo (37.3 mg, $55 \%)$ as a colorless oil.<smiles>Cc1cccc(-c2ccccn2)c1/C=C/c1ccccc1</smiles>

(E)-2-(3-Methyl-2-styrylphenyl)pyridine (204bo) ${ }^{1} \mathrm{H}$ NMR $\left(600 \mathrm{MHz}, \mathrm{CDCl}_{3}\right) \delta=8.66$ (ddd, $J=4.9$, 1.8, $1.1 \mathrm{~Hz}, 1 \mathrm{H}), 7.60$ (ddd, J = 7.7, 7.7, $1.8 \mathrm{~Hz}, 1 \mathrm{H}), 7.43-7.36(\mathrm{~m}, 2 \mathrm{H}), 7.30-7.23(\mathrm{~m}, 6 \mathrm{H}), 7.22-7.17$ (m, 1H), $7.15(\mathrm{ddd}, J=7.5,4.9,1.1 \mathrm{~Hz}, 1 \mathrm{H}), 7.10(\mathrm{~d}, J=16.6 \mathrm{~Hz}, 1 \mathrm{H}), 6.28(\mathrm{~d}, J=16.6 \mathrm{~Hz}, 1 \mathrm{H}), 2.46(\mathrm{~s}$, 3H). ${ }^{13} \mathrm{C}$ NMR $\left(125 \mathrm{MHz}, \mathrm{CDCl}_{3}\right) \delta=160.1\left(\mathrm{C}_{\mathrm{q}}\right), 149.1(\mathrm{CH}), 140.2\left(\mathrm{C}_{\mathrm{q}}\right), 137.4\left(\mathrm{C}_{\mathrm{q}}\right), 136.6\left(\mathrm{C}_{\mathrm{q}}\right), 135.6$ $\left(\mathrm{C}_{\mathrm{q}}\right), 135.5(\mathrm{CH}), 134.9(\mathrm{CH}), 130.4(\mathrm{CH}), 128.4(\mathrm{CH}), 127.9(\mathrm{CH}), 127.3(\mathrm{CH}), 126.9(\mathrm{CH}), 126.7(\mathrm{CH})$, $126.1(\mathrm{CH}), 125.1(\mathrm{CH}), 121.3(\mathrm{CH}), 21.2\left(\mathrm{CH}_{3}\right)$. IR (ATR) $v=3057,1585,1452,1426,967,749,732$ 
$\mathrm{cm}^{-1}$. MS (ESI) m/z (relative intensity): $272(100)[\mathrm{M}+\mathrm{H}]^{+}$. HR-MS (ESI) m/z calcd for $\mathrm{C}_{20} \mathrm{H}_{18} \mathrm{~N}[\mathrm{M}+\mathrm{H}]^{+}$: 272.1434, found: 272.1430 .

A suspension of 2-( $m$-tolyl)pyridine $(20 \mathrm{~d})(42.3 \mathrm{mg}, 0.25 \mathrm{mmol})$, ethynylbenzene (8o) $(66.1 \mathrm{mg}, 0.50$ $\mathrm{mmol}), \mathrm{HOAc}(9.0 \mu \mathrm{L}, 60 \mathrm{~mol} \%),\left[\mathrm{MnBr}(\mathrm{CO})_{5}\right](20.6 \mathrm{mg}, 20.0 \mathrm{~mol} \%)$ in 1,4-dioxane $(1.0 \mathrm{~mL})$ was stirred at $100{ }^{\circ} \mathrm{C}$ for $16 \mathrm{~h}$ under $\mathrm{N}_{2}$. After cooling to ambient temperature, the mixture was transferred into a round bottom flask with $\mathrm{CH}_{2} \mathrm{Cl}_{2}(20 \mathrm{~mL})$ and concentrated in vacuo. Purification by column chromatography on silica gel ( $n$-hexane/EtOAc: $20 / 1)$ yielded 74 do $(17.0 \mathrm{mg}, 25 \%)$ as a colorless oil.<smiles>Cc1ccc(/C=C/c2ccccc2)c(-c2ccccn2)c1</smiles>

(E)-2-(5-Methyl-2-styrylphenyl)pyridine (74do) ${ }^{1} \mathrm{H}$ NMR $\left(400 \mathrm{MHz}, \mathrm{CDCl}_{3}\right) \delta=8.77-8.66(\mathrm{~m}, 1 \mathrm{H})$, 7.71 (ddd, $J=7.7,7.7,1.6 \mathrm{~Hz}, 1 \mathrm{H}), 7.65$ (d, $J=8.0 \mathrm{~Hz}, 1 \mathrm{H}), 7.43$ (dd, $J=8.0,1.1 \mathrm{~Hz}, 1 \mathrm{H}), 7.38-7.35$ (m, 3H), 7.33-7.15 (m, 6H), 7.00 (d, $J=16.2 \mathrm{~Hz}, 1 \mathrm{H}), 2.40$ (s, 3H). ${ }^{13} \mathrm{C}$ NMR $\left(100 \mathrm{MHz}, \mathrm{CDCl}_{3}\right) \delta=158.9$ $\left(\mathrm{C}_{\mathrm{q}}\right), 149.5(\mathrm{CH}), 139.5\left(\mathrm{C}_{\mathrm{q}}\right), 137.7\left(\mathrm{C}_{\mathrm{q}}\right), 137.6\left(\mathrm{C}_{\mathrm{q}}\right), 135.9(\mathrm{CH}), 132.8\left(\mathrm{C}_{\mathrm{q}}\right), 130.7(\mathrm{CH}), 129.5(\mathrm{CH})$, $129.2(\mathrm{CH}), 128.6(\mathrm{CH}), 127.4(\mathrm{CH}), 127.3(\mathrm{CH}), 126.5(\mathrm{CH}), 126.2(\mathrm{CH}), 125.1(\mathrm{CH}), 121.8(\mathrm{CH}), 21.2$ $\left(\mathrm{CH}_{3}\right)$. IR (ATR) $v=3023,1585,1565,1497,1462,964,750,693 \mathrm{~cm}^{-1}$. MS (ESI) m/z (relative intensity): $272[\mathrm{M}+\mathrm{H}]^{+}$. HR-MS (ESI) m/z calcd for $\mathrm{C}_{20} \mathrm{H}_{18} \mathrm{~N}[\mathrm{M}+\mathrm{H}]^{+}:$272.1434, found: 272.1430 .

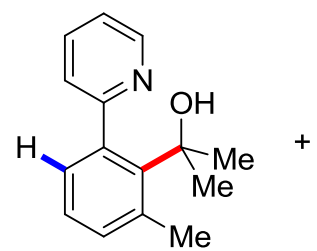

203b

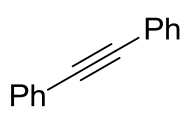

$8 \mathbf{a}$<smiles>Cc1cccc(-c2ccccn2)c1/C(=C/c1ccccc1)c1ccccc1</smiles>

204ba: $71 \%$

A suspension of 2-[2-methyl-6-(pyridin-2-yl)phenyl]propan-2-ol (203b) (56.8 mg, $0.25 \mathrm{mmol}$ ), methyl 2-\{[(tert-butoxycarbonyl)oxy]methyl\}acrylate (8a) $(89.1 \mathrm{mg}, 0.50 \mathrm{mmol})$ and $\left[\mathrm{MnBr}(\mathrm{CO})_{5}\right]$ $(6.9 \mathrm{mg}, 10.0 \mathrm{~mol} \%)$ in 1,4 -dioxane $(1.0 \mathrm{~mL})$ was stirred at $120^{\circ} \mathrm{C}$ for $16 \mathrm{~h}$ under $\mathrm{N}_{2}$. After cooling to ambient temperature, the mixture was transferred into a round bottom flask with $\mathrm{CH}_{2} \mathrm{Cl}_{2}(20 \mathrm{~mL})$ 
and concentrated in vacuo. Purification by column chromatography on silica gel ( $n$-hexane/EtOAc: $20 / 1$ ) yielded 204 ba (61.4 $\mathrm{mg}, 71 \%$ ) as a colorless oil.<smiles>Cc1cccc(-c2ccccn2)c1/C(=C/c1ccccc1)c1ccccc1</smiles>

(E)-2-[2-(1,2-Diphenylvinyl)-3-methylphenyl]pyridine (204ba) ${ }^{1} \mathrm{H}$ NMR $\left(400 \mathrm{MHz}, \mathrm{CDCl}_{3}\right) \delta=8.50$ (ddd, $J=4.9,1.8,1.0 \mathrm{~Hz}, 1 \mathrm{H}), 7.48(\mathrm{ddd}, J=7.7,7.7,1.8 \mathrm{~Hz}, 1 \mathrm{H}), 7.44-7.38(\mathrm{~m}, 2 \mathrm{H}), 7.32(\mathrm{dd}, J=7.5$, $7.5 \mathrm{~Hz}, 1 \mathrm{H}), 7.27$ (ddd, $J=7.5,1.6,0.7 \mathrm{~Hz}, 1 \mathrm{H}), 7.17-7.09(\mathrm{~m}, 3 \mathrm{H}), 7.07-6.94(\mathrm{~m}, 8 \mathrm{H}), 6.49(\mathrm{~s}, 1 \mathrm{H})$, $2.26(\mathrm{~s}, 3 \mathrm{H}) .{ }^{13} \mathrm{C}$ NMR $\left(100 \mathrm{MHz}, \mathrm{CDCl}_{3}\right) \delta=160.0\left(\mathrm{C}_{\mathrm{q}}\right), 148.9(\mathrm{CH}), 142.2\left(\mathrm{C}_{\mathrm{q}}\right), 141.2\left(\mathrm{C}_{\mathrm{q}}\right), 140.0\left(\mathrm{C}_{\mathrm{q}}\right)$, $139.6\left(\mathrm{C}_{\mathrm{q}}\right), 137.6\left(\mathrm{C}_{\mathrm{q}}\right), 137.0\left(\mathrm{C}_{\mathrm{q}}\right), 135.1(\mathrm{CH}), 131.9(\mathrm{CH}), 130.4(\mathrm{CH}), 129.9(\mathrm{CH}), 128.9(\mathrm{CH}), 127.9$ $(\mathrm{CH}), 127.6(\mathrm{CH}), 127.5(\mathrm{CH}), 127.3(\mathrm{CH}), 126.7(\mathrm{CH}), 126.6(\mathrm{CH}), 124.3(\mathrm{CH}), 121.1(\mathrm{CH}), 20.8\left(\mathrm{CH}_{3}\right)$. IR (ATR) $v=3055,3020,1586,1492,1444,909,772,732,695 \mathrm{~cm}^{-1}$. MS (ESI) m/z (relative intensity): 348 (100) $[\mathrm{M}+\mathrm{H}]^{+}$. HR-MS (ESI) m/z calcd for $\mathrm{C}_{26} \mathrm{H}_{22} \mathrm{~N}[\mathrm{M}+\mathrm{H}]^{+}: 348.1747$, found: 348.1744.

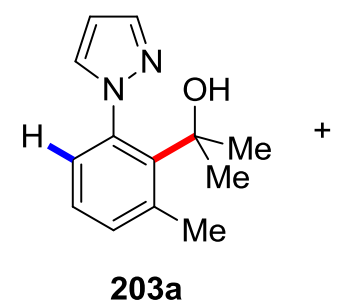

203a

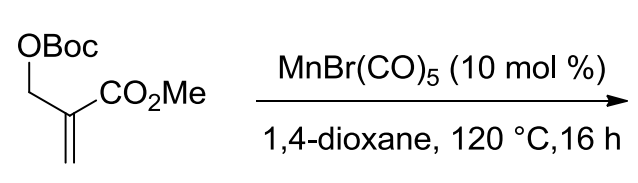

201a<smiles>C=C(COC)Cc1c(C)cccc1-n1cccn1</smiles>

205aa: $82 \%$

A suspension of 2-[2-methyl-6-(1H-pyrazol-1-yl)phenyl]propan-2-ol (203a) (54.1 mg, $0.25 \mathrm{mmol}$ ), methyl 2-\{[(tert-butoxycarbonyl)oxy]methyl\}acrylate (201a) (108.1 mg, $0.50 \mathrm{mmol}),\left[\mathrm{MnBr}(\mathrm{CO})_{5}\right]$ (6.9 mg, $10.0 \mathrm{~mol} \%)$ in 1,4-dioxane $(1.0 \mathrm{~mL})$ was stirred at $120^{\circ} \mathrm{C}$ for $16 \mathrm{~h}$ under $\mathrm{N}_{2}$. After cooling to ambient temperature, the mixture was transferred into a round bottom flask with $\mathrm{CH}_{2} \mathrm{Cl}_{2}(20 \mathrm{~mL})$ and concentrated in vacuo. Purification by column chromatography on silica gel ( $n$-hexane/EtOAc: 6/1) yielded $205 \mathrm{aa}(52.7 \mathrm{mg}, 82 \%$ ) as a colorless oil. 
<smiles>C=C(Cc1c(C)cccc1-n1cccn1)C(C)=O</smiles>

Methyl 2-[2-methyl-6-(1H-pyrazol-1-yl)benzyl]acrylate (205aa) ${ }^{1} \mathrm{H}$ NMR $\left(600 \mathrm{MHz}, \mathrm{CDCl}_{3}\right) \delta=7.63$ (dd, $J=1.8,0.7 \mathrm{~Hz}, 1 \mathrm{H}), 7.45(\mathrm{dd}, J=2.4,0.7 \mathrm{~Hz}, 1 \mathrm{H}), 7.25-7.21(\mathrm{~m}, 2 \mathrm{H}), 7.18(\mathrm{dd}, J=6.6,2.4 \mathrm{~Hz}, 1 \mathrm{H})$, $6.33(\mathrm{dd}, J=2.4,1.8 \mathrm{~Hz}, 1 \mathrm{H}), 6.14(\mathrm{td}, J=1.8,0.9 \mathrm{~Hz}, 1 \mathrm{H}), 5.04(\mathrm{td}, J=1.1,0.9 \mathrm{~Hz}, 1 \mathrm{H}), 3.71(\mathrm{~s}, 3 \mathrm{H})$, $3.46(\mathrm{dd}, J=1.8,1.1 \mathrm{~Hz}, 2 \mathrm{H}), 2.26(\mathrm{~s}, 3 \mathrm{H}) .{ }^{13} \mathrm{C} \mathrm{NMR}\left(125 \mathrm{MHz}, \mathrm{CDCl}_{3}\right) \delta=167.0\left(\mathrm{C}_{\mathrm{q}}\right), 140.7\left(\mathrm{C}_{\mathrm{q}}\right), 140.2$ $(\mathrm{CH}), 138.8\left(\mathrm{C}_{\mathrm{q}}\right), 138.4\left(\mathrm{C}_{\mathrm{q}}\right), 132.7\left(\mathrm{C}_{\mathrm{q}}\right), 130.6(\mathrm{CH}), 130.6(\mathrm{CH}), 127.1(\mathrm{CH}), 124.9\left(\mathrm{CH}_{2}\right), 124.7(\mathrm{CH})$, $106.0(\mathrm{CH}), 52.0\left(\mathrm{CH}_{3}\right), 30.1\left(\mathrm{CH}_{2}\right), 19.7\left(\mathrm{CH}_{3}\right)$. IR (ATR) $v=2950,1715,1516,1394,1278,1255,1135$, 947, $749 \mathrm{~cm}^{-1}$. MS (ESI) m/z (relative intensity): 279 (65) $[\mathrm{M}+\mathrm{Na}]^{+}, 257(100)[\mathrm{M}+\mathrm{H}]^{+}, 225(10)$. HR-MS (ESI) m/z calcd for $\mathrm{C}_{15} \mathrm{H}_{17} \mathrm{~N}_{2} \mathrm{O}_{2}[\mathrm{M}+\mathrm{H}]^{+}: 257.1285$, found: 257.1280 .

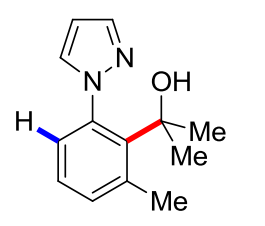

203a

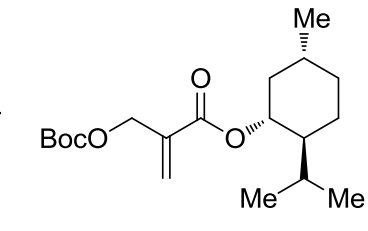

201b

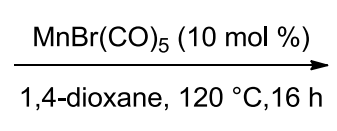

205ab: $91 \%$

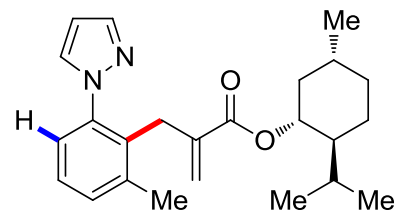

A suspension of 2-[2-methyl-6-(1H-pyrazol-1-yl)phenyl]propan-2-ol (203a) (54.0 mg, $0.25 \mathrm{mmol})$, $(1 R, 2 S, 5 R)$-2-isopropyl-5-methylcyclohexyl 2-\{[(tert-butoxycarbonyl)oxy]methyl)\} acrylate (201b) (136.2 mg, $0.50 \mathrm{mmol})$, and $\left[\mathrm{MnBr}(\mathrm{CO})_{5}\right](6.9 \mathrm{mg}, 10.0 \mathrm{~mol} \%)$ in 1,4-dioxane $(1.0 \mathrm{~mL})$ was stirred at $120^{\circ} \mathrm{C}$ for $16 \mathrm{~h}$ under $\mathrm{N}_{2}$. After cooling to ambient temperature, the mixture was transferred into a round bottom flask with $\mathrm{CH}_{2} \mathrm{Cl}_{2}(20 \mathrm{~mL})$ and concentrated in vacuo. Purification by column chromatography on silica gel ( $n$-hexane/EtOAc: $9 / 1 \rightarrow 6 / 1$ ) yielded 205ab (86.6 mg, 91\%) as a colorless oil.<smiles>C=C(Cc1c(C)cccc1-n1cccn1)C(=O)O[CH+]C1CC(C)CCC1C(C)C</smiles>

(1R,2S,5R)-2-Isopropyl-5-methylcyclohexyl 2-[2-methyl-6-(1H-pyrazol-1-yl)benzyl]acrylate (205ab)

${ }^{1} \mathbf{H}$ NMR $\left(600 \mathrm{MHz}, \mathrm{CDCl}_{3}\right) \delta=7.63(\mathrm{dd}, J=1.9,0.7 \mathrm{~Hz}, 1 \mathrm{H}), 7.45(\mathrm{dd}, J=2.4,0.7 \mathrm{~Hz}, 1 \mathrm{H}), 7.27-7.18$ 
(m, 3H), 6.34-6.30 (m, 1H), $6.11(\mathrm{td}, J=1.7,1.2 \mathrm{~Hz}, 1 \mathrm{H}), 5.02(\mathrm{td}, J=2.1,1.2 \mathrm{~Hz}, 1 \mathrm{H}), 4.71(\mathrm{ddd}, J=$ $10.9,10.9,4.4 \mathrm{~Hz}, 1 \mathrm{H}$ ), 3.45 (dd, $J=2.1,1.7 \mathrm{~Hz}, 2 \mathrm{H}), 2.28(\mathrm{~s}, 3 \mathrm{H}), 2.01-1.94(\mathrm{~m}, 1 \mathrm{H}), 1.75$ (heptd, $J=$ 6.9, $2.7 \mathrm{~Hz}, 1 \mathrm{H}), 1.70-1.61(\mathrm{~m}, 2 \mathrm{H}), 1.48(\mathrm{tdt}, J=12.0,6.7,3.3 \mathrm{~Hz}, 1 \mathrm{H}), 1.40-1.34(\mathrm{~m}, 1 \mathrm{H}), 1.10-1.00$ (m, 1H), $0.96(\mathrm{td}, J=12.1,10.9 \mathrm{~Hz}, 1 \mathrm{H}), 0.88(\mathrm{~d}, J=6.6 \mathrm{~Hz}, 3 \mathrm{H}), 0.86-0.84(\mathrm{~m}, 4 \mathrm{H}), 0.72(\mathrm{~d}, J=6.9 \mathrm{~Hz}$, 3H). ${ }^{13} \mathrm{C}$ NMR $\left(125 \mathrm{MHz}, \mathrm{CDCl}_{3}\right) \delta=166.1\left(\mathrm{C}_{\mathrm{q}}\right), 140.6\left(\mathrm{C}_{\mathrm{q}}\right), 140.1(\mathrm{CH}), 139.1\left(\mathrm{C}_{\mathrm{q}}\right), 138.7\left(\mathrm{C}_{\mathrm{q}}\right), 133.2$ $\left(\mathrm{C}_{q}\right), 130.7(\mathrm{CH}), 130.6(\mathrm{CH}), 127.0(\mathrm{CH}), 124.7(\mathrm{CH}), 124.4\left(\mathrm{CH}_{2}\right), 105.9(\mathrm{CH}), 74.7(\mathrm{CH}), 47.1(\mathrm{CH})$, $40.8\left(\mathrm{CH}_{2}\right), 34.3\left(\mathrm{CH}_{2}\right), 31.4(\mathrm{CH}), 30.1\left(\mathrm{CH}_{2}\right), 26.5(\mathrm{CH}), 23.6\left(\mathrm{CH}_{2}\right), 22.1\left(\mathrm{CH}_{3}\right), 20.8\left(\mathrm{CH}_{3}\right), 19.7\left(\mathrm{CH}_{3}\right)$, $16.5\left(\mathrm{CH}_{3}\right)$. IR (ATR) $v=2953,2927,2869,1708,1516,1476,1393,1250,1132,746 \mathrm{~cm}^{-1}$. MS (ESI) $\mathrm{m} / \mathrm{z}$ (relative intensity): $783(58)[2 \mathrm{M}+\mathrm{Na}]^{+}, 403(60)[\mathrm{M}+\mathrm{Na}]^{+}, 381(100)[\mathrm{M}+\mathrm{H}]^{+}$. HR-MS (ESI) m/z calcd for $\mathrm{C}_{24} \mathrm{H}_{33} \mathrm{~N}_{2} \mathrm{O}_{2}[\mathrm{M}+\mathrm{H}]^{+}: 381.2537$, found: 381.2533 .
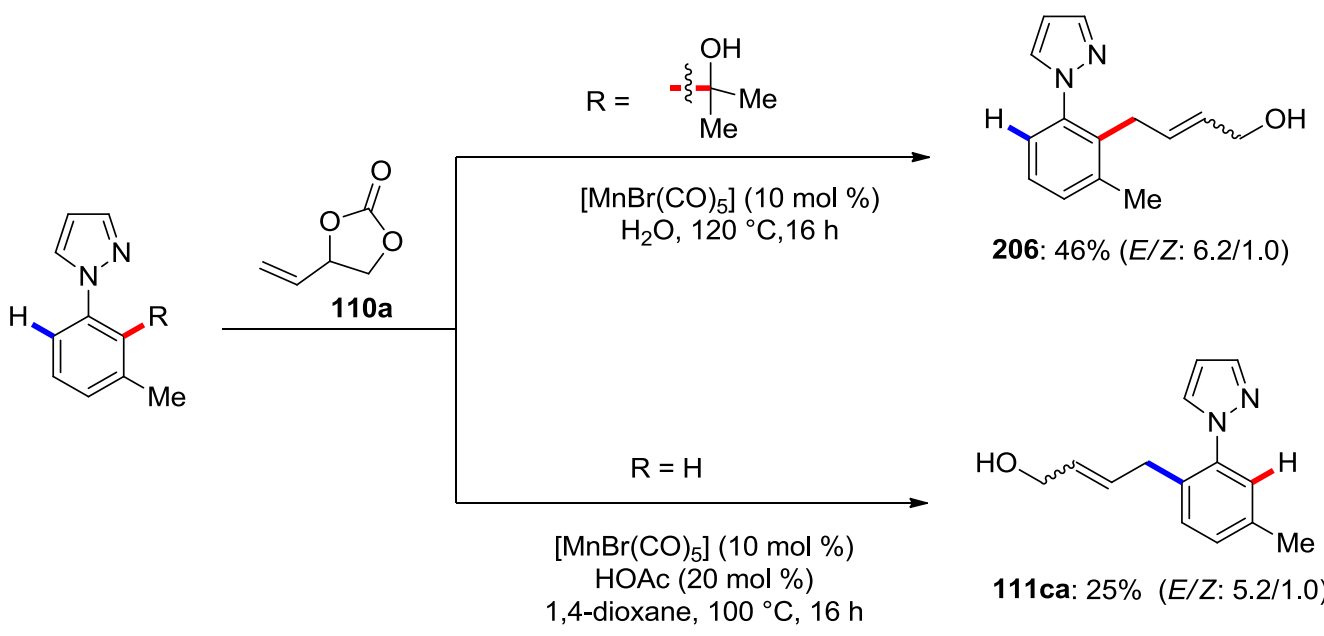

111ca: $25 \%(E / Z: 5.2 / 1.0)$

A suspension of 2-[2-methyl-6-(1H-pyrazol-1-yl)phenyl]propan-2-ol (168a) (54.1 mg, $0.25 \mathrm{mmol})$, 4-vinyl-1,3-dioxolan-2-one (110a) (48.0 $\mu \mathrm{L}, 0.50 \mathrm{mmol}),\left[\mathrm{MnBr}(\mathrm{CO})_{5}\right](6.9 \mathrm{mg}, 10.0 \mathrm{~mol} \%)$ in $\mathrm{H}_{2} \mathrm{O}$ $\left(1.0 \mathrm{~mL}\right.$ ) was stirred at $120^{\circ} \mathrm{C}$ for $16 \mathrm{~h}$ under $\mathrm{N}_{2}$. After cooling to ambient temperature, EtOAc (10 $\mathrm{mL}$ ) was added and the mixture was dried over $\mathrm{Na}_{2} \mathrm{SO}_{4}$, washed with EtOAc $(30 \mathrm{~mL})$ and concentrated in vacuo. Purification by column chromatography on silica gel ( $n$-hexane/EtOAc: $2 / 1$ ) yielded 206 ( $26.1 \mathrm{mg}, 46 \%, E / Z=6.2 / 1.0$ by ${ }^{1} \mathrm{H}$ NMR $)$ as a colorless oil. 
<smiles></smiles>

4-[2-Methyl-6-(1H-pyrazol-1-yl)phenyl]but-2-en-1-ol (206) ${ }^{1} \mathrm{H}$ NMR $\left(600 \mathrm{MHz}, \mathrm{CDCl}_{3}\right) \delta=7.71-7.69$ $(J=1.9,0.7 \mathrm{~Hz}, 0.14 \mathrm{H}), 7.66(J=1.9,0.7 \mathrm{~Hz}, 0.86 \mathrm{H}), 7.57-7.49(\mathrm{~m}, 1 \mathrm{H}), 7.25-7.09(\mathrm{~m}, 3 \mathrm{H}), 6.41(\mathrm{dd}$, $J=2.1,1.9 \mathrm{~Hz}, 0.14 \mathrm{H}), 6.37(\mathrm{dd}, J=2.1,1.9 \mathrm{~Hz}, 0.86 \mathrm{H}), 5.64(\mathrm{dtt}, J=15.4,6.4,1.4 \mathrm{~Hz}, 0.86 \mathrm{H}), 5.53$ (dtt, $J=15.4,6.4,1.4 \mathrm{~Hz}, 0.14 \mathrm{H}), 5.40(\mathrm{dtt}, J=15.4,6.4,1.4 \mathrm{~Hz}, 0.14 \mathrm{H}), 5.34(\mathrm{dtt}, J=15.4,6.4,1.4 \mathrm{~Hz}$, $0.86 \mathrm{H}), 3.97(\mathrm{dt}, J=5.9,1.2 \mathrm{~Hz}, 1.72 \mathrm{H}), 3.93(\mathrm{dd}, J=5.9,1.2 \mathrm{~Hz}, 0.28 \mathrm{H}), 3.26(\mathrm{dd}, J=5.9,1.5 \mathrm{~Hz}$, $0.28 \mathrm{H}), 3.19(\mathrm{dd}, J=5.9,1.5 \mathrm{~Hz}, 1.72 \mathrm{H}), 2.37(\mathrm{~s}, 0.42 \mathrm{H}), 2.35(\mathrm{~s}, 2.58 \mathrm{H}), 1.92(\mathrm{brs}, 1 \mathrm{H}) .{ }^{13} \mathrm{C}$ NMR $(125$ $\left.\mathrm{MHz}, \mathrm{CDCl}_{3}\right)$ Major isomer: $\delta=140.1\left(\mathrm{C}_{\mathrm{q}}\right), 134.0(\mathrm{CH}), 138.4\left(\mathrm{C}_{\mathrm{q}}\right), 134.3\left(\mathrm{C}_{\mathrm{q}}\right), 131.0(\mathrm{CH}), 130.7(\mathrm{CH})$, 130.0 (CH), $129.4(\mathrm{CH}), 126.6(\mathrm{CH}), 124.7(\mathrm{CH}), 105.9(\mathrm{CH}), 63.3\left(\mathrm{CH}_{2}\right), 30.9\left(\mathrm{CH}_{2}\right), 19.9\left(\mathrm{CH}_{3}\right)$. Minor isomer: $\delta=140.2(\mathrm{CH}), 139.9\left(\mathrm{C}_{\mathrm{q}}\right), 138.1\left(\mathrm{C}_{\mathrm{q}}\right), 135.2\left(\mathrm{C}_{\mathrm{q}}\right), 131.2(\mathrm{CH}), 130.9(\mathrm{CH}), 129.2(\mathrm{CH}), 129.1$ (CH), $126.5(\mathrm{CH}), 124.8(\mathrm{CH}), 106.1(\mathrm{CH}), 58.0\left(\mathrm{CH}_{2}\right), 26.9\left(\mathrm{CH}_{2}\right), 19.9\left(\mathrm{CH}_{3}\right)$. IR (ATR) $v=3335,2856$, 1514, 1475, 1395, 1046, 973, $754 \mathrm{~cm}^{-1}$. MS (ESI) m/z (relative intensity): 251 (60) [M+Na] $]^{+}, 229$ (30) $[\mathrm{M}+\mathrm{H}]^{+}, 211$ (100). HR-MS (ESI) m/z calcd for $\mathrm{C}_{14} \mathrm{H}_{17} \mathrm{~N}_{2} \mathrm{O}[\mathrm{M}+\mathrm{H}]^{+}:$229.1335, found: 229.1333 .

A suspension of 1-( $m$-tolyl)-1H-pyrazole (20c) (39.6 mg, $0.25 \mathrm{mmol})$, 4-vinyl-1,3-dioxolan-2-one (110a) (48.0 $\mu \mathrm{L}, 0.50 \mathrm{mmol}), \operatorname{HOAc}(3.0 \mu \mathrm{L}, 20 \mathrm{~mol} \%),\left[\mathrm{MnBr}(\mathrm{CO})_{5}\right](6.9 \mathrm{mg}, 10.0 \mathrm{~mol} \%)$ in 1,4-dioxane $(1.0 \mathrm{~mL})$ was stirred at $100{ }^{\circ} \mathrm{C}$ for $16 \mathrm{~h}$ under $\mathrm{N}_{2}$. After cooling to ambient temperature, the mixture was transferred into a round bottom flask with $\mathrm{CH}_{2} \mathrm{Cl}_{2}(20 \mathrm{~mL})$ and concentrated in vacuo. Purification by column chromatography on silica gel ( $n$-hexane/EtOAc: $2 / 1$ ) yielded 111ca (14.3 mg, 25\%, E/Z = 5.2/1.0 by ${ }^{1} \mathrm{H}$ NMR) as a colorless oil.

\section{$\mathrm{C}-\mathrm{C}$ versus $\mathrm{C}-\mathrm{H}$ Activation Experiments}

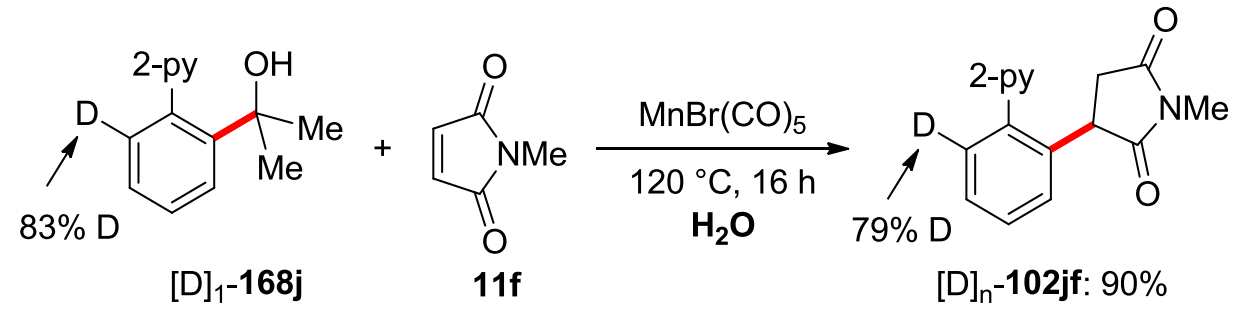


A suspension of 2-[2-(pyridin-2-yl)phenyl]propan-2-ol ([D $\left.]_{1}-168 j\right) \quad(53.5 \mathrm{mg}, 0.25 \mathrm{mmol})$, 1-methyl-1H-pyrrole-2,5-dione (11f) $(55.6 \mathrm{mg}, 0.50 \mathrm{mmol}),\left[\mathrm{MnBr}(\mathrm{CO})_{5}\right](6.9 \mathrm{mg}, 10.0 \mathrm{~mol} \%)$ in $\mathrm{H}_{2} \mathrm{O}$ $(1.0 \mathrm{~mL})$ was stirred at $120^{\circ} \mathrm{C}$ for $16 \mathrm{~h}$ under $\mathrm{N}_{2}$. After cooling to ambient temperature, the mixture was dried over $\mathrm{Na}_{2} \mathrm{SO}_{4}$, washed with EtOAc $(30 \mathrm{~mL})$ and concentrated in vacuo. Purification by column chromatography on silica gel afforded $[D]_{n}-102 j f$ (60.0 $\left.\mathrm{mg}, 90 \%\right)$. The deuterium incorporation was determined by ${ }^{1} \mathrm{H}$ NMR spectroscopy.

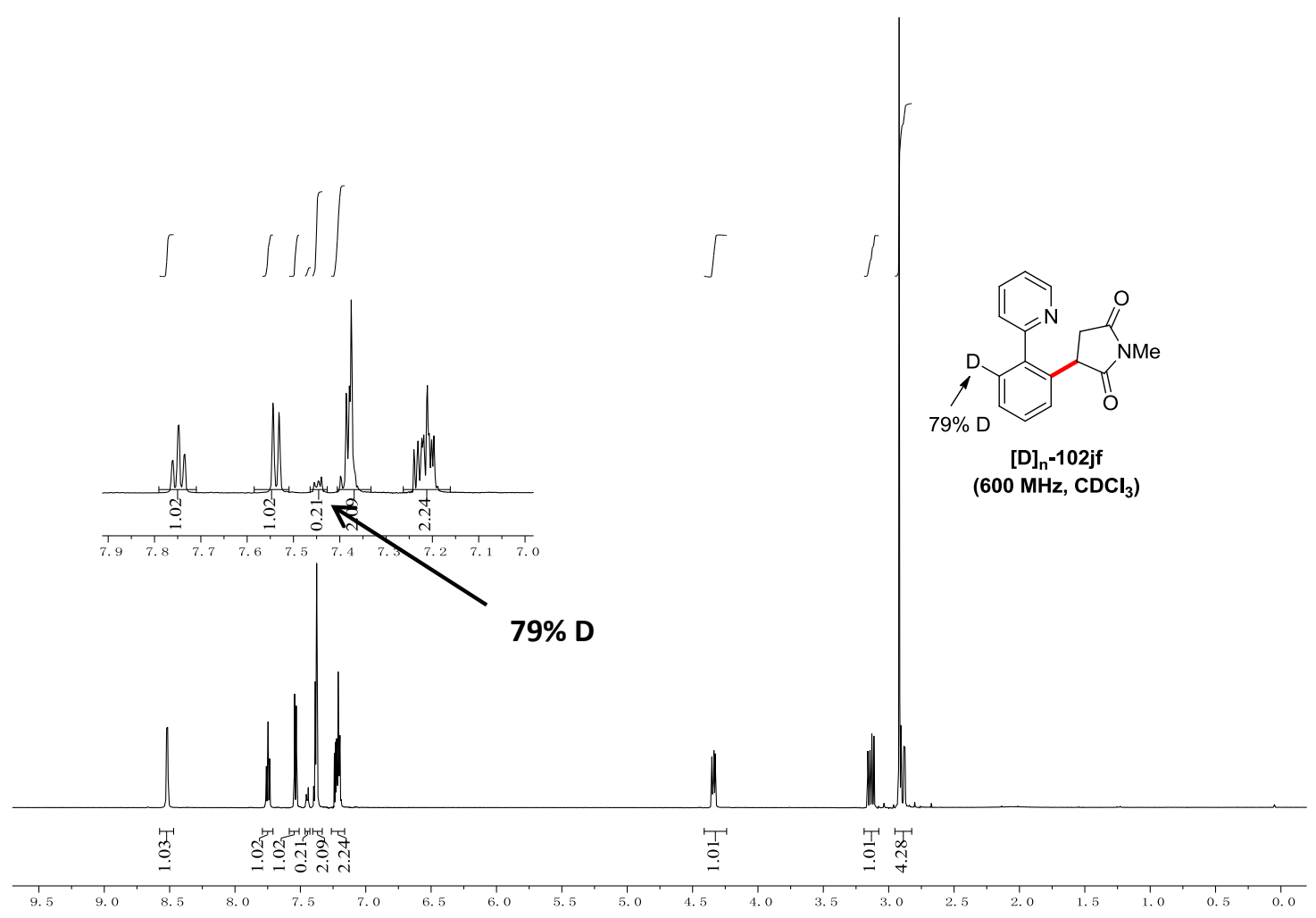

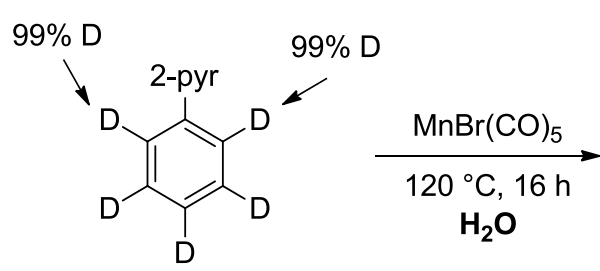

$[\mathrm{D}]_{5}-20 \mathrm{~b}$

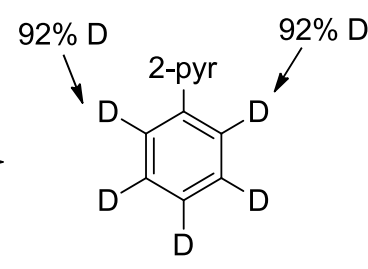

$[D]_{n}-20 b: 95 \%$

A suspension of 1-phenyl-1H-pyrazole ([D $\left.]_{5}-20 \mathrm{~b}\right)(37.3 \mathrm{mg}, 0.25 \mathrm{mmol}),\left[\mathrm{MnBr}(\mathrm{CO})_{5}\right](6.9 \mathrm{mg}, 10.0$ mol \%) in $\mathrm{H}_{2} \mathrm{O}(1.0 \mathrm{~mL})$ was stirred at $120{ }^{\circ} \mathrm{C}$ for $16 \mathrm{~h}$ under $\mathrm{N}_{2}$. After cooling to ambient temperature, the mixture was dried over $\mathrm{Na}_{2} \mathrm{SO}_{4}$, washed with EtOAc $(30 \mathrm{~mL})$ and concentrated in 
vacuo. Purification by column chromatography on silica gel afforded $[D]_{n}-20 b$ (35.4 mg, 95\%). The deuterium incorporation was determined by ${ }^{1} \mathrm{H}$ NMR spectroscopy.

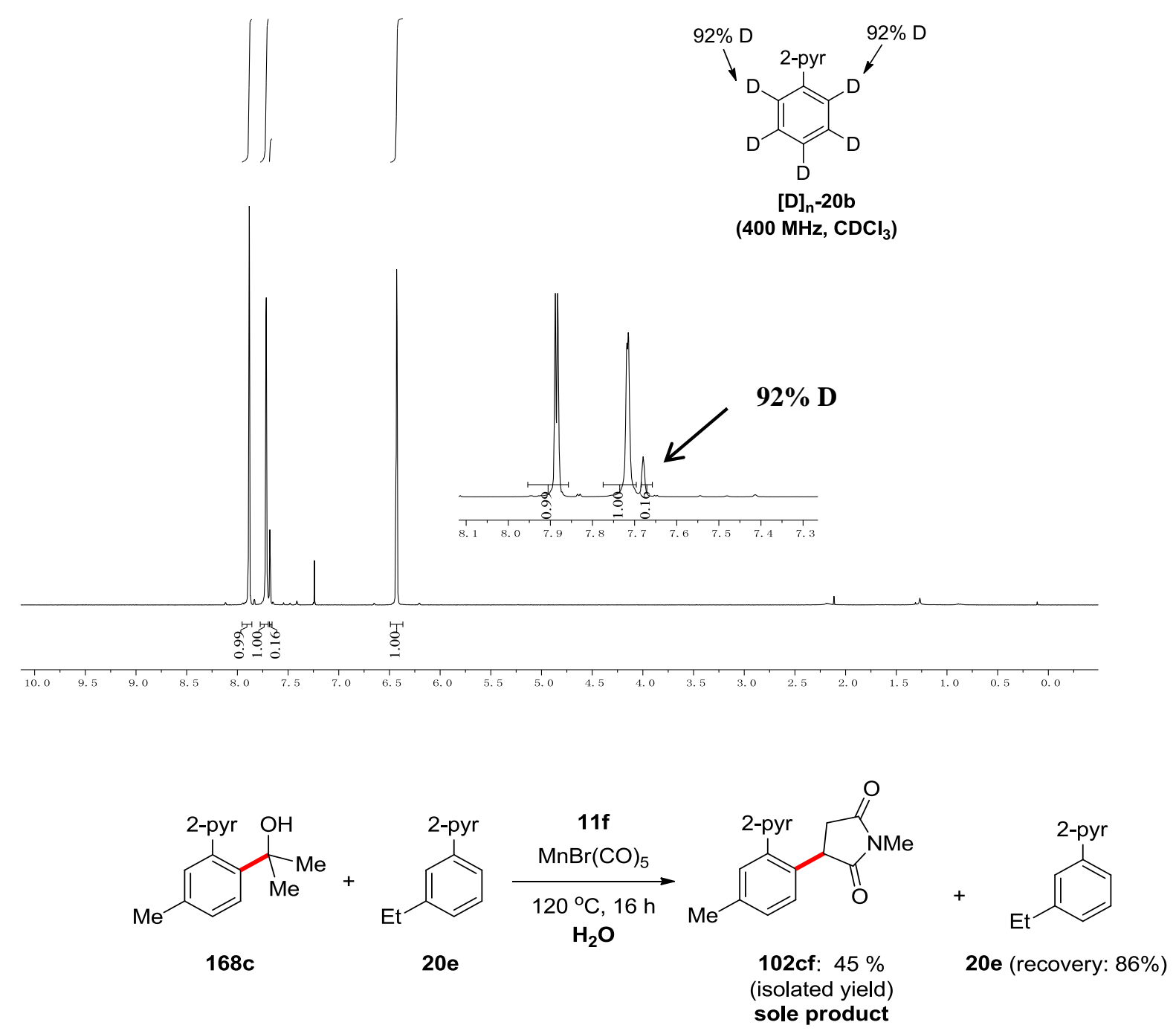

A suspension of 2-[4-methyl-2-(1H-pyrazol-1-yl)phenyl]propan-2-ol (168c) (108.2 mg, $0.50 \mathrm{mmol})$, 1-(3-ethylphenyl)-1H-pyrazole (20e) (86.2 mg, $0.50 \mathrm{mmol}), 1$-methyl-1H-pyrrole-2,5-dione (11f) (55.6 mg, $0.50 \mathrm{mmol}),\left[\mathrm{MnBr}(\mathrm{CO})_{5}\right](6.9 \mathrm{mg}, 10.0 \mathrm{~mol} \%)$ in $\mathrm{H}_{2} \mathrm{O}(1.0 \mathrm{~mL})$ was stirred at $120^{\circ} \mathrm{C}$ for 16 h under $\mathrm{N}_{2}$. After cooling to ambient temperature, the mixture was dried over $\mathrm{Na}_{2} \mathrm{SO}_{4}$, washed with EtOAc $(30 \mathrm{~mL})$ and concentrated in vacuo. Purification by column chromatography on silica gel afforded $102 \mathrm{cf}$ (61.0 $\mathrm{mg}, 45 \%)$ and $20 \mathrm{e}(74.0 \mathrm{mg}, 86 \%$ recovered). 


\section{H/D Exchange Experiments}

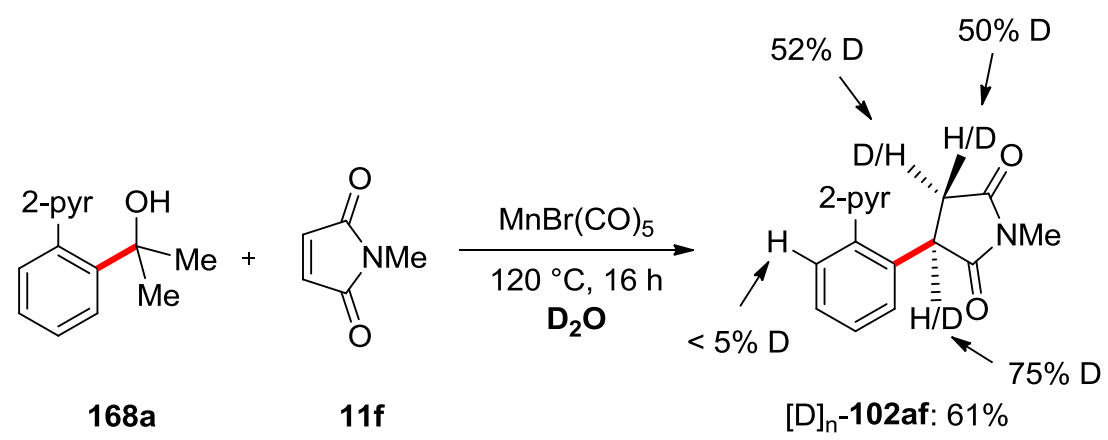

A suspension of 2-[2-(1H-pyrazol-1-yl)phenyl]propan-2-ol (168a) (50.6 mg, $0.25 \mathrm{mmol})$, 1-methyl-1H-pyrrole-2,5-dione (11f) $(55.6 \mathrm{mg}, 0.50 \mathrm{mmol}),\left[\mathrm{MnBr}(\mathrm{CO})_{5}\right](6.9 \mathrm{mg}, 10.0 \mathrm{~mol} \%)$ in $\mathrm{D}_{2} \mathrm{O}$ $(1.0 \mathrm{~mL})$ was stirred at $120^{\circ} \mathrm{C}$ for $16 \mathrm{~h}$ under $\mathrm{N}_{2}$. After cooling to ambient temperature, the mixture was dried over $\mathrm{Na}_{2} \mathrm{SO}_{4}$, washed with EtOAc $(30 \mathrm{~mL})$ and concentrated in vacuo. Purification by column chromatography on silica gel afforded $[D]_{n}-102 a f$ (39.0 mg, 61\%). The deuterium incorporation was determined by ${ }^{1} \mathrm{H}$ NMR spectroscopy.

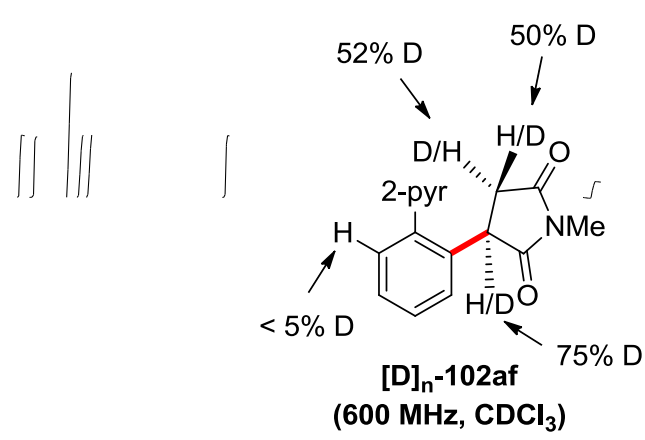

$50 \%$ D

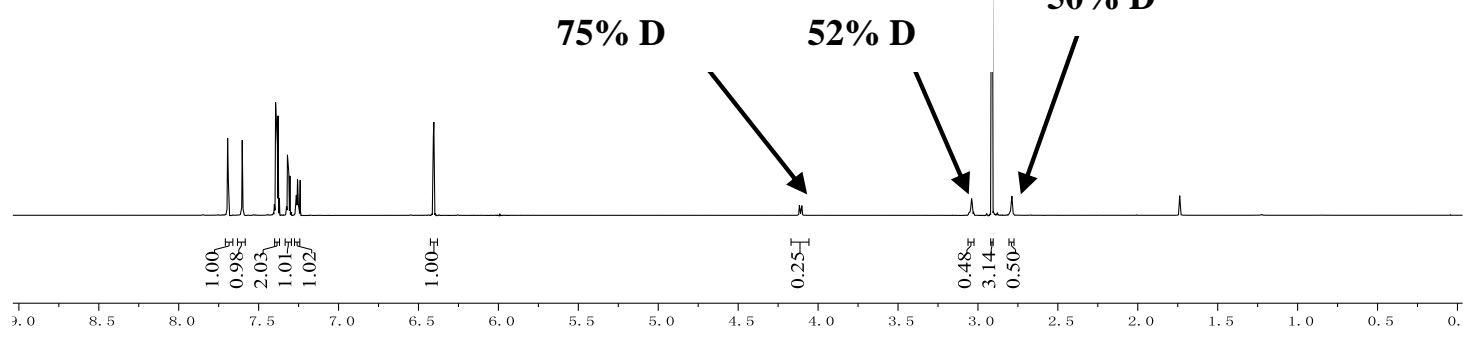




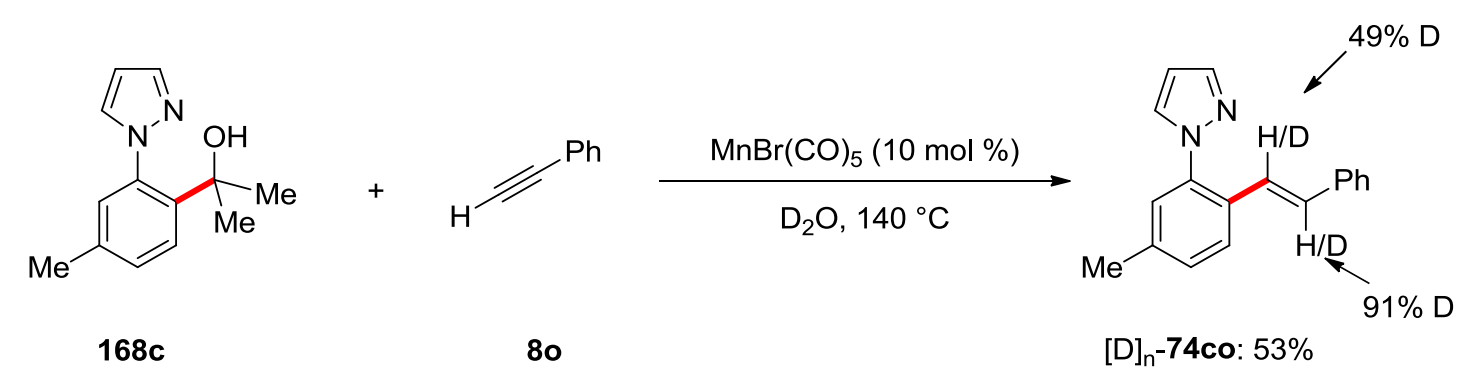

A suspension of 2-[4-methyl-2-(1H-pyrazol-1-yl)phenyl]propan-2-ol (168c) (54.1 mg, $0.25 \mathrm{mmol})$, ethynylbenzene (8o) $(51.6 \mathrm{mg}, 0.50 \mathrm{mmol}),\left[\mathrm{MnBr}(\mathrm{CO})_{5}\right](6.9 \mathrm{mg}, 10.0 \mathrm{~mol} \%)$ in $\mathrm{D}_{2} \mathrm{O}(1.0 \mathrm{~mL})$ was stirred at $140{ }^{\circ} \mathrm{C}$ for $16 \mathrm{~h}$ under $\mathrm{N}_{2}$. After cooling to ambient temperature, the mixture was dried over $\mathrm{Na}_{2} \mathrm{SO}_{4}$, washed with EtOAc $(30 \mathrm{~mL})$ and concentrated in vacuo. Purification by column chromatography on silica gel afforded $[D]_{n}-74 c o(35.0 \mathrm{mg}, 53 \%)$. The deuterium incorporation was determined by ${ }^{1} \mathrm{H}$ NMR spectroscopy.
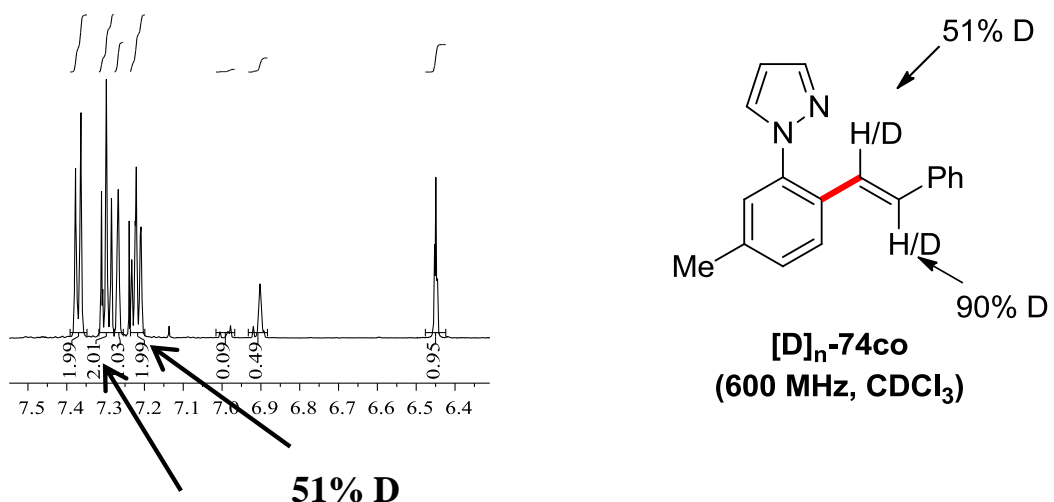

$90 \% \mathrm{D}$

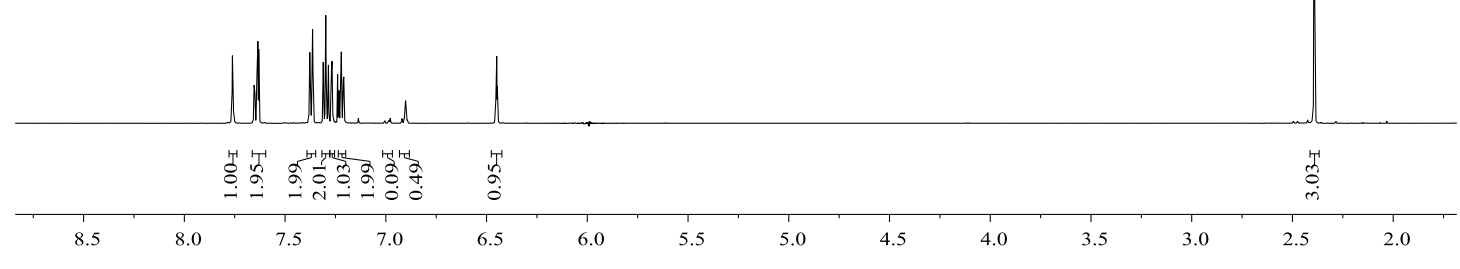


Experimental Section<smiles>Cc1ccc(C(C)(C)O)c(-n2cccn2)c1</smiles><smiles>[2H]C#Cc1ccccc1</smiles>

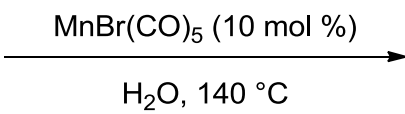

$168 \mathrm{c}$

$[D]_{1}-80$

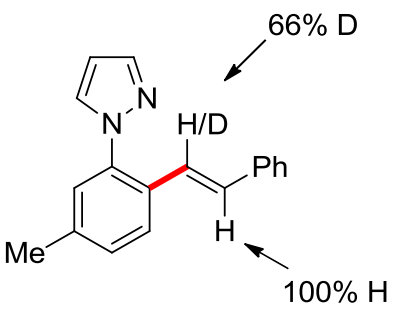

$[D]_{n}-74 c o: 60 \%$

A suspension of 2-[4-methyl-2-(1H-pyrazol-1-yl)phenyl]propan-2-ol (168c) (54.1 mg, $0.25 \mathrm{mmol})$, $[D]_{1}$-ethynylbenzene ([D $\left.]_{1}-80\right)(51.6 \mathrm{mg}, 0.50 \mathrm{mmol}),\left[\mathrm{MnBr}(\mathrm{CO})_{5}\right](6.9 \mathrm{mg}, 10.0 \mathrm{~mol} \%)$ in $\mathrm{H}_{2} \mathrm{O}(1.0$ $\mathrm{mL}$ ) was stirred at $140{ }^{\circ} \mathrm{C}$ for $16 \mathrm{~h}$ under $\mathrm{N}_{2}$. After cooling to ambient temperature, the mixture was dried over $\mathrm{Na}_{2} \mathrm{SO}_{4}$, washed with EtOAc $(30 \mathrm{~mL})$ and concentrated in vacuo. Purification by column chromatography on silica gel afforded $[D]_{n}-74 c o(39.1 \mathrm{mg}, 60 \%)$. The deuterium incorporation was determined by ${ }^{1} \mathrm{H}$ NMR spectroscopy.
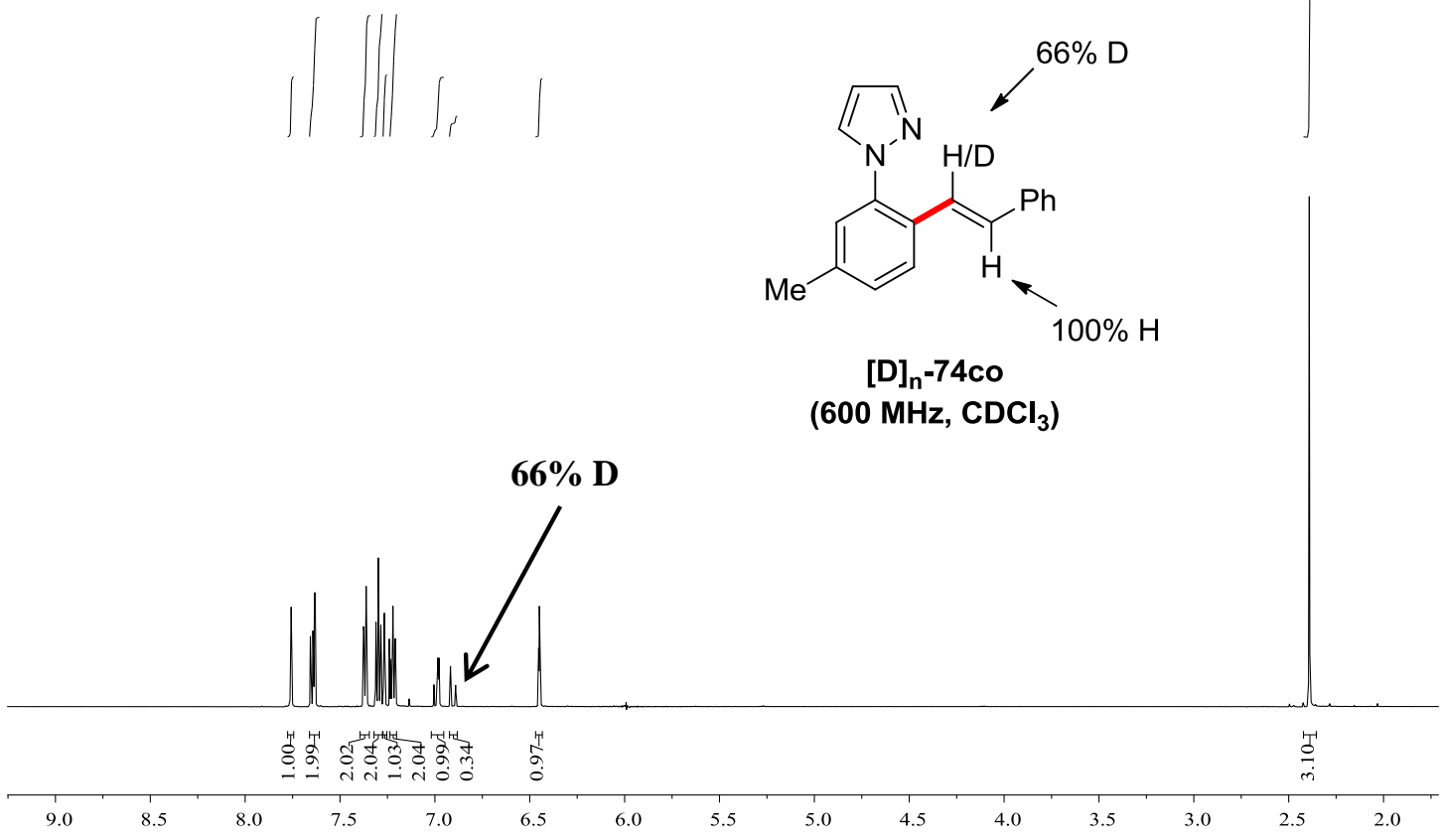

299 


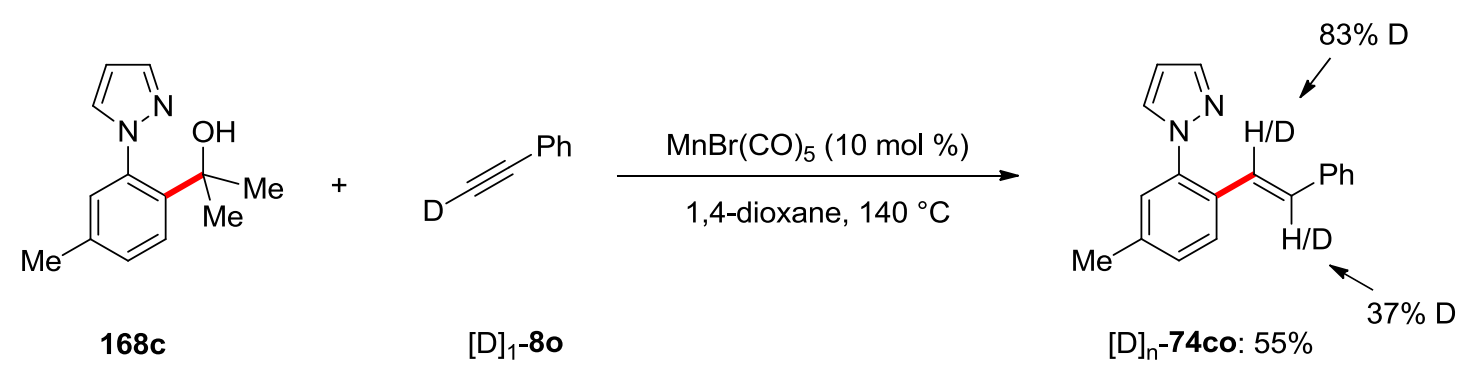

A suspension of 2-[4-methyl-2-(1H-pyrazol-1-yl)phenyl]propan-2-ol (168c) (54.1 mg, $0.25 \mathrm{mmol})$, $[D]_{1}$-ethynylbenzene $\left([D]_{1}-80\right)(51.6 \mathrm{mg}, 0.50 \mathrm{mmol}),\left[\mathrm{MnBr}(\mathrm{CO})_{5}\right](6.9 \mathrm{mg}, 10.0 \mathrm{~mol} \%)$ in 1,4-dioxane $(1.0 \mathrm{~mL})$ was stirred at $140{ }^{\circ} \mathrm{C}$ for $16 \mathrm{~h}$ under $\mathrm{N}_{2}$. After cooling to ambient temperature, the mixture was transferred into a round bottom flask with $\mathrm{CH}_{2} \mathrm{Cl}_{2}(20 \mathrm{~mL})$ and concentrated in vacuo. Purification by column chromatography on silica gel afforded $[D]_{n}-74 c o$ (35.9 mg, 55\%). The deuterium incorporation was determined by ${ }^{1} \mathrm{H}$ NMR spectroscopy.
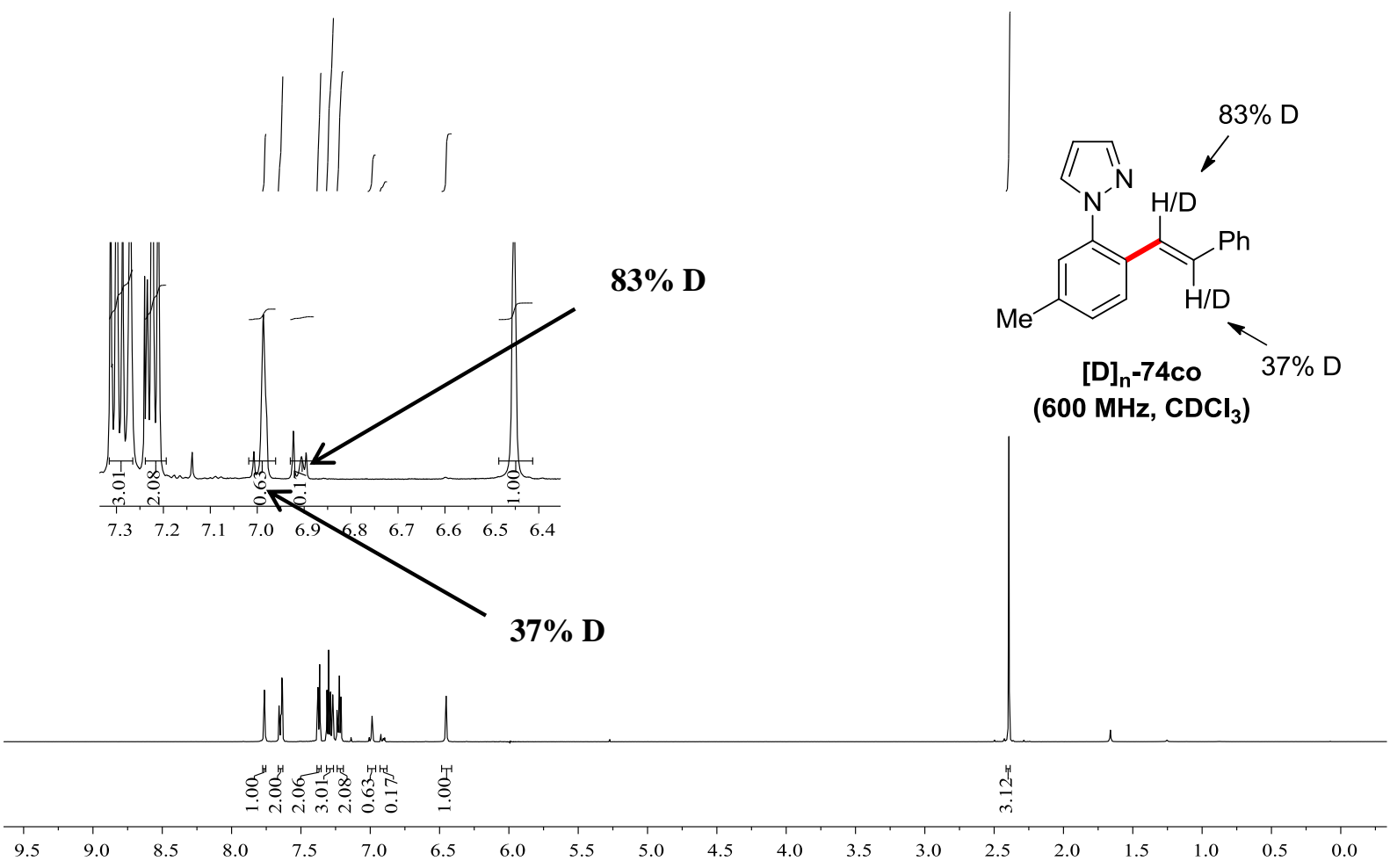


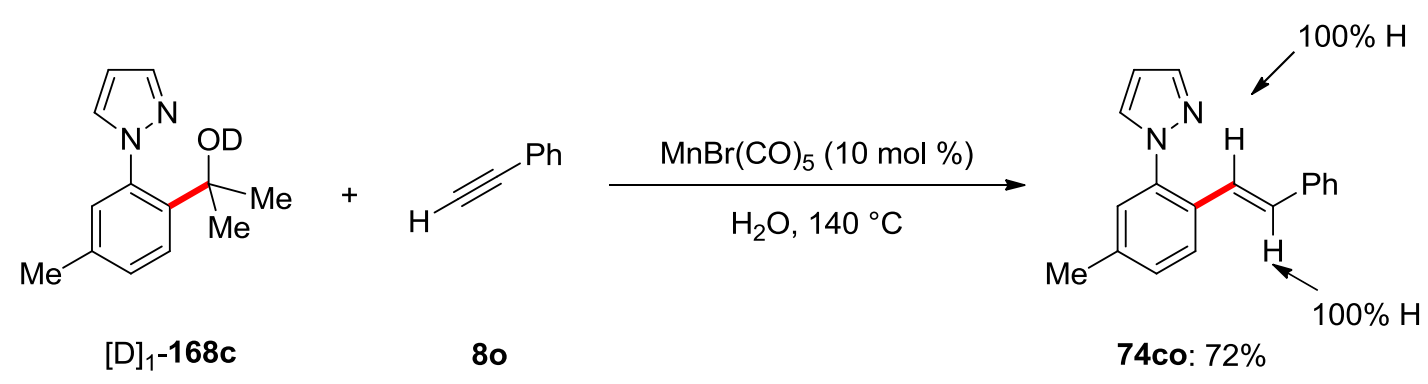

A suspension of $[D]_{1}-2-\left[4-m e t h y l-2-(1 H \text {-pyrazol-1-yl)phenyl]propan-2-ol ([D }]_{1}-168 c\right)(54.1 \mathrm{mg}, 0.25$ mmol), ethynylbenzene (8o) (51.6 mg, $0.50 \mathrm{mmol}),\left[\mathrm{MnBr}(\mathrm{CO})_{5}\right](6.9 \mathrm{mg}, 10.0 \mathrm{~mol} \%)$ in $\mathrm{H}_{2} \mathrm{O}(1.0 \mathrm{~mL})$ was stirred at $140{ }^{\circ} \mathrm{C}$ for $16 \mathrm{~h}$ under $\mathrm{N}_{2}$. After cooling to ambient temperature, the mixture was dried over $\mathrm{Na}_{2} \mathrm{SO}_{4}$, washed with EtOAc $(30 \mathrm{~mL})$ and concentrated in vacuo. Purification by column chromatography on silica gel afforded $[D]_{n}-74 c o(46.7 \mathrm{mg}, 72 \%)$. The deuterium incorporation was determined by ${ }^{1} \mathrm{H}$ NMR spectroscopy.

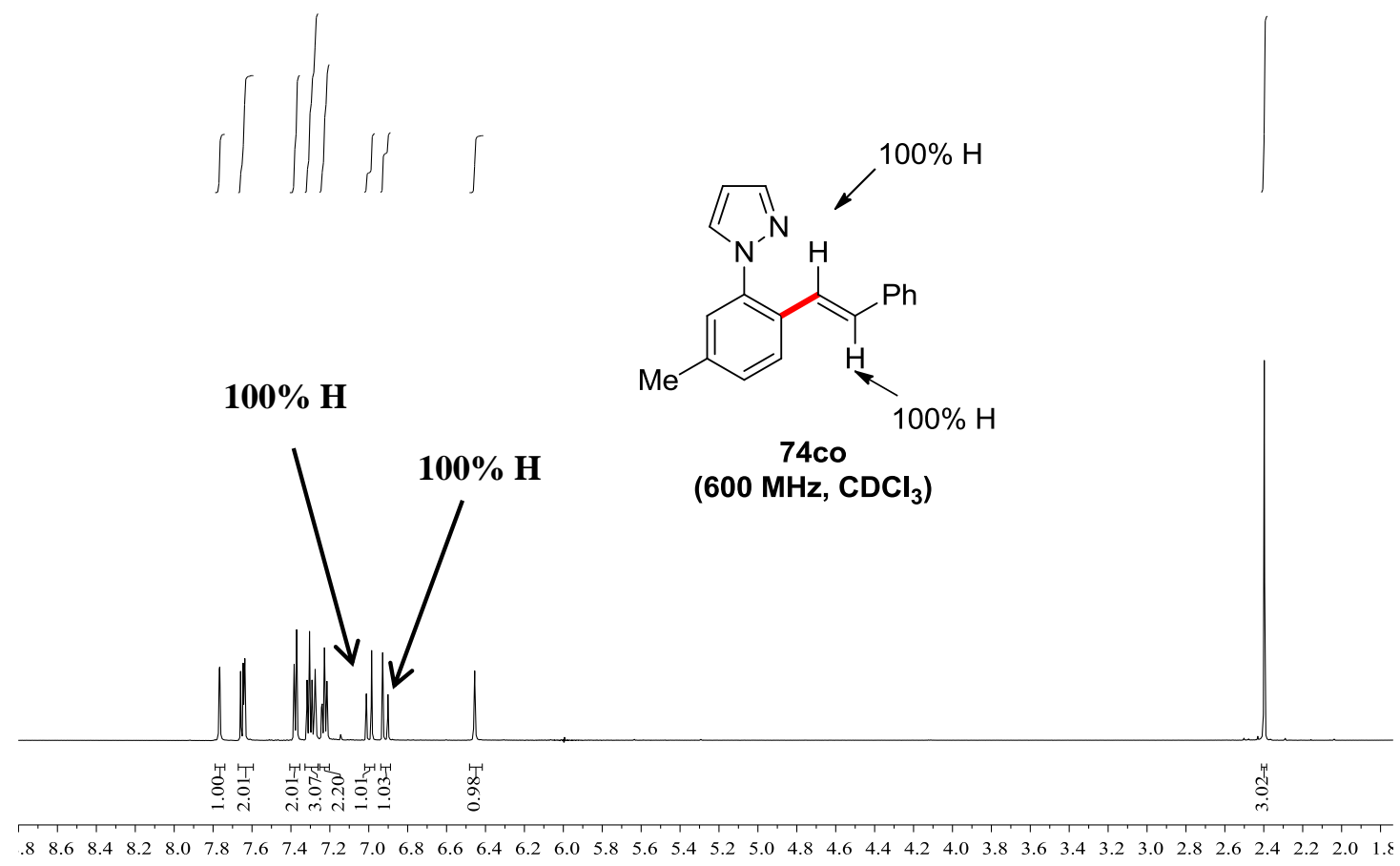




\section{${ }^{1} \mathrm{H}$ NMR Studies: Temperature Dependence on the C-C Cleavage}
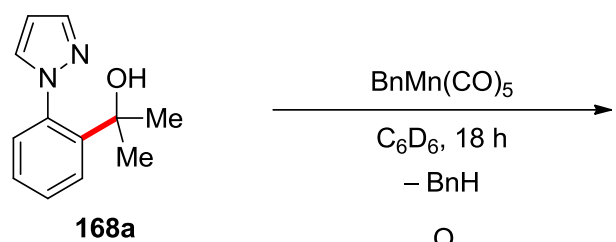

${ }_{\mathrm{Me}} \stackrel{\mathrm{O}}{\mathrm{Me}}_{\mathrm{N}}$

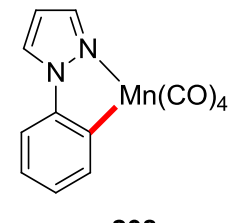

208

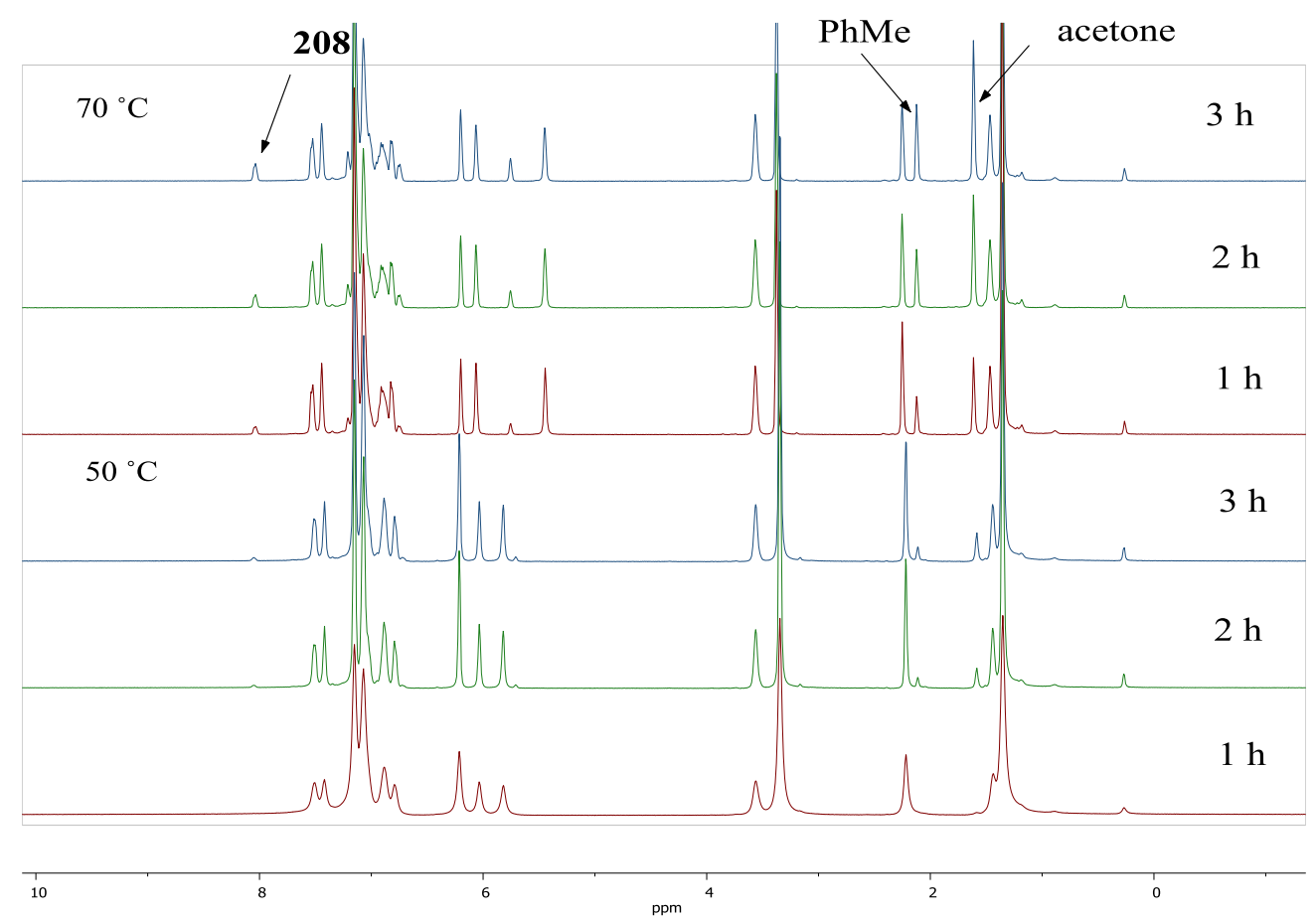

Preparation of the sample: inside glovebox, an oven dried NMR tube was charged with 2-[2-(1H-pyrazol-1-yl)phenyl]propan-2-ol (168a) (10.2 mg, $0.05 \mathrm{mmol}), \mathrm{BnMn}(\mathrm{CO})_{5}(14.3 \mathrm{mg}, 0.05$ mmol), 1,3,5-trimethoxybenzene $(2.8 \mathrm{mg}, 0.017 \mathrm{mmol})$ and $\mathrm{C}_{6} \mathrm{D}_{6}(0.6 \mathrm{~mL})$. The tube was transferred out of the glove box and the reaction was monitored at 60,120 and 180 min by ${ }^{1} \mathrm{H}$ NMR at 25,50 and $70{ }^{\circ} \mathrm{C}$. Toluene and acetone were progressively formed and quantified at $2.33 \mathrm{ppm}$ and 1.55 ppm, respectively. 


\section{Synthesis of Complex $C^{\prime}$}

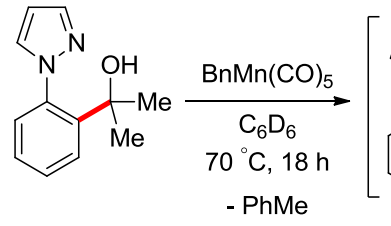

$168 \mathrm{a}$

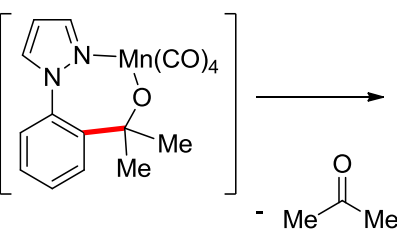

207

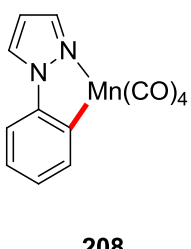

208

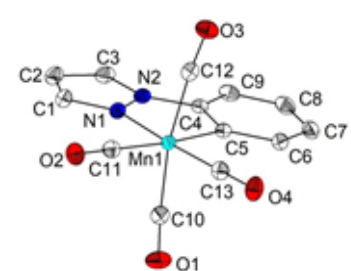

A $10 \mathrm{~mL}$ oven-dried Schlenk-tube was charged with 2-[2-(1H-pyrazol-1-yl)phenyl]propan-2-ol (168a) (70.1 mg, $0.25 \mathrm{mmol}), \mathrm{MnBn}(\mathrm{CO})_{5}(71.6 \mathrm{mg}, 0.25 \mathrm{mmol})$ and $\mathrm{C}_{6} \mathrm{D}_{6}(1.0 \mathrm{~mL})$. The mixture was stirred at $70{ }^{\circ} \mathrm{C}$ for $18 \mathrm{~h}$ under $\mathrm{N}_{2}$ in the glovebox. After cooling to ambient temperature, the solution was filtered to through a pipette packed with cotton wool, and removal of solvent under reduced pressure yielded a yellow solid (56.6 mg, 73\%). Crystals suitable for X-ray diffraction were obtained by slow evaporation from $n$-hexane, providing light yellow crystals $208 .{ }^{1} \mathbf{H} \mathbf{N M R}\left(400 \mathrm{MHz}, \mathrm{CDCl}_{3}\right) \delta$ $=8.11(\mathrm{~d}, J=2.7 \mathrm{~Hz}, 1 \mathrm{H}), 7.96-7.91(\mathrm{~m}, 1 \mathrm{H}), 7.71(\mathrm{~d}, J=2.1 \mathrm{~Hz}, 1 \mathrm{H}), 7.36-7.09(\mathrm{~m}, 3 \mathrm{H}), 6.51(\mathrm{~s}, 1 \mathrm{H})$.

${ }^{13} \mathrm{C}$ NMR $\left(100 \mathrm{MHz}, \mathrm{CDCl}_{3}\right) \delta=219.7(\mathrm{CO}), 214.6(\mathrm{CO}), 211.9(\mathrm{CO}), 157.1\left(\mathrm{C}_{\mathrm{q}}\right), 143.5\left(\mathrm{C}_{\mathrm{q}}\right), 143.2(\mathrm{CH})$, $142.5(\mathrm{CH}), 126.9(\mathrm{CH}), 126.4(\mathrm{CH}), 124.5(\mathrm{CH}), 111.8(\mathrm{CH}), 109.3(\mathrm{CH})$.

\section{Detection of the $\mathrm{CO}_{2}$ Formation}<smiles>COc1ccc(-n2cccn2)c(C(O)c2ccccc2)c1</smiles>

$168 d^{\prime}$<smiles>C=CC1COC(=O)O1</smiles>

$110 a$

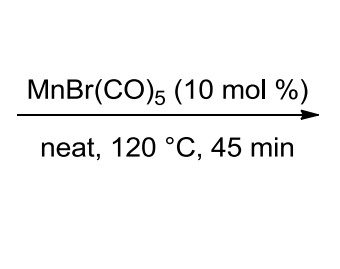

$\mathrm{CO}_{2}$ formation

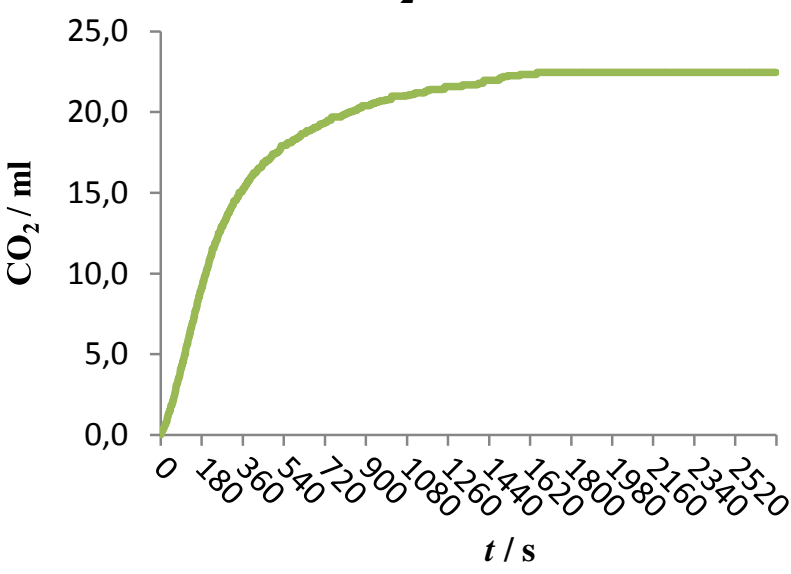


A $10 \mathrm{~mL}$ oven-dried Schlenk-tube was charged with [5-methoxy-2-(1H-pyrazol1-yl)phenyl](phenyl)methanol (168d') (280.3 mg, $1.0 \mathrm{mmol}$ ), 4-vinyl-1,3-dioxolan-2-one (110a) (228.2 $\mathrm{mg}, 2.0 \mathrm{mmol}), \operatorname{MnBr}(\mathrm{CO})_{5}(27.5 \mathrm{mg}, 10 \mathrm{~mol} \%)$. The mixture was connected to a gas detection system (GM5-KONT). Subsequently, the reaction was placed in a preheated oil bath at 120 ${ }^{\circ} \mathrm{C}$. The generation of $\mathrm{CO}_{2}$ was detected.

\section{Kinetic Analysis}

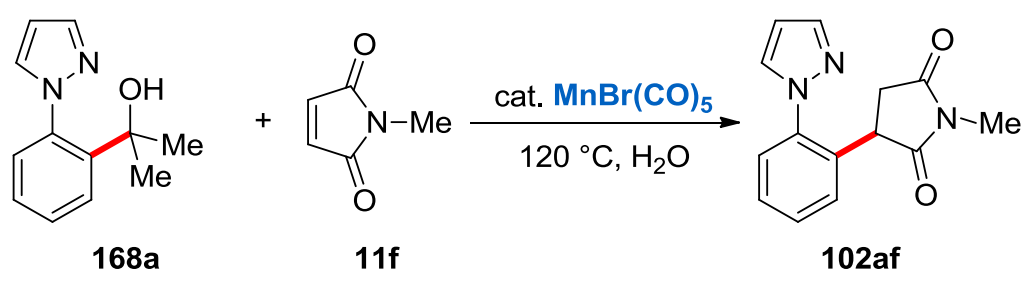

\section{Order with respect to $\left[\mathrm{MnBr}(\mathrm{CO})_{5}\right]$}

The reaction order with respect to $\left[\mathrm{MnBr}(\mathrm{CO})_{5}\right]$ was examined using the initial rate method. ${ }^{11} \mathrm{~A}$ Schlenk-tube was charged with 2-[2-(1H-pyrazol-1-yl)phenyl]propan-2-ol (168a) (50.6 mg, 0.25 mmol), 1-methyl-1H-pyrrole-2,5-dione (11f) (55.6 mg, $0.50 \mathrm{mmol}),\left[\mathrm{MnBr}(\mathrm{CO})_{5}\right](5.0,7.5,10.0,12.5$ mol \%) and 1,3,5-trimethoxybenzene (14.0 mg, $0.083 \mathrm{mmol}) . \mathrm{H}_{2} \mathrm{O}(1.0 \mathrm{~mL})$ was added and the mixture was stirred at $120^{\circ} \mathrm{C}$. Six parallel reactions with the same amount of $\operatorname{MnBr}(\mathrm{CO})_{5}$ were performed. A reaction was stopped every $5 \mathrm{~min}$ and cooled to $0{ }^{\circ} \mathrm{C}$ immediately. The mixture was diluted with EtOAc $(1.0 \mathrm{~mL})$, filtered through a short plug of silica gel and analyzed by gas chromatography.

\begin{tabular}{cccc}
\hline $\mathrm{MnBr}(\mathrm{CO})_{5} / \mathrm{mol} \%$ & $\Delta\left[\mathbf{1 0 2 \mathrm { af } ]} \Delta t^{-1} / 10^{-3} \mathrm{~mol} \mathrm{~L}^{-1} \mathrm{~s}^{-1}\right.$ & $\log \left(\mathrm{c} / \mathrm{mol} \mathrm{L}^{-1}\right)$ & $\log \left(\Delta[\mathbf{1 0 2} \mathrm{af}] \Delta t^{-1} / \mathrm{mol} \mathrm{L}^{-1} \mathrm{~s}^{-1}\right)$ \\
\hline 5.0 & 2.71 & -1.90 & -2.57 \\
7.5 & 3.73 & -1.73 & -2.43 \\
10.0 & 5.53 & -1.60 & -2.26 \\
12.5 & 6.24 & -1.51 & -2.20 \\
\hline
\end{tabular}




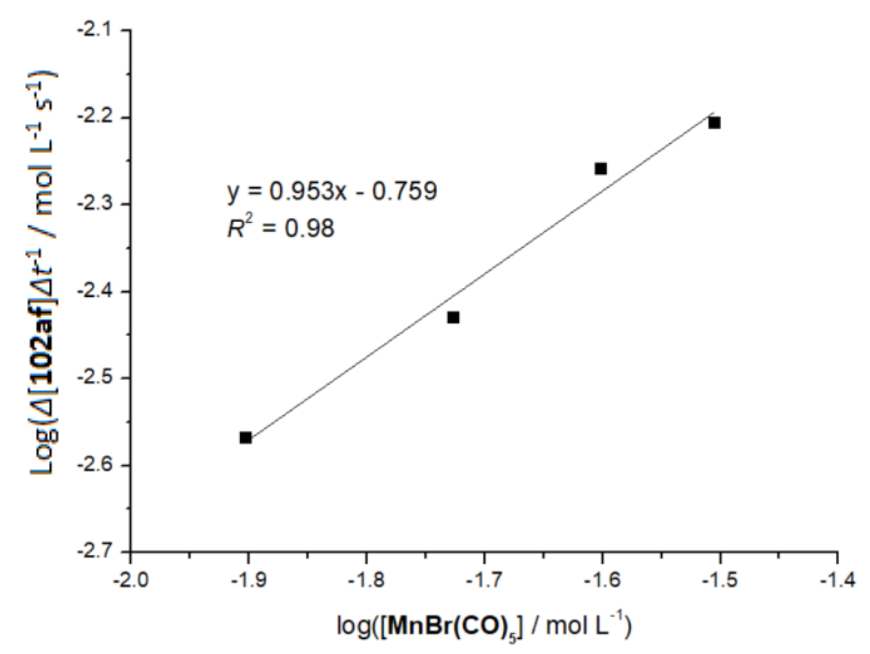

\section{Order with respect to 168 a}

The reaction order with respect to 168 a was examined using the initial rate method. ${ }^{9} \mathrm{~A}$ Schlenk-tube was charged with 2-[2-(1H-pyrazol-1-yl)phenyl]propan-2-ol (168a) $(0.15,0.20,0.25$, $0.30 \mathrm{mmol}$ ), 1-methyl-1H-pyrrole-2,5-dione (11f) $(55.6 \mathrm{mg}, 0.5 \mathrm{mmol}),\left[\mathrm{MnBr}(\mathrm{CO})_{5}\right](6.9 \mathrm{mg}, 0.025$ mmol) and 1,3,5-trimethoxybenzene $(14.0 \mathrm{mg}, 0.083 \mathrm{mmol}) . \mathrm{H}_{2} \mathrm{O}(1.0 \mathrm{~mL})$ was added and the mixture was stirred at $120^{\circ} \mathrm{C}$. Six parallel reactions with the same amount of 168a were performed. A reaction was stopped every $5 \mathrm{~min}$ and cooled to $0{ }^{\circ} \mathrm{C}$ immediately. The mixture was diluted with EtOAc $(1.0 \mathrm{~mL})$, filtered through a short plug of silica gel and analyzed by gas chromatography.

\begin{tabular}{cccc}
\hline 168a $/ \mathrm{mmol}$ & $\Delta\left[\mathbf{1 0 2 \mathrm { af } ]} \Delta t^{-1} / 10^{-3} \mathrm{~mol} \mathrm{~L}^{-1} \mathrm{~s}^{-1}\right.$ & $\log \left(\mathrm{c} / \mathrm{mol} \mathrm{L}^{-1}\right)$ & $\log \left(\Delta[\mathbf{1 0 2} \mathrm{af}] \Delta t^{-1} / \mathrm{mol} \mathrm{L}^{-1} \mathrm{~s}^{-1}\right)$ \\
\hline 0.15 & 2.46 & -0.82 & -2.46 \\
0.20 & 4.80 & -0.70 & -2.32 \\
0.25 & 5.53 & -0.60 & -2.26 \\
0.30 & 6.84 & -0.52 & -2.17 \\
\hline
\end{tabular}

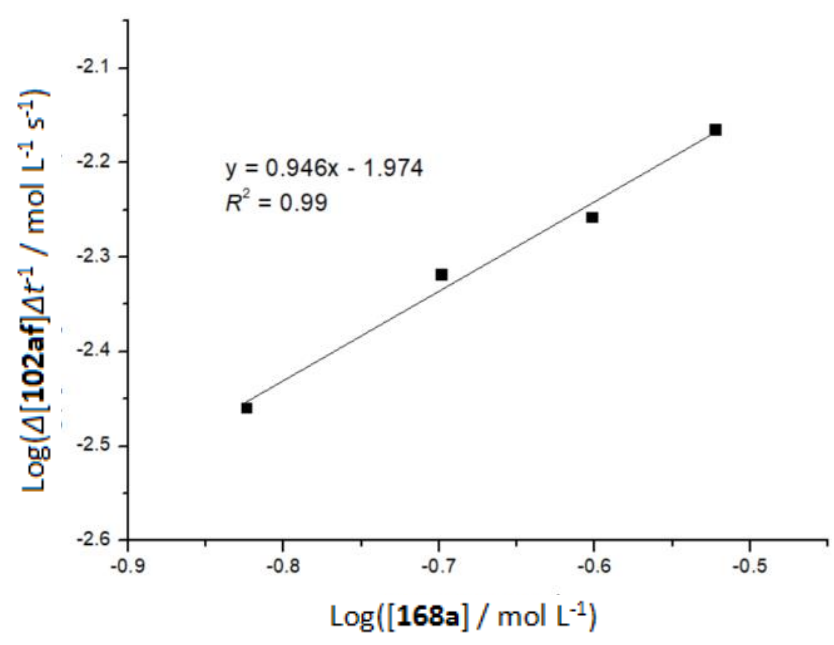




\section{Order with respect to $\mathbf{1 1 f}$}

The reaction order with respect to $11 \mathbf{f}$ was examined using the initial rate method. ${ }^{9}$ A Schlenk-tube was charged with 2-[2-(1H-pyrazol-1-yl)phenyl]propan-2-ol (168a) (50.6 mg, $0.25 \mathrm{mmol})$, 1-methyl-1H-pyrrole-2,5-dione (11f) $\left(1.0,1.5,2.0,2.5,3.0\right.$ equiv), $\left[\mathrm{MnBr}(\mathrm{CO})_{5}\right](6.9 \mathrm{mg}, 0.025 \mathrm{mmol})$ and 1,3,5-trimethoxybenzene $(14.0 \mathrm{mg}, 0.083 \mathrm{mmol}) . \mathrm{H}_{2} \mathrm{O}(1.0 \mathrm{~mL})$ was added and the mixture was stirred at $120{ }^{\circ} \mathrm{C}$. Six parallel reactions with the same amount of $11 \mathrm{f}$ were performed. A reaction was stopped every $5 \mathrm{~min}$ and cooled to $0{ }^{\circ} \mathrm{C}$ immediately. The mixture was diluted with EtOAc (1.0 $\mathrm{mL})$, filtered through a short plug of silica gel and analyzed by gas chromatography.

\begin{tabular}{cccc}
\hline 11f / equiv & $\Delta[$ 102af $] \Delta t^{-1} / 10^{-3} \mathrm{~mol} \mathrm{~L}^{-1} \mathrm{~s}^{-1}$ & $\log \left(\mathrm{c} / \mathrm{mol} \mathrm{L}^{-1}\right)$ & $\log \left(\Delta[\right.$ 102af $\left.] \Delta t^{-1} / \mathrm{mol} \mathrm{L}^{-1} \mathrm{~s}^{-1}\right)$ \\
\hline 1.0 & 5.21 & -0.60 & -2.28 \\
1.5 & 6.00 & -0.43 & -2.22 \\
2.0 & 5.53 & -0.30 & -2.26 \\
2.5 & 6.60 & -0.20 & -2.18 \\
3.0 & 5.81 & -0.13 & -2.24 \\
\hline
\end{tabular}

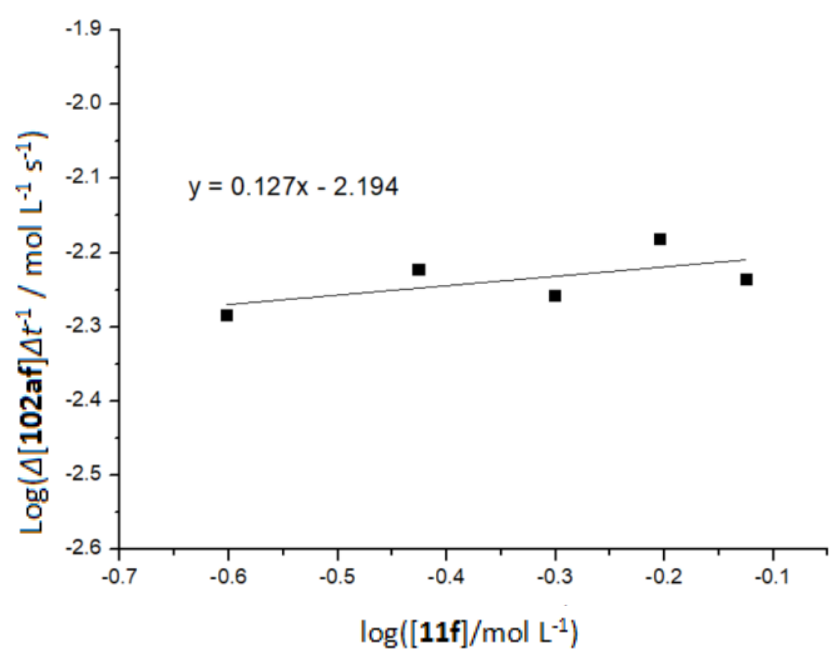




\section{Removal of Pyrazole Group}

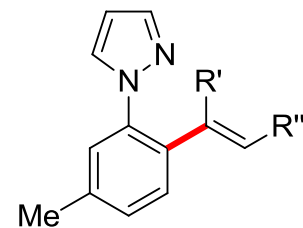

74
1) $\mathrm{TMSCl}, \mathrm{TMPMgCl} \cdot \mathrm{LiCl}$ $36 \mathrm{~h}, 0^{\circ} \mathrm{C}$

2) aq. $\mathrm{HCl}, \mathrm{MeOH}$ $40^{\circ} \mathrm{C}, 90 \mathrm{~min}$<smiles>[R]C=C([R])c1ccc(C)cc1N</smiles>

209<smiles>Cc1ccc(/C=C/c2ccccc2)c(N)c1</smiles>

209a: $72 \%$

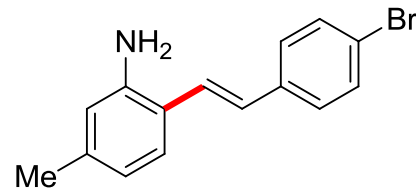

209b: $53 \%$<smiles>Cc1ccc(/C(=C/c2ccccc2)c2ccccc2)c(N)c1</smiles>

209c: $59 \%$

To a solution of $74(1.0 \mathrm{mmol})$ and $\mathrm{TMSCl}(217.3 \mathrm{mg}, 2.0 \mathrm{mmol})$ in THF $(5.0 \mathrm{~mL})$ was added TMPMgCl. $\mathrm{LiCl}$ in THF $(1.0 \mathrm{M}, 4.0 \mathrm{mmol})$ dropwise, and the mixture was stirred for $36 \mathrm{~h}$ at $0 \stackrel{\text { o }}{ }$. Then, water was added, and the mixture was then extracted with $\mathrm{Et}_{2} \mathrm{O}(3 \times 20 \mathrm{~mL})$. The combined organic layers were washed with brine, dried over $\mathrm{MgSO}_{4}$, filtered and concentrated. The crude material

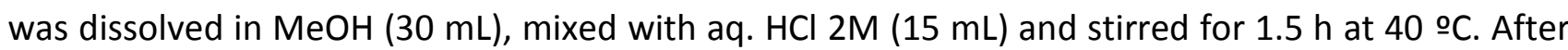
this period, the mixture was neutralized with saturated aq. $\mathrm{NaHCO}_{3}(15 \mathrm{~mL})$ and extracted with EtOAc $(3 \times 20 \mathrm{~mL})$. The combined organic layers were washed with brine, dried over $\mathrm{MgSO}_{4}$, filtered and concentrated. Purification by column chromatography on silica gel ( $n$-hexane/EtOAc: $15 / 1 \rightarrow 20 / 1)$ yielded 209.<smiles>Cc1ccc(/C=C/c2ccccc2)c(N)c1</smiles>

(E)-5-Methyl-2-styrylaniline (209a) (150.5 mg, 72\% yield) White solid, M.p. $=79-81{ }^{\circ} \mathrm{C}^{1} \mathbf{H}$ NMR $\left(400 \mathrm{MHz}, \mathrm{CDCl}_{3}\right) \delta=7.49(\mathrm{~d}, J=7.4 \mathrm{~Hz}, 2 \mathrm{H}), 7.43-7.28(\mathrm{~m}, 3 \mathrm{H}), 7.27-7.20(\mathrm{~m}, 1 \mathrm{H}), 7.14(\mathrm{~d}, J=16.1$ $\mathrm{Hz}, 1 \mathrm{H}), 6.95(\mathrm{~d}, J=16.1 \mathrm{~Hz}, 1 \mathrm{H}), 6.63(\mathrm{~d}, J=7.8 \mathrm{~Hz}, 1 \mathrm{H}), 6.54(\mathrm{~s}, 1 \mathrm{H}), 3.75$ (brs, 2H), $2.28(\mathrm{~s}, 3 \mathrm{H}) .{ }^{13} \mathrm{C}$ NMR $\left(100 \mathrm{MHz}, \mathrm{CDCl}_{3}\right) \delta=143.8\left(\mathrm{C}_{\mathrm{q}}\right), 138.7\left(\mathrm{C}_{\mathrm{q}}\right), 137.8\left(\mathrm{C}_{\mathrm{q}}\right), 129.3(\mathrm{CH}), 128.6(\mathrm{CH}), 127.3(\mathrm{CH})$, $127.1(\mathrm{CH}), 126.3(\mathrm{CH}), 124.2(\mathrm{CH}), 121.1\left(\mathrm{C}_{\mathrm{q}}\right), 120.1(\mathrm{CH}), 116.9(\mathrm{CH}), 21.2\left(\mathrm{CH}_{3}\right)$. IR $(\mathrm{ATR}) v=3437$, 3360, 3031, 1609, 1505, 1343, 966, 800, 753, $689 \mathrm{~cm}^{-1}$. MS (ESI) m/z (relative intensity) 210 (100) $[\mathrm{M}+\mathrm{H}]^{+}$. HR-MS (ESI) m/z calcd for $\mathrm{C}_{15} \mathrm{H}_{16} \mathrm{~N}[\mathrm{M}+\mathrm{H}]^{+}: 210.1277$, found: 210.1277 . 
<smiles>Cc1ccc(/C=C/c2ccc(Br)cc2)c(N)c1</smiles>

(E)-2-(4-Bromostyryl)-5-methylaniline (209b) (152.7 mg, 53\% yield) Pale yellow solid, M.p. = 124$125{ }^{\circ} \mathrm{C}^{1} \mathrm{H}$ NMR $\left(400 \mathrm{MHz}, \mathrm{CDCl}_{3}\right) \delta=7.44(\mathrm{~d}, J=8.4 \mathrm{~Hz}, 2 \mathrm{H}), 7.33(\mathrm{~d}, J=8.4 \mathrm{~Hz}, 2 \mathrm{H}), 7.27(\mathrm{~d}, J=7.8$ $\mathrm{Hz}, 1 \mathrm{H}), 7.11(\mathrm{~d}, J=16.1 \mathrm{~Hz}, 1 \mathrm{H}), 6.86(\mathrm{~d}, J=16.1 \mathrm{~Hz}, 1 \mathrm{H}), 6.62(\mathrm{dd}, J=7.8,1.7 \mathrm{~Hz}, 1 \mathrm{H}), 6.54(\mathrm{~s}, 1 \mathrm{H})$, 3.84 (brs, 2H), $2.26(\mathrm{~s}, 3 \mathrm{H}) .{ }^{13} \mathrm{C}$ NMR $\left(100 \mathrm{MHz}, \mathrm{CDCl}_{3}\right) \delta=143.7\left(\mathrm{C}_{\mathrm{q}}\right), 139.1\left(\mathrm{C}_{\mathrm{q}}\right), 136.7\left(\mathrm{C}_{\mathrm{q}}\right), 131.7$ $(\mathrm{CH}), 127.9(\mathrm{CH}), 127.8(\mathrm{CH}), 127.1(\mathrm{CH}), 124.9(\mathrm{CH}), 121.0\left(\mathrm{C}_{\mathrm{q}}\right), 120.8\left(\mathrm{C}_{\mathrm{q}}\right), 120.3(\mathrm{CH}), 117.1(\mathrm{CH})$, $21.3\left(\mathrm{CH}_{3}\right)$. IR (ATR) $v=3433,3357,1612,1484,1268,1072,970,867,815,511 \mathrm{~cm}^{-1} . \mathrm{MS}(\mathrm{ESI}) \mathrm{m} / \mathrm{z}$ (relative intensity) $288(100)[\mathrm{M}+\mathrm{H}]^{+}\left({ }^{79} \mathrm{Br}\right), 290(98)[\mathrm{M}+\mathrm{H}]^{+}\left({ }^{81} \mathrm{Br}\right)$. HR-MS (ESI) m/z calcd for $\mathrm{C}_{15} \mathrm{H}_{15}{ }^{79} \mathrm{BrN}[\mathrm{M}+\mathrm{H}]^{+}:$288.0382, found: $288.0384 ; \mathrm{m} / \mathrm{z}$ calcd for $\mathrm{C}_{15} \mathrm{H}_{15}{ }^{81} \mathrm{BrN}[\mathrm{M}+\mathrm{H}]^{+}: 290.0362$, found: 290.0364 .<smiles>Cc1ccc(/C(=C/c2ccccc2)c2ccccc2)c(N)c1</smiles>

(E)-2-(1,2-Diphenylvinyl)-5-methylaniline (209c) (168.4 mg, 59\% yield) White solid, M.p. = 142$143^{\circ} \mathrm{C} .{ }^{1} \mathbf{H}$ NMR $\left(400 \mathrm{MHz}, \mathrm{CDCl}_{3}\right) \delta=7.28-7.22(\mathrm{~m}, 5 \mathrm{H}), 7.19-7.12(\mathrm{~m}, 3 \mathrm{H}), 7.12-7.07(\mathrm{~m}, 2 \mathrm{H}), 7.05$ (d, J = 7.7 Hz, 1H), $6.77(\mathrm{~s}, 1 \mathrm{H}), 6.59$ (dd, J = 7.7, 1.7Hz, 1H), 6.50-6.47 (m, 1H), 3.54 (brs, $2 \mathrm{H}), 2.28$ (s, 3H). ${ }^{13} \mathrm{C}$ NMR $\left(100 \mathrm{MHz}, \mathrm{CDCl}_{3}\right) \delta=144.1\left(\mathrm{C}_{\mathrm{q}}\right), 140.7\left(\mathrm{C}_{\mathrm{q}}\right), 139.9\left(\mathrm{C}_{\mathrm{q}}\right), 138.8\left(\mathrm{C}_{\mathrm{q}}\right), 137.4\left(\mathrm{C}_{\mathrm{q}}\right), 131.0$ (CH), $130.2(\mathrm{CH}), 129.7(\mathrm{CH}), 129.4(\mathrm{CH}), 128.6(\mathrm{CH}), 128.0(\mathrm{CH}), 127.5(\mathrm{CH}), 127.2\left(\mathrm{C}_{\mathrm{q}}\right), 126.7(\mathrm{CH})$, $119.2(\mathrm{CH}), 116.6(\mathrm{CH}), 21.2\left(\mathrm{CH}_{3}\right)$. IR (ATR) $v=3478,3390,1613,1443,1315,1257,1074,777,715$ $\mathrm{cm}^{-1}$. MS (ESI) m/z (relative intensity) $286(100)[\mathrm{M}+\mathrm{H}]^{+}$. HR-MS (ESI) m/z calcd for $\mathrm{C}_{21} \mathrm{H}_{20} \mathrm{~N}[\mathrm{M}+\mathrm{H}]^{+}$: 286.1590, found: 286.1590 .

\section{Single-Crystal Structure Analysis}

Crystal Data for $\mathrm{C}_{13} \mathrm{H}_{7} \mathrm{MnN}_{2} \mathrm{O}_{4}(M=310.15 \mathrm{~g} / \mathrm{mol})$ : monoclinic, space group $\mathrm{P} 2{ }_{1} / \mathrm{c}$ (no. 14), $a=$ 8.5614(4) $\AA, b=6.8901(3) \AA, c=21.4151(11) \AA, b=92.838(2), V=1261.70(10) \AA^{3}, Z=4, T=99.97 \mathrm{~K}$, $\mu($ MoK $\alpha)=1.060 \mathrm{~mm}^{-1}, D_{\text {calc }}=1.633 \mathrm{~g} / \mathrm{cm}^{3}, 18532$ reflections measured $(6.212 \leq 2 \Theta \leq 60.992), 3828$ unique $\left(R_{\text {int }}=0.0179, R_{\text {sigma }}=0.0147\right)$ which were used in all calculations. The final $R_{1}$ was $0.0213(I>$ 
$2 \sigma(I))$ and $w R_{2}$ was 0.0596 (all data).

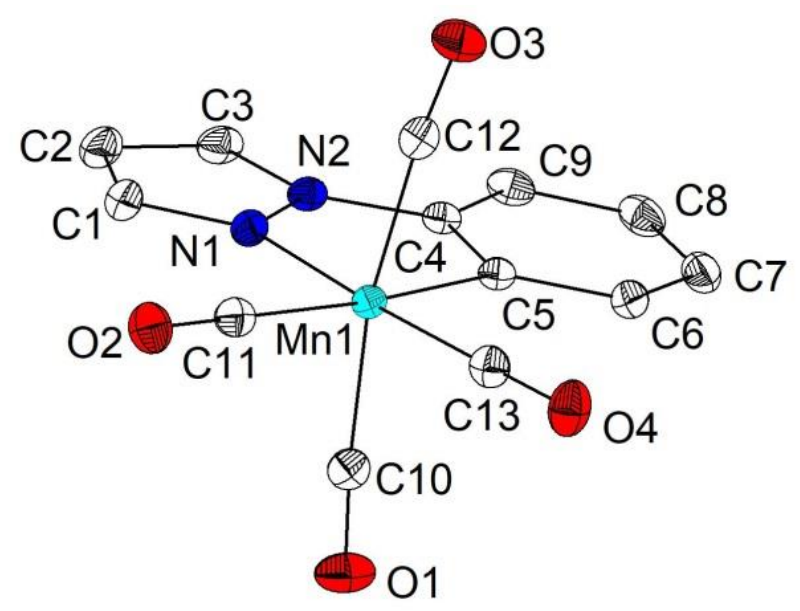

Molecular structure of $\mathbf{2 0 8}$ in the crystal. (Anisotropic displacement parameters are depicted at the $50 \%$ probability level.)

Crystal data and structure refinement for 208:

\begin{tabular}{|c|c|}
\hline Compound & 208 \\
\hline Empirical formula & $\mathrm{C}_{13} \mathrm{H}_{7} \mathrm{MnN}_{2} \mathrm{O}_{4}$ \\
\hline Identification code & 0455_CG_0m \\
\hline Empirical formula & $\mathrm{C}_{13} \mathrm{H}_{7} \mathrm{MnN}_{2} \mathrm{O}_{4}$ \\
\hline Formula weight & 310.15 \\
\hline Temperature/K & 99.97 \\
\hline Crystal system & monoclinic \\
\hline Space group & $\mathrm{P} 2_{1} / \mathrm{c}$ \\
\hline $\mathrm{a} / \AA ̊$ & $8.5614(4)$ \\
\hline $\mathrm{b} / \AA ̊ A$ & $6.8901(3)$ \\
\hline$c / \AA ̊$ & $21.4151(11)$ \\
\hline$\alpha /^{\circ}$ & 90 \\
\hline$\beta /{ }^{\circ}$ & $92.838(2)$ \\
\hline$\gamma /{ }^{\circ}$ & 90 \\
\hline Volume $/ \AA^{3}$ & $1261.70(10)$ \\
\hline Z & 4 \\
\hline$\rho_{\text {calc }} g / \mathrm{cm}^{3}$ & 1.633 \\
\hline$\mu / \mathrm{mm}^{-1}$ & 1.06 \\
\hline$F(000)$ & 624 \\
\hline
\end{tabular}


Crystal size $/ \mathrm{mm}^{3}$

Radiation

$2 \Theta$ range for data collection $/^{\circ}$

Index ranges

Reflections collected

Independent reflections

Data/restraints/parameters

Goodness-of-fit on $\mathrm{F}^{2}$

Final $R$ indexes $[1>=2 \sigma(I)]$

Final $R$ indexes [all data]

Largest diff. peak/hole / e $\AA^{-3}$
$0.452 \times 0.202 \times 0.174$

$\operatorname{MoK} \alpha(\lambda=0.71073)$

6.212 to 60.992

$-11 \leq h \leq 12,-9 \leq k \leq 9,-30 \leq \mathrm{I} \leq 30$

18532

$3828\left[R_{\text {int }}=0.0179, R_{\text {sigma }}=0.0147\right]$

$3828 / 0 / 181$

1.056

$\mathrm{R}_{1}=0.0213, \mathrm{wR}_{2}=0.0591$

$\mathrm{R}_{1}=0.0220, \mathrm{wR}_{2}=0.0596$

$0.44 /-0.39$

Bond lengths $[\AA ̊]$ for 208:

\begin{tabular}{|c|c|c|c|c|c|}
\hline Atom & Atom & Length/Å & Atom & Atom & Length/Å \\
\hline Mn1 & N1 & $2.0351(8)$ & N1 & $\mathrm{C} 1$ & $1.3368(12)$ \\
\hline Mn1 & C5 & $2.0584(9)$ & N2 & $\mathrm{C} 3$ & $1.3538(12)$ \\
\hline Mn1 & C10 & $1.8630(10)$ & N2 & $\mathrm{C} 4$ & $1.4179(12)$ \\
\hline $\mathrm{Mn} 1$ & C11 & $1.8423(10)$ & $\mathrm{C} 1$ & $\mathrm{C} 2$ & $1.4003(15)$ \\
\hline Mn1 & C12 & $1.8546(11)$ & $\mathrm{C} 2$ & $\mathrm{C} 3$ & $1.3770(16)$ \\
\hline Mn1 & C13 & $1.8032(10)$ & C4 & C5 & $1.3992(12)$ \\
\hline 01 & C10 & $1.1321(13)$ & C4 & C9 & $1.3889(13)$ \\
\hline $\mathrm{O} 2$ & C11 & $1.1408(13)$ & C5 & C6 & $1.3998(13)$ \\
\hline $\mathrm{O} 3$ & C12 & $1.1361(13)$ & C6 & $C 7$ & $1.3944(14)$ \\
\hline O4 & C13 & $1.1451(13)$ & $\mathrm{C7}$ & $\mathrm{C} 8$ & $1.3889(15)$ \\
\hline N1 & N2 & $1.3588(11)$ & $\mathrm{C} 8$ & $\mathrm{C} 9$ & $1.3860(15)$ \\
\hline
\end{tabular}

Bond angles $\left[^{\circ}\right]$ for 208 :

\begin{tabular}{|c|c|c|c|c|c|c|c|}
\hline Atom & Atom & Atom & Angle $^{\circ}$ & Atom & Atom & Atom & Angle/ $^{\circ}$ \\
\hline $\mathrm{N} 1$ & $\mathrm{Mn} 1$ & $\mathrm{C} 5$ & $79.10(3)$ & $\mathrm{C} 3$ & $\mathrm{~N} 2$ & $\mathrm{~N} 1$ & $110.99(8)$ \\
\hline $\mathrm{C} 10$ & $\mathrm{Mn} 1$ & $\mathrm{~N} 1$ & $91.87(4)$ & $\mathrm{C} 3$ & $\mathrm{~N} 2$ & $\mathrm{C} 4$ & $132.88(9)$ \\
\hline
\end{tabular}




\begin{tabular}{|l|l|l|l|l|l|l|l|}
\hline $\mathrm{C} 10$ & $\mathrm{Mn} 1$ & $\mathrm{C} 5$ & $86.35(4)$ & $\mathrm{N} 1$ & $\mathrm{C} 1$ & $\mathrm{C} 2$ & $110.27(9)$ \\
\hline $\mathrm{C} 11$ & $\mathrm{Mn} 1$ & $\mathrm{~N} 1$ & $92.24(4)$ & $\mathrm{C} 3$ & $\mathrm{C} 2$ & $\mathrm{C} 1$ & $105.62(9)$ \\
\hline $\mathrm{C} 11$ & $\mathrm{Mn} 1$ & $\mathrm{C} 5$ & $171.34(4)$ & $\mathrm{N} 2$ & $\mathrm{C} 3$ & $\mathrm{C} 2$ & $107.11(9)$ \\
\hline $\mathrm{C} 11$ & $\mathrm{Mn} 1$ & $\mathrm{C} 10$ & $93.88(4)$ & $\mathrm{C} 5$ & $\mathrm{C} 4$ & $\mathrm{~N} 2$ & $114.95(8)$ \\
\hline $\mathrm{C} 11$ & $\mathrm{Mn} 1$ & $\mathrm{C} 12$ & $95.85(4)$ & $\mathrm{C} 9$ & $\mathrm{C} 4$ & $\mathrm{~N} 2$ & $121.04(8)$ \\
\hline $\mathrm{C} 12$ & $\mathrm{Mn} 1$ & $\mathrm{~N} 1$ & $91.87(4)$ & $\mathrm{C} 9$ & $\mathrm{C} 4$ & $\mathrm{C} 5$ & $124.01(9)$ \\
\hline $\mathrm{C} 12$ & $\mathrm{Mn} 1$ & $\mathrm{C} 5$ & $84.65(4)$ & $\mathrm{C} 4$ & $\mathrm{C} 5$ & $\mathrm{Mn} 1$ & $114.01(6)$ \\
\hline $\mathrm{C} 12$ & $\mathrm{Mn} 1$ & $\mathrm{C} 10$ & $169.43(4)$ & $\mathrm{C} 4$ & $\mathrm{C} 5$ & $\mathrm{C} 6$ & $115.46(8)$ \\
\hline $\mathrm{C} 13$ & $\mathrm{Mn} 1$ & $\mathrm{~N} 1$ & $172.85(4)$ & $\mathrm{C} 6$ & $\mathrm{C} 5$ & $\mathrm{Mn} 1$ & $130.52(7)$ \\
\hline $\mathrm{C} 13$ & $\mathrm{Mn} 1$ & $\mathrm{C} 5$ & $93.77(4)$ & $\mathrm{C} 7$ & $\mathrm{C} 6$ & $\mathrm{C} 5$ & $121.83(9)$ \\
\hline $\mathrm{C} 13$ & $\mathrm{Mn} 1$ & $\mathrm{C} 10$ & $87.16(4)$ & $\mathrm{C} 8$ & $\mathrm{C} 7$ & $\mathrm{C} 6$ & $120.42(9)$ \\
\hline $\mathrm{C} 13$ & $\mathrm{Mn} 1$ & $\mathrm{C} 11$ & $94.89(4)$ & $\mathrm{C} 9$ & $\mathrm{C} 8$ & $\mathrm{C} 7$ & $119.63(9)$ \\
\hline $\mathrm{C} 13$ & $\mathrm{Mn} 1$ & $\mathrm{C} 12$ & $87.91(4)$ & $\mathrm{C} 8$ & $\mathrm{C} 9$ & $\mathrm{C} 4$ & $118.62(9)$ \\
\hline $\mathrm{N} 1$ & $\mathrm{~N} 1$ & $\mathrm{Mn} 1$ & $115.76(6)$ & $\mathrm{O} 1$ & $\mathrm{C} 10$ & $\mathrm{Mn} 1$ & $175.19(9)$ \\
\hline $\mathrm{C} 1$ & $\mathrm{~N} 1$ & $\mathrm{Mn} 1$ & $138.22(7)$ & $\mathrm{O} 2$ & $\mathrm{C} 11$ & $\mathrm{Mn} 1$ & $178.43(9)$ \\
\hline $\mathrm{C} 1$ & $\mathrm{~N} 1$ & $\mathrm{~N} 2$ & $106.01(8)$ & $\mathrm{O} 3$ & $\mathrm{C} 12$ & $\mathrm{Mn} 1$ & $175.27(9)$ \\
\hline $\mathrm{N} 1$ & $\mathrm{~N} 2$ & $\mathrm{C} 4$ & $116.11(7)$ & $\mathrm{O} 4$ & $\mathrm{C} 13$ & $\mathrm{Mn} 1$ & $177.70(9)$ \\
\hline
\end{tabular}




\section{References}

[1] (a) R. L. Rawls, Chem. Eng. News 2001, 79, 45-51; (b) J. W. Szostak, D. P. Bartel, P. L. Luisi, Nature 2001, 409, 387-390; (c) T. A. Byassee, W. C. W.Chan, S. Nie, Anal. Chem. 2000, 72, 5606-5611.

[2] (a) B. R. Stockwel, Nature 2004, 432, 846-854; (b) R. K. Gilpin, C. S. Gilpin, Anal. Chem. 2011, 83, 4489-4507; (c) A. S. Carlini, L. Adamiak, N. C. Gianneschi, Macromolecules 2016, 49, 4379-4394.

[3] (a) W. W. Irion, O. S. Neuwirth, W. W. Irion, O. S. Neuwirth, in "Oil Refinine", Wiley-VCH, 2005, Weinheim, 1-52; (b) Ramón A. Alvareza, S. W. Pacalab, J. J. Winebrake, W. L. Chameides, S. P. Hamburge, Proc. Natl. Acad. Sci. 2012, 109, 6435-6440.

[4] (a) F. E. Celik, B. Peters, M.-O. Coppens, A. McCormick, R. F. Hicks, J. Ekerdt, ACS Catal. 2017, 7, 8628-8640; (b) X. Zhang, M. Fevre, G. O. Jones, R. M. Waymouth, Chem. Rev. 2018, 118, 839-885.

[5] Green Chemistry, Theory and Practice, (Eds.: P. T. Anastas, J. C. Warner), Oxford University Press, Oxford, 1998.

[6] S. J. Blanksby, G. B. Ellison, Acc. Chem. Res. 2003, 36, 255-263.

[7] (a) P. Hong, B.-R. Cho, H. Yamazaki, Chem. Lett. 1979, 50, 339-342; (b) L. N. Lewis, J. F. Smith, J. Am. Chem. Soc. 1986, 108, 2728-2735.

[8] (a) K. Gao, N. Yoshikai, Acc. Chem. Res. 2014, 47, 1208-1219; (b) Z. Dong, Z. Ren, S. J. Thompson, Y. Xu, G. Dong, Chem. Rev. 2017, 117, 9333-9403; (c) J. R. Hummel, J. A. Boerth, J. A. Ellman, Chem. Rev. 2017, 117, 9163-9227; (d) Y. Park, Y. Kim, S. Chang, Chem. Rev. 2017, 117, 9247-9301; (e) Y. F. Yang, X. Hong, J. Q. Yu, K. N. Houk, Acc. Chem. Res. 2017, 50, 2853-2860.

[9] The Nobel Prize in 2010. https://www.nobelprize.org/prizes/chemistry/2010/summary/.

[10] N. K. Garg, R. Sarpong, B. M. Stoltz, J. Am. Chem. Soc. 2002, 124, 13179-13184.

[11] D. Mandal, A. D. Yamaguchi, J. Yamaguchi, K. Itami, J. Am. Chem. Soc. 2011, 133, 19660-19663.

[12] (a) D. Balcells, E. Clot, O. Eisenstein, Chem. Rev. 2010, 110, 749-823; (b) T. Sperger, I. A. Sanhueza, I. Kalvet, F. Schoenebeck, Chem. Rev. 2015, 115, 9532-9586; (c) D. L. Davies, S. A. Macgregor, C. L. McMullin, Chem. Rev. 2017, 117, 8649-8709.

[13] (a) J. A. Labinger, J. E. Bercaw, Nature 2002, 417, 507-514; (b) L. Ackermann, Chem. Rev. 2011, 111, 1315-1345.

[14] A. H. Janowicz, R. G. Bergman, J. Am. Chem. Soc. 1982, 104, 352-354.

[15] (a) P. L. Watson, J. Am. Chem. Soc. 1983, 105, 6491-6493; (b) M. E. Thompson, S. M. Baxter, A. R. Bulls, B. J. Burger, M. C. Nolan, B. D. Santarsiero, W. P. Schaefer, J. E. Bereaw, J. Am. 
Chem. Soc. 1987, 109, 203-219.

[16] S. S. Stahl, J. A. Labinger, J. E. Bercaw, Angew. Chem. Int. Ed. 1998, 37, 2180-2192.

[17] C. C. Cummins, S. M. Baxter, P. T. Wolczanski, J. Am. Chem. Soc. 1988, 110, 8731-8733.

[18] D. Lapointe, K. Fagnou, Chem. Lett. 2010, 39, 1118-1126.

[19] (a) Y. Boutadla, D. L. Davies, S. A.Macgregor, A. I. Poblador-Bahamondeb, Dalton Trans. 2009, 5820-5831; (b) Y. Boutadla, D. L. Davies, S. A.Macgregor, A. I. Poblador-Bahamondeb, Dalton Trans. 2009, 5887-5893.

[20] J. Oxgaard, W. J. Tenn, R. J. Nielsen, R. A. Periana, W. A. Goddard, Organometallics 2007, 26, 1565-1567.

[21] W. Ma, R. Mei, G. Tenti, L. Ackermann, Chem. Eur. J. 2014, 20, 15248-15251.

[22] D. Zell, M. Bursch, V. Muller, S. Grimme, L. Ackermann, Angew. Chem. Int. Ed. 2017, 56, 10378-10382.

[23] B. A. Arndtsen, R. G. Bergman, T. A. Mobley, T. H. Peterson, Acc. Chem. Res. 1995, 28, 154-162.

[24] I. V. Seregin, V. Gevorgyan, Chem. Soc. Rev. 2007, 36, 1173-1193.

[25] (a) T. W. Lyons, K. L. Hull, M. S. Sanford, J. Am. Chem. Soc. 2011, 133, 4455-4464; (b) N. Kuhl, M. N. Hopkinson, J. Wencel-Delord, F. Glorius, Angew. Chem. Int. Ed. 2012, 51, 10236-10254.

[26] (a) F. Zhang, D. R. Spring, Chem. Soc. Rev. 2014, 43, 6906-6919; (b) Y. Kuninobu, H. Ida, M. Nishi, M. Kanai, Nat. Chem. 2015, 7, 712-717.

[27] W. Ma, P. Gandeepan, J. Li, L. Ackermann, Org. Chem. Front. 2017, 4, 1435-1467.

[28] (a) V. Ritleng, C. Sirlin, M. Pfeffer, Chem. Rev. 2002, 102, 1731-1769; (b) D. A. Colby, R. G. Bergman, J. A. Ellman, Chem. Rev. 2010, 110, 624-655; (c) P. B. Arockiam, C. Bruneau, P. H. Dixneuf, Chem. Rev. 2012, 112, 5879-5918; (d) Y. F. Han, G. X. Jin, Chem. Soc. Rev. 2014, 43, 2799-2823.

[29] (a) I. T. Horváth, P. T. Anastas, Chem. Rev. 2007, 107, 2167-2168; (b) R. A. Sheldon, Chem. Soc. Rev. 2012, 41, 1437-1451.

[30] S. R. Neufeldt, M. S. Sanford, Acc. Chem. Res. 2012, 45, 936-946.

[31] X. Qi, Y. Li, R. Bai, Y. Lan, Acc. Chem. Res. 2017, 50, 2799-2808.

[32] J. A. Labinger, Chem. Rev. 2017, 117, 8483-8496.

[33] L. Ackermann, Org. Process Res. Dev. 2015, 19, 260-269.

[34] S. Pan, T. Shibata, ACS Catal. 2013, 3, 704-712.

[35] (a) J. R. Ludwig, C. S. Schindler, Chem 2017, 2, 313-316; (b) P. Gandeepan, T. Muller, D. Zell, G. Cera, S. Warratz, L. Ackermann, Chem. Rev. 2019, DOI: 10.1021/acs.chemrev.8b00507.

[36] P. E. Brubaker, J. P. Moran, K. Bridbord, F. Gordon, Hueter, Environ. Health Perspect. 1975, 10, 39-56.

[37] (a) T. Yoshino, S. Matsunaga, Adv. Synth. Catal. 2017, 359, 1245-1262; (b) DonghuiWei, X. Zhu, Jun-LongNiu, M.-P. Song, ChemCatChem 2016, 8, 1242-1263; (c) P. G. Chirila, C. J. 
Whiteoak, Dalton Trans. 2017, 46, 9721-9739; (d) L. Ackermann, J. Org. Chem. 2014, 79, 8948-8954; (e) M. Moselage, J. Li, L. Ackermann, ACS Catal. 2016, 6, 498-525; (f) S. Wang, S. Y. Chen, X. Q. Yu, Chem. Commun. 2017, 53, 3165-3180.

[38] S. Murahashi, J. Am. Chem. Soc. 1955, 77, 6403-6404.

[39] J. K. Kochi, R. T. Tang, T. Bernath, J. Am. Chem. Soc. 1973, 95, 7114-7123.

[40] G. Halbritter, F. Knoch, A. Wolski, H. Kisch, Angew. Chem. Int. Ed. 1994, 33, 1603-1605.

[41] (a) C. P. Lenges, M. Brookhart, J. Am. Chem. Soc. 1997, 119, 3165-3166; (b) C. P. Lenges, P. S. White, M. Brookhart, J. Am. Chem. Soc. 1998, 120, 6965-6979.

[42] A. D. Bolig, M. Brookhart, J. Am. Chem. Soc. 2007, 129, 14544-14545.

[43] C. P. Lenges, M. Brooldaart, B. E. Grant, J. Organomet. Chem. 1997, 528, 199-203.

[44] H.-F. Klein, M. Helwiga, U. Kocha, U. Flörke, H.-J. Haupt, Z. Naturforsch. 1993, 48b, 778-784.

[45] S. Camadanli, R. Beck, U. Florke, H. F. Klein, Dalton Trans. 2008, 5701-5704.

[46] H.-F. Klein, S. Camadanli, R. Beck, D. Leukel, U. Flörke, Angew. Chem. Int. Ed. 2005, 44, 975-977.

[47] R. Beck, H. Sun, X. Li, S. Camadanli, H.-F. Klein, Eur. J. Inorg. Chem. 2008, 3253-3257.

[48] (a) H.-F. Klein, S. Schneider, M. He, U. Floerke, H.-J. Haupt, Eur. J. Inorg.Chem. 2000, 2295-2301; (b) H.-F. Klein, R. Beck, U. Flörke, H.-J. Haupt, Eur. J. Inorg. Chem. 2003, 1380-1387.

[49] A. Wang, H. Sun, X. Li, Organometallics 2008, 27, 5434-5437.

[50] K. Gao, P.-S. Lee, T. Fujita, N. Yoshikai, J. Am. Chem. Soc. 2010, 132, 12249-12251.

[51] (a) P. S. Lee, T. Fujita, N. Yoshikai, J. Am. Chem. Soc. 2011, 133, 17283-17295; (b) B. H. Tan, J. Dong, N. Yoshikai, Angew. Chem. Int. Ed. 2012, 51, 9610-9614; (c) Z. Ding, N. Yoshikai, Angew. Chem. Int. Ed. 2013, 52, 8574-8578; (d) N. Yoshikai, Bull. Chem. Soc. Jpn. 2014, 87, 843-857

[52] (a) Q. Chen, L. Ilies, E. Nakamura, J. Am. Chem. Soc. 2011, 133, 428-429; (b) Q. Chen, L. Ilies, N. Yoshikai, E. Nakamura, Org. Lett. 2011, 13, 3232-3234; (c) L. Ilies, Q. Chen, X. Zeng, E. Nakamura, J. Am. Chem. Soc. 2011, 133, 5221-5223.

[53] (a) W. Song, L. Ackermann, Angew. Chem. Int. Ed. 2012, 51, 8251-8254; (b) B. Punji, W. Song, G. A. Shevchenko, L. Ackermann, Chem. Eur. J. 2013, 19, 10605-10610; (c) J. Li, L. Ackermann, Chem. Eur. J. 2015, 21, 5718-5722; (d) M. Moselage, N. Sauermann, S. C. Richter, L. Ackermann, Angew. Chem. Int. Ed. 2015, 54, 6352-6355.

[54] (a) J. V. Obligacion, S. P. Semproni, P. J. Chirik, J. Am. Chem. Soc. 2014, 136, 4133-4136; (b) B. J. Fallon, E. Derat, M. Amatore, C. Aubert, F. Chemla, F. Ferreira, A. Perez-Luna, M. Petit, J. Am. Chem. Soc. 2015, 137, 2448-2451; (c) L. Zhang, Z. Huang, J. Am. Chem. Soc. 2015, 137, 15600-15603.

[55] M. Brookhart, A. F. V. Jr., D. M. Lincoln, I. T. Horvath, J. M. Millar, J. Am. Chem. Soc. 1990, 112, 5634-5636.

[56] T. Yoshino, H. Ikemoto, S. Matsunaga, M. Kanai, Angew. Chem. Int. Ed. 2013, 52, 2207-2211. 
[57] L. Ackermann, A. V. Lygin, Org. Lett. 2011, 13, 3332-3335.

[58] T. Yoshino, H. Ikemoto, S. Matsunaga, M. Kanai, Chem. Eur. J. 2013, 19, 9142-9146.

[59] B. Sun, T. Yoshino, S. Matsunaga, M. Kanai, Adv. Synth. Catal. 2014, 356, 1491-1495.

[60] (a) D. M. Roe, P. M. Maitlis, J. Chem. Soc. (A) 1971, 20; (b) W. Li, L.-H. Weng, G.-X. Jin, Inorg. Chem. Commun. 2004, 7, 1174-1177.

[61] L. Grigorjeva, O. Daugulis, Angew. Chem. Int. Ed. 2014, 53, 10209-10212.

[62] J. Li, L. Ackermann, Angew. Chem. Int. Ed. 2015, 54, 3635-3638.

[63] D. G. Yu, T. Gensch, F. de Azambuja, S. Vasquez-Cespedes, F. Glorius, J. Am. Chem. Soc. 2014, 136, 17722-17725.

[64] A. B. Pawar, S. Chang, Org. Lett. 2015, 17, 660-663.

[65] J. A. Marshall, Chem. Rev. 2000, 10, 3163-3185.

[66] (a) I. S. Kim, M.-Y. Ngai, M. J. Krisch, J. Am. Chem. Soc. 2008, 130, 6340-6341; (b) H. Wang, N. Schroder, F. Glorius, Angew. Chem. Int. Ed. 2013, 52, 5386-5389; (c) S. Yu, X. Li, Org. Lett. 2014, 16, 1200-1203; (d) R. Murakami, K. Sano, T. Iwai, T. Taniguchi, K. Monde, M. Sawamura, Angew. Chem. Int. Ed. 2018, 57, 9465-9469.

[67] M. Moselage, N. Sauermann, J. Koeller, W. Liu, D. Gelman, L. Ackermann, Synlett 2015, 26, 1596-1600.

[68] (a) Y. Suzuki, B. Sun, K. Sakata, T. Yoshino, S. Matsunaga, M. Kanai, Angew. Chem. Int. Ed. 2015, 54, 9944-9947; (b) Y. Bunno, N. Murakami, Y. Suzuki, M. Kanai, T. Yoshino, S. Matsunaga, Org. Lett. 2016, 18, 2216-2219.

[69] L. Kong, S. Yu, G. Tang, H. Wang, X. Zhou, X. Li, Org. Lett. 2016, 18, 3802-3805.

[70] D. Zell, Q. Bu, M. Feldt, L. Ackerman, Angew. Chem. Int. Ed. 2016, 55, 7408-7412.

[71] L. Ackermann, Acc. Chem. Res. 2014, 47, 281-295.

[72] (a) Z.-H. Peng, K. A. Woerpe, J. Am. Chem. 2003, 125, 6018-6019; (b) J. R. Chen, X. Q. Hu, L. Q. Lu, W. J. Xiao, Chem. Rev. 2015, 115, 5301-5365; (c) X. Chen, S. Yang, H. Li, B. Wang, G. Song, ACS Catal. 2017, 7, 2392-2396; (d) C. Q. Wang, L. Ye, C. Feng, T. P. Loh, J. Am. Chem. 2017, 139, 1762-1765.

[73] S. Prakash, K. Muralirajan, C. H. Cheng, Angew. Chem. Int. Ed. 2016, 55, 1844-1848.

[74] H. Ikemoto, T. Yoshino, K. Sakata, S. Matsunaga, M. Kanai, J. Am. Chem. Soc. 2014, 136, 5424-5431.

[75] J. R. Hummel, J. A. Ellman, J. Am. Chem. Soc. 2015, 137, 490-498.

[76] J. Li, M. Tang, L. Zang, X. Zhang, Z. Zhang, L. Ackermann, Org. Lett. 2016, 18, 2742-2745.

[77] S. Wang, J. T. Hou, M. L. Feng, X. Z. Zhang, S. Y. Chen, X. Q. Yu, Chem. Commun. 2016, 52, 2709-2712.

[78] M. Sen, B. Emayavaramban, Nagaraju Barsu, J. R. Premkumar, B. Sundararaju, ACS Catal. 2016, 6, 2792-2796.

[79] N. Barsu, M. A. Rahman, M. Sen, B. Sundararaju, Chem. Eur. J. 2016, 22, 9135-9138.

[80] F. Pesciaioli, U. Dhawa, J. C. A. Oliveira, R. Yin, M. John, L. Ackermann, Angew. Chem. Int. Ed. 
2018, 57, 15425-15429.

[81] (a) V. Ritleng, C. Sirlin, M. Pfeffer, Chem. Rev. 2002, 102, 1731-1769; (b) C. G. Newton, S. G. Wang, C. C. Oliveira, N. Cramer, Chem. Rev. 2017, 117, 8908-8976.

[82] T. V. Peres, M. R. Schettinger, P. Chen, F. Carvalho, D. S. Avila, A. B. Bowman, M. Aschner, BMC Pharmacol. Toxicol. 2016, 17, 57.

[83] (a) C. Wang, Synlett 2013, 24, 1606-1613; (b) W. Liu, L. Ackermann, ACS Catal. 2016, 6, 3743-3752; (c) Y. Hu, B. Zhou, C. Wang, Acc. Chem. Res. 2018, 51, 816-827.

[84] (a) R. V. Ottenbacher, D. G. Samsonenko, E. P. Talsi, K. P. Bryliakov, Org. Lett. 2012, 14, 4310-4313; (b) D. Shen, C. Miao, S. Wang, C. Xia, W. Sun, Org. Lett. 2014, 16, 1108-1111; (c) A. M. Adams, J. Du Bois, H. A. Malik, Org. Lett. 2015, 17, 6066-6069.

[85] (a) W. Liu, J. T. Groves, J. Am. Chem. Soc. 2010, 132, 12847-12849; (b) W. Liu, X. Huang, M.-J. Cheng, R. J. Nielsen, W. A. Goddard, J. T. Groves, Science 2012, 337, 1322-1325; (c) W. Liu, J. T. Groves, Angew. Chem. Int. Ed. 2013, 52, 6024-6027; (d) X. Huang, W. Liu, H. Ren, R. Neelamegam, J. M. Hooker, J. T. Groves, J. Am. Chem. Soc. 2014, 136, 6842-6845.

[86] (a) X. Huang, T. M. Bergsten, J. T. Groves, J. Am. Chem. Soc. 2015, 137, 5300-5303; (b) S. M. Paradine, J. R. Griffin, J. Zhao, A. L. Petronico, S. M. Miller, M. Christina White, Nat. Chem. 2015, 7, 987-994; (c) X. Huang, T. Zhuang, P. A. Kates, H. Gao, X. Chen, J. T. Groves, J. Am. Chem. Soc. 2017, 139, 15407-15413.

[87] A. Horsfield, A. Wassermann, W. Ramsey, R. Forster, J. Chem. Soc. A 1970, 3202-3204.

[88] A. Suárez, J. M. Vila, M. T. Pereira, E. Gayoso, M. Gayoso, J. Organomet. Chem. 1987, 335, 359-363.

[89] C. Morton, D. J. Duncalf, J. P. Rourke, J. Organomet. Chem. 1997, 530, 19-25.

[90] M. I. Bruce, B. L. Goodall, M. Z. Iqbal, F. G. A. Stone, J. Chem. Soc. D 1971, 1595-1596.

[91] N. P. Robinson, L. Main, B. K. Nicholson, J. Organomet. Chem. 1988, 349, 209-218.

[92] (a) J. M. Cooney, L. H. P. Gommaus, L. Main, B. K. Nicholson, J. Organomet. Chem. 1988, 349, 197-207; (b) G. J. Depree, L. Main, B. K. Nicholson, N. P. Robinson, G. B. Jameson, J. Organomet. Chem. 2006, 691, 667-679.

[93] R. C. Cambie, L. C. M. Mui, P. S. Rutledge, P. D. Woodgate, J. Organomet. Chem. 1994, 464, 171-182.

[94] J. M. Ressner, P. C. Wernett, C. S. Kralhanzel, A. L. Rhelngold, Organometallics 1988, 7, 1661-1663.

[95] Y. Kuninobu, Y. Nishina, T. Takeuchi, K. Takai, Angew. Chem. Int. Ed. 2007, 46, 6518-6520.

[96] B. Zhou, H. Chen, C. Wang, J. Am. Chem. Soc. 2013, 135, 1264-1267.

[97] L. Shi, X. Zhong, H. She, Z. Lei, F. Li, Chem. Commun. 2015, 51, 7136-7139.

[98] (a) N. P. Yahaya, K. M. Appleby, M. Teh, C. Wagner, E. Troschke, J. T. Bray, S. B. Duckett, L. A. Hammarback, J. S. Ward, J. Milani, N. E. Pridmore, A. C. Whitwood, J. M. Lynam, I. J. Fairlamb, Angew. Chem. Int. Ed. 2016, 55, 12455-12459; (b) L. A. Hammarback, I. P. Clark, F. Clarke, S. Meyer, I. V. Sazanovich, I. J. S. Fairlamb, M. Towrie, J. M. Lynam, Nat. Catal. 2018, 1, 
830-840.

[99] B. Zhou, P. Ma, H. Chen, C. Wang, Chem. Commun. 2014, 50, 14558-14561.

[100] B. Zhou, Y. Hu, C. Wang, Angew. Chem. Int. Ed. 2015, 54, 13659-13663.

[101] Y. F. Liang, L. Massignan, W. Liu, L. Ackermann, Chem. Eur. J. 2016, 22, 14856-14859.

[102] Y.-F. Liang, L. Massignan, L. Ackermann, ChemCatChem 2018, 10, 2768-2772.

[103] B. Zhou, Y. Hu, T. Liu, C. Wang, Nat. Commun. 2017, 8, 1169.

[104] W. Liu, S. C. Richter, Y. Zhang, L. Ackermann, Angew. Chem. Int. Ed. 2016, 55, 7747-7750.

[105] Q. Lu, F. J. R. Klauck, F. Glorius, Chem. Sci. 2017, 8, 3379-3383.

[106] J. Ni, H. Zhao, A. Zhang, Org. Lett. 2017, 19, 3159-3162.

[107] Q. Lu, S. Gressies, F. J. R. Klauck, F. Glorius, Angew. Chem. Int. Ed. 2017, 56, 6660-6664.

[108] R. Alajarín, C. Burgos, in "Modern Heterocyclic Chemistry" Eds.: J. Alvarez-Builla, J. J. Vaquero, J. Barluenga, Wiley-VCH, 2011, Weinheim, 1527-1629.

[109] (a) E. C. Franklin, F. W. Bergstrom, Heterocyclic Nitrogen Compounds; Part II A. Hexacyclic Compounds: Pyridine, Quinoline, and Isoquinoline. 1994, pp: 77-277; (b) R. D. Larsen, R. A. Reamer, E. G. Corley, P. Davis, E. J. J. Grabowski, P. J. Reider, I. Shinkai, J. Org. Chem. 1991, 56, 6034-6038; (c) C. Kornhaass, J. Li, L. Ackermann, J. Org. Chem. 2012, 77, 9190-9198.

[110] R. He, Z. T. Huang, Q. Y. Zheng, C. Wang, Angew. Chem. Int. Ed. 2014, 53, 4950-4953.

[111] (a) T. Gerfaud, L. Neuville, J. Zhu, Angew. Chem. Int. Ed. 2009, 48, 572-577; (b) N. Guimond, K. Fagnou, J. Am. Chem. Soc. 2009, 131, 12050-12051; (c) Y. F. Wang, K. K. Toh, J. Y. Lee, S. Chiba, Angew. Chem. Int. Ed. 2011, 50, 5927-5931.

[112] Q. Lu, S. Gressies, S. Cembellin, F. J. R. Klauck, C. G. Daniliuc, F. Glorius, Angew. Chem. Int. Ed. 2017, 56, 12778-12782.

[113] W. Liu, D. Zell, M. John, L. Ackermann, Angew. Chem. Int. Ed. 2015, 54, 4092-4096.

[114] C. Wang, A. Wang, M. Rueping, Angew. Chem. Int. Ed. 2017, 56, 9935-9938.

[115] S.-Y. Chen, X.-L. Han, J.-Q. Wu, Q. Li, Y. Chen, H. Wang, Angew. Chem. Int. Ed. 2017, 56, 9939-9943.

[116] W. Liu, S. C. Richter, R. Mei, M. Feldt, L. Ackermann, Chem. Eur. J. 2016, 22, 17958-17961.

[117] X. Yu, J. Tang, XinxinJin, Y. Yamamoto, M. Bao, Asian J. Org. Chem. 2018, 7, 550-553.

[118] Z. Ruan, N. Sauermann, E. Manoni, L. Ackermann, Angew. Chem. Int. Ed. 2017, 56, 3172-3176.

[119] (a) K. Ruhland, Eur. J. Org. Chem. 2012, 2683-2706; (b) L. Souillart, N. Cramer, Chem. Rev. 2015, 115, 9410-9464; (c) P. H. Chen, B. A. Billett, T. Tsukamoto, G. Dong, ACS Catal. 2017, 7, 1340-1360; (d) D. S. Kim, W. J. Park, C. H. Jun, Chem. Rev. 2017, 117, 8977-9015.

[120] (a) J. A. Labinger, J. E. Bercaw, Organometallics 1988, 7, 926-928; (b) J. A. M. Simoes, J. L. Beauchamp, Chem. Rev. 1990, 90, 629-688; (c) P. E. M. Siegbahn, J. Phys. Chem. 1995, 99, 12723-12729.

[121] M. Murakami, N. Ishida, J. Am. Chem. Soc. 2016, 138, 13759-13769.

[122] R. D. Bach, O. Dmitrenko, J. Am. Chem. Soc. 2004, 126, 4444-4452. 
[123] G. Fumagalli, S. Stanton, J. F. Bower, Chem. Rev. 2017, 117, 9404-9432.

[124] (a) M. Tobisu, Y. Kita, Y. Ano, N. Chatani, J. Am. Chem. Soc. 2008, 130, 15982-15989; (b) M. P. Watson, E. N. Jacobsen, J. Am. Chem. Soc. 2008, 130, 12954-12959; (c) M. Tobisu, R. Nakamura, Y. Kita, N. Chatani, J. Am. Chem. Soc. 2009, 131, 3174-3175; (d) D.-G. Yu, M. Yu, B.-T. Guan, B.-J. Li, Y. Zheng, Z.-H. Wu, Z.-J. Shi, Org. Lett. 2009, 11, 3374-3377; (e) K. Nakai, T. Kurahashi, S. Matsubara, J. Am. Chem. Soc. 2011, 133, 11066-11068; (f) K. Nakai, T. Kurahashi, S. Matsubara, Org. Lett. 2013, 15, 856-859.

[125] (a) A. Dreis, C. Douglas, In C-C Bond Activation; Dong, G., Ed.; Springer: Berlin 2014, 346, 85-110; (b) C.-H. Jun, J.-W. Park, In C-C Bond Activation; Dong, G., Ed.;Springer: Berlin, 2014, 346, 59-83.

[126] R. B. King, A. Efraty, J. Am. Chem. Soc. 1972, 94, 3373-3379.

[127] (a) M. Murakami, H. Amii, K. Shigeto, Y. Ito, J. Am. Chem. Soc. 1996, 118, 8285-8290; (b) T. Matsuda, M. Shigeno, M. Murakami, Chem. Lett. 2006, 35, 288-289.

[128] T. Seiser, T. Saget, D. N. Tran, N. Cramer, Angew. Chem. Int. Ed. 2011, 50, 7740-7752.

[129] H. Yorimitsu, K. Oshima, Bull. Chem. Soc. Jpn. 2009, 82, 778-792.

[130] C. F. H. Tipper, J. Chem. Soc. 1955, 2043.

[131] D. M. Adams, J. Chatt, R. G. Guy, N. Sheppard, J. Chem. Soc. (Resumed) 1961, 738-742.

[132] M. H. Shaw, E. Y. Melikhova, D. P. Kloer, W. G. Whittingham, J. F. Bower, J. Am. Chem. Soc. 2013, 135, 4992-4995.

[133] M. Moselage, J. Li, F. Kramm, L. Ackermann, Angew. Chem. Int. Ed. 2017, 56, 5341-5344.

[134] C. Kashima, S. Hibi, T. Maruyama, K. Harada, Y. Omote, J. Heterocycl. Chem. 1987, 24, 637-639.

[135] H. Li, Y. Li, X. S. Zhang, K. Chen, X. Wang, Z. J. Shi, J. Am. Chem. Soc. 2011, 133, 15244-15247.

[136] (a) K. Chen, H. Li, Z. Q. Lei, Y. Li, W. H. Ye, L. S. Zhang, J. Sun, Z. J. Shi, Angew. Chem. Int. Ed. 2012, 51, 9851-9855; (b) K. Chen, H. Li, Y. Li, X.-S. Zhang, Z.-Q. Lei, Z.-J. Shiab, Chem. Sci. 2012, 3, 1645-1649.

[137] E. Ozkal, B. Cacherat, B. Morandi, ACS Catal. 2015, 5, 6458-6462.

[138] (a) A. E. Shilov, G. B. Shul'pin, Chem. Rev. 1997, 97, 2879-2932; (b) L. Yang, H. Huang, Chem. Rev. 2015, 115, 3468-3517.

[139] (a) J. Li, K. Korvorapun, S. De Sarkar, T. Rogge, D. J. Burns, S. Warratz, L. Ackermann, Nat. Commun. 2017, 8, 15430; (b) M. Bauer, W. Wang, M. M. Lorion, C. Dong, L. Ackermann, Angew. Chem. Int. Ed. 2018, 57, 203-207; (c) R. Mei, N. Sauermann, J. C. A. Oliveira, L. Ackermann, J. Am. Chem. Soc. 2018, 140, 7913-7921.

[140] (a) K. Parthasarathy, C.-H. Cheng, J. Org. Chem. 2009, 74, 9359-9364; (b) N. Guimond, S. I. Gorelsky, K. Fagnou, J. Am. Chem. Soc. 2011, 133, 6449-6457; (c) R. K. Chinnagolla, S. Pimparkar, M. Jeganmohan, Org. Lett. 2012, 14, 3032-3035; (d) K. Muralirajan, R. Kuppusamy, S. Prakash, C.-H. Cheng, Adv. Synth. Catal. 2016, 358, 774-783.

[141] H. Wang, J. Koeller, W. Liu, L. Ackermann, Chem. Eur. J. 2015, 21, 15525-15528. 
[142] (a) B. Robinson, The Fischer Indole Synthesis. 1962, pp: 373-401; (b) G. R. Humphrey, J. T. Kuethe, Chem. Rev. 2006, 106, 2875-2911; (c) D. F. Taber, P. K. Tirunahari, Tetrahedron 2011, 67, 7195-7210; (d) L. L. Tao, J. Jiang, Y. C. Pan, X. Yang, B. L. Li, Adv. Mater. Res. 2013, 661, 150-153.

[143] (a) T. Guo, F. Huang, L. Yu, Z. Yu, Tetrahedron Lett. 2015, 56, 296-302; (b) S. Agasti, A. Dey, D. Maiti, Chem. Commun. 2017, 53, 6544-6556.

[144] H. Wang, M. Moselage, M. J. González, L. Ackerman, ACS Catal. 2016, 6, 2705-2709.

[145] (a) L. McMurray, F. O'Hara, M. J. Gaunt, Chem. Soc. Rev. 2011, 40, 1885-1898; (b) J. Wencel-Delord, T. Droge, F. Liu, F. Glorius, Chem. Soc. Rev. 2011, 40, 4740-4761.

[146] Y. J. Liu, H. Xu, W. J. Kong, M. Shang, H. X. Dai, J. Q. Yu, Nature 2014, 515, 389-393.

[147] H. Wang, M. M. Lorion, L. Ackermann, Angew. Chem. Int. Ed. 2006, 55, 10386-10390.

[148] H. Wang, M. M. Lorion, L. Ackermann, ACS Catal. 2017, 7, 3430-3433.

[149] H. Wang, M. M. Lorion, L. Ackermann, Angew. Chem. Int. Ed. 2017, 56, 6339-6342.

[150] (a) T. N. Glasnov, C. O. Kappe, Chem. Eur. J. 2011, 17, 11956-11968; (b) D. T. McQuade, P. H. Seeberger, J. Org. Chem. 2013, 78, 6384-6389; (c) S. G. Newman, K. F. Jensen, Green Chem. 2013, 15, 1456-1472; (d) H. P. Gemoets, Y. Su, M. Shang, V. Hessel, R. Luque, T. Noel, Chem. Soc. Rev. 2016, 45, 83-117.

[151] (a) D. Zell, U. Dhawa, V. Muller, M. Bursch, S. Grimme, L. Ackermann, ACS Catal. 2017, 7, 4209-4213 2017, 7, 4209-4213; (b) C. Zhu, J. L. Schwarz, S. Cembellin, S. Gressies, F. Glorius, Angew. Chem. Int. Ed. 2018, 57, 437-441.

[152] H. Wang, F. Pesciaioli, J. C. A. Oliveira, S. Warratz, L. Ackermann, Angew. Chem. Int. Ed. 2017, $56,15063-15067$.

[153] M. Moselage, J. Li, F. Kramm, L. Ackermann, Angew. Chem. Int. Ed. 2017, 56, 5341-5344.

[154] H. Wang, I. Choi, T. Rogge, N. Kaplaneris, L. Ackermann, Nat. Catal. 2018, 1, 993-1001.

[155] K. Parthasarathy, C.-H. Cheng, J. Org. Chem. 2009, 74, 9359-9364.

[156] J. Li, L. Ackermann, Angew. Chem. Int. Ed. 2015, 54, 8551-8554.

[157] P. C. Too, S. H. Chua, S. H. Wong, S. Chiba, J. Org. Chem. 2011, 76, 6159-6168.

[158] E. Fisoher, F. Jourden, Berichte der Deutschen Chemischen Gesellschaft. 1883, 16, 2241-2245.

[159] (a) D.-H. Wang, K. M. Engle, B.-F. Shi, J.-Q. Yu, Science 2010, 327, 315-319; (b) K. M. Engle, J. Q. Yu, J. Org. Chem. 2013, 78, 8927-8955.

[160] J. Li, S. Warratz, D. Zell, S. De Sarkar, E. E. Ishikawa, L. Ackermann, J. Am. Chem. Soc. 2015, $137,13894-13901$.

[161] Z. Zhou, G. Liu, Y. Chen, X. Lu, Adv. Synth. Catal. 2015, 357, 2944-2950.

[162] R. B. Dateer, S. Chang, J. Am. Chem. Soc. 2015, 137, 4908-4911.

[163] (a) G. Bringmann, A. J. Price Mortimer, P. A. Keller, M. J. Gresser, J. Garner, M. Breuning, Angew. Chem. Int. Ed. 2005, 44, 5384-5427; (b) G. Bringmann, T. Gulder, T. A. M. Gulder, M. Breuning, Chem. Rev. 2011, 111, 563-639. 
[164] Y. Yang, J. Lan, J. You, Chem. Rev. 2017, 117, 8787-8863.

[165] A. Ivanković, A. Dronjić, A. M. Bevanda, S. Talić, Int. J. Sus. \& Green Energy 2017, 6, 39-48.

[166] (a) H. Lu, X. P. Zhang, Chem. Soc. Rev. 2011, 40, 1899-1909; (b) H. Yi, G. Zhang, H. Wang, Z. Huang, J. Wang, A. K. Singh, A. Lei, Chem. Rev. 2017, 117, 9016-9085.

[167] (a) L. F. Tietze, G. Brasche, K. M. Gerick, "Domino Reactions in Organic Synthesis", Wiley-VCH, 2006, Weinheim, 1-617; (b) L. Tietze, G. Brasche, K. M. Gericke, J. Am. Chem. Soc. 2007, 129, 7476; (c) L. J. Sebren, J. J. Devery, C. R. Stephenson, ACS Catal. 2014, 4, 703-716.

[168] (a) H. V. Dang, H. T. B. Le, L. T. B. Tran, H. Q. Ha, H. V. Le, N. T. S. Phan, RSC Adv. 2018, 8, 31455-31464; (b) N. Saha, H. Wang, S. Zhang, Y. Du, D. Zhu, Y. Hu, P. Huang, S. Wen, Org. Lett. 2018, 20, 712-715; (c) G. Dyker, Chem. Ber. 1994, 127, 739-742.

[169] B. Weiner, A. Baeza, T. Jerphagnon, B. L. Feringa, J. Am. Chem. Soc. 2009, 131, 9473-9474.

[170] N. K. Mishra, S. Sharma, J. Park, S. Han, I. S. Kim, ACS Catal. 2017, 7, 2821-2847.

[171] (a) C. Zhu, J. o. C. A. Oliveira, Z. Shen, H. Huang, L. Ackermann, ACS Catal. 2018, 8, 4402-4407; (b) F. Ferlin, S. Santoro, L. Ackermann, L. Vaccaro, Green Chem. 2017, 19, 2510-2514; (c) Y. F. Liang, R. Steinbock, L. Yang, L. Ackermann, Angew. Chem. Int. Ed. 2018, 57, 10625-10629.

[172] (a) U. K. Sharma, H. P. L. Gemoets, F. Schröder, T. Noël, E. V. V. d. Eycken, ACS Catal. 2017, 7, 3818-3823; (b) H. P. L. Gemoets, G. Laudadio, K. Verstraete, V. Hessël, T. Noël, Angew. Chem. Int. Ed. 2017, 56, 7161-7165.

[173] (a) N. Hofmann, L. Ackermann, J. Am. Chem. Soc. 2013, 135, 5877-5884; (b) G. Cera, T. Haven, L. Ackermann, Angew. Chem. Int. Ed. 2016, 55, 1484-1488.

[174] H. Guo, M. S. Mortensen, G. A. O'Doherty, Org. Lett. 2008, 10, 3149-3152.

[175] S.-K. Kang, D.-G. Cho, J.-U. Chung, D.-Y. Kim, Tetrahedron: Asymmetry 1994, 5, 21-22.

[176] W. Guo, L. Martinez-Rodriguez, R. Kuniyil, E. Martin, E. C. Escudero-Adan, F. Maseras, A. W. Kleij, J. Am. Chem. Soc. 2016, 138, 11970-11978.

[177] Y. F. Liang, N. Jiao, Acc. Chem. Res. 2017, 50, 1640-1653.

[178] C. H. Jun, Chem. Soc. Rev. 2004, 33, 610-618.

[179] (a) J. Zhu, J. Wang, G. Dong, Nat. Chem. 2018, doi.org/10.1038/s41557-018-0157-x; (b) R. Zeng, G. Dong, J. Am. Chem. Soc. 2015, 137, 1408-1411; (c) T. Sun, Y. Zhang, BoQiu, Y. Wang, Y. Qin, G. Dong, TaoXu, Angew. Chem. Int. Ed. 2018, 57, 2859-2863.

[180] M. Lautens, Y. Ren, P. M. Delanghe, J. Am. Chem. Soc. 1994, 116, 8821-8822.

[181] S.-S. Zhang, J.-Q. Wu, X. Liu, H. Wang, ACS Catal. 2015, 5, 210-214.

[182] P. C. Too, Y.-F. Wang, S. Chiba, Org. Lett. 2010, 12, 5688-5691.

[183] M. J. Mio, Lucas C. Kopel, Julia B. Braun, T. L. Gadzikwa, K. L. Hull, R. G. Brisbois, C. J. Markworth, P. A. Grieco, Org. Lett. 2002, 4, 3199-3202.

[184] S.-G. Lim, J. H. Lee, C. W. Moon, J.-B. Hong, C.-H. Jun, Org. Lett. 2003, 5, 2759-2761.

[185] D. A. Evans, H.-J. Song, K. R. Fandrick, Org. Lett. 2006, 8, 3351-3354.

[186] B. Lu, C. Li, L. Zhang, J. Am. Chem. Soc. 2010, 132, 14070-14072. 
[187] V. K. Yadav, K. G. Babu, Eur. J. Org. Chem. 2005, 452-456.

[188] V. Bizet, L. Buglioni, C. Bolm, Angew. Chem. Int. Ed. 2014, 53, 5639-5642.

[189] N. Sauermann, M. J. Gonzalez, L. Ackermann, Org. Lett. 2015, 17, 5316-5319.

[190] (a) S. Xu, X. Huang, X. Hong, B. Xu, Org. Lett. 2012, 14, 4614-4617; (b) V. K. Tiwari, N. Kamal, M. Kapur, Org. Lett. 2015, 17, 1766-1769.

[191] V. P. W. Bohm, T. Weskamp, C. W. K. Gstottmayr, W. A. Herrmann, Angew. Chem. Int. Ed. 2000, 39, 1602-1604.

[192] S. S. Zhang, J. Q. Wu, Y. X. Lao, X. G. Liu, Y. Liu, W. X. Lv, D. H. Tan, Y. F. Zeng, H. Wang, Org. Lett. 2014, 16, 6412-6415.

[193] W. Liu, S. C. Richter, Y. Zhang, L. Ackermann, Angew. Chem. Int. Ed. 2016, 55, 7747-7750.

[194] L. Zheng, J. Ju, Y. Bin, R. Hua, J. Org. Chem. 2012, 77, 5794-5800.

[195] S.-C. Chuang, P. Gandeepan, C.-H. Cheng, Org. Lett. 2013, 15, 5750-5753.

[196] W. C. Shih, C. C. Teng, K. Parthasarathy, C. H. Cheng, Chem. Asian J. 2012, 7, 306-313.

[197] P. He, Y. Du, G. Liu, G. Pang, RSC Adv. 2013, 3, 18345-18350.

[198] H. H. Nguyen, M. J. Kurth, Org. Lett. 2013, 15, 362-365.

[199] F. Wang, H. Wang, Q. Wang, S. Yu, X. Li, Org. Lett. 2016, 18, 1306-1309.

[200] S. Battula, R. A. Vishwakarma, Q. N. Ahmed, RSC Adv. 2014, 4, 38375-38378.

[201] M. Lombardo, F. Pasi, C. Trombini, Eur. J. Org. Chem. 2006, 3061-3063.

[202] R. Qiu, L. Xu, H. Li, Adv.Synth. Catal. 2015, 357, 1229-1236.

[203] M. Sen, BaskerSundararaju, B. Emayavaramban, J. R. Premkumar, N. Rajesh, Chem. Eur. J. 2018, 24, 342-346.

[204] Z. Zhang, S. Han, M. Tang, L. Ackermann, J. Li, Org. Lett. 2017, 19, 3315-3318. 


\section{Acknowledgements}

Herein, I would like to extend my sincere gratitude to my supervisor Prof. Dr. Lutz Ackermann during my graduate study. Without his constant encouragement, excellent guidance, patience in the past four years. I would never be able to accomplish my doctoral degree. I learned not only the basic skills in chemistry, but also the spirit of a chemist from him.

I gratefully acknowledge China Scholarship Council (CSC) for the financial support during my research stay in Germany

I am also very grateful to Dr. Alexander Breder for his kindly accepting to be the second supervisor for my PhD study.

I deeply thank Nikolaos Kaplaneris, Joachim Loup, Torben Rogge, Dr. Fabio Pescaioli, Dr. Joao Carlos Agostinho de Oliveira, Dr. Santhi Vardhana Yetra, Korkit Korvorapun, Isaac Choi, Ralf Alexander Steinbock, Dr. Hao Yu, Zhigao Shen, Shou-Kun Zhang, for their patience and time to correct this thesis.

I deeply thank Ms. Gabriele Keil-Knepel for kindly assistance in the laboratory as well as kind help whenever I encountered any problem in daily life. I thank Mr. Stefan Beußhausen for the technical assistance with the computer, software and network and Mr. Karsten Rauch for his helpful suggestions concerning the lab work.

I would like to thank all the members of the analytical departments at the Institute of Organic and Biomolecular Chemistry.

I thank Julian Koeller, Dr. Weiping Liu, Dr. Marc Moselage, María J. González, Dr. Mélanie M. Lorion, Dr. Fabio Pesciaioli, Dr. João C. A. Oliveira, Dr. Svenja Warratz, Isaac Choi, Torben Rogge, Nikolaos Kaplaneris, very much for their contributions to my PhD projects.

I thank all the group members in Ackermann Group, particularly the past and current members in Lab 306, Dr. Suman De Sarkar, Dr. Mélanie Lorion, Dr. Marc Moselage, Dr. Svenja Warratz, Dr. Fabio Pescaioli, Dr. Santhi Vardhana Yetra, Dr. Youai Qiu, Cuiju Zhu, Dr. Jongwoo Son, Dr. Hao Yu, Julian Koeller, Korkit Korvorapun, Nikolaos Kaplaneris, Isaac Choi, Maximilian Stangier and Julia Struwe. Special thanks should give to my wife, my son, my parents, and other families for their continuous support and encouragement. I love you all forever. 


\title{
Curriculum Vitae
}

\section{Personal Information}

Name:

Date of Birth:

Place of Birth:

Gender:

Nationality:

Academic Education

$10 / 2014-03 / 2019$

09/2011-07/2014

09/2007-07/2011
Hui Wang

$$
\text { 03.10.1987 }
$$

Hefei, Anhui (P. R. China.)

Male

Chinese

\section{PhD Candidate in Organic Chemistry}

Institut für Organische und Biomolekulare Chemie,

Georg-August-Universität Göttingen

Supervisor: Prof. Dr. Lutz Ackermann

Thesis: Cobalt(III)- and Manganese(I)-Catalyzed C-H and C-C Activations

\section{Sc. in Organic Chemistry}

College of Chemistry and Molecular Engineering

Zhengzhou University

Supervisor: Prof. Dr. Xiuling Cui

Thesis: Direct Dimerization and Phosphonation of Heteroaromatic

Compounds under Metal- and External Oxidant- Free Conditions

\author{
B.Sc. in Chemistry \\ Department of Chemistry \\ Zhengzhou University
}




\section{Conferences}

24-29/09, 2017

Poster of the $1^{\text {st }}$ Summer School on Organic Catalysis for Energy Conversion, Göttingen, Germany.

19-20/09, 2016 Poster of the $4^{\text {th }}$ NikaS Symposium, TU Braunschweig, Germany.

17-20/10, 2013. $8^{\text {th }}$ National Conference on Organic Chemistry, Chongqing, China.

\section{Publications}

1. H. Wang, ${ }^{+}$I. Choi, ${ }^{+}$T. Rogge, N. Kaplaneris, L. Ackermann, ${ }^{*}$ Versatile and Robust C-C Activation by Chelation-Assisted Manganese-Catalysis. Nature Catal. 2018, 1, 993-1001.

2. H. Wang, ${ }^{+}$F. Pesciaioli, ${ }^{+}$J. C. A. Oliveira, S. Warratz, L. Ackermann, ${ }^{*}$ Synergistic Manganese(I) $\mathrm{C}-\mathrm{H}$ Activation Catalysis in Continuous Flow: Chemoselective Hydroarylation. Angew. Chem. Int. Ed. 2017, 56, 15063-15067.

3. H. Wang, ${ }^{+}$M. M. Lorion, ${ }^{+}$L. Ackermann, ${ }^{*}$ Air-Stable Manganese(I)-Catalyzed C-H Activation for Decarboxylative $\mathrm{C}-\mathrm{H} / \mathrm{C}-\mathrm{O}$ Cleavages in $\mathrm{H}_{2} \mathrm{O}$. Angew. Chem. Int. Ed. 2017, 56, 6339-6342.

4. H. Wang, ${ }^{+}$M. M. Lorion, ${ }^{+}$L. Ackermann, ${ }^{*}$ Overcoming the Limitations of $\mathrm{C}-\mathrm{H}$ Activation with Strongly Coordinating N-Heterocycles by Cobalt Catalysis. Angew. Chem. Int. Ed. 2016, 55, 10386-10390. (Highlight by Synfacts 2016, 12, 1126)

5. H. Wang, M. M. Lorion, L. Ackermann, * Domino $\mathrm{C}-\mathrm{H} / \mathrm{N}-\mathrm{H}$ Allylations of Imidates by Cobalt Catalysis. ACS Catal. 2017, 7, 3420-3433.

6. H. Wang, M. Moselage, M. J. González, L. Ackermann,* Selective Synthesis of Indoles by Cobalt(III)-Catalyzed C-H/N-O Functionalization with Nitrones. ACS Catal. 2016, 6, 2705-2709.

7. H. Wang, J. Koeller, W. Liu, L. Ackermann,* Cobalt(III)-Catalyzed C-H/N-O Functionalizations: Isohypsic Access to Isoquinolines. Chem. Eur. J. 2015, 21, 15525-15528.

8. H. Wang, X. Cui, * Y. Pei, Q. Zhang, J. Bai, D. Wei, Y. Wu, * Direct Regioselective Phosphonation of Heteroaryl $\mathrm{N}$-oxides with $\mathrm{H}$-phosphonates under Metal and External Oxidant Free Conditions. Chem. Commn. 2014, 50, 14409-14411.

9. H. Wang, Y. Pei, J. Bai, J. Zhang, Y. Wu, ${ }^{*}$ X. Cui, ${ }^{*}$ Dimerization of Heteroaromatic N-oxides Under Metal-Free Conditions. RSC Adv. 2014, 4, 26244-26246.

10. N. Kaplaneris, T. Rogge, R. Yin, H. Wang, G. Sirvinskaite, L. Ackermann,* Late-Stage 
Diversification by Manganese-Catalyzed C-H Activation: Access to Acyclic, Hybrid and Stapled Peptides. Angew. Chem. Int. Ed. 2019, doi.org/10.1002/ange.201812705.

11. S. R. Yetra, Z. Shen, H. Wang, L. Ackermann,* Thiocarbonyl-Enabled Ferrocene C-H Nitrogenation by Cobalt(III) Catalysis: Thermal and Mechanochemical. Beilstein J. Org. Chem. 2018, 14, 1546-1553.

12. R. Mei, H. Wang, S. Warratz, S. A. Macgregor, L. Ackermann, ${ }^{*}$ Cobalt-Catalyzed Oxidase $\mathrm{C}-\mathrm{H} / \mathrm{N}-\mathrm{H}$ Alkyne Annulation: Mechanistic Insights and Access to anti-Cancer Agents. Chem. Eur. J. 2016, 22, 6759-6763.

13. Q. Zhang, X. Cui, ${ }^{*}$ L. Zhang, S. Luo, ${ }^{*}$ H. Wang, Y. Wu, ${ }^{*}$ Redox Tuning of a Direct Asymmetric Aldol Reaction. Angew. Chem. Int. Ed. 2015, 54, 5210-5213.

14. Q. Zhang, D. Wei, X. Cui, ${ }^{*}$ D. Zhang, H. Wang, Y. Wu, ${ }^{*}$ Direct Diphosphonylation of Quinolines with $\mathrm{H}$-phosphonates under Metal-Free Conditions. Tetrahedron 2015, 71, 6087-6093.

15. J. Bai, X. Cui, * H. Wang, Y. Wu, * Copper-Catalyzed Reductive Coupling of Aryl Sulfonyl Chlorides with $\mathrm{H}$-phosphonates Leading to S-aryl Phosphorothioates. Chem. Commn. 2014, 50, 8860-8863.

16. H. Zhang, X. Cui,* X. Yao, H. Wang, J. Zhang, Y. Wu,* Directly Fused Highly Substituted Naphthalenes via Pd-Catalyzed Dehydrogenative Annulation of $\mathrm{N}, \mathrm{N}$-Dimethylaminomethyl Ferrocene Using a Redox Process with a Substrate. Org. Lett. 2012, 14, 3012-3015.

$\left(^{+}\right.$Equal contribution) 